







\section{SEINEN GEEHRTEN FREUNDEN}

\section{ANTONIO FAVARO}

UND

\section{GIOVANNI MARINELLI,}

PROFESSOREN AN DER UNIVERSITÄT PADUA,

VEREHRUNGSVOLL GEWIDMET

VOM

VERFASSER. 



\section{V o r w o r t.}

Es mag als ein Wagniss erscheinen, ein Lehrbuch der terrestrischen Physik gerade in einer Zeit der Oeffentlichkeit zu übergeben, während deren durch die Werke von Supan, Ziegler, Hann-Hochstetter-Pokorny, Peschel-Leipoldt, durch E. Suess' grossartiges ${ }_{7}$ Antlitz der Erde" und endlich nicht zum mindesten durch die Ratzel'sche Sammlung trefflicher Einzeldarstellungen etwaigen Bedürfnissen der deutschen Leserwelt so ausgiebig Rechnung getragen wird. Als der Plan zu dem vorliegenden Buche gefasst ward, war jedoch von all' jenen Publikationen noch verhältnissmässig wenig bekannt, und nachher gewann es doch den Anschein, als sei ein im Sinne jenes Planes gearbeitetes Lehrbuch kein Ueberfluss. Unser Bestreben lässt sich in Kürze dahin formuliren, dass in möglichst systematischem Aufbau der einzelnen Lehren zugleich der mathematischen Entwickelung ein grösserer Spielraum gewährt und dabei auch auf die geschichtliche Entstehung und Ausbildung unseres Wissens umfassend Bedacht genommen werden sollte. Diesem Zwecke sollen auch die literarischen Nachweise dienen.

Man wird, wie der Verf. hofft, nirgendwo der mathematischen Behandlung nachsagen können, dass sie sich unnöthig in den Vordergrund dränge; es ist im Gegentheile nur dann - dann aber auch rückhaltslos - auf sie zurückgegriffen worden, wenn Theorieen, wie z. B. diejenige des Geoides, ohne diese Hülfe nicht wissenschaftlich genügend vorgetragen werden können. Die Geographen, und insbesondere die Studirenden der Erdkunde, scheuen heute nicht mehr, wie ehedem, vor Formeln zurück, sie wissen, dass mathematische und physikalische Vorkenntnisse ihnen ebenso unentbehrlich sind, wie geologische und historische, und wüssten sie es noch nicht, die Lesung Einer Seite der ausgezeichneten Berichte, welche Zöppritz in Hermann Wagner's „geograph. Jahrbuch" über die Fortschritte der Geophysik erstattet, würde sie eines andren belehren. Der Verf. benützt mit Freuden 
die sich ihm hier darbietende Gelegenheit, öffentlich seinen Dank für die Förderung auszusprechen, welche ihm für sein eigenes Unternehmen gerade aus diesen Referaten erwachsen ist.

Ursprünglich war das vorliegende Buch nur auf Einen Band berechnet. Der Verf. fühlt sich der Verlagshandlung, welche auch sonst mit hoher Bereitwilligkeit auf seine Wünsche eingieng, sehr zu Dank verpflichtet dafür, dass sie sich mit einer Trennung in zwei gleichstarke Bände einverstanden erklärte. Dieser erste Band umfasst etwa diejenigen Gegenstände, welche auf Seite 30 als eventuell der Geophysik angehörig bezeichnet werden, während der zweite der physikalischen Geographie im Speziellen gewidmet ist. Insoferne für Meteorologie, Erdmagnetismus, Meereskunde u. s. w. bereits monographische Lehrmittel von anerkannter Bedeutung in genügender Menge vorliegen, durfte im zweiten Bande die Darstellung eine kürzere und gedrängtere werden. Namentlich konnte der biologische Theil nur sehr kurz abgehandelt werden; derselbe ist auch nicht für Geographen als solche, sondern lediglich für solche Studirende der mathematischen Wissenschaften bestimmt, welche auch der - für den Analytiker ja noch ein so weites Arbeitsfeld eröffnenden - Disciplin der Erdphysik ihr Interesse zuzuwenden gedenken. - Die Figuren wurden ausnahmslos vom Verf. selbst gezeichnet, ein Umstand, der, wie er hofft, als Entschuldigungsgrund für manche technische Unvollkommenheit gelten kann.

Die Bemerkung auf Seite 285 über die Erfindungsgeschichte der Wasserwage stützt sich auf Rudolf Wolf's in den I. Band von Boncompagni's „Bullettino“ eingerückte Note „Matériaux divers pour servir à l'histoire des mathématiques". Der Autor hat jedoch später in seiner „Geschichte der Astronomie" sich selbst berichtigt und Thevenot wieder in seine Rechte eingesetzt.

Ansbach, im März 1884.

S. Günther. 


\title{
Inhalts-Uebersicht.
}

\section{Geschichtlich-literarische Einleitung.}

\author{
Erste Abtheilung.
}

\section{Die kosmische Stellung der Erde.}

Kapitel I. Die Kant-Laplace'sche Hypothese.

§. 1. Kosmogonische Hypothesen im Allgemeinen . . . . . . . 36

§. 2. Die Kant'sche Hypothese . . . . . . . . . . . . . . 38

§. 3. Kritik der Kant'schen Originalhypothese . . . . . . . . 40

§. 4. Laplace's neue Formulirung der Kant'schen Ideen . . . . . 41

§. 5. Plateau's Versuche . . . . . . . . . . . . . . . . 42

§. 6. Gründe, welche gegen Kant-Laplace sprechen . . . . . . 43

§. 7. Astronomische und physikalische Konsequenzen. . . . . . 45

§. 8. Das Endschicksal der Weltsysteme . . . . . . . . . . 49

Kapitel II. Die physische Konstitution der Körper des Sonnensystemes.

§. 1. Die Sonne . . . . . . . . . . . . . . . . . . . 52

§. 2. Die Photosphäre . . . . . . . . . . . . . . . . . 53

§. 3. Fackeln und Flecke. . . . . . . . . . . . . . 53

§. 4. Die Wilson-Herschel'sche Hypothese . . . . . . . . . . 55

§. 5. Neuere wissenschaftliche Hypothesen. . . . . . . . . . 57

§. 6. Rotation, Fleckenvertheilung und Fleckenperiodicität. . . . 60

§. 7. Chromosphäre, Protuberanzen und Korona. . . . . . . . 62

$\S$. 8. Allgemeines über die Beschaffenheit und Temperatur des Son-

§. 9. Die Planeten : . . . . . . . . . . . . . . . . . . . 646

§. 10. Die Kometen . . . . . . . . . . . . . . . . . . . 69

§. 11. Aeltere und neuere Kometentheorieen . . . . . . . . . 71

§. 12. Hypothesen, welche eine polare Kraft zu Hülfe nehmen : . 75

§. 13. Die Meteorite . . . . . . . . . . . . . . . 77

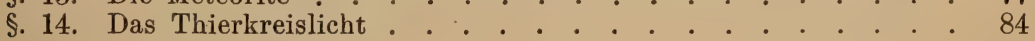

§. 15. Der Weltraum und seine Erfülliung . . . . . . . . . . 89

Kapitel III. Die der Erde ähnlichen Planeten und der Mond.

§. 1. Die astronomischen Nachbarn der Erde . . . . . . . . 97

§. 2. Die Venus . . . . . . . . . . . . . . . 97

§. 3. Mars und seine Monde . . . . . . . . . . . . . 100

§. 4. Geschichte der physischen Marsforschung . . . . . . . . 102 
§. 5. Oberflächenbeschaffenheit und Atmosphäre des Mars nach Schiaparelli .............. 103

§. 6. Weitere Schlüsse aus der Analogie zwischen Mars und Erde 107

§. 7. Der Erdmond . . . . . . . . . . . . . . . . . 108

§. 8. Licht, Wärme und Atmosphäre des Mondes . . . . . . . 111

§. 9. Die Mondtopographie in ihrer geschichtlichen Entwickelung . 114

§. 10. Allgemeine Beschreibung der Mondoberfläche . . . . . . 117

$\S$ 11. Der lunare Vulkanismus und die physischen Veränderungen der Mondoberfläche. . . . . . . . . . . 119

§. 12. Die Frage nach der Bewohnbarkeit der Himmelskörper . . . 124

\section{Zweite Abtheilung.}

\section{Allgemeine mathematische und physikalische Verhältnisse des Erdkörpers.}

\section{Kapitel I. Die Erde als Kugel und Rotationssphäroid.}

§. 1. Allmählige Entwickelung der Sphäricitätslehre . . . . . . 129

§. 2. Gründe für die Kugelform des Erdkörpers . . . . . . . 132

§. 3. Störungen der Kugelform . . . . . . . . . . . . . . 135

§. 4. Methoden der Erdmessung . . . . . . . . . . . . . 136

§. 5. Die Gradmessungsmethode . . . . . . . . . . . . . . 138

§. 6. Zweifel an der geometrischen Kugelform der Erde; weitere Gradmessungen . . . . . . . . . . . 142

§. 7. Gradmessungen zur Festsetzung eines Naturmaasses . . . 144

§. 8. Die Längengradmessungen und die europäische Gradmessung 145

§. 9. Sphäroidische Formeln und Rechnungen . . . . . . . . 146

§. 10. Dimensionen des Erdsphäroides . . . . . . . . . . . 149

§. 11. Bedenken gegen den Fundamentalsatz der mathematischen Geographie . . . . . . . . . . 150

Kapitel II. Die Attraktionsphänomene und deren Anwendung zur Bestimmung der Gestalt und Dichte der Erde.

§. 1. Die allgemeine Gravitation . . . . . . . . . . . . 154

§. 2. Mittel, die Schwere und ihre Variationen zu messen . . . . 156

§. 3. Attraktionsprobleme . . . . . . . . . . . . . . . 161

§. 4. Lothanziehung und Lothabstossung . . . . . . . . . 167

§. 5. Die Erdgestalt unter dem vereinigten Einflusse von Schwere und Centrifugalkraft . . . . . . . . . . . . . . 169

§. 6. Das Pendel als geodätisches Instrument . . . . . . . . . 171

§. 7. Ueberblick über die der geophysikalischen Anwendung des Pendels gewidmeten Untersuchungen . . . . . . . 172

§. 8. Die Clairaut'sche und die Unferdinger'sche Pendelformel . . 178

§. 9. Aeltere Methoden der Dichtigkeitsbestimmung für die Erde . 181

§. 10. Die Wägungsmethode . . . . . . . . . . . . 187

Kapitel III. Das Geoid.

§. 1. Unregelmässigkeiten der Erdgestalt . . . . . . . . . . 191

§. 2. Die Gestalt der Meeresoberfläche . . . . . . . . . . . 192

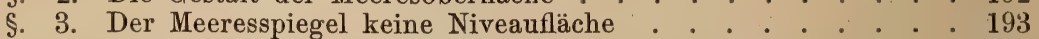

§. 4. Aeltere und neuere Erklärungsversuche dieser Abweichung . 195

§. 5. Ph. Fischer's Untersuchungen . . . . . . . . . . 196

§. 6. Das Geoid . . . . . . . . . . . . . . . . . . 198

§. 7. Definition und Bestimmung des Geoides nach Bruns . . . . 200

§. 8. Schematische Berechnung extremer Werthe . . . . . . . 203

§. 9. Festlegung des Geoides gegenüber dem Sphäroid . . . . . 204

§. 10. Geodätische Konsequenzen der Lehre vom Geoid . . . . . 207

Kapitel IV. Die Bewegung der Erde im Raume.

§. 1. Die Axendrehung. . . . . . . . . . . . . . . . . 210

§. 2. Unveränderlichkeit der Rotationsaxe und Rotationsdauer . . 213 
§. 3. Konsequenzen aus der Axendrehung der Erde . . . . . . 219

§. 4. Der Foucault'sche Pendelversuch und dessen Abänderung durch

Onnes . . . . . . . . . . . 227

§. 5. Aeltere Weltsysteme . . . . . . . . . . . . . 233

§. 6. Die heliocentrische Reform und deren Begründung . . . . 238

§. 7. Der Axen-Parallelismus . . . . . . . . . . . . . . 243

§. 8. Die Kepler'schen Gesetze . . . . . . . . . . . . . 245

§. 9. Drei geophysikaliseh wichtige Perturbationen . . . . . . 250

§. 10. Trepidation und Präcession . . . . . . . . . . . . 253

§. 11. Mechanische Erklärung der Präcession . . . . . . . . . 255

§. 12. Weitere Bemerkungen über die Präcession . . . . . . . . . 262

§. 13. Nutation . . . . . . . . . . . . . . . . . . . 263

§. 14. Die Fortbewegung des Sonnensystemes im Raume . . . . 265

Kapitel V. Die Graphik im Dienste der physischen Erdkunde.

§. 1. Kartenprojektion . . . . . . . . . . . . . . . . . 271

§. 2. Die gebräuchlichen Projektionsmethoden . . . . . . . . 275

§. 3. Chorographie und Terrainzeichnung . . . . . . . . . . 283

§. 4. Darstellung der Höhenverhältnisse, Isohypsen und Isobathen . 286

§. 5. Flächenmessung . . . . . . . . . . . . . . 292

§. 6. Anderweite Darstellungen der Erdoberfläche oder ihrer einzelnen Theile . . . . . . . . . . . . . 294

\section{Dritte Abtheilung.}

\section{Geophysik im engeren Sinne; dynamische Geologie.}

\section{Kapitel I. Die Wärmeverhältnisse des Erdinneren.}

§. 1. Das Eindringen der Sonnenwärme . . . . . . . . . . 300

§. 2. Die Zunahme der Wärme jenseits der neutralen Schicht . . 303

§. 3. Temperaturbeobachtungen in Gruben . . . . . . . . . 305

§. 4. Temperaturbeobachtungen in Bohrlöchern . . . . . . . . . 306

§. 5. Temperaturbeobachtungen in Tunnels . . . . . . . . . 308

§. 6. Allgemeine Resultate und theoretische Schlussfolgerungen . 309

Kapitel II. Der innere Zustand der Erde.

§. 1. Aeltere Hypothesen . . . . . . . . . . . . . . . . 314

§. 2. Gründe für die Starrheit der Erde

§. 3. Gründe für und wider die Elasticität des Erdinneren . . . 317

§. 4. Die Auffassung des Erdinneren als einer gasförmigen Masse . 319

§. 5. Das Magma und die Ryakohypse . . . . . . . . . . . 322

§. 6. Allgemeines über die Physik der Erdrinde . . . . . . . 324

Kapitel III. Die vulkanischen Erscheinungen.

§. 1. Definition und allgemeine Beschreibung der Vulkane. . . . 329

§. 2. Die Stratovulkane . . . . . . . . . . . . . . . . . 329

§. 3. Domvulkane ... . . . . . . . . . . . . . . . 332

§. 4. Uneigentliche Vulkane . . . . . . . . . . . . . . 333

§. 5. Reihung und Anordnung der eigentlichen Vulkane . . . . 338

§. 6. Geographische Vertheilung der Vulkane . . . . . . . . . 339

§. 7. Der Eruptions-Akt und die ihn begleitenden Umstände . . . 347

§. 8. Die Eruptionsprodukte . . . . . . . . . . . . . 350

§. 9. Aeltere vulkanistische Erklärungsversuche . . . . . . . 353

§. 10. Die Humboldt-Buch'sche Periode . . . . . . . . . . . . 356

§. 11. Die nicht-magmatischen Theorieen der neuesten Zeit . . . . 358

$\S$. 12. Die magmatischen Theorieen der neuesten Zeit . . . . . 361

§. 13. Die vegetative Bekleidung der Vulkane . . . . . . . . 365

Kapitel IV. Erdbeben.

§. 1. Beschreibung einzelner Erdbebenphänomene und Erdbebengebiete . . . . . . . . . . . 369 
§. 2. Allgemeine Schilderung des Verlaufes einer Erderschütterung 372

§. 3. Seebeben und Erdbebenfluthen . . . . . . . . . . . . 376

§. 4. Anzeichen und Schutzmittel . . . . . . . . . . . . . 380

§. 5. Seismographen und Seismometer . . . . . . . . . 385

§. 6. Geometrie und Mechanik der seismischen Punkt- und Linien-

§. 7. Theoretische Spekulationen über die Natur der Erdbeben . 388

§. 8. Die Perrey-Falb'sche Hypothese . . . . . . 400

§. 9. Grundsätzliche Unterscheidung vulkanischer und tektonischer Erdbeben .. . . . . . . . . . . . . 401 


\section{Geschichtlich-literarische Einleitung.}

Wenn wir im Folgenden mit kurzen Zügen ein Bild von dem allmählichen Anwachsen und Erstarken der grossartigen Disciplin zu entwerfen versuchen, welche die Brücke zwischen der Naturlehre und Erdkunde bildet, so sehen wir uns Schwierigkeiten gegenüber, welche durchaus in dem eigentlichen Wesen der Sache selbst begründet und deshalb auch nicht leicht zu besiegen sind. Wer einen geschichtlichen Abriss der Philosophie, Mathematik, Medizin, ja wohl auch der Physik oder Geographie selbst zu liefern unternimmt, der hat es mit einer in sich mehr oder weniger fest abgeschlossenen $W$ issenschaft zu thun, deren besonderer Charakter zu allen Zeiten anerkannt war, mit deren Nennung Jedermann und von je einen bestimmten Begriff zu verbinden gelernt hat. Anders im vorliegenden Falle. Als ein selbstständiger Wissenszweig ist der für die exakte Forschung zugängliche Theil der Geographie erst von einem verhältnissmässig späten Datum an betrieben worden, und doch würde der Geschichtschreiber ein schweres Unrecht thun, wollte er mit seiner erzählenden Thätigkeit auch nicht früher, als in jenem vorgerückten Momente beginnen. Denn lange vor dem Termine einer scharfen Begriffsbestimmung - soferne von einer solchen auch beute überhaupt die Rede sein kann - hatte doch eine Fülle von Schriftstellern theils instinktiv, theils mehr oder weniger bewusst die Nothwendigkeit einer consequenten Anwendung physikalischer Untersuchungsmethoden auf Fragen der allgemeinen Erdkunde erkannt und, jeder an seinem Theile, Beiträge zum Aufbau dieser Zukunftswissenschaft geliefert; ja selbst bis in altersgraue Vorzeit hinauf lassen sich die Spuren derartiger Thätigkeit deutlich erkennen. Wir

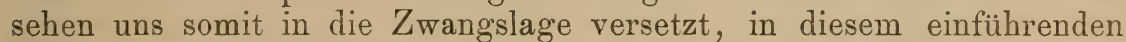
Kapitel einen Weg einzuschlagen, der eine den sonst betretenen geradezu entgegengesetzte Richtung einhält. Ohne uns in eine an sich schwer zu lösende Aufgabe jetzt schon einzulassen, diejenige nämlich, den Umfang des von uns zu kultivirenden Gebietes genau zu umschreiben, schildern wir, sofort in medias res eintretend, die allmähliche Entwickelung der Gedankenreihe, welche in diesem Buche die Form eines Wissenssystemes erhalten soll. An der Hand dieser historischen Betrachtung hoffen wir aber auch zu einem Ziele zu gelangen, welches 
auf anderen Bahnen minder leicht zu erreichen wäre, nämlich zu dem Ziele einer möglichst präcisen Charakterisirung jenes Theiles der Gesammtwissenschaft, welches durch die, wenn auch verschieden zu deutenden, so doch ihrem Hauptabsehen nach synonymen Namen der Geophysik, der physischen oder physikalischen Geographie bezeichnet zu werden pflegt.

Naive Gelegenheitsversuche, sich von irgend einem tellurischen Vorgang eine dem menschlichen Causalitätsbedürfniss entsprechende Rechenschaft zu geben, treten uns schon sehr frühe im Alterthum entgegen. Strenge genommen müssten die Kosmogonieen der alten Kulturvölker, ihre mannigfach gegliederten und doch offenbar von dem nämlichen Grundgedanken beherrschten Sintfluthhypothesen, hierher gerechnet werden. Homer's Gesänge verdienten wohl, einmal eingehender Durchforschung in diesem Sinne unterworfen zu werden, und wenn auch bei ihm das phantastische Element noch sehr vorwaltet, so tritt der Sinn für nüchterne Naturbetrachtung um so augenfälliger hervor bei seinem Nachfolger Hesiod, dessen Lehrgedicht „Werke und Tage uns klar zur Anschauung bringt, wie sich die Alten das Wechselverhältniss zwischen der Erdoberfläche und den von den Himmelskörpern ausgehenden Kräften dachten. Die kosmologischen und damit zusammenhängend natürlich auch die geophysikalischen Spekulationen der jonischen Naturphilosophen schienen sich lange Zeit hindurch unserer näheren Kenntniss gänzlich zu entziehen, wie denn selbst Zeller [1] den Versuch, aus den plutarchischen Ueberlieferungen heraus die Theorieen des Thales reconstruiren zu wollen, für einen aussichtslosen erklärte. Seitdem uns jedoch Diels mit seiner trefflichen Ausgabe der antiken Naturphilosophen zweiter Ordnung beschenkt hat*) [2], ist unsere Stellung: der jonischen Schule gegenüber eine wesentlich andere geworden. Des Theophrast grosses Werk ist, wie sich nunmehr zeigt, nicht spurlos verloren gegangen, vielmehr ist ein grosser Theil der Materialien, welche derselbe für die Geschichte der Physik von den ältesten Zeiten bis auf Platon zusammengetragen hatte, in ein viel späteres Sammelwerk übergegangen, welches nach Diels [3] in die sechs Abschnitte „de principiis", „de mundo", „de sublimibus", „de terrestribus", , de anima", „de corpore" zerfiel, welches bereits von dem römischen Polyhistor Varro ausgenützt und von einem gewissen Aetius für seine ${ }_{\text {}}$ Epitome " excerpirt wurde, welch' letztere dann wieder als eine freilich schon ziemlich trübe Quelle für zahlreiche spätere Autoren diente. Für uns hier ist als das wichtigste Ergebniss dieser bedeutungsvollen Arbeiten ein Satz anzusehen, welcher in einer neueren Schrift, auf die wir uns mehrfach zu beziehen haben werden, die nachstehende Formulirung empfangen hat [4]: „Auch in die entlegenen Zeiten des Anfanges der griechischen Philosophie leitet uns ein Führer, Theophrast; diesem haben wir zu vertrauen, ihm aber auch uns unterzuordnen." Geleitet durch diesen Führer können wir jetzt den Scharfsinn bewundern, welcher sich in Thales' kühnem Wagniss ausspricht [5], die Wesensgleichheit

*) Wir wählen diese vielleicht nicht ganz einwurfsfreie Bezeichnung deshalb, weil es sich hier nicht um Forscher von originaler Bedeutung, sondern um Commentatoren und Compendienschreiber handelt, deren Sammeleifer wir freilich zu grossem Danke verpflichtet sind. 
der Erde mit den Himmelskörpern zu behaupten, wir können Anaximander's hohen Schwung in der Zurückführung aller kosmischen Erscheinungen auf Bewegungsvorgänge anstaunen [6] und die merkwürdige Thatsache constatiren, dass die geniale Einfachheit der Erklärungen dieses hervorragenden Mannes schon seinen nächsten Nachfolgern nicht genügte und sie, z. B. den Anaximenes, zu allerlei Künsteleien herausforderte [7]. Die pythagoreische Schule zeichnete sich durch ihre Betonung des mathematischen Elementes vortheilhaft aus und gelangte so zu jenen richtigeren Ansichten über Erdgestalt und Erdbewegung, deren in einem kommenden Kapitel ausführlicher Erwähnung zu thun sein wird. Die Philosopheme eines Demokrit, Heraklit und Anaxagoras mögen hier von einer näheren Erörterung ausgeschlossen bleiben, da sie nachweislich einen unmittelbaren Einfluss auf die Folgezeit nicht ausgeübt haben, dagegen wäre es ungerecht, nicht von Empedokles zu sprechen, den die Natur seines Vaterlandes Sizilien zum Studium des Vulkanismus anleitete, der die bezüglichen Phänomene sowohl als auch die Thermalquellen aus der feurig-flüssigen Beschaffenheit des Erdinneren erklärte [8] und der Sage nach durch diesen Eifer sogar dem Tode im Krater des Aetna verfiel. Platon endlich war zwar gleich seinen Vorgängern ebensowenig Physiker, als Geograph, doch haben gelegentliche Bemerkungen von ihm über Fragen der physischen Erdkunde eine weiter tragende Bedeutung gehabt, und insbesondere soll nach Berger's Meinung [9] die von jenem und von Theopomp in Umlauf gesetzte geographische Mrthe von der verschwundenen Insel Atlantis den Anstoss zu jenen üppig wuchernden Doktrinen über den Wechsel ron Festlandboden und Meeresfläche gegeben haben, mit welchen sich noch der Geologe unserer Tage zu rechnen genöthigt sieht.

Hatten wir bislang ausschliesslich von solchen Männern zu sprechen, welche entweder einer bekannten Philosophenschule anǧehörten oder sozusagen auf eigene Hand Naturphilosophie trieben, so begegnen wir im V. Jahrhundert unserer Zeitrechnung zwei Griechen, die von einer ganz anderen Seite her an die naturwissenschaftlich-geographischen Studien herantraten und somit, da nicht sowohl geistreiche Reflexion, als vielmehr eine gestählte Erfahrung ihren Leitstern abgab, einen höchst fördernden Einfluss auf jene ausübten. Es versteht sich von selbst, dass wir Herodot und den Koer Hippokrates im Auge haben. Mag der Erstere, soweit theoretische Begriffe in Frage kamen, noch so sehr in den Vorstellungen seiner Zeit befangen gewesen sein, so hat ihn doch ein auf weiten Reisen geschärfter Blick manche glückliche Entdeckung machen, manche treffende Idee aussprechen lassen, deren Fortbildung vielleicht erst nach Jahrtausenden möglich wurde, und zumal für die geognostischen Verhältnisse der von ihm besuchten Länder, für die Wechselbeziehungen von Land und Wasser, ja sogar für die ungleiche Vertheilung des Regens in den einzelnen Jahreszeiten [10] interessirte er sich auf das Lebhafteste. Man braucht der hellenischen Alluvionenlehre, die Megasthenes für Indien, Hekataeus für Aegypten nutzbar gemacht und die eben Herodot [11] am Nile bestätigt gefunden hatte, kein übertriebenes Lob zu zollen und kann trotzdem die fruchtbringende Bedeutung gerade dieser herodotischen Theorie der Schwemmländer vollständig anerkennen. Was Hippokrates anlangt, so legt kein Anderer, als Haeser, der trefflichen kleinen 
Schrift dieses ursprünglichen Denkers und Beobachters, die von Luft, Wasser und Ortslage im Zusammenhang mit den physischen Eigenschaften des Menschen handelt, den Werth eines selbstständigen Abrisses der physikalischen Erdkunde bei [12], wie denn u. a. darin die korrektesten Gedanken über die Entstehung der Winde, von deren Verhältniss zum Meere, von ihrer Bedingtheit durch die Jahreszeiten und durch lokale Einflüsse niedergelegt sind. Ja selbst dann, wenn beide Forscher, der Entdeckungsreisende, wie der Arzt, Spekulationen sich hingeben, die den geläuterten physikalischen Anschauungen der Neuzeit bedenklich und irreführend erscheinen müssen, kann der unpartheiische Beurtheiler kaum umhin, Bewunderung über eine so eigenartige Hypothesenbildung zu empfinden. So weist das, was Herodot über die Ursache der periodisch wiederkehrenden Nilüberschwemmungen aussagt, hinüber auf eine ganze Reihe von Theorieen, welche neuerdings zur Erklärung der sogenannten Eiszeit aufgestellt worden sind [13], und die auf den ersten Blick so sonderbar anmuthende Angabe des Hippokrates, dass die Laufrichtung eines Quellgewässers wohl zu beachten sei, wenn man über die sanitären Eigenschaften des letzteren zu entscheiden habe, illustrirt doch auch wieder besonders klar den feinen Sinn des grossen Forschers für Naturbeobachtung*). Wenn von der Grundsteinlegung des stolzen Gebäudes der physischen Erdkunde die Sprache ist, werden die Namen Hippokrates und Herodot stets unter den vordersten zu nennen sein.

Mittlerweile war die Disciplin, an deren Aufbau alle die genannten Koryphäen antiker Wissenschaft sich betheiligt hatten, weit genug fortgeschritten, um allmählich einer mehr organischen und zusammenfassenden Bearbeitung theilhaftig zu werden. Dieser Arbeit unterzog sich der grösste Systematiker nicht blos seiner Zeit, sondern aller Zeiten, Aristoteles vor Stagiros. Einzelheiten geophysikalischer Natur finden sich in sehr vielen Schriften desselben, doch ist es besonders die „Meteorologie“, die ein mehr systematisches Gepräge an sich trägt. Allerdings dürfen wir dieses Wort nicht in der verengerten Bedeutung von heute als eine Lehre von den atmosphärischen Erscheinungen auffassen, denn diese bildet nur einen Bestandtheil des Werkes, von welchem wir nach Heller [15] die nachstehende kurze Inhaltsübersicht geben. Das erste Buch sucht den Plan des Ganzen und den Inhalt des Faches darzulegen, als hodegetisches Hülfsmittel folgt sodann die bekannte Elementenlehre, und daran reihen sich Betrachtungen über den Himmel, speziell über Milchstrasse und Kometen, die Natur der Gestirne, des Weltäthers, der Luft und der ihr entstammenden Niederschläge, endlich über die Winde und fliessenden Wasser der Erde. Das zweite Buch beginnt mit einer Art von Oceanographie, handelt von den Beziehungen zwischen Luft und Meer, von den Winden, wobei die Bedingungen für das periodische Wehen eines Windes während gewisser Jahreszeiten ganz richtig erkannt werden; zum Schlusse werden die Erdbeben und jene - modern gesprochen - elektrischen Entladungen der Atmo-

*) Auf diese wenig bekannte Stelle wieder hingewiesen und sie mit einigen Erläuterungen versehen zu haben, ist das Verdienst Kästner's gewesen [14]. Indessen will es uns bedünken, als sei der Sachverhalt noch durchaus nicht genügend aufgeklärt und biete dem Spürsinn der Interpreten noch vielen Spielraum. 
sphäre besprochen, welche das Alterthum mit den Erschütterungen der Erdfeste in einen Causalnexus zu bringen liebte. Die meteorologische Optik erfüllt das dritte Buch, doch werden in dasselbe auch die Orkane und Wirbelstürme mit herein genommen, und das vierte ist physikalischer Natur, insoferne dort die allen materiellen Körpern gemeinsamen Grundeigenschaften erörtert werden. Es kann hier natürlich nicht unsere Aufgabe sein, den einzelnen Entdeckungen oder wohl auch Fehlgriffen des Stagiriten nachzugehen; aus de'm Mitgetheilten erhellt bereits, dass er der erste Schriftsteller grossartigeren Maassstabes auf dem Gebiete der tellurischen Physik war, und so werden wir uns auch nicht darüber wundern dürfen, dass seine Thätigkeit schulemachend wirkte. Unmittelbar von ihm unterrichtet war beispielsweise jener Dikaearch, der durch die ersten nicht auf roher Schätzung beruhenden Bestimmungen von Bergeshöhen zuerst einige Ordnung in die abenteuerlichen orographischen Anschauungen seines Volkes brachte [16]. Weit wichtiger als er ist aber der verdienstvolle didaktische Schriftsteller des Griechenthums, der uns bereits bekannte Theophrast, der namentlich auch für die mannigfachen kosmographischen Anregungen empfänglich war, welche sich aus der rasch anwachsenden Literatur über den Alexanderzug ergaben [17], während der Meister selbst gerade mit Rücksicht auf die von jenem zu erwartende Bereicherung unseres Naturwissens noch eine gewisse Zurückhaltung beobachten zu sollen geglaubt hatte [18]. Hierher gehört auch der nicht genau be-

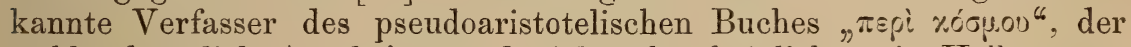
wohl schwerlich Apulejus und viel wahrscheinlicher ein Hellene aus der alexandrinischen Periode war*). Möglicherweise wäre die Autorschaft zurückzuführen auf den gelehrten Posidonius, der - von seinen Verdiensten um die rein mathematischen Partieen der Erdkunde abgesehen - an dieser Stelle namentlich um seines Strebens willen genannt werden muss, die Physik des Meeres und in dieser wiederum besonders die Lehre von den Gezeiten übersichtlich darzustellen [20]. Als wissenschaftlicher Enkel des Aristoteles darf endlich der Lampsacener Straton, ein Schüler des Theophrast, gelten, der sich eifrig jener Abtheilung der physischen Erdkunde widmete, die man am Besten als dynamische Geologie bezeichnet.

Die alexandrinische Astronomenschule, deren Vertreter wir, soweit es sich um geographische Dinge handelt, in Eratosthenes, Hipparch und dem allerdings weit späteren Ptolemäus zu erblicken gewohnt sind, nahm, wie Berger [21] hervorhebt, von dem physikalischen Zweige der Wissenschaft so gut wie gar keine Notiz und bereitete durch diese Einseitigkeit den ganz naturgemässen Rückschlag vor. Denn es bahnte sich so eine Richtung an, welche umgekehrt der so nothwendigen Controle der Geometrie entrathen zu können glaubte und so einen Irrweg inaugurirte, auf dem man leider auch jetzt noch nur zu viele Freunde der Erdkunde dahinwandeln sieht**). Als einen

*) Diese Meinung, welche sich auf die grosse Aehnlichkeit zwischen des Apulejus Schrift "De mundo" und dem angeblich aristotelischen Traktate stiitzt, ist hauptsächlich von Goldbacher [19] zu nichte gemacht worden.

**) Besonders übel kann den Gegnern der mathematischen Methode in der Erdkunde diess allerdings nicht genommen werden, wenn man sich solcher geometrischer Uebertreibungen im anderen Lager schuldig machte, wie es der Stoiker 
der hervorragendsten Choragen dieser Schule müssen wir Polybius anführen, der die Geographie, ähnlich wie es die Schulvorschriften vieler deutscher Länder thun, zu einer blossen Hülfswissenschaft der Geschichte degradirt wissen wollte, der den von Pytheas aus der Ferne mitgebrachten Erfahrungsthatsachen nur spöttisches Misstrauen entgegenbrachte, dem aber bei alle dem Berger das folgende lobende Zeugniss auszustellen sich gedrungen fühlt [23]: „Er knüpfte an die Besprechung der günstigen Lage von Byzanz ein treffliches Referat der stratonischen Lehren über die Abdämmung der Mäotis und des Pontus Euxinus. Partieen der physischen Erdkunde scheint er mit Vorliebe eingeflochten zu haben. ${ }^{\text {" }}$ Immer erkennbarer tritt die kritischzersplitternde und eine in damaliger Zeit noch nicht so sehr nöthige Arbeitstheilung begünstigende Tendenz hervor bei den auf Polybius folgenden Geographen, bei Agatharchides, Artemidor, Theophanes.u. a., die zu dem freilich nicht minder einseitigen, durch natürliche Genialität diesen Fehler aber reichlich wieder ausgleichenden grössten Geographen der Antike, zu Strabon aus Amasia, hinüberleiten [24]. Zu billigen ist es freilich nicht, dass ein Mann, wie er, die Einheitlichkeit der Wissenschaft so wenig hoch schätzte und das weite Arbeitsfeld der astronomisch mathematischen Geographie als ein von dem eigenen weit seitab liegendes betrachtete, das wohl einzelne auch für seine Zwecke brauchbare Früchte hervorbringe, sonst aber eine Domäne des Geometers bilde und den Geographen als solchen nichts angehe. Ein Glück nur, dass dieser Theil seiner Lehren von der Folgezeit nicht berücksichtigt worden ist.

Ein um so hellerer Blick spricht sich in allen Ausführungen Strabon's aus, sobald er auf die naturwissenschaftliche Seite der Geo. graphie und namentlich auf die Morphologie der Erdoberfläche zu reden kommt. Wir verweisen Jeden, der sich über diese Punkte bequemer als auf dem Wege des Quellenstudiums einen Ueberblick zu verschaffen wünscht, auf jene reichhaltige Programmabhandlung H. Fischer's [25], die wir im weiteren Fortgange dieses Buches noch sehr oft zu citiren haben werden, und begniigen uns mit der Heraushebung einiger besonders bemerkenswerther Einzelheiten. Die vertikale Gliederung des Erdreliefs erschien ihm als dem Ersten wichtig genug, um einer besonderen Klassifikation zu bedürfen [26], die Hebungen und Senkungen des festen Erdbodens untersuchte er weit genauer als seine Vorläufer Hipp arch und Posidonius [27], die erosive Wirkung der Gewässer war ihm kein Geheimniss [28], und wie er überhaupt mit Vorliebe hydrographische Untersuchungen anstellte (z. B. über Schwemmland, Deltabildung u. dgl.) so widersetzte er sich auch mit Glück dem Beginnen, unmögliche Theorieen über den Lauf und die Verzweigung der Ströme zur Geltung zu bringen. Ebenso bestimmt war er in der Erkenntniss des Faktums „dass successive Erhebung über den Meeresspiegel eine ähnliche Wärmeabnahme und in deren Gefolge auch ähnliche pflanzengeographische Erscheinungen bedingt, wie eine stetige Fortbewegung an der Meeresoberfläche in nordsüdlicher Richtung “ [29]. Aus einer unlängst veröffentlichten quellenkritischen Arbeit K. J. Neumann's über

Krates that [22]. Dessen Versuch, die Begrenzungslinien des Festen und Flüssigen symmetrisch zu fixiren, soll auf einem Erdglobus in Pergamum (II. Jahrhundert v. Chr.) versinnlicht worden sein. 
Strabon [30] zieht ferner deren Recensent, A. Kirchhoff, den Schluss [31], dass der kleinasiatische Forscher durch seine "Taurusgrenze " nicht blos eine wichtige Wasserscheide, sondern auch eine klimatologische Scheidelinie festzulegen beabsichtigte, welche die kalten Nordländer von dem Gebiete des gemässigten Mittelmeerklima's trennt. Man wird diese Deutung nicht für zu kühn erachten, wenn man sich vergegenwärtigt, dass Strabon eben zur Eröffnung weittragender Perspektiven ganz der richtige Mann war; stehen doch auf gleicher Höhe seine Ausführungen über die Küstengliederung eines Landes und den Zusammenhang, der diese rein geometrische Eigenschaft an die Rolle knüpft, welche das fragliche Land in der Geschichte der Menschheit zu spielen berufen ist. Und hätten wir nur den einzigen Ausspruch Strabon's bewahrt von dem ,vielgestaltigsten " Welttheil Europa, so würde er allein uns eine Ahnung von der freien und klugen Anschauungsweise des Mannes beibringen können [32].

Mit Strabon erreicht die wissenschaftliche Erdkunde der Griechen nicht allein ihren Höhepunkt, sondern leider gleichzeitig auch ihr Ende, denn was das Gros der „Geographi minores “ geleistet, beschränkt sich wesentlich auf Commentirung und Wiederholung des Vorhandenen und trägt nirgends mehr den Stempel selbstständiger Geistesarbeit. In drastischer Sprache hat diese Wahrheit Berger ausgesprochen [33], der freilich auch in seiner Werthschätzung Strabon's der Tendenz seiner geschichtlichen Untersuchung entsprechend nicht so weit geht, wie wir diess thun zu sollen glaubten. Nur eine einzige Schrift der spätgriechischen Literatur möchten wir noch besonderer Erwähnung würdigen, da sie zwar auch zunächst nur den Werth eines Sammelkastens besitzt, gerade aber aus diesem Grunde für die Historiker, die sich bislang nur recht wenig mit ihr beschäftigt haben, eine Fundgrube darbieten dürfte. Diess ist des Plutarch Büchlein ${ }^{2}$ De facie in orbe lunae". Der Grundgedanke desselben gipfelt in dem Bemühen, Analogieen zwischen der Oberflächengestaltung von Mond und Erde ausfindig zu machen, und wenn auch durch dieses Streben einzelne recht sonderbare Blasen zum Aufsteigen gebracht werden*), so nimmt der Tieferblickende in demselben doch die Keime jenes fruchtbaren Ineinandergreifens von Astronomie und Geologie wahr, auf welches zumal die englischen Selenographen der Gegenwart mit ebensoviel Eifer als Erfolg hingewirkt haben. Des Ptole mäus Werk gehört nicht hierher. -

Von den Griechen lenken wir unsere Schritte hinüber zu deren westlichen Nachbarn. Dass der Sinn der Römer für exakte Forschung und speziell für exakte Naturbetrachtung kein besonders feiner war, ist eine vielleicht nur zu sehr bekannte Thatsache, denn es führt diess $\mathrm{zu}$ der landläufigen und von K. v. Littrow sogar in einer akademischen Schrift [35] verfochtenen Annahme, dass man die römische Seite des klassischen Alterthums gänzlich ausser Acht lassen dürfe, sobald es sich um geschichtlich-naturwissenschaftliche Fragen handelt. Wir werden den Beweis antreten, dass wenigstens für die physische Erdkunde der

*) A. v. Humboldt nimmt u. a. Bezug auf die in dieser Schrift befürwortete und merkwürdigerweise auch dem orientalischen Vorstellungskreise genehme Ansicht, dass die Umrisslinien, welche schon das unbewaffnete Auge im Vollmonde unterscheidet, nur ein Spiegelbild der irdischen Continentalgrenzen seien [34]. 
Sachverhalt denn doch ein sehr verschiedener ist. Schon die Dichter des goldenen und silbernen Zeitalters geben uns manche brauchbare Aufschlüsse über die Art und Weise, wie sich der feingebildete Römer das Wesen der auf die Erdoberfläche einwirkenden Kräfte zurecht legte; das Windsystem des Horaz, Vergil's häufig wiederkehrende Hinweisungen auf Astrometeorologie und die zum Theil einen kenntnissreichen Beobachter verrathenden Bemerkungen über geologische Erscheinungen, welche sich in den Metamorphosen des Ovidius finden, verdienen alle Aufmerksamkeit eines dereinstigen Spezialhistorikers der physikalischen Geographie. In noch weit höherem Grade gilt diess von den eigentlichen Naturgedichten der Lateiner, von den sechs Büchern ${ }_{\pi} \mathrm{De}$ rerum natura" des Lucretius und von dem geologischen Lehrgedicht ,Aetna", welches nach Teuffel [36] den Lucilius zum Verfasser haben soll. Die modellirende und umformende Wirksamkeit des Wassers hat der auch als Hydrotechniker berühmte Baumeister Vitruvius im achten Buche seines bekannten Werkes „De architectura " einlässlich geschildert. Auch an Systematikern hat es den Römern in unserem Fache keineswegs gefehlt, und wenn wir auch den Ausspruch B. Studer's [37], Plinius der Aeltere habe im zweiten Buche seiner Naturgeschichte, im Gegensatz zu der speziellen Erdkunde der vier folgenden Bücher, eine allgemeine physische Geographie gegeben, nicht so ganz unterschreiben möchten, weil doch dann die Anforderungen, die man an eine solche $\mathrm{zu}$ stellen berechtigt ist, gar zu sehr heruntergeschraubt werden müssten, so wollen wir andererseits dem Werke des vielgelehrten Compilators das Lob einer sehr reichhaltigen Materialiensammlung nicht streitig machen. Allein Rom hat auch einen wirklichen Systematiker hervorgebracht, um den man sich nur bei weitem noch nicht genug gekümmert hat, und diess ist Lucius Annaeus Seneca. Wir folgen, indem wir sein Verdienst mit einigen Worten kennzeichnen, der trefflichen Monographie, die Nehring [38] über den unter seinen Zeitgenossen einzig dastehenden Naturphilosophen publicirte.

Obwohl mit einem gewissen Rechte die "Naturales Quaestiones" ihrer ganzen Ausdehnung nach hierher gehören, so sind es doch wesentlich das dritte und sechste Buch, die für uns in Betracht kommen. Das erstgenannte ist der Hydrologie gewidmet; es [39] handelt von der mechanischen und chemischen Aktion der Meteorwasser und von der Entstehung der laufenden Gewässer, wobei nicht blos die Temperatur und Farbe derselben, sondern auch die Sedimentbildung, die periodisch fliessenden Quellen zur Besprechung gelangen. Sowohl die formbildende Gewalt des Wassers durch Erosion, als auch dessen nivellirende Thätigkeit bei der Bildung von Schwemmland sind dem Seneca genau bekannt, der uns auch, gleich so manchem Vertreter der modernen Neptunistenschule, als entschiedener Anhänger der Theorie von einer periodisch wirkenden Erdüberfluthung entgegentritt. Im sechsten Buche [40] spricht er von den Erdbeben, über deren Verlauf er umfassende Erfahrungen eingezogen haben muss, da er insbesondere auch über die geographischen Vorbedingungen dieser Erscheinungen völlig klar urtheilt und hier manche Wahrheiten anticipirt, die noch heute wenig verändert in den geologischen Lehrbüchern vorgetragen werden. Die gleichfalls alle wichtigen Punkte streifende Vulkanlehre Seneca's [41] gemahnt auf das Lebhafteste an die Epoche Leopold's v. Buch und 
Alexander's v. Humboldt. Im dritten und vierten Buche finden wir gelegentliche Bemerkungen eingestreut, welche ein tiefergehendes Verständniss meteorologischer Thatsachen erkennen lassen. $\mathrm{Zu}$ allem Ueberflusse nennen wir noch die Titel der einzelnen Bücher des Werkes in der Reihenfolge, welche Nehring [42] aus inneren Gründen denselben anweisen will. Wenn man hört, dass dieselben folgeweise von den himmlischen Lichterscheinungen, von den Kometen, vom Hagel, von den Winden, von den Erdbeben (und Vulkanen), vom Blitz, vom Wasser und endlich - gewissermassen zur Anwendung der entwickelten Lehrsätze auf einen interessanten Einzelfall — vom Nil handeln, so wird man uns die Berechtigung dazu nicht absprechen können, die naturwissenschaftlichen Fragen des Seneca als eine in ihrer Art sogar sehr vollständige Encyklopädie der physischen Erdkunde zu bezeichnen.

Die spätere römische Literatur bietet, je mehr wir uns dem Beginne des Mittelalters nähern, um so weniger Ausbeute für unsere Zwecke dar. Der Geschichtschreiber unserer Disciplin freilich, der auch die Nachtseite derselben żu berücksichtigen gesonnen wäre, müsste bei manchem spätlateinischen Autor Halt machen und insbesondere mit Macrobius sich beschäftigen. Die eigenthümlichen Ansichten, welche bei ihm und bei seinen Zeitgenossen zu finden sind betreffs des Grössenverhältnisses des Wassers und Festlandes, hat Humboldt zum Gegenstande einer seiner geistvollen Untersuchungen gemacht [43]. Wir an diesem Orte glauben diese Ausläufer ebensowohl mit Stillschweigen übergehen zu dürfen, wie den von Peschel mit dem Namen einer Periode der "patristischen" Geographie belegten [44] Zeitraum, denn so wenig wir in Abrede zu stellen gemeint sind, dass auch bei den vielfach in unser Gebiet übergreifenden Betrachtungen der Kirchenväter über das Hexaëmeron ab und zu ein ganz gesunder Gedanke durchblitze ${ }^{*}$ ), so kommt dergleichen doch zu vereinzelt vor, um in dieser genetischen Skizze einen Platz beanspruchen zu können. - Auch von den Arabern, die sich auf einem anderen Boden nicht allein als Bewahrer des ihnen Ueberlieferten, sondern auch als selbstständige und fruchtbringende Arbeiter bethätigt haben, vermögen wir nur wenig zu berichten, denn nicht blos an geographischem Sinne fehlte es den meisten Orientalen, sondern auch an jener feinsinnigen naturwissenschaftlichen Auffassung, welche einem Strabon und Seneca zu so manchem glücklichem Funde verhalf, obwohl beide wohl weniger reelle physikalische Kenntnisse besassen, als ein gewöhnlicher arabischer Durchschnittsgelehrter. Albîrunî, der auf weiten Fahrten sich einen schärferen Blick als viele seiner Landsleute angeeignet hatte und z. B. das Auf- und Abschweben der Koralleninseln im indischen Meere richtig erkannte [45], und Massudi, der zwischen der physischen Beschaffenheit einiger ihm bekannter Länder treffende Vergleiche anstellte [46], sind eigentlich die einzigen Schriftsteller der arabischen Zeit, welche man einigermassen den grossen Männern des Alterthums an die Seite stellen darf. Ausserdem darf vielleicht noch genannt werden $\mathrm{Jbn}$ Haitham - bekannter unter dem Namen Alhazen - wegen seiner unleugbaren Verdienste um die meteorologische Optik [47] und Alkbazînî, der in seinem Traktat lernen.

*) Ein Beispiel dieser Art werden wir gleich im nächsten Kapitel kennen 
von der Wage auf die Angabe von Mitteln dachte, um die Sommertemperatur graduell von derjenigen des Winters zu unterscheiden [48]. Sonst aber haben die muhammedanischen Geographen des Mittelalters ihrer Wissenschaft sogar direkten Schaden zugefügt, indem sie ihrem Hange zur Mythenbildung die Zügel schiessen liessen; so haben sie in die Lehre von den Stromsystemen eine später nur schwer wieder auszurottende Verwirrung hineingetragen [49], und was sie auf diesem Felde sündigten, machte sich um so fühlbarer, als es selbst den besseren ihrer darstellenden Geographen, einem Istachri und Edrisi, an eigentlich kartographischem Talente gänzlich gebrach. Die Lehrbücher unseres Faches machen, soviel des Merkwürdigen und Anziehenden sie in kulturgeschichtlicher Beziehung auch darbieten, keine Ausnahme von der allgemeinen Regel; die durchgehende Tendenz, das Unwahrscheinliche und Sonderbare dem Natürlichen und Einfachen vorzuziehen, macht sich gleicherweise geltend in jenen Schriften, deren Autoren, wie Shemseddîn von Damaskus [50] oder Zacharias von Kaswin [51], einen orthodox-mosleminischen Standpunkt vertreten, oder welche, wie das encyklopädische Werkchen der ,lauteren Brider ${ }^{*}[52]$, einem rationalistischen Zuge ihre Entstehung verdanken. Kazwîni, um von diesem hervorragendsten Compendiographen einige Worte zu sagen, hat seinem Buche einen ganz rationellen Plan zu Grunde gelegt: er giebt zuerst einen Ueberblick über die astronomischen Erscheinungen, indem er die Sphäre jedes einzelnen Wandelsternes getrennt für sich ảohandelt, sodann schildert er, von oben niedersteigend, nach einander die Sphären des Feuers, der Luft, des Wassers und der Erde. Jedes der bekannten Meere erhält seine eigene Charakteristik, dann wird das Relief des Erdkörpers beschrieben und der Veränderungen gedacht, welche Erdbeben und andere Umwälzungen in diesem hervorbringen; merkwürdige Berge, Flüsse und Quellen werden aufgezählt, und eine populäre Mineralogie und Gesteinslehre beschliesst das Ganze. Soweit wäre Alles gut, allein die Einzelschilderungen laufen grossentheils auf die Erzählung von Märchen und Reiseabenteuern hinaus, und nur selten entschädigen den modernen Leser für solchen Ballast gesunde Ansichten, wie sie z. B. über den Zusammenhang der Luftströmungen mit lokalem Regenfall geäussert werden*). Im guten Sinne anregend können derartige schriftstellerische Produkte auf das abendländische Gelehrtenthum nicht gewirkt haben.

Man liest in geschichtlichen Werken gar nicht selten, die Stagnation der Naturwissenschaften sei im Mittelalter eine so vollkommene gewesen, dass man diese Periode ruhig überschlagen könne, und Mancher ist geneigt, dieses absprechende Urtheil ohne Weiteres auch auf die Kosmographie auszudehnen. Wer so schliessen wollte, begienge aber ein schweres Unrecht. Anfänglich natürlich, als man zu den Wissenschaften wieder zurückzukehren anfieng, musste man sich mit dem Wenigen begnügen, was aus spärlich fliessenden und noch dazu abgeleiteten Quellen des antiken Wissens, aus Marcianus Capella, Isidorus Hispalensis u. a., zu schöpfen war; was man in jener frühen Zeit

*) Auch die Bemerkungen über Winde, die an schneebedeckten Gebirgen und Wüsten hinstreichen und durch diese einen besonderen Charakter erhalten, sind zutreffend [53]. 
von der Erde und den Naturkörpern wusste, ersieht man recht gut aus einem Manuale des Hrabanus Maurus, welches beim Unterrichte in den Klosterschulen gebraucht, neuerdings aber durch die erläuternde Ausgabe Fellner's auch weiteren Kreisen zugänglich gemacht ward [54]. Allein schon mit Scotus Erigena wird es heller auf unserem Gebiete, und die "Magna de naturis philosophia" des Wilhelm von Conches, ein Werk aus der ersten Hälfte des XII. Jahrhunderts, steht nach K. W erner [55], soweit man aus den uns erhaltenen Ueberresten schliessen darf, völlig auf der Höhe, die sich eben damals überhaupt erreichen liess. Selbstständige Denker und gleichzeitig auch Männer, deren soziale Stellung ihnen eine Fülle von Thatsachen ungesucht zuführen musste, waren die Vertreter der scholastischen Glanzzeit, Albertus Magnus, Roger Bacon, Thomas von Aquin. Bacon's naturwissenschaftliche Bedeutung ist zu bekannt, als dass wir länger bei ihr zu verweilen brauchten, von Albert aber pflegt sonst weniger gesprochen zu werden, und doch hat gerade er der physikalischen Seite der Geographie seine besondere Zuneigung gewidmet. Humboldt sagt von ihm [56]: „Die Schrift , liber geographicus de natura locorum ${ }^{6}$ ist ein Abriss der physischen Erdkunde, in welchem der Verfasser nicht ohne Scharfsinn entwickelt, wie der Unterschied der Breite und die Beschaffenheit der Erdoberfläche gleichzeitig die Verschiedenheit der Klimate bedingen." Auch eigneten dem grossen Dominikaner bereits korrekte pflanzengeographische Anschauungen; er wusste, dass neben der Art der Insolation anch die topische Beschaffenheit des Standortes für die einzelnen Gattungen und Familien von Bedeutung sei [57]. Nicht minder ist des Vincentius Bellovacensis ,Speculum naturale ${ }^{6}$ Jedem unentbehrlich, der über das geographische Wissen und die naturwissenschaftliche Initiative der so viel verlästerten christlichen Aristoteliker ein billiges Urtheil gewinnen möchte. Einigermassen gewährt die Mittel hiezu auch das "Weltbild ${ }^{*}$ des spätscholastischen Kardinals Peter von Ailli, der den Stoff zu seinem voluminösen Werke nach der Aeusserung seines Biographen Tschackert [58] zwar wesentlich aus Plinius, Orosius, Isidor und Bacon zusammengetragen hat, gerade deshalb aber von dem Gesammtwissen seiner eigenen und einer weiter zurückliegenden Periode ein entsprechendes Bild liefert. Dass neben solchen besseren Arbeiten, namentlich in den entlegeneren Klöstern, auch sehr untergeordnete kosmographische Compilationen ihr Dasein fristeten, kann nicht überraschen; von einer solchen hat der Verfasser dieses bei einer früheren Gelegenheit [59] eine detaillirte Beschreibung gegeben.

All' die Männer der Wissenschaft, deren wir als mittelalterlicher Koryphäen bisher zu erwähnen hatten, gehörten der Kirche an, doch hat auch das Laienthum seine Verdienste, und namentlich die Italiener des XIII. und XIV. Jahrhunderts verdienen in dieser Beziehung genannt zu werden. Was Boccaccio und Petrarca als geographische Schriftsteller leisteten, erbebt sich allerdings nicht eben über das Durchschnittsniveau ihrer Zeit, um so heller aber strahlt die Ruhmeskrone eines ihnen congenialen oder noch überlegenen Dichters, Dante Alighieri's. In seiner Jugend hatte dieser grosse Mann den Unterricht Pietro Latini's genossen, der in Folge der Bürgerzwiste seine Heimath Florenz verlassen und sich in Paris niedergelassen hatte, wo er in altfranzösischer Sprache sein geographisch nicht minder wie geschichtlich 
wichtiges Sammelwerk "Der Schatz" abfasste, von welchem wir seit einigen Jahrzehnten eine leider blos textuelle Ausgabe [60] besitzen. Jedenfalls hat seine Unterweisung auf den lernbegierigen Schüler im hohen Grade anregend gewirkt, denn Dante fasste ein lebhaftes Interesse für physisch-geographische Fragen und wusste demselben vorkommendenfalls einen bestimmten Ausdruck zu verleihen. Viele Stellen seiner „Divina Commedia" könnten als Belege herangezogen werden, auch im "Convito" begegnen wir, wie Libri [61] rühmt, den anschaulichsten Schilderungen von Naturvorgängen, allein auch als monographischer Schriftsteller betrat der Dichterfürst das Gebiet der anscheinend so wenig reizvollen Geophysik. Die aus der Peschel'schen Schule hervorgegangene Schrift von W. Schmidt [62], welche uns Näheres über den Naturforscher Dante mittheilt, gestattet uns einen Blick in das Getriebe wissenschaftlicher Zänkereien zu werfen, welche sich betreffs der Streitfrage erhoben hatten, ob der Schwerpunkt der festen Erdkugel zugleich auch der Schwerpunkt für die irdischen Wassermassen sei, oder nicht. Da war es eben Dante vorbehalten, durch die Betonung des mechanischen Satzes, dass jedem wie immer zusammengesetzten Körper nur ein einziger Schwerpunkt zukomme, dass also die Anordnung der festen wie flüssigen Erdbestandtheile eine diesem gemeinsamen Schwerpunkt entsprechende sein müsse [63], dem ganzen Streit die Spitze abzubrechen; zugleich aber verbreitete er sich bei diesem Anlass auch über andere Themen und erwies sich dabei in allen Sätteln gerecht. Ein Zeitgenosse Dante's, Ristoro von Arezzo, ist ferner der Verfasser einer kosmischen Physik, die man füglich als typisch für die Methode des Mittelalters betrachten kann. Wie systematisch er in diesem von Narducci herausgegebenen Werke [64] verfuhr, erhellt vielleicht dann am Besten, wenn wir ohne besondere Wahl die Ueberschriften einiger aufeinanderfolgender Abschnitte hier reproduciren [65]: „Della figura della terra discoperta; s'ella dee essere tutta piana, o parte piana o parte montuosa“ ... „Della cagione, perch'egli fu mestieri che la terra abitabile avesse permessione dell'acque sopra essa e intra essa, correnti e non correnti“ “.. „Della cagione, perch' egli fu mestieri che l'acqua che corre per la terra vegna dal mare e torni nel mare, e della ragione della necessità del mare Mediterraneo. ${ }^{\text {" }}$ Die Art der Fragestellung weicht von der modernen höchstens insoferne beträchtlich ab, als etwas zu grosse Anforderungen an den Erklärer gestellt werden, für die Beantwortung aber erwies sich die vorgefasste Idee höchst nachtheilig, dass Alles, was auf der Erde vorgeht, einen astronomischen, beziehungsweise astrologischen Grund haben müsse, und dass namentlich die Vertheilung der Fixsterne auf der nördlichen und sïdlichen Himmels-Hemisphäre in gewissen Verschiedenheiten der beiden irdischen Halbkugeln sich abspiegle. -

In dem Maasse, als durch die geographischen Eroberungszüge der Spanier und Portugiesen die Grenzen des länderkundlichen Wissens weiter hinausgerückt wurden, in demselben Maasse gewann auch das Studium der geophysikalischen Eigenschaften unseres Planeten an Tiefe und Umfang. Neue Sternbilder erschienen am Himmel, die thörichte alte Lehre von einer ,zona combusta seu inhabitabilis" verlor ganz von selbst ihren Halt, Luft- und Meeresströmungen von bisher unbekannter Regelmässigkeit legten den Gedanken nahe, dass auch die zweite und 
dritte Elementarsphäre, um in dem noch immer beliebten Style des Aristoteles zu reden, von festen Gesetzen beherrscht werde, und die Veränderlichkeit der magnetischen Missweisung eröffnete noch mehr den Blick in neue Gebiete. Konnte sich doch selbst der weit mehr praktisch denn theoretisch angelegte Colon der Versuchung nicht entziehen, für die angebliche Ortsveränderung des Polarsternes und für die Hochfluth an der Orinoko-Mündung groteske Hypothesen aufzustellen [66]. Ebensowenig, wie Colon, waren die Conquistadoren ihrer grossen Mehrzahl nach Leute von wissenschaftlicher Bildung, doch folgten ihnen nicht selten Begleiter, deren Kenntnisse den eigenen zur Ergänzung dienten, und die sich theilweise auch durch eine feine Beobachtungsgabe auszeichneten. Erinnert sei nur an Petrus Martyr de Anghiera, der über die Verschiedenheit der klimatischen Verhältnisse in der alten und neuen Welt ganz treffende Betrachtungen anstellte und z. B. die von der Erwärmung abhängige Verschiebung der Schneegrenze erkannte [67]. Das weitaus hervorragendste Werk der üppigen Reiseliteratur, die seit der Entdeckung neuer Erdtheile emporwuchs, ist die allerdings einer etwas späteren Zeit entstammende, für die physische Geographie noch jetzt bedeutungsvolle Beschreibung der ,indischen " Länder; welche den Jesuiten-Missionär D'A costa zum Verfasser hat [68]; ein zweites Werk aus seiner Feder über den neuen Welttheil ist nur zum Theil erschienen.

Niemand wird erwarten, dass angesichts der damaligen Verkehrsverhältnisse die befruchtenden neuen Anschauungen, welche die seefahrenden Völker wohl oder übel in sich aufnehmen mussten, besonders rasch auch in die mehr binnenländische Literatur Eingang gefunden hätten. Dort, namentlich in Deutschland, fand die physische Erdkunde für's Erste noch gar keinen Boden, und nur wenige Schriftsteller besassen, man möchte fast sagen, die Kühnheit, für diesen noch nicht zum Range einer eigentlichen und zünftigen Fachwissenschaft erhobenen Zweig ein gewisses Interesse an den Tag zu legen. Einen Ehrenplatz unter diesen wenigen verdient der wackere deutsche Kosmograph Sebastian Münster. In einer neueren Abhandlung von Döderlein über diesen polyhistorisch gebildeten Mann - er war auch als Theologe, Hebräist und Geometer erfolgreich thätig - wird allerdings darauf hingewiesen [69], dass derselbe noch in den hydrographischen Wahnvorstellungen der Araber und ihrer westländischen Nachtreter befangen war; dafür aber muss man ihn als einen der Begründer der wissenschaftlichen Gebirgskunde gelten lassen, und namentlich mit den Gletschern hat er sich unter den Neueren zuerst eingehender beschäftigt [70]. Ein etwas älterer Zeitgenosse Münster's würde, wenn ihn sein Lebensberuf zur schriftstellerischen Thätigkeit hingeführt hätte, im höchsten Grade anregend auf das XVI. Jahrhundert gewirkt haben, allein leider blieben seine nicht blos kühnen, sondern auch auf die Erfahrung gebührend Rücksicht nehmenden Gedanken über geographische und geologische Probleme in seinen Manuskripten begraben. Lionardo da Vinci, der gründliche Kenner der Erosionswirkungen, verdient Peschel's Lob [71], dass das Beste von dem, was seine Periode bezüglich der an der Erdoberfläche vor sich gegangenen Veränderungen zu Tage förderte, von ihm herrühre. Das Jahrhundert, in welchem wir uns soeben bewegten, schloss jedoch nicht, ohne noch eine literarische 
Leistung ersten Ranges hervorgebracht zu haben; wir meinen William Gilbert's grossartiges Werk über die magnetischen Erdkräfte, welches gerade im Jahre 1600 das Licht der Welt erblickte [72].

Die Schwelle des neuen Säkulums überschreitend, begegnen wir sofort einer Reihe von Männern, deren die Geschichte der Erdphysik mit Achtung zu gedenken hat. Was Johann Kepler für unsere Disciplin leistete, ist allerdings minder leicht, als bei Anderen festzustellen, da es meist nur gelegentliche Betrachtungen und Aeusserungen sind, die hier in Frage kommen, und da nur für ein spezielles Fach bis jetzt der - sehr gelungene - Versuch gemacht ward, die Ansichten des grossen Astronomen einheitlich darzustellen, nämlich für die Meteorologie [73], so bleibt künftigen Geschichtsforschern noch manche dankbare Aufgabe vorbehalten. An zweiter Stelle steht uns Lord Bacon of Verulam. Nicht leicht sind über einen Naturforscher so widersprechende Urtheile in die Welt gesandt worden, wie über diesen Mann, denn während die Einen in ihm den Vater der induktiven Forschungsmethode verehren, glauben Andere jedwedes Verdienst ihm absprechen zu sollen, und unter diesen Letzteren hat sich Liebig durch die Heftigkeit seiner Angriffe hervorgethan [74]. Wenigstens soweit die physikalische Geographie in Frage kommt, dürfte wohl auch in diesem Falle die Wahrheit in der Mitte liegen, denn wenn auch so mancher Ausspruch des in mathematischen Dingen nicht besonders bewanderten Mannes unser Erstaunen erregt*), so machen doch auf der anderen Seite seine Reflexionen über die Aehnlichkeit der Kontinentalbildung [76] und seine ᄁTheoria ventorum “ wieder einen um so besseren Eindruck, und Wohlwill, dem wir [77] für seine musterhaft objektive Darlegung der für und wider Bacon sprechenden Gründe überhaupt zu Dank verpflichtet sind, sagt mit Recht [78]: „Humboldt spricht wiederholt von Bacon's , berühmter " Naturgeschichte der Winde; Dove findet in ihr die erste Auffassung des Drehungsgesetzes, das durch ihn zur Grundlage der neneren Meteorologie erhoben ist. Whewell, der in der Lehre von Ebbe und Fluth selbst thätiger Forscher ist, gesteht Bacon sinnreiche Bemerkungen über den Gegenstand zu, obwohl ihm noch die Anziehung des Mondes als eine mystische Erklärung erscheint." Immerhin war die Thätigkeit eines Kepler und Bacon für unsere Disciplin mehr eine anregende und wegzeigende; in dem laufenden Jahrhundert begegnen uns aber auch sehr achtbare Versuche systematischer Darstellung des ganzen Wissensgebietes. Die Namen Varenius, Riccioli und Athanasius Kircher sind jedem Physiker und jedem Geographen wohlbekannt.

Ueber die Lebensgeschichte des Ersteren haben neuerdings die Forschungen Breusing's volles Licht verbreitet [79]. Wir wissen jetzt, dass derselbe 1622 zu Hitzacker im Hannöverschen geboren ward, in Hamburg unter Jungius studirte und der im Jahre 1649 erschienenen Beschreibung Japan's sein Hauptwerk, wenn auch noch nicht in ganz vollendeter Gestalt, im nächsten Jahre folgen liess [80], wovon nicht

*) Z. B. der nachstehend angeführte [75]: „Deshalb treiben die Philosophen Possen, wenn sie sagen, dass, wäre die Erde durchbohrt, die schweren Körper aufhören würden, zu fallen, sobald sie zu dem Mittelpunkt gekommen wären." In ähnlicher Unklarheit über das Wesen der Schwerkraft befanden sich aber die meisten Zeitgenossen Bacon's, und man darf ihm deshalb obige Stylblume nicht allzusehr veriibeln. 
weniger als elf Ausgaben existiren; die beste derselben ist von $\mathrm{J}$. Newton [81] besorgt worden*). Nach A. v. Humboldt's klassischem Zeugniss ist Varen's Methode, obwohl dieser selbst das Wort „Geographia comparativa" in einem engeren Sinne gebraucht, eine ächt vergleichende [82]; seine Untersuchungen über die Streichungsrichtung der Gebirge, seine Liste der brennenden und erloschenen Vulkane, seine Studien über die Inselvertheilung und die Meerestiefen, seine Versuche, die Meeresströmungen gleichzeitig durch den Einfluss der Winde, des verschiedenen Salzgehaltes und der Küstengestalt zu erklären, das Alles berechtigt den Verfasser des Kosmos zu dem Ausspruche (a. a. O.): -Das überaus wichtige Werk des Varenius ist im eigentlichen Sinne des Wortes eine physische Erdbeschreibung." Riccioli's fleissiges Sammelwerk [83] erhebt sich, wie man zugestehen muss, nicht bis $\mathrm{zu}$ dieser Höhe, dafür aber hat es unzweifelhaft einen ungleich grösseren Leserkreis sich erworben, als die "Geographia generalis". Kircher's Arbeiten richtig zu würdigen, in ihnen die stets reichlich vorhandene Spreu von dem Weizen zu sondern, ist erst der neuesten Zeit vorbehalten gewesen. Man darf, wie neuerdings von Zöckler [84] hervorgehoben worden ist, nicht ausser Acht lassen, dass die dickleibigen Bände des gelehrten Jesuiten nicht blos Lesefrüchte enthalten, dass er vielmehr auch Reisen zu physisch-geographischen Zwecken machte, die Quellen des Tiber untersuchte, auf Malta den Process der SeesalzGewinnung durch Autopsie kennen lernte, den Vesuv, den StromboliVulkan und den Aetna persönlich erforschte und die Tiefe der Krater nicht ohne Lebensgefahr mit einem neu erfundenen geodätischen Messwerkzeug zu bestimmen sich bemühte. So darf sein Versuch, in einem eigenen Werke [85] die Physik der Erdrinde wissenschaftlich zu begründen - eine Disciplin, zu der die Grundlage allerdings von einem deutschen Bergmanne bereits gelegt war [86] -, ebensowohl unsere Anerkennung in Anspruch nehmen, wie seine grossentheils auf eigenen Experimenten beruhende Schrift über Magnetismus [87]. Aus der zweiten Hälfte des laufenden Säkulums sind noch zwei Forscher von besonderem Verdienste als die Begründer selbstständiger Unterabtheilungen physisch-geographischen Wissens anzuführen: der Däne Steno, dem die geognostische Schichtenlehre ihren Ursprung verdankt [88], und der Franzose Fournier, der in einem voluminösen Werke [89] eine Fülle von Materialien sammelte, die in ihrer Gesammtheit unserer modernen Oceanographie entsprechen würden.

Von dieser Zeit ab hat die Physik der Erde, ohne sich freilich zunächst noch als selbstständige Wissenschaft zu fühlen, einen grossartigen Aufschwung genommen. Newton und Leibniz schufen die Rechnungsweisen, deren Anwendung auch schwierigere Probleme der Mechanik zu erledigen gestattete, Halley, Hadley und Mairan trugen den Geist exakter Ergründung in die Lehre von den Lufterscheinungen hinein, die grossen Bewegungen des Weltmeeres fanden in den Ber-

*) Die sehr lebenszähe Behauptung, Newton habe sich auf eine einfache Textausgabe beschränkt, ist, wie Breusing (a. a. O.) darthut, nichtsdestoweniger falsch. Freilich war seine verbessernde Thätigkeit eine ganz geräuschlose, allein er hat, um nur Eines zu sagen, 23 neue Zeichnungen hinzugefügt und einen Irrthum rektificirt, welchen sich Varen bei der Erklärung der stereographischen Projektion hatte zu schulden kommen lassen. 
noulli, Euler, D'Alembert ihre Meister, und auch die Physik der Süsswasser erlangte eine festere Begründung durch den noch zu wenig gewürdigten Mariotte [90]. Zugleich brachten grosse Reisen, unter denen nur diejenigen von Dampier, Chazelles, Tournefort und die zum Zwecke der Erdmessung unternommenen Expeditionen nach Peru und Lappland genannt sein mögen, neve Gesichtspunkte in Menge, und eine Menge geistiger Kraft musste verarbeitet werden, um dieselben einigermaassen mit en dbisher in Geltung stehenden Ideen zur Ausgleichung zu bringen. Allerdings hatten alle diese Entdeckungsreisenden stets bestimmte, engere Zwecke im Auge, und nur ausnahmsweise erhoben sich geistreiche Männer, wie Pallas oder De la Condamine, zur Conception umfassenderer Anschauungen. Das XVIII. Jahrhundert, das Zeitalter der Aufklärung, sollte jedoch nicht scheiden, ohne dass ihm eine ganz neue Art des wissenschaftlichen Reisens entsprossen. wäre, von welcher man bis dahin wenig wusste, die aber für die Erforschung des Wechselspieles der Naturkräfte auf der Erdoberfläche von ganz unberechenbarem Nutzen gewesen ist. Schon die schwedische Regierung hatte daran gedacht, den Wallfischfängern Gelehrte mitzugeben, deren einzige Bestimmung die Beobachtung und Aufzeichnung der sich darbietenden Naturmerkwürdigkeiten sein sollte [91], doch blieb dieser erste Versuch zunächst noch ohne weitere Folgen. Um so mehr Glück hatte in dieser Beziehung die englische Admiralität, als sie 1772 dem Weltumsegler Cook bei dessen zweiter Fahrt den trefflichen Johann Reinhold Forster mit dem Auftrage beigab, „philosophische Bemerkungen" über dás Gesehene und Erlebte niederzuschreiben. Man muss in dem interessanten Essay Rittau's über Forster [92] selbst nachlesen, wie dieser geniale Reisende die Configuration der Festlandmassen, die Struktur und Lage der Inseln, die Gebirge der von ihm besuchten Länder, die Quellen und Flüsse der Küstenstriche, die Tiefe, Farbe, Dichtigkeit und Wärme des Weltmeeres, das Leuchten der See, die Eisbildung und die mit den klimatischen Verhältnissen nach Art und Intensität variirenden Erscheinungen des Luftkreises durchweg von ganz neuen Seiten her aufzufassen und Verwandtes in Gruppen zusammenzustellen verstand, um einen Begriff davon zu bekommen, wie fruchtbringend Forster's Reisebericht für alle Zweige der physischen Erdkunde werden musste, ganz besonders aber für jene, deren Objekt die gestaltverändernden Beziehungen zwischen Land und Wasser sind. Und was noch mehr, aus diesem Werke und ebenso aus nahem persönlichem Verkehr mit dem Verfasser hat der grösste Forschungsreisende aller Zeiten die mächtigste Förderung gezogen: Alexander v. Humboldt. Freilich, nicht blos ferne Oceane und unbekannte Länder boten Neues und Wunderbares, auch im eigenen Lande war noch genug zu thun übrig geblieben. Ueber die Flachländer und niedrigen Gebirgszüge hinaus lag das geographische Wissen noch gar sehr im Argen, und C. Ritter hatte gar nicht Unrecht, wenn er in einem unlängst erst bekannt gewordenen Akademievortrage von der "Entdeckung“" der Gebirge sprach [93]. Aus dem Alterthum haben wir nur ganz vereinzelte Detailbeschreibungen merkwürdiger Berge, z. B. diejenige des Stenagoras für den Olymp, und auch im Mittelalter dachte man kaum an dergleichen. Die Pyrenäenkette wurde erst durch Pedro de Mareia's politisch-geographisches 
Werk "Limes hispanus" (Paris 1688) bekannt, und von den Alpen wussten selbst die Schweizer lange Zeit hindurch so wenig, dass die Montblancgruppe, die „montagnes maudites", von zwei englischen Touristen geradezu aufgefunden werden musste. Die physikalische Geographie der Alpen als solche begründet zu haben, ist ein Ruhmestitel des Zürichers Scheuchzer [94], aber erst um die Mitte des Jahrhunderts erschien die erste Monographie der Gletscherwelt von Altmann [95]; aus so unscheinbaren Anfängen erwuchs eine der schönsten und wichtigsten Disciplinen der Erdphysik, die glaciale Geologie. Dann allerdings entwickelte sich in Genf eine förmliche Schule der alpinen Forschung; den Jallabert und Bonnet folgten Senebier, Deluc, Pictet und zumal die beiden Saussure, und die Ufer des Leman scheinen ihre eigenthümliche Anziehungskraft für Studien dieser Art sich bis auf den heutigen Tag bewahrt zu haben, wie die Namen A. Favre, Dufour und Forel beweisen. Die physische Geographie der Alpen hat in B. Studer ihren Spezialhistoriker gefunden, auf dessen verdienstliche Schrift [96] wir nicht unterlassen wollen besonders aufmerksam zu machen.

Es erübrigt uns jetzt, noch einen Blick auf die didaktische Literatur zu werfen, wie sie im Laufe des XVIII. Jabrhunderts sich entfaltet hat. Im Allgemeinen ist hier Erfreuliches zu berichten. Für die Mittelschule hatte freilich der grosse Fortschritt des gelehrten Wissens noch keine rechten Früchte gezeitigt; die Physiker und $\mathrm{Ma}$ thematiker begannen sich zwar bereits für das umfangreiche, neue Grenzgebiet zu interessiren, allein die geographischen Schriftsteller, auch noch der Büsching'schen Schule, vermochten sich nur schwer von dem Gedanken loszureissen, dass die Erdkunde eine Notizensammlung oder bestenfalls ein Anhängsel der Statistik sei, und erst Gatterer hat, wie unlängst von Kropatschek betont ward [97], den Schulbüchern eine bessere Direktion in dem Sinne gegeben, dass auch die physische Seite der Wissenschaft gehörig betont wurde [98]. Die gelehrte $\mathrm{Pe}$ danterie machte nur zu gerne den guten Vorsätzen der Pädagogen einen Strich durch die Rechnung, wie z. B. aus dem Lehrplane des Geraer Gymnasialdirektors Hauptmann (1766) erhellt, in welchem nicht weniger als 24 Unterarten des geographischen Unterrichtes unterschieden werden, darunter als Nummer $4{ }_{\text {"Hydrographie }}$, als Nummer 8 ,Oekonomische Geographie", als Nummer 11 "Physikalische Geographie, von der Luft, Speisen und Krankheiten " [99]. Aber die Universitäten konnten jetzt wenigstens zum Theile das ersetzen, was der Schulunterricht noch nicht in richtiger Weise darbot; zwar fehlen uns auch hierüber die genaueren Nachweisungen, doch scheint es, dass in Göttingen die beiden Tobias Mayer, Lichtenberg und Kästner, in Greifswald Röhl, in Upsala Celsius und Berg man in ähnlichem Sinne gewirkt haben*). Man gewöhnte sich allgemach daran, mit dem Worte

*) Aus noch früherer Zeit möchte sich dem ersten Anscheine nach nur sehr wenig Gutes und Beachtenswerthes über den geographischen Universitätsunterricht mittheilen lassen. Bis etwa hundert Jahre nach der Reformationszeit - in katholischen Territorien noch weit länger - deckte sich ja der Vortrag der Naturwissenschaft mit demjenigen der aristotelischen Physik, welche der Hörer jedoch nur ganz selten aus den Originalquellen kennen gelernt haben dürfte. Ein 
"physische Geographie" einen klaren und bestimmten Sinn zu verbinden. Buache freilich, der zuerst von einer "Géographie physique" sprach, verstand darunter etwas Anderes, Beschränkteres, wie wir, obwohl seine Eintheilung derselben in eine "géographie extérieure ${ }^{4}$ und „intérieure" Manches für sich hat [102]; die Lehre vom Luftkreis z. B. hätte in seiner Begriffsbestimmung keinen Platz gefunden. Das erste Lehrbuch grossen Styles lieferte der Holländer Lulofs [103]; es ward von Kästner [104] deutsch bearbeitet und enthält - vornämlich in dieser seiner zweiten Gestalt - so ziemlich dieselben Materien, die man noch heutzutage in einem Werke dieser Art zu suchen pflegt. Eine in vielen Beziehungen verwandte Leistung repräsentirt Bergman's Compendium [105], von Röhl [106] in unsere Sprache übertragen; das räumlich überwiegende Kapitel "Von zufälligen Veränderungen“ gewährt auch dem modernen Leser noch reiche Belehrung. . Sehr brauchbare Werke rühren vom jüngeren Tob. Mayer [107], ferner von Mitterpacher [108] und dem Astronomen Bode [109] her, deren letzteres sich volle 34 Jahre lang seine Stellung zu bewahren wusste (die letzte Auflage erschien erst 1820). Der zweite Theil dieses weit verbreitet gewesenen Lehrbuches ist der Sternkunde und mathematischen Geographie gewidmet, der erste dagegen handelt von der physischen Beschaffenheit der Erdrinde, der Länder und der Meere, dem Luftund Dunstkreis, den Jahreszeiten und dem Klima, den physischen Veränderungen der Erdoberfläche, als welche Ueberschwemmungen, Erdfälle, Erdbeben und Vulkanausbrüche zusammengefasst werden, endlich noch von der physischen Geschichte des Erdballes. Höher jedoch als all' diese gewiss nicht unverdienstlichen Lehrmittel steht jener Cyklus von Vorträgen über physische Geographie, welche der grosse Königsberger Philosoph Kant an der dortigen Hochschule gehalten hat. Er selbst ist nicht dazu gekommen, sein Heft systematisch für den Druck zu bearbeiten, doch giebt es von demselben mehrere gute Ausgaben, die uns mit dem Inhalte dieser - nach den Aussagen von Zeitgenosen ungemein anregend wirkenden - Vorlesungen bekannt machen [110]. Wir begnügen uns, der bis in's Einzelne gehenden Würdigung zu gedenken, welche Zöllner den Kant'schen Arbeiten auf dem Gebiete der tellurischen Naturerforschung hat angedeihen lassen [111], und bemerken lediglich, dass nicht eben die Menge beigebrachten Stoffes, wohl aber die Eigenartigkeit der Betrachtungsweise in zahlreichen Einzelfällen - Erderschütterungen, Passatwinde, Thalbildung - das Auszeichnende in den verschiedenen Abhandlungen ausmacht, welche wir von dem genialen Denker erhalten haben. Wir werden uns zu demselben im Folgenden gar häufig zurückgeführt sehen. -

fleissiger Forscher hat trotzdem jedoch Aussicht, auf diesem für steril gehaltenen Felde Früchte einzuheimsen. Wie.V. A. Huber [100] berichtet, trug im XIII. Jahrhundert ein gewisser Girald us zu Oxford über "Topographia Cambriae" vor, und zwar scheint es sich dabei nicht um ein blos isolirtes Vorkommniss zu handeln. Unter den Vorgängern des Galilei auf der mathematischen Lehrkanzel von Padua führt Favaro[101] auch einen sonst wenig bekannten Mann auf, der vom Senate beauftragt war, speziell über Hydrographie und Anemographie zu lesen;, also über Gegenstände, die heute eben Theile der physischen Erdkunde darstellen. Es verlohnte wohl der Mühe, nach dieser Richtung hin einmal planmässig Untersuchungen anzustellen. 
Bei der Besprechung des Jahrhunderts, in welchem wir uns jetzt befinden, werden wir uns insoferne kürzer fassen müssen, als dasselbe nur bedingt den Untergrund für eine pragmatische Geschichtserzählung abgeben kann. Denn einer unseres Erachtens ganz treffenden Bemerkung Peschel's zufolge sollte als untere Grenze für ein historisch-geographisches Werk gegenwärtig die Zeit des Erscheinens von Humboldt's "Kosmos" und von Berghaus' physikalischem Atlas angesehen werden. Wir, denen an diesem Orte der didaktische Zweck in erster, der wissenschaftlich-geschichtliche erst in zweiter Reihe steht, dürfen uns von dieser Bestimmung vielleicht ein wenig emancipiren, obwohl wir voll und ganz Peschel's Urtheil [112] über die genannten beiden Werke anerkennen: „Beide bilden einen Rechnungsabschluss, ein Inventar über fast alle einzelnen Fächer der naturwissenschaftlichen Erdkunde." Ganz natürlich müssen wir davon absehen, die Entwickelungsgeschichte der Einzeldisciplinen, wenn auch nur in groben Umrissen, schildern zu wollen; es muss hinreichend sein, eine Reihe besonders hervorragender Namen zu nennen. Laplace, Lagrange, Poisson sind die Begründer der „Mécanique céleste“, eines Gesetzbuches, aus welchem für die Oberflächenform der Erde, ihre innere Beschaffenheit und die Meeresgezeiten gleichmässig die Normen ent. fliessen; die Oceanographie ist von Lubbock, Whewell und Maury zum Range einer Wissenschaft erhoben worden; Dove, Kämtz, Kupffer, Buys-Ballot schufen eine Meteorologie auf exakter Basis; von Hansteen, Gauss und A. v. Humboldt datirt die an Strenge keinem Theile der Physik nachstehende Theorie des Erdmagnetismus, der sich allmählich die von Franklin geahnte, von Steinheil und Lamont schärfer umrissene Lehre von der Erdelektricität an die Seite stellen durfte. Mit Hopkins beginnt, als eine englische Spezialität, die - im engeren Sinne so genannte - geophysikalische Schule, von deren Vertretern Airy, Stokes, W. Thomson, G. H. Darwin auch den deutschen Geographen wohl bekannt sind, und während diese Männer die dynamische Geologie unter Aufbietung der mächtigsten mathematischen Hülfsmittel förderten, zeichneten Poulett Scrope, Mallet, v. Seebach, De Rossi, Suess u. a. neue Wege für die Ergründung der vulkanischen und seismischen Phänomene vor. Die alte Frage nach der Entstehung des Erdkörpers in seiner jetzigen Gestalt auf feurigem oder nassem Wege, diese im Ausgange des vorigen Jahrhunderts nach ihren Anfangsstadien durch die Namen A. Werner's und Hutton's bezeichnete Frage, ist neuerdings in nahe Beziehung zu dem Probleme der Gebirgsbildung getreten und hat von den Resultaten der Experimentalgeologie (im Sinne Daubrée's und F. Pfaff's) erhebliche Unterstützung zu gewärtigen. Als umfängliche und selbstständige Wissenschaften stehen die Lehre von der geographischen Vertheilung der Pflanzen und Thiere vor uns, während es doch kaum hundert Jahre her ist, dass für diese letztere Disciplin Zimmermann [113] mit schüchterner Hand die ersten Grundlinien zu entwerfen versuchte.

Freilich tragen alle diese Bemühungen den Charakter der Spezialforschung, und ihre Ergebnisse haben der physischen Erdkunde als solcher erst mittelbar Nutzen gebracht. Die eigentlichen Koryphäen der Gesammtwissenschaft sind unleugbar zwei auf der Grenzscheide des neuen Jahrhunderts stehende Männer, Leopold v. Buch und Ale- 
xander v. Humboldt. War auch der Erstgenannte der jüngere von beiden, so hat er doch eher als sein ihm kongenialer Freund angefangen, direkten Einfluss auf die Mitwelt zu üben, da er eher in der Lage war, die reifen Früchte seiner ausgedehnten Reisen dem Publikum zu Gute kommen zu lassen. Hatte schon die Beschreibung seiner Nordlandfahrt [114], bei welcher die lange angezweifelte Thatsache einer säkulären Oscillation der Festlandmassen zum erstenmale eine feste Gestalt annahm, das allseitigste Interesse erregt, so gab sein Werk über die canarischen Inseln [115], welches man nicht mit Unrecht als ein "standard work" der modernen erdphysikalischen Forschung bezeichnen könnte, den auf die Ergründung des inneren $\mathrm{Zu}$ sammenhanges der tellurischen Erscheinungen gerichteten Studien eine ganz neue Richtung. Die meisterhafte Schilderung der meteorologischen Verhältnisse jener gesegneten Erdgegend ist wohl das' erste Beispiel einer dem Individualcharakter des Landes angepassten Klimatologie; für die Pflanzengeographie boten die Tropengewächse ganz neue Anhaltspunkte dar; der glückliche Gedanke endlich, die Vulkane der Inselgruppe mit den Feuerbergen anderer Länder geometrisch sowohl wie ursächlich in Zusammenhang zu bringen*), realisirte in unvergleichlich besserer Weise den an sich richtigen Gedanken Buache's, dem derselbe nur eben nicht den treffenden Ausdruck zu geben vermocht hatte (s. o.). Von 1799 bis 1804 weilte Humboldt, dem Aimé Bonpland als treuer Arbeitsgenosse zur Seite stand, in Süd- und Mittelamerika und erwarb sich daselbst jenen Schatz von Erfahrungen, ohne welcher. sein erst gegen den Lebensabend hin zur Vollendung gediehenes Riesenwerk des "Kosmos" eine gleiche Bedeutung nicht hätte gewinnen können. Es ist ja wahr, dass in dem Vierteljahrhundert, welches seit dem Abschluss dieses Werkes verstrichen ist, ganze Theorieen sowohl, wie noch mehr einzelne Anschauungen eine vollkommene Umwälzung über sich ergehen lassen mussten, allein, wenn dadurch auch mancher Abschnitt ein wenig veraltet sein mag, so wird der Kosmos als Ganzes gleichwohl noch für viele Jahrzehnte ein unentbehrliches Handbuch für jeden Freund der physikalischen Geographie bleiben, und dieser Umstand wird es rechtfertigen, wenn wir nachstehend einen kurzen Ueberblick über denselben geben. Das Werk [117] setzt sich zusammen aus vier Bänden: in dem ersten wird ein Gesammtbild von dem entworfen, was sich am Himmel und auf der Erde in naturwissenschaftlicher Hinsicht Wissenswerthes darbietet; der zweite ist geschichtlichen Inhaltes, und namentlich wird darin mit unübertroffener Feinsinnigkeit der Nachweis geliefert, wie aus dem blossen Beschauen neuer Dinge, z. B. fremder Pflanzenformen, der Trieb zur Naturbetrachtung sich entwickelte; den Inhalt des dritten Bandes bilden die physische und topographische Astronomie, während der vierte der Geologie im weitesten Wortsinne sich widmet. Schon vorher hatte der grosse Reisende durch seine populäre Schilderung besonders merkwürdiger Eindrücke und Reminiscenzen aus fernen Ländern einem grösseren Leserkreis Begeisterung für derartige Aufgaben einzuflössen

*) Das sechste Kapitel verbreitet sich [116] „über die Natur der vulkanischen Erscheinungen auf den canarischen Inseln und ihre Verbindung mit anderen Vulkanen der Erdfläche". 
gewusst [118]. Streng wissenschaftlicher Natur ist auf der anderen Seite das grosse amerikanische Reisewerk [119], bei dessen Ausarbeitung: sich Humboldt durch einen wahren Generalstab bedeutender Gelehrter (Bonpland, Kunth, Oltmanns, Gay-Lussac u. a.) unterstützt sah, und in die gleiche Kategorie gehören die drei Bände [120], welche die im reifen Mannesalter unternommene Reise nach Hocbasien schildern. Wollte man mit geschichtlicher Treue die Verdienste im Detail registriren, welche sich $\mathrm{Humboldt}$ um die physische Erdkunde erwarb, man. würde eine äusserst schwierige Aufgabe in Angriff zu nehmen haben; sebr viel ist nach dieser Richtung hin bereits geleistet durch die von Bruhns besorgte Lebensbeschreibung, deren Schlussband [121] den Mann der Wissenschaft zu kennzeichnen bestimmt ist; wenn wir erwähnen, dass für denselben G. Wiedemann den erdmagnetischen, Ewald den geologischen, Dove den meteorologischen, Grisebach den pflanzengeographischen Theil und Peschel die Erdkunde im Grossen und Ganzen übernommen hatten, so ist damit wohl genug gesagt. Drei Punkte aber müssen auch wir als besonders wichtige hervorheben: die Einführung des Begriffes der Isothermen, die Schaffung einer korrekten und bezeichnenden orographischen Terminologie und die Begründung des Systemes magnetischer Korrespondenzbeobachtungen. Schon diese drei Schöpfungen würden hingereicht haben, den Namen Humboldt's zu einem verehrungswürdigen zu machen.

Es dürfte sich empfehlen, gleich hier in unmittelbarer Anknüpfung: an Buch und Humboldt der Vortheile Erwähnung zu thun, welche unserer Disciplin aus grossen und von entsprechenden Gesichtspunkten geleiteten wissenschaftlichen Reisen im Laufe der letzten Decennien erwachsen sind*). Auf Weltumsegelungen haben u. a. A. v. Chamisso, Horner und Ch. Darwin (s. 11.) Gelegenheit zu wichtigen Bemerkungen und Verallgemeinerungen bekannter Thatsachen g€wonn€n, Spix und Martius haben uns das vordem wenig bekannte Innere des brasilianischen Kaiserstaates aufgeschlossen, Sabine umsegelte die Erde, ausschliesslich um geodynamische und magnetische Konstanten $\mathrm{zu}$ sammeln, Rüppell trug physikalische Instrumente und Beobachtungsmethoden tief nach Aethiopien hinein, worin ihm später $\mathrm{D}^{\prime} \mathrm{Ab}$ badie nachgefolgt ist, und $\mathrm{Russegger}$ durfte in einer Reihe von Gegenden exakte Messungen anstellen, welche seit Carsten $\mathrm{Niebuhr}$ kein wissenschaftlich gebildeter Europäer betreten hatte. War auch die grosse Exkursion Hansteen's und Erman's nach Nordasien wesentlich der Einsammlung erdmagneti-

*) Allerdings ist uns dabei die Pflicht, kurz zu sein, um so mehr auferlegt, als die Geschichte der modernen Entdeckungsreisen bei Peschel [122] eine zusammenhängende und lückenlose Darstellung erfahren hat. Nur einen kleinen Nachtrag hiezu wollen wir an dieser Stelle liefern, weil das Mitzutheilende einen deutlichen Beleg für die Thatsache liefert, dass grosse Neuerungen auf geistigem Gebiete häufig geradezu in der Luft liegen und sich auch unter den ungünstigsten äusseren Verhältnissen vorbereiten müssen. Unter den eingeborenen Begleitern Humboldt's in Südamerika ragt hersor der Ecuadorianer Cáld as, über den uns neuerdings von $\mathrm{Schumacher} \mathrm{höchst} \mathrm{anziehende} \mathrm{Mittheilungen} \mathrm{gemacht} \mathrm{worden} \mathrm{sind} \mathrm{[123].} \mathrm{Durch-}$ aus ein selbstgemachter Mann, wenn auch natiurich durch seinen Reisegefährten mächtig angeregt, hat derselbe während eines kurzen Lebens - er fiel 1816 als Opfer der Insurrektionskämpfe - eine Anzahl von Arbeiten geschaffen, die sich nach ihrer Tendenz und Ausführung auch neben denen $\mathrm{Humboldt}$ s noch sehen lassen dürfen. 
scher Daten gewidmet, so hatte dieselbe doch auch für die anderen Zweige der physischen Erdkunde eine nicht zu unterschätzende Bedeutung. Ueberhaupt hat Russland, dessen gigantischer Länderbesitz zur Erforschung zwingend auffordert, in dieser Richtung Vieles gethan, wie man am besten aus Mädler's sehr vollständiger Skizze [124] ersehen kann; Göbel am kaspischen Meere, Hofmann und Abich in Armenien, v. Middendorff im Taymirlande, Prshewalski in Ostturkestan sind klassische Zeugen dieser Rührigkeit. Von neueren Expeditionen, deren Zweck einzig und allein die Erweiterung unseres erdphysikalischen Wissens war, während das sonst vorwaltende Interesse der spezifisch geographischen Forschung bei ihnen zurücktrat, seien drei hier genannt: die von Desor und Escher v. d. Linth zur Ergründung der Heimath des Fönwindes nach Afrika unternommene Reise, der Winteraufenthalt der französischen Forscher Bravais, Lottin und Martins in Lappland, der in dem Letzterwähnten einen trefflichen Geschichtschreiber fand [125], und die von deutscher Seite in's Werk gesetzte Untersuchung der libyschen Wiiste, in welche sich Rohlfs, Zittel, Aschers on und Jordan theilten [126]. In noch weit höherem Grade pflegen, wie Jedermann weiss, Polarfahrten die allgemeine Aufmerksamkeit auf sich zu ziehen. Die ersten guten Nachrichten über die physikalischen Verhältnisse dieser unwirthlichen Zonen verdanken wir eigenthümlicherweise nicht eigentlichen Fachmännern, sondern dem Schiffsarzt Martens, der gegen Ende des XVII. Jahrhunderts seine auf mehrjährigem Besuch der nordischen Meere beruhende treffliche Beschreibung derselben veröffentlichte [127], und dem Kapitän Scoresby, dessen arktisches Werk heute noch eine Hauptquelle unserer Kenntnisse bildet [128]. Durch Kan e, Hayes, Torell, Nordenskjöld, Nares, Koldewey, Bessels und Andere sind wir mit den Zuständen der Eismeerländer verhältnissmässig genau bekannt geworden, doch bleibt auch hier immer noch genug zu thun übrig, und es ist deshalb hoch erfreulich, dass in Konsequenz der von dem früh verstorbenen W eyprecht ausgegangenen Vorschläge [129] seitens fast aller grösseren Kulturnationen mit der Anlegung planmässig organisirter polarer Beobachtungsstationen energisch vorgegangen wurde. - In allerneuester Zeit haben fachmännisch gebildete Geographen auf Grund gründlich durchgeführter Autopsie die physikalische Erdkunde grösserer Länderräume in systematischer Form darzustellen begonnen, und diese Werke statuiren einen bedeutsamen Fortschritt in theoretischer, wie in methodologischer Hinsicht. Mag auch Burmeister's Schilderung der La Plata-Länder [130] dem Ideale weniger entsprechen, so thun diess um so mehr Rein's und Ratzel's Werke über Japan [131] und Nordamerika [132]. Ganz besonders ragt aber v. Richthofen's China hervor, von dem einstweilen der erste, zweite und vierte Band vorliegen, denn jenes merkwürdigen und fast jungfräulichen Landes Oberflächenbeschaffenheit bot dem Kennerblicke des berühmten Geologen so viel des Neuen und Unbekannten dar, dass seine Wahrnehmungen uns zur Modifikation so mancher anscheinend fest begründeten Theorie genöthigt haben. Von diesem Buche [133] durfte Wappäus mit Recht behaupten [134]: „Wer sich der Zeit noch erinnert, als v. Buch's Werk über die canarischen Inseln erschien und in den geologischen Forschungen der damals Lebenden eine neue und fruchtbare Richtung hervorrief, wird eines ähnlichen Eindruckes sich bewusst werden, wenn er die 
vorliegende, grossartige Arbeit auch nur in ihren hervorragenden Abschnitten durchmustert hat"*). -

Getreu unserem Principe wenden wir uns von diesen die Vervollkommnung und Bereicherung unseres geophysikalischen Wissens anstrebenden Werken jenen literarischen Leistungen unseres Jahrhunderts $\mathrm{zu}$, welche sich die Verbreitung desselben zum Ziele gesetzt haben. In chronologischer Reihenfolge zählen wir hier auf die Werke von G. F.P arrot [135] **), Desmarest [137] (diess in lexikographischer Anordnung) und F. Hochstetter [138]. Im Jahre 1822 kam Carl Ritter's in mehr als einer Hinsicht bahnbrechendes Werk [139] an das Licht. Wir lassen dessen „vergleichende“ Tendenz einstweilen bei Seite und verweilen nur für einen Augenblick bei der neuerlich vielfach diskutirten Frage, ob durch dieses Werk und andere Schriften des grossen Mannes gerade auch der physischen Erdkunde im engeren Sinne eine nennenswerthe Förderung zu Theil geworden sei. Wir glauben diese Frage für Ritter ganz ebenso wie für den im Ganzen auf gleichem Boden stëhenden Zeune [140] bejahen zu sollen, und stützen uns bei dieser Meinungsäusserung wesentlich auf den schönen Essay von Marthe [141], worin besonders auf den grossen und sehr zu Gunsten Ritter's sprechenden Unterschied in der Behandlung der Orographie hingewiesen wird, der zwischen Ritter's "Europa" und dem bald darauf herausgekommenen, sonst ganz tüchtigen Handbuch von Link [142] konstatirt werden kann; noch ungleich dürftiger ist die Darstellung dieser Verhältnisse in dem verbreiteten Sammelwerke von Cannabich, dessen erster Band [143] freilich nur bedingt als eine physische Erdkunde gelten kann. Bei einer anderen Gelegenheit sagt Marthe [144]: „Von den Lehrbüchern Ritter's muss abgesehen werden und es muss auch besonderes Gewicht gelegt werden auf eine Reihe von ihm herrührender episodischer Monographieen, die sich durch sämmtliche Bände seiner grossen Erdkunde hindurchziehen und die räumliche Verbreitung von Thieren, Pflanzen und Gesteinsarten, die besonders für den menschlichen Haushalt bedeutungsvoll sind, zum Gegenstande haben. Auch hierdurch ist Ritter ein thatkräftiger Mitarbeiter für die physische Erdkunde geworden." Damit harmonirt das, was uns der von Ritter mit dem bekannten Mineralogen Hausmann geführte Briefwechsel an die Hand giebt; man vergleiche beispielsweise in diesem die Betrachtungen über die Gebirge am Rhein und an der Lahn, deren Plastik, mit ihren fast mathematisch regulirten Gestaltungen " für die Weinkultur einen massgebenden Faktor zu bilden scheine [145], oder auch über die Quellbildungen in Kleinasien [146]. Nehmen wir nach dieser Einschaltung den Faden unserer literargeschichtlichen Erzählung wieder auf. Dem Jahre 1830 entstammen zwei bedeutendere didaktische Ar-

*) Der grossartigen, aber ganz spezifisch aus oceanographischem Interesse hervorgegangenen Schiffsexpeditionen der neuesten Zeit, durch welche die Namen .Porcupine", "Tuscarora", "Norara", „Challenger", ,Gazelle", ,Travailleur" zu hoher Berühmtheit gelangt sind, gedenken wir hier nur im Vorübergehen, da die Physik des Meeres uns noch mehrfach Gelegenheit rerschaffen wird, uns mit ihnen zu bechäftigen.

$\left.{ }_{* *}^{*}\right)$ Auch von dem älteren Bruder dieses fleissigen Schriftstellers, Chr. F. Parrot, ist ein übrigens weniger bedeutendes Werkchen [136] über den gleichen Gegenstand vorhanden. 
beiten, die Lehrbücher von Muncke [147] — der übrigens auch in der durch ihn besorgten Neu-Auflage des physikalischen Wörterbuches von Gehler eine Menge Beiträge zu unserem Fache lieferte - und von J. C. E. Schmidt [148]. Der zweite Band des letzteren Werkes, welches mit grossem Erfolg auf die exakte Behandlung physisch-geographischer Themen hinarbeitet, theilt den Lehrstoff in die folgenden Hauptabtheilungen ein: Allgemeine Uebersicht der Erdoberfläche, die Atmosphäre, die Erdtemperatur im Inneren wie an der Aussenseite, Bestandtheile des Erdkörpers (Geologie), Dichtigkeit der Erde, Veränderungen an der Oberfläche und Hypothesen über Entstehung und Umbildung des Erdballes, Erdmagnetismus. Wenn schon der Leser unserer Zeit in dieser Eintheilung kein rechtes System wird erblicken können, so thut dieser Mangel dem strengwissenschaftlichen Gehalte des Buches doch kaum etwelchen Eintrag, und H. Wagner durfte jüngst mit Fúg behaupten 149), man erkenne in jenem so recht, wie sich die Geophysik auch im Rahmen eines Lehrbuches fördern lasse. Eine recht übersichtliche und gut geordnete Anleitung ist ferner diejenige K. Schmidt's [150], wenn sie sich auch durchweg nur auf Definitionen und kurze Beschreibungen beschränkt. v. Raum er's „Allgemeine Geographie“ [151] erschien 1835, das folgende Jahr brachte zwei französische Leitfäden von Lecoq [152] und L. C. Prévost-Bassano [153], sowie das ein sichtliches Ringen nach systematischer Gestaltung bekundende Lehrbuch von Fröbel [154]. Wieder einen weiteren Abschnitt markiren Fr. Hoffmann und Berghaus. Ist das hochinteressante Werk des Ersteren [155] auch nicht ganz gleichmässig gearbeitet, wie denn z. B. die Lehre von den Quellen darin nicht weniger als 116 Seiten umfasst [156], so haben wir doch alle Ursache, dem trefflichen v. Dechen für die Herausgabe desselben, das ursprünglich nur ein Kollegienheft darstellte, Dank zu wissen. Gerade diese Vorlesungen haben dereinst auf die Studirenden der Berliner Universität eine gewaltige Anziehungskraft ausgeübt; übrigens hat uns v. Richth ofen an dem konkreten Beispiele der Insel-Klassifikation gezeigt [157], wie viel wir auch heute noch von Fr. Hoffmann lernen können. Gleichzeitig mit einem so vorzüglichen Lehrbuche empfieng die studirende Welt das zweite unentbehrliche Lehrmittel des physikalisch-geographischen Unterrichtes, den aus 90 Karten bestehenden Atlas von Berghaus [158]. Damit sind wir denn an jener Grenze angelangt, welche nach Peschel's Ansicht (s. o.) die eigentlich geschichtliche Zeit von der Gegenwart trennt*). Doch sei noch daran erinnert, dass diese letzte Periode auch Zeitschriften hervorgebracht hat, die eigens der wissenschaftlichen Erdkunde dienen sollten. Die von Berghaus im Vereine mit K. F. V. Hoffmann geleitete "Hertha" [162] nahm allerdings auch anderweite Artikel auf, dafür aber koncentrirten sich die von Fröbel und Heer herausgegebenen Mittheilungen völlig auf unsẹ Fach [163]. Leider haben es dieselben

*) Wenn wir die in die soeben abgeschlossene Periode fallenden Unterrichtsbücher der französischen Mathematiker Lacroix [159] und Léon Bezout [160] blos in dieser Randnote aufführen, so geschieht diess darum, weil in ihnen das physikalisché Element sehr gegen das mathematisch-astronomische zurücktritt. Hingegen darf wohl beiläufig des grossen Werkes $\nabla$. Hoff's [161] gedacht werden, welches man ja, sobald man sich nicht allzu ängstlich an die strikte Wortbedeutung hält, ebenfalls als ein didaktisches bezeichnen kann. 
nur zu einem einzigen Bande gebracht, doch ist dessen Inbalt reich genug, um uns das frühe Eingehen eines so tüchtigen Journales bedauern zu lassen. Da finden wir den Entwurf eines detaillirten Systemes der geographischen Disciplinen, eine allgemeine Orographie, eine Sammlung barometrischer Höhenmessungen, Beiträge zur Gebirgskunde der Schweiz, eine Uebersicht über die Gletschertheorieen und ein paar interessante Studien zur Pflanzen- und Thiergeographie, welche namentlich den Einfluss des Alpenklima's auf Organismen betreffen. Ein gleiches Ziel hatten sich die seit 1842 erscheinenden „Annales des sciences géologiques" gesteckt.

Bezüglich der allerneuesten Zeit können wir, da unsere Aufzählung durchaus keinen Anspruch auf Vollständigkeit erhebt, uns kurz fassen. Ein dauerndes Denkmal in der neuesten Epoche der Geophysik haben sich die Gebrüder Schlagintweit, deren einer sein feuriges Interesse an der Hinausrückung der Grenzen unserer Erkenntniss bald nachher mit dem Leben bezahlen sollte, durch ihre alpinen Untersuchungen [164] gesetzt. Sowohl die generellen Auffassungen, zu welchen uns dieselben emporleiten, sind von bleibendem Werthe, wie auch nicht minder das gründliche Studium der physikalischen Verhältnisse einzelner bemerkenswerther Gebirgsstöcke, z. B. der Kaiser- und Wetterstein-Gruppe. Von Lehrbiichern nennen wir zuerst B. Studer's grosses und durch stete Betonung des literarischen Elementes ausgezeichnetes Werk [165], sodann die physische Geographie des jüngeren v. Klöden [166] als Bestandtheil seines umfänglichen Systemes der Erdkunde. E. Reclus' physikalische Erdbeschreibung [167], die durch Ule auch den Deutschen zugänglich gemacht wurde, zeichnet sich durch die Grossartigkeit der darin entwickelten Perspektiven aus. Von englischen Arbeiten verdient namhaft gemacht zu werden das liebenswürdige Büchlein von Mary Sommerville[168], das allerdings mehr den Charakter einer naturwissenschaftlichen Länderbeschreibung, als jenen einer Physik der Erde trägt (Meteorologie, Erdmagnetismus und Luftelektricität sind z. B. in Einem Kapitel vereinigt), ferner das auf einer höheren Stufe stehende Werk John Herschel's [169] und, soweit blos die $Z$ wecke ganz elementarer Unterweisung in Frage kommen, die Lehrbücher von Geikie*) [170] und Blanford [171]. Die bezüglichen Schriften des Engländers Canstedt und des Franzosen Cortambert müssen wir uns begnügen, einfach zu nennen, weil wir keine nähere Kenntniss von ihnen zu erlangen vermochten. Das Gleiche gilt von zwei wohl ganz verdienstlichen, wenn auch mehr in das Gebiet der populärwissenschaftlichen Literatur gehörigen Büchern des Zürichers R. Meyer: "Astronomische und physikalische Geographie (Zürich 1852) und "Physik der Schweiz" (Leipzig 1854). Nicht minder registriren wir hier aus gleichen Gründen kurz die folgenden deutschen Werke: Zamminer, Die Physik der Erdrinde und der Atmosphäre populär dargestellt" (Stuttgart 1853); Landgrebe, "Grundzüge der physikalischen Erdkunde" (2 Bände, Leipzig 1861-62); TVinkler, „Leitfaden zur physikalischen und mathematischen Geographie" (Dresden 1875). In mancher

*) Die Trübner'sche Verlagsbuchhandlung hat eine deutsche Uebersetzung dieses höchst zweckmässigen Grundrisses in ihre bekannte Kollektion aufgenommen. 
Hinsicht originell ist die „Physikalische Geographie, fasslich dargestellt, ${ }^{\text {" }}$ von Wittwer, dem bekannten Kommentator des Humboldt'schen Kosmos (Leipzig 1858), nicht minder, namentlich, soweit die oceanographischen Partieen in Frage kommen, Keith Johnston's „Handbook of physical geography“ (Edinburgh und Lond. 1870) und Houghton's "Six lectures on physical geography" (Dublin 1882). Zu der Klasse der Elementarbücher im Sinne Blanford's sind noch zu rechnen: Hughes "A class book of physical geography, revised by Williams" (Lond. 1882) und Hugues, "Corso di geografia fisica ad uso dei licei“ (Torino 1881). Vorwiegend vom Standpunkte des Physikers aus, wennschon ohne andere als die einfachsten mathematischen Hülfsmittel zur Anwendung zu bringen, behandelt J. Müller die Physik des Erdkörpers als Unterfall einer allgemeineren kosmischen Physik [172], wogegen das neueste grössere Elaborat der Fachliteratur, Le ip old t's physische Erdkunde [173], sich schon dadurch als ein mehr geographisches kennzeichnet, dass es theilweise aus den von Peschel gehaltenen Universitätsvorträgen erwuchs*). Wer geringere Anforderungen stellt und lediglich einen Ueberblick über die die Wissenschaft bewegenden Fragen zu bekommen wünscht, dem sind die Grundlinien von Cornelius [174] bestens zu empfehlen, oder auch das die physische Erdkunde in deren weitestem Umfang geradezu erschöpfende Werkchen der drei österreichischen Forscher Hann, v. Hochstetter und Pokorny [175]. Noch populärer verfahren Lippert [176] und Geistbeck [177], von denen namentlich der letztere eine recht gute Kompilation bietet. Die ungarische Sprache besitzt neuerdings ein Lehrbuch der physischen Geographie von F. Roth [178], und für die Länder slavischer Zunge dürfte das lieferungsweise erschienene Werk von Studnička[179] sehr nutzbringend werden. Wir Deutsche dagegen dürfen, wie wir zu unserer Befriedigung berichten können, in Bälde einem Handbuch aus der erprobten Feder Supan's entgegensehen; dem eigentlichen Fachstudium aber werden in noch höherem Grade nach ihrer Vollendung jene Spezialwerke entgegenkommen, welche unter der Aufsicht Ratzel's erscheinen sollen. Von dem Herausgeber selbst bearbeitet liegt uns die Anthropogeographie vor, während Hann die geographische Meteorologie bereits lieferte, v. Boguslawski die Meereskunde, Drude die Pflanzen-, Vetter die Thiergeographie liefern wird. - Atlanten zur physischen Erdkunde giebt es nunmehr in grösserer Anzahl, man denke nur an die Namen Glaser, Bromme, Stieler, Peschel-Andreeu. s. w. Auch hat man sich mit solchen kartographischen Darstellungen nicht begnügt, sondern neuerdings auch damit begonnen, erläuternde Bilder und Modelle den Lernenden in die Hand zu geben. Simony, Letoschek, Supan, A. Kirchhoff und A. Heim haben auf diesem Gebiete einen bedeutsamen Anfang gemacht. -

Von der "vergleichenden" Geographie ist bislang höchstens nur ganz gelegentlich die Rede gewesen, und doch wird mancher unserer Leser erwarten, von dieser Stelle einen Aufschluss über unsere eigene

*) Dieses Werk hat, obgleich seine Aufnahme in kritischen Kreisen nicht immer die günstigste war, trotzdem unleugbare Verdienste. Auch wir verdanken ihm viel und werden uns öfter darauf berufen, freilich mit Umgehung des darin zu Tage tretenden Bestrebens, für verwickelte Erscheinungen sofort neue Erklärungen zu geben. 
Stellung zu diesem von der Ritter'schen Schule mit besonderer Liebe gepflegten Studiengebiete zu erhalten. Wir haben oben gesehen, dass Varenius sich dieses Ausdruckes zuerst bediente, während Ritter denselben verallgemeinerte und zur Basis eines selbstständigen geographischen Systemes erhoben zu haben glaubte. Dem gegenuiber behauptete Peschel, als er dem Worte einen neuen und zwar mehr einen physikalischen Sinn beilegte[180], sein Vorgänger habe Probleme der vergleichenden Erdkunde nicht nur nicht zu lösen, sondern nicht einmal richtig zu stellen vermocht [181]. Es ist schwer, sich aus diesem Dilemma herauszufinden und eine sachgemässe Definition des vielumstrittenen Kunstwortes zu geben, das beweist u. a. der neueste Versuch v. Hellwald's [182]. Peschel selbst hat wohl einzelne begeisterte Anhänger und Nachahmer gefunden, allein es ist seinem Andenken auch der herbste Widerspruch nicht erspart geblieben, und P. Lehmann z. B. glaubt den Problemen Peschel's jedweden günstigen Einfluss auf die Bereicherung unseres morphologischen Wissens absprechen zu sollen [183]; „sie sind," so drückt er sich aus, „der Versuch eines geistreichen Mannes, eine Physiognomik à la Lavater auf dem Angesichte der Erde zu begründen." Ist diess Urtheil nun auch unseres Erachtens viel zu hart ausgefallen*), so können wir doch auch selbst nicht in Abrede stellen, dass dem Begriffe des Vergleichens bei Peschel etwas Mystisches anhaftet, und wir können ebensowenig sagen, dass die Lektüre der philosophisch-geographischen Schriften Kapp's [186], in welchen noch dazu die physische Erdkunde sehr hinter der politisch-kulturgeschichtlichen zurücktritt, uns auf andere Gedanken gebracht hätte. Fasst man dagegen das bedenkliche Wort in dem einfachen und natürlichen Sinne auf, wie es A. v. Humboldt im Kosmos thut, so schwinden alle Schwierigkeiten; mit dieser Interpretation deckt sich auch die von Schouw gegebene, die in ihrer negativen Formulirung also lautet [187]: "Compendia, quae nomen geographiae physicae in fronte gerunt, notiones tantum generales hujus scientiae de mari, montibus, fluminibus, climate caeterisque continent; non vero, orbe terrarum in partes naturales diviso, has partes singulas tractant et inter se conferunt." In solcher Weise die Erscheinungen der einen Erdgegend zu denen einer anderen in Parallele stellend sind bereits Forster, A. v. Humboldt, L. v. Buch vorgegangen, ehe man noch nach einer methodologischen Begriffsbestimmung für ihre Thätigkeit gesucht hatte, und auch $\mathrm{Ch}$. Darwin hat diese Untersuchungsmethode zu hoher Ausbildung gebracht**). Halten wir diess fest, so erkennen wir, dass der uns schon

*) Wir freuten uns, im neuesten Wagner'schen Jahrbuche konstatiren zu können, dass unsere schon vorher niedergeschriebenen Sätze völlig jenen Anschauungen entsprechen, welche der verdiente Vertreter der geographischen Methodenlehre dortselbst niedergelegt hat [184], um so mehr, da Niemand H. Wag n er allzugrosser Voreingenommenheit für Peschel wird zeihen wollen. Man wird übrigens auch mit Vortheil den geistreichen Essay A. Kirchhoff's über die drei Koryphäen der deutschen Erdkunde [185] zu Rathe ziehen.

***) Wer sich darüber recht klar werden will, der lese das Schriftchen [188] nach, in welchem Marinelli die geographischen Verdienste des grossen Naturforschers mit fachmännischem Auge würdigt. Darwin vergleicht die patagonischen Gletscher mit denjenigen der europäischen Alpen; er stellt die klimatischen Eigenthümlichkeiten der beiden irdischen Hemisphären einander gegenüber; wie sich unter verschiedenen Himmelsstrichen die Beziehungen zwischen den Erd- 
bekannte Fr. Hoffmann, in dessen Erstlingsschrift [189] der vergleichende Gedanke auf das Unzweideutigste hervortritt, kurz und bündig sagen durfte [190]: „Die physikalische Geographie ist vergleichende Erdkunde; die einzelnen Verhältnisse in der Natur der Länder, Meere und Himmelsstriche bieten das Klassifikationsprincip dar." In ähnlichem Sinne haben auch wir ein Recht, die physikalische Geographie, so wie wir sie im weiteren Verlaufe darzustellen gesonnen sind, als eine komparative $\mathrm{zu}$ bezeichnen, ohne dass es uns jedoch beigehen könnte, damit im Entferntesten den Begriff von etwas Auszeichnendem verbinden zu wollen *).

Noch ein paar Zeilen müssen wir, ehe wir uns der Schlussbetrachtung zuwenden, einer Unterabtheilung unseres Wissenszweiges widmen: der wissenschaftlichen Landeskunde. Das Bedürfniss nach einer solchen hat man an manchen Orten schon vor geraumer Zeit empfunden, und ihm verdanken wir das erste und zugleich in seiner Art vollkommene Terk dieser Art, welches vor nunmehr fast 200 Jahren Johann W eichard Freiherr v. Valvasor über sein Vaterland Krain veröffentlichte [192]. Gerade dieses Land, welches Abraham a Sta. Clara „das Land der Wunder" nannte - man denke nur an die Quecksilbergruben von Idria, an die Adelsberger Grotte und an den für den Karstcharakter der Gebirge bezeichnenden intermittirenden Wasserstand des Zirknitzer See's -, musste wie kaum ein anderes zu einer so eingehenden physikalisch-ethnologischen Beschreibung einladen, wie sie eben Valvasor gegeben hat. Bald nachher skizzirte der Luzerner Cappeler seinen Plan, eine monographische Schilderung des heimathlichen Pilatus-Berges zu liefern, in einem (unter'm 25. December 1725 geschriebenen) Briefe an Scheuchzer, wie folgt: „1 $1^{0}$. Montis Situs, Nomen, Fama. $2^{\circ}$. Chorographia viciniarum montis. $3^{\circ}$. Iconographia et Orthographia. $4^{\circ}$. Origo. $5^{0}$. Aerographia, Meteora etc. $6^{0}$. Hydrographia, Fontes, Torrentes, Lacus, etc. $7^{\circ}$. Soli et Subterraneorum descriptio, etc. $8^{\circ}$. Botanica. $9^{\circ}$. Animalia. $10^{\circ}$. Spectra et fabulosa. ${ }^{*}$ Diess deutet auf klare Conception einer, wenn auch natürlich in das Zeitkostüm gekleideten physischen Landeskunde; A. v. Haller hat sich über das erst weit später aus den nachgelassenen Papieren des Verfassers herausgegebene Werk (Mauricii Antonii Cappelerii Pilati montis historia, $a b$ amico in lucem protracta atque academicis Helvetiae societatibus sacra, Basileae 1767) in seiner "Bibliothek der Schweizergeschichte sehr günstig ausgesprochen. Aus den zahlreichen Literaturprodukten des vergangenen Jahrhunderts, die als hier einschlägig gelten können, heben wir hervor Pallas' Arbeiten für Theile Russlands [193], sowie diejenigen von J. A. Cramer für die Harzgegend [194] und von Goldfuss-Bisch of für das Bayreutherland [195], welch' letztere allerdings erst nach 1800 gedruckt wurde. Später hat in dieser Weise Ple is c bl

stössen und dem Zustand der Atmosphäre gestalten, diess festzustellen, reizt seinen Forschungstrieb. Und so in vielen anderen Dingen.

*) Selbstrerständlich kann es, sobald man sich auf diesen Standpunkt stellt, nicht schwer halten, auch unter älteren geographischen Schriftstellern Leute ausfindig zu machen, die sich mit "vergleichenden" Studien der bezeichneten Art beschäftigten. So mag wohl auch Tollin ganz Recht haben, wenn er [191] seinen Helden Michael Servet ob der in dessen Ausgabe des Ptolemäus durchgeführten Betrachtungsweise als einen Vorläufer C. Ritter's feiert. 
die Landeskunde Böhmens [196] und Pusch (1790-1846) diejenige Polen's [197] bearbeitet. Aus der Fluth neuerer Publikationen ragt hervor Guthe's Monographie der Welfenländer[198]; an die Seite dürfte dieser Schrift zu stellen sein, was Wittwer in dem durch König Max II. in's Leben gerufenen Prachtwerke "Bavaria" und G. Karsten in lokalen Sammelschriften Schleswig-Holstein's niedergelegt haben. Will man auch von ausserdeutschen Ländern einen Beleg beigebracht haben, so sei auf Hull's physikalische Geographie von Irland [199] verwiesen. Vor ganz Kurzem nun hat R. Lehmann sich an die dankenswerthe Aufgabe gemacht, das Wesen der wissenschaftlichen Landeskunde schärfer, als vordem geschehen, zu präcisiren [200]. Es ist wesentlich das Bodenrelief, wie es sich unter der modellirenden Einwirkung von Luft und Wasser gestaltet hat, welches für den Geographen Interesse besitzt. Die Witterungslehre im Allgemeinen stellt für eine gewisse Gegend die Temperatur- und Niederschlagsverhältnisse fest und knüpft eventuell daran eine Lokalprognose; der Geograph dagegen in seiner Eigenschaft als Vertreter der landeskundlichen Forschung hat zuzusehen, wie unter den kombinirten Einflüssen des Bodenreliefs, der Bewaldung, der menschlichen Kulturen u. s. w. dieses theoretisch bestimmte Klima sich abändert, und gleichzeitig studirt er die klimatischen Existenzbedingungen der in seinem Territorium verbreiteten Organismen, zu deren näherer Kenntniss er sich das Material vom botanischen und zoologischen Systematiker verschafft. Diese Andeutungen mögen genügen, um die nahen Wechselbeziehungen zwischen physikalischer Geographie und wissenschaftlicher Landeskunde in's richtige Licht zu stellen; es steht zu hoffen, dass die vom II. deutschen Geographentage niedergesetzte permanente Kommission zur Förderung der letztgenannten Disciplin durch die eifrige Arbeit, in welcher wir sie bereits begriffen sehen, auch den Interessen der mütterlichen Wissenschaft, der Erdphysik, Vorschub leisten werde. -

Nachdem wir somit der im Eingange übernommenen Pflicht, einen Ueberblick über die allmähliche Entwickelung der physikalisch-geographischen Uebergangswissenschaft zu liefern, nach Möglichkeit nachzukommen uns bestrebt haben, übrigt es uns noch, darzulegen, nach welchen Grundsätzen wir den ungeheuren Stoff, den es zu verarbeiten gilt, systematisch zu durchschalten suchten. Von vorne herein erklären wir auf das Bestimmteste, dass wir auf principielle Erörterungen über die Stellung unserer Wissenschaft zu den geographischen Schwesterdisciplinen und zu der Erdkunde als solcher uns einzulassen weder vermögend noch auch gewillt sind; wer sich nach dieser Richtung hin orientiren möchte, der lese die methodologischen Referate H. Wagner's im achten und neunten Bande des geographischen Jahrbuches nach. Dort wird er finden, welche Ansichten und Vorschläge von einer Anzahl gelehrter Männer ausgegangen sind, von denen wir hier die Italiener Dalla Vedova und Marinelli, die Niederländer Bos und Dozy, den Dänen Löffler, die Deutschen Wappäus, v. Richth ofen *), C. Neumann, Marthe, W. Cramer, Ratzel, W. Götz und endlich Wagner selber nennen wollen. Noch erscheinen uns die durch einander

*) Vergl. dessen akademische Antrittsrede: Aufgaben und Methoden der heutigen Geographie, Leipzig 1883. 
wogenden Theorieen zu wenig feste Gestalt angenommen zu haben, als dass wir unser eigenes Thun durch dieselben maassgebend beeinflussen lassen könnten. Eine grosse Anzahl von Bezeichnungen existirt für unser Fach: man spricht von physischer und physikalischer Geographie, tellurischer oder Geophysik (Physik der Erde); bei den romanischen Nationen ist der Name „Physique du globe" ein beliebter geworden, der von Saigey [201] und Quetelet*) in Aufnahme gebracht worden ist. Für uns sind alle diese Ausdrücke so gut wie synonym, und wir glauben unsere Berechtigung zu dieser Auffassung leicht durch eine indirekte Beweisführung erhärten zu können, indem wir nämlich darauf hinweisen, wie wenig glücklich B. Studer's Versuch [203] ausgefallen ist, zwischen der physischen Erdkunde, der physikalischen Erdkunde und der Erdphysik einen erkennbaren Unterschied zu stipuliren. Auch Zöppritz hat [204] mit glücklichem Schlage den gordischen Knoten gelöst und seine bekannten vortrefflichen Jahresberichte, die sich ganz genau über denselben Stoff verbreiten, wie unser Buch, als geophysikalische bezeichnet. In der That: die Methode, nach welcher gearbeitet wird, ist eine physikalische, die Objekte, an welchen diese Methode sich versucht, sind geographische, es lässt sich also die Geophysik von der physikalischen Erdkunde begrifflich gar nicht trennen. Allenfalls liesse sich sagen, dass der erste Ausdruck sich besser empfiehlt, solange von der Erde als Weltkörper und von ihrer inneren Beschaffenheit gehandelt wird, dass dagegen die ältere Bezeichnung dann mehr am Platze ist, wenn die Oberfläche unseres Planeten den Betrachtungsgegenstand bildet; diesem Gedanken glaubten wir insoferne Rechnung tragen zu sollen, als wir für die Aufschrift dieses Lehrbuches den Doppeltitel wählten. Indess kann sich Niemand darüber täuschen, dass selbst bei Zugrundelegung dieses Scheidungsprincipes die Grenzlinien beider Gebiete in ununterbrochenem gegenseitigem Ineinanderfliessen begriffen sind und sein müssen. Ein mächtiger Bundesgenosse für diese unsere Auffassung ist uns, nachdem Vorstehendes schon längst niedergeschrieben war, in $\mathrm{W}$. W und $\mathrm{t}$, dem berühmten Vertreter der philosophischen Methodenlehre, erstanden, der im. II. Bande seiner Logik (Stuttgart 1883, S. 228) sich also vernehmen lässt: „Die Geophysik ist derjenige Zweig der Astrophysik, welcher der vollkommensten Ausbildung fähig ist, so dass hier das praktische Bedürfniss zu einer Theilung in verschiedene Zweige geführt hat. Unter ihnen nimmt die physikalische Geographie die Stelle einer allgemeinen Geophysik ein, indem sie von den allgemeinstenEigenschaften des Erdkörpers und ihren wechselseitigen Beziehungen Rechenschaft zu geben sucht. Sie stützt sich dabei theils auf die speziellen Theile der Geophysik, welche sich nach einzelnen Seiten hin mit den physischen Eigenschaften der Erde beschäftigen, wie Meteorologie und Klimatologie, Chorologie und Geologie; theils verbindet sie sich mit der organischen Naturgeschichte und bildet so die besonderen Disciplinen der Pflanzen-, Thier- und Anthropogeographie. Hier berührt sich aber wieder die Geologie mit

*) Der berühmte belgische Geophysiker hat allerdings ein selbstständiges Werk über sein Lieblingsfach nicht erscheinen lassen, indess kann man seine generellen Ideen darüber wohl ebensogut aus anderen seiner Schriften kennen lernen, am besten aus seiner Witterungskunde Belgiens [202]. 
der Chemie, die Pflanzen- und Thiergeographie mit der Biologie, und die Anthropogeographie tritt in ein näheres Verhältniss zu den Geisteswissenschaften, insbesondere zur Geschichte und Völkerkunde."

Die systematische Gliederung des Lehrstoffes ist demgemäss eine sehr einfache. Ein erster grösserer Abschnitt wird die kosmische Stellung unseres Erdkörpers zum Gegenstande zu nehmen haben, doch ist hiebei - und hierin weichen wir vollbewusst von zahlreichen $\mathrm{Au}$ toren $\mathrm{ab}$ - die physische Astronomie nur in dem engen Rahmen zu behandeln, den uns die ausschliessliche Rücksichtnahme auf terrestrische Fragen von selbst darbietet*). Ebenso haben wir im zweiten Abschnitte, worin wir die Oberflächenform der Erde und ihre Bewegung im Raume besprechen, darauf Bedacht zu nehmen, dass wir nicht allzutief in das freilich nahe angrenzende Gebiet der mathematischen Geographie hineingerathen. Die geologischen und geodynamischen Kapitel bilden den dritten, die Lehren von den magnetischen und elektrischen Erdkräften den vierten Hauptabschnitt. Zweifelhaft kann man darüber sein, $o b$ nunmehr die Luft- oder die Wasserhülle der Erde an die Reihe zu kommen habe. Beide stehen ja in den mannigfaltigsten Wechselbeziehungen zu einander, allein uns schien die Erwägung von durchschlagender Bedeutung zu sein, dass nach der besten der umlaufenden Theorieen die Meeresströmungen nur Spiegelbilder der atmosphärischen Strömungen sind, und so mussten wir uns entschliessen, die Oceanographie der Atmosphärologie nachzustellen. An siebenter Stelle erörtern wir die Oberflächenveränderungen, welche aus dem Kampfe zwischen Meer und Festland resultiren, an achter schildern wir die Eigenschaften der festen Bestandtheile unserer Erdoberfläche, sowie der über die Erdfeste sich erstreckenden Süsswasserbedeckung. Dass der neunte und letzte Abschnitt der physischen Geographie der Organismen vorbehalten bleibt, versteht sich von selbst; in der Vorrede sind aber die Gründe beigebracht, welche uns veranlasst haben, dieser Schlussabtheilung nur einen so beschränkten Raum zuzugestehen. Die einzelnen Kapitel, in welche wiederum jeder dieser grossen $\mathrm{Ab}$ schnitte zerfällt, können im Inhaltsverzeichniss nachgesehen werden.

[1] Zeller, Die Philosophie der Griechen, 1. Band, Tübingen 1844. S. 179. [2] Diels, Doxographi graeci, Berolini 1879. - [3] Ibid. S. 181. - [4] M. Sartorius, Die Entwickelung der Astronomie bei den Griechen bis Anaxagoras und Empedokles in besonderem Anschluss an Theophrast, Halle 1883. S. 6. - [5] Ibid. S. 49. ff. - [6] Ibid. S. 25 ff. - [7] Ibid. S. 32 ff. - [8] Peschel-Ruge, Geschichte der Erdkunde bis auf Alexander ron Humboldt und Carl Ritter, München 1877. S. 64. - [9] Berger, Zur Entwickelung der Gengraphie der Erdkugel bei den Hellenen, Grenzboten, 39. Jahrgang. S. 412. - [10] Peschel-Ruge, S. 73. - [11] Ibid. S. 67. - [12] Haeser, Lehrbuch der Geschichte der Medicin und der epidemischen Krankheiten, 1. Band, Jena 1875. S. 144. - [13] Günther, Studien zur Geschichte der mathematischen und physikalischen Geographie, Halle 1879. S. 132. - [14] Käst-

*) Die Astronomie ist ebenso wie die Geologie eine selbstständige Wissenschaft, und es kann deshalb in einem Lehrbuche der physischen Erdkunde ohne schwere Schädigung der Sache selbst keiner von beiden eine bevorzugte Stelle eingeräumt werden; sie sind für uns blos Hülfswissenschaften. Man vergleiche über den inneren Zusammenhang der an sich verschiedenen Disciplinen eine anregend geschriebene Abhandlung von Marinelli [205]. 
ner, Weitere Ausführung der mathematischen Geographie, Göttingen 1795. S. 503 ff. - [15] A. Heller, Geschichte der Physik von Aristoteles bis auf die neueste Zeit, 1. Band, Stuttg. 1882. S. 59 ff. - [16] Peschel-Ruge, S. 63. - [17] Berger, Zur Entw. etc. S. 413. - [18] Ibid. S. 409. - [19] Goldbacher, Zur Kritik von Apulejus de mundo, Zeitschr. f. d. österr. Gymn., 1873. S. 670 ff. - [20] Berger, S. 436. - [21] Ibid. S. 458. - [22] Ibid. S. 408 - [23] Ibid. S. 460. - [24] Ibid. S. 460 ff. - [25] H. Fischer, Ueber einige Gegenstände der physischen Geographie bei Strabon, als Beitrag zur Gesch. der alten Geographie, Wernigerode 1879. - [26] Peschel-Ruge, Gesch. etc. S. 64. - [27] Ibid. S. 67. - [28] Ibid. S. 68 ff. - [29] Ibid. S. 72. - [30] K. J. Neumann, Strabon's Quellen im elften Buche, Halle 1881. - [31] A. Kirchhoff, Recension hiezu, Zeitschr. f. wissensch. Geogr., 3. Jahrgang. S. 158. - [32] Peschel-Ruge, S. 77. - [33] Berger, S. 462. - [34] A. v. Humboldt, Kosmos, 1. Band, Stuttgart und Augsburg 1845. S. 471. - [35] K. v. Littrow, Ueber das Zurückbleiben der Alten in den Naturwissenschaften, Wien 1869. - [36] Teuffel, Geschichte der römischen Literatur, 1. Band, Leipzig 1873. S. 669 ff. - [37] B. Studer, Lehrbuch der physischen Geographie und Geologie, 1. Theil, Bern, Chur und Leipzig 1843. S. 7. - [38] Nehring, Die geologischen Anschauungen des Philosophen Seneca, 1. Theil, Wolfenbüttel 1873; 2. Theil, ibid. 1876. - [39] Ibid. 1. Theil. S. 13. [40] Ibid. 1. Theil. S. 17 ff. - [41] Ibid. 2. Theil. S. 4 ff. - [42] Ibid. 2. Theil. S. 25. - [43] A. v. Humboldt, Examen critique de l'histoire de la géographie du nouveau continent et des progrès de l'astronomie nautique dans les $15^{\mathrm{e}}$ et $16^{\mathrm{e}}$ siècle, tome I, Paris 1835. S. 180 ff. - [44] Peschel-Ruge, S. 96 ff. - [45] Ibid. S. 150. - [46] Ibid. S. 156. - [47] Rosenberger, Die Geschichte der Physik, 1. Theil, Braunschweig 1882. S. 79 ff. - [48] Ibid. S. 85. - [49] Peschel-Ruge, S. $151 \mathrm{ff}$. - [50] Manuel de la cosmographie du moyen âge, traduit de l'arabe de Shemseddîn ed Demitschki par Mehren, Copenhague 1874. - [51] Zakarija ben $\mathrm{Mu}$ hammed ben Mahmûd el Kazwîni's Kosmographie, deutsch von Ethé, 1. Band, Leipzig 1868. - [52] Dieterici, Die Naturanschauung und Naturphilosophie der Araber im zehnten Jahrhundert, Posen 1874. - [53] Kazwîni, S. 197 ff. - [54] Fellner, Ein Kompendium der Naturwissenschaft in der Schule zu Fulda im neunten Jahrhundert, Berlin 1878. - [55] Werner, Die Kosmologie und Naturlehre des scholastischen Mittelalters mit spezieller Rücksicht auf Wilhelm von Conches, Sitzber. d. k. k. Akad. d. Wissensch. zu Wien, Phil.-hist. Kl. 1873, II; S. 309 ff. -. [56] A. v. Humboldt, Ueber die historische Entwickelung der Kenntnisse von der neuen Welt, 1. Band, Berlin 1852. S. 66. - [57] Fellner, Albertus Magnus als Botaniker, Wien 1881. S. 71 ff. - [58] Tschackert, Peter von Ailli, Gotha 1877. - [59] Günther, Studien, S. 217 ff. - [60] Les livres du trésor, par Brunetto Latini, publié d'après les manuscrits de la bibliothèque impériale par $\mathrm{P}$. Chabaille, Paris 1863. - [61] Libri, Histoire des sciences mathématiques en Italie, tome II, Paris 1832. S. 182. - [62] W. Schmidt, Ueber Dante's Stellung in der Geschichte der Kosmographie, Graz 1876. - [63] Günther, Studien, S. 154 ff. - [64] La composizione del mondo di Ristoro d'Arezzo, testo italiano del 1882 pubblicato da E. Narducci, Roma 1859. - [65] Ibid. S. 78 ff. - [66] Günther. Studien, S. 172 ff. [67] A. v. Humboldt, Kosmos, 1. Band. S. 355 - [68] D'Acosta, Historia natural y moral de los Indias, Sevilla 1590. - [69] Döderlein, Sebastian Münster, ein Wiedererwecker des Ptolemaeus, Bl. f. d. bayr. Gymn.- u. Realschulwesen, 15. Band. S. 399. - [70] Ibid. S. 435. - [71] Peschel-Ruge, S. 427. - [72] Gilbert, De magnete magneticisque corporibus et de magno magnete tellure physiologia nova, Londini 1600. - [73] Brocard, La météorologie de Kepler, I. Grenoble 1879, II. ibid. 1880. - [74] Liebig, Ueber Francis Bacon von Verulam und die Methode der Naturforschung, München 1863. - [75] Franz Bacon's neues Organon, übersetzt, erläutert und mit einer Lebensbeschreibung des Verfassers versehen von v. Kirchmann, Berlin 1870. S. 280. - [76] Peschel, Neue Probleme der vergleichenden Erdkunde als Versuch einer Morphologie der Erdoberfläche, Leipzig 1878. S. 70. - [77] Wohlwill, Bacon von Verulam und die Geschichte der Naturwissenschaft, Constitut. Jahrbücher, 9. Band. S. 383 ff. 10. Band. S. 207 ff. - [78] Ibid. 9. Band. S. 404. - [79] Breusing, Lebensnachrichten von Bernhard Varenius, Petermann's geogr. Mittheil., 18. Band. S. $136 \mathrm{ff}$. - [80] Varenius, Geographia generalis, in qua affectiones generales telluris explicantur, Amstelodami 1650. - [81] Varenius, Geographia generalis, ed. Js. Newton, Cantabrigiae 1672. - [82] A. v. Humboldt, Kosmos, 1. Band. S. 74 ff. - [83] Riccioli, Geographia et hydrographia reformata, Bononiae 1661. - [84] Zöckler, Gottes Zeugen im Reiche der Natur; Biographieen und Bekenntnisse grosser Naturforscher aus alter und neuer Zeit, 1. Theil, Gütersloh 1881. S. 275 ff. - [85] Kircher, Mundus subterraneus, in quo universae naturae 
majestas et divitiae demonstrantur, Amstelodami 1664. - [86] Agricola, De ortu et causis subterraneorum, Basileae 1546. - [87] Kircher, Magnes seu de arte magnetica opus tripartitum, Romae 1641. - [88] Fr. Hoffmann, Geschichte der Geognosie und Schilderung der vulkanischen Erscheinungen, Berlin 1838. S. 40 ff. [89] Fournier, L'hydrographie, contenant la théorie et la pratique de la navigation, Paris 1643. - [90] Mariotte, Traité du mouvement des eaux et des autres corps fluides, Paris 1686. - [91] Torell-Nordenskjöld, Die schwedischen Expeditionen nach Spitzbergen und Bären-Eiland, ausgeführt in den Jahren 1861, 1864 und 1868, deutsch von Passarge, Jena 1869. S. 339 ff. - [92] Rittau, Johann Reinhold Forster's Bemerkungen auf seiner Reise um die Welt, Hanau 1881. - [93] C. Ritter, Ueber Gebirgsentdeckung, Deutsche Rundschau f. Geogr. u. Stat., 5. Jahrgang. S. 301 ff. - [94] Scheuchzer, Beschreibung der Naturgeschichten des Schweizerlandes, Zürich 1706-18. - [95] Altmann, Versuch einer historischen und physischen Beschreibung der helvetischen Eisberge, Zürich 1751. - [96] B. Studer, Geschichte der physischen Geographie der Schweiz, Bern und Zürich 1865. - [97] Kropatschek, Zur geschichtlichen Entwickelung des geographischen Unterrichtes, Verhandl. des II. Deutschen Geographentages, Berlin 1882. S. 129. - [98] PeschelRuge, S. 707. - [99] Kropatschek, S. 127. - [100] V. A. Huber, Die englischen Universitäten, 1. Band, Kassel 1839. S. 124. - [101] Favaro, Galileo Galilei e lo studio di Padova, Tomo I, Firenze 1882. S. 135. - [102] Buache, Essai de géographie physique, où l'on propose des vues générales sur l'espèce de charpente du globe, composée de chaînes de montagnes qui traversent les mers comme les terres, Mém. de l'acad. des sc. de Paris, 1756. S. 399 ff. - [103] Lulofs, Inleidinge tot eene natuur - en wiskoundige beschouwing des aardkloots, tot dienst der landgenoten geschriewen, Leyden 1750. - [104] Johann Lulofs Anleitung zu der mathematischen und physikalischen Erkenntniss der Erdkugel, aus dem Holländischen übersetzt von Kästner, Göttingen und Leipzig 1755. - [105] Bergman, Physisk beskrifning över jordsklot, Upsala 1766. - [106] Physikalische Beschreibung der Erdkugel, auf Veranlassung der kosmographischen Gesellschaft verfasst von Bergman, aus dem Schwedischen übersetzt von Röhl, Greifswald 1791. [107] Tob. Mayer, Lehrbuch über die physikalische Astronomie, Theorie der Erde und Meteorologie, Göttingen 1805. - [108] Mitterpacher v. Mitterburg, Physikalische Erdbeschreibung, Wien 1789. - [109] Bode, Anleitung zur allgemeinen Kenntniss der Erdkugel, Berlin 1786. - [110] Vorlesungen über physische Geographie, auf Verlangen Kant's aus seiner Handschrift herausgegeben von Rink, Königsberg 1802. Immanuel Kant's Schriften zur physischen Geographie, herausgegeben von F. W. A. Schubert, Leipzig 1839. S. 299 ff. (Auch in v. Kirchmann's "Philosoph. Bibliothek"). - [111] Zöllner, Ueber die Natur der Kometen, (3. Aufl.) Leipzig 1883. S. 231 ff. - [112] Peschel, Abhandlungen zur Erd- und Völkerkunde, herausgeg. von Löwenberg, 1. Band, Leipzig 1877. S. 265. - [113] Zimmermann, Geographische Geschichte der Menschen und der allgemein verbreiteten vierfüssigen Thiere, Leipzig 1778-83. - [114] L. v. Buch, Reise nach Norwegen und Lappland, Berlin 1810. - [115] Id., Physikalische Beschreibung der romanischen Inseln, Berlin 1825. - [116] Ibid. S. 321 ff. - [117] A. v. Humboldt, Kosmos, Versuch einer physischen Weltbeschreibung, Stuttgart und Tübingen 1845-58. [118] Id., Ansichten der Natur, mit wissenschaftlichen Erläuterungen, Stuttgart und Tübingen 1808. - [119] Id., Voyage aux régions équinoxiales du nouveau continent, fait en 1799-1804, Paris 1811-25 (resp. 1816--31). - [120] Id., Asie centrale, recherches sur les chaînes de montagnes et la climatologie comparée, Paris 1843. - [121] Bruhns, A. v. Humboldt, Eine wissenschaftliche Biographie, 3. Band, Leipzig 1872. - [122] Peschel-Ruge, S. 535 ff. - [123] H. A. Schumacher, Ueber Francisco de Cáldas, den neugranadinischen Naturforscher und Geographen, Verhandl. d. Ges. f. Erdk. zu Berlin, 7. Band. S. 98 ff. - [124] Mädler, Russlands geographische Arbeiten und Entdeckungen, Reden u. Abhandl. über Gegenst. d. Himmelskunde, Berlin 1870. S. 380 ff. - [125] Martins, Von Spitzbergen zur Sahara, deutsch von C. Vogt, Jena 1872. - [126] Jordan, Physische Geographie und Meteorologie der libyschen Wüste, Kassel 1876. - [127] Martens, Spitzbergische oder Grönlandische Reisebeschreibung, Hamburg 1675. - [128] Scoresby, An account of the aretic regions, London 1820. - ]129] Weyprecht, Tageblatt der 48. Versammlung deutscher Naturforscher und Aerzte, Graz 1875. S. 38 ff. [130] Burmeister, Physikalische Beschreibung der Argentinischen Republik nach eigenen und den vorhandenen fremden Beobachtungen, 1. Band, Buenos Ayres und Leipzig 1875. - [131] Rein, Japan nach Reisen und Studien, 1. Band, Leipzig 1881.

Günther, Geophysik. I. Band. 
- [132] Ratzel, Physikalische Geographie und Naturcharakter der Vereinigten Staaten von Nordamerika, München 1877. - [133] v. Richthofen, China; Ergebnisse eigener Reisen und darauf gegründeter Studien, drei Bände, Berlin 1877-82. [134] Wappäus, Recension hiezu, Gött. gel. Anz. 1877. S. 865. - [135] G. F. Parrot, Grundriss der Physik der Erde und Geologie, Riga und Leipzig 1815. - [136] Chr. F. Parrot, Versuch einer vollständigen Einleitung in die mathematisch-physische Stern- und Erdkunde, Bayreuth 1792. - [137] Desmarest-Bory St. Vincent, Dictionnaire de géographie physique de l'encyclopédie méthodique, Paris 1798-1828. [138] F. Hochstetter, Allgemeine mathematische und physikalische Erdbeschreibung, Stuttgart 1820-23. - [139] C. Ritter, Erdkunde im Verhältniss zur Natur und zur Geschichte des Menschen, oder allgemeine vergleichende Geographie, Berlin 1822. - [140] Zeune, Gea, Versuch einer wissenschaftlichen Erdbeschreibung, Berlin 1808. - [141] Marthe, Was bedeutet Carl Ritter für die Geographie?, Zeitschr. d. Ges. f. Erdk. zu Berlin, 14. Band. S. 356 ff. - [142] Link, Handbuch der physikalischen Erdbeschreibung, Berlin 1826. - [143] Gaspari-Hassel-Cannabich, Handbuch der neuesten Erdbeschreibung, 1. Band, Berlin 1819. - [144] Marthe, Festrede auf Carl Ritter, Verhandl. d. Ges. f. Erdk. zu Berlin, 6. Band. S. 289. - [145] Carl Ritter's Briefwechsel mit Joh. Friedr. Ludw. Hausmann, herausgeg. v. Wappäus, Leipzig 1879. S. 136. - [146] Ibid., S. 153. - [147] Muncke, Handbuch der mathematischen und physischen Geographie nebst Atmosphärologie, Heidelberg 1830. [148] J. C. E. Schmidt, Lehrbuch der mathematischen und physischen Geographie, 2. Theil, Göttingen 1830. - [149] H. Wagner, Geogr. Jahrbuch, 9. Band, Gotha 1883. S. 687. - [150] K. Schmidt, Physische Geographie oder Darstellung unserer Erde nach ihrer natürlichen Beschaffenheit und Einrichtung, Leipzig 1832. - [151] v. Raumer, Lehrbuch der allgemeinen Geographie, Leipzig 1835. - [152] Lecoq, Éléments de géographie physique et de météorologie, Clermont 1836. - [153] L. C. PrévostBassano, Traité élémentaire de géographie physique, Paris 1836. - [154] Fröbel, Die physische Geographie, als systematische Wissenschaft gemeinfasslich dargestellt, Zürich 1836. - [155] Fr. Hoffmann, Physikalische Geographie, Berlin 1837. - [156] Ibid: S. 423 ff. - [157] v. Richthofen, Bemerkungen zum genetischen Inselsystem, Zeitschr. f. wissensch. Geogr., 3. Jahrgang. S. 237 ff. - [158] Berghaus, Physikalischer Atlas, Gotha 1837-48. - [159] Lacroix, Introduction à la géographie mathématique et critique et à la géographie physique, Paris 1811. [160] L. Bezout, Géographie physique, Paris 1825. - [161] v. Hoff, Geschichte der durch Ueberlieferung nachgewiesenen natürlichen Veränderungen der Erdoberfläche, Gotha 1822-34; fortgesetzt v. Berghaus, Berlin 1840-41. - [162] BerghausHoffmann, Hertha, Berlin 1826-29. - [163] Fröbel-Heer, Mittheilungen aus dem Gebiete der theoretischen Erdkunde, 1. Band, Zürich 1836. - [164] H. und A. Schlagintweit, Untersuchungen über die physikalische Geographie der Alpen in ihren Beziehungen zu den Phänomenen der Gletscher, zur Geologie, Meteorologie und Pflanzengeographie, Leipzig 1850; Neue Untersuchungen über die physikalische Geographie und Geologie der Alpen, ibid. 1854. - [165] B. Studer, Lehrbuch der physikalischen Geographie und Geologie, Bern, Chur und Leipzig 1844-47. [166] v. Klöden, Handbuch der Erdkunde, 1. Band, Berlin 1856, 5. Auflage, ibid. 1873. - [167] Reclus, La terre, Paris 1868-69. - [168] M. Sommerville, Physical geography, London 1851. - [169] J. Herschel, Physical geography of the globe, Edinburgh 1875. - [170] Geikie, Elementary physical geography; questions for the use of schools, London 1877. - [171] Blanford, Rudiments of physical geography for indian schools, London 1878. - [172] J. Müller, Lehrbuch der kosmischen Physik, Braunschweig 1856; 4. Aufl. ibid. 1875. - [173] Leipoldt, Physische Geographie, nach den hinterlassenen Manuskripten Oscar Peschel's selbstständig bearbeitet und herausgegeben, Leipzig 1879-82. - [174] Cornelius, Grundriss der physikalischen Geographie, Halle 1851; 3. Aufl. ibid. 1868. - [175] Hannv. Hochstetter-Pokorny, Allgemeine Erdkunde; ein Leitfaden der astronomischen Geographie, Meteorologie, Geologie und Biologie, Prag 1872. - [176] Lippert, Die Oberfläche der Erde; einer volksverständlichen Geographie physischer oder 1. Theil, Prag 1879. - [177] Geistbeck, Leitfaden der mathematischen und physikalischen Geographie, Freiburg i. B. 1881. - [178] F. Roth, Vergleichende physische Geographie (ungarisch), Budapest 1878. - [179] Studnička, Vs̉eobecný zeměpis čili astronomická, mathematická a fysikální geografie, Prag 1881-83. - [180] Peschel, Neue Probleme etc., Leipzig 1869; 4. Aufl. ibid. 1883. - [181] Ibid. S. 1 ff. [182] v. Hellwald, Comment on comprend et comment on étudie la géographie en Allemagne et en Autriche, Congrès national de géographie à Nancy, 1881. S. 94 ff. - [183] P. Lehmann, Kritischer Exkurs über Peschel's Morphologie der Erdober- 
fläche, Verhandl. d. Gesellsch. f. Erdk. zu Berlin, 10. Band. S. 97 ff. - [184] H. Wágner, Geogr. Jahrbuch, 9. Band, Gotha 1883. S. 669. - [185] A. Kirchhoff, Humboldt, Ritter und Peschel, die drei Hauptlenker der modernen Erdkunde, Deutsche Rundschau, 2. Jahrgang, 4. Heft. - [186] Kapp, Philosophie der Erdkunde, Braunschweig 1845; Vergleichende allgemeine Erdkunde in wissenschaftlicher Darstellung, ibid. 1868. - [187] Schouw, Specimen geographiae physicae comparativae, Hauniae 1828. S. 4. - [188] Marinelli, Carlo Roberto Darwin e la geografia, Venezia 1883. - [189] Fr. Hoffmann, De vallium in Germania boreali principalium directione memorabili congrua, Halae 1823. - [190] Id., Physikalische Geographie, S. 5. - [191] Tollin, Michael Servet, ein Vorläufer C. Ritter's und Alex. v. Humboldt's, Zeitschr. d. Gesellsch. f. Erdkunde zu Berlin, 14. Band. S. 356 ff. - [192] v. Valvasor, Die Ehre dess Herzogthums Crain: Das ist, Wahre, gründliche und recht eigendtliche Belegen- und Beschaffenheit dieses, in manchen alten und neuen Geschicht-Büchern zwar rühmlich berührten, doch bisher nie annoch recht beschriebenen Römisch-Keyserlichen herrlichen Erblandes, Laybach 1689. [193] Pallas, Neue nordische Beiträge zur physikalischen und geographischen Erdbeschreibung, Petersburg und Leipzig 1781-96. - [194] J. A. Cramer, Physikalische Briefe über die Gegend von Hildesheim, Hannover 1796. - [195] Goldfuss-K. G. Ch. Bischof, Physikalisch-statistische Beschreibung des Fichtelgebirges, Nürnberg 1816. - [196] Pleischl, Beiträge zur physikalischen Geographie Böhmens, Prag 1838. - [197] Pusch*), Physikalische Geographie von Polen. [198] Guthe, Die Lande Braunschweig und Hannover, Hannover 1865. - [199] Hull, Physical geology and geography of Ireland, London 1878. - [200] R. Lehmann, Ueber systematische Förderung wissenschaftlicher Landeskunde von Deutschland, Verhandl. d. II. Deutschen Geographentages, Berlin 1882. S. 102 fi. - [201] Saigey, Petite physique du globe, Paris 1832. - [202] Quetelet, Météorologie de la Belgique, comparée à celle du globe, Bruxelles et Paris 1867. - [203] B. Studer, S. 3 ff. - [204] Zöppritz, Geogr. Jahrb., 8. Band, Gotha 1882. S. 1 ff.; 9. Band, ibid. 1883. S. 1 ff. - [205] Marinelli, Della geografia scientifica e di alcuni suoi nessi collo sviluppo degli studî astronomici e geologici, Roma 1879.

*) Wir entnehmen diese Nachricht von einem Autor, um dessen Gedächtniss sich etwas anzunehmen zunächst den polnischen Geographen überlassen bleiben muss, Poggendorff's „Biogr.-liter. Handwörterbuch zur Geschichte der exakten Wissenschaften" (Leipzig 1863. S. 545). Alldort werden auch zahlreiche andere Beiträge notirt, welche Pusch zur physikalischen Landeskunde Polens geliefert hat, wie jenes posthume Manuskript. 


\title{
Erste Abtheilung. \\ Die kosmische Stellung der Erde.
}

\author{
Kapitel I. \\ Die Kant-Laplace'sche Hypothese.
}

§. 1. Kosmogonische Hypothesen im Allgemeinen. Genaues über die Art und Weise, wie sich unser Erdkörper zu dem entwickelt hat, als welchen wir ihn gegenwärtig wạhrnehmen, lässt sich natürlicherweise nicht beibringen; alle Spekulationen über diese Frage müssen der Natur der Sache nach den Stempel des Hypothetischen tragen. Bei den Erklärungen, welche die religiösen Schriften aller Nationen für den Hergang der Weltentstehung gaben, vermochten Viele sich nicht zu beruhigen, und so sehen wir denn bereits im frühen Mittelalter Männer von sonst unantastbarer Gläubigkeit die biblischen Nachrichten über das Sechstagewerk in theilweise sehr rationalistischer Weise interpretiren. Besonders merkwürdig ist, was Zöckler [1] in dieser Hinsicht von einem der hervorragendsten der Kirchenväter, von Gregor von Nyssa (IV. Jahrhundert), berichtet: „Ganz evolutionistisch, an die Kosmogonieen der Neuzeit seit Kant anklingend, lautet, was zur Erläuterung der Gestirnschöpfung am vierten Tage beigebracht wird. Aus dem die Erde gleich einem mächtig leuchtenden Nebel umkreisenden Urlichte entstanden Sonne, Mond und Sterne auf naturgesetzlich vermittelte Weise, durch Zusammenballung der rotirenden Lufttheilchen, von welchen sich das Leichtere immer zum Leichteren, das Schwerere zum Schwereren, überhaupt Gleichartiges zu Gleichem gesellte. Man wird fast an Plateau's Oeltropfen-Versuch*), das berühmte Experiment zur Veranschaulichung des Grundgedankens der Laplace'schen Weltbildungslehre, erinnert, wenn dieses Sichgesellen der gleichartigen Elemente der kreisenden Lichtmaterie durch die Hinweisung auf eine Mischung von Quecksilber, Wasser und Oel illustrirt wird, die längere Zeit in einem Gefässe geschüttelt, die Wahrnehmung ergebe, dass das Quecksilber sich,zu unterst, das

*) Hievon wird weiter unten (in §. 5) eingehend gesprochen werden. 
Wasser in der Mitte, das Oel zu oberst ablagere." Man wird nicht in Abrede stellen können, dass diese Auffassung den geltenden Naturgesetzen sich jedenfalls weit besser anpasste, als so manche weit später entstandene. An eine ähnliche wirbelnde Bewegung der zu einzelnen Hauptmassen zusammengerinnenden Theilchen dachte auch Cartesius, für den ja [2] ein solcher Bewegungszustand die Grundlage seiner ganzen Kosmologie war. Von ihm zeigt sich auch einigermassen abhängig Leibniz in seiner für die Geschichte der Geologie noch heute [3] bedeutsamen "Protogaea" [4], in welcher die Erde als ein der Sonne von Hause aus konform gebildeter Körper geschildert wird, der schliesslich in einen schlackigen Granitklumpen sozusagen degenerirte; noch entschiedener aber beeinflusste die cartesische Wirbeltheorie, die selbst in Newton's Vaterlande nur langsam dem Gravitationsgedanken die Bahn frei gab, die Schule der englischen Physikotheologen. Durch die kreisende Bewegung der einzelnen Weltkörper lässt Burnet [5] die Gewässer der Tiefe die dünne Rinde eines jeden Planeten sprengen, denen auch er somit einen durchaus gleichartigen Ursprung zuschreibt; bei diesen Sintfluthen habe es dann für jeden einzelnen Himmelskörper mehr oder minder heftige Katastrophen abgesetzt, besonders auf dem Saturn, wo in Folge eines solchen Ereignisses der Ring sich abgetrennt habe. Ihm folgten Andere, die die Hauptrolle bei der Herstellung unseres Sonnensystemes in seiner gegenwärtigen Form einem Kometen zudachten und diesen als deus ex machina ganz nach ihrer Einbildungskraft schalten und walten liessen; hierher, zu den von Zöckler bezeichnend "Kometomanen" Genannten [6], gehörten Whiston, Clüver und sogar der als naturwissenschaftlicher Schriftsteller sonst hoch geschätzte Buffon, während der gelehrte W o odward (1695) in seiner "Natürl. Geschichte der Erde" sich gegen diese Herbeiziehung eines völlig unkontrolirbaren Momentes erklärte [7]. In Buffon's Schrift [8] stösst ein Komet an die Sonne, und zwar excentrisch; dadurch wird ein Stück des Sonnenkörpers - Buffon weiss genau, dass. es ein Sechshundertundfünfzigstel von dessen Volumen ist - losgerissen, aus welchem dann, wenn weitere Schweifsterne sich zur Verfügung stellen, allmählig die einzelnen Planeten und deren Trabanten sich abtrennen. Ja der grosse Komet von 1811 war sogar im Stande, noch eine neue Phase dieser eigenthümlichen Abart kometarischen Aberglaubens zu bewirken; Gruithuisen, Gelpke, Smithson-Tennant sprachen sich [9] in diesem Sinne aus, und der ebenso geistreiche als phantastische Steffens begründete seine Lehre vom Menschen [10] auf ein geographisches System, welches einem Mondstadium der Erde ein Kometenstadium und diesem erst das eigentliche Planetenzeitalter folgen liess - ziemlich umgekehrt so, wie wir jetzt den Fortbildungsprocess auffassen zu müssen glauben. Wir übergehen andere Hypothesen, die nur beweisen, wie äusserst langsam die gesunden Ideen Kant's sich Bahn zu brechen im Stande waren; man denke nur an die freilich mit grossem mathematischem Aufputz hervorgetretenen geogonischen Systeme des älteren [11] und des jüngeren [12] Silberschlag. Noch lange nachher entwickelte Späth [13] seine Embryonentheorie; an solchen Stellen des Weltraumes, welche von allen Seiten her ungefähr einer gleich starken Anziehung ausgesetzt waren, bildeten sich gasartige Sphäroide als „Embryonen“ des 
künftigen stellaren Körpers; „diese Embryonen mochten von der Natur in verschiedener Grösse angelegt worden seyn, während jeder derselben aus zweien unter sich ungleichartigen Gasen gemischt war." Bei aller Sonderbarkeit dieser Ansichten macht sich hier doch bereits eine gewisse Einwirkung der durch Kant angebahnten, durch Laplace vollendeten Reform bemerkbar. Als ein wirklicher Vorläufer Kant's muss dagegen der bekannte Emanuel Swedenborg mit allem Rechte gelten, in welchem Phantasterei und exaktes Denken zu eigenartiger Mischung sich vereinten; namentlich in §. IV, 3 seines 1734 erschienenen Werkes über Naturphilosophie - derselbe führt den Titel „De chao universali solis et planetarum, deque separatione ejus in planetas et satellites" - entwickelt der Autor, den von Nyrén [14] gegebenen Auszügen zufolge, eine systematische Weltbildungslehre auf der Bașis der cartesischen Wirbel.

§. 2. Die Kant'sche Hypothese. Im zweiten Theile seiner mit Recht berühmt gewordenen "Naturgeschichte des Himmels", welche im Vereine mit einer von Lambert ausgegangenen Schrift von verwandter Tendenz [15] auf die ganze Weltanschauung des XVIII. Jahrhunderts umgestaltend einwirkte, kommt der Königsberger Philosoph darauf zu sprechen, dass doch die das ganze Planetensystem beherrschende Gleichmässigkeit*) des Dreh- und Bewegungssinnes bei Rotation und Revolution von einer gemeinsamen leitenden Ursache abhängen müsse [16]. Alle Bestandtheile unseres Sonnensystemes, Planeten wie Kometen, befanden sich ,im Anfang aller Dinge ${ }^{6}$ in einem gleichmässigen Zustande des Aufgelöstseins. Natürlich herrschte ein nur labiles Gleichgewicht, so dass innere Kräfte - von deren Herkunft freilich weiter nicht die Rede ist - leicht eine Störung hervorbringen und einzelne dichtere Klumpen bilden konnten, auf welche sich dann die benachbarten Theilchen zubewegten. Alle Theilchen sind von Hause aus mit einer gleichförmigen Bewegung **) und mit gewissen Zurückstossungskräften ausgestattet; diese letzteren bewirken in Verbindung mit der Attraktion der bereits gebildeten dichteren Centren, dass die gleichförmig geradlinige Bewegung in eine kreisförmige sich verwandelt, und zwar muss sich so ein Zustand herausbilden, bei welchem die einzelnen Bewegungen einander am wenigsten durchkreuzen und stören. "Diess geschieht," sagt Kant [17], ,erstlich, indem die Theilchen, eines der andern Bewegung so lange einschränken, bis alle nach einer Richtung fortgehen; zweitens, dass die Partikeln ihre Vertikalbewegung, vermittelst der sie sich dem Centrum der Attraktion nähern, so lange einschränken, bis sie alle horizontal, d. i. in parallel laufenden Cirkeln um die Sonne als ihren Mittelpunkt bewegt, einander nicht mehr durchkreuzen, und durch die Gleichheit der Schwung-

*) Dass es auch Ausnahmen von dieser Regel gäbe, war zu Kant's Zeit noch unbekannt. Wir werden in \$. 6 von diesen Ausnahmen zu sprechen haben.

***) Newton war [19] der Meinung, die verschieden dichten Planeten hätten deshalb in jenen Distanzen von der Sonne angebracht werden müssen, welche wir beobachten, damit jeder Planet, im Verhältniss seiner Dichtigkeit, mehr oder weniger stark von der ersteren erleuchtet und erwärmt werde. Je dichter nämlich ein Stoff sei, um so mehr Wärme werde erfordert, damit dieselbe unter sonst gleichen Umständen die nämliche erhitzende Wirkung haben könne. 
kraft mit der senkenden sich in freien Cirkelläufen in der Höhe, da sie schweben, immer erhalten, so dass endlich nur diejenigen Theilchen in dem Umfange des Raumes schweben bleiben, die durch ihr Fallen eine Geschwindigkeit, und durch die Widerstehung der andern eine Richtung bekommen haben, dadurch sie eine freie Cirkelbewegung fortsetzen können."

In der Mitte all' dieser Kreise, welche die Weltatome beschreiben, befindet sich nun ein Körper von etwas dichterem Gefüge: die spätere Sonne. Kant betont nachdrücklich, dass zur Bildung dieses inneren Kernes die Newton'sche Gravitation nicht ausgereicht haben könne, dass vielmehr wohl eine Art chemischer Wahlverwandtschaft zur Erklärung hinzugezogen werden müsse. Gewisse Massentheilchen, die in angenähert gleichen Entfernungen vom Centralkörper um diesen ihren Umlauf vollziehen, ballen sich zu einem weiteren Körper zusammen, welcher sich in gleicher Richtung bewegt. So ist der erste Planet entstanden; ihm folgen mehrere. Dass deren Bahnen theilweise ein wenig vom Kreise abweichen und auch nicht ganz und gar in dieselbe Ebene fallen, erklärt sich einfach aus den Verschiedenheiten in der Stärke der Anziehung. Ein - allerdings nicht näher formulirtes — statisches Gesetz weist [18] den Materien des Weltalls deren „Höhen (Abstände von Centrum) nach dem umgekehrten Verhältnisse ihrer Dichtigkeit an; dieses Gesetz soll die teleologischen Gründe ersetzen, welche Newton für die mit wachsender grosser Axe der Planetenbahn abnehmende spezifische Schwere der Wandelsterne angegeben hatte. Die Nebenplaneten hält Kant für durchaus dichter als die zugehörigen Hauptplaneten und legt sich dieses Verhältniss in der Weise zurecht, dass erstere mehr, aus dem Ausschusse der elementarischen Materie", die letzteren dagegen ,ohne Unterschied aus den Materien aller vorhandenen Gattungen " formirt seien. Die Dichtigkeit aller Planeten zusammen müsse als arithmetisches Mittel dieselbe Zahl, wie jene der Sonne, ergeben, und in der That bestehe auch nach Buffon das Verhältniss 64:65. Die Kometen sind ebenfalls regelrechte Mitglieder unseres Sonnensystemes; nur bilden sie sich [20] in sehr grossen Entfernungen vom Hauptkörper da, wo die Kraft, „welche sie zum Sinken bringt", nur noch eine schwache Wirkung ausüben kann. Für die Kometen als Weltkörper, meint unser Gewährsmann, sei nur die grosse Excentricität ihrer Bahnen charakteristisch, denn ihre Lichthüllen und Schweife erhielten sie erst bei ihrer Annäherung an die Sonne. Jeder Planet stellt nun wieder [21] eine Sonne im Kleinen dar; von ihm lösen sich wieder kleinere Kugeln los, und zwar wird ein Planet um so mehr Nebenplaneten besitzen, je grösser seine Entfernung vom Centralkörper ist. Die Axen sämmtlicher dem Sonnensystem angehöriger Bälle stehen senkrecht, „gegen die allgemeine Beziehungsfläche des planetarischen Systemes, welche nicht weit von der Ekliptik abweicht". Zuletzt wird noch dem Saturn eine eingehendere Diskussion gewidmet [22]. Derselbe soll anfänglich ein kometarischer Planet gewesen sein und seinen Umlauf in einer vom Kreise sehr stark abweichenden Bahn vollzogen haben. In Folge der ungleichartigen Insolation hatten sich schweifbildende Dünste um ihn gesammelt, die sich schliesslich zu einem Ringe verdichteten. Zuerst war derselbe aller Wahrscheinlichkeit nach ein der Saturnkugel kon- 
centrischer sphärischer Ring, mit der Zeit aber folgten sämmtliche 'Theilchen der ihnen innewohnenden Tendenz, sich in die Aequatorialebene zu begeben. Jedem anderen Kometen könne unter entsprechend günstigen Umständen das Gleiche widerfahren. Kant wagt es sogar, die teleskopisch angeblich nicht zu eruirende Umdrehungsdauer des Ringes theoretisch zu bestimmen; die inneren Theilchen sollen etwa 10 , die äusseren etwa 15 Stunden zu Einem Umlauf brauchen, und auch die Axendrehung des Planeten selber wird aprioristisch auf $6^{\mathrm{h}} 25^{\prime} 53^{\prime \prime}$ festgesetzt*). Ja, der geniale Rationalist geht sogar so weit, jene ,oberhimmlischen" Wasser, welche der kosmischen Physik der Kirchenväter so grosse Schwierigkeiten bereiteten, mit einem früheren hypothetischen Ringe der Erde in Verbindung zu bringen, dessen. Abbild man dann im Regenbogen erblickt habe!

§. 3. Kritik der Kant'schen Originalhypothese. Ueber die 'Theorie, deren Grundzüge wir soeben im engsten Anschlusse an das Original erörtert haben, sind sehr verschiedene Urtheile laut geworden. $H$. J. Klein meinte, es würde von dem ganzen Systeme nicht viel übrig bleiben, wenn man das Secirmesser in aller Strenge daran anlegen wollte [24], und Z öllner hinwiederum, der begeisterte Lobredner des Naturforschers Kant, sucht durch textuelle Nebeneinanderstellung der bezüglichen Stellen in des letzteren und in Laplace's Werke den augenscheinlichen Beweis dafür zu erbringen, dass der französische Erneuerer des Kant'schen Gedankens ganz unvergleichlich weniger tief in die Sache eingedrungen séi [25]. Die Wahrheit dürfte wohl auch hier in die Mitte zu liegen kommen. Daran kann doch wohl nicht gezweifelt werden, dass Kant mit physikalischen Sätzen bei der Grundlegung seines Systemes ziemlich unbekümmert umspringt und die Pflicht des konstruirenden Kosmologen, sich auch selbst Einwürfe zu machen, verabsäumt. Die Rückläufigkeit mancher Kometen konnte ihm, der die Fachliteratur seiner Zeit wie irgend einer beherrschte, unmöglich unbekannt sein, und trotzdem wird dieser gefährlichen Klippe mit keiner Sylbe gedacht. Und zweitens sind die einzelnen Erwägungen doch nicht sowohl mechanischer, als vielmehr teleologischer Natur, wie denn den Theilchen immer nur eine nicht weiter aufgeklärte Tendenz zu gewissen Bewegungen zugeschrieben wird**). Man

*) Freilich sagt schon bei Lebzeiten des Autors sein Kommentator Sommer [23]: „Ich habe die Data, die Hr. Prof. Kant bey dieser Berechnung zu Grunde gelegt hat, nicht genau herausbringen können." Gleichwohl sind Kant's Zahlen annähernd richtig.

**) In neuester Zeit hat ein eifriger Anhänger Darwin's dessen in der organischen Welt sich so wunderbar bethätigendes Princip der natürlichen Auslese auch auf die Körperwelt und die himmlischen Bewegungen auszudehnen versucht. Mit Bezugnahme auf das atomistische Lehrgedicht des Römers Lucretius sucht Du Prel [26] die Nothwendigkeit, dass aus dem wirren Durcheinandertreiben der Massentheilchen eine zweckmässige Weltordnung sich habe heraus entwickeln müssen, durch den Hinweis auf eine Gruppe von Tänzern klarzulegen, deren jeder ohne die geringste Rücksicht auf seine Nebenleute eine ganz bestimmte Tour zu tanzen habe, mit der Bedingung jedoch, dass jeder beim ersten Anprall an einen Genossen aus dem Reigen auszuscheiden habe. Nach und nach werde nur eine kleine Anzahl im Kampfe um das Dasein sich behaupten, und es werde sich ein regelmässiger Kunsttanz ergeben. Gegen diese Vergleichung, an welche Kant's 
weiss aus anderen Schriften Kant's, dass er den Anforderungen an eine mechanische Naturerklärung bei anderen Veranlassungen weit besser zu genügen verstand, als gerade im vorliegenden Falle. Wir werden, wenn wir zuvor noch die Hypothese in der verbesserten Form kennen gelernt haben werden, welche ihr Laplace ertheilt hat, nicht umhin können, Faye darin Recht zu geben, dass Kant sich hohe Verdienste um die Schaffung einer konsequent durchgeführten Weltentstehungslehre erworben, seinem Nachfolger aber doch auch noch ein Stück Arbeit hinterlassen habe [28]. Die von A. Meydenbauer in einer eigenen Schrift [29] vertretene Ansicht, dass Kant's Auffassung der Laplace'schen sachlich vorzuziehen sei, dürfte nicht von Vielen getheilt werden.

§. 4. Laplace's neue Formulirung der Kant'schen Ideen. Anscheinend ohne von früheren verwandten Leistungen etwas $\mathrm{zu}$ wissen, sah sich der Verfasser der ,Mécanique céleste ${ }^{\complement}$ von selbst auf eine ähnliche kosmologische Annahme geführt. Ihn leitete [30] eine Probabilitätsbetrachtung, er erwog, wie ungemein gross die Wahrscheinlichkeit dafür sei, dass die allen Planeten gemeinsame Bewegungsrichtung, sowie der für die Planeten und Satelliten - im Allgemeinen identische Sinn der Rotation auch auf einen Kausalnexus hindeute. Die Sonnenatmosphäre erstreckte sich dereinst bis über die äusserste gegenwärtige Planetenbahn hinaus, und als die Umdrehungsgeschwindigkeit des aus sehr feiner Materie gebildeten Körpers, d. h. eben der Sonne, eine gewisse Grenze erreicht hatte, hielt sich die Centrifugalkraft gerade noch das Gleichgewicht mit der Schwere. Gleich darauf siegte die erstere, längs des Aequators löste sich eine dünne Körperschicht ab und vereinigte sich zu einem Ringe, dem aber die Umdrehung bereits durch seine bisherige Bewegung eingeprägt war. Da natürlich der Ring nicht an allen Stellen die gleiche Dicke hatte, so zerriss er an rerschiedenen Stellen, und an seinen Platz traten kleine Kugeln oder doch wenigstens Eine kleine Kugel. So war die Planetenbildung eingeleitet, der Centralball hatte in Folge seiner Massenverminderung eine beschleunigtere Umdrehung um seine Axe erhalten, und so waren auf's Neue die nothwendigen Bedingungen für die Entstehung eines zweiten Wandelsternes gegeben. Nach dieser Auffassung ist mithin die Ringperiode nur ein Durchgangsstadium in der Entwickelungsgeschichte jedes einzelnen Planeten, nicht aber etwas Aussergewöhn. liches, an die Kometen Erinnerndes, wie Kant annehmen zu müssen geglaubt hatte. Wesentlich in dieser Modifikation erblicken wir den durch La place angebahnten Fortschritt, denn nunmehr war der frühere Unterschied zwischen Mond und Ring gefallen, und der Anblick, welchen uns das Saturnsystem gewährt, erschien als ein solcher, den in früheren Zeiten jede andere Planetengruppe gleichfalls geboten haben konnte. Und noch mehr: mit dieser Verbesserung war für die KantLaplace'sche Theorie die Möglichkeit einer Bestätigung durch den Versuch gewonnen.

Behauptung lebhaft gemahnt, dass die Partikeln allmählig ganz von selbst in gewisse Bahnen hineingedrängt würden, hat J. $\mathrm{Hu}$ ber [27] gewichtige Gründe angeführt. 
§. 5. Plateau's Versuche. Ueber die von dem belgischen Physiker in verschiedenen Jahrgängen der Akademie zu Brüssel beschriebenen Experimente werde hier nach der sehr anschaulichen Schilderung von Wüllner [31] berichtet. In einem Kasten befindet sich (s. o. §. 1) ein Gemisch von Wasser und Alkohol, welches so regulirt ist, dass sein spezifisches Gewicht genau mit jenem des Olivenöles übereinstimmt. Ein Tropfen dieses letzteren wird mittelst einer Pipette in die Mischung gebracht; sowie jene zurückgezogen ist, bleibt der Oeltropfen, welcher ja dem Einflusse der Schwere vollständig entzogen ist, an dem zuletzt eingenommenen Orte schweben und nimmt, da einzig und allein die allenthalben gleiche Oberflächenspannung sich äussern kann, die reine Kugelform an. Nun werde ferner ein Eisenstab eingeführt, der etwa in seiner Mitte eine kleine Metallscheibe trägt, während an seinem oberen, aus dem Kasten hervorragenden Ende eine Kurbel angebracht werden kann (in Fig. $1 \mathrm{c}$ ist dieses Scheibchen wahrzunehmen). Wurde die Scheibe vorher mit Oel befeuchtet, so kann man die Oelkugel mittelst eines Eisenstäbchens so an erstere heranführen, dass die Theilchen des Balles sich symmetrisch um den Stab herumlagern, wodurch das Scheibchen gewissermassen zur Aequatorebene des Oeltropfens wird. Die Kurbel wird nunmehr sanft in Bewegung gesetzt; dann tritt zu den bisher allein wirksam gewesenen Molekularaktionen der Cohäsion und Adhäsion (an den Eisenstab) noch die Centrifugalkraft hinzu, und es treten folgeweise die Erscheinungen auf, welche in Fig. 1, a, b und c abgebildet

Fig. 1.

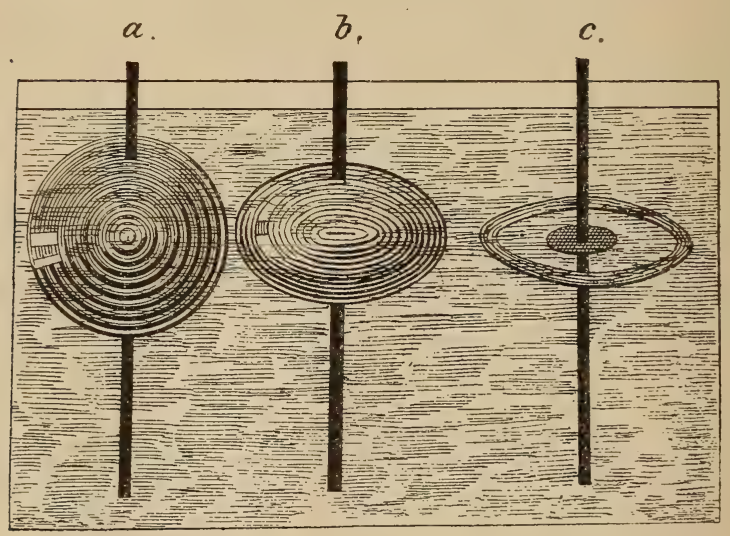

sind. Durch besondere Kunstgriffe wusste es Plateau sogar dahin zu bringen, dass ein Theil des Oeles an der Scheibe haften blieb und als abgeplattetes Sphäroid weiter rotirte, während der Ueberrest als Ring sich loslöste, und damit hatte man ein völlig entsprechendes Modell des Saturn erhalten. Bei grösserer Steigerung der Umdrehungsgeschwindigkeit zerreisst der Ring, die Stücke ballen sich zu kleineren sphärischen Klumpen zusammen, deren jeder wiederum mit einer im gleichen Sinne vor sich gehenden Rotation begabt ist. Es wird Nie- 
mandem einfallen, den Plateau'schen Versuch für einen strengen Beweis der kosmogonischen Hypothese erklären zu wollen, denn hiezu sind die Entstebungsbedingungen viel zu wenig gleichartige, doch bleibt die Uebereinstimmung immerhin eine sehr merkwürdige und werthvolle *).

§. 6. Gründe, welche gegen Kant-Laplace sprechen. Die Art und Weise, wie Kant auch die Kometen in seinem Systeme unterzubringen wusste, wird heutzutage wohl Niemandes Billigung erfahren können, aber auch Laplace ist der Frage, wie diesem Dilemma zu begegnen sei, aus dem Wege gegangen. Die später zu besprechenden neueren Theorieen der Schweifsterne, in Folge deren man letztere als selbstständige kosmische Wolken aufzufassen und den hyperbolischen Bahnen eine weit grössere Wahrscheinlichkeit als den elliptischen beizumessen sich gewöhnt hat, brachten uns die gewünschte Abhülfe, denn wenn der Komet überhaupt kein Vollbürger unseres Systemes ist, sondern nur durch eine zufällig sehr stark sich äussernde Gravitationswirkung in dessen Machtbereiche festgehalten wurde, so braucht uns eine stark excentrische oder sogar in rückläufigem Sinne beschriebene Bahn nicht weiter zu bekümmern.

Unter dem philosophischen Gesichtspunkte kann unserer Weltentstehungslehre entgegengehalten werden, dass sie nicht für alle $\mathrm{Mo}_{0}$ mente eine Auskunft in Bereitschaft halte - ein Schicksal, welches sie freilich mit allen menschlichen Theorieen theilt. Unerklärt bleibt nämlich, woher der in Umdrehung um seine Axe befindliche Gasball, welcher dereinst unser Sonnensystem darstellte, eben diese seine Rotation gehabt habe. Der blosse Ballungsakt konnte eine solche nicht ertheilen. Ennis hat allerdings diese Einwände zu entkräften gesucht [33], indess ist noch ein zweites Bedenken vorhanden, welches vielleicht noch schwerer zu heben sein dürfte. Meissel hat nämlich neuerdings auch darauf hingewiesen [34], dass selbst das Bestehen einer Rotation noch kein zureichender Grund für die Abtrennung der Planeten sei. Es werde mit $\mathrm{I}$ die Masse der Urkugel in ihrem Anfangszustande, mit $\mathrm{r}$ ihr Halbmesser, mit $\omega$ die Winkelgeschwindigkeit bezeichnet; dann hat man, den Anziehungsfaktor $=1$ gesetzt, $\omega^{2} \mathrm{r}<$ $M: r^{2}, \omega^{2} r^{2}<M: r$. Dadurch, dass die Kugel bis auf den Radius ? sich verkürzt hat, vergrösserte sich auch die Winkelgeschwindigkeit, die nunmehr $\omega_{1}$ heissen möge; mit Rücksicht auf das Princip der Erhaltung der lebendigen Kraft muss $r^{2} \omega^{2}=p^{2} \omega_{1}{ }^{2}$ und sohin auch

$$
p^{2} \omega_{1}^{2}<\frac{M}{\rho}, \omega_{1}^{2} p<\frac{M}{\rho^{2}}
$$

*) Es mag kühn erscheinen, im Laboratorium kosmische Processe reproduciren oder sozusagen Experimentalastronomie treiben zu wollen. Indess steht Plate a u's Beginnen keineswegs rereinzelt da. So hat u. a. Planté [32] zwei durch den Draht einer Batterie rerbundene Kupferstäbchen mit ihren freien Enden in ein Gefäss, gefüllt mit verdünnter Schwefelsäure, eingetaucht und, nachdem so der Strom hergestellt war, der positiven Elektrode den gleichnamigen Pol eines Magnetes genähert; das rom positiven Pole sich ablösende Kupferoxrd gerieth dann in eine Wirbelbewegung, täuschend ähnlich derjenigen. welche man - vergl. $\mathrm{Schellen's} \mathrm{Zeichnungen} \mathrm{-} \mathrm{auch} \mathrm{als} \mathrm{in} \mathrm{den} \mathrm{spiralförmigen} \mathrm{Nebelflecken} \mathrm{der} \mathrm{Jagd-}$ hunde und des Haares der Berenice vor sich gehend annehmen muss. 
sein. Die Planetenbildung würde aber, wie Laplace (s. o. §. 4) ausdrücklich betont, umgekehrt die Relation $\omega_{1}{ }^{2} \rho>\frac{M}{\rho^{2}}$ voraussetzen(Centrifugalkraft $>$ Anziehungskraft). Man muss also wohl noch an einen zweiten äusseren Impuls denken, welcher die Abtrennung des ersten Nebenkörpers vorbereitete, etwa an einen excentrischen Stoss oder an starke Annäherung eines anderen Centralkörpers u. dgl.

Theoretischer Natur ist auch ein von A. Ritter geäussertes Bedenken [35]. Derselbe kommt durch eine Reihe tiefgehender analytischer Ueberlegungen zu dem folgenden Schlusse: „Für jeden gasförmigen Weltkörper giebt es eine obere Volumengrenze, bei deren Ueberschreitung die Masse derselben im unendlichen Raume sich zerstreuen würde." Bestätigt sich dieser - zunächst ja nur am speziellen Falle erschlossene - Satz anderweit, so wird sich die moderne Kosmogonie damit allerdings auseinanderzusetzen haben, denn die Voraussetzung eines beliebig grossen Volumens für den Anfangszustand wäre jetzt nicht mehr gestattet. Früher schon hatte Zöllner eine ähnliche, aber ungleich apodiktischer gefasste Behauptung aufgestellt. Er hatte [36] die Differentialgleichung hergeleitet, welche die Beziehung zwischen dem Drucke in irgend einem Punkte einer Gaskugel und dem Abstand dieses Punktes vom Centrum ausdrückt, wenn die Kugel, deren Bestandtheile einzig und allein den Gesetzen von Newton und Mariotte unterworfen sein sollen, frei im Raume schwebt. Obschon das totale Integral dieser nicht linearen und deshalb gewiss auch nur sehr schwer aufzulösenden Gleichung zur Zeit noch nicht ermittelt ist, glaubte sich Zöllner doch ermächtigt, auf eine Partikularlösung derselben Schlüsse von ungemeiner Tragweite begründen zu dürfen und namentlich zu erklären, dass im gewöhnlichen (euklidischen) Raume unter den obigen Voraussetzungen eine völlige Verflüchtigung des Stoffes werde eintreten müssen; er suchte sich dadurch zu helfen, dass er dem Weltraume ein wenn auch nur sehr geringes positives Krümmungsmaass im Riemann'schen Sinne beilegte [37]. Budde hat aber [38] mit Recht eingewendet, die ganze Betrachtung Zöllner's stehe und falle mit der Voraussetzung eines Gleichgewichtszustandes im Universum, und dafür, dass ein solcher bestehe, ist der Beweis nicht einmal anzutreten versucht worden. Nachdem diese Zeilen längst geschrieben waren, erschien im Osterprogramm der Oberrealschule zu Coblenz 1883 eine Abhandlung von Most (Neue Darlegung der absoluten Geometrie und Mechanik, mit Berücksichtigung der Frage nach den Grenzen des Weltenraumes), in deren drittem Theile der Versuch gemacht wird, jene Gleichungen der Astronomie, in welchen Nutation, Aberration und Parallaxe neben einander auftreten, der Riemann'schen Theorie gemäss umzuändern und zuzusehen, ob die hiernach berechneten Werthe mit den Beobachtungen harmoniren. Wir gestehen, auch von der Betretung dieses allerdings rationelleren Weges uns keinen besonderen Vortheil versprechen zu können.

Von der grössten Schwierigkeit jedoch, welche die KantLaplace'sche Theorie gerade im gegenwärtigen Augenblicke zu überwinden hat, konnten ihre beiden Urheber keine Ahnung haben. Bis vor Kurzem schien es ja ausser allem Zweifel zu stehen, dass die einzelnen Trabanten sich ganz im gleichen Sinne um ihren Planeten be- 
wegten, wie dieser selbst um die Sonne. Die Trabanten des Uranus haben uns aber darüber belehrt, dass diese Uebereinstimmung keine durchgehende ist, denn diese sind retrograd, und wollte man die Bahn eines dieser Trabanten mit der Bahn irgend eines anderen Satelliten im Sonnensysteme zur Deckung bringen, so müsste man die betreffende Ebene um mehr als $100^{\circ}$ drehen [39]. Faye hat sich viele Mühe gegeben, um diese nicht wegzuleugnende Anomalie möglichst zu beseitigen. Wenn der in Bewegung befindliche Nebelfleck, so argumentirt er [40], in jenes Stadium eintritt, wo bereits die Homogeneität der Massenvertheilung gestört erscheint, so entsteht eine Wirbelbewegung der Moleküle um eine gewisse Axe. Während der ganzen Koncentration dauert dieselbe an und bewirkt, dass die Nebelmasse in einen äusseren und inneren Theil zerfällt. Die Gegensätzlichkeit dieser beiden Zonen sucht er in dem genannten Aufsatze zu charakterisiren, wie folgt. Rechtläufig wird die Revolution der aus der glühenden Gasmasse sich entfernenden Einzelkörper nur dann, wenn die äusseren Theile des Planetenringes eine grössere Geschwindigkeit hatten, als die inneren, und diess traf eben nur für die innere der beiden erwähnten Zonen zu, nicht aber auch zugleich für die äussere. Bei den Spiralnebeln z. B. erscheinen ebenfalls die äusseren Theile sehr verzögert in ihrer Bewegung gegenüber jener dér weiter nach innen belegenen Partieen. Dieser Rettungsversuch ist recht scharfsinnig, nur sieht man nicht recht ab, warum nur bei den Begleitern von Uranus und Neptun*), nicht aber bei den Hauptkörpern selbst und nicht auch bei den unter wesentlich ähnlichen Verhältnissen entstandenen Saturnsmonden die Randgeschwindigkeit so erheblich zurückgeblieben sein sollte. Ohlert hat [42] für den Saturnsring beim dereinstigen Zerreissen Aehnliches in Aussicht gestellt.

§. 7. Astronomische und physikalische Konsequenzen. Gesteht man der Nebularhypothese ihre Richtigkeit zu, so kann man aus ihr so manchen interessanten Wahrscheinlichkeitsschluss für andere kosmologische Fragen entnehmen. Der Phantasie ist hier allerdings ein weiter Spielraum gegönnt, wie u. a. aus einer anonymen Abhandlung hervorgeht, welche den morphologischen Spekulationen des bekannten Kartographen Habenicht gewidmet ist [43]. Die Entstehung aller Unregelmässigkeiten im Erdrelief, die „Hemisphärenblasenbildungen“, die Oberflächenbeschaffenheit des aus der Erde hervorgegangenen Mondes, die Schiefe der Ekliptik und andere Dinge werden dort in Verbindung gebracht mit der Theorie von Kant-Laplace. Insbesondere wird auf den Akt des Zerreissens eines Planetenringes Gewicht gelegt. In dem Momente nämlich, wo der endgültige Riss erfolgte, hätten sich beide Enden nach aussen umgebogen und zu Spiralen aufgewickelt, welche in einem der Trennungsstelle diametral gegenüberliegenden Punkte aufeinandergeprallt wären. Da die Bewegung der einen Spirale die wuchtigere war - welche, wird a. a. O. mit nicht sehr durchschla-

*) Auch bei dem einzigen sicher konstatirten Gefolgstern des Neptun hat sich nämlich Aehnliches ergeben. Der Neigungswinkel seiner Bahn gegen die mittlere Ebene der Trabantenbahnen ist sogar [41] ein noch weit grösserer, als bei Uranus. 
genden Gründen nachzuweisen gesucht - so konnte der Zusammenstoss nicht zum Stillstand führen, vielmehr führte er die Umdrehung des sich -neu bildenden Körpers und zugleich eine schiefe Neigung von dessen Aequator gegen die Bahnebene herbei. Die einzelnen Himmelskörper hätten nach der Vereinigung beider Spiralen die Form einer eingekerbten runden Frucht gehabt, und diese Kerbe soll auf unserer Halbkugel noch heute durch die tiefe Rinne des atlantischen Meeres angedeutet sein. Man sieht, dass diese für Manchen vielleicht sehr bestechenden Deduktionen in's Bereich der Konjekturalastronomie fallen.

Auf einem etwas festeren Boden fussen die Betrachtungen, welche Ohlert [44] über eine in früheren Zeiten anders beschaffene Vertheilung und Gestalt der Planetenbahnen angestelit hat. Während jetzt die Sonne sich nicht merklich von einer Kugel unterscheidet, muss sie damals, als sie dem ersten Planeten das Leben gab, die Gestalt eines Umdrehungsellipsoides besessen haben, dessen Meridianellipse sehr weit vom Kreise abwich, und damit waren, wie wir in einem der folgenden Kapitel sehen werden, auch ganz andere Verhältnisse der Anziehung gegeben, und gerade so verhielt sich später jeder einzelne Planet den von ihm erzeugten Nebenplaneten gegenüber. In erster Linie musste die Umlaufsbahn der jüngsten Abkömmlinge in die Länge gedehnt werden, wis denn in der That die Excentricität der Merkursbahn, deren elliptischen Charakter wahrscheinlich schon König Alphons (im XIII. Jahrhundert) wahrgenommen hat [45], viermal so gross ist, als die grösste der vier oberen Planeten. Sehr im Rechte ist Ohlert auch da, wo er den von gewissen Theoretikern wohl zu beherzigenden Satz ausspricht [46]: "Wir dürfen uns nicht wundern, wenn weder das Bode-Titius'sche Gesetz, noch die ähnlichen Reihen für die Abstände der Jupiter- und Saturnsmonde, die man den Ergebnissen der Beobachtung geglaubt hat anpassen zu können, recht stimmen wollen, da die jetzigen Abstände jedenfalls beträchtlich von denen, die sie ursprünglich von ihrem Centralkörper hatten, abweichen."

Von grosser Bedeutung ist die Nebulartheorie, wenn es sich darum handelt, für die physische Konstitution der näheren und entfernteren Gestirne gewisse allgemeine Anhaltspunkte zu gewinnen. Das eine Axiom, von welchem Kant ausgegangen war, ist durch die Spektralanalyse nahezu zum Range eines bewiesenen Lehrsatzes erhoben worden, dasjenige nämlich, dass alle Materie bis hinein in die entfernten Räume, von denen das Licht erst in Jahrzehnten zu uns herabgelangt, im Wesentlichen von gleichartiger Beschaffenheit sei. Namentlich Huggin s und Miller bekräftigen am Schlusse ihrer berühmten und erfolgreichen Arbeit über die Sternspektra [47], dass die nämlichen chemischen Elementarstoffe, aus welchen unsere Sonne sich zusammensetzt, bei sämmtlichen Fixsternen wiederkehren. Nicht minder hat die optisch-chemische Untersuchung der Nebelflecke, um welche die nämlichen beiden Forscher sich verdient gemacht haben [48], die Wahrscheinlichkeit dafür erhöht, dass diese kosmischen Gebilde in ihrer Mehrzahl nicht noch unaufgelöste Sternhaufen, sondern vielmehr wirkliche Dunstmassen in sehr hohem Temperaturzustande repräsentiren; aus den von G. Kirchh off [49] entwickelten Fundamentalsätzen dürfte hervorgehen, dass die das Spektrum der sogenannten planetarischen Nebel charakterisirenden hellen Linien einer glühenden Gasmasse ihre Entstehung 
verdanken, so zwar, dass nicht der mit nur geringer Emissionsfähigkeit begabte Kernkörper, sondern hauptsächlich die längs der Oberfläche desselben vertheilten glühenden Gasschichten das Licht entsenden. Nach Zöllner werden sich im Ganzen für jeden planetarischen Nebel, der schliesslich in ein Sonnensystem nach Art des unsrigen sich verwandelt, fünf Entwickelungsphasen nachweisen lassen [50], nämlich die Periode des glühend-gasförmigen Zustandes, die Periode des gluthflüssigen Zustandes, die Periode der Schlackenbildung, während deren eine kalte und dunkle Oberfläche sich zu bilden beginnt, die Periode der Eruptionen, während welcher die bereits starr gewordene Rinde noch $a b$ und zu von der gluthflüssigen Masse des Inneren gewaltsam durchbrochen wird, und schliesslich die Zeit der vollendeten Erkaltung. Zur ersten Kategorie gehören alle planetarischen Nebel, solange sie noch keine Spur einer beginnenden Differentiirung erkennen lassen, zur zweiten die in ihrer Helligkeit unveränderten Fixsterne, doch tritt ein deutlicher Uebergang vom ersten zum zweiten Stadium schon bei jenen Nebelmassen hervor, in deren Innerem Fernröhre von grosser raumdurchdringender Kraft bereits einzelne ausgebildete Sternchen zu erblicken gestatten. Auch die Individuen der zweiten Klasse weisen Unterschiede auf, die eine entwickelungsgeschichtliche Deutung zulassen. Wie nämlich Secchi als eines der werthvollsten Ergebnisse langjähriger, dem nämlichen Ziele zugewandter Forschung ermittelt hat, zerfallen die Spektra aller Fixsterne in vier gesonderte Typen, deren letzter uns hier nicht besonders zu beschäftigen braucht [51 $\left.{ }^{*}\right)$; bereits Rutherfurd hatte [53] auf die Möglichkeit einer solchen Klassifikation angespielt. Der erste Typus umfasst eine überwiegende Anzahl der helleren Sterne (Sirius, Wega, Rigel im Orion u. s. w.); äusserlich sind dieselben durch ein weisses Licht mit leicht bläulichem Schimmer ausgezeichnet, und ihr Spektrum lässt neben vielen schwachen $\mathrm{Ab}$ sorptionslinien **) noch vier starke Streifen erkennen, wie sie auch das Wasserstoffspektrum in der Geissler'schen Röhre zeigt. Diesen Himmelskörpern muss also auch eine verhältnissmässig sehr grosse Hitze zugeschrieben werden, welche die meisten Stoffe noch verhindert, aus dem dissociirten Gaszustand sich heraus zu individualisiren, während

*) Diese Sterne, fast ausschliesslich in Schjellerup's Katalog der rothen Sterne verzeichnet, unterscheiden sich von den vorher genannten besonders darin, dass in ihrem Spektrum das Maximum der Lichtstärke gerade auf der entgegengesetzten Seite liegt [52].

**) Das Wesen der Spektralanalyse muss hier als bekannt vorausgesetzt werden; nur zur Auffrischung der Erinnerung mögen ein paar Worte über diese grosse Erfindung Bunsen's und G. Kirchhoff's - eine geschichtliche Beleuchtung der namentlich von W. Thomson für Stokes geltend gemachten Prioritätsansprüche ist bei Zöllner [54] nachzusehen - Platz finden. Wollaston und Fraunhofer hatten erkannt, dass wenn ein homogenes Lichtbündel prismatisch gebrochen wird, in dem entstehenden Streifen der Regenbogenfarben gewisse dünne schwarze Linien erscheinen. Dieselben rühren nun, wie jene deutschen Forscher fanden, davon her, dass das Sonnenlicht durch gewisse in Gasform der Sonnenatmosphäre einverleibte metallische Stoffe hindurchgeht, welche an und für sich bei der spektralanalytischen Untersuchung charakteristische Farbenstreifen genau an dem Orte wahrnehmen lassen, wo sich im solaren Spektrum die dunklen Streifen finden. Diese Umkehrung des Spektrums setzt uns demgemäss in den Stand, festzustellen, durch welche Gase oder Metalldämpfe das von einer fernen Lichtquelle uns zugeschickte Licht hindurchgegangen ist. 
einzelne Elemente von sehr geringem Atomgewichte - darunter eben das Wasserstoffgas - doch bereits zu dieser Verdichtung gelangt sind. Das Licht der Sterne vom zweiten Typus besitzt einen mehr gelblichen Grundton (Capella, Aldebaran, Arktur), und ihr Spektrum deckt sich, besonders auch in Anbetracht der zahlreichen Absorptionsstreifen, so vollkommen mit jenem der Sonne, dass wir kaum fehlgehen können, wenn wir die letztere mit all' diesen Sternen in Eine Reihe stellen. Für den dritten Fixsterntypus, dessen Mitglieder äusserlich durch eine röthliche Färbung kenntlich sind, ist ein aus verwaschenen Streifen und breiten Bändern sich zusammensetzendes Spektrum bezeichnend, welches auf die absorbirende Wirkung grösserer Wolkenmassen schliessen lässt. Die Sterne des zweiten und dritten Grundtypus würden somit in die dritte der von Zöllner aufgestellten Kategorieen fallen*); dafür aber, dass der Abkühlungsakt bereits soweit fortgeschritten, wäre, um einen Stern als zur vierten Kategorie gehörig zu signalisiren, würdé dessen plötzliches Aufleuchten am Himmelsgewölbe gefordert werden müssen. Diess träfe zu für die neuen Sterne in der Kassiopeja und im Ophiuchus, an welche sich die Namen Tycho Brahe's (1572) und Johann Kepler's (1604) knüpfen, und diese Art von himmlischen Phänomenen würde in einen gewissen Gegensatz zu den veränderlichen Sternen treten, welche man bisher in den Lehrbüchern stets mit den ersteren vereint zu behandeln pflegte $\left.{ }^{* *}\right)$. Unsere Planeten gehören unter diesem morphologischen Gesichtspunkte auch nicht mehr in dieselbe Rubrik, vielmehr sind in ihnen sehr verschiedene entwickelungsgeschichtliche Stadien und Uebergangsphasen vertreten, wie sich in den nächsten beiden Kapiteln des Näheren ausweisen wird. Bemerkt sei noch, dass Zöllner [59] durch Anwendung seines neu erfundenen Sternphotometers zur Bestimmung einer ganzen Reihe cölestischer Lichtintensitäten seinen deduktiven Schlüssen auch eine empirische Stütze verliehen hat. - Ja, Helmholtz ist sogar noch einen Schritt weiter gegangen und hat in einer höchst geistreich geschriebenen Abhandlung ,über die Entstehung des Planetensystemes" [60] gerade aus den Resultaten der spektralanalytischen Himmelsforschung heraus die Nothwendigkeit einer ursächlich begründeten kosmogonischen Hypothese darzuthun versucht, wie sie von Kant und Laplace geliefert wurde.

*) Für die Erklärung des von den sogenannten veränderlichen Sternen uns dargebotenen Phänomenes dachte man sonst wohl an eine Axendrehung oder auch, nach Klinkerfues [56], an eine Ebbe und Fluth in den lichtabsorbirenden Atmosphären zweier sehr nahe stehender und durch optische Hülfsmittel gar nicht mehr von einander zu trennender Doppelsterne. Dieser Gedanke verdient um so eingehendere Prüfung, als seitdem durch Schiaparelli Sternpaare von ganz überraschend kurzer Umlaufszeit um den gemeinsamen Schwerpunkt aufgefunden worden sind [56]. Uebrigens bringt Klinkerfues bei einer späteren Gelegenheit selbst seine Hypothese in Verbindung mit derjenigen von Kant-Laplace [56], indem er betont, dass man den Kondensationsprocess ja sehr wohl auch von zwei oder mehreren selbstleuchtenden Massen ausgehen lassen könne. „Ein solches System würde weniger durch Schwankungen in der Lichtproduktion, als durch den schnellen Wechsel der Absorptionsverhältnisse, in seinem Uebergangsstadium ähnliche Veränderlichkeit des Lichtes wahrnehmen lassen, als die Variablen zeigen."

**) Auch Loomis hat, wie Cornelius mittheilt [58], den veränderlichen Sternen, wie der Sonne, dunkle Flecken zugeschrieben, deren wechselnde $\mathrm{Zu}$ - und Abnahme Schwankungen der Lichtintensität bedinge. 
§. 8. Das Endschicksal der Weltsysteme. Sowie ein Weltkörper definitiv in das fünfte Zöllner'sche Stadium, das der völligen Erkaltung eingetreten ist, wie wir diess mit hoher Wahrscheinlichkeit bei unserem Erdmonde annehmen dürfen, kann derselbe auch kein passender Aufenthaltsort mehr für Organismen irgendwelcher Art sein, wir können ihn als einen abgestorbenen bezeichnen. In einem weiteren Sinne jedoch muss das individuelle Leben eines Sternes, vorab eines Planeten, als endlich begrenzt gelten. Es hat allerdings Schriftsteller gegeben, die, wie $\mathrm{Czolbe}$ [61], für eine absolute Anfangslosigkeit der Welt eingetreten sind, und diese müssen wohl auch Gegner der Nebularhypothese sein; allein wer der letzteren beipflichtet, wird mit Cornelius [62] zu einem zeitlichen Anfang und hiemit schon aus allgemein-philosophischen Gründen auch zu einem zeitlichen Abschlusse jenes Aggregates von Körpern gelangen müssen, welches man kurz als die "Welt" bezeichnet*). Die mechanische Wärmetheorie hat uns die Mittel an die Hand gegeben, mittelst des von ihr formulirten Satzes, dass die Entropie der Welt einem Maximum zustrebe, bestimmtere Vorstellungen über die schliesslichen Geschicke wenigstens unseres eigenen Sonnensystemes uns zu bilden. Die Bewegungen der den Centralkörper umkreisenden Planeten gehen nicht im leeren Raume, sondern, wie im nächsten Kapitel gezeigt werden wird, in einem Medium vor sich, das seiner grossen Feinheit ungeachtet den darin sich bewegenden Körpern einen gewissen Widerstand entgegensetzt und die grossen Bahnaxen verkleinert. So muss es kommen, dass nach und nach sämmtliche Planeten auf die Sonne herabstürzen, und wenn durch jedes einzelne Ereigniss dieser Art auch stets ein bedeutendes Quantum mechanischer Arbeit in Wärme umgesetzt wird **), so muss doch endlich einmal der Zeitpunkt eintreten, bei welchem die unausgesetzte Licht- und Wärmeabgabe der Sonne nicht mehr durch Zufuhr von aussen kompensirt werden kann. Die Amplitude der von uns mit dem Namen der Wärme belegten Aetherschwingungen múss kleiner und kleiner werden, und mit ihrem definitiven Verschwinden ist auch der endgültige Stillstand eingetreten; indess würde nach Clausius [65] schon dadurch eine Vernichtung jedweder Veränderung und damit der Tod der Natur herbeigeführt werden, dass alle Theilchen der Materie um stabile Gleichgewichtslagen schwingen. Man hat [66] an einen

*) Einer der schärfsten Denker auf dem Gebiete der Erkenntnisstheorie, A. Fick, erschliesst die Nothwendigkeit eines zeitlichen Beginnes, resp. eines Schöpfungsaktes aus der Thatsache, dass die Welt noch immer durch unsere Sinne zu uns in Beziehung tritt. Wäre dieselbe nämlich von Ewigkeit her da, so müsste der finale Zustand bereits erreicht sein - was Niemand zugeben wird [63].

***) Kennt man die Masse des auftreffenden Körpers, die Geschwindigkeit im Momente des Zusammenstosses und den Winkel, unter welchem die Bahn des Körpers die im Berührungspunkt beider Kugeln gelegte gemeinsame Tangentialebene trifft, so kann man die durch den Stoss erzeugte Wärmemenge vermittelst der Erfahrungswahrheit berechnen, dass (nach Joule) 425 Meterkilogramm einer sogenannten Kalorie entsprechen. Es ist sogar möglich, unter passenden Voraussetzungen Näherungswerthe für die aus dem ursprünglichen Ballungsakte der Stofftheilchen resultirenden Wirkungsgrössen und Wärmemengen zu berechnen. Redtenbacher hat diess gethan [64] und mit Zugrundelegung der Nebulartheorie ermittelt, dass die Anfangstemperaturen von Merkur, Venus, Erde, Mars, Jupiter, Saturn, Uranus und Sonne sich zu einander verhalten wie $0,4: 0,95: 1: 0,23: 30: 12: 4: 32,26$.

Günther, Geophysik. I. Band. 
periodischen Wechsel von Tod und Neubildung der Weltsysteme gedacht, und insbesondere hat Rankine in einer Sitzung der britischen Naturforschergesellschaft sinnreiche Gedanken über eine solche Wiederkehr des kosmischen Lebens ausgesprochen. Er knüpfte dem uns vorliegenden Berichte [67] zufolge an W. Thomson's Behauptung an, dass gegenwärtig im Weltall für alle in verschiedenen Formen auftretenden Bewegungs-Energieen, die wir Kraft, Licht, Magnetismus, Elektricität, Wärme oder wie immer nennen*), eine Tendenz bestehe, sich in Wärme umzusetzen, womit dann auch deren gleichmässige Zerstreuung durch die ganze Materie verbunden ist. Sowie dieser Process zum Abschlusse gelangt, von Temperaturunterschieden also keine Rede mehr wäre, würde der Stillstand im Universum eintreten; allein Rankine meint, diese zerstreute Energie könne sich doch wiederum in einzelnen Heerden koncentriren und aus den inaktiven Verbindungen, welche sich unausgesetzt bilden, könnten im gegebenen Falle neue Anhäufungen chemischer Kraft werden. Diese Idee verdiente es vielleicht, weiter verfolgt zu werden, während der weitere Schluss, dass an der Grenze des doch nur in endlicher Menge vorhandenen Weltäthers eine totale Reflexion eintreten und damit auch einige Koncentrationswärme entstehen müsste, zu mancherlei Bedenken Anlass giebt **). - Wie dem auch sei, wie auch das künftige Geschick unserer Welt sich gestalten möge, so viel hat uns die konsequente Analyse der kosmogonischen Vorgänge doch zur Evidenz bewiesen, dass unserem Sonnensystem noch eine sehr lange Dauer beschieden sein wird. Man vergleiche auch die von Wundt meisterhaft gekennzeichnete Gedankenreihe, welche sich vom Standpunkte des kriticistischen Phänomenalismus an das supponirte Faktum anknüpfen-lässt, dass der VerwandlungsInhalt der Welt-Energie ein Grösstes werde [73].

*) Die hier angedeutete Ansicht, dass alle diese Agentien nur verschiedene Bethätigungen des nämlichen Urvermögens aller Materie seien, ist besonders von den englischen Naturforschern von jeher vertreten worden. Die klarste Darstellung dieser mit dem üblichen Kraftbegriffe vollständig brechenden Lehre hat Grove [68] gegeben.

**) Das Stabilitätsproblem des Sonnensystemes hat eine doppelte Seite, und oben ist von diesen nur die eine in's Auge gefasst worden. Früher begnügte man sich, die Frage rein mechanisch aufzufassen und nur zu untersuchen, ob nicht durch die Störungen, welche die einzelnen Bestandtheile des Systemes unausgesetzt auf einander ausüben, der Fortbestand desselben gefährdet werde. Hierauf ist durch die grossartigen Arbeiten Laplace's, zu denen Lagrange und $\mathrm{Po}$ isson noch einige Nachträge lieferten, ein endgültig verneinender Bescheid gegeben worden. Bei Möbius, der diese scheinbar so verwickelten Verhältnisse mittelst ganz einfacher geometrischer Betrachtungen klarzulegen weiss, lesen wir [69], dass die Garantie für eine unbestimmbar lange Dauer von drei Bedingungen abhängt: Die mittleren Entfernungen der Planeten von der Sonne und damit auch die nach dem dritten Kepler'schen Gesetze von jenen abhängigen Umlaufszeiten müssen konstant sein, die Excentricitätenwerthe dürfen stets nur kleine Brüche bleiben, und endlich muss sich im Raume eine unveränderliche Ebene konstruiren lassen, mit welcher die einzelnen Bahnebenen nur ganz kleine Winkel bilden. Eine solche Ebene, deren Dasein bereits Kepler geahnt hatte, suchte zuerst Euler auf analytischem Wege zu ermitteln [70], doch gelang ihre exakte Bestimmung erst Laplace [71]. Die beste und umfassendste Auskunft über Alles, was mit dem mechanischen - nicht mit dem thermodynamischen Theile der Frage nach der Dauer unserer Planetenwelt zusammenhängt, bietet der Artikel „Stabilitätsproblem “ in N ürn b er g e r's Lexikon, welcher von J. W. H. Leh$m$ ann herrührt [72]. 
[1] Zöckler, Geschichte der Beziehungen zwischen Theologie und Naturwissenschaft, mit besonderer Rücksicht auf Schöpfungsgeschichte, 1. Abtheilung, Gütersloh 1877. S. 200. - [2] Ibid. S. 240. - [3] Fi. Hoffmann, Geschichte der Geognosie und Schilderung der vulkanischen Erscheinungen, Berlin 1868. S. 54. - [4] Leibniz, Protogaea sive de prima facie telluris et antiquissimae historiae vestigiis in ipsis naturae monumentis, ed. Scheidt, Gottingae 1748. - [5] Zöckler, Geschichte etc., 2. Abtheilung, Gütersloh 1879. S. 143 ff. - [6] Ibid. S. 154 ff. [7] Ibid. S. 166. - [8] Buffon, Les époches de la nature, Paris 1780. - [9] Zöckler, Geschichte etc., 2. Abtheilung. S. 520 ff. - [10] Steffens, Anthropologie, Breslau 1822. - [11] J. E. Silberschlag, Geogenie oder Erklärung der mosaischen Erderschaffung nach physikalischen und mathematischen Grundsätzen, Berlin 1780-83. [12] G. Chr. Silberschlag, Neue Theorie der Erde und ausführliche Untersuchung der ursprünglichen Bildung der Erde, nach den Berichten der heiligen Schrift und den Grundsätzen der Naturlehre und Mathematik, Berlin 1764. - [13] Späth, Ueber die Entstehung und Ausbildung des Sternhimmels oder Cosmogenie, Nürnberg 1815. - [14] Nyrén, Ueber die von Emanuel Swedenborg aufgestellte Kosmogenie, Vierteljahrsschr. d. astr. Gesellsch., 14. Jahrg. S. 80 ff. - [15] J. H. Lambert, Kosmologische Briefe über die Einrichtung des Weltbaues, Augspurg 1761. [16] Kant, Schriften zur physischen Geographie, herausgeg. von J. W. Schubert, Leipzig 1839. S. 93 ff. - [17] Ibid. S. 99. - [18] Ibid. S. 104 ff. - [19] Sir Isaac Newton's mathematische Principien der Naturlehre, deutsch von Wolfers, Berlin 1872. S. 394 ff. - [20] Kant, Schriften etc. S. 114 ff. - [21] Ibid. S. 122 ff. - [22] Ibid. S. 131 ff. - [23] Sommer, William Herschel, Ueber den Bau des Himmels, drei Abhandlungen aus dem Englischen übersetzt: nebst einem authentischen Auszuge aus Kant's Allgemeiner Naturgeschichte des Himmels, Königsberg 1791. S. 193. - [24] H. J. Klein, Entwickelungsgeschichte des Kosmos, Braunschweig 1870. S. 38. - [25] Zöllner, Ueber die Natur der Cometen; Beiträge zur Geschichte und Theorie der Erkenntniss (3. Aufl.), Leipzig 1883. S. 268 ff. [26] Du Prel, Entwickelungsgeschichte des Weltalls, Leipzig 1882. S. 22 ff. [27] J. Huber, Zur Philosophie der Astronomie, München 1878. S. 33 ff. [28] Faye. Sur les idées cosmogoniques de Kant, à propos d'une réclamation de M. Schloetel, Compt. rend. de l'acad. franc., tome XC, S. 124 ff. - [29] A. Meydenbauer, Kant oder Laplace? Kosmologische Studie, Marburg 1880. - [30] Laplace, Exposition du système du monde, Paris 1796. S. 343. - [31] Wüllner, Lehrbuch der Experimentalphysik, 3. Band. Leipzig 1870. S. 236 ff. - [32] Planté, Sur les nébuleuses spirales, Compt. rend. de l'acad. franç., tome LXXXI, S. 749. - [33] Ennis, Physical and mathematical principles of the nebular theory, Philos. Mag. [5] Vol. III. S. 262 ff. - [34] Meissel, Ueber Reihen, denen man bei der numerischen Lösung des Problemes der drei Körper begegnet, wenn die Anfangsgeschwindigkeiten Null sind, Kiel 1882. S. 11. - [35] A. Ritter, Untersuchungen über die Höhe der Atmosphäre und über die Constitution gasförmiger Weltkörper, Ann. d. Phys. u. Chem. (2), 11. Band. S. 344. - [36] Zöllner, Ueber die Natur etc. S. 92 ff. - [37] Ibid. S. 100. - [38] Budde, Zur Kosmologie der Gegenwart, Bonn 1872. S. 19. - [39] Newcomb, Populäre Astronomie, deutsch von Engelmann, Leipzig 1881. S. 388. - [40] Faye, Sur l'origine du système solaire, Compt. rend. de l'acad. franç., tome XC, S. 637 ff. - [41] Newcomb, Pop. Astr. S. 394. - [42] Ohlert, Die Rückläufigkeit der Monde des Uranus, Gaea, 13. Jahrgang. S. 243. - [43] Die Theorie der sphärischen Kraterbecken, Grenzboten, 41. Jahrgang. S. 404 ff. - [44] Ohlert, Die Veränderung der Planeten und Mondbahnen in der Zeit der Bildung des Sonnensystemes, Gaea, 13. Jahrgang. S. $147 \mathrm{ff}$. [45] Maedler, Geschichte der Himmelskunde von den ältesten bis auf die neuesten Zeiten, 1. Band, Braunschweig 1873. S. 351 ff. - [46] Ohlert, Die Veränderung etc. S. 157. - [47] Huggins-Miller, On the spectra of some of the fixed stars, Philosoph. Transact., 1864. S. 413 ff. - [48] Huggins-Miller, On the spectra of some of the nebulae, a supplement to the paper of the fixed stars, ibid. S. 437 ff. - [49] G. Kirchhoff, Ueber den Zusammenhang zwischen Emission und Absorption von Licht und Wärme, Ann. d. Phys. u. Chem. (1), 119. Band. S. 275 ff. - [50] Zöllner, Fhotometrische Untersuchungen mit besonderer Rücksicht auf die physische $\mathrm{Be}$ schaffenheit der Himmelskörper, Leipzig 1865. S. 241. - [51] Secchi, Die Sonne, deutsch von Schellen, Braunschweig 1872. S. 775 fi. - [52] Ibid. S. $781 \mathrm{ff} .-$ [53] Rutherfurd, Astronomical observations with the spectroscope, Boston 1863. - [54] Zöllner, Ueber die Natur der Cometen etc. S. XXXIV ff. - [55] Klinkerfues, Ueber den Lichtwechsel der Veränderlichen. Nachr. der k. Gesellsch. d. Wiss. zu Göttingen, Sitzung vom 7. Januar 1865. - [56] Schiaparelli, Misure 
di alcune principali stelle doppie di rapido movimento orbitale, Milano 1882. [57] Klinkerfues, Ueber den neuen Veränderlichen bei $\varepsilon$ Coronae Borealis, Nachrichten d. k. Gesellsch. d. Wiss., Sitzung vom 4. August 1866. - [58] Cornelius, Ueber die Entstehung der Welt, Halle 1870. S. 30. - [59] Zöllner, Phot. Untersuch. S. 264 ff. - [60] Helmholtz, Populäre wissenschaftliche Vorträge, 3. Heft, Braunschweig 1876. S. 99 ff. - [61] Czolbe, Die Grenzen und der Ursprung der menschlichen Erkenntniss im Gegensatze zu Kant und Hegel, Jena und Leipzig 1865. S. 130 ff. - [62] Cornelius, Ueber die Bedeutung des Causalprincips in der Naturwissenschaft, Halle 1867. S. 20 ff. - [63] A. Fick, Die Naturkräfte in ihrer Wechselwirkung, Würzburg 1869. S. 70. - [64] Redtenbacher, Die anfänglichen und gegenwärtigen Erwärmungszustände der Körper des Sonnensystemes, Karlsruhe 1862. - [65] Clausius, Abhandlungen zur mechanischen Wärmetheorie, 2. Band, Braunschweig 1876. S. 42 ff. - [66] H. J. Klein, Entwickelungsgesch. etc. S. 35. - [67] Rankine, Wiederkoncentrirung der mechanischen Energie des Weltalls, Sirius, 16. Band. S. 13 ff. - [68] Grove, Die Verwandtschaft der Naturkräfte, deutsch von v. Schaper, Braunschweig 1871. [69] Möbius, Die Elemente der Mechanik des Himmels, auf neuem Wege ohne Hülfe höherer Rechnungsarten dargestellt, Leipzig 1843. S. 292 ff. - [70] L. Euler, De circulo maximo fixo in coelo constituendo, ad quem orbitae planetarum et cometarum referuntur, Novi Comment. Soc. Petrop., tom. XX. S. 509 ff. [71] Laplace, Traité de mécanique céleste, Vol. I, Paris 1799. S. 318 ff. [72] Nürnberger, Populäres astronomisches Handwörterbuch, 2. Band, Kempten 1848. S. 475 ff. - [73] Wundt, Ueber das kosmologische Problem, Vierteljahrsschr. f. wiss. Philos., 1. Jahrgang. S. 80 ff.

Kapitel II.

\section{Die physische Konstitution der Körper des Sonnensystemes.}

§. 1. Die Sonne. Für fast alle Probleme der tellurischen Physik hat sich der Centralkörper unseres Planetensystemes als ein höchst einflussreicher Faktor herausgestellt. Die Attraktionswirkung der Sonne bedingt neben derjenigen des Mondes die periodischen Wallungen der Meere und nach einer wenigstens sehr verbreiteten Meinung auch gewisse Schwankungen in unserer Lufthülle und in dem feurig-flüssigen Erdkern; die Licht- und Wärmemengen, welche unsere Erde je nach ihren verschiedenen Stellungen zur Sonne von dieser zugesandt erbält, treten uns als Ursachen der mannigfachsten meteorologischen und hydrologischen Veränderungen entgegen, und unmittelbar davon abhängig erweist sich alles organische Leben. Die physische Beschaffenheit der Sonne muss demnach auch ein wichtiges Studienobjekt für uns bilden. Von einem solchen Studium kann natürlich erst seit der Erfindung des Fernrohres die Rede sein, doch haben auch nach diesem Zeitpunkte mehr denn zwei Jahrhunderte unser Wissen vom Sonnenkörper nicht in dem Maasse gefördert, wie die kurze Spanne' Zeit, welche die Gegenwart von der ersten Anwendung der Spektralanalyse und der Sternphotographie trennt. Seitdem erst darf dieser Theil der Astrophysik, um welchen sich ein Spörer, Vogel, Lockyer, Janssen, Secchi, Tacchini und viele Andere hohe Verdienste erworben haben, mit anderen Theilen der Wissenschaft sich in Eine Reihe stellen. 
Was wir von der Sonne, sei es nun mit unbewaffnetem oder mit bewaffnetem Auge, wahrnehmen, ist die sogenannte Photosphäre, die leuchtende Oberfläche. Gewisse unregelmässige Lichtanhäufungen und Lichtdefekte in derselben werden als Sonnenfackeln und Sonnenflecke bezeichnet. Die freilich nur selten eintretenden Erscheinungen totaler oder ringförmiger Sonnenfinsternisse haben uns auch die Möglichkeit verschafft, die fernere Umgebung des Sonnenrandes etwas genauer kennen zu lernen, und da fand es sich, dass um die Photosphäre herum noch ein weiterer Kugelring aus schwächer leuchtender Materie sich lagert, welcher von seinen Entdeckern den Namen der Chromosphäre erhalten hat. Gewisse Einzelbestandtheile dieser Chromosphäre, die Protuberanzen, ziehen neuerdings die Aufmerksamkeit der Forscher am meisten auf sich. Jenseits dieser Hülle endlich begegnen wir der Korona.

§. 2. Die Photosphäre. Bei gehöriger Vergrösserung erkennt man, dass - von den eigentlichen Flecken völlig abgesehen - die Oberfläche der Sonne durchaus nicht in gleichförmigem Lichte leuchtet; dieselbe erscheint nach Secchi [1] bedeckt mit einer unendlichen Anzahl kleiner Körner von annähernd gleicher Grösse, aber sehr verschiedener Gestalt, deren Zwischenräume sich zu einem weit weniger hellen Netzwerk aneinanderreihen. Man spricht häufig von den Reiskörnern der Photosphäre, weil das granulirte Aussehen derselben den Eindruck einer Flüssigkeit mit darin aufgelösten Körnern hervorruft. Die von Nasmyth geäusserte Ansicht, dass diese sonderbare Struktur durch über einander liegende schmale Objekte, die Weidenblätter, hervorgerufen werde, konnte schon Secchi [2] nicht völlig theilen, und heute ist, wie wir aus dem zusammenstellenden Referate Newcomb's [3] entnehmen, durch die Beobachtungen von Langley und Janssen so viel festgestellt, dass diese Granulationen durch wirr verstreute kleine Lichtpunkte, die sich ab und zu zu grösseren Körnern zusammenballen, bedingt sind. Die kleinsten noch sichtbaren Einzelkörperchen mögen etwa eine lineare Ausdehnung von $200 \mathrm{~km}$ besitzen.

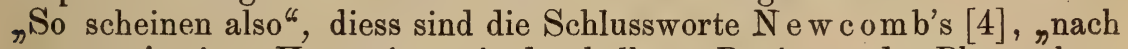
unseren jetzigen Kenntnissen in den helleren Regionen der Photosphäre wesentlich drei Aggregationsformen zu bestehen: wolkenähnliche Gebilde, die jederzeit sichtbar sind; Lichtknoten oder Reiskörner (Weidenblätter), in welche sich die Wölkchen auflösen, und die mit einem guten Fernrohr bei guter Luftbeschaffenheit stets gesehen werden können; endlich die kleinen, die Körner bildenden Lichtpunkte. ${ }^{\text {" }}$

§. 3. Fackeln und Flecke. Schon bald, nachdem die Sonne unter teleskopische Beobachtung genommen war, erkannte man die Flecke und die meistentheils in deren nächster Umgebung anzutreffenden helleren Stellen, welche man als Sonnenfackeln bezeichnete. Dieselben kommen allenthalben auf der Sonne vor und meiden besonders die Pole nicht; ihre Dimensionen sind oft ungeheure, wie denn Secchi von einer Fackel spricht, welche sich wie eine grosse Lichtwelle über die Hälfte der Sonnenscheibe erstreckt habe [5]. Man kann im Allgemeinen deren Entstehung einem aufsteigenden heissen Luftstrom das Wort „Luft" natürlich im solaren Sinne genommen - zuschreiben 
und annehmen, dass dieselben sich etwas über dem Durchschnittsniveau der Photosphäre befinden; der französische Astronom Li a is, der manche hervorragende Arbeit über Sonnenphysik veröffentlicht hat, spricht sich darüber folgendermassen aus [6]: „Dans les points où la photosphère s'élève au-dessus de son niveau général, on devra voir des facules." Neuerdings beginnt man sich für die den Flecken gegenüber längere Zeit ein wenig vernachlässigten Fackeln aus dem Grunde wieder mehr zu interessiren, weil man ihre nahe Verwandtschaft mit den Protuberanzen erkannt zu haben glaubt.

Sonnenflecke von ungewöhnlicher Grösse haben mit blossem Auge oder auch (nach Seneca) mit einem Hohlglas, in welches Oel gegossen war, bereits die Römer und Araber wahrgenommen, doch hielten sie dieselben für einen auf der Sonnenscheibe schwarz erscheinenden Planeten, wie denn selbst Kepler 1607 einen Merkurdurchgang wahrgenommen zu haben glaubte. Die chinesischen Annalenschreiber waren mit den Flecken als solchen bereits ganz gut bekannt und überlieferten uns in Betreff derselben manch' schätzenswerthe Nachricht. Als G alilei das erste astronomische Fernrohr zusammengesetzt hatte, bemerkte er auch die von Licht entblössten Stellen in der Sonne und erwähnte derselben in einem Nachtrage [7] zu seinem berühmten "Sidereus Nuntius", doch hat wohl R. Wolf Recht, wenn er sagt, dass in der Fülle seiner Entdeckungen der grosse Naturforscher gerade über die hier in Frage kommende sich nicht völlig klar geworden sei [8], und insoferne kann der Jesuit Scheịner, der sein Teleskop allerdings etwas später erst nach der Sonne richtete, dafür aber die volle Wichtigkeit der Flecke erkannte und sich in einem voluminösen Werke [9] darüber verbreitete, recht wohl als Mitentdecker gelten. Jedenfalls darf diese Ehre der jüngere Fabricius beanspruchen [10], der schon im December 1610 die "Ungleichheiten" und "Rauhigkeiten" der Sonnenoberfläche sah und richtig deutete, und wahrscheinlich war auch Harriot, von dem wir eine konsequent durchgeführte Beobachtungsreihe im Manuskript überkommen haben, unabhängig zu seinem Funde gelangt. Von nun ab hat es nie an Astronomen gefehlt, welche dem Studium der Sonnenflecke ihre Aufmerksamkeit zuwendeten; den Marius und Cysatus reihten sich Vater und Sohn Kirch, Rost, Staudacher im XVIII. Jahrhundert an; Flaugergues, Placidus Heinrich, A. Stark u. A. brachten ein respektables Material zusammen, und Schwabe endlich liess fast ein halbes Jahrhundert hindurch kaum einen Tag vergehen, an welchem er nicht mit seinem guten Instrumente das Centralgestirn betrachtete [11]. R. Wolf hat sich die gewaltige Aufgabe gestellt, in den von ihm herausgegebenen "Astron. Mittheilungen " nach und nach die gesammte auf Sonnenflecke bezügliche Literatur zusammenzustellen und kritisch zu verarbeiten, und man darf sagen, dass diese Riesenaufgabe heute schon für gelöst angesehen werden kann.

Galilei erblickte in diesen Unterbrechungen der Lichthülle etwas Wolkenartiges, Fabricius und Marius dachten an Schlacken, die von dem brennenden Körper ausgestossen würden, Andere wieder, wie Scheiner, Tarde und Malapert, wollten aus metaphysischen Gründen keine Verunreinigung der Sonne zugeben und erklärten die nicht wegzuleugnenden Flecke deshalb für kleine um jene kreisende Planeten 
[12]. Die von Rost angedeutete Idee, dass die Flecke kraterförmige Vertiefungen seien, findet sich in etwas anderer Form auch bei $\mathrm{Hausen}$ [13] vor; Wiedeburg nahm an, dass kleine Körperchen sich unaufhörlich in die Sonne stürzten [14], wie ja heute von den Meteoriten ganz Aehnliches angenommen wird. Eine offenbare Folge der Thatsarhe, dass man in jener Zeit mit den Mondbergen sich angelegentlicher zu beschäftigen begann, ist es, wenn D. Cassini und De la Hire die Berge des angeblich dunklen Sonnenkörpers durch die denselben umfluthende und nicht selten zerreissende Lichtumhüllung herausblicken lassen [15]. „Sonderbar genug“6, meint Kästner [16], „dass eine und dieselbe Erscheinung dem einen Beobachter Erhöhung, dem anderen Grube ist." Diese angesichts der ungeheuren Entfernung des zu prüfenden Gegenstandes doch kaum so sehr auffällige Zwiespältigkeit der Ansichten wird uns auch späterhin noch öfter begegnen. Jedenfalls wusste jene Anschauung, die eben in den Flecken Vertiefungen sah, gewaltig Boden zu erringen.

§. 4. Die Wilson-Herschel'sche Hypothese. Um das Wesen dieser dereinst allmächtigen und selbst jetzt noch vielfach nachwirkenden Theorie der Sonnenflecke zu verstehen, ist es nöthig, sich einen solchen genauer im Detail anzusehen. Fig. 2 stellt uns einige derselben vor

Fig. 2.

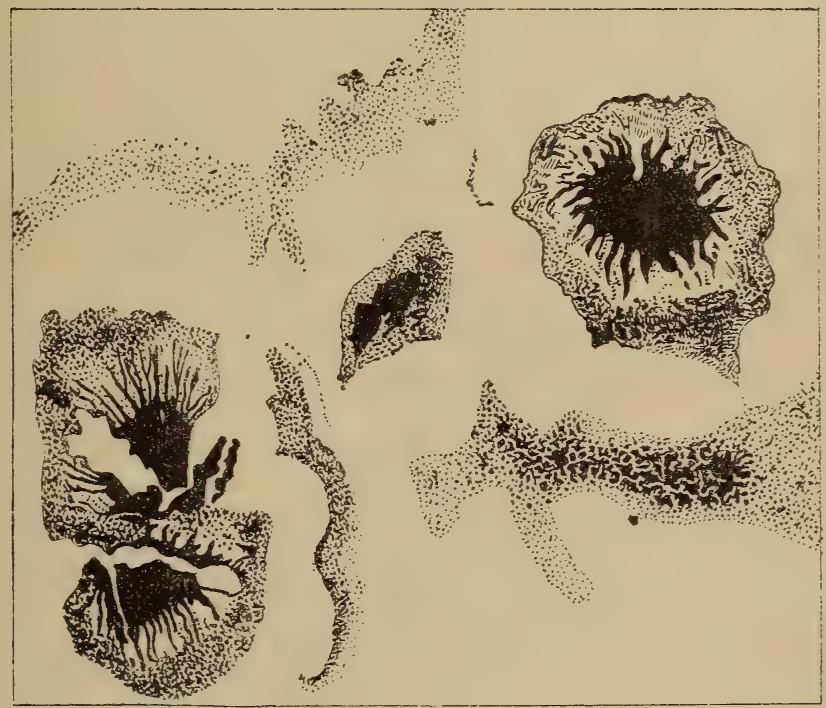

Augen, und namentlich dürfte der nach Secchi's Zeichnung [17] reproducirte Fleck rechts oben die Bezeichnung eines typischen verdienen. Eine Anzahl von Körnern (s. o. §. 2) drängen sich zusammen; zwischen ihnen erscheint [18] ein kleiner runder schwarzer Kreis von unregelmässiger Begrenzung, eine Pore. Soll es zur Bildung eines Sonnenfleckes (im engeren Sinne) kommen, so schieben sich diese Poren mit grosser Schnelligkeit hin und her, eine derselben gewinnt die Oberhand 
und verbreitert sich; häufig freilich, wenn die Photosphäre sich nicht in Ruhe befindet, vollzieht sich die Fleckbildung in weit stürmischerer Weise [19]. Als Bestandtheile unterscheidet man den tiefschwarzen Kern und die hellere, wennschon noch deutlich gegen die umgebende Helle abstechende Penumbra. Ist endlich der Process als beendigt anzusehen, so nimmt der Kern eine annähernd kreisrunde Gestalt an, und gleich darauf beginnen von Neuem Lichtfäden, die sogenannten Brücken, sich über ihn hinwegzuspinnen [20] (vgl. die Figur), so dass im Momente der höchsten Vollendung zugleich auch bereits die Vernichtung beginnt. Im Inneren der Flecke zeigt sich nicht selten eine wirbelnde Bewegung. Um noch von der Penumbra im Besonderen zu sprechen, so bemerkt man in ihr gewöhnlich die von $\mathrm{D}$ a we s mit dem Namen Strohbündel belegte parallele Lagerung der einzelnen Lichtbündel, während die kleinen in den Rand hinein verstreuten Flecke sich zu einer Art Schweif des Kernfleckes zusammensetzen [21]. Die rothgefärbten Schleier, welche die centralen Partieen des Gebildes nicht selten überdecken, sind nach Secchi nicht etwa blos aus subjektiver Täuschung zu erklären, sondern wirklich vorhanden [22].

Schon aus der bisherigen Beschreibung mag hervorgehen, dass ohne besonderes Aufgebot der Phantasie recht wohl diese Flecke für Höhlungen in der Photosphäre gehalten werden können. Dieser Eindruck musste sich noch verstärken, wenn man sah, dass in Folge der Axendrehung der Sonnenkugel die dunklen Stellen sich auf dieser fortbewegten und dadurch auch eine Gestaltänderung erlitten. In dem Maasse nämlich, als der Fleck dem Rande sich nähert, verschwinden seine centralen Theile, bis zuletzt nur noch die eine Hälfte der $\mathrm{Pe}$ numbra sichtbar ist, und weiterhin verschwindet allgemach auch diese. Nach bekannten Lehren der Perspektive musste sonach angenommen werden, man habe es hier mit einer in die Lichthülle sich einsenkenden Kluft zu thun, und Wilson fand allgemeinen Anklang bei dem gelehrten Publikum, als er es unternahm, die hier nur angedeutete Ansicht, dass die Sonnenflecke Höhlungen seien, tiefer zu begründen und darauf eine neue Theorie dieser eigenthümlichen Gebilde aufzubauen [23]. Einige Jahre vorher waren von einem württembergischen Astronomen, Schülen, ähnliche Vermuthungen geäussert worden [24], und auch B ode sprach sich in diesem Sinne aus, noch ehe er von Wils on's Veröffentlichung Kenntniss hatte; der Kernfleck ist ihm nichts Anderes als der lichtlose Sonnenkörper selber, welchen man durch eine Lücke in der Photosphäre erblickt, während zwischen der letzteren und der Sonnenkugel eine nur matt erleuchtete $Z_{w}$ ischenschicht eingeschaltet ist, von welcher eben die Penumbra einen kleinen Theil darstellt. Der Grund des entstandenen Trichters erscheint mehr oder minder dunkel, , je nachdem die Oeffnung in der Oberfläche des Sonnenkörpers sandiges oder felsiges Erdreich, oder Meere trifft" [25]. In etwas weitherziger Auslegung können sogar einzelne Stellen aus den Schriften des Kardinals Nicolaus v. Cus a beigezogen werden, aus denen hervorgeht, dass dieser geistreiche Polyhistor den Sonnenkern dunkel und von einer nach aussen zu heller und heller werdenden Atmosphäre umgeben annahm; dass man freilich mit Clemens [26] um dieses gelegentlich hingeworfenen Gedankens willen in dem Kirchenfürsten einen 
wirklichen Beobachter von Sonnenflecken - 150 Jahre vor Erfindung des Fernrohres - anerkennen werde, glauben wir nicht.

Wilson's Anschauungen begannen gleichwohl erst von dem Zeitpunkte an zur allgemeinen Anerkennung durchzudringen, als der grosse William Herschel mit dem ganzen Schwergewichte seiner Autorität für dieselben einzutreten begann. Wolf drängt [27] die Quintessenz der bezüglichen Abhandlung [28], welche im Jahre 1801 erschien, in die nachstehenden Sätze zusammen: „Die Sonne ist ein dunkler Körper und mit einer transparenten Atmosphäre umgeben, auf welcher die wolkenähnliche Photosphäre schwimmt: zuweilen steigen von dem Sonnenkörper Dämpfe auf und zerreissen die Photosphäre, so dass man auf den relativ dunkeln Sonnenkörper hinabsieht, und so glaubt man einen dunkeln Fleck zu sehen, der, wenn man noch rings um ihn etwas von den tiefer liegenden, wolkenartigen Theilen der Photosphäre sieht, von einer Art Hof eingefasst scheint. ${ }^{.}$Diese hier allerdings nur in ihren Umrissen skizzirte Theorie hat sich als äusserst zählebig erwiesen; hervorragende Männer, wie A rago und A. v. H umbold t [29], haben sich zu ihr bekannt, und erst in der neuesten Zeit hat sich den Fachmännern mehr und mehr die Ueberzeugung aufgedrängt, dass dieselbe weder die feineren Beobachtungen ausreichend genau darstelle, noch auch mit gewissen physikalischen Grundwahrheiten harmonire. Namentlich blieb es unbegreiflich, wie der eigentliche Sonnenkörper in nächster Nähe einer glühenden Gasmasse, der Photosphäre, nicht auch allmählich bis zur Gluthhitze erwärmt werden sollte, und wenn John Herschel diesem Einwand damit begegnen zu können glaubte, dass eine absolut reflektirende Dunsthülle den Kern gegen die Strahlung der Wärme sehr wohl schützen könne, so ist dieser mit grosser Sicherheit vorgetragenen Behauptung [30] entgegenzuhalten, dass solche Stoffe unseren sonstigen Erfahrungen nach überhaupt nicht existiren, von den doch auch vorhandenen Konsequenzen der Wärmeleitung ganz zu geschweigen. So durfte denn G. Kirchho ff mit Recht sagen, die Herschel'sche Hypothese müsse von einer fortschreitenden Naturlehre selbst dann aufgegeben werden; wenn diese nichts Besseres an ihre Stelle zu setzen hätte. Glücklicherweise ist Letzteres aber möglich.

§. 5. Neuere wissenschaftliche Hypothesen. Hierher rechnen wir die Wolkentheorie G. Kirchhoff's, die Schlackentheorie Zöllner's und die von Reye und Faye - allerdings mit nicht unerheblichen Verschiedenheiten - vertretene Trombentheorie. Eine endgültige Entscheidung zwischen diesen drei auf dem Boden der modernen Physik erwachsenen Hypothesen hat die Wissenschaft noch nicht getroffen, dieselbe muss vielmehr einer vielleicht ziemlich fernen Zukunft überlassen bleiben.

Nachdem Kir chh off aus seinen spektralanalytischen Untersuchungen [31] den Schluss gezogen hatte, dass nicht eine glühende Lufthülle, sondern der weissglühende Sonnenkörper selbst uns leuchtende und wärmende Strahlen zusende, dass ihn jedoch ein Mantel glühender Gase umgebe, in welchem zahlreiche der Erde angehörige Elemente in aufgelöstem Zustande sich befinden, entwickelte er weiter die Analogieen, welche zwischen den atmosphärischen Vorgängen auf 
der Sonne und auf unserer Erde obwalten. Hier wie dort ist die Temperaturvertheilung keine ganz gleichmässige, hier wie dort müssen sich lokale Temperaturerniedrigungen ergeben, und mit solchen wird auf beiden Himmelskörpern eine Wolkenbildung eingeleitet. Ueber jeder sich neu bildenden Wolke entsteht ein kühlerer Raum, die Wolke wächst von oben her an und kühlt sich unter Umständen bis zu einem unter der Gluthhitze liegenden Wärmegrade ab, so dass sie auch undurchsichtig wird, und in diesem Zustande erscheint sie uns als der Kern eines Sonnenfleckes. In höheren Regionen aber kommt eine zweite Wolke zu Stande, minder dicht als die frühere und theilweise durchsichtig, so dass sie bei entsprechender Ausdehnung wie ein Halbschatten neben der tiefer liegenden Wolke gesehen wird. Die bis dahin als maassgebend festgehaltene Auffassung der Flecke als Vertiefungen muss nach Kirchhoff fallen gelassen werden, insofern sie sich auf eine optische Täuchung zurückführen liesse.

Zöllner steht, was den Ausgangspunkt seiner Gedankenreihe anlangt, mit G. Kirchhoff auf gleichem Boden, indem er [32] mit Letzterem als bewiesen annimmt, dass der glühende Sonnenkern dem festen oder tropfbarflüssigen Aggregatzustand angehöre, und diese Thatsache auf Grund seiner an den Protuberanzen gewonnenen Ansichten dahin verschärft, dass weit gewichtiger€ Argumente für die zweitgenannte Annahme sprechen. Dagegen widerspreche es Allem, was wir von den irdischen Wolken wissen, dass solch' leichtvergängliche Gebilde auf der Sonne durch Wochen hindurch ihre Gestalt im Wesentlichen beibehalten sollten. Z ölln e r glaubt, dass dieser Charakter verhältnissmässiger Invariabilität sich nur mit dem festen Aggregatzustand gut vertrage. An der Sonnenoberfläche müssen die Luftströmungen des Aequatorial- und Polarstromes ganz ähnlich auftreten, wie an der Erdoberfläche, und da, wo beide Ströme sich durchdringen - also in dem unserer Kalmenzone entsprechenden Gebiete - werden Trübungen zu bemerken sein. Es wird diess am Aequator und zugleich in der Nähe der Pole der Fall sein, und diese Gegenden werden mithin, da in ihnen die Ausstrahlung mehr oder weniger verzögert ist, der Fleckenbildung sich ungünstig erweisen. Innerhalb eines jeden Passatgürtels dagegen ist die Atmosphäre ruhig und klar, die Wärmestrahlung des Sonnenkörpers hat nur mit einem Minimum von Hindernissen zu kämpfen, und so können sich auch mit Leichtigkeit schlackenartige Absonderungen auf der glühendflüssigen Oberfläche bilden. Diese ausgestossenen Massen repräsentiren die schwarzen centralen Partieen der Flecke, die Penumbra dagegen soll ihre Entstehung dem Umstande verdanken, dass rings um die Schlacke herum die Temperatur sinkt und Wolken sich ansammeln, welche, in absteigender Bewegung begriffen, nach dem Rande des Fleckes sich senken und eine trichterförmige Vertiefung hervorbringen. Man sieht, dass Z öllner dasjenige, was ihm an Kirchhoff's und auch an Wilson's Hypothese richtig erschien, geschickt in sein eigenes System hinein zu verweben verstand, und insbesondere mit Rücksicht auf das zuletzt Gesagte ist es nicht recht begreiflich, dass Secchi die Zöllner'sche Lehre von den Sonnenflecken um desswillen verworfen wissen wollte, weil sie von den Höhlungen keine Rechenschaft gebe [33]. Beachtenswerthere Bedenken sind von Reye geltend gemacht worden, namentlich in dem Sinne, 
dass noch viel weniger als Kirchhoff's Wolken die Zöllner'schen Schlackenmassen sich längere Zeit hindurch erhalten könnten, da, wenn man etwa annehme, der fünfte Theil der zugesandten Wärmemenge werde von ihnen absorbirt, schon dieses Fünftel im Verlaufe eines Monates eine Eisschicht von $90000 \mathrm{~m}$ Mächtigkeit zu schmelzen vermöge [34]. Es will uns bedünken, dass Zöllner diesen anscheinend durchschlagenden Gegengrund durch theoretische Betrachtungen mit Glück zurückgewiesen hat, indem er nämlich zeigte [35], dass hier eine Verwechselung der Zeit als eines Maasses der Wärmestrahlung mit jener Zeit vorliegt, welche zur Verwandlung der ausgestrahlten Wärmemenge in ein ihr äquivalentes Arbeitsquantum erfordert wird.

Reye selbst stellt den früheren Ansichten eine neue gegenüber, die sich auf die Aehnlichkeit resp. Identität der terrestrischen und solaren Luftbewegungen stützt. Ueber einem aus irgend einem Grunde besonders heissen Punkte der Sonnenoberfläche werden [36] die dort befindlichen unteren Schichten von Gasen und Metalldämpfen üherhitzt, sie steigen auf und dehnen sich aus. In einer gewissen Höhe erkaltend verdichten sie sich wieder, eine Quantität bisher latent gewesener Wärme wird frei und verstärkt den Auftrieb der übrigen Dampf- und Gasmassen, und es bildet sich eine rasch wachsende Wolke: „die Sonnenflecke sind wolkenartige Verdichtungsprodukte in den unteren Regionen der Sonnenatmosphäre, welche sich ähnlich wie die grossen Wolkenschichten der irdischen Cyklonen von unten her erneuern. ${ }^{*}$ Die Theorieen von Reye und Faye [37] stimmen darin überein, dass cyklonen- und trombenähnlichè Vorgänge zur Erklärung der Sonnenflecke herangezogen werden, nur nimmt der deutsche Mathematiker, wie erwähnt, eine wirbelnde Bewegung von unten nach oben, der französische Astronom dagegen eine solche von oben nach unten an. Zwischen beiden Gelehrten haben neuerlich lebhafte Auseinandersetzungen über die relativen Vorzüge ihrer Hypothesen stattgefunden, wobei Re ye mit Recht hervorhob [38], dass sein Widerpart die bedeutende Druckabnahme im Inneren einer Trombe gänzlich ausser Acht lasse und auch die Kraft gar nicht zu erklären versuche, welche das Herniedersteigen der Wettersäulen bedinge. Freilich ist aus Tacchini's und Secchi's Beobachtungen zu schliessen, dass die Wirbeltheorie für sich allein überhaupt noch nicht die ausreichende Grundlage der Erklärung bietet, weil sonst viel häufiger jene spiralförmigen Bewegungsvorgänge in den genannten Gebilden zu konstatiren sein müssten, als diess insbesondere nach Tacchini's Zeugniss zutrifft. Daran, dass man an den Flecken gar keine eigene Drehung: wahrnimmt, stösst sich, wie Newcomb berichtet [39], auch Young, der im Uebrigen die Fay e'sche Theorie für die zureichendste hält, worin er mit seinem Landsmann Langley [40] übereinstimmt.

Mit Zöllner's Anschauungen haben sich dagegen in jüngster Zeit Bredichin, Lohse und Spörer*) - wenigstens im Grossen und Ganzen - einverstanden erklärt [41]. Es kommt der Umstand hinzu, dass diese Hypothese wohl am besten dazu sich eignet, einer

*) Es ist dieser Beitritt eines der hervorragendsten Astrophysiker unserer Zeit für die Zöllner'sche Auffassung ein um so werthvollerer Gewinn, weil Spörer sich früher mehr der Kirchhoff'schen Wolkentheorie zugeneigt hatte. 
Reihe weiterer merkwürdiger Erscheinungen zur Erklärungsbasis zu dienen, von welchen im nächsten Paragraphen die Rede sein soll*).

Endlich sei noch der ganz isolirt dastehenden Hypothese v. L üdinghausen-Wolff's [42] gedacht, welche nur scheinbar an die von Herschel vertretenen Anschauungen wieder anknüpft. Ihm sind allerdings die Sonnenflecke Vertiefungen, durch welche man auf den Sonnenkörper selbst hinabsieht; dieser aber ist nicht etwa dunkel im gewöhnlichen Sinne, sondern so furchtbar überhitzt, dass unser Auge den von ihm ausgesendeten ungeheuer kurzwelligen Lichtstrahlen gegenüber den Dienst versagt, wie auch das Ohr nur innerhalb gewisser Grenzen der Wellenlängen den Eindruck eines Tones empfängt. Es erscheint jedoch nicht ungefährlich, im Weltall mit Gesetzen zu operiren, für welche uns die irdische Physik zur Zeit noch nicht die Analogie geliefert hat. - Nach Adams und Reis sind die Flecke "Roststaubwolken" (Die Sonne, Mainz 1869).

§. 6. Rotation, Fleckenvertheilung und Fleckenperiodicität. Scheiner war es, der zuerst die Rotationszeit der Sonne und die Lage des Sonnenäquators bestimmte [43], indem er sich an gewisse Flecke von charakteristischer Gestalt hielt, die am einen Sonnenrande verschwanden und nach Umfluss einer bestimmten Zeit am anderen Rande wieder zum Vorschein kamen. Hausen (s. o.), Boscovich, Delisle, Euler, Sylvabelle, Kästner, Fixlmillner haben ihre Kräfte an dem gleichen Probleme versucht, dessen Lösung durch die neueren Arbeiten von Kysaeus [44], Bö hm [45] und Spörer [46] bis zu einem hohen Grade der Genauigkeit gefördert wurde. Doch kann dieser Grad der Natur der Sache nach nicht verglichen werden mit jenen Genauigkeitsgrenzen, die sich bei Bestimmung der Rotationsdauer anderer Himmelskörper von starrer Oberfläche erzielen lassen, und wir müssen zufrieden sein, dieses wichtige astronomische Zeitelement in das Intervall von 25-27 Tagen einzuschliessen [47] (s. u.). Die synodische Umdrehungszeit, d. h. jene Zeit, welche vergeht, bis derselbe Beobachter den nämlichen Fleck auch wieder an der nämlichen Stelle der Sonnenoberfläche erblickt, ist um etwa 2 Tage grösser, weil ja der Beobachter nicht stille im Raume steht, sondern mit der Erde eine Bewegung macht, welche der Rotationsbewegung der Sonne gleichgerichtet ist.

Die erwähnte Schwierigkeit, die Rückkehr eines bestimmten Fleckes chronologisch genau zu fixiren, ist eben darin begründet, dass dieser Fleck der in fortwährender Wallung begriffenen Oherfläche des Centralkörpers angehört und mit einer oft nicht unbeträchlichen Einzelbewegung begabt ist. Es ward bereits erwähnt, dass aus theoretischen Gründen auf eine gewisse Driftströmung in der Sonnenatmosphäre geschlossen werden muss, in Folge deren zwei den Passatzonen der Erde entsprechende Sonnengürtel als zur Fleckenbildung besonders prädisponirt erscheinen, und dieses Ergebniss der Theorie hat sich durch

*) Man möge nicht vergessen, dass die Deutung der Flecke als schlackenartiger Absonderungen sich am besten an die Konsequenzen anschliesst, welche wir oben (Kap. I, \$. 7) aus der Kant-Laplace'schen Hypothese zogen, indem ja dort die Sonne als ein Mitglied des zweiten Fixstern-Typus von Secchi erkannt ward. 
die Beobachtungen auch im Wesentlichen bestätigt gefunden. Nach Sömmering und Thilo [48] existiren auf der Sonne Streifen meridianaler Richtung, innerhalb deren viele Jahre hindurch überhaupt kein Fleck sich bildet, und anderwärts drängen sich die Flecke wieder zu dichten Gruppen zusammen. Wenn nun Passatströmungen für die Fleckebildung ein maassgebendes Moment sind, so ist die Annahme gerechtfertigt, dass die Eigenbewegung eines Fleckes von seiner heliographischen Breite sich abhängig zeigt, und da die wirklich wahrgenommene Bewegung die Resultante aus dieser Eigenbewegung und der Drehbewegung des Sonnenkörpers darstellt, so wird ein Gleiches auch von dieser gelten. Nach Zölln er kann die Winkelgeschwindigkeit eines unter der heliographischen Breite $\varphi$ gelegenen Ortes mit grosser Annäherung durch die Formel

$$
\frac{\mathrm{a}-\mathrm{b} \sin ^{2} \varphi}{\cos \varphi}
$$

ausgedrückt werden, in welcher $\mathrm{a}$ und $\mathrm{b}$ empirisch zu ermittelnde Konstanten bedeuten [45]; die lange Positionsreihe, welche Carring ton [50] mittheilt, fügt sich sehr gut diesem Ausdrucke, und die von Zöllner eingehend widerlegten Einwürfe Reye's [51] beziehen sich auch nur auf die physikalische Grundlage, nicht aber auf die rechnerische Brauchbarkeit der angeführten Relation.

Ganz neuerlich hat Spörer [52] der Zöllner'schen Formel die folgende substituirt:

$$
8^{0}, 548+5^{0}, 798 \cdot \cos \varphi ;
$$

mit Benützung derselben gestatteten einige günstige, $d$. h. durch zwei Rotationsperioden hindurch sichtbare, Flecke die Rotationszeit zu 25,234 Tagen zu bestimmen. Der genannte Sonnenforscher ist bei der Herleitung seiner Formel davon ausgegangen, dass auch die aus dem Inneren des Sonnenkörpers kommenden Strömungen zu berücksichtigen seien, welche die geringere lineare Rotationsgeschwindigkeit aus dem Inneren an die Oberfläche mitbringen.

Für die kosmische Physik gewinnen die Sonnenflecke aus dem Grunde eine stets wachsende Bedeutung, weil ihrem Auftreten der Charakter periodischer Wiederkehr anhaftet, der sich dann auch wieder in einer Menge ganz anders gelagerter Verhältnisse abspiegelt. Seit 1847 betreibt R. Wolf [53] das Studium der Periodicitätsfrage, und schon drei Jahre darauf führte er die sogenannten Relativzahlen ein, welche sich bei Untersuchungen dieser Art als ein unentbehrliches Hülfsmittel erwiesen haben. Mit diesen Zahlen hat es folgende Bewandtniss. Bezeichnet man mit $\mathrm{g}$ die Anzahl von Fleckengruppen, die an einem bestimmten Tage gesehen worden sind, indem man isolirte Flecke als Gruppen mitzählt, bezeichnet man ferner mit $f$ die Anzahl der in sämmtlichen Gruppen enthaltenen Flecke (diese Zahl ist annähernd dem mit Flecken bedeckten Theile der Sonnenoberfläche proportional) und endlich mit $\mathrm{k}$ einen von der Individualität des $\mathrm{Be}$ obachters und seines Instrumentes abhängigen Erfahrungsfaktor*), so ist nach Wolf's Definition [54] die Zahl

$$
\mathrm{r}=\mathrm{k}(\mathrm{f}+10 \mathrm{~g})
$$

*) $\mathrm{k}$ ward $=1$ gesetzt für den Erfinder selbst und für seinen vierfüssigen 
die Relativzahl für den betreffenden Tag. Mit Hülfe eines in dieser Weise angesammelten ungeheuren Zahlenmateriales gelang es dem schweizerischen Astronomen, ein Faktum ausser Zweifel zu stellen, welches vor ihm der einzige Horrebow geahnt hatte, als er im Jahre 1776 in sein Beobachtungstagebuch die Worte eintrug [55]: „Es ist zu hoffen, dass man durch eifriges Beobachten auch für die Veränderungen und den Wechsel der Sonnenflecke eine Periode auffinden werde, wie in den Bewegungen der übrigen Himmelskörper; dann erst wird es an der Zeit sein, zu untersuchen, in welcher Weise die Körper, die von der Sonne getrieben und beleuchtet sind, durch die Sonnenflecke beeinflusst werden." Wolf's Resultat lässt sich dahin formuliren [56]: "Die Frequenz der Flecken variirt periodisch seit ihrer im Jahre 1610 erfolgten Entdeckung, und zwar beträgt die mittlere Länge einer einzelnen Periode - nach deren Ablauf also die Relativzahlen ziemlich in der gleichen Aufeinanderfolge wiederkehren - 11/1/9 Jahre." Lamont und Sabine wurden nahe gleichzeitig zu der Wahrnehmung geführt [57], dass in gewissen Schwankungen des Erdmagnetismus eine synchrone Periode auftrete, wie die von Wolf in der Wiederkehr der Sonnenflecke aufgedeckte; doch trat besonders Sabine erst dann mit seinem Funde hervor, als es Wolf und dem Genfer Gautier [58] bereits geglückt war, den Parallelismus zwischen den Zahlreihen von Lamont und Schwabe (s. o. §. 3) ausser Zweifel zu setzen. Auch zu vielen anderen Phänomenen des physikalischen Lebens auf der Erde hat man die Sonnenfleckenperiode in Beziehung zu setzen gesucht. Wir behalten uns vor, auf diese Beziehungen in jenen Abschnitten unseres Buches zurückzukommen, welche der kosmischen Meteorologie und dem Erdmagnetismus gewidmet sind, und erwähnen einstweilen nur, dass die ganze weitverzweigte Frage den kundigsten Darsteller in Fritz [59] gefunden hat.

§. 7. Chromosphäre, Protuberanzen und Korona. Rings um jene äusseren Theile des Sonnenkörpers, welche wir als den Tummelplatz der Sonnenflecke kennen gelernt haben, legt sich eine weitere dünne Hülle, die jedoch sehr hell leuchtet und von Lockyer, der sich um ihre nähere Erforschung besonders bemühte, den Namen der Chromosphäre erhielt [60]. Dieselbe scheint der Hauptsache nach aus Wasserstoffgas $\mathrm{zu}$ bestehen und sich in einem Zustande der höchsten Unruhe zu befinden. Ibre Existenz wäre unter gewöhnlichen Umständen verborgen geblieben; erst bei Gelegenheit einiger ausgezeichneter Sonnenfinsternisse hat man sie aufgefunden, und nachgerade haben die Spektroskopiker es möglich gemacht, dieselbe auch ohne jenes selten zur Verfügung stehende Hülfsmittel zu erkennen und zu untersuchen. "Das Bild der Sonne wird“, so schildert Lockyer [61] sein Verfahren, , auf ein Diaphragma geworfen, in dessen Mitte sich eine kreisförmige Messingscheibe von der Grösse des Sonnenbildes befindet, welche das Sonnenlicht aufhält, dagegen das Licht der

Fraunhofer mit vierundsechzigmaliger Vergrösserung. Durch Vergleichung der Aufzeichnungen während bestimmter Zeiträume erhielt man das anderen Verhältnissen angepasste $\mathbf{k}$. 
Chromosphäre ungehindert vorbeigehen lässt. Das Licht der Chromosphäre wird dann an derjenigen Stelle vereinigt, an welcher sich gewöhnlich der Spalt des Spektroskopes befindet, und man sieht dann im Okular die Chromosphäre in Kreisen, welche der Linie C oder anderen Linien des Spektrums entsprechen."

Was uns diese äussere zarte Lichtumhüllung der Sonne besonders interessant macht, das sind in erster Linie die aus ihr hervorbrechenden und mit ihr jedenfalls in engster Verbindung stehenden Protuberanzen, die zuerst im Jahre 1842 von Airy, Baily, Struve und Schidlofisky als zahnartige, rothgefärbte Auswüchse an dem Rande des vom Monde bedeckten Sonnenkörpers wahrgenommen wurden [62]. v. Feilitzsch's [63] Meinung, dass dieses Phänomen erst in unserem Auge, durch Diffraktion der Randstrahlen, entstehe, hat sich nicht viele Anhänger erworben, um so weniger, da Janssen und Zöllner bald auch das Spektroskop so zu adaptiren verstanden, dass man die Protuberanzen nicht blos unter ausserordentlichen Verhältnissen, sondern zu jeder beliebigen Zeit wahrzunehmen in der Lage war. Man hat die Höhe dieser Auswüchse gemessen und gefunden, dass dieselben sich in überraschend kurzer Zeit 6-10 Erdhalbmesser über das Sonnenniveau erheben. Da die charakteristische helle Linie des Protuberanzenspektrums völlig mit jener des Wasserstoffgases sich deckt, so lag die Annahme nahe, dass man es hier mit kolossalen Eruptionen dieses Gases zu thun habe; nach Zöllner's Theorie (s. o.) finden sich Gasmassen allenthalben in der die Sonnenoberfläche konstituirenden Flüssigkeit, theils nur mechanisch von ihr umschlossen, theils vollkommen absorbirt, und durch die Druckdifferenz zwischen dem Druck dieser Massen und demjenigen der äusseren Atmosphäre, welcher durch die Kohärenz und Schwere der oberen Flüssigkeitsmassen noch vergrössert wird, werden jene gewaltsamen Ausbrüche bewirkt. Damit wollen freilich die nicht eben seltenen Fälle nicht stimmen, welche Spörer [64] aus den Denkschriften des Vereines italienischer Spektroskopiker zusammengetragen hat, und bei welchen die Protuberanzen vom Sonnenkörper losgelöst und durch oft beträchtliche Distanzen getrennt erscheinen; auch Spörer und K e mp f haben Individuen dieser Art gesehen, die ganz gewiss nicht von der Oberfläche herstammten. Die schon früher von dem verdienten Observator der Potsdamer Sonnenwarte vorgeschlagene Eintheilung der fraglichen Gebilde in gewöhnliche Wasserstoffprotuberanzen und in die durch Intensität und spitze Formen ausgezeichneten flammigen Protuberanzen [65] - S'ecchi pflegte letztere die metallischen zu nennen scheint sich zu bewähren, und die letzteren, deren Spektrum durch die Magnesiumlinie charakterisirt erscheint, haben muthmaasslich in chemischen Processen ihren Grund, zu deren Beurtheilung uns noch die erforderlichen Daten fehlen [66].

Schliesslich mögen noch nach Klinkerfues' Beschreibung [67] einige Worte folgen über den Glorienschein, die sogenannte Korona, welcher im Momente der Totalität die Sonnenkugel noch jenseits der Chromosphäre umgiebt. Weisslich-grünen Lichtes, wird sie von Strahlen durchzuckt, die einigermassen an das bekannte Strahlenschiessen des Nordlichtes gemahnen, wie denn auch eine der hellen Linien des Koronenspektrums mit einer der Nordlichtlinien übereinstimmt. Da 
im Uebrigen das erstgenannte Spektrum eine Sonderstellung einnimmt und keine Vergleichungen mit den Spektren irdischer Stoffe zu machen gestattet, so muss man vorläufig mit dem freilich nicht ganz befriedigenden Schlusse sich zufrieden geben, dass in den äusseren Hüllen mancher Himmelskörper gewisse Gase und Dämpfe im Zustande hochgradigster Feinheit vorkommen, zu welchen ein Analogon in unseren Laboratorien auszumitteln noch nicht gelungen ist und vielleicht auch niemals gelingt*). Ein solches Gas dürfte wohl das Helium sein.

§. 8. Allgemeines über die Beschaffenheit und Temperatur des Sonnenkörpers. Wenn wir uns, nachdem wir vorstehend unser Wissen von der Sonne mit wenigen Strichen zu zeichnen bestrebt waren, nunmehr fragen, in welchem Zustande sich denn eigentlich der riesige Ball befindet, in welchem wir den Regulator alles planetarischen Lebens erkennen, so haben wir auf zwei sich zunächst noch gegenüberstehende Ansichten Rücksicht zu nehmen, zwischen welchen jedoch eine Konkordanz nicht unmöglich erscheint. Nach Z öllner ist, wie wir sahen, ein grosser Theil des Sonnenkörpers, ganz wie es bei dessen Grösse die Nebulartheorie fordert, noch heute im gluthflüssigen Zustande, wenn auch die dem Mittelpunkte näher gelegenen Partieen durch hohen Druck bereits bis zu einem gewissen Grade verfestigt sein können. Dann hat der alte Kant Recht, wenn er [69] behauptet, die Sonne sei ein wirklich flammender Körper und nicht blos eine erhitzte Masse glühender Materie; man darf den von den Physikern des ausgehenden XVIII. und beginnenden XIX. Jahrhunderts für eine Ungeheuerlichkeit**) erklärten Satz aussprechen : Die Sonne brennt [71]. Unter dieser Voraussetzung hat v. d. Gröben's Versuch, die Periodicität der Sonnenflecke zu erklären, Manches für sich [72]. Mit

*) Anhangsweise gedenken wir hier einiger Resultate, welche Secchi für die Frequenz der wichtigeren solaren Phänomene und den gegenwärtigen Zustand der Sonne aus einer längeren Beobachtungsreihe gezogen hat [68]. Auf Grund von 55 Rotationen stellte er Tabellen her, welche die Flecke u. s. w. nach Gruppenzahl und Areal vorführen. Die tägliche Frequenz der Protuberanzen war wenigstens nach 1875 - im Abnehmen begriffen und näherte sich einem Minimum. Wenn die grossen Flecke aufhören, so hören allmählich auch die Eruptionen auf. Die mittlere Höhe der Protuberanzen, nach der Breite geordnet, blieb sich wesentlich gleich, wogegen die Anzahl der verhältnissmässig hohen Protuberanzen sich verminderte. Beträchliche Veränderungen traten in der Vertheilung der Fackeln ein; so sind dieselben während des betrachteten Zeitraumes z. B. aus der Nähe der Pole, wo sie früher förmliche Kronen bildeten, ganz verschwunden und haben sich auf das Dominium der Flecke und Protuberanzen beschränkt, bei denen gleichfalls eine Tendenz zur Bewegung nach dem Aequator hin vorwaltete. Secchi schliesst daraus, was ja auch mit den von Wolf ermittelten Thatsachen im Einklange steht, dass die Sonnenthätigkeit jeweils aus einem Maximum einem Minimum und wieder aus einem Minimum einem Maximum zustrebt.

**) Man denke z. B. an das, was im Jahre 1788 der Berliner Professor E. G. Fis cher, der Lehrer der Gebrüder $\mathrm{Hu} \mathrm{m}$ boldt, an seinen mathematischen Freund J. F. Pfaff in Helmstedt schreibt [70]: „Silberschlag hat kürzlich in der Akademie der Wissenschaften Vorlesungen über die Sonne gehalten. Das Resultat seiner vermeintlich unwidersprechlichen Gründe ist kürzlich dieses: Die Sonne ist ein wirkliches, wahres Küchenfeuer, und die Flecke derselben sind Rauchwolken und grosse Russhaufen." Der ganze Brief ist von bitterster Ironie durchzogen. 
Zugrundelegung der Zöllner'schen Ansichten wird die von Bunsen gegebene Erklärung der Geysir-Quellen auf die Sonnenoberfläche übertragen. Den intermittirenden Entladungen dieser Heisswasserbrunnen entsprechend müssen auch auf jener Zeiten der Ruhe und der siedenden Aufwallung einander folgen, und zwar findet dieses Sieden in der Tiefe da seine Grenze, wo die Differenzen zwischen der wahren und der Siedetemperatur zu gross zu werden beginnen, als dass der Gleichgewichtszustand durch vorübergehende Druckerleichterungen und Erniedrigungen der Siedewärme noch gestört werden könnte [73]. R. Wolf beurtheilt diesen Erklärungsversuch, der freilich noch einen ausgesprochen hypothetischen Anstrich hat, keineswegs ungünstig [74]. Andererseits hat Duponchel die elfjährige Fleckenperiode durch die Einwirkung des Jupiter auf die Sonne und die Anomalieen durch den störenden Einfluss der oberen Planeten in ihrer Gesammtheit zu erklären gesucht [75], dabei aber, wie ihm Wolf nachweist, das Zahlenmaterial unrichtig verwerthet [76]. Dem gleichen Gewährsmann entnehmen wir die Nachricht, dass Wigard in einer noch ungedruckten Arbeit mit mehr Erfolg eine Art von Ebbe und Fluth auf der 'Sonne in Folge der wechselseitigen Stellungen von Erde, Venus und Jupiter wahrscheinlich gemacht hat [77], und wirklich coincidiren 13 synodische Umläufe der'Venus sehr nahe mit 19 Revolutionen des Jupiter und zugleich mit dem Doppelten der Sonnenfleckenperiode. Loomis und Cornelius [78] hatten schon früher die Frage aufgeworfen, ob nicht vielleicht magnetische Kräfte, von den Planeten auf die Sonne ausgeübt, für die kleinen periodischen Schwankungen der Fleckenkurven verantwortlich zu machen wären. - Welcher Auffassung man aber auch beipflichten mag, stets wird man, wenn man die Sonne als flüssigen und damit durch eine Menge der verschiedensten Agentien beeinflussten Körper betrachtet, die Existenz nicht blos einer einzigen, sondern einer mehrfachen Periode muthmassen müssen. R. Wolf's nach dieser Richtung hin angestellte Untersuchungen haben für's Erste allerdings kein Ergebniss geliefert [79], allein in der Fortsetzung seiner Arbeit scheint auch er die Möglichkeit längerer Perioden darunter einer solchen von ungefähr 170 Jahren - zugeben zu wollen [80].

In scheinbar striktem Gegensatze zu Zöllner spricht sich A. Ritter, dessen umfängliche Studien über die Aggregatzustände der Himmelskörper wir bereits im vorigen Kapitel (§.6) zu citiren hatten, dahin aus [81], dass das Innere der Sonne wahrscheinlich aus einem einatomigen Gase bestehe, welches als Dissociationsprodukt der konstituirenden Gase gewissermassen den Urstoff repräsentirt; nur eine verhältnissmässig dünne und als Atmosphäre aufzufassende Oberflächenschicht würde nicht unter diese Bestimmung fallen [82], weil eben die Spektralanalyse in dieser Schicht bereits das Vorhandensein getrennter Materien nachwies. Wer die Betrachtungen nachliest, welche im zweiten Kapitel der dritten Abtheilung über die Beschaffenheit des Erdinneren angestellt werden, findet vielleicht, dass Zöllner's und Ritter's Anschauungen durchaus nicht so unvereinbar sind, wie man auf den ersten Blick glauben könnte.

Ueber die Temperaturverhältnisse auf der Sonne wissen wir im Ganzen wenig. Nach Zöllner [83] herrscht daselbst an der OberGünther, Geophysik. I. Band. 
fläche eine Hitze von $26000^{\circ}-29000^{\circ}$, Young enthält sich, eine bestimmte Zahl namhaft zu machen, und hält nur dafür, die Wärme auf der Sonne müsse eine viel intensivere sein, als jene des elektrischen Kohlenlichtes [84]. Secchi schätzt die Temperatur sogar auf mehrere Millionen von Graden [85]. Langley und Spörer fanden mittelst der Thermosäule, dass der Kern eines Fleckes immer noch $2 / 3$ der Wärme aussendet, wie die helle Umgebung [86]. Die gewöhnlichen aktinometrischen Messungen verdienen, wie Soret [87] hervorhebt, wenig Vertrauen, da die Berechnung der ersteren mit Hülfe der von Dulong und A. T. Petit aufgestellten Formel ( $\mathrm{T}$ die Temperatur der Wärmequelle, $\mathrm{t}$ diejenige der Thermometerkugel des Instrumentes, $\Theta$ die konstante Temperatur der Umgebung)

$$
1,0077^{\mathrm{t}}-1,0077^{\Theta}=\frac{1,0077^{\mathrm{T}}}{188960}
$$

erfolgen muss, welche nur in dem Bereiche zwischen $0^{\circ}$ und $300^{\circ}$ strenge gültig ist. Dass auf der Sonne eine die höchste auf der Erde erzielbare Verbrennungswärme weit übersteigende Temperatur herrschen muss, unterliegt keinem Zweifel; wie viel tausend Grade sie aber höher sein mag, das entzieht sich unserer Entscheidung.

§. 9. Die Planeten. Die physische Erdkunde nimmt als solche an den Planeten nur insoweit ein direktes Interesse, als das Studium von deren Oberflächenbeschaffenheit und kosmischem Charakter auch für die bessere Kenntniss des Schwesterplaneten Erde nützlich erscheint. Hierher gehört in erster Linie Mars, in zweiter Venus, und diesen beiden Himmelskörpern ward denn auch in Verbindung mit dem allein hier in Frage kommenden Nebenplaneten, dem Erdmond, ein besonderes Kapitel gewidmet.

Die Anzahl der uns bekannten Planeten ist zur Zeit 238. Die Abstände derselben von der Sonne entsprechen nur sehr nothdürftig dem sogenannten Titius-Bode'schen Gesetze, selbst mit der von Wurm daran angebrachten Verbesserung [88]. Wenn die Entfernung. des Merkur vom Sonnenmittelpunkte gleich 4 gesetzt wird, so sollen den Bahnradien von Venus, Erde, Mars, Jupiter und Saturn die Zahlwerthe $4+2^{0} \cdot 3=7 ; 4+2^{1} \cdot 3=10 ; 4+2^{2} \cdot 3=16 ; 4+2^{4} \cdot 3=52$; $4+2^{5} .3=100$ entsprechen - eine Reihe, der freilich nach Gauss' Einwurf das Anfangsglied fehlt, welches nicht 4, sondern $4+2^{-1} \cdot 3=5,5$ sein müsste [89]. Immerhin trifft das Fortschreitungsgesetz auch für Uranus und Neptun so leidlich zu, dass Leverrier seiner Errechnung des unbekannten transuranischen Planeten eine der W urm'schen Reihe angepasste grosse Halbaxe zu Grunde legen durfte, und auch für die Auffindung der Planetoiden erwies sich diese Reihe sehr nützlich, indem das fehlende Glied $4+2^{3} .3=28$ eine Lücke in unserem Planetensysteme aufzeigte, deren Vorhandensein höchstens ein Naturphilosoph wie Hegel in einer höchst sonderbaren Schrift leugnen konnte [90]. „Und der Bauherr sollte diesen Raum leer gelassen haben?" rief Titius [91] aus.

$\mathrm{Ob}$ zwischen Merkur und Sonne noch ein Planet die Sonne umkreist, wie Leverrier aus gewissen Störungen der Merkurbahn schliessen zu müssen geglaubt hatte, ist trotz der sorgfältigen Nach- 
suchungen Herrick's und trotz der angeblichen Entdeckung Lescarbault's noch immer fraglich, wo nicht unwahrscheinlich; man vergleiche hiezu die sehr umsichtige Zusammenstellung Haase's [92]. Auf Merkur folgt bekanntlich Venus*), dieser schliesst sich die Erde mit ihrem Monde, dieser wiederum der von zwei Satelliten begleitete Mars an. Die (s. o.) von den Teleologen des vorigen Jahrhunderts geahnte Oeffnung zwischen Mars und Jupiter ist nunmehr durch die sogenannten Planetoiden oder kleinen Planeten ausgefüllt, um deren Entdeckung sich nach und nach Piazzi (1800), Olbers, Harding, Hencke, Chacornac, Luther, De Gasparis, H. Goldschmidt, $\mathrm{H}$ ind und neuerdings besonders $\mathrm{Pal}$ is a verdient gemacht haben. Thre Zahl belief sich im September 1882, nach dem neuesten Funde $\mathrm{De} B$ all's, auf 230, für welche es neuerdings der sonst unerschöpflichen griechisch-römisch-altnordischen Mythologie kaum mehr die nöthigen Namen abzuringen giebt [94]. Die Olbers-Kirkwood'sche Hypothese, dass diese kleinen Körperchen, deren Grösse nicht mehr zu messen, sondern meist nur durch eine beiläufige photometrische Schätzung zu ermitteln ist, durch Zerspringen eines grösseren Planeten entstanden seien, billigen wir nicht, vielmehr scheint uns die Nebulartheorie eine plausiblere Entstehung derselben zu ermöglichen [95], und mit letzterer scheint sich auch besser das von D'Arrest [96] formulirte Gesetz zu vertragen, dass nämlich jede Bahn eines dieser ,Taschenplaneten", wie sich A. v. Humboldt ausdrückte, in jede andere eingreift. Eine neuerdings (s. o.) von der k. dänischen Akademie ausgeschriebene Konkurrenzarbeit verspricht über manche dunkle Punkte, die unsere Kenntniss des Planetoidengürtels entstellen, Licht zu verbreiten**). - Als obere Planeten bezeichnet man Jupiter, Saturn, Uranus und Neptun. Den ersteren umgeben vier, den zweiten acht Trabanten [97] nebst einem mehrfach getheilten Ringe, dem Uranus dürfen, im Gegensatze zu älteren Nachrichten, nur vier Monde zugeschrieben werden [98], und Neptun endlich scheint sich mit einem einzigen Begleiter ***) begnügen zu müssen. Der Saturnsring ist allem Vermuthen nach keine konsistente Masse, sondern nur ein Konglomerat von Einzelkörperchen; die Trennungslinien haben sich einer von W. Meyer aufgestellten Hypothese zufolge unter dem attraktiven Einflusse der Saturnsmonde gebildet. Man halte mit dieser Annahme das zusammen, was soeben über den Planetoidenring ausgesagt wurde.

*) Der phantasievolle Kepler nahm in seiner Erstlingsschrift keinen Anstand [93], je einen Planeten zwischen Mars und Jupiter und auch zwischen Merkur und Venus einzusetzen, die uns nur ihrer Lichtschwäche halber noch nicht zu Gesichte gekommen wären.

**) „Die Akademie wünscht eine statistische Untersuchung der Bahnen der kleinen Planeten, indem dieselben als Theile eines Ringes um die Sonne betrachtet werden. Gestalt und Lage des Ringes und die relative Massenvertheilung müssen wenigstens soweit bestimmt werden, als es nothwendig ist, um die Störungen zu berechnen, welche dieser Ring auf die Planeten und Kometen ausüben kann."

***) N ew comb bemerkt hiezu [99]: ${ }_{n} L$ asse1l, der mit seinen grossen Reflektoren den Planeten in Malta wie in England häufig beobachtet hat, glaubte anfangs einen Ring oder dem ähnliches Anhängsel wahrzunehmen; indessen haben spätere, unter günstigeren Bedingungen angestellte Beobachtungen nichts Derartiges zu erkennen gegeben." 
Ueber die Planetenspektra hat H. V o gel eine vortreffliche Schrift geschrieben.[100], aus welcher die folgenden Angaben entlehnt sind. Die Spektra fast sämmtlicher Planeten enthalten neben den bekannten Linien des Sonnenlichtes auch solche, welche nur bei sehr tiefem Sonnenstande wahrzunehmen und deshalb unserer Atmosphäre zuzuschreiben sind; somit scheinen alle diese Planeten auch eine Atmosphäre zu besitzen. Die Merkuratmosphäre in ihrem gewöhnlichen Zustande ähnelt unserer Lufthülle dann, wenn diese letztere eben die erwähnte absorbirende Wirkung im Maximum zeigt. Auch Venus weist die irdischen Absorptionsstreifen auf, und zwar scheint ihre Lufthülle reich an Wasserdämpfen zu sein und eine starke Reflexionskraft gegenüber den Sonnenstrahlen zu haben. Wenig verschieden verhält sich Mars, dessen rothe Färbung auf eine starke und allgemeine Absorption der blauen und violetten Strahlen zurückgeführt werden dürfte, indem an dem betreffenden Ende des Spektrums keine gesonderten Absorptionsstreifen auftreten. Von den lichtschwächsten Planetoiden ist wenig zu berichten, doch sind bei dem hellsten Mitglied der Gruppe, bei Vesta, Andeutungen einer Atmosphäre vorhanden. Beim Jupitersspektrum treten zu den Sonnenlinien im helleren Ende einige dunkle Streifen hinzu, während Blau und Violett abgeschwächt erscheint, was auf die Anwesenheit von Wasserdämpfen schliessen lässt. Ein eigenthümlicher Streifen im Roth kann von einer dem grossen Planeten eigenthümlichen Substanz, möglicherweise aber auch von besonderen Druck- und Wärmeverhältnissen herrühren; im Uebrigen gilt betreffs der rothen Färbung für Jupiter dasselbe, wie für Mars. Sonderbar ist der Unterschied in den Spektren des Saturn und seines Ringes; ersteres nämlich enthält eine dem Jupiterstreifen analoge atmosphärische Linie, während letzteres derselben ermangelt, was auf eine dichte umhüllende Gasschicht hindeutet. Vom Uranus kennt man zur Zeit mit Gewissheit blos fünf Streifen. Die grössten Unterschiede gegen das solare weist das Neptunspektrum auf, in welchem einige breite Absorptionsbänder auftreten. Im Wesentlichen deckt sich das Facit der spektralanalytischen Forschung mit den aus der Kant-Laplace'schen Theorie gezogenen Folgerungen. Die oberen Planeten sind im Erkaltungsprocesse noch weniger weit vorgeschritten, als die unteren, ihr Gefüge ist ein lockeres, vielleicht dem tropfbar-flüssigen Aggregatzustande nahekommendes, ausgedehnte Atmosphären umgeben jede Planetenkugel. Namentlich für Saturn und Saturnsring ist eine noch andauernde Gluthflüssigkeit sehr wahrscheinlich geworden, wie denn neueren Beobachtern (Webb, Airy, Coleridge) der Körper des Planeten im stark vergrössernden Fernrohr nicht als Kreis oder Ellipse, sondern als Quadrat mit abgerundeten Ecken sich dargestellt haben soll [101].

Als Vergleichsobjekt für die irdische Meteorologie kann vielleicht das eigenartige Farbenspiel mit der Zeit werthvoll werden, welches die dicke, wolken- und dampfreiche Atmosphäre Jupiters aufweist. ,Seit 1878 ist in dessen südlicher Hemisphäre ein grosser, fast ovaler, von hellem Rande umgebener und auffallend stark roth gefärbter Fleck beobachtet worden, der allmählichen Veränderungen unterworfen ist " [102]. Die umfassendste Untersuchung über diese Wolkenbildung hat W olf er [103] angestellt, er findet, wie R. W olf mittheilt [104], dass der zur Zeit sehr schwer erkennbare Fleck nicht wirklich im Verschwinden 
begriffen, sondern nur - was auch Lohse annimmt - durch darüberlagernde anderweite Luftgebilde unkenntlich gemacht sei.

§. 10. Die Kometen. Mit diesem Namen bezeichnen wir die nicht zu den vollbürtigen Bürgern unseres Sonnensystemes gehörigen Wandelsterne, die ihren Namen Schweif- oder Haarsterne meistentheils mit grossem Rechte tragen, wiewohl mancher von ihnen dieses Anhanges gänzlich entbehrt. Man hat lange gebraucht, bis man diese sonderbaren Körper unter dem astronomischen Gesichtspunkte betrachtete, obwohl schon die Chaldäer auf dem richtigeren Wege waren [105], und auch die chinesischen Geschichtschreiber, vorab Ma-twan-lin, die Erscheinungen der Kometen Jahrhunderte hindurch mit solcher Treue registrirten, dass Williams [106] durch Zusammenstellung dieser Notate den rechnenden Astronomen eine werthvolle Hülfe für kometarische Bahnbestimmungen bieten konnte. Den Griechen waren die Kometen gleichgültig, der ptolemaeische Almagest thut ihrer nicht einmal Erwähnung. Dagegen reizten sie den Klassifikationstrieb des" älteren Plinius, der aus ihnen nach freilich recht äusserlichen Merkmalen neun Hauptkategorieen zusammenstellte, den eigentlichen Haarstern ( $\varkappa \omega \mu \eta^{\prime} \tau \eta_{5}$, crinita), den Pogonias (Bartstern), Akontias (Wurfspeer), Xiphias (schwertförmigen Stern), den runden Disceus, den fassförmigen Pitheus, das Horn (Ceratias), die Fackel (Lampadias) und den mähnenförmigen Stern; ;fit et candidus cometes", fährt er fort [107], , argenteo crine, ita refulgens, ut vix contueri liceat ... Fiunt et hirti villorum specie, et nube aliqua circumdati." Ungleich höher als sein vielbelesener Zeitgenosse steht der Philosoph Seneca da, der in merkwürdiger Vorahnung die Kometen für Konglomerate unzähliger kleiner Körperchen (,stellae erraticae*) erklärt, welche sich in sehr langgestreckten Bahnen bewegten und nur wegen dieser Länge ihrer Umlaufszeit noch nicht als den Planeten gleichwerthig erkannt worden seien [108]. Während des Mittelalters blühte der Kometenaberglaube; dann aber entwarf Regiomontan [109] mit sicherer Hand die Grundlinien eines mathematischen Systemes zur genauen Bestimmung der Kometenörter; Peter Apian verfolgte ausdauernd den Weg dieser Fremdlinge am Himmelsgewölbe, und er, wie schon früher der Italiener Fraca s tor [110], überzeugte sich auch von dem merkwürdigen Umstande, dass bei jeder Stellung des Gestirnes die Schweifaxe in ihrer Verlängerung über den Kopf des Kometen hinaus durch die Sonne hindurchgehe [111]. Was die Bahn eines solchen Sternes anlangt, so dachte sich Apian dieselbe kreisförmig, Cysatus und Kepler waren für die gerade Linie; Borelli und ein halb mythischer Graf Henry Percy von Northumberland galten als diejenigen, welche zuerst den Kometen in einer Ellipse um die Sonne sich bewegen liessen [112]. Mindestens gleichzeitig mit Borelli erklärte sich der Jesuit P. Petit mit noch grösserer Bestimmtheit für eine Kegelschnittbahn [113]. Des Hevelius Ausspruch, dass durch die jedem geradlinig bewegten Himmelskörper innewohnende Neigung nach der Sonne hin der Schweifstern in eine parabolische Bahn hineingerathe, war ein gelegentliches Aperçu ohne eigentliche Begründung [114]; erst Dörffel kam, wie unlängst sein Biograph Reinhardt [115] im Detail nachwies, durch so folgerichtige und mit den Beobachtungen harmonirende Schlüsse zu einem analogen 
Resultate, dass man in ihm den eigentlichen Entdecker des astronomischen Fundamentalsatzes zu verehren hat, die Sonne stehe im Brennpunkt der parabolischen Kometenbahn. Newton gab hierauf [116] die von Olbers [117] ungemein vervollkommneten Vorschriften, aus drei geocentrischen Beobachtungen eine solche Bahn wirklich zu berechnen, und Halley machte davon die berühmte Anwendung auf den nach ihm benannten Kometen, bei dessen von Lalande, Clairaut und Madame Lepa ute genau vorausbestimmter Wiederkehr im Jahre 1756 die Theorie ihre höchsten Triumphe feierte [118]. Seitdem hat man noch eine grössere Anzahl von Kometen kürzerer Umlaufszeit gefunden, unter welchen die nach ihren Entdeckern resp. Berechnern genannten Kometen von Brorsen, v. Biela, Faye und Encke die bekanntesten sind. Im Allgemeinen aber ist für einen neu aufgefundenen Stern dieser Art die hyperbolische Bahn als die wahrscheinlichste anzunehmen, wennschon bequemeren Kalkuls halber meistentheils von der Parabel als einer ersten Näherung Gebrauch gemacht wird. Einen sehr vollständigen „Abriss einer Geschichte der Kometenerscheinungen“ hat Mädler [119] seiner populären Astronomie einverleibt.

Die physische Beschaffenheit und die Art des Lichtes eines Kometen blieben so lange Gegenstand einer blos hypothetischen Erörterung, als man lediglich durch das Fernrohr zu diesen räthselhaften Weltkörpern in Beziehung zu treten vermochte. Arago bediente sich zuerst des Polariskopes, und durch dasselbe ward konstatirt [120], dass der Komet zweierlei Licht aussendet, nämlich solches, das ihm eigen und solches, das solaren Ursprunges, von ihm aber reflektirt ist. Das Spektrum ist aus wenigen verwaschenen hellen Banden zusammengesetzt und gestattet den allerdings nicht über jeden Zweifel erhabenen Schluss, dass die glühenden Gase einiger Kohlenstoffverbindungen den Hauptbestandtheil der Kometenmaterie ausmachen; nach Newcomb's Ansicht dürfte eine zunächst nicht näher $\mathrm{zu}$ eruirende Verbindung fester und gasförmiger Stoffe vorherrschen. Dass das Gefüge dieser Wandelgestirne ein sehr wenig kompaktes ist, erhellt $u$. a. aus der wohlbekannten Thatsache, dass der Biela'sche Komet, einer von den periodisch wiederkehrenden, im Januar 1846 sich in zwei getrennte Kometen von ziemlich identischem Aussehen zertheilte, die das nächstemal auch wirklich als Doppelkomet wieder erschienen. Die Sonne übt natürlich auf diese kosmischen Gewölke die mächtigsten Wirkungen aller Art aus, wie denn die Spektra bei verschiedenen Abständen des Kernes vom Centralkörper auch verschieden ausfallen. Im Kometen vollzieht sich, wie H. Vogel bemerkt hat [121], ein ganz ähnlicher Vorgang, wie bei den stark verdünnten Gasen der Geissler'schen Röhren, "wo bei gesteigerter elektrischer Intensität in dem Momente, wo die Spektra von Metalldämpfen erscheinen, die Spektra aller sonst vorhandenen Gase stark zurücktreten und in dem Massse abnehmen, als die Intensität der Metallspektra zunimmt". Auf die ungemein grosse Dünnheit der im Kerne - und also noch weit mehr im Schweife - vertheilten Materie lässt auch W. Meyer's aus Beobachtungen und theoretischen Erwägungen gleichzeitig gezogene Angabe [122] schliessen, dass die Substanz, aus welcher der Kopf des Kometen III. von 1881 bestand, sich optisch wie ein Gas verhielt, dessen brechende Kraft in einer Entfernung von $10200 \mathrm{~km}$ vom Kerne gleich 0,0000093 wäre. 
Wir gehen sonach wohl nicht fehl, wenn wir, auch ohne zunächst von den eigentlichen Kometentheorieen Akt zu nehmen, einstweilen Folgendes feststellen: Die Schweifsterne sind lockere, grossentheils gasförmige, kosmische Wolken, die an sich frei durch den Weltraum streifen und durch die übermächtige Anziehung eines Fixsternes, z. B. der Sonne, sei es vorübergehend, sei es dauernd, zum Verbleiben in dem Trabanteusystem dieses Centralkörpers genöthigt werden. Ein Zusammenstoss des Kometenkernes mit unserer Erde ist, wie eine Wahrscheinlichkeitsbetrachtung lehrt, vernünftigerweise nicht zu befürchten, würde aber gegebenen Falles auch kaum zu solchen Katastrophen führen können, wie sie Buffon (Kap. I, §. 1) uns ausmalen möchte. Vielleicht würde (s. §. 13) ein recht ergiebiger Sternschnuppenfall die einzige Folge eines solchen Ereignisses sein, und Pogson ist sogar der Meinung, dass der am 27. November 1872 zu Madras beobachtete Sternschnuppenregen auf den Durchgang unseres Planeten durch den Schweif des Kometen von Biela zurückgeführt werden müsse [123]. Schon Kant [124] stellte jede Gefahr in Abrede.

§. 11. Aeltere und neuere Kometentheorieen. In diesem Paragraphen soll eine gedrängte Uebersicht über eine Anzahl von Kometentheorieen gegeben werden. Dieselben haben theils nur unter dem geschichtlichen Gesichtspunkte und um deswillen Interesse, weil sie für die Gesammtanschauung ihrer Zeit charakteristisch sind, zum Theile auch bilden sie noch heute den Gegenstand wissenschaftlicher Diskussion.

a) Peter Apian. Die Lehre dieses verdienten Kometenforschers ist vielfach, auch von Mädler [125], falsch verstanden worden. Der Erstere nimmt, getreu den Traditionen der aristotelischen Schulphysik an, dass irdische Dünste in die Elementarregion des Feuers emporsteigen, sich allda unter der Einwirkung der Sonnenstrahlen entzünden und nun zu einem Feuermeteore zusammenballen [126]. Die Mondbahn reisst dieses in ihrem Umschwung mit sich fort. Aehnliche Theorieen beherrschten noch das ganze XVI. Jahrhundert, und erst dann begann man sich von diesen loszusagen, als man erkannt hatte, dass ein Komet keine erkennbare Parallaxe besitze. Diesen Punkt besonders scharf betont zu haben, ist ein Verdienst von Peter Apian's Sohn Philipp [127].

b) Kepler. Seinen freien Blick bethätigte der grosse deutsche Astronom besonders auch in seiner Auffassung der Kometen. Dess zum Zeugniss seien einige Sätze aus seinem deutsch geschriebenen Traktate über diese Himmelskörper*) [128] hier wörtlich wiedergegeben: "Von den Cometen ist diss mein einfältige Meynung, dass, wie es natürlich, dass aus jeder Erden ein Kraut wachse, auch ohne Saamen, und in jedem Wasser, sonderlich im weiten Meer, Fische wachsen und darinnen umbschweben, allermaassen sey es auch mit der himmlischen, überall durchgängigen und ledigen Lufft beschaffen, dass nemlich dieselbige diese Art habe, aus ihr selber die Cometen zu gebären. $\left.{ }^{* * *}\right) \ldots$ tragen.

*) Ursprünglich deutsch geschrieben, nachher erst in's Lateinische über-

華) Man bemerke die mancherlei Anklänge, die sich bei Kepler betreffs der Generatio aequiroca finden. 
„Wann die Lufft etwa an einem Ort dick wird, also dass die Sonne und die Sterne ihre Straalen nicht wohl hindurch schiessen und auff Erden leuchten können, alsdann ist es Zeit, und bringt es dieser himmlischen Lufft lebhafte Natur mit sich, dass solche dicke, feiste Materi gleichsam als in ein Apostem zusammengezogen und ihrer Natur nach erleuchtet und wie andere Sterne mit einer Bewegung begabt werde" „Wann nun also ein durchsichtige, liechte Kugel oder Klumpff im Himmel schwebt, und die Sonne mit ihren rechtlinigen Straalen darauf trifft, denselben auch durchgehet, so haltt ich, dass solche Straalen etwas von der Materi der Cometenkugel mit sich davon führen und also den Cometen bleichen, waschen, saigern, durchtreiben und endlich gar vertilgen, inmaassen bei uns hier auf Erden die Sonne alle Farben aus leinen Tüchern vertilget, verzehret und vertreibet und sie also schneeweiss machet. " Man braucht gerade nicht jedes Wort der Apotheose zu unterschreiben, welche Zöllner anlässlich dieser Sätze an die Manen Kepler's richtet [129], um solche Anschauungen gleichwohl für höchst merkwürdig und über ihre Zeit sich erhebend zu erklären. Von Kepler's unmittelbaren Zeitgenossen hat wohl nur der freisinnige P e ir es c [130] die Richtigkeit derartig kühner Thesen zuzugeben gewagt.

c) Hevel. Die Kometen gehen aus den Atmosphären der Planeten hervor, welche nur die gröberen Ausdünstungen dieser Himmelskörper zurückbehalten, die feineren aber aufsteigen lassen. Ballen sich dieselben auch noch innerhalb der Atmosphäre zusammen, so verlassen sie dieselbe doch und bewegen sich nach der Sonne hin, weil der dichte Körper angeblich mehr Neigung zur Bewegung habe, als der minder dichte - offenbar eine missverstandene aristotelische Reminiscenz. Indem der so in der Entstehung begriffene Komet die Sphären anderer Planeten durchschneidet, zieht er mehr und mehr Ausdünstungsstoffe an sich; liegen mehrere Planeten in ein und derseiben Geraden, so ist die Kometenbildung erleichtert, wie verschiedene Conjunktionen gezeigt haben [131].

d) Jakob Bernoulli. Eine nicht uninteressante Theorie, besonders deshalb, weil sie den ernstgemeinten Versuch darstellt, den Aberglauben der Zeit mit der eigenen besseren Ueberzeugung durch ein Kompromiss zu versöhnen. Kern und Schweif sind strenge von einander zu scheiden; der erstere ist ein Himmelskörper wie jeder andere und zwar Trabant eines weit entfernten transsaturnischen Planeten, der Schweif dagegen ist etwas der natürlichen Erkenntniss entzogenes, an welchem sich astrologische Deutungskunst beliebig versuchen kann. Mit Wolf [132] halten wir dafür, dass die betreffende Schrift B ernoulli's [133] einen Fortschritt signalisirte - freilich nicht gegenüber den Ideen Kepler's, wohl aber gegenüber denen von hundert anderen Fachmännern.

e) Newton. Die Kometen sind feste und dauerhafte Körper, denn wären sie diess nicht, so müssten sie beim Durchgang durch das Perihel - Newton dachte besonders an den der Sonne ungeheuer nahe gekommenen Schweifstern von 1680 - sich verflüchtigen und könnten nicht aus den Sonnenstrahlen wieder zum Vorschein kommen [134]. Die Materie der Schweife dagegen ist dünn und fein und entfernt sich deshalb von der Sonne, weil sie noch zarter ist, als jene Materie, mit welcher der Weltraum in der Umgebung des Kometen 
erfüllt ist. So entfernt sich trotz der von der Erde ausgeübten Anziehungskraft der Rauch von dieser. Indess wird K epler's Ansicht, nach welcher die Sonne durch ihre Strahlen läuternd auf die Kometenstoffe wirkt, ausdrücklich als , nicht absurd" bezeichnet [135]. In seiner ausführlichen Kritik aller bestehenden Kometentheorieen [136] hat Flaugergu es auch speziell die $\mathrm{New}$ to n'sche als mit den Grundsätzen der Physik in Widerspruch stehend zu erweisen versucht, indess ist sein Nachweis keineswegs tadelfrei.

f) Piazzi. Diesem Astronomen zufolge [137] sind im Weltraum alliuberall kleine materielle Punkte verstreut. Ein irgendwie entstandenes Konglomerat aus diesen wirkt attraktiv auf die in der Nachbarschaft schwebenden Partikeln, und es entsteht nach und nach eine Masse, dicht genug, um zugesandtes Licht nicht blos diffus zurückwerfen und zugleich eigenes Licht in zur Sichtbarkeit hinreichender Menge abgeben zu können.

g) Herschel-Laplace. Eine von William Herschel [138] autgestellte und von Laplace [139] gebilligte Hypothese gipfelt darin, dass die Kometenmaterie nichts anderes sei, als diejenige kosmische Urmaterie, aus welcher heute noch die teleskopisch unzerlegbaren Nebelflecke bestehen, und aus welcher nach der Nebulartheorie auch alle Körper unseres Sonnensystemes hervorgegangen sind. Eine isolirte Masse dieser Art wird von der Sonnengravitation zum Beschreiben eines Kegelschnittes um den Centralkörper gezwungen; ursprïnglich sphärisch geballt, verlängert sich der wandernde Nebelfleck unter dem Einflusse der Sonnenstrahlen immer mehr in der der Sonne abgewandten Richtung, ein Theil der Masse verliert sich in den Weltraum und diese - der Verdunstung terrestrischer Flüssigkeiten vergleichbare - Verflüchtigung bringt es mit sich, dass ein Komet ein um so festeres Gefüge erlangt, je häufiger er bereits in seine Sonnennähe kam. Die Aehnlichkeit mit $\mathrm{New}$ ton's Hypothese ist unverkennbar.

h) J. W. H. Lehmann. Dieser berühmte astronomische Rechner ist der Begründer [140] der kometarischen Ebbe- und Fluth-Theorie. Die schweiflosen Kometen sollen den Planeten ähnlich sein und eine analog kurze Rotationsdauer besitzen, während die gewöhnlichen Schweifsterne stets die nämliche Seite, wie der Mond der Erde, der Sonne zuwenden. Die den Kometen umgebende Materie ist mit einer gewissen Expansivkraft ausgestattet, und da an der der Sonne abgekehrten Seite des Kernes die Anziehungskraft geringer ist, so entsteht dort ein Uebermaass von Expansivkraft, und die Theilchen fluthen nach dem am weitesten von der Sonne entfernten Punkte hin, der also als Ausgangspunkt der Schweifbildung erscheint. Freilich bildet sich auf unserer Erde gleichzeitig auch die Nadirfluth, von welcher auf dem Kometen nach Lehmann nichts zu verspüren sein würde.

i) Tyndall. Schon vor langer Zeit war der Gedanke gelegentlich aufgetaucht, dass ein Kometenschweif lediglich ein subjektiv-optisches Phänomen sei, in Wirklichkeit aber gar nicht existire; Cardanus erdachte ein Experiment zur Veranschaulichung des Vorganges, wie er ihn sich dachte, und $\mathrm{De}$ Laune suchte weitere Beweise in diesem Sinne beizubringen [141]. Auf ähnlicher Basis erwuchs die freilich von den allermodernsten Theorieen der Experimentalphysik Gebrauch machende Kometenlehre von Tyndall [142]. Die Sonnenstrahlen 
wirken chemisch zersetzend auf den ruhenden Aether, der wesentlich durch sehr fein vertheilte Kohlenwasserstoffdämpfe gebildet wird, und es treten dadurch Erscheinungen ein, wie sie Tyndall vorher in seinem Kabinet zur Darstellung gebracht hatte. Wurde nämlich ein Glasrohr mit Amylnitrit oder Allyljodid angefüllt und alsdann durch elektrisches Licht beleuchtet, so verdichteten sich die Dämpfe sofort und bildeten eine aktinische Wolke, indem zumal die Sonne ausser ihrer Licht- und Wärmeaktion auch noch eine spezifisch aktinische Wirkung ausübt. Mit solchen Wolken werden Kopf und Schweif des Kometen identificirt. Es hält schwer, sich den Weltraum von so selten vorkommenden Verbindungen angefüllt zu denken, wie es nach der Tyndall'schen Hypothese erforderlich ist, auch ist durchaus nicht ersichtlich, durch welches Hinderniss der Kern des Kometen die kalorischen Strahlen der Sonne soweit abzuhalten vermag, um den aktinischen einen freien Platz für ihre Thätigkeit zu verschaffen. Nach der vernichtenden Kritik, die Zöllner [143] an dieser Hypothese geübt hat, ist an ein Verbleiben derselben auf der wissenschaftlichen Tagesordnung nicht zu denken, und wir möchten sie auch nicht mit Leipold t [144] als eine "der beiden wichtigsten der bisher aufgestellten Kometentheorieen" "bezeichnen. Ungleich beachtenswerther dünken uns besonders jene zu sein, von denen weiterhin in diesem Paragraphen die Rede sein wird.

k) Schwedoff - v. Dellingshausen. Der genannte russische Mathematiker betritt einen neuen Weg in einer kleinen Schrift [145], von welcher wir hier allerdings nur durch die paraphrasirende Bearbeitung v. Dellingshausen's [146] unterrichtet sind. Nach letzterem lautet Schwed off's Hauptsatz folgendermassen: „Die Kometenschweife sind Verdichtungswellen, welche durch die Bewegung des Kometenkernes in einem Widerstand leistenden Mittel angeregt und, von der Sonne oder von dem Kerne aus beleuchtet, für uns sichtbar werden. Nur der Kern ist also ein Körper im strengen Wortsinne; hierin ähnelt die vorgetragene Theorie der Tyndall'schen. Schwed off hat seiner ersten Abhandlung eine weitere mit mathematischem Kommentar folgen lassen [147], indess findet v. Dellingshausen, die hierin enthaltene Definition des intraplanetaren Mediums verderbe wieder die vorher erzielten Erfolge [148]. Er selbst identificirt, um konsequenter zu sein, die Kometen mit den Wirbelatomen der englischen Naturphilosophen: »die Kometenschweife sind nur die Spur, welche die Wirbel hinter sich lassen, Wellenbewegungen des intraplanetaren Mittels, das theils noch selbstleuchtend, theils von der Sonne beschienen, für uns als heller Nebel sichtbar wird" [149]. Eignet aber, diese Frage liesse sich wohl aufwerfen, diesen kosmischen "vortex atoms" auch die an letzteren von Helmholtz nachgewiesene Eigenschaft der Unzerstörbarkeit?

l) Zenker. Die Substanz des Kometenkernes ist in der Hauptsache eine solche, dass sie durch Wärme verflüchtigt, durch Kälte wieder kondensirt werden kann [150]. Die Sonnenstrahlen lösen einen Theil der Substanz in Dämpfe auf, und der Rückstoss dieses sich entwickelnden und fortgeschleuderten Dampfes tritt als treibende Kraft auf. Die kleinen den Kometenkern begleitenden Massen, aus welchen auf der der Sonne zugekehrten Seite fortwährend Dämpfe entströmen, werden durch die Reaktion der Stosskraft wie Raketen, deren Aus- 
strömungsöffnung der Sonne zugewandt wäre, von dieser fortgeschleudert. Diese Bewegung ist eine beschleunigte, und zwar muss die Beschleunigung zunehmen, so lange die einseitige Verdampfung stattfindet [151]. Zenker denkt sich jene Massen speziell als aus gefrorenem Wasserdampf entstanden und nimmt somit an, dass die einseitige Erwärmung dieser Eisbälle eine repulsive Kraft in's Leben rufen müsse; durch Rechnung sucht er darzuthun, dass für die Bälle die Wahrscheinlichkeit, grosse Geschwindigkeiten und damit auch grosse Entfernungen zu erreichen, mit ihrer Zahl und Dichtigkeit wachse [152].

m) v. Miller-Hauenfels. Mit der Schwedoff'schen und der Zenker'schen Hypothese hat die jetzt zu besprechende das gemein, dass ihr Urheber seine Imagination durch eingehende analytische Diskussion der angeregten Fragen vor Irrthümern zu bewahren suchte. Im Wesentlichen stützt sich derselbe auf die bereits von Rankine (s. o. Kap. I. §. 8) angenommene ideelle Grenzfläche des Weltraumes, an welcher eine Art von Gegendruck stattfinde, der zwar weit unter die Markirungsgrenze auch der allerempfindlichsten Manometer fiele, gleichwohl aber [153] sseine Aufgabe erfüllen und die Anhäufung atmosphärischer Hüllen um die solideren Weltkörper, sowie die Ansammlung selbstständiger Gasmassen im freien Weltraume möglich machen werde." Durch Betrachtung der Druck- und Temperaturverhältnisse isolirt im Raume schwebender Gasmassen von kugelförmiger und sphäroidischer Gestalt werden dann auch die kometarischen Formen als solche erkannt, wie sie unter dem Gesammteinflusse der Attraktion, der Centrifugalkraft, des Mariotte-Gay-Lussac'schen Gesetzes und endlich jenes hypothetischen Bahndruckes aus einer solchen kosmischen Gasmasse sich ergeben müssen. Durch Studium der Niveaulinien geschweifter Kometen, welche mit den Isophoten oder Ortskurven gleicher Lichtstärke einerlei sein sollen [154], glaubt v. MillerHauenfels auch die eigenthümlichen Wirbelbewegungen im Inneren der Kometenschweife der Erklärung zugänglich machen zu können [155]. Man wird seinem Systeme logische Anordnung der einzelnen Bestandtheile und konsequenten Aufbau nicht abstreiten können und nur bedauern, dass dasselbe auf einer so wenig sicheren Prämisse, wie dem Gegendruck des Weltäthers, aufgebaut worden ist.

§. 12. Hypothesen, welche eine polare Kraft zu Hülfe nehmen. Im Jahre 1744 erschien ein Komet von grossem Glanze, an dessen Kopfe eigenthümliche, fächerartige Ausströmungen bemerklich waren. Der Petersburger Akademiker Heinsius hat uns in einer besonderen, mit sehr schönen Darstellungen versehenen Schrift [156] eine genaue Beschreibung dieses Phänomenes geliefert. Neuerdings hat man Aehnliches öfter am Kerne und an der Koma - dem Scheitel der lichterfüllten Parabel, als welche der Komet sich mehrentheils darstellt beobachtet; von dem Halley'schen Kometen (1835) haben Bessel, von dem Donati'schen Kometen (1858) Bond und J. Schmidt Zeichnungen in dem fraglichen Stadium entworfen, von welchen man sämmtlich bei J. Müller [157] eine treffliche Reproduktion findet. Auch der Komet von 1881 gehört in diese Kategorie, und der dritten Auflage des Zöllner'schen Kometenwerkes sind zwei Stiche Weinek's beigegeben, welche die charakteristischen Umbiegungen der vom Kerne 
ausgehenden Strahlen sehr gut zum Ausdrucke bringen; bei diesem Kometen ist auch erstmalig eine photographische Aufnahme des Schweifes (durch Janssen) geglückt, so dass wir künftig auch von dieser Seite her neuen Aufschlüissen über die Strömungserscheinungen entgegensehen dürfen [158].

Theoretische Betrachtungen knüpften an diese Erscheinungen zuerst Olbers [159] und Bessel [160] an. Der letztere kommt auf Grund sorgfältigsten Beobachtungsmateriales zu dem Schlusse, dass eine Polarkraft nicht allein in den Kometen von 1744, 1811 und 1835 gewirkt habe, sondern dass dieselbe auch eine allgemeinere, wo nicht die allgemeine Eigenschaft sämmtlicher Kometen sei. „Die Planeten und die Kometen scheinen dadurch verschieden zu sein, dass in jenen die Schwerkraft, in diesen Polarkräfte die vorherrschenden sind." Welcher Art diese Anziehungs- und Abstossungskräfte sein möehten, liess Bessel in seiner bekannten vorsichtigen Art unentschieden, und an diesem Punkte war es eben, wo Zöllner einsetzte und in seinem bekannten Buche, dessen wir nun schon oftmals Erwähnung zu thun hatten, eine bestimmte Behauptung jenen früheren Andeutungen gegenüberstellte. Bezüglich der Annahme, dass die Kometen in erster Linie kosmische Gasmassen sind, die an sich mit der sehr niedrigen Temperatur des Weltraumes (vgl. §. 14) im Wärmegleichgewicht stehen, befindet sich Zöllner mit manchen unter den früheren Kometentheoretikern (s. o. §. 11) im Einklange, und auch darin befindet er sich auf gleicher Linie mit älteren Anschauungen, dass er einen solchen unregelmässig begrenzten Gasball, wenn derselbe in die Nähe eines Fixsternes - z. B. der Sonne - gelangt, einem Siede- und Verdampfungsprocess unterliegen lässt. Wie aber werden diese Dämpfe selbstleuchtend? Ueber diesen Punkt, auf welchen doch nach den Beobachtungen Arago's mit dem Polariskop (s. o. §. 10) ungemein viel ankommt, sind sich frühere Forscher offenbar nicht genügend klar gewesen, und Zöllner hat deshalb, indem er an bekannte Sätze der Elektricitätslehre appellirte, eine entschieden vorhandene Lücke ausgefült. Versuche von Faraday, Riess, Abendroth u. a., die z. B. an Wasserfällen und Springbrunnen angestellt wurden, lehren uns, dass mit jeder Zerreissung von Flüssigkeitsmassen durch mechanische Gewalt, mit jeder Zerstäubung und Dampfbildung das Auftreten aktiver (Reibungs-) Elektricität verbunden ist. Denken wir uns, durch ähnliche Vorgänge im Grossen bilde sich am Kern des Kometen ein Heerd irgendwie bezeichneter - sagen wir negativer - Elektricität, so wird dieselbe von der durch die Sonne gelieferten gleichnamigen also ebenfalls negativen Elektricität abgestossen werden. Dass aber eine solche durch die mannigfachen Umbildungen an der Oberfläche des Sonnenkörpers in reichem Maasse geliefert werde, ist mindestens als höchst wahrscheinlich zu bezeichnen. Dieser Akt der polaren Abstossung erklärt somit Dreierlei gleichzeitig: das Leuchten der ausströmenden Theile, welches mit anderen bekannten elektrischen Glüherscheinungen ziemlich auf gleicher Stufe stehen würde, die Schweifentwickelung selbst, und endlich auch den Erfahrungssatz des alten Apian, dass der Schweif stets - oder besser gesagt, fast stets - eine von der Sonne abgewandte Richtung besitzt. Eine Reihe von Zenker gegen diese Theorie erhobener Einwendungen, worunter uns der schwerst- 
wiegende der zu sein scheint, dass die auf der Sonne vorhandenen Mengen der beiden ungleichnamigen Elektricitäten einander gleich sein müssen [161], hat $\mathrm{Z} o ̈ l n$ er in einer umfänglichen Abhandlung [162] widerlegt, indem er sich betreffs der von ihm stipulirten elektrischen Fernewirkung des Centralkörpers auf mehrere seinen Ansichten günstige Forschungsresultate von Becquerel, G. Wiedemann und Hornstein [163] beruft. Eine nicht zu verachtende Stütze ist der elektrischen Kometentheorie später von Seiten des Engländers Crookes, des Erfinders des Radiometers, zu Theil geworden, der die Wahrnehmung machte, dass die wesentlichen chemischen Charaktere der Moleküle auch bei den höchsten Verdünnungsgraden erhalten bleiben; diess hatte Zöllner schon früher behauptet und im Anschluss daran die Anwesenheit von Wasserstoff und Kohlenstoff im Kometenschweife für höchst wahrscheinlich erklärt. Beide Elemente sind von Huggins auch wirklich mit Hülfe des Spektroskopes herausgefunden worden [164]. Endlich hat Bredichin die Zöllner'schen Voraussetzungen und insbesondere den Satz, dass die Repulsivkräfte der Sonne den spezifischen Gewichten der Schweiftheilchen umgekehrt proportional seien, durch mühevolle Rechnung auf Grund Bessel'scher Formeln bei einer Reihe von Kometentypen bestätigt gefunden [165]. Für diese Hypothese spricht auch noch der Umstand, dass sie zu den sofort zu erörternden verwandtschaftlichen Beziehungen zwischen den Kometen und einer anderen Klasse von Himmelskörpern in keinerlei Widerspruch steht. Bredichin berechnet für den zweiten Kometen des Jahres 1882 eine etwa dreimal so rasche Bewegung der Schweiftheile als des Kernes und knüpft an dieses Ergebniss die Bemerkung [166]: „Voilà l'une des plusieurs raisons par lesquelles l'étude sérieuse des comètes a dû conduire à l'admission de la force centrale repulsive (réelle ou apparente), dont la cause physique nous reste inconnue comme celle de l'attraction Newtonienne. ${ }^{6}$ Nach Bredichin ist in vielen Fällen, abgesehen von dem durch Helligkeit und Schärfe ausgezeichneten Hauptschweif, der aus Kohlenwasserstoff theilchen besteht, ein innerer Schweif aus festerem Materiale zu unterscheiden; der sich der Sonne zuwendende Theil werde von Molekülen gebildet, welche selbst nur von den entfernteren und schneller bewegten mit fortgerissen würden, selbst jedoch keiner erkennbaren Abstossungskraft unterworfen zu sein schienen.

§. 13. Die Meteorite. Dass Steine und metallische Körper vom Himmel auf die Erde fallen, war längst bekannt, ehe ein grosser Theil der Gelehrten die Thatsache zugestehen wollte. Im Jahre 467 v. Chr. schon konnte der Philosoph Anaxagoras ein solches Ereigniss bei Aigospotamoi am Hellespont konstatiren und (nach Plutarch) mit der Schnelligkeit des Himmelsumschwunges in Verbindung bringen. Sowohl das Alterthum, wie auch das Mittelalter erblickte in solchen Katastrophen ominöse Winke des Himmels und nahm daraus Anlass zu einer Art von Meteorkultus*), an den noch heute das musleminische

*) Dieses Wort rührt her von dem Freiherrn v. Dalberg, dem Bruder des bekannten Fürsten Primas; der Erstere hat darüber eine eigene Monographie [167] geschrieben. Auch der scythische Mythus "vom heiligen Golde" soll nach A. v. Humboldt's Meinung auf meteorische Metallmassen hindeuten. 
Religionsheiligthum, der schwarze Stein in der Kaaba zu Mekka, gemahnt. Im Jahre 823 sollen in Sachsen laut Klosterchroniken einige Dörfer durch fallende Steine angezündet worden sein [168], und aus dem Jahre 1366 (21. Oktober) wird uns von zwei ihrer gegenseitigen Unabhängigkeit wegen gewiss ganz vertrauenswürdigen Quellen, einer böhmischen und einer portugiesischen, ein ungeheurer Sternschnuppenregen gemeldet [169]. Der 4. September 1511 brachte den furchtbaren Steinfall bei Crema in Oberitalien, den Petrus Martyr und Cardanus beschreiben, der die Luft verfinstert und selbst grössere Thiere erschlagen habe [170]; ja sogar einem Mönch soll derselbe den Tod gebracht haben. Wir unterlassen es, weitere Fakta dieser Art aus älterer Zeit anzuführen, verweisen vielmehr auf H. J. Klein's sorgfältige Zusammenstellung aller darauf Bezug habenden Notizen [171] und wenden uns gleich der Neuzeit zu. Gestützt auf diese doch nicht ganz in das Reich der Fabeln zu verweisenden Angaben der Historiker und auf den weiteren Umstand, dass der Naturforscher Pallas eine Eisenmasse von sichtlich aussertellurischem Ursprunge aus Sibirien mit heimgebracht hatte, wagte es der Physiker Chladni [172], das Niederfallen von Meteorsteinen für eine wissenschaftlich unantastbare Wahrheit zu erklären und zugleich diese Gebilde mit den Sternschnuppen und Feuerkugeln ursächlich zu verknüpfen. Sein Wagniss wäre wohl kaum so gut gelungen, wenn nicht einige Zeit darauf der Meteorfall von Aigle, den eine Sachverständigenkommission unter J. B i o t's Leitung genau untersuchte, um mit $\mathrm{Humboldt}$ [173] zu reden, der ,endemischen

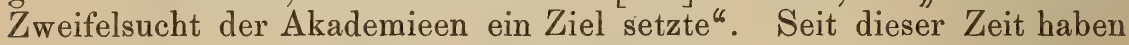
die Meteorite erst ihr volles Bürgerrecht in der Wissenschaft erlangt, und man hat sich mehr und mehr daran gewöhnt, die Meteorsteine im engeren Sinne, die Sternschnuppen und Feuerkugeln im Geiste Chladni's unter obigem Gesammtnamen zusammenzufassen. Man versteht darunter nämlich kleine im Weltraume frei sich bewegende Körper, welche beim Durchdringen der irdischen Lufthülle leuchtend werden und uns als schnell dahinschiessende Sternschnuppen, oder bei besonders hellem Glanze als Feuerkugeln erscheinen, schliesslich aber als Meteorsteine zur Erde fallen. Nur ganz ausnahmsweise ist gegen diese jetzt allenthalben maassgebende Auffassung Widerspruch erhoben worden, wovon später die Rede sein wird.

Chemisch untersucht, zeigen sich diese aus dem Weltraume zu uns gelangten Körperchen als im Wesentlichen aus den nämlichen Elementarstoffen zusammengesetzt, welche uns aus unserer Umgebung bereits bekannt sind. Nach G. Rose, dem man eine Reihe hochwichtiger Arbeiten über die Zusammensetzung und den mineralogischen Charakter der Meteormassen verdankt, kommen die nachstehend genannten Mineralien so ziemlich in allen Individuen vor: Gediegenes, meteorisches Eisen mit Nickelgehalt, Tänit, Schreibersit (eine Verbindung von Phosphor, Nickel und Eisen), Rhabdit, Graphit, Troilit oder Einfachschwefeleisen, Magnetkies, Chromeisenerz, Quarz, Olivin, Shepardit, Augit und Anorthit*). Auf Grund dieses Befundes hat G. Rose eine Klassifikation der Meteorite zu liefern gesucht [174],

*) Neuerdings sind als bisher unbekannte Körper der Celestialit und der Daubré elit dargestellt worden. 
welche jedoch nicht allen Anforderungen genügt und vielleicht besser durch diejenige des verdienten Experimentalgeologen $\mathrm{D}$ a u b ré e ersetzt würde [175]. Dem ersteren Eintheilungsprincipe zufolge zerfallen die Meteorkörper in Eisenmeteorite und Steinmeteorite, deren Spezialcharakter durch das Wort schon gekennzeichnet erscheint; zur ersteren Klasse gehören 3, zur letzteren 7 Unterabtheilungen, indessen ist die Scheidung keine ganz scharfe, sondern der Mesosiderit, ein körniges Gemenge von Meteoreisen und Magnetkies mit Olivin und Augit, repräsentirt eine Uebergangsform. Ein trennendes Kriterium würden übrigens auch, wenn W right Recht behält [176], die Gaseinschlüsse der Körper hergeben, indem die Eisenmeteorite Sauerstoffverbindungen des Wasserstoffes und nicht, wie die Steinmeteorite, Sauerstoffverbindungen des Kohlenstoffes in sich enthielten. Die Steinmeteorite, die in ihrer petrographischen Struktur die weitaus grössere Mannigfaltigkeit aufweisen, kommen als Individuen ungleich seltener vor; so sind z. B. nach Gümbel's Zählung unter sämmtlichen innérhalb der Grenzen Bayerns niedergefallenen Meteoren nur fünf für die Steinmeteorite anzusprechen, während ein sechstes Exemplar, das in Würzburg existirte, den vorhandenen Beschreibungen nach wohl auch dahin zu zählen ist [177]. Daubrée bildet nach dem spezifischen Gewicht (dasjenige des reinen Wassers $=1$ gesetzt) die Gruppe der Sideriten (Holosideriten mit der Dichte 7 bis 8; Syssideren mit der Dichte 7,5 bis 8,5 ; Sporasideren mit der Dichte 3 bis 7 , letztere wieder in Polysideren, Oligosideren und Kryptosideren zerfallend) und der Asideriten. Damit ist denn eine weit leichter erkennbare Scheidelinie gezogen, als durch Rose's beide Kategorieen. Nickel und Magnetkies*) sind übrigens Stoffe, die fast durchgängig in allen Meteoriten angetroffen werden. Nicht minder ist für sie jene schwarze Schlackenkruste charakteristisch, welche sie ringsum in der Dicke von einigen Millimetern umschliesst und aller Wahrscheinlichkeit nach dem Oxydations- und Verbrennungsprocesse entstammt, welchem die mit oft rapider Schnelligkeit in die Erdatmosphäre eindringende Sternschnuppe ausgesetzt und durch welchen auch die Lichterscheinung bedingt ist. Eine überwiegende Anzahl dieser kleinen Metallbälle findet vermuthlich in der Luft auf diese Weise ihren Untergang; die Verbrennungsprodukte gehen in der Atmosphäre auf. Auf Wahrscheinlichkeitsschlüsse gestützt haben Coulvier-Gravier und Newcomb die Zahl der an der oberen Luftgrenze sich entzündenden Meteorite, der eine zu 40 Millionen, der andere gar zu 146 Milliarden, berechnet [179], während es doch keinem Zweifel unterliegt, dass nur ein winziger Bruchtheil dieser Mengen die Erdoberfläche wirklich erreicht. - Etwas Auszeichnendes für viele Meteormassen, jedoch nicht für alle**), sind die sogenannten Widmanstätten'schen Figuren. Deren

*) L. Smith hat festgestellt [178], dass die attraktive Kraft des Meteoreisens wesentlich von den darin eingesprengten Quantitäten Nickel und Kobalt herrührt und nach Beseitigung derselben verschwindet. Das gewöhnliche, bei $110^{\circ}$ getrocknete Eisenoxydhydrat ist noch schwach magnetisch und verliert die letzten Spuren von Magnetismus erst bei einer Temperatur von $400^{\circ}$.

**) So berichtet der nämliche Forscher, dessen in der vorigen Randnote gedacht wurde, von einem in Amerika gefallenen Sideriten, der, obwohl aus 
Entdecker, Edler v. Widmanstätten, hat zwar selbst nichts über seine Beobachtungen veröffentlicht, wohl aber berichtet $\mathrm{v}$. Schreibers [181], dass derselbe zuerst den glücklichen Einfall gehabt habe, einzelne Bruchflächen im Meteoreisen anzuschleifen, zu poliren und mit verdünnter Schwefelsäure zu behandeln, worauf dann geometrische Figuren in ziemlich verwickelter Zeichnung hervortraten. Für die krystallographische Untersuchung der Meteore und die mineralogische Orientirung ihrer Schnittflächen hat Bresina [182] diese Gebilde zu verwerthen gelehrt, und hiefür eignen sie sich weit besser, als zum Kennzeichen des Meteorcharakters einer Eisenmasse, wie denn leider untrügliche Kennzeichen überhaupt noch nicht aufgefunden sind. Selbst hervorragende Autoritäten haben bei diesen Bestimmungen Irrthümer nicht vermeiden können [183].

Die Bewegungsverhältnisse dieser neuen Art von Himmelskörpern hat man seit etwa 80 Jahren eingehend zu erforschen begonnen, nachdem bereits der uns von den Kometen her bekannte Dörffel gegen das Ende des XVII. Jahrhunderts eine auf ganz richtige Grundsätze basirte Bahnbestimmung für eine Feuerkugel durchgeführt hatte [184]. Aus einer längeren Reihe von Korrespondenzbeobachtungen kann man, wie Brandes und Benzenberg in einer gemeinsam ausgearbeiteten Schrift darlegten [185], die Geschwindigkeit, die Bewegungsrichtung, sowie den Ort des Aufleuchtens und Verschwindens mit ziemlich grosser Genauigkeit ermitteln, und es kommt also wesentlich darauf an, viele und gute, womöglich auch synchrone Aufzeichnungen über den Gang einer Sternschnuppe am Himmel zur Verfügung zu haben, zu welchem Zweck nach $\mathrm{He}$ is und Lehmann-Filhès parallatisch montirte Maschinchen, die sogenannten Meteoroskope, dienen, mittelst deren Rektascension, Deklination und Positionswinkel für irgend einen Punkt der Meteorbahn unmittelbar zu erhalten sind [186]. Um den mathematischen Charakter der hier in Frage kommenden Aufgaben an einem allerdings sehr speziellen Falle zu erläutern, sei auf Fig. 3 verwiesen,

Fig. 3.

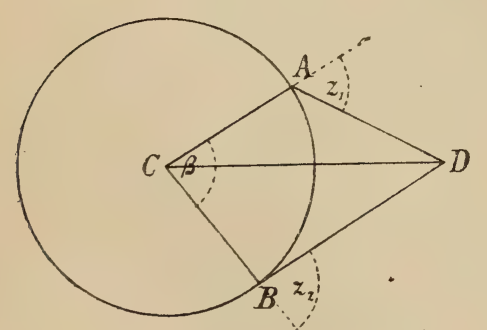

wo $A$ und $B$ auf der kugelförmigen Erde (Mittelpunkt C) zwei unter dem nämlichen Meridiane gelegene Orte von bekanntem Breitenunterschied $\beta(=\Varangle \mathrm{ACB})$ vorstellen sollen, während in $\mathrm{D}$ ein Meteor sich befinde, dessen augenblickliche Entfernung $\mathrm{D}$ C vom Erdcentrum man zu kennen wünscht. Haben zur gleichen Zeit die in A und B stationirten Beobachter die Zenithdistanzen $z_{1}$ und $z_{2}$ gemessen, resp. andere. Winkelgrössen eruirt, aus welchen diese Bestimmungsstücke berechnet werden können, so

kennt man in dem Viereck $\mathrm{ACBD}$ die Seiten $\mathrm{AC}=\mathrm{BC}=\operatorname{dem}$ Erdhalbmesser, $\Varangle \mathrm{ACB}=\beta, \Varangle \mathrm{CAD}=180^{\circ}-\mathrm{z}_{1}, \Varangle \mathrm{CBD}$ $=180^{\circ}-z_{2}$, und aus diesen fünf Stücken ergiebt sich die gesuchte

Eisen, Nickel, Kobalt, Phosphor und Kupfer bestehend, gleichwohl nichts den Widmanstätten'schen Figuren Aehnliches erkennen liess [180]. 
Diagonale CD des Viereckes nach bekannten Vorschriften der ebenen Trigonometrie. Nachdem durch Anwendungen auch der feinsten Rechnungsweisen Heis*), Denis on Olmsted, Quetelet, A. Herschel, H. A. Newton und viele Andere ausreichende Daten über die Lage einer Reihe von Meteoritenbahnen im Raume zur Verfügung gestellt hatten, schrieb Schiaparelli sein klassisches Werk über diesen Gegenstand, durch welches viele der einschlägigen Fragen endgültig entschieden, viele wenigstens der Lösung näher geführt wurden. Wir geben von diesem Werke, resp. von der deutschen Bearbeitung desselben, welche wir G. v. Boguslawski verdanken [188], nachstehend eine gedrängte Analyse. Zuerst werden die verschiedenen Geschwindigkeiten und Erscheinungs- oder Verschwindungshöhen der Sternschnuppen erörtert, sodann zeigt der Verfasser, wie die Periodicität einzelner Meteoransammlungen **) - man spricht von Mete or schwärmen und unter Umständen sogar von Meteorschauern - sowie das an diesen wahrgenommene Herabkommen-von fixen Punkten des Himmelsgewölbes, den Radiationspunkten, mehr und mehr den kosmischen Ursprung dieser Körper zur Gewissheit machte. Die Bewegung der Erde bringt es mit sich, dass an dem Punkt des Himmels, auf welchen die augenblickliche Tangente der Erdbahn hin gerichtet ist, die Radiationspunkte sich zusammenzudrängen, an dem diametral entgegengesetzten dagegen auseinanderzurücken scheinen; ein Blick auf die wohl ohne weitere Erläuterung verständliche Fig. 4 verschafft die Ueberzeugung, dass die Dichte der Sternschnuppen am Apex eine weit grössere sein muss, als am Antiapex (ungefähr das sechsunddreissigfache). Es wird weiter gezeigt, unter welchen Verhältnissen die Anziehung der Erde das Herabfallen der Meteore bedingt; die Schnelligkeit, mit welcher sich dieselben der Erde nähern, ist, unter o die eigene Bahngeschwindigkeit der Erde verstanden, zwischen den Grenzen

$$
(\sqrt{ } 2+1) v=2,414 v \text { und }(\sqrt{ } 2-1) v=0,414 v
$$

eingeschlossen. Im siebenten Kapitel diskutirt Schiaparelli die von den Planeten auf die Meteorzüge ausgeübten Störungen, durch welche die Bahnen in der sonderbarsten Weise umgestaltet werden können,

*) Ein wahres Musterbeispiel für die Art und Weise, wie ein Meteoritenforscher vorkommenden Falles eine Detailuntersuchung anzustellen habe, ist Heis' Bahnbestimmung der grossen Feuerkugel rom 4. März 1863 . Von allen möglichen Orten her wusste er Nachrichten über dieses Phänomen einzuziehen, und da diese auf den Osten Hollands als den Ort des Niederfalles hinzuweisen schienen, reiste er mit improvisirten Instrumenten selbst dorthin und ermöglichte es durch sein eigenthümliches Inquirirungssystem, nicht blos für die Elemente der von dem Meteor beschriebenen hyperbolischen Bahn die nöthigen Daten erlangen, sondern auch mit grosser Sicherheit eine Gegend von wenigen Quadratkilometern Inhalt ausmitteln zu können, innerhalb deren ersteres in den Boden eingedrungen sein musste [187].

**) Am wichtigsten und am meisten in die Augen fallend sind die Schwärme des August und des November (der letztgenannte führt in alten englischen Manuskripten den Namen der Thränen des heiligen Laurentius). In der Nacht vom 11. zum 12. November 1799 beobachtete A. v. Hamboldt einen Sternschnuppenregen in Cumana, bei welchem vier Stunden lang Sternschnuppen und Feuerkugeln mit breiten leuchtenden Streifen zu Tausenden fielen. Das Phänomen war nahezu gleich intensiv auf einem Gebiete von 921000 Quadratmeilen Flächeninhalt beobachtet worden [189].

Günther, Geophysik. I. Band. 
im achten und neunten aber stellt er jene Betrachtungen über die Stabilität kosmischer Wolken an, welche ihn zu seiner berühmten Theorie von den innigen verwandtschaftlichen Beziehungen zwischen Kometen und Sternschnuppenschwärmen geführt

Fig. 4.

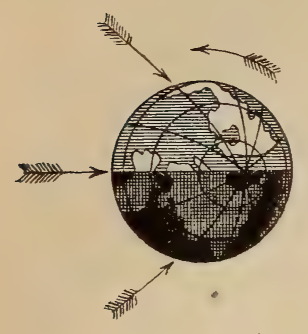

haben. Sobald ein Komet im Perihel sich der Sonne auf eine Distanz nähert, die noch unter der - theoretisch mit einer gewissen Annäherung zu bestimmenden-Stabilitätsgrenze bleibt, so wird durch die Anziehung der Sonne der Komet völlig zerstreut, wenn er vorher ein gleichförmiges Gefüge besass; falls aber seine Dichte

gegen das Centrum hin zunimmt, trennen sich zuerst die äusseren Theile los, und der Auflösungsprocess schreitet mit der Verminderung der Sonnendistanz immer mehr.nach innen zu fort. Kometen wären demgemäss als Konglomerate von Meteorkörpern, Meteorschwärme, denen eine selbstständige Kegelschnittbahn mit der Sonne im Brennpunkte zukommt, als aufgelöste Kometen zu betrachten. Nachstehendes Beispiel in der Randnote*) mag darthun, wie genau hie und da berechnete Bahnkurven von Kometen und Meteorschwärmen übereinstimmen. Uebrigens ist Schiaparelli als vorsichtiger Forscher weit davon entfernt, die absolute Identität von Kometen und Meteorringen behaupten zu wollen, wie er denn sogar auch die Identität von Sternschnuppen und Meteoren nicht für sicher gewährleistet erachtet. In Uebereinstimmung mit E. Weiss' trefflicher Recension des Schiaparelli'schen Werkes halten wir diese Rücksichten für allzu skrupulös und die positiven Gründe für durchschlagend [191]. Andere Fachmänner, wie Sec chi [192], betonen entschieden, dass der Unterschied zwischen Kometen und Sternschnuppenschwärmen ein rein äusserlicher sei. So geistreich

*) Newcomb stellt dem Auguststrom einen Kometen von längerer Umlaufszeit zur Seite [190]. Ein Blick auf das Vergleichsschema zeigt, dass die Differenz der beiderseitigen Elemente geringer ist, als der wahrscheinliche Fehler, mit welchem man angesichts der Rechnungs- und Beobachtungsschwierigkeiten jedes Element behaftet denken muss. Nur bei den Umlaufszeiten, für welche ein genauer Werth am schwersten zu finden ist, erscheint eine grössere Kluft.

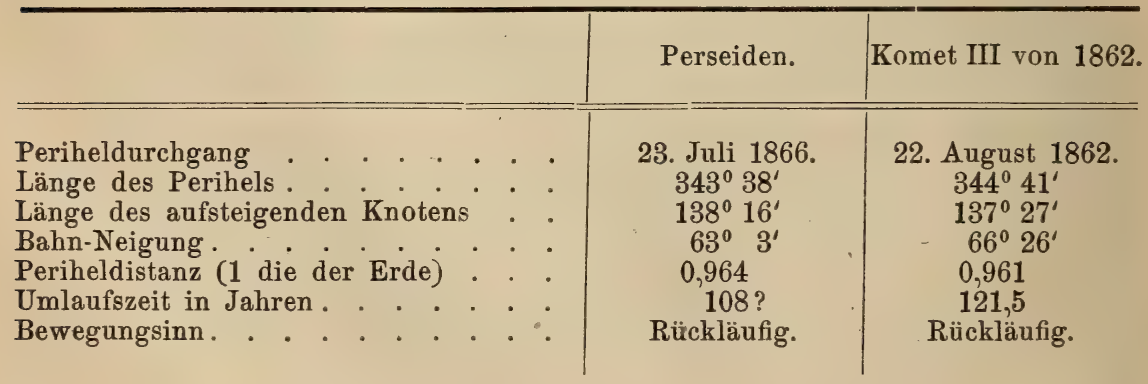


diese Identitätstheorie auch ist, und so sehr sie bei ihrem ersten Auftreten allseitig den Eindruck des Neuen, Ueberraschenden, ja Verblüffenden machte, so ist sie dennoch nicht gänzlich als „proles sine matre creata" zu bezeichnen. Piazzi hatte in seiner uns bereits bekannten Monographie [193] des Kometen von 1811 auf manche Analogieen zwischen beiden Gattungen von Weltkörpern aufmerksam gemacht, und nach Chladni [194] hatten auch schon Hevel, Wallis, Halley und Hartsoeker die kometenartige Natur der Feuermeteore bemerkt. - Wir fügen noch bei, dass eines der wenigen Argumente, die gegen Schiaparelli zu sprechen schienen, durch LehmannFilhè s [195] beseitigt worden ist. Die Vertheilung der parabolischen Meteorbahnen im Raume sollte nämlich nach den Annahmen des Mailänder Astronomen eine zufällige sein, und diess widersprach der $\mathrm{Er}$ fahrung; es widerspricht ihr aber nicht mehr, sobald man sich vergegenwärtigt, dass ja der Standpunkt des Beobachters kein mathematischer Punkt ist, sondern auf einem runden Körper von immerhin beträchtlichen Dimensionen sich befindet. Mit dieser Korrektion erscheinen die Radiationspunkte am Himmel gleichmässig vertheilt. Der Augustschwarm strahlt aus vom Sternbilde des Perseus, der Novemberschwarm vom Löwen, weshalb für beide Phänomene auch die Bezeichnungen Perseiden und Leoniden gebräuchlich geworden sind.

Wohl die grosse Mehrzahl der Astronomen und Physiker erblickt zur Zeit also in den Sternschnuppen- und Meteoritenschwärmen eine besondere Art von Himmelskörpern, die einen selbstständigen Charakter tragen und mit der Kant-Laplace'schen Kosmogonie sehr wohl sich vertragen [196]. Tschermak freilich, der auch einen Unterschied zwischen Meteoren und Sternschnuppen statuiren möchte, fasst den kosmischen Ursprung der ersteren anders auf. Wenn nämlich andere Weltkörper im Verlaufe der auf ihnen vor sich gehenden geologischen Umwälzungen heftige vulkanische Auswürfe erleben, so sollen diese Auswürflinge in den Weltraum hinausgeschleudert werden und zum Theile in die Attraktionssphäre der Erde gelangen, was immerhin denkbar und jedenfalls weit eher möglich ist, als dass im Sinne Meuni er's und Bell's die Eruptionsprodukte irdischer Vulkane sich solange im Universum herumtreiben sollten, bis sie gelegentlich wieder auf ihren Mutterplaneten niederfielen. Mit speziellem Bezug auf den Mond hatte ein alter italienischer Naturforscher, Namens Ter zago, den Tschermak'schen Gedanken über die Herkunft der Meteorsteine ausgesprochen [197]: "Labant philosophorum mentes sub horum lapidum ponderibus; ni dicere velimus, lunam terram alteram, sive mundum esse, ex cujus montibus divisa frusta in inferiorem nostrum hunc orbem delabantur." An die hiemit angeregte Frage sind später Olbers, $\mathrm{Brandes}, \mathrm{L}$ a place, $\mathrm{B}$ i o t und $\mathrm{P}$ o iss on herangetreten, und A. v. Humboldt hat uns über die Stellungnahme dieser Männer zu dem Probleme einen genauen Bericht erstattet [198]*). Ballistisch

*) A. v. Humboldt erwähnt auch des Einfalles griechischer Philosophen, von denen Diogenes Laertios berichtet, dass nämlich die Sonne die Heimath der Meteorite sei. Fusinieri nahm an [199], in den höchsten Schichten unserer Atmosphäre schwebten metallauflösende Gase, die an sich einen weiten Raum einnähmen, sich aber plötzlich und rasch verdichten könnten. 
betrachtet, scheitert die Möglichkeit eines Zusammenhanges der Meteoriten mit den Mondvulkanen an den furchtbaren Anfangsgeschwindigkeiten, welche die Lapilli erhalten haben müssten, und für welche uns der irdische Vulkanismus gar keine Vergleichspunkte bietet. Man kann jene Anfangsgeschwindigkeit leicht berechnen, wenn man erwägt, dass der emporgeschleuderte Stein mindestens bis zu einem neutralen Punkte getrieben werden müsste, der von Erde und Mond gleichstark angezogen wird. Wenn d die Distanz der Centra beider Himmelskörper, $\mathrm{x}$ die Entfernung des neutralen Punktes vom Mondmittelpunkt, $\mathbf{M}_{1}$ und $\mathrm{M}_{2}$ die Massen von Erde und Mond bedeuten, so ist x der Proportion

$$
\mathrm{x}:(\mathrm{d}-\mathrm{x})=\sqrt{\overline{\mathrm{M}}_{2}}: \sqrt{\mathrm{M}_{1}}
$$

zu entnehmen und hierauf nach den Gesetzen der gleichförmig verzögerten Bewegung aus der durchlaufenen Wegstrecke die von dem ursprünglichen Impuls herrührende Geschwindigkeit herzuleiten. Es kommt noch hinzu, dass, wie im nächsten Kapitel des Näheren erhellen wird, von einer energischen vulkanischen Thätigkeit auf dem Monde wenig mehr zu verspüren ist.

Pilar ist geneigt [200], den Meteoriten auch eine hohe Bedeutung in rein geophysikalischer Beziehung beizumessen. Dieselben entziehen, indem ihre Nickel- und Silikatverbindungen in der Luft oxydiren, letzterer den Sauerstoff und, wenn nachgerade die Oxyde in Hydrate übergehen, wird irdisches Wasser durch sie gebunden, so dass Luft und Wasser einen unausgesetzten. Verlust durch das Auftreffen der Meteorsteine erleiden. Auch reissen tangential bewegte Massen kleine Theilchen der Atmosphäre los und führen sie in den Weltraum fort. Qualitativ sind diese Defekte gewiss vorhanden, allein quantitativ sind sie als unmessbar klein zu bezeichnen, und die Wissenschaft sowohl der Gegenwart als auch einer ziemlich fernen Zukunft hat mit ihnen ebensowenig zu rechnen, wie mit der unleugbaren Thatsache, dass die Volumina und Massen sämmtlicher Planeten und der Sonne selbst unter dem Einflusse des Meteorhagels sich stetig vergrössern.

§. 14. Das Thierkreislicht. Arabische, persische und türkische Schriftsteller unterscheiden zwischen einer wahren und einer falschen Morgendämmerung, welch letztere auch als "Wolfsschwanz" bezeichnet wird, wegen der länglichen, schlanken Form, in welcher sie am Himmel erscheine, und die Ritualvorschriften der Muhammedaner, den Koran nicht ausgeschlossen, machen den Geistlichen, welche den Beginn des Tages von der Spitze des Minarets aus zu verkündigen haben, scharfe Trennung der ganz verschiedenen Phänomene zur Pflicht. Redhouse, dem wir für diese Nachweisungen [201] zu Danke verpflichtet sind, sucht in einer zweiten Abhandlung den Beweis dafür zu erbringen, dass diese falsche Dämmerung der Orientalen völlig dasselbe ist, was wir heute als Thierkreis- oder Zodiakallicht kennen, und verschiedene Astronomen (Airy, Piazzi Smith), deren Meinungsäusserungen er eingeholt hat, stimmen seiner Auffassung zu [202]. Die Thatsache scheint hienach festzustehen, dass eine Erscheinung, an welcher die abendländischen Fachleute lange Zeit achtlos vorübergiengen, den unter einem günstigeren Himmelsstriche wohnenden Laien längst bekannt war, und hiemit vereinigt sich auch ganz gut, was 
H u m b old t mittheilt [203]: „Mit nicht geringer Wahrscheinlichkeit kann man vermuthen, dass das merkwürdige, von der Erde pyramidal aufsteigende Licht, welches man auf der Hochebene von Mexiko 1509 vierzig Nächte lang am östlichen Himmel beobachtete, und dessen Erwähnung ich in einem altaztekischen Manuskripte der königl. Pariser Bibliothek, im Codex Telleriano-Ramensis aufgefunden habe, das Thierkreislicht war. ${ }^{*}$ Wenn man etwa die Berechtigung eines Zweifels an Redhouse's Angaben daraus herleiten wollte, dass Delambre mit gewohnter Eilfertigkeit die Entdeckung des Zodiakallichtes dem Reisenden Chardin zuschreibt [204], der den persischen Hofastronomen den ihnen noch ganz unbekannten Lichtschein („die kleine Lanze $^{\text {( ) }}$ zuerst gezeigt habe, so ist zu erwiedern, dass nach $\mathrm{Hum}$ boldt's genauerer Untersuchung in diesem Falle gar nicht vom Zodiakallicht, sondern von einem Kometenschweife die Rede war, dessen Kopf der Osthalbkugel verborgen blieb [205]. Von Männern der Wissenschaft hat Rothmann, der Hofastronom des Landgrafen WilheIm von Hessen-Kassel, das Zodiakallicht zuerst gesehen [206], im Druck erwähnt findet es sich erstmalig bei Childrey [207], aber seine Erforschung datirt erst von Dominic Cassini und dem Genfer Fatio de Duiller, welch' ersterer so überrascht von dem ihm plötzlich sich bemerklich machenden Dasein einer neuen Himmelserscheinung war, dass er kurzweg behauptete, bis vor wenigen Jahren könne es etwas Aehnliches noch gar nicht gegeben haben [208]. Cassini gab dem gelehrten Publikum in einem eigenen Schriftchen [209] Nachricht von dem, was er und Fatio am 18. März 1683 gesehen hatten, und der letztere stellte sodann auf seinem Gute Duiller durch $2^{1 / 2}$ Jahre sorgfältige Beobachtungen an, die er in einem offenen Briefe [210] an seinen Freund und Lehrer beschrieb, und aus denen er gewisse wichtige Erfahrungssätze zog, wie, dass der Lichtschein der Sonne nachfolge, dass er im Herbste vor Sonnenaufgang zu sehen sei u. s. w. [211]. Eingehend beschäftigte sich mit diesem neuen Objekt astronomischer Forschung der bekannte Akademiker $\mathrm{M}$ a iran, dessen grosses Werk [212], obwohl es von phantastischen Spekulationen nicht frei ist und zumal das Zodiakallicht in eine ganz unnatürliche Verbindung mit den Polarlichtern hineinzwängt, gleichwohl ein wichtiges Repertorium für die älteren Beobachtungen und Hypothesen bildet. Nachher verlor sich das Interesse an dem der exakten Forschung freilich sehr schwer zugänglichen Phänomen, und in Europa sind während des langen Zeitraumes von 1750-1800 blos gelegentliche Beobachtungen und Bemerkungen darüber von Messier und A. E. Schön [213] zu verzeichnen. Dagegen drängte sich dasselbe den wissenschaftlichen Reisenden auf, welche die Tropenländer besuchten, einem Lacaille, einem Pingré und vornehmlich dem Weltumsegler Horner, der die erste ganz zuverlässige Zeichnung davon lieferte [214]. Wie schon aus der obigen Entdeckungsgeschichte des Thierkreislichtes hervorgeht, eignen sich eben südliche Gegenden ganz ungleich besser dazu, den Lichtschein nach allen Seiten hin zu ergründen, und so hat man ganz natürlich darauf Bedacht genommen, die Reisenden mit den nöthigen Anweisungen zu versehen. Faye arbeitete in diesem Sinne eine Instruktion für die Offiziere der Armee aus [215], welche im Jahre 1862 unter Bazaine's Kommando nach Mexiko abgieng, Heis gab den 
sechs Jahre später zur Beobachtung des Venusdurchganges ausziehenden Gelehrten beherzigenswerthe Winke [216] mit, und E. Weiss widmete demselben Gegenstande nicht weniger als sieben Seiten seiner trefflichen „Anweisung zur Beobachtung allgemeiner Phänomene am Himmel mit freiem Auge oder mittelst solcher Instrumente, wie sie dem Reisenden zur Verfügung stehen $\left.{ }^{*}[217]^{*}\right)$. Neuerdings haben hervorragende Astronomen, wie Julius Schmidt, Neumayer, Brorsen u. a., dem zielbewussten Studium des Zodiakallichtes ihre Kräfte geweiht, Heis legte die aus langjährigen Beobachtungen auf der Sternwarte zu Münster gewonnenen Ergebnisse vor [219], Houzeau berichtete über seine unter einem südlichen Himmel erhaltenen Eindrücke [220], Jones machte uns mit den Erfahrungen seiner Seereisen bekannt [221], und später kam noch die ausgedehnte Beobachtungsserie des Amerikaners Lewis in Germantown hinzu, über welche Holetschek referirte [222]. Vieles ist also schon geleistet worden, doch bleibt auch Vieles noch aufzuklären, und namentlich den wissenschaftlichen Expeditionen öffnet sich hier noch ein weites Feld segensreicher Thätigkeit; wir werden übrigens sofort Gelegenheit erhalten, uns zu überzeugen, dass unsere Entdeckungsreisenden zum Theil dieser ihrer Pflicht eingedenk geblieben sind. Das Thatsächliche, was wir von der Erscheinung wissen, besteht nun in Kürze in Folgendem.

Im Frühling (von Januar bis April) ist das Licht auch in unseren höheren Breiten, 1-2 Stunden nach Sonnenuntergang, deutlich zu erkennen. Die Längsaxe des der Milchstrasse ähnelnden und von dem Dämmerungsgürtel nicht immer mit genügender Schärfe sich abhebenden Schimmers**) fällt annähernd in die Ekliptik, daher der eigenthümliche Name. Je steiler die Ekliptik über den Horizont emporsteigt, um so günstiger sind die Verhältnisse für die Beobachtung gelagert. Indess ist die Neigung des Lichtscheines eine sehr veränderliche, wie wir erst kürzlich wieder durch v. Mechow erfuhren, denn während dieser Afrikareisende in Malange den Lichtkegel immer so aufsteigend gesehen hatte, dass am Nordfusse ein spitzer, am Südfusse ein stumpfer Winkel sich bildete, stand bei einer anderen Beobachtung unter $8^{\circ} 52^{\prime}$ lat. austr. das Licht plötzlich als ein fast überall gleich breiter Streifen auf dem Horizont, mit diesem rechte Winkel einschliessend [224]. Ferner verschiebt sich das Zodiakallicht stets dem Auf- und Untergangspunkt der Sonne folgend am Horizonte, und zwar so regelmässig, dass Rohlfs, der in der Wüste das Phänomen allnächtlich ohne jede Voreingenommenheit theoretischer Natur betrachtete, sich des Eindrucks nicht erwehren konnte, dasselbe leuchte

*) Das oben gelegentlich der Sternschnuppenbeobachtungen erwähnte Meteoroskop hatte nach den ursprünglichen Intentionen seines Erfinders Ne umayer wesentlich auch den Zweck, mechanisch die Grenzlinien des Zodiakallichtes zu umreissen. Sobald der Zeichenstift angesetzt war, begannen sofort die Deklinations- und die Rektascensionswalze des Instrumentes sich zu drehen [218].

***) La m bert, dem wir die ersten einlässlichen Studien über Art und Dauer der Dämmerung verdanken, berührt die hierin liegende Schwierigkeit mit folgenden Worten [223]: "Paullatim crepusculum miscetur lumini zodiacali, unde hane ob causam et ob frigus intensum observatio est abrupta." Wie in diesem Einzelfalle mag es wohl auch in anderen Fällen ergehen, und die orientalische Kennzeichnung des Thierkreislichtes als einer falschen Dämmerung findet in solchen Vorkommnissen ihre Rechtfertigung. 
der Sonne gewissermassen vor und nach [225]. Bei genauerem $\mathrm{Zu}-$ sehen hat man drei Sondererscheinungen als maassgebend hervorzuheben gelernt: den Zodiakalkegel, den Zodiakalstreifen und den Gegenschein, auf welch' letzteren zuerst von Brorsen aufmerksam gemacht wurde. Nur der erstgenannte Bestandtheil ist erheblichen Gestaltveränderungen unterworfen. Schwer pflegt der Zodiakalstreifen gehörig unterschieden zu werden, eine Lichtzone, welche etwas breiter als die Milchstrasse ist und längs der Ekliptik von Horizont zu Horizont zieht. Der Gegenschein ist ein Lichtfleck am Himmel, der von der Sonne ziemlich um $180^{\circ}$ abliegt und somit, um mit jener in Opposition zu bleiben, an dem Horizonte hinwandert. Sehr selten zeigt sich darin ein hellerer Kern, der dann etwa $2^{\circ}$ nördlich von der scheinbaren Sonnenbahn zu liegen kommt. Mit dem Gegenschein darf man ja nicht den auf eine Reflexwirkung zurückzuführenden Wiederschein verwechseln [226]. Nach Heis [227] und Serpieri [228] kommt das Zodiakallicht auch in eigenthümlichen halbkreisartigen, brücken- und ringartigen Erscheinungen vor, doch sind dieselben bisher nur selten beobachtet worden.

All' das, was wir bisher von den Eigenschaften des merkwürdigen Himmelslichtes mittheilten, beruhte auf blossen Beobachtungen, und ein Gleiches gilt von den Theoremen Jones', dass z. B. der Lichtschein mit dem Beobachter von Nord nach Süd und umgekehrt wandere, dass auch das Zodiakallicht unter Umständen einer Art von Mondreflexion entspringen könne - Theoreme, die freilich noch gar sehr der Bestätigung bedürfen. Die physikalische Untersuchung hat erst vor nicht gar langer Zeit ihren Anfang genommen, aber doch bereits zu ganz erfreulichen Resultaten geführt. Während E. Weiss mit allem Rechte noch vor neun Jahren schreiben durfte [229], dass die polariskopische Prüfung des Lichtes durch Liais keine Spur von Polarisation*) ergeben habe, meldet Wright [230] umgekehrt, dass nur das übliche Savart'sche Polariskop für diese feinen Messungen zu schwach befunden worden sei. Deshalb wurde ein vervollkommneter Apparat konstruirt, und mit diesem und dem Spektroskop fand sich Folgendes: I. Das Zodiakallicht ist in einer durch die Sonne gehenden Ebene polarisirt; II. der Betrag der Polarisation ist ungefähr $15 \% 0$; III. das Spektrum ist, abgesehen von seiner geringeren Lichtstärke, von demjenigen der Sonne nicht verschieden; IV. das Licht stammt demnach von der Sonne und wird von einer starren Substanz zurückgeworfen. Ausser Wright hat auch Angström in seinen berühmten Untersuchungen über das solare Spektrum [231] gelegentlich von dem des Thierkreislichtes gesprochen und einige Aehnlichkeit desselben mit

*) Es sei daran erinnert, dass den herrschenden Lehren der Vibrationstheorie zufolge die Lichttheilchen ihre Schwingungen normal zum Lichtstrahl vollziehen, und zwar nach allen möglichen Richtungen hin, die sich in einer zum Strahle normalen Ebene denken lassen. Durch gewisse Zwangsmittel, wie z. B. beim Durchgang durch doppeltbrechende Krystalle, lässt sich diese Willkürlichkeit der Oscillationsrichtungen aufheben und bewirken, dass dieselben ausschliesslich in eine Ebene resp. in zwei zu einander normale Ebenen verlegt werden, und dieser erst durch gewisse Vorrichtungen erkennbare Zustand des Lichtes führt nach Biot den Namen der Polarisation, obwohl die Annahme, welche diesen Namen bedingte, längst wieder aufgegeben ist. 
dem fast monochromatischen Nordlichtspektrum dargethan; eine gewisse Linie ist für beide charakteristisch und liefert so einen besseren Beleg für die Analogie beider Erscheinungen, als ihn seiner Zeit Mairan mit Aufgebot aller Mühe zu erbringen vermögend gewesen war. „Ich fand sogar, “ sagt Angström [232], „Spuren dieser Linie während einer sternhellen Nacht, wo der Himmel gewissermassen phosphorescirte, in dem Spektrum des von allen Theilen des Firmamentes ausgesandten schwachen Lichtes."

Wiewohl Houzeau das Zodiakallicht jenen astronomischen Räthseln beizählt, welche noch ihres Oedipus warten [233], fehlt es trotzdem nicht an Erklärungsversuchen, ja deren Anzahl ist eine so grosse, dass die nachfolgende Besprechung sich jedenfalls nur auf einen Theil derselben erstreckt. Doch werden sich in unserer Aufzählung wenigstens die wichtigeren Theorieen befinden.

a) Regner. Wir wissen von dieser Hypothese nur durch Muncke's Referat [234]. Die der Sonne zugewandte Halbkugel der Erde soll das von jener kommende Licht anziehen und verdichten, so dass dasselbe während der Nacht sichtbar wird. Die perioptischen Experimente von Delisle und Marat sollen dieser Ansicht als Stütze dienen.

b) Mairan. Das Zodiakallicht ist nichts anderes als die linsenförmig abgeplattete Sonnenatmosphäre. Dem widerspricht die Mechanik, denn es folgt aus den Gesetzen der Centrifugalkraft, dass eine solche Atmosphäre nicht über Punkte hinausreichen kann, deren Abstand vom Sonnencentrum nur 0,436 des Merkurabstandes beträgt. Die Ausdehnung des Lichtes ist aber eine weit grössere [235].

c) Kant-Piazzi Smith. Der Erstere erklärt das Thierkreislicht ganz im Sinne seiner kosmogonischen Hypothese als einen die Sonne umschwebenden Nebelring , von feinem und dunstigem Wesen", als einen ${ }_{\text {Halsschmuck der Sonne }}$ [236]. Mit der Nebulartheorie bringt dasselbe gleichfalls in Verbindung der Schotte Piazzi Smith, der zur Erforschung solcher Himmelserscheinungen, welche sich unter den Tropen am besten beobachten lassen, eine eigene Station auf dem Pik von Teneriffa gegründet hatte. Man vergleiche Mädler's Detailbeschreibung dieser Expedition und im Besonderen der Untersuchungen über das Zodiakallicht [237].

d) Jones-Heis. Beide treffliche Beobachter (s. o.) entscheiden sich für einen Nebelring, in dessen Mittelpunkt die Erde steht. Theilweise deckt sich mit dem Resultate der mühevollen Forschungen dieser Männer dasjenige von

e) Houzeau. Allerdings ist die schimmernde Materie ein Begleiter der Erde, nicht aber ist ihre Anordnung eine ringförmige [238]. Vielmehr ist es eher ein in der Ebene der Erdbahn gelegener Federbusch oder Kreissektor, dessen Axe sich der Sonne zukehrt. Der obere Theil des Sektors umfasst an der Erdoberfläche eine schmale Zone (von etwa $40^{\circ}-50^{\circ}$ Breite), deren Begrenzungskreise annähernd parallel der Ekliptik verlaufen.

f) Cassini. Der erst später ausgebildeten Theorie des Entdeckers zufolge ist die Erscheinung zurückzuführen auf eine Unzahl kleiner planetarischer Körper, welche in Ringform die Sonne umgeben. Er brachte sogar den Fall von Feuerkugeln mit dem Durchgang der Erde durch den Zodiakalring in ursächliche Verbindung. 
g) Fatio de Duiller. Der Mitbeobachter Cassini's verkleinert noch dessen kleine Planeten und erblickt im Thierkreisscheine einen Gürtel atomartiger, das Licht stark reflektirender Aethertheile. Nur deutet er nicht, wie Kant, darauf hin, dass die Sonne und ihr Gürtel gleichen Ursprungs seien. Auch Laplace, Poisson und Th. Schubert hielten diese Ansicht für die plausibelste, und in engem Kontakt mit ihr befindet sich auch diejenige, an welche unter i) die Reihe kommt, geschildert zu werden.

h) Suchsland. Sonnenstrahlen werden an der Marsatmosphäre total reflektirt (?) und vereinigen sich nach der Reflexion in dem anderen Brennpunkt der Marsbahn [239].

i) L. Euler-Geelmuyden. Die Analogie des Zodiakallichtes mit den Kometenschweifen hatte bereits Leonhard Euler zum Gegenstande einer besonderen Abhandlung [240] gemacht. Für jene Zeit aber hatte es eben mit diesem geistreichen Analogieenspiel sein Bewenden, und die Anregung blieb ohne alle weiteren Folgen. Ganz anders heute, wo der Norweger Geelmuyden seine auf einem verwandten Gedanken basirende Theorie [241] an diejenige Schiaparelli's von dem Wechselverhältniss zwischen Kometen und Meteorschwärmen anzulehnen in der Lage war. Natürlich könnte nur an Kometen von sehr kurzer Umlaufszeit gedacht werden. Interessant ist Geelmuyden's theoretische Bestimmung der vom Lichtkegel des Zodiakallichtes uns zugesandten Lichtmenge; es gelingt, auf einfache elliptische Integrale die Lösung des Problemes zu reduciren, in dessen Behandlung übrigens bereits der Verf. dieses dem genannten Autor vorangegangen war [242]. -

Ein völlig befriedigender Entscheid über das Wesen des Zodiakallichtes liegt noch in weiter Ferne; ist es doch noch nicht einmal gelungen, sich völlig darüber zu vergewissern, ob dasselbe mehr der Sonne oder mehr der Erde als Anhängsel zuzurechnen sei. Sammlung von Beobachtungsmaterial bleibt die Hauptsache, und es wird die Sache aller Betheiligten, der Physiker und Astronomen, wie der geographischen Forschungsreisenden sein, dafür zu sorgen, dass auf sie nicht der Tadel des alten Mairan falle: „Je ne comprends pas par quel sort un objet, qui touche de si près l'astronomie moderne et la physique céleste, a été négligé jusqu'à ce point par les astronomes et les auteurs météorologiques. ${ }^{6}$

§. 15. Der Weltraum und seine Erfüllung. Ob man nicht ausser den in den bisherigen Paragraphen dieses Kapitels verzeichneten Körpern mit der Zeit noch andere in den Kreis der Betrachtung wird ziehen müssen, bleibe dahingestellt. Chladni [243] zählt hieher gewisse nebelförmige Gebilde, die sich auf der Sonne projicirt hätten, namentlich jenes, welches De Rostan am 9. August 1762 durch die Camera obscura abgezeichnet habe. Höchstens könne man damit die Wolke vergleichen, welche $458 \mathrm{n}$. Chr. unter der Regierung des byzantinischen Kaisers Leo Thrax erschienen sei, und den Stern, den des Gregor von Tours "Historia Franconum" vor dem Monde sich zeigen lässt. Es liegt auf der Hand, dass wir, wenn man überhaupt die Realität solcher Nachrichten gelten lässt, die bezüglichen Erscheinungen wohl ebensogut in das Reich der meteorologischen Optik, als in dasjenige der Kosmologie verweisen können. Vielleicht verhält es. 
sich ähnlich auch mit jenen ,trockenen Nebeln" von 1783 und 1823, welche Houzeau (s. o.) nebst dem Zodiakallichte zu den ,phénomènes énigmatiques" rechnet. A. v. Humboldt zählt 17 historisch leidlich beglaubigte Fälle auf, in denen eine unerklärliche Abnahme des Tageslichtes bemerkt worden ist [244]; sonderbarerweise fehlt es in der allem Wunderglauben abholden Neuzeit gänzlich an Beobachtungen dieser Art, für die nicht sofort im Höhenrauch oder ähnlichen terrestrischen Vorgängen die genügende Erklärung gegeben werden konnte. Der angeblich kosmische Staub, den Nordenskiöld in den Polarländern auffand - auch der von ihm auf grönländischem Binneneise mitgenommene Krykonit gehört hierher - wird uns später noch beschäftigen; die Behauptung des berühmten Polarforschers [245] ist vielleicht noch nicht fest genug begründet, doch würde nach den Aufkläruugen, welche wir über die Meteorite und deren theilweise Verflüchtigungen in der Luft gewonnen haben, das Niederfallen von Meteorstaub auf die Erde nicht unwahrscheinlich sein.

Ueber die Frage, ob die intrastellaren und intraplanetaren Räume mit irgend einem - selbstverständlich äusserst feinen und nach den überkommenen Begriffen imponderablen - Medium erfüllt seien, sind die Meinungen von jeher auseinandergegangen. Von dem geistvollen Schweizer Loys de Cheseaux hat man eine dieses Thema behandelnde Abhandlung „Sur la force de la lumière et sa propagation dans l'éther", welche als Bestandtheil seiner grösseren Kometenschrift [246] erschien. Er verbreitet sich daselbst über die Verbreitung der Fixsterne, deren Anzahl er als unbegrenzt gross betrachtet, und folgert weiter, dass, wenn der Weltraum absolut leer wäre, das ganze Firmament uns in gleichmässigem Strahlenglanze erscheinen müsste. Erfahrungsgemäss verhält es sich anders, und es bleibt daher nur übrig anzunehmen, dass eine Auslöschung des Lichtes bei dessen Durchgang durch den Weltäther statthaben müsse. Die Dichtigkeit desselben soll sich zu jener des Wassers wie 1:330000 Trillionen verhalten. Halley hatte vorher schon um die Prämisse von Loys' Hypothese dadurch herumzukommen gesucht [247], dass er die unendliche Vielzahl der selbstleuchtenden Weltkörper in Abrede zog, aber Olbers [248] und Struve [249] pflichteten der „Extinktionstheorie" bei. Neuerdings hat auch Huggins die Möglichkeit angedeutet [250], dass vielleicht die Einförmigkeit des Nebenspektrums in einem Verschwinden der Lichtstrahlen seinen Grund habe, und zwar wäre, wenn es damit seine Richtigkeit hätte, anzunehmen, „dass das Absorptionsvermögen des Weltraumes für Lichtstrahlen ein allgemeines und nicht blos ein elektives sei, d. h. dass alle Strahlengattungen gleichförmig absorbirt werden."

Von einem ganz anderen Standpunkte aus kam Encke auf die Annahme eines die Räume erfüllenden Mittels. Ihm ist bekanntlich der - von v. Lindenau als die schönste astronomische Entdeckung des XIX. Jahrhunderts bezeichnete - Nachweis zu danken, dass dem von Pons im Jahre 1811 entdeckten Kometen nur eine Umlaufszeit von drei Jahren zukomme. "Bald nachher, " schreibt Wolf [251], „fand Encke, dass die rein elliptische Umlaufszeit des Kometen zwischen jeder Erscheinung um drei Stunden kürzer wird, worauf Olbers schloss, es möchte sich da ein Widerstand des Mittels offenbaren, eine 
Ansicht, die Encke nun weiter ausführte, während Bessel fand, der Grund könnte ebensogut mit der Bildung und dem späteren Verluste des Schweifes zusammenhängen “*). v. Asten, der bezüglich der späteren Wiederkünfte des periodischen Kometen in Encke's Fusstapfen trat, hat gleichwohl die Nothwendigkeit der Annahme eines Widerstand leistenden Mittels viel weniger gefühlt, er will, wie er am Schlusse einer längeren Auseinandersetzung über diesen Punkt [252] betont, die Existenz eines solchen Stoffes zwar nicht gerade leugnen, aber dass derselbe, wenn vorhanden, sehr viel weniger dicht sei, als Encke angenommen hatte, das wagt er jetzt schon zu behaupten. Der neueste Bearbeiter der auf den Kometen influirenden Störungen, Backlund [253], sieht ebenfalls von der Berücksichtigung dieses Elementes gänzlich ab. Jedenfalls geben diese neueren theoretischen Arbeiten uns die Beruhigung, dass Jene, welche aus dem widerstehenden Mittel ein Hauptargument für den endlichen Zerfall unseres Sonnensystemes herleiten (Kap. I, §. 8), nur mit ungeheuer grossen Zeiträumen rechnen dürfen.

Ebenso prekär erscheint die Hülfe, welche der Annahme eines intrastellaren Aethers vielleicht von Seiten der theoretischen Physik erwachsen könnte. Es ist ja freilich wahr, dass nach den in dieser Wissenschaft mehr und mehr heimisch werdenden Anschauungen Licht, Wärme und Polarität auf Aetherschwingungen zurückgeführt werden, allein diesem Aether der Physiker gehen völlig jene Eigenschaften einer gewissen Kompaktheit und Widerstandskraft ab, die für Encke's Medium charakteristisch sind. Zudem ist als Träger und Leiter der Elektricität der Aether nicht mehr ein so nothwendiges Rüstzeug der Naturlehre, wie früher, denn Edlund hat die höchst merkwürdige Thatsache festgestellt, dass elektrische Wirkungen sich auch durch den leeren Raum fortpflanzen können [254]. Was uns persönlich am meisten für die Hypothese des Weltäthers stimmt, ist hingegen $\mathrm{Hug}$ gins' - von H. J. Klein [255] ausführlich besprochene - Entdeckung, dass die Wärme der Fixsterne noch durch Experimente auf der Erde nachgewiesen werden kann, denn dass auch die Wärmeschwingungen ohne ein permeables Mittel sich bis zu uns sollten fortpflanzen können, erscheint denn doch unmöglich.

Alles in Allem dürfte hienach die grössere Wahrscheinlichkeit für das Dasein einer äusserst fein differentiirten Materie im Weltraume sprechen, deren Resistenz höchstens Körpern, denen selbst ein Minimum von Dichte zukommt, wie den Kometen, fühlbar werden kann. Meibauer geht noch einen Schritt weiter und behauptet [256], dass eine Grenze für die Atmosphären der einzelnen Weltkörper nicht bestehen könne, dass vielmehr diese Atmosphären unmerklich in das übergehen, was man gewöhnlich als Aether bezeichnet, was aber in Wirklichkeit von einer mechanischen Mengung permanenter Gase im Zustande äusserster Verdünnung nicht verschieden sei.

Welche Temperatur besitzt nun dieser Weltraum? Zwei grosse französische Analytiker, Fourier [257] und Poisson [258], haben

*) Diese Meinungsverschiedenheit Encke's und Bessel's legte den Grund $\mathrm{zu}$ einer heftigen und nie wieder gänzlich behobenen Entzweiung der beiden grossen Astronomen. 
hierüber und über das Maass der Verschluckung, welcher die Sternwärme beim Durchwandern riesiger Entfernungen ausgesetzt ist, tiefe Untersuchungen angestellt, allein freilich ist der mathematische Werth dieser letzteren ein ungleich höherer, als ihr physikalischer. Die Ausführungen Poisson's werden uns noch im Kapitel von der Erdwärme (Abtheil. III, Kap. I) beschäftigen müssen. Dass eine gewisse Sternenwärme als Summe der von allen Fixsternen nach einem bestimmten Punkte des Weltraumes entsandten Wärmestrahlen allerorts vorhanden sein müsse, erschliesst Saigey [259] schon aus dem Umstande, dass sonst eine endlose Abkühlung unserer irdischen Atmosphäre eintreten würde. Aktinometrisch hat Pouillet [260], durch Betrachtungen über Strahlenbrechung hat der ältere Svanberg [261] die Temperaturziffer zı ergründen sich bemüht. Freilich stimmen die einzelnen Angaben so schlecht unter einander überein, dass zunächst nur die Unzulänglichkeit der bislang angewandten Methoden hervortritt. So findet Poisson - $13^{\circ}$, Svanberg - 50 $0^{\circ}$ was mit Fourier's oberflächlicher Schätzung $\left(50^{\circ}-60^{\circ}\right)$ einigermassen harmonirt, Saigey $-65^{\circ}$, Pouillet endlich $-142^{\circ}$. Verhältnissmässig das meiste Zutrauen muss man gewiss dieser letzteren Zahl schenken, denn erstens ist wohl soviel sicher, dass die Wärme im leeren oder fast leeren Raume keine höhere sein kann, als man sie häufig auf der Erde selbst antrifft, und zweitens dürfte die fragliche Temperatur auch nicht allzuweit von jener Grenze entfernt bleiben, welche die neuere Thermodynamik als absoluten Nullpunkt der Temperatur. bezeichnet. Diese Grenze hat aber Häussler auf $-162^{\circ}$, statt, wie früher, auf $-273^{\circ}$ festgesetzt [262].

[1] Secchi, Die Sonne, deutsch von Schellen, Braunschweig 1872. S. $47 \mathrm{ff}$. - [2] Ibid. S. 51. - [3] Newcomb, Populäre Astronomie, deutsch von Engelmann, Leipzig 1881. S. 268 ff. - [4] Ibid. S. 270. - [5] Secchi, Die Sonne. S. 106. - [6] Liais, Sur l'état physique de la surface du soleil, Mém. de la soc. de Cherbourg, 1867. S. 334. - [7] Galilei, Continuazione del nuntio sidereo di Galileo Galilei Linceo, overo saggio di storia dell' ultime sue osservazioni fatte in Saturno, Marte, Venere e Sole, Bologna 1641. - [8] R. Wolf, Geschichte der Astronomie, München 1877. S. 314. - [9] Scheiner, Rosa Ursina, Bracciani $1626-30$. - [10] Wolf, Geschichte etc. S. 388. - [11] Ibid. S. 655. [12] Ibid. S. 393 ff. - [13] Hausen, Theoria motus solis circa proprium axem, Lipsiae 1726. - [14] Wiedeburg, Neue Muthmassungen über Sonnenflecken, Cometen und die erste Geschichte der Erde, Gotha 1776. - [15] Wolf, Geschichte etc. S. 650 . - [16] Kästner, Anfangsgründe der angewandten Mathematik, II. Theil, 2. Abtheilung, Göttingen 1791. S. 119. - [17] Secchi, Die Sonne. S. 68. - [18] Ibid. S. 53. - [19] Ibid. S. 58 ff. - [20] Ibid. S. 65. [21] Ibid. S. 84 ff. - [22] Ibid. S. 95. - [23] Wilson, Observations of the solar spots', Phil. Transact., Vol. LXIV. S. 1 ff. - [24] Wolf, Geschichte etc. S. 650. - [25] Bode, Gedanken über die Natur der Sonne und die Entstehung ihrer Flecken, Beschäft. d. Berlinischen Gesellsch. naturf. Freunde, 2. Band. S. 237 ff. - [26] Clemens, Giordano Bruno und Nicolaus von Cusa, Bonn 1847. S. 101. - [27] Wolf, Geschichte etc. S. 651. - [28] W. Herschel, Observations tending to invest the nature of the sun, in order to find the causes or symptomes of its variable emission of light and heat, Phil. Transact., Vol. LXXXXI. S. $84 \mathrm{ff}$. - [29] A. v. Humboldt, Kosmos, Entwurf einer physischen Weltbeschreibung, 3. Band, Stuttgart und Augsburg 1850. S. 341 ff. - [30] J. Herschel, Outlines of astronomy, London 1875. S. 258. - [31] G. Kirchhoff, Untersuchungen über das Sonnenspektrum und die Spektren der chemischen Elemente, Abhandl. d. k. preuss. Akad. d. Wissensch., M. - ph. Kl. 1861. S. 83 ff. - [32] Zöllner, Ueber die Periodicität und heliographische Verbreitung der Sonnenflecke, Sitzungsber. 
d. k. sächs. Gesellsch. d. Wissensch., M.-ph. Kl. 1870. S. 338 ff. Ueber den Aggregatzustand der Sonnenflecke, ibid. 1873. S. 505 ff. - [33] Secchi, Die Sonne. S. 111. - [34] Reye, Die Wirbelstürme, Tornados und Wettersäulen in der Erdatmosphäre, mit Berücksichtigung der Stürme in der Sonnenatmosphäre, Hannover 1872. S. 177. - [35] Zöllner, Ueber den Aggregatzustand etc. S. 522. [36] Reye, Die Wirbelstürme etc. S. 179 ff. - [37] Faye, Cyclones solaires, Compt. rend. de l'acad. franç., tome LXXVIII. S. 929 ff. - [38] Reje, Réponse aux remarques de $\boldsymbol{M}$. Faye sur les trombes terrestres et solaires, ibid. tome LXXVIII. S. 59 ff. - [39] Newcomb, Pop. Astr. S. 309. - [40] Ibid. S. 312. - [41] Ibid. S. 314. - [42] Wolf. Geschichte etc. S. 394. - [43] $\nabla$. Lüdingshausen-Wolff, Neue Hypothese über Sonnenflecken, Humboldt, 1. Jahrg. S. 347 ff. - [44] Kysaeus, Ueber die Axendrehung der Sonne, Siegen 1846. - [45] Böhm, Beobachtungen von Sonnenflecken und Bestimmung der Rotationselemente der Sonne, Wien 1852. - [46] Spörer. Beobachtungen von Sonnenflecken und daraus abgeleitete Elemente der Rotation der Sonne, Anclam 1862. - [47] Newcomb, Pop. Astr. S. 282. - [48] Thilo, Dissertatio de maculis solis ab ipso summo viro Soemmeringio observatis, Francofurti 1828. S. 32. - [49] Zöllner, Ueber das Rotationsgesetz der Sonne und der grossen Planeten, Sitzungsber. d. k. sächs. Gesellsch. d. Wissensch., M.-ph. Kl. 1871. S. $90 \mathrm{ff}$. - [50] Carrington, Observations of the spots of the sun made at Redhill 1853-69, London 1863. - [51] Zöllner, Erwiederung auf die Bedenken des Herrn Reye gegen meine Erklärung der Sonnenflecke, Ann. d. Phys. u. Chem., 150. Band. S. 426 ff. - [52] Spörer, Resultate aus den Sonnenbeobachtungen, Tagebl. d. 54. Versamml. d. Naturf. u. Aerzte, Salzburg 1881. 2. Abtheil., S. 43. - [53] Wolf, Geschichte etc. S. 656. - [54] Wolf, Mémoire sur la période commune à la fréquence des taches solaires et à la variation de la déclinaison magnétique, Londres 1878. S. 6. - [55] Wolf, Geschichte etc. S. 654. [56] Wolf, Mémoire etc. S. 2. - [57] Wolf, Geschichte etc. S. 657 ff. [58] Gautier, Recherches relatives à l'influence que le nombre et la permanence des taches observées sur le disque de soleil peuvent exercer sur les températures terrestres, Ann. de chim, et de phys. (3) tome XII., S. 57 ff. - [59] Fritz, Die Beziehungen der Sonnenflecke zu den magnetischen und meteorologischen Erscheinungen der Erde, Haarlem 1878. - [60] Newcomb, Pop. Astr. S. 287. [61] Lockyer; Die Beobachtung der Sonne sonst und jetzt, deutsch von Siebert, Braunschweig 1880. S. 484. - [62] Secchi, Die Sonne. S. 354 ff. [63] Mädler, Geschichte der Himmelskunde von der ältesten bis auf die neueste Zeit, 2. Band, Braunschweig 1873. S. 242. - [64] Spörer. Ueber die Entstehung der Protuberanzen durch chemische Processe, Monatsber. d. k. pr. Akad. d. Wissensch., 1878. S. 755. - [65] Spörer, Beobachtungen von Protuberanzen der Sonne, ibid. 1871. S. 666 ff. - [66] Spörer, Ueber die Entstehung etc. S. 753 ff. - [67] Mädler, Populäre Astronomie, 7. Aufl, bearb. von Klinkerfues, Strassburg 1882. S. 729. - [68] Secchi, Étude des taches et des protubérances solaires de 1871 à 1875, Compt. rend. de l'acad. franc.., tome LXXX. S. 1273 ff. [69] J. Kant's Schriften zur physischen Geographie, herausgeg. von F. W. Schubert, Leipzig 1839. S. 173 ff. - [70] Bruhns, Alexander v. Humboldt: eine wissenschaftliche Biographie, 1. Band, Leipzig 1872. S. 45. - [71] Emsmann, Die Sonne brennt, Leipzig 1865. - [72] v. d. Gröben, Ein Versuch zur Erklärung der Periodicität der Sonnenflecke, Gaea, 18. Jahrg. S. 193 ff. - [73] Ibid. S. 198. - [74] R. Wolf, Astronomische Mittheilungen, LVI. S. 187. - [75] Duponchel, Les taches solaires régies par l'excentricité des mourements planétaires, Paris 1882. - [76] R. Wolf, Astr. Mitth. LVI. S. 182. - [77] Ibid. S. 185. [78] Cornelius, Ueber die Entstehung der Welt, Halle 1870. S.30. - [79] R. Wolf, Astr. Mitth. LVII. S. 231. - [80] R. Wolf, Astr. Mitth. LVIII. S. 278 ff. [81] A. Ritter, Untersuchungen über die Höhe der Atmosphäre und die Constitution gasförmiger Weltkörper, Ann. d. Phys. u. Chem., (2) 11. Band. S. 992 ff. - [82] Ibid. S. 995. - [83] Zöllner, Photometrische Untersuchungen mit besonderer Rücksicht auf die physikalische Beschaffenheit der Himmelskörper, Leipzig 1865. S. 245 ff. - [84] Newcomb, Pop. Astr. S. 310. - [85] Ibid. S. 305. - [86] Spörer, Resultate etc. S. 42. - [87] Soret, On the temperature of the sun, Philos. Mag. Vol. L. S. 155 ff. - [88] A. v. Humboldt, Kosmos, 3. Band. S. 442 ff. - [89] Ibid. S. 444. - [907 Hegel, Dissertatio philosophica de orbitis planetarum, Jenae 1800. - [91] K. Bonnet, Betrachtung über die Natur, deutsch von Titius, Leipzig 1772. S. 7. - [92] Haase, Einige Zusammenstellungen als Beitrag zu der Frage, ob ausser Merkur uud Venus in dem Raume zwischen Sonne und Erde noch andere planetenartige Körper vorhanden sind, Hannover 1864. - 
[93] Kepler, Prodromus dissertationum cosmographicarum, continens mysterium cosmographicum de admirabili proportione orbium coelestium, Tubingae 1596. S. 7. - [94] Holetschek, Eine Preisfrage über den Asteroidengürtel, Deutsche Rundschau f. Geogr. u. Stat., 5. Jahrg. S. 427 ff. - [95] Newcomb, Pop. Astr. S. 361. - [96] D'Arrest, Ueber das System der kleinen Planeten zwischen Mars und Jupiter, Leipzig 1851. - [97] Newcomb, Pop. Astr. S. 383. - [98] Ibid. S. 387. - [99] Ibid. S. 393. - [100] H. Vogel, Untersuchungen über die Spektra der Planeten, Leipzig 1874. - [101] Peschel-Leipoldt, Physische Erdkunde, 1. Band. S. 96. - [102] Newcomb, Pop. Astr. S. 362. - [103] R. Wolf, Astr. Mitth. LVIII. S. 285 ff. - [104] Ibid. S. 300. - [105] R. Wolf, Gesch. d. Astr. S. $9 \mathrm{ff}$ - $-[106]$ Williams, Observations of comets from B. C. 611 to. A. D. 1640, extracts from the Chinese annals, London 1871. - [107] C. Plinii Secundi historiae naturalis libri XXXVII, lib. VI. cap. 22. - [108] L. Aenaei Senecaennaturalium quaestionum libri VII, cap. 22, 25, 26. - [109] Joannis de Monte regio de cometae magnitudine longitudineque ac de loco ejus vero problemata XVI, ed. Schöner, Norimbergae 1531. - [110] Günther, Peter und Philipp Apian, zwei deutsche Mathematiker und Kartographen, Prag 1882. S. 60. - [111] R. Wolf, Gesch. d. Astr. S. 409. - [112] Ibid. S. 411. - [113] P. Petit, Dissertation sur la nature des comètes, Paris 1665. - [114] J. H. Westphal, Leben, Studien und Schriften des Astronomen Johann Hevelius, Königsberg 1820. S. 85. [115] C. Reinhardt, Magister Georg Samuel Dörffel, ein Beitrag zur Geschichte der Astronomie im XVII. Jahrhundert, Plauen 1882. S. 44. - [116] Sir Isaak Newton's mathematische Principien der Naturlehre, deutsch von Wolfers, Berlin 1872. S. $467 \mathrm{ff}$. - [117] Olbers, Abhandlung über die leichteste und bequemste Methode, die Bahn eines Kometen aus einigen Beobachtungen zu berechnen, Weimar 1797, 2. Aufl. (bes. v. Encke) ibid. 1847. - [118] R. Wolf, Gesch. d. Astr. S. 703. - [119] Mädler-Klinkerfues, S. 327 ff. - [120] A. v. Humboldt, Kosmos, 3. Band. S. 566 ff. - [121] H. Vogel, Beobachtungen des Septemberkometen 1882, Astr. Nachr. N. 2466. - [122] W. Meyer, Wahrscheinliche Lichtbrechung im Kopfe des Kometen III 1881, Sirius, (2) 6. Band. S. 18. [123] Mädler - Klinkerfues, S. 748. - [124] J. Kant's Schriften etc. S. 452. [125] Mädler, Geschichte der Himmelskunde, 2. Band, Braunschweig 1873. S. 172. - [126] Günther, Peter und Philipp Apian, S. 61 ff. - [127] Ibid. S. 119. - [128] Kepler, De cometis libri tres, Augustae Vindelicorum 1619. [129] Zöllner, Ueber die Natur der Cometen: Beiträge zur Geschichte und Theorie der Erkenntniss, 3. Aufl., Leipzig 1883. S. 31 ff. - [130] Geschichte der Astronomie, von den ältesten bis auf gegenwärtige Zeiten, 1. Band, Chemnitz 1792. S. 373. - [131] Westphal, Lehen etc. S. 82 ff. - [132] R. Wolf, Biographieen zur Kulturgeschichte der Schweiz, 1. Cyk'us, Zürich 1858. S. 138 ff. - [133] Jac. Bernoulli, Conamen novi systematis cometarum pro motu eorum sub calculum revocando et apparitionibus praedicendis, Amstelodami 1682. - [134] NewtonWolfers, S. 487. - [135] Ibid. S. 494. - [136] Flaugergues, Examen critique de différentes hypothèses imaginées pour expliquer l'apparence connue sous le nom de queue ou chevelure des comètes, Journ. de phys., tome LXXXV. S. $173 \mathrm{ff}$. tome LXXXV. S. $193 \mathrm{ff}$. tome LXXXVI. S. $101 \mathrm{ff}$. tome LXXXVII. S. $81 \mathrm{ff} .-$ [137] Piazzi, Della cometa dell' anno 1811, Palermo 1812. - [138] W. Herschel, Observations of a comet, with remarks on the constitution of its differents parts. Phil. Transact., Vol. CII. S. 115 ff. - [139] Laplace, Exposition du système du monde, Paris 1796. S. 127 ff. - [140] J. W. H. Lehmann, Disquisitiones nonnullae mechanicae de origine caudarum cometarum. Gottingae 1822. - [141] De Laune, Traité et définition des comètes, Rouen 1813. - [142] Tyndall, Ueber die Wärme als eine Art der Bewegung, deutsch von Helmholtz und Wiedemann, Braunschweig 1871. S. 684 ff. - [143] Zöllner, Ueber die Natur etc. S. 1 ff. - [144] Peschel-Leipoldt, Phys. Erdkunde. S. 429. [145] Schwedoff, Idées nouvelles sur l'origine des formes cométaires, Odessa 1877. - [146] v. Dellingshausen, Prof. Th. Schwedoff's neue Theorie über den Ursprung der Kometenformen, Kosmos, 3. Band. S. 297 ff. - [147] Schwedoff, Théorie mathématique des formes cométaires, Odessa 1879. - [148] v. Dellingshausen, Das Räthsel der Gravitation, Heidelberg 1880. S. 167. - [149]. Ibid. S. 170. - [150] Zenker, Ueber die physikalischen Verhältnisse und die Entwickelung der Kometen, Berlin 1872. S. 17. - [151] Ibid. S. 21. - [152] Ibid. S. 31. - [153] v. Miller-Hauenfels, Die Gesetze der Kometen abgeleitet aus dem Gravitationsgesetze, Graz 1875. S. 7. - [154] Ibid. S. 50. - [155] Ibid. S. 72 ff. - $[156]$ Heinsius, Beschreibung des im Jahre 1744 erschienenen Co- 
meten, St. Petersburg 1744. - [157] J. Müller, Lehrbuch der kosmischen Physik, Braunschweig 1875. S. 228 ff. - [158] Zöllner, Ueber die Natur etc. S. XCII ff. - [159] Olbers, Ueber den Schweif des grossen Kometen von 1811, Bode's astr. Jahrb. f. 1826. - [160] Bessel, Beobachtungen über die physische Beschaffenheit des Halley'schen Kometen und dadurch veranlasste Bemerkungen, ibid. 1836. - [161] Zenker, Ueber etc. S. 15. S. 76. - [162] Zöllner, Ueber die physische Beschaffenheit der Cometen, Sirius, 9. Band. S. 227 ff. S. 265 ff. [163] Hornstein, Ueber den Einfluss der Elektricität der Sonne auf den Barometerstand, Wien 1872. - [164] Zöllner, Das Skalenphotometer, ein neues Instrument zur mechanischen Messung des Lichtes, Leipzig 1879. S. 69. - - [165] Bredichin, Sur la constitution probable des queues des comètes, Moscou 1879. [166] Bredichin, Sur la queue du I. type de la comète 1882 II, Astron. Nachr. Nr. 2532. - [167] v. Dalberg, Ueber den Meteoritenkultus der Alten, vorzüglich in Bezug auf Steine, die vom Himmel gefallen sind, Heidelberg 1811. [168] Peschel-Leipoldt, Phys. Erk. S. 107. - [169] A. v. Humboldt, Kosmos, 3. Band. S. 621. - [170] Ibid. S. 623. - [171] H. J. Klein, Handbuch der allgemeinen Weltbeschreibung, vom Standpunkt der kosmischen Weltanschauung, 1. Band, Braunschweig 1869. S. 263 ff. - [172] Chladni, Ueber den Ursprung der von Pallas gefundenen und anderer ähnlicher Eisenmassen, Leipzig 1794. [173] A. v. Humboldt, Kosmos, 3. Band. S. 611. - [174] G. Rose, Beschreibung und Eintheilung der Meteorite, Abh. d. k. pr. Akad. der Wissensch., M.-ph. Kl. 1863. S. 23 ff. - [175] H. J. Klein, Handbuch etc. 1 Band. S. 288 ff. [176] Wright, Examen des gaz extraits de la météorite du 12. Février 1875, Mondes (2) XXXVIII. S. 530. - [177] Gümbel, Ueber die in Bayern gefundenen Steinmeteoriten, Sitzungsber. d. k. bayr. Akad. d. Wissensch., M.-ph. Kl., 1881. S. 14 ff. - [178] L. Smith, Ueber den Magnetismus des aus Meteoreisen dargestellten Oxydes, Naturforscher, 1875. S. 135. - [179] Flammarion, Astronomie populaire, Paris 1880. S. 659. - [180] L. Smith, Meteoreisen von Havard, Ausland 1874. S. 60. - [181] v. Schreibers, Beiträge zur Geschichte und Kenntniss der meteorischen Stein- und Metallmassen, Wien 1820. S. 70. - [182] Brezina, Meteoritenstudien, 2. Abtheilung. Wien 1882. - [183] H. J. Klein, Handbuch etc., 1. Band. S. 287. - [184] C. Reinhardt, Magister etc. S. 58 ff. [185] Brandes-Benzenberg, Versuche, die Entfernung, die Geschwindigkeit und die Bahnen der Sternschnuppen zu bestimmen, Hamburg 1800. - [186] Lehmann-Filhès, Ueber die Bestimmung des Radiationspunktes eines Sternschnuppenschwarmes mit Hülfe eines neuen Meteoroskopes, Astr. Nachr. N. 2296. - [187] Heis, Die grosse Feuerkugel, welche am Abende des 4. März 1863 in Holland, Deutschland, Belgien, England gesehen worden ist, Wochenschr. f. Astron. Meteorol. u. Geogr., (2) 6. Jahrgang. S. 137 ff. S. 145 ff. S. 156 ff. S. 172 ff. S. 180 ff. S. 185 ff. S. 193 ff. S. 204 ff. S. 236 ff. S. 240 ff. - [188] Schiaparelli, Entwurf einer astronomischen Theorie der Sternschnuppen, deutsch von G. v. Boguslawski, Stettin 1871. - [189] Bruhns, A. v. Humboldt, 3. Band. S. 14 ff. - [190] Newcomb, Popul. Astron. S. 435. - [191] E. Weiss, Recension zu Schiaparelli, Vierteljahrsschr. d. astr. Gesellsch., 7. Jahrgang. S. 294 ff. - [192] Secchi, Die Sonne. S. 754. - [193] Vgl. [137]. - [194] Chladni, Ueber Dinge, die sich im Weltraume befinden, und von den bekannten Weltkörpern verschieden sind, und über noch einige kosmologische Merkwürdigkeiten, Zeitschr. f. Astr. u. verw. Wissensch., 4. Band. S. 353 ff. - [195] Lehmann-Filhès, Ueber die Vertheilung der Radiationspunkte an der Himmelskugel, Astr. Nachr. N. $2327 \mathrm{ff}$. [196] E. Weiss, Recension etc. S. 296. - [197] Terzago, Musaeum Septalianum, Tortonae 1664. S. 44. - [198] A. v. Humboldt, Kosmos, 1. Band. S. 400 ff. - [199] Ibid. S. 403. - [200] Pilar, Grundzüge der Abyssodynamik, Agram 1881. S. 20. - [201] Redhouse, On the natural phaenomenon, known in the east by the names Sub-hi-Kazib, Journal of the royal asiatic society, (2) Vol. X. S. $344 \mathrm{ff}$. - [202] Redhouse, Identification of the false down of the Muslims with the Zodiacal light of the Europeens, ibid. (2) Vol. XII. S. 327 ff. - [203] A. v. Humboldt, Kosmos, 1. Band, S. 145. - [204] Delambre, Histoire de l'astronomie moderne, tome II., Paris 1821. S. 742. - [205] Humboldt, Kosmos, 1. Band. S. 409 ff. - [206] R. Wolf, Gesch. d. Astron. S. 693. - [207] Childrey, Britannia Baconica, Londini 1661. S. 183. - [208] J. C. Fischer, Geschichte der Naturlehre, 2. Band, Göttingen 1802. S. 527. - [209] D. Cassini, Découverte de la lumière céleste qui paroist dans le zodiaque, Paris 1685. - [210] Fatio de Duiller, Lettre à M. Cassini sur une lumière extraordinaire qui paroît dans le ciel depuis quelques années, Amsterdam 1686. - [211] R. Wolf, Biogr. etc., 
4. Cyklus, Zürich 1862. S. 69 ff. - [212] Mairan, Traité physique et historique de l'aurore boréale, Paris 1733. - [213] A. E. Schön, Bemerkungen über das Zodiakallicht, über Uranus, über Algol und über einige veränderliche Sterne im Schützen, Bode's astron. Jahrb. f. 1789. - [214] Gehler's physik. Wörterbuch, 2. Auflage, 10. Band, 3. Abtheilung, Leipzig 1844. S. 2420. S. 2444 ff. - [215] Das Zodiakallicht, Wochenschr. f. Astron., Meteorol. u. Geogr., (2) 6. Jahrgang. S. 105 ff. - [216] Heis, Beobachtungen, deren Anstellung den Mitgliedern der Expedition zur Beobachtung des Durchganges der Venus anempfohlen wird, Gaea, 10. Jahrgang. S. 487 ff. - [217] Neumayer, Anleitung zu wissenschaftlichen Beobachtungen auf Reisen, Berlin 1875. S. 50 ff. - [218] Neumayer, Correspondenznachrichten aus Australien, Wochenschr. f. Astron., Meteorol. u. Geogr., (2) 6. Jahrgang. S. 247. - [219] Heis, Zodiakallichtbeobachtungen aus den letzten 29 Jahren. 1847-1875, Münster 1875. - [220] Houzeau, Résumé de quelques observations astronomiques et météorologiques faites dans la zone surtempérée et entre les tropiques, Bruxelles 1875. - [221] Jones, United States Japan Expedition; Observation of the Zodiacallight, Washington 1856. - [222] Holetschek, Das Zodiakallicht, Deutsche Rundschau f. Geogr. u. Stat., 5. Jahrgang. S. 226. ff. [223] Lambert, Photometria sive de mensura et gradibus lucis, colorum et umbrae, Augustae Vindelicorum 1760. S. 449. - [224] v. Mechow, Bericht über die von ihm geführte Expedition zur Aufklärung des Kuango-Stromes, Verhandl. d. Gesellsch. f. Erdk. zu Berlin, 9. Band. S. 479. - [225] Rohlfs, Die Oase Djofra, Zeitschr. d. Gesellsch. f. Erdk. zu Berlin, 15. Band. S. 143. - [226] Heis, Beobachtungen etc. S. 489. - [227] Ibid. S. 490. - [228] Apparenze straordinarie della luce zodiacale la sera del 12 dicembre 1873, Lettere del Prof. Alessandro Serpieri al Prof. G. V. Schiaparelli, Milano 1874. - [229] Neumayer, Anleitung ete. S. 52. - [230] Wright, On the nature of the Zodiacal light and the distribution of matter, which occasions it, Nature X. S. 443 ff. - [231] Angström, Recherches sur le spectre solaire, Upsala 1868. - [232] Roscoe, Die Spektralanalyse in einer Reihe von sechs Vorlesungen, deutsch von v. Schorlemmer, Braunschweig 1870. S. 180. - [233] Houzeau, Sur certains phénomènes énigmatiques de l'astronomie, Bull. de la soc. royale belgique, (2) tome XLVI. S. 951 ff. - [234] Gehler's phys. Wörterb., 2. Auflage, 10. Band, 3. Abtheilung. S. 2428. - [235] H. J. Klein, Handbuch etc., 1. Band. S. 53. - [236] I. Kant's Schriften etc. S. 148 ff. - [237] Mädler, Gesch. d. Himmelsk., 2. Band. S. 289 ff. - [238] Houzeau, Résumé etc. S. 280 ff. - [239] Suchsland, Das Zodiakallicht eine Folge des Baues unseres Planetensystemes, Stolp 1882. - [240] L. Euler, Recherches physiques sur la cause de la queue des comètes, de la lumière boréale et de la lumière zodiacale, Mém. de l'acad. royale de Berlin, Année 1746. S. 117 ff. - [241] Geelmuyden, Om Zodiakallyset, Arch. f. Math. og Naturvidensk., III. S. $250 \mathrm{ff}$. - [242] Günther, Studien zur theoretischen Photometrie, Erlangen 1872. S. 32 ff. - [243] Vgl. [194]. - [244] A. v. Humboldt, Kosmos, 3. Band. S. 412 ff. - [245] Nordenskiöld, Ueber kosmischen Staub, der mit atmosphärischen Niederschlägen auf die Erde herabfällt, Ann. d. Phys. u. Chem., 151. Band. S. $154 \mathrm{ff}$ - - [246] Loys de Cheseaux, Traité de la comète qui a paru en décembre 1743 et en janvier 1744, et diverses observations astronomiques, Lausanne 1744. - [247] Halley, On the infinity of the sphere of fixed stars, Phil. Trans. Vol. XXI. S. 22 ff. - [248] Olbers, Ueber die Durchsichtigkeit des Weltraumes, Bode's astr. Jahrb. f. 1826. - [249] Struve, Études d'astronomie stellaire, St. Pétersbourg 1847. S. 93 ff. - [250] Roscoe- v. Schorlemmer, S. 246. - [251] R. Wolf, Gesch. d. Astron. S. 715. - [252] v. Asten, Ueber die Existenz eines widerstehenden Mittels im Weltraum, Gaea, 11. Jahrgang. S. 41 ff. - [253] Backlund, zur Theorie des Encke'schen Kometen, St. Petersburg 1881. - [254] Emsmann, Der leere Raum, ein Leiter der Elektricität, Gaea, 19. Jahrgang. S. 159 ff. - [255] H. J. Klein, Handbuch etc., 2. Band. S. 11. - [256] Meibauer, Die physische Beschaffenheit des Sonnensystemes, Berlin 1872. S. $58 \mathrm{ff}$ - - [257] Fourier, Théorie analytique de la chaleur, Paris 1822. S. X ff. - [258] Poisson, Théorie mathématique de la chaleur, Paris 1835. S. 436 ff. S. 521 ff. - [259] Saigey, Petite physique du globe, Paris 1842. S. 77. [260] Pouillet, Mémoire sur la chaleur solaire, sur les pouvoirs rayonnants et absorbants de l'atmosphère et sur la température de l'espace, Compt. rend. de l'acad. franç., tome VII. S. 25 ff. - [261] Svanberg, Disquisitiones analyticae in theoriam refractionum astronomicarum, Upsalae 1827. - [262] Häussler, Beiträge zur mechanischen Wärmetheorie, Leipzig 1882. 
Kapitel III.

\section{Die der Erde ähnlichen Planeten und der Mond.}

§. 1. Die astronomischen Nachbarn der Erde. Als solche kann man gewiss mit Recht die Planeten Venus und Mars bezeichnen, zwischen welchen die Erde ihren Umlauf um die Sonne vollzieht, sowie den unzertrennlichen Begleiter der Erde, den Mond. Die Sternkunde als solche hat keinerlei Veranlassung, gerade diese Nachbarkörper für sich und aus dem allgemeinen Zusammenhange losgelöst zu betrachten, allein um so mehr Grund, diess zu thun, ist für denjenigen vorhanden, der sich auf dem Grenzgebiete zwischen astronomischer und physikalischer Geographie bewegt. Sowohl die Venus. als der Mars sind uns nahe genug, um durch gute Teleskope ihre Oberflächenbeschaffenheit und ihre atmosphärischen Verhältnisse erforschen und dadurch Anhaltspunkte für eine ganz neue Art von vergleichender Erdkunde gewinnen zu können, umsomehr, als der Allgemeincharakter für alle drei Planeten so ziemlich derselbe ist. Was den Mond anlangt, so sind die physikalischen Verhältnisse desselben von jenen unserer Erde allerdings ziemlich verschieden, allein erstens ist dieser Gegensatz für die physische Erdkunde an sich schon interessant, und zweitens wird er es noch mehr, wenn man in Erwägung zieht, dass in naturgemässer Konsequenz der Kant-Lapla ce'schen Theorie der kleine Mond heute schon einem Schicksal verfallen ist, welchem wir die weit grössere Erde erst allmählig entgegengehen sehen.

§. 2. Die Venus. Nach den von Newcomb [1] mitgetheilten und zur Zeit wohl aus keinem astronomischen Werke zuverlässiger zu entnehmenden Daten beträgt der mittlere Abstand der Venus von der Sonne $108000000 \mathrm{~km}$; ihr Durchmesser dürfte höchstens $100 \mathrm{~km}$ kleiner sein, als derjenige unseres Planeten. Bekannt ist, dass Venus je nach der Jahreszeit als Morgenstern (Phosphorus) oder als Abendstern (Hesperus) auftritt, und es mag wohl richtig sein, dass man in grauer Vorzeit diese Erscheinungen auf zwei verschiedene Sterne bezogen habe, doch stimmen wir Wolf [2] bei, wenn er annimmt, dass schwerlich erst Pythagoras die Identität derselben erkannt haben dürfte. Die Venusbahn hat die geringste Excentricität unter allen Planetenbahnen, und zwar beträgt die siderische Umlaufszeit $224^{\mathrm{a}} 16^{\mathrm{h}} 49^{\prime} 7^{\prime \prime}$, die tropische $224^{\mathrm{a}} 16^{\mathrm{b}} 41^{\prime} 25^{\prime \prime}$, weshalb das Venusjahr zum Erdenjahr sich nahe wie 5:8 verhält [3]. Die verschiedenen Stellungen des Planeten gegenüber der Sonne, von welcher er sein Licht empfängt, und dem Auge eines Beobachters auf der Erde bedingen es, dass wir nicht stets die vollbeleuchtete Scheibe, sondern nur Theile derselben wahrnehmen; diese Phasen hatte zuerst Galilei bemerkt und durch einen anagrammatisch verstellten Hexameter dem Publikum bekannt gegeben [4] ("Cynthiae figuras aemulatur mater amorum ${ }^{*}$ ). Aehnliche Lichtgestalten beobachtet man bekanntlich auch am Mond und Merkur, und der Theorie zufolge fehlen sie auch nicht den oberen Planeten, obwohl sie an diesen der Wahrnehmung sich fast gänzlich entziehen. Angesichts des Umstandes, dass die Licht$G$ ünther, Geophysik. I. Band. 
menge, welche der überhaupt sichtbare Theil der Venuskugel-Kalotte, welche von der Sonne direkt erleuchtet wird, uns Erdenbewohnern zusendet, von einer ganzen Anzahl von Faktoren abhängt, nämlich von den variablen Entfernungen der Venus von Sonne und Erde, von dem ebenfalls variablen Incidenzwinkel u. s. w., ist es nicht verwunderlich, dass die Bestimmung des Zeitpunktes, zu welchem Venus in ihrer grössten Helligkeit erscheint, ein ziemlich verwickeltes Problem der höheren Analysis involvirt. Die beste Formel zur Berechnung dieses Momentes hat J. J. v. Littrow gegeben [5]; nach ihr richten sich auch die Herausgeber des englischen "Nautical Almanac". Photometrische Bestimmungen des Venuslichtes haben mit der Schwierigkeit zu kämpfen, dass wir die beiden unteren Planeten zur Zeit ihrer Opposition niemals vor Augen haben. Auch die helle Lichtstrahlung der Venus erwies sich, als Seidel seine berühmte Beobachtungsreihe anstellte, als ein bedeutendes Hinderniss [6], und erst mit Zöllner's verbessertem Polarisationsphotometer konnte der Logarithmus des mittleren Helligkeitsverhältnisses, in welchem unser Planet zu dem Fixstern Capella steht, ungefähr auf 1,6 festgesetzt werdeu [7]. Was die Masse der Venus anlangt, so ist dieselbe nur um sehr wenig (etwa 1/23) kleiner als diejenige der Erde, und da auch die Durchmesser beider Weltkörper so sehr nahe mit einander übereinstimmen, so folgt, dass nach bekannten Gesetzen der Mechanik auch die Dichte, die Fallhöhen, die Längen des Sekundenpendels u. s. w. nicht viel von einander $a b-$ weichen können [8]. Es tritt also jetzt schon eine unverkennbare Aehnlichkeit zu T'age.

Ganz ebenso offenbart sich dieselbe in den Tageslängen. Bianchini hatte freilich aus der Bewegung einzelner Flecke, die er an der Oberfläche der Venus aufgefunden zu haben glaubte, auf eine Rotationsdauer von $24^{\mathrm{d}} 8^{\mathrm{h}}$ geschlossen [9], und Flaugergues war auf seine Seite getreten, allein schon die längere Zeit hindurch fortgesetzten Beobachtungen Dominic und Jacques Cassini's liessen sich mit dieser auffälligen Angabe nicht in Einklang bringen. Da die Methode Bianchini's keine sicheren. Schlüsse gestattete, untersuchte der eifrigste Vertreter der topographischen Astronomie während des verflossenen Jahrhunderts, Schröter in Lilienthal, die rhythmisch wiederkehrenden Aenderungen der Sichelgestalt und zog daraus eine Drehungsperiode. von $23^{\mathrm{h}} 21^{\mathrm{f}}$, nahe übereinstimmend mit dem Werthe der Cassini's [10]. Endlich erhielt die Frage ihren vorläufigen Abschluss durch $\mathrm{D}$ e Vico, dessen Bestimmung dieses wichtigen astronomischen Elementes als entscheidend angesehen werden darf; ihm zufolge beträgt der Venustag [11] $23^{\text {h }} 21^{\prime} 22^{\prime \prime}$, so dass also dem Erdentage gegenüber nur die unwesentliche Differenz von etwa 39 Minuten übrig bleibt.

Der Anhänger der Nebulartheorie wird, nachdem es jetzt feststeht, dass die Abkühlungs- und Erstarrungszustände für Venus und Erde so ziemlich die gleichen sind, von vorn herein erwarten müssen, dass erstere auch von einer Atmosphäre umgeben sein wird. Schon Rittenhouse hatte diess aus der von ihm bei Gelegenheit des Venusdurchganges von 1769 festgestellten Thatsache erschlossen, dass die gerade noch ausserhalb der Sonnenscheibe befindliche Halbscheibe der Venus bereits in schwacher Beleuchtung sichtbar war. Safarik hat 
[12] mit ungemeinem Fleisse 22 beglaubigte Zeugnisse von zuverlässigen Astronomen zusammengebracht, welche sämmtlich den von der Sonne nicht unmittelbar beleuchteten Theil der uns zugewandten Venuskugel in einem mehr oder minder hellen („phosphorescirenden ") Lichte erblickt haben und Win $\mathrm{necke}$ hat dieses Material noch dadurch vermehrt, dass er auf sechs Beobachtungen der Astronomen des Collegio Romano aufmerksam machte [13], die sämmtlich dem Jahre 1841 entstammen. Mädler sieht in dem Phänomen das Produkt einer nur unter ganz ungewöhnlichen Umständen an der Oberfläche des Planeten hervortretenden Lichtentwickelung, und K linkerfues meint [14]: ${ }_{\text {„Leb- }}$ hafte Nordlichter auf der Venus könnten sehr gut eine solche Erscheinung bewirken." Wie dem auch sei, das Vorhandensein einer die Dämmerungserscheinungen begünstigenden Lufthülle erscheint gesichert, mag man nun als erste Ursache des Lichtes ein Polarlicht oder andere uns unbekannte Dinge anerkennen. Safarik lässt uns in diesem Punkte die Wahl zwischen nicht weniger als acht Hypothesen, die freilich nicht alle auf gleicher Wahrscheinlichkeitsstufe stehen, wie uns denn namentlich die Möglichkeit einer blos subjektiven Kontrastwirkung gar nicht einleuchten will. Eine sehr merkwürdige Abart des $\mathrm{Phä-}$ nomenes ist die von $\mathrm{Lym}$ an [15] beschriebene: sowohl 1866, als auch 1874 erweiterte sich bei der unteren Konjunktion der Venus deren Sichel zu einem feinen Lichtringe, der auch bei dem im letztgenannten Jahre stattgehabten Vorübergang vor der Sonne sich bereits fünf Stunden vor der ersten Berührung wieder einstellte. Lyman denkt dabei an die Horizontalrefraktion innerhalb der Venusatmosphäre, welche von Mädler mittelst Messung der Distanz der Sichelspitzen auf 43,7' geschätzt worden war*); er selbst berechnet den Betrag dieser Strahlenbrechung zu 44,5' - ungefähr um den vierten Theil mehr als in der Lufthülle der Erde.

Schröter glaubte auf der Venus verschiedene hohe Berge zu erkennen und unternahm es sogar, für einzelne derselben die relative Höhe (Vertikalabstand von den sie umgebenden Partieen) zu messen. Auf Tafel VIII des zweiten seiner bekannten Werke über die Venus [17] kann man eine vergleichende Liste über die Berghöhen auf diesem Planeten, auf dem Mond und auf der Erde finden, und zwar enthält dieselbe für die erstgenannte Kategorie Werthe von 6500, 9000, 9500, 16000 und 22300 (!) altfranzösischen Toisen. Neuere Beobachtungen und Messungen dieser Art fehlen aus leicht begreiflichen Gründen, und auch mit Schröter's Kettengebirgen von 200 Meilen Länge scheint es nicht sehr sicher bestellt zu sein. Betrachtungen, wie sie Littrow, auf Schröter's Aussagen sich stützend, über gewisse Analogieen zwischen Erde und Venus anstellt**), haben deshalb kaum

*) N e i s o n hat jüngst in den Untersuchungen Mädler's über die Refraktion der Venus einen das Resultat beeinträchtigenden Rechnungsfehler entdeckt [16].

**) „Es ist auffallend, dass bei allen Planeten, die wir in dieser Beziehung näher untersuchen können, die südliche Hemisphäre immer auch die gebirgigere und die kältere ist, so dass Süd und Nord in unserem Weltsysteme nicht blos eine rein mathematische Unterscheidung begründen, sondern auch in ihren physischen Eigenschaften wesentlich von einander verschieden zu sein scheinen, etwa wie bei dem Magnetismus der Erde, was auch Franklin schon behauptet hat" [18]. Mit dem gebirgigen Charakter hat es, wie wir oben sahen, seine eigene Bewandt- 
einen wirklichen Werth, so wichtig auch andererseits der Nachweis reeller Aehnlichkeiten für den einer kosmologischen Betrachtungsweise zugänglichen Geographen ist.

Von einem Venusmonde ist im Verlaufe des XVIII. Jahrhunderts sehr viel gesprochen und noch mehr gefabelt worden. Die älteren Nachrichten über dieses mythische astronomische Objekt sind sehr zerstreut und schwer vergleichbar, und es ist deshalb nur mit Dank anzuerkennen, dass durch die bekannte Monographie von Schorr [19] eine ernsthafte Prüfung dieser immer wieder auftauchenden Frage ermöglicht wurde. Direkt gesehen haben einen Stern, den sie für den Trabanten hielten, Fontana, D. Cassini, Short (?) und Montaigne, während De la Hire, Bianchini und Bode von festbegrenzten Flecken erzählen, die allenfalls auf den vor der Venusscheibe dahinziehenden Mond gedeutet werden könnten. Versuchte doch Lambert schon Tafeln für den - mit dem Namen D'A le mbert zu belegenden - neuen Himmelskörper zu berechnen. Wenn nun auch Schorr der Ansicht ist, an der Existenz eines Venusmondes von etwa 12,17 tägiger Umlaufszeit dürfe man noch nicht völlig zweifeln, so sprechen doch weit überwiegende Gründe für N ew co m b's Meinung, derselbe sei überhaupt nicht vorhanden. Dieser grosse Kenner der praktischen Sternkunde erörtert mit Scharfsinn die Möglichkeit, dass die genannten Beobachter einer optischen Täuschung (den falschen R(-flexionsbildern oder ghosts") $^{\text {") }}$ zum Opfer gefallen sein möchten [20]. In diesem Sinne hatten früher schon Hell und Wargentin sich vernehmen lassen [21].

§. 3. Mars und seine Monde. In einer ziemlich langgestreckten Ellipse bewegt sich Mars um die Sonne, so dass seine Apheldistanz $(248000000 \mathrm{~km})$ die Periheldistanz $(206000000 \mathrm{~km}) \mathrm{um} 42000000 \mathrm{~km}$ übertrifft. Der Durchmesser der Planetenkugel beträgt wenig mehr als $6700 \mathrm{~km}$, und zwar scheint von einer Abplattung gänzlich abgesehen werden zu müssen, obwohl $\mathrm{Adams}$ und T'issandier auf theoretischem Wege einen durch wirkliche Beobachtung kaum zu kontrolirenden Werth $(1 / 200)$ dafür ausgemittelt haben wollen [22]. Hartwig, der alle älteren Messungen von Bessel, F. Kaiser, Encke, Galle, J. Sch midt, Secchi, Pritchett u. a. einer sehr sorgfältigen Musterung unterworfen hat, erwähnt, dass auch Arago als Vertheidiger der Existenz einer messbaren Abplattung aufgetreten sei [23], und er selbst kann nicht umhin, auf Grund einer mit allen Kautelen moderner Beobachtungskunst durchgeführten Beobachtungsreihe eine Differenz zwischen dem äquatorialen und polaren Diameter zu stipuliren [24]. Dieselbe ist freilich in keinem Falle so gross, dass es sich verlohnen könnte, über die Frage nachzudenken, ob die Ellipticität des Planeten besser mit der Annahme eines früher flüssigen Zustandes oder mit der einer Oberflächenerosion sich vertrage, wie diess Hennessy [25] gethan hat. Die Umlaufsdauer beträgt 687 Tage, die synodische Umlaufszeit, nach deren Ablauf die Oppositionen des Planeten wiederkehren, 737 Tage. Kein anderer Himmelskörper ist so starken Schwankungen

niss, und auch der klimatische Unterschied zwischen den beiden Halbkugeln der Erde stellt sich neuerdings in einem ganz anderen Lichte dar, als zu Littrow's Zeit. 
seiner Lichtstärke unterworfen, wie Mars (falls nicht etwa von den eigentlichen veränderlichen Sternen die Rede sein sollte); am hellsten leuchtet er, wenn die Zeit der Opposition mit der Zeit des Durchganges sich annähernd deckt, und so danken denn auch die Entdeckungen Hall's und Schiaparelli's der besonders günstigen Opposition vom September $1877 \mathrm{ihr}$ Zustandekommen [26]. Der Logarithmus des Verhältnisses der Lichtintensität des Mars (mittlere Oppositionen angenommen) zur Lichtintensität der Capella ist nach Zöllner [27] gleich 0,9016. Setzt man die Lichtmenge, welche unsere Erde von der Sonne erhält, $=1$, so entsprechen dem Mars die Lichtmengen 0,$36 ; 0,43 ; 0,52$, je nachdem seine Entfernung vom Centralkörper ihren kleinsten, mittleren oder grössten Werth annimmt. Die Dichte verhält sich zu der der Erde etwa wie 18:25, allein da der Planet selbst beträchtlich kleiner als jene ist, so sind Schwerkraft, Fallhöhen und Pendellängen daselbst höchstens halb so gross, als wir dieselben kennen [28].

${ }_{\text {„Ausser der Erde, }}$ " sagt Newcomb [29], „ist Mars der einzige Planet, dessen Rotationsdauer wir mit vollkommener Schärfe, durch die Unveränderlichkeit vieler Flecken, bestimmen können. Zwei Jahrhunderte alte Zeichnungen von $\mathrm{Huygens}$ weisen Stellen auf, die wir noch jetzt erkennen können; theils aus der Vergleichung dieser, theils aus der späterer mit neueren Darstellungen haben Kaiser und Schmidt die Umdrehungszeit zu $24^{\text {h }} 37^{\prime} 22^{\prime \prime}, 6$ gefunden, welche bis auf wenige Hundertel der Sekunde genau sein wird." Auch im natürlichen Zeitmaasse gleicht sonach der Mars der Erde fast vollkommen, dafür aber ist auf ersterem die Ungleichheit von Tag und Nacht eine schärfer markirte [30], und die starke Excentricität der Bahnellipse macht sich für die beiden Hälften des Planeten in der Weise fühlbar, dass auf der Nordhalbkugel mehr ein Seeklima, auf der Südhalbkugel mehr ein kontinentales Klima (terrestrisch gesprochen) zur Herrschaft gelangen muss.

Der Mangel eines Mondes bei einem der Erde sonst in so vielen Beziehungen ähnelnden Himmelskörper war von manchen Freunden teleologischer Weltbetrachtung mehrfach schon als etwas Auffälliges vermerkt worden. Kepler, dem es (vgl. Kap. II. \&. 9) durchaus nicht auf die Kreirung neuer Gestirne nach theoretischen Motiven ankam, theilte dem Mars zwei Begleiter zu, und zwei Satyriker des XVIII. Jahrhunderts, Swift und Voltaire, suchten sich, wie Hall in der seiner klassischen Entdeckungsschrift [31] angehängten geschichtlichen Skizze erwähnt [32], dadurch an den Gelehrten ihres Zeitalters zu reiben, dass sie den Astronomen entfernter Weltkörper die Entdeckung zweier Marsmonde zuschrieben, von denen deren irdische Kollegen gar keine Ahnung hätten. Der Kapuziner Schyrlaeus de Rheita glaubte dergleichen Monde auch wirklich entdeckt zu haben [33]. Nachdem jedoch W. Herschel die Umgebung des Mars plangemäss abgesucht und doch nicht den mindesten Erfolg dabei erzielt hatte, schienen weitere Bemühungen nicht mehr am Platze zu sein, und nur der vorsichtige D'Arrest theilte den allgemeinen Glauben nicht, indem er sich auf die Bemerkung beschränkte, dass allfallsige Marsmonde nur in der nächsten Nähe des Planeten zu suchen wären [34]. Die Ueberraschung war nichtsdestoweniger gross, als man in 
Europa (1877) von der glïcklichen Entdeckung zweier Marstrabanten durch Assaph Hall in Washington [35] erfuhr; kein volles Jahr darauf publicirte derselbe die uns bereits bekannte Schrift, welche nicht nur über den Hergang der Entdeckung nähere Mittheilungen brachte, sondern auch die Ephemeriden der neuen Wandelsterne und deren Bahnelemente in einer Vollständigkeit enthielt, dass durch spätere Forschungen an diesen vorläufigen Ergebnissen nicht mehr viel geändert zu werden brauchte. Beide Monde, denen die Namen Phobos und Deimos beigelegt sind, erscheinen als Sterne zwölfter Grösse, allein nur der äussere (Deimos) ist leidlich gut sichtbar, da sein Gefährte gar zu wenig aus den Sonnenstrahlen heraustritt. Die Entfernungen der beiden Monde vom Marscentrum betragen resp. 9300 und $23000 \mathrm{~km}$; ihre Umläufe vollziehen sie in $7^{\mathrm{h}} 39^{\prime}$ und $30^{\mathrm{h}} 18^{\prime}$, so dass der äussere ziemlich genau das Vierfache der Umlaufszeit des inneren Mondes braucht. Es scheint hierin ein für die Satelliten sämmtlicher Planeten gültiges Gesetz zum Ausdrucke zu kommen [36]. Trotz ihrer Kleinheit - Pickering berechnete die Grösse der Durchmesser photometrisch auf $10 \mathrm{~km}$ - mögen diese Monde immerhin auf die Wasserbedeckung des Hauptplaneten einen starken attraktiven Einfluss ausüben, da bekanntlich, die Gravitationswirkung in erheblicherem (quadratischem) Maasse durch die Distanz, als durch die Masse bedingt ist.

§. 4. Geschichte der physischen Marsforschung. Es liegt auf der Hand, dass hier nur ein ganz kurzer Abriss dieser Geschichte gegeben werden kann, denn das zu bewältigende Material ist ein viel zu massenhaftes; Houzeau's Zusammenstellung aller Arbeiten, die sich mit der Oberflächenbeschaffenheit des Mars und mit seiner Lufthülle beschäftigen, umfasst nicht weniger als 213 Nummern [37]. Einen kurzen Bericht über den Stand der Frage hat Terby, selbst einer der fleissigsten Arbeiter auf diesem Gebiete, im Jahre 1875 geliefert [38]. Damals existirten 1092 Marszeichnungen, deren erste F on tan a und Huygens anfertigten; von dem letzteren besitzt man noch jetzt 13 feine Federzeichnungen (ausgeführt in dem Zeitraume 1659-95), und ihm gebührt (vgl. den vorigen Paragraph) das Verdienst, die Form gewisser ausgezeichneter Flecke ein für allemal richtig bestimmt zu haben. Aus der frühesten Zeit sind noch Zucchi (um 1640) und Maraldi (um 1716) als fleissige Marsbeobachter zu nennen [39]*). Dann trat der rastlose Schröter auf den Plan, der 217 Skizzen entwarf und dieselben für ein umfassendes Werk zu verwerthen gedachte, das jedoch damals nicht zu Stande kam; die Manuskripte wurden erst durch Terby der Vergessenheit entrissen und 1873 der Akademie in Brüssel vorgelegt, und der niederländische Astronom Van de Sande Bakhuizen war so glücklich, das von Terby entdeckto Manuskript für die Sternwarte Leyden erwerben und herausgeben zu können [41]. Da Schröter sich nicht von der Ansicht trennen konnte, dass die

*) Wundern muss man sich, dass Hevelius [40] so oberflächlich vom Mars handelt. Er schrieb ihm zwar eine Atmosphäre zu, aber nicht auf Grund von Autopsie, sondern blos seiner sonderbaren Kometentheorie (Kap. II. §. 11) zuliebe. 
Marsflecken einen rein atmosphärischen Ursprung besässen, so sind seine Zeichnungen und die daran geknüpften Erörterungen mehr blos von historischem, als von sachlich bleibendem Werthe. Unter den neueren Astronomen haben sich Herschel, Arago, Secchi, Nasmith, Lord Rosse, Dawes, Fergola, Browning, Holden, v. Konkoly und viele andere um die schärfere Festsetzung vieler Einzelheiten verdient gemacht: auch von dem unermüdlichen $\mathrm{Jul}$. Schmidt sind noch 67 unedirte Aufnahmen vorhanden. In grösserem Style aber förderten das Marsstudium Beer und Mädler [42], Linsser [43] und Kaiser [44]. Proctor wagte es zuerst, eine Landkarte der Marsoberfläche zu verzeichnen [45], und zwar in cylindrischer Projektion. Selbstverständlich galt es erst, eine areographische Nomenklatur zu schaffen; Terby gieng von der Ansicht aus, dass die einzelnen Gegenden nach Astronomen zu benennen seien, deren Arbeiten ihnen ein Recht verliehen, gerade auf dem Mars sich verewigt zu sehen. So zerfällt ihm zufolge das ganze Areal in sechs Hauptregionen: KaiserMeer und Dawes-Ocean, Herschel-Enge, De la Rue-Ocean, Hooke- und Maraldi-Meer, Tycho- und Delambre-Meer, Beer- und Airy-Meer. Hiezu kommt dann noch ein Lockyer-Meer, auf dem man - nach Terby mit Unrecht - sturmartige Bewegungen beobachtet haben wollte, und ein Oudemans-Pass. Terby erkannte die Unvollkommenheit des bisherigen areographischen Wissens an, wies aber darauf hin, dass die nächsten Oppositionen die beste Gelegenheit zur Vervollständigung unserer Kenntnisse bieten würden.

Diese Hoffnung ist denn auch in Erfüllung gegangen. Denn nachdem Schiaparelli vom 12. September 1877 bis zum April 1878 unausgesetzt mit einem $\mathrm{Merz}$ 'schen Refraktor von 322- resp. $468 \mathrm{ma-}$ liger Vergrösserung den Mars beobachtet hatte, war er im Stande, der Accademia dei Lincei ein Werk [46] über denselben vorzulegen, welches wohl als ein abschliessendes bezeichnet werden darf. Wir gedenken im Folgenden unseren Lesern eine Uebersicht der wichtigeren von ihm erhaltenen Resultate vorzulegen, indem wir uns dabei zugleich auf die von drei deutschen Astronomen, Remeis [47], Böddiker [48] und Holetschek [49] veranstalteten Auszüge beziehen — namentlich auf den letzterwähnten, der durch seine Vollständigkeit ausgezeichnet ist. Wir werden dabei die Ueberzeugung gewinnen, dass das, was R. Wolf [50] über die Beziehungen zwischen den älteren Untersuchungen Herschel's und jenen der neuesten Zeit bemerkt*), auf voller Wahrheit beruht.

§. 5. Oberflächenbeschaffenheit und Atmosphäre des Mars nach Schiaparelli. Die erste Aufgabe Schiaparelli's war eine möglichst genaue Bestimmung der Umdrehungsaxe des Mars, wozu der den früheren Marsforschern bereits wohlbekannte südliche Polarfleck

*) „Als sodann Herschel mit der ihm eigenen Omsicht und Ausdauer diesen Planeten verfolgte, konnte er 1784 in der Abhandlung „On the remarkable appearances at the polar regions of the planet Mars" mit aller Evidenz nachweisen, dass die Polarflecke den Jahreszeiten des Mars konform sind, und dass überhaupt Mars eine Atmosphäre, Wasser, ja nach allen Richtungen der Erde entsprechende klimatische Verhältnisse hat. Seine Schlussfolgerungen sind durch die seitherigen Forschungen vollständig bestätigt worden." 
die nöthige Hülfe bot. Alsdann wurden von 62 möglichst gleichmässig auf der Oberfläche des Planeten ausgesäeten Punkten die genauen areographischen Längen und Breiten ermittelt. Die Opposition von 1877 fügte es, dass der Südpol der Erde zunächst zu liegen kam, und so musste natürlich auch in Schiaparelli's Marszeichnungen die Südhemisphäre eine unwillkürliche Bevorzugung erfahren. Unsere Fig. 5

Fig. 5 .

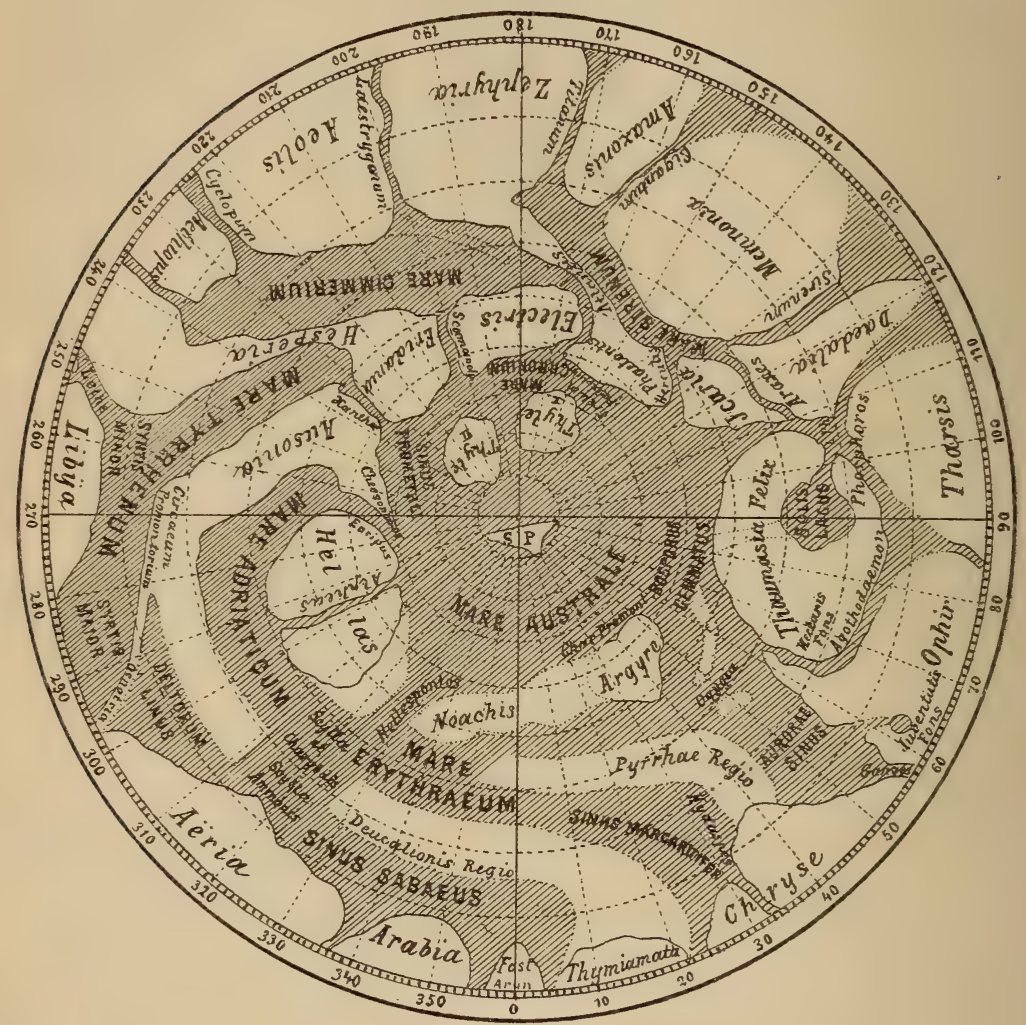

stellt diese Halbkugel in der hier ganz von selbst sich darbietenden orthographischen Polarprojektion (vgl. Kap. V der zweiten Abtheilung) dar. Als Nullpunkt der - bis $360^{\circ}$ in gleichem Sinne fortlaufenden - Längenzählung wurde der in den Sinus Sabaeus hineinragende Landvorsprung Aryn*) gewählt. Schiaparelli schloss sich nämlich nicht dem Vorgange Terby's (s. o.) an, sondern belegte die einzelnen Gegenden mit neuen Namen, die durchaus der mythologischen Geographie der älteren und mittleren Zeit entlehnt sind. Sein Entdecker-

*) S chi a parelli fusst bei der Wahl dieses Namens auf einer kosmographischen Sage, die von den Arabern herrührt und das ganze Mittelalter durchzieht. In Innerasien sollte die Erde sich glockenförmig nach oben wölben, und an diese Bergkuppel Aryn wurden die sonderbarsten Hypothesen geknüpft [51]. 
recht hiezu steht unseres Erachtens ausser allem Zweifel, denn bei aller Verehrung für die wackeren Leistungen seiner Vorgänger müssen wir in ihm doch den ersten wissenschaftlichen Mars-Kartographen mit dem nämlichen Rechte anerkennen, mit welchem wir (s. §. 9) die exakte Selenographie erst von Tobias Mayer datiren lassen. Die mikrometrische Festlegung der Fundamentalpunkte erhebt in diesen beiden Fällen die darauf begründeten Pläne hoch über das Niveau der früheren Faustzeichnungen, deren Richtschnur allein das doch immer trügerische Augenmaass war. Allein $\mathrm{K}$ a is e r [52] sowohl wie Secchi [53] hatten den variablen Umrissen der Marsflecken gegenüber den Muth zu schärferen Ortsbestimmungen verloren.

$\mathrm{Ob}$ die neuen Bezeichnungen Meer, See, Busen, Meerenge, Vorgebirge u. s. w. wirklich genau das bezeichnen, was man in der Geographie darunter versteht, muss natürlich für's Erste eine offene Frage bleiben, allein man hat doch jetzt den grossen Vortheil, mit jedem areographischen Objekte einen festen Begriff verbinden zu können. Die dunkleren und helleren Partieen der Marsoberfläche hat man übrigens von je mit Wasser und Festland identificirt, und ebenso lag es gleich von Anfang nahe genug, in den mit den Jahreszeiten ihre Grösse ändernden Polarflecken S'chneezonen zu erblicken [54]. Der südliche Fleck, an welchem in Folge der oben geschilderten Umstände unser Interesse zunächst haften muss, bleibt übrigens vom Pole immer 5-6 Grade entfernt, wie auch sein Umfang nach anderen Seiten hin sich ändern mag; diese schon von Linsser erkannte Thatsache mag darin ihren Grund haben, dass nahe auf der dem Polarfleck entgegengesetzten Seite des Axenendes die beiden grossen Inseln Thyie liegen. Die Ausdehnungen und Zusammenziehungen der Mars-Polarflecke erinnern in ihren zeitlichen Verhältnissen lebhaft an das, was wir auf der Erde zu sehen gewohnt sind, wo ja auch die der Polarschifffahrt günstigste Zeit erst nach der. Sommersonnenwende eintritt [55]. Schiaparelli bekennt sich bezïglich dieser Flecke zu der Ansicht, dass in ihnen Dämpfe zu erblicken seien, welche bei niedriger Temperatur in den festen Aggregatzustand übergeführt wurden, und da nach Vogel's Untersuchungen die Marsoberfläche von Wasserdämpfen erfüllt ist, darf wohl der feste Aggregatzustand des Wassers, Schnee und Eis, als das die Flecke bildende Material betrachtet werden, obgleich eine völlige Sicherheit hierüber noch nicht gewonnen ist. An Eismassen ist deshalb wohl weniger zu denken, weil diese schwerlich zu einem so kompakten Ganzen vereinigt bleiben würden, vielmehr spricht Manches dafür, dass eine feste Schnee-Kalotte der Oberfläche des Planeten und dem Grunde der - vielfach seichten - Meere aufgesetzt ist.

Von diesem ausgezeichneten Flecken abgesehen, sind die. Flecke des Mars durch ihren Helligkeitsgrad sehr leicht von einander zu unterscheiden. Die dunklen Flecke, deren düstrer Lichtton sich im nördlichen Theile des tyrrhenischen Meeres, im Sinus Sabaeus und im Sinus Margaritifer bis zur vollständigen Schwärze steigert, gelten als Meere, weil man weiss, dass die irdischen Kontinentalmassen das ihnen zugesandte Sonnenlicht grossentheils reflektiren, die Wasserflächen dagegen absorbiren. Die Abstufungen in der Dunkelheit können in der ungleichen Tiefe, in der verschiedenen Durchsichtigkeit des Meer- 
wassers, oder auch in dessen chemischer Zusammensetzung ihren Grund haben. Freilich ist eingewandt worden, dass in diesen Meeren und Seen das Sonnenbild sich wiederspiegeln müsse, allein die Oberfläche derselben dürfte schon in Folge der von den Monden bewirkten Gezeiten (s. o.) und auch in Folge atmosphärischer Beunruhigung schwerlich den zur Reflexion erforderlichen glatten Spiegel darbieten [56]. Die hellen Flecke halten wir für festes Land; ihre Lichtnuancen bringen wir mit den darüber lagernden Wolken und Nebeln in Verbindung. Zweifelhafter kann man sein bezüglich der Regionen von mittlerem Lichtton (westlicher Theil von Ausonia sammt Oenotria und Japygia, sodann Noachis, Pyrrha-, Deukalion-, Proteus-Land, Ogygia, Atlantis II und der schmale Theil der Halbinsel Hesperia). Recht wohl möglich ist es, dass man es bei diesen Partieen, deren Reflexfähigkeit geringer als beim Festland, deren Absorptionsfähigkeit dagegen wieder geringer als beim Meere ist, mit einem Mitteldinge, mit submarinen Bänken und Untiefen, zu thun habe.

Für die Umrisslinien des Festen und Flüssigen auf der Meeresoberfläche sind die nachstehenden sieben, eine allgemeine Konfigurationslehre in sich schliessenden Sätze Sch iap a r elli's maassgebend [57]: I. Die weitaus überwiegende Landmasse liegt, nur von schmalen Wasseradern durchzogen, in einer äquatorialen Zone; II. Zwischen dieser und der südlichen gemässigten Zone breiten sich zusammenhängende Binnenmeere aus, unterbrochen durch lange, von Nordwest nach Südost gerichtete Halbinseln; III. Auf der Südhemisphäre ordnen sich die Länder nach zwei der Mittelzone wesentlich parallel verlaufenden Gürteln, deren kleinerer allerdings blos durch die beiden Inseln Thyle gebildet wird; IV. Wo die in II genannten Halbinseln an die beiden kontinentalen Zonen anschliessen, münden zu ihren beiden Seiten geräumige Kanäle, welche jene Zonen durchziehen (Eridania, Hesperia's Ausläufer, wird beispielsweise von Skamander und Xanthus eingeschlossen u.s.w.); V. Diesen Kanälen eignet im Allgemeinen eine meridionale Richtung, die sich am schärfsten beim Alpheus ausprägt; VI. Auch die Aequatorzone wird - diess zu erkennen, reicht unsere Karte nicht mehr aus - durch Kanäle getheilt, welche aber mehr der Richtung der Parallelkreise folgen; VII. Die Vertheilung von Wasser und Land ist eine gänzlich verschiedene von jener auf der Erde, welch' letztere zwei Weltinseln in noch weit ausgedehntere Wassermassen eingebettet aufweist, auch ist der Uebergang vom Festen zum Flüssigen ein weit unmerklicherer als bei uns. All' diess zusammengehalten, muss man wohl die Ueberzeugung gewinnen, dass das Studium der Areographie, welche uns in grossen Hauptzügen so manche Aehnlichkeit mit unseren irdischen Verhältnissen, im Detail dagegen wieder so manche Verschiedenheit vor Augen stellt, einen sehr hohen Werth nicht nur für die "vergleichende" Erdkunde, sondern auch für die Geologie besitzt. Wir lernen diesen Werth noch höher veranschlagen, wenn wir zum Schlusse auch auf die meteorologischen Eigenthümlichkeiten des Mars einen Blick werfen.

Dass der Planet überhaupt von einer Atmosphäre umschlossen ist, erhellt aus der grösseren Helligkeit, welche den Rand seiner Scheibe gegenüber den centralen Partieen auszeichnet, aus der vorübergehenden Trübung, die ab und zu an den verschiedensten Orten eintritt, und 
aus der konstanten Triubung, welche die Flecke nicht selten erleiden, sobald sie in Folge der Axendehnung dem Rande sich nähern [58]. Genauere Untersuchungen zeigen uns, dass die Wolken des Mars der Hauptsache nach ein ähnliches Verhalten an den Tag legen, wie die Wolken der Erde. Eine durch Trübungen ausgezeichnete Kalmenzone ist nicht vorhanden, was jedenfalls mit der eigenthümlichen Vertheilung von Wasser und Land zusammenhängt, dafür aber scheint zur Zeit der Solstitien die Luft auf der einen Halbkugel im Zustande der Verdampfung, auf der anderen im Zustande der Verdichtung sich zu befinden, während in der Zwischenzeit die Verdampfungszone nach Süd und Nord von zwei Kondensationsgebieten begrenzt erscheint. Diesen allgemeinen Andeutungen gemäss muss es uns vorkommen, als sei die Areometeorologie eine minder verwickelte Wissenschaft, als ihre irdische Gefährtin; bestätigt sich diess aber, so wird unsere Witterungskunde aus den an der Marsoberfläche sich abspielenden Vorgängen ganz ebenso Nutzen zu ziehen im Stande sein, wie aus der Betrachtung der Witterungsverhältnisse Nordamerika's, für welche deren Einförmigkeit charakteristisch ist.

§. 6. Weitere Schlüsse aus der Analogie zwischen Mars und Erde. Der Umstand, dass die Bahnkurve des Mars eine ungleich entschiedenere Abweichung von einem Kreise aufweist, als die Bahn irgend eines anderen Planeten, hat die Veranlassung dazu gegeben, gewisse geologische Theorieen, welche neuere Naturforscher an die Excentricität der Erdbahn anzuknüpfen beflissen waren, an dem Planeten Mars zu prüfen, und in der That kann derselbe aus dem angegebenen Grunde als ein ganz geeignetes Prüfungsobjekt gelten. Es kommen wesentlich die drei Hypothesen von Adhémar, Croll und Schmick*) in Frage, und dieser Letztere ist es auch gewesen, der in einer eigenen Schrift [60] die Vergleichung von Erde und Mars unter den angeführten Gesichtspunkten anregte. Bei all' diesen Spekulationen handelt es sich um eine chronische Verschiebung des Erdschwerpunktes in Folge von Wasseransammlungen, und zwar denkt sich Adhémar jenen Erdpol, für welchen die Excentricitätsschwankung der Bahnkurve eine andauernd niedrigere Temperatur bedingen soll, von einer mehr und mehr wachsenden Eiskruste umgeben, durch deren Masse der Schwerpunkt der Erde gegen den kälteren $\mathrm{Pol}$ hin verrückt werde; hiedurch endlich würden auch die Gewässer der wärmeren Halbkugel nach der kälteren hinzuströmen veranlasst. Wäre diese Anschauung, mit welcher diejenige Croll's manches Gemeinsame hat, begründet, so müsste an dem von der Wärme minder begünstigten Marspol sich allerdings eine kontinuirliche Vergrösserung des Eispanzers beobachten lassen, und es spricht, wie Schmick ganz richtig bemerkt, auf das Entschiedenste gegen Adhémar, dass alle Marsforscher übereinstimmend von einem an enge zeitliche Grenzen gebundenen $\mathrm{Zu}$ - und Abnehmen der Polar-

*) Es wird von jenen Theorieen eingehender gehandelt werden in dem Kapitel der V. Abtheilung, welches die Schwankungen des Klima's innerhalb längerer Perioden zum Gegenstande hat. An diesem Orte müssen wir uns natürlich auf eine summarische Skizzirung der Grundgedanken beschränken, verweisen aber zugleich auf die früher von uns gegebene Sachkritik des ganzen Vorstellungskreises [59]. 
flecke berichten. Allein ebenso ungerechtfertigt erscheint es, von einer Rechtfertigung der bekannten Schmick'schen Lehre, nach welcher in ungeheuer langen Perioden je die eine und die andere Planetenhalbkugel überfluthet werden soll, durch die von der Marsoberfläche dargebotenen Erscheinungen sprechen zu wollen. Es nützt auch der $\mathrm{Zu}$ satz nichts, dass die gegenwärtige Landgruppirung des Mars als ein ᄁgreisenhaftes " Residuum jener Ereignisse bezeichnet wird, welche sich früher begeben haben sollen, denn eben aus dürftigen Residuen verbietet es sich, Schlüsse auf einen mehr entwickelten Zustand zu machen. Sehr sprechend ist, wie A. Kir chh off in seiner Recension des Schmickschen Buches [61] hervorhebt, die Aehnlichkeit zwischen dem äquinoktialen Landgürtel des Mars und gewissen Archipelen der Eurde (z. B. der hinterindischen oder dänischen Inselwelt). Kein Geologe aber denkt so leicht daran, diesen Inseln eine gewissermassen, dynamische Entstehung zuzuschreiben, sie als Bruchstücke einer durch Sturmfluthen (im Sinne Schmick's) zerrissenen Festlandmasse aufzufassen, vielmehr führt man die Bildung eines Archipelagus durchweg auf säkuläre Senkungen zurück. Der Versuch, aus den zwischen Mars und Erde unleugbar vorhandenen Analogieen Kapital zu Gunsten einer selbst für terrestrische Verhältnisse noch sehr zweifelhaften Hypothese schlagen $\mathrm{zu}$ wollen, erscheint als nicht geglückt*).

§. 7. Der Erdmond. Aus der fast einen Grad $\left(57^{\prime} 2^{\prime \prime}\right)$ betragenden Horizontalparallaxe des. Mondes berechnet sich für diesen eine relativ kleine Erddistanz, die blos 384000 Kilometer beträgt, doch ist diess nur ein Mittelwerth; der wahre Werth kann auf $414000 \mathrm{~km}$ steigen, auf $354000 \mathrm{~km}$ fallen. Der Durchmesser des Mondes beträgt $3475 \mathrm{~km}$, sein Rauminhalt etwa 1/50 von demjenigen der Erde, seine Masse 1/80 der Erdmasse, weshalb seine Dichte etwa die Hälfte der mittleren Erddichte ausmacht. Diese Zahlen sind Newcomb [63] entnommen, während Mädler [64] zumal den Werth für die Dichte etwas höher ansetzt. Eine Abplattung der Mondkugel im gewöhnlichen Sinne ist kaum vorhanden, doch wird sich bald ergeben, dass wir trotzdem nicht von einer reinen Kugelform dieses unseres Begleiters sprechen dürfen.

Eine charakteristische Eigenthümlichkeit des Mondes ist es, dass er uns - geringfügige Ausnahmen vorläufig unberücksichtigt gelassen - stets nur dieselbe Seite zuwendet. Merkwürdigerweise wollte man hierin früher einen Beweis dafür erblicken, dass der Mond gar keine Axendrehung habe, und in dem für seine Zeit ausgezeichneten mathematischen Lehrbuche Chr. v. Wolf's findet sich z. B. folgende Stelle [65]: „Von dem Monden weiss man gewiss, dass er sich nicht um seine Axe beweget, sondern immer eine Seite der Erde zukehret. ${ }^{*}$ Ein wenig Nachdenken führt zu dem umgekehrten Schlusse, dass allerdings der Mond sich um seine Axe dreht und diese Umdrehung genau in der nämlichen Zeit vollendet, welche er zur Vollendung einer Um-

*) Ein anderes Beispiel allzuweit getriebener Parallelisirungsversuche ist einer Abhandlung Lambert's über den Mond zu entnehmen [62]: Die Erde werde ihrer Wälder halber einem Mondbewohner in grünlichem Lichte erscheinen, und ebenso sei die rothe Farbe des Marslichtes vielleicht die Folge einer rothgefärbten Vegetationsdecke dieses Planeten. 
wälzung um die Erde benöthigt; mit anderen Worten: Tag und Jahr sind für den Mond ein und dasselbe. Es ist, wie Newcomb [66] betont, sehr unwahrscheinlich, dass dieses Verhältniss völliger Gleichheit der Rotations- und Revolutionsdauer von allem Anfang an bestanden haben sollte, vielmehr lässt sich vermuthen, dass die beiden Zeitmaasse ursprünglich um eine wenn auch kleine Grösse verschieden waren, und dass erst die Anziehung der Erde auf den in flüssigem oder halbflüssigem Zustand befindlichen Mondkörper nach und nach den gegenwärtigen Zustand herstellte. Es hängt diess zusammen mit einer anderen bemerkenswerthen Eigenschaft des Mondkörpers, zu deren richtiger Charakterisirung wir jedoch etwas weiter auszuholen genöthigt sind.

Wenn eine flüssige schwere Masse rotirt, so dass also deren sämmtliche Theilchen einerseits der gegenseitigen Anziehung, andererseits der Centrifugalkraft unterworfen sind, so braucht die Masse durchaus nicht, wie man früher glaubte, die Form eines an den Polen abgeplatteten Rotationssphäroides anzunehmen, vielmehr hat schon Jacobi gezeigt, dass auch die Oberfläche des dreiaxigen Ellipsoides eine Gleichgewichtsfläche sei [67]. Während der berühmte Engländer W. Thomson einmal den Wunsch aussprach, das Problem der Gleichgewichtsfiguren möchte doch endlich generell in Angriff genommen werden, ist diess thatsächlich schon längst durch den deutschen Physiker Matthiessen geschehen, der am Schlusse seiner den Gegenstand allgemein erörternden Abhandlung [68] eine Liste aller hieher zu zählenden Körperformen mittheilt. Speziell für satellitische Gleichgewichtsfiguren (bei weit entferntem Centralkörper von sphäroidaler Form) sind folgende Variationen möglich: Hohl- und Vollkugel, Verlängerte zwei- oder dreiaxige Ellipsoide - von Roche [69] als Mondfiguren bezeichnet - und Ringe mit elliptischem Querschnitte, wie schon von Laplace in dessen grundlegender Schrift über die Figur der Planeten [70] erkannt worden war. Diess vorausgesetzt, kann also der Mond schon von Hause aus jede beliebige ellipsoidische Gestalt besessen haben, und die Attraktion der Erde konnte die nach ihr hin sich richtende Axe nur in dem Sinne verlängern, wie ja auch die Attraktion des Mondes stets die Wasserhülle unserer Erde aus einer Kugel in ein Ellipsoid zu verwandeln strebt. Die kürzeste Axe wurde die Drehungsaxe, die nächstlängere kam in die Richtung der Mondbewegung zu liegen, und die längste gieng in ihrer Verlängerung durch den Erdmittelpunkt hindurch. Letzterer Umstand ist es eben, der die allmählige Koincidenz von Tages- und Jahresdauer bewirkte. Uebrigens ist die Differenz zwischen den drei Axen des Mondellipsoides nur eine sehr geringe, die grösste Axe ist etwa um 75 Meter länger als die kleinste.

Der Schwerpunkt eines dreiaxigen Ellipsoides fällt zwar bei homogener Vertheilung der Masse mit dessen geometrischem Mittelpunkte zusammen, beim Monde aber scheint es sich anders $z$ u verhalten. Kant hat [71] dieses Auseinanderfallen beider Punkte geahnt, Hansen in einem am 4. November 1854 abgesandten Briefe an Airy den Beweis dafür angetreten. Zöllner selbst stellte die Aeusserungen beider Forscher neben einander [72], und wir lassen seine Zusammenstellung hier folgen: 


\section{Kant (1794).}

„Nach anderweitigen bewundernswerthen Entdeckungen ebendesselben Astronomen *), die Struktur der Mondfläche betreffend, scheint die uns zugekehrte Hälfte des Mondes ein einer ausgebrannten vulkanischen Schlacke ähnlicher und unbewohnbarer Körper zu sein. Wenn man aber annimmt, dass die Eruption der elastischen Materien aus dem Innern desselben, solange er noch im Zustande der Flüssigkeit war, sich mehr nach der der Erde zugekehrten, als von ihr abgekehrten Seite gewandt haben (welches, da der Unterschied der Anziehungen der ersteren von der des Mittelpunkts des Mondes grösser ist, als der zwischen der Anziehung des Mittelpunkts und der abgekehrten Seite, und elastische in einem Flüssigen aufsteigende Materien destomehr sich ausdehnen; je weniger sie gedrückt werden, beim ersteren dieses Weltkörpers auch grössere Höhlungen im Inwendigen desselben auf der ersteren als auf der letzteren Hälfte hat zurücklassen müssen); so wird man sich gar wohl denken können, dass der Mittelpunkt der Schwere mit dem der Grösse dieses Körpers nicht zusammentreffen, sondern zu der abgekehrten Seite hin liegen werde, welches dann zur Folge haben würde, dass Wasser und Luft, die sich etwa auf diesem Erdtrabanten befinden möchten, die erstere Seite verlassen, und indem sie auf die zweite abflossen, diese dadurch allein bewohnbar gemacht hätten. “
Hansen (1854).

„Erlauben Sie mir zum Schluss einige wenige Bemerkungen über vorstehende Erklärung der Vergrösserung der Koefficienten der Mondstörungen. Aus dem oben angeführten Werthe des Faktors folgt, dass der Mittelpunkt der Figur des Mondes ungefähr 59000 Meter, d. i. ungefähr 8 geographische Meilen (15 Meilen auf einen Aequatorgrad gerechnet) näher nach uns zu als der Schwerpunkt liegt, wonach zwischen der uns zugekehrten und der von uns abgekehrten Mondhemisphäre ein beträchtlicher Unterschied in $\mathrm{Be}$ treff des Niveau, des Klima und aller andern davon abhängigen Umstände stattfinden muss ......"

„Unter solchen Umständen haben wir uns nicht zu wundern, dass der Mond, von der Erde aus gesehen, ein dürres Aussehen hat, weder eine Atmosphäre, noch thierisches oder pflanzliches Leben zeigt. Denn wenn auf dem Monde ein verhältnissmässig ebenso hoher Berg existirte, der also eine Höhe von 216000 Meter oder 29 geogr. Meilen hätte, so würde auf seinem Gipfel nicht die geringste Spur einer Atmosphäre oder von irgend etwas, was davon abhängt, zu sehen sein."

„Fragen wir jetzt nach der Ursache dieser Beschaffenheit des Mondes, so halte ich es nicht für unmöglich, dass vulkanische und andere ähnliche Kräfte im Innern dieses Weltkörpers bei weitem weniger Widerstand auf einer seiner Halbkugeln als auf der andern gefunden und daher viel grössere Erhebungen - der Oberfläche auf der ersteren statt letzteren bewirkt haben."

*) Es ist Schröter gemeint. 
Soweit der Wortlaut dieser allerdings äusserst merkwürdigen Parallelstellen. Das Auseinanderliegen des statischen und des geometrischen Centrums dürfte sonach wohl unter die feststehenden wissenschaftlichen Fakta zu zählen sein, doch muss man sich hüten, die Thatsache im Sinne eines Depuis u. a. vorschnell für die Zwecke der Konjekturalastronomie auszubeuten [73].

Oben schon ward erwähnt, dass geringfügige Schwankungen der Mondkugel einen kleinen Theil (etwa ${ }^{1 / 10}$ ) der jenseitigen Hemisphäre zu übersehen gestatten. Man unterscheidet eine Libration in Länge (Maximum $7^{0} 53^{\prime}$ ), eine Libration in Breite (Maximum $6^{\circ} 47^{\prime}$ ), eine parallaktische Libration und eine physische Libration. Letztere wird eben durch das vorstehend erörterte Uebergewicht der uns abgewandten Halbkugel verursacht. Sie pflegt in den Lehrbüchern häufig: vernachlässigt $\mathrm{zu}$ werden, und es wird sich deshalb verlohnen, mitzutheilen, was Mädler von ihr aussagt [74]: ,Die neuesten Arbeiten über diesen Gegenstand hat Wichmann veröffentlicht. Er hat die bereits von Bessel begonnenen, von ihm und Schlüter fortgesetzten Beobachtungen eines Ringgebirges auf dem Monde dazu benützt, die Elemente der Rotation und Libration genauer zu untersuchen. Indess lässt sich bis jetzt aus seinen Rechnungen nur schliessen, dass die physische Libration zu klein sei, um daraus bestimmt zu werden."

Einem (imaginären) Mondbewohner würde selbstverständlich die Erde wesentlich anders erscheinen, als uns der Mond sich darstellt. Die grosse leuchtende Kugel, auf welcher die Umrisse der Kontinente deutlich erkennbar wären, geht weder auf noch unter, sondern sie schwebt stets am Firmamente, und ändert ihren Ort nur wenig, indem sie sich innerhalb eines für jeden Mondort leicht abzugrenzenden sphärischen Parallelogramms hin- und herbewegt. Näheres hierüber ist in Mädler's Astronomie [75] zu finden.

§. 8. Licht, Wärme und Atmosphäre des Mondes. Den Bestimmungen Bouguer's zufolge verhält sich die Intensität des Mondlichtes zu demjenigen des Sonnenlichtes wie 1:(250000-300 000), jenen Leslie's zufolge wie $1: 150000$ [76]. Bond fand [77], dass die mittlere Sonne $470980 \mathrm{mal}$ heller sei, als der mittlere Mond. Alle diese früheren Versuche wurden in den Schatten gestellt durch die umfassenden Untersuchungen Zöllner's, der nach zwei verschiedenen Methoden für den fraglichen Verhältnisswerth 1:619600 ermittelte, wobei dem Resultate ein wahrscheinlicher Fehler von 2,7\% anhaftet [78]. Leslie's Behauptung (a. a. O.), dass die Mondoberfläche wie ein sogenannter Lichtsauger (Bologneser Leuchtstein) wirke, ist eine isolirte geblieben oder hat sich doch nur (s. u.) insoweit bestätigt, dass allerdings ein starkes Absorptionsvermögen nachgewiesen ward. Er war zu dieser Annahme. einer Phosphorescenz des Mondlichtes wesentlich durch die Erwägung gedrängt worden, dass, wenn der Mond uns reflektirtes Licht zusendete, das Bild der Sonne an ihm wie an einem Spiegel wiederstrahlen müsste. Roger Bacon und der Araber Averroes waren nach Kästner [79] bereits in demselben Irrthum befangen gewesen, der sich doch durch den Hinweis auf die wenigstens zu Leslie's Zeit sehr wohl bekannte Thatsache beseitigen lässt, dass ja die Mondoberfläche nicht glatt, sondern im 
Gegentheile so rauh wie nur möglich ist. Diese Rauhigkeit bringt es mit sich, dass, wie Arago zuerst feststellte, im Mondlichte auch polarisirtes Licht vorhanden ist, denn die polyedrische Gestalt der Bergadern bietet eben diejenigen Neigungswinkel der Fläche dar, welche zur Polarisation des zurückgeworfenen Sonnenlichtes eine Vorbedingung sind $[80]$.

Hier ist auch der Ort, von dem aschgrauen Licht des Mondes („lumière cendrée") zu sprechen. Je weniger der Mond für die Erde erleuchtet erscheint, je dünner mithin seine Sichel ist, um so mehr Licht erhält er von der Erde zugesandt, und dieses, das bekanntlich nicht von letzterer selbst stammt, sondern der Sonne entlehnt ist, besitzt noch Leuchtkraft genug, um durch abermalige Reflexion den an sich unsichtbaren Theil der uns zugewendeten Mondhalbkugel in einem Dämmerlichte erscheinen zu lassen. Es ist merkwürdig, dass die hier vorgetragene Erklärung nahezu gleichzeitig von Mästlin und Galilei [81] gegeben wurde; für ersteren erhob sein grosser Schüler Kepler [82] die Prioritäts-Reklamation. Allein schon ein volles Jahrhundert früher hatte Lionardo da Vinci das $\mathrm{Phä-}$ nomen richtig gedeutet, ohne es doch der Mühe werth gehalten zu haben, seine Entdeckung zu veröffentlichen [83]. Etwas sanguinisch spricht Arago [84] die Hoffnung aus, man werde dereinst aus der wechselnden Intensität des aschgrauen Lichtes, dessen Strahlen ja allerdings zweimal unsere Atmosphäre durchkreuzen müssen, Schlüsse auf den mittleren Durchsichtigkeitszustand der Erdluft ziehen können*).

Dass der Mond wenig oder keine Wärme ausströmt, war schon den alten Kulturvölkern bekannt; die Inder nannten ihn deshalb den "kaltstrahlenden", und Plutarch wie Macrobius konstatirten, dass der Mond die von der Sonne ihm übermittelten Wärmestrahlen zurückhalte [87]. Bis auf Forbes herab missgliuckten alle Versuche gewandter Experimentatoren, irgend welche Einwirkungen des Mondlichtes auf das Thermometer zu erzielen, obwohl De la Hire und v. Tschirnhaus die mächtigsten Brennspiegel und Sammellinsen zur Anwendung brachten. Derselbe Spiegel, mit welchem der Letztgenannte im Winter Asbest zu Glas verbrannte, und zwar im Verlaufe von nur zwölf Minuten, liess, wenn in seinem Fokus die Vollmondstrahlen gesammelt wurden, zwar vermehrte Helligkeit, nicht aber eine erhöhte Temperatur wahrnehmen. Erst der von Melloni erfundene Thermomultiplikator ermöglichte es diesem Gelehrten, im Vereine mit Belli und Mossotti schwache Spuren der Mondwärme nachzuweisen [88]. Marié-Davy und Lord Rosse setzten diese Forschungen fort, und namentlich dem Letzteren war das Glück hold [89].

*) Von einem anderen Phänomen, dessen Beschreibung vielfach, auch im "Kosmos", mit jener des Erdlichtes verbunden wird, reden wir hier nur vorübergehend, da dessen Erörterung eigentlich in die Lehre von der irdischen Strahlenbrechung gehört. Bei einer totalen Mondfinsterniss ist der Mond selten ganz verschwunden, meistentheils bleibt die verfinsterte Scheibe in schmutzigrothem Lichte sichtbar. Plinius erzählt, was er von dieser Erscheinung wusste, mit den Worten [85]: „Mirum, quanam ratione, quum solis exortu' umbra illa heliotatrix sub terra esse debeat, semel jam acciderit, ut in occasu luna deficeret, utroque super terram conspicue sidere." Die bis heute beibehaltene Erklärung schreibt sich von Kepler [86] her. 
Er vermochte nicht nur darzuthun, dass die vom Monde zu uns gelangenden Wärmestrahlen nicht sowohl der Reflexion als vielmehr der Einschluckung und nachberigen Wiederausstrahlung ihr Dasein verdanken, sondern es gelang ihm auch, schätzungsweise einige Aufklärung über die Temperaturdifferenzen zu erhalten, die für irgend einen Mondort zwischen Tag und Nacht bestehen und namentlich deshalb zu beträchtlicher Grösse $\left(300^{\circ}\right)$ anwachsen müssen, weil keine irgend erhebliche Atmosphäre die Ausstrahlung der absorbirten Strahlen in den Weltraum verhindert.

Denn dass, wenn überhaupt eine Atmosphäre des Mondes vorhanden ist, diese doch nur einen Grad der Feinheit und Verdünnung besitzt, wie man ihn mit unseren Luftpumpen kaum herzustellen in der Lage wäre, scheint ausser Zweifel zu stehen. Die Frage nach der Existenz einer Mondluft steht seit zweihundert Jahren schon auf der wissenschaftlichen Tagesordnung. Hevelius entschied dieselbe ohne viel Bedenken in bejahendem Sinne [90], und ebenso stellte C. v. Wolf den ,Lehrsatz" auf [91]: „Umb den Mond herumb ist eine elastische und schweere Luft, darinnen die Dünste aufsteigen und durch Regen oder Thau wieder herunter fallen. " Möglicherweise hatte zu letzterer Behauptung Mästlin die Veranlassung gegeben, der einen Mondregen beobachtet haben wollte [92]. Systematisch und ruhig prüfte dagegen den Gegenstand der Altdorfer Mathematiker H. Müller [93], indem er den damals natürlich noch in hohem Ansehen stehenden Angaben Hevel's diejenigen eines Huygens, Duhamel und Eimmart gegenüberstellt, welch letzterer mit Bestimmtheit erklärt hatte: „Tenuis aër non videtur esse suffusus luna, alioquin non cernerentur minutiae subtilissimae tam clare atque distincte in tanta remotione. ${ }^{*}$ Müller selbst zieht, das Für und Wider sorgsam abwägend, das Facit seiner Untersuchung mit den Worten [94]: „Atmosphaera circa lunam prorsus negari non potest." Gegen die Annahme einer der irdischen irgend vergleichbaren Atmosphäre sprechen insbesondere zwei Umstände: die scharfe Begrenzung der Schatten, welche die Mondberge werfen, und die bei Sternbedeckungen gemachten Erfahrungen, indem der Stern bis zu dem Augenblicke, in welchem der Mondrand ihn verdeckt, in ungeschwächtem Glanze leuchtet. Bessel beschäftigte sich mit der an ihm stets gewohnten Sorgfalt mit dieser Frage und fand [95], dass der höchste Werth einer lunaren Strahlenbrechung, welcher allenfalls noch als mit den Beobachtungen verträglich angenommen werden könnte, eine Sekunde sei, und dass unter Zugrundelegung dieses Werthes die obere Grenze für die Dichtigkeit der Mondatmosphäre höchstens auf $1 / 1000$ der Dichtigkeit unserer irdischen Atmosphäre gewerthet werden könne. Neuerdings endlich haben die englischen Astronomen, welche das Studium der Mondkunde sich zur besonderen Aufgabe gestellt haben, entgegengesetzte Ansichten verlautbaren lassen, welche man in den berühmten selenographischen Werken, deren der folgende Paragraph eingehender zu gedenken haben wird, vorgetragen findet, bei Nasmyth-Carpenter im fünften, bei Neison im zweiten Kapitel. Die beiden Ersteren sprechen dem Monde jedwede Lufthülle nicht nur für die Gegenwart ab, sondern gehen sogar so weit, zu erklären, dass es eine solche zu gar keiner Zeit gegeben haben könne, $\mathrm{N}$ eis on dagegen, der schon früher in Bessel's bezüglichen Rechnungen Gủnther, Geophysik. I. Band. 
eine nicht unwichtige Vernachlässigung bemerkt hatte, schliesst aus seiner Diskussion der lunaren Horizontalrefraktion, dass recht wohl eine Atmosiphäre von der Dichtigkeit ${ }^{1 / 400}$ angenommen werden dürfe. Wir werden sonach wohl berechtigt sein, den vorsichtigen Ausspruch des alten Müller (s. o.) auch heute noch gelten zu lassen. Eine sehr beachtenswerthe Wahrnehmung ist diejenige des absolut zuverlässigen Julius Schmidt, dass ihm einmal ein Kratergrund in mattgrauer Färbung erschienen sei, während ringsum noch tiefes Dunkel die Gebirge einhüllte, ein Anomalon, dessen Erklärung am besten in der Weise gegeben werden könne, dass man die Tiefe des Kraters als durch eine Gas- oder Dampfmaterie erfüllt sich denke, deren die Ränder übersteigende Oberfläche von der aufgehenden Sonne erleuchtet werde [96].

\section{§. 9. Die Mondtopographie in ihrer geschichtlichen Entwickelung.} Schon das Alterthum interessirte sich für das "Gesicht" im Monde, wie es die in der historischen Einleitung erwähnte plutarchische oder pseudoplutarchische Schrift nennt; eben dort ist auch von dem Einfall des Agesianax [97] die Rede gewesen, dass der Mond die Konfiguration der Erdkonturen wiederspiegle. Wie Peschel erzählt [98], entwarf zuerst Anaxagoras Zeichnungen von den Mondflecken, in welchen er Höhen und Tiefen erblickte, und ihm soll der gleichen Quelle [99] zufolge der Scholastiker Alexander Neckam beigepflichtet haben, indem er sagte: „Aliis visum est, corpus lunae non esse rotundum, sed in quibusdam suis partibus esse eminentius, in aliis depressius"*). Zur Klarheit über das Wesen der Unregelmässigkeiten in der Mondscheibe konnte natiurlich erst das Fernrohr verhelfen, und so sehen wir denn gleich nach Erfindung des Fernrohres Galilei, Hirzgarter, Schyrle de Rheita u. a. eifrig an der Arbeit, Skizzen des Mondes anzufertigen [103]; besonderes Interesse scheint dem Monde nach neueren Studien Cassani's und Favaro's [104] auch Galilei's gelehrter Freund Paolo Sarpi entgegengebracht zu haben. Die erste diesen Namen verdienende Mondkarte ist diejenige des spanischen Hofkosmographen Van Langren, die unter dem Titel „Planisphaerium lunae, a se mediantibus telescopiis observatum ", während des Zeitraumes 1647-57 ausgegeben wurde; genauer weiss selbst Quetelet [105] den Zeitpunkt nicht zu präcisiren. Langren legte den auffälligeren Unebenheiten die Namen von Heiligen und biblischen Persönlichkeiten bei. Auf einer höheren Stufe sowohl wissenschaftlicher als auch namentlich künstlerischer Ausführung steht die in Hevel's berühmtem Mondwerke [106] mitgetheilte Vollmondkarte, zu deren Herstellung sich

*) Eine wie immer originelle, aber leider sehr schwer verständliche Theorie von der Natur des Mondes hatte sich $\mathrm{D}$ ante gebildet; man findet dieselbe paraphrasirt im zweiten Gesange des Paradieses, wo von Vers 85 an eine eigenthümliche, physikalische Auseinandersetzung beginnt; deren Anfang lautet nach Nott e r's Uebersetzung folgendermassen [100]:

,Ist locker nicht des Mondes ganze Schichte,

So muss ein Endpunkt sein, von wo nicht frei

Der Strahl kann nicht mehr ziehen durch das Dichte."

Obwohl ein Mossotti [101] und ein Fürst B oncompagni [102] sich an der Interpretation dieser Stellen, namentlich wegen des darin beschriebenen katoptrischen Versuches, betheiligt haben, besteht doch immer noch nicht volle Klarheit. über den eigentlichen Sinn. 
der fleissige Mann durch mühsame Phasenzeichnungen vorbereitete. Ihm hatte ursprünglich der Gedanke vorgeschwebt, die Berge u. s. w. nach bekannten Astronomen zu benennen, allein er verwarf ihn wieder aus Furcht, da und dort anzustossen, und übertrug deshalb eine Reihe geographischer Kunstwörter auf den Mond, während er die von ihm als Meere betrachteten Dunkelstellen mit Phantasienamen (Mare serenitatis, mare imbrium u. s. w.) belegte [107]. Was Riccioli's bald nachher publicirte Mondkarte anlangt, die eigentlich von seinem Freunde Grimaldi, dem Entdecker der Lichtbeugung, herrührte, so war dieselbe zwar weniger vollkommen, als diejenige Hevel's, allein, da er ausführte, was jener nur gewollt hatte, und da seine Terminologie der Mondberge sich allgemein Eingang verschaffte, so ward er als Selenograph fast bekannter, als sein Vorgänger [108]; von Hevel's Bezeichnungen haben sich nur diejenigen der "Meere" zu erhalten gewusst. D. Cassini, De la Hire, Rost u. a. lieferten ebenfalls Mondkarten, die aber vor den bereits vorhandenen kaum einen Vorzug verdienten, da sie eben auch nicht auf eigentlicher Messung beruhten.

Hier Wandel geschafft zu haben, ist eines der vielen unsterblichen Verdienste des älteren Tobias Mayer, der das mit Mikrometer ausgerüstete Fernrohr wesentlich deshalb auf den Mond anwandte, um die selenographische Orientirung der wichtigeren Flecke ermöglichen und so Anhaltspunkte für seine Untersuchungen über die Mondrotation [109] gewinnen zu können. Seine Karte, obwohl nur klein dem Formate nach, übertraf weit alles bisher Geschaffene. Schröter dagegen, der nach einem neuen Plane die Topographie unseres Begleiters bearbeitete, hat in strenger Konsequenz dieses in einem voluminösen Werke [110] beschriebenen Planes vielleicht nicht ganz das geleistet, was man von seinen optischen Hülfsmitteln zu erwarten berechtigt gewesen wäre, doch verlangt nach Wolf's [111] Urtheil die Gerechtigkeit, dass man nicht ganz ohne Weiteres sich zu Mädler's ungünstigem Urtheil [112] bekenne. Um so reiflicher durchdacht war der Plan, welchen dreissig Jahre später Lohrmann seiner grossartigen Vermessungsarbeit des Mondes zu Grunde legte; leider starb er über dessen Ausführung, und es ist von dem Riesenwerke ausser vier Sektionsblättern nur eine treffliche Generalkarte erschienen. J. Schmidt danken wir es, die Lohrmann'schen Karten nunmehr in einer dem Standpunkte der neuesten Zeit angepassten Prachtausgabe [113] zu besitzen. Werthvolle Ergänzungen zu Lohrmann's Arbeiten lieferte F. W. Opelt [114]. Ziemlich gleichzeitig begann Mädler, in Gemeinschaft mit Beer, seine dankenswerthen selenographischen Arbeiten ; beide zusammen lieferten die rasch berühmt gewordene Mondkarte [115] und das grosse beschreibende Textwerk [116] dazu, während Mädler allein den noch jetzt als Einleitung in die Mondkunde warm zu empfehlenden Auszug daraus [117] veröffentlichte. Vielseitig ward nach Beendigung dieser Arbeiten der Meinung Ausdruck gegeben, unser Wissen vom Monde sei jetzt ein abgeschlossenes, allein man braucht blos an den Maassstab der Mädler'schen Karte zu denken, um die Irrigkeit dieser Ansicht zu begreifen. „Dieser Maassstab, " sagt Bessel [118], „bringt 16 deutsche Meilen auf jeden Zoll. Spezieller, als man ein Land der Erde, nach einem Maassstabe eines Zolles für 16 Meilen dargestellt, in einer Entfernung von 13 Zollen erkennen kann, können also die Mondkarten 
nicht sein. Eine Karte, welche ganz Frankreich auf einem Quartblatte darstellt, ist so speziell, als die Mondkarten sein können. " In der That trat zwanzig Jahre nachher Jul. Schmidt, der seit 1840 zuerst in Olmütz, nachher aber unter dem günstigeren Himmel Athen's ein unverdrossener Beobachter unseres Trabanten ist, mit einem neuen trefflichen Werke [119] über diesen hervor, und auch seit dieser Zeit hat derselbe eine Reihe wichtiger selenographischer Beiträge geliefert, unter welchen sein Katalog der Rillen und die am Schlusse des vorigen Paragraphen genannte Arbeit obenanstehen. In Deutschland ist zur Zeit der eifrigste Erforscher des Mondes H. J. Klein, von welchem in diesem Kapitel noch mehrfach die Rede sein wird. Der eigentliche Brennpunkt der Wissenschaft des Mondes ist aber gegenwärtig England; dort blüht eine eigene "Selenographical Society", dort arbeitet Birt im Auftrage der "British Association" an einer neuen grossen Mondkarte [120], dort endlich haben Nasmyth-Carpenter [121] und Neison [122] jene ausgezeichneten Werke geschrieben, deren wir schon gedachten, deren Kenntniss uns Deutschen eben durch Klein's Mühwaltung vermittelt worden ist. Zumal mit Neison's Schrift scheint wieder einmal ein Stufenjahr unseres selenographischen Lebens und Forschens erreicht, und es ist wenigstens für die nächsten Jahre keine wesentliche Bereicherung unserer Kenntnisse mehr zu erwarten, falls nicht etwa das Kapitel der physischen Veränderungen einen von menschlicher Initiative unabhängigen Zuwachs erfahren sollte. Eine gute neuere Schrift der populär-astronomischen Literatur Deutschlands ist diejenige M. Opelt's [123]*).

Die Absicht, einen Mondglobus zu konstruiren, soll zuerst De la Hire gehegt haben, doch fand dieselbe ihre Realisirung nicht [124]. Auch Tobias Mayer kam nicht mit diesem Geschäfte in's Reine, obwohl er die fertigen Segmente in musterhafter Ausführung hinterliess, dagegen sind später wirkliche Mondgloben hergestellt worden durch Riedl v. Leuenstern, durch Dickert und namentlich durch Mädler's Schwiegermutter, die Hofräthin Wilhelmine Witte [125]. Was aus einer gegen Ende des vorigen Jahrhunderts von J. Russell ziemlich pomphaft angekündigten künstlichen Mondkugel [126] geworden ist, wissen wir nicht zu sagen. Doch ist der Mangel an solchen Hülfsmitteln wohl wenig zu beklagen, da dieselben, so gut sie zur Veranschaulichung mancher Verhältnisse sich eignen mögen, doch kaum den Fortschritten der Wissenschaft zu dienen im Stande sind. Um so mehr thut diess die Mondphotographie im Vereine mit der Spektroskopie, die schon mit Daguerre ihren Anfang nimmt, aber erst nach und nach durch Bond, Whipple, Black, S. Wolf, Warren de la Rue, Rutherfurd, Draper und Janssen zur gegenwärtigen Vollen-

*) Sollte es einem Leser auffallen, dass Gruithuisen's oben gar nicht gedacht worden ist, so wolle er bedenken, dass derselbe eine ganz eigenthümliche Stellung einnimmt. Es ist wahr, derselbe hat in den von ihm herausgegebenen Zeitschriften ("Analekten für Erd- und Himmelskunde", "Astronomisches Jahrbuch für physische und naturhistorische Himmelsforscher "und Geologen") manch" brauchbares Material gesammelt, und man hat neuerdings (vgl. Abtheil. III, Kap. II) erkannt, dass doch mehr hinter ihm steckt, als zumal Mä.dler glauben machen wollte, allein ein Astronom im Sinne der Neuzeit war er eben doch nicht, und nur von diesen wurde oben gesprochen. 
dung gebracht ward [127]. Dass auch die Spektralanalyse des Mondes nicht uneingedenk blieb, versteht sich wohl von selbst, doch konnte man, da ja unser Trabant kein eigenes Licht aussendet, von vornherein erwarten, dass Sonnen- und Mondspektrum sich nicht von einander unterscheiden würden, eine Erwartung, die Huggins bestätigt fand [128].

§. 10. Allgemeine Beschreibung der Mondoberfläche. Wenn wir, wie im Folgenden stets geschieht, uns strenge an die von $\mathrm{Nei}$ is on (im III. Kapitel) vorgeschlagene Klassifikation der Mondgebilde als an die zur Zeit gewiss beste halten, so haben wir zu unterscheiden: Dunkle Ebenen, etwa $2 / 5$ der Gesammtoberfläche, Kratergebilde, die am häufigsten vorkommende und für den Mond besonders charakteristische Formation, endlich Erhebungen schlechtweg, wozu dann noch die Rillen als etwas ganz Spezifisches hinzutreten. Die Ebenen erster Art zerfallen wieder in Hevel-Riccioli's "Maria“, dunkle, grosse Flecke, die schon das unbewaffnete Auge wahrnimmt, "Paludes“ und "Lacus", kleinere, hellere und minder gut begrenzte "Flächen, endlich "Sinus" als scharf markirte Ausbuchtungen der sogenannten Meere, die natürlich diesen Namen nicht eigentlich verdienen, da zugleich mit der. fast gänzlichen Abwesenheit von Luft auch das Fehlen von Wasser auf dem Monde festgestellt ist. Die Krater stellen sich uns dar als kreisrunde oder ovale Gebilde, deren umschliessende Wälle nach aussen weit sanfter als nach innen abfallen, während auch im Inneren niedrigere Erhebungen zu finden sind. Neison's feinerer Unterscheidung verdanken wir die folgenden Einzelkategorieen: Wallebenen, deren Durchmesser bis zu $240 \mathrm{~km}$ anwächst, unregelmässig begrenzte und verzweigte Ringe, ein Mittelding zwischen "Meer" und Krater repräsentirend; B er gringe ( mountain-rings"), den Wallebenen ähnlich, jedoch mehr differentiirt und Spuren von Zerstörung an sich tragend; Ringgebirge im Mädler'schen Sinne (,ring-plains"), von kreisförmigen, ungleich hohen Wällen umgebene Ebenen, in deren Mitte ein deutlicher Centralberg bemerkbar ist; Kraterebenen, den Ringgebirgen im Allgemeinen ähnlich, aber zerrissener und wilder; Eigentliche Krater, kleine (7-20 km im Durchmesser haltende) Gebilde mit regelmässiger, nicht sehr hoher Wallbegrenzung, ausgezeichnet durch Helligkeit; Krater chen (,craterlet"), Niniaturkrater von 1-9 km Durchmesser, durch alle Formationen ausgestreut, nicht zu verwechseln mit den früher damit konfundirten Kratergrübchen („crater-pits“), deren Wallring durch eine sehr geringe Neigung gegen die umgebende Ebene ausgezeichnet ist; man darf in ihnen gewöhnliche Einsenkungen („depressions") erblicken, wie sie auch auf der Erde vorkommen, und braucht gerade nicht an vulkanischen Ursprung zu denken. Doch giebt es auch noch Depressionen im engeren Sinne, thalartige Bildungen, denen der Wallring gänzlich fehlt, und isolirte steile Kraterkegel mit centralen Vertiefungen, die kaum bis zur Hälfte des Konus hinabreichen; ihre Aehnlichkeit mit den irdischen Vulkanen fällt am meisten in's Auge. Alle diese auf eine vulkanische Thätigkeit des Mond-Inneren hinweisenden Erhöhungen fallen nicht unter den Begriff der von Hevelius als „montes" bezeichneten Bodenerhebungen; wohl aber gehören in diese dritte Kategorie die eigentlichen Gebirgsketten („mountain-ranges"), welche zum Theile den 
Längengebirgen, zum Theile den Hochplateau's der Erde vergleichbar sind, die isolirten Berge oder Piks, die verzweigten Hügellandschaften und die den wilderen Regionen angehörigen Bergrücken ( mountain-ridges" ${ }^{\prime \prime}$. Hiezu endlich treten noch jene sonderbaren, langzeiligen Adern, deren Besonderheiten zu ergründen den Selenographen noch nicht gelungen ist. Engelmann, dessen eingehender Besprechung des Neison'schen Buches wir im Vorstehenden schon mehrfach gefolgt sind, berichtet hierüber [129]: ${ }_{n}$ Als eine Klasse für sich betrachtet Neis on schliesslich die räthselhaften Rillen; oft $300-500 \mathrm{~km}$ lange, enge und tiefe Schluchten und Kanäle; gewöhnlich gerade, oft verzweigt, nicht selten einander schneidend und selbst alle Wälle, Rücken oder Gruben auf ihrem Wege ohne Unterbrechung durchsetzend. Sie finden sich in allen Gegenden und Formationen und spotten bei ihrer grossen Zartheit aller Versuche, Natur und Entstehung zu erforschen. Die Aehnlichkeit mancher nach Form und Lage mit ausgetrockneten Flussbetten scheint Neison nicht zu-

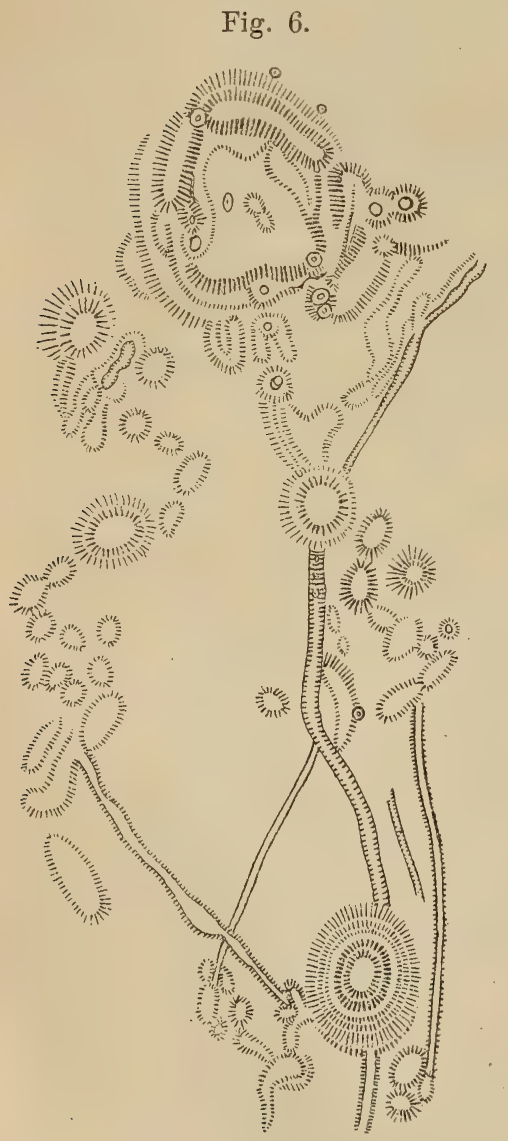
fällig zu sein; andere deuten nach Schmidt hingegen auf vulkanische Entstehung. Ihre Anzahl ist seit Schröter von 11 schon nahe auf 1000 gestiegen."

Höhen der Mondberge sind seit Galilei, der zur Lösung dieser Aufgabe sofort den richtigen Weg vorzeichnete [130], häufig gemessen worden, doch haben solche Bestimmungen nur einen relativen Werth, da das für irdische Höhenmessungen von selbst sich darbietende Meeresniveau hier fehlt, so dass die angegebene Zahl lediglich festsetzt, um wieviel Längeneinheiten eine Bergspitze sich über die umgebenden Niederungen erhebt. Die Methode der Messung kann eine doppelte sein. Befindet sich ein Kegelberg gerade am Rande der Mondscheibe, so lässt sich mittelst einer mikrometrischen Vorrichtung der Bogenwerth des Berges in seinem Verhältniss zu dem scheinbaren (sphärischen) Radius der Scheibe bestimmen, woraus daun durch einfache Rechnung das Verhältniss der entsprechenden linearen Grössen hergeleitet werden kann. Andererseits muss die Zeit beobachtet werden, welche von dem Augenblicke an, wo ein der Nachtseite des Mondes angehöriger Gipfel zuerst in den Strahlen der aufgehenden Sonne erglänzt, bis zu dem weiteren Augenblicke verstreicht, da die sehr scharf abgegrenzte Schattenlinie bis an den Lichtpunkt selbst herangerückt ist. Nach 
Neison erheben sich die Berge im Durchschnitt von $900-1500 \mathrm{~m}$, einzelne bis zu $2460 \mathrm{~m}$, ja die Hochplateau's erreichen sogar eine relative Höhe von $6150 \mathrm{~m}$. Im Allgemeinen kann man sagen, dass die Unebenheiten im Relief der Mondoberfläche die reine Kugelform des Mondkörpers in weit höherem Maasse beeinträchtigen, als diess für die Erde der Fall ist.

Unsere Fig. 6, die einer Schmidt'schen Skizze nachgebildet ist, sucht einen Ueberblick über die charakteristischen Eigenthümlichkeiten der lunaren Gebirgswelt zu geben; sie stellt das vom Ringgebirge Campanus (oben in der Figur) ausgehende und am Hippalus vorüberstreichende Rillensystem dar und lässt einen Einblick in den sozusagen unmotivirten Verlauf dieser Gebilde thun. Aber auch gewisse vulkanische Gegenden der Erde weisen Züge auf, die denen des Mondes geradezu verwandtschaftlich sind. Namentlich die Inseln des grünen Vorgebirges sind reich an Konglomeraten kleinerer Kraterkegel, deren Gesammteindruck derselbe ist, wie bei einer Mondlandschaft;

Fig. 7.

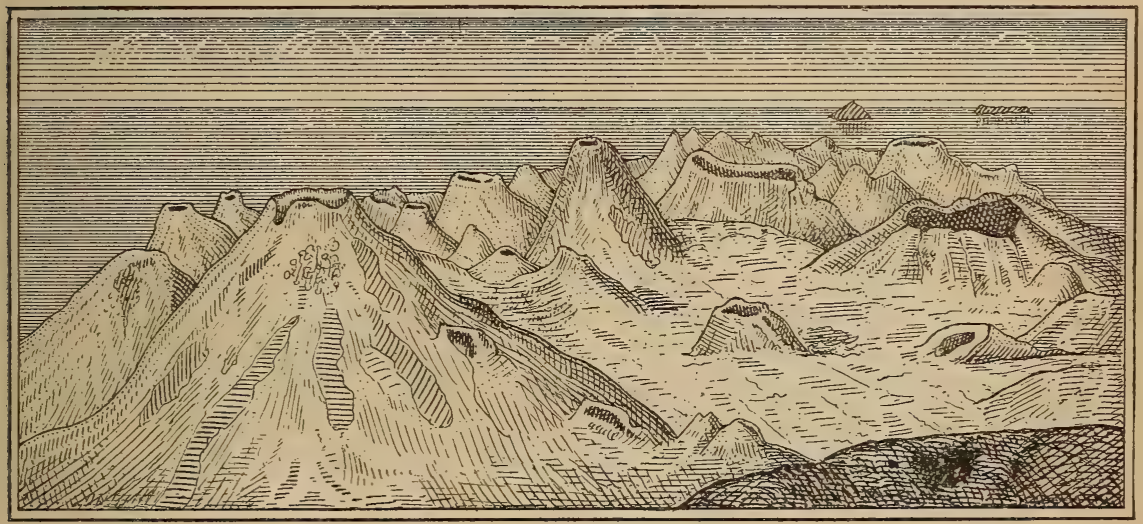

Fig. 7, eine-Reproduktion der zweiten Tafel in Dölter's trefflicher Monographie jener Inselvulkane [131], mag zum besten Belege dienen.

§. 11. Der lunare Vulkanismus und die physischen Veränderungen der Mondoberfläche. Ueber den Zusammenhang gewisser Gebirgsformen des Mondes mit der Aktion vulkanischer Kräfte kann wohl kein Zweifel mehr obwalten, wohl aber über die näheren Modalitäten der fraglichen Kraftäusserung. Das achte Kapitel des Werkes von Nasmyth und Carpenter ist wesentlich der Entwickelung einer neuen, speziell den lunaren Verhältnissen angepassten Theorie der vulkanischen Erscheinungen gewidmet, welcher der Rezensent Leipoldt [132] nur eine bedingte Gültigkeit zugestehen kann. Da wir in der dritten Abtheilung dieses unseres Lehrbuches vom terrestrischen Vulkanismus des Näheren handeln müssen, so werden wir vorläufig nur jene Punkte berühren, welche eben nach der Meinung der englischen Selenographen eine Verschiedenheit zwischen Erde und Mond erkennen lassen.

Dem Wasserdampf darf nach dieser Theorie so gut wie gar keine einflussreiche Rolle zugewiesen werden, so sehr auch die Vulkanforscher 
gewohnt sind, ihn eine solche spielen zu sehen, denn der Mond besitzt ja nicht nur jetzt kein Wasser, sondern er hat auch in früheren Jahren nie mehr als eine minimale Quantität inne gehabt. Ein hinlänglich stichhaltiger Beweis scheint von Nasmyth und Carpenter für diese These freilich nicht erbracht worden zu sein. Die Basis der neuen Lehre ist von Letzteren schon im dritten Kapitel ihres Werkes [133] gelegt worden, und zwar ist sie wesentlich dieselbe, auf welcher auch die modernsten Theorieen der Gebirgsbildung beruhen. Die ursprünglich gluthflüssige Masse des Mondes erkaltete und zog sich zusammen, da aber mit der Erstarrung eine Ausdehnung der Körper eintrete, so sanken die Oberflächenstoffe nicht etwa in dem feurigen Brei unter, sondern um diesen herum bildete sich eine starre Kruste, welche von der darunter befindlichen Flüssigkeit, sobald deren obere Schichten dem Festwerden näher kamen, an vielen Stellen durchbrochen und zerrissen werden musste. Damals, als die beiden Briten schrieben, konnten sie sich zunächst nur auf Mallets bekannte Untersuchungen berufen, die allerdings noch nicht beweiskräftig genug waren und namentlich wegen ihrer Zuhülfenahme einer unbekannten mystischen Kraftwirkung („repellent force") bei den Physikern nur sehr getheilten Beifall zu finden fähig sich zeigten [134]. Die neue, exakte Versuchsreihe, welche Nies und Winkelmann kürzlich publizirt haben [135], dient nun freilich der Mallet'schen Theorie zu einer so willkommenen Bestätigung, wie sie kaum erwartet werden durfte. Beide Forscher konnten sich nur auf wenige Vorarbeiten von Réaumur, Marx u. a. stuitzen und fanden bei Durchmusterung der Literatur, dass noch kein Metall von Allen, die es geprüft hatten, im gleichen Sinne beurtheilt worden war; sie unterwarfen deshalb Zinn, Kupfer, Blei, Zink, Wismuth, Kadmium, Antimon, Eisen, Silikate und gewisse Legirungen einer erneuten Prüfung. Da ergab denn [136] der Fundamentalversuch, dass, Blei und Kadmium ausgenommen, bei jedem Metalle der Uebergang vom flüssigen zum festen Zustande mit einer Ausdehnung verbunden ist, dass also das feste Metall ein geringeres spezifisches Gewicht besitzt, als das schmelzflüssige [136]. Was die Legirungen betraf, so ergab die auf gleiche Art angestellte Untersuchung weit weniger zuverlässige Resultate, indem ein als Gussstück aus der flüssigen Masse herausgehobener Bestandtheil nicht nothwendig mit jener eine gleichheitliche Zusammensetzung haben muss. Auch für die Silikate liegt noch keine endgültige Entscheidung vor, doch scheint auch für sie nach Lang eine Ausdehnung wahrscheinlicher zu sein, als die von Bischof behauptete Zusammenziehung, und somit ist der landläufigen Theorie, dass der Kern eines ursprünglich gluthflüssigen Weltkörpers fest sein müsse, eine kräftige Stütze entzogen [137]. Von dieser Seite her hat somit die Nasmyth-Carpenter'sche Theorie, zu der sich im Wesentlichen auch H. J. Klein [138] bekennt, keine bedenkliche Gegnerschaft zu erwarten, wohl aber darf man einwerfen, dass durch ein blosses Emportreiben feuriger Massen allenfalls die Bildung eines homogenen Vulkanes, nicht jedoch die eines zerrissenen Kraters leicht zu erklären sei. Auch mit der Erosionsthätigkeit der Lavaströme wird sich nicht Jedermann befreunden können.

Betreffs der Art und Weise, wie man sich den angedeuteten Anschauungen gemäss die Entstehung eines Mondvulkanes zu denken 
habe, sei auf Fig. 8 verwiesen. $\mathrm{C}$ stellt in allen vier Fällen das im flüssigen Gluthzustande befindliche Innere des Mondes dar, B eine zunächst anliegende, von vertikalen Kanälen durchsetzte Schicht der Kruste, in welcher die durch die horizontalen Pfeile versinnlichten Spannungen herrschen, A endlich eine oberflächliche Schicht. Durch die Zusammenziehung der tiefer liegenden Flüssigkeitsmasse entstehen Runzelungen der äusseren Kruste, die in Fig. 8, I blos zu einer wellenförmigen Falte geführt haben, unter welcher sich ein Hohlraum bildete. Erfolgte die Faltung energischer, so ergab sich ein Bruch (Fig. 8, II), aus welchem auch eine theilweise Verschiebung und Ueberschiebung der Ränder (Fig. 8, III) resultiren konnte. Traf es sich nun endlich so, dass der in Fig. 8, II dargestellte Riss gerade der Oeffnung einer mit dem Inneren kommunicirenden Spalte gegenüber erfolgte, so schob sich ein Theil des Gluthbreis in den Hohlraum vor, füllte, wie man aus Fig. 8, IV ersehen kann, zunächst diesen aus und drang aus ihm durch die Bruchstelle an die Aussenseite empor, wo sich eine glockenförmige

$$
\text { 1. Fig. } 8 . \quad \pi
$$
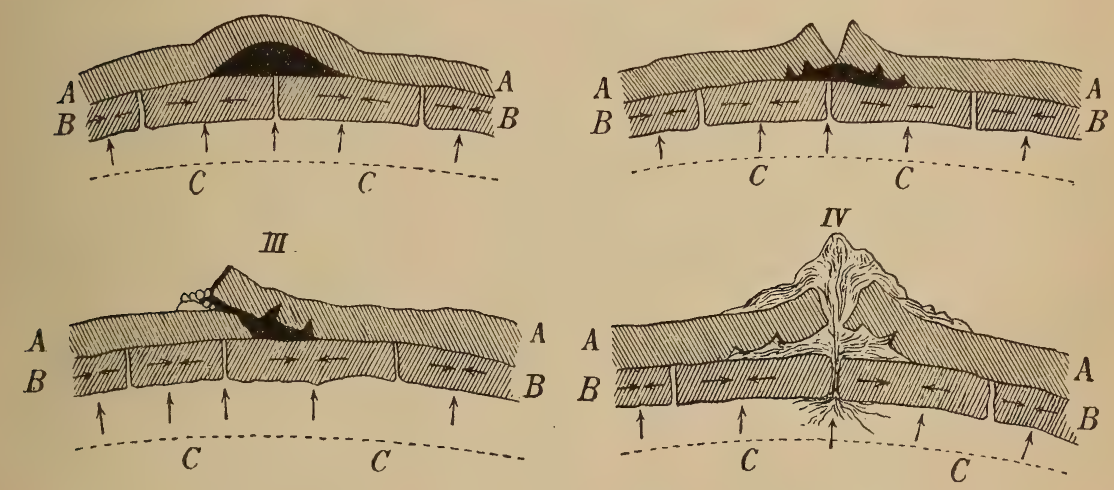

Aufschüttung mineralischer Stoffe bildete, die natürlich bald erstarrte. Im Grossen und Ganzen kann dieser Theorie eine gewisse Berechtigung wohl nicht abgesprochen werden, nur glauben wir daran festhalten zu müssen, dass das zerklüftete Aussehen der Mondvulkane nicht durchweg mit ersterer harmonirt.

Originell darf auch die vulkanistische Erklärungsweise genannt werden, welche Nasmyth und Carpenter [139] für die sogenannter. Strahlensysteme geben, helle Striche, die von einzelnen grösseren Kratern radial nach allen Seiten hin auslaufen und oft über $1000 \mathrm{~km}$ weit sich erstrecken. Namentlich bei dem grossen Gebirge Tycho ist dieses Radialsystem derart ausgebildet, dass es auf einer kleineren Mondkarte völlig den Eindruck einer Schaar von Meridianen erweckt, die in dem Pole einer künstlichen Himmelskugel zusammenlaufen. Wenn man nun im Laboratorium eine hohle und mit Wasser gefüllte Glaskugel zum Zerspringen bringt, indem man sie dem Gefrieren aussetzt*),

*) Man erinnere sich, dass Wasser seine Maximaldichte bei $4^{0}$ erreicht und somit im Momente des Gefrierens sich energisch ausdehnt. Näheres darüber bringt die Lehre vom Gletschereis. 
so zerspringt die Kugel nur selten in mehrere getrennte Stücke, sondern von einem bestimmten Punkte des geringsten Widerstandes aus strahlen die entstehenden Risse nach allen Seiten aus, und ähnlich soll der Process auch auf dem Monde sich vollzogen haben. Zwischen den mysteriösen Rillen und den soeben geschilderten Strahlensystemen statuiren die englischen Naturforscher eine gewisse Verwandtschaft. Jedenfalls scheint die Erklärung, welche die Strahlen mit Sprüngen der sich zusammenziehenden Mondkruste identificirt, sich besser den Thatsachen anzuschmiegen, als die von Lamey [140] gegebene. Derselbe hält nämlich dafür, dass bei heftigen Gasausbrüchen aus der Tiefe geschmolzene Massen in Fülle mit emporgerissen würden, die alsdann nach allen Seiten hin niederfielen; dadurch erklärten sich die häufigen, in weisslichem Glanze schimmernden Unterbrechungen und die auffälligen Verschiedenheiten in der Lichtstärke. Allein die ungeheure Ausdehnung einzelner Strahlen lässt sich mit dieser Entstehungshypothese nicht vereinigen.

Wenn frühere Forscher über die vulkanischen Ereignisse auf dem Monde debattirten, so litten sie immer unter dem ungünstigen Erfahrungsmaterial, über welches allein zu verfügen war. Eine der lehrreichsten Abhandlungen über den Gegenstand ist diejenige Kant's "Ueber die Vulkane im Monde ${ }^{*}[141]$. Wir ersehen aus derselben, dass Don Ulloa's Nachricht über ein von jenseits erleuchtetes Loch, das er in der Mondkugel wahrgenommen haben wollte [142], damals viel Staub aufwirbelte, dass.man die freilich nur halb geglaubte Notiz mit Vulkanen in Verbindung brachte und vielfach erfreut war, durch W. Herschel's Beobachtung vom 4. Mai 1783 endlich einen wirklichen Beweis für die Existenz thätiger feuerspeiender Berge auf unserem Trabanten beigebracht zu sehen. Aepinus, Beccaria und Lichtenberg sprachen sich in diesem Sinne aus, nur Kant selbst blieb Skeptiker und wandte sich insbesondere gegen Beccaria's Auffassung der Strahlensysteme als Ströme erhärteter Lava. In Kap. II, §. 13 haben wir uns überzeugt, wie kurze Zeit ein enthusiastischer Eifer für die Zurückführung der Meteorfälle auf die Thätigkeit des lunaren Vulkanismus herrschte, der freilich vor der nüchternen Kritik der Rechnung nicht auszudauern vermochte. Schröter gab sich sodann die erdenklichste Mühe, physische Veränderungen auf der Mondoberfläche nachzuweisen, und er glaubte schliesslich auch auf einige Früchte seines Fleisses hinweisen zu können, allein Klein belehrt uns, dass von sämmtlichen Angaben des Lilienthaler Astronomen höchstens eine einzige, und diese nur bedingt, als richtig angenommen werden dürfte [143]. Die Männer der Wissenschaft begegneten deshalb bis zu unseren Tagen allen neueren Berichten über physische Umgestaltungen einzelner Theile des Mondes mit dem äussersten Misstrauen [144]; es ist diess an sich gewiss völlig gerechtfertigt, indem ein Zuviel immer minder schädlich wirken wird, wie ein Zuwenig.

Gleichviel haben sich neuerdings auch Stimmen im entgegengesetzten Sinne vernehmen lassen, und zwar gehen dieselben von angesehenen Mondtopographen aus, die in diesem heiklen Falle wohl allein als zur Abgabe eines vollwichtigen Urtheiles geeignet erscheinen dürften. H. J. Klein machte auf fünf lunare Oertlichkeiten aufmerksam, betreffs deren seine Beobachtungen mit den vorhandenen guten 
Karten eines Mädler, Lohrmann u. s. w. durchaus nicht in Einklang zu bringen waren, und zumal am Krater Hyginus schien eine Neubildung ausser allem Zweifel zu stehen [145]. Neison, der seiner eigenen Aussage nach anfänglich gar nicht geneigt war, Modifikationen der ihm aus gründlichstem Studium wohlbekannten Mondgegend zuzugestehen, trat nach nochmaliger Prüfung des Sachverhalts in einer eigens zu diesem $\angle w e c k e$ verfassten grösseren Arbeit für die Richtigkeit der Klein'schen Behauptung ein [146]. Endlich hat sich ein dritter Selenograph allerersten Ranges, Jul. Schmidt, ganz vor Kurzem entschieden mittelst eines an Klein gerichteten offenen Briefes für die Realität der am Hyginus entdeckten Metamorphose ausgesprochen [147]. Ein unbedingt anzuerkennender Beweis dafür, dass diese Veränderungen auf die Manifestirung vulkanischer Kräfte zurückgeführt werden müssten, liegt allerdings noch nicht vor. Man hat zur Zeit noch ein Recht, an blos mechanische Kraftäusserungen, an Bergschlipfe oder auch an Zertrümmerungen zu denken, welche in dem grellen Unterschiede in der Insolation und Erwärmung zur Tag- und Nachtzeit ihren Grund hätten. Nachdem - namentlich durch die ,Selenographical Society" - die Parole ansgegeben worden ist, dass möglichst ausschliesslich blos Mondlandschaften von geringer Ausdehnung, dafür aber unter den allerverschiedensten Beleuchtungsverhältnissen, dem Studium zu unterwerfen seien, dürfen wir wohl in Bälde weiterer Erfahrungsthatsachen gewärtig sein. Jedenfalls macht uns die Hypothese eines annoch thätigen vulkanischen Lebens auf dem Monde allein schon der Umstand mundgerechter, dass J. Schmidt sich zu ihr bekennt, ein Gelehrter, dessen Bekanntschaft mit den lunaren Erscheinungen cine ebenso gründliche ist, wie mit den Erscheinungen, welche aus den Reaktionen des glühendflüssigen Erdinneren gegen die umhüllende Kruste sich ergeben*).

* Es mangelt natürlich auch nicht an anderweiten Hypothesen, welche die Oberflächenform des Mondes ohne Beiziehung des Vulkanismus befriedigend zu erklären sich vorgesetzt haben. Schmick bringt jene mit seiner uns im Umrisse bereits bekannten Ueberfluthungslehre (§. 6) in Verbindung, indem die Gravitation der so nahen Erde auf dem gluthflüssigen Balle des Trabanten die heftigsten Gezeitenbewegungen hervorgerufen hätte [148]. Ein Anonymus [149] kündigt der Eruptionstheorie um deswillen Fehde an, weil die umherliegende Gebirgsmasse dem Volumen des Kraters an Grösse durchaus nicht entspreche; die Maare und die neuseeländischen Kraterseen würde freilich das nämliche Argument treffen. Kosmische Körper, Meteore, die früher in noch weit grösserer Menge den Weltraum durchzogen haben sollen, trafen auf den noch im Zustande feurigflüssiger Wallung befindlichen Mond, sanken in dessen Masse unter und veranlassten rings um die Stelle ihres Untertauchens eine Aufstïlpung der Schmelzflüssigkeit, welche dann beim Erstarren das Aussehen eines Bergwalles gewinnen musste. Asterios führt seine Theorie immerhin weit besser durch, als diess kosmologische Reformer im Allgemeinen zu thun pflegen, doch gelingt es nicht, alle Blössen derselben zu verdecken, wie Geinitz in seiner Besprechung des Schriftchens zur Genüge nachgewiesen hat [150]. Eine anmuthige Abwechselung bringt in dieses Spiel mit Hypothesen A. Meydenbauer [151], der dem Mond den flüssigen Aggregatzustand auch für die frühesten Zeiten abspricht (der Mond ist ihm zufolge "das nackte unveränderte Produkt eines sekundären Kugelwirbels"), dabei aber "doch den in der Einkleidung des Asterios noch immer etwas. wahrscheinlicher klingenden Satz aufstellt: „Die Mondoberfläche dankt ihre Beschaffenheit dem Sturze staubförmiger Massen auf eine staubförmige Unterlage." 
§. 12. Die Frage nach der Bewohnbarkeit der. Himmelskörper. Der Zweck dieses Kapitels war, darzuthun, dass durch genauere Betrachtung der physikalischen Verhältnisse solcher Planeten, welche unter ähnlichen kosmischen Existenzbedingungen, wie die Erde selbst, ihre Bahn um die Sonne, - sei es selbstständig, sei es in der Gefolgschaft eines anderen Körpers - beschreiben, manch beachtenswerther Gesichtspunkt auch für die tellurische Naturforschung zu gewinnen sei. Der Geograph, für den die Wechselbeziehungen zwischen Natur und Menschheit von jeher ein anziehendes Problem gebildet haben, nimmt deshalb auch ein gewisses Interesse an der Frage, ob Organismen von der Art, wie wir sie durch irdische Erfahrungen ganz allein kennen lernen konnten und noch können, möglicherweise auch noch andere Körper im weiten Universum bewohnen oder ob deren Existenz mit unserem Planeten für unzertrennlich zu halten sei.

Schon die Alten haben diese Frage gelegentlich gestreift; ernstlicher ist an dieselbe der treffliche Huygens in einem selbstständigen Werke [152] herangetreten, welches freilich des wissenschaftlichen Aufputzes unerachtet mit den sonstigen Leistungen gerade dieses Mannes nicht in eine Linie gestellt werden darf. Theilweise berührte sich mit ihm der Anlage nach die "Himmelsreise" des Athanasius Kircher [153], doch beschrieb dieser nur im Allgemeinen den landschaftlichen Charakter der einzelnen Planeten und enthielt sich aus theoretischen Gründen, denselben auch Lebewesen zuzutheilen. „Die Entscheidung des Sieges der heliocentrischen Physik durch Newton", bemerkt Zöckler [154], zieht den Sieg der vorher theilweise heftig angefeindeten Annahme bewohnter Welten alsbald nach sich." Den umfangreichen Mittheilungen $Z$ öckler's ist auch ein Theil dessen entnommen, was wir noch über die Geschichte der Pluralitätshypothese - dieser Name beginnt sich mehr und mehr einzubürgern - beizubringen gewillt sind. Wilkins, Goodwin, der Lustspieldichter Gherardi mit seiner Posse „Arlequin l'Empereur dans la lune“ (1684) bevölkerten den Mond mit Organismen, was den Pater Daniel zu einer gelungenen Satyre veranlasste [155]. Höher an wissenschaftlichem Werthe steht Fontenelle's formvollendete astronomische:Novelle [156], deren Schlussergebniss für jene Zeit auch passiren mag: auf den Planeten giebt es gewiss menschenähnliche Wesen, auf dem Monde vielleicht, auf der Sonne ganz gewiss nicht. Die englischen Naturtheologen, Newton selbst eingerechnet, ein Whiston, Derham, Burnet dachten ähnlich, auch Leibniz und Chr. v. Wolf gehörten zu dieser Schule, und Swinden verlegte in die Sonne den Wohnplatz der Verdammten [157]. Scharfsinniger und zutreffender, wenn schon nach unseren modernen Begriffen etwas phantastisch, waren die Betrachtungen Bonnets und Kant's [158]. Selbst das ausgehende XVIII. Jahrhundert sah noch so sonderbare Spekulationen, wie diejenigen eines E. G. Fischer [159], der unter gewissen Voraussetzungen in den Kometen eine geeignete Wohnstätte für Menschen erblickte, oder eines Bode [160], der die für die Hohlheit anthropomorphischer Gottesverehrung bezeichnende Aeusserung iiber das Planetensystem that: „Wozu alle diese Einrichtungen, wenn nicht vernünftige Wesen von diesem nächtlichen Scheine" - der Hauptplaneten - "Nutzen ziehen sollten?" Man mag jedoch über solche Ausschreitungen noch so hart urtheilen, so 
sind dieselben doch noch weit dem engherzigen Philisterthum der Hegel'schen Schule vorzuziehen, für welches es im Weltraum ausser der Erde gar keinen der Beachtung würdigen Gegenstand giebt [161]. Einen sehr lesenswürdigen Essay „über die Pluralität der Welten“ hat Peschel geschrieben [162]. Wir lesen dort, dass Payne die Hypothese als den christlichen Glauben gefährdend verwarf, Chalmers dagegen, einen alten Gedanken Sweden bor g's aufgreifend, das Paradies auf einen fernen Planeten verlegte. Brewster hielt die Annahme mehrerer Welten gleichmässig für ein Bedürfniss des Philosophen wie des Christen und nahm als Anhänger der Wilson-Herschel'schen Hypothese sogar den Sonnenkörper keineswegs aus; hierin traf er mit Arago zusammen. Vom astronomischen Standpunkt aus bekannten sich Jakob und Baden Powell für die Pluralität, wogegen Whewell in einer besonderen Schrift [163] das Bekenntniss des strenggläubigen Antipluralisten formulirte. Mit der Darwin'schen Theorie ist die uns hier beschäftigende Frage in engen Zusammenhang von Du Prel [164] gebracht worden.

Fasst man die Sache objektiv und wählt eine präcise Fragestellung, so kann dieselbe doch nur folgendermassen lauten: Auf welchen Planeten - denn die Sonne fällt selbstverständlich ganz ausser Betracht - sind die atmosphärischen und Gravitationsverhältnisse, die Modalitäten der Insolation und der von der Neigung der Planetenaxe zur Bahnebene abhängige Wechsel der Jahreszeiten in grossen Zügen denjenigen der Erde vergleichbar, so dass allenfalls dorthin versetzte Menschen und höher organisirte Thiere ihr Dasein zu fristen im Stande wären? Es bedarf nach den Ausführungen dieses Kapitels nicht mehr des besonderen Nachweises, dass lediglich Mars und Venus den Namen erde-ähnlicher Planeten verdienen, wie schon von verschiedenen Autoren - z. B, von Whewell — hervorgehoben wurde [165]. Wir mögen uns etwa vorstellen, dass ein Polarbewohner am Aequator des Mars und ein Tropenbewohner in den Polarregionen der Venus sich leidlich wohl fühlen könnten. Weitere Erörterungen hierüber dürften der strengen Wissenschaft kaum geziemen.

[1] Newcomb, Populäre Astronomie, deutsch von Engelmann, Leipzig 1881. S. $323 \mathrm{ff}$. - [2] R. Wolf, Geschichte der Astronomie, München 1877. S. 188. - [3] Mädler, Populäre Astronomie, 7. Aufl., bes. v. Klinkerfues, Strassburg 1882. S. 141. - [4] R. Wolf, Gesch. d. Astr. S. 398. - [5] J. J. v. Littrow, Theoretische und praktische Astronomie, 2. Band, Wien 1824. S. 247. [6] Seidel, Untersuchungen über die Lichtstärke der Planeten Venus, Mars, Jupiter und Saturn, verglichen mit Sternen, und über die relative Weisse ihrer Oberflächen, München 1859. S. 16. - [7] Zöllner, Photometrische Untersuchungen mit besonderer Rücksicht auf die physische Beschaffenheit der Himmelskörper, Leipzig 1865. S. 154. - [8] Mädler-Klinkerfues, Popul. Astron. S. 142. [9] Bianchini, Hesperi et Phosphori nova phaenomena, sive observationes circa planetam Veneris, Romae 1728. - [10] Mädler-Klinkerfues, Popul. Astron. S. 143 ff. - [11] De Vico, Osservazioni fatte nella specola dell' università Gregoriana in Collegio Romano, Romae 1842. - [12] Safarik, Ueber die Sichtbarkeit der dunklen Halbkugel der Venus, Prag 1873. - [13] Winnecke, Mittheilung unbeachteter Beobachtungen der Nachtseite der Venus, Vierteljahrsschr. d. astronom. Gesellsch., 11. Jahrgang. S. 77 ff. - [14] Mädler-Klinkerfues, Popul. Astron. S. 147. - [15] Lyman, On Venus as a luminous ring, Philos. Mag., Vol. IL. S. $159 \mathrm{ff}$. - [16] Neison, On the atmosphere of Venus, Monthly notices of the 
r. astr. soc., XXXVI. S. 347 ff. - [17] Schröter, Beobachtungen über die Gebirge und die Rotation der Venus, Erfurt 1793; Aphroditographische Fragmente, Helmstädt 1796. - [18] Gehler's physik. Wörterbuch, 2. Aufl., 9. Band, 3. Abtheilung, Leipzig 1840. S. 1649. - [19] Schorr, Der Venusmond, Braunschweig 1875. - [20] Newcomb, Popul. Astron. S. 329. - [21] J. J. v. Littrow, Die Wunder des Himmels, 1. Band, Stuttgart 1865. S. 367. - [22] Newcomb, Popul. Astron. S. 353. - [23] Hartwig, Untersuchungen über die Durchmesser der Planeten Venus und Mars nach Heliometermessungen auf der provisorischen Universitätssternwarte zu Strassburg, Leipzig 1879. S. 71. - [24] Ibid. S. 51. - [25] Hennessy, Sur la figure de la planète Mars, Compt. rend. de l'acad. franc., tome XC. S. 1419 ff. - [26] Newcomb, Popol. Astron. S. 354. - [27] Zöllner, Phot, Unters., S. 131. - [28] Mädler-Klinkerfues, Popul. Astron. S. 212. - [29] Newcomb, Popul. Astron. S. 357. - [30] Mädler - Klinkerfues, Popul. Astron. S. 222. S. 218. - [31] A. Hall, Observations and orbits of the satellites of Mars with data for ephemerids in 1879, Washington 1878. - [32] Ibid. S. 44 ff. - [33] Schyrlaeus de Rheita, Novem stellae circa Jovem visae, circa Saturnum sex, circa Martem nonnullae, a P. Ant-Rheita detectae, Lovanii 1643. - [34] D'Arrest, Notiz über die Unwahrscheinlichkeit, einen Marsmond in grösserer Entfernung vom Planeten zu entdecken, Astr. Nachr. (2) N. 64. - [35] Henry, Dépêche annonçant la découverte de deux satellites de Mars, par A. Hall, à Washington, Compt. rend. de l'acad. franç., tome LXXXV. S. 437. - [36] Newcomb, Popul. Astron. S. 258. - [37] Houzeau-Lancaster, Bibliographie générale de l'astronomie, tome II., Bruxelles 1880. S. 328 ff. - [38] Terby, Aréographie ou étude comparative des observations faites sur l'aspect physique de la planète Mars depuis Fontana (1636) jusqu'à nos jours, Mondes (2) XXXVII. S. 384 ff. [39] H. J. Klein, Handbuch der allgemeinen Himmelsbeschreibung, vom Standpunkte der kosmischen Weltanschauung dargestellt, 1. Band, Braunschweig 1869. S. 137 ff. - [40] Hevelius, Selenographia sive lunae descriptio, Gedani 1647. S. 66. - [41] Terby, Areographische Fragmente, manuscrits et dessins originaux et inédits de l'astronome J. H. Schröter, de Lilienthal, Bruxelles 1873; J. H. Schröter, Areographische Beiträge zur genaueren Kenntniss und Beurtheilung des Planeten Mars; nach dem Manuskripte auf der Leydener Sternwarte herausgegeben von H. G. van de Sande-Bakhuyzen, Leyden 1881. - [42] BeerMädler, Physicalische Beobachtungen des Mars in der Erdnähe, Berlin 1830. [43] Linsser, Correspondenznachrichten aus Russland, Wochenschr. f. Astron., Meteorol. u. Geogr., (2) 7. Jahrgang. S. 117 ff. - [44] Kaiser, Untersuchungen über den Planeten Mars, bei dessen Oppositionen in den Jahren 1862 und 1864, Ann. d. Sternw. zu Leyden, 3. Band. S. 1 ff. -- [45] Proctor, Stereograms of Mars with a chart of Mars in Mercator's projection, London 1869. - [46] Schiaparelli, Osservazioni astronomiche e fisiche sull' asse di rotazione e sulla topografia del pianeta Marte, fatte nella reale specola di Brera in Milano coll' equatoriale di Merz durante l'opposizione del 1877, Roma 1878. - [47] Remeis, Schiaparelli's Untersuchungen der Oberfläche des Planeten Mars während dessen Erdnähe im Jahre 1877, Gaea, 15. Jahrgang. S. 92 ff. S. 151 ff. - [48] Böddicker, Ueber die physische Beschaffenheit der Oberfläche des Planeten Mars, Mittheil. d. mathem. Gesellsch. zu Hamburg, N. 22. - [49] Holetschek, Die Oberfläche des Mars nach Schiaparelli, Deutsche Rundschau f. Geogr. u. Stat, 1. Jahrgang. S. 499 ff. - [50] R. Wolf, Gesch. d. Astr. S. 673 ff. - [51] Günther, Studien zur Geschichte der mathematischen und physikalischen Geographie, Halle 1879. S. 144. - [52] Kaiser, Untersuch. etc. S. 54. - [53] Secchi, Memorie dell' osservatorio del Collegio Romano, Roma 1859. S. 17. - [54] MädlerKlinkerfues, Popul. Astron. S. 220. - [55] Holetschek, Die Oberfl. etc. S. 501. - [56] Ibid. S. 505. - [57] Ibid. S. 507 ff. - [58] Ibid. S. 503. - [59] Günther, Studien etc. S. 158 ff. - [60] Schmick, Der Planet Mars eine zweite Erde, nach Schiaparelli, Leipzig 1879. - [61] A. Kirchhoff, Recension hiezu, Leopoldina 1881. S. 27 ff. - [62] Lambert, Sur la lumière cendrée de la lune, Mém. de l'acad. r. de Berlin, Année 1773. S. 46. - [63] Newcomb, Pop. Astr. S, 340 ff. - [64] Mädler-Klinkerfues, Pop. Astr. S. 176. - [65] Chr. v. Wolf, Der Anfangs-Gründe aller mathematischen Wissenschaften dritter Theil, Halle 1717. S. 319. - [66] Newcomb, Pop. Astr. S. 241 ff. - [67] Jacobi, Ueber die Figur des Gleichgewichtes, Ann. d. Phys. u. Chem., 33. Band. S. 229 ff. - [68] Matthiessen, Neue Untersuchungen über frei rotirende Flüssigkeiten im Zustande des Gleichgewichtes, Kiel 1859. - [69] Roche, Mémoire sur les figures ellipsoidales qui conviennent à l'équilibre d'une masse fluide sans mouvement de rotation, 
Compt. rend. de l'acad. franç., tome XXIV. S. 515. - [70] Laplace, Théorie du mouvement et de la figure elliptique des planètes, Paris 1784. - [71] J. Kant's Schriften zur physischen Geogr., herausgeg. von F. W. Schubert, Leipzig 1839. S. 406. - [72] Zöllner, Ueber die Natur der Cometen; Beiträge zur Geschichte und Theorie der Erkenntniss, Leipzig 1883. S. 275. - [73] Mädler-Klinkerfues, Pop. Astr. S. 206. - [74] Ibid. S. 170. - [75] Ibid. S. 174 ff. - [76] Fortschritte der Physik in der neuesten Zeit, (Baumgartner- v. Ettingshausen's) Zeitschr. f. Phys. u. Math., 2. Band. S. $80 \mathrm{ff}$. - [77] Bond, On the relative hightness of the sun and moon from observations made at the observatory of Harward College, Cambridge (Am.) 1861. - [78] Zöllner, Phot. Unters. S. 110. - [79] Kästner, Wie Körper leuchten, die kein eigenthümliches Licht haben; Averroes, Roger Baco, Euler, (Hindenburg's) Archiv f. reine u. angew. Mathem., 2. Band. S. 8 ff. - [80] A. v. Humboldt, Kosmos, 3. Band, Stuttgart und Tübingen 1850. S. 496. - [81] Galilei, Sidereus Nuncius, Venetiis 1610. S. 26. - [82] Kepler, Ad Vitellionem Paralipomena, quibus astronomiae pars optica traditur, Francofurti 1604. S. 254. - [83] Venturi, Essai sur les ouvrages physico-mathématiques de Léonardo da Vinci, Paris 1797. S. 11. - [84] A. v. Humboldt, Kosmos, 3. Band. S. 498. [85] C. Plinii Secundi historiae naturalis libri XXXVII, lib. II, cap. 10. - [86] Kepler Paralip. etc. S. 893. - [87] A. v. Humboldt, Kosmos, 3. Band. S. 539. [88] Melloni, Lettre à M. Arago sur la puissance calorifique de la lumière de la lune, Compt. rend. de l'acad. franc., tome XXII. S. 541 ff. - [89] Earl of Rosse, On the radiation of heat from the moon, the law of its absorption by own atmosphere, and of its variation in amount with her phases, London 1873. [90] J. H. Westphal, Leben, Studien und Schriften des Astronomen Johannes Hevelius, Königsberg 1811. S. 72. - [91] Chr. v. Wolf, Der math. Anf.-Gr. etc. S. 307 ff. - [92] H. J. Klein, Handbuch etc. 1. Band. S. 124. - [93] H. Müller, Quaestio curiosa physico-mathematica, an luna cingatur atmosphaera, Altdorfi 1710. - [94] Ibid. S. 10. - [95] Bessel, Populäre Vorlesungen über wissenschaftliche Gegenstände, herausgeg. von Schumacher, Hamburg 1848. S. 618. - [96] Jul. Schmidt, Karte der Gebirge des Mondes nach eigenen Beobachtungen, in den Jahren 1870-74 entworfen, Berlin 1878. S. 46 ff. - [97] A. v. Humboldt, Kosmos, 3. Band. S. 544. - [98] Peschel, Abhandlungen zur Erd- und Völkerkunde, herausgeg. จ. Löwenberg, 2. Band, Leipzig 1878. S. 327. - [99] Ibid. S. 335. [100] Dante Alighieri's göttliche Komödie, übers. v. Fr. Notter, 2. Band, Stuttgart 1872. S. $383 \mathrm{ff}$. - [101] Intorno ad uno passo della divina commedia di Dante Alighieri, lettera del prof. Ottavio Mossotti à B. Boncompagni, Atti dell' accad. pontif. dei nuovi lincei, tomo XVIII, Sessione del 7 maggio 1865. [102] Boncompagni, Intorno alla precedente lettera del prof. Mossotti, ibid. [103] Mädler, Geschichte der Himmelskunde von der ältesten bis auf die neueste Zeit, 1. Band, Braunschweig 1872. S. 293. - [104] Favaro, Fra Paolo Sarpi fisico e matematico secondo i nuovi studi del prof. F. Cassani, Venezia 1883. S. 16. [105] Quetelet, Histoire des sciences mathématiques et physiques chez les Belges, Bruxelles 1871. S. 249. - [106] J. H. Westphal, Leben etc. S. 69 ff. - [107] Ibid. S. 70. - [108] R. Wolf, Gesch. d. Astr. S. 397. - [109] T. Mayer, Abhandlung über die Umwälzung des Mondes um seine Axe und die scheinbare Bewegung der Mondflecke, Kosmogr. Nachr. u. Samml, auf das Jahr 1748, Nürnberg 1750. [110] Schröter, Selenotopographische Fragmente, 1. Theil, Lilienthal und Helmstädt 1791；2. Theil, Göttingen 1802. - [111] R. Wolf, Gesch. d. Astr. S. 237. [112] Mädler-Klinkerfues, Pop. Astr. S. 194. - [113] W. G. Lohrmann, Mondkarte in 25 Sektionen und 2 Erläuterungstafeln, herausgeg. von Jul. Schmidt, Leipzig 1878. - [114] F. W. Opelt, Selenographische Ortsbestimmungen in Lohrmann's Topographie der sichtbaren Mondoberfläche, Dresden und Leipzig 1824. [115] Mädler-Beer, Mappa selenographica, Berolini 1834-36. - [116] Mädler-Beer, Der Mond nach seinen kosmischen und individuellen Verhältnissen, oder allgemeine vergleichende Selenographie, Berlin 1837. - [117] Mädler, Kurzgefasste Beschreibung des Mondes, ein Auszug aus der grösseren Selenographie, Berlin 1839. - [118] Bessel, Pop. Vorl. S. 613 ff. - [119] Jul. Schmidt, Der Mond; ein Ueberblick über den gegenwärtigen Umfang und Standpunkt unserer Kenntnisse von der Oberflächengestaltung und Physik dieses Weltkörpers, Leipzig 1856. [120] R. Wolf, Gesch. d. Astr. S. 669. - [121] Nasmyth-Carpenter, The Moon considered as a planet, a world and a satellite, London 1874; deutsche Ausgabe von H. J. Klein, Leipzig 1880. - [122] Neison, The Moon und the conditions and configurations of its surface, London 1876; deutsche Ausgabe von H. J. Klein, Braunschweig 1878. - [123] M. Opelt, Der Mond, Leipzig 1879. - [124] R. Wolf, 
Gesch. d. Astr. S. 666. - [125] Mädler, Gesch. d. Himmelsk. 2. Band. S. 512 ff. - [126] J. Russell, Proposals for publishing by subscription a globe of the moon, (Hindenburg's) Archiv f. reine u. angew. Mathem., 2. Band. S. $112 \mathrm{ff}$. [127] H. J. Klein, Handb. etc. 1. Band. S. 105. - [128] R. Wolf, Gesch. d. Astr. S. 671. - [129] Engelmann, Recension zu Neison, Vierteljahrsschr. d. astr. Gesellsch., 13. Jahrgang. S. 25. - [130] R. Wolf, Gesch. d. Astr. S. 396. - [131] Dölter, Die Vulkane der Cap Verden und ihre Produkte, Graz 1882. - [132] Leipoldt, Recension zu Nasmyth-Carpenter, Zeitschr. f. wissensch. Geogr., 3. Jahrgang. S. 20 ff. - [133] Nasmyth-Carpenter, Der Mond, deutsch von Klein. S. 107 ff. - [134] Mallet, On volcanic energy, Phil. Transact., Vol. CLXIII. S. 201. - [135] Nies-Winkelmann, Ueber Volumveränderungen einiger Metalle beim Schmelzen, Sitzungsber. d. k. bayr. Akad. d. Wissensch., M.-ph., K]. 1881. S. 63 ff. - [136] Ibid. S. $104 \mathrm{ff}$. - [137] Ibid. S. 109 ff. - [138] H. J. Klein, Ueber den Bau und die Entstehung der Mondoberfläche, Gaea, 12. Jahrgang. S. 65 ff. - [139] Nasmyth-Carpenter, Der Mond, deutsch v. Klein, S. 115 ff. - [140] Lamey, Sur les bandes rayonnantes de la lune, Mondes (2) XXXVI. S. 4 ff. - [141] J. Kant's Schriften etc. S. 391 ff. - [142] Don Juan Ulloa, El eclipse del sol con el anillo refractario de sus rayos: la luz de este astro vista del través de la luna, Madrid 1779. [143] H. J. Klein, Veränderungen auf der Mondoberfläche, Gaea, 13. Jahrgang. S. 528. - [144] Valentiner, Bez. zu Neison, Z. f. Math. u. Ph., 25. Jahrg. H.-L. Abth. S. 138 ff. - [145] H. J. Klein, Veränderungen etc. S. 530. - [146] Neison, Der neue Krater bei'm Hyginus auf dem Monde. Gaea, 15. Jahrgang. S. 636 ff. [147] Die vulkanischen Vorgänge auf dem Monde, Zeitschr. f. Schulgeogr., 4. Jahrgang. S. 40 ff. - [148] Schmick, Der Mond, Leipzig 1877. - [149] Asterios, Die Physiognomie des Mondes; Versuch einer neuen Deutung im Anschluss an die Arbeiten von Mädler, Nasmyth und Carpenter, Nördlingen 1879. - [150] Geinitz, Ueber eine neue Hypothese der Gebirgsbildung, Leopoldina 1883. S. 49 ff. S. $71 \mathrm{ff}$. - [151] A. Meydenbauer, Kant oder Laplace? Kosmologische Studie, Marburg 1880. S. 34. - [152] Huygens, Kо jecturae, Hagae Comitum 1698. - [153] Kircher, Iter ecstaticum coeleste seu opificium, quo coeli siderumque natura, vires et structura exponuntur, Romae 1656. - [154] Zöckler, Geschichte der Beziehungen zwischen Theologie und Naturwissenschaft, mit besonderer Rücksicht auf Schöpfungsgeschichte, 2. Abtheilung, Gütersloh 1879. S. 55. - [155] Ibid. S. 57. - [156] Fontenelle, Entretiens sur la pluralité des mondes, Paris 1686. - [157] Zöckler, Gesch. etc., 2. Abtheilung. S. 60. - [158] Ibid. S. 164 ff. - [159] E. G. Fischer, Betrachtungen über die Kometen, bey Gelegenheit der vermutheten Wiedererscheinung eines Kometen im Jahre 1789, Berlin 1787. S. 14 ff. - [160] Bode, Anleitung zur Kenntniss des gestirnten Himmels, Berlin 1806. S. 629. - [161] Zöckler, Gesch. etc., 2. Abtheilung. S. 431. - [162] Peschel, Abhandl. etc., 2. Band. S. $187 \mathrm{ff}$. - [163] Whewell, On the plurality of worlds, London 1853. - [164] Du Prel, die Planetenbewohner und die Nebularhypothese, Leipzig 1880. - [165] Peschel, Abhandl. etc., 2. Band. S. 194. 
Zweite Abtheilung.

\title{
Allgemeine mathematische und physikalische Verhältnisse des Erdkörpers.
}

\author{
Kapitel I.
}

\section{Die Erde als Kugel und Rotationssphäroid.}

§. 1. Allmählige Entwickelung der Sphäricitätslehre. Die alte Okeanoshypothese des Homer, nach welcher sich die Erde als eine platte, vom Weltmeer umgebene Seheibe darstellte, behauptete bis zu den Zeiten des Herodot, der sich sehr spöttisch über die gegentheilige Annahme einer kugelförmigen Erde äusserte [1], ihre Existenz. Ganz konsequent dachte sich der grosse Historiker natürlich auch, dass die am Ostrande gelegenen Erdgegenden bei aufsteigender, die dem Westrande näheren bei sinkender Sonne am stärksten erhitzt würden [2]. In der That muss manche der Ansichten, die gelegentlich von Mitgliedern der jonischen und eleatischen, ja auch späterhin der stoischen und epikureischen Philosophenschule ausgesprochen wurden, noch für viel absurder gelten als der doch wenigstens auf naiver Autopsie beruhende Realismus Herodot's. Einzelne dachten sich die Erde linsenförmig, Leukipp gab ihr [3] die Form einer umgekehrten Pauke, selbst der weiterblickende A naxagoras stand im Wesentlichen noch auf dem herodotischen Standpunkte [4], und als der weitgereiste Py theas in seinem leider zu Verlust gegangenen Buche „über den Okeanos" von selbstgesehenen Erscheinungen erzählte, deren Thatsächlichkeit allerdings mit keiner anderen Lehre, als mit derjenigen der Kugelgestalt, sich vereinigen lassen wollte, zweifelten die Meisten die Richtigkeit seiner Angaben einfach an [5]. Selbstverständlich konnte bei solchen Anschauungen auch die von der indischen Mythologie durch alle möglichen Kombinationen heiliger Thiere zu lösen versuchte Frage, worauf denn eigentlich der Erdkörper ruhe, nicht umgangen werden [6], und wenn Demokrit denselben auf (zusammengepresster) Luft aufliegen lassen wollte, so mochte immer noch Xenophanes' Ausspruch, dass die Erde nach unten zu im Unendlichen wurzle, während die Luft oben in's Unendliche sich erstrecke, einen gewissen Fortschritt 
andeuten [7]. Dass Thales bereits die Sphäricität gelehrt habe, ist möglich, aber keineswegs gewiss, und jedenfalls ist Köler's Schluss (a. a. O.); man müsse diess wohl glauben, da sich sonst die Voraussagung von Finsternissen nicht begreifen lasse, für Niemanden ein zwingender, der mit dem Wesen der cyklischen Berechnung vertraut ist. Ganz zweifellose Anhänger der sphärischen Doktrin sind Pythagoras und Parmenides gewesen, von welch' letzterem auch die noch jetzt übliche Zoneneintheilung herstammt, indess war Peschel wohl im Rechte, wenn er bemerkte [8], die pythagoreische Schule habe sich minder von inneren Gründen, als vielmehr von geometrischen Schicklichkeitsgründen" leiten lassen. Durch Aristoteles und Archimedes ward der Satz, dass die Erde eine vollkommene Kugel sei, zum Range einer festen wissenschaftlichen Wahrheit erhoben, und während des eigentlichen Alterthums ist keinerlei Widerspruch gegen diese allseitig anerkannte Thesis mehr laut geworden.

Erst der Verfall der Wissenschaften im beginnenden Mittelalter bahnte auch auf diesem Gebiete einen verhängnissvollen Rückschritt an. Theilweise trug hieran die Schuld die Neigung des Zeitalters, einen Wahn- und Wunderglauben an die Stelle ernster Gedankenarbeit zu setzen, theilweise muss man das Hereindringen rabbinischer Vorstellungskreise in das griechisch-römische Geistesleben dafür verantwortlich machen. Denn die Ausleger des Talmud gaben sich in kosmographischen Dingen, wie man aus einer lehrreichen Schrift von Bergel [9] ersehen kann, den verwunderlichsten Ideen hin. So kam es, dass von den Schriftstellern der Kirchenväterzeit namentlich die Orientalen bis zum Homer oder sogar bis zu einer noch kindlicheren Aera zurïckkehrten; „Ephräm, " sagt Zöckler, dessen Führung wir uns auch hier [10] vertrauend überlassen*), ${ }_{n}$ Diodorus, Theodor von Mopsuestia, Acacius von Cäsarea, Chrysostomus, Severianus denken sich das Verhältniss des Himmels zur Erdfläche als das eines halbkugelförmigen oder gar flachen Daches zum überdachten Fussboden. ${ }^{*}$ Von den Autoren lateinischer Zunge verfällt namentlich der grosse Lactantius in den gleichen Irrthum [13], wofür ihn dann freilich ein frommer Sohn der katholischen Kirche, Coppernicus, einen kindischen Schriftsteller und sehr schwachen Mathematiker nennt [14]. Gregor von Nyssa und Augustin hielten sich von solchen Absurditäten ferne. Ein anonymer Geograph von Ravenna theilte [15] die Erde in eine Licht- und Schattenseite, beide durch hohe Gebirge getrennt, und der Indienfahrer Kosmas begründete auf diese altsyrische Schrulle ein neues kosmographisches System. Dasselbe ist häufig, schon von Montfaucon, in Diagrammen darzustellen versucht worden, doch kann als authentisch wohl nur jene Zeichnung gelten, welche wir nach Marinelli in Fig. 9 reproduciren, und die uns besser wie manche künstlerische Nachbildung die Sonderbarkeit dieser wissenschaftlichen Missgeburt vor Augen führt [16]. Noch im VIII. Jahrhundert hatte der Salzburger Bischof Virgilius heftige Anfeindung

*) Abgesehen von Zö ckler's ausgezeichnetem Werke eignet sich für Jene, die leichter und rascher einen Einblick in die langsame und oft unterbrochene Entwickelung dieses Theiles unserer Disciplin gewinnen wollen, ein Aufsatz des Verf. [11] und die gelehrte Spezialschrift Marin elli's [12]. 
durch den heiligen Bonifacius und den von diesem beeinflussten Papst Zacharias zu erfahren, weil er die ,iniqua haeresis" vertrete, dass es Antipoden gebe [17]*). Doch griffen Männer von wirklicher Ge-

Fig. 9.

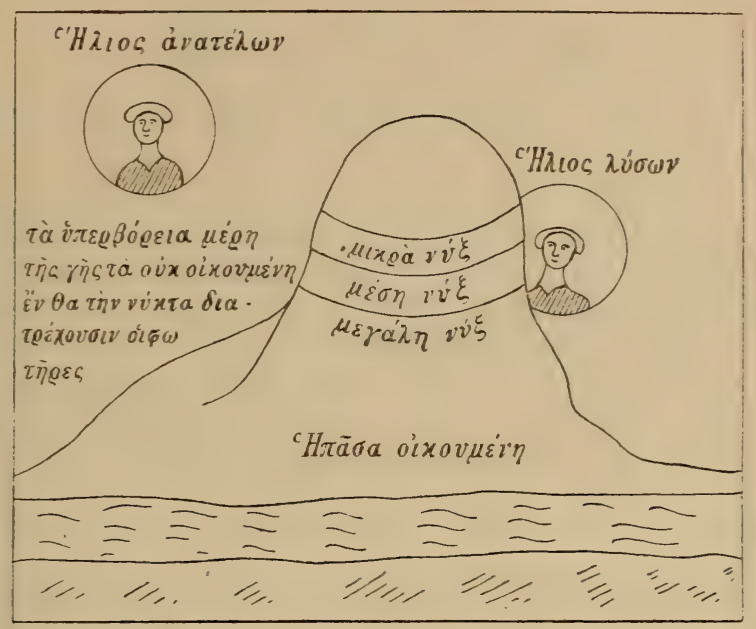

lehrsamkeit, Beda Venerabilis, Johannes Scotus Erigena u. a. immer entschiedener auf die ptolemäischen Grundlagen zurück, und damit war der Sieg der Sphäricitätslehre entschieden, an deren Richtigkeit in der scholastischen Zeit höchstens von ganz Unkundigen noch gezweifelt wurde. Ein Gleiches gilt von der Neuzeit; eine Reihe Kartenskizzen, die unlängst Sir John Hampden unter Voraussetzung einer planen Erde veröffentlicht und der Verf. [21] näher beschrieben hat, wird, wie man hoffen darf, ein Unikum verbleiben. Schon im XII. Jahrhundert erörtert ein gewisser $\mathrm{Omons}$ in altfranzösischem

*) Es soll hiebei nicht verschwiegen werden, dass katholische Schriftsteller apologetischer Tendenz die Sache so hinzustellen bestrebt sind, als habe man bei jenen Streitigkeiten über die Antipodenfrage deren mathematisch-geographische Seite völlig ausser Acht gelassen. Es sei jenen Theologen sehr gleichgültig gewesen, ob man die Erde als kugelrund anzusehen habe oder nicht; nur der Umstand, dass die Bibel nichts ron jenen weit entfernten Völkern und ron deren Erlösung melde, habe an der Existenz derselben gerechte Zweifel hegen lassen. Neuerdings hat der belgische Mathematiker Gilbert [18] eine gelehrte Streitschrift gegen des Verf. obengenannte Schrift vom Stapel gelassen; er hätte auch erwähnen können, dass der grosse Leonhard Euler von einem seiner Herausgeber energisch rektificirt worden war [19], weil er im achtundvierzigsten seiner Briefe an eine deutsche Prinzessin die Lehre von den Gegenfüsslern als eine in den Augen der Kirchenväter ketzerische bezeichnet hatte. Man mag aber sagen, was man wolle, uns scheint eben doch soviel sicher zu stehen, dass den meisten Gelehrten der Merovinger- und Karolingerzeit die Lehre von den Antipoden eine an sich falsche zu sein schien. Unverwerflicher Zeuge dess ist eine - aus Isidor entlehnte - Stelle in dem bekannten encyklopädischen Wörterbuch des Bischofs $\mathrm{S}$ a l o mo von Kostnitz (IX. - X. Jahrhundert) [20]: "Antipodes nulla ratione credendi sunt, quia nec soliditas patitur, nec centrum terrae, sed neque hoc ulla historiae cognitione firmatum, sed hoc poetae quasi ratiocinando conjectant." Man sieht, die - sozusagen - physikalischen Gegengründe kommen noch vor den geschichtlichen. 
Idiom die Folgen, die sich ergeben würden, wenn zwei Menschen von irgend einem Orte aus mit gleicher Geschwindigkeit in entgegengesetzter Richtung sich bewegen; sie würden an einem dem Ausgangspunkt diametral gegenüberliegenden Punkte zusammentreffen, oder, wie er sich ausdrückt [22]:
${ }_{\text {} S \mathrm{Si}}$ que andui egaument alassent,
Il comendroit qu'il s'encontrassent
Dessus le leu dont il se mûrent."

Wer so schrieb, dem stand die Kugelgestalt der Erde natürlich unverbrüchlich fest.

Es ist wahr, der Araber Abulfeda hatte noch früher die hierin liegende Wahrheit erkannt und dahin verallgemeinert, dass beim Umreisen der Erde ein Tag verloren oder gewonnen werden müsse [23], eine Wahrheit, die den Mannschaften der Magelhaens'schen Expedition sich zuerst praktisch fühlbar machte. Nach dem von $\mathrm{Pe}$ schel [24] citirten Ibn el Wardi und nach gewissen Aeusserungen Kazwîni's [25] scheint es, dass auch im Orient die gesunde mathematische Theorie mit Wahngebilden aller Art einen Kampf zu bestehen hatte, doch rang sich die Wahrheit leichter durch, als bei den westlichen Zeitgenossen, und die Gelehrtenwelt wenigstens fühlte sich erhaben über die vulgären Meinungen; so führt ein Münchener Manuskript nach Steinschneider den Titel [26]: „Das Buch, dass Derjenige, der keine Uebung im Beweise hat, sich nicht vorstellen kann, dass die Erde kugelförmig sei und die Menschen rings um dieselbe seien." Abul Hassan Ali besitzt, wie uns Sédillot's verdienstliche Bearbeitung des von ihm verfassten Lehrbuches der astronomischen Instrumentenkunde bezeugt [27], eine klare Vorstellung von einem sphärischen Theoreme, deren Verständniss dem Laien auch heute noch vergleichsweise schwer zu vermitteln ist, von dem Unterschiede zwischen wahrem und scheinbarem Horizont. Der spanische Jude Isaakben-Josef-ben-Israel definirt um 1310 korrekt den Unterschied, welcher in der Parallaxe eines nicht allzuweit entfernten Himmelskörpers dadurch bedingt wird, dass man denselben entweder vom Erdmittelpunkt oder von der Oberfläche aus betrachtet [28]. In Fleisch und Blut des Volkes sind diese mehr esoterischen Doktrinen nun allerdings nicht übergegangen, noch im Anfange dieses Jahrhunderts hatten selbst hochgebildete Perser keine Ahnung von der Rundung der Erde [29].

Hingegen in einem noch östlicher gelegenen Lande, in Japan, hat diese Lehre schon vor mehr denn zwei Jahrhunderten Eingang gefunden. Heeren berichtet [30], dass ein dortiger Globenverfertiger schon um 1670 sein Unternehmen mit nachstehenden Worten begründete: ,Bisher sah man die Erde als flach an; weshalb hast du nun die Erde rund dargestellt? So hat man mich gefragt. Ich habe geantwortet: in To-shio-shen steht geschrieben, die Erde ist rund, wie eine Kugel, darum habe ich sie so dargestellt. ${ }^{*}$ Auch den chinesischen Gelehrten ist diese Kenntniss wenigstens nicht ganz vorenthalten geblieben.

§. 2. Gründe für die Kugelform des Erdkörpers. In vielen, namentlich älteren Lehrbüchern pflegt eine grosse Anzahl solcher 
Gründe aufgeführt zu werden, die sich bei näherem Zusehen jedoch als sehr wenig stichhaltig erweisen. Es ist ein unbestreitbares Verdienst $\mid B i r n-$ baum's [31], die kritische Sonde energisch an diese angeblichen Beweise angelegt zu haben*). Wenn z. B. darauf hingewiesen ward, dass auch die anderen Planeten als Scheiben erscheinen, so haften dieser Beweisart nicht weniger als drei Mängel an: erstens kann nach didaktischen Gründen von der Planetennatur der Erde schon deshalb kein Gebrauch gemacht werden, weil im Systeme der Beweis für jene doch erst an einer viel späteren Stelle zu erbringen ist, als derjenige für die Rundung, zweitens darf man nicht auf Thatsachen sich berufen, deren Feststellung dem unbewaffneten Auge unmöglich ist, und zum dritten endlich erscheinen nicht einmal alle Planeten - man denke an Saturn (Kap. II, §. 9 der vorigen Abtheilung) - als reine Scheiben. Auch Aristoteles gieng zu weit, wenn er aus der kreisförmigen Schattengrenze der theilweise verfinsterten Mondscheibe ein zwingendes Argument für die Erdrundung herleiten wollte, denn auch andere krummflächig begrenzte Körper, als nur die Kugel allein, vermögen einen annähernd oder wirklich kreisförmigen Schatten zu werfen. Auch der zweite mehr physikalische Schluss des Aristoteles, dass nämlich alle Materie um den Mittelpunkt des Universums herum in gleichen Entfernungen sich anordnen müsse, krankt an mehreren Gebrechen, so verdienstlich er auch für eine Zeit war, welche von dem Wesen der Schwerkraft noch keine rechte Vorstellung besass. Noch weit weniger taugt natürlich das Beweismittel der wirklichen Erdumseglungen, denn diese geben doch nur davon Zeugniss, dass die Aussenseite des Erdkörpers eine (im Riemann'schen Sinne) einfach zusammenhängende und von Ecken wie Kanten freie Oberfläche ist. Wissenschaftlich höher steht der vom Verschwinden und Auftauchen sich bewegender Körper hergenommene Beleg, denn wenn auf dem Meere oder einem grossen Landsee - nach J. Müller's sorgfältigen Beobachtungen zeigt schon der Bodensee die Erscheinung ganz deutlich [33] — von einem näher kommenden Schiffe zuerst die Mastspitzen, sodann die Segel und erst ganz zuletzt auch die einzelnen Theile des Schiffsrumpfes vor Augen treten, so kann es keinem $Z_{\text {weifel }}$ mehr unterliegen, dass die Wasserfläche eine konvexe Krümmung besitzt, die freilich deshalb noch gerade keine sphärische zu sein brauchte. Die malayischen Seeräuber sind in ihrer Art mit der Rundung der Erde ganz wohl vertraut, denn Jag or, der genaue Kenner der hinterindischen Gewässer, berichtet [34]: „Die Piraten, gewöhnlich schon durch ihre Spione gewarnt, sehen den Rauch des Dampfbootes früh genug, um mit ihren flachen Kähnen zu entschlüpfen." Sie schlagen eben eine zu dem Kurse des Kriegsschiffes senkrehte Route ein und bergen sich so hinter der Erdwölbung wie hinter einem Dache.

Ein neues geistreiches Mittel, die Krümmung einer grösseren Wassermasse durch direkte Messung zu konstatiren, haben vor Kurzem die beiden waadtländischen Naturforscher Forel und Dufour an die Hand gegeben [35]. Wäre die Fläche eines See's eine glatte Ebene,

*) Namentlich in pädagogischer Hinsicht werthroll sind zwei die Unzu?änglichkeit der landläufigen Beweisversuche behandelnde Aufsätze ron Fahle und Pick [32]. 
so müsste das Bild eines entfernten sich darin abspiegelnden Gegenstandes, mit einem Winkelmessinstrumente auf seine Dimensionen geprüft, genau eben so gross erscheinen wie das Objekt selbst, wenn aber jener Fläche die Eigenschaft eines Konvexspiegels zukommt, so muss nach bekannten katoptrischen Sätzen ein verkleinertes Bild entstehen. Scharfe Messungen haben diese z. B. auch für das Sonnenbild gültige Thatsache ausser Zweifel gesetzt.

Wichtiger jedoch, als diese indirekten Beweisgründe, ist der

Fig. 10 .

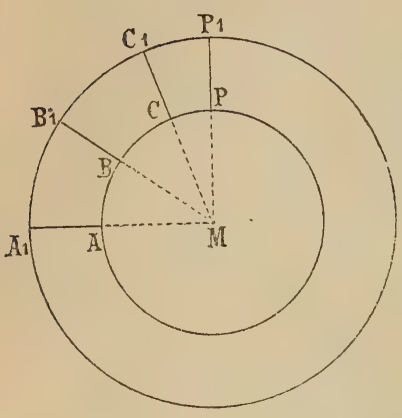
bereits dem Eratosthenes und Ptolemäus bekannt gewesene geometrische $\mathrm{Be}$ weis, der nur von zwei vulgären Erfahrungswahrheiten Gebrauch macht. Sei M (Fig. 10) der Mittelpunkt der Himmelskugel, $\mathrm{P}_{1}$ der bei der täglichen scheinbaren Umdrehung unbewegt bleibende Punkt oder Pol, A, B, C seien drei genau in der Nordrichtung gelegene Erdorte, und zwar sei $\mathrm{AB}=\mathrm{BC}$. Man bestimme durch das Loth die Zenithalpunkte $\mathrm{A}_{1}, \mathrm{~B}_{1}, \mathrm{C}_{1}$ von $\mathrm{A}, \mathrm{B}, \mathrm{C}$ und messe astronomisch deren Winkeldistanzen vom Pole $\mathrm{P}_{1}$; dann lehrt die Praxis, dass

$$
\operatorname{arc} \mathrm{A}_{1} \mathrm{~B}_{1}=\operatorname{arc} \mathrm{B}_{1} \mathrm{C}_{1} ; \Varangle \mathrm{A}_{1} \mathrm{MB}_{1}=\Varangle \mathrm{B}_{1} \mathrm{M} \mathrm{C}_{1}
$$

ist. Daraus folgt nach bekannten Sätzen, dass auch $A, B$ und $C$ auf einem koncentrischen Kreise gelegen sein müssen. Damit wäre zunächst zwar nur ausgesagt, dass in einer bestimmten Richtung die Krümmung der Erdoberfläche eine gleichförmige sein muss, so dass also vorläufig auch ein Kreiscylinder von endlicher Grösse, der aber von der Himmelskugel unendlich weit entfernt wäre, der Voraussetzung genügen würde. Andererseits ist aber bekannt, dass, wenn einer genau ostwestlichen Vorwärtsbewegung von s Raumeinheiten eine Verzögerung des Sonnenaufganges von t Zeiteinheiten entspricht, einer analogen Bewegung von $\mathrm{m} . \mathrm{s}$ Raumeinheiten eine proportionale Verzögerung des Sonnenaufganges um m.t Zeiteinheiten entspreche; diess kann, da das Fortschreiten der Sonne in ihrer Bahn ein völlig gleichmässiges ist, nur davon herrühren, dass auch in der Ostwestrichtung die Erde allenthalben das nämliche Krümmungsmaass besitzt. Die Stereometrie lehrt, dass keiner anderen als der Kugelfläche eine gleichförmige Krümmung nach zwei auf einander normalen Richtungen eignet, und damit ist in aller Strenge bewiesen, dass die Erde eine der Himmelskugel koncentrische Kugel ist, für welche es einen Punkt $\mathrm{P}$ geben muss, der ihr gegenüber dieselbe Rolle spielt, wie gegenüber ersterer der Himmelspol $\mathrm{P}_{1}$.

Vorstehende Deduktion hat den grossen Vortheil, dass sie für die Erde im Ganzen gilt, nicht blos für deren tropfbar flüssige Bedeckung. Dass für letztere die Kugelform die einzig mögliche ist, hatte bereits Archimedes erkannt und in seiner nur in schlechtem Arabisch auf uns gekommenen Schrift „Von den schwimmenden Körpern" exakt erwiesen; das bezügliche Theorem (das zweite des Buches) lautet in lateinischer Uebersetzung [36]: „Omnis humidi consistentis 'ica, 
ut maneat immotum, superficies habebit figuram sphaerae habentis centrum idem cum terra $\left.{ }^{\alpha *}\right)$.

§. 3. Störungen der Kugelform. Dass nur die Meeresfläche eine wirkliche Krümmung besitzen könne, während auf dem Festlande die Unebenheiten der Berge und Thäler die Sphäricität beeinträchtigen müssen, verstand sich von selber. Doch wussten auch die Alten recht wohl, dass die hiedurch bedingte Unterbrechung der geometrischen Gestalt von keinem Belang sei. Jener Omons, dessen wir im ersten Paragraphen zu gedenken hatten, sagt in dieser Hinsicht ganz bezeichnend [38]: „Les hauteurs ni les vallées n'ôtent rien à la terre de sa rondeur. " Und dem ist wirklich so. Legt man, da überdiess die Einsenkungen gegen die Erhebungen über dem Meeresspiegel gänzlich vernachlässigt werden dürfen, für den Erdradius die Listing'sche Zahl (s. u.), für die Vertikalerhebung des höchsten Berges, des Gaurisankar, die von $\mathrm{H}$. Wagner [39] angegebene Zahl zu Grunde, so ist das Verhältniss der ersteren zur letzteren

$$
6370000: 8840=720: 1 \text {. }
$$

Eine künstliche Erdkugel muss sonach schon einen recht respektablen Durchmesser besitzen, wenn ein einziges Häufchen auf ihrer Oberfläche an einander gereihter Sandkörnchen ihre Sphäricität nur in gleichem Maasse entstellen soll, wie das Himalayagebirge diejenige der Erde.

Hier war mithin von Schwierigkeiten der Auffassung durchaus nichts zu finden, allein da man keine solchen vorfand, so konstruirte man sie künstlich. Die auf der Elementenlehre des Stagiriten basirende Naturphilosophie des Mittelalters nahm in ihrer Weise ganz richtig an, dass Wasser, Luft, Feuer und Aether in koncentrischen Kugelschalen sich um die Erde herumlegten; plötzlich aber tauchte die gegentheilige Meinung auf, dass der Mittelpunkt der Erd- und Wassersphäre nicht zusammenfielen. Möglicherweise datirt diese Irrlehre aus dem Alterthum, wenigstens stellt Köler [40] die Hypothese auf, ydass Thales sich die Erde wie eine grosse Wasserkugel oder seiner eigentlichen Vorstellung nach näher wie eine trommelförmige Wassermasse vorstellte, auf deren oberer Seite die eiförmig gestaltete Erdfläche schwämme. ${ }^{*}$ Sei dem, wie immer, jedenfalls verfochten schon seit dem XIII. Säkulum, wie die Beispiele eines Latini [41] und Ristoro [42] darthun, ge-

*) Bekanntlich gewinnt namentlich der Neuling bei vollkommen freiem Horizonte, wie ihn die hohe See darbietet, leicht den Eindruck, als befinde er sich an einer relativ tiefsten Stelle, als stiege die Erde konkav ringsum in die Höhe. Dass aber in Wahrheit die Erde allenthalben konvex und nirgendwo hohl sei, erläutert ein netter Anschauungsbeweis des $\mathrm{Abraham} \mathrm{Bar}$ Chija [37]. AB (Fig. 11) bedeutet einen Durchschnitt der hohl vorausgesetzten Erde, deren (ideelles) Centrum M zugleich das der Himmelskugel ist. Der Beobachter in D befindet sich westlich von dem Beobachter in $\mathrm{C}$ und erkennt trotzdem den der täglichen Bewegung unterworfenen Stern F weit näher dem Aufgangspunkte, als der andere, dessen Gesichtsfeld erst mit $\mathrm{E}$ beginnt. Diess widerspricht aber der Wirklichkeit.

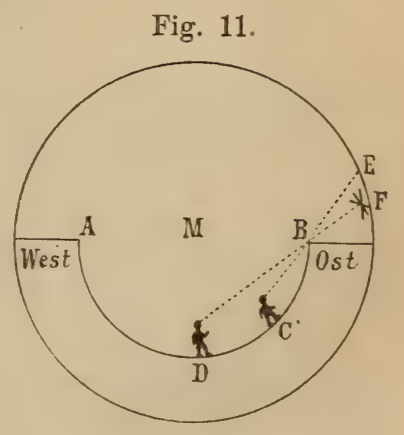


lehrte Männer die Lehre, dass die Erdfeste excentrisch in eine übergreifende Wasserkugel eingebettet liege, und zwar meinte letzterer, dem reichgestirnten Nordhimmel entspreche die Gebirgsmasse der Erde,

Fig. 12.

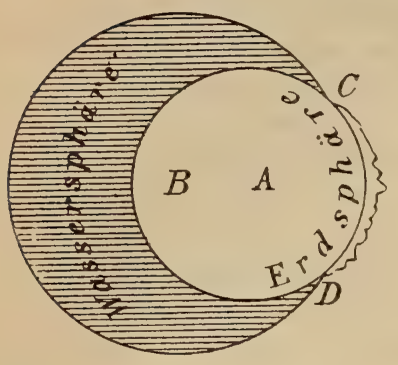
dem sternarmen Südhimmel die Wasseranschwellung. In Fig. 12 ist A Centrum der Erdsphäre, B Centrum der Wassersphäre, CD der von Gebirgen bedeckte und aus dem Flüssigen hervorragende Theil der ersteren. Der treffliche Dante eröffnete gegen dieses Phantom eine erfolgreiche Polemik in seiner Schrift „De aqua et terra“, auf deren Bedeutung für die Geophysik W. Schmidt [43] und - mit steter Bezugnahme auf andere D ante-Stellen - Poletto [44] hingewiesen haben. Damit schien denn allerdings die Wahrheit gesiegt zu haben, doch verschuldeten Mathias Doring und Capuanus de Manfredonia hundert Jahre später noch manchen Rückfall [45], und noch Coppernicus hielt es für zweckmässig, in längerer Diatribe festzustellen [46], „wie das Land mit dem Wasser eine Kugel ausmacht".

§. 4. Methoden der Erdmessung. Wir stellen in diesem Paragraphen einige Methoden zusammen, die rein theoretisch gleich gut dem Zwecke dienen können, die Grösse des Radius oder Umfanges eines Hauptkreises der Erde zu bestimmen, die aber sämmtlich aus praktischen Gründen, weil nämlich der Fehlerquellen zu viele sind, verworfen werden müssen.

a) Methode des Tangentialkegels. Man erhebe sich von einem Punkte D (Fig. 13) der Erdoberfläche aus ver-

Fig. 13.

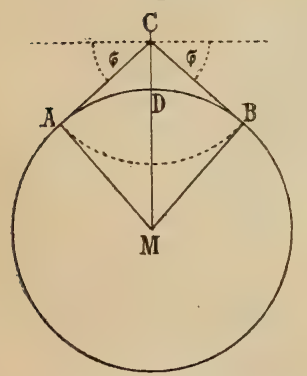
tikal bis zu beliebiger Entfernung $\mathrm{CD}=\mathrm{a}$ von der Erde. Dann übersieht man eine Kalotte der Erdkugel, deren Grösse von dem zu messenden Winkel $\varphi$, der Kimmtiefe oder Horizontaldepression, abhängt, welche man erhält, wenn man von $\mathrm{C}$ aus den Tangentialkegel $\mathrm{CAB}$ an die Erde zieht und zugleich durch $\mathrm{C}$ eine Ebene normal zu CD legt; jede Seitenlinie dieses Kegels ist gegen die Ebene um den $\Varangle \varphi$ geneigt. Die Radien MA und $\mathrm{MB}$ bilden mit $\mathrm{CA}$ und $\mathrm{CB}$ rechte Winkel, und es ist somit $\Varangle \mathrm{CMB}$ $=\Varangle \mathrm{CMA}=\varphi$ und weiter, wenn $\mathrm{r}$ wie gewöhnlich den Erdhalbmesser bezeichnet,

$$
\cos \varphi=\frac{r}{r+a}, r=\frac{a \cos \varphi}{1-\cos \varphi}=\frac{a \cos \varphi}{2 \sin ^{2} \frac{1}{2} \varphi} .
$$

Die genaue Messung des $\Varangle \varphi$ wird nur leider durch die Strahlenbrechung und andere Umstände auf das äusserste erschwert. Umgekehrt kann diese Formel auch dazu dienen, die angulare und daraus - wenn der Erdradius bekannt ist - auch die lineare Entfernung eines Beobachters von einem weit entfernten Objekte, einem Leuchtthurm z. B., abzuschätzen. R. v. Schlagintweit und Koldewey 
haben, wie Leipoldt [47] mittheilt, einfache Formeln gegeben, um aus der Höhe a auf die von $\varphi$ abhängige Weite des Gesichtskreises einen näherungsweisen und von der Benützung trigonometrischer Tafeln unabhängigen Schluss zu ziehen. Einer auch sonst interessanten $\mathrm{Ab}$ handlung von Holetschek [48] entnehmen wir die nachfolgende, von A. Steinhauser gerechnete Tabelle, welche zeigt, wie beim Wachsen der Höhe in arithmetischer Progression der Radius des Gesichtskreises zuerst rasch, dann immer langsamer, zunimmt.

\begin{tabular}{c|c|c|c|c|c}
\hline Höhe in m & Radius in km & Zunahme & Höhe in $\mathrm{m}$ & Radius in km & Zunahme \\
\hline \hline & & & & \\
\hline \multirow{2}{*}{10} & 11,3 & 0,0 & 60 & 27,7 & 2,4 \\
30 & 16,0 & 4,7 & 70 & 29,9 & 2,2 \\
40 & 19,6 & 3,6 & 80 & 31,9 & 2,0 \\
50 & 22,6 & 3,0 & 90 & 33,8 & 1,9 \\
& 25,3 & 2,7 & 100 & 35,7 & 1,9 \\
\hline
\end{tabular}

b) Methode von Ghetaldi. Der dalmatinische Mathematiker Ghetaldi (zweite Hälfte des XVII. Jahrhunderts) gab, wie sein Biograph Gelcich erwähnt [49], ebenfalls ein selbstständiges Verfahren zur direkten Berechnung des Erdradius an*). An zwei Punkten B und $\mathrm{C}$ der Erde (Fig. 14), deren Mittelpunkt M ist, soll man zwei vertikale Latten $\mathrm{BD}=\mathrm{a}$ und $\mathrm{CE}=\mathrm{b}$ aufstellen, sodann den zwischenliegenden Punkt A aufsuchen, für welchen die Endpunkte D und E zu beiden Seiten gerade im Horizonte verschwinden, und hierauf die Entfernungen $\mathrm{AD}=\mathrm{c}$ und $\mathrm{AE}=\mathrm{d}$ mes . sen. Zweimalige Anwendung des pythagoreischen Lehrsatzes liefert dann die Gleichungen

Fig. 14.

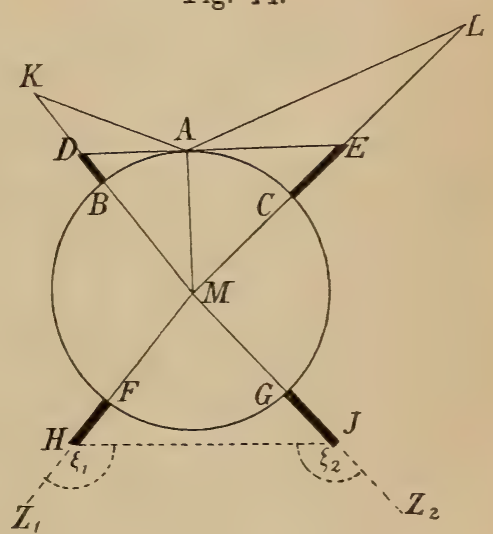
$\mathrm{AM}^{2}$
woraus nach einiger Umformung hervorgeht:

$$
\overline{\mathrm{AM}}^{2}=(\mathrm{r}+\mathrm{a})^{2}-\mathrm{c}^{2}=(\mathrm{r}+\mathrm{b})^{2}-\mathrm{d}^{2},
$$

$$
\mathrm{r}=\frac{\mathrm{c}^{2}-\mathrm{a}^{2}+\mathrm{b}^{2}-\mathrm{d}^{2}}{2(\mathrm{a}-\mathrm{b})} \text {. }
$$

c) Modificirte Methode von Dufour. Es bedarf der Erwähnung kaum, dass das von Ghetaldi in Vorschlag gebrachte Messungsverfahren aus den verschiedensten Gründen thatsächlich undurchführbar ist. Doch verdient es immerhin aufbewahrt zu werden und zwar mit um so mehr Recht, als auch die beiden zunächst zu besprechenden Methoden auf einem ähnlichen Grundgedanken beruhen. Dufour löst

*) Nach den von Herrn Marineschuldirektor Gelcich in Lussin piccolo gegebenen näheren Aufschlüssen; die darüber im Detail handelnde Note [50] erschien erst später und konnte nicht mehr benützt werden. 
bei seinen uns schon bekannten Untersuchungen über Seespiegelung diə folgende Aufgabe (a. a. O.): Wenn in K (Fig. 14) eine Lichtquelle Strahlen nach der spiegelnden Erde in A sendet, so dass in $\mathrm{L}$ ein Bild von $\mathrm{K}$ entsteht, aus den gegebenen Grössen KB, LC, DE und $\mathrm{r}$ die unbekannten Grössen DB, EC, DA und EA zu berechnen. Diese Aufgabe ist offenbar eine Art von Umkehrung des in der Geschichte der Optik berühmt gewordenen Problemes des Alhazen: Bei gegebenem Aug- und Bildpunkt die Lage des Reflexionspunktes auf einer spiegelnden Kugelfläche zu ermitteln; die allgemeinste und eleganteste Lösung dieses Problemes hat Pelz auf deskriptivem Wege gegeben [51]. Ungleich einfacher ist jedoch die nahe verwandte Aufgabe, welche wir folgendermassen formuliren (Fig. 14). Man misst in $\mathrm{K}$ sowohl als in $\mathrm{L}$ die Winkel $\mathrm{MKA}=\alpha$ und $\mathrm{MLA}=\beta$, welche die nach dem Reflexionspunkte gezogenen Strahlen KA und L.A mit der Vertikalen bilden, sowie auch die vertikalen Entfernungen $\mathrm{KB}=\mathrm{m}$ und $\mathrm{LC}=\mathrm{n}$. Diess vorausgesetzt, entnimmt man den beiden Dreiecken MAK und MAL, worin $\Varangle \mathrm{KAM}=\Varangle \mathrm{LAM}=\psi$ ist, die Proportionen $\mathrm{r}:(\mathrm{r}+\mathrm{m})=\sin \alpha: \sin \psi, \quad \mathrm{r}:(\mathrm{r}+\mathrm{n})=\sin \beta: \sin \psi$, woraus unmittelbar folgt

$$
(\mathrm{r}+\mathrm{m}) \sin \alpha=(\mathrm{r}+\mathrm{n}) \sin \beta, \quad \mathrm{r}=\frac{\mathrm{m} \sin \alpha-\mathrm{n} \sin \beta}{2 \cos \frac{\beta+\alpha}{2} \sin \frac{\beta-\alpha}{2}} .
$$

d) Methode von Klose. Dieselbe besteht in Folgendem. Man wählt zwei hochgelegene Punkte H und J (Fig. 14), aus deren jedem der andere anzuvisiren ist, und bestimmt die Winkel $\mathrm{Z}_{1} \mathrm{HJ}=\zeta_{1}$ und $\mathrm{Z}_{2} \mathrm{JH}=\zeta_{2}$, welche in jedem Punkte die Visirlinie mit dem verlängerten Erdradius einschliesst. Jeder Aussenwinkel eines Dreieckes ist gleich der Summe der beiden von ihm getrennt liegenden Innenwinkel; man hat also: $\zeta_{2}=180^{\circ}-\zeta_{1}+\Varangle$ HMJ ; $\Varangle \mathrm{HMJ}=\zeta_{1}+\zeta_{2}-180^{\circ}$. Wenn nun noch ferner die lineare Distanz der Fusspunkte $F$ und $G$ jener Höhen geodätisch $=\mathrm{d}$ ermittelt ist, so kann man zur Berechnung des Erdhalbmessers $\mathrm{r}$ die Proportion $\left(\zeta_{1}+\zeta_{2}-180^{\circ}\right): 360^{\circ}=\mathrm{d}: 2 \mathrm{r} \pi$ verwenden. Oberst Klose wählte nach dem Berichte J. Müller's [52] für FH und GJ die Durlacher Warte und den Strassburger Münsterthurm und fand $\zeta_{1}=89^{\circ} 48^{\prime}, \zeta_{2}=89^{\circ} 35^{\prime}, \zeta_{1}+\zeta_{2}-180^{\circ}=37^{\prime}$, und da $d=71,058 \mathrm{~km}$ bekannt war, so ergab sich für den Erdumfang die Ziffer $41480 \mathrm{~km}$. Ohne Berücksichtigung der Refraktion und anderer Umstände durfte eine genauere nicht erwartet werden.

§. 5. Die Gradmessungsmethode. Die zuletzt behandelte Methode war schon keine ganz direkte mehr; sie gieng nicht unmittelbar auf die Eruirung des Erdhalbmessers selbst aus, sondern setzte sich lediglich die Bestimmung eines aliquoten Theiles des Erdumfanges zum Ziel, aus welchem dann letzterer selbst berechnet werden konnte. Diese Methode ist zugleich die einzige wirklich annehmbare; zuerst verfiel auf sie der gelehrte Bibliothekar von Alexandria, Eratosthenes (276-195 v. Chr.). Aus dem gelehrten Werke Berger's über diesen Mann als Geographen lassen sich alle Data über die eratosthenische Gradmessung völlig genügend entnehmen*) [53], und es ist damit

*) Einen erläuternden Auszug aus den bezüglichen Theilen des Berger- 
Sprenger's Meinung, dass man es bei jener nicht sowohl mit wirklicher Messung, als vielmehr mit einer blos oberflächlichen Schätzung zu thun habe [56], als beseitigt anzusehen. Eratosthenes glaubte zu wissen, dass zu Syene (Assuan) in Oberägypten am Tage des Sommersolstitiums die Sonne einen tiefen Brunnen bis zum Grunde erleuchte, d. h. also in dessen Zenith stehe, während er selbst zur gleichen Zeit für seinen Wohnsitz Alexandria eine Sonnenhöhe von $7^{\circ} 12^{\prime}$ ermittelt hatte. Fig. 15 veranschaulicht uns, wie er zu dieser Zahl gelangte. CD sei die Himmelskugel, M der Standpunkt des Beobachters und zugleich Centrum einer halbkreisförmigen Sonnenuhr AB, in deren tiefstem Punkte der schattenwerfende Zeiger MN angebracht ist. Der Schatten, welchen die Sonne S ergiebt, endigt in $Q$ und are $\mathrm{NQ}=\Varangle \mathrm{NMQ}$ ward eben gleich ${ }^{1 / 50}$ der Peripherie gefunden. Die Sonnenhöhe war in Alexandria $=\varphi^{\circ}$, in Syene $=90^{\circ}$, somit repräsentirte der

Fig. 15.

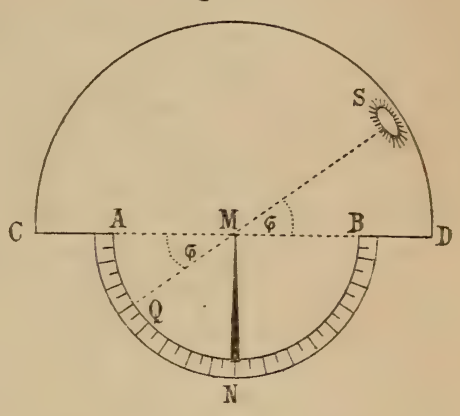
Bogen $90^{\circ}-\varphi=7^{\circ} 12^{\prime}$ die Winkeldistanz beider Städte. 5000 Stadien betrug nach den Katasterlisten der lineare Abstand, und so ergab sich denn aus der Proportion

$$
1 / 50: 1=5000: u
$$

der Erdumfang u zu 250000 Stadien, eine Zahlangabe, die, von den nachweislich vorgekommenen Irrthümern abgesehen, schon dadurch für uns an Werth verliert, dass wir ausser Stande sind, das gebrauchte Stadium mit den modernen Längenmaassen genau zu vergleichen.

Das Verfahren des Eratosthenes fand im Alterthum und Mittelalter mehrfach Nachahmer*). Dionysodoros freilich, der einer von Plinius [62] mitgetheilten Sage zufolge den Erdradius auf 42000 Stadien angegeben haben soll, dürfte nach Bailly's Meinung diesen Werth wohl blos in der Weise gefunden haben [63], dass er ihn mit $\mathrm{Zu}$ grundelegung des archimedischen Kreisverhältnisses aus dem angeblich chaldäischen Werthe für den Erdumfang (264000 Stadien) berechnete. Sonst sind uns aus dem Alterthum noch folgende Maassangaben verblieben [64]: die des Aristoteles (400000 Stadien), die des Kleomedes (300000 Stadien), die des Ptolemäus (180000 Stadien) und die des Posidonius (240000 Stadien). Der Letztgenannte verfuhr

schen Werkes hat der Terf. besorgt [54] und dabei auch auf die Resultate einer neueren Abhandlung von Lepsius [55] gebührend Bedacht genommen.

*) Bei der Zusammenstellung der nun folgenden geschichtlichen Nachweisungen dienten einige besonders tüchtige Arbeiten zur Richtschnur, auf welche zur Ergänzung des Wenigen, was an diesem Orte gegeben werden durfte, verwiesen sein möge. Bis zum Jahre 1827 giebt es wohl keine umfassendere Darstellung. als diejenige, welche II u cke [57] seiner Neubearbeitung des Gehlerschen Wörterbuches einverleibt hat; ausserdem empfiehlt sich für die früheren Versuche die Monographie ron Posch [58]. Die neuere Zeit dagegen und die gegenwärtig den Gradmessungsarbeiten gesteckten Ziele lernt man am besten kennen aus den Schriften r. B a u ernfeind's [59] und S a de beck's [60]; ausserdem hat das Berliner geodätische Institut einen Katalog aller hierher gehörigen literarischen Arbeiten herausgegeben [61]. 
ganz im Geiste des Eratosthenes, indem er die angulare Entfernung zwischen Rhodus und Alexandria der Differenz der Höhen gleichsetzte, bis zu welchen sich in beiden Städten der Stern Kanopus über den Horizont erhob. Im VIII. Jahrhundert unserer Zeitrechnung liess der Kalife Al Mamun zuerst in der palmyrenischen Wüste, sodann in der Ebene Sindjar einen Grad messen; von der ersteren Messung berichtet uns Ibn Junis [65], und das Resultat der zweiten fasst Alfragan [66] in die folgenden Worte: „Invenimus per hoc, quod portio unius gradus circuli ex rotunditate terrae sit 56 milliarium et duarum tertiarum unius milliarii per milliarium, quod est 4000 cubitorum per gradus aequales." Im Abendlande nahm der französische Arzt Fernel (1525) diese Versuche wieder auf; sein darüber verfasstes Buch [67] belehrt uns, dass er in einem Wagen von Paris aus nordwärts gefahren sei, bis astronomische Beobachtung ihm gezeigt habe, dass er um einen ganzen Grad vorwärts gekommen war; ein am Fuhrwerk angebrachtes Hodometer mass die hiezu erforderlich gewesenen Umdrehungen eines Wagenrades und aus diesen berechnete sich ein Breitegrad auf 57070 Toisen - eine Genauigkeit, die angesichts der mangelhaften Methode wohl nur durch ganz besondere Zufälligkeiten erreichbar, wenn nicht am Ende gar erschlichen war.

So unbestreitbar richtig der von Eratosthenes verfolgte Grundgedanke auch war, so litt doch dessen praktische Verwirklichung noch unter zahllosen Unvollkommenheiten. Diesen fast endgültig abgeholfen zu haben, ist das hohe Verdienst des jüngeren Snellius, der Anno 1615 zwischen Alkmaar und Bergen op Zoom jene berühmte Bestimmung eines aliquoten Theiles des Erdumfanges in's Werk setzte, welche seitdem den charakteristischen Namen Gradmessung trägt. Dieselbe führte zwar noch nicht zu sehr genauen Ergebnissen, da Snellius noch kein Fernrohr mit seinen Messwerkzeugen verbunden hatte - Musschenbroek hat sie später unter Anwendung solcher Hülfsmittel wiederholt und verbessert - , allein dem Geiste des Verfahrens nach hat die Nachwelt nichts mehr zu verändern gefunden.

Man wählt nach Snellius [68] zwei auf gleichem Meridian gelegene Orte A und B (Fig. 16), misst deren zenithale Poldistanzen und findet so durch Subtraktion den Winkel $\gamma$, welchen die nach A und B gezogenen Erdradien mit einander bilden. Von A aus misst man ferner geodätisch eine Strecke AC, deren Richtung mit dem Meridian einen (bekannten) Winkel $\varphi$ bilden möge. Alsdann visire man von $\mathrm{A}$ und C nach einem entfernten Punkte D (gewöhnlich wählt man Thurmspitzen, in deren Ermangelung sogenannte trigonometrische Signale errichtet werden) und messe die Winkel CAD und $\mathrm{ACD}$; dann kennt man in dem Dreieck ACD eine Seite und die beiden anliegenden Winkel und kann die Seiten AD und CD trigonometrisch berechnen. $\mathrm{CD}$ als neue Grundlinie benützend, bestimmt man $\Varangle \mathrm{CDE}$ und $\Varangle \mathrm{DCE}$, unter E einen neuen Signalpunkt verstanden, und findet dadurch die Längen $\mathrm{CE}$ und $\mathrm{DE}$. In dieser Weise schreitet man fort ; F, G, H, J werden als neue $Z$ wischenpunkte eingeschaltet, und zuletzt erhält man ein geschlossenes Polygon ACEGJBHFD, dessen sämmtliche Seiten und Winkel $(\alpha, \gamma, \delta, \varepsilon, \zeta, \eta, \vartheta, \iota, \beta)$ bekannt sind, während die Länge der Diagonale $A B$ als einzige Unbekannte zu bestimmen übrig bleibt. Die Regeln der sogenannten Polygonometrie liefern diese Un- 
bekannte ohne grosse Mühe. Man fällt nämlich von den einzelnen Eckpunkten des Vielecks Lothe $\mathrm{CC}_{1}, \mathrm{DD}_{1}, \mathrm{EE}_{1}, \mathrm{FF}_{1}, \mathrm{GG}_{1}, \mathrm{HH}_{1}$, $\mathrm{J} \mathrm{J}_{1}$ auf die Diagonale; dann ist, wenn noch die Linien $\mathrm{EC}_{2}, \mathrm{GE}_{2}$, $G J_{2}$ parallel zu $\mathrm{AB}$ gezogen werden,

$\mathrm{AB}=\mathrm{AC}_{1}+\mathrm{C}_{1} \mathrm{E}_{1}+\mathrm{E}_{1} \mathrm{G}_{1}+\mathrm{G}_{1} \mathrm{~J}_{1}+\mathrm{J}_{1} \mathrm{~B}=\mathrm{AC}_{1}+\mathrm{C}_{2} \mathrm{E}+\mathrm{E}_{2} \mathrm{G}+\mathrm{GJ}_{2}+\mathrm{J}_{1} \mathrm{~B}$ oder, mit Anwendung bekannter Formeln vom rechtwinkligen Dreieck, $\mathrm{AB}=\mathrm{AC} \cos \varphi+\mathrm{CE} \cos (\varphi+\gamma)+\mathrm{EG} \cos (\varphi+\gamma+\varepsilon)+\mathrm{GJ} \cos (\varphi+\gamma+\varepsilon+\eta)$ $+J B \cos (\varphi+\gamma+\varepsilon+\eta+\imath)$

wobei die Summe natürlich als eine algebraische aufzufassen ist. Als Kontrole kann ebenso die Relation

$\mathrm{AB}=\mathrm{AD} \cos (\alpha-\varphi)+\mathrm{DF} \cos (\alpha-\varphi+\delta)+\mathrm{FH} \cos (\alpha-\varphi+\delta+\zeta)$

$$
+\mathrm{HB} \cos (\alpha-\varphi+\delta+\zeta+\vartheta)
$$

dienen, und zudem ist nicht ausser Acht zu lassen, dass die neuere Wahrscheinlichkeitsrechnung zur Ausgleichung der unvermeidlichen Messungsfehler die besten Mittel an die Hand gegeben hat. Zuletzt gilt die Proportion: $\gamma: 360=\mathrm{AB}: \mathrm{u}$.

Das Auszeichnende dieser Manier, eine Erdstrecke auszumessen, liegt darin, dass nur eine einzige Strecke von viel geringerer Ausdehnung, die sogenannte B asis, der unmittelbaren Bestimmung durch die Messkette unterliegt, während Alles sonst von Winkelmessungen abhängt. Es leuchtet ein, dass diese letzteren mit ganz ungemein grösserer Exaktheit zu bewerkstelligen sind. Und während man früher der Grundlinie $\mathrm{AB}$ doch immer noch eine respektable Länge zu sichern bemüht war, um recht genaue Resultate zu erzielen, hat Schwerd [69] späterhin gezeigt, dass mit Beobachtung gewisser Vorsichtsmaassregeln auch diese Fundamentallinie ziemlich klein genommen werden dürfe. Als Schwerd seine kleine Basis zu zwei wiederholten Malen ausmass, fand er blos eine Längendifferenz $=0,000895$ der ganzen

Fig. 16.

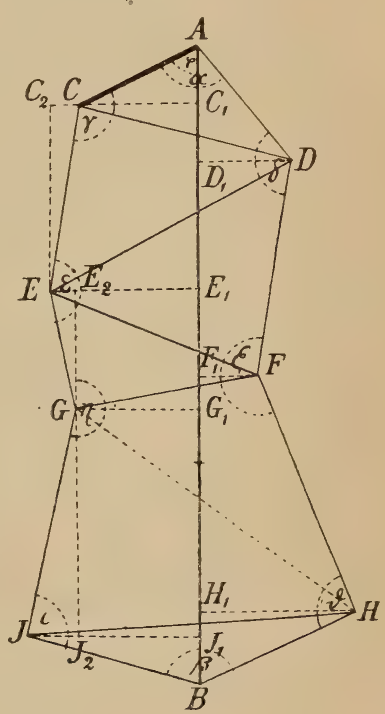

Strecke [70]; diess ist aber eine bei grösseren Grundlinien unmöglich zu erreichende Genauigkeit.

Von späteren Gradmessungen der alten Art sind noch diejenigen von Norwood und Riccioli zu nennen [71]. Der Erste dagegen, der im Sinne Snell's arbeitete, war sein Landsmann Blaeu, der denn auch nach Picard Löbliches geleistet zu haben scheint [72]. Dieser französische Geometer war wiederum der Erste, der die Alhidade seiner Quadranten mit Fernröhren versah und in dem Brennpunkte derselben das die Schärfe der Ablesung erst eigentlich ermöglichende Fadenkreuz anbrachte. Er mass von 1669 bis 1670 einen Bogen zwischen Malvoisine und Amiens, fand den Polhöhenunterschied gleich $1^{0} 22^{\prime} 58^{\prime \prime}$ und berechnete hieraus die Länge eines Breitegrades zu 57060 Toisen. Sein Werk über diese Gradmessung [73] erscheint in der Geschichte der exakten Wissenschaften noch mit einem besonderen Glorienscheine, denn nur dadurch, dass Isaak Newton dasselbe in 
die Hand bekam, ward es ihm möglich, in seine schon früher angestellten Rechnungen über den Zusammenhang der Mondbewegung mit der Erdschwere den richtigen Werth des Erdhalbmessers einzusetzen und mit dieser Substitution ein Gesetz zu entdecken, dessen Gültigkeit ihm bereits wieder zweifelhaft geworden war [74].

\section{§. 6. Zweifel an der geometrischen Kugelform der Erde; weitere} Gradmessungen. Gründe, auf deren Wesen erst im nächstfolgenden Kapitel eingegangen werden kann, machten es gegen Ende des XVII. Jahrhunderts wahrscheinlich, dass die Erde keine eigentliche Kugel sei, sondern am Aequator eine wenn auch geringe Anschwellung besitze. Da ohnehin Picard den Wunsch hegte, seine Gradmessung bis zu einem das ganze Frankreich überspannenden Meridianbogen ausgedehnt zu sehen, so lagen genügende Momente zur Wiederaufnahme der bezüglichen Operationen vor. Der Minister Colbert sagte dem Werke seine Unterstiitzung zu, doch dauerte es 20 Jahre (von 1680 bis 1700), bis dasselbe, an welchem sich Dominic und Jacques Cassini, Maraldi, Couplet, Chazelles und De la Hire betheiligten, zu Ende geführt war. Das Schlussergebniss, dass nämlich im nördlichen Frankreich ein Meridiangrad gleich 56960, im südlichen dagegen $=57097$ Toisen gefunden wurde [75], schien allerdings gegen die Annahme zu sprechen, welche ursprünglich den Anstoss zur Gradmessung gegeben hatte, doch war damit immer so viel festgestellt, dass die Form der Erde keine rein sphärische*); sondern eine elliptische sei. Ueber die Art dieser Ellipticität bestand völlige Klarheit noch nicht.

Fig. 17 stellt eine Ellipse dar, deren grosse Axe AB und kleine Axe CD sich im Mittelpunkte M rechtwinklig schneiden. Um M sei mit beliebigem Radius ein koncentrischer

Fig. 17.

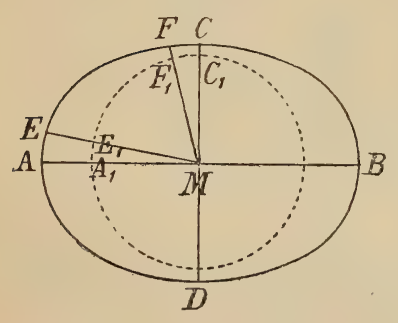

Kreis konstruirt, der die $\mathrm{MA}$ und $\mathrm{MC}$ resp. in $A_{1}$ und $C_{1}$ schneidet. Legt man nun in $\mathrm{M}$ an $\mathrm{MA}$ und $\mathrm{MC}$ zwei beliebige, aber gleiche Winkel an, deren Endschenkel die Ellipse in $\mathrm{E}$ und $\mathrm{F}$, den Kreis dagegen in $\mathrm{E}_{1}$ und $\mathrm{F}_{1}$ treffen, so ist zwar auf dem Kreise arc $\mathrm{A}_{1} \mathrm{E}_{1}=\operatorname{arc} \mathrm{C}_{1} \mathrm{~F}_{1}$, auf der Ellipse dagegen are $\mathrm{AE}<\operatorname{arc} \mathrm{CF}$. Einen strengen Beweis für die Richtigkeit dieser übrigens auch schon durch den Augenschein zu konstatirenden Thatsache werden wir demnächst

*) Bis dahin waren Zweifel an der rein sphärischen Rundung der Erdoberfläche nur gelegentlich laut geworden. Bei Cas siod or kommt nach M. Canto r's Mittheilung [76] eine merkwürdige Stelle vor: "Mundi figuram curiosissimus Varro longae rotunditati in geometriae volumine comparavit, formam ipsius ad ovi similitudinem trahens, quod in latitudine quidem rotundum, sed in longitudine probatur oblongum." Der römische Polyhistor war diesen Worten zufolge ein Anhänger jener Hypothese, der später (s. o.) Ca s sini zuneigte, nicht aber ein Verfechter der Erdabplattung im Newton'schen Sinne, wie Chas les fälschlich annahm [77]. Im Mittelalter sagt der gelehrte Petrus de A bano einmal [78]: "Terra non est sphaerica, imo est oblonga"; ein sonderbares Bild von einer nicht vollkommen sphärischen Erde beherrschte auch die Phantasie des Columbus [79]. In des Schweizers Vadian "Epistola Rudolpho Agricola e Juniori Rhoeto", die $1512 \mathrm{zu}$ Wien gedruckt wurde, wird ein Beweis dafür angetreten, dass die Erde 
folgen lassen. Vorläufig steht fest, dass in der Nähe der Endpunkte der kleinen Axe die Ellipsenbögen, welche einem Centriwinkel von $1^{0}$ Oeffnung entsprechen, grösser sind, als in der Nähe der Endpunkte der grossen Axe. Hält man diess fest, so musste das anscheinend sichere Resultat der zweiten französischen Gradmessung in der Sprache der Geodäsie folgendermassen lauten: Die Erde ist kein abgeplattetes, sondern ein verlängertes Sphäroid (Umdrehungsellipsoid); ihre Rotationsaxe fällt nicht mit der kleinen, sondern mit der grossen Axe der Meridianellipse zusammen.

Jacques Cassini machte diese Behauptung zur Grundlage eines gelehrten Werkes [81], und auch Eisenschmidt schrieb eine in diesem Sinne gehaltene Dissertation [82], in welcher nach den Messungen von Eratosthenes, Fernel, Snellius, Riccioli und Picard die Gestalt der Erde als ein gedehntes Sphäroid ermittelt ward, dessen Polardurchmesser 10 890, dessen Aequatorialdurchmesser blos 8288 römische Meilen betrüge. Allein von englischer Seite erhob man, gestützt auf theoretische Gründe und auf die gewichtige Autorität Newton's, unausgesetzt Widerspruch, und Voltair e spottete, wer von London nach Paris komme, müsse seinen Gedanken immer eine ganz andere Richtung geben, denn dort betrachte man die Erde als Orange, hier aber als Citrone. Um den Streit endgültig $\mathrm{zu}$ begleichen, ordnete König Lo u is XV. in den Jahren 1735 und 1736 je eine Gradmessungskommission nach Peru und Lappland ab; die Mitglieder der ersteren waren Bouguer, Godin und De la Condamine nebst ihren Seitens der spanischen Krone beigesellten Reisebegleitern Don Jorge Juan y Santacilia und Don Antonio de Ulloa, während Le Monnier, Clairaut, Camus, Outhier und der Schwede Celsius unter Maupertuis' Führung nach Norden giengen [83]. Am Aequator ward Rühmliches geleistet, und Bouguer's Beschreibung der ganzen Arbeit [84] wird mit dem später gelieferten Nachtrag [85] stets die Bezeichnung eines klassischen Werkes verdienen. Maupertuis fasste seine Aufgabe etwas zu leicht auf, und sein Reisebericht [86], von dem Nürnberger lange nachher eine deutsche Ausgabe veranstaltete [87], ist mehr in allgemein-geographischer, als speziell in mathematischer Hinsicht lesenswerth. Immerhin musste aus den einzelnen Messungen das Resultat gezogen werden, dass ein Meridiangrad unter dem Polarkreis grösser als ein solcher in der Breite von Paris und dieser wieder grösser als ein solcher in der Breite Null sei, und hiemit war die alte Streitfrage im Sinne Newton's und der auf seiner Seite stehenden Physiker entschieden.

von Ost nach West ausgedehnter sei, als von Nord nach Süd, doch scheint uns diess mehr eine Wiederaufnahme der alten Chlamys-Theorie des Eratosthenes zu sein, in welcher der Keim zu der später beliebten Trennung der Erde in eine zona habitabilis und inhabitabilis lag, als eine Vorahnung der Abplattungslehre, an welche in jener frühen Zeit wohl kaum Jemand dachte. Auch Picard scheint bereits an die Möglichkeit einer Abweichung gedacht zu haben, allein noch 1690 äusserten sich, wie Wolf erzählt, die Pariser Akademiker dahin: anlässlich der Wahrnehmung, dass die Jupiterscheibe im Teleskop nicht ganz kreisrund erscheine, sei auch von ihnen die Möglichkeit diskutirt worden, dass Aehnliches bei der Erde statthabe; man habe aber in ihren Kreisen den Gedanken wieder fallen lassen, da der Schatten der Erde auf dem Monde stets in der Kreisform gesehen werde [80]. Ueber die Unzuverlässigkeit dieses Argumentes vgl oben §. 2. 
Spätere Gradmessungen konnten sonach blos eine Verfeinerung des peruanisch-lappländischen Ergebnisses anstreben. Es sind solche ausgeführt worden von La Caille im Kaplande [88], von Boscovich und Maire im Kirchenstaate [89], von Christian Mayer in der Rheinpfalz [90], von Mason und Dixon in Nordamerika (worüber Maskelyne's Beschreibung [91] zu vergleichen ist, von Liesganig in Oesterreich [92]*), von Beccaria und Canonica in Piemont [95], von Roy [96] und dem vierten Astronomen Cassini [97] zur geodätischen Verbindung Englands mit Frankreich, von Burrow und Dalby [98] in Bengalen und endlich von Svanberg in Lappland [99], durch welch' letztere Messung besonders Maupertuis' Irrthümer berichtigt werden sollten und auch wirklich berichtigt wurden. Die Hypothese des abgeplatteten Sphäroides ward durch all' diese Bemühungen immer wieder bestätigt und schliesslich zum Range einer feststehenden wissenschaftlichen Theorie erhoben.

§. 7. Gradmessungen zur Festsetzung eines Naturmaasses. In ein neues Stadium trat die Gradmessungsfrage, als zur Zeit der französischen Revolution die Idee zur Herrschaft gelangte, es müsse sich ein sogenanntes Naturmaass ausfindig machen lassen, welches, wenn auch sämmtliche Normalmaassstäbe verloren gehen sollten, doch immer wieder von Neuem genau in derselben Grösse bestimmt werden könne. Eine aus den hervorragendsten Pariser Mathematikern bestehende Kommission (Laplace, Lagrange und Monge gehörten zu den Mitgliedern) beschloss, 1/4000000 jenes Meridians, der durch die Sternwarte der Hauptstadt geht, als Längeneinheit unter dem Namen Meter („mètre ${ }^{*}$ ) einzuführen und darauf ein konsequentes Maass- und Gewichtssystem zu begründen [100]. Dieser Plan ist denn auch, wie alle Welt weiss, im vollsten Umfange durchgeführt worden. Im Interesse der wohlthätigen metrologischen Umwälzung führten Méchain, der aber darüber starb, J. Biot und Arago die französische Messung bis $\mathrm{zu}$ den balearischen Inseln fort und gelangten so $\mathrm{zu}$ neuen und besseren Werthen für die Erdabplattung [101].

Das Naturmaass an sich ward freilich nur zu bald als eine Chimäre erkannt. Es ist nicht recht verständlich, wie es Geometern von dem Range der genannten verborgen bleiben konnte, dass Messungsfehler unter allen Umständen jedem aus menschlichen Operationen gezogenen Resultate anhaften müssen, und so stellte sich denn auch nur zu bald heraus, dass das Meter das durchaus nicht war, was es ursprünglich sein sollte. Bessel wiederholte nämlich die gewaltige Rechnung, welche die Grösse der Normaleinheit geliefert hatte, indem er dabei auf den

*) Die Arbeit Liesganig's erfreut sich ihres Ergebnisses wegen keines besonders guten Rufes, doch ist nicht zu leugnen, dass die Anlage derselben den wissenschaftlich-methodischen Normen, welche man damals für maassgebend erachtete, völlig entspricht; namentlich die Betrachtungen über die Verschiedenheiten in der Länge eines steyermärkischen und eines kroatischen Grades, welche durch die Attraktion der Berge bedingt sein sollen [93], stellen der Kritik des gelehrten Jesuiten kein ungünstiges Zeugniss aus. Es müssen daher wohl konstante Fehler besonderer Art seine Rechnung nachtheilig beeinflusst haben, und da nach Fris cha uf [94] die Endpunkte von Liesganig's Basis heute noch durch fixe Marken deutlich erkennbar sind, möchte es sich verlohnen, seine Untersuchung nochmals zu rekapituliren. 
von Puissant entdeckten Fehler Rücksicht nahm, welchen die französischen Geodäten bei Bestimmung der Abstände der Parallelkreise von Montjouy und Mola (auf Formentera) im Jahre 1808 begangen hatten; es zeigte sich dabei, dass das Meter etwas zu klein angesetzt worden war [102]. Bessel war es aber auch, der darauf aufmerksam machte [103], dass die Beziehungen des Meters zum Erdmeridian nur als etwas Willkürliches und Sekundäres anzusehen wären, wogegen der wahre Werth des metrischen Systemes einzig und allein in dessen harmonischem und konsequentem Aufbau zu suchen sei. Ueber diese Naturmaasse spricht sich ein neuerer Forscher, Listing, in folgender beachtenswerther Weise aus [104]. Es bieten sich im Ganzen vier derselben dar, die Länge des Sekundenpendels, die jedoch von der selbst veränderlichen Grösse der Schwerkraft abhängig ist, die Gauss'sche Gravitationskonstante k, die bislang zwar als unveränderlich erkannt ward, jedoch nur dem sachkundigen Astronomen verständlich ist, die von Weber mit c bezeichnete Grösse in der Elektricitätslehre und die Wellenlänge des einer bestimmten Stelle im Spektrum entsprechenden Lichtstrahles; selbst im letzteren Falle würde jedoch eine Unsicherheit bis zu $0,00025 \mathrm{~m}$ übrig bleiben, während bei der Vergleichung von Maassstäben noch kleinere Beträge in Betracht kommen. Das Normalmaass der Natur entnehmen zu wollen, bleibt deshalb ein illusorisches Beginnen.

Wir gedenken hier noch anhangsweise einiger Breitegradmessungen aus den ersten Jahrzehnten unseres Jahrhunderts. Diejenigen, welche H. C. Schumacher [105] in Jütland, Bessel und Baeyer [106] in Ostpreussen, Gauss [107] in Hannover ausführten, erstreckten sich allerdings nur über kleinere Erdräume, dafür aber zeichneten sie sich durch hohe Genauigkeit aus, und namentlich die von Gauss geleiteten Arbeiten wirkten schule- und epochemachend auf die höhere Geodäsie ein. Ungleich ausgedehnter waren die von Lambton und Everest [108] im östlichen Hindostan, von W. Struve [109] in Russland und von Maclear [110] in Südafrika gemessenen Längen. Gleichwohl standen die aus den einzelnen Operationen errechneten Dimensionen des Erdkörpers unter sich noch in keiner rechten Verbindung, und immer entschiedener erkannte man die Nothwendigkeit, die vielfach zersplitterte Thätigkeit in den einzelnen Ländern einheitlich zusammenzufassen.

§. 8. Die Längengradmessungen und die europäische Gradmessung. Hiezu kam noch eine weitere Anregung von Belang. Schon im XVIII. Jahrhundert hatten nämlich D'Alembert und Gerlach [111] sich davon überzeugt, dass Messungen im Meridian nicht ausreichten, um über die Gestalt der Erde vollständig in's Klare zu kommen, dass vielmehr auch in einer dazu senkrechten Richtung Längen gemessen und astronomisch bestimmt werden müssten. Eine detaillirte Triangulation des fünfundvierzigsten Parallelkreises ward von 1811 an auf Laplace's Vorschlag von den Obersten Brousseau und Maurice Henry vorgenommen [112]. Umfänglichere Arbeiten dieser Art jedoch datiren erst von der Gründung des grossen Gradmessungswerkes, welches in dem noch immer thätigen, hochbetagten, preussischen General v. Ba ey er (geb. 1794), dem einstigen Gehülfen Bessel's, seinen Schöpfer verehrt. 
Im Jahre 1861 veröffentlichte derselbe eine Schrift [113], welche den Plan, nach welchem das Studium der Erdkonfiguration systematisch $\mathrm{zu}$ betreiben ist, in seinen Einzelheiten darlegt. Die Messungen der Breitengrade dienen zur Bestimmung der Gestalt und Grösse der Meridiane, während genaue Längengradmessungen allmählig zur Beantwortung der Frage führen können: Ist die Erde ein Rotationskörper, oder ist sie es nicht? Alle Maassnahmen in diesem Sinne bedürfen aber vorhergehender Verständigung der Mitarbeiter, damit nicht Zeit und Kraft nutzlos zersplittert werden, und so erliess denn die preussische Regierung auf v. Baeyer's gutachtliche Aeusserung hin Einladungen an sämmtliche europäische Staaten, um deren Beitritt zur Anfertigung eines Gesammtplanes zu erlangen [114]. Schon im gleichen Jahre 1861 erklärten Frankreich, Dänemark, Coburg-Gotha, Holland, Russland, die Schweiz, Baden, Sachsen, Italien, Oesterreich, SchwedenNorwegen, Bayern, Mecklenburg, Hannover und Belgien (die Reihenfolge der Staaten ist die chronologische) ihre Bereitwilligkeit, in Verhandlungen auf der vorgeschlagenen Basis einzutreten; auf der im Oktober 1864 zu Berlin abgehaltenen Konferenz einigte man sich dahin, die oberste Leitung der - zunächst mitteleuropäischen - Gradmessung einer aus Bevollmächtigten aller Reiche zusammengesetzten permanenten Deputation zu übertragen und das Centralbureau mit der Ausführung der Beschlüsse zu betrauen [115]. Der ursprünglich gewählte Name erwies sich bald als ein zu enger für das riesige Unternehmen, an welchem zur Zeit alle europäischen Staaten mit alleiniger Ausnahme der Türkei participiren. Jedes Land nimmt innerhalb dieser europäischen Gradmessung seine besondere Stellung ein, einem jeden sind selbstständige Aufgaben zugewiesen, über deren Natur man sich am Besten in der mehrfach citirten Broschüre Sadebeck's unterrichten kann [116]. Wir unterlassen es einstweilen, die Endziele der noch auf lange Jahre hinaus den Geodäten und Astronomen eine segensreiche Thätigkeit gewährleistenden Gradmessungsarbeit zu skizziren, da uns das dritte Kapitel dieser Abtheilung ohnehin zu dem vorliegenden Gegenstande zurückführen wird. Nur des Umstandes sei gedacht, dass nach einem Entwurfe W. Struve's vom Jahre 1857 die Längengradmessung längs des zweiundfünfzigsten Parallels von Valentia in Irland bis Orsk an der Ostgrenze des europäisch-russischen Reiches fortgeführt werden soll [117], und dass die vorbereitenden Operationen - insbesondere die Herstellung telegraphischer Zeitbestimmungen zwischen den Hauptsternwarten - bereits zu einem hohen Grade der Vollendung gediehen sind.

§. 9. Sphäroidische Formeln und Rechnungen. Wird die Erde als ein Umdrehungsellipsoid betrachtet, so erfahren die üblichen mathematisch-geographischen Begriffe Abänderungen und Erweiterungen, von welchen in Kürze zu sprechen hier der richtige Platz sein wird. Unsere hierauf bezüglichen Erörterungen lehnen sich theilweise an das auch in dieser Beziehung mustergültige Lehrbuch von Martus [118] an.

a) Die Abplattung der Erde. Um die Grösse der Abweichung der Meridianellipse von einem Kreise zu taxiren, stehen uns zwei Wege offen. Man kann nämlich entweder die Excentricität $\varepsilon$ dieser Kurve 
angeben, welche durch die Relation

$$
\varepsilon^{2}=\frac{a^{2}-b^{2}}{a^{2}}
$$

bestimmt ist, wo a und b die Halbaxen der Ellipse bedeuten. Es ist dieser stets unächte Bruch $\varepsilon$ gleich der Quadratwurzel aus einem Quotienten, dessen Zähler das Quadrat der Entfernung eines Brennpunktes vom Mittelpunkte, dessen Nenner gleich dem Quadrate der kleinen Halbaxe ist. Gewöhnlich jedoch ersetzt man die Excentricität durch die Abplattung

$$
\alpha=\frac{a-b}{a}
$$

zwischen beiden Grössen besteht die Proportion $\varepsilon: a=\sqrt{a+b}: \sqrt{a-b}$.

b) Geographische und geocentrische Breite. Die Definition des Begriffes der Breite kann auf der kugelförmigen Erde in doppelter Weise gegeben werden, denn es ist offenbar einerlei, ob man die Breite als den Winkel bezeichnet, welchen ein an den betreffenden Ort gezogener Erdradius mit der Aequatorebene bildet, oder als den Winkel, welchen eine in jenem Orte an die Erdoberfläche gezogene Normale mit der Aequatorebene bildet. Beide Erklärungen stimmen jedoch nicht mehr überein auf dem Rotationsellipsoid oder sie thun diess doch wenigstens nur für Punkte, welche entweder auf dem Aequator gelegen sind, oder mit einem der Pole zusammenfallen. Es muss demnach jetzt ein Unterschied zwischen geographischer und geocentrischer Breite gemacht werden. In Fig. 18 haben $\mathrm{A}, \mathrm{B}, \mathrm{C}, \mathrm{D}, \mathrm{M}$ die nämliche Bedeutung wie in Fig. 17, E ist ein willkürlicher Punkt der Meridianellipse. Verfahren wir nun bei der Breitenbestimmung in der gewöhnlichen Weise, so legen wir in $\mathrm{E}$ eine berührende (d. h. horizontale) Gerade an die Ellipse und errichten auf ihr in E eine senkrechte (die vertikale) Linie, welche die grosse Axe in $\mathrm{H}$ schneidet; $\mathrm{EH}$ wird mit dem Radiusvektor EM im Allgemeinen nicht koincidiren. $\Varangle \mathrm{AHE}=\varphi$ stellt uns die geographische, $\Varangle \mathrm{AME}=\varphi^{\prime}$ die geocentrische Breite dar. Die Beziehung zwischen $\varphi$ und

Fig. 18.

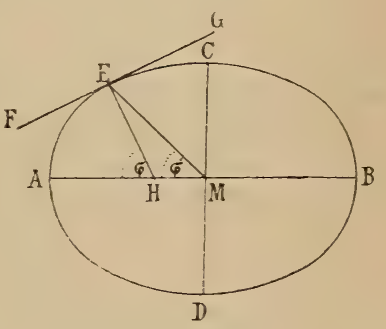
$\varphi^{\prime}$ ist sehr einfach herzustellen. Bekanntlich ist nämlich die trigonometrische Tangente des Winkels, welchen eine Normale an der Kurve $\mathrm{f}(\mathrm{x}, \mathrm{y})=\mathrm{o}$ mit der Abscissenaxe einschliesst, gleich $-\frac{\mathrm{dx}}{\mathrm{dy}}$, und da $a^{2} y^{2}+b^{2} x^{2}=a^{2} b^{2}$ die Ellipsengleichung ist, so wird $\frac{d x}{d y}=-\frac{a^{2} y}{b^{2} x}$ gefunden. Da also tang $\varphi=\frac{a^{2} y}{b^{2} x}$, tang $\varphi^{\prime}=\frac{y}{x}$ ermittelt ward, so hat man

$$
\frac{\operatorname{tang} \varphi}{\operatorname{tang} \varphi^{\prime}}=\frac{a^{2}}{b^{2}}, \operatorname{tang} \varphi^{\prime}=\frac{b^{2}}{a^{2}} \operatorname{tang} \varphi .
$$

c) Bestimmung der Excentricität durch zwei beliebige Radien. Kennt man für zwei beliebige geocentrische Polhöhen $\varphi_{1}^{\prime}$ und $\varphi_{2}^{\prime}$, die natürlich 
zuerst nach der vorigen Formel aus zwei wirklich gemessenen Polhöhen oder Breiten berechnet sein können, die zugehörigen Erdradien $r_{1}$ und $\mathrm{r}_{2}$, so lässt sich die Excentricität der Meridianellipse bestimmen. Versteht man nämlich unter $\mathrm{x}_{1}, \mathrm{y}_{1}$ und $\mathrm{x}_{2}, \mathrm{y}_{2}$ die rechtwinkligen Koordinaten der fraglichen Erdorte, so müssen offenbar die Gleichungen

$$
a^{2} y_{1}{ }^{2}+b^{2} x_{1}^{2}=a^{2} b^{2}, \quad a^{2} y_{2}^{2}+b^{2} x_{2}^{2}=a^{2} b^{2}
$$

oder, wenn man statt der orthogonalen polare Koordinaten einführt, auch die Gleichungen

$a^{2} r_{1}^{2} \sin ^{2} \varphi_{1}^{\prime}+b^{2} r_{1}^{2} \cos ^{2} \varphi_{1}^{\prime}=a^{2} b^{2}, \quad a^{2} r_{2}^{2} \sin ^{2} \varphi_{2}^{\prime}+b^{2} r_{2}{ }^{2} \cos ^{2} \varphi_{2}^{\prime}=a^{2} b^{2}$ gelten. Komparation und nachherige Division liefert die neue Gleichung

$$
\frac{\mathrm{b}^{2}}{\mathrm{a}^{2}}=\frac{\mathrm{r}_{1}{ }^{2} \sin ^{2} \varphi_{1}^{\prime}-\mathrm{r}_{2}{ }^{2} \sin ^{2} \varphi_{2}^{\prime}}{\mathrm{r}_{2}^{2} \cos ^{2} \varphi_{2}^{\prime}-\mathrm{r}_{1}^{2} \cos ^{2} \varphi_{1}^{\prime}} \text {. }
$$

Zieht man endlich noch die beiden Seiten von der Einheit ab, so ergiebt sich

$$
\begin{gathered}
\varepsilon^{2}=\frac{a^{2}-b^{2}}{a^{2}}=\frac{r_{2}^{2}\left(\cos ^{2} \varphi_{2}^{\prime}+\sin ^{2} \varphi_{2}^{\prime}\right)-r_{1}^{2}\left(\cos ^{2} \varphi_{1}^{\prime}+\sin ^{2} \varphi_{1}^{\prime}\right)}{r_{2}^{2} \cos ^{2} \varphi_{1}^{\prime}-r_{1}^{2} \cos ^{2} \varphi_{1}^{\prime}} \\
=\frac{\left(r_{2}-r_{1}\right)\left(r_{2}+r_{1}\right)}{\left(r_{2} \cos \varphi_{2}^{\prime}+r_{1} \cos \varphi_{1}^{\prime}\right)\left(r_{2} \cos \varphi_{2}^{\prime}-r_{1} \cos \varphi_{1}^{\prime}\right)} .
\end{gathered}
$$

d) Berechnung der Excentricität aus gemessenen Gradlängen. Die Berechnung der neueren Gradmessungen stützte sich meistentheils auf eine elegante Formel Bohnenberger's [119], welche wir nachstehend herleiten. Berechnet man in Fig. 18 die Normale $\mathrm{EH}=\mathrm{n}$ aus dem Dreieck $\mathrm{EMH}$, in welchem $\mathrm{EM}=\sqrt{\mathrm{x}_{1}{ }^{2}+\mathrm{y}_{1}{ }^{2}}, \mathrm{HM}=\varepsilon \mathrm{x}_{1}$ und $\dot{\gamma} \varphi^{\prime}$ $=\operatorname{arctang}\left(\frac{b^{2}}{a^{2}} \operatorname{tang} \varphi\right)$ bekannt sind, so findet man, falls zur Abkürzung noch der halbe Parameter $\mathrm{p}$ eingeführt wird,

$$
\mathrm{n}=\frac{\mathrm{p}}{\sqrt{1-\varepsilon^{2} \sin ^{2} \varphi}}
$$

Einem bekannten Lehrsatze der analytischen Geometrie zufolge verhält sich aber der Krümmungsradius $\left.{ }^{*}\right)$ der Ellipse R im Punkte $\left(\mathrm{x}_{1}, \mathrm{y}_{1}\right)$ zur Normale n, wie das Quadrat dieser Normale zum Quadrate des halben Parameters, d. h. es ist

$$
\mathrm{R}=\frac{\mathrm{n}^{3}}{\mathrm{p}^{2}}=\frac{\mathrm{p}}{\left(1-\varepsilon^{2} \sin ^{2} \varphi\right)^{3 / 2}}
$$

Unter der Polhöhe $\varphi$ sei nun ein Grad von der Länge $G$, unter einer anderen Polhöhe $\psi$ ein Grad von der Länge $g$ gemessen worden; kleine Ellipsenbögen darf man ohne nennenswerthen Fehler ihren Krümmungsradien proportional setzen, und hat also **)

$$
G: g=\left(1-\varepsilon^{2} \sin ^{2} \psi\right)^{3 / 2}:\left(1-\varepsilon^{2} \sin ^{2} \varphi\right)^{3 / 2}
$$

*) Unter dem Krümmungskreise einer Kurve versteht man bekanntlich einen Kreis, der durch drei benachbarte Kurvenpunkte $(x, y),(x+d x, y+d y),(x-d x$, $\mathrm{y}-\mathrm{dy}$ ) hindurchgeht und der Kurve sich inniger anschmiegt als irgend ein anderer Kreis zu thun vermöchte.

**) Diese Formel liefert auch den strengen Beweis für die früher nur veranschaulichte Wahrheit, dass mit wachsender Polhöhe auf dem Umdrehungsellipsoid die Gradlängen grösser werden müssen. Ist nämlich $\varphi>\psi$, so ist auch $\varepsilon^{2} \sin ^{2} \varphi>\varepsilon^{2} \sin ^{2} \psi$ und $\left(1-\varepsilon^{2} \sin ^{2} \psi\right)>\left(1-\varepsilon^{2} \sin ^{2} \varphi\right)$. Diese Eigenschaft erhält sich, wenn man jede der beiden Grössen auf eine beliebige Potenz erhebt, und es ist also der Nachweis geführt, dass der unter einer höheren Breite $\varphi$ gemessene Bogen $G$ den unter einer niedrigeren Breite $\psi$ gemessenen Bogen $\mathrm{g}$ an Grösse übertrifft. 
Hieraus aber berechnet sich durch eine einfache algebraische Transformation

$$
\varepsilon=\sqrt{\frac{G^{2 / 3}-g^{2 / 3}}{G^{2 / 3} \sin ^{2} \varphi-g^{2 / 3} \sin ^{2} \psi}} .
$$

e) Radius einer dem Sphäroid inhaltsgleichen Kugel. Da die Abplattung der Erde, wie wir im nächsten Paragraphen sehen werden, keine sehr beträchtliche ist, so empfiehlt es sich häufig, dem Erdsphäroid eine Kugel zu substituiren, deren Halbmesser gewissermassen das Mittel aus den ungleichen Halbmessern des ersteren repräsentirt. Gewöhnlich wählt man hiezu jene Kugel, deren Volumen demjenigen des Ellipsoides gleich ist. Der Kubikinhalt der Kugel wird durch $\frac{4}{3} r^{3} \pi$, jener des Sphäroides durch $\frac{4}{3} a^{2} b \pi$ ausgedrückt; demgemäss wäre

$$
\frac{4}{3} \mathrm{r}^{3} \pi=\frac{4}{3} \mathrm{a}^{2} \mathrm{~b} \pi, \quad \mathrm{r}=\sqrt[3]{\mathrm{a}^{2} \mathrm{~b}}
$$

Dieser Vermittelungsgrösse werden wir bald wieder begegnen.

§. 10. Dimensionen des Erdsphäroides. Für die Abmessungen des Erdkörpers findet man in den verschiedensten Werken auch verschiedene Zahlen angegeben, je nachdem man sich an die eine oder andere Berechnung hält. Ausführliche Untersuchungen auf Grund des zu ihrer Zeit vorliegenden Materiales haben in diesem Sinne v. Linden au [120], E. Schmidt [121], Bessel [122] und Encke [123] angestellt. Wir ziehen es vor, die von Listing bestimmten Mittelwerthe hier mitzutheilen. Er theilte die wichtigeren Gradmessungen in Gruppen ein und bestimmte für jede einzelne Gruppe das ihren relativen Werth charakterisirende Gewicht. Auf Grund dieser Eintheilung nahm er eine Neuberechnung vor und gelangte so dahin, ein typisches Sphäro id in Vorschlag zu bringen, welches sich am besten zur Vergleichung der bisherigen wie künftigen Sphäroidformen eignen soll [124]. Danach wäre $\mathrm{a}=6377365 \mathrm{~m}, \mathrm{~b}=6355298 \mathrm{~m}, \alpha=\frac{\mathrm{a}-\mathrm{b}}{\mathrm{a}}=\frac{1}{289}$, ein Meridionalquadrant $=10000218 \mathrm{~m}$, ein Aequatorialquadrant $=10017542 \mathrm{~m}, \mathrm{r}=\sqrt[3]{\mathrm{a}^{2} \mathrm{~b}}=6370000 \mathrm{~m}$, die mittlere Länge eines Breitengrades $=57009,49$ Toisen. Die alte populäre Rechnung, welche den Erdumfang auf 5400, die Länge eines Aequatorgrades auf 15 und den Erdradius auf 859,5 Meilen anschlägt, kann dabei immer noch nebenher bestehen bleiben; Listing hat auch auf sie Rücksicht genommen und (a. a. O.) für sein typisches Sphäroid die Meile $=\frac{\mathrm{a} \pi}{2700}=7420,4 \mathrm{~m}$ gesetzt.

Man halte jedoch daran fest, dass all' das Gesagte ausschliesslich dann gilt, wenn die Erde als ein abgeplattetes Drehungsellipsoid aufgefasst wird, dessen kleine Axe zugleich die Rotationsaxe darstellt. Diese Eigenschaften können nur angenähert als für den Erdkörper charakteristisch gelten, und es hat nicht an gelehrten Männern gefehlt, welche die eine oder andere ernstlich in Zweifel ziehen zu sollen glaubten. 
§. 11. Bedenken gegen den Fundamentalsatz der mathematischen Geographie. In diesem Paragraphen sollen blos solche Bedenken zur Sprache kommen, welche diesen Fundamentalsatz nicht ernstlich zu gefährden vermögen. Von anderen wird später die Rede sein.

a) Die Erosionshypothese. Bereits vor hundert Jahren sprach ein Oesterreicher, Gerlach, die Ansicht aus, die Erde sei eigentlich eine Kugel oder doch ein nur ganz unmerklich von jener verschiedener Körper, und man werde sich dereinst davon überzeugen, wenn man hinreichend viele und gute Bestimmungen von Meerestiefen zur Verfügung habe [125]. Denselben Gedanken vertrat G. Bischof in einer besonderen Monographie [126]; die Abplattung ist nach seiner Behauptung nicht ein Erzeugniss der Centrifugalkraft, sondern ein solches der erosiven Kräfte, welche auf der Erdoberfläche ihr ungehindertes Spiel treiben. Der Meeresboden dagegen habe sich, da ihm die Erosion so gut wie gar nicht beikommen könne, seine rein sphärische Form bewahrt, und aus den vorhandenen Lothungen lasse sich dafür der Beweis entnehmen. Sind nämlich $r_{1}, r_{2}, r_{3} \ldots$ für beliebige Punkte auf dem Meere die Radienvektoren, $l_{1}, l_{2}, l_{3} \ldots$ die daselbst gelotheten Meerestiefen, so ist nach Bischof

$$
\mathbf{r}_{1}-\mathrm{l}_{1}=\mathbf{r}_{2}-\mathrm{l}_{2}=\mathbf{r}_{3}-\mathrm{l}_{3}=\ldots=\text { Konst., }
$$

und diese Konstante ist eben der Halbmesser der eigentlichen Erdkugel. H. J. Klein's eingehende Widerlegung dieser Hypothese [127] betont namentlich die Unmöglichkeit, aus unserem noch so geringen oceanographischen Wissen so weittragende Schlüsse zu ziehen.

b) Die Hypothese des dreiaxigen Ellipsoides. Elie Ritter's Versuch [128], die vorhandenen Messungen einem Rotationskörper von nur annähernd elliptischem Meridianschnitte anzupassen, führte nach R. Wolf wesentlich nur zu einer Verifikation der Bessel'schen Zahlen [129]. Dagegen wagte es G. Th. Schubert, direkt das dreiaxige Ellipsoid an Stelle des zweiaxigen zu setzen [130], ein Versuch, der um so näher liegen mochte, als nach Jacobi's Entdeckung (I. Abtheilung, Kap. III, §. 7) die Möglichkeit eines theoretischen Einwandes gegen die Neuerung geschwunden war. Schubert fand $\mathrm{a}_{1}=6378556 \mathrm{~m}$, $\mathrm{a}_{2}=6377837 \mathrm{~m}, \mathrm{~b}=6356719 \mathrm{~m}$; der Aequator ist ja jetzt kein Kreis mehr, sondern selbst eine Ellipse, und folglich müssen wir auch für ihn die grosse Halbaxe $a_{1}$ von der kleinen Halbaxe $a_{2}$ unterscheiden. Die erstere trifft auf der Osthalbkugel den Aequator unter $58^{\circ} 44^{\prime}$ long. (von Ferro), die andere unter $148^{\circ} 44^{\prime}$ long. Sehr viel Anklang hat, zumal in England, die neuerdings von James und Clarke [131] unternommene Untersuchung des dreiaxigen Erdellipsoides gefunden, welcher zufolge $a_{1}=6378294 \mathrm{~m}, a_{2}=6376350, b=6356068 \mathrm{~m}$ ermittelt ward *). „Der grösste Radius kommt nach Clarke auf $15^{\circ} 34^{\prime}$ östliche Länge von Greenwich zu liegen; der grösste Meridiankreis trifft somit Spitzbergen, das Riesengebirge, Messina, den Tsad-See, sowie die Sandwich-Inseln und die westlichsten Theile von Aliaska;

*) Die Differenz $\left(a_{1}-a_{2}\right)$ ist jedenfalls eine sehr geringe. Hind freilich denkt sie sich [132] noch viel geringer, als Schubert oder Clarke, und lässt doch diesen winzigen und nur durch scharfe Rechnung konstatirbaren Unterschied Hebungen und Senkungen, sowie auch die Meeresströmungen hervorrufen! Die Eigenthümlichkeiten der Oberflächengestaltung Nordamerika's leitet er aus dieser einzigen Ursache her. 
der kleinste hingegen, $105^{\circ} 34^{\prime}$ östliche Länge von Greenwich, berührt nahezu das asiatische Nordkap und Irkutsk, führt durch die Mongolei und Hinterindien, geht endlich an der Westküste Patagoniens vorbei und über Ecuador, die Ostspitze China's und Canada nach der Baffinsbay" [133]. Der Grund, weshalb die aus den jedenfalls höchst verdienstlichen Arbeiten Clarke's gezogenen Resultate heute schon wieder verlassen zu werden beginnen, liegt einfach darin, dass gewisse Unregelmässigkeiten der Erdgestalt sich mit dem dreiaxigen Ellipsoide nicht schlechter, aber auch durchaus nicht besser vereinigen lassen, als mit dem zweiaxigen, während es für die Rechnung ungleich bequemer ist, von diesem letzteren auszugehen.

c) Fergola's Hypothese. Der Anhänger der Kant-Laplace'schen Nebulartheorie wird sich nicht mit dem Gedanken befreunden können, dass die Umdrehungsaxe des nach und nach in Erstarrung übergegangenen Gasballes, welcher unsere Erde von jetzt darstellt, nicht auch zugleich mit dem kleinsten Durchmesser dieses ellipsoidischen Balles zusammengefallen sei. Gleichwohl ist eine absolute Garantie für diese Koincidenz von geometrischer und kinematischer Axe nicht von vornherein gegeben, und es war deshalb sehr zu billigen, dass Fergola [134] die Prüfung dieser Frage einmal ernstlich in Angriff nahm. Wäre die Sachlage wirklich so, wie sie der neapolitanische Mathematiker voraussetzte, so würden sehr verwickelte Verhältnisse die Folge davon sein. Geometrischer Meridian wäre jeder die geometrische Axe in sich enthaltende ebene Schnitt, und senkrecht dazu stünde der durch das Centrum des Erdellipsoides hindurchgehende geometrische A equator. Schwieriger wäre der astronomische Meridian eines Ortes zu ermitteln; man müsste in diesem Punkte eine Normale an die Ellipsoidfläche ziehen und durch sie eine Ebene parallel zur Umdrehungsaxe legen; würden dann alle Punkte, deren Meridianebenen selbst wieder parallel verlaufen, durch einen Kurvenzug verbunden, so wäre eben dieser selbst identisch mit dem gesuchten astronomischen Meridian. Alle Punkte, für welche die Normalen einen und denselben Winkel mit der Rotationsaxe einschliessen, erfüllen einen geographischen $\mathrm{P}$ arallel; derselbe wäre im Allgemeinen eine unregelmässige Raumkurve von doppelter Krümmung, und ein Gleiches gälte für jede Orthogonalkurve des Parallels, $d$. h. für den geographischen Meridian. Glücklicherweise bleibt diese Scheidung für unsere Erde belanglos, denn während nach Fergola's erster Berechnung der Winkel zwischen beiden Axen einen Werth von $1^{0} 8^{\prime} 24^{\prime \prime}$ erreichen sollte, gelangt die zweite Schrift, welche der genannte Autor diesem interessanten Gegenstande widmete [135], zu dem beruhigenden Schlusse [136], dass, obwohl eine kleine Ablenkung der mechanischen gegenüber der geometrischen Axe nach wie vor als im Bereiche der Möglichkeit liegend anerkannt werden müsse, doch für die Praxis das Zusammenfallen beider Axen als eine Thatsache hingenommen werden dürfe. -

Somit schiene denn die Newton'sche Theorie vom Rotationsellipsoid gegen alle Einwürfe siegreich zu bleiben. Gewisse Erwägungen des nächsten Kapitels werden uns dagegen mit gefährlicheren Schwierigkeiten bekannt machen, und im dritten Kapitel erst wird gezeigt werden können, wie sich diesen Schwierigkeiten begegnen lässt, ohne mehr 
als einige minder wesentliche Nebenpunkte der sphäroidischen Hypothese zu opfern.

[1] Herodoti historia, lib. IV. cap. 36. - [2] Ibid. lib. III. cap. 104. [3] Köler, Allgemeine Geographie der Alten, Lemgo 1803. S. 89. - [4] PeschelRuge, Geschichte der Erdkunde bis auf Alexander v. Humboldt und Carl Ritter, München 1877. S. 30. - [5] H. Berger, Zur Entwickelung der Geographie der Erdkugel bei den Hellenen, Grenzboten, 39. Jahrgang. S. 411. - [6] Köler, Allg. Geogr. etc. S. 90 ff. - [7] Stölzle, Die Lehre vom Unendlichen bei Aristoteles mit Berücksichtigung früherer Lehren über das Unendliche, Augsburg 1882. S. 5. - [8] Peschel-Ruge, Gesch. d. Erdk. etc. S. 34. - [9] Bergel, Der Himmel und seine Wunder; eine archäologische Studie nach alten jüdischen Mythographen, Leipzig 1881. - [10] Zöckler, Geschichte der Beziehungen zwischen Theologie und Naturwissenschaft, mit besonderer Rücksicht auf Schöpfungsgeschichte, 1. Abtheilung, Gütersloh 1878. S. 124. - [11] Günther, Die kosmographischen Anschauungen des Mittelalters, Deutsche Rundschau f. Geogr. u. Stat., 4. Jahrgang. S. 249 ff. S. 313 ff. S. 345 ff. - - [12] Marinelli, La geografia e i padri della chiesa, Roma 1882. - [13] Zöckler, Gesch. etc. 1. Abtheil. S. 125 ff. - [14] Nicolaus Coppernicus aus Thorn über die Kreisbewegungen der Weltkörper, deutsch von Menzzer, Thorn 1879. S. 7. - [15] Pindter-Parthey, Ravennatis Anonymi Cosmographia, Berolini 1860. - [16] Marinelli, La geografia etc. S. 41. - [17] Günther, Studien zur Geschichte der mathematischen und physikalischen Geographie, Halle 1879. S. 5 ff. - [18] Gilbert, Le pape Zacharie et les antipodes, Bruxelles 1882 . [19] Défense de la révélation contre les objections des forts esprits par M. Euler, suivies des pensées de cet auteur sur la réligion, Paris 1805. - [20] v. Stälin, Württembergische Geschichte, 1. Band, Stuttgart 1841. S. 405. - [21] Günther, Die Kartenprojektionslehre im Verlaufe des letzten Jahrzehntes, Wagner's geogr. Jahrb., 9. Band. S. 435 ff. - [22] Notices" et extraits des manuscrits de la bibliothèque nationale et autres bibliothèques, Tome IV, Paris An VII. S. 260. [23] Günther, Studien etc. S. 69. - [24] Peschel-Ruge, Gesch. d. Geogr. etc. S. 120. - [25] Günther, Studien etc. S. 71. - [26] Ibid. S. 63. - [27] J. F. Sédillot, Traité des instruments astronomiques des Arabes composé au treizième siècle, par Aboul Hhas'an Ali, de Maroc, Paris 1834. S. 73. -- [28] Günther, Studien etc. S. 106. - [29] Ibid. S. 88. - [30] Heeren, Eine japanische Erdkugel, Mittheil. d. Gesellsch. f. Natur- und Völkerkunde Ostasiens, 1. Band, 2. Heft. S. 9 ff. [31] Birnbaum, Grundzüge der astronomischen Geographie, Leipzig 1852. S. $11 \mathrm{ff}$. - [32] Fahle, Die Kugelgestalt der Erde, Zeitschr. f. math. u. naturw. Unterricht, 2. Jahrgang. S. 322 ff.; Pick, Die Kugelgestalt der Erde, ibid. 2. Jahrgang. S. 505 ff. - [33] J. Müller, Lehrbuch der kosmischen Physik, Braunschweig 1875. S 47. [34] Jagor, Reise in den Philippinen, Berlin 1873. S. 180. - [35] Dufour, De l'altération des images par réflexion sur la surface des eaux, Bull. de la soc. vaud. des sc. natur., Vol. XIII. S 303 ff. - [36] Archimedis opera omnia, cum commentariis Eutocii, ed. Heiberg, Vol. II., Lipsiae 1881. S. 366. - [37] Günther, Studien etc. S. 100. - [38] Notices et extraits etc., Tome IV. S. 261. - [39] GutheWagner, Lehrbuch der Geographie, 1. Band, Hannover 1882. S. 444. - [40] Köler, Allg. Geogr. etc. S. 93 ff. - [41] Günther, Studien etc. S. 146 ff. - [42] Ibid. S. $148 \mathrm{ff}$ - [43] W. Schmidt, Ueber Dante's Stellung in der Geschichte der Kosmographie, 1. Theil, Graz 1876. - [44] Poletto, L'opusculo di Dante Allighieri, "De aqua et terra", in raffronto al moderno progresso delle scienze fisiche, Venezia 1883. - [45] Günther, Studien etc. S. 163 ff. - [46] Nicolaus Coppernicus etc. S. 12 ff. - [47] Peschel-Leipoldt, Physische Erdkunde, 2. Band, Leipzig 1879. S. 142 . - [48] Holetschek, Erdkrümmungsfragen, Zeitschr. f. Schulgeogr., 4. Jahrgang. S. $155 \mathrm{ff} .-[49]$ Gelcich, Eine Studie über die Entdeckung der analytischen Geometrie, Abh. z. Gesch. d. Math., 4. Heft, Leipzig 1882. S. 209. - [50] Gelcich, Ueber den Vorschlag des Marino Ghetaldi, die Grösse der Erde zu bestimmen, Zeitschr. f. Math. n. Phys., h.-l. Abth. 28. Jahrgang. S. 130 ff. - [51] Pelz, Ueber das Problem der Glanzpunkte, Wien 1871. - [52] J. Müller, Lehrb. d. kosm. Phys. S. 50 ff. - [53] H Berger, Die geographischen Fragmente des Eratosthenes neu gesammelt, geordnet und besprochen, Leipzig 1880. S. $101 \mathrm{ff}$. - [54] Günther, Die Erdmessung des Eratosthenes, Deutsche Rundschau f. Geogr. u. Stat., 3. Jahrgang. S. 327 ff. - [55] Lepsius, Das Stadium und die Gradmes- 
sung des Eratosthenes auf Grundlage der ägyptischen Maasse, Zeitschr. f. ägypt. Sprache und Alterthumskunde, 15. Jahrgang. S. \& ff. - [56] Sprenger, Zur Geschichte der Erdmessungen im Alterthum, Ausland 1867. S. 1016 ff. - [57] Gehler's physik. Wörterbuch, 2. Auflage, 3. Band, Leipzig 1827. S. 843 ff. - [58] Posch, Geschichte und System der Breitengradmessungen. Freising 1860. - [59] v. Bauernfeind, Die Bedeutung moderner Gradmessungen, München 1866. - [60] Sadebeck, Entwickelungsgang der Gradmessungsarbeiten und gegenwärtiger Stand der europäischen Gradmessung, Berlin 1876. - [61] Zusammenstellung der Literatur der Gradmessungsarbeiten, Berlin 1876. - [62] Caji Plinii Secundi historiae naturalis libri XXXVII. lib. II. cap. 109. - [63] Bailly, Geschichte der neueren Astronomie, deutsch von Bartels, 1. Band, Leipzig 1796. S. 37 ff. - [64] Ibid. S. 211. [65] Notes et extraits etc., Tome VII, Paris 1804. S. 95. - [66] Brevis ac perutilis compilatio Alfragani astronomorum peritissimi, totum id continens, quod ad rudimenta astronomica est opportunum, Norimbergae 1537. Fol. 8. - [67] Fernel, Cosmotheoria seu de forma mundi et de corporibus coelestibus, Parisiis 1528. [68] Willebr. Snellius, Eratosthenes Batavus seu de terrae ambitus vera quantitate suscitatus, Lugduni Batavorum 1617. - [69] Schwerd, Die kleine Speyerer Basis, Speier 1822. - [70] Heel, Dr. Friedrich Magnus Schwerd, ein Nekrolog, Speier 1872. S. 10. - [71] Montucla, Histoire des mathématiques, tome II, Paris 1758. S. 315. - [72] Gehler's Physik. Wörterb., 3. Band. S. 847. - [73] Picard, La mesure de la terre, Paris 1671. - [74] J. J. v. Littrow, Geschichte der Entdeckung der allgemeinen Gravitation durch Newton, Wien 1835. S. 38 ff. - [75] Gehler's Physik. Wörterb., 3. Band. S. 849 ff. - [76] Cantor, Mathematische Beiträge zum Kulturleben der Völker, Halle 1864. S. 398. - [77] Chasles, Geschichte der Geometrie, hauptsächlich mit Rücksicht auf die neueren Methoden, deutsch von Sohncke, Halle 1839. S. 517. - [78] Günther, Studien etc. S. 162. - [79] Ibid. S. 171 ff. - [80] R. Wolf, Geschichte der Astronomie, München 1877. S. 614. - [81] Jacques Cassini, Traité de la grandeur et de la figure de la terre, Paris 1720. - [82] Eisenschmidt, Diatribe de figura telluris elliptico-sphaeroide, ubi una exhibitur ejus magnitudo per singulas dimensiones consensu omnium observationum comprobata, Argentorati 1691. - [83] R. Wolf, S. 616 ff. - [84] Bouguer, La figure de la terre, déterminée par les observations de M. M. De la Condamine et Bouguer, Paris 1749. - [85] Bouguer, Justification des mémoires de l'académie et du livre sur la figure de la terre, Paris 1752. - [86] Maupertuis, Sur la figure de la terre, déterminée par les observations de M. M. Maupertuis, Clairault, Camus, Le Monnier et Outhier, Amsterdam 1738; Id., La figure de la terre déterminée par les observations faites par ordre du roy dans le cercle polaire, Paris 1738. - [87] Nürnberger, Populäres astronomisches Handwörterbuch, 1. Band, Kempten 1856. S. $1011 \mathrm{ff}$. - [88] La Caille, Journal historique du voyage fait au cap de Bonne-Espérance, publié par Carlier, Paris 1763. - [89] Boscovich-Maire, De litteraria expeditione per pontificiam ditionem ad dimetiendos duos meridiani gradus, Romae 1755. [90] Chr. Mayer, Basis Palatina, anno 1762 ad normam Academiae Regiae Parisinae scientiarum exactam bis dimensa, Manhemi 1763. - [91] Maskelyne, Introduction to the observations made by Chr. Mason and J. Dixon for determining the length of a degree of latitude in the provinces of Maryland and Pennsylvania, London 1768. - [92] Liesganig, Dimensio graduum meridiani Viennensis et Hungarici Augg. jussu et auspiciis peracta, Vindobona 1770. - [93] Ibid. S. 209 ff. [94] Frischauf, Gebirgsführer durch die österreichischen Alpen und die angrenzenden Theile von Bayern, Italien und Montenegro, Wien 1883. S. 15. - [95] Beccaria, Gradus Taurinensis, Augustae Taurinorum 1774. - [96] Roy, An account of the trigonometrical operations, whereby the distance between the meridians of the royal observatories of Greenwich and Paris are determined, London 1790. [97] J. D. Cassini, Exposition des observations faites en France 1787, pour la jonction des méridiens de Paris et de Greenwich, Paris 1792. - [98] Dalby, A short account of the late $R$. Burrow's measurement of a degree of longitude and another of latitude near the tropic in the years 1791 and 1792, London 1796. [99] Svanberg, Exposition des operations faites en Lapponie pour la détermination d'un arc du méridien en 1801-3 par Öfverbom, Svanberg, Holmquist et Palander. Stockholm 1805. - [100] R. Wolf, Gesch. d. Astr. S. 621 ff. - [101] Ibid. S. 625. - [102] Bessel, Ueber einen Fehler in der Berechnung der französischen Gradmessung und seinen Einfluss auf die Bestimmung der Figur der Erde, Astron. Nachr. Nr. 438. - [103] Bessel, Populäre Vorlesungen über wissenschaftliche Gegenstände, herausgeg. v. Schumacher, Hamburg 1848. S. 283. - [104] Listing, Ueber unsere jetzige Kenntniss von der Gestalt und Grösse der Erde, Nachr. v. 
d. k. Gesellsch. d. Wissensch. zu Göttingen, 1873. S. 76 ff. - [105] H. C. Schumacher, Nachricht über den Apparat, dessen er sich 1820 zur Messung der Basis bei Braake bediente, Altona 1821. - [106] Bessel, Gradmessung in Ostpreussen, Berlin 1838. - [107] Gauss, Bestimmung des Breitenunterschiedes zwischen den Sternwarten von Göttingen und Altona, Göttingen 1828. - [108] Everest, An account of the measurement of an arc of the meridian, London 1830. [109] W. Struve, Arc du méridien de $25^{\circ} 10^{\prime}$ entre le Danube et la mer glaciale, mesuré $1810-55$ sous la direction de C. de Tenner, Chr. Hansteen, N. H. Selander, W. Struve, St. Pétersbourg 1860. - [110] Maclear, Verification and extension of La Caille's arc of meridian at the Cape of Good Hope, London 1866. - [111] Gerlach, Die Bestimmung der Gestalt und Grösse der Erde, Wien 1782. S. 36 ff. - [112] R. Wolf, Gesch. d. Astr. S. 627 ff. - [113] v. Baeyer, Ueber die Figur und Grösse der Erde, Berlin 1861. - [114] Sadebeck, Entwickelungsgang etc. S. 21. - [115] Ibid. S. 22. - [116] Ibid. S. 35 ff. - [117] Ibid. S. 19. - [118] Martus, Astronomische Geographie, ein Lehrbuch angewandter Mathematik, Leipzig 1880. S. 219 ff. - [119] Bohnenberger, Astronomie, Tübingen 1811. S. $187 \mathrm{ff}$. - [120] v. Lindenau, Ueber den Gebrauch der Gradmessungen zur Bestimmung der Gestalt und Grösse der Erde, (v. Zach's) Monatl. Corresp. z. Bef. d. Erd- u. Himmelskunde, XIV. S. 138 ff. - [121] E. Schmidt, Ueber die Dimensionen des Erdkörpers, Harding's Ephemeriden 1831. - [122] Vgl. N. 102. [123] Encke, Ueber die Dimensionen des Erdkörpers, nebst Tafeln nach Bessel's Bestimmungen, Astron. Jahrb. f. 1852. - [124] Listing, Ueber unsere jetzige Kenntniss etc. S. 41 ff. - [125] Gerlach, Die Bestimmung etc. S. 61 ff. [126] G. Bischof, Die Gestalt der Erde und der Meeresfläche und die Erosion des Meeresbodens, Bonn 1867. - [127] H. J. Klein, Entwickelungsgeschichte des Kosmos nach dem gegenwärtigen Standpunkte der gesammten Naturwissenschaften, Braunschweig 1870. S. 7 ff. - [128] E. Ritter, Recherches sur la figure de la terre, Genève 1861. - [129] R. Wolf, Gesch. d. Astr. S. 631. - [130] G. Th. Schubert, Essai d'une détermination de la véritable figure de la terre, Mém. de l'ac. imp. des sc. de St. Pétersbourg, (VII) tome I. N. 6. - [131] Clarke, Comparison of the standards of length made at the Ordnance Survey Office, London 1866. S. $285 \mathrm{ff} .-[132]$ Hind, The figure of the earth in relation to geological inquiry, Nature, Vol. X. S. 156 ff. - [133] Peschel-Leipoldt, Phys. Erdk. S. 166. - [134] Fergola, Sulla posizione dell' asse di rotazione della terra rispetto all' asse della figura, Napoli 1874. - [135] Fergola, Dimensioni della terra e ricerca della posizione del suo asse di figura rispetto a quello di rotazione, Napoli 1876. [136] Ibid. S. 26.

Kapitel II.

\section{Die Attraktionsphänomene und deren Anwendung zur Bestim- mung der Gestalt und Dichte der Erde.}

§. 1. Die allgemeine Gravitation. Die Vorstellung, dass allen Körpern eine gegenseitige Anziehungskraft zukomme, reicht in unbestimmten Umrissen bis in das Alterthum hinauf, wie denn schon Aristoteles (§. 2 des vorigen Kapitels) die sphärische Rundung sich selbst überlassener Massen in dieser Weise zu erklären suchte. Einigermaśsen klarer dachte hierüber Kepler, dessen Ideen man am besten in seinem berühmten Werke über den Planeten Mars vereinigt findet, und der u. a. bereits die These aufstellte [1], dass, wenn die Erde nicht rund wäre, für die Fallrichtung der Körper sich kein so bestimmtes Gesetz aufstellen liesse, wie wir es bekanntlich zu thun in der Lage sind. Welche Unklarheiten gleichwohl selbst bei den besseren Köpfen des XVII. Jahrhunderts über diese Fragen noch herrschten, 
erhellt aus der Thatsache, dass in einem gelehrten Werke [2] Beaugrand's, eines sonst nicht ungeschickten Mathematikers, ein geometrischer Beweis dafür erbracht werden sollte, ein Körper habe ein um so grösseres Gewicht, je näher er sich dem Mittelpunkte der Erde befinde. Erst Newton's grosse Entdeckung machte eine kausale Begreifung der kosmischen Erscheinungen möglich; er prüfte an der Hand der Rechnung, ob nicht der ihm zufällig gekommene Gedanke, dass der Mond von derselben Kraft in seiner Kreisbahn erhalten werde, welche den losgelassenen Stein zur Erde fallen macht, eine tiefere Bedeutung: habe, und fand seine Vermuthung vollständig gerechtfertigt; niedergelegt ist diese Entdeckung in dem denkwürdigen 4. Theorem des 3. Buches seiner "Principia naturalis philosophiae mathematica", das in Wolfers' Verdeutschung lautet [3]: „Der Mond ist gegen die Erde schwer, er wird durch die Schwere von der geradlinigen Bewegung abgezogen und in

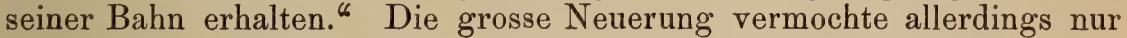
sehr langsam sich Bahn zu brechen, namentlich auf dem Festlande, wo selbst ein Johann Bernoulli und Euler ihr widerstrebten, indem sie freilich ohne Scheu die Newton'schen Regeln bei ihren Rechnungen benützten [4], doch gelang es dem unermüdeten Eifer eines Halley, Louville, D'Alembert, Clairaut u. a., dem Gravitationssysteme noch im Laufe des XVIII. Säkulums zum endgültigen Siege zu verhelfen. Newton's Fundamentalsatz besagt Folgendes: Zwei Massen $\mathrm{M}_{1}$ und $\mathrm{M}_{2}$, deren gegenseitige Entfernung $\mathrm{r}$ beträgt, ziehen sich mit einer Kraft an, deren mathematischer Ausdruck

$$
\mathrm{k} \cdot \frac{\mathrm{M}_{1} \cdot \mathrm{M}_{2}}{\mathrm{r}^{2}}
$$

ist, unter $\mathrm{k}$ die sogenannte Gravitationskonstante verstanden. Es ist namentlich darauf Gewicht zu legen, dass die Anziehung keine einseitige, sondern zufolge dem ebenfalls von Newton [5] gefundenen Satze von der Gleichheit zwischen Wirkung und Gegenwirkung eine relative ist; die einzelnen Planeten bewegen sich nicht etwa um die in absoluter Ruhe verbleibende Sonne, sondern diese Planeten kreisen sammt der Sonne um den gemeinsamen Schwerpunkt des ganzen Systemes, der nur wegen der Ueberwucht des Centralkörpers sich nicht sehr weit von dem Schwerpunkte des letzteren entfernen kann. Worin eigentlich das Wesen der Schwerkraft bestehe, wissen wir nicht zu sagen, obwohl es von Newton - der selbst jedoch nur mit grosser Vorsicht diesen Punkt erörterte - bis auf Zöllner an Hypothesen in dieser Richtung keineswegs gemangelt hat. Eine treffliche Uebersicht über diese Theorieen bietet das Werk von Isenkrahe [6], in welchem gleichzeitig nicht ohne Glück der Versuch gemacht wird, die Anziehung der Massen durch den Stoss von Aetheratomen zu erklären.

In neuester Zeit ist viel davon gesprochen worden, dass der obige Ausdruck des Gravitationsgesetzes zwar nicht gerade unrichtig, aber doch nur als eine erste Näherung für eine allgemeinere Formel anzusehen sei, welche die attraktiven und repulsiven Wirkungen innerhalb der Körperwelt regle. Namentlich Zöllner hat in jenem Abschnitte seines uns nun schon mehrfach bekannten Kometenwerkes, welcher „über die allgemeinen Eigenschaften der Materie" handelt [7], die Möglichkeit ausführlich erörtert, dass dem Newton'schen das W eber'sche elektrodynamische Grundgesetz zu substituiren sei, welches für einen 
unendlich grossen Werth der darin vorkommenden Konstante eben in ersteres übergeht; Scheibner habe die Substitution astronomisch geprüft und sei zu folgendem Resultate gekommen [8]: "Unter Beibehaltung des numerischen Werthes der Weber'schen Konstante*) könnte ein Unterschied höchstens in der Bewegung des Merkur beobachtet werden, indem hier eine säkuläre Aenderung des Perihels von 6,73 Bogensekunden hervorgebracht würde. Bei der Venus betrüge dieser Einfluss nur noch 1",43. " So kleine Differenzen geben uns die Beruhigung, dass an der Newton'schen Grundformel zunächst keine Korrektion angebracht zu werden braucht. Auch v. Oppolzer entscheidet sich am Schlusse einer tief eingehenden Prüfung des Gegenstandes [9] in diesem Sinne. Er selbst hat [10] versucht, gelegentlich den Anomalieen in der Bewegung des Encke'schen Kometen mittelst der Hülfsvorstellung beizukommen, dass die Schwerkraft zu ihrer Fortpflanzung im Raume einer endlichen Zeit bedürfe, allein auch die Einführung dieser Hypothese war nicht dazu angethan, volle Befriedigung zu schaffen. Wir können also darauf verzichten, diese Möglichkeit in den Kreis unserer Betrachtungen zu ziehen, ebenso wie manche andere, z. B. die von Isenkrahe [11] angedeutete, dass Temperaturänderungen die Intensität beeinflussen möchten - und wir können diess um so eher, als wir es hier der Hauptsache nach nur mit irdischen, also vergleichsweise sehr kleinen Entfernungen zu thun haben.

§. 2. Mittel, die Schwere und ihre Variationen zu messen. Das wichtigste der Hülfsmittel, über welche man zu dem angegebenen Zwecke verfügt, wird im fünften und sechsten Paragraphen einer gesonderten Besprechung unterzogen werden; hier sollen einige Verfahrungsweisen von an sich mehr untergeordneter Bedeutung besprochen werden, welche jedoch eine gewisse Wichtigkeit für die tellurische Physik theils schon erlangt haben, theils möglicherweise noch zu erreichen berufen sind $\left.{ }^{* *}\right)$.

a) Hengler's Schwungwage. In den zwanziger Jahren dieses Jahrhunderts gab ein junger Physiker, Namens Lorenz Hengler, über dessen ungewöhnlichen Lebensgang die biographische Notiz Zech's [13] nachzusehen ist, unter dem Namen Schwung- oder Pendelwage eine eigenthümliche Vorrichtung zum Messen sehr kleiner anziehender Kräfte an, auf welche, da der betreffende Aufsatz [14] ]ängst verschollen war, erst durch die geschichtlichen Artikel von Safařik [15] und Zöllner [16] wieder von Neuem aufmerksam gemacht werden musste. Das Princip der bifilaren Aufhängung, später von Gauss zur höchsten Vollendung gebracht, ist bereits von Hengler angewandt worden. Eine lange dünne Stange CD (Fig. 19) ist nahe ihrem einen Ende durch zwei gleichlange Fäden DE und FA mit zwei festen Punkten verbunden, deren ersterer, $\mathrm{E}$, sich auf dem Fussboden $\mathrm{xy}$ befindet, während der andere, A, sich in einer gewissen Höhe befindet, so zwar, dass der Fusspunkt B eines von A auf die Horizontalebene gefällten Lothes nicht mit E zusammenfällt, sondern um eine kleine Strecke EB

*) Dieselbe hat nämlich an und für sich schon einen sehr hohen Werth.

*) Vgl. einen zusammenfassenden Aufsatz [12] des Verf. über die geophysikalische Verwerthung solcher Methoden. 
von ihm abliegt. In C trägt die Stange einen Index, der, sobald erstere in Schwingungen gerathen ist, deren Grösse auf einer senkrecht über $\mathrm{P}$ errichteten horizontalen Skale MN markirt. Hengler hat mit dieser empfindlichen Vorrichtung zahlreiche Versuche über die ablenkende Kraft angenäherter schwerer Körper angestellt und, wie $\mathbf{z}$. B. sein Lehrer Gruithuis en , mittheilt [17], konnte die Attraktion einer Kanonenkugel bereits deut. lich sichtbar gemacht werden. Hengler bedauerte nur sein Unvermögen, stöFig. 19.

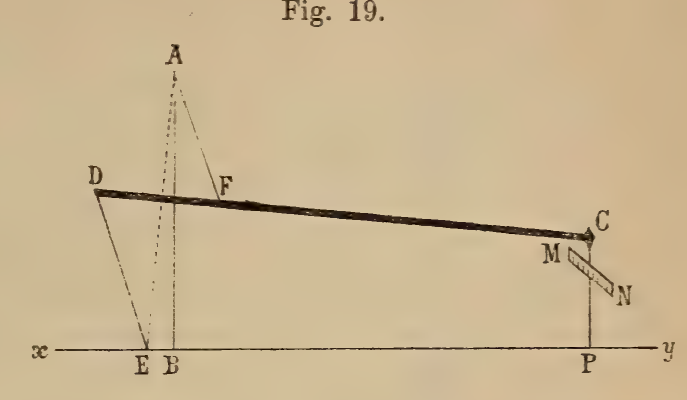
rende Einflüsse (Wärme, Luftströmungen u. s. w.) von seinem Apparate ferne zu halten; , ich bin überzeugt, “ schrieb er [18], „dass man die Attraktionskraft des Mondes selbst und daher auch seine Masse durch dieses Instrument genau bestimmen kann, sobald man ein dazu taugliches Lokal hat." Von anderen Versuchen mit der Schwungwage im IV. Kapitel.

b) Perrot's Apparate. Auf einem ähnlichen Grundgedanken beruht offenbar der zweite der beiden Apparate, mit welchen Perrot [19] kleine Aenderungen in Grösse und Richtung der Schwerkraft zu messen gedachte. Der erste, sinnreich kombinirt, allein von allzuvielen Fehlern abhängig, besteht wesentlich aus einer Platte, die an einem langen Spiraldraht aufgehängt wird. Legt man auf selbe ein Gewicht, so wird eine doppelte Bewegung eingeleitet, eine rotatorische und eine vertikal nach unten gerichtete. Letztere vernachlässigend, meint Perrot, könnte man etwa noch 1/10000000 in der Veränderung der Erdschwere durch Drehung konstatiren, d. h. eine Aktion, zehnmal geringer, wie die vom Monde ausgeübte. Der zweite Apparat war, wie schon gesagt, ein an zwei Drähten aufgehängter Stab, den sein Verfertiger sensibler zu machen sich getraute, als eine Wasserwage, bei welcher die Ablenkung der Blase um $3 \mathrm{~mm}$ einer Bogensekunde entspricht. Den Einwirkungen der Temperaturschwankung glaubte Perrot [20] begegnen zu können.

c) Zöllner's Horizontalpendel. Ohne von den Vorarbeiten Hengler's und Perrot's Kenntniss zu haben, ersann Zöllner eine dem Wesen nach analoge, nur in den Einzelheiten weit zuverlässigere Vorrichtung zur Messung sehr kleiner Kräfte (elektrische und magnetische Minimalaktionen, irdische Centrifugalkraft u. s. w.) [21]; später hat er den Verdiensten jener Vorläufer ausdrücklich Rechnung getragen (s. o.). Er nannte das Instrument Horizontalp endel, brachte die zu Hengler's Zeit noch unbekannte Poggendorff'sche Spiegelablesung daran an und stellte es in dem einer sehr gleichmässigen Temperatur sich erfreuenden Keller des Leipziger Universitätsgebäudes auf; später kam es, da sich doch seismische Störungen daselbst bemerklich machten, in einen eigens dafür hergestellten Kuppelbau des astrophysikalischen Observatoriums*). Zöllner's Beschreibung [23] ist folgende: Uhrfedern

*) Das astrophysikalische Observatorium (Sonnenwarte) bei Potsdam besitzt 
a, $a^{\prime}$ vertreten die Stelle der Drähte: dieselben werden durch das Gewicht A mit dem Spiegel C in Spannung erhalten (Fig. 20). Die Uhrfedern sind in $\mathrm{c}$ und $\mathrm{c}^{\prime}$ eingeschraubt, und die parallelepipedischen

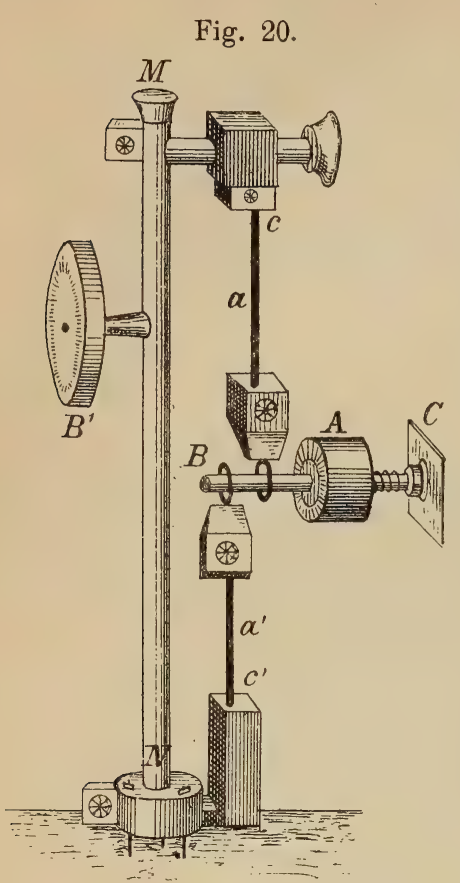

Büchsen, in welchen sie endigen, stehen in direkter Verbindung mit dem oberen und unteren Ende der Vertikalsäule $M N$, welche das Ganze trägt. ' B' ist ein $\mathrm{Ge}$ gengewicht. Das Ganze ruht auf dem gewöhnlichen, mit drei Stellschrauben versehenen Stativ, und zwar muss eine dieser Stellschrauben in der durch die Aufhängepunkte $\mathrm{c}$ und $\mathrm{c}^{\prime}$ bestimmten Vertikalebene enthalten sein. Der Spiegel konstatirte noch Ablenkungen von der Lothlinie, die nicht grösser waren, als 1/1000 Bogensekunde. Zöllner ist der Meinung, dass, wenn das Instrument in einem tiefen Schachte aufgestellt und daselbst nicht etwa durchimmerhin denkbare Fluthbewegungen des feurigflüssigen Erdinneren alterirt würde, dadurch recht wohl jene geringen Anziehungen von Sonne und Mond nachzuweisen wären, welche Peters (s. unten) berechnete. Das Pendel muss sowohl beim Aufund Untergang, als auch bei den Kulminationen dieser Himmelskörper durch den Meridian gehen, und zwar nicht verspätet, wie dies bei den Gezeiten des

Meeres der Fall ist, sondern synchron; vielleicht liesse sich also auch mit seiner Hülfe die von Zöllner selbst und von v. Oppolzer (s. o.) aufgeworfene Frage entscheiden, ob der Gravitation eine Momentanwirkung zukomme oder nicht. Eine elegante und einfache mathematische Theorie des Horizontalpendels haben wir von Stoll [24]; dort wird gezeigt, dass die beschleunigende Kraft beim letzteren sich von jener beim Vertikalpendel nur um den Faktor tang $\varphi$ unterscheidet, wo $\varphi$ den sehr kleinen Winkel bedeutet, welchen eine die Punkte c und $\mathrm{c}^{\prime}$ (Fig. 20) verbindende Gerade mit der Vertikalen bildet.

d) Messung der Schwerkraft durch die Wasserwage. Gruithuisen erzählt im Eingang seiner oben erwähnten Abhandlung, der berühmte Mechaniker G. v. Reichenbach habe ihm für solche Messungen eine sehr grosse Wasserwage vorgeschlagen. Hengler gedachte die letztere durch seine neue Nivellirwage zu ersetzen, welche (s. o.) nach seiner Angabe auch wirklich durch den Mechaniker Weissenbach ausgeführt und der Münchener Akademie vorgelegt worden wäre. Eingehende Untersuchungen über den Einfluss der Attraktion auf eine Libelle oder Wasserwage hat Peters [25] angestellt. Eine solche besteht bekannt-

ein Horizontalpendel, welches seinen geeigneten Platz auf der Sohle des tiefen Brunnenschachtes gefunden hat [22]. Messungen scheinen übrigens mit demselben noch nicht angestellt worden zu sein. 
lich aus einer gekrümmten Glasröhre, deren Krümmungsradius aber sehr gross sein muss; gefüllt ist sie mit Weingeist oder einer anderen Flüssigkeit, jedoch nicht gänzlich, vielmehr ist ein kleiner luftleerer Raum übrig gelassen [26], der fälschlich als Luftblase bezeichnet wird. Diese Blase muss bei jeder Bewegung der Röhre stets den höchsten Platz einnehmen, und die auf einer - im Glase eingeritzten Theilung abzulesende Ausschlagsgrösse liefert ein Maass für die Grösse der Bewegung. Nun habe ein Gestirn vom Erdmittelpunkt und vom Apparate resp. die Entfernungen $r$ und $r^{\prime}$, die Zenithdistanzen, unter welchen das Gestirn, dem die Masse m zukommt, von beiden Punkten aus gesehen wird, seien $z$ und $z^{\prime}$; berechnet man dann jene Komponenten der auf die Flüssigkeit wirkenden Gestirnsattraktion, welche auf der durch Gestirn und Libelle gelegten Vertikalebene senkrecht steht, so ist dieselbe gleich $\mathrm{mr}^{\prime-2} \sin \mathrm{z}^{\prime}$, während die auf die Röhre ausgeübte Attraktion durch $\mathrm{mr}^{-2} \sin \mathrm{z}$ ausgedrückt ist. Jene Kraft also, die den flüssigen Inhalt in einer dem Azimut des anziehenden Himmelskörpers entsprechenden Richtung bewegen will, ist gleich der Differenz

$$
\mathrm{m}\left(\frac{\sin \mathrm{z}^{\prime}}{\mathrm{r}^{\prime 2}}-\frac{\sin \mathrm{z}}{\mathrm{r}^{2}}\right) \text {. }
$$

Bedeutet $h$ die in Sekunden ausgedrückte Horizontalparallaxe des Sternes, $P$ den Halbmesser, M die Masse der Erde, so ist der Ablenkungswinkel

$$
\mathrm{m}\left(\frac{\sin \mathrm{z}^{\prime}}{\mathrm{r}^{\prime 2}}-\frac{\sin \mathrm{z}}{1^{2}}\right): \frac{\mathrm{M}}{\rho^{2}}=\frac{3 \mathrm{~m}}{2 \mathrm{M}} \mathrm{h}^{3} \sin 2 \mathrm{z} \sin 1^{\prime \prime} .
$$

Wird endlich jener Theil der Ablenkung berechnet, welcher auf ein vom Azimut a differirendes Azimut a' entfällt, so ist dieser Betrag gleich

$$
\frac{3 \mathrm{~m}}{2 \mathrm{M}} \mathrm{h}^{3} \sin 2 \mathrm{z} \cos \left(\mathrm{a}-\mathrm{a}^{\prime}\right) \sin ^{2} 1^{\prime \prime} .
$$

Bei gleichen $z^{\prime}$ a und $a^{\prime}$ verhalten sich die Ablenkungen von Sonne und Mond zu einander wie 0,0080:0,0174. Die Ablenkung des Mondes, obwohl an sich die stärkere, wird für gewöhnlich vernachlässigt werden können, jene der Sonne aber nur unter besonderen Verhältnissen, welche Peters näher erörtert*).

e) Messung der Schwere durch die veränderliche Länge von Quecksilbersäulen. Die bisher besprochenen Vorrichtungen hatten wesentlich die Sichtbarmachung und eventuelle Messung von Kraftäusserungen kosmischen Ursprunges zum Zwecke. Speziell für terrestrische Schweredifferenzen brachte Mascart, auf einen schon früher ausgesprochenen Gedanken Boussingault's zurückgreifend, die variable Länge einer Quecksilbersäule in Vorschlag [28]. Eine bestimmte Gasmasse wird auf stets konstanter Temperatur erhalten, und der Druck, welchen sie

*) Eine sehr grosse Schärfe wird sich bei all' diesen Messungen mit der Libelle freilich um deswillen niemals erreichen lassen, weil für den Gang der Luftblase noch allzuviele andere Faktoren bestimmend sind. P. Plantamour hat [27] ausgedehnte Versuchsreihen über die diskontinuirlichen Bewegungen des Bodens geliefert, die zeitweise allerdings einen periodischen Charakter annahmen, deren Ursache aber nur zum Theile zu ergründen gelang. Lange andauernde Kälteperioden sind dabei jedenfalls mit im Spiele. 
in dieser Verfassung ausübt, wird verglichen mit der Höhe einer Quecksilbersäule, welche je nach Maassgabe der vom Erdkörper auf sie ausgeübten Anziehung steigt oder fällt. Hiezu dient eine Art von Heberbarometer, dessen kürzerer zugeschmolzener Schenkel die fragliche Gasmasse enthält. $\mathrm{Ob}$ aber die auf diese Weise zu erreichende Genauigkeit wirklich mit derjenigen einer Pendelmessung konkurriren könne, möchten wir bezweifeln. Erheblich verfeinert ist der auf dem gleichen Grundsatz beruhende Messungsapparat Issel's [29]; L L' (Fig. 21) ist eine U-förmig gebogene, in $L$ geschlossene Röhre, an

Fig. 21.

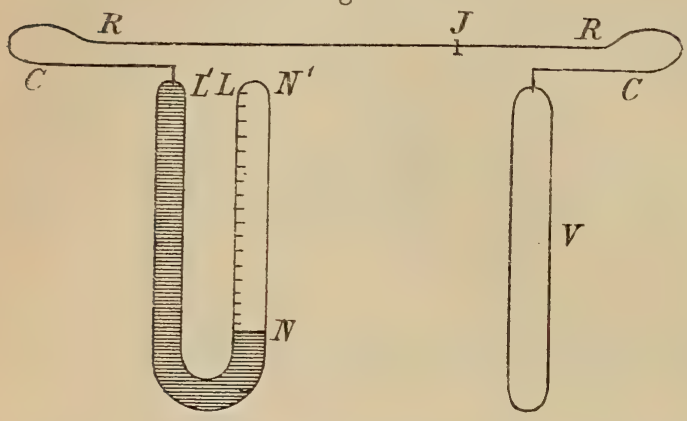
welche in $L^{\prime}$ eine Capillarröhre $\mathrm{CC}$ angeschmolzen ist, die sich auf der anderen Seite in die Röhre V öffnet. Die enge Röhre enthält in sich einen Index J, der zwischen den Punkten $\mathrm{R}$ hin- und herwandert, über dieselben jedoch deshalb nicht hinaus gelangen kann, weil in diesen Punkten eine Krümmung nach aufwärts eintritt. $\mathrm{L}$ ist mit trockener Luft gefüllt, welche verhindert, dass das in die Röhre L eingegossene Quecksilber höher als bis zum Theilstrich N ansteigt; gleichfalls mit trockener Luft gefüllt ist die Capillarröhre. Bezeichnen wir das obere Ende der Röhre L mit $N^{\prime}$, so haben wir den auf die in L eingeschlossene Luftmasse wirkenden Druck drei Faktoren proportional zu setzen: einer Flüssigkeitssäule $=\mathrm{N} \mathrm{N}^{\prime}$, deren wechselnder Dichte und der Schwere. Gelangt man mit dem Instrumente an einen Ort stärkerer Schwerewirkung, so wird unter sonst gleichen Verhältnissen die Säule $\mathrm{N} \mathrm{N}^{\prime}$ kürzer werden, die Luft in $\mathrm{C} \mathrm{C}^{\prime}$ gewinnt die Möglichkeit sich auszudehnen, und der Index tritt eine Wanderung nach links an, im entgegengesetzten Falle nach rechts. Selbstverständlich muss auch hier der Apparat auf durchaus gleicher Temperatur erhalten werden und beim Transport in Mitte schlecht leitender Substanzen sich befinden. $\mathrm{Zu}$ gleicher Zeit wird es sich empfehlen, eine Kompensationsvorrichtung mit zu beobachten, in welcher die mit Quecksilber und die mit Luft gefüllte Röhre ihre Rollen vertauscht haben.

f) Beobachtungen an Uhren. Eine merkwürdige Beobachtung Bohnenberger's, welche entschieden hierher gehört, scheint noch keine Berücksichtigung gefunden zu haben. Dieser äusserst exakte und zuverlässige Forscher berichtet [30], dass seinen Wahrnehmungen zufolge der Gang einer Pendeluhr Störungen erleide, wenn das Uhrgewicht der Linse gerade gegenüber zu stehen komme - Störungen, welche man nur aus der gegenseitigen Anziehung von Linse und Gewicht erklären könne. Auch der berühmte englische Uhrmacher Emery habe derartige Unregelmässigkeiten bemerkt. Da nach Bohnenberger's Messungen die Störungen im Gange der Uhr numerisch ausdrückbar, die Massen von Gewicht und Linse aber bekannt sind, so würde es möglich sein, aus diesen gegebenen Grössen einen Rück- 
schluss auf das einzige noch unbekannte Element, nämlich auf die Masse des Erdkörpers, zu machen (s. u.).

g) Der Darwin'sche Messapparat. Im Jahre 1881 zeigte G. H. Darwin der zu York versammelten „British Association“ ein Instrument dieser Art vor, von welchem dann nachgehends auch eine Beschreibung in deutscher Sprache gegeben wurde [31]. Der gewöhnliche Spiegel eines Galvanometers ist durch zwei dünne, gleichlange Kokonfäden einmal mit dem unteren Ende der Pendellinse, einem schweren Kupfergewicht, das andere Mal mit einer Stütze verbunden, welche auf dem Fundament des das Pendel tragenden Gerüstes angebracht ist. Bewegt sich nun das Pendel mit Bezug auf sein Fundament, so stellt die Rotation des Spiegels um eine vertikale Axe diejenige Komponente der Pendelbewegung vor, welche in einer Ebene erfolgt senkrecht zu der durch die ursprüngliche Lage der Kokonfäden bestimmten. Die Beobachtung selbst vollzieht sich in ganz ähnlicher Weise, wie beim Galvanometer, doch müssen die zwei Seidenfäden, wenn eine sehr grosse Genauigkeit beabsichtigt ist, einander möglichst nahe gebracht sein; Schraubenvorrichtungen reguliren die Empfindlichkeit. Um die Oscillationen etwas zu dämpfen, liess $\mathrm{D}$ arw in das Pendel zu Cambridge in einer Mischung von Wasser und Alkohol schwingen, wobei noch 1/200 Winkeldeviation zu konstatiren war. Was nun die Beobachtungen anlangt, so liess das Pendel eine tägliche Periode von Schwingungen im Mittagskreis wahrnehmen; ferner bewegte sich die mittlere tägliche Lage des ersteren innerhalb mehrerer Wochen nach einer bestimmten Richtung hin, wiewohl die Schwingungen nicht selten durch unerklärliche Umkehrungen unterbrochen wurden. In eigentlicher Ruhe war die Linse zu keiner Zeit, doch gab es Perioden relativer Ruhe und wieder relativer Bewegungsstärke. Es sind hier noch manche Geheimnisse aufzuklären, und zwar birgt deren der Apparat selbst genug in sich; ist doch seine Reizbarkeit eine so grosse, dass selbst dann ein namhafter Ausschlag eintritt, wenn sich der Experimentirende um einen Schritt nähert oder entfernt.

§. 3. Attraktionsprobleme. Nachdem wir uns nunmehr überzeugt haben, wie Anziehungswirkungen durch das Experiment nachgewiesen und hinsichtlich ihrer Grösse geschätzt werden können, haben wir weiter danach zu fragen, wie solche Wirkungen der Rechnung zu unterwerfen seien. Die für uns allein wichtige Aufgabe ist: die Wirkung eines beliebig gestalteten Körpers auf einen gegebenen Punkt zu bestimmen. Der fragliche Punkt habe in Bezug auf ein rechtwinkliges Koordinatensystem die Koordinaten a, b, c; irgend ein Punkt im Inneren des attrahirenden Körpers sei durch x, y, z bestimmt; dann ist deren Distanz $d=\sqrt{(x-a)^{2}+(y-b)^{2}+(z-c)^{2}}$. Die Masse des Elementarparallelepipeds, dessen Schwerpunkt (x, y, z) sein soll, wird durch $\rho \mathrm{dxdydz}$ dargestellt, unter $\rho$ die Dichte verstanden. Nimmt man in (a, b, c) ein Raumelement von der Masse 1 gelegen an, so lässt sich nach dem Newton'schen Gesetze die wechselseitige Anziehung beider Massentheilchen anschreiben und es gilt nur noch, diesen Ausdruck eüber den ganzen in Betracht kommenden Körper auszudehnen. Demgemäss wird diese wechselseitige Anziehung durch 
das dreifache Integral

dargestellt sein*).

$$
\rho \iiint \frac{d x d y d z}{(x-a)^{2}+(y-b)^{2}+(z-c)^{2}}
$$

Ein einfaches Beispiel, welches wir Thomson-Tait [34] entnehmen, mag den Berechnungsvorgang erläutern. In Fig. 22 ist OB

Fig. 22 .

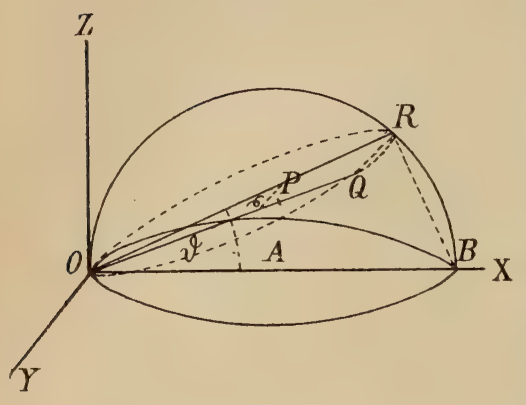

Durchmesser einer Halbkugel vom Halbmesser $\mathrm{OA}=\mathrm{AB}=\mathrm{k}$ und von der allenthalben gleich vertheilten Dichte $\rho$; die Anziehung dieser Halbkugel auf den Punkt $O$ ist zu finden. Man wähle $\mathrm{O}$ zum Ursprung eines Orthogonalsystemes, die X-Axe falle mit $\mathrm{OB}$ zusammen, die Z-Axé stehe senkrecht auf dem Grundkreise. P sei ein willkürlicher Punkt im Inneren der Halbkugel; man lege durch ihn eine auf der XZ-Ebene senkrecht stehende Ebene, welche aus der Kugel den Kreis OR ausschneidet, und ver-

binde $\mathrm{P}$ mit $\mathrm{O}$ durch eine Strecke, welche in ihrer Verlängerung über $\mathrm{P}$ hinaus die Peripherie des zuletzt genannten Kreises in $\mathrm{Q}$ trifft. Nunmehr kann man mit Vortheil an Stelle der rechtwinkligen polare Koordinaten einführen. $\mathrm{P}$ ist fixirt: erstens durch seine Entfernung $\mathrm{PO}=\mathrm{r}$ vom Ursprung oder $\mathrm{Pol} \mathrm{O}$, zweitens durch den $\Varangle \mathrm{QOR}=\varphi$ und drittens durch den $\Varangle \mathrm{ROB}=\vartheta$. Der Fahrstrahl $\mathrm{r}$ variirt zwischen 0 und $O Q$, zieht man noch die Hülfslinien $R Q$ und $R B$, so folgt aus den rechtwinkligen Dreiecken ORQ und ORB

$$
\mathrm{OQ}=\mathrm{OR} \cos \varphi=\mathrm{OB} \cos \vartheta \cos \varphi \text {. }
$$

Der Winkel $\varphi$ hat rechts und links zur Seite der OR einen Spielraum von $0^{\circ}$ bis $90^{\circ}$, während $\vartheta$ nur einmal von $0^{\circ}$ bis $90^{\circ}$ wachsen kann. Das Körperelement $d x d y d z$ geht durch die polare Transformation in unserem Falle über in $\mathrm{r}^{2} \cos \varphi \mathrm{d} \varphi \mathrm{d} \vartheta \mathrm{d} \mathrm{r}$, die Entfernung $\mathrm{OP}=\mathrm{d}$ (s. o.) ist in unserem Falle einfach $=r$ zu setzen. Unser dreifaches Integral von oben nimmt somit, wenn seine Funktion, zur Projicirung auf $\mathrm{OZ}$, mit $\cos \varphi \sin \vartheta$ multiplicirt wird, diese Gestalt an:

$$
\rho \int_{0}^{\frac{\pi}{2}} \sin \vartheta d \vartheta \quad \int_{-\frac{\pi}{2}}^{\frac{\pi}{2}} \cos ^{2} \varphi d \varphi \int_{0}^{2 \mathrm{r}} \frac{\mathrm{r}^{2}}{\mathrm{r}^{2}} \mathrm{cos} \vartheta \cos \varphi
$$

Ohne Mühe findet sich hieraus die Anziehung $=\frac{4}{3} \rho \mathrm{k}$ längs $\mathrm{OZ}$.

*) Für die kosmische sowohl wie für die tellurische Physik hervorragend wichtig hat sich im Laufe der Zeiten die Aufgabe erwiesen, die Anziehung eines Ellipsoides zu berechnen; Paraira [32] und Grube [33] haben hierüber in Monographieen gehandelt. Wir entnehmen denselben, dass Newton das Problem nur für einen speziellen Fall synthetisch löste, Cotes die von jenem nur angedeutete Integration wirklich ausführte, dass Stirling und Clairaut ebenfalls nur Ellipsoide von annähernd kugelförmiger Gestalt behandelten, und dass erst M a c Laurin mit dem Rotationsellipsoid in's Reine kam. Für das dreiaxige erbrachte zuerst D'Alembert eine Lösung, die nicht viel weniger leistet, als man 
Denken wir uns in $\mathrm{O}$ die Kugel eines freihängenden Bleilothes befindlich, so erleidet diese eine Ablenkung im berechneten Betrage. Gesetzt, man wolle die Polhöhe des Punktes $O$ messen, während nördlich von ihm ein halbkugelförmiger homogener Berg sich erhebt. Wählt man zur Festlegung der Zenitalrichtung ein rein geodätisches Verfahren, so ist keine Fehlerquelle vorhanden, und man erhält die wahre Polhöhe $\varphi$; wenn man sich jedoch eines Winkelmessinstrumentes mit Bleiloth bedient, so erhält man eine falsche, durch die Lothabweichung entstellte Polhöhe $\varphi^{\prime}$, und zwar ist, wenn G den Gesammtbetrag der Erdanziehung, $\mathrm{R}$ den Erdradius vorstellt, für die Südseite

$$
\varphi-\varphi^{\prime}=\frac{2}{3} \pi \rho \mathrm{k}:\left(\mathrm{G}-\frac{4}{3} \rho \mathrm{k}\right)=\frac{2}{3} \pi \rho \mathrm{k}:\left(\frac{4}{3} \pi \sigma \mathrm{R}-\frac{4}{3} \rho \mathrm{k}\right) \text {. }
$$

$\sigma$ ist die Dichte des Erdballes, $\frac{2}{3} \pi \rho \mathrm{k}$ die Berganziehung längs $\mathrm{OX}, \frac{4}{3} \pi \sigma \mathrm{R}$ die Anziehung der Erde selbst $\left(=\frac{4}{3} \pi \sigma \mathrm{R}^{3}: \mathrm{R}^{2}\right)$. Da der Subtrahend in der Klammer gegen den Minuenden verschwindet, so kann man

$$
\varphi-\varphi^{\prime}=\frac{2}{3} \pi \rho \mathrm{k}: \frac{4}{3} \pi \sigma \mathrm{R}=\frac{1}{2} \rho \mathrm{k}: \sigma \mathrm{R}
$$

setzen. Zwei nördlich und südlich unmittelbar am Fusse des Berges gelegene Stationen, deren Polhöhenunterschied von Rechtswegen $=\frac{2 \mathrm{k}}{\mathrm{R}}$ sein würde, haben somit, wegen der Attraktion des Berges, den scheinbaren Breitenunterschied $\frac{\mathrm{k}}{\mathrm{R}}\left(2+\frac{\rho}{\sigma}\right)$. Umgekehrt stellt sich das Verhältniss, wenn man zwei am Rande einer breiten, westöstlich verlaufenden Schlucht sich gegenüber liegende Orte in's Auge fasst.

Derjenige Körper, welcher die Anziehung ausübt, braucht natürlich kein fester zu sein, vielmehr kann er auch einem anderen Aggregatzustande angehören. Nach Thomson-Tait war es bereits Robison aufgefallen, dass die gewaltigen Fluthen in der Fundy-Bay eine Lothablenkung bewirken [35], und wenn diess der Fall, so muss natürlich auch schon eine geringere Wasseranschwellung zu der gleichen Wahrnehmung führen. Die genannten englischen Physiker lehren die Wirkung der Fluth folgendermassen zu berechnen. L (Fig. 23a) stellt jenen Punkt des Ufers dar, bis zu welchem das.Meer gewöhnlich, O jenen, bis zu welchem es in einem Ausnahmsfalle ansteigt. Nimmt man an, dass das Gestade zu beiden Seiten der durch $\mathrm{O}$ und $\mathrm{L}$ gelegten Vertikalebene symmetrisch verlaufe, so wird offenbar das Plus der Lothabweichung einzig und allein bedingt durch das mit Wasser ausgefüllte Trapez $O \mathrm{~K}^{\prime} \mathrm{L}^{\prime} \mathrm{L}$, an dessen Stelle mit hinreichender Annäherung auch das Rechteck K K' L'L genommen werden kann. In Fig. $23 \mathrm{~b}$ stellt $\mathrm{A} \mathrm{A}^{\prime} \mathrm{B}^{\prime} \mathrm{B}$ ein

auch heute noch zu leisten im Stande ist; Lagrange beschränkte sich in der Hauptsache darauf, die bis dahin gewonnenen Sätze mit strengen analytischen Beweisen zu versehen. 
Rechteck vor, dessen Anziehung auf einen ausserhalb gelegenen Punkt $\mathrm{zu}$ ermitteln ist; fällt man von $\mathrm{O}$ auf $\mathrm{A}^{\prime} \mathrm{B}^{\prime}$ die Normale $\mathrm{O} \mathrm{E}^{\prime}$, welche $\operatorname{der} \mathrm{AB}$ in $\mathrm{E}$ begegnet, und zieht die Hülfslinien $\mathrm{OA}, \mathrm{OB}, \mathrm{OA}^{\prime}$, $\mathrm{OB}^{\prime}$, so ist, wie a. a. O. zu ersehen, die

Fig. $23 \mathrm{~b}$.

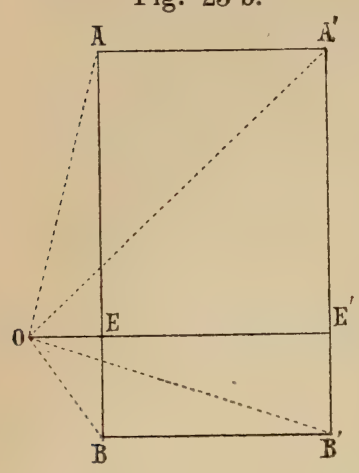
gesuchte Anziehung gleich

$$
\rho \log \left[\frac{(\mathrm{OA}+\mathrm{AE}) \cdot(\mathrm{OB}+\mathrm{BE}) \cdot \overline{\mathrm{OE}^{\prime 2}}}{\left(\mathrm{OA}^{\prime}+\mathrm{A}^{\prime} \mathrm{E}^{\prime}\right) \cdot\left(\mathrm{OB}^{\prime}+\mathrm{B}^{\prime} \mathrm{E}^{\prime}\right) \cdot \overline{\mathrm{OE}^{2}}}\right],
$$

unter $\rho$ die Dichte des Meerwassers verstanden. Einführung geeigneter Zahlenwerthe lehrt, dass unter gewissen Umständen das Bleiloth aus der Lage, welche es zur Zeit der Ebbe inne hatte, durch eine horizontal gerichtete Kraft entfernt wird $>\frac{1}{4000000}$ der vertikalen Kraft; entsprechend findet man den Winkelwerth der Ablenkung, wenn man jenen Bruch mit $57^{0} 18^{\prime}=\left(\frac{360}{2 \pi}\right)^{0}$ multiplicirt.

Eingehendere Untersuchungen über die Abhängigkeit der Gravitationsrichtung vom Wasserstande enthält Keller's Abhandlung: Sulle piccole variazioni della direzione della gravità prodotte dalle mare e nella località situate presso la spiagia del mare, Roma 1873.

Die Frage, nach welcher Richtung hin die - ihrer numerischen Grösse nach bekannte - Anziehung wirke, hat uns bisher noch nicht beschäftigt, doch ist sie ebenfalls von hervorragender Wichtigkeit. An sich ist klar, dass, wenn einer Fläche oder einem Körper eine Symmetrieaxe zukommt, um welche herum also die Masse durchaus gleich vertheilt ist, und wenn ferner der beeinflusste Punkt in der Verlängerung dieser Linie gelegen ist, alsdann die Resultante aus all den unendlich vielen Anziehungskräften der einzelnen Massentheile zusammenfällt mit der Symmetrielinie. Für die Kugel ist jeder Durchmesser eine solche Axe, und es braucht deshalb wohl kaum der an sich so eleganten Beweise Newton's [36] und v. Ettingshausen's [37] für die Thatsache, dass man die Masse eines sphärischen Körpers in dessen Mittelpunkt koncentrirt denken kann. Sind die sich anziehenden Körper sehr weit von einander entfernt, so dass ihre Abweichungen von der Kugelgestalt numerisch gegen die Distanz nicht in Betracht kommen, so dürfen wir ebenfalls die Massen in den Schwerpunkten vereinigen und nach dem für Kugeln geltenden Gesetze behandeln; diese an sich einleuchtende Behauptung lässt sich, wie Schlömilch gezeigt hat, leicht analytisch bekräftigen [38 $\left.]^{*}\right)$. Wie aber verhält es sich, wenn jene Vernachlässigung nicht mehr gestattet werden kann?

*) In einer früheren Mittheilung [39] des Verf. ward darauf hingewiesen, wie man elementar an einem Spezialfalle den für Anfänger wichtigen Beweis führen könne, dass die Anziehungsrichtung $\mathrm{nicht}$, resp. nur ausnahmsweise, durch den Schwerpunkt des anziehenden Gebildes hindurchgehe. Die Figur A BCDE (Fig. 24) besteht aus einem Halbkreise ABC und einem Rechtecke ACDE, so zwar dass der Radius $\mathrm{AM}=\mathrm{CM}=\mathrm{BM}(\perp \mathrm{AC})$ den Rechtecksseiten $\mathrm{AE}$ und CD gleich ist. Man bestimme die Anziehung dieser (homogen vorausgesetzten) Figur auf den Punkt E. Vervollständigt man den Halbkreis zum Vollkreis, 
Im Jahre 1777 machte Lagr an ge [40] die folgenreiche Bemerkung, dass, wenn man die Resultante der Attraktion parallel zu den drei Axen des Orthogonalsystemes in Seitenkräfte zerlege, jede derselben mittelst der Relationen $X=\frac{\partial \Omega}{\partial x}, Y=\frac{\partial \Omega}{\partial y}, Z=\frac{\partial \Omega}{\partial z}$ auf eine einzige Funktion $\Omega$ zurückgeführt werden könne. Diese Funktion ist aber nichts anderes, als die Summe sämmtlicher in Betracht kommenden Massentheile, jeder multiplicirt mit einer gewissen Funktion seiner Entfernung von dem angezogenen Punkte, und zwar geht letztere Funktion für den Fall des uns einzig hier beschäftigenden Newton'schen Gravitationsgesetzes in die reciproke Entfernung über. Will man also zugleich mit der Anziehungsgrösse A auch die Richtung der ihr entsprechenden Resultante im Raume haben, so bildet man zuerst

$$
\Omega=\int \frac{\mathrm{dm}}{\mathrm{r}}, \mathrm{X}=\frac{\partial \Omega}{\partial \mathrm{x}}, \mathrm{Y}=\frac{\partial \Omega}{\partial \mathrm{y}}, \mathrm{Z}=\frac{\partial \Omega}{\partial \mathrm{z}}
$$

und hat dann, die gewöhnliche Winkelbezeichnung der analytischen Raumgeometrie beibehalten,

$$
\begin{gathered}
A=\sqrt{X^{2}+Y^{2}+Z^{2}}, \cos (A, X)=\frac{X}{A}, \cos (A, Y)=\frac{Y}{A}, \\
\cos (A, Z)=\frac{Z}{A}, \cos ^{2}(A, X)+\cos ^{2}(A, Y)+\cos ^{2}(A, Z)=1 .
\end{gathered}
$$

Die Funktion $\Omega$ hat Green [41] Potentialfunktion, Gauss [42] schlechtweg Potential genannt, und obwohl mehrere Schriftsteller, besonders Clausius [43], zwischen diesen beiden Bezeichnungen einen gewissen Unterschied machen zu müssen glaubten, so hat sich doch deren Gebrauch als Synonyma mehr und mehr eingebürgert. Bacharach hat [44] eine sehr verdienstliche Geschichte der Yotentialtheorie geschrieben, auf welche wir mit Nachdruck verweisen, da eben diese Theorie gerade für die wissenschaftliche Erdkunde nach verschiedenen Seiten hin eine fundamentale genannt werden muss.

Dess zum Belege verweben wir in unsere Darstellung die wichtigsten Ergebnisse einer inhaltsreichen Abhandlung [45], in welcher Zöppritz eben die Anwendung des Potentiales bei der Diskussion erdphysikalischer Fragen behandelt. Will man, so heisst es dort, das

welcher $\mathrm{DE}$ in $\mathrm{K}$ berührt, so wirken auf $\mathrm{E}$ anziehend drei Flächenräume: der Kreis um M, das gemischtlinige Dreieck AKE und das gemischtlinige Dreieck CKD. Erstere beide zusammen geben die Figur EABCK, auf deren Symmetrieaxe E selbst liegt; E F sei die von jener ausgeübte Attraktion. Die Anziehungsrichtung von $\mathrm{CKD}$ würde etwa $\mathrm{ES}_{3}$ sein, wir wollen sie aber zum Ueberflusse mit ED zusammenfallen lassen und ihrer Grösse nach $=\mathrm{EG}$ setzen. Alsdann ist $\mathrm{EH}$ die Gesammtresultante, welche $\mathrm{KB}$ in $\mathrm{J}$ schneidet. Für $\mathrm{MS}_{1}=\frac{4}{3 \pi} \mathrm{AM}, \mathrm{MS}_{2}$ $=\frac{1}{2} \mathrm{AM}$ und $\mathrm{S}_{1} \mathrm{~S}: \mathrm{S}_{2} \mathrm{~S}=2 \overline{\mathrm{AM}}^{2}: \frac{1}{2} \overline{\mathrm{AM}}^{2} \pi$ ist $\mathrm{S}$ der Schwerpunkt der ganzen Figur, und eine kleine Rechnung ergiebt MS $>$ MJ. Um so mehr würde diess gelten, wenn EG seiner Grösse nach auf $\mathrm{ES}_{3}$ abgetragen worden wäre.

Fig. 24 .

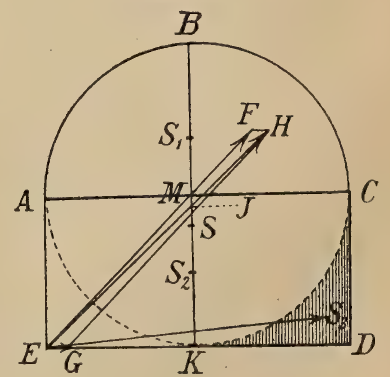


Potential der Erde in Bezug auf andere Himmelskörper betrachten, so reicht es hin, dieselben aus homogenen und annähernd koncentrischen Schichten zusammengesetzt anzunehmen und den Unterschied der Trägheitsmomente um verschiedene Axen hinlänglich klein vorauszusetzen. Mögen die Massen auch ungleich und ungleich vertheilt sein, die grossen Entfernungen $\mathbf{r}$ in der Summe $\left(\frac{\mathrm{m}_{1}}{\mathrm{r}_{1}}+\frac{\mathrm{m}_{2}}{\mathrm{r}_{2}}+\frac{\mathrm{m}_{3}}{\mathrm{r}_{3}}+\ldots\right)$ wirken fehlerausgleichend. Für einen Punkt der Erdoberfläche sieht natürlich das Gravitationspotential ganz anders aus; namentlich ist die Meeresfläche keine Oberfläche von einheitlichem geometrischem Bildungsgesetze. Denkt man sich dieselbe zunächst noch als sphäroidisch und bezeichnet für einen bestimmten Punkt derselben ihren normalen $\mathbf{A b}$ stand von einer - im nächsten Kapitel einlässlich zu besprechenden Hülfsfläche mit h, ferner mit $(-\Omega)$ das Potential eines über das Meeresniveau emporragenden Festlandes (mittlere Dichte 2,5), mit $\gamma$ die Schwere und erwägt, dass jede Massenverminderung eine positive Potentialdifferenz $\Delta \Omega$, jede entsprechende Massenvermehrung an anderer Stelle die negative Potentialdifferenz $\left(-\Delta \Omega^{\prime}\right)$ bedingt, so kann man

$$
\mathrm{h}+\Delta \mathrm{h}=\frac{1}{\gamma}\left(\Omega+\Delta \Omega-\Delta \Omega^{\prime}\right), \Delta \mathrm{h}=\frac{1}{\gamma}\left(\Delta \Omega-\Delta \Omega^{\prime}\right)
$$

setzen. Nimmt man an, dass ein Kontinent um eine feste Axe eine sogenannte Schwengelbewegung ausführt, so muss man, um die hieraus für einen gewissen Küstenpunkt resultirende Niveauveränderung zu erhalten, die Potentiale des emporgehobenen und des untergetauchten Theiles mit Bezug auf obigen Punkt bestimmen. Handelt es sich um Sedimentablagerungen, so kann man eventuell das eine Potential vernachlässigen; namentlich gilt diess für die Deltabildungen, weil hier das abgesetzte Material fast ausschliesslich vom Oberlaufe der Flüsse, also von Orten herstammt, deren Entfernung vom Delta gross ist. Dieses grosse $r$ lässt wiederum die Brüche $\frac{\mathrm{m}}{\mathrm{r}}$ unter die Grenze der zu berücksichtigenden Grössen herabsinken [46]. Von weiteren Bemerkungen dieser Arbeit werden wir späterhin, namentlich bei der Strandlinienfrage, Notiz zu nehmen haben.

Zum Schlusse dieses Paragraphen erwähnen wir noch einer Definition, auf welche wir uns später zu berufen haben werden. Nur für eine homogene Kugel laufen sämmtliche Anziehungsrichtungen in ein und demselben Punkte zusammen, für andere Raumgebilde ist diess nicht möglich. Gerade die kosmische Physik hat sich aber vielfach mit Körpern zu befassen, welchen die erwähnte Eigenschaft zwar nicht in aller Strenge, aber doch annähernd zukommt, und solche Körper bezeichnet man nach englischem Sprachgebrauche als centrobarisch. Thomson und Tait verstehen [47] unter einem harmonischen Sphäroid ein dreiaxiges Ellipsoid, dessen Fahrstrahlen für beliebige Oberflächenpunkte von den Radien einer gewissen koncentrischen Kugel nur um ein Unendlichkleines sich unterscheiden. Ein harmonisches Sphäroid von beliebigem Grade $n>2$ ist eine algebraische Fläche nter Ordnung, die näherungsweise sphärisch gekrümmt, dabei aber allerdings noch anderen Bedingungen unterworfen ist. Alle von solchen Flächen begrenzten Körper sind centrobarisch. 
§. 4. Lothanziehung und Lothabstossung. Wir haben im vorigen Paragraphen gesehen, dass Unregelmässigkeiten der Erdoberfläche auch bei einem in der Hauptsache centrobarischen Körper, wie es unsere Erde ist, das Loth von der eigentlichen Richtung abzulenken vermögen, und zwar, wenn es Erhöhungen sind, im Sinne einer Anziehung. Das Maass für eine solche Ablenkung ist im Bogenmaasse auszudrücken und wird (s. o.) dadurch gefunden, dass man erstens die Polhöhe des zu untersuchenden Ortes direkt bestimmt und zweitens eine geodätische Triangulirung einleitet, welche den Werth dieses Winkels unabhängig von allen Beobachtungen am Orte selbst liefert. Zieht man von der beobachteten Polhöhe die berechnete ab, so hat man die Lothablenkung in Folge von Lokalanziehung gefunden.

Angaben über die Geschichte der Lokalattraktion findet man in Humboldt's "Kosmos" [48] und in grösserer Fülle in den monographischen Werken, welche v. Zach [49] und Philipp Keller [50] diesem Thema gewidmet haben. Hier kann natürlich nur einiger Hauptmomente gedacht werden. Bouguer prüfte zuerst die von dem mächtigen Chimborazo auf das Bleiloth seines Quadranten ausgeübte Attraktion und fand für den betreffenden Winkel [51] den freilich viel zu kleinen Werth von etwas über 7". Beccaria und Liesganig (s. o. Kap. I, §. 6) konstatirten die mächtigen Einwirkungen des Alpenmassives; der letztere sagt u. a. [52]: „Quidni? Si unius montis Chimboraço actio octo circiter secundorum deviationem perpendiculo intulit, quidni, inquam, suspicari liceat, a tanta ingentium pinguiumque superioris Styriae montium massa, sectoris quoque mei perpendiculum ad 12 secundorum angulum dimoveri?" Genauere Beobachtungen über Berganziehung stellten Maskelyne und Hutton [53] an einer schottischen Gebirgsgruppe an. In unserem Jahrhundert waren es besonders Carlini und Plana [54], die sich mit der Ausgleichung der auf die Massenwirkung der Alpen zurückzuführenden Deviationsfehler zu schaffen machten, und Denzler folgte ihnen darin nach [55]; die lombardische Bergkette war die Ursache davon, dass ein Meridiangrad, statt, wie zu erwarten gewesen wäre, 57013 Toisen, in Wirklichkeit 57687 Toisen mass. v. Baeyer verfolgte den Einfluss der Berge systematisch, weil dadurch die Vermessungen in Deutschland vielfach beeinträchtigt wurden, und namentlich war es das sozusagen klassische Lothablenkungsgebiet unseres Vaterlandes, der Harz, welches seine Aufmerksamkeit auf sich ziehen musste. Eine von ihm mitgetheilte Tabelle [56] stellt die an einigen Hauptstationen der mitteldeutschen Gebirge erhaltenen Zahlenwerthe zusammen, wie folgt:

\begin{tabular}{|c|c|c|c|c|c|}
\hline Ort & öhe über d. Ostsee & Berechnete & e Polhöhe & Gemessene Polhöhe & Differenz \\
\hline $\begin{array}{l}\text { Inselsberg . . . . . } \\
\text { Seeberg . . . } \\
\text { Mühlhausen } \\
\text { Tettenborn . . . . } \\
\text { Hohe-Geis . . . . } \\
\text { Brocken } \\
\text { Ilsenburg . . . . . } \\
\text { Fallstein . . . . } \\
\text { Asse . . . . . . }\end{array}$ & $\begin{array}{r}916,14 \mathrm{~m} \\
357,83 \\
227,45 \\
322,47 \\
639,65 \\
1141,49 \\
259,87 \\
204,65 \\
211,14\end{array}$ & $\begin{array}{lr}50^{\circ} & 51^{\prime} \\
50 & 56 \\
51 & 12 \\
51 & 34 \\
51 & 39 \\
51 & 48 \\
51 & 52 \\
52 & 1 \\
52 & 8\end{array}$ & $\begin{array}{r}8,40^{\prime \prime} \\
5,84 \\
10,10 \\
22,13 \\
58,12 \\
1,15 \\
24,60 \\
5,65 \\
20,12\end{array}$ & $\begin{array}{l}-=11,75^{\prime \prime} \\
=-\quad 5,84 \\
=-6,18 \\
=-17,29 \\
=-57,02 \\
=-10,59 \\
=-35,71 \\
=-9,34 \\
-\quad-20,38\end{array}$ & $\begin{array}{l}+\quad 3,35^{\prime \prime} \\
-\quad 0,00 \\
=\quad 4,00 \\
=\quad 4,84 \\
=\quad 1,10 \\
+\quad 9,44 \\
+\quad 11,11 \\
+\quad 3,69 \\
+\quad 0,26\end{array}$ \\
\hline
\end{tabular}


Es ergaben sich drei Nullpunkte der Ablenkung: im Breitenkreise der Sternwarte Seeberg (bei Gotha), zwischen Hohe-Geis und Brocken und auf der Assse, einem niedrigen Rücken in der Nähe von Wolfenbüttel. Offenbar repräsentirt demnach die Gebirgsmasse des Harzes, welche je eine Zone mit nördlicher und südlicher Lothabweichung trennt, einen Anziehungskern, und zwar ist es den ausgeführten Längenbestimmungen gemäss sehr wahrscheinlich, dass das eigentliche Centrum der Anziehung im Meridian des Brockens gelegen ist. Die Zahlen sind übrigens nur oberflächlich richtig und harren der Verschärfung, an welcher eben gegenwärtig rüstig gearbeitet wird. Was die Jtaliener und Schweizer für die Alpen, was v. Baeyer für das deutsche Hochland, das hat Stebnitzki nach Leipoldt's Mittheilungen [57] für den Kaukasus geleistet. Wladikawkas an der Nordseite weist eine Ablenkung von 35,8", Duschet an der Südseite eine solche von 18,3", auf.

Es ist einleuchtend, dass die Grösse der Ablenkung ausser von den geometrischen Verhältnissen des attrahirenden Massives wesentlich auch von dem spezifischen Gewicht der in jenem vereinigten Gesteinsarten abhängen muss. Diesem letzteren Momente muss deshalb aber auch eine erhöhte Aufmerksamkeit zugewendet werden, doch ist diess gleichwohl längere Zeit nicht in dem erwünschten Maasse geschehen, und erst jüngst hat Lossen einen erfreulichen Anfang damit gemacht, indem er, einem Gedanken v. Richthofen's Folge gebend, im Harz den Zusammenhang zwischen der Vertheilung der Lothablenkungswerthe und der Vertheilung der Gebirgsglieder von verschiedenem Eigengewichte auszumitteln sich bestrebte [58]. Die Anordnung der Diabase und ihrer Tuffe, denen eine besonders grosse Dichte ( $=3$ im Durchschnitt) zukommt, musste dabei besonders in's Gewicht fallen. Der Harz, das „unzerstückte Massengebirge", wie ihn Friedrich Hoffmann nannte, wirkt in jeder Beziehung als ein Gebirgsknoten. Die positiven Deviationen wiegen vor den negativen vor, zumal im Norden und Nordosten, was mit der Stellung der Granitstöcke in jenen Gegenden ganz gut harmonirt [59]. Zweimal kulminiren die Werthe (bei Harzburg und Ballenstedt); diesem Verhältnisse entsprechen anscheinend die beiden dynamischen Brennpunkte des inneren Gebirgsbaues, die sich neutralisirenden Hauptgranitmassen im Brocken und im Rammelsberg. Auch ist charakteristisch, dass die Maximalwerthe diesen Centren nicht direkt gegenüber, sondern vielmehr am Rande des Berglandes liegen. Nicht minder korrespondirt nach Art und Maass des Ansteigens die Differenz zwischen den beiden Kulminationswerthen mit der verschiedenen Protrusion und Volumentfaltung der beiden Granitmassive, wie denn der blosse Höhenunterschied des Nordost- und Nordwestharzes zur Erklärung nicht ausreichend befunden werden würde, selbst wenn man ausser der Höhe selbst noch die Volumina der über eine gewisse Durchschnittsebene aufragenden Gebirgstheile in Betracht ziehen wollte.

In §. 3 ward schon bemerkt, dass ebenso, wie eine Erhöhung anziehend auf das Senkel wirkt, eine Vertiefung anscheinend eine $\mathrm{Ab}$ stossung hervorrufe. Bereits Kant scheint sich über dieses Faktum ganz klar gewesen zu sein. Fig. 25 zeigt uns eine Kant'sche Originalzeichnung, die dem kleinen und nur wenige Worte enthaltenden Fragmente "Von der veränderlichen Richtung der Schwere" beigegeben ist [60]. Der Sinn ist jedoch unschwer zu errathen: Wäre A FEG 
eine homogene Vollkugel so fiele deren Anziehungsresultante in Bezug auf Punkt A mit dem Diameter AC zusammen, wenn aber eine hohle excentrische Kugel B vorhanden ist, so wird die Anziehungsrichtung von dieser abgelenkt, etwa nach AD. Die erste sichere Beobachtung dieser Art machte Schweizer, indem er in der Umgebung von Moskau ausgedehnte unterirdische Hohlräume konstatirte [61]. Auch Stebnitzki fand Aehnliches für Transkaukasien; so sollte Schemacha eine positive Ablenkung von $28^{\prime \prime}$ haben und weist in Wahrheit eine negative Ablenkung von $15^{\prime \prime}$ auf - ein der grossen Nähe mächtiger Bergriesen halber auffälliges Vorkommniss, welches W. Struve mit dem höhlenreichen, vulkanischen und den Erdbeben nur allzu günstigen Charakter dieses Theiles von Dagestan in Zusammenhang bringen möchte [62].

Fig. 25 .

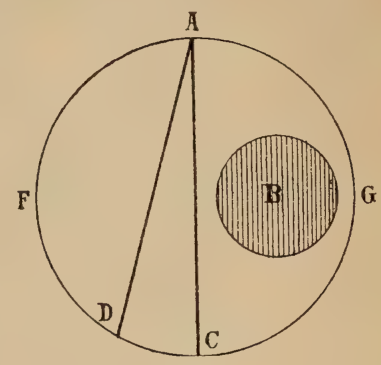

§. 5. Die Erdgestalt unter dem vereinigten Einflusse von Schwere und Centrifugalkraft. Wiewohl von den Bewegungen des Erdkörpers erst im zweitnächsten Kapitel besonders gesprochen werden wird, so dürfen wir doch natürlich auch hier schon die Thatsache voraussetzen, dass der Erdball sich in 24 Stunden einmal mit gleichförmiger Geschwindigkeit um seine Axe dreht. Diese Bewegung musste, wenn die Erde im Sinne der Nebulartheorie ursprünglich eine weiche, breiartige Masse war, eine allmählige Abplattung derselben hervorrufen, wie jede Töpferkugel auf der Drehscheibe und der bekannte Vorlesungsversuch mit der aus elastischen Reifen zusammengesetzten Kugel zur Genüge darthun. Am Pole ist nämlich die Centrifugalkraft gleich Null, am Aequator erreicht sie ihren Maximalwerth, und es geht sonach die Erde, wie es Newton von Anfang an behauptete und wie es auch die Gradmessungen auswiesen, in ein abgeplattetes Sphäroid über. Den Grad der Abplattung kann man mit einiger Annäherung durch theoretische Betrachtungen feststellen; wir führen dieselben hier durch, indem wir uns dabei wesentlich auf das Newton'sche Originalwerk [63] und die dessen Darstellung vortrefflich in die moderne Ausdrucksweise übersetzende Physik von Fliedner [64] beziehen.

Die Centrifugalbeschleunigung $\mathrm{f}_{0}$ eines Aequatorpunktes im Meeresniveau ist, wenn $\mathrm{r}=6377365 \mathrm{~m}$ den Aequatorhalbmesser, $\mathrm{t}=23^{\mathrm{h}}$ $56^{\prime} 4^{\prime \prime}=86164^{\prime \prime}$ die genaue Umdrehungsdauer darstellt, einem bekannten dynamischen Satze nach diese:

$$
\mathrm{f}_{0}=\frac{4 \mathrm{r} \pi^{2}}{\mathrm{t}^{2}}=\frac{4 \cdot 6377365 \cdot 3,14^{2}}{86164^{2}}=0,0339 \mathrm{~m} .
$$

Diese Centrifugalbeschleunigung ist der Fallbeschleunigung direkt entgegen gerichtet, sie lässt einen jeden Körper leichter erscheinen, als er auf einer ruhenden Erde sein würde. Da nun die Beschleunigung der Schwere am Aequator $\mathrm{g}_{0}=9,7806 \mathrm{~m}$ gefunden wurde*), so ist,

*) Eine von Pendelmessungen unabhängige Bestimmungsweise der Fallkonstante hat, wie Poggendorf anführt [65], bereits Galil ei angegeben. Er liess polirte Kugeln in Rinnen herablaufen, die gegen den Horizont (um den $\Varangle \alpha$.) 
unter $\gamma$ die Fallbeschleunigung auf einer Erde ohne Axendrehung verstanden, $\gamma=\mathrm{g}_{0}+\mathrm{f}_{0}=9,8145$ und $\frac{\mathrm{f}_{0}}{\mathrm{~g}_{0}}$ sehr nahe $=\frac{1}{289}$.

Es liegt uns nun ob, die Veränderung der Schwere auf der kugelförmig vorausgesetzten Erde zu verfolgen. Der Weg, den A (Fig. 26)

Fig. 26.

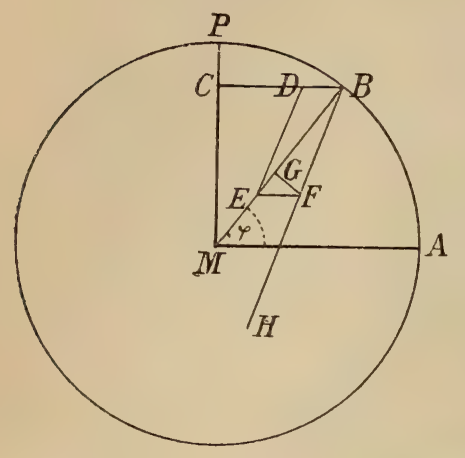
täglich beschreibt, ist $=2 \mathrm{AM} . \pi=2 \mathrm{r} \pi$, der Weg, den B beschreibt, ist $=2 \mathrm{BC} . \pi$ $=2 \mathrm{r} \cos \varphi \cdot \pi$ (unter $\varphi$ die geographische Breite verstanden), der von $\mathrm{P}$ beschriebene Weg endlich ist $=0$. Die theoretische Fallbeschleunigung in $B$ sei durch $\mathrm{BE}$ ausgedrückt, während $\mathrm{BD}$ die Centrifugalbeschleunigung und $\mathrm{BF}$ die wirkliche Fallbeschleunigung repräsentirt; die thatsächliche Fallrichtung $\mathrm{BH}$, auf welcher $\mathrm{BD}$ abgetragen werden musste, würde nur dann mit BM zusammenfallen, wenn die Erde stille stände. Die 4 Punkte $\mathrm{B}, \mathrm{D}, \mathrm{E}, \mathrm{F}$ müssen die Ecken eines Parallelogrammes bilden, $\mathrm{BF}$ möge durch $\mathrm{g}_{\varphi}$ bezeichnet sein, so dass also, wenn $\mathrm{B}$ in den Pol $\mathrm{P}$ zu liegen kommt, $\mathrm{g}_{90} \mathrm{zu}$ schreiben wäre. Fällt man von $\mathrm{F}^{\prime}$ auf $\mathrm{EB}$ das Perpendikel $\mathrm{FG}$, so ist $\mathrm{EG}=\mathrm{BD} \cdot \cos \varphi$, oder, da $\mathrm{BD}=\mathrm{f}_{0} \cos \varphi$ ist, $\mathrm{EG}=\mathrm{f}_{0} \cos ^{2} \varphi$. Der Winkel EBF ist stets sehr klein (er steigt höchstens auf $6^{\prime}$ an), und so kann hinlänglich exakt $\mathrm{BF}=\mathrm{BG}=\mathrm{BE}-\mathrm{EG}$ gesetzt werden, d. h. es ist $\mathrm{g}_{\varphi}=\gamma-$ $\mathrm{f}_{0} \cos ^{2} \varphi=\mathrm{g}_{0}+\mathrm{f}_{0}-\mathrm{f}_{0} \cos ^{2} \varphi$,

$$
g_{\varphi}=g_{0}+f_{0}\left(1-\cos ^{2} \varphi\right)=g_{0}+f_{0} \sin ^{2} \varphi \text {. }
$$

Der letzterhaltenen Gleichung kann man die folgenden F ormen ertheilen:

$$
\mathrm{g}_{\varphi}=\mathrm{g}_{0}\left(1+\frac{\mathrm{f}_{0}}{\mathrm{~g}_{0}} \sin ^{2} \varphi\right)=\mathrm{g}_{0}\left(1+\frac{1}{289} \sin ^{2} \varphi\right) .
$$

Für den Pol $P$ ist $\sin ^{2} \varphi=1$, also haben wir für die Zunahme der Schwere vom Aequator bis zum Pol den Werth

erhalten.

$$
\mathrm{g}_{90}-\mathrm{g}_{0}=\frac{1}{289} \cdot \mathrm{g}_{0}
$$

Auf diese Thatsache begründet Newton (a. a. O.) seine Abplattungstheorie durch ein Raisonnement, welches wir seiner hohen und zwar nicht blos historischen Bedeutung halber hier wörtlich wiedergeben (Fig. 27) : „Es stelle nun APBQ die Figur der Erde vor, welche nicht mehr sphärisch, sondern durch Umdrehung einer Ellipse um ihre kleine Axe PQ entstanden gedacht wird, und es sei ACQ q a ein Kanal, welcher vom Pol $\mathrm{Qq}$ bis zum Centrum $\mathrm{Cc}$ und von diesem bis zum Aequator Aa mit Wasser angefüllt ist. Alsdann muss das Gewicht

geneigt und zur Vermeidung der Reibung mit Pergament ausgefüttert waren. Für ein kleines $\alpha$ waren der Fallraum $s$ und die Fallzeit $t$ leicht zu messen, und dann lieferte die Relation $\mathrm{s}=\frac{1}{2} \mathrm{gt}^{2} \sin \alpha$ den Werth jener Konstante. Treffliche Dienste leistet bei solchen Versuchen auch die Atwood'sche Fallmaschine. 
des Wassers im Zweige ACca sich zu dem Gewicht des im Zweige QCcq vorhandenen Wassers verhalten, wie $289: 288$, und zwar deshalb, weil die aus der Kreisbewegung entspringende Centrifugalkraft einen Theil von 289 trägt und aufhebt, und daher die 288 Theile Wassers im Schenkel ACca die 289 Theile im anderen Schenkel tragen." Denkt man sich also die durchaus flüssig Erdkugel in unendlich viele und unendlich schmale Kanäle dieser Art zerlegt, so gilt für einen jeden Newton's Beweis, und es muss also in jenem Gleichgewichtszustande, welcher der Erstarrung der Erde unmittelbar vorangieng, der Polarhalbmesser b zum Aequatorialhalbmesser a das Verhältniss $288: 289$ besessen haben. Somit ist

Fig. 27.

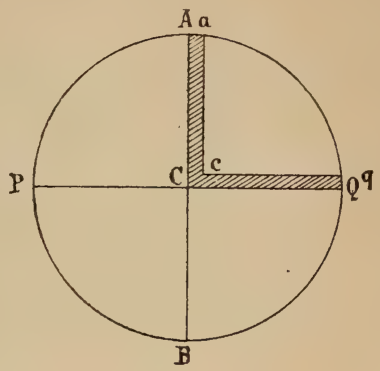

$$
\frac{\mathrm{a}}{\mathrm{b}}-1=\frac{289-288}{289}=\frac{1}{289}=\alpha,
$$

und wir haben jenen Abplattungswerth wieder bekommen, welchen Listing (s. o. Kap. I, §. 10) seinem typischen Sphäroid zu Grunde legte.

Nicht minder verdient als ein merkwürdiges Zusammentreffen bemerkt zu werden, dass Huygens [66] und Hamberger [67] durch eine eigenthümliche theoretische Kombination zu dem nämlichen Werthe geführt wurden. Sie erblickten die Ursache der Schwere in der Schwungbewegung eines intramolekularen Aethers und schlossen aus Experimenten, die sie mit leichten Körperchen in einem auf der Centrifugalmaschine stehenden Wasserglase gemacht hatten, dass die Geschwindigkeit des Aethers zur Rotationsgeschwindigkeit der Erde sich wie $17: 1(=\sqrt{289}: \sqrt{1})$ verhalte.

§. 6. Das Pendel als geodätisches Instrument. Weitaus das beste und sicherste Hülfsmittel, die Variationen der Erdschwere und die mit diesen in engster Beziehung stehenden Unregelmässigkeiten der Erdgestalt zu studiren, ist unstreitig das Pendel. Der Grund hievon ist leicht einzusehen. Macht ein mathematisches Pendel, resp. ein schwerer und an sehr dünnem Faden oder Draht aufgehängter Körper, Schwingungen, deren Elongation durch $\alpha$ bezeichnet wird, während 1 die Pendellänge vorstellt, so wird die Schwingungsdauer t durch folgende Gleichung gegeben:

$$
\mathrm{t}=\pi \sqrt{\frac{1}{\mathrm{~g}}}\left(1+\frac{1}{4} \sin ^{2} \frac{1}{2} \alpha+\frac{9}{64} \sin ^{4} \frac{1}{2} \alpha+\ldots\right) .
$$

Bei Ausschlagswinkeln unter $5^{\circ}$ - und mit anderen hat die Geophysik nicht zu rechnen - werden die Potenzen von $\sin \frac{1}{2} \alpha$ so klein, dass man blos das Anfangsglied der Reihe zu berücksichtigen braucht, und es verbleibt die einfache Formel*)

$$
\mathrm{t}=\pi \sqrt{\frac{\mathrm{l}}{\mathrm{g}}},
$$

*) Einen Weg, durch elementare Konstruktion, ohne jede Zuhülfenahme aller höheren Rechnungsweisen, diese Formel zu beweisen, hat zuerst K ulik [68] 
welche den von Bürgi und Galilei unabhängig entdeckten [70] Isochronismus der Pendelschwingungen ausdrückt. Für uns ist ausschliesslich das Sekundenpendel von Bedeutuug, für welches mithin $t=1$ ist; hieraus ergiebt sich dessen Länge

$$
\mathrm{L}=\frac{\mathrm{g}}{\pi^{2}} \text {. }
$$

Damit ist aber bewiesen, dass die Länge des Sekundenpendels der Konstanten der Schwerkraft direkt proportional ist, und dass Messungen dieser Länge ein Maass für die uns bereits bekannte Fundamentalgrösse $g$ liefern.

Weiter fliesst hieraus der Lehrsatz: Obwohl g nicht für alle Punkte der Erdkugel den nämlichen Werth besitzt und somit auch L durch den Index $\varphi$ als eine mit der geographischen Breite $\varphi$ variirende Grösse charakterisirt werden muss, so ist doch

$$
\frac{\mathrm{L}_{\varphi}-\mathrm{L}_{0}}{\sin ^{2} \varphi}=\text { Konst. }
$$

Nach den Ergebnissen des vorigen Paragraphen ist nämlich

$$
\mathrm{L}_{\varphi}-\mathrm{L}_{0}=\frac{\mathrm{g} \varphi-\mathrm{g}_{0}}{\pi^{2}}=\frac{\mathrm{f}_{0} \sin ^{2} \varphi}{\pi^{2}} \text { und } \frac{\mathrm{L}_{\varphi}-\mathrm{L}_{0}}{\sin ^{2} \varphi}=\frac{\mathrm{f}_{0}}{\pi^{2}}=\text { Konst. }
$$

Bezeichnen wir letztere der Kürze halber mit $B$, so ist allgemein $\mathrm{L}_{\varphi}=\mathrm{L}_{0}+\mathrm{B} \sin ^{2} \varphi$. Nunmehr ist klar, dass, wenn man von sekundären Einflüssen absieht, zwei unter verschiedenen Breiten $\varphi_{1}$ und $\varphi_{2}$ vorgenommene Messungen des Sekundenpendels genügen müssen, um sowohl $\mathrm{L}_{0}$ als $\mathrm{B}$ zu berechnen. Denn aus $\mathrm{L} \varphi_{1}=\mathrm{L}_{0}+\mathrm{B} \sin ^{2} \varphi_{1}$,
folgt durch Subtraktion unverzüglich

$$
\begin{gathered}
\mathrm{B}=\frac{\mathrm{L} \varphi_{1}-L \varphi_{2}}{\sin ^{2} \varphi_{1}-\sin ^{2} \varphi_{2}}=\frac{L \varphi_{1}-L \varphi_{2}}{\left(\sin \varphi_{1}+\sin \varphi_{2}\right)\left(\sin \varphi_{1}-\sin \varphi_{2}\right)} \\
=\frac{L \varphi_{1}-L \varphi_{2}}{\sin \left(\varphi_{1}+\varphi_{2}\right) \sin \left(\varphi_{1}-\varphi_{2}\right)}
\end{gathered}
$$

und durch nachherige Rücksubstitution

$$
\mathrm{L}_{0}=\mathrm{L}_{\varphi_{1}}-\frac{\left(\mathrm{L}_{\varphi_{1}}-\mathrm{L}_{\varphi_{2}}\right) \sin ^{2} \varphi_{1}}{\sin \left(\varphi_{1}+\varphi_{2}\right) \sin \left(\varphi_{1}-\varphi_{2}\right)}=\mathrm{L}_{\varphi_{2}}-\frac{\left(\mathrm{L}_{\varphi_{1}}-\mathrm{L}_{\varphi_{2}}\right) \sin ^{2} \varphi_{2}}{\sin \left(\varphi_{1}+\varphi_{2}\right) \sin \left(\varphi_{1}-\varphi_{2}\right)} \text {. }
$$

Solchergestalt haben wir die nöthige theoretische Grundlage gewonnen, um uns mit den sozusagen geodätischen Anwendungen des Pendels im Zusammenhange bekannt machen zu können.

§. 7. Ueberblick über die der geophysikalischen Anwendung des Pendels gewidmeten Untersuchungen. Im Jahre 1671 ward ein französischer Akademiker, Namens Kicher, nach Cayenne gesandt, wo er zwei Jahre verweilte und allerhand naturwissenschaftliche Beobachtungen anstellte, deren Verarbeitung später das Material zu einem stattlichen Reiseberichte [71] lieferte; über die uns hier interessirenden Stellen dieses Buches verbreitet sich auch Newton [72] einlässlich. Richer fand bald nach der Ankunft, dass seine in Paris vollkommen richtig

vorgezeichnet. Eine Menge anderer Mathematiker ist ihm auf diesem Wege gefolgt, doch scheint uns keine einwurfsfreiere Methode bisher zu diesem Behufe in Vorschlag gebracht worden zu sein, als die unlängst von B e s s o [69] angegebene, obschon es allerdings manche rascher zum Ziele führende giebt. 
gehende Uhr nicht mehr genau Sekunden schlug, und es bedurfte einer nambaften Verkürzung der Pendelstange, um die frühere Verwendung des Zeitmessers wieder zu ermöglichen. Der Grund dieser Erscheinung liegt für uns nicht ferne, die wir wissen, dass ein nahe dem Aequator der - immerhin centrobarischen - Erde befindlicher Punkt dem Newton'schen Gesetze nach weniger kräftig angezogen wird, als ein in höherer Breite $\varphi$ gelegener. Da $\left.g_{\varphi}\right\rangle g_{0}$, so folgt aus den Gleichungen

$$
\mathrm{L}_{0}=\frac{\mathrm{g}_{0}}{\pi^{2}}, \quad \mathrm{~L}_{\varphi}=\frac{\mathrm{g}_{\varphi}}{\pi^{2}}
$$

sofort auch $\mathrm{L}_{\varphi}>\mathrm{L}_{0}$, d. h. Richer musste die mitgebrachte Pendellänge verkleinern, um sein Pendel, das dieser Eigenschaft verlustig gegangen war, wieder in ein Sekundenpendel umzuwandeln. Der französische Naturforscher ahnte auch den Sachverhalt ganz richtig, allein seine Pariser Freunde waren weit davon entfernt, den Kausalzusammenhang zu begreifen und stellten allerlei andere Erklärungen auf, welche von Newton [73] mit kühler Besonnenheit zurückgewiesen wurden, von denen aber die sonderbarste jene war, welche die grössere Wärme des Tropenlandes für die Ausdehnung der Pendelstange verantwortlich machen wollte. Nach R. Wolf hat Bertrand berechnet [74], dass, wenn es mit dieser Frklärung der Pariser Akademie seine Richtigkeit gehabt hätte, der Temperaturunterschied zwischen Frankreich und Guiana $200^{\circ}$ betragen haben müsste! Richer's Beobachtung hatte gleichwohl das Verdienst, die Gradmessungsarbeiten in Fluss zu bringen, von welchen im vorigen Kapitel die Rede war, und bei diesen sollte von nun an auch das Pendel eine Rolle von mehr und mehr steigender Wichtigkeit übernehmen.

Der Erste, welcher den Pendelmessungen eine erhöhte Theilnahme zuwandte, war Bouguer, der insbesondere den Rath gab, ein für allemal unveränderliches Pendel herzustellen und aus den an diesen beobachteten Schwingungszeiten die Länge des Sekundenpendels rechnerisch herzuleiten [75]. Zu hoher Genauigkeit erhob Borda [76] diese Gattung physikalischer Versuche; er hing eine Platinkugel an einem dünnen Metallfaden von beträchtlicher Länge auf, hing letzteren an einer Messerschneide über horizontalen Achatplatten auf und zählte die Schwingungen vermittelst der Koincidenzen - ein Verfahren, dessen Vorzüge Bessel voll und ganz anerkannte. Es wird hier das Versuchspendel neben die Uhr gestellt, und man notirt die Momente, in welchen die Spitze der Pendellinse mit jener des Uhrpendels genau gleichzeitig durch die Ruhelage geht. $\mathrm{Zu}$ den bedeutendsten und verdienstlichsten Versuchsreihen aus dem vorigen Jahrhundert zählt jene, zu deren Anstellung Malaspina sich nach Amerika begeben und deren Berechnung Oltmanns übernommen hatte [77].

$\mathrm{Zu}$ Anfang des laufenden Jahrhunderts erfuhr der instrumentelle Theil der bezüglichen Versuche eine höchst schätzbare Bereicherung. Huygens hatte in seinem berühmten Werke von der Pendeluhr gewisse Sätze bewiesen [78], aus welchen Bohnenberger ohne Mühe die Principien eines neuen unveränderlichen Pendels abzuleiten vermochte [79], dessen Länge beim Gebrauche an den verschiedensten Orten der Erde ein und dieselbe bleibt, während die absolute Länge des Sekundenpendels für den betreffenden Ort aus der genau beobachteten Zahl der Schwingungen beobachtet werden kann. Unter dem 
Namen Reversionspendel gab der Engländer Kater sieben Jahre später die nämliche Vorrichtung an [80], und dieselbe feierte ihre Triumphe in den Händen des damaligen Kapitains, nachmaligen Generals Sabine, der zum Zwecke exakter Pendelmessungen einen sehr grossen Theil der Erde bereiste und seine Beobachtungen in einem höchst schätzbaren Werke [81] niederlegte. Nahe gleichzeitig wurde die klassische Arbeit Bessel's über diesen Gegenstand publicirt [82], durch welche zumal auch die Frage zum endgültigen Abschlusse gebracht ward, ob etwa die Anziehung der Erde für Körper verschiedenen Stoffes eine verschiedene sei. Der Königsberger Astronom verfertigte nämlich seine Pendellinse aus dem heterogensten Materiale, so z. B. auch aus Meteoreisen, schloss in den hohlen Linsenkörper alle möglichen Flüssigkeiten ein und erhielt doch in allen Fällen ganz die gleichen Längen für das Sekundenpendel. Nur beim Wasserpendel schien sich eine Ungleichheit fühlbar zu machen, je nachdem mit längeren oder kürzeren Pendeln operirt worden war; Lïbeck hat aber nachgewiesen [83], dass bei kurzen Pendeln die relative Bewegung der Flüssigkeit zum umschliessenden Cylinder von erkennbarem Einflusse ist, indem eine Oscillation um eine zur Ebene der Pendelbewegung normale Axe eintritt. Wird diese in Rechnung gezogen, so kann man an den Bessel'schen Zahlen die erforderlichen Verbesserungen anbringen, ohne selbst auf die innere Flüssigkeitsreibung Bedacht zu nehmen. Ueberhaupt gehören diese Experimente zu den feinsten, die es giebt, und eine Fülle von Fehlerquellen gilt es durch Rechnung aus der Welt zu schaffen. So musste Bessel Mittel und Wege angeben, den Widerstand der Luft zu eliminiren [84], und ein noch glänzenderes Zeugniss seines Scharfsinnes bildet seine Analyse des Fehlers [85], der dadurch entsteht, dass die stets angewandte Messerschneide nicht wirklich eine Schneide im geometrischen Sinne, sondern eine kegelschnittförmig gekrümmte Fläche darstellt.

Je mehr Zahlenwerthe für die Länge des Sekundenpendels, unter verschiedenen Breiten gemessen, den Rechnern in Vorlage kamen, um so unmöglicher erschien es, aus denselben einen einheitlichen Werth der Erdabplattung herzuleiten. J. Biot gelangte auf diese Weise zu dem Schlusse [86], dass die Grösse $\alpha$ zwischen $0^{0}$ und $45^{\circ} \mathrm{im}$ Mittel $\frac{1}{276,38}$, zwischen $45^{\circ}$ und $90^{\circ} \mathrm{im}$ Mittel $\frac{1}{306,33}$ betrage, woraus als

Gesammtwerth für das Intervall von $0^{\circ}$ bis $90^{\circ}$ allerdings ein von $\frac{1}{289}$ nur sehr wenig abweichender Werth folgen würde. Die Pendellänge hat nach Biot in Millimetern den Durchschnittswerth (991,027015 $\left.+5,161948 \sin ^{2} \varphi\right)$. Pouillet fand für die nämliche Fundamentalgrösse den Werth $\left(991,0256+5,0719 \sin ^{2} \varphi\right)$ und Listing endlich [87] gab die Relation $g_{\varphi}=\left(9,780728+0,050875 \sin ^{2} \varphi\right) \mathrm{m}$ an, woraus sich nach unseren obigen Formeln unschwer der zugehörige Werth von $\mathrm{L}_{\varphi}$ berechnet. Albrecht [88] giebt folgende die besten Bestimmungen zusammenfassende Tabelle*):

*) Von den massenhaften Einzelbeobachtungen, die man reisenden Physikern und Seefahrern verdankt, kann natürlich hier blos anhangsweise die Rede sein; es genüge, ausser den schon genannten Männern noch die Namen Couplet, 


\begin{tabular}{|c|c|c|}
\hline Autor & Länge des Sekundenpendels in Metern & $\begin{array}{l}\text { Anzahl der Pendel- } \\
\text { messungen. }\end{array}$ \\
\hline 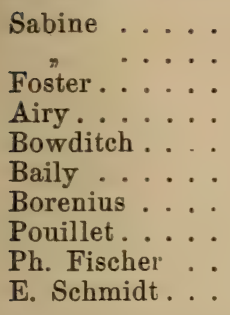 & $\begin{array}{l}0,9909893+0,0051341 \sin ^{2} \varphi \\
0,9912771+0,0051422 \sin ^{2} \varphi \\
0,9910057+0,0051495 \sin ^{2} \varphi \\
0,9910170+0,0050868 \sin ^{2} \varphi \\
0,9910002+0,0051330 \sin ^{2} \varphi \\
0,9910217+0,0050987 \sin ^{2} \varphi \\
0,9910250+0,0051160 \sin ^{2} \varphi \\
0,9910256+0,0050719 \sin ^{2} \varphi \\
0,9910108+0,0051049 \sin ^{2} \varphi \\
0,9909780+0,0051536 \sin ^{2} \varphi\end{array}$ & $\begin{array}{l}13 \\
25 \\
15 \\
49 \\
52 \\
79 \\
47 \\
44 \\
73 \\
47\end{array}$ \\
\hline
\end{tabular}

Mittelwerth unter Berücksichtigung der zuzuertheilenden Gewichte in $\mathrm{m}$ : $0,99102+0,00510 \sin ^{2} \varphi$.

Schwerkraft im Meeresniveau für die Polhöhe $\varphi$ in $\mathrm{m}$ : $\mathrm{g}_{\varphi}=9,7810+0,0503 \sin ^{2} \varphi$.

In neuester Zeit haben wir von hervorragenden Arbeiten auf unserem Gebiete in erster Linie die umfassenden Untersuchungen E. Plantamour's mit dem Reversionspendel zu nennen [91], welche mit Benützung des Repsold'schen Kathetometers angestellt wurden. Die Beobachtungen auf dem Rigi ermöglichten es u. a. auch, die Attraktion dieses Berges in einem Werthe von $\frac{1}{12300}$ (mit einem wahrscheinlichen Fehler $= \pm \frac{1}{300000}$ ) zu bestimmen. Eine andere Untersuchung lieferte bemerkenswerthe Beiträge für die Táxirung der Verlässlichkeit älterer Messungen. Ziemlich um dieselbe Zeit nämlich, wo Bessel seine Versuche über die Pendellänge zu Königsberg und Berlin anstellte, suchten Schumacher und C. A. F. Peters den analogen Werth für Schloss Guldenstein in Holstein mit möglichster Genauigkeit festzustellen, und diese damaligen Forschungen sind neuerdings von C. F. W. Peters [92] und Helmert [93] einer erneuten kritischen Bearbeitung unterzogen worden, die mancherlei interessante Resultate lieferte, namentlich betreffs des retardirenden Einflusses, welchen der Magnetismus der am Apparate befindlichen Eisenmassen auf die Schwingungen ausüben kann. Ein neuer Vorschlag Finger's [94], das Reversionspendel durch das sogenannte Kommutationspendel zu ersetzen, hat jedenfalls unter dem theoretischen Gesichtspunkte Manches für sich, wenn schon zur Erhebung von Erfahrungsthatsachen für oder wider bislang noch die Zeit gemangelt hat. Sei die Dreh-

Godin, Ulloa, Warin, Des Hayes, v. Zach, Rumowski, Freycinet, Duperrey, B. Hall, v. Lütke, v. Krusenstern, Mathieu, Arago und Foster zu nennen. Eine sehr detaillirte Reihe indischer Pendelproben verdankt man neuerdings J. Herschel dem jüngeren [89]. Eine für Entdeckungsreisende beachtenswerthe Schilderung der Manipulationen, welche der Pendelapparat besonders in solchen Gegenden erheischt, wo der Beobachter einzig und allein auf sich angewiesen ist, kann man in Bes sels' Beschreibung der Polaris-Expedition nachlesen [90]. 
axe A, die Masse des schwingenden Pendels M. Eine grössere Masse $\mathrm{m}_{1}$ und eine kleinere Masse $\mathrm{m}_{2}\left(\mathrm{~m}_{1}-\mathrm{m}_{2}=\mathrm{m}\right)$ sollen mit dem Pendel so in Verbindung gebracht werden, dass die Schwerpunkte von $M_{1}, m_{1}$ und $\mathrm{m}_{2}$ in einer durch A gehenden Ebene liegen, „und dass der Schwerpunktsabstand von dieser Drehaxe während des ersten Schwingungsversuches $x_{1}$ für die Masse $m_{1}$ und $x_{2}$ für $m_{2}$, dagegen während einer zweiten Schwingungsreihe bei $\mathrm{m}_{1} \ldots \mathrm{x}_{2}$, bei $\mathrm{m}_{2} \ldots \mathrm{x}_{1}$ wird, demnach die Massen $\mathrm{m}_{1}$ und $\mathrm{m}_{2}$ im zweiten Falle nur vertauscht sind. " Es existirt nun der eben von Finger gefundene merkwürdige Satz [95], dass diese Vertauschbarkeit unbeschadet der Schwingungsdauer und der (reducirten) Pendellänge $\mathrm{l}$ nur für $\mathrm{l}=\mathrm{x}_{1}+\mathrm{x}_{2}$ möglich ist. Der Autor hält dafür, dass Gravitationsmessungen mit seinem Kommutationspendel die Vortheile der Kater'schen und der Bessel'schen Methode in sich vereinigen würden [96].

Es war bisher (s. o.) vorausgesetzt, dảss alle diese Pendelversuche am Meeresniveau angestellt seien, wo also die Verschiedenheit der Fallkonstante einzig der wechselnden Schwungkraft und den Variationen der Erdgestalt zur Last zu legen waren. Bei vielen Beobachtungen, besonders von Sabine und Malaspina, gilt diess ja auch, allein im Allgemeinen werden doch solche Beobachtungen an Orten gemacht werden müssen, welche in einiger Entfernung - sei diese eine positiv oder negativ zu nehmende - vom Meeresspiegel gelegen sind. Im ersteren Falle hat $g$ einen zu kleinen, im zweiten einen zu grossen Werth, und wir müssen deshalb auf Mittel denken, um die auf Bergen oder in Schachten ermittelten Zahlen auf den Spiegel des Meeres zu reduciren. Bezeichnen wir [97] die Beschleunigung der Schwere an jenem mit $\mathrm{g}$, in der Höhe $\mathrm{h}$ mit $\mathrm{g}_{1}$ und, wie gewöhnlich, den Erdradius mit $\mathrm{r}$, so ist nach $\mathrm{New}$ to n's Gesetze

$$
\mathrm{g}_{1}: \mathrm{g}=\mathrm{r}^{2}:(\mathrm{r}+\mathrm{h})^{2}, \quad \mathrm{~g}_{1}=\mathrm{g} \cdot \frac{\mathrm{r}^{2}}{(\mathrm{r}+\mathrm{h})^{2}}=\mathrm{g}\left(1-\frac{2 \mathrm{hr}+\mathrm{h}^{2}}{\mathrm{r}^{2}+2 \mathrm{hr}+\mathrm{h}^{2}}\right) .
$$

Im Nenner kann, da $h$ nur einen sehr kleinen Bruchtheil von $r$ vorstellt, die Summe h $(2 r+h)$ ebenso gegen $r^{2}$, wie im Zähler $h^{2}$ gegen $2 \mathrm{hr}$ vernachlässigt werden, und man bekommt so die für gewöhnliche Verhältnisse völlig brauchbare Näherungsformel $g_{1}=g\left(1-\frac{2 h}{r}\right)$, woraus, da $\mathrm{L}: \mathrm{L}_{1}=\mathrm{g}: \mathrm{g}_{1}$, sofort auch $\mathrm{L}=\mathrm{L}_{1}:\left(1-\frac{2 \mathrm{~h}}{\mathrm{r}}\right)$ hervorgeht. Schweremessungen im Inneren der Erde stehen uns zur Zeit nur erst in sehr beschränktem Maasse zu Gebote, und es ist deshalb eine Mittheilung v. Sterneck's [98] über eine umfängliche Versuchsreihe dieser Art um so dankenswerther. Die nachfolgende Tabelle v. Sterneck's bietet manches Bemerkenswerthe.

\begin{tabular}{c|c|c|c|c}
\hline Seehöhe in $\mathrm{m}$ & $\begin{array}{c}\text { Tiefe unter der } \\
\text { Oberfläche in } \mathrm{m}\end{array}$ & Schwingungszeit & $\begin{array}{c}\text { Anz. d. Schwing. an } \\
\text { einem Tage }\end{array}$ & Voreilen d. Uhr \\
\hline \hline & & & & \\
\hline & 0,0 & 0,5008550 & 172505,0 & 0,0 \\
$-463,4$ & 516,0 & 0,5008410 & 172509,8 & 2,4 \\
& 972,5 & 0,5008415 & 172509,6 & 2,3
\end{tabular}


Es ist hervorzuheben, dass die Pendelschwere im Inneren der Erde nur so höchst wenig variirt; es stimmt diess mit einer älteren Wahr-

Fig. 28.

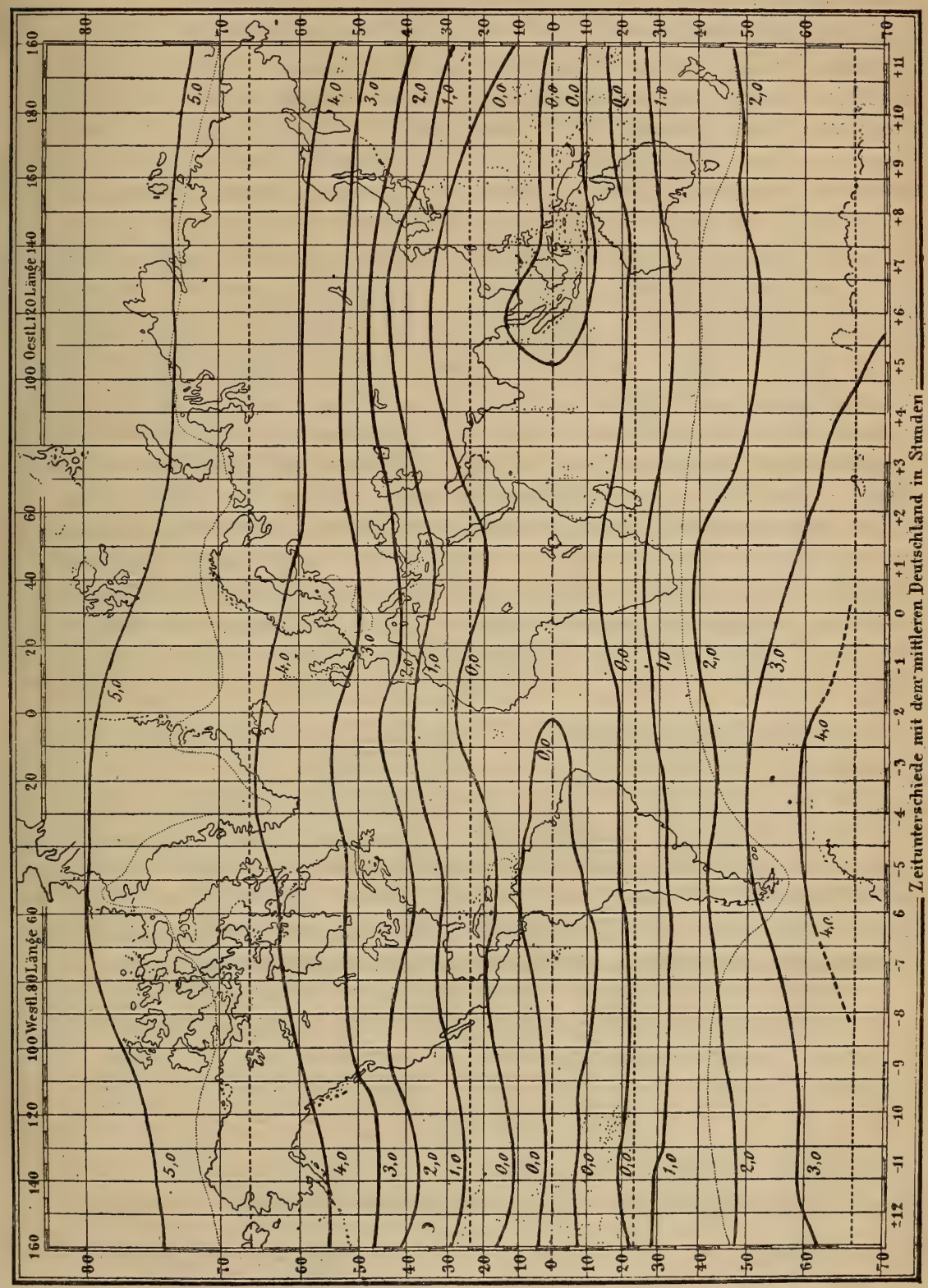

nehmung Airy's, der in einer Tiefe von $383 \mathrm{~m}$ das Voreilen der Uhr auf $2,25^{\prime \prime}$, also fast ebenso gross, bestimmte. Es ist hiebei zu beachten, dass, einem $\mathrm{Newton'schen} \mathrm{Theoreme} \mathrm{[99]} \mathrm{zufolge,} \mathrm{die} \mathrm{An-}$ $\mathrm{G}$ ủnther, Geophysik. I. Band. 
ziehung einer Kugelschale auf einen im Inneren befindlichen Punkt den Werth Null hat.

Eine auch nur einigermassen auf Vollständigkeit Anspruch machende Uebersicht über die Vertheilung der Pendelschwere an der Erdoberfläche würde sich an dieser Stelle schon aus dem Grunde nicht empfehlen, weil grössere tabellarische Zusammenstellungen sich nur für ein Handbuch eignen. Wer sich hiefür interessirt, findet überreichen Stoff in einer Inauguraldissertation van Galen's [100] und auch in dem von Muncke trefflich bearbeiteten Artikel "Pendel“ des neuen Gehler'schen Wörterbuches [101]. A. Steinhauser's in Gemeinschaft mit dem bekannten Feldzeugmeister v. Hauslab ausgearbeitete Uebersichtskarte, welche auf der Pariser Weltausstellung zu sehen war, eine Vervielfältigung jedoch noch nicht erfahren hatte, stellt uns in Fig. 28 den ungefähren Verlauf der Linien gleicher Pendelschwere*) vor Augen; seitdem ist allerdings viel neues Beobachtungsmaterial neu hinzugekommen, wodurch jedoch der Gesammteindruck, welchen unser Bild gewährt, nicht wesentlich beeinträchtigt werden dürfte. Man überzeugt sich, dass im Allgemeinen diese Kurven von den Breitekreisen nicht allzusehr abweichen - abgesehen von der merkwürdigen geschlossenen Nullkurve, welche der Aequator als Durchmesser durchzieht. Die Zahlen sind Millimeter und drücken die Differenzen der unter verschiedenen Polhöhen gemessenen Längen des Sekundenpendels gegenüber der für den Aequator geltenden Länge aus. Freilich ist dieselbe nicht für den ganzen Verlauf dieses Hauptkreises konstant, vielmehr beträgt die Abweichung von der zu Grunde gelegten Zahl da, wo der Gleicher die afrikanische Westküste trifft, $+0,440$ und an den ebenfalls unter der Linie gelegenen Galapagos-Inseln - 0,049 mm.

§. 8. Die Clairaut'sche und die Unferdinger'sche Pendelformel. Fassen wir all das, was bisher über das Pendel gesagt wurde, zusammen, so können wir aussprechen, dass zur Zeit bei aller Anerkennung der in $\S .2$ dieses Kapitels skizzirten Messungsmethoden kein besseres Hülfsmittel zur Erkennung und zahlenmässigen Abschätzung der Variationen der Erdschwere existirt, als eben das Pendel. Noch aber haben wir nicht gezeigt, wie die Pendelmessungen auch unmittelbar dazu dienen können, die Abplattung des Erdsphäroides zu berechnen.

Schon um die Mitte des vorigen Jahrhunderts hatte Clairaut einen Lehrsatz gefunden, der eine solche Berechnung ermöglicht [102]. Wir leiten denselben nachstehend im Anschluss an Thomson-Tait's originelle Beweismethode her [103]. Eine Flüssigkeit rotirt um eine Axe, und es entsteht ein Umdrehungsellipsoid, dessen Schichten sich so lagern, dass in ähnlichen und ähnlich liegenden Ellipsoiden gleiche Dichtigkeit herrscht. Wir nehmen die Umdrehungsaxe als Z-Axe eines Orthogonalsystemes, bezeichnen die Winkelgeschwindigkeit mit $\omega$ und erhalten so das Potential der Schwungkraft $=\frac{1}{2} \omega^{2}\left(x^{2}+y^{2}\right)$.

*) Wir ziehen es vor, diese an sich verständliche Bèzeichnung zu wählen und nicht die an solchen Ausdrücken schon reiche Geophysik durch eine vielleicht hybride neue Wortform von zweifelhafter Etymologie zu bereichern. 
Da $r^{2}=x^{2}+y^{2}+z^{2}$, können wir jenes Potential $P$ auch $=\frac{1}{3} \omega^{2} r^{2}$ $+\frac{1}{6} \omega^{2}\left(x^{2}+y^{2}-2 z^{2}\right)$ setzen. a sei der Halbmesser einer Kugel, welche sich mit der rotirenden Masse $M$ annähernd vertauschen lässt, ferner seien die Polarkoordinaten $r, \varphi$, bezeichnet*), mit den rechtwinkligen $x, y, z$ durch die Gleichungen $\mathrm{x}=\mathrm{r} \cos \vartheta \cos \varphi, \mathrm{y}=\mathrm{r} \sin \vartheta \cos \varphi, \mathrm{z}=\mathrm{r} \sin \varphi$

verbunden. Setzt man also in dem obigen Ausdrucke für's Potential $\mathrm{r}=\mathrm{a}, \mathrm{z}=\mathrm{a} \sin \varphi$, so wird

$$
\mathrm{P}=\frac{1}{3} \omega^{2} \mathrm{a}^{2}+\frac{1}{2} \omega^{2} \mathrm{a}^{2}\left(\frac{1}{3}-\sin ^{2} \varphi\right) .
$$

Das Schwungkrafts- und das Gravitationspotential ergeben für jeden Punkt $(r, \varphi, \vartheta)$ der rotirenden Oberfläche eine konstante Summe; das letztere Potential, welches $\mathrm{P}_{1}$ heissen möge, ist sonach, unter $\mathrm{F}$ eine nicht näher bestimmte Funktion verstanden,

$$
\mathrm{P}_{\mathrm{I}}=\frac{\mathrm{M}}{\mathrm{a}}[1+\mathrm{F}(\varphi ; \vartheta)]-\frac{1}{2} \omega^{2} \mathrm{a}^{2}\left(\frac{1}{3}-\sin ^{2} \varphi\right) .
$$

Entwickelt man rechts nach steigenden Potenzen von $\frac{\mathrm{a}}{\mathrm{r}}$ und lässt das Funktionszeichen $\mathrm{F}$ in ähnlicher Weise weiter gelten, wie bisher, so ergiebt sich

$$
\begin{gathered}
\mathrm{P}_{1}=\frac{\mathrm{M}}{\mathrm{a}}\left[\frac{\mathrm{a}}{\mathrm{r}}+\frac{\mathrm{a}^{3}}{\mathrm{r}^{3}}\left(\mathrm{~F}_{1}(\varphi, \vartheta)-\frac{1}{2} \mathrm{~m}\left(\frac{1}{3}-\sin ^{2} \varphi\right)\right)+\frac{\mathrm{a}^{4}}{\mathrm{r}^{4}} \mathrm{~F}_{2}(\varphi, \vartheta)\right. \\
\left.+\frac{\mathrm{a}^{5}}{\mathrm{r}^{5}} \mathrm{~F}_{3}(\varphi, \vartheta)+\ldots\right],
\end{gathered}
$$

wo $\mathrm{m}$ für $\omega^{2} \mathrm{a}: \frac{\mathrm{M}}{\mathrm{a}^{2}}$ gesetzt ward; $\mathrm{m}$ bedeutet das Verhältniss der äquatorialen Centrifugalkraft zur Schwerkraft im Abstande a. Will man die Grösse $\gamma$ der reinen (d. h. nicht von der Centrifugalkraft entstellten) Schwere haben, so findet sich aus Obigem

$\gamma=\frac{\mathrm{M}}{\mathrm{a}^{2}}\left(1+\mathrm{F}_{1}(\varphi, \vartheta)-\frac{3}{2} \mathrm{~m}\left(\frac{1}{3}-\sin ^{2} \varphi\right)+2 \mathrm{~F}_{2}(\varphi, \vartheta)+3 \mathrm{~F}_{3}(\varphi, \vartheta)+\ldots\right)$.

Die Beschleunigung g der sichtbaren Schwere endlich resultirt hieraus durch Subtraktion der radialen Schwerkraftskomponente, deren Ausdruck

$$
\begin{aligned}
& \left(\frac{2}{3} \omega^{2} \mathrm{a}+\omega^{2} \mathrm{a}\left(\frac{1}{3}-\sin ^{2} \varphi\right)\right) \text { ist; so folgt } \\
& \mathrm{g}=\frac{\mathrm{M}}{\mathrm{a}^{2}}\left(1-\frac{2}{3} \mathrm{~m}+\mathrm{F}_{1}(\varphi, \vartheta)-\frac{5}{2} \mathrm{~m}\left(\frac{1}{3}-\sin ^{2} \varphi\right)+2 \mathrm{~F}_{2}(\varphi, \vartheta)\right. \\
& \left.\quad+3 \mathrm{~F}_{3}(\varphi, \vartheta)+\ldots\right) .
\end{aligned}
$$

Noch ist über die Funktionen $\mathrm{F}$ nicht verfügt worden; wir können jetzt

$$
\mathrm{F}_{1}(\varphi, \vartheta)=\alpha\left(\frac{1}{3}-\sin ^{2} \varphi\right), \quad \mathrm{F}_{\mathrm{k}}(\varphi, \vartheta)=0 \ldots(\mathrm{k} \geqq 2)
$$

*) Um mit früher gebrauchten Bezeichnungen möglichst im Einklang zu bleiben, konnte die Bezeichnungsweise der britischen Physiker nur zum Theile beibehalten werden. Auch die Darstellung musste im Interesse der Gemeinver- ständlichkeit einigermassen paraphrasirt werden. 
setzen und erhalten

$$
\mathrm{g}=\frac{\mathrm{M}}{\mathrm{a}^{2}}\left(1-\frac{2}{3} \mathrm{~m}-\left(\frac{5}{2} \mathrm{~m}-\alpha\right)\left(\frac{1}{3}-\sin ^{2} \varphi\right)\right)
$$

Je nachdem $\varphi=0^{\circ}$ oder $=90^{\circ}$ gesetzt wird, ist also

$\mathrm{g}_{0}=\frac{\mathrm{M}}{\mathrm{a}^{2}}\left(1-\frac{2}{3} \mathrm{~m}-\frac{1}{3}\left(\frac{5}{2} \mathrm{~m}-\alpha\right)\right) ; \mathrm{g}_{90}=\frac{\mathrm{M}}{\mathrm{a}^{2}}\left(1-\frac{2}{3} \mathrm{~m}+\frac{2}{3}\left(\frac{5}{2} \mathrm{~m}-\alpha\right)\right)$.

Zieht man die zweite Gleichung von der ersten ab, so restirt

$$
\mathrm{g}_{0}-\mathrm{g}_{90}=-\frac{\mathrm{M}}{\mathrm{a}^{2}}\left(\frac{5}{2} \mathrm{~m}-\alpha\right) \text {. }
$$

Setzt man aber für $m$ den uns bekannten Werth ein, so wird, da $\frac{M}{a^{2}}=g_{0}$ ist,

$$
\mathrm{g}_{90}-\mathrm{g}_{0}+\alpha \mathrm{g}_{0}=\frac{5}{2} \cdot \omega^{2} \mathrm{a}, \quad \alpha=1+\frac{\frac{5}{2} \cdot \omega^{2} \mathrm{a}-\mathrm{g}_{90}}{\mathrm{~g}_{0}} \text {. }
$$

Mit v. Lang [104] $\mathrm{g}_{90}-\mathrm{g}_{0}=0,05091, \omega^{2} \mathrm{a}=0,03367$ setzend, bekommen wir $\alpha=\frac{1}{294}$, was mit dem uns bekannten Abplattungswerthe $\frac{1}{289}$ so ziemlich stimmt.

Nach Clairaut sollte dieses Theorem zwar zunächst nur für einen tropfbar flüssigen, dann aber auch für jeden festen Körper gelten, dessen innere Massenanordnung derjenigen einer Flüssigkeit analog wäre. Stokes bewies aber [105], dass die Gültigkeit eine noch allgemeinere ist und alle diejenigen festen Körper umfasst, für deren Inneres die Ortsflächen gleichen Potentiales harmonische Sphäroidalflächen (s. o. §. 3) sind, mögen im Uebrigen die geometrischen Oerter gleicher Dichte beschaffen sein, wie sie wollen. Philipp Fischer bemerkt [106], dass die allermeisten Bearbeiter des Problemes der Erdgestalt sich mit der obigen Clairaut'schen Formel begnügt und kein Bedürfniss verspürt hätten, den oben bei Seite gelassenen Grössen F andere Werthe als Null zu substituiren; nur der einzige Paucker [107] sei darüber hinausgegangen. In einem als entsprechende Verallgemeinerung der Clairaut'schen Relation anzusehenden Ausdrucke müssten auch die Dichtigkeitsverhältnisse im Erdinneren einen Platz finden.

Gerade, während Fischer so schrieb, erschien eine umfangreiche Abhandlung von Unferdinger [108], welche eben diese verwickeltere Aufgabe in Angriff zu nehmen bestimmt war. Wir verstehen unter $g_{0}$ und $g_{\varphi}$, was wir immer darunter verstanden, jedoch mit der ausdrücklichen Bestimmung, dass die Erde zunächst als nicht rotirend zu gelten habe, und deuten durch $\mathrm{r}_{\varphi}$ den der Breite $\varphi$ entsprechenden Radius Vektor des Erdsphäroides an. Nach Unferdinger ist dann zu setzen

$$
g_{\varphi}=g_{0}\left(\frac{r_{0}}{r_{\varphi}}\right)^{2}\left(1+A_{1} \sin ^{2} \varphi+A_{2} \sin ^{4} \varphi+\ldots\right) .
$$

Der sonst nicht übliche quadratische Faktor ward beigefügt, um den Satz mitprüfen zu können, dass die Intensitäten der Schwere an der Oberfläche den Quadraten der Fahrstrahlen umgekehrt proportional seien; aus einer mit der Zeit eintretenden Veränderlichkeit der Koefficienten A sollte auf Veränderungen im Gefüge der Erde geschlossen 
werden können. Setzt man $\mathrm{e}=$ der Excentricität, so wird die Länge $\mathrm{L}_{\varphi}$ des Sekundenpendels gleich

$$
\frac{g_{0}}{\pi^{2}}\left(1+A_{1} \sin ^{2} \varphi+A_{2} \sin ^{4} \varphi+\ldots\right) \cdot \frac{1+\left(1-e^{2}\right) \operatorname{tang}^{2} \varphi}{1+\left(1-e^{2}\right)^{2} \operatorname{tang}^{2} \varphi} .
$$

$g_{0}+f_{0} \sin ^{2} \varphi=g_{\varphi}$ ist, wie wir wissen, die wirkliche Schwerkraft in der Breite $\varphi$; verstehen wir wieder unter $f_{0}$ die Centrifugalbeschleunigung am Aequator, unter $\vee$ den Bruch $f_{0}: g_{0}$, so wird

$$
\begin{gathered}
\mathrm{L} \varphi=\mathrm{L}_{0}\left(1+\mathrm{A}_{1} \sin ^{2} \varphi+\mathrm{A}_{2} \sin ^{4} \varphi+\therefore\right)\left(1+\frac{\nu}{1-\nu} \sin ^{2} \varphi\right) \\
\times \frac{\cos ^{2} \varphi+\left(1-\mathrm{e}^{2}\right) \sin ^{2} \varphi}{\cos ^{2} \varphi+\left(1-\mathrm{e}^{2}\right)^{2} \sin ^{2} \varphi}
\end{gathered}
$$

Diese allgemeinste Formel besteht also, von $\mathrm{L}_{0}$ abgesehen, aus drei Faktoren, welche sich resp. auf die Dichteverhältnisse im Erdinneren, auf die Fliehkraft und auf die wirkliche Abplattung beziehen. Mit Rücksicht auf die Bessel'schen Werthe liefert die Methode der kleinsten Quadrate zur Bestimmung von $\mathrm{L}_{\varphi}$ (in Par. Linien) folgende Gleichung [109]:

$$
\begin{array}{r}
\log L_{\varphi}=2,6427568+\log 7,35147 \sin ^{2} \varphi+\log 5,3198 \sin ^{4} \varphi \\
+\log 3,457 \sin ^{6} \varphi
\end{array}
$$

Die Vergleichung der hienach ausgearbeiteten Tabelle liess darüber keinen Zweifel, dass die Grössen A keine Konstanten, sondern erst noch näher zu bestimmende Funktionen der geographischen Breite, resp. von anderen uns noch unbekannten Instanzen abhängig sind.

Gewissen auffallenden Anomalieen in der Pendelschwere vermag auch die Unferdinger'sche Formel kein Genüge zu thun, vielmehr spricht deren Urheber ganz mit Recht sich dahin aus, dass diese Anomalieen auch bei der exaktesten Berechnungsformel wieder auftreten müssen, solange letztere auf der Annahme einer rein ellipsoidischen Erde beruht. Hieraus scheint aber mit Sicherheit zu folgen, dass diese Annahme eben keine ganz zutreffende sei. Das nächste Kapitel wird den mit diesem Zweifel angedeuteten Sachverhalt näher in's Auge fassen; für den Augenblick aber müssen wir diesen Gegenstand verlassen und uns mit der Bedeutung der Attraktionserscheinungen für das Problem, das spezifische Gewicht des Erdkörpers zu finden, beschäftigen.

§. 9. Aeltere Methoden der Dichtigkeitsbestimmung für die Erde. Jedes Verfahren, durch welches wir in $\S .2,3$ und 5 Anziehungsgrösse und Anziehungsrichtung irgend eines terrestrischen Körpers für einen ausserhalb gelegenen Punkt feststellten, kann zugleich zur Bestimmung der Masse $\mathbf{m}$ der Erde benützt werden. Ist diese bekannt, so folgt deren Dichte oder spezifisches Gewicht $d$ aus der Relation (r Erdradius):

$$
\text { Dichte } \times \text { Volumen }=\text { Masse } ; \mathrm{d} \cdot \frac{4}{3} \mathrm{r}^{3} \pi=\mathrm{m} .
$$

Selbstverständlich aber sind nicht alle diese Methoden gleich gut zu ihrem Zwecke geeignet, vielmehr haben sich nach und nach die im Folgenden beschriebenen als die besten bewährt. Wir ordnen dieselben nicht chronologisch, sondern nach dem Grade ihrer Brauchbarkeit.

I. Die Methode der Berganziehung. Nachdem Maskelyne und Hutton (s. o. §. 3) die Anziehung des Shehallien auf das Bleiloth 
festgestellt hatten, giengen sie sofort auch dazu über, aus dem Betrage dieser Ablenkung einen Schluss auf die Grösse m zu ziehen. M (Fig. 29) sei der Mittelpunkt der Erde, B ein isolirter Berg, von dem man sowohl die Masse $\mathrm{m}^{\prime}$, als auch die Lage des Schwerpunktes S zuvor

Fig. 29.

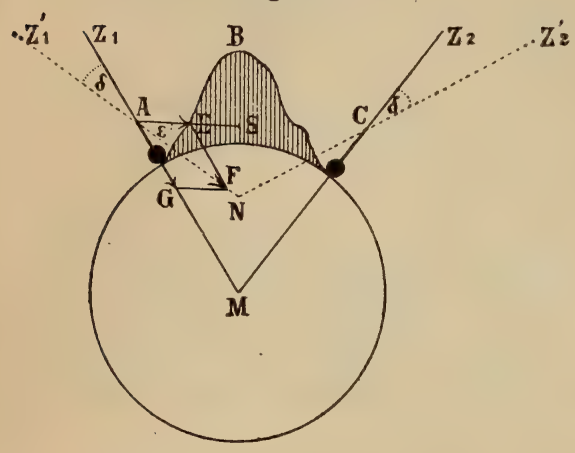
genau ermittelt hat. An zwei zu Füssen dieses Berges befindlichen Punkten $\mathrm{A}$ und $\mathrm{C}$ sind Lothe aufgehängt, deren Richtungen $\mathrm{Z}_{1} \mathrm{~A}$ und $\mathrm{Z}_{2} \mathrm{C}$ sich, wenn die Erhebung nicht vorhanden wäre, im Mittelpunkt M der Erde schneiden würden; so aber begegnen sich die Lothrichtungen $\mathrm{Z}_{1}{ }^{\prime} \mathrm{A}$ and $\mathrm{Z}_{2}{ }^{\prime} \mathrm{C}$ in einem der Erdoberfläche näher gelegenen Punkte N. Die beiden Winkel $Z_{1} A Z_{1}^{\prime}$ und $\mathrm{Z}_{2} \mathrm{CZ}_{2}^{\prime}=\delta$ sind dadurch zu erhalten, dass man von der geodätisch ermittelten Differenz der Polhöhen beider Orte die wirklich gemessene subtrahirt. Nun wirken auf die Kugel A zwei Kräfte: die Berganziehung, deren numerischer Werth durch $\mathrm{k} \cdot \frac{\mathrm{m}^{\prime}}{\overline{\mathrm{AS}}^{2}}$ auszudrücken ist, wenn wir (s. o.) mit Begehung eines allerdings nicht erheblichen Fehlers die Masse des Gebirgstockes in dessen Schwerpunkt vereinigt annehmen, und andererseits die Erdanziehung k. $\frac{\mathrm{m}}{\mathrm{r}^{2}}$, wenn k hier, wie vorhin (s. o. §. 1) die Gravitationskonstante bedeutet. AE und AG mögen in der Figur diesen beiden Anziehungskräften entsprechen, wo dann die wirkliche Lothrichtung der Lage nach mit der Diagonale AF des Kräfteparallelogramms zusammenfällt. $\Varangle \mathrm{EAF}=\varepsilon$ kann jetzt ebenfalls gemessen werden, und wir entnehmen so dem Dreieck AFE die folgenden Proportionen:

$$
\mathrm{AE}: \mathrm{EF}=\sin \delta: \sin \varepsilon ; \mathrm{k} \cdot \frac{\mathrm{m}^{\prime}}{\overline{\mathrm{AS}}^{2}}: \mathrm{k} \cdot \frac{\mathrm{m}}{\mathrm{r}^{2}}=\sin \delta: \sin \varepsilon .
$$

Hieraus berechnet sich

$$
\mathrm{m}=\frac{\mathrm{m}^{\prime} \cdot \mathrm{r}^{2} \cdot \sin \varepsilon}{\overline{\mathrm{AS}}^{2} \cdot \sin \delta}
$$

Maskelyne und Hutton fanden [110] damals für d den Werth 4,7 - eine immerhin recht respektable Annäherung an den wahren Werth (s. u.), wenn man bedenkt, wie die Grössen AS und $\varepsilon$ erst durch eine mühsame und doch nicht mit sehr grosser Genauigkeit zu bewerkstelligende Verbindung geodätischer und geognostischer Operationen zu bestimmen waren. Diese Operationen würden bei anderen Körpern leichter anzustellen sein.

So hat nach C. A. F. Peters' Berichte [111] der ältere Struve (s. o. §. 3) vorgeschlagen, zu beiden Seiten eines Kanales oder Meerbusens - z. B. desjenigen von Bristol - die Abweichungen in der Lothlinie genau astronomisch festzustellen, welche durch den höchsten und tiefsten Stand des Wassers in dieser Rinne bedingt werden. Er 
fasst diesen Wasserkörper als ein Parallelepipedum von der Breite a, Länge 2 b, Höhe c, Dichte d', nimmt die Pendelkugel als in der obersten Seitenfläche gelegen und von der nächsten Kante um $f$ abstehend an und findet so die zur Vertikalrichtung senkrechte Attraktionskomponente gleich

$$
2 d^{\prime}\left(-f a r \operatorname{tang} \frac{c}{f}+c+c \log \frac{2 a b}{\sqrt{c^{2}+f^{2}}\left(b+\sqrt{a^{2}+b^{2}}\right)}\right) .
$$

Unter der Voraussetzung, dass die mittlere Dichte der Erde 5,67, jene des Seewassers 1,2 ist, ergiebt sich hieraus für die Ablenkung am Ufer $0,23^{\prime \prime}$, als eine immerhin messbare Grösse. Natürlich aber würde keine grosse Genauigkeit zu erreichen sein, wenn man diese Winkelgrösse direkt messen und aus ihr dann die Erdmasse berechnen wollte. Peters will daher [112] den flüssigen durch einen festen Körper, z. B. die Cheops-Pyramide, ersetzen, wo sich selbst noch in einer Entfernung von 10 Toisen von der Basis eine Deviation von fast $1^{\prime \prime}$, an der Basis aber von mehr denn 1" ergeben würde. Allein viele Gründe sprechen für das Vorhandensein ausgedehnter Hohlräume im Inneren der Pyramiden, und wenn diess der Fall, so verbietet es sich, die Dishte des Bauwerkes geometrisch zu schätzen*).

II. Die Methode der Pendelmessungen. D robis ch hat [114] zuerst gezeigt, wie man durch Beobachtung und Zählung der Pendelschwingungen die Grösse d finden könne; v. Lang, dem wir hier folgen, hat die Rechnungsschemate vereinfacht [115]. Die Tiefe eines Schachtes sei $h$, die daselbst aus Pendelbeobachtungen erschlossene Fallbeschleunigung G, die Fallbeschleunigung an der Erdoberfläche g. Letztere Grösse ist eine Kombination aus der Anziehung einer Kugelschale von der Dicke $\mathrm{h}$ und einer Kugel vom Radius $\rho=\mathrm{r}-\mathrm{h}$; die Dichte dieser letzteren Kugel darf unbedenklich mit d identificirt werden. Dann ist die Anziehungsgrösse

$g=k \cdot \frac{4}{3} \pi \cdot \frac{\left[(p+h)^{3}-p^{3}\right] \cdot d_{1}+p^{3} \cdot d}{(\rho+h)^{2}}=k \cdot \frac{4}{3} \pi\left[(p+h) \cdot d_{1}+\rho \cdot \frac{d-d_{1}}{(1+h: p)^{2}}\right]$, wenn man mit $d_{1}$ die Dichte der äusseren Erdschale bezeichnet. h : $\rho$ ist ein kleiner Bruch, von welchem nur die erste Potenz berücksichtigt zu werden braucht; thut man diess aber, so wird

$\mathrm{g}=\mathrm{k} \cdot \frac{4}{3} \pi \cdot\left[(\rho+\mathrm{h}) \cdot \mathrm{d}_{1}+\left(\mathrm{d}_{1}-\mathrm{d}\right)(\rho-2 \mathrm{~h})\right]=\mathrm{k} \cdot \frac{4}{3} \pi \cdot\left[(\rho-2 \mathrm{~h}) \cdot \mathrm{d}+3 \mathrm{~h} \mathrm{~d}_{1}\right]$.

In der Tiefe $h$ ist, da nach dem am Schlusse von $\S .7$ citirten Newton'schen Theoreme die Kugelschale sich völlig neutral verhält, die Anziehung

$$
\mathrm{G}=\mathrm{k} \cdot \frac{4}{3} \pi \cdot \mathrm{p} \cdot \mathrm{d},
$$

somit durch Division und nachherige Umformung

$$
\frac{g}{G}=\frac{1}{\rho} \cdot\left[\rho-2 h+\frac{3 h d_{1}}{d}\right] ; \frac{d_{1}}{d}=\frac{2}{3}-\frac{\rho}{3 h} \cdot\left(1-\frac{g}{G}\right) \text {. }
$$

*) Es scheint neuerdings jedoch, dass auch an Bergen, wenn man nur mit den nöthigen Vorsichtsmaassregeln arbeitet, genauere Ergebnisse zu erzielen sind, wenigstens berichtet $\mathrm{W}$ allentin [113], dass James späterhin am Shehallien dieselben Beobachtungs - und Messungsoperationen vornahm, wie hundert Jahre früher Maskelyne und Hutton, dass er dabei aber zu dem von der Wahrheit weit weniger abweichenden Werthe $d=5,32$ gelangte. 
Schon 1826 gieng A iry daran, im Geiste dieses Verfahrens die Dichtigkeit der Erde zu ermitteln, doch misslang damals sein Versuch [116], und erst als er achtundzwanzig Jahre später mit Anwendung galvanischer Signale denselben in der Kohlengrube Harton bei Newcastle wiederholte, gelang [117] die Feststellung des Werthes 6,6 für $d$, der freilich zu hoch war; $\left(1-\frac{g}{G}\right)$ war $=1: 19200 ; \rho: h=$ $16000, d_{1}=2,5$ gesetzt worden. Haughton hat später aus Airy's Zahlangaben den zweifellos richtigeren Werth 5,48 berechnet; allein auch aus den oben (§. 7) angefübrten Beobachtungen v. Sterneck's scheint zu folgen, dass völlig befriedigende Resultate überhaupt auf diese Weise nicht zu erzielen sind.

Umgekehrt kann, statt in einer Vertiefung, natürlich auch auf einer Erhöhung das Verhältniss der Fallbeschleunigungen ermittelt und dieses nachher zur Berechnung von d verwendet werden. Plana und Carlin i haben den Montcenis zu diesem Zwecke benützt, und E. Schmidt. hat [118] rechnerisch aus deren Angaben $d=4,837$, also einen etwas zu kleinen Zahlenwerth, hergeleitet. Ein solcher Berg besitze die Dichtigkeit $d_{1}$, das Volumen $V_{1}$, und sein Gravitationsmittelpunkt sei $u m r_{1}$ von dem auf seiner Spitze schwingenden Pendel entfernt, während d, V und $\mathbf{r}$ das Nämliche für die Erdkugel bedeuten mögen. Wäre der Berg nicht vorhanden, so würde für den Meereshorizont unter gleicher Breite 1 die Länge des Sekundenpendels sein, während die Messungen auf dem Gipfel die Länge $l^{\prime}(<1)$ lieferten. Dann gilt die Proportion

woraus folgt:

$$
\frac{d_{1} V_{1}}{r_{1}^{2}}: \frac{d V}{r^{2}}=\left(1-l^{\prime}\right): l
$$

$$
\mathrm{d}=\frac{\mathrm{d}_{1} \cdot \mathrm{V}_{1} \cdot \mathrm{r}^{2} \cdot 1}{\mathrm{~V} \cdot \mathrm{r}_{1}^{2} \cdot\left(\mathrm{l}-\mathrm{l}^{\prime}\right)^{\circ}}
$$

Es ist natürlich, dass diese Methode die besten Garantieen dann gewährt, wenn die Körpergestalt des Berges einige geometrische Regelmässigkeit besitzt. Deshalb wählte $\mathrm{M}$ endenhall den Vulkan Fusiyama auf Nipon, der als gerader Kegel von $138^{\circ}$ Oeffnung betrachtet werden kann. Auch fand sich $d=5,77$, also ein gut stimmender Werth [119].

III. Die Methode der Drehwage. Dieses eben so einfache und bescheidene, als ingeniöse Werkzeug zur Messung kleiner anziehender und abstossender Kräfte wird gemeiniglich auf $\mathrm{Coulo} \mathrm{mb}$ zurückgeführt, welcher allerdings auf dasselbe die von ihm geschaffene Disciplin der Elektrostatik begründete [120]. Allein es ist keinem Zweifel unterworfen, dass ein genialer Physiker des XVIII. Jahrhunderts, der im Jahre 1793 gestorbene Schotte Michell, schon früher einen solchen Apparat erdacht und konstruirt hatte, und zwar in der ausgesprochenen Absicht, die Stossstärke der Sonnenstrahlen zu messen [121]; ihm schwebte offenbar ganz dieselbe Idee vor, welche später Crookes durch sein bekanntes Radiometer so trefflich zu realisiren verstand. Dieses Instrument jedoch, und zwar sofort mit grossem Erfolg, zur Bestimmung der Erdmasse und Erddichte angewandt zu haben, diess ist das unleugbare Verdienst Liord Ca vendish's [122]. Unsere Fig. 30 
gewährt ein allerdings nur schematisches Bild dieser Vorrichtung; die Darstellung der Methode selbst lehnt sich an diejenige Maxwell's [123] an.

Die Dreh-oder Torsionswage besteht wesentlich aus einem Stabe CD, der in B, seinem Schwerpunkt, an einem Drahte hängt, der selbst wieder in den Zapfen A der Zimmerdecke eingeklemmt ist. Dieser Stab stellt sich horizontal ein, und an dieser seiner Eigenschaft ändert sich nichts, wenn an den Enden C, D zwei gleichlange Drähte angebracht werden, an welchen hinwiederum die einander völlig gleichen kugelförmigen Massen $\mathrm{F}$ und $\mathrm{G}$ hängen. Gesetzt nun, der Kugel G werde eine andere Kugel E genähert, die auch an einem Drahte $\mathrm{H}$ aufgehängt ist und in jede beliebige Entfernung von G gebracht werden kann; dann wird der von $\mathrm{E}$ auf $\mathrm{G}$ geübte attrahirende Einfluss von einer gewissen $\mathrm{Ma}$ ximaldistanz an sich fühlbar machen, $G$ nähert sich seinerseits der $\mathrm{E}$, und diese $\mathrm{Be}$ wegung bewirkt eine Drillung des Drahtes $\mathrm{AB}$, durch welche bewirkt wird, dass der Stab CD kleine horizontale Schwingungen um seine frühere Ruhelage auszuführen beginnt. Coulo $\mathrm{mb}$ hat die Torsionskraft eines Drahtes oder Fadens zu bestimmen gelehrt: dieselbe ist proportional dem Ausschlagswinkel und der vierten Potenz des Fadendurchmessers, umgekehrt proportional der Länge dieses Fadens und zugleich der Länge des schwingenden Stabes. Mittelst einer

Fig. 30.

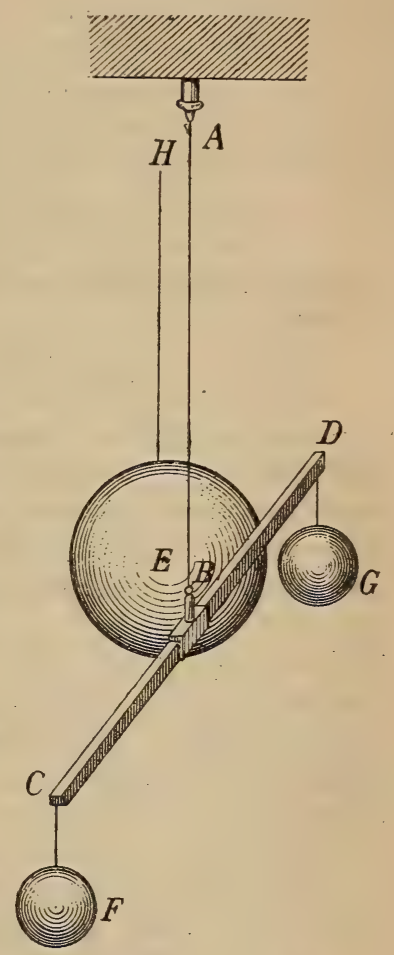
Poggendorff'schen Spiegelvorrichtung beobachtet man jene Theilpunkte der Skala, welche den Endpunkten einer einzelnen Schwingung entsprechen, und findet diese um die Länge $x$ und y von der Gleichgewichtslage entfernt. An diesen beiden Punkten befindet sich der Stab C D momentan in Ruhe, er leistet gar keine Arbeit, und da die Gesammtenergie offenbar dieselbe ist, so muss die der Endlage $x$ entsprechende potentielle Energie*) derjenigen potentiellen Energie gleich sein, welche der Endlage y zukommt. Unter T die Dauer einer Doppelschwingung verstanden, ist die dem ersteren Momente entsprechende Energie durch

$$
\frac{2 \pi^{2} \cdot \mathrm{m} \cdot \mathrm{x}^{2}}{\mathrm{~T}^{2}}
$$

*) Die neuere Dynamik unterscheidet sorgfältig zwischen aktueller und potentieller Energie, welche zwei Begriffe Z ölln er in seinem Bestreben, psychische Vorstellungen in die anorganische Naturlehre hineinzutragen, durch Lust und Unlust wiedergegeben wissen wollte. Jede der beiden Energieen kann sich sofort in die andere verwandeln; ein auf einer Unterlage liegender Stein z. B. ist ein Kraftreservoir, entwickelt aber nach Wegnahme jener unverzüglich aktuelle Energie. 
und die aus der Anziehung zwischen der grossen und kleinen Kugel entspringende Energie durch

$$
\mathrm{K}-\mathrm{k} \cdot \frac{\mathrm{m} \cdot \mathrm{M}}{\mathrm{a}-\mathrm{x}}
$$

auszudrücken. $\mathrm{m}$ und $\mathrm{M}$ sind resp. die Massen der kleineren und der grösseren Kugel, K ist die von der Schwere geleistete Arbeit; den im Subtrahenden stehenden Bruch würden wir auch als das Potential der beiden Massen bezeichnen können. Addiren wir beide Ausdrücke und erwägen, dass der solchergestalt erhaltene Ausdruck sich nicht ändern kann, sobald $\mathrm{y}$ an die Stelle von $\mathrm{x}$ tritt, so haben wir zur Berechnung der Gravitationskonstante $\mathrm{k}$ die folgende Bedingungsgleichung:

$$
\mathrm{K}-\mathrm{k} \cdot \frac{\mathrm{m} \cdot \mathrm{M}}{\mathrm{a}-\mathrm{x}}+\frac{2 \pi^{2}: \mathrm{m} \cdot \mathrm{x}^{2}}{\mathrm{~T}^{2}}=\mathrm{K}-\mathrm{k} \cdot \frac{\mathrm{m} \cdot \mathrm{M}}{\mathrm{a}-\mathrm{y}}+\frac{2 \pi^{2} \cdot \mathrm{m} \cdot \mathrm{y}^{2}}{\mathrm{~T}^{2}}
$$

hiernach muss sein, da links $(y-x)$ gegen $\left(y^{2}-x^{2}\right)$ zur Rechten sich forthebt,

$$
\mathrm{k}=\frac{2 \pi^{2}}{\mathrm{M} \cdot \mathrm{T}^{2}}(\mathrm{x}+\mathrm{y})(\mathrm{a}-\mathrm{x})(\mathrm{a}-\mathrm{y}) .
$$

$\mathrm{x}, \mathrm{y}$ und a sind in Metermaass, $\mathrm{M}$ ist in Grammen, $\mathrm{T}$ in Sekunden ausgedrückt, $k$ demnach vollständig bestimmt. Sobald aber die Gravitationskonstante numerisch ausgedrückt ist, hat es keine Schwierigkeit mehr, auch die Masse und damit das spezifische Gewicht der Erde auf die entsprechenden Einheiten zurückzuführen; es ist eben $\mathrm{d}=\frac{3}{4} \cdot \frac{\mathrm{g}}{\mathrm{k} \cdot \mathrm{r} \cdot \pi}$. Auf die Details der Rechnung können wir uns hier nicht einlassen, doch findet man ein vollständig durchgeführtes Rechnungsbeispiel in der kosmischen Physik von J. Müller [124]. Die Substanz der Kugeln ist, wie schon aus den Bessel'schen Pendelversuchen zu entnehmen war, ohne Einfluss auf das Resultat, und B aily's gleich näher zu besprechende Experimente, bei welchen Massen, aus den verschiedensten Stoffen verfertigt, zur Verwendung gelangten, vermochten somit nur zu bestätigen, was man bereits anderweit wusste. Cavendish selbst fand auf einem ähnlichen Wege (a. a. O.) $\mathrm{d}=\dot{5}, 48$. Später stellte Reich (1837 und 1847) je eine ausgedehnte Versuchsreihe an; beide Reihen führten zu fast übereinstimmenden Resultaten [125], indem zuerst 5,49 und später 5,583 erhalten wurde. Aus etwa 2000 Experimenten mit der 'Torsionswage zog der Engländer Baily die Zahl 5,66 [126]. Endlich haben in neuester Zeit Cornu und Baille nochmals die Drehwage angewendet [127] und dabei Werthe erlangt, welche zwischen 5,50 und 5,56 schwankten. Es liegt auf der Hand, dass diese Messungsmethode eine viel zu feine und viel zu sehr gelegentlichen Fehlern ausgesetzte ist, um eine absolute Genauigkeit verbürgen zu können. Man stellt zwar die ganze Vorrichtung in einem Gehäuse auf, und der Beobachter kontrolirt die Schwingungen durch ein in diesem angebrachtes Glasfenster, allein je feiner die einzelnen Theile gearbeitet und mit einander verbunden sind, um so einflussreicher erweisen sich die nämlichen Störungen, deren schon oben bei Beschreibung des Darwin'schen Pendelapparates gedacht wurde.

Da man seit Gauss weiss, dass Messungen bei bifilarer Aufhängung im Allgemeinen stets genauere Ergebnisse liefern, als bei blos unifilarer Aufhängung, so erschiene es angezeigt, das Hengler- 
Zöllner'sche Horizontalpendel (§. 2) zur Bestimmung der Erddichte nutzbar zu machen. Zöllner hat zwar diese Aufgabe auf sein Programm gesetzt gehabt, sich aber.später zu sehr mit überirdischen Dingen beschäftigt, um der tellurischen Frage ein weiteres Interesse zuzuwenden. Jetzt aber verfügt man über ein noch weit vollkommeneres Hülfsmittel zur Lösung des Problemes, welches alle übrigen in den Hintergrund gedrängt hat.

§. 10. Die Wägungsmethode. Nachdem der Münchener Physiker v. Jolly bereits bei früheren Gelegenheiten darauf aufmerksam gemacht hatte, dass die gewöhnliche zweiarmige Wage nicht blos für andere Aufgaben der Präcisionsphysik, sondern auch speziell für Gravitationsmessungen das zweckdienlichste Instrument sei, weil sich der Wägungsfehler bis auf 0,001 Milligramm herabdrücken lasse [128], zeigte er in einer späteren Abhandlung [129] auch, wie durch einfache Wägungen die Dichte unseres Erdkörpers gefunden werden könne. Der Gedanke, von welchem er sich hiebei leiten liess, ist durch seine Einfachheit ausgezeichnet. Im Oberstock eines vor Erschütterungen zu bewahrenden Gebäudes ist eine feine Wage aufgestellt; die Schwingungen der Zunge lassen sich mittelst eines Ablesefernrohres aus einer solchen Entfernung beobachten, dass die Person des Beobachters keine attrahirende Wirkung mehr ausüben kann. Von jeder der beiden Schalen führt ein 20-25 m langer Metalldraht wiederum zu einer Schale. Gesetzt nun, ein Körper von der Masse M sei in einer der oberen Schalen durch Gewichtstücke genau äquilibrirt; nimmt man jetzt den Körper fort und legt ihn in die entsprechende untere Schale, so wirkt die Anziehungskraft der Erde stärker auf ihn ein, und damit steigt die mit den Gewichten beschwerte obere Schale in die Höhe. Aus dieser Bewegung lässt sich die Gewichtszunahme des Körpers berechnen. Bringt man aber direkt unter die den Körper enthaltende untere Schale eine hinreichend grosse Bleikugel, so wirkt diese ihrerseits anziehend auf jenen, und eine stärkere Schwankung des Wagebalkens wird die Folge sein. Ist $a_{1}$ die zuerst, $a_{2}$ die unter dem Einflusse der Bleikugel beobachtete Gewichtszunahme, so stellt $a=a_{2}-a_{1}$ die attraktive Wirkung der Bleikugel dar. Nun haben aber die drei im vorigen Paragraphen beschriebenen Methoden den gemeinsamen Zug, dass unmittelbar aus der Anziehung, welche ein Körper von bekannter Grösse und Dichte auf einen zweiten Körper ausübt, auch auf die Grösse der Anziehung der Erde und damit zugleich auf die Masse der letzteren geschlossen wurde. Genau so hat man im vorliegenden Falle zu handeln.

Die Bleikugel besitzt die Masse $\mu$, das spezifische Gewicht $\delta$, den Radius $r_{1}$ und ihr Mittelpunkt ist um $s$ von dem Schwerpunkt des in die untere Schale der Doppelwage gelegten Körpers entfernt. Dann ist die Kraft K, mit welcher der Körper und die Bleikugel sich gegenseitig anziehen, gegeben durch

$$
\mathrm{K}=\mathrm{k} \cdot \frac{\mathrm{M} \cdot \mu}{\mathrm{s}^{2}}=\frac{4}{3} \cdot \mathrm{k} \cdot \mathrm{M} \cdot \delta \cdot \mathrm{r}_{1} \cdot \frac{\mathrm{r}_{1}{ }^{2}}{\mathrm{~s}^{2}} \pi .
$$

Wenn dagegen $r$ und $d$ ihre uns von früher her bekannten Bedeutungen beibehalten, so ist $\operatorname{die}^{\prime}$ zwischen dem Prüfungskörper und der 
Erdkugel obwaltende Anziehung, für welche wiederum der Buchstabe g eintreten möge,

$$
\mathrm{g}=\frac{4}{3} \cdot \mathrm{k} \cdot \mathrm{r} \cdot \mathrm{d} \cdot \pi \cdot \mathrm{M}
$$

Durch Division folgt hieraus, da M sich forthebt,

$$
\frac{\mathrm{K}}{\mathrm{g}}=\frac{\mathrm{r}_{1}}{\mathrm{r}} \cdot \frac{\delta}{\mathrm{d}} \cdot \frac{\mathrm{r}_{1}^{2}}{\mathrm{~s}^{2}} \text {. }
$$

Dem Obigen zufolge ist $M K=a_{2}-a_{1}=a, M g=a_{1}, K: g=\left(a_{2}-a_{1}\right): a_{1}$. Wird dieser Werth in der zuletzt erhaltenen Gleichung substıtuirt, so folgt schliesslich

$$
\frac{\mathrm{r}_{1}{ }^{3} \cdot \delta}{\mathrm{r} \cdot \mathrm{d} \cdot \mathrm{s}^{2}}=\frac{\mathrm{a}_{2}-\mathrm{a}_{1}}{\mathrm{a}_{1}} ; \quad d=\frac{\mathrm{a}_{1} \cdot \mathrm{r}_{1}{ }^{3} \cdot \delta}{\mathrm{a} \cdot \mathrm{r} \cdot \mathrm{s}^{2}} \text {. }
$$

$\mathrm{r}, \mathrm{s}, \mathrm{r}_{1}$ und $\delta$ sind von Anfang an völlig bekannt; $\mathrm{a}_{2}$ aber und $a_{1}$ vermögen mit einer Akribie gemessen zu werden, wie nur selten bei physikalischen Experimenten. Demnach verdient der Werth v. Jolly's, $\mathrm{d}=5,692$ (mit einem wahrscheinlichen Fehler $= \pm 0,068$ ) wohl das meiste Vertrauen unter allen bisher abgeleiteten, ${ }^{\text {weil }}{ }^{*}$, wie sich Zöppritz ausdrückt [130], „das Instrument, womit die Zahl erlangt ist, die Wage, unter allen physikalischen Messapparaten theoretisch wie praktisch am besten bekannt und am leichtesten kontrolirbar ist."

Völlig unabhängig von Jolly hat ein englischer Physiker, Poynting in Manchester, einen ähnlichen Apparat erfunden und in gleichem Sinne nutzbar gemacht [131]. Er machte 11 Einzelbestimmungen und fand für die mittlere Dichtigkeit der Erde Werthe zwischen 4,415 und 7,172 , im Mittel aber, ganz wie v. Jolly, 5,69.

Diesen Zahlwerth werden wir also von nun an dauernd festzuhalten haben. Die neuere Naturlehre unterscheidet allerdings in etwas zwischen den Begriffen Dichte und spezifisches Gewicht, doch hat diese mehr philosophische Trennung für die Geophysik zunächst noch keine Bedeutung. Unser $d$ ist eine reine Zahl, von der nullten Dimension, deren Sinn in Kürze dahin ausgesprochen werden kann: Wäre der Erdball ein homogener Körper, so würde ein Kubikmeter Erdmaterie dmal mehr wiegen, als ein Kubikmeter destillirten Wassers im Zustande der grössten Koncentration. Die Dichte derjenigen Substanzen, aus welchen der unserer direkten Einsicht zugängliche Theil unseres Planeten sich zusammensetzt, ist eine weit geringere, indem für die ganze Erdkruste nur eine Durchschnitts-Eigenschwere $=2,5$ angenommen werden darf; hieraus scheint zu folgen, dass die Dichtigkeit wachsen wird, je mehr man sich von der Erdoberfläche entfernt.

[1] Kästner, Geschichte der Mathematik, 4. Band, Göttingen 1800. S. 241. - [2] Chasles, Geschichte der Geometrie, hauptsächlich mit Bezug auf die neueren Methoden, deutsch von Sohncke, Halle 1839. S. 348. - [3] Sir Isaac Newton's mathematische Principien der Naturlehre, deutsch von Wolfers, Berlin 1872. S. 386. - [4] R. Wolf, Geschichte der Astronomie, München 1877. S. 466 ff. - [5] Newton's math. Princ. etc. S. 167. - [6] Isenkrahe, Das Räthsel der Schwerkraft, Kritik der bisherigen Lösungen des Gravitationsproblemes und Versuch einer neuen auf rein mechanischer Grundlage, Braunschweig 1879. - [7] Zöllner, Ueber die Natur der Cometen; Beiträge zur Geschichte und Theorie der Erkenntniss, Leipzig 1883. S. 105 ff. - [8] Ibid. S. 127. - [9] v. Oppolzer, Ist das Newton'sche Anziehungsgesetz zur Erklärung der Bewegungen der. Himmelskörper ausreichend; hat man Veranlassung, dasselbe nur als Näherungsausdruck zu bezeichnen? Tagebl. 
d. 54. Versamml. d. Naturf. u. Aerzte, Salzburg 1881. 1. Abtheilung, S. 125 ff. [10] Ibid. S. 132. - [11]. Isenkrahe, Das Räthsel etc. S. 195. - [12] Günther, Geophysikalische Hypothesen, geprüft durch Libellen- und Pendelapparate, Humboldt, 2. Jahrgang. S. 328 ff. - [13] Zech, Lorenz Hengler, Erfinder des Horizontalpendels, Ann. d. Phys. u. Chem., 150. Band. S. 496. - [14] Hengler, Astronomische Pendelwage, nebst einer neuen Nivellirwage, Dingler's polytechn. Journal, 43. Band. S. 81 ff. - [15] Safařik, Beitrag zur Geschichte des Horizontalpendels, Ann. d. Phys. u. Chem., 150. Bd. S. 150 ff. - [16] Zöllner, Zur Geschichte des Horizontalpendels, ibid. 150. Band. S. 140 ff. - [17] Gruithuisen, Ritter Bessel's Versuche über die Kraft, mit welcher die Erde Körper von verschiedener Beschaffenheit anzieht, und von des Herausgebers Elkysmometer und Hengeller's Schwungwage, Neue Analekten f. Erd- u. Himmelskunde, 1. Heft. S. 39 ff. - [18] Hengler, Astron. Pendelwage etc. S. 146. - [19] Perrot, Appareils à rendre manifestes et mesurables les variations occasionnées dans l'intensité et la direction de la pesanteur à la surface de la terre, par les mouvements de notre globe et l'attraction des corps célestes, Compt. rend. de l'acad. franç., tome LIV. S. 728 ff. - [20] Ibid. S. 851. - [21] Zöllner, Ueber eine neue Methode zur Messung anziehender und abstossender Kräfte, Ann. d. Phys. u. Chem., 150. Band. S. 131 ff. - [22] H. J. Klein, Vierteljahrsrevue der Naturwissenschaften, 1. Heft, Leipzig und Köln 1875. S. 2. - [23] Zöllner, Beschreibung und Anwendung des Horizontalpendels, Ann. d. Phys. u. Chem., 150. Band. S. 134 ff. - [24] Stoll, Mathematisch-physikalische Miscellen, Bensheim 1878. S. 1 ff. - [25] C. A. F. Peters, Von den kleinen Ablenkungen der Lothlinie und des Niveau's, welche durch die Anziehung der Sonne, des Mondes und einiger terrestrischer Gegenstände hervorgebracht werden. Bull. de la physico-math. de l'acad. imp. de St.- Pétersbourg, tome III. S. $212 \mathrm{ff}$. [26] Carl, Die Principien der astronomischen Instrumentenkunde, Leipzig 1863. S. 88. - [27] $\mathrm{Ph}$. Plantamour, Sur les mouvements périodiques du sol, Compt. rend. de l'acad. franç., tome XCIII. S. 329 ff. - [28] Mascart, Sur les changements de la gravitation, ibid. tome XCVI. S. $126 \mathrm{ff}$. - [29] Issel, Note sur un instrument destiné à mesurer l'intensité de la pesanteur Bull. de la soc. impér. des natural. de Moscou, Année 1882. I. S. 134 ff. - [30] Bohnenberger, Anleitung zur geographischen Ortsbestimmung, vorzüglich vermittelst des Spiegelsextanten, Göttingen 1795. S. 165. - [31] G. H. Darwin, Ueber ein Instrument zur Beobachtung und Messung kleiner Aenderungen in der Richtung der Schwerkraft, Beibl. z. d. Ann. d. Phys. u. Chem., 6. Band, 2. Stück. S. 59 ff. - [32] Paraira, Over de methoden ter bepaling van te aantrekking eener ellipsoide op en willekeurig punt, Amsterdam 1879. - [33] Grube, Zur Geschichte des Problemes der Anziehung der Ellipsoide, Schleswig 1883. - [34] Thomson-Tait, Handbuch der theoretischen Physik, deutsch von Helmholtz-Wertheim, 1. Band, 2. Theil, Braunschweig 1874. S. 27. - [35] Ibid. S. 379 ff. - [36] Newton's math. Princ. etc. S. 192 ff. [37] Kunzek, Lehrbuch der Physik mit mathematischer Begründung, Wien 1860. S. 102 ff. - [38] Schlömilch, Der Attraktionscalcül, Halle 1851. S. 7 ff. - [39] Günther, Ueber elementare Behandlung gewisser Punkte der mathematischen Geographie, Zeitschr. f. math. u. naturw. Unterricht, 7. Jahrgang. S. $91 \mathrm{ff}$. - [40] Lagrange, Remarques générales sur le mouvement de plusieurs corps qui s'attirent mutuellement en raison inverse des carrés des distances, Nouv. Mém. de l'acad. de Berlin, Année 1777. S. $155 \mathrm{ff}$. - [41] Green, Essay on the application of mathematical analysis on the theories of electricity and magnetism, Nottingham 1828. - [42] Gauss, Allgemeine Lehrsätze in Beziehung auf die im verkehrten Verhältnisse des Quadrates der Entfernung wirkenden Anziehungs- und Abstossungskräfte, Göttingen 1840. - [43] Clausius, Das Potential und die Potentialfunktion, Leipzig 1877. S. 1 ff. - [44] Bacharach, Abriss einer Geschichte der Potentialtheorie, Göttingen 1883. - [45] Zöppritz, Ueber die Schwankungen des Meeresspiegels in Folge von geologischen Veränderungen, Ann. d. Phys. u. Chem., (2) 11. Band. S. $1016 \mathrm{ff}$. - [46] Ibid. S. $1022 \mathrm{ff}$. - [47] Thomson-Tait, Theor. Phys. S. 324 ff. - [48] A. v. Humboldt, Kosmos, 4. Band, Stuttgart und Tübingen 1849. S. 30 ff. - [49] v. Zach, L'attraction des montagnes, Avignon 1814. - [50] Ph. Keller, Ricerche sull: attrazione delle montagne, Roma 1872. [51] Bouguer, La figure de la terre, déterminée par les observations de MM. De la Condamine et Bouguer, Paris 1749. S. $388 \mathrm{ff}$ - - [52] Liesganig, Dimensio graduum meridiani Viennensis et Hungarici jussu et auspiciis Augg. peracta, Vindobonae 1770. S. $211 \mathrm{ff}$. - [53] Maskelyne, An account of observations made on the mountain Shehallien for finding its attraction, Phil. Transact. Vol. LXV. S. 500 ff. - [54] R. Wolf, Gesch. d. Astr. S. 628. - [55] Denzler, 
Die Ablenkung des Senklothes durch die Gebirge, Zürich 1866. - [56] v. Baeyer, Ueber den Einfluss der lokalen Lothablenkungen auf geodätische Operationen. Astr. Nachr. (2) Nr. 87. - [57] Peschel-Leipoldt, Physische Erdkunde, 1. Band, Leipzig 1879. S. 175. - [58] Lossen, Ueber den Zusammenhang der Lothablenkungswerthe auf und vor dem Harz mit dem geologischen Bau des Gebirges, Sitzungsber. d. Gesellsch. naturf. Freunde zu Berlin, 1881. S. 19 ff. - [59] Ibid. S. 24 ff. - [60] I. Kant's Schriften zur physischen Geographie, herausgeg. von - F. W. Schubert, Leipzig 1839. S. 786. - [61] Schweizer, Untersuchungen über eine in der Nähe von Moskau stattfindende Lokalattraktion, Moskau 1864. [62] Peschel-Leipoldt, Phys. Erdk. S. 176. - [63] J. Newton's math. Princ. etc. S. $401 \mathrm{ff}$. - [64] Fliedner, Lehrbuch der Physik, Braunschweig 1880. S. 148 ff. - [65] Poggendorff, Geschichte der Physik, Leipzig 1879. S. 230. - [66] Huygens, De causa gravitatis, Op. rel., Tom. I, Lugduni Batavorum 1703. S. 93. - [67] Hamberger, Dissertatio de experimento ab Hugenio pro causa gravitatis explicanda invento, Jenae 1723. - [68] Kulik, Elementarischer Beweis der Formel für die Schwingungszeit des einfachen Pendels, (Baumgartner- v. Ettingshausen's) Zeitschr. f. Phys. u. Math., 1. Band. S. 337 ff. - [69] Besso, Sulla durata dell' oscillazione del pendolo semplice circolare, Roma 1883. - [70] Günther, Vermischte Untersuchungen zur Geschichte der mathematischen Wissenschaften, Leipzig 1876. S. 330. - [71] Richer, Observations astronomiques et physiques, faites en l'isle de Cayenne, Päris 1679. - [72] Newton's math. Princ. S. 406 ff. - [73] Ibid. S. 408. - [74] R. Wolf, Gesch. d. Astr. S. 614. - [75] Bouguer, Figure de la terre etc. S. 338 ff. - [76] Delambre, Base du système métrique, Vol. III, Paris 1810. S. 337. - [77] Oltmanns, Beobachtungen über die Schwere, welche in den Häfen von Europa, Amerika und Asien, auf dem stillen Meere und in Neuholland während Malaspina's Weltumsegelung mit dem unveränderlichen Pendel angestellt worden sind, Journ. f. d. reine u. angew. Mathem., 4. Band. S. 72 ff. - [78] Huygens, Horologium oscillatorium, Parisiis 1673. S. 88. - [79] Bohnenberger, Astronomie, Tübingen 1811. S. 448. - [80] Kater, Experiments for determining the length on the pendulum vibrating seconds in latitude of London, Phil. Trans., Vol. CXII. S. 33 ff. - [81] Sabine, An account of experiments to determine the figure of the earth, London 1825. - [82] Bessel, Untersuchungen über die Länge des einfachen Sekundenpendels, Berlin 1828. - [83] Lübeck, Notiz zu den Besselschen Pendelversuchen, Ann. d. Phys. u. Chem., 150. Band. S. $476 \mathrm{ff},-$ [84] Bessel, Untersuch. etc. S. 32 ff. - [85] Ibid. S. 69 ff. - [86] J. Biot, Sur la figure de la terre, Mém. de l'acad. royale des sciences, Année 1829. S. 1 ff. - [87] Listing, Neue geometrische und dynamische Constanten des Erdkörpers, Nachr. v. d. k. Gesellsch. d. Wissensch. zu Göttingen, 1877. S. 797 ff. - [88] Bremiker's logarithmisch-trigonometrische Tafeln mit sechs Decimalstellen, neu bearbeitet von Albrecht, Berlin 1883. S. 597. - [89] J. Herschel, Account of the operations of the great trigonometrical survey of India, Vol. V, Calcutta 1879. - [90] Bessels, Die amerikanische Nordpol-Expedition, Leipzig 1879. S. 224 ff. S. 317. [91] E. Plantamour, Expériences faites à Genève avec le pendule à reversion, Genève et Bâle 1866; Nouvelles expériences faites avec le pendule à reversion et détermination de la pesanteur à Genève et au Righi-Kulm, Genève et Bâle 1872. - [92] C. F. W. Peters, Beobachtungen mit dem Bessel'schen Pendelapparate in Königsberg und Güldenstein, ausgeführt im Auftrage des geodätischen Institutes, Hamburg 1874. - [93] Helmert, Recension hiezu, Vierteljahrsschr. d. astron. Gesellsch., 11. Jahrgang. S. 33 ff. - [94] Finger, Ueber ein Analogon des Katerschen Pendels und dessen Anwendung zu Gravitationsmessungen, Wien 1881. [95] Ibid. S. 4 ff. - [96] Ibid. S. 25. - [97] Fliedner, Auflösungen zu den Aufgaben aus der Physik, Braunschweig 1880. S. 52. - [98] v. Sterneck, Untersuchungen über die Schwere im Inneren der Erde, ausgeführt im Jahre 1882, in dem $1000 \mathrm{~m}$ tiefen Adalbertsschachte des Silberbergwerkes zu Pribřam, Mittheil. d. k. k. militärgeogr. Inst. zu Wien, 2. Band, Wien 1882. - [99] Newton's math. Princ. etc. S. 191. - [100] van Galen, Dissertatio mathematica inauguralis de pendulo ejusque applicatione ad telluris figuram determinandam, Amstelodami 1830. [101] Gehler's physikalisches Wörterbuch, 2. Auflage, 7. Band, 1. Abtheilung, Leipzig 1832. S. 375 ff. - [102] Clairaut, Théorie de la figure de la terre, Paris 1743. S. 139 ff. - [103] Thomson-Tait, Theor. Phys. S. $351 \mathrm{ff}$. - [104] v. Lang, Einleitung in die theoretische Physik, 1. Theil, Braunschweig 1867. S. 98. [105] Stokes, On the variation of gravity, at the surface of the earth, Cambridge 1849. - [106] Ph. Fischer, Untersuchungen über die Gestalt der Erde, Darmstadt 1868. S. 16. - [107] Paucker, Die Gestalt der Erde, Bull. de la cl. 
physico-mathém. de l'acad. imp. d. sc. de St.-Pétersbourg, N. 303 ff. - [108] Unferdinger, Das Pendel als geodätisches Instrument, Archiv d. Math. u. Phys., 49. Theil. S. 309 ff. - [109] Ibid. S. 315 ff. - [110] Maskelyne-Hutton, An account of the calculation made from the survey and measure's taken of Shehallien, in order to ascertain the mean density of the earth, Phil. Trans. Vol. LXVIII. S. 689 ff. - [111] C. A. F. Peters, Von den kleinen Ablenkungen etc. S. 217 ff. - [112] Ibid. S. 222. - [113] Wallentin, Ueber die Methoden zur Bestimmung der mittleren Dichte der Erde und eine neue hierauf bezügliche Anwendung der Wage, Humboldt, 1. Jahrgang. S. 214. - [114] Drobisch, Ueber die Pendelbeobachtungen in den Gruben von Dolcoath, Ann. d. Phys. u. Chem., 10. Band. S. 444 ff. [115] v. Lang, Einleitung etc. S. 104 ff. - [116] Peschel-Leipoldt, Phys. Erdk. S. 179. - [117] Airy, Account of pendulum experiments undertaken in the Harton Colliery, for the purpose of determining the mean density of the earth, Phil Trans. Vol. CXLVI. S. 297 ff. - [118] E. Schmidt, Lehrbuch der mathematischen und physischen Geographie, 2. Band. Göttingen 1830. S. 481 ff. - [119] Zöppritz, Die Fortschritte der Geophysik, Wagner's geogr. Jahrb., 9. Band, Gotha 1883. S. 4. - [120] Poggendorff, Gesch. d. Phys. S. 890 ff. - [121] Ibid. S. 892 . [122] Cavendish, Experiments to determine the density of the earth, Phil. Trans. Vol. LXXXVIII. S. 469 ff. - [123] Maxwell, Substanz und Bewegung, deutsch von v. Fleischl, Braunschweig 1879. S. 134 ff. - [124] J. Müller, Lehrbuch der kosmischen Physik, Braunschweig 1875. S. 273 ff. - [125] Reich, Versuche über die mittlere Dichtigkeit der Erde mittelst der Drehwage, Freiberg 1838; Neue Versuche mit der Drehwage, Abh. d. k. säıhs. Gesellsch. d. Wisschftn., M.-ph. Kl. 1. Band. S. 383 ff. - [126] Baily, Experiments with the torsion rood for determining the mean density of the earth, London 1843. - [127] Cornu-Baille, Détermination nouvelle de la constante de l'attraction et de la densité moyenne de la terre, Compt. rend. de l'acad. franç., tome LXXVI. S. 954 ff. - [128] Wallentin, Ueber die Methoden etc. S. 215. - [129] v. Jolly, Anwendung der Wage auf Probleme der Gravitation, Abh. d. k. bayr. Akad. d. Wisschftn., M. - ph. Ki., 14. Band; Ann. d. Phys. u. Chem., (2) 14. Band. S. 331 ff. - [130] Zöppritz, Die Fortschritte etc. S. 5. - [131] Poynting, On a method of using the balance with great delicacy and on its employment to determine the mean density of the earth, Proceed. of the r. society of London, XXXVIII. S. 2 ff.

Kapitel III.

Das Geoid.

§. 1. Unregelmässigkeiten der Erdgestalt. Wir haben schon im ersten Kapitel dieser Abtheilung gesehen, dass die geodätische Vermessung der Erde keine Resultate ergab, welche mit irgend einer strenge mathematischen Oberflächenform jener in vollkommenen Einklang zu bringen gewesen wären, und so verfielen nach Gerlach's Angabe bereits im vorigen Jahrhundert einzelne Gelehrte, wie Buffon, De la Condamine und Boscovich auf die Meinung [1], dass die Erde überhaupt keine regelmässige Gestalt besitze, dass vielmehr die Meridiane sämmtlich einander unähnlich gebildet seien. Die mühsamsten Versuche eines Bessel und Walbeck [2], denen aus neuerer Zeit noch diejenigen von Clarke (s. o.) und ganz besonders von Santini [3] hinzuzufügen wären, vermochten nicht, sämmtliche verschiedene Längen von Breiten- und Längengraden auf ein und demselben Ellipsoid, mochte dasselbe nun als ein zwei- oder dreiaxiges angenommen werden, gehörig unterzubringen. Jedem einzelnen Landkomplex schien 
sozusagen ein besonderer Abplattungswerth zuzukommen. Die Schwierigkeit steigerte sich noch, als man an die Sichtung des reichlich aufgespeicherten Materiales von Pendelbeobachtungen herantrat; denn während es schon schwer genug war, Beobachtungen dieser Art, die an verschiedenen Stellen der Erde angestellt waren, mit der sphäroidischen Hypothese zu vereinigen, so wollte es doch noch viel weniger gelingen, aus den Grad- und aus den Pendelmessungen übereinstimmende Abplattungswerthe herzuleiten.

§. 2. Die Gestalt der Meeresoberfläche. Dass von dem Festlande völlig abzusehen sei, wenn man eine Konkordanz der vorbezeichneten Art herzustellen beabsichtige, darüber war man sich im Beginne des laufenden Jahrhunderts klar genug, da man die lothablenkende Wirkung der Gebirgsmassen nur zu deutlich erkannt hatte. Die Meeresoberfläche dagegen schien Einflüssen stärkeren Betrages durchaus nicht zu unterliegen, und es schien nichts im Wege zu stehen, dieser Fläche, welche man sich in unzähligen Kanälen unter den Kontinenten fortgesetzt dachte, nunmehr ein mehr Erfolg verheissendes Studium zuzuwenden. Diese Fläche hatte, so nahm man an, eine wirklich geometrische Form, wenn auch nicht gerade diejenige eines Ellipsoides; sie musste sich demzufolge durch eine Gleichung $f\left(x, y, z, a_{1}, a_{2} \ldots a_{n}\right)$ ausdrücken lassen, und Gradmessungen sowohl wie Gravitationsbeobachtungen hatten nur mehr den Zweck, die konstanten Grössen $a_{1} \ldots a_{n}$ zu liefern. Gradmessungen auf offenem Meere giebt es nun allerdings nicht $\mathrm{zu}$ verwerthen. Es ist uns überhaupt nur ein einziger dahin zielender Vorschlag bekannt, derjenige des Sicilianers Philippus Arena, welcher sehr ausführlich die Idee entwickelte [4], an den Endpunkten eines astronomisch fixirten Meridionalbogens Schiffe fest zu verankern und die Bestimmung ihres linearen Abstandes durch direkte Kettenmessung zu bewerkstelligen. Aus naheliegenden Gründen hat man dieser an sich ganz sinnreichen Anregung keine Folge gegeben. Da sonach der geodätische Weg nicht betretbar war, so erschien es um so nothwendiger, die physikalische Methode energisch in den Dienst des Problemes zu stellen, welches die Bestimmung der Meeresgestalt anstrebte; Gauss [5] und Bessel [6] erwarben sich das Verdienst, die Lösung so weit zu führen, als sie unter der zu Grunde gelegten ungenauen Annahme überhaupt geführt werden konnte.

OX YZ (Fig. 31) sei ein orthogonales Koordinatensystem im Raume, der willkürlich angenommene Punkt $P$ sei durch $\mathrm{x}, \mathrm{y}, \mathrm{z}$ gegeben und um $\mathrm{r}$ von dem der Erde angehörigen Massenelemente $\mathrm{dm}$ entfernt, während $\rho$ dessen Entfernung von der Rotationsaxe RR darstellen möge. Das über die Gesammtmasse der Erde erstreckte Integral

$$
\int \frac{\mathrm{d} m}{\mathrm{r}}=\Omega
$$

ist, wie wir uns aus Kapitel II, §. 3 erinnern, das Pótential der Erde mit Bezug auf den Punkt (x, y, z). $\omega$ sei die Winkelgeschwindigkeit der rotirenden Erde; alsdann ist

$$
\mathrm{W}=\Omega+\frac{1}{2} \omega^{2} \rho^{2}
$$

die sogenannte Kräftefunktion. Versteht man ferner unter D die 
Dichte im Punkte $\mathrm{P}$, so gilt, wie die Potentialtheorie beweist, die partielle Differentialgleichung

$$
\frac{\partial^{2} W}{\partial x^{2}}+\frac{\partial^{2} W}{\partial y^{2}}+\frac{\partial^{2} W}{\partial z^{2}}=-4 D \pi+2 \omega^{2} \text {. }
$$

Die Gleichung $W=0$ signalisirt, geometrisch gedeutet, ein Gebilde zweiter Dimension, d. h. eine Fläche, und zwar führt die betreffende Fläche den Namen einer Niveaufläche. Die Schwere ist für eine solche Niveaufläche konstant, ihre Grösse ist durch die Relation $\mathrm{g}=-(\mathrm{dW}: \mathrm{dn})$ gegeben, wo $\mathrm{dn}$ das nach aussen gerichtete Linienelement der an die Fläche gezogenen Normale bedeutet. Die Funktion W ist sammt ihren ersten Ableitungen stetig, aus welchem Grunde auch die Niveauflächen stetig sind und keinerlei Diskontinuitäten in Form von Ecken oder Kanten aufweisen können. Es ist wohl zu beachten, dass die einzelnen Niveauflächen nicht etwa dasjenige sind, was die Raumgeometrie Parallelfä̈chen nennt; d. h. der Abstand zweier benach-

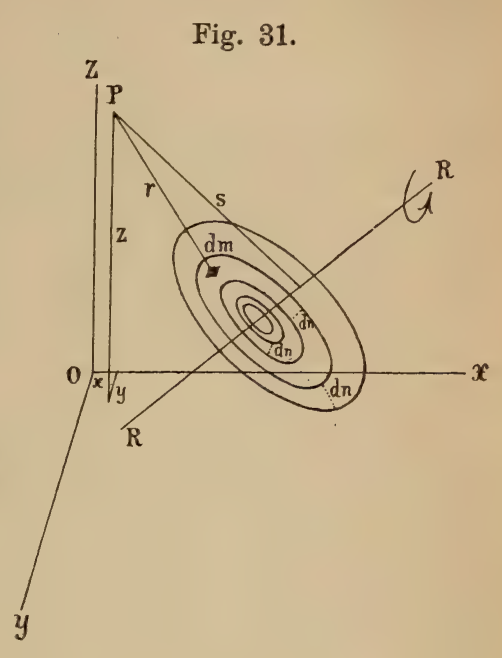
barter Niveauflächen ist nicht allenthalben gleich gross, sondern, wenn man ihn längs der Normalen misst, umgekehrt proportional der Schwere. Einem schon von Dahlander [7] angedeuteten Satze zufolge ist nämlich (s. o.)

$$
\mathrm{dn}=-\frac{\mathrm{dW}}{\mathrm{g}} * \text {. }
$$

Gauss und Bessel fehlten nun darin, dass sie den Spiegel des Meeres mit einer Niveaufläche identificirten. Dass das Gleichgewicht kein absolutes, vielmehr ein durch die Gezeiten, durch Winde und eine Fülle anderer Ursachen getrübtes sei, konnten selbstverständlich Männer von dem hohen Range der genannten keinen Augenblick übersehen, doch hielten sie diese Störungen für unwesentlich. Erst die fortschreitende Wissenschaft hat uns mit dieser Auffassung, wie mit so mancher anderen, allmählig brechen lassen.

§. 3. Der Meeresspiegel keine Niveaufläche. Die Ansicht nämlich, dass es ein gewisses mittleres Durchschnittsniveau der Meere geben müsse, auf welches als auf eine stets gleichbleibende Fläche alle Distanzen u. s. w. bezogen werden könnten, hat sich mehr und mehr als eine unhaltbare herausgestellt. Die neueren Nivellements haben

*) Zur Seite steht dieser Relation die folgende: $h=C \cdot \triangle N$, wo $h$ den (endlichen, aber kleinen) Abstand zweier Niveauflächen, $\triangle \mathrm{N}$ die Differenz der auf je einen Tag entfallenden Pendelschwingungen in beiden Flächen und C eine Konstante bezeichnet, die etwa $120 \mathrm{~m}$ beträgt. H a n n, der für diesen Satz einen sehr einfachen Beweis mittheilt, erklärt [8] das Pendel für ein wichtiges Höhenmessungsinstrument, und diess ist es zweifelsohne auch, wenn der Begriff "Höhe" richtig verstanden wird. 
die früher vielfach behauptete und wieder bestrittene Thatsache ausser Zweifel gesetzt, dass auch die Normalpegel verschiedener Meere eine Höhendifferenz ergeben. Zudem kann, selbst wenn Ebbe und Fluth auf irgend eine Weise als ausser Berücksichtigung bleibend erkannt worden sein sollten, die Oberfläche des Meeres noch immer nicht als eine ruhige gelten, denn dasselbe wirkt doch stets als ein Wasserbarometer von gigantischen Dimensionen, und die stetig wechselnde Temperatur bewirkt Luftdruckschwankungen, welche sich wieder in den Oscillationen des Niveau's abspiegeln. Von den stationären Meeresströmungen ist dabei noch nicht einmal die Rede gewesen. Einer der rührigsten Vertreter der englischen geodynamischen Schule, G. Darwin, hat jüngst [9] den Effekt zu berechnen versucht, welchen ein Wechsel im Luftdruck auf die Gestalt der Erde auszuüben vermag, und wenn auch dieser Effekt der festen Erde gegenüber kein erheblicher ist, so vermag er sich doch sehr energisch an deren tropfbarflüssiger Umhüllung $\mathrm{zu}$ bethätigen.

Alle diese Irregularitäten treten jedoch in den Hintergrund vor einer anderen konstant wirkenden Störung, mit welcher wir uns jetzt eingehender beschäftigen müssen. Eine je grössere Menge von genauen Messungen der Pendelschwere man nämlich unter die Hand bekam, um so klarer stellte es sich heraus, dass zwischen den am Rande eines Festlandes oder auf einer frei liegenden Insel vorgenommenen Messungen ein tief greifender Unterschied obwalte, welcher sich unmöglich durch Beobachtungsfehler erklären liess, sondern gebieterisch eine mechanische Erklärung herausforderte. Saigey [10] bleibt das Verdienst, zuerst eine solch vergleichende Uebersicht der aus den Pendelversuchen folgenden Zahlen gegeben und das dieselben beherrschende Gesetz angedeutet zu haben. Wir glauben mit geringem Wortaufwande den Charakter dieser ,Unregelmässigkeit von regelmässigem Charakter" nicht besser schildern zu können, als wenn wir im Folgenden Hann's Darstellung [11] vollinhaltlich wiedergeben: "Wenn man die Stationen mit ihren Fehlern in Reihen anordnet, so dass sie von der See landeinwärts sich folgen, so kann man deutlich die Abnahme der Intensität in dieser Richtung erkennen, z. B. $\left.{ }^{*}\right)$ :

Spitzbergen $+4,3$; Hammerfest $-0,4$; Drontheim 2,7. Dünkirehen - 0,1; Paris - 1,9; Clermont - 3,9; Figeac - 3,8; Toulon - 0,1.

$$
\text { Padua }+ \text { 0,7; Mailand - 2,8. Jamaika - 0,8; Trinidad - 5,2. }
$$

Aus der Zusammenstellung der Abweichungen zwischen den beobachteten und berechneten Schwingungszahlen per Tag nach der Berechnung von Borenius (Abplattung gleich $\frac{1}{285,3}$ ) lässt sich folgende Uebersicht geben:

*) Als Norm für die folgende Tabelle ist die Anzahl der Schwingungen genommen, welche das Sekundenpendel zu London im Verlaufe Eines Tages macht. Wäre diese Zahl a und an einem anderen Orte $(a \pm b)$, so würde oben jener Ort mit der Zahl $\pm \mathrm{b}$ anzusetzen sein. Die eingeklammerte Ziffer bedeutet die Anzahl der Beobachtungen. Was die benützte Arbeit von Borenius [12] anlangt, so entstammt sie allerdings schon dem Jahre 1843. 
Mittlere Fehler in Schwingungen des Londoner Sekundenpendels per Tag.

\begin{tabular}{l|l|c}
\hline \multicolumn{1}{c|}{ Stations-Gruppen } & Küstenpunkte & Inseln \\
\hline \hline A. $23^{\circ}$ S. bis $28^{\circ}$ N. Breite . . . . & $-4,0(9)$ & $+3,7(13)$ \\
B. $33^{\circ}$ bis $51^{0}$ N. und S. Breite . . . & $-2,0(7)$ & $\begin{array}{c}\text { fehlen } \\
+1,6(7)\end{array}$ \\
C. Jenseits $51^{0}$ N. und S. . . . . . . & $-0,6(11)$ &
\end{tabular}

Die durchschnittliche Differenz der Intensität der Schwere auf Inseln und Küstenpunkten beträgt in der Gruppe A, welche die einzige ist, die Inseln fern von Kontinenten enthält, 8 Schwingungen des Londoner Sekundenpendels per Tag, es erhöht sich diese Zahl auf 9, wenn man die oceanischen Inseln allein den Küstenpunkten gegenüberstellt."

\section{§. 4. Aeltere und neuere Erklärungsversuche dieser Abweichung.} Den allein richtigen $W e g$, zu einem richtigen Verständnisse dieser anscheinend so seltsamen Unregelmässigkeiten in der Vertheilung der Schwerkraft zu gelangen, hatte bereits A. v. Humboldt mit dem ihn stets auszeichnienden Takte erkannt. Anknüpfend an den von Bessel [13] ausgesprochenen Satz, dass die Voraussetzung einer absolut gleichbleibenden Schwere selbst für ein und denselben Ort der Erde keine zutreffende sei, sagt er im Kosmos [14], „örtliche Modifikationen der Anziehungskraft und durch dieselbe hervorgebrachte veränderte Krümmung einer Portion des flüssigen Elementes" vermöchten recht wohl eine Aenderung in den Höhenverhältnissen der irdischen Gebirge herbeizuführen. Humboldt war also mit sich darüber im Reinen, dass es einen fixen Nullpunkt nicht gäbe. In bestimmteren Sätzen formulirte Rozet [15], was sein Vorgänger nur obenhin ausgesprochen hatte: das Meer werde an einzelnen Stellen durch die Anziehung der dem Gestade benachbarten Massen in die Höhe gezogen, an anderen wieder trete es zurück, und es würden so Oertlichkeiten blossgelegt, die sich eigentlich unter dem Meeresspiegel befinden müssten. Gleicher Meinung huldigte Bruchhausen in einem Schriftchen, welches er $1846 \mathrm{im}$ Manuskripte an H umboldt sandte, und von welchem Penck [16] einige Auszüge mittheilt. Saigey (a. a. O.) und Stokes [17] traten der Frage auch rechnerisch näher, und der Erstere zumal wollte gefunden haben, dass an den Küsten von Europa, Asien, Afrika, Nord- und Südamerika das Meer in Folge der kontinentalen Attraktion resp. um 36, 144, 172, 54 und 76 Meter gehoben werden müsse.

Mag auch diese Schätzung - denn von einer eigentlichen Berechnung kann man nicht sprechen - auf Genauigkeit wenig Anspruch machen können, so war doch gewiss der ihr zu Grunde liegende Gedanke ein fortbildungsfähiger. Gleichwohl konnten Männer von Gewicht dieser Meinung nicht beitreten, verfielen vielmehr auf Hypothesen, die uns zum Theile recht sonderbar anmuthen. Dem trefflichen Airy wollte insbesondere die Richtigkeit der Thatsache nicht einleuchten, dass die Lokalattraktion der gigantischen Gebirgsmassen, von welchen die vorderindische Halbinsel im Norden umsäumt wird, sich so gar nicht fühlbar machen sollte, dass sogar an vielen Orten diese Anziehung eher einen negativen Werth anzunehmen schien, und da das Faktum selbst 
nicht in Abrede zu stellen war, so verfiel er auf eine Erklärung [18], welche er selbst nicht umbin konnte als eine "sonderbare" zu bezeichnen. Die Berge und Tafelländer sollen nach ihm in die feurigflüssige Masse hinabtauchen und von dieser theilweise getragen werden, so dass dem archimedischen Gesetze entsprechend ein erheblicher Gewichtverlust eintreten muss. Die Flüssigkeit wird dadurch verdichtet, die Niveauflächen sind unter sonst gleichen Umständen unterhalb einer Bergkette weiter von einander entfernt, als unterhalb des Meeresbodens. Ja man könnte hienach sogar sagen: die Erde ist ungleich dick, dünner unter den Meeren, als unter den Kontinenten. Eine sehr eingehende Darstellung und Prüfung der Airy'schen Hypothese gab Zanotti-Bianco [19]. Gerade die umgekehrte Ansicht, wie Airy, hat sich Faye [20] gebildet, er nimmt an, dass in Folge ungleicher Abkühlung die Erdkruste unter den Oceanen dicker sei, als unter den Festländern. Im Uebrigen erachtet der Pariser Astronom, gewiss mit Unrecht, den durch Schwerebeobachtungen festgestellten Gravitationsunterschied an verschiedenen Orten für zu gering, um bei Bestimmung der Erdgestalt überhaupt in Frage zu kommen.

§. 5. Ph. Fischer's Untersuchungen. Gegen das Ende der sechziger Jahre war trotz der Rührigkeit der Geodäten und des Eifers der Physiker das Studium der Frage nach der wahren Gestalt der Erde in eine gewisse Stagnation gerathen; es hatten sich Schwierigkeiten erhoben, die mit den gewöhnlichen Hülfsmitteln nicht besiegt werden zu können schienen. „Es erschien mir die Zeit gekommen," schrieb damals Philipp Fischer [21], swo die Sache ernstlich in die Hand genommen werden musste; ich fühlte eine Aufforderung hiezu und unterzog mich gerne der sehr weit ausschauenden Arbeit." In der That darf diese Arbeit als eine äusserst dankenswerthe bezeichnet werden, denn mit dem die Früchte derselben sammelnden Buche Fischer's war das Eis gebrochen, und es konnte wieder rüstig weiter gearbeitet werden. Angesichts der zeitgeschichtlichen Bedeutung dieses Werkes dürfte es sich daher wohl empfehlen, einen kurzen Ueberblick über dessen Inhalt hier einzuschalten.

Nachdem Fischer das Wesen der beiden Methoden, welche durch direkte Gradmessung und durch vergleichende Zusammenstellung von Pendelbeobachtungen die Oberflächenform des Erdkörpers bestimmen wollen, ohne Rücksicht auf störende Einflüsse gekennzeichnet hat, analysirt er [22] mit einer Sorgfalt, wie sie bis dahin noch nicht aufgewendet worden war, die Störungen der normalen Schwerkraft. Die Integralausdrücke für die Ablenkung, welche das Bleiloth in der Nähe von Gebirgsmassen erkennen lässt (Kap. II, §. 4) werden aufgestellt und diskutirt; nicht minder wird direkt und numerisch erörtert [23], um wie viel ein Pendel in der Nähe solcher ablenkender Körper rascher oder langsamer schwinge, als unter gewöhnlichen Umständen. Die aus dem Gegensatze zwischen Land und Meer entspringenden Lothablenkungen wagt der Autor bei der Unsicherheit der empirischen Daten vorsichtigerweise nicht eigentlich $\mathbf{z u}$ berechnen, doch taxirt er sie wenigstens obenhin und überzeugt sich [24] von der ,enormen Grösse des Betrages der betreffenden Lothablenkungen". Hieran schliesst sich eine scharfe Kritik des Grundprincipes der Pendelmes- 
sungen, basirend auf dem Satze, dass man Messungen auf dem Festlande als das Normale zu betrachten habe [25]. Wohl den wichtigsten Theil des Ganzen aber repräsentiren in ihrer Gesammtheit das vierte und fünfte Kapitel [26], in welchen untersucht wird, welcherlei konstante und zufällige Fehler jedes geodätische oder geophysikalische Resultat entstellen, und wie sich bisher die Ausgleichungsrechnung, die Methode der kleinsten Quadrate, mit diesen Fehlern abgefunden hat. Wir verweisen auf unsere Einleitung in die Meteorologie (5. Hauptabtheilung, Kap. I), wo wir das Wesen dieser fruchtbaren Methode mit wenigen Strichen zu zeichnen versuchen, und bemerken hier nur so viel: Dieses Verfahren kann nur dann mit Sicherheit angewendet werden, wenn die unschädlich zu machenden Irrthümer in die Klasse der sogenannten zufälligen, d. h. unvermeidlichen Fehler gehören; konstante Fehler müssen dagegen unabhängig von jener Rechnung ermittelt und beseitigt werden, ehe man den schematischen Kalkul beginnt. $\mathrm{Ph}$. Fischer gieng, das lässt sich nicht leugnen, in seiner Abneigung gegen die höhere Wahrscheinlichkeitsrechnung viel zu weit, allein darin hatte er zweifellos Recht, dass er den bisher von der Geodäsie begangenen Fehlschluss aufdeckte, der darin bestand, dass man die aus der Lokalattraktion resultirenden Unrichtigkeiten mit den übrigen Fehlern der Beobachtung, des Instrumentes u. s. w. ganz unter den gleichen Gesichtspunkten betrachtet und behandelt hatte. Namentlich war damit auch die Genesis jener "negativen Anziehung“ oder Lothabstossung aufgedeckt, welche man irrigerweise dem Himalaya zugeschrieben und mit Hülfe geschraubter Hypothesen (§. 4) zu begreifen versucht hatte. Eine Ahnung des Richtigen hatte der von Fischer [27] citirte Döllen, der sich bei einer Kritik des Schubert'schen Versuches (Kap. I, §. 11), dem zweiaxigen Erdellipsoid ein solches mit drei Axen zu substituiren, folgendermassen aussprach: „Die ganze Schrift scheint uns ein recht dringliches Beispiel, wohin man gelangt, wenn man meint, auf Zahlen, die der Beobachtung entnommen sind, weiter bauen zu dürfen, ohne zuvor eine ganz präcise Vorstellung von der denselben, ihrer Natur und der Art ihrer Herleitung nach, anhaftenden Unsicherheit gewonnen zu haben. ${ }^{*}$ Besonders gründlich beschäftigt sich F ischer [28] mit den Ansichten, die Airy (s. o.) der ostindischen Gradmessung abgewonnen hatte, sowie mit den Arbeiten Pratt's, der schon 1855 gegen die hydrostatische Senkungstheorie seines Landsmannes aufgetreten war [29]. Pratt ist es [30] auch gewesen, der die Grundlage der Lehre Airy's durch den Hinweis auf die Wirkung des Meeres vernichtete, doch scheint ihm die Tragweite dieser Wahrnehmung nicht zum vollen Bewusstsein gekommen zu sein [31]. Um so energischer ward dieselbe von Fischer ausgebeutet, der die Ergebnisse seines mühsamen Untersuchungswerkes in neun Thesen zusammenfasste. Dieselben werden ihrer fundamentalen Bedeutung halber nachstehend wörtlich reproducirt [32]: "I. Dem zwischen den Grundformeln zur Bestimmung der Gestalt und Grösse der Erde einerseits und den durch die Praxis der Messungen andererseits herrschenden Zwiespalt muss ein grösseres Gewicht beigelegt werden, als bisher geschah, und ihm muss bei Benützung der vorhandenen Messungen zur Ermittelung jener Resultate besonders Rechnung getragen werden. II. Der Gegensatz der Dichtigkeit der kontinentalen und oceanischen Massen verursacht 
allgemeine Lothablenkungen, welche in einerlei Art über ausgedehnte Erdstriche herrschen. Aehnliches wird durch die Wirkung massenhafter Gebirge und Hochländer verursacht. III. Auf der Halbinsel von Vorderindien finden sich alle die Umstände vereinigt, welche grössere allgemeine Lothablenkungen verursachen; es ist deshalb diese Halbinsel ein zu Breitengradmessungen durchaus nicht geeignetes Land, und die dort vollendete Messung steht in den ihren Resultaten hiedurch anhängenden Mängeln mit den Forderungen der Theorie so entschieden im Widerspruch, dass sie nicht zur Berechnung der Gestalt und Grösse der Erde mit benützt werden darf. IV. Die grossen Fehler der Amplituden der ostindischen Messung verbergen sich bei den mit Hülfe der Methode der kleinsten Quadrate geführten Rechnungen durch Mitwirkung der grossen Koefficienten. V. Schliesst man die Resultate der ostindischen Messung bei der Berechnung der Erdgestalt vollständig aus, so liefern diejenigen der übrigen Gradmessungen einen wesentlich anderen Werth der Abplattung, als unter der Mitwirkung jener Messung. Der erstere Werth stimmt sehr nahe mit dem aus den Pendelmessungen erhaltenen überein. VI. Das von E. Schmidt in die Rechnungsmethode eingeführte Verfahren zur Berechnung der Polhöhefehler leistet im Allgemeinen nicht, was es verspricht, bei allgemeinen Lothablenkungen führt es aber nur zu Täuschungen der übelsten Art. VII. Das A ir y'sche Theorem, wonach Hochlandmassen keine beträchtlich ablenkende Wirkung auf das Loth ausüben sollen, ist im Allgemeinen völlig unrichtig, und die Punkte der ostindischen Messung haben grosse Lothablenkungen. VIII. Die Gegensätze der Dichtigkeit der kontinentalen und oceanischen Massen, ebenso wie die hohen Tafelländer, erzeugen sehr grosse Unregelmässigkeiten in der sogenannten mathematischen Gestalt der Erde, welche als mehrere hundert Toisen hohe wellenförmige Erhebungen, deren breiter Saum auf der Meeresoberfläche wirklich vorhanden ist, und deren höchste Punkte auf der eingebildeten mathematischen Erdoberfläche über den Kontinenten liegen, auftreten. IX. Diese in der wirklichen Meeresoberfläche sich findenden Abweichungen von der Fläche des Rotationsellipsoides sind die Ursachen, weshalb die unter gleicher Breite liegenden Punkte nicht gleiche Grösse der Schwerkraft zeigen; sie erklären die bis jetzt nicht genügend aufgeklärten Abnormitäten in der Grösse der Schwerkraft, welche durch die Pendelmessungen zu Tage gefördert worden sind."

§. 6. Das Geoid. Fischer's Kritik der früheren Leistungen, sein Nachweis der Fehler, an welchen jede - geodätische oder geophysikalische - Lösung des Problemes der Erdgestalt bisher gekrankt hatte, seine Vernichtung der Ansicht, dass man mit einem wie immer beschaffenen Ellipsoide zur Darstellung aller vorhandenen Messungen ausreichen könne - das Alles hat seinen bleibenden Werth. Doch war sein Verdienst immerhin mehr ein negatives, und wenn auch Niemand darüber im Zweifel sein kann, dass ein fehlerhaft angelegter Bau selbst dann niedergerissen werden muss, wenn es nicht möglich ist, unverzüglich einen besseren an dessen Stelle aufzurichten, so mochte doch freilich der Stand des Problemes, nachdem Fis cher sein Werk geschrieben hatte, als ein ziemlich trostloser erscheinen. Denn offenbar 
hatte sich jetzt die völlig neue Fragestellung ergeben: Was hat man unter den Worten Gestalt der Erde eigentlich zu verstehen? Eine anscheinend recht befriedigende Antwort auf diese sich aufdrängende Frage glaubte Listing gegeben zu haben, indem er vorschlug, die Meeresoberfläche, wie sie sich unter dem attraktiven Einflusse der Landmassen gestaltet, als das Geoid zu bezeichnen [33]. Er entwarf auch ein skizzenhaftes Bild von dem Verlaufe dieser Fläche, erklärte es aber für hoffnungslos, jetzt schon ein dem Geoid sich möglichst nahe anschmiegendes Sphäroid ausfindig machen zu wollen; „zur Erfüllung der idealen Forderung, ein Rotationsellipsoid zu finden der Art, dass erstens die geoidischen Erhöhungen über und die Vertiefungen unter der Ellipsoidfläche gleiche Beträge, oder dass Geoid und Sphäroid gleiches Volumen erhalten, und dass zweitens die Summe der Beträge von Erhöhungen und Vertiefungen ein Minimum sei, werden unsere Messungen, wie bisher, so auch noch in sehr fernen Zeiten unzureichend $\operatorname{sein}^{\prime \prime}[34]$.

Die Terminologie Listing's wurde als eine sehr praktische von den Fachmännern angenommen, über seine Annahme dagegen, dass der Spiegel der See ein wirkliches Geoid repräsentire, musste weggegangen werden. Wusste man doch (s. o. §. 3), dass die Meeresfläche unmöglich eine Niveaufäche sein könne, und nur Hand in Hand mit dem Studium dieser letzteren durfte, davon überzeugte man sich täglich mehr, die Forschung nach der wahren Gestalt der Erde ihre Aufgabe zu lösen hoffen. Thomson-Tait stellen [35] einige Betrachtungen zu dem Zwecke an, den Einfluss der Oberflächenbeschaffenheit auf den Verlauf der Niveauflächen zu ermitteln. Allerdings ist dabei die nicht ganz mit der Wirklichkeit stimmende Voraussetzung gemacht, dass die Erde ein homogenes harmonisches Sphäroid sei; sämmtliche Niveaufächen würden dann harmonische Sphäroidalfä̈chen von der nämlichen Ordnung sein. Jene Niveaufäche, die einen der Erde inhaltsgleichen Körper umschliesst, schneidet die Erdoberfläche in einer Linie oder in einer Gruppe von Linien, welche die mittlere Niveaulinie darstellt. Wäre $\mathrm{k}$ die Ordnung der bezüglichen harmonischen Funktion, so betrüge die Abweichung der Niveaufläche $\frac{3}{2 \mathrm{k}+1}$ von der Abweichung der sphäroidalen Oberfläche, jede dieser Abweichungen von einer gewissen mittleren Kugelfläche aus gerechnet. „Wenn die Substanz der Erde homogen wäre, so würde eine Reihe paralleler Bergketten und Thäler eine entsprechende, näherungsweise wellenförmige Gestalt der Niveaufläche in dem mittleren Distrikt erzeugen; die Höhe, zu welcher sich dieselbe unter jedem Bergkamme erhebt, oder sich unter die Höhe der ungestörten Niveaufläche über der Mitte eines Thales herabsenkt, ist das Dreifache desselben Bruchtheiles der Höhe des Berges über dem mittleren Niveau oder der Tiefe des Thales unter demselben, welches die Breite des Berges oder Thales von dem Umfange der Erde ist" ${ }^{\text {" }}[36]$.

Ueberlegungen dieser Art mussten endlich dahin führen, den Begriff des Geoides in einem erweiterten Sinne zu fassen. Eine kleine, aber inhaltsreiche Schrift eines deutschen Mathematikers [37] hat diese Erweiterung angebahnt und zugleich allen auf schärfere Bestimmung der Erdgestalt gerichteten Versuchen Wege vorgezeichnet, deren Ver- 
folgung zur Erreichung des wenn auch noch weit entfernten, aber doch schon deutlich erkennbaren Zieles hinleiten wird*).

§. 7. Definition und Bestimmung des Geoides nach Bruns. Das charakteristische Moment dieser wichtigen Neuerung ist folgendes: Keine der unendlich vielen Niveauflächen der Erdrinde hat das geringste Recht, vor den übrigen irgend ausgezeichnet zu werden. Hätte der Seespiegel die ihm früher zugeschriebenen Eigenschaften, so wäre es selbstverständlich das Nächstliegende, sich an ihn zu halten, allein da eben jene Annahme eine unrichtige war, so bleibt die Meeresoberfläche zunächst ganz ausser Betracht und muss auf die Bezeichnung

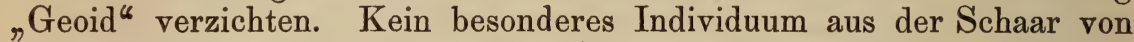
Niveauflächen, welche als ,Erdrinde" bezeichnet werden mag, darf den anderen gegenüber das Geoid heissen; wohl aber ist es gestattet, irgend ein solches Individuum aus der Menge willkürlich herauszugreifen, und diejenigen Eigenschaften desselben, welche es mit den übrigen gemein hat, sind wirklich geoidische. Halb unbewusst haben diesem Grundsatze bis jetzt schon alle Gradmessungen gehuldigt, indem jede einzelne diejenige Niveaufläche besonders auszeichnete, in welche sie den Nullpunkt ihrer Nivellements verlegte. Die Geoide sind also unter sich keineswegs identisch; kennt man aber eines unter ihnen, so führt dessen Kenntniss vermittelst der uns bereits bekannten Gleichung $\mathrm{g}=-(\mathrm{dW}: \mathrm{dn})$ zur Kenntniss aller benachbarten Geoide.

Was nun die allgemeinen Eigenschaften der Geoide betrifft, so steht zunächst Folgendes fest: Das Bildungsgesetz einer solchen Fläche lässt sich nicht durch einen wie immer gearteten Ausdruck darstellen, die Fläche ist mithin geometrisch irregulär, doch setzt sie sich zusammen aus einzelnen Stücken regulärer Oberflächen. Durch Kanten u. dgl. können diese Einzelbestandtheile nach dem, was uns über die analytischen Merkmale einer Niveaufläche bekannt ist, nicht mit einander in Verbindung stehen, vielmehr ist der Uebergang ein unmerklicher und kontinuirlicher. Es würde natürlich nichts im Wege stehen, den irregulären Charakter der Geoidfläche durch Entwickelung in trigonometrische Reihen zu verwischen, doch wäre angesichts der zu erwartenden langsamen Konvergenz dieser Reihen keinerlei praktischer Nutzen von solch' mühsamer Arbeit abzusehen. Nachdem schon Bessel in seiner ostpreussischen Gradmessung den fruchtlosen. Versuch gemacht hatte, einen geschlossenen analytischen Ausdruck für das Geoid zu eruiren, kam Yvon Villarceau, als die permanente Gradmessungskommission vor neun Jahren in Paris zusammentrat, wieder auf diesen Gedanken zurück, doch dürfte wohl Bruns Recht behalten, wenn er das Vergebliche all' dieser Bemühungen mit den treffenden Worten kennzeichnet [40]: „Ebensowenig, wie man versuchen wird, das Bild, welches eine geognostische Karte gewährt, mit einigem Anspruch auf Treue in eine Formel zu zwängen, wird man auf ein brauchbares Resultat rechnen dürfen, wenn man es unternimmt, für die Gestalt der

*) Eine sehr verdienstliche Popularisirung der theilweise nicht ganz leicht verständlichen Ideen, von welchen die Bruns'sche Abhandlung getragen wird, verdankt man $\mathrm{Zech}$ [38]. Auch der Verf. dieses ist bestrebt gewesen [39], diese neuen Anschauungsweisen zugleich mit einer Reihe anderer für das Problem der Erdgestalt belangreicher Fragen einem grösseren Publikum mundgerecht zu machen. 
Geoide einen Ausdruck zu suchen, der die wahre Form derselben bis auf Quantitäten von der Ordnung der Beobachtungsfehler angiebt." Bruns spricht hier fast mit denselben Wendungen einen Gedanken aus, dem schon ein Geometer des XVIII. Jahrhunderts Ausdruck verlieh, als er sich gegen die Sucht seiner Zeitgenossen wandte, durch Entwickelung in Potenzreihen für jede Aufgabe der mathematischen Physik eine stereotype Lösung erzwingen zu wollen [41]. Den Namen des klugen Mannes hat man uns leider nicht überliefert.

Wenn nun auch, wie erwähnt, die Krümmung der Geoidfläche, als lediglich von den ersten Ableitungen beeinflusst, durchweg eine stetige sein muss, so verhält es sich doch ganz anders mit dem sogenannten Maasse der Krümmung, in dessen analytischen Ausdruck bekanntlich auch zweite Differentialquotienten eingehen. Dieses Krümmungsmaass erleidet sprungweise Aenderungen. Im Allgemeinen sind die Geoide durchaus nach aussen konvex, doch ist an sich eine gegentheilige Krümmung keineswegs ausgeschlossen. Dass die Niveauflächen der Erdkruste keine konkaven Stellen besitzen, lässt sich mit grosser Wahrscheinlichkeit aus dem Umstande erschliessen, dass Lothstörungen von besonders grossem Betrage zur Zeit nicht bekannt sind. Die tiefer in der Erde gelegenen Niveauflächen besitzen dagegen zweifellos jenen wellenförmigen Durchschnitt, welchen wir auch auf unserer Fig. 33 zum Ausdruck zu bringen versucht haben.

Erwähnt sei noch, dass man für das Wesen der bisher rein analytisch aufgefassten Niveauflächen auch eine noch weit übersichtlichere Anschauung gewinnen kann, sobald man mit $\mathrm{Zech}$ [42] den Begriff der mathematischen Arbeit zu Hülfe nimmt. Jeder von einem Geoid umschlossene Körper darf als ein centrobarischer gelten, und es ist somit auch erlaubt, nach wie vor von einem Erdmittelpunkte zu reden. Denkt man sich nun von diesem Punkt aus einen materiellen Punkt nach verschiedenen Richtungen fortgeschoben, so erfüllen alle Punkte, bis zu welchen der fragliche Massenpunkt in der nämlichen Zeit mittelst Aufwendung des nämlichen Arbeitsquantums emporgehoben werden konnte, eine Niveaufläche, welche demgemäss natürlich auch eine geschlossene sein muss. Dass diese Flächen in einer homogenen oder doch wenigstens in koncentrischen Ringen eine gleiche Massenvertheilung aufweisenden Kugel selbst sphärisch sein müssen, leuchtet ein, und nicht minder wird klar, dass, wenn die Vertheilung der Masse keine reguläre ist, auch die mit dieser Anordnung im allerengsten Zusammenhange stehenden Niveauflächen keinen geometrisch-regulären Charakter besitzen können.

Konstruirt man die orthogonalen Trajektorien der Geoide, Kurven, welche die Flächen sämmtlich unter rechten Winkeln durchschneiden, so erhält man die sogenanten Kraftlinien, deren Berührende im Durchschnittspunkt die Gravitationsrichtung anzeigen. Diese Kurven sind stetig gekrümmt, ohne Spitzen oder Rückkehrpunkte, wohl aber ist ihr Krümmungsmaass ebenso wie das Azimut ihrer Schmiegungsebenen den von der Massenvertheilung abhängigen Unstetigkeiten unterworfen.

Treten wir jetzt der mathematischen Betrachtung der Geoide näher. Wie oben (in Fig. 31) seien x, y, z die Koordinaten eines beliebigen Punktes $\mathrm{P} ; \mathrm{x}^{\prime}, \mathrm{y}^{\prime}, \mathrm{z}^{\prime}$ diejenigen eines Massenelementes $\mathrm{dm}$ 
des Erdkörpers; das Potential von $\mathrm{dm}$ ist dann

$$
\Omega=\int \frac{\mathrm{dm}}{\sqrt{\left(\mathrm{x}-\mathrm{x}^{\prime}\right)^{2}+\left(\mathrm{y}-\mathrm{y}^{\prime}\right)^{2}+\left(\mathrm{z}-\mathrm{z}^{\prime}\right)^{2}}} .
$$

Wenn, wie in unserem Falle, $\mathbf{r}=\sqrt{\mathrm{x}^{2}+\mathrm{y}^{2}+\mathbf{z}^{2}}$ einen hinreichend grossen Werth hat, so kann $\Omega$ in eine Reihe nach fallenden Potenzen von $\mathrm{r}$ entwickelt werden, und zwar wird, $\sqrt{\mathrm{x}^{\prime 2}+\mathrm{y}^{\prime 2}+\mathrm{z}^{\prime 2}}=\mathrm{r}^{\prime}$ gesetzt,

$$
\begin{aligned}
& \Omega=\frac{1}{\mathrm{r}} \int \mathrm{d} \mathrm{m}+\frac{1}{\mathrm{r}^{3}} \int \mathrm{dm}\left(\mathrm{xx}^{\prime}+\mathrm{yy}^{\prime}+\mathrm{zz}^{\prime}\right)+ \\
& \frac{1}{2 \mathrm{r}^{5}} \int \mathrm{d} \mathrm{m} \cdot \frac{3\left(\mathrm{xx}^{\prime}+\mathrm{yy}^{\prime}+\mathrm{zz}^{\prime}\right)-\mathrm{r}^{2} \mathrm{r}^{\prime 2}}{2}+\ldots
\end{aligned}
$$

Da über die Wahl des Koordinatensystems nichts vorausgesetzt war, so können wir dessen Axen mit den im Schwer- oder Mittelpunkt der Erde zusammentreffenden $\mathrm{Hauptträgheitsaxen} \mathrm{des} \mathrm{Erdkörpers}$ identificiren; ist dann $\mathrm{M}$ die Erdmasse, M A, M B, M C je eines der Trägheitsmomente*) für diese Axen, so gelten nach bekannten Sätzen der Dynamik nachstehende Relationen:

$$
\begin{gathered}
\int d m=0, \int x^{\prime} d m=\int y^{\prime} d m=\int z^{\prime} d m=\int x^{\prime} y^{\prime} d m=\int y^{\prime} z^{\prime} d m= \\
\int z^{\prime} x^{\prime} d m=0, \int d m\left(y^{\prime 2}+z^{\prime 2}\right)=M A, \int d m\left(z^{\prime 2}+x^{\prime 2}\right)=M B \\
\int d m\left(x^{\prime 2}+y^{\prime 2}\right)=M C ;
\end{gathered}
$$

das zweite Glied der obigen Reihe kommt in Wegfall, und man hat

$$
\begin{gathered}
\Omega=\frac{\mathrm{M}}{\mathrm{r}}+\frac{\mathrm{M}}{2 \mathrm{r}^{5}}\left[\mathrm{x}^{2}(\mathrm{~B}+\mathrm{C}-2 \mathrm{~A})+\mathrm{y}^{2}(\mathrm{C}+\mathrm{A}-2 \mathrm{~B})\right. \\
\left.+\mathrm{z}^{2}(\mathrm{~A}+\mathrm{B}-2 \mathrm{C})\right]+\ldots
\end{gathered}
$$

Lassen wir alle Glieder dieser Reihe, mit Ausnahme der wirklich hingeschriebenen, bei Seite, so ist $\Omega$ annähernd gleich diesem Ausdruck U, und wird hiezu noch das Schwungkraftspotential $\frac{1}{2} \omega^{2}\left(x^{2}+y^{2}\right)$ addirt, so hat man die Kräftefunktion W, resp. man hat empirisch die Ueberzeugung gewonnen, dass die Differenz

$$
\mathrm{W}-\left(\mathrm{U}+\frac{1}{2} \omega^{2}\left(\mathrm{x}^{2}+\mathrm{y}^{2}\right)\right)
$$

für alle Punkte der Erdrinde klein genug ist, um in erster Annäherung vernachlässigt werden zu können, und lediglich diesem Faktum hat man es zu danken, dass der an sich ungerechtfertigte Versuch, ein Erdellipsoid geodätisch und zugleich durch Pendelbeobachtungen dessen Abplattung ermitteln zu wollen, noch so leidlich gelungen ist. Die Flächen $U=$ Konst. wären die geeigneten geometrischen Vertreter der nun einmal nicht geometrisch, sondern allein mechanisch definirbaren Geoide; freilich sind auch erstere keine eigentlichen Sphäroide, aber doch harmonische Sphäroidalflächen im Sinne der Thomson-Taitschen Terminologie.

*) Wir erinnern daran, dass für ein Massenelement $d \mathrm{~m}$, welches mit einem Schwungradius $r$ rotirt, das Trägheitsmoment für jene Rotationsaxe durch $r^{2} d m$ auszudrücken ist. Hat man es nicht mit einem Elemente, sondern mit einem ganzen Körper zu thun, so ist durch einen Summations-, resp. Integrationsprocess der Ausdruck über alle dem Körper angehörende Elemente zu erstrecken. 
Versteht man unter h den Abstand eines Geoidpunktes vom zugeordneten Sphäroid, unter $\gamma$ die Komponente der Schwere für den nämlichen Punkt, unter $\mathrm{g}$ die wirklich zu ermittelnde Schwere und unter $\varepsilon$ den Winkel, welchen die Richtungen von $\gamma$ und $g$ mit einander einschliessen, so ist

$$
\mathrm{h}=\frac{\mathrm{U}-\mathrm{W}}{\gamma \cos \varepsilon} .
$$

Die Differenz (U - W) liefert also, wenn man von einem konstanten Faktor absieht, das Maass für die Hebungen und Senkungen des Geoids gegenüber jener Sphäroidalf̈̈̈che, welcher der gleiche Potentialwerth zukommt. „Die grössten Beträge von $h$ werden von denjenigen Unregelmässigkeiten der Massenvertheilung herrühren, welche durch den Gegensatz von Kontinent und Ocean repräsentirt werden; den Oceanen werden Einsenkungen, den Kontinenten Erhebungen des Geoids entsprechen $^{\text {" }}[43]$.

§. 8. Schematische Berechnung extremer Werthe von h. Um feste Anhaltspunkte zu gewinnen, denkt sich Bruns den Erdkern als eine homogene Kugel vom Radius a und vom spezifischen Gewichte $\mathrm{d}=5,55$ und ersetzt Oceane wie Festländer durch unendlich dünne Massenbelegungen von denselben Umrissen; deren Belegungen haben bezüglich die Eigengewichte $d_{1} H_{1}\left(d_{1}=-1,5\right), d_{2} H_{2}\left(d_{2}=2,5\right)$, wo $\mathrm{H}_{1}$ und $\mathrm{H}_{2}$ die mittlere Tiefe der Weltmeere und die mittlere Höhe des Festlandes vorstellen. Auf der östlichen Halbkugel gleichen sich die Wirkungen beider Arten von Belegungen fast gänzlich aus, und so mag erstere bei der jetzt anzustellenden Schätzung ausser Betracht bleiben. Fig. 32 stellt die westliche Halbkugel dar; N ist der Nord-, S der Südpol, M das Erdcentrum, $A_{1}$ und $A_{2}$ sind die beiden Aequatorpunkte, denen die Längen $0^{\circ}$ und $180^{\circ}$ entsprechen. Es genügt dann, als mit Festlandmasse bedeckt einen (in der Figur gestrichelten) Kugelstreifen anzusehen, dessen Grenzmeridiane $30^{\circ}$ und $75^{\circ}$ geographische Länge haben. Es gilt nun, das Potential eines homogenen Kugelzweieckes N S auf den Punkt A auszumitteln, in welchem einer seiner Grenzmeridiane den Aequator $\mathbf{A}_{1} \mathbf{A}_{2}$ trifft. $\mathrm{P}$ sei ein Punkt im Inneren jenes Streifens, und es sei ferner arc $\mathrm{AP}=\mathrm{w}, \Varangle \mathrm{PAA}_{2}=\psi, \mathrm{DH}$

Fig. 32.

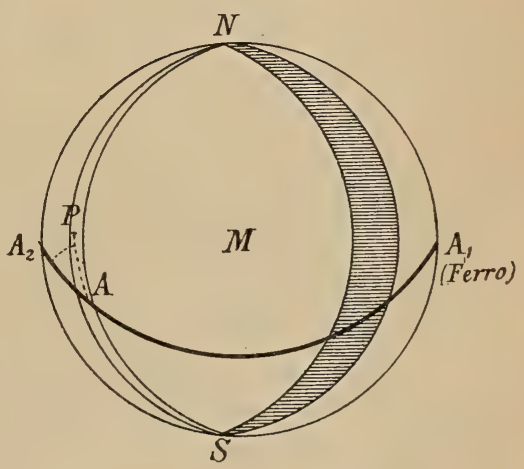
die Masse. Erkennt man dem Punkt A die Länge l zu, so ist für ihn das gesuchte Potential

$$
\Omega_{(1)}=\frac{a^{2}}{2 a} \iint \frac{D H \sin w d w d \psi}{\sin \frac{1}{2} w},
$$

wobei sich das Integral über das ganze $Z$ weieck auszudehnen hat. Nach $\mathrm{w}$ ist eine geschlossene Integration möglich; führt man diese 
aus und setzt sodann mit Bruns [44] tang $\mathrm{w}_{1}=\operatorname{tang} 1 \mathrm{sec} \psi$, so wird schliesslich

$$
\Omega_{(1)}=2 \mathrm{aDH} \int_{-\frac{\pi}{2}}^{\frac{\pi}{2}} \sin \frac{1}{2} \mathrm{w}_{1} \mathrm{~d} \psi \text {. }
$$

Hier liegt nun ein verwickeltes elliptisches Integral vor, dessen Werthbestimmung unser Autor mittelst mechanischer Quadratur ermöglicht. Für $\mathrm{l}=125^{\circ}$ fand sich $\mathrm{h}=1384 \mathrm{~m}$, für $\mathrm{l}=10^{\circ}$ fand sich $\mathrm{h}=1078 \mathrm{~m}$; es kommen somit beim wirklichen Erdkörper Ausbiegungen des Geoides gegen das zugeordnete Sphäroid vor, welche $1000 \mathrm{~m}$ erreichen, wo nicht übersteigen. Diese Quantität ist aber um ein Namhaftes grösser, als die aus den Polhöhenfehlern abgeleiteten Fehler der Halbaxen des „wahrscheinlichsten " Erdellipsoides. Man kann jetzt auch zahlenmässig den Nachweis für die uns aus §. 3 und 4 bekannte Thatsache erbringen, dass der Gegensatz zwischen Land und Wasser beträchtliche Lothablenkungen hervorruft, welche bei den Gradmessungen, wenn diese sich über sehr grosse Bögen erstreckten, gerade nicht mit Nothwendigkeit hervorzutreten brauchten. Entsprechen doch beispielsweise den Werthen $1=60^{\circ}$ und $1=280^{\circ}$ die fast ganz gleichen Werthe $\mathrm{h}=531 \mathrm{~m}$ und $\mathrm{h}=511 \mathrm{~m}$, während andere Punkte derselben Strecke nennenswerthe Abweichungen darbieten.

Oben sahen wir schon, dass der Unterschied zwischen Geoid und Sphäroid den Gang einer Pendeluhr zu beeinflussen vermag. Bedeutet im Gegensatze zum obigen $\gamma$ die Grösse $\gamma^{\prime}$ die nach der Formel $\left(p+q \sin ^{2}\right.$ lat.) berechnete Schwere, so gilt näherungsweise die Proportion $3 \mathrm{~h}: 2 \mathrm{a}=\left(\mathrm{g}-\boldsymbol{\gamma}^{\prime}\right): \gamma$. Es ist aber der Ausdruck

$$
\frac{1}{2} \cdot \frac{3 \mathrm{~h}}{2 \mathrm{a}} \cdot 86400^{\mathrm{s}}=\frac{\mathrm{h}}{\mathrm{a}} \cdot 64700^{\mathrm{s}}
$$

für $\mathrm{h}=1000 \mathrm{~m}$ in den Werth $10,2^{\mathrm{s}}$ übergegangen, und eine solche Zeitdifferenz ist wahrlich schon fühlbar genug.

§. 9. Festlegung des Geoides gegenüber dem Sphäroid. §. 7 lehrte uns bereits, dass der Versuch, analytische Formeln für die Geoidfläche erhalten $\mathrm{zu}$ wollen, ein ganz aussichtsloser ist. Was man wirklich anzustreben hat, das ist nach $\mathrm{Bruns}$ erstens ein Koordinatenverzeichniss für möglichst viele Punkte eines und desselben, wenn auch sonst willkürlichen Geoides sammt den zugehörigen Werthen von W und $g$ und sodann zweitens eine graphische Darstellung, die so wenig, wie irgend eine der bei topographischen Aufnahmen sich ergebenden Linien einer Uebersetzung in die Sprache der Koordinatengeometrie fähig zu sein braucht. Die Frage ist nur: Lässt sich die hiemit umschriebene Aufgabe ohne Beiziehung von Hypothesen mit einem relativen Maximum von Exaktheit lösen? Wäre dem nicht so, dann müsste man freilich trotz all' ihrer Unvollkommenheit zur analytischen Darstellung seine Zuflucht nehmen. Zum wenigsten möglich ist aber eine solche Lösung und zwar dann, wenn drei unter sich völlig verschiedene Operationen ineinandergreifen, von denen bislang jeder einzelnen die Kraft irrig zugeschrieben wurde, welche sie nur im engsten Vereine zu entfalten im Stande sind. Es ist diese Entdeckung, welche wir eben 
Bruns verdanken, eine um so wichtigere, als unsere Vorstellungen von dem, was wir bisher unter Gradmessungsarbeit verstanden, mancherlei Abänderungen erfahren. Die drei Methoden, welche in ihrer Kombination zum Ziele führen, sind folgende: Die astronomisch-trigonometrische Messung, das geodätische Nivellement, und die Bestimmung der Pendelschwere; jedes Verfahren muss für sich besprochen werden.

I. Die astronomisch-trigonometrische Messung. $\mathrm{P}$ und $\mathrm{P}_{1}$ (Fig. 33) seien zwei beliebige Punkte der Geoidfläche $F, K K$ und $K_{1} K_{1}$ die

Fig. 33.

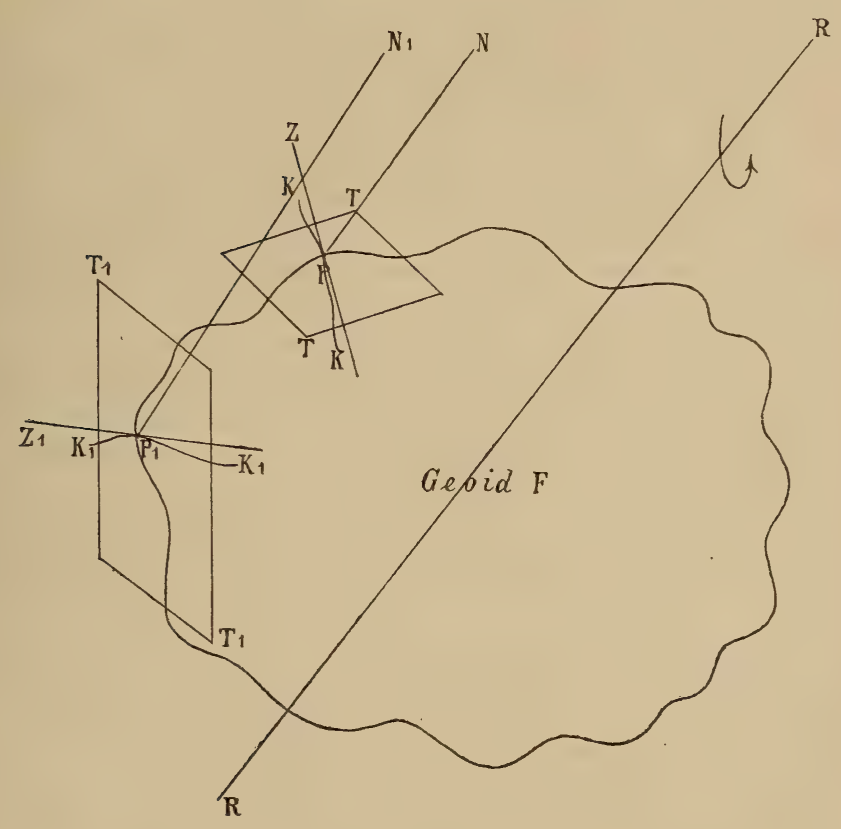

diesen Punkten entsprechenden Kraftlinien, deren Tangenten verlängert durch die Zenitalpunkte $Z$ und $Z_{1}$ von $P$ und $P_{1}$ hindurchgehen würden. Zieht man $\mathrm{PN}$ und $\mathrm{P}_{1} \mathrm{~N}_{1}$ parallel der Rotationsaxe $\mathrm{R} R$, so zeigen beide Gerade nach dem (unendlich entfernten) Nordpol des Himmels hin; die $\Varangle \mathrm{N} \mathrm{PZ}$ und $\mathrm{N}_{1} \mathrm{P}_{1} \mathrm{Z}_{1}$ ergänzen die astronomischen Polhöhen der beiden Orte zu neunzig Grad. Will man die scheinbaren Horizonte haben, so lege man in $\mathrm{P}$ und $\mathrm{P}_{1}$ je eine Berührungsebene $\mathrm{T} T$ und $\mathrm{T}_{1} \mathrm{~T}_{1}$ an $\mathrm{F}$. Als astronomische Meridiane haben die Ebenen $\mathrm{NPZ}$ und $\mathrm{N}_{1} \mathrm{P}_{1} \mathrm{Z}_{1}$ zu gelten. $\Varangle \mathrm{ZP} \mathrm{P}_{1}$ ist die astronomische Zenitdistanz der zwei Punkte, der von den Ebenen Z P N und Z P $\mathrm{P}_{1}$ gebildete Winkel liefert das Azimut von $\mathrm{P}_{1}$ für $\mathrm{P}$, und der von den Ebenen Z P N und $Z_{1} P_{1} N_{1}$ gebildete Winkel ist der Unterschied der geographischen Längen. Alle diese Winkelgrössen sind einer direkten Messung fähig.

Messungen dieser Art setzen uns in Verbindung mit den Basismessungen in den Stand, ein Polyeder im Raume abzugrenzen, von welchem Gestalt und Grösse der einzelnen Seitenflächen genau be- 
stimmbar sind, ebenso die Winkel, welche die einzelnen Seitenflächen mit der Drehungsaxe bilden. Wie weit dagegen diese Fundamentallinie von den einzelnen Kanten und Ecken entfernt ist, darüber vermag der bis jetzt betretene Weg keine Klarheit zu liefern, man müsste denn irgend eine neue Hypothese zu Hülfe nehmen. Letzteres ist denn auch bei allen Gradmessungen geschehen, insoferne deren Berechner dem Geoid ein bestimmtes Umdrehungsellipsoid substituirten. Man projicirte die einzelnen Stationspunkte auf dieses Ellipsoid und erhielt dadurch auf dessen Oberfläche ein System geodätischer Dreiecke, welche nach bekannten Regeln berechnet wurden. Der Grösse nach wichen die Ellipsoide, die bei verschiedenen Gradmessungen benützt wurden, nicht von einander $a b$, wohl aber der Lage nach, und daran allein hielt man fest, dass der Schwerpunkt stets die nämliche Lage im Raume beibehielt. Diese Annahme ist zwar von Hause aus keine in sich begründete, doch zeigt die Uebereinstimmung zwischen Berechnung und Beobachtung bei allen von der Mondparallaxe abhängigen Erscheinungen, dass die Annahme erlaubt war. Freilich aber kann es doch geschehen, dass der Einklang der durch verschiedene Gradmessungen für die Dimensionen des Erdsphäroides gefundenen Zahlen noch keine volle Gewähr der Richtigkeit liefert, weil ja ganz eigenthümliche Kompensationen der Lothablenkungsfehler im Bereiche der Möglichkeit gelegen sind - man denke an Das, was Ph. Fischer (§. 5) für die ostindischen Messungen festgestellt hat. Die astronomisch-trigonometrische Vermessungsarbeit fixirt also - und mehr von ihr zu verlangen, wäre unvernünftig - die Gestalt des Gradmessungspolyeders sammt dem zugehörigen Vertikalensysteme, sowie dessen Orientirung gegen die Erdaxe. Der Abstand der Eckpunkte von dieser Geraden ist vorläufig nicht zu bestimmen.

II. Das geometrische Nivellement. Die übliche wissenschaftliche Redeweise pflegt nicht zwischen $\mathrm{Meereshöhenunterschied} \mathrm{und}$ $\mathrm{Niveaudifferenz} \mathrm{zu} \mathrm{unterscheiden,} \mathrm{doch} \mathrm{sind} \mathrm{die} \mathrm{beiden} \mathrm{Ausdrücke}$ strenge genommen keine synonymen. Wählt man irgend ein Geoid der die Erdrinde bildenden Schaar als Meeresspiegel und fällt aus irgend einem anderen Punkte der Erdrinde auf ersteres eine Normale, so stellt die Länge dieser Normale die Meereshöhe fraglichen Punktes vor, und der geometrische Ort aller Punkte von gleicher Meereshöhe ist eine Parallelfläche zum Geoid. Wären also die einzelnen Geoide Parallelfächen, so wäre der erwähnte Unterschied nicht vorhanden, allein bereits §. 2 dieses Kapitels warnte vor der Täuschung, die Niveauflächen als allenthalben gleichabständig anzunehmen. Wohl aber ist die Niveaudifferenz zweier homologer Punkte auf zwei verschiedenen Graden durchaus konstant, nur wird dieselbe nicht geometrisch, sondern durch die Differenz der Werthe gemessen, welche die Kräftefunktion W in beiden Punkten annimmt. B ru ns beweist nun folgenden Lehrsatz [45]: Multiplicirt man die Differenz der Lattenablesungen mit der zu der Station gehörigen Schwere und summirt diese Produkte für die ganze in Betracht kommende Strecke s, d. h. bildet man das Integral $\int \mathrm{gdh}$, so ist das Ergebniss einzig von der Lage der Endpunkte der Strecke s abhängig und identisch mit der Niveaudifferenz dieser Endpunkte. Diese wichtige Grösse fliesst also bei richtiger Reduktion 
direkt aus den Angaben der Nivellirinstrumente. Sind endlich $W_{1}$ und $\mathrm{W}_{2}$ die Spezialwerthe von $\mathrm{W}$ in den nämlichen Punkten, während $\mathrm{g}_{1}$ einen bestimmten Mittelwerth aus den Werthen von $g$ längs $\mathrm{h}$ darstellt, so ist die Meereshöhe $=\frac{1}{\mathrm{~g}_{1}}\left(\mathrm{~W}_{1}-\mathrm{W}_{2}\right)$.

Das geometrische Nivellement ergänzt sonach das trigonometrische, welch' letzteres mit diesem wenig passenden Namen besser gar nicht bezeichnet würde, und zwar besteht diese Ergänzung in Folgendem. Legt man durch einen der eben fixirten Polyederpunkte das übliche Erdellipsoid, so kann astronomisch-trigonometrisch die Vertikaldistanz eines jeden der übrigen Eckpunkte von jenem Ellipsoid bestimmt werden, während das Nivellement analog die Vertikaldistanz vom Geoid ergiebt. Die Differenz beider Distanzen giebt hiernach die Entfernung beliebig vieler Ellipsoidpunkte von den zugeordneten Geoidpunkten, und darauf kommt es ja in letzter Linie hauptsächlich an.

III. Die Schweremessung. Der Umstand, dass in die obige Nivellirungsformel auch die Grösse $\mathrm{g}_{1}$ eingieng, belehrt uns darüber, dass dem Nivellement Schweremessungen stets zur Seite gehen müssen. Die direkt durch Beobachtungen erhältliche Pendelschwere ist nichts anderes als der Differentialquotient $d W: d n$. Ein seiner theoretischen Grundlage nach zur Verfolgung der Aenderungen dieser Grösse trefflich sich eignendes Instrument wäre auch der Seetiefenmesser von William Siemens, über welchen das von der Bathometrie handelnde Kapitel Näheres beibringen wird; nur ist man bei Anwendung dieses Apparates allerdings gezwungen, aus dem äusseren Potential eines Körpers, nämlich der Erde, auf dessen innere Massenanordnung einen nicht sicheren Schluss zu machen.

§. 10. Geodätische Konsequenzen der Lehre vom Geoid. Dieser Konsequenzen giebt es gar mancherlei, wenn die Wissenschaft sich nicht gegen die Resultate der neuesten Forschung ablehnend verhalten, sondern von diesen auch für ihre praktischen Aufgaben den richtigen Nutzen ziehen will. Nur einzelne Punkte können natürlich hier in aller Kürze ihre Erörterung finden. Wenn z. B. Oudemans [46] bei Diskussion der in geodätischen Kreisen neuerdings vielfach venti-

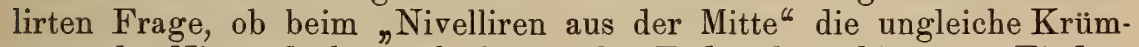
mung der Niveaufläche nach den beiden Endpunkten hin einen Einfluss auf die Höhendifferenz dieser Zielpunkte ausübe, den Erdmeridian als reguläre Ellipse auffasst und so nur einen verschwindenden Schlussfehler herausrechnet, so lässt er eben die geoidischen Unregelmässigkeiten ausser Acht. Z a chariae, Wittstein und Helmert betheiligten sich an dieser Debatte, deren Ende uns durch den Letztgenannten herbeigeführt worden zu sein scheint, indem er - völlig im Einklange mit Bruns (s. o.) - als Höhenunterschied zweier Orte $\mathrm{A}$ und $\mathrm{B}$ die Differenz zwischen den Potentialwerthen der durch A und B gehenden Niveauflächen definirte und diese Differenz dem linearen Normalabstand beider Flächen, multiplicirt mit der Schwere, gleichsetzte [47].

Auch die bisherige Praxis der Gradmessungsarbeiten wird der Bruns'schen Abhandlung mancherlei neue Direktiven zu entnehmen haben. So wird z. B. von Metzger [48] betont, dass die mit Auf- 
gebot aller Mittel in's Werk gesetzte Gradmessung auf den hinterindischen Inseln trotzdem ihren Zweck verfehlt habe, weil neben den mit besonderem Fleisse ausgeführten astronomisch-trigonometrischen Bestimmungen das Nivellement und die Pendelbeobachtung keinen Platz im Programm finden konnte. Wichtiger als ausgedehnte Basismessungen und Triangulationen erscheint zur Zeit die Vornahme spezieller Präcisionsnivellements in den einzelnen Ländern; solche sind namentlich in Bayern vorgenommen worden, und der Leiter dieser Operationen, v. Bauernfeind, hat dieselben in einer Reihe von Publikationen beschrieben [49]; die vierte dieser Publikationen enthält auch [50] ein neues Verfahren zur Ausgleichung polygonaler Schlussfehler, welches, obwohl weit einfacher als die Methode der kleinsten Quadrate, gleichwohl fast die nämliche Genauigkeit erzielen lässt.

Bruns selbst kennzeichnet die Zukunftsideen der Gradmessung, wenn dieser Ausdruck gestattet ist, etwa in folgender Weise. Durch Zusammengreifen der drei uns bekannten Gattungen von Operationen ist zu ermitteln die Gestalt der Geoide, deren Orientirung gegen die Erdaxe und, bis auf eine Konstante, die Kräftefunktion W. Diese Konstante, und zugleich die Lage des Erdschwerpunktes, wäre zu ermitteln, wenn sich eine Dreiecksmessung rings um die ganze Erde herum durchführen liesse, was freilich an äusseren Gründen scheitert. Jedenfalls ist zunächst die Frage zu beantworten, ob die europäische Gradmessung (Kap. I, §. 8) all' jene Data liefert, welche Bruns für seine $\mathrm{Zwecke}$ verlangt. Wie wir wissen, giebt es zwei Gruppen jener Data: die Basis- und Winkelmessungen zur Festlegung eines Erdpolyeders und die Nivellements und Schweremessungen, von welchen die Kenntniss der Meereshöhen und Niveaudifferenzen abhängt. Für die zweite Gruppe ist bereits ausreichend gesorgt, zumal, wenn das Siemens'sche Bathometer sich als verwendbar erweist. Die erste Gruppe anlangend muss dagegen, wenn der Verlauf der Lothablenkungen genau erforscht werden soll, für jeden Ort sowohl Polhöhe als auch Azimut bestimmt werden - eine freilich weitgehende Forderung, die nicht weniger verlangt, als dass jede Station zu einem Hauptdreieckspunkt erhoben werden müsste, die aber doch unerlässlich ist, wenn der Endzweck erreicht werden soll. Sehr hinderlich wird sich dabei besonders auch unsere unvollkommene Kenntniss der irdischen Strahlenbrechung erweisen. Kurz, es steht noch Ungeheures zu leisten bevor; , die ganze auf Grund der ellipsoidischen Hypothese bereits geleistete

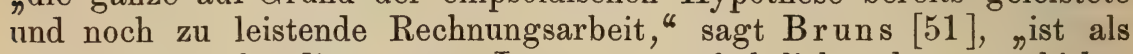
Vorbereitung für die strenge Lösung unentbehrlich, aber was bisher als definitives, die Gradmessungsoperationen abschliessendes Ergebniss angesehen wurde, das hat von den hier entwickelten Gesichtspunkten aus lediglich den Charakter einer nothwendigen Vorarbeit. Die strenge Lösung beginnt erst da, wo man bei der bisherigen Auffassung die Aufgabe bereits als erledigt ansah." Bruns zeigt dann noch, wie vermittelst der Wahrscheinlichkeitsrechnung zuerst die Niveaudifferenzen, sodann die Azimute und schliesslich die Zenitdistanzen ibre Ausgleichung finden, und wie damit die relativ beste Form für das allen Beobachtungen entsprechende Erdpolyeder gefunden wird. „Trägt man die durch das geometrische Nivellement und die Schweremessungen gefundenen Meereshöhen auf den Vertikalen von den 
Polyederecken aus ab, so kennt man damit die Koordinaten der den einzelnen Stationen entsprechenden Punkte eines bestimmten Geoides. Diese Punkte bilden ein Netz von Geoidpunkten erster Ordnung, welches dann als Grundlage für die Einschaltung beliebig vieler neuer Punkte mittelst trigonometrischer Messungen und geometrischer Nivellements dient" [52].

Detaillirte Nachweisungen über die Art und Weise, wie man eine dem Geoid sich möglichst enge anschliessende ellipsoidische Referenzfläche erhalten kann, findet man in dem ausgezeichneten Werke von Helmert [53].

[1] Gerlach, Die Bestimmung der Gestalt und Grösse der Erde, Wien 1782. S. 36. - [2] Walbeck, Dissertatio de forma et magnitudine telluris ex dimensionis arcubus meridianis definiendis, Aboae 1819. - [3] Santini, Delle recenti ricerche intorno alla vera figura della terra dedotta dalle principali misure de' suoi meridiani, Mem. del R. Istit. Ven., Vol. XL. S. 219 ff. - [4] Ph. Arena, Dissertatio geographica de dimensione et figura telluris, Panormi 1757. S. 21. [5] Gauss, Bestimmung des Breitenunterschiedes zwischen den Sternwarten von Göttingen und Altona, Göttingen 1828. - [6] Bessel, Ueber den Einfluss der Unregelmässigkeit der Figur der Erde auf geodätische Arbeiten, Astr. Nachr. 14. Band. S. 269. - [7] Dahlander, Ueber den Einfluss, den die Unebenheiten der Erdoberfläche auf das Niveau des Meeres üben, Ann. d. Phys. u. Chem., 117. Band. S. 148 ff. - [8] Hann, Ueber gewisse beträchtliche Unregelmässigkeiten des Meeres-Niveau's, Gaea, 12. Jahrgang. S. 140. - [9] G. Darwin, On the mechanical effects of barometrical pressure on the earth's surface, Phil. Mag., 1882. S. 409 ff. - [10] Saigey, Petite physique du globe, tome II, Paris 1842. S. 137. - [11] Hann, Ueber gewisse etc. S. 138 ff. - [12] Borenius, Ueber die Berechnung der mit dem unveränderlichen Pendel zur Bestimmung der Abplattung der Erde angestellten Beobachtungen, St. Petersburg 1843. - [13] Bessel, Ueber Maass und Gewicht, Schumacher's astr. Jahrbuch, 1840. S. 134. - [14] A. v. Humboldt, Kosmos, 1. Band, Augsburg und Stuttgart 1845. S. 312. - [15] Rozet, Extrait d'un mémoire sur quelques-unes des irrégularités que présente la structure du globe terrestre, Bull. de la soc. géol. de France, tome XII. S. 176. - [16] Penck, Schwankungen des Meeresspiegels, München 1882. S. 6. - [17] Stokes, On the variation of gravity at the surface of the earth, Cambridge 1849. - [18] Airy, On the attraction of mountains, Phil. Trans., Vol. CXLV. S. 101 ff. - [19] Zanotti-Bianco, Il problema meccanico della figura della terra esposto secondo i migliori autori, Parte I, Firenze-Torino-Roma 1880. S. 242 ff. - [20] Faye, Sur les variations séculaires de la figure mathématique de la terre, Compt. rend. de l'acad. franç., tome XC. S. 1185 ff. - [21] Ph. Fischer, Untersuchungen über die Gestalt der Erde, Darmstadt 1868. S. VII. - [22] Ibid. S. 35 ff. - [23] Ibid. S. 70 ff. [24] Ibid. S. 86. - [25] Ibid. S. 101. - [26] Ibid. S. 107 ff. - [27] Ibid.. S. 194. - [28] Ibid. S. 212 ff. - [29] Pratt, On the attraction of the Himalaya Mountains, Phil. Trans., Vol. CXLV. S. 53 ff. - [30] Pratt, On the deflection of the plumb-line in India, caused by the attraction of the Himalaya Mountains, ibid. Vol. CXIX. S. 745 ff. - [31] Ph. Fischer, Untersuch. etc. S. 219 ff. - [32] Ibid. S. 317 ff. - [33] Listing, Ueber unsere jetzige Kenntniss der Gestalt und Grösse der Erde, Nachr. v. d. k. Gesellsch. d. Wissensch. zu Göttingen, 1873. S. 33 ff. [34] Ibid. S. 88. - [35] Thomson-Tait, Handbuch der theoretischen Physik, deutsch von Helmholtz-Wertheim. I. Band, 2. Theil, Braunschweig 1874 S. $343 \mathrm{ff}$. - [36] Ibid. S. 345. - [37] Bruns, Die Figur der Erde; ein Beitrag zur europäischen Gradmessung, Berlin 1876. - [38] Zech, Die europäische Gradmessung, Deutsche Revue, II. Jahrgang, 2. Band. S. $341 \mathrm{ff}$. - [39] Günther, Ueber die neuesten Bemühungen um schärfere Bestimmung der Erdgestalt, Verhandl. d. III. d. Geographentages, Berlin 1883. - [40] Bruns, Die Figur der Erde, S. 28. [41] Recension zu Rohde, Mathematische Abhandlungen (Potsdam 1867), (Hindenburg's) Archiv f. d. reine u. angew. Mathem., 2. Band. S. 355. - [42] Zech, Die europ. Gradm., S. $346 \mathrm{ff}$ - - [43] Bruns, Die Figur der Erde, S. $17 \mathrm{ff}$ - [44] Ibid. S. 23. - [45] Ibid. S. 34 ff. - [46] Oudemans, Ueber den Schlussfehler wegen 
der sphäroidalen Gestalt der Erde, Astr. Nachr. (2) N. 83. - [47] Helmert, Zur Theorie des geometrischen Nivellirens, ibid. (2) N. 81. - [48] Metzger, Beiträge zur Kartographie von Niederländisch-Ostindien, speziell von Java, Zeitschr.f. wissensch. Geogr., 3. Jahrgang. S. 186. - [49] v. Bauernfeind, Das bayrische Präcisions-Nivellement, 1. Mittheil. München 1870; 2. Mittheil. ibid. 1872; 3. Mittheil. ibid. 1874 ; 4. Mittheil. ibid. 1876 ; 5. Mittheil. ibid. 1879 ; 6. Mittheil. ibid. 1883. - [50] Ibid. 4. Mittheil. S. 40 ff. - [51] Bruns, Die Figur der Erde, S. 47. [52] Ibid. S. 49. - [53] Helmert, Die mathematischen und physikalischen Theorieen der höheren Geodäsie, 1. Theil, Leipzig 1881. S. 564 ff.

Kapitel IV.

\section{Die Bewegung der Erde im Raume.}

§. 1. Die Axendrehung. Nachdem wir in den drei vorangehenden Kapiteln über die Gestalt unseres Erdkörpers zur Klarheit gelangt sind, liegt uns die weitere Pflicht ob, die Bewegungsverhältnisse desselben zu betrachten, welche sich in mehr denn einer Beziehung als für die Geophysik höchst bedeutsam erweisen. An erster Stelle zieht die Drehung der Erde um ihre Axe unsere Aufmerksamkeit auf sich. Der Augenschein spricht allerdings dafür, dass im Verlaufe eines sogenannten Sterntages die Himmelskugel mit gleichförmiger Geschwindigkeit um die Weltaxe rotire, doch leuchtet ein, dass alle von dieser Rotationsbewegung abhängigen Erscheinungen ganz ebensowohl auch durch die Annahme erklärt werden können, die Erde drehe sich mit gleicher Geschwindigkeit und entgegengesetztem Drehsinn um eine Axe, deren Verlängerung nach beiden Seiten hin durch je einen der beiden Weltpole geht, während jene Punkte, in welchen diese Gerade die Erdoberfläche schneidet, die uns von früher her bekannten Erdpole repräsentiren. Einen wirklich strengen mathematischen Beweis für die Richtigkeit dieser letzteren Annahme zu erbringen war erst der allerneuesten Zeit vorbehalten, und wir dürfen es deshalb den Astronomen des Alterthums und des Mittelalters nicht allzusehr verargen, wenn sie bei der dem Sinneseindrucke entsprechenden Vorstellung verharrten, welcher das ptolemäische Weltsystem eine Art von Gesetzeskraft verlieh.

Doch war auch diese Regel keineswegs frei von zahlreichen Ausnahmen. Ob freilich der Aegyptologe $\mathrm{Chabas}$ Recht hat, wenn er die Anrede eines Unterthanen an den Pharao, „tu es le gouvernail de la terre entière; la terre navigue selon ta volonté", auf die Erdbewegung deutet [1], möchten wir dahingestellt sein lassen. Auch die pythagoreische Schule lehrte nicht eigentlich das, was wir heutzutage unter Drehung der Erde verstehen; ihre Anschauung, wie sie namentlich durch Philolaos zum Ausdruck gebracht ward, hat für uns etwas sehr Befremdendes. Henri Martin [2] und Schiaparelli [3], welch' letzterer sich um die antike Vorgeschichte der coppernicanischen Weltordnung ein unvergängliches Verdienst erwarb, gehen betreffs des $\mathrm{Philolaos}$ von ganz verschiedener Grundlage aus und gelangen doch zu dem nämlichen Ergebnisse. Alkmaion, der unmittelbarste Schüler des Pythagoras, formulirte den Satz, dass die Bewegung der Planeten 
in entgegengesetztem Sinne wie diejenige der Fixsterne vor sich gehe [4], und damit ist wohl ausgesagt, dass man in jener frühen Zeit die Erde noch als ruhend gelten liess. Philoloas führte, wie Boeckh zuerst klarstellte [5], die sogenannte Gegenerde (Antichthon) ein, welche ebensogut wie die Sonne, der Mond, die Planeten und die Erde, nur in geringerer Entfernung als diese, um das im Centrum der Welt befindliche Centralfeuer kreise, so zwar, dass beide Weltkörper dem letzteren - wie der Mond der Erde - stets die nämliche Seite zuwendeten. Sehr viel ist über Platon's Stellung zur Rotationsfrage geschrieben worden, wie aus den vergleichenden Zusammenstellungen von Shiaparelli [6] und Heller [7] hervorgeht; namentlich durch Grote [8] dürfte eine Entscheidung in dem Sinne herbeigeführt worden sein, dass im "Timaios" die Umdrehung der Erde um ibre Axe als Mittel zur Erklärung der himmlischen Phänomene in Anwendung zu bringen versucht wurde. Unzweideutig erklärte sich in diesem Sinne zuerst der Platoniker Herakleides Pontikos [9], und ein Gleiches wird von Hiketas und Ekphantos, zwei Syrakusanern, berichtet [10]. In die Fussstapfen des Herakleides trat Aristarch von Samos [11], der jedoch, wie wir später sehen, nicht bei der Axendrehung stehen blieb, sondern auch die Fortbewegung der Erde behauptete. Auch im fernen Indien hatte die erstere Lehrmeinung ihre Anhänger, die Kommentatoren Brahmagupta und Chaturveda bezeugen ausdrücklich [12], dass der berühmte Aryabhatta (etwa um $500 \mathrm{n}$. Chr.) einen Luftstrom angenommen habe, der sich um die Erdkugel herumbewege und diese zwinge, mit einer Minutengeschwindigkeit von 1 „Prana sich um ihre Axe zu drehen. Selbst im Mittelalter fehlt es nicht an Männern, die wenigstens eine Ahnung davon haben, dass der Wechsel von Tag und Nacht einer anderen Ursache zuzuschreiben sein könne, als dem Umschwung des Himmelsgewölbes. So erwähnt der Kirchenvater Origenes des Ekph an tos [13], und der Scholastiker Thomas Aquinas zeigt sich mit den Ansichten des Herakleides und Aristarchos vertraut [14], ja der Kardinal Nikolaus von Cusa stellte sogar eine neue, eigenthümliche Rotationstheorie auf, deren Kern nach früher vom Verf. dieses gegebenen Aufklärungen [15] dahin zu präcisiren ist: I. Die Erde dreht sich in 24 Stunden von Ost nach West um ihre mit derjenigen der Welt zusammenfallende Axe. II. Gleichzeitig wird sie von der achten Sphäre, welche sich im entgegengesetzten Sinne, aber mit der doppelten Winkelgeschwindigkeit um dieselbe Axe dreht, mit fortgenommen. III. Die Sonne nimmt an dem letztgenannten Umschwung Theil, aber mit einer Verlangsamung, welche im Laufe eines Jahres auf $360^{\circ}$ anwächst. Auch einzelne Araber wichen in diesem Punkte von der hergebrachten Doktrin ab, so Ibn el Wardi [16], und wenn auch Katibi (um 1272) diese Neuerung in eingehender Weise kritisirt und verurtheilt [17], so scheint doch eben hieraus hervorzugehen, dass ein guter Grund zu dieser Bekämpfung vorlag. In dem kabbalistischen Buche Sohar findet sich ein merkwürdiger Passus, der in Wackerbarth's Version folgendermassen lautet [18]: „Obiges wird deutlicher im Buche Rabbi Hamnuna's des Aelteren erklärt, dass nämlich die Erde wie eine Kugel im Kreise sich um sich selber dreht, und dass die einen oben, die anderen unten sind. All' diese Menschen sind unter dem Einflusse verschiedener Klimate verschieden 
gestaltet, stehen aber alle aufrecht. So giebt es Orte auf der Erde, wo die Einen Licht und Tag haben, während für die Anderen Finsterniss und Nacht besteht, ja es giebt einen Platz, wo immer Tag und nur für eine kurze Frist Nacht ist."

Man sieht, völlig unbereitet ist des Coppernicus Reform nicht in die Welt getreten. Kurz vor diesem Zeitpunkte machten Tallavia [19] und Lionardo da Vinci [20] dahin zielende Andeutungen, während allerdings die hie und da laut gewordene Behauptung, auch Regiomontan habe sich in diesem Sinne ausgesprochen, mit der Wahrheit in Widerspruch steht [21]. Hingegen unterliegt es keinem Zweifel, dass Celio Calcagnini (1479-1541) seinen Traktat „de perenni motu terrae", den Hipler nach den Quellen edirt [22] und Schlüter in's Deutsche übertragen hat [23], geraume Zeit vor dem Erscheinen von Coppernic's Hauptwerk abgefasst hatte. Freilich hat Prowe [24] es sehr wahrscheinlich gemacht, dass Coppernicus und Calcagñini Anno 1503 zu Ferrara freundschaftlichen Umgang mit einander pflogen, wobei die Gedanken des Einen wohl befruchtend auf den Anderen eingewirkt haben mögen. Jedenfalls begann der deutsche Forscher bald nachher, im Jahre 1506, mit der Aufzeichnung der kosmischen Vorstellungen, durch welche er die ptolemäischaristotelischen $\mathrm{zu}$ verdrängen gedachte [25]. Jedoch verzögerte sich eine endgültige Ausarbeitung zum Druck bis 1543, obgleich schon früher unter dem Titel „Commentariolus de hypothesibus motuum caelestium“ eine Zusammenstellung der wichtigeren Sätze von dem Autor gegeben worden war; Tycho Brahe kannte dieselbe wohl, allein später verlor man diese Schrift völlig aus den Augen, und Curtze musste sie erst förmlich wieder entdecken [26].

Ihren Abschluss erhielt, wie schon bemerkt, die neue Lehre durch das gerade noch vor dem Tode des Verfassers rechtzeitig erschienene grosse Hauptwerk des Coppernicus: De revolutionibus corporum coelestium. Wir beziehen uns im Folgenden auf Menzzer's anerkennenswerthe deutsche Bearbeitung dieses Werkes [27]. Für uns hier sind von besonderer Wichtigkeit die Kapitel 5 bis 8 des ersten Buches. Im fünften Kapitel erörtert der Autor, und zwar mit Bezug auf einzelne der in diesem Paragraphen bereits angeführten Stellen älterer Schriftsteller, die Möglichkeit einer ,kreisförmigen Bewegung der Erde" ; im sechsten stellt er der Unermesslichkeit der Himmelsräume die winzige Kleinheit der Erdkugel gegenüber*); im siebenten bespricht er die von den Alten für die Ruhe unseres Wohnkörpers beigebrachten Beweise, und im achten widerlegt er dieselben mit Ruhe und Sachlichkeit. Eigentlich durchschlagende Gründe für seine eigene Be-

*) Es waren besonders diese Ausführungen, welche dem Coppernicus die Gegnerschaft protestantischer Theologen, vor Allem Melanchthon's zuzogen. L u ther selbst, der von gelehrten Schrullen weit weniger eingenommen war, als sein Mitarbeiter, kümmerte sich nicht viel um die mit der heliocentrischen Reform freilich unlöslich verknüpfte Degradirung des Erdkörpers, wie er denn beispielsweise einmal sagte [28]: "Ich gläube, dass ein Stern grösser ist, denn die ganze Welt." Um so weniger freilich behagte seiner naiven Weltanschauung die Umdrehung des „Erdreiches“, dass „die Erde beweget würde und nicht der Himmel" [29]. Theologische Einwendungen scheinen dem Reformator auf religiösem Gebiete jedoch ebenso ferne gelegen zu haben, wie sie dem weitaus grössten Theile der katholischen Gottesgelehrten anfänglich lagen. 
hauptung ist er freilich (s. o.) noch nicht anzugeben im Stande und begnügt sich deshalb mit dem seine edle Bescheidenheit trefflich kennzeichnenden Schlussworte [30]: „Man sieht also, dass aus allem Diesem die Bewegung der Erde wahrscheinlicher ist, als ihre Ruhe, zumal in Bezug auf die tägliche Umdrehung, welche der Erde am eigenthümlichsten ist."

Im Verlaufe des XVI. Jahrhunderts gewann die neue Lehre nicht eben weiten Boden. Von Tycho Brahe z. B. muss leider gesagt werden, dass er in seinen Briefen an Rothmann die absurdesten Gegengründe geltend machte [31], wie etwa den, ein auffliegender Vogel werde das rasch unter ihm wegbewegte Nest nicht wiederfinden; noch 100 Jahre später weiss Riccioli den 49 für Coppernicus sprechenden Argumenten 77 gegentheilige gegenüberzustellen [32] vielleicht freilich nur deshalb, um nicht mit der pflichtmässigen Astronomie seines, des Jesuiten-Ordens, in Konflikt zu gerathen [33]. Bemerkt $\mathrm{zu}$ werden verdient, dass der ungeheure Vortheil, der auch nur unter dem Utilitätsgesichtspunkte in der Annahme einer sich drehenden Erde liegt, von einer Reihe Gelehrter wohl beherzigt wurde, die im Uebrigen Bedenken trugen, dem kühnen Gedankenfluge Coppernic's sich anzuvertrauen. Dahin gehören Reimarus Ursus und Longomontanus [34], insbesondere aber auch Origanus, der in der Einleitung zu seinen Ephemeriden von 1609 sich unumwunden dahin ausspricht [35], die Erdkugel nehme zwar die Mitte der Welt ein, drehe sich aber um ihre Axe und verursache so die Erscheinung der täglichen Himmelsbewegung.

§. 2. Unveränderlichkeit der Rotationsaxe und Rotationsdaner. Nachdem man einmal wusste, dass die Erde sich um ihre Axe drehe, warf man die weitere Frage auf, ob diese Umdrehungsaxe zu allen Zeiten ein und dieselbe gewesen sei. Die kosmogonischen Hypothesen, welche das XVIII. Jahrhundert im Ueberflusse lieferte, operirten mit Axenversetzungen ganz nach Belieben, indem sie dieselben durch den Anstoss anderer Himmelskörper erklärten (Buffon, Klee, Boucheporn u. A.). Eine ausführliche Widerlegung dieser mehr oder minder absurden Theorieen ist in Mädler's Aufsatz „Die Erdaxe“ zu finden [36], auch hatte schon vor längerer Zeit Bode die Zulässigkeit solch' gewaltsamer Umänderungen der Erdaxenlage bestritten und behauptet, die Erdpole hätten ,ihre schicklichste Lage" inne [37]. Dagegen hat neuerdings wieder Stark diesen Deus ex machina herbeigerufen [38], um für gewisse geologische Veränderungen verwerthet zu werden. Ihm zufolge umgiebt die Erdkruste freischwebend den sphärischen, aus geschmolzenen Massen bestehenden Erdkern; schlägt diese Flüssigkeit unter der Einwirkung irgend welchen Agens an die Innenfläche des festen Kugelringes, so bewirkt sie jene geologischen Störungen, und als das Hauptagens, von dem die Rede war, gilt eine Umsetzung der Erdaxe, die selbst wieder ihren Grund darin hat, dass die Gebirgsmassen einem aus der Centrifugalkraft resultirenden Tangentialschub Folge leisten. Man kann darüber streiten, ob bei dieser Auffassung der Erklärungsversuch leichter zu begreifen sei, als das zu erklärende Phänomen.

Es ist jedenfalls zu bedauern, dass solche Hypothesen von ihren Autoren gewöhnlich nicht mit denjenigen strenge mathematischen Hülfs- 
mitteln geprüft zu werden pflegen, welche doch bereit vorliegen. Allerdings ist hierzu vorher völlige Einsicht in das Wesen einer Axenbewegung zu erlangen, und dass diese Einsicht nicht so ganz einfach ist, beweist schon der Umstand, dass sie dem Coppernicus fehlte. Erst die mit Galilei beginnende Vervollkommnung der theoretischen Mechanik hat uns in den Stand gesetzt, den fraglichen Bewegungsvorgang folgendermassen ganz allgemein zu interpretiren. Für jeden Punkt eines Körpers lassen sich im Allgemeinen drei freie Axen oder Hauptaxen angeben, um welche der Körper sich ganz in gleicher Weise dreht, sei es nun, dass die betreffende Axe in zwei Punkten festgehalten wird oder sich selbst parallel im Raume fortschreitet. Speziell von Bedeutung sind diese drei Axen dann, wenn sie im Schwerpunkte des Körpers senkrecht auf einander stehen. Das Trägheitsmoment jenes ist nämlich alsdann in Bezug auf die eine dieser Axen grösser, in Bezug auf eine zweite kleiner als in Bezug auf irgend eine andere den Schwerpunkt in sich schliessende Umdrehungsaxe. Die Fundamentaleigenschaft der dritten Hauptaxe lässt sich nicht mit so wenigen Worten definiren. Man lege eine Ebene (I,III) durch die erste und dritte, eine andere Ebene (II,III) durch die zweite und dritte Axe: dann ist das Trägheitsmoment hinsichtlich III kleiner als hinsichtlich einer in (I,III) liegenden und durch den Schwerpunkt gehenden Geraden und grösser als hinsichtlich jeder beliebigen in (II,III) liegenden und ebenfalls durch den Schwerpunkt gehenden Geraden. Wenn es sich um die praktische Ermittelung dieser freien Axen handelt, so kann man nach Gregory folgenden Weg einschlagen [39]. Man weiss, dass, sobald der Körper um eine dieser Axen rotirt, alle Centrifugalkräfte sich das Gleichgewicht halten, und begründet auf diese Thatsache die Einrichtung des in Fig. 34 abgebildeten Apparates. Das Rad C ertheilt

Fig. 34 .

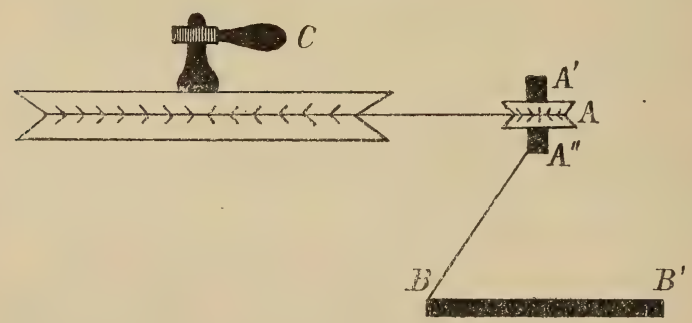

der Rolle A eine horizontale Drehbewegung; an der Axe $\mathrm{A}^{\prime} \mathrm{A}^{\prime \prime}$ wird ein Faden A"B befestigt, an welchem hinwiederum für's Erste ein Stab BB' aufgehängt sein möge. Sowie die Umdrehung beginnt, stellt sich dieser Stab horizontal ein, während A"B einen Kegelmantel beschreibt. Statt des Stabes kann jedoch ein Körper jedweder Art mit verschiedenen Punkten angeheftet werden, und es lassen sich so die Hauptträgheitsaxen direkt bestimmen.

Erleidet nun die Rotationsaxe der Erde irgendwie eine Ortsveränderung, so geschieht ein Gleiches mit den beiden anderen permanenten Axen. Auch der Schwerpunkt wird, wenn auch nicht unbedingt nothwendig, seinen Ort verändern, und so werden auch die Polhöhen und 
Mittagsunterschiede der einzelnen Erdorte Variationen erfahren. Diese letzteren hat Bessel [40] zu schätzen gelehrt. Er bezeichnet durch $\beta^{\prime}$ und $\lambda^{\prime}$ die mittlere Breite und (geocentrische) Länge, deren Werth sich ergeben würde, wenn die Drehung um die veränderte Polarhauptaxe vor sich gienge, mit $\beta$ und $\lambda$ dagegen die ursprüngliche Breite und Länge - letzteren Winkelwerth von demjenigen Punkte des Aequators aus gerechnet, in welchem dieser von der Hauptaxe I geschnitten wird (Hauptaxe III ist die faktische Umdrehungsaxe). Versteht man ferner unter $\mathrm{E}$ und $\mathrm{E}^{\prime}$ die Ebenen der ursprünglichen und der neuen Hauptaxen, unter $\vartheta$ den von diesen Ebenen gebildeten Winkel, unter $\psi$ die Länge des gemeinsamen Anfangspunktes der $\lambda$ und $\lambda^{\prime}$, diessmal von dem aufsteigenden Knoten der $\mathrm{E}$ auf $\operatorname{der} \mathrm{E}^{\prime}$ aus gezählt, so liefern die bekannten Transformationsformeln für Raumkoordinaten nachstehendes System:

$$
\begin{aligned}
\cos \beta^{\prime} \cos \left(\lambda^{\prime}+\psi\right) & =\cos \beta \cos (\lambda+\psi), \\
\cos \beta^{\prime} \sin \left(\lambda^{\prime}+\psi\right) & =\cos \beta \sin (\lambda+\psi) \cos \vartheta-\sin \beta \sin \vartheta \\
\sin \beta^{\prime} & =\cos \beta \sin (\lambda+\psi) \sin \vartheta+\sin \beta \cos \vartheta
\end{aligned}
$$

Diese Gleichungen ermöglichen es, die neuen Koordinaten eines Ortes nach erfolgter Umsetzung der Erdaxe aus den alten zu berechnen. Bedeuten ferner A, B, C die drei Hauptträgheitsmomente der Erde, $\mu$ das Stück Masse, dessen Ortsveränderung die Transposition der Rotationsaxe nach sich zog, l, b ; l' $\mathrm{l}^{\prime}$ die geographischen Koordinaten der Orte, an welchen der Schwerpunkt von $\mu$ sich ursprünglich befand und sich nunmehr befindet, $\mathrm{m}$ endlich die Erdmasse, so gelten die weiteren Formeln:

$$
\begin{aligned}
& \lambda^{\prime}-\lambda=\frac{-\mu \tan \beta}{A+B-2 C}\left[\sin 2 b^{\prime} \sin \left(1^{\prime}-\lambda\right)-\sin 2 b \sin (1-\lambda)\right], \\
& \beta^{\prime}-\beta=\frac{\mu}{A+B-2 C}\left[\sin 2 b^{\prime} \cos \left(1^{\prime}-\lambda\right)-\sin 2 b \cos (1-\lambda)\right] ;
\end{aligned}
$$

$\mathrm{A}+\mathrm{B}-2 \mathrm{C}$ ist dabei $=-(133 \mathrm{~m}: 67626) \mathrm{zu}$ nehmen. Hiernach ermittelt Bessel, dass, wenn die maassgebende Grösse

$\mu:(\mathrm{A}+\mathrm{B}-2 \mathrm{C})$
auch nur $1^{\prime \prime}$ betragen soll, das Gewicht der Masse $\mu$ einem Blocke von 114 geographischen Kubikmeilen entsprechen muss, dessen Eigengewicht demjenigen der Erde gleichkommt. Dieses Ergebniss zeigt recht deutlich, welch' minimalen Einfluss auf die Lage der Rotationsaxe die gewaltigsten geologischen Umwälzungen ausüben.

W eit sorgfältiger noch und mit Aufbietung der feinsten rechnerischen Hülfsmittel haben die von Bessel angeregte Frage zwei ausgezeichnete Mathematiker der Neuzeit behandelt, Gyl dén [41], und G. D a rwin [42], und zwar hat sich der erstere mehr auf den astronomischen Standpunkt gestellt, während Darwin vorwiegend die geodynamische Seite in Betracht zog. Diese Untersuchungen bestätigen im Wesentlichen unser früheres Resultat; selbst ein grossartiges geologisches Ereigniss, wie die Entstehung eines neuen Kontinentes, würde, solange dem Erdkörper der ihm gegenwärtig zukommende Grad von Festigkeit verbleibt, die kleinste Hauptaxe nur um 3 Grade aus ihrer Lage herauszudrehen vermögen. Früher, als diese gegenwärtige Kohäsionskraft noch nicht erreicht war, mag es sich anders verhalten haben, indess entziehen sich eben die damaligen Verhältnisse zu sehr unserer Kenntniss, als dass mit 
denselben gerechnet werden könnte*). Die von Schmick theoretisch aus seiner bekannten Hypothese der Meeresumsetzung gefolgerten Aenderungen der Polhöhe sollen uns hier nicht näher beschäftigen, da sie mit der Hypothese selbst stehen und fallen, zur Besprechung dieser aber späterhin eine weit geeignetere Gelegenheit sich ergeben wird. Im 5. Bande der 2. Serie des "Geological Magazine " findet man eine interessante Diskussion, geführt zwischen Hill ( ${ }_{\eta} \mathrm{On}$ the possibility of changes in the earth's axis“, S. $262 \mathrm{ff}$.) und Fisher („On the possibility of changes in the latitudes of places on the earth's surface", S. $291 \mathrm{ff}$., S. $551 \mathrm{ff}$.); dieselbe knüpft an die Frage nach dem eigentlichen $\mathrm{Zu}$ stande des Erdinneren und damit an Gegenstände an, welche im zweiten Kapitel der nächsten Abtheilung ihre Erledigung finden werden. In England trägt man zur Zeit diesen Dingen ein lebhaftes Interesse entgegen, verliert sich aber auch wohl zuweilen in Abenteuerlichkeiten, wie z. B., wenn man die säkuläre Abnahme in der Intensität der Mondstrahlung mit der Versetzung der Erdaxe in Verbindung bringen wollte.

Wenn nun schon nach allem Vorhergehenden für eine irgend erhebliche Ablenkung der Erdaxe von einer früher eingenommenen Lage nur eine geringe Wahrscheinlichkeit besteht, so ist doch diejenige Wahrscheinlichkeit noch weit kleiner, welche für eine nachweisbare Veränderung der Rotationsgeschwindigkeit anzuführen wäre, wenigstens insoweit es sich um historische Zeiten handelt. An und für sich sollte man eigentlich das Gegentheil glauben, denn zwei Momente scheinen gegen eine solche Konstanz zu sprechen. Im ersten Kapitel der ersten Abtheilung lernten wir die Erde als einen in stets fortschreitendem Erkaltungsprocesse befindliche Kugel kennen, und da mit jeder Erkaltung eine Zusammenziehung verbunden ist, so müsste der ein immer geringeres Volumen gewinnende Körper allmählig ein rascheres Tempo in seiner Umdrehung annehmen. Andererseits macht Robert Mayer [45] - man vergleiche den Abdruck seiner diesem Gegenstande gewidmeten Darlegung, begleitet von Zöllner's Bemerkungen, in dem Kometenwerke des Letzteren - darauf aufmerksam, dass die Fluthwelle eine retardirende Wirkung auf die Geschwindigkeit des Erdumschwunges ausüben müsse. Die Erde dreht sich von

*) Da, wie wir sahen, die geographischen Breiten unmittelbar von der Lage der Drehungsaxe abhängig sind, so können auch die ersteren so lange keiner periodischen oder unperiodischen - Veränderung unterworfen sein, als die letztere unverrückt dem nämlichen Punkte der Himmelskugel zugewendet ist. Domenico Maria di Novara, der Lehrer des jungen Coppernicus, hatte, worüber Näheres bei Prowe [43] nachzulesen ist, die Behauptung aufgestellt, dass die Polhöhen seit der ptolemäischen Epoche stetig sich vergrösserten; Magin i, Gilbert, Riccioli und Snellius nahmen von dieser Angabe Notiz, wenn auch nur theilweise in zustimmendem Sinne. Von Gilbert erfahren wir aber, dass auch die entgegengesetzte Ansicht ihre Anhänger hatte; was der berühmte Physiker hierüber mittheilt, hat den folgenden Wortlaut [44]: "Ita juxta has D ominici Mariae observationes polus Boreus altius elevatur et latitudines regionum majores existunt, quam, olim; unde immutationem arguit latitudinum. Jam vero Stadius contraria prorsus opinione decrevisse latitudines per observationes probat." Novara glaubte sich freilich überzeugt halten zu dürfen, dass seine Messungen sehr genau seien, die Neuzeit jedoch vermochte die von ihm aus dem Vergleiche mit Hipparch und Ptolemäus gezogenen Differenzen einfach auf Beobachtungsfehler zurückzuführen. 
West nach Ost, während die dem scheinbaren Laufe der Gestirne folgende Mond- und Sonnenfluthwelle von Ost nach West um die Erde herumkreist. Sie schlägt somit unaufhörlich an die Ostränder der Kontinente und trägt langsam dazu bei, die aktuelle Energie der Rotationsbewegung zu konsumiren. Sollte jeder der beiden störenden Einflüsse für sich von differentieller Kleinheit sein, oder sollten sich beide gegenseitig neutralisiren - so viel steht fest, dass es bislang noch nicht gelungen ist, einen derselben thatsächlich nachzuweisen*); Hertz allerdings hält es [46] mit Thomson und Tait für wahrscheinlich, dass die Erde im Verlaufe eines Jahrhunderts 22 Sekunden hinter einem richtigen Chronometer zurückbleibe - eine Verzögerung, die nur durch eine längs des Aequators konstant von Ost nach West gerichtete Kraft von $530000000 \mathrm{kgm}$ zu erklären wäre. Das Meer müsste sich zu dem Ende an den Westküsten der Oceane um $0,3 \mathrm{~m}$ über die durch jene gelegten Niveauflächen erheben. Aus einer $\mathrm{Ab}$ handlung von Tägert (vgl. §. 13) scheint zu erhellen, dass bei tieferer analytischer Untersuchung die Angelegenheit noch nicht spruchreif und es verfrüht ist, die Verzögerung der Erdrotation durch die Fluthreibung als eine Thatsache zu behandeln. Wie aber wäre überhaupt ein solcher Nachweis zu erbringen?

J. J. v. Littrow charakterisirt das zu diesem Behufe dienliche Verfahren so einfach und elegant in seinem Gehler-Artikel "Tag* [47], dass wir nicht umhin können, die wesentlichsten Punkte aus seiner Erörterung hier niederzulegen. Seit den ältesten kontrolirbaren Beobachtungen von Finsternissen, welche wir den Chaldäern verdanken, sind 2500 Jahre verflossen; dieser nicht eben kurze Zeitraum steht uns also für unsere Betrachtungen zur Verfügung. Betrüge nun etwa die konstant sich wiederholende Verkürzung der Tagesdauer den aten Theil des heutigen Tages, als des letzten der angenommenen Periode, und wäre $n$ der Bogen, welchen der Mond im Verlaufe eines mittleren Tages am Himmel zurücklegt, so hätte man, den gegenwärtigen mittleren Tag zur Zeiteinheit genommen, für die in den der Reihe nach vorhergehenden Tagen beschriebenen Bogen des Mondlaufes die Werthe:

$$
\mathrm{n}, \mathrm{n}(1+\alpha), \mathrm{n}(1+2 \alpha), \mathrm{n}(1+3 \alpha) \ldots \mathrm{n}[1+(\mathrm{t}-1) \alpha]
$$

$\mathrm{t}$ bezeichnet die Anzahl der Tage in dem ganzen Intervall. Man hat hier eine arithmetische Reihe vor sich, deren Summe

$$
\mathrm{S}=\frac{\mathrm{t}}{2}[\mathrm{n}+\mathrm{n}+\mathrm{n} \alpha(\mathrm{t}-1)]=\mathrm{nt}+\frac{1}{2} \mathrm{n} \alpha \mathrm{t}(\mathrm{t}-1)
$$

gefunden wird, wofür aber angesichts des grossen Zahlenwerthes von $\mathrm{t}$ auch

$$
\mathrm{S}=\mathrm{nt}+\frac{1}{2} \mathrm{n} \alpha \mathrm{t}^{2}
$$

*) Von dem Widerstande des Aethers nimmt die Wissenschaft aus den in Kap. II, §. 15 der ersten Abtheilung entwickelten Gründen Abstand. Eher könnte der Meteoritenfall in Betracht kommen, doch hat auch für diese Weltkörper $\mathrm{New-}$ $\mathrm{c} 0 \mathrm{mb}$ in seiner gleich nachher zu erwähnenden Abhandlung dargethan, dass sie, um die Tagesdauer zu alteriren, in ganz unverhältnissmässig grösserer Menge der Erde begegnen müssten, als nach unseren bisherigen Erfahrungen anzunehmen ist. 
gesetzt werden kann. Um das zweite Glied $\frac{1}{2} \mathrm{n} \alpha \mathrm{t}^{2}$ dieses Ausdrucks wäre also die tabellarische Länge des Mondes zu vermehren. Wären $n^{\prime}$ und $S^{\prime}$ analoge Grössen für die Sonnenbewegung, so wäre

$$
\mathrm{S}^{\prime}=\mathrm{n}^{\prime} \mathrm{t}+\frac{1}{2} \mathrm{n}^{\prime} \alpha \mathrm{t}^{2}
$$

zu setzen, und durch Subtraktion fände sich

$$
\mathrm{S}-\mathrm{S}^{\prime}=\mathrm{t}\left(\mathrm{n}-\mathrm{n}^{\prime}\right)+\frac{1}{2} \alpha \mathrm{t}^{2}\left(\mathrm{n}-\mathrm{n}^{\prime}\right)=\mathrm{t}\left(\mathrm{n}-\mathrm{n}^{\prime}\right)+\delta .
$$

Wegen der Tagesverkürzung müsste sohin für eine t Tage vor unserer Zeit beobachtete Sonnenfinsterniss die tabellarische Längen-Differenz $\left(\mathrm{S}-\mathrm{S}^{\prime}\right)$ der beiden Hauptgestirne um die Grösse $\delta$ vergrössert werden. Führt man die betreffende Rechnung wirklich durch, so findet man, dass selbst dann, wenn $\alpha$ mit einem Zehnbilliontel der Zeiteinheit identificirt wird, der Tafelfehler, der bisher nur auf wenige Bogensekunden sich belief, auf den hohen Werth von 30 Bogenminuten gesteigert würde. Gestützt darauf, darf man getrost die bereits von Laplace erkannte Wahrheit aussprechen, dass zur babylonischen Zeit der Tag noch nicht um 0,01 Zeitsekunden länger war, als heute.

Statt von Sonne und Mond kann man, wie Schönfeld [48] betont, bei der Entscheidung der vorwürfigen Frage auch von jedem beliebigen anderen Himmelskörper ausgehen, dessen mittlere säkuläre Bewegung genau bekannt ist, und zwar mit um so mehr Erfolg, je rascher er sich in seiner Bahn bewegt. Weiter erinnert der genannte Astronom daran, das es an einer völlig genügenden Mondtheorie noch immer fehle, dass die von Hansen aufgestellte hinter den an sie geknüpften Erwartungen zurückgeblieben sei, und dass auch durch die tiefgreifenden Untersuchungen eines Adams, Delaunay und Newc o m b das vorgesteckte Ziel einer völligen Konkordanz von Berechnung und Beobachtung nicht habe errreicht werden können. Diese Nichtübereinstimmung zu erklären, gäbe es nur zwei Annahmen: entweder sind noch unentdeckte Fehler vorhanden oder die Rotationsgeschwindigkeit der Erde, das astronomische Normalzeitmaass, besitzt keinen konstanten Werth. Ersteres wird als das weitaus Wahrscheinlichere bezeichnet, doch ist die Möglichkeit nachgerade nicht ausgeschlossen, dass seit einem Vierteljahrhundert jeder Tag um 1/3000000 Sekunde kürzer geworden sei, als sein unmittelbarer Vorgänger. Newcomb hält es nicht für undenkbar, dass die Axendrehung Ungleichheiten von langer Periode und unregelmässigem Charakter unterworfen wäre, diskutirt vielmehr diese Hypothese sehr ernsthaft [49]. Er weist nämlich darauf hin, dass das Erdinnere wahrscheinlich durch eine flüssige, mit grosser Beweglichkeit der Theilchen begabte Masse erfüllt wird. Gelangt nun ein erhebliches. Quantum dieser Masse durch eine wie immer beschaffene Ursache aus der Umgebung des Aequators in höhere Breiten, und nähert es sich so der Drehungsaxe, so gewinnt der Erdkern ein grössere, die feste Kruste eine kleinere Winkelgeschwindigkeit, bis allmählig die Reibung eine Ausgleichung und schliesslich sogar eine beschleunigte Rotation der Umbüllung herbeiführte. Fortgesetzte Beobachtungen des Mondes, sowie der Durchgänge der beiden unteren 
Planeten durch die Sonnenscheibe verschaffen uns vielleicht einige Einsicht in dieses merkwürdige Wechselspiel.

Auf eine autonome Bewegung der Erdkruste, die aber eben vermuthlich auch in den soeben geschilderten Verhältnissen begründet wäre, deuten gewisse Bewegungsphänomene, deren Kenntniss wir Bertelli [50] verdanken. Einige Beobachtungen von Mersenne*) [51], von Lecat [52], von Toaldo [53] über unregelmässige Oscillationen freihängender Pendel gehören hierher; wenigstens lassen sie sich aus dem Foucault'schen Pendelversuche nicht kausal erklären. Ebenso nahm D'Abbadie auf seiner äthiopischen Reise Schwankungen der Luftblase seiner Libelle wahr, welche er nur mit einer durch die Attraktion von Sonne und Mond bewirkten Eigenbewegung der Erdkruste in Verbindung bringen zu können glaubte. Parnisetti [54] will diese Bewegung statistisch nachgewiesen haben. Endlich mag auch bei diesem Anlasse an die so manches Räthsel in sich schliessenden Experimente Ph. Plantamour's erinnert sein. Derselbe nahm wahr, dass die Blase des Instrumentes periodische Oscillationen vollzog, ob ihre Axe nun in die Meridanebene fiel oder auf dieser senkrecht stand. Für ein bestimmtes Beobachtungsjahr konnte an eine in bestimmter Richtung erfolgte Bodensenkung gedacht werden, allein im Grossen und Ganzen vermochte dieser Umstand ebensowenig, wie der eine und andere leichte Erdstoss, das Kausalitätsbedürfniss zu befriedigen. Plantamour musste sich damit begnügen, von der Zukunft weitere Aufschlüsse zu erhoffen; „ces observations des niveaux, ${ }^{\text {}}$ sagt er [55], seront continuées, et la comparaison des mouvements périodiques du sol pendant plusieurs années amènera peut-être à connaître la cause ou les causes multiples qui les produisent." Uns will bedünken, dass $\mathrm{Newcomb}$ wenigstens einen der Schlüssel zur Ergründung dieser Mysterien uns in die Hand gegeben habe; Zöppritz führt das Phänomen auf die ungleiche Erwärmung des Untergrundes zurück.

§. 3. Konsequenzen aus der Axendrehung der Erde. Wenn wir in diesem Paragraphen von den Folgerungen sprechen, welche aus der als wahr anerkannten Lehre von der Erdrotation entfliessen, so verfahren wir in einem der üblichen didaktischen Methode gerade entgegengesetzten Sinne. Man ist nämlich gewohnt, die Erscheinungen, mit welchen wir uns zu beschäftigen gedenken, als Beweismittel für den ersten Satz des coppernicanischen Systemes zu verwerthen, während wir diesen Satz als ipso facto gültig betrachten und zusehen, welcher Art die sichtbaren und fühlbaren Manifestationen der Axendrehung unserer Erde sind $\left.{ }^{* *}\right)$. Scheinbeweise wie z. B. der, dass ja auch die übrigen Planeten eine solche Bewegung aufweisen, können ohnehin in einer wissenschaftlichen Darstellung keine Stelle finden.

a) Fallversuche. Während Tycho Brahe (s. o.) von der Ansicht ausgieng, ein freifallender Körper müsse westlich von dem Punkte zur Erde gelangen, von welchem aus man ihn fallen liess, erkannte

*) Die sechzehnte Proposition in Mersenne's „Ballistica et acontismologia" will "quid circa pendulum, quod aliqui vocant sexhorarium, contingat, ex observationibus aperire."

**) Verf. bezieht sich hier auf einen früher publicirten und den Gegenstand mehr im Detail behandelnden Aufsatz [56]. 
Newton zuerst, dass sich Alles gerade umgekehrt verhalten müisse, indem ja alle im Anziehungsbereiche der Erde befindlichen Körper unbedingt an deren Umschwung theilnehmen. Im November 1679 verständigte er sich mit dem berühmten Experimentator Hooke über Versuche, welche in dieser Absicht anzustellen wären [57], doch glückte es damit ebensowenig, wie mit jenen Proben, die Gassendi schon früher auf eigene Hand an den Mastbäumen schnellsegelnder Schiffe gemacht hatte [58]. Etwas besser gelang der Versuch dem Italiener Guglielmini [59], aber erst B en z en berg brachte es 1804 im Inneren des Michaelisthurmes zu Hamburg zu einer solchen Genauigkeit [60], dass Laplace seine Ergebnisse dem Wahrscheinlichkeitskalkul gemäss zu bearbeiten und mit ihrer Hülfe die Wahrscheinlichkeit für eine wirkliche Axendrehung der Erde auf 7999/3000 anzusetzen in der Lage war. Die neueste und beste Versuchsreihe dieser Art verdankt man Reich, der den tiefen Freiberger Dreibrüderschacht zu seinen Beobachtungen benützte [61]. Ist M (Fig. 35) der Erdmittelpunkt, A B ein auf der Oberfläche befindlicher Thurm,

Fig. 35 .

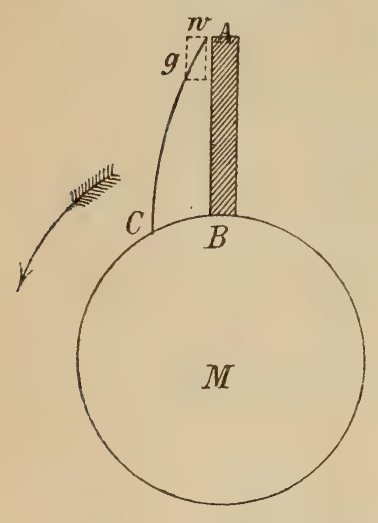
und lässt man von der Spitze A desselben einen schweren Körper vertikal herabfallen, so wirken auf dessen Schwerpunkt zwei Kräfte: die Fallbeschleunigung $g$ und der aus der Umdrehung entspringende, der Geschwindigkeit von A gleiche Impuls. Der Körper beschreibt sonach eine Parabel oder richtiger einen kubischen Kegelschnitt und trifft die Erdoberfläche in einem Punkte C, der von B gegen Osten gelegen, ausserdem aber etwas nach Süden von der Mittagslinie abgelenkt ist; eine Formel zur Berechnung der östlichen Ablenkungsgrösse ist von Olbers dem erwähnten Benzenberg'schen Buche einverleibt worden. Nach Wernick e (Grundzüge der Elementarmechanik, Braunschweig 1883, S. 227) ist, wenn $g \varphi, R$ die der Breite $\varphi$ entsprechende Fallbeschleunigung auf einer Erdkugel vom Radius $\mathrm{R}$ bedeutet, wenn die Höhe der Fallstrecke $\mathrm{z}$ und die Umdrehungszeit der Erde $\mathrm{T}$ ist, östliche und südliche Abweichung sehr angenähert resp. durch einen der beiden folgenden Ausdrücke gegeben:

$$
\frac{4 \pi \cos \varphi \cdot \mathrm{z}}{3 \mathrm{~T}} \sqrt{\frac{2 \mathrm{z}}{\mathrm{g} \varphi, \mathrm{R}+\mathrm{z}}} \text { und } \mathrm{z} \cdot \tan g \varphi \cdot \frac{0,03391 \cos ^{2} \varphi}{\mathrm{g} \varphi, \mathrm{R}+\mathrm{z}} .
$$

Störungen der verschiedensten Art bringen es zuwege, dass die Punkte des Auftreffens bei wiederholten Versuchen nicht ganz genau mit einander übereinstimmen; um den wahrscheinlichsten Fallpunkt zu ermitteln, muss man sich die einzelnen Punkte als mit gleichen Gewichten belastet vorstellen und den Schwerpunkt der Punktgruppe aufsuchen.

b) Lothrechter Wurf. Wird ein Gegenstand senkrecht in die Höhe geworfen oder geschossen, so gelangt er successive in Regionen, welche zwar die gleiche angulare, aber eine grössere lineare Geschwindigkeit besitzen, als der Ausgangspunkt. In Folge dessen wird das 
Projektil eine Ablenkung im Sinne der Erddrehung erfahren und östlich von dem Punkte zum Erdboden zurück gelangen, in welchem es den letzteren verliess. Den ersten Versuch dieser Art beschreibt

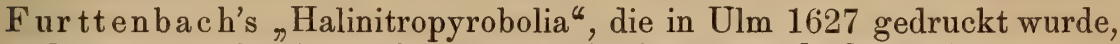
und zwar beschreibt nach Kästner's Auszügen [62] der Autor seine Erfahrungen in originellster Weise. Er setzte sich, klug berechnend, unmittelbar nach Abgabe des Schusses auf die Mündung des vertikal in die Erde eingegrabenen Böllers, in welche seinem richtigen Schlusse gemäss die Kugel nicht mehr zurückkehren konnte. Kästner giebt über diese Frage auch noch einige andere geschichtliche Notizen, die um so interessanter sind, als es an neueren ballistischen Versuchen dieser Art gänzlich zu mangeln scheint; höchst auffällig ist jedoch der Umstand, dass der durchaus nicht unbedeutende Mathematiker den wahren Grund der Abweichung gar nicht bemerkt, sondern diese der mangelhaften Anordnung des Experimentes zur Last legt. Folgendes sind seine Worte [63]: „Mersennus liess eine Kanonenkugel aufwärts schiessen. Man sahe sie nicht wieder, die Philosophen machten allerley seltsame Hypothesen deswegen, darüber auch Butler, im Hudibras, spottet, wo er den Sydrophel schildert. Der natürlichste Gedanke fiel ihnen nicht ein, dass die Kugel nicht ganz vertikal aufgestiegen, also an einen Ort gefallen, wo man sie nicht suchte. In Observations curieuses sur toutes les parties de la Physique T. IV. Par. 1771 stehen Versuche dieser Art, da bey sorgfältiger vertikalen Richtung, die Kugel doch weit von der Stelle niedergefallen."

c) Azimutalveränderungen horizontaler Bewegungen. Jedwede an der Oberfläche der Erde vor sich gehende Bewegung wird unter dem Einflusse der Erdrotation auf der Nordhalbkugel nach rechts, auf der Südhalbkugel nach links abgelenkt. Dass dem unter allen Umständen so sein müsse, beweist der nachstehend mitgetheilte Beweis, der ursprünglich von $\mathrm{Buff}$ [64] herrührt, von $\mathrm{Z}$ öppritz aber in die gegenwärtige Form gebracht wurde [65]. Ein materieller Punkt würde, wenn die Erde stille stände, auf horizontaler Ebene in der Zeiteinheit den Weg AD (Fig. 36a) zurücklegen, während er in der gleichen Zeit auf der sich drehenden Erde den Weg AB beschreibt. Es tritt also der Satz vom Parallelogramm der Bewegungen in Kraft, und der Punkt bewegt sich thatsächlich durch die Diagonale AC des Parallelogrammes A BCD. Der nach B versetzte Beobachter muss somit den Eindruck bekommen, als sei von dem ursprünglich in's Auge gefassten Punkte die Strecke BC durchlaufen worden. Die Grösse der Ablenkung ist leicht zu bestimmen, sobald die Nordlinien AN und BN gezogen werden*). Das anfängliche Azimut war $\Varangle \mathrm{NAD}=\alpha$, das nachherige ist $\Varangle \mathrm{NBC}=\alpha^{\prime}$;

*) Benoni erklärt den Buff'schen Beweis für unrichtig, weil AN und $\mathrm{BC}$ in Wirklichkeit zwei windschiefe Gerade seien, die gar keinen gemeinsamen Punkt E besässen [66]. Dieser Einwurf mag auf den ersten Blick einigen Schein für sich haben, ist jedoch nichtsdestoweniger ganz belanglos. Denn was ist eine Horizontalebene in A anders als eine in diesem Punkte an die Erdkugel gelegte Tangentialebene? Angesichts der Kleinheit des Weges A B kann aber ohne Irrthum auch der Punkt $B$ als in derselben Ebene liegend angenommen werden, und es liegen demnach alle die Fig. 36 a bildenden Linien in Wirklichkeit in der Papierebene. 
verlängert man $\mathrm{BC}$, bis es die $\mathrm{AN}$ in $\mathrm{E}$ schneidet, so ist auch $\Varangle \mathrm{AEB}$ als Wechselwinkel $=\alpha . \quad \mathrm{AEB}$ ist ein Aussenwinkel des Dreiecks $\mathrm{BEN}$, es ist also, wenn noch $\Varangle \mathrm{BNA}=\delta$ gesetzt wird, $\alpha=\delta+\alpha^{\prime}$, $\delta=\alpha-\alpha^{\prime}$. Der Winkel $\delta$ giebt an, um wieviel das ursprüngliche Azimut am Ende des ersten Zeittheiles kleiner geworden ist; dass die

Fig. 36

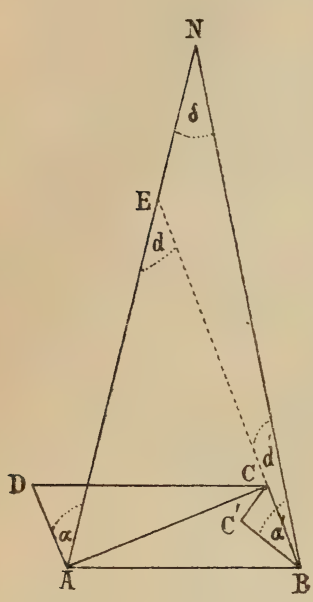

a

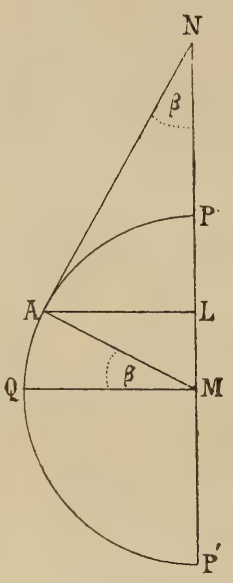

b. Ablenkung eine rechtseitige war, erhellt aus der Figur. Würde man in der Horizontalebene an $\mathrm{BN}$ in $\mathrm{B}$ den Winkel $\mathrm{NBC}^{\prime}=\alpha$ anlegen, so wäre natürlich $\Varangle \mathrm{CBC}^{\prime}=\delta$; der obige Beobachter wird also noch weiter glauben müssen, der Punkt A habe sich um $\mathrm{CC}^{\prime}=\sigma$ von ihm entfernt. Setzen wir die Eigengeschwindigkeit $\mathrm{AD}=\mathrm{BC}$ des Mobiles $=\nabla$, den Weg $\mathrm{AB}=\mathrm{s}$ und $\mathrm{AN}=\mathrm{k}$, so haben wir, da die gleichschenkligen Dreiecke ABN und $\mathrm{CC}^{\prime} \mathrm{B}$ einander ähnlich sind, zur Bestimmung von $\sigma$ die Proportion $\sigma: \mathrm{s}=\mathrm{v}: \mathrm{k} ;$ es ist $\sigma=\frac{\mathrm{vs}}{\mathrm{k}}$.

Die Grössen $\mathbf{k}$ und $\mathrm{s}$ ergeben sich aus Fig. 36b. Darin bedeutet M den Mittelpunkt der Erde, MQ einen Aequatorialhalbmesser, PAP' den Meridian, welchem der Punkt A in Fig. 36a angehörte. Zieht man $\mathrm{AM}$ und errichtet in $\mathrm{A}$ auf $\mathrm{AM}$ ein Loth, so schneidet dieses die verlängerte Polaraxe $\mathrm{P}^{\prime} \mathrm{P}$ in einem Punkt $\mathrm{N}$, welcher dem früheren $\mathrm{N}$ entspricht. Wird endlich noch von $\mathrm{A}$ auf $\mathrm{P}^{\prime} \mathrm{P}$ die Senkrechte $\mathrm{AL}$ gefällt, so ist $\Varangle \mathrm{QMA}=\Varangle \mathrm{MAL}=\Varangle \mathrm{ANL}=\beta$ (geographische Breite). Aus dem in A rechtwinkligen Dreieck AMN folgt zunächst, unter $\mathrm{r}$ den Erdhalbmesser verstanden, $A N=\mathrm{k}=\frac{\mathrm{r} \cos \beta}{\sin \beta}$. Versteht man ferner unter $\omega$ die Winkelgeschwindigkeit der Erde, so ist der unter der Breite $\beta$ in der Sekunde als Zeiteinheit beschriebene Weg $\mathrm{s}=\mathrm{AL} . \omega$, und, da $\mathrm{AL}=\mathrm{r} \cos \beta, \mathrm{s}=\omega \mathrm{r} \cos \beta$. Ein Sterntag hat 86164 Sekunden; also ist

und

$$
\omega=\frac{2 \pi}{86164}
$$

$$
\sigma=\frac{\mathrm{vs}}{\mathrm{k}}=\mathrm{v} \omega \mathrm{r} \cos \beta \cdot \frac{\sin \beta}{\mathrm{r} \cos \beta}=\omega \mathrm{v} \sin \beta=\frac{\pi \mathrm{v} \sin \beta}{43082} .
$$

Dieser Ausdruck ist für alle horizontalen Deviationen maassgebend. Bislang war nur von der Zeiteinheit die Rede; dauert die Bewegung t Sekunden an, so setzt Buff (a. a. O.) die entsprechende Ablenkung $\sigma_{t}=\omega \cdot v \cdot t \cdot \sin \beta$. Dem gegenüber hebt Zöppritz hervor, dass hier nicht von einer gleichförmigen, sondern von einer gleichförmig beschleunigten Bewegung die Rede sei, indem ja der nämliche Impuls zu Beginn jedes neuen Zeittheilchens immer wieder sich geltend macht. 
Die Beschleunigung besitzt die Grösse $2 \omega \nabla \sin \beta *$ ), und es ist deshalb, wenn man die Bewegung als aus der Ruhe vor sich gehend denkt, in aller Strenge

$$
\sigma_{t}=\frac{1}{2} \cdot 2 \omega \cdot \nabla \cdot \sin \beta \cdot t^{2}=\omega \cdot \nabla \cdot \sin \beta \cdot t^{2}
$$

zu setzen. Auf der Südhemisphäre ergiebt sich analog eine Ablenkung nach der linken Seite hin. Solche Richtungsänderungen treten nun bei horizontal bewegten Körpern in der That hervor, und wir stellen im Folgenden eine Anzahl der auffälligsten Erscheinungen dieser Art zusammen, uns vorbehaltend, diejenigen Einzelfälle hier nur vorübergehend $\mathrm{zu}$ streifen, welche sich für besondere Zweige der Geophysik wichtig erweisen und deshalb in den einschlägigen $\mathrm{Ka}$ piteln dieses Buches einer besonderen Betrachtung unterzogen werden müssen.

I. Die Deviation der Geschosse. Je intensiver eine Bewegung ist, um so stärker wird sich auch die laterale Abweichung fühlbar machen; ist doch (s. o.) $\sigma_{t}$ der Grösse $v$ direkt proportional. So erkannte denn auch schon D'Alembert diese Deviation, als er über die Bewegung geschleuderter Körper seine berühmte Abhandlung schrieb [67], in welcher auch eine richtige Deutung des Mersenne'schen Schiessversuches (s. o.) zu finden ist. Noch genauer gieng Poisson [68] auf die Sache ein, indem er zeigte, dass die Rechts- (resp. Links-) Abweichung in Wahrheit aus zwei Theilen sich zusammensetze. Der erste Bestandtheil, welcher der Grösse nach erheblich überwiegt und in unserer obigen Ableitung auch allein abgehandelt wurde, ist rein mechanisch durch das Trägheitsgesetz bedingt und von dem Azimut der Bewegung völlig unabhängig, wie denn auch in unseren Formeln der Winkel $\alpha$ nicht vorkommt; der zweite Bestandtheil resultirt daraus, dass das Projektil Parallelkreise von verschiedener Winkelgeschwindigkeit durchschneidet. Sein Maximum erreicht dieser Betrag bei meridionaler Richtung der Seelenaxe, indessen ist derselbe so unverhältnissmässig kleiner als der erste - selbst auch nur sehr kleine - Summand, dass bei den in der Artillerie vorkommenden Geschwindigkeiten nur dieser letztere einigermassen berücksichtigt zu werden braucht. Auch Poisson betrachtete übrigens mehr nur einen ideellen Fall, er sah vom Luftwiderstand $a b$, nahm die Erde nicht als sphäroidal, sondern als kugelförmig an und verzichtete damit auf die unmittelbare praktische Anwendbarkeit seiner Resultate. Um so uneingeschränkter waren die Voraussetzungen, welche neuerdings Finger seiner die Frage zu einem einstweiligen Abschluss bringenden Arbeit [69] zu Grunde legte. Er fand, dass die bekannte Deviationsformel nur eine erste Annäherung darstellt, dass überhaupt in der ganz allgemeinen Relation das Azimut nicht verschwindet, dass aber die seitliche Ablenkung durchaus nicht etwa für eine nördliche oder südliche Richtung ein Grösstes wird; die Abweichungsgrösse wird vielmehr ein Maximum, wenn der Körper

*) Bei jeder gleichförmig beschleunigten Bewegung ist der im ersten Zeittheil zurückgelegte Weg halb so gross, als die Beschleunigung. Der freie Fall z. B. gehört in diese Kategorie; bei ihm ist die Beschleunigung $\mathrm{g}=9,80896$, demnach legt ein aus der Ruhe fallender Körper in der ersten Sekunde einen Weg von $4,40448 \mathrm{~m}$ zurück. 
nach Osten, ein Minimum, wenn er nach Westen sich bewegt. Dieses Faktum scheint sich mit den landläufigen Anschauungen freilich nicht recht vereinigen lassen $\mathrm{zu}$ wollen, allein es hat nicht blos die mathematische Autorität seines Entdeckers hinter sich, sondern auch das Zeugniss der praktischen Ballistik, indem Darapsky's Versuche [70] Folgendes ergaben: Wird das Projektil unter einem östlichen Azimut abgeschossen, so wird seine Rechts-Ablenkung immer grösser und grösser und erreicht ihren grössten Werth, wenn direkt von Westen nach Osten geschossen wird; im nord- und im südwestlichen Quadranten findet gerade das Entgegengesetzte statt. Aus dem, was Darapsky folgert, lässt sich der weitere Schluss ziehen, dass Poisson's Worte (a. a. O.) »ces déviations sont également négligeables dans le tir du canon, et dans tous les mouvements, qui ont lieu suivant une direction à peu près horizontale" heutzutage, wo sich die Tragweite der Belagerungsgeschosse gegen damals mehr denn verdoppelt hat, nicht mehr auf Treu und Glauben hingenommen werden dürfen.

II. Der seitliche Schienendruck bei Eisenbahnen. Bisher ward angenommen, die Bahn des Mobiles sei eine vollkommen freie, dasselbe vermöge der lateral ablenkenden Tendenz ungehindert zu folgen. Bewegt sich der Punkt dagegen in einer vorgeschriebenen Bahn, etwa in einer Röhre, so wird die fragliche Tendenz sich durch einen auf unserer Halbkugel rechtsseitigen - Druck gegen die Wandung der Röhre geltend machen. Der bekannte amerikanische Physiker Ma ury wollte nun auch die weitere Wahrnehmung gemacht haben [71], dass auf Eisenbahnen von meridionaler Richtung die nach Norden fahrenden Züge östlich, die nach Süden fahrenden dagegen westlich aus den Schienen zu springen geneigt seien. Eine analoge Erfahrung soll nach Martus [72] auch in Deutschland gemacht worden sein. ,Ein ungleiches Vorrücken der Schienen, ${ }^{*}$ heisst es, ,tritt auf der meridional laufenden Hamburg-Harburger Eisenbahn sehr deutlich hervor, dadurch begünstigt, dass der Bahnkörper über weichen Moorgrund geht. Von den vier Schienen des Doppelgeleises schreitet jede äussere, welche für die in der einen oder der anderen Richtung fahrenden Züge die rechtsliegende ist, in einem Vierteljahre durchschnittlich acht Centimeter weiter vor, als jede andere; nämlich die rechte $15 \mathrm{~cm}$, die linke nur $7 \mathrm{~cm}$. Und dieses Verschieben stellt sich nach jeder Bahnregulirung in etwa drei Monaten in solcher Grösse immer wieder her, so sehr man auch in der Unterbettung der Geleise durch gutes Stopfmaterial dem entgegenzuwirken sucht. ${ }^{\star}$ Zöppritz hat mit Recht an dieser Darstellung einen Punkt zu tadeln [73], denjenigen nämlich, dass auf die Nord-Südrichtung der Trace Gewicht gelegt wird; ähnliche Erscheinungen müssten, ganz unabhängig von der Richtung, bei jeder Bahn zu konstatiren sein, welche über weichen Grund geht und Geleise besitzt, die stets nur in dem nämlichen Sinne befahren werden. Die fragliche Bahn hat, von Hamburg aus gerechnet, die Richtung: Süd-Südost, sie fällt also in einen Quadranten, welcher nach F in ger (s. o.) dem Zustandekommen der Erscheinung nicht einmal besonders günstig ist. In der That aber ist auch in Martus' Berechnungsformel das Azimut gar nicht eingegangen. Eine solche Formel lässt sich nach Schrader [74] sehr einfach herleiten, wenn man sich auf die Eingangs dieses Paragraphen festgestellten Thatsachen bezieht. Mit Beibehal- 
tung der dortselbst gebrauchten Bezeichnung würde, wenn die Radkränze nicht wären, die Lokomotive eines Bahnzuges um $\omega \mathrm{v} \sin \beta t^{2}$ nach rechts gedrängt worden sein. Für diesen Weg kann aber auch ein zweiter Ausdruck aufgestellt werden; sei D der zu bestimmende Druck auf die rechtslaufende Schiene, $Q$ das Gewicht des Dampfwagens, so ist $\mathrm{g} \cdot \frac{\mathrm{D}}{\mathrm{Q}}$ die Beschleunigung, $\frac{1}{2} \mathrm{~g} \cdot \frac{\mathrm{D}}{\mathrm{Q}} \mathrm{t}^{2}$ der zurückgelegte Weg, und es bestehen die Gleichungen

$$
\frac{1}{2} g \cdot \frac{D}{Q} t^{2}=\omega v \sin \beta t^{2} ; D=\frac{2 Q \omega v \sin \beta}{g} .
$$

Nimmt man als Durchschnittsgeschwindigkeit einen Werth $v=10 \mathrm{~m}$ an, so ergiebt sich für die mittlere Breite von Deutschland das Verhältniss D : Q annähernd wie 1:10000. Irgend eine erhebliche Wirkung scheint nach dieser Rechnung die Erdrotation nicht hervorzubringen. Man könnte einwenden, unser Berechnungsmodus sei ein etwas summarischer und nicht vollkommen strenger; mag diess aber auch zuzugeben sein, so lässt sich doch nicht ein Gleiches behaupten von der Arbeit eines hervorragenden Eisenbahntechnikers, Hallb a u er's, welche der Sache wirklich auf den Grund geht [75]. Bei der gewöhnlichen Spurweite von $1,436 \mathrm{~m}$ und bei der - schon sehr hoch gegriffenen - Maximalgeschwindigkeit von $25 \mathrm{~m}$ in der Sekunde genügt es, die Schiene zur Rechten um $0,0004 \mathrm{~m}$ zu erhöhen, um den aus der Rotation entspringenden Einfluss ein für allemal zu paralysiren. Dass aus einem Höhenunterschiede, der mit unbewaffnetem Auge kaum erkannt werden kann, nicht wirkliche Gefahren für den Bahnbetrieb resultiren, dürfte wohl nicht bestritten werden. Beobachtungen, wie die von Martus erwähnten, sind also nicht geradezu als unglaubwürdig zu bezeichnen, allein mit grosser Vorsicht wird man ihnen gewiss gegenüberzutreten haben. Jene mit Rücksicht auf die Ablenkungstendenz gearbeitete Statistik der Eisenbahnunfälle, welche K. E. v. Bär gewünscht hat [76], wird, wenn unsere Ausführungen das Richtige treffen, weder für die Geophysik noch für die Betriebstechnik besonderen Werth beanspruchen können*).

III. Ausflusserscheinungen. Perrot nahm ein cylindrisches Gefäss, füllte es mit Wasser und brachte genau im Mittelpunkt der unteren Grundfläche ein Loch an; alsdann streute er leichte Schwimmkörperchen in die Flüssigkeit und beobachtete die Bahnen, welche jene beschrieben [79]. Man musste erwarten, dass die nahe dem Boden befindlichen Schwimmer sich radial der Ausflussöffnung nähern würden, allein obwohl die Bahnkurven anfänglich geradlinig waren, so krümmten sie sich späterhin doch immer mehr und mehr nach der rechten Seite hin, so dass sämmtliche Körper zuletzt in Spiralen von rechtseitigem Drehsinne um die Oeffnung rotirten: „le mouvement de la terre se manifeste donc par cette direction que prennent les corpuscules en arrivant vers le centre d'écoulement." Auch hier-

*) Weitere theoretische Erörterungen über den in Rede stehenden Gegenstand verdankt man $\mathrm{Brasch}$ ann [77] und Lindelöf [78]. 
über hat sich Braschmann in längerer Auseinandersetzung verbreitet $[80]$.

IV. Wind- und Meeresströmungen. Darüber, dass bei der Gestaltung der charakteristischen Stromsysteme in den unseren Erdkörper umhüllenden elastisch- und tropfbar-flüssigen Kugelschalen die Rotation, an welcher beide natürlich gleichen Antheil nehmen, eine wichtige Rolle spiele, herrscht kein Zweifel mehr. Gewisse Kapitel der fünften und der sechsten Abtheilung werden uns Gelegenheit geben, der Sache näher zu treten.

V. Die Verschiedenheit der Flussufer. Jener Seitendruck, welchen wir weiter oben bei den Eisenbahnschienen studirten, muss bis zu einem gewissen Grade auch bei den Uferwänden der Ströme zu konstatiren sein. Doch halten wir es für angezeigt, hierauf und auf das sogenannte Bär'sche Gesetz erst in dem von der Thalbildung handelnden Kapitel der achten Abtheilung näher einzugehen.

Hiemit wäre denn den aus der Erddrehung entspringenden Richtungsänderungen horizontal bewegter Körper ihr Recht geworden, und wir können in aller Kürze noch auf einige minder belangreiche Nebenfragen unseren Blick richten.

d) Anderweite terrestrische Erscheinungen. Der schweizerische Mathematiker Denzler war einer der Ersten, welche der oben in V. genannten Frage ihr Interesse zuwandten; er publicirte darüber eine Abhandlung [81], in welcher er den Nachweis führen zu können glaubte, dass eine "Tendenz nach rechts" bei den allerverschiedensten Ereignissen hervortrete. Hierher rechnete er z. B. das Voreilen der sinkenden und das Zurückbleiben der steigenden Wolken (beide gelangen allmählig in Gegenden von anderer Geschwindigkeit), ferner die an der Ostseite angeblich am stärksten hervortretende Verwitterung der Gesteine, die Ostabdachung der Kontinente, die Variation der magnetischen Elemente und noch manches Andere. Es scheint aus den Worten von Denzler's Biographen R. Wolf hervorzugehen [82], dass die Umgebung des Ersteren in diesen Hypothesen ganz richtig Phantasmen erkannte, und etwas Anderes wird man kaum darin finden können.

Einige Behutsamkeit dürfte auch gegenüber den ab und zu namhaft gemachten botanischen Aeusserungen der Erdumdrehung am Platze sein. Am sichersten bezeugt und durch die elliptische Form der Jahresringe kontrolirbar ist die vorläufig nicht gut anders zu erklärende Verschiedenheit des Dickenwachsthums gewisser Holzpflanzen, namentlich der Koniferen, von welcher Ludwig [83] berichtet. Eine Allee in unmittelbarer Nähe der Stadt Wiesbaden lässt bei sämmtlichen Bäumen gewisse Sprünge wahrnehmen, welche möglicherweise auch dadurch entstanden sind, dass unter dem Einflusse der Rotation der Stammdurchmesser in der Ostwestrichtung ein stärkeres Wachsthum besitzt, als in der dazu senkrechten*). Es ist, wenn man sich gewisse anderweite Resultate der Pflanzenphysik**) vergegenwärtigt, allerdings

*) Der Verf. verdankt den Hinweis auf diese jedenfalls bemerkenswerthe und weiterer Untersuchung würdige Erscheinung Herrn Prof. Unverzagt zu Wiesbaden.

**) Den Zusammenhang der Pflanzengestalt mit Schwer- und Rotationswir- 
nicht undenkbar, dass es auf diesem Gebiete noch so manche uns unbekannte Manifestation der Erdbewegung gäbe, allein leicht wird es niemals sein, dieselbe aus der Fülle verhüllender Nebenumstände herauszuschälen. Von Interesse ist eine bezügliche Bemerkung Bianchi's gegen Musset (Gaea, 3. Jahrg. S. 542, 5. Jahrg. S. 431).

§. 4. Der Foucault'sche Pendelversuch und dessen Abänderung durch Onnes. Den striktesten Beweis für die Richtigkeit des Satzes, dass nicht durch die Umdrehung des Himmels, sondern durch die Umdrehung der Erde der Wechsel von Tag und Nacht bewirkt wird, bietet der nach dem Pariser Akademiker Foucault benannte Pendelversuch. Nicht, als ob vor Foucault Niemand daran gedacht hätte, dass in den Schwingungen eines aus seiner Ruhelage herausgebrachten Pendels ein noch zu entschleierndes Geheimniss ruhe, ja man kann sogar, wie der Verf, zeigte [86], eine förmliche Vorgeschichte des Experimentes liefern. Möglicherweise spielte schon Galilei auf eine ähnliche Beobachtung an, als er seinem Salviati im Dialog über die Weltsysteme, nachdem derselbe die gewöhnlichen Argumente zu Gunsten der Erddrehung angeführt hat, diese Worte in den Mund legte [87]: Exsurgit in hoc tempore quinta quaedam novitas, ex qua mobilitas globi terrestris argui queat, per ea quae subtilissime detegit illustrissimus dominus Caesar, e nobilissima Marsiliorum Bononiensium familia satus, et ipse collegio lynceorum academicorum adscriptus; qui in quodam doctissimo scripto tradit, observasse se continuam quandam mutationem, etsi tardissimam, in linea meridiana." So fasst wenigstens Caramuel von Lobkowitz die Schwankung des Meridians, welche Marsigli entdeckt haben wollte*), in jenem merkwürdigen Schriftchen [90] auf, welches er selbst den angeblich spontanen Pendelschwingungen widmete, die Peirinsius und Gassendi [91] entdeckt haben wollten, Schwingungen, deren Existenz Caramuel allerdings entschie-

kungen hat insbesondere Wiesner zum Gegenstande seiner Forschungen gewählt [84]; seine Resultate lassen sich kurz zusammenfassen, wie folgt [85]. Die Richtung der Pflanzentheile, wahrscheinlich aber auch deren Form und relative Grösse, wird von der Schwerkraft bestimmt, zumal in Bezug auf das Längenwachsthum. Das Wort Geotropismus dient dazu, den ganzen Komplex hierher gehöriger Thatsachen unter einen Gesammtbegriff zu bringen. Seit Knight's Versuchen (1806) weiss man, dass gewisse Organe unter dem Einflusse der Schwerkraft nach aufwärts, andere nach abwärts wachsen. Setzt man ferner eine Pflanze auf die Centrifugalmaschine, so sieht man, wie sich die Keimaxe in die Resultirende zwischen Schwung- und Schwerkraft einstellt.

*) Uns freilich erscheint es zweifelhaft, ob Caramuel Recht hatte, Marsigli mag vielmehr unseres Erachtens an etwas ganz Anderes gedacht haben. Während des ganzen XVII. Jahrhunderts stritt man sich darüber, ob eine nach allen Regeln der Wissenschaft gezogene Mittagslinie von freien Stücken, beziehungsweise unter dem Einflusse einer uns noch unbekannten Kraftäusserung, ihre Lage oder Richtung zu ändern vermöge, oder nicht; namentlich stützten sich die Vertheidiger dieser Ansicht auf eine wenig beweiskräftige Angabe des Plinius, wonach ein als Zeitmesser zu Rom aufgestellter Obelisk nach und nach einen falschen Mittag gezeigt habe. Der bekannte englische Mathematiker Wallis sah sich bemüssigt, in einer gelehrten Abhandlung [88] den Gegenstand nach allen Seiten hin zu prüfen. Von deutschen Schriftstellern hat Kordenbusch [89] eine Uebersicht über die für und wider beigebrachten Beweise gegeben und sich am Schlusse derselben nachdrücklich gegen die Annahme irgendwelcher Variabilität der Meridianebene ausgesprochen. 
den ableugnen zu sollen glaubte. Man vergleiche hiemit, was oben (in §. 2 dieses Kapitels) über gewisse unerklärliche Oscillationen langer Bleilothe bemerkt wurde. Bouguer [92] und Andreas Mayer [93] stellten ebenfalls durch korrekt ausgeführte Versuchsreihen fest, dass absolut geschützte Pendel nicht von selbst in Bewegung übergehen können, und auch Eimmart, der ursprünglich aus dem von ihm aufgefundenen „Motus retardationis " Kapital zu Gunsten des coppernicanischen Systemes schlagen zu können geglaubt hatte, kam allmählig wieder von dieser Ansicht zurück [94]. Immerhin war, wie man sieht, die Frage, ob nicht das Pendel ein unmittelbares Beweismittel für die Existenz der Drehung der Erde um ihre Axe abgeben könne, nun einmal auf die wissenschaftliche Tagesordnung gesetzt, und mehr und mehr begann man das Richtige zu ahnen. „Der Pendelversuch," sagt $R$. Wolf [95], soll übrigens schon früher von Augustin Stark (Augshurg 1777 bis Augsburg 1839; Lehrer der Mathematik und Domherr daselbst) unternommen worden sein, ja schon die Mitglieder der accademia del cimento scheinen das dem Versuche zu Grunde liegende Gesetz von der Konstanz der Schwingungsebene geahnt zu haben, jedenfalls ist derselbe durch L. Poinsinet de Sivry (Versailles 1733? bis 1804; Literat) im Anhange zu seiner Ausgabe des Plinius ganz klar ausgesprochen worden. " Foucault fand also, als er mit seinem eigenen Gedanken hervortrat [96], das Feld schon bis zu einem gewissen Grade bereitet vor, womit natürlich nicht gesagt sein soll, dass dieser Gedanke nicht voll und ganz sein geistiges Eigenthum gewesen wäre.

Fig. 37 bringt das Wesen des Foucault'schen Pendelversuches zur Anschauung. M ist der Mittelpunkt der Erde, N der

Fig. 37.

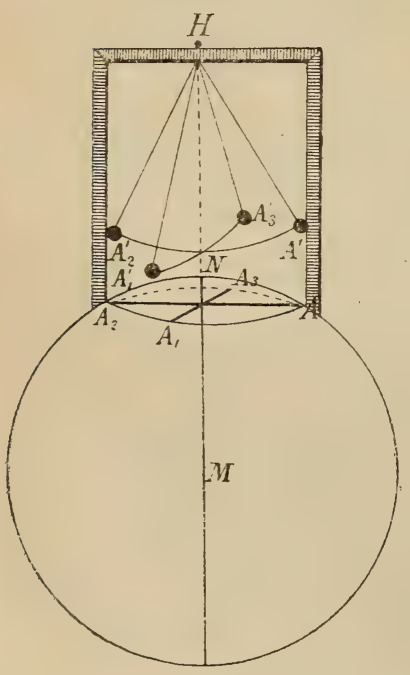
Nordpol; über diesem denken wir uns an einem zweckmässig konstruirten Galgen ein Pendel so aufgehängt, dass dessen Ruhelage mit der verlängerten Erdaxe zusammenfällt. Der Pendelfaden wird gehoben und straff gespannt in der Hauptebene des Gerüstes an diesem befestigt. Hierauf brennt man den Faden durch und beobachtet die Schwingungen; die zuerst natürlich in der genannten Ebene vor sich gehen müssen und, wenn die Erde in Ruhe wäre, aus dieser gar nicht heraustreten könnten. Der Beobachter möge sich auf dem durch die äquidistanten Punkte $A, A_{1}, A_{2}, A_{3}$ bezeichneten Parallelkreise befinden, und zwar soll er in dem Anfangsmomente der Bewegung seinen Standort in dem Punkt A haben, durch welchen die ursprüngliche Schwingungsebene hindurchgeht. Da bei der von uns gewählten Aufhängung kein Grund vorhanden ist, welcher eine Drehung jener Ebene bewirken könnte, so bleibt dieselbe unverändert, gleichwohl aber wird der Anblick, welcher sich dem von der rotirenden Erde mit fortgeführten Beobachter darbietet, mit jedem Augenblicke sich ändern. 
Anfänglich nämlich bemerkte derselbe blosse Hebungen und Senkungen der Pendelkugel, nachher erscheint ihm der von letzterer beschriebene Kreisbogen als eine stark excentrische Ellipse, die sich aber immer mehr einem Kreise nähert, bis $\mathrm{ihm}$ dann, wenn er in $\mathrm{A}_{1}$ angelangt ist, dieser Bogen in seiner vollen Reinheit sich darstellt. Beim Durchwandern des nächsten Quadranten $A_{1}, A_{2}$ werden sich die nämlichen Erscheinungen wiederholen, nur in umgekehrter Reihenfolge, ein Gleiches wird für $\mathrm{A}_{2} \mathrm{~A}_{3}$ und für $\mathrm{A}_{3} \mathrm{~A}_{4}$ gelten. $\mathrm{A}^{\prime}, \mathrm{A}_{1}^{\prime}, \mathrm{A}_{2}^{\prime}, \mathrm{A}_{3}^{\prime}$ stellen die Pendelkugel in den den vier Punkten $\mathbf{A}, \mathbf{A}_{1}, \mathbf{A}_{2}, \mathbf{A}_{3}$ entsprechenden grössten Elongationen dar. Wenn wir uns nun die Thatsache vergegenwärtigen, dass ja der Beobachter von seiner Ortsveränderung der Schwingungsebene gegenüber nicht weiss und fühlt, so erkennen wir, dass er nicht umhin können wird, eine fortgesetzte Drehung der Schwingungsebene um die Axe HN anzunehmen, und zwar dauert diese Drehung genau 24 Stunden.

Der Pol ist nun allerdings für uns unerreichbar, allein schon eine einfache Ueberlegung lehrt, dass die Erscheinung auch an anderen Orten auf der Erde, den einzigen Aequator ausgenommen, in qualitativ nicht verschiedener Weise eintreten muss. Seit Foucault sind Versuche dieser Art von vielen Physikern an verschiedenen Plätzen angestellt worden; es genüge, diejenigen von Secchi in Rom, von Garthe in Köln, von Schrader in Halle, von Bunt in Bristol namhaft zu machen. Selbstverständlich muss die Pendellänge eine bedeutende sein, und es bedarf umfassender Vorsichtsmassregeln, um den Erfolg des Experimentes zu sichern, wie denn nach Hansen's gründlicher Diskussion aller begleitenden Umstände [97] die geringste eigene Drehbewegung der Pendelkugel von der störendsten Wirkung ist. Damit die Abweichung der Schwingungsebene von ihrer ursprünglichen Stellung im Raume recht bald sichtbar werde, pflegt man einen Kreis, auf dessen Mittelpunkt die unten an der Pendellinse anzubringende Spitze im Ruhezustand hinweist, mit Sand zu belegen, um zu sehen, wie die von jener Spitze in die Belegung eingezeichneten radialen Linien sich immer mehr von der Anfangsrichtung entfernen.

Ehe wir an die Entscheidung der Frage herantreten, wie denn mit Veränderung der Polhöhe auch die Drehungsgeschwindigkeit der Schwingungsebene variire, haben wir erst noch die Vorfrage zu stellen und zu erledigen, ob denn überhaupt der obige Ausdruck ein korrekter sei. Ersichtlich kann derselbe kein ganz strenger sein. Denn es würde damit gesagt sein, dass die Bewegung der Pendelkugel keine stetige sei, sondern je nach Vollendung einer Schwingung sprungweise ihre Richtung ändere, und diesen Widerspruch gegen alle sonstigen Naturgesetze wird Niemand zuzugeben geneigt sein. Mit Recht hebt Röthig [98] hervor, dass diese Gewohnheit, von einer thatsächlich gar nicht existirenden festen Schwingungsebene des Pendels zu reden, zu vielen Unrichtigkeiten geführt habe und noch stets führe. Verfolgt man die von dem einem bestimmten Gesetze folgenden sphärischen Pendel beschriebene Trajektorie genauer, so überzeugt man sich sofort, dass die einzelne Oscillation nicht mit einem Kreisbogen, sondern weit eher mit einer sehr langgestreckten sphärischen Ellipse übereinstimmt. Unter dieser Voraussetzung, dass nämlich die Horizontalprojektion der Pendel- 
kurve eine ebene Ellipse sei, deren grosse Axe stetig ihre Richtung ändert, hat Ordinaire de Lacologne [99] das Foucault'sche Problem einer Neubearbeitung unterzogen. Allein auch diese Annahme involvirt nur eine Annäherung an die Wahrheit; nach den unseres Wissens noch unwiderlegten Resultaten von Franz [100] ist die Bahn eine noch verwickeltere Kurve doppelter Krümmung, eine sphärische Hypotrochoide. Sie besteht aus einer Reihe zusammenhängender Blätter, deren Scheitel A, B, C, D, E, F . . (Fig. 38) einem

Fig. 38 .

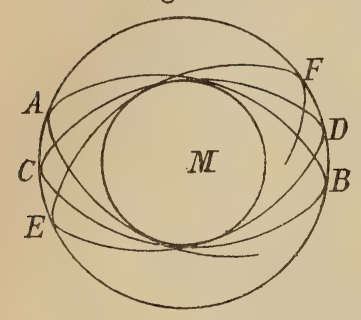
gewissen kleinen Kugelkreise angehören, während die Aeste zugleich einen zweiten koncentrischen Kugelkreis (M) umhüllen. Unsere Figur giebt der geometrischen Haupteigenschaft treuen Ausdruck, freilich aber liegen in der Natur die Punkte A, C, E ... und B, D, F . . ganz ungleich näher an einander, und das Verhältniss des inneren zum äusseren Kreisradius, welches die Zeichnung ungefähr $=\frac{1}{2}$ annimmt, sollte eigentlich einem sehr

kleinen ächten Bruche gleichkommen.

Dass angesichts dieser ziemlich verwickelten kinematischen Verhältnisse eine genügende und nur mit elementaren Hülfsmitteln arbeitende Deduktion des Gesetzes, nach welchem die Abweichung der momentanen Schwingungsebene mit der geographischen Breite in Beziehung steht, keine leichte Sache sein kann, bedarf kaum eines Beweises. Pick hat sich in dankenswerthester Weise die Mühe gegeben, nicht weniger als 13 Ableitungen, die von Jelinek, Grunert, Crahay, Marignac, Pagani, Coombe, J. J. v. Littrow, Eschweiler, Schelle, Hullmann, Friedlein-Bielmayr, Schaub und Bunt herrühren, kritisch zu prüfen [101] und nachzuweisen, welche Mängel der grossen Mehrzahl anhaften. Ebenfalls eine gute Kritik der elementaren Beweismethoden, verbunden mit einer die höhere Rechnung jedoch nicht ausschliessenden Herleitung, haben wir von Tammen [102]. Es sind im Wesentlichen blos zwei Formeln, welche in Frage stehen. Nach der von Foucault selbst herrührenden und fast allseitig acceptirten soll der Winkel $\psi$, um welchen nach Umfluss der Zeit $t$ unter der Breite $\varphi$ die sogenannte Schwingungsebene sich aus ihrer Anfangsstellung herausgedreht hat, einfach durch die Relation $\psi=\mathrm{t} \sin \varphi$ gegeben sein, wobei $\psi$ und $\mathrm{t}$ natürlich in der gleichen Maasseinheit auszudrücken wären. Andererseits ist auch die Gleichung

$$
\sin \psi=\frac{\sin t \sin \varphi}{\sqrt{1-\sin ^{2} 2 \varphi \sin ^{4} \frac{t}{2}}}
$$

in Vorschlag gebracht worden. Schon der Umstand, dass dieselbe für $\mathrm{t}=\pi$ den Ausschlagswinkel Null liefert, erweckt kein günstiges Vorurtheil für sie, und in der That ist dieselbe auch nur in der Weise gewonnen worden, dass man Rotationen nach dem Satze vom Parallelogramm der Kräfte zu einer resultirenden Drehung zusammensetzte. Allein diese Zusammensetzung ist nach Poinsot's bekannten Regeln nur so lange erlaubt, als die Komponenten unendlich klein sind, und 
für diesen extremen Fall stimmen auch beide Formeln völlig überein; sowie jedoch die Drehungen eine endliche Grösse besitzen, wird die Resultante nach einer ganz anderen Vorschrift bestimmt*). Die Relation $\psi=\mathrm{t} \sin \varphi$ ist offenbar die gleiche, welche in $\S .3$ für die Azimutaländerung beliebiger horizontal bewegter Körper aufgestellt ward, und insoferne dürfen wir uns eines neuen Beweises überhoben betrachten. Man hat sich eben, um den völligen Einklang herzustellen, nur zu denken, dass an Stelle der Schwingungsbögen die in deren tiefstem Punkte an sie gelegten geradlinigen Tangenten treten.

Damit ist schon ausgesagt, dass unsere Formel eine blosse Approximation, wenn schon eine sehr genaue, darstellt. Pick entnimmt den Mittheilungen Bunt's über eine von ihm in der "Philosophical Institution" ${ }^{*} \mathrm{zu}$ Bristol mit einem 22,73' langen "und 35 Pfund schweren Bleipendel angestellte Versuchsreihe nachstehende Tabelle [104]:

\begin{tabular}{|c|c|c|c|c|c|}
\hline Dauer der & Beobachtung & $\begin{array}{c}\text { Drehung der } \\
\text { Schwingungsebene }\end{array}$ & $\begin{array}{c}\text { Nach der Sinusformel } \\
\text { berechneter Werth }\end{array}$ & Differenz & \\
\hline $2^{\mathrm{h}}$ & $54 \mathrm{~m} 4$ & $35^{\circ} 70$ & $34^{0} \quad 19$ & -10 & 51 \\
\hline 2 & $59, \quad 5$ & $35, \quad 30$ & $35, \quad 19$ & $-\quad 0$ & 11 \\
\hline 3 & 34,7 & $43, \quad 40$ & $42, \quad 09$ & -1, & 31 \\
\hline 4 & $39, \quad 0$ & $52, \quad 73$ & $54, \quad 70$ & +1 & 97 \\
\hline 5 & $41, \quad 0$ & 64,80 & $66, \quad 86$ & +2 & 06 \\
\hline 11 & $26, \quad 3$ & $137, \quad 10$ & $134, \quad 56$ & -2, & 54 \\
\hline 12 & 40,5 & 140,50 & $149, \quad 11$ & +8 & 61 \\
\hline 13 & $4, \quad 0$ & 154,45 & $153, \quad 71$ & -0 & 74 \\
\hline 13 & $30, \quad 0$ & 158,75 & 158,81 & $+\quad 0$ & 06 \\
\hline 13 & $30, \quad 2$ & $155, \quad 30$ & $158, \quad 85$ & +3, & 55 \\
\hline 13 & 44,5 & $167, \quad 50$ & $161, \quad 65$ & -5, & 85 \\
\hline 15 & 1,0 & $169, \quad 20$ & $176, \quad 66$ & +7, & 46 \\
\hline 16 & $52, \quad 0$ & $197, \quad 30$ & $198, \quad 42$ & +1, & 12 \\
\hline 37 & $2, \quad 0$ & $446, \quad 00$ & $435, \quad 65$ & -10 & 35 \\
\hline 38 & 4,5 & $449, \quad 50$ & $447, \quad 91$ & -1, & 59 \\
\hline
\end{tabular}

*) Dem von Leonhard Euler aufgestellten Satze ertheilt W. Schell [103] folgende Fassung: „Die Folge zweier Rotationen um zwei Axen $(\alpha, a)$ und $(\beta, b)$, welche sich in einem Punkte $O$ schneiden, ist äquivalent einer einzigen Rotation um eine dritte Axe $(\gamma, c)$, welche gleichfalls durch den Schnittpunkt $O$ jener hindurchgeht; die drei Kanten $\mathrm{a}, \mathrm{b}$ und $(\gamma, \mathrm{c})$ bilden die Kanten eines dreiseitigen pyramidalen Raumes, in welchem die beiden Seitenebenen, die durch die Axe $(\gamma, c)$ gehen, mit der dritten, durch $a$ und $b$ gehenden Seitenebene an den Kanten a und $\mathrm{b}$ Winkel bilden, welche den halben Amplituden der Rotationen um diese Axen gleich sind, und zwar liegen diese Winkel bei der Axe a, um welche die erste Rotation erfolgt, auf entgegengesetzter Seite der Ebene a b, bei der anderen Axe b auf derselben Seite, nach welcher hin die betreffende Rotation erfolgt. Die halbe Amplitude der resultirenden Rotation um die Axe $(\gamma, c)$ ist gleich dem an der Axe $(\gamma, c)$ liegenden Aussenwinkel des pyramidalen Raumes; die Aufeinanderfolge der Rotationen ist nicht vertauschbar." Man sieht, dass für unendlich kleine Drehungen die letztere Eigenschaft ihre Gültigkeit verliert, wie eben auch in der elementaren Statik die Reihenfolge, in welcher zusammengesetzt wird, sich gleichbleibt. Das Symbol $(\alpha, a)$ sagt aus, es solle das System um die ihm angehörende Gerade $\alpha$ rotiren, und es solle diese Gerade während der Rotation mit der Linie a des Raumes zusammenfallen. 
Diese Gegenüberstellung von berechneten und empirischen Daten bestätigt zur Genüge unsere obige Behauptung, allein über die Bedeutung einer Näherungsformel geht die Sinusformel nicht hinaus. Behandelt man die Differentialgleichungen, zu welchen die Aufgabe führt, nach den allgemeinen Maassnahmen G. Kirchhoff's, so ergiebt sich nach Pieper [105] Folgendes: „Unsere Formel giebt die Ablenkung eines Pendels auf der rotirenden Erde unter der Beschränkung, dass die Schwingungsamplitude gegen die Pendellänge unendlich klein ist, und dass das Quadrat der Winkelgeschwindigkeit ohne merklichen Fehler gleich Null gesetzt werden darf."

Dabei ward zudem stillschweigend vorausgesetzt, dass der Luftwiderstand belanglos sei. Im Allgemeinen ist das aber nicht der Fall, vielmehr hat Siac ci gezeigt, dass alsdann die Bahnkurve mit noch weniger Recht durch eine Gerade ersetzt werden könne. Wie verwickelt die Verhältnisse sich dann gestalten, mag Siacci's Hauptsatz [106] darthun: die Projektion irgend eines Punktes der vom Foucault'schen Pendel in freier Luft beschriebenen Trajektorie ist eine gleichwinklige Spirale, deren Centrum eine der vorigen gleiche Spirale in entgegengesetztem Sinne durchläuft. Die Bahngeschwindigkeit des beschreibenden Punktes ist für beide Spiralen eine abnehmende und den RadienVektoren proportional.

An Stelle des gewöhnlichen Pendels kann behufs augenfälliger Demonstration der Erddrehung auch das konische treten, wie es, als Centrifugalregulator, bei unseren Dampfmaschinen dient. Die Umdrehungsdauer $\mathrm{T}$ eines Kegelpendels von der Länge 1 und dem Ausschlagswinkel $\alpha$ ist durch

$$
\mathrm{T}=2 \pi \sqrt{\frac{1 \cos \alpha}{\mathrm{g}}}
$$

gegeben. Nach dieser Formel müsste es einerlei sein, ob die Schwingungen im Sinne des Uhrzeigers oder diesem entgegen vor sich giengen, allein dem ist nicht so, vielmehr hat Bravais rechnerisch und versuchsmässig nachgewiesen [107], dass sowohl in diesem wie in manchem anderen Falle [108] die Ungleichheit der Schwingungsdauer je nach dem Drehsinn auf den Umstand zurückzuführen ist, dass ja das schwingende System nicht auf einer ruhenden, sondern auf einer selbst sich drehenden Kugel befestigt ist.

Eine höchst beachtenswerthe Modifikation des Foucault'schen Experimentes ist endlich in neuester Zeit von $\mathrm{K}$ amerlingh Onnes in Vorschlag gebracht worden, der zu seinen bezüglichen tiefgehenden Untersuchungen [109], eigener Angabe zufolge, durch G. Kirchhoff angeregt worden war. Es ist eigenthümlich, dass die Idee des niederländischen Mathematikers von keinem Geringeren, als von Gauss, bereits im Stillen gehegt worden war, allein das Verdienst des Erstgenannten wird dadurch nur erhöht, nicht geschmälert, denn Schering, dem die nachgelassenen Papiere des grossen Denkers zur Verfügung standen, hat aus diesen die betreffende Notiz gezogen und zugleich hinzugefügt, dass von Gauss' Absicht niemals etwas in die Oeffentlichkeit gedrungen sei [110]. Der dünne Draht des Foucault'schen Pendels wird hiernach ersetzt durch die cardanische Auf- 
hängung*) eines festen Pendels. Für gewöhnlich werden die Trägheitsmomente des Pendels mit Bezug auf die beiden in der Ruhelage horizontalen Axen, der Theorie entgegen, unter sich verschieden sein, und diese Verschiedenheit birgt bereits eine Fehlerquelle in sich : bei Onnes' Anordnung des Versuches wird jene von vorn herein beseitigt, und da die Schwingungen sich stets in einem geschlossenen Raume von starker Luftverdünnung vollzogen, so konnte auch der Einfluss des Luftwiderstandes ausser Acht gelassen werden. Die unter diesen Kautelen angestellten Versuche ergaben ungeachtet der weit geringeren Pendellänge und des weit kürzeren Beobachtungs-Zeitraumes trotzdem eine grössere Annäherung an die Wahrheit, als irgend eine der bislang vorliegenden Versuchsreihen.

$\mathrm{Kamerlingh} \mathrm{Onnes}$ hat sich indessen nicht auf den erfahrungsmässigen Theil seiner Aufgabe beschränkt, der im Gegentheil in seiner Schrift erst an späterer Stelle erscheint [111], sondern auch theoretischen Materiales bietet dieselbe eine Fülle. Von grosser Wichtigkeit ist der von ihm gefundene neue Satz, dass die Bewegung eines der Schwerkraft unterworfenen Körpers mit zwei zu einander rechtwinkligen und bei der Ruhelage in derselben Horizontalebene sich befindenden Axen, wenn die Trägheitsmomente bezüglich jener Axen unter sich und gleichzeitig dem Trägheitsmomente bezüglich der dritten Axe gleich sind, lediglich mit Hülfe der elliptischen Transscendenten vollständig bestimmt werden kann. Weiter wird aber noch bewiesen, dass die Schwingungen eines Stabes, dessen eines Ende mit einer rotirenden Axe verbunden ist, die Rotation der Erde sozusagen wiederspiegeln, und dass auch bei den sogenannten Lissajous-Kurven jener Einfluss hervortritt. Mit Einem Worte: bei sehr vielen Bewegungsvorgängen, welche mit der Axendrehung der Erde gar nichts zu thun zu haben scheinen, macht sich deren Einfluss so fühlbar, dass ihn die Rechnung und geschickte Versuche gewissermassen ad oculos zu demonstriren vermögen.

§. 5. Aeltere Weltsysteme. Neben den sogenannten Erscheinungen der täglichen Bewegung beschäftigte die Astronomen von je eine Doppel.

*) Diese Art der Aufhängung ist besonders bei Kompassen, Schiffslampen u. s. w. beliebt, weil durch sie eine nahezu vertikale, durch Stösse und Schlingern des Schiffes wenig beeinträchtigte Stellung des betreffenden Gegenstandes verbürgt ist. Wenn M N Q (Fig. 39) die Kompassbüchse ist, so begegnet man im Innern derselben zunächst zweien Stiften A, B, welche sich diametral gegenüberstehen und einen um die Axe A B frei drehbaren Ring tragen. An diesem Ringe sind, je um $90^{\circ}$ von $\AA$ und $B$ entfernt, die Stifte D und E befestigt, und diese tragen einen zweiten koncentrischen Ring, der sich demnach um die Axe DE drehen kann. Dieser innere Ring umschliesst den eigentlichen Kompass, resp. den mit möglichster Bewegungsfreiheit aufzuhängenden Gegenstand.

Fig. 39.

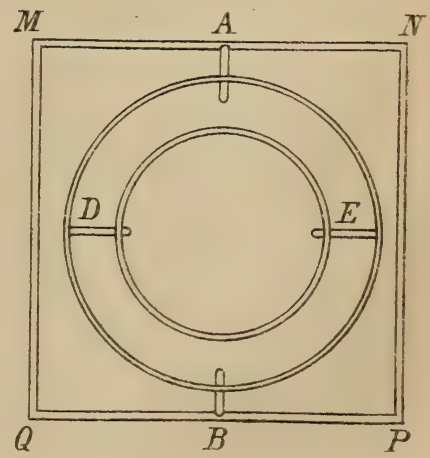


frage: Wie kommt es, dass die Durchmesser von Sonne und Monddie übrigen Wandelsterne erscheinen dem unbewaffneten Auge nur als leuchtende Punkte - nicht zu allen Zeiten unter dem nämlichen Gesichtswinkel, also gleich gross, erscheinen? Wie kommt es zweitens, dass die Bahnen der Planeten, namentlich der oberen, so regellos verlaufen, dass Stillstände, rückläufige Bewegung und Schleifenbildung an jenen erkannt werden? Im Alterthum bezeichnete man die beiden Komplexe von Erscheinungen, von welchen hier die Rede war, kurz als die erste und zweite Ungleichheit. Von Anfang an fehlte es nicht an Theorieen, durch welche diese anscheinenden Unregelmässigkeiten als Ausfluss einiger weniger genereller Gesetze dargestellt werden sollten. Hauptsächlich vier dieser Weltsysteme spielen, vom coppernicanischen abgesehen, eine gewisse historische Rolle.

a) Das System des Eudoxos. Es ist dieses das älteste Weltsystem, das seinen Namen wirklich verdient; merkwürdigerweise hat ihm aber erst die neueste Zeit zu seinem Rechte verholfen. Die älteren Historiker, Montucla, Bailly, Dela mbre und selbst Schaubach, wussten durchaus nicht, was sie aus den allerdings unzureichenden Nachrichten machen sollten, und erst mit Id eler [112] und Corn ewall Lew is [113] brachen sich richtigere Anschauungen Bahn, bis dann Schiaparelli in einer zum klassischen Muster dienenden Monographie [114], von der auch eine gute deutsche Bearbeitung existirt [115], das wahre Wesen dieser geistvollen altgriechischen Theorie völlig klar legte. Wir bemerken noch, dass Henri Martin [116] die Folgerungen Schiaparelli's zwar für die eigentlichen Planeten adoptirt, für Sonne und Mond dagegen abgelehnt hat, während dann wieder Tannery [117] mit guten Gründen für die Aufrechthaltung der ursprünglichen Ergebnisse eintrat. An diese letzteren wird sich auch unser gegenwärtiger Bericht halten. Eudoxos der Knider schuf im IV. vorchristlichen Jahrhundert sein System der homocentrischen Sphären; jeder Planet, Sonne und Mond natürlich mitinbegriffen, befand sich angeheftet an eine zur Erde koncentrische Kugel, welche sich in 24 Stunden einmal um ihre Axe dreht. Ausserdem aber dachte er sich mit jener ersten Kugel noch eine Anzahl fester Sphären verbunden, denen ebenfalls eine gleichförmige Rotationsbewegung zukam, nicht jedoch um die vorige, sondern um eine räumlich von ihr verschiedene, den speziell zu erfüllenden Bedingungen entsprechend gewählte Axe. Die beiden grossen Himmelskörper erhielten je drei, die Planeten je vier solche Kugelschalen zugeordnet, und die Aufgabe, völlige Harmonie der hiedurch eingeleiteten mit den wirklichen himmlischen Bewegungen herzustellen, reducirte sich auf ein allerdings nicht ganz leichtes Problem der sphärischen Geometrie. Eudoxos gewann so eine sphärische Kurve, die "Hippopede", welche namentlich die sonderbaren Verschlingungen der Planetenbahnen auf das Treueste wiedergab. Die zweite Ungleichheit (s. o.) war somit in einer den Zeitbegriffen trefflich sich anpassenden Weise erklärt; für die erste Ungleichheit liess das System allerdings im Stiche, allein deren Bedeutung trat damals auch noch sehr zurück. Kalippos und Aristoteles änderten an dem Sphärensystem herum und vermehrten besonders die Anzahl der Planetenkugeln; Eudoxos reichte mit 27 aus, während sein erster Nachfolger deren 33, 
sein zweiter gar 55 für nöthig erachtete. Mochte durch diese Zusätze auch manche kleinere Anomalie des Planetenlaufes richtig erklärt werden, so entstand doch allmählig eine solche Schwerfälligkeit des Aufbaues der einzelnen Bestandtheile, dass die Astronomen nach einfacheren Hülfsmitteln der Erklärung sich umsahen. Aristoteles hat durch sein wohlgemeintes Streben nach Genauigkeit am meisten dazu beigetragen, die Sphärenlehre des Eudoxos in jenen Misskredit zu bringen, aus welchem sie erst durch Schiaparelli errettet ward *).

b) Das ptolemäische System. Schon Pythagoras soll die Irregularitäten der Planetenbahnen für eine optische Täuschung angesehen haben, während sie Eudoxos, wie wir sahen, als etwas Reelles behandelte. Eine aus dem Theon in Beda's Werke übergangene Stelle besagt wenigstens [121]: ${ }_{\text {P }}$ thag oras planetas neque retrogradari, neque stare, neque anomaliam aliquam esse dicebat, sed omnes in aequali spatio temporis aequaliter complere spatium locorum." Die Hypothese des excentrischen Kreises dürfte nach Schiaparelli's Ansicht schon den späteren Pythagoreern mundgerecht gewesen sein [122]. Wissenschaftlich formulirt hat sie Hipparch von Nicäa (um 130 v. Chr.), der die erste Ungleichheit für die Sonne - und ähnlich für den Mond - in folgender gewiss geistreicher Weise verdeutlichte. Der äussere Kreis in Fig. 40 repräsentirt die - in beliebiger Entfernung zu denkende - Himmelskugel, M ist deren Mittelpunkt und zugleich der Mittelpunkt der Erdkugel. Das Centrum der von der Sonne beschriebenen Kreisbahn liegt in N so, dass die Entfernung MN gleich 1/24 des Halbmessers der Sonnenbahn wird. In $\mathrm{P}$ erreicht die Sonne ihr Perigäum, in A ihr A pogäum, und damit ist die Veränderlichkeit ihrer Grösse genugsam erklärt. Die beiden in $\mathbf{M}$ auf einander senkrechten Geraden $V \Omega$ und 696 theilen allerdings den äusseren Kreis in seine vier gleichen

Fig. 40.

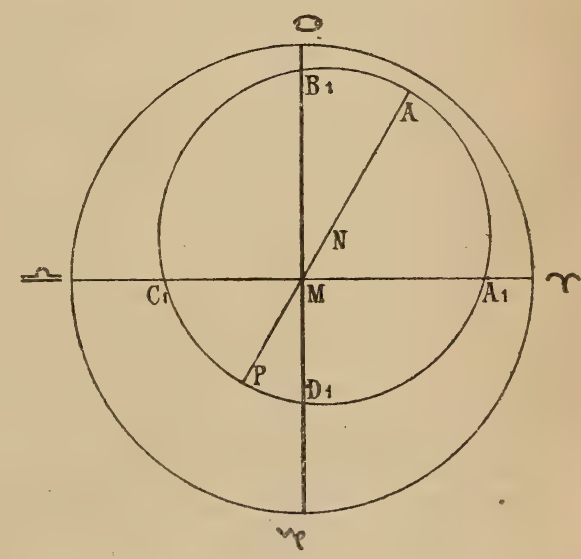

*) Auch im früheren und späteren Mittelalter fehlte es nicht an Gelehrten, die, mit den mancherlei Unwahrscheinlichkeiten der ptolemäischen Weltordnung unzufrieden, auf die Sphärentheorie zurückgreifen zu sollen glaubten. So berichtet der grosse jüdische Polyhistor Moses ben Maimon oder Maimonides, der selbst eine doppelte Buchführung liebte und als philosophischer Theoretiker dem Eudoxos, als praktischer Astronom aber dem Ptolemäus huldigte [118], in seinem "Führer der Irrenden" nach M unk's Uebersetzung [119]: „Dès le commencement du XIIe siècle, les astronomes arabes d'Espagne reconnurent ce qu'il $\mathrm{y}$ avait d'invraisemblable dans cette hypothèse, par laquelle $\mathrm{P}$ tolémée cherche à expliquer certaines anomalies dans le mouvement de diverses planètes. IbnBadja s'éleva le premier contre l'hypothèse des épicycles, et Ibn-Tofeil rejeta à la fois les excentriques et les épicycles... Un peu plus tard A bou-Is'hak al Bitrôdji, ou Alpetragius, essaya de substituer d'autres hypothèses à celle de Ptolémée." Auch der Reformversuch des Italieners Fracastor [120] lenkte wesentlich in die alte Bahn der Homocentriker ein. 
Quadranten, dagegen sind die vier Kreisbögen $A_{1} B_{1}, B_{1} C_{1}, C_{1} D_{1}$, $\mathrm{D}_{1} \mathrm{~A}_{1}$ ersichtlich ungleich, und zwar gelten die Proportionen:

$\operatorname{arc} A_{1} B_{1}: \operatorname{arc} B_{1} C_{1}: \operatorname{arc} C_{1} D_{1}: \operatorname{arc} D_{1} A_{1}=94^{1 / 2}: 92^{1 / 2}: 88: 90$;

Hipparch hatte nämlich ermittelt, dass auf den Frühling $94^{1} / 2$, auf den Sommer 92/2, auf den Herbst 88 und auf den Winter 90 Tage treffen. Einen trefflichen Auszug aus den Betrachtungen, durch welche Hipparch und Ptolemäus (im III. Buche seines "Almagest") zu der beschriebenen Konstruktion geführt wurden, hat R. Wolf [123] gegeben.

War so der ersten Ungleichheit Genüge gethan, so war damit doch noch keineswegs die Basis für die Erklärung jener auffälligen Abweichungen von der reinen Kreisbahn gewonnen, mit denen besonders Ptolemäus bei seinen feineren Untersuchungen über den Mondlauf zu rechnen hatte, als er zu einer bereits bekannten Ungleichheit noch eine zweite hinzugefunden hatte. „Derselbe war daher genöthigt, ${ }^{*}$ sagt der verdienstvolle Geschichtschreiber der Sternkunde [124], „die

Fig. 41.

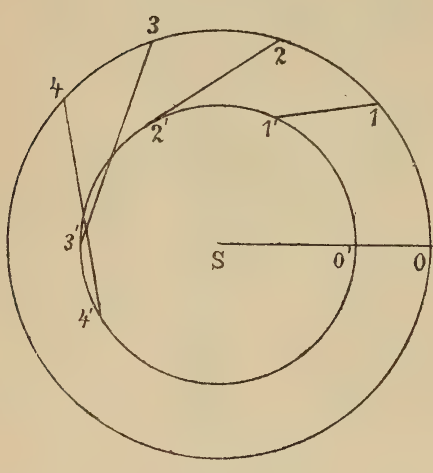

a.

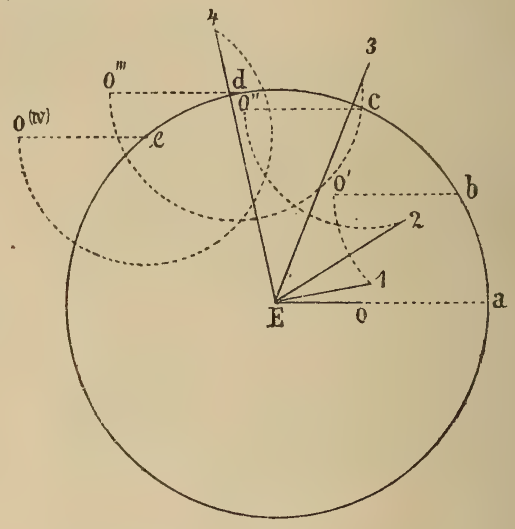

b.

Arbeit noch einmal an die Hand zu nehmen, und zog nun vor, den excentrischen Kreis zur Darstellung der neuen Ungleichheit aufzusparen, für die frühere, oder die sogenannte Gleichung, dagegen ein Hülfsmittel zu verwerthen, das Apollonios schon vor alten Zeiten zu solchem $Z$ wecke vorgeschlagen, aber Hipparch entweder gar nicht, oder höchstens probeweise gebraucht hatte, weil es ihm nicht naturgemäss erschien." Fig. 41, die wir einer Darstellung H. J. Klein's [125] entlehnen, versinnlicht das Wesen der epicyklischen Bewegung zugleich mit der natürlicheren Erklärung, durch welche Coppernicus jene theilweise - durchaus nicht gänzlich - ersetzte. Fig. 41a entspricht dem coppernicanischen, $41 \mathrm{~b}$ dem ptolemäischen System, $\mathrm{E}$ ist die Erde, $\mathrm{S}$ die Sonne. Stände die Erde fest, so wäre abcde der sogenannte $\mathrm{De}$ ferenzkreis, auf dessen Peripherie das Centrum des Epicykels oder Beikreises mit gleichförmiger Geschwindigkeit fortrückt, während der Planet wiederum gleichförmig den Umfang des Beikreises durchläuft. Das Centrum befinde sich in a, der Planet in o, E 0 ist die Gesichtslinie. Nach der Zeit $t$ ist das Centrum bis $b$ gekommen, der Planet hat, 
wenn $\mathrm{b} 0^{\prime} \| \mathrm{E} 0$ ist den Bogen $0^{\prime} 1$ beschrieben, so dass nunmehr E1 die Gesichtslinie geworden ist. Ebenso sei ferner $b c=c d=d e=a b$ und $\mathrm{c} 0^{\prime \prime}\left\|\mathrm{d} 0^{\prime \prime \prime}\right\| \mathrm{e} 0^{(\text {IV) }} \| \mathrm{E} 0,0^{\prime \prime} 2=2.0^{\prime} 1,0^{\prime \prime \prime} 3=3.0^{\prime} 1,0^{(\text {IV })} 4=4.0^{\prime} 1$; unter diesen Umständen sind E2, E3, E4 die jedesmal von der Erde nach dem Wandelsterne gezogenen Gesichtslinien. Fig. 41a dagegen weist als den inneren der beiden koncentrischen Kreise die Erdbahn, als den äusseren die Bahn eines oberen Planeten, etwa des Mars, auf. Während die Erde nach und nach die Punkte $0^{\prime}, 1^{\prime}, 2^{\prime}, 3^{\prime}, 4^{\prime}$ erreicht, steht der Planet resp. in $0,1,2,3,4$, die Strecken $0^{\prime} 0,1^{\prime} 1,2^{\prime} 2,3^{\prime} 3,4^{\prime} 4$ stellen mithin nach Lage und Grösse die Gesichtslinien vor. Durch geeignete geometrische Vèrzeichnung kann man es aber, wie auch in der Figur der Fall, dahin bringen, dass

$$
\mathrm{E} 0 \# 0^{\prime} 0, \mathrm{E} 1 \# 1^{\prime} 1, \mathrm{E} 2 \# 2^{\prime} 2, \mathrm{E} 3 \# 3^{\prime} 3, \mathrm{E} 4 \# 4^{\prime} 4
$$

wird, und damit ist der Beweis geliefert, dass unter dem ausschliesslich formal-mathematischen Gesichtspunkte beide Auffassungen gleich gut zum Ziele führen. Ja, Möbius hat später gezeigt [126], dass wir auch heute noch mit der epicyklischen Bewegung mehr zu thun haben, als wir meinen, indem jede Entwickelung in trigonometrische Reihen, welche nach Sinus und Cosinus der Vielfachen eines Winkels fortschreiten, ihre geometrische Interpretation eben in dieser Art der Bewegung findet.

Ptolemäus setzte, wie schon bemerkt, in die Mitte des Universums die Erde und liess um dieselbe die zu seiner Zeit bekannten Wandelkörper in folgender Ordnung kreisen: Mond, Merkur, Venus, Sonne, Mars, Jupiter, Saturn. Excentrische Kreise und Epicykel glichen alle Unregelmässigkeiten der Bahnen aus; wo Ein Beikreis nicht hinreichend erschien, verlegte man den Planeten in einen zweiten, für welchen der erste Epicykel nun selbst wieder zum Deferenten wurde. Das mechanische Paradoxon, dass ein fester Körper sich um die absolute Leere herum bewegen sollte, fiel in der Zeit vor Galilei wenig auf, der geometrische Schönheitssinn der Alten aber war befriedigt. Nur die mehr philosophisch angelegten Geister vermochten an den sich stetig häufenden Epicykeln keine Freude zu empfinden, und König Alfons von Kastilien that deswegen den von seinen politischen Feinden später so sehr gegen ihn ausgenützten Ausspruch [127], er würde, wenn er von dem Weltschöpfer um seine Meinung befragt worden wäre, den Ausbau des Kosmos in einfacherer Weise vollzogen haben.

c) Das ägyptische System. Merkur und Venus entfernen sich bekanntlich immer nur wenig von der Sonne und treten niemals zu dieser in Opposition. Diess war den Alten bereits aufgefallen, und einer von Schiaparelli aufgestellten, sehr plausiblen Hypothese zufolge war es bereits Herakleides Pontikos, der den beiden genannten Planeten eine Sonderstellung anwies und sie zu speziellen Trabanten der Sonne machte, so dass sie also zunächst um diese und erst mit ihr auch um die Erde kreisen sollten [128]. Eine missverstandene Stelle des Macrobius brachte es zuwege [129], dass man diese Anordnung der Planetenbahnen mit dem Namen des ägyptischen Weltsystemes belegte. Am meisten Anklang scheint dasselbe bei den Römern, bei Terentius Varro, Vitruvius, Marcianus Capella u. s. w. gefunden zu haben; der letztgenannte Kompilator drückt sich darüber aus, wie folgt [130]: 
$N a m$ Venus Mercuriusque licet ortus occasusque cotidianos ostendant, tamen eorum circuli terras omnino non ambiunt, sed circa Solem laxiore ambitu circulantur denique circulorum suorum centron in Sole constituunt." Narducci hat mit gewohntem Fleisse die Aussprüche der Historiker über diese Stelle gesammelt [131], von welcher soviel feststeht, dass sie sowohl auf Coppernicus selbst anregend, als auf Tycho Brahe sogar bis zu einem gewissen Grade bestimmend eingewirkt habe.

d) Das tychonische System. Dieses System ist, wie aus dem unmittelbar Vorhergehenden erhellt, in Wahrheit nur eine Verallgemeinerung und Weiterbildung des sogenannten ägyptischen. Drei Gründe mögen auch den dänischen Astronomen, der als Beobachter ungleich grösser dasteht, wie als selbstständiger Denker, dahin vermocht haben, der Weltordnung des sonst von ihm so hoch verehrten Coppernicus seine Zustimmung zu versagen: einmal das vielleicht etwas zu sehr emporgeschraubte Gefühl eigener Werthschätzung, sodann das Bestreben, mit den kirchlichen Dogmen in keinen Konflikt zu gerathen, und dann auch wohl das an sich richtige Empfinden, dass in dem ägyptischen Systeme ein ganz richtiger Kern enthalten sei. Indem sonach Tycho um die unbeweglich stehende Erde zuerst den Mond und dann die Sonne, um diese letztere aber sämmtliche Planeten in der Reihenfolge Merkur, Venus, Mars, Jupiter, Saturn sich umwälzen liess [132], handelte er zwar als Sohn seiner noch immer in Vorurtheilen befangenen Zeit, aber keineswegs so thöricht, wie man schon öfter in populären Schilderungen hat glauben machen wollen. „Momentane Berechtigung als Uebergangssystem," das sind die Worte R. Wolf's [133], „hatte damals das tychonische System allerdings, während dasjenige, welches fast ein Jahrhundert später Riccioli aufstellte, und bei welchem auch noch Jupiter und Saturn Trabanten der Erde bleiben sollten, besser ganz unaufgestellt geblieben wäre, da ihm damals, nachdem Kepler bereits vor Jahrzehnten das coppernicanische System purificirt hatte, jede Bedeutung und Berechtigung abgieng". Man vergleiche auch die von Gerechtigkeitsgefühl getragene Apologie von Schinz [134]. Allerdings hat Raimarus Ursus aus Dithmarsen in einer die gröbsten Verdächtigungen gegen $\mathrm{Br}$ ahe schleudernden Zuschrift, welche er dem Landgrafen Moritz von Hessen widmete [135], die Behauptung aufgestellt, das tychonische Weltsystem rühre eigentlich von ihm her, und jener habe ihm dasselbe mit Unterstützung des landgräflichen Hofmathematikers Rothmann gestohlen, indessen vermochte er diesen Vorwurf keineswegs sicher zu begründen, und es scheint ihm als zweifelloses Verdienst blos Das zu verbleiben [136], dass er - wie Longomontan und Origanus mit dem coppernicanischen (s. o. §. 1) - so mit dem tychonischen Systeme den Begriff einer sich um ihre Axe drehenden Erde verband.

§. 6. Die heliocentrische Reform und deren Begründung. Die Quintessenz des coppernicanischen Systemes kann man nicht schärfer und zugleich umfassender ausziehen, als es durch dessen Begründer selbst in dem uns bereits bekannten "Commentariolus " geschehen ist. Sechs "Axiome" werden daselbst aufgestellt, die wir nach Prowe's Verdeutschung [137] hier reproduciren: 
und deren Bahnen giebt es nur Einen Mittelpunkt. II. Der Mittelpunkt der Erde ist nicht der Mittelpunkt der Welt, sondern nur der Mittelpunkt der Mondbahn und der Schwerpunkt aller Dinge auf der Erde. III. Alle Planeten umkreisen die Sonne, die im Mittelpunkte aller Bahnen steht; es ist deshalb um die Sonne der Mittelpunkt des Weltalls zu setzen*). IV. Das Verhältniss der Entfernung der Sonne und der Erde zur Weite des Firmamentes ist geringer, als das Verhältniss des Halbmessers der Erde zur Entfernung der Sonne, und zwar in solchem Grade, dass das Verhältniss zur Höhe des Firmamentes gar nicht anzugeben ist. V. Was wir von Bewegungen am Himmel sehen, rührt nicht von einer Bewegung des Himmels her, sondern ist eine Folge der Bewegungen der Erde. Die Erde nämlich mit ihrer nächsten Umgebung**) dreht sich einmal täglich um sich selbst ganz herum, indem ihre beiden Pole dabei unverändert ihre Richtung beibehalten, das Firmament aber und die letzten Himmelsräume ganz unbewegt bleiben. VI. Was wir von Bewegungen bei der Sonne sehen, das ist nicht eine Folge ihrer Bewegung, sondern rührt her von der Bewegung der Erde und ihrer Sphäre****). Mit ihnen umkreisen wir die Sonne, gleichwie jeder andere Planet. Die Erde hat sonach eine mehrfache Bewegung. Was uns an den Planeten als ein Zurückweichen und Vorschreiten erscheint, das ist nicht Folge ihrer Bewegung, sondern rührt von der Bewegung der Erde her. Die Bewegung der Erde allein genügt sonach, um die Mannigfaltigkeit und Verschiedenheit der Erscheinungen am Himmel zu erklären."

Direkte und schlagende Beweise für die Richtigkeit dieser Thesen waren nach damaliger Sachlage, wie wir vorher (in §. 1) schon bei der Rotationsfrage sahen, noch nicht zu erbringen, das sah Coppernicus selbst ganz wohl ein. Er konnte sich darauf berufen, dass sein System (s. o. §. 5 b) die Planetenbahnen und deren Abweichungen ganz ebenso gut erkläre, wie das ptolemäische, dass ein Gleiches auch für die Jahreszeiten gelte, und dass dabei seine Erklärung für den mit den Grössenverhältnissen des Weltalls Vertrauten etwas ungleich Naturgemässeres und Ungezwungeneres besitze, wie irgendwelche andere.

*) Im Originale: „ideoque circa Solem esse centrum mundi“.

**) Aehnlich, nur etwas unmathematischer und gerade deshalb in diesem Falle überzeugender drückte dieses Faktum Aristarch aus, der einzige Grieche, der als wahrer und ächter Vorläufer des Coppernicus in jedem Sinne gelten kann. Seine bezügliche Schrift ist allerdings nicht auf uns gekommen; was diesen Namen trägt, ist ein zur Irreführung der Gelehrten zurechtgemachtes Falsifikat Roberval's [138], aber Archimedes berichtet im Eingange zu seiner "Sandrechnung" darüber mit hinlänglicher Genaujgkeit (wir citiren nach Heiberg's. lateinischer Version [139]): "A ristarchus Samius libros quosdam edidit, qui hy. potheses inscribuntur, in quibus ex iis, quae supponuntur, adparet, mundum multiplicem esse, quam supra diximus. Supponit enim, stellas fixas solemque immobilia. manere, terram vero circum solem in medio cursu positum secundum circuli ambitum circumvolvi, sphaeram autem stellarum fixarum circum idem centrum positam, circum quod sol positus sit, tantam esse, ut circulus, secundum quem terram circumvolvi supponit, eam rationem habeat ad distantiam stellarum fixarum, quam habeat centrum terrae ad superficiem."

***) Man beachte, dass sich Coppernic sehr wohl darüber klar war, wie. auch die Atmosphäre der Erde an deren Umdrehung theilnehmen müsse. Den Gegnern entgieng dieser wichtige Zusatz, und so liessen sie sich zu den ungereimtesten Gegengründen verleiten, wie z. B. dass der Durchgang der Erdkugel durch die stille stehende Luft einen Sturmwind hervorrufen müsse, $\boldsymbol{u}$. dgl. mehr. 
Hiebei aber musste es einstweilen sein Bewenden haben, und es vergiengen Jahrzehnte, ja Jahrhunderte, bis astronomis che Beweismittel von wirklich überzeugender Kraft an die Hand gegeben werden konnten. Rein tellurisch kann die Bewegung der Erde um die Sonne nicht nachgewiesen werden; ein Versuch, das Pendel auch nach dieser Richtung hin zu verwerthen, ist zwar von J.W. H. Lehmann [140] gemacht worden, doch hat Kamerlingh Onnes (s. o. §. 4) in dessen Rechnungen fundamentale Fehler aufgedeckt. Was aber die astronomischen Beweise für den zweiten Hauptsatz Coppernic's anlangt, so können deren, wenn einige minder wichtige, wo nicht zweifelhafte unterdrückt werden, im Wesentlichen drei auf Berücksichtigung Anspruch machen.

a) Die Phasen der Planeten. Es scheint, dass Coppernicus bereits die Nothwendigkeit erkannt hatte, es müssten auch die Planeten, ähnlich wie der Mond, je nach ihrer Stellung zur Erde und Sonne wechiselnde Lichtgestalten aufweisen. Das unbewaffnete Auge konnte hierüber keinen Entscheid treffen; kaum aber hatte Galilei das neuentdeckte Fernrohr gegen den Himmel gerichtet, so erkannte er auch sofort die Phasen der Venus. Am 11. December 1610 legte er seinen Fund in einem Anagramm nieder, am 1. Januar des nächstfolgenden Jahres gab er dazu öffentlich die Lösung: „Cynthiae figuras aemulatur mater amorum" [141]. Die Phasen des Mars*) und Merkur nahm zuerst Fontana etwa dreissig Jahre später wahr, und gleichzeitig erwähnte ihrer auch der Schweizer Hirzgarter in seiner „Detectio dioptrica corporum planetarum verorum " [142]. Galilei sprach sich auch gleich anfangs in seinem Briefe an Christoph Clavius dahin aus, dass nunmehr der Thatbeweis für die Richtigkeit der coppernicanischen Kosmologie angetreten werden könne, doch machte seltsamerweise diese augenfällige Demonstration auf die Zeitgenossen minderen Eindruck als der in der Entdeckung der Jupiterstrabanten liegende Wahrscheinlichkeitsbeweis, durch welchen dargethan wurde [143], dass nicht nothwendig alle Gestirne gerade um die Erde als das prästabilirte Centrum des Weltganzen sich herumbewegen müssten.

b) Die Parallaxe der Fixsterne. Unter der Parallaxe eines Fixsternes hat man den Winkel zu verstehen, unter welchem einem auf dem betreffenden Sterne (richtiger in dessen Mittelpunkt) befindlichen Auge der etwa 40000000 geographische Meilen oder 149000000 Kilometer betragende Durchmesser der Erdbahn erscheint. Befände sich der Stern in unendlich grosser oder doch in einer menschlichen Messungsmethoden absolut unzugänglichen Entfernung, so wären zwei etwa zur Zeit des Winter- und Sommersolstitiums nach ersterem gezogene Gesichtslinien in aller Strenge parallel; so hatte sich Coppernicus (s. o. seine These IV) die Sache gedacht und damit klugerweise jeden Einwand vernichtet, der sonst aus dem Fehlen von Fixsternparallaxen nothwendig gegen sein System hergeleitet werden musste. Aber schon

*) Nicht selten findet man über die Sichelgestalten der Wandelsterne ungenaue Angaben, aus denen hervorzugehen scheint, es könne diese Erscheinung nur bei den unteren Planeten statthaben. Der Theorie nach müssen sämmtliche Planeten Phasen erkennen lassen, allein bei den entfernteren wird der beschattete Theil sehr schmal und deshalb nicht mehr gut wahrnehmbar. 
Galilei - wir folgen in der nachstehenden kurzen Geschichte des Kampfes um die Parallaxe den Angaben R. Wolf's [144] und J. v. Littrow's [145] - begnügte sich bei diesem negativen Standpunkte nicht mehr, und nunmehr begann ein emsiges Ringen geschickter Observatoren, den ungemein kleinen Winkel, um welchen es sich allein handeln konnte, durch möglichste Verschärfung der Beobachtungswerkzeuge wirklicher Messung zu unterstellen. Tycho Brahe, Riccioli, Hooke, Flamsteed und Römer betheiligten sich erfolglos an diesem Wettkampfe, ganz sicher glaubte der Irländer Brinkley eine Reihe von Parallaxen gefunden zu haben, allein Pond's mauerfest auf ihr Ziel gerichtete Riesenfernrohre lieferten dem widersprechende Resultate, und auch Bradley's durch Jahre musterhaft fortgeführte Beobachtungsreihe förderte zwar in anderer Weise die Wissenschaft (s. u. c.), lieferte aber nicht Das, was sie eigentlich zu liefern bestimmt war. Auch Callandrelli's Hoffnung, für Wega in der Leyer eine sichere Parallaxe von 44" eruirt zu haben, erwies sich Bessel's einlässlicher Prüfung gegenüber als illusorisch. Endlich bahnte William Herschel's Idee, nicht sowohl die Parallaxe eines Sternes direkt, sondern die Parallaxendifferenz zweier optischer Doppelsterne zu bestimmen, einen wirklichen Fortschritt an, und es gelang Bessel [146], die Jahresparallaxe von 61 Cygni $=0^{\prime \prime}, 348$ wirklich zu ermitteln. Seitdem haben W. und O. v. Struve, Henderson, Maclear, Krüger, Peters, Auwers u. a. Fixsternparallaxen in grösserer Menge gemessen, wie folgende kleine Zusammenstellung darthun mag: $\alpha$ Bootis 0", 13; N. 1830 des Sternenverzeichnisses von Gr o o m brid ge e $0^{\prime \prime}, 14$; Wega 0", 15 , ๙. Ursae minoris (Polarstern) 0",18; Sirius 0",23; $\alpha$ Centauri 0",92. Der letzte Fixstern steht unserem Sonnensystem am nächsten. $\mathrm{Ob}$ nun auch die neueren Methoden, die Gyldén [147] und Ch. Dufour [148] dieser mittelst des Spektroskopes - zum Behufe der Parallaxenschätzung angegeben haben, das vorhandene Material wesentlich vermehren werden, muss dahin gestellt bleiben: der strikte mathematische Beweis dafür, dass die Erde alljährlich einen Kreis um die Sonne beschreibt, ist bereits durch die bislang ermittelten Thatsachen als geleistet anzusehen.

c) Die Aberration des Lichtes. Es war soeben von Bradley's Bemühungen um die Parallaxenbestimmung die Rede. Seit 1725 beobachtete dieser treffliche Mann, der im Verein mit Brahe und Bessel das Dreigestirn repräsentirt, durch welches die praktische Astronomie auf ihren heutigen Standpunkt erhoben wurde, im Verein mit Molyneux den Stern $\gamma$ Drakonis an einem Zenithsektor, einem Instrumente, welches nur in einem ganz kleinen Spielraum zu beiden Seiten des Scheitelpunktes, dort aber mit äusserster Genauigkeit Winkel zu messen gestattete*). Nachdem die Beobachtungen einige Jahre hindurch fortgesetzt worden waren, stand allerdings soviel ausser Zweifel, dass der genannte Fixstern alljährlich eine kleine Ellipse an der Himmelskugel beschrieb, und dieser Umstand schien auf den ersten Blick zu Gunsten einer vorhandenen Parallaxe zu sprechen, wie Fig. 42 des

*) Unsere Darstellung lehnt sich hier der Hauptsache nach an diejenige J. v. Littrow's [149] an, welche den Vorzug besonderer Uebersichtlichkeit, namentlich hinsichtlich der Figuren, besitzt. 
Näheren nachweist. In dieser stellt EBKA den Durchschnitt der bis zur scheinbaren Himmelskugel ausgedehnten Ekliptik mit ersterer, L den Nordpol der Ekliptik, C den Ort der Sonne vor. $\mathrm{e}_{1} \mathrm{e}_{3}$ ist die grosse, $e_{2} e_{4}$ die kleine Axe der Ellipse, welche die Erde innerhalb der Ebene EBKA jährlich beschreibt*); die augenblicklichen Bewegungsrichtungen sind durch Pfeile angedeutet. Die Ellipse $e_{1} e_{2} e_{3} e_{4}$ bestimmt mit einem Sterne $S$, der ihr nahe genug ist, um überhaupt eine Parallaxe hervortreten zu lassen, den Mantel eines schiefen Kegels, dessen Ergänzungskegel die Himmelskugel in einer sphärischen Ellipse durchschneiden wird, so zwar, dass den Kardinalpunkten $\mathrm{e}_{1}, \mathrm{e}_{2}, \mathrm{e}_{3}, \mathrm{e}_{4}$ auch wiederum die Kardinalpunkte $\mathrm{s}_{1}, \mathrm{~s}_{2}, \mathrm{~s}_{3}, \mathrm{~s}_{4}$ entsprechen, während auch die Mittelpunkte c und s mit der Spitze $S$ beider Kegel in ein und derselben Geraden liegen. So also hätte die parallaktische Ellipse sich darstellen müssen, allein in Wirklichkeit machte Bradley eine ganz

Fig. 42.

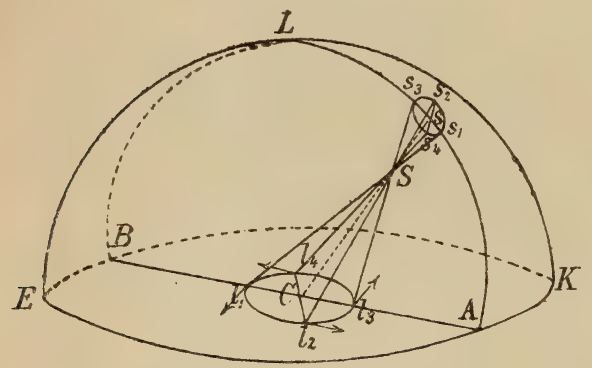

Fig. 43.

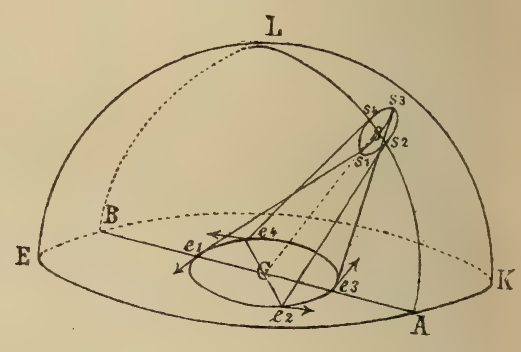

andere Wahrnehmung, diejenige nämlich, welche Fig. 43 veranschaulicht. Von $e_{1}$ aus sah man den Stern in $s_{1}$, von $e_{2}$ aus in $s_{2}$, von $e_{3}$ aus in $s_{3}$ und von $e_{4}$ aus in $s_{4}$; die vier Punkte $s_{1}, s_{2}, s_{3}$, $s_{4}$ lagen allerdings auch wieder auf dem Umfang einer sphärischen Ellipse vom Mittelpunkt $\mathrm{s}$, aber diessmal fiel deren kleine Axe $\mathrm{s}_{2} \mathrm{~s}_{4}$ in die nämliche Ebene mit der grossen Axe $e_{1} e_{3}$ der Erdbahnellipse: die Ellipse von vorhin war gewissermassen um $90^{\circ}$ gedreht worden. Bradley entdeckte als Ursache dieser unerwarteten Abweichung die sogenannte Aberration des Lichtes. Seit Römer gefunden hatte**), dass die Fortpflanzung des Lichtes nicht instantan erfolge, sondern eine gewisse

*) Wir hoffen wegen der kleinen Inkonsequenz leicht Indemnität zu erhalten, die allerdings darin liegt, dass schon hier die Erdbahn als Ellipse behandelt wird, während erst in $\S .8$ diese ihre Eigenschaft näher erörtert werden kann. Rücksichten auf den Zusammenhang liessen vor diesem Fehler nicht zurückschrecken, der wohl um so weniger in's Gewicht fällt, als sich ja das vorliegende Buch nicht an gänzlich unvorgebildete Leser wendet.

**) Eine sehr interessante Studie über die Umstände, welche Römer's Gedankengang leiteten, als er aus seinen Beobachtungen des Jupitersystemes auf eine endliche Lichtgeschwindigkeit schloss, verdankt man W ernicke [150]. Es wird darin namentlich auch gezeigt, wie der Einfluss des mächtigen und von seiner ersten Geneigtheit für Röm er's Entdeckung (einmal sagte er selbst, „que la lumière emploie quelque temps à venir du satellite jusqu’à nous ${ }^{\text {) }}$ ) rasch zurückgekommenen Dominic Cassini hinreichte, die maassgebenden Kreise der grossen Neuerung zu verschliessen und diese selbst so vollkommen in den Hintergrund zu drängen, dass erst durch Bradley wieder Römer's Namen zu der verdienten Ehre verholfen werden musste. 
Zeit benöthige - nach W. v. Struve braucht ein von der Sonne ausgehender Lichtimpuls 497,78 Sekunden, bis er auf der Erde bemerkbar wird -, hatte man auch diesen Faktor in die Berechnungen aufzunehmen gelernt. Bradley sagte sich, dass ein Stern nicht genau an dem Orte des Himmels gesehen wird, an welchem er sich thatsächlich befindet, sondern dass diese wahre Gesichtslinie um einen Aberrationswinkel aus ihrer Richtung abgelenkt werden muss, der gleich are tang $\frac{\mathrm{e}}{\mathrm{l}} \mathrm{zu}$ setzen ist, wenn e die tangentiale Geschwindigkeit der Erde in ihrer Bahn, l die Fortpflanzungsgeschwindigkeit des Sternenlichtes bedeutet. W. v. Struve bestimmt diese Aberrationskonstante [151] zu 20",4451. Nunmehr sind die Besonderheiten der Fig. 43 leicht zu erklären. Der Licht aussendende Punkt wird immer im Sinne der Erdbewegung um den kleinen Aberrationswinkel nach vorwärts geschoben und muss so im Laufe eines Jahres eine kleine ellipsenförmige Kurve zurücklegen, deren Mittelpunkt s der wahre heliocentrische Ort des Sternes ist; die grösste Länge fällt in die Opposition, die kleinste in die Konjunktion. Es leuchtet ein, dass diese an bestimmte Periodicitätsgrenzen gebundene Ortsveränderung der Fixsterne mit nicht minderem Rechte, wie die parallaktische Verschiebung, einen direkten und unumstösslichen Beweis für den zweiten Hauptsatz des coppernicanischen Weltsystemes involvirt, denn wenn die Erde feststünde oder sich blos um ihre Axe drehte, könnte die Abirrung der Lichtstrahlen nicht für uns sinnenfällig werden.

§. 7. Der Axen-Parallelismus. Ausser dem Umschwung um die Axe und der Umwälzung um den Centralkörper hatte Coppernicus der Erde noch eine dritte Bewegung zuschreiben zu müssen vermeint. Aus der regelmässigen Wiederkehr der Jahreszeiten, ebenso wie aus anderen Gründen, war zu schliessen, dass die Erdaxe sich im Raume stets parallel bleibe und im Laufe eines Jahres einen schiefen Cylindermantel, mit der Erdbahn als Leitlinie, beschreibe - eine gewisse dem Coppern icus wohlbekannte Durchbrechung dieses Gesetzes, von welcher später die Sprache sein wird, ist hier einstweilen ausser Acht gelassen. Dass diess sich von selbst so mache, erschien ihm unglaublich, was nach dem damaligen Zustande der Mechanik gewiss sehr verzeihlich ist, und so ersann er jenen dritten, von ihm als Deklination bezeichneten Bewegungsmodus, durch welchen die Axe in ihrer unveränderten Neigung gegen die Ekliptik erhalten werden sollte. "Es folgt also," so lautet seine Erklärung [152], „die dritte Bewegung der Deklination, ebenfalls im jährlichen Kreislaufe, aber rückläufig, d. h. entgegengesetzt der Bewegung des Mittelpunktes. Und so kommt es durch beide, einander fast gleiche und entgegengesetzte Bewegungen, dass die Axe der Erde, und also auch der Aequator, als der grösste Parallelkreis, fast nach derselben Himmelsgegend gerichtet bleiben, gleich als ob sie unbeweglich wären."

Eine interessante Monographie über diesen Irrthum des grossen Astronomen, dessen Quelle und Geschichte, besitzen wir von Menzzer [153], der in seiner Verehrung gegen Coppernicus bei diesem Anlass allerdings doch etwas zu weit geht. Jedenfalls war das unbestrittene Dasein der Deklinationsbewegung nur ein sehr kurzes. Nach Wolf 
[154] hätte nämlich bereits Rothmann dieselbe als überflüssig, Galilei aber geradezu als fehlerhaft bezeichnet. Eine völlig korrekte Stellung nahm von Anfang an der umsichtige Gassendi zu dieser Frage ein, die er in seiner "Institutio astronomica" - nach Menzzer's Verdeutschung [155] - folgendermassen beurtheilt: „Die Bewegung der Deklination ist jenes Abwenden der Erdaxe von ihrer mit der Axe der Ekliptik parallelen Lage, und das in allen Stellungen stattfindende Erhalten einer mit sich selbst parallelen Richtung, wodurch sie mit der Axe der Welt immer parallel bleibt: also könnte diese Bewegung nicht sowohl eine wirkliche neue Bewegung, als vielmehr ein Gesetz der beiden anderen Beobachtungen genannt werden. Sie kann nämlich in derselben Weise aufgefasst werden, in welcher die Axe eines Kinderkreisels, während er sich auf einer Ebene dreht und mit seiner Spitze verschiedene Kreise beschreibt, sich selbst parallel bleibt oder in senkrechter Lage verharrt."

Gassendi hatte völlig Recht mit seiner Meinung, dass bei einer Vereinigung von Rotation und Revolution für einen homogenen sphärischen Körper der stete Parallelismus der Axe sich von selbst einstellen müsse, und auch das von ihm zum Vergleiche herangezogene Beispiel des tanzenden Kreisels war ein sehr glücklich gewähltes. Die theoretische Mechanik lehrt, dass jede freie Rotationsaxe (vgl. §. 2) diese Eigenschaft hat, und es fehlt, vom Kreisel*) abgesehen, nicht an Vorrichtungen, durch welche der Parallelismus in der augenfälligsten Weise dergethan wird. Th. Gilbert sammelte Alles, was auf diesem Gebiete geleistet worden, in einem von uns vielfach benützten Aufsatze [156], und wenn er dabei auch nicht-deutsche Leistungen etwas

Fig. 44.

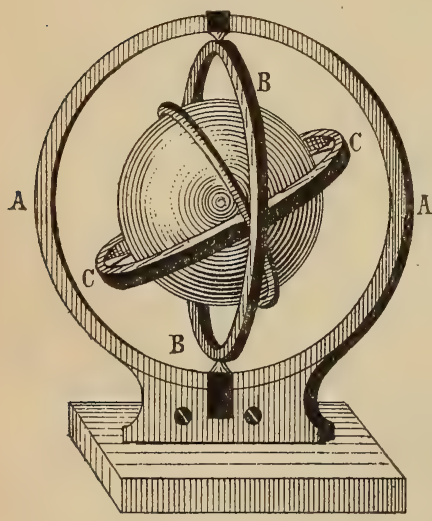
mehr, als uns recht dünkt, in den Vordergrund stellt, so ist uns doch gerade diese Sammlung schwerer zugänglicher Materialien werthvoll gewesen. An erster Stelle erscheint das von seinem Erfinder in einer eigenen Schrift [157] beschriebene Bohnenberger'sche Maschinchen (Fig. 44). Ein Kreisring A ist fest auf einem Postamente befestigt; in zwei sich diametral entgegenstehenden Punkten ist ein zweiter, um eine vertikale Axe drehbarer Kreisring B an ersterem angebracht, und er selbst trägt wieder in ähnlicher Weise den um eine horizontale Axe frei drehbaren Kreisring C, innerhalb dessen eine Kugel in rasche Drehung versetzt werden kann, sei es, dass man um ihre

*) Englische Mechaniker haben es in der Verfertigung von Kreiseln zu so hoher Vollendung gebracht, dass die freie Axe derselben mehrere Minuten lang eine genau vertikale und also die auf der Axe senkrechte Oberfläche ebensolang eine genau horizontale Lage annahm. Gab man dieser Oberfläche einen Spiegelschliff, so konnte man sich derselben mit demselben Rechte und auch mit derselben Beruhigung als eines künstlichen Horizontes beim Nehmen von Polhöhen und bei anderen astronomischen Geschäften bedienen, wie man sonst zu diesem Zwecke den Spiegel einer ruhenden Quecksilbermasse zu verwenden pflegt. 
Axe eine Schnur wickelt und diese rasch abzieht, sei es, dass man das ganze Maschinchen auf die Scheibe eines Centrifugalapparates stellt. Solange die Kugel sich noch in Ruhe befindet, besitzt sie die der cardanischen Aufhängung entsprechende Bewegungsfreiheit und lässt sich durch den leisesten Fingerdruck in jede beliebige Lage bringen; ist sie aber einmal in ihrer Rotationsbewegung begriffen, so behält ihre freie Drehaxe die zuerst ertheilte Richtung mit solcher Energie bei, dass die Hand, ehe sie eine Aenderung zu bewirken vermag, einen sehr fühlbaren Widerstand zu überwinden hat. Dabei ist es gleichgültig, ob die Maschine ruhig stehen bleibt oder beliebig im Zimmer umhergetragen wird.

Es giebt noch andere Apparate zur Demonstration der Erhaltung der Rotationsebene, doch versparen wir deren nähere Erörterung für einen späteren Zeitpunkt. Alle jene haben nämlich den weiteren Zweck, auch eine gewisse Abweichung der Axenbewegung von der uns bekannten Regel zur Anschauung zu bringen, und von dieser werden wir besser erst dann sprechen, wenn die allgemeinen gestaltlichen Verhältnisse der Erdbahn völlig klar gestellt sind.

§. 8. Die Kepler'schen Gesetze. Man irrt, wenn man annimmt, Coppernicus habe mit den ptolemäischen Epicyklen endgültig aufgeräumt. Diess war nicht möglich, solange man aus mathematischphilosophischen Gründen an der reinen Kreisform der Planetenbahnen festhielt; Coppernic vermochte zwar die Anzahl der Hülfskreise erheblich zu vermindern, vollständig aber beseitigte dieselben erst Kepler. Allerdings war die Möglichkeit, dass auch andere als Kreisbahnen im Weltraume vorkommen könnten, schon vorher schüchtern angedeutet worden; im „Libros del saber" des Königs Alfons wird z. B. die Merkurbahn elliptisch abgebildet [158], Fracastor dachte sich die sogenannte Trepidationsbewegung der Aequinoktialpunkte als auf einer Ellipse vor sich gehend [159], und dass auch Coppernicus selbst seine aprioristische Auffassung nicht für die allein maassgebende hielt, beweisen einige von Curtze aufgefundenen Worte, die er an den Rand des Originalmanuskriptes schrieb [160]: „Estque hic obiter animadvertendum, quod, si circuli h $\mathrm{g}$ et $\mathrm{cf}$ fuerint inaequales manentibus caeteris condicionibus, non rectam lineam, sed conicam sive cylindricam sectionem describent, quam ellypsim vocant mathematici; sed de his alias." Von All' dem war jedoch dem Kepler ohne allen $Z_{w}$ eifel nichts bekannt, er selbst und sein Genie war die einzige Quelle, woraus er schöpfen konnte.

Die beiden ersten Gesetze des Planetenlaufes, welche seinen Namen tragen, verkündet Ke pler in seinem Hauptwerke ,Astronomia nova" (Heidelberg 1609), während das dritte erst in der späteren

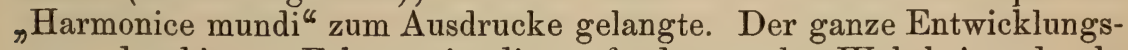
gang, der bis zur Erkenntniss dieser fundamentalen Wahrheiten durchzumachen war, findet sich trefflich geschildert in einer Monographie von Göbel [161], auf welche wir uns im Folgenden beziehen werden. Nicht durch theoretische Deduktion im Sinne Newton's, noch weniger allerdings durch Beobachtungen im Sinne Brahe's*), sondern durch

*) Leider ist die Fabel, Kepler sei ein vorzüglicher. Beobachter gewesen, 
eine ihm allein eigene Verbindung kühner, ja oft phantastischer Spekulation mit einem Rechentalent, welches die sofortige numerische Prüfung einer jeden einmal aufgestellten Hypothese gestattete, hat Kepler ein Ziel erreicht, über dessen eigentliches Wesen er bei Beginn seiner Arbeit noch durchaus nicht mit sich im Reinen war. Nachdem sich die von ihm in etwa 70 Einzelumdrehungen erprobte ,Hypothesis varia", welche zwar die erste, nicht aber die zweite Ungleichheit (s. o. §. 5) richtig darstellte, als unbrauchbar erwiesen hatte [163], fand er allerdings sein erstes Gesetz, welches für jede Art von Centralbewegung gültig ist [164], allein noch konnte er sich nicht dazu entschliessen, die von dem Zeitbewusstsein ängstlich festgehaltene Vorstellung der reinen Kreisbahn fallen zu lassen, und nur mit Ueberwindung gestand er sich und seinen Lesern endlich zu, dass die vom Planeten Mars beschriebene Kurve eine ovale Gestalt besitze [165]. Zuerst dachte er an eine ${ }_{\text {Ooide }}$ oder Eilinie, eine geschlossene Kurve also, die aber nicht zwei Symmetrieaxen, sondern blos deren eine hat [166], dieser substituirte er sodann eine mlinea buccosa" oder Wangenlinie [167], und erst als auch diese Annahme der Rechnung nicht Stand zu halten vermochte, iiberzeugte er sich, dass nur eine wirkliche Ellipse den tychonischen Oertern entspreche [168]. Die Entdeckung des dritten Gesetzes endlich glückte erst nach mühsamster Untersuchung aller planetarischen Zahlen mit Rücksicht auf musikalischharmonische und geometrisch-symmetrische Verhältnisse [169]. Die drei Gesetze sind nun, chronologisch geordnet, die folgenden:

I. Bei jeder Bewegung eines Punktes um einen Centralpunkt überstreicht der von letzterem ausgehende Fahrstrahl in gleichen Zeiten auch gleiche Flächenräume*). II. Die Bahn jedes Planeten ist eine Ellipse, in deren einem Brennpunkte die Sonne steht. III. Für zwei beliebige Planeten verhalten sich die Quadrate der Umlaufszeiten wie die Kuben der mittleren Entfernungen von der Sonne.

Nachdem diese Wahrheiten einmal erkannt waren, hielt es minder schwer, dieselben nachträglich auch mit neuen und einfacheren der allgemeinen Bewegungslehre entnommenen Beweisen zu versehen.

Beweis zu I. S (Fig. 45) sei der Centralkörper, A der Planet, der seinem momentanen Bewegungsimpuls folgend in dem gerade beginnenden Zeittheil den Weg A B zurücklegen würde, während er, wenn blos die Centralkraft auf ihn wirkte, in gleicher Zeit sich durch die Strecke A C bewegte. Thatsächlich durchläuft er die Diagonale AD des Parallelogrammes ABDC und würde in alleiniger Konsequenz des Beharrungsvermögens im nächsten Zeittheil die Strecke $\mathrm{DH}=\mathrm{AD}$

aus den Lehrbüchern nicht auszurotten, erst in jüngster Zeit reproducirt Himmer dieselbe [162]. In früher Jugend freilich stellte jener mit Lust und Liebe Beobachtungen an, doch hat er in diesen nie Hervorragendes geleistet, und der Zustand seiner Augen zwang ihn bald, seine Arbeitskraft auf das für ihn passendere Gebiet theoretischer Forschung zu koncentriren.

*) Aus dem ersten Gesetze folgt ohne weiteres als Korollar, dass die Geschwindigkeit eines Planeten variirt, sobald dessen Bahn von einem Kreise abweicht, und dass insbesondere für den Fall einer Kegelschnittsbewegung die Bahngeschwindigkeit in unmittelbarer Nähe des von der Sonne eingenommenen Brennpunktes (also im Perihelium) ein Maximum ist und mit wachsender Sonnendistanz abnimmt. Auf der Ellipse erreicht der Planet das Minimum in der Nähe des zweiten Brennpunktes der Bahn (im A phelium). 
beschreiben. Die Centripetalkraft dagegen treibt ihn um die Strecke D F, die im Allgemeinen von $\mathrm{AC}$ an Grösse verschieden sein wird. Am Ende des zweiten Zeittheiles ist somit der bewegte Punkt in E, dem Endpunkte der Diagonale DE des Parallelogrammes DFEH, und scheint sich nach $\mathrm{G}$ weiterbewegen zu wollen. Nun kommt der Satz, dass zwei Dreiecke von gleicher Grundlinie und Höhe flächengleich sind, zweimal zur Geltung; es ist danach $\triangle \mathrm{SAD}=\triangle \mathrm{SDH}$ und $\Delta \mathrm{SDH}=\Delta \mathrm{SDE}$, also durch Komparation $\triangle \mathrm{SAD}=\Delta \mathrm{SDE}$. Nimmt man die beiden Zeittheile unendlich klein, so verwandelt sich die gebrochene Linie ADE in eine gekrümmte, und der Satz ist bewiesen.

Beweis zu II. Das zweite Gesetz lautet in der ihm von Newton ertheilten Verallgemeinerung so: wird ein Körper durch einen einmaligen Stoss in Bewegung gesetzt*) und zugleich von einem anderen Körper im umgekehrten Verhältnisse des Quadrates der Entfernung angezogen, so beschreibt er eine Kurve zweiter Ordnung, in deren einem Brennpunkte jener zweite Körper steht. Beim Beweise dieses Lehrsatzes ist die höhere Analysis nicht wohl zu entbehren. Der sich bewegende Punkt erfahre in der Entfernung $r$ vom Centralkörper nach diesem hin die Beschleunigung $\gamma$, in der Entfernung $r^{\prime}$ die Beschleunigung $\gamma^{\prime}$; dann gilt die Proportion $\gamma: \gamma^{\prime}=\frac{1}{\mathrm{r}^{2}}: \frac{1}{\mathrm{r}^{22}}$, woraus, unter $\mathrm{k}$ die Konstante $\gamma^{\prime} \mathrm{r}^{\prime 2}$ Iverstanden, $\gamma=\frac{\mathrm{k}}{\mathrm{r}^{2}}$ folgt. Es ist also, wenn $\mathrm{C}$ die Integrationskonstante bedeutet,

$$
\int \gamma d r=\int \frac{k d r}{r^{2}}=-\frac{k}{r}+C \ldots .
$$

Die Differentialgleichungen aber sind folgende:

$$
\frac{\mathrm{d}^{2} \mathrm{x}}{\mathrm{dt}^{2}}=-\gamma \cdot \frac{\mathrm{x}}{\mathrm{r}}, \frac{\mathrm{d}^{2} \mathrm{y}}{\mathrm{dt}^{2}}=-\gamma \cdot \frac{\mathrm{y}}{\mathrm{r}}
$$

multiplicirt man erstere mit $d x$, letztere mit $d y$ und addirt beide hierauf, so findet sich

$$
\frac{d x \cdot d^{2} x+d y \cdot d^{2} y}{d t^{2}}=-\frac{r}{r}(x d x+y d y) \ldots
$$

*) Die Annahme dieses primären Stosses bildet den einzigen nicht aufgeklärten Punkt des wohlgefügten N ewto n'schen Systemes, und in der That scheint diese Annahme nicht durch Besseres verdrängt werden zu können. Denn auch die Kant-Lapl a c e'sche Nebulartheorie leistet, wie wir uns aus Kap. I. der ersten Abtheilung entsinnen, nicht die gewünschte Aushülfe; der Fragepunkt wird durch dieselbe nicht aus der Welt geschafft, sondern nur verschoben, indem jetzt nach der Ursache zu forschen ist, welche in der gleichmässig vertheilten Urmasse die erste Bewegung einzelner Massentheile einleitete. Und eine solche Ursache ist (s. o.) zur Zeit noch nicht bekannt. 
Der Zähler der linken Seite der Gleichung (2) ist das vollständige Differential von $\frac{1}{2}\left(\mathrm{~d} \mathrm{x}^{2}+\mathrm{d} \mathrm{y}^{2}\right)$, rechts in der Klammer steht ebenso das Differential von $\frac{1}{2}\left(x^{2}+y^{2}\right)=\frac{1}{2} r^{2}$, also erhält man, da $\mathrm{d} \mathbf{r}^{2}=2 \mathrm{rdr}$ ist, sogleich folgende Differentialgleichung sammt ihrem Integrale:

$$
\mathrm{d}\left(\frac{\mathrm{dx^{2 }}+\mathrm{dy}^{2}}{\mathrm{dt^{2 }}}\right)=-\frac{\gamma}{\mathrm{r}} \cdot \mathrm{d} \mathbf{r}^{2}, \frac{d x^{2}+d y^{2}}{d t^{2}}=C^{\prime}-\int \gamma d \mathbf{r} \ldots . .(3)
$$

hier bedeutet $\mathrm{C}^{\prime}$ eine neue Konstante. Gehen wir jetzt von den orthogonalen Koordinaten zu polaren $(r, \varphi)$ über, so haben wir die bekannten Umformungen zu machen:

$$
\mathrm{x}=\mathrm{r} \cos \varphi, \quad \mathrm{y}=\mathrm{r} \sin \varphi, \mathrm{dx}=\cos \varphi \mathrm{d} \mathrm{r}-\mathrm{r} \sin \varphi \mathrm{d} \varphi,
$$

Thun wir diess, so nimmt (3) folgende Gestalt an:

$$
\frac{\mathrm{r}^{2} \mathrm{~d} \varphi^{2}+\mathrm{dr}^{2}}{\mathrm{dt}^{2}}=\mathrm{C}^{\prime}-2 \int \gamma \mathrm{dr} \ldots \ldots
$$

Das uns bereits bekannte erste Kepler'sche Theorem gestattet in der Sprache der Differentialrechnung, wenn c eine Konstante bedeutet, ersichtlich diese Fassung: $\mathrm{r}^{2} \mathrm{~d} \varphi=\mathrm{cdt}$; eliminirt man aus dieser und Gleichung (4) das Zeitelement dt, so erhält man:

$$
\frac{c^{2}}{r^{2}}+\frac{c^{2} d r^{2}}{r^{4} d \varphi^{2}}=C^{\prime}-2 \int \gamma d r \ldots .
$$

Hierin ersetzt man den Integralwerth durch den ans Gleichung (1) zu entnehmenden und bekommt die neue Gleichung $\left(\mathrm{C}^{\prime}-2 \mathrm{C}=\mathrm{C}^{\prime \prime}\right)$

$$
\frac{\mathrm{c}^{2}}{\mathrm{r}^{2}}+\frac{\mathrm{c}^{2} \mathrm{~d} \mathrm{r}^{2}}{\mathrm{r}^{4} \mathrm{~d} \varphi^{2}}=\mathrm{C}^{\prime}-2 \mathrm{C}+\frac{2 \mathrm{k}}{\mathrm{r}}=\mathrm{C}^{\prime \prime}+\frac{2 \mathrm{k}}{\mathrm{r}},
$$

oder, wenn noch $\mathrm{r}=\rho^{-1}$ gesetzt und nach $d \varphi$, aufgelöst wird,

$$
\mathrm{d} \varphi=\frac{ \pm \mathrm{cd} \rho}{\sqrt{\mathrm{C}^{\prime \prime}+\frac{\mathrm{k}^{2}}{\mathrm{c}^{2}}-\left(\mathrm{c} \rho-\frac{\mathrm{k}}{\mathrm{c}}\right)^{2}}} \ldots \ldots
$$

Die Integration nach $\rho$ ergiebt keine Schwierigkeiten; es folgt aus (6), wenn $\left(-\varphi^{\prime}\right)$ die neu einzuführende Konstante vorstellt,

$$
\varphi-\varphi^{\prime}=\arccos \frac{\mathrm{c} \rho-\frac{\mathrm{k}}{\mathrm{c}}}{\sqrt{\mathrm{C}^{\prime \prime}+\frac{\mathrm{k}^{2}}{\mathrm{c}^{2}}}} .
$$

Geht man vom Arcus zum Kosinus über und setzt $\varphi-\varphi^{\prime}=\psi$, so wird

$$
\mathrm{c} \rho-\frac{\mathrm{k}}{\mathrm{c}}=\cos \psi \cdot \sqrt{\mathrm{C}^{\prime \prime}+\frac{\mathrm{k}^{2}}{\mathrm{c}^{2}}},
$$

und setzt man wiederum für $\rho$ seinen obigen $W$ erth $r^{-1}$, setzt man weiter der Kürze wegen $\mathrm{c}^{2}=\mathrm{kp}, 1+\frac{\mathrm{C}^{\prime \prime} \mathrm{c}^{2}}{\mathrm{k}^{2}}=\mathrm{e}^{2}$, so gelangt man zu der den Radiusvektor durch die Amplitude ausdrückenden Schlussgleichung:

$$
r=\frac{p}{1+e \cos \psi} \text {. }
$$

Diess ist aber die Polargleichung eines Kegelschnittes, und zwar fällt 
der Pol des Koordinatensystemes mit dem einen Brennpunkte zusammen; der halbe Parameter ist $p$, die Excentricität e und, wenn $r_{0}$ den vom Pol nach dem Perihel gezogenen Fahrstrahl bedeutet, $\Varangle\left(\mathbf{r}, \mathbf{r}_{0}\right)=\psi$. Ist e ein ächter Bruch, $C^{\prime \prime}$ negativ, so entsteht eine Ellipse, ist $\mathrm{e}=1, \mathrm{C}^{\prime \prime}$ gleich Null, so entsteht eine Parabel; ist endlich e $>1$, C" also positiv, so entsteht eine Hyperbel. Bei näherem Zusehen zeigt sich, dass die Stärke des Anfangsstosses, von welchem man sich das Mobil, resp. den Planeten betroffen denkt, über die Beschaffenheit des Kegelschnittes entscheidet.

Beweis zu III. Unter der für unser Planetensystem sehr nahe zutreffenden Voraussetzung, dass die Massen $m$ sämmtlicher Planeten der ungeheuer überwiegenden Sonnenmasse M gegenüber als gleich zu betrachten und dass sämmtliche Bahnkurven ohne Fehler als Kreise zu betrachten seien, lässt sich das dritte Gesetz leicht elementar erweisen. q sei die sich stets gleichbleibende Attraktionskonstante, $r_{1}$ und $r_{2}$ seien die Bahnhalbmesser zweier Planeten; dann sind die Beschleunigungen, welche diese Planeten gegen die Sonne hin erfahren, durch

$$
\gamma_{1}=\mathrm{k} \cdot \frac{\mathrm{m} \mathrm{M}}{\mathrm{r}_{1}{ }^{2}}, \quad \gamma_{2}=\mathrm{k} \cdot \frac{\mathrm{mM}}{\mathrm{r}_{2}{ }^{2}}
$$

gegeben. Dem bekannten Gesetze der Centrifugalkraft gemäss ist aber auch

$$
\gamma_{1}=\frac{\mathrm{m}_{1}^{2}}{\mathrm{r}_{1}}, \quad \gamma_{2}=\frac{\mathrm{mv}_{2}^{2}}{\mathrm{r}_{2}},
$$

wo $\nabla_{1}$ und $v_{2}$ die Bahngeschwindigkeiten vorstellen. Durch zweimalige Anwendung des Komparationsgrundsatzes folgt hieraus,

$$
\begin{aligned}
& \mathrm{k} \cdot \frac{\mathrm{mM}}{\mathrm{r}_{1}{ }^{2}}=\frac{\mathrm{m}_{1}{ }^{2}}{\mathrm{r}_{1}}, \mathrm{k} \cdot \frac{\mathrm{mM}}{\mathrm{r}_{2}{ }^{2}}=\frac{\mathrm{m}_{2}{ }^{2}}{\mathrm{r}_{2}}, \mathrm{k}=\frac{\mathrm{r}_{1} \mathrm{v}_{1}{ }^{2}}{\mathrm{M}}=\frac{\mathrm{r}_{2} \mathrm{v}_{2}{ }^{2}}{\mathrm{M}} \\
& r_{1} \nabla_{1}^{2}=r_{2} \nabla_{2}^{2} \text {. }
\end{aligned}
$$

Es ist aber $\nabla_{1}=\frac{2 r_{1} \pi}{T_{1}}, \nabla_{2}=\frac{2 r_{2} \pi}{T_{2}}$, unter $T_{1}$ und $T_{2}$ die vollen Umlaufszeiten beider Planeten verstanden; diess eingesetzt giebt

was zu beweisen war.

$$
\frac{4 \mathrm{r}_{1}{ }^{3} \pi^{2}}{\mathrm{~T}_{1}{ }^{2}}=\frac{4 \mathrm{r}_{2}{ }^{3} \pi^{2}}{\mathrm{~T}_{2}{ }^{2}} \text { oder } \frac{\mathrm{r}_{1}{ }^{3}}{\mathrm{r}_{2}{ }^{3}}=\frac{\mathrm{T}_{1}{ }^{2}}{\mathrm{~T}_{2}{ }^{2}},
$$

Nimmt man strenger die Massen $\mathrm{m}_{1}$ und $\mathrm{m}_{2}$ der beiden Planeten verschieden an, so ergiebt sich die nur wenig komplicirtere Relation

$$
\frac{\mathrm{T}_{1}^{2}}{\mathrm{~T}_{2}^{2}}=\frac{\left(\mathrm{M}+\mathrm{m}_{1}\right) \mathrm{r}_{1}{ }^{3}}{\left(\mathrm{M}+\mathrm{m}_{2}\right) \mathrm{r}_{2}^{3}}
$$

die aber wieder nur durch eine Infinitesimalbetrachtung hergeleitet werden kann [170].

Zu sämmtlichen Kepler'schen Gesetzen sei bemerkt, dass dieselben sich auf den Schwerpunkt der die Sonne umkreisenden Planetenkugel beziehen, und dass es nicht gestattet ist, verschiedene Punkte ein und derselben Kugel als von verschiedenen Impulsen beeinflusst anzunehmen. Aus diesen Gründen ist eine Hypothese a priori zu verwerfen, welche Wettstein [171] aufgestellt und mit unleugbarem Geschick als in den mannigfachsten $\mathrm{Z}_{\text {weigen }}$ der physischen Erde sich geltend machend nachzuweisen versucht hat. Versteht man unter $A_{1}$ und $A_{2}$ zwei Antipodenpunkte der Erde, deren Verbindungslinie durch den Mittelpunkt der Sonne hindurchgeht, unter $r_{1}$ und $r_{2}$ deren 
Entfernungen von jenem Punkte, unter $\mathbf{v}_{1}$ und $\mathbf{v}_{2}$ die Bahngeschwindigkeiten, welche diesen Punkten zukommen würden, wenn jeder von ihnen einzeln um die Sonne liefe, unter $\mathrm{T}_{1}$ und $\mathrm{T}_{2}$ die entsprechenden Umlaufszeiten, so könnte man nach Wettstein sämmtliche obige Gleichungen, wie sie zum Beweise des dritten Gesetzes dienten, anschreiben. Derselbe setzt $r_{1}=24000-1=23999, r_{2}=24000+1$ = 24 001, die Umlaufszeit des Erdmittelpunktes gleich 31558200 Zeitsekunden, und hat somit die Gleichungen

$$
\begin{gathered}
\mathrm{r}_{1} \mathrm{v}_{1}{ }^{2}=\mathrm{r}_{2} \mathbf{v}_{2}{ }^{2}, 24000^{3}: 23999^{3}=31558200^{2}: \mathrm{T}_{1}{ }^{2}, \\
24000^{3}: 24001^{3}=31558200^{2}: \mathrm{T}^{2} .
\end{gathered}
$$

Für einen Aequatorpunkt berechnet er so, dass die Geschwindigkeiten um Mittag, um sechs Uhr des Abends und Morgens und um Mitternacht sich wie

$$
29865,42: 29864,82: 29864,22
$$

zu einander verhalten. Diese Wirkung der Sonnengravitation soll zur Folge haben, dass den Körpern im Aequator eine Bewegung mitgetheilt wird, deren Richtung jener der Erdrotation entgegengesetzt ist. Ein Körper an der Erdoberfläche sei hiernach mit einer mittleren rückläufigen Bewegung von 0,26 m begabt, und diese Retardation scheine sich in den von $\mathrm{Ph}$. Plantamour wahrgenommenen Schwankungen der Libellenblase zu manifestiren [172] (s. o. §. 2). Näher ist diese Wettstein'sche Theorie von Zöppritz [173] und dem Verf. [174] in Betracht gezogen worden; in des letzteren Abhandlung ist einmal das Wort „Bahngeschwindigkeiten“ durch „Umläufe" zu ersetzen. Wie schon erwähnt, ist jene bei all' ihrer scheinbaren Geschmeidigkeit mechanisch unhaltbar; auch stehen ihr empirische Thatsachen in genügender Menge entgegen [175].

§. 9. Drei geophysikalisch wichtige Perturbationen. Mit der streng kausalen Begründung der K epler'schen Gesetze durch New ton, sowie mit dessen genialer Leistung, durch welche sämmtliche kosmische Geschehnisse als Ausflüsse des Gravitationsprincipes dargestellt wurden, haben wir uns an dieser Stelle nicht weiter zu beschäftigen. Auch die Lehre von den Planetenstörungen ist an sich für uns nebensächlich; durch die Thatsache, dass in Folge der wechselseitigen Anziehung der Planeten keiner derselben eine rein elliptische Bahn beschreibt, sondern von dieser idealen Bahn jederzeit nach der einen oder anderen Seite, nach oben oder unten abgezogen wird, scheint das Spiel der physikalischen Kräfte auf und in der Erde zunächst nicht beeinflusst zu werden. Indessen kommen unter diesen sogenannten Störungen oder Perturbationen doch auch solche vor, welche möglicherweise einer geophysikalischen Bethätigung fähig wären, und dieser zu gedenken, ist unsere Pflicht.

Man unterscheidet in der Störungstheorie periodische und säkuläre Störungen [176]; doch ist diese Scheidung nicht eigentlich eine principielle, indem nur die zuletzt erwähnten an eine sehr lange Periode geknüpft sind. Maassgebend für erstere Störungen sind drei Laplace'sche Gleichungen, die wir hier mittheilen, und in welchen $\mathrm{m}, \mathrm{m}_{1}, \mathrm{~m}_{2} \ldots$ die Massen, $\mathrm{e}, \mathrm{e}_{1}, \mathrm{e}_{2} \ldots$ die Excentricitäten, $a, a_{1}, a_{2} \ldots$ die halben grossen Axen der Planeten, $\varphi, \varphi_{1}, \varphi_{2} \ldots$ die Neigungen ihrer Bahnen gegen die unveränderliche Ebene (Abth. I, 
Kap. I, §. 8), endlich $1, l_{1}, l_{2} \ldots$ die Längen der Knotenlinien dieser Bahnen darstellen. Es ist

I. $\mathrm{me}^{2} \sqrt{\mathrm{a}}+\mathrm{m}_{1} \mathrm{e}_{1}^{2} \sqrt{\mathrm{a}_{1}}+\mathrm{m}_{2} \mathrm{e}_{2}{ }^{2} \sqrt{\mathrm{a}_{2}}+\ldots$ $=$ Konst.

II. $\mathrm{m}$ tang $\varphi \sqrt{\bar{a}}+\mathrm{m}_{1} \operatorname{tang} \varphi_{1} \sqrt{\overline{a_{1}}}+\mathrm{m}_{2} \operatorname{tang} \varphi_{2} \sqrt{\mathrm{a}_{2}}+\ldots=$ Konst. III. $m \operatorname{tang} \varphi \sin l \sqrt{\bar{a}}+m_{1} \operatorname{tang} \varphi_{1} \sin l_{1} \sqrt{a_{1}}+m_{2} \operatorname{tang} \varphi_{2} \sin l_{2} \sqrt{a_{2}}+\ldots=$ Konst. Dieses Gleichungssystem wird uns allen Aufschluss geben, dessen wir bei unseren weiteren Betrachtungen bedürfen werden. Drei Beeinträchtigungen des planetarischen Gleichgewichtszustandes sind es wesentlich, auf welche man sich ab und zu zur Erklärung tellurischer Erscheinungen berufen hat.

a) Die Schwankung der Ekliptikschiefe. Die scheinbare Sonnenbahn bildet mit dem Aequator einen Winkel, der in runder Zahl 23 ${ }^{1 / 2}{ }^{0}$ beträgt; um diesen Winkel ist also in Wirklichkeit die - zunächst noch als sich selbst stets parallel bleibend angenommene - Erdaxe von einer senkrecht auf der Erdbahn errichteten Geraden abgelenkt. Die Grösse dieses Neigungswinkels ist für den Wechsel der Jahreszeiten, für die Eintheilung der Erdoberfläche in klimatische Zonen u. s. w. maassgebend; plötzliche Aenderungen desselben müssten die terrestrische Wärmevertheilung und damit das organische Leben auf der Erde in einschneidendster Weise beeinflussen. Bis zu einem gewissen Grade ist die Neigung der Ekliptik nun in der That variabel. Schon Domenico Maria, der, wie in $\S .2$ dieses Kapitels erwähnt ward, unrichtige Ansichten über die Schwankung der Erdaxe kundgegeben hatte, glaubte Aehnliches für die Ekliptik bemerkt zu haben, und diessmal befand er sich in besserem Rechte, obwohl er sich bezüglich des Sinnes der wahrgenommenen Bewegung irrte. Coppernicus hat uns in seiner Originalhandschrift der ${ }_{\text {Revolutiones }}$ ältere Messungen der Ekliptikschiefe aufbehalten; ,Joannes Regiomontanus, ${ }^{*}$ meldet er [177], , reperit partes XXIIIscrupulaXXVIIIs.*), Georgius Pu rbachius anno Christi MCCCLX partes, ut illi, XXIII, scrupula vero XXVIII adnotavit, Dominicus Maria Novariensis anno Christi MCCCCXCI ultra partes integras scrupula XXVIIII et amplius quiddam." Von P e urbach zu Regiomontan, von diesem zu Novara hätte sich mithin der Winkel stetig, wenn auch nicht erheblich, vergrössert. Laplace hat dann die Nothwendigkeit einer solchen periodischen $\mathrm{Zu}$ - und $\mathrm{Ab}$ nahme der Schiefe der Ekliptik analytisch dargethan, zugleich jedoch auch die Grenzen festgestellt, zwischen denen die Oscillation erfolgt, und diese einander sehr nahe liegend gefunden [178]; für unser Jahrhundert ist die Neigung durch den Ausdruck $23^{\circ} 28^{\prime} 42, " 19-0, " 483408$ t $-0^{\prime \prime}, 000002723 \mathrm{t}^{2}$ gegeben, in welchem $\mathrm{t}$ die Anzahl der seit 1700 verflossenen Jahre bedeutet. Der Neigungswinkel wird nicht grösser als $27^{1 / 2} 2^{\circ}$, nicht kleiner als $21^{1 / 2}{ }^{\circ}$, und in jedem Jahre macht die Veränderung - gegenwärtig sind wir in der Abnahme begriffen - etwa eine halbe Bogensekunde aus. Die zweite der obigen drei Gleichungen giebt uns eine Gewähr dafür, dass bedeutende Veränderungen nicht eintreten können. Da nämlich (vgl. die Notizen über das Stabilitätsproblem im ersten Kapitel der ersten Abtheilung) die Grössen a unveränderlich und da zur Zeit, wie bekannt, die Grössen $\varphi$ sämmtlich

*) Es bedeutet diess $23^{\circ} 28^{\prime} 30^{\prime \prime}$. 
sehr klein sind, so muss die Grösse $\mathrm{m}_{\mathrm{i}}$ tang $\varphi_{\mathrm{i}}$ ebenfalls einen kleinen Werth annehmen, und ein Gleiches gilt für $\Sigma \mathrm{m}_{i} \operatorname{tang} \varphi_{\mathrm{i}}=$ Konst. Diese letztere ändert sich für alle Folgezeit nicht, sonach können auch die Neigungen $\varphi$ eine sehr mässige Grenze nicht übersteigen. Und überhaupt sind grosse Abänderungen der verschiedenen für unser Planetensystem charakteristischen Neigungswinkel nicht möglich*); auch die Ekliptikschiefe des Uranus, welche nach menschlichen Begriffen eine höchst ungünstige ist, wird annähernd immer die gleiche bleiben [179]. Es bleibt deshalb nur übrig, die mancherlei Hypothesenkonstruktionen, welche sich bereits mit der periodischen Schwankung des Erdbahnwinkels zu schaffen gemacht baben, in das Reich der Mythenbildung, wie diese z. B. von Whiston und Pluche schwunghaft betrieben worden ist, zu verweisen. "Diese geringen Veränderungen," sagt Mädler sehr treffend [180], „können in Bezug auf Klimate keine merkliche Wirkung äussern. Wenn z. B. nach 8-10000 Jahren die Schiefe bis auf $21^{1} / 2^{0}$ sich vermindert haben wird, so werden die Sommertage in unseren Gegenden um 25 Minuten kürzer, die Wintertage um ebensoviel länger werden, als gegenwärtig. Die Wärme der Sommer wird durchschnittlich etwa um $1 / 2{ }^{0}$ geringer, die Kälte der Winter aber in demselben Maasse milder werden; für die Uebergangszeiten, sowie für das Jahr im Durchschnitt, würde sich keine Veränderung herausstellen. Wenn demnach die Erde, wie einige Thatsachen darzuthun scheinen, einst beträchtlich wärmer als jetzt war, so kann der Grund nicht in diesen Verhältnissen gesucht werden."

b) Die Veränderlichkeit der Excentricität der Erdbahn. Auch dieses Element ist steten Veränderungen unterworfen, doch geht aus Gleichung I von Laplace durch ein dem vorhin angestellten völlig entsprechendes Raisonnement hervor, dass auch hier Periodicitätsgrenzen vorhanden sind, und dass zumal die von der Erde beschriebene Ellipse niemals in einen Kreis ausarten kann; , wie die Neigungen können auch die Excentricitäten der Bahnen zweier einander störender Planeten gewisse Grenzen nicht überschreiten, und wenn die eine wächst, muss die andere abnehmen" [181]. Croll theilt nach einer Revision Leverrier's mit, dass für die variirende Excentricität e die Ungleichungen $0,07775>$ e $>0,003314$ bestünden, und dass die Periode 23980 Jahre betrage [182]. Adhémar, John Herschel und besonders Croll suchten diese Störung als das eigentliche Motiv der sogenannten Eiszeit der Erde hinzustellen, und wir werden in dem von den Temperaturperioden handelnden Kapitel der fünften Abtheilung hierauf zurückzukommen haben.

c) Die Verschiebung der Länge des Periheliums. Die jedenfalls

*) Diejenige Neigung, mit welcher wir es hier zu thun haben, gehört allerdings nicht zu den Winkeln $\varphi$, welche, einzelne Ausnahmen, z. B. bei Pallas, abgerechnet, durchweg $<23^{1 / 2}{ }^{\circ}$ sind. Allein, wenn durch Gleichung I dargethan ist, dass Neigungswinkel innerhalb des Planetensystemes selbst dann nahe invariabel sind, wenn die allergewaltigsten Attraktionswirkungen sich offenbaren, wie z. B. bei den Planeten Jupiter und Saturn, so ist bei unserer Erde, welche in Folge ihrer Kleinheit und ihrer Stellung im System weit minder intensiv beeinflusst wird, noch weit weniger Grund zu erheblichen Störungen nach dieser Richtung hin vorhanden. Insoferne gilt somit jene Gleichung indirekt auch für den uns hier beschäftigenden Fall. 
einflussreichste planetarische Umgestaltung liegt in dem Vorrücken der grossen Bahnaxen von West nach Ost; J. J. v. Littrow, dessen inhaltsreicher Artikel „Sonnennähe" uns diessmal überhaupt zur Vorlage dient, erblickt in dem Wandern des Perihels „die einzige wahre Säkulargleichung, die es in unserem Sonnensysteme giebt ${ }^{\star}$ [183]. Es bezeugt diess auch die Laplace'sche Gleichung III, in welcher die Grössen $\sin l_{i}$ alle möglichen Werthe annehmen können, so dass auch die Konstante nicht, wie früher, an kleine Werthe gebunden ist. Unsere Erde besass zur Epoche 1800 die Perihellänge $99^{\circ} 36^{\prime} 5^{\prime \prime}$; da die säkuläre Verschiebung 6201" beträgt, so fiel das Perihelium etwa um 4000 v. Chr. mit der Frühlings-Tag- und Nachtgleiche zusammen, und Anno 6470 unserer Zeitrechnung wird das Perihel in der Ekliptik um $180^{\circ}$ vom Anfangspunkte der Zählung $(\Omega)$ verschieden sein [184]. Die Wärmeverhältnisse der Erde können durch diese Drehung der Apsidenlinie allerdings alterirt werden. Gegenwärtig ist die Erde bald nach der Sommersonnenwende am weitesten und bald nach der Wintersonnenwende am wenigsten weit von der Sonne entfernt, im Aphelium ist die Bahngeschwindigkeit geringer als im Perihelium (vgl. §. 8), und so dauern die beiden wärmeren Jahreszeiten, Frühling und Sommer, zusammen etwas länger als die beiden kälteren; die Differenz beläuft sich auf nahe acht Tage. Allmählig wird sich nun für unsere Halbkugel das Verhältniss zu deren Ungunsten verschieben, und auch die hieraus entspringende chronische Wärmedifferenz hat man mit der abwechselnden Vereisung der einen und anderen Hemisphäre in Verbindung gebracht.

Wenn nun auch diese durchaus langsam vor sich gehenden Schwankungen, jede für sich, wenig dazu geeignet scheinen, einer grossartigen generellen Erklärung der irdischen Temperaturveränderungen als Untergrund zu dienen, so ist doch andererseits nicht zu leugnen, dass kumulative Wirkungen eintreten können und müssen. Hierauf hat Croll sein Hauptaugenmerk gerichtet. Er liefert eine von Stone ausgearbeitete Tabelle [185], welche für jedes Jahr eines mit 1800 beginnenden Zeitraums von 10000 Jahren Excentricität und Perihellänge angiebt, so dass durch Vergleichung die für besonders günstige oder ungünstige klimatische Verhältnisse einer bestimmten Halbkugel erforderliche Summirung der von beiden Faktoren abhängigen Einflüsse unmittelbar herausgefunden werden kann. Und innerhalb dieses Rahmens könnte nach Croll [186] sogar die oben als ein sehr geringfügiges Element erkannte Variation der Ekliptikschiefe eine nicht ganz unbedeutende Rolle spielen. Jedenfalls haben Croll's zielbewusste Untersuchungen, man mag im Einzelnen über sie wie immer denken, ein Recht darauf, nicht mit anderen und zum Theil wüsten Spekulationen über das Ineinandergreifen von kosmischer und tellurischer Physik unter Einen Hut gebracht zu werden.

§. 10. Trepidation und Präcession. Als im Jahre 134 v. Chr. der griechische Astronom Hipparchos, durch das Aufleuchten eines neuen Sternes hiezu veranlasst, einen neuen Sternkatalog anzulegen beschloss, hatte er in erster Linie seine eigenen Ortsbestimmungen mit denjenigen zu vergleichen, welche 150 Jahre früher die alexandrinischen Beobachter Aristyllos und Timocharis gemacht hatten.[187]. 
Da fand sich denn, dass die astronomischen Längen ausnahmslos eine Vergrösserung erfahren hatten, und zwar traf auf das Jahr eine für jeden Stern gleiche Verschiebung von $36^{\prime \prime}$ in der Richtung der täglichen Bewegung. Dieser Werth war etwas zu klein, im Mittelalter bestimmte der Perser Nasr Ed-din [188] ihn richtiger zu 51" pro Jahr. Mit Hipparch's Entdeckung war auch die Nothwendigkeit gegeben, für das Wort „Jahr" verschiedene Begriffe einzuführen; das tropische Jahr markirt den Zeitraum, welchen die Sonne (in ptolemäischer Redeweise) braucht, um wieder zu demselben Aequinoktialpunkte oder Solstitialpunkte zurückzukehren, das siderische Jahr dagegen führt die Sonne wieder zu dem nämlichen Sterne der Ekliptik zurück. Es ist selbstrerständlich, dass, als in $\S .2$ dieses Kapitels die Konstanz der Jahreslänge behauptet ward, damit nur das siderische Jahr gemeint sein konnte; bei der Bestimmung der Länge des tropischen Jahres ist dagegen die Verschiebung der Fixpunkte der Zählung in Betracht zu ziehen, und gleichfalls muss auf dieselbe Rücksicht genommen werden, wenn es sich um das oben erörterte Herumwandern des Perihels auf der Ekliptik handelt. Zu den unmittelbaren Folgen dieses Phänomens, für welches der Name Präcession oder Vorrücken der Aequinoktialpunkte üblich wurde, gehört - man vergleiche $J$. J. v. Littrow's sorgfältige Zusammenstellung [189] - zunächst der Umstand, dass die Zodiakalzeichen mit den Zodiakalsternbildern heute nicht mehr, wie zur griechischen Zeit, übereinstimmen, sowie dass der Weltpol seine Lage unter den festen Gestirnen beständig wechseln muss. Die Ekliptik nämlich bleibt fest, und ein Gleiches gilt natürlich auch für ihre um etwa $23^{1 / 2} 2^{0}$ von den Himmelspolen abstehenden Pole, der Aequator dagegen rückt parallel mit sich selbst auf der festen Ekliptik von Ost nach West vor, und so muss der bewegliche Pol des Aequators um den fixen Pol der Ekliptik einen kleinen Kugelkreis von $23^{1 / 2} 2^{0}$ sphärischem Radius beschreiben. Der heutige Polarstern, der schon jetzt diesen Namen nicht mehr recht verdient, wird mit der Zeit jeden Anspruch auf seinen Titel verlieren. Würde, was aber allerdings nicht der Fall, die jährliche Bewegung der Weltpole von der Zeit völlig unabhängig sein, so würde es 25900 Jahre dauern, bis der bewusste Kreis vollständig vom Pole durchlaufen und jeder einzelne Stern genau in die früher diesem Pole gegenüber eingenommene Stellung zurückgekehrt wäre. Man nennt diesen Zeitraum das grosse platonische Jahr; ehedem verband man mit dessen Ablauf die Vorstellung grosser Erdrevolutionen*). Sternkarten und Sterngloben

*) In einer aus dem Arabischen in's Lateinische übertragenen Handschrift, welche den Titel „De causis libellus proprietatum elementorum A ristoteli adscriptus" führt und auch in die den arabischen Aristoteles vollständig reproducirende Venetianische Ausgabe desselben aufgenommen ist [190], kommt z. B. nachstehender Passus vor [191]: "Nos autem invenimus ratione geometrica, et operatione mensurali, quod rotunditas terrae est XXIIII milia miliaria, quod est revolutio terrae super XXVI annorum milia, invenitur ergo illud in civitatibus propinquis litoribus marium, ut approximet eis mare, sicut civitas Axym et civitas Medanel, et civitas Serendib, et insulae auri." Es gewährt einigen Reiz, zu sehen, wie die Phantasie des Orientalen bemüht ist, die umlaufenden geographischen Sagen von im Meere untergegangenen Land- und Ortschaften auf irgend ein grosses Ereigniss am gestirnten Himmel zurückzuführen, und dazu eignete sich der vollendete Umlauf der Weltpole allerdings vorzüglich. 
werden hiernach von Zeit zu Zeit immer wieder unbrauchbar, wenn sie nicht mit einer von Segner [192] erdachten, die Stellung der Himmelspole korrigirenden Vorrichtung versehen sind. Endlich kann die Präcession auch ein brauchbares Hülfsmittel bei geschichtlichen Untersuchungen abgeben, wie dieselbe denn bei dem Streite über das Alter des bekannten Thierkreises von Denderah, an welchem sich Letronne, Visconti, Laplace u. a. betheiligten, ihre Rolle spielte [193]. Auch die praktische Astronomie hat derselben sehr häufig Rechnung zu tragen, wenn es nämlich gilt, die Positionen der Sterne auf verschiedene Epochen zu reduciren [194].

Bei jener Genauigkeit, mit welcher das Alterthum und Mittelalter auch im günstigsten Falle Oerter und Distanzen am Himmel zu messen im Stande war, hätte die Präcession als eine absolut gleichförmige Bewegung erscheinen müssen. Den Griechen jedoch scheint sich bereits die unrichtige Vorstellung aufgedrängt zu haben, dass die achte Sphäre, an welcher man sich die Aequinoktial- und Solstitialpunkte befestigt dachte, eine schwankende oder besser eine alternirende Bewegung besitze. So entstand die im Mittelalter allgemein verbreitete und mit einer gewissen Liebe gepflegte Lehre von der Trepidation der.Fixsterne, deren Hauptzüge der Verfasser früher zu schildern versucht hat [195]. Die damit in nächster Verbindung stehende falsche Theorie einer Nutation der Sonne, welche ja nicht mit der in $\S .12 \mathrm{zu}$ besprechenden wirklichen Nutation der Erdaxe zu verwechseln ist, hat mit Rücksicht auf die Nachrichten des Attalos und Plinius Schiaparelli [196] zum Gegenstande einer tief eindringenden Nachforschung gewählt. Zur höchsten wissenschaftlichen Feinheit, wenn dieser Ausdruck bei einer Irrlehre erlaubt ist, erhoben die Theorie von einem ungleichförmigen Wachsthum der Präcession Werner [197] und Fracastor [198], indem sie festsetzten, dass die Aequinoktialpunkte auf einem kleinen Kugelkreise - Letztgenannter wollte an dessen Stelle sogar eine Ellipse setzen (§. 8) - umliefen, dessen Centrum selbst auf der Ekliptik weiter rücke. Coppernicus zerschmetterte Werner's Argumente in einem an den Krakauer Domherrn Wapowski gerichteten Sendschreiben, über dessen Inhalt die Angaben des Verfassers [199] und L. Prowe's [200] nachgesehen werden können, doch suchte auch er noch einen Theil der Schwankungshypothese dadurch zu retten, dass er diese mit dem von ihm eingeführten dritten Bewegungsmodus der Erde in kausale Beziehung brachte. Erst seit Tycho Brahe ist die Gleichförmigkeit der Präcessionsbewegung eine allseitig anerkannte wissenschaftliche Wahrheit geworden.

§. 11. Mechanische Erklärung der Präcession. Es war nach den soeben erhaltenen Aufschlüssen also nur bedingt richtig, in $\S .7$ von einem Parallelismus der Erdaxe zu sprechen, da thatsächlich diese Gerade, wenn auch in langsamstem Tempo, einen Kreiskegelmantel beschreibt, der $47^{\circ}$ Oeffnung besitzt. Nachdem wir diess wissen, haben wir uns die Frage vorzulegen, wie diese Abweichung von einer Regel, die durch den Versuch an Bohnenberger's Maschine ausser Zweifel gestellt schien, physikalisch zu rechtfertigen sein möchte. Die richtige Erklärung scheint sich Newton, nachdem er den Begriff der 
Körperanziehung im Sinne von Kap. II, §. 3 klar erfasst hatte, ganz von selbst dargeboten zu haben, wenigstens konnte in qualitativer Hinsicht seinen bezüglichen Darlegungen [201] später nicht mehr sehr viel hinzugefügt werden. Die beste Paraphrasirung des an sich nicht ganz einfachen Gedankens scheint uns von neueren Autoren V. v. Lang [202] gegeben zu haben, an den wir uns deshalb auch vorwiegend anschliessen. Dass nur die sphäroidale Gestalt der Erde das Vorrücken der Nachtgleichen bedinge, dass bei einer homogenen und sphärischen Erde dergleichen nicht möglich sei, das wurde auch von sonstigen Gegnern des Newton'schen Systemes niemals ernsthaft bestritten, von bekannteren Autoren wenigstens gab nur der einzige Gerlach [203] einen Scheinbeweis dafür, dass es auch eine Drehung für die Axe einer geometrischen Kugel gäbe.

Fig. 46 stellt die Erde dar im Augenblicke des Sommersolstitiums; die Papierebene umfasst gleichzeitig den Mittelpunkt $\mathrm{S}$ der Sonne,

Fig. 46 .

P

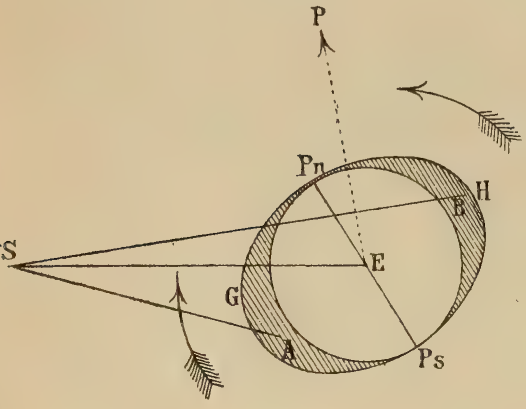
denjenigen $\mathrm{E}$ der Erde und deren Umdrehungsaxe $P_{n} P_{s}$, so dass also $\Varangle \mathrm{SEP}_{\mathrm{n}}=66^{1 / 2}$ ist. Es genügt dann, wenn man nicht die Grösse der Attraktionswirkungen, sondern blos deren allgemeine Beziehungen kennen lernen will, an Stelle des ganzen Erdellipsoides blos die mit der Zeichnungsebene zusammenfallende Meridianellipse in's Auge zu fassen, zu deren beiden Seiten die Masse ja symmetrisch vertheilt ist. Nun beschreibe man über $P_{n} P_{s}$ als Durchmesser einen Kreis, welcher die bezeichnete Ellipse in den Punkten $P_{n}$ und $P_{s}$ berührt. Die Ellipse zerfällt so in drei Theile: in den Vollkreis um $\mathrm{E}$ und in die beiden - schraffirten Mondfiguren $\mathrm{P}_{n} \mathrm{GP}_{\mathrm{s}}$ und $\mathrm{P}_{n} \mathrm{HP}_{\mathrm{s}}$; jeder dieser drei Theile erleidet vom Punkte $S$ eine besondere Anziehung. Die Anziehungslinie für den Kreis geht, wie wir wissen, durch den Mittelpunkt $\mathrm{E}$ hindurch, und dàmit scheidet diese Figur völlig von der Betrachtung aus; für die beiden Lunulen kann man sich etwa die Massen in $\mathrm{A}$ und $\mathrm{B}$ koncentrirt denken. Da beide Massen gleich gross sind, Punkt A aber der Sonne näher liegt, als Punkt B, so muss die Anziehung längs SA stärker sein, als längs SB. Errichten wir in E auf der Papierebene die Senkrechte EP, so suchen die beiden Attraktionskräfte, deren wir soeben gedachten, die Meridianellipse, resp. die ganze Erde, um EP als Axe zu drehen, und zwar im Sinne der beigesetzten Pfeile. In unserer Figur ist der dem Drehsinn des Uhrzeigers konform gerichtete Pfeil zugleich der die stärkere Drehung anzeigende, und so wird jene uns bereits bekannte Drehbewegung der Erdaxe eingeleitet; letztere wird bei ungeänderter Rotationsdauer der Erde langsam und mit konstanter Neigung gegen die Ekliptik in einem der Axendrehung entgegengesetzten Sinne rotiren. Zunächst galt diese Deduktion allerdings nur für eine gewisse ausgezeichnete Stellung des Erdsphäroides, allein auch dann, wenn irgend eine willkürliche Stellung desselben herausgegriffen wird, erhellt ebenso, dass 
die Axe der von der Sonnengravitation bewirkten Drehbewegung auf der durch Radius Vektor und Erdaxe gelegten Ebene senkrecht steht.

Wäre die Sonne allein vorhanden, so würden in gleichen Zeiten von der verlängerten Erdaxe auch immer gleiche Bögen an der scheinbaren Himmelskugel beschrieben werden. Nun bringt aber der Mond seinerseits eine ganz ähnliche, wennschon weit weniger energische Wirkung hervor, wie die Sonne, und deshalb bewegt sich der Frühlingspunkt zwar stets in derselben Richtung, jedoch nicht stets mit der nämlichen Geschwindigkeit, da die beiden anziehenden Himmelskörper, je nach ihrer wechselnden Stellung zur Erde, sich gegenseitig in ihren Einwirkungen unterstützen oder hemmen können. Man spricht deshalb am Richtigsten von einer Lunisolarpräcession.

Newton's Kalkul, so geistreich derselbe auch war - es kommt darin die einzige eigentliche Integration des ganzen Werkes vor ergab doch für die Grösse der Präcession den viel zu kleinen Werth von kaum 10 Sekunden, weil einzelne der nothgedrungenerweise zu Grunde gelegten vereinfachenden Annahmen nicht zutrafen [204]. Deshalb trat D'Alembert in einer seiner verdienstlichsten Schriften, von welcher wir glücklicherweise eine gute deutsche Ausgabe besitzen [205], von Neuem an das schwierige Problem heran und integrirte den Differentialausdruck, welchen ihm für die Attraction des uns bekannten Meniskus aufzustellen gelungen war, mit Hülfe von Methoden [206]. deren nähere Kenntnissnahme der Geschichte der reinen Mathematik anzuempfehlen ist. Später gab dann Laplace [207] jene Zahlen, die im Grossen und Ganzen noch heute gültig sind, obwohl im Einzelnen dieselben natürlich manche Verschärfung erfuhren. Nimmt man mit Laplace die Lage, welche die Ekliptik am 1. Januar 1750 hatte, als feste Ekliptik an, so weicht auf dieser der Frühlingspunkt unter dem alleinigen Einflusse der Lunisolarpräcession um einen Bogen zurück, der durch den Ausdruck (50",37572 t - 0",000127945 $\mathrm{t}^{2}$ ) gegeben ist, wo, wie immer, t die Anzahl der verstrichenen Jahre ist.

Ist die hier entwickelte Theorie der Präcessionsbewegung richtig, so muss dieselbe auch durch den Versuch nachgewiesen werden können, und dieser Versuch ist denn auch schon vielfach mit allen möglichen Veränderungen angestellt worden. In §. 8 war z. B. davon die Rede, dass Kreisel in Rotation ihre Axe so lange parallel erhalten, doch war dabei vorausgesetzt, dass der tanzende Kreisel sofort vertikal auf seine Unterlage gestellt werde. Geschieht diess aber nicht, so beschreibt der Kreisel einen Kegelmantel, genau ebenso wie die Erdaxe - vgl. Fig. 47 -, und wenn auch nach und nach der von der Axe des Kreisels mit der loth. rechten Axe des Kegels gebildete Winkel immer kleiner und kleiner wird, so ist doch daran nur die im Weltraume unwirksame Reibung zwischen Axe und Basis schuld. Nicht minder lässt sich eine analoge Erscheinung auch beim Bohnen bergerschen Apparate nachweisen, sobald man an das Ende der Umdrehungs- 
axe (Fig. 44) ein kleines Uebergewicht anhängt. Dieses bringt nämlich nicht etwa, wie man erwarten sollte, eine Neigung der Axe innerhalb der durch diese gelegten Vertikalebene zuwege, sondern, wenn nur die Drehgeschwindigkeit eine hinreichend grosse ist, beginnt diese Axe, ohne ihre Neigung gegen den Horizont zu ändern, sich längs eines Kegelmantels in Bewegung zu setzen. Von Fessel's Drehscheibe wollen wir erst später sprechen, weil sich an diese bequem die theoretische Prüfung dieser eigenthümlichen Vorgänge anknüpfen lässt, wohl aber ist jetzt die Zeit, der von Gilbert erwähnten und aus $\S .4$ bis zu diesem Paragraphen zurückgestellten Vorrichtungen im $\mathrm{Zu}$ sammenhange zu gedenken. An erster Stelle fesselt unsere Aufmerksamkeit das von Foucault in Verbindung mit Froment ausgeführte und am 27. September 1852 der Pariser Akademie vorgezeigte Gyroskop [208]. Ein Torus*) T aus Bronze (Fig. 48) ist auf eine Axe von Stahl aufgesetzt, deren Endpunkte frei auf zwei dem Metall-

Fig. 48.

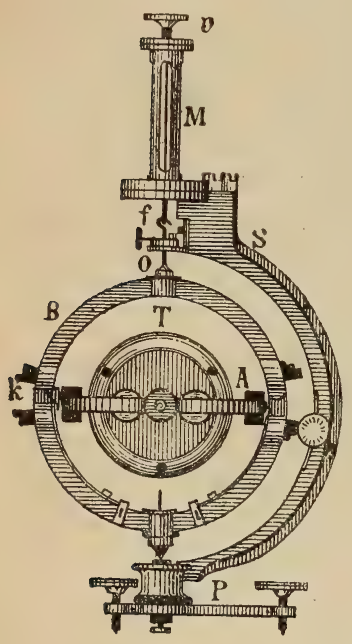
ringe A eingefügten Schrauben liegen. Dieser Ring liegt mit Stahlschneiden auf zwei horizontalen Platten, die wiederum von dem vertikalen Ringe B getragen werden, und dieser Ring ist an einem torsionslosen Faden $f$ aufgehängt, der innerhalb der Röhre $M$ vor Luftzug geschützt und durch die Schraube V regulirbar ist. Ein kräftiger Support S trägt das Ganze; am Postamente $\mathrm{P}$ sind Stellschrauben angebracht. In die Masse des Torus sind kleine Schräubchen eingesenkt, und auch sonst befinden sich da und dort Schrauben, wie $\mathrm{k}$, an den Ringen, welche gar keinen anderen Zweck haben, als durch successives Anziehen und Nachlassen den Schwerpunki des Systemes zu verändern. Durch Probiren kann man es so dahin bringen, dass der Schwerpunkt genau dahin zu liegen kommt, wo die Schneiden des Ringes A, die ja in ein und derselben horizontalen Geraden sich befinden, die verlängerte Vertikale $f$ treffen. Dieser Schwerpunkt ist jetzt der einzige Fixpunkt des ganzen Systemes; ein Hauch des Mundes genügt nunmehr, jenes in Bewegung zu versetzen, und man hat völlig das, was die Statik indifferentes Gleichgewicht nennt. Sowie aber die ganze Vorrichtung auf einen Rotationsapparat aufgesetzt und eine hinlängliche Umdrehungsgeschwindigkeit erreicht ist, beginnt das System seine eigene Bewegung. "Si l'axe," so beschreibt Gil bert selbst (a. a. O.) den merkwürdigen Vorgang „était d'abord pointé sur une étoile, il continue à viser cette étoile tant que la vitesse du tore ne descend pas au-dessous d'une certaine limite, et par le déplacement apparent qu'il prend ainsi relativement aux objets environnants, comme une lunette monté sur un pied parallactique, déplacement que l'on observe au moyen

*) Unter einem Torus versteht die Geometrie einen Rotationskörper, der durch Umdrehung eines Kreises um eine willkürliche in dessen Ebene gelegene Gerade entstanden ist. 
d'un microscope, soit sur l'axe même, soit sur une des pièces de l'appareil; il révèle à l'observateur le mouvement réel de notre globe dans l'espace." Eine grosse Reihe der interessantesten Versuche lässt sich mit diesem genial ausgedachten Apparate anstellen, je nachdem man in irgend einer Weise die volle Bewegungsfreiheit des Systemes einschränkt, und insbesondere lässt sich natürlich auch damit die konische Bewegung der Präcession nachweisen. Trefflich leistet dieses Letztere auch das gyroskopische Pendel von Sire [209], welches in den Lehrbüchern sehr häufig mit dem eigentlichen Gyroskope verwechselt wird; doch bietet dasselbe an und für sich noch gar manche andere Räthsel dar. Auf der Platte P (Fig. 49), welche um die vertikale Axe D drehbar ist, befindet sich ein vertikaler Träger $\mathbf{S}$, der, wie man sieht, unten eine Höhlung hat. Oben an demselben ist nämlich ein Draht befestigt, der, solange vollständige Ruhe herrscht, vertikal herabhängt und einen Ring $\mathrm{C}$ trägt, und innerhalb dieses Ringes spielt wiederum die horizontale Axe eines Torus T. Die Aequatorialebene von $\mathrm{T}$ ist demnach vertikal; die Höhlung dient dazu, dem Torus im Ringe eine ungezwungene Ruhelage zu ermöglichen. Dreht man jetzt das Ganze um die Axe D, so ereignet sich durchaus nichts Besonderes, ebensowenig, wenn man bei sonstiger Ruhe aller übrigen Theile dem Torus für sich eine Rotationsgeschwindigkeit ertheilt. Ganz anders dagegen, wenn beide Bewegungen gleichzeitig stattfinden; dann hebt sich nämlich der Ring C, ähnlich, wie es bei dem in §. 2 dieses Kapitels geschilderten Gregory'schen Experimente der Fall ist, bis die durch unsere Figur gekennzeichnete horizontale Stellung des Verbindungsdrahtes erreicht ist. Dabei war vorausgesetzt, dass mittelst der Richtschraube $\mathrm{R}$ die aus der Zeichnung zu ersehende Anordnung der einzelnen Theile des Apparates hergestellt worden sei; würde jedoch in gleicher Weise der Träger $\mathrm{S}$ um $90^{\circ}$ gedreht werden, so würden sich Erscheinungen einstellen, welche unser Gewährsmann als ,aussi paradoxaux" bezeichnet. „Le pendule, obéissant au même principe, se porte en avant ou en arrière du mouvement du bâti P, selon le sens de la rotation qu'on a imprimée d'avance au tore." Gilbert selbst ist dann noch einen bedeutsamen Schritt weiter gegangen. Im Vereine mit dem Mechaniker Ducretet hat er das Barogyroskop konstruirt [210], welches alle irgend auf die Rotation der Körper und zugleich auf diejenige der Erde bezüglichen Phänomene mit bis dahin unerreichter Schärfe darstellt, doch ist die Einrichtung und Theorie desselben eine zu wenig einfache, um an diesem Orte anders als historisch berührt werden zu können.

Diese Konstruktion des neuen Universalapparates haben wesentlich theoretische Erwägungen geleitet, während für F oucault und Sire mehr die glückliche Inspiration des genialen Erfindertalentes maassgebend gewesen ist. Gilbert war auch der Erste, dem es gelang, die 
Integration der Bewegungsgleichungen des Gyroskopes vollständig auf bekannte Funktionen, nämlich auf elliptische Integrale, zurückzuführen [211]. Ferner verdankt man demselben Manne einen hochinteressanten Rückblick auf die Geschichte des Problemes [212], zu dessen Lösung ein Poinsot, Richelot, Jacobi, Somoff, Bour u. a. ihr Schärflein beigetragen haben. Insbesondere ersieht man aus diesem Essay, wie schwierig genügende elementare Erklärungen aller jener Thatsachen zu geben sind, welche die zur Veranschaulichung der Präcession ersonnenen Instrumente hervortreten lassen. Selbst die übliche Pog gendorff'sche Deutung der Kreiselbewegung und der Drehscheibe operirt mit Bewegungsimpulsen, die in der Natur nicht eigentlich vorhanden sind. Vielleicht kommen wir unserem Ziele, ohne höhere Rechnung eine Begründung der maschinellen Präcession zu liefern, dadurch am nächsten, dass wir einen neuerdings von Munker [213] vorgezeichneten Weg betreten. Wir knüpfen diese Betrachtung an den kleinen, aber sinnreichen Apparat, welchen der auf dem Gebiete der Feinmechanik mit Ehren genannte Fessel [214] angegeben hat.

In einer cardanischen Aufhängung befindet sich eine massive Metallscheibe, die in Drehung versetzt werden kann. Eine am äussersten Ringe angebrachte Axe ist horizontal auf einen vertikalen Ständer aufgesetzt, und ein auf der anderen Seite der Axe verschiebbares Gegengewicht vermittelt die Aequilibrirung. Wird nun das Gegengewicht grösser oder kleiner gewählt, als zu dem gedachten Zwecke erforderlich wäre, so tritt, solange die Scheibe keine eigene Bewegung besitzt, den Umständen gemäss eine Hebung oder Senkung des Gewichtes ein; sobald jedoch der Scheibe eine hinlänglich schnelle Axendrehung ertheilt ward, beginnt sich die Axe horizontal einzustellen und in der Horizontalebene eine Drehung auszuführen, und zwar nach entgegengesetzten Richtungen, je nachdem das Gegengewicht zu klein oder zu gross ist. Fig. 50 giebt ein schematisches Bild des Vorganges. $O$ ist der Mittelpunkt der im Sinne des Pfeiles rotirenden Scheibe, AO die Drehaxe, A der Punkt, in welchem diese Axe auf dem Piedestal AN aufruht, $\mathrm{Q}$ das Gegengewicht, welches etwas kleiner angenommen werden mag, als das Gewicht der Scheibe. Die Differenz beider Gewichte ist durch die in $\mathrm{O}$ vertikal wirkende Kraft OP repräsentirt. Es hindert nichts, in A zwei gleiche und entgegengesetzt gerichtete Kräfte $\mathrm{AM}=\mathrm{AR}=\mathrm{OP}$ anzunehmen; dann setzt sich $\mathrm{AR}$ mit $O P$ zu einem Kräftepaare vom Momente OP.AO zusammen, welches den Apparat in der Ebene AOP um A zu drehen bestrebt ist, während die noch übrige Kraft A M sich lediglich in einem Drucke auf die Axe äussert. Das Moment eines Paares versinnlicht man bekanntlich durch eine auf der Ebene des letzteren senkrecht errichtete Gerade, auf welcher nach irgend einem Maassstabe eine der Grösse des Paares proportionale Strecke abgetragen wird; kommen mehrere Momente in Betracht, so kann man die resultirende Momenten-Axe nach den für das Kräfteparallelogramm gültigen Regeln ermitteln und besitzt in dieser Axe nach Lage, Grösse und Drehsinn*) ein Maass für das resultirende Kräftepaar. Die für Rechtsdrehung positive

*) Die rechtsdrehenden Paare erhalten eine von ihrer Ebene aus nach oben, die linksdrehenden eine von dieser Ebene aus nach unten errichtete Momenten-Axe. 
Momenten-Axe unseres Paares ist horizontal und normal zu AO; AC möge dieselbe darstellen. Die Scheibe ward bislang noch als bewegungslos betrachtet; sowie man auch sie mit einer gewissen Rotations-

Fig. 50 .

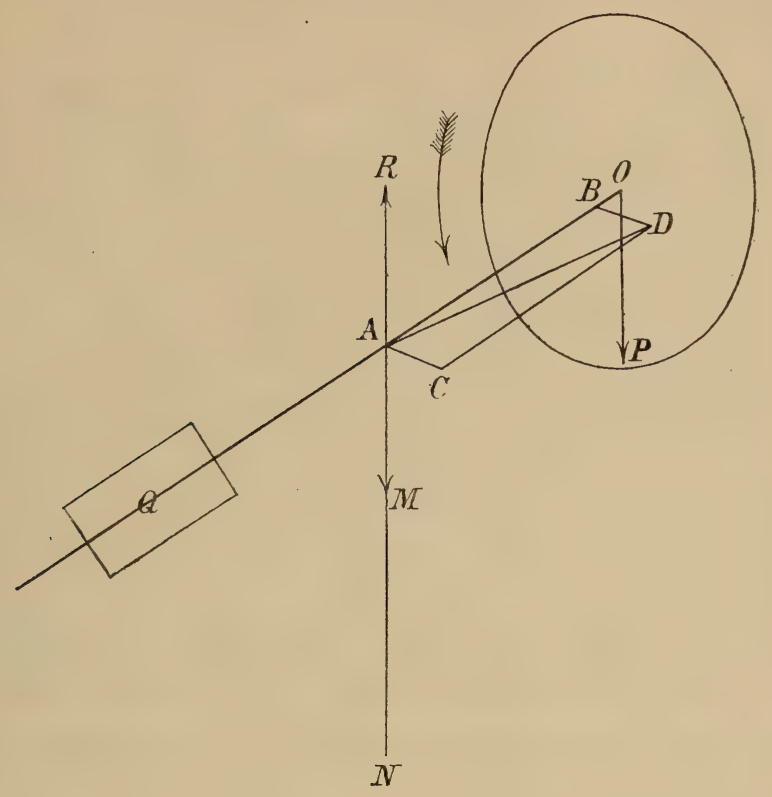

geschwindigkeit begabt annimmt, hat man als deren Repräsentanten ein zweites Kräftepaar einzuführen, dessen positive Axe in A O liegt, dessen Momenten-Axe AB sein möge. Nach obiger Vorschrift sind $A B$ und $A C$ zu einem Parallelogramm ABDC zusammenzusetzen, dessen Diagonale AD ebenfalls in die Horizontalebene fällt; damit ist die horizontale Umdrehung der Axe AO sicher gestellt. Da ferner $\Varangle \mathrm{ABD}=90^{\circ}$, so ist $\mathrm{AD}>\mathrm{AB}$. Hierin schiene nun allerdings ein Paradoxon zu liegen, denn wenn in der That nach Umfluss der Zeit dt - wir hatten stets unendlich kleine Drehbewegungen vor Augen das Drehungsmoment der Scheibe sich vergrössert hätte, so würde damit gesagt sein, dass die Umdrehungsgeschwindigkeit durch die Präcession vermehrt würde, und dieses Ergebniss entspräche keineswegs den Erfahrungen. Nun ist aber, $\Varangle \mathrm{BAD}=\psi$ gesetzt, die $\mathrm{Zu}-$ nahme $\delta=A D-A B=A D(1-\cos \psi)=2 A D \sin ^{2} 1 / 2 \psi$. Der Winkel $\psi$, als im Zeitelement $d \mathrm{t}$ beschrieben, ist unendlich klein von der ersten Ordnung, ein Gleiches gilt für seinen Sinus, und dessen Quadrat wiederum wird unendlich klein von der zweiten Ordnung, d. h. gleich Null. Auch der Kalkul bestätigt mithin bei schärferer Prüfung, was wir schon wissen, dass nämlich die Umdrehung, wenn nicht noch andere Einflüsse in's Spiel kommen, mit gleichförmiger Geschwindigkeit vor sich geht.

Von der die Sache wesentlich komplicirenden Reibung ist hier abgesehen worden. Wir verschliessen uns den Bedenken nicht, welche 
auch gegen die vorgetragene Erklärung sich allenfalls erheben lassen, halten aber gleichwohl dafür, dass dieselbe weit überzeugender ist, als die von Poggendorff (s. o.) gegebene, und dass Munker, der auch die Bewegung des Kreisels unter neuen Gesichtspunkten zu betrachten lehrt [215], namentlich der populärwissenschaftlichen Literatur entschiedenen Vorschub geleistet hat.

§. 12. Weitere Bemerkungen über die Präcession. Die Lunisolarpräcession ist nach mehr denn einer Seite hin eine für die mathematische und physische Geographie bedeutsame Erscheinung. Erstens, weil sie, richtig aufgefasst, ein Mittel zur Bestimmung der Erdgestalt abgiebt. Wenn nämlich aus den Dimensionen des Erdsphäroides im Sinne von D'Alembert und Laplace ein Werth für die Grösse des Präcessionsbogens hergeleitet werden konnte, der mit den Messungen wenigstens theilweise stimmte, so muss auch die umgekehrte Fassung der Aufgabe zulässig sein: aus der empirisch gefundenen Grösse der Präcession einen Rückschluss auf die Abplattung des die Erscheinung bedingenden Ellipsoides zu machen. Man hat sich dabei natürlich gegenwärtig zu halten, dass nach Kap. II dieser Abtheilung die Erde ja keine streng geometrisch regelmässige Gestalt besitzt, und so wird man auch an die hier angedeutete Methode keine allzuhohen Anforderungen stellen dürfen. Muncke stellt in seinem Lexikon-Artikel „Erde ${ }^{\star}$ eine Reihe von Abplattungswerthen einander gegenüber; welche aus den Störungen der Mondbewegung durch die sphäroidische Erde hergeleitet wurden [216]; v. Lind ena u fand $\frac{1}{315,82}$, Laplace $\frac{1}{305}$ nach Bürg, $\frac{1}{299}$ nach Bouvard und B urckhardt. Letzterer Werth stimmt mit den in Kap. II auf verschiedene Weisen erhaltenen Zahlen befriedigend überein. - Von noch gewichtigerer Bedeutung erweist sich eine mit möglichster Präcision durchgeführte Theorie des Vorrückens der Nachtgleichen dann, wenn es sich darum handelt, die Beschaffenheit des Erdinneren zu studiren. Kap. II der nächsten Abtheilung soll uns auf diesen Gegenstand wieder zurückführen.

Gerade aus dieser früher ungeahnten Erweiterung der Thatfrage hat aber die Sache selbst grossen Nutzen gezogen. Der belgische Mathematiker Folie giebt an [217], gelegentlich seiner Versuche, die Existenz einer flüssigen Schicht im Inneren der Erde durch Analysirung der Präcessionserscheinungen darzuthun, sei er darauf gekommen, dass die Präcession - und mit ihr die im nächsten Paragraphen zu erörternde Nutation - auch eine tägliche Periode besitze. Theoretisch zugestanden hatte diese Periode auch Laplace, allein ihre Erkennbarkeit hatte er geleugnet; Folie aber ist es eigener Aussage zufolge gelungen, die bezüglichen Differentialgleichungen, für welche sein grosser Vorgänger nur Näherungslösungen kannte, erstmalig in geschlossener Form $\mathrm{zu}$ integriren und so zu weit zuverlässigeren Zahlwerthen zu gelangen. Selbst in dem ungünstigsten Falle eines festen Erdinneren, so findet er (a. a. O.), würde die tägliche Nutation es bewirken, dass der Polarstern um mindestens $0,8^{\prime \prime}$ in Rektascension sich von seinem wahren 
Orte entfernt; die tägliche Präcession würde umgekehrt für den Stern $\lambda$ Ursae minoris im Verlaufe eines Achtelstages eine solche Verschiebung von $0,5^{\prime \prime}$ zuwege bringen. Vergleichungen, welche Folie an den Oertern gewisser Cirkumpolarsterne anstellte, wie diese in den astronomischen Kalendern von Greenwich, Paris, Washington und Berlin mitgetheilt werden, haben ihm gezeigt, dass wirklich beträchtliche Unterschiede in gerader Aufsteigung den Schwankungen der Erdaxe von täglicher Periode zuzuschreiben seien. Diese einstweiligen Andeutungen sind ganz geeignet dazu, Aufsehen zu erregen und den lebhaften Wunsch nach anderweiten, bestätigenden oder abändernden * Mittheilungen von unbetheiligter Seite nahezulegen. -

Der Einfluss der Planeten ist bis jetzt, da ausschliesslich von der Lunisolarpräcession die Rede war, ausser Acht geblieben, und in der That ist er an und für sich von keiner Erheblichkeit. Allein in §. 9 haben wir erfahren, dass, ganz unabhängig von der Präcession, die Ekliptik eine langsame Schwengelbewegung ausführt, und dass diese beiden Bewegungen sich irgendwie kombiniren müssen, ist klar. Der Aequator geht lediglich in Folge der Präcession auf der ruhend gedachten Ekliptik rückwärts, also geht er auch noch auf der durch die Planeten bewegten Ekliptik rückwärts, und dieses letztere Rückwärtsgehen, dessen Grösse die Astronomie mit dem Buchstaben $\psi_{t}$ bezeichnet, heisst allgemeine Präcession der Aequinoktialpunkte [218]. Nach den neuesten Untersuchungen darf für den Zeitraum von $t$ Jahren $\psi_{\mathrm{t}}=50^{\prime \prime}, 21129 \mathrm{t}+0^{\prime \prime}, 0001221483 \mathrm{t}^{2}$ gesetzt werden [219].

§. 13. Nutation. Wir haben in §. 6 Bradley's Versuche kennen gelernt, durch Beobachtungen an Zenitalsternen deren jährliche Parallaxe zu finden, und wir erfuhren damals, dass dieser nächste $Z$ weck freilich nicht erreicht, wohl aber eine Entdeckung von vielleicht noch grösserer Tragweite, nämlich die der Licht-Aberration, gemacht wurde. Ein zweites Nebenprodukt jener mühsamen Untersuchung bildet die sogenannte Nutation. Am 31. December veröffentlichte Bradley ein an Lord Macclesfield gerichtetes Sendschreiben, welches später in die von Rigaud besorgte Briefsammlung aufgenommen wurde [220]. Darin stellte er folgende zwei Thesen auf: I) Die Erdaxe ist während eines Umlaufes der Mondknoten einem Schwanken unterworfen, welches bis auf 18" steigt; II) Dieses Schwanken ist auch mit einer Ungleichheit im Vorrücken der Tag- und Nachtgleichen verknüpft. Unterstützt durch den unermüdlichen Zahlenrechner Machin, gab der Entdecker eine einstweilige Hypothese zur Erklärung dieser neuen Bewegungsanomalie an; diese Erklärung kommt dem Grundgedanken nach auf das Nämliche heraus, wie früher die (in $\S .10$ abgehandelte) Trepidationshypothese, drückte aber die Beobachtungen bis auf etwa 2" genau aus. Sodann gelang es D'Alembert, auch die Nutation mit dem Newton'schen Gesetze und mit der sphäroidalen Gestalt der Erde in Uebereinstimmung zu bringen [221].

Der äquatoriale Wulst der Erde bewirkt, wie wir sahen, die Präcession; würde die (scheinbare) Sonne, statt in der Ebene der Ekliptik, in derjenigen des Aequators umlaufen, so würde diese Massenanhäufung sich nicht durch attraktive Störungen geltend machen können. Immerhin ist das Vorrücken des Aequators, soweit die Sonne allein 
in Frage kommt, ein gleichförmiges, weil jene genau ein halbes Jahr über und genau ein halbes Jahr unter dem Aequator sich befindet. Nun kommt aber noch der Mond hinzu, der nicht in der Ebene der Ekliptik seine Bahn beschreibt und deswegen auch nicht gleichförmig an den Wirkungen der Präcession participirt. Seine Bahnebene bildet mit der Ekliptik einen Winkel von etwas mehr als $5^{\circ}$, und in 18 Jahren gehen die gemeinschaftlichen Durchschnittspunkte (Knoten) beider Kreise einmal um die ganze Peripherie herum. Es muss mithin der Antheil, welcher bei der Lunisolarpräcession allein auf den Mond kommt, ein veränderlicher, jedoch, wie eben schon Bradley fand, an eine Periode von 18 Jahren gebunden sein. Fig. 51, die nach J. J. v. Littrow [222] gehalten ist, versucht das Wesen der oscillatorischen Gesammtbewegung im Bilde darzustellen. PQRS

Fig. 51.

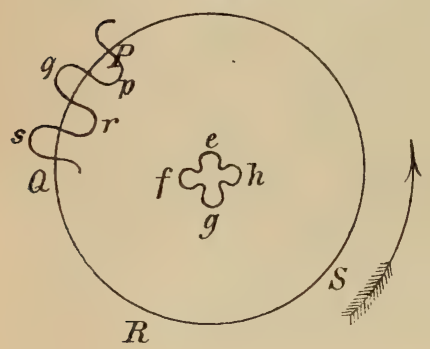
ist ein um den Pol E der Ekliptik mit einem Radius von $23^{1 / 2}{ }^{0}$ beschriebener Kugelkreis, in dessen Peripherie der Pol P, der Richtung des Pfeiles folgend und jener der Zeichen entgegen, jährlich um etwa 50" sich weiter bewegt. Die allgemeine Präcession (der Planeten) bringt die Ekliptik aus ihrer Lage und bewirkt so, dass der Pol der Ekliptik nicht mehr ganz ruhig verbleibt, sondern den Punkt $\mathrm{E}$ in einer gekrümmten Linie ef $\mathrm{g} \mathbf{h}$ umliiuft: Damit endlich auch der Nutation ihr Recht werde, darf man den Aequator-Pol nicht mehr einfach in einem Kreise, sondern in einer Wellenlinie Ppgrs einhergehen lassen, in welcher der wahre Pol $p$ dem mittleren Pol $\mathrm{P}$ gegenüber bald etwas voran-, bald etwas nachsteht, indem er sich zugleich dem mittleren Pole der Ekliptik jetzt etwas nähert, dann wieder von ihm entfernt.

Die Nutation ändert sowohl die Lage des aufsteigenden Knotens der Mondbahn, als auch die Schiefe der Ekliptik. Unter $\Omega$ verstehen wir im Folgenden die Länge des aufsteigenden Knotens, unter $\odot$ und $\mathbb{C}$ die Länge der Mittelpunkte von Sonne und Mond, unter P die Länge des Perihels der Sonne, unter $\mathrm{P}^{\prime}$ diejenige des Perigäums der Mondbahn, unter $\lambda$ diejenige eines Sternes, unter $\varepsilon$ die Ekliptikschiefe. Dann sind die auf Rechnung der Nutation zu setzenden Abänderungen $\Delta \lambda$ und $\Delta \varepsilon$ durch folgende von C. A. F. Peters [223] aufgestellte Gleichungen gegeben:

$$
\begin{gathered}
\Delta \lambda=-17^{\prime \prime}, 2405 \sin \Omega+0^{\prime \prime}, 2073 \sin 2 \Omega-1^{\prime \prime}, 2692 \sin 2 \odot \\
-0^{\prime \prime}, 2041 \sin 2 \llbracket+0^{\prime \prime}, 1279 \sin (\odot-\mathrm{P})-0^{\prime \prime}, 0213 \sin (\odot+\mathrm{P}) \\
+0^{\prime \prime}, 0677 \sin (\varangle-\mathrm{P}) \\
\Delta \varepsilon=+9^{\prime \prime}, 2231 \cos \Omega-0^{\prime \prime}, 0897 \cos 2 \Omega+0^{\prime \prime}, 5509 \cos 2 \odot \\
+0^{\prime \prime}, 0886 \cos 2 \varangle+0^{\prime \prime}, 0093 \cos (\odot+\mathrm{P}) .
\end{gathered}
$$

Als Epoche gilt der Anfang des Jahres 1800. Anderweite Forschungen über Art und Grösse der Nutation besitzt man von v. Lindenau [224], Lundahl [225], Nyrén [226] und Tägert [227]. Dem Letztgenannten gebührt das Verdienst, den Beweis für die bereits von Laplace erkannte Thatsache, dass bei ausschliesslicher Berücksichtigung der ersten Potenzen der störenden Kräfte die Meeres- 
schwankungen auf Präcession und Nutation nicht erkennbar einwirken, auch auf die Quadrate jener kleinen Grössen erstreckt zu haben*).

§. 14. Die Fortbewegung des Sonnensystemes im Raume. Alle kosmisch nachweisbaren Bewegungen der Erde sind in den dreizehn ersten Paragraphen dieses Kapitels durchgesprochen worden, eine einzige ausgenommen. Diese letztere würde nach der Ansicht Mancher überhaupt aus einem Lehrbuche der Geophysik fortbleiben dürfen, da ihr auf den ersten Blick allerdings keine Bedeutung für unsere Zwecke zugeschrieben werden zu können scheint. Und doch beruht diese Meinung auf einem Irrthume, denn schon im ersten Kapitel der nun folgenden dritten Abtheilung werden wir uns überzeugen, dass von einem Fachmanne ersten Ranges, von Poisson, diese Bewegungsform in nächsten Zusammenhang mit dem gegenwärtigen Erwärmungszustande des Erdkörpers gebracht worden ist. Wir meinen diejenige Bewegung der Erde, welche sie im Gefolge der selbst ihren Ort im Raume wechselnden Sonne mitzumachen genöthigt ist, und welche für einen im Raume absolut stabil aufgestellten Beobachter - Körper Alpha ach Carl Neumann's Definition [229] - den Eindruck hervorrufen muss, dass die Erde nicht sowohl in einer geschlossenen Ellipse, als vielmehr in einer Epicykloide mit Durchschlingungen sich fortbewege.

Der erste Astronom, welcher den altehrwürdigen Begriff „Fixstern" in's Schwanken brachte und für eine ganze Anzahl dieser Gestirne eine von den bekannten Ortsveränderungen innerhalb des Sonnensystemes unabhängige Eigenbewegung nachwies, war der ältere Tobias Mayer [230]. Weitere Schlüsse zog er aus dieser Wahrnehmung zunächst nicht; es musste also dahin gestellt bleiben, ob hier wirklich Fixsternbewegungen vorlagen, oder ob vielleicht die Sonne die ihr beigelegte Eigenschaft völliger Unbeweglichkeit nicht besass, oder ob wohl gar beide Bewegungsgattungen in einander griffen. Für die Fortbewegung der Sonne im Raume sprach sich mit aller Entschiedenheit zuerst Lambert anlässlich seiner grossartig kühnen Konstruktion der Sternsysteme höherer Ordnung aus. Schon der Umstand, dass sich die Sonne um ihre eigene Axe dreht, schien ihm genügend, ihr auch eine fortschreitende Bewegung als unumgängliche begleitende Eigenschaft beizulegen [231]; „Die Sonne, ${ }_{\text {, diess sind }}$ seine Worte [232], „mag immerhin im Mittelpunkt ihres Systemes sein und die Planeten und Kometen um sich her wandeln lassen. Sie ist es nicht mehr als Jupiter und Saturn in Absicht auf ihre Trabanten. Dass sie aber im Mittelpunkt des ganzen Weltgebäudes seie, das ist noch lange nicht ausgemacht, und wenn sie es auch einmal wäre, so würde sie bald wieder daraus weggerückt werden." $\mathrm{Ja}$, er sprach sogar schon die Hoffnung aus, dass es dereinst gelingen werde, die von der bewegten Sonne innegehaltene Richtung anzugeben oder, wie man sich später ausdrückte, den Apex der Sonnenbewegung an der Himmelskugel zu ermitteln. Dieses Problem lösten denn auch

*) Aus dem oben Angeführten folgt, dass es auch eine solare Nutation von halbjähriger Periode geben muss, indessen ist diese nur sehr klein und erhebt sich im Maximum zu einer halben Sekunde [228]. 
W. Herschel [233] und P. Prevost [234], doch war Letzterer nach R. Wolf [235], als er seine Arbeit begann, schon nicht mehr ganz ohne Kenntniss von Herschel's Entwürfen. Der Gedankengang des Letzteren ist ein überaus einfacher. A (Fig. 52) stellt den Mittelpunkt der Ekliptik PQRS dar; es wird angenommen, dass sich die Sonne in der Richtung des Diameters DC bewege und nach einiger Zeit in B ankomme. Rings herum in der Ebene dieses Kreises sind Sterne vertheilt, und wenn nur AB gross genug ist, um den parallaktischen Winkel genügend hervortreten zu lassen, so müssen die - auf der Ekliptik abgemessenen - Längen jener Sterne eine Veränderung er-

Fig. 52 .

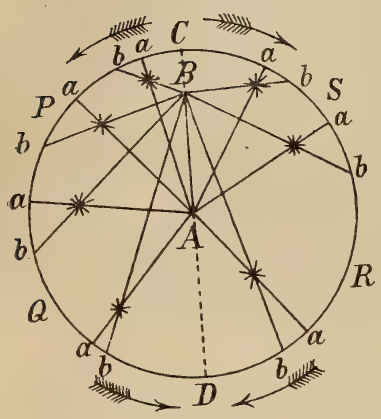
leiden; jeder einzelne Stern erscheint von a nach $b$ verschoben. Zur rechten Hand wachsen die astronomischen Längen, zur linken nehmen sie ab. Speziell gegen den Apex C hin treten die Sterne aus einander, gegen den diametral entgegengesetzten Punkt D hin nähern sie sich einander, wie beides die Pfeile ausdrücken. Eine ähnliche Erscheinung stellt sich einem Jeden vor Augen, der eine lange Allee durchwandert. Man erkennt jetzt aber, wie Herschel durch das Studium einer möglichst zahlreiche Längen-Veränderungen enthaltenden Tabelle die Lage von $\mathrm{AC}_{\mathrm{Cu}}$ fixiren in den Stand gesetzt wurde.

Neuen Aufschwung erhielt dieser interessante $\mathrm{Zweig}$ astronomischer Forschung durch eine Monographie Argelander's [236]. Ausser ihm haben Gauss, Lundahl, Galloway, Main, Stone, Proctor, Gould u. a. Beiträge geliefert; besonders eingehend hat sich mit der Frage auch Mädler beschäftigt, der aus drei gesonderten Sterngruppen, resp. 227, 663 und 1273 Einzelsterne umfassend, für Rektascension und Deklination des Apex jeweils diese Werthe erhielt [237]:

$262^{\circ} 0^{\prime}, 8$ und $39^{\circ} 35^{\prime}, 2 ; 261^{\circ} 14^{\prime}, 4$ und $37^{\circ} 53^{\prime}, 6 ; 261^{\circ} 32^{\prime}, 2$ und $42^{\circ} 21^{\prime}, 9$.

Der Punkt hat positive Deklination, gehört also der Nordhalbkugel an.

Auf diesem Wege wird man sich den wahren Werthen mit immer grösserer Genauigkeit zu nähern und wohl auch mit der Zeit die Geschwindigkeit der translatorischen Bewegung unseres Systemes zu schätzen vermögen*). Wahrscheinlich ist diese keine so schnelle, dass die aus ihr folgende Versetzung der Erde in immer neue kosmische Regionen irgendwelche tellurische Rückwirkung äussern könnte.

*) Doppler hat bekanntlich [238] das farbige Licht der Sterne aus deren eigener Bewegung zu erklären versucht, indem diese, je nach ihrem Sinne, die Lichtwellen verlängere oder verkürze. Man hat deshalb auch wohl daran gedacht, dieses Doppler'sche Princip für die oben ventilirte Frage nutzbar zu machen, doch wird die Hoffnung, dass diess gelingen werde, von Newcomb mit Recht als eine sehr unsichere bezeichnet, wie z. B. folgende Betrachtung lehrt [239]: „Einer Bewegung von $75 \mathrm{~km}$ in der Sekunde entspricht nur eine Verschiebung von einem Sechstel der Entfernung der beiden Natriumlinien oder von 0,000001 mm, und Bewegungen von dieser Grösse kommen zwar am Sternhirnmel vor, scheinen aber nicht sehr häufig zu sein." 
[1] Chabas, Sur un texte égyptien relatif au mouvement de la terre, Zeitschr. f. ägypt. Spr. u. Alterthumsk., Decemb. 1864. - [2] H. Martin, Hypothèse astronomique de Pythagore, Bullett. di bibliogr. e di storia delle science mat. e fis., Tomo V. S. 99 ff.; Id., Hypothèse astronomique de Philolaus, ibid. Tomo V. S. 127 ff. - [3] Schiaparelli, Die Vorläufer des Coppernicus im Alterthum, deutsch von Curtze, Leipzig 1876. S. 2 ff. - [4] Ibid. S. 5. - [5] Böckh, Philolaos des Pythagoreers Leben und Bruchstücke aus seinen Werken, Berlin 1819. S. $90 \mathrm{ff}$. [6] Schiaparelli, Die Vorläufer etc. S. 22 ff, - [7] Heller, Geschichte der Physik von Aristoteles bis auf die neueste Zeit, 1. Band, Stuttgart 1882. S. 32 ff. [8] Grote-Holzamer, Platon's Lehre von der Rotation der Erde und die Auslegung derselben durch Aristoteles, Prag 1861. - [9] Schiaparelli, Die Vorläufer etc. S. $47 \mathrm{ff} .-[10]$ Ibid. S. 49 . - [11] Ibid. S. 69 ff. - [12] Ibid. S. 79 ff. [13] Ibid. S. 99. - [14] Günther, Studien zur Geschichte der mathematischen und physikalischen Geographie, Halle 1879. S. 53. - [15] Ibid. S. 28 ff. - [16] PeschelRuge, Geschichte der Erdkunde bis auf Alexander v. Humboldt und Carl Ritter, München 1877. S. 132. - [17] Sprenger, The Copernican system of astronomy among the Arabs, journal of the r. asiatic society of Bengal, Vol. XXV. S. $189 \mathrm{ff}$ - [18] Günther, Studien etc. S. 113. - [19] Carové, Galileo Galilei, Siegen und Wiesbaden 1842. S. 47. - [20] Venturi, Essai sur les ouvrages de Léonard da Vinci, Paris 1797. S. 7. - [21] R. Wolf, Geschichte der Astronomie, München 1877. S. 231. - [22] Hipler, Die Vorläufer des Nikolaus Coppernicus, insbesondere Celio Calcagnini, Mitth. d. Copp.-Vereines f. Wissensch. u. Kunst zu Thorn, 4. Heft S. 69 ff. - [23] Celii Calcagnini de perenni motu terrae tractatus, deutsch von Schlüter, Natur u. Offenbarung, 1879. S. 575 ff. - [24] Prowe, Nikolaus Copper. nicus, I. Band, 1. Theil, Berlin 1883. S. 317. - [25] Ibid. I. Band, 1. Theil, S. 343. - [26] Ibid. I. Band, 2. Theil, S. 382 ff. - [27] Nikolaus Coppernicus aus Thorn, Ueber die Kreisbewegungen der Weltkörper, deutsch von Menzzer, Thorn 1S79. [28] Zöckler, Geschichte der Beziehungen zwischen Theologie und Naturwissenschaft, mit besonderer Rücksicht auf Schöpfungsgeschichte, 1. Abtheilung, Gütersloh 1877. S. 663. - [29] Ibid. S. 591. - [30] Nik. Coppernicus, Ueber etc. S. 22 - [31] Mädler, Geschichte der Himmelskunde von der ältesten bis auf die neueste Zeit, 1. Band, Braunschweig 1873. S. 200 ff. - [32] Ibid. S. 319. - [33] Ibid. S. 289. - [34] R. Wolf, Gesch. d. Astr. S. 245. - [35] Kästner, Geschichte der Mathematik, 4. Band, Göttingen 1800. S. 113. - [36] Mädler, Reden und Abhandlungen über Gegenstände der Himmelskunde, Berlin 1870. S. 133 ff. - [37] Bode, Gedanken über vermuthete Veränderungen der Erdpole und Axe, der Gesellsch. naturf. Freunde zu Berlin neue Schriften, 2. Band. S. $303 \mathrm{ff}$. - [38] Stark, Ueber die Möglichkeit einer Axenveränderung der Erde, München 1875. - [39] Gregory, Versuche über die permanenten Rotationsaxen, Ann. d. Phys. u. Chem., (1) 14. Band. S. 57 ff. - [40] Bessel, Ueber den Einfluss der Veränderungen des Erdkörpers auf die Polhöhen, Zeitschr. f. Astr. u. verw. Wissensch., 5. Band. S. 25 ff. [41] Gyldén, Recherches sur la rotation de la terre, Upsala 1871. - [42] G. H. Darwin, On the influence of geological chances on the earth's axis of rotation, Phil. Transact., Vol. CLXVII. S. 271 ff. - [43] Prowe, Nik. Coppernicus, I. Band, 1. Theil. S. 240 ff. - [44] W. Gilbert, De magnete magneticisque corporibus et de magno magnete tellure physiologia nova, Londini 1600. S. 212. - [45] Zöllner, Ueber die Natur der Cometen, Beiträge zur Geschichte und Theorie der Erkenntniss, Leipzig 1883. S. 118 ff. - [46] Hertz, Betrachtungen über die continuirlichen Ströme, welche die flutherregende Wirkung der Gestirne im Meere veranlassen muss, Verhandl. d. phys. Gesellsch. in Berlin vom 5. Januar 1883. - [47] Gehler's Physikalisches Wörterbuch, 2. Auflage, IX. Band, 1. Abtheilung, Leipzig 1838. S. $61 \mathrm{ff}$. - [48] Schönfeld, Neuere Untersuchungen über die Constanz der Rotationszeit der Erde, Ausland 1879. S. 181 ff. - [49] Newcomb, On the possible variability of the earth's axial rotation, as investigated by M. Glasenapp, Boston 1874 . [50] Bertelli, Appunti storici intorno alle ricerche sui piccoli e spontanei moti dei pendoli, fatte dal secolo XVII in poi, Bullett. di bibliogr. e di storia delle scienze mat. e fis., tomo VI. S. 1 ff. - [51] Ibid. S. 5. - [52] Ibid. S. 14. [53] Ibid. S. 17. - [54] Parnisetti, Osservazioni meteorologiche fatte in Alessandria alla specola del seminario durante l'eclisse parziale del sole 18 luglio, Alessandria 1860. - [55] $\mathrm{Ph}$. Plantamour, Sur les mouvements périodiques du sol, Compt. rend. de l'acad. franç., tome XCII. S. 330. - [56] Günther, Die sichtbaren und fühlbaren Wirkungen der Erdrotation, Humboldt, 1. Jahrgang. S. 328 ff. S. $359 \mathrm{ff}$ - - [57] J. J. v. Littrow, Wunder des Himmels, (5. Auflage) Stuttgart 1865. S. 49. - [58] Poggendorff, Geschichte der Physik, Leipzig 1879. S. 303. 
- [59] Guglielmini, De diurno terrae motu, experimentis mathematico-physicis confirmato, Bononiae 1791. - [60] Benzenberg, Versuche über die Gesetze des Falles, den Widerstand der Luft und die Umdrehung der Erde, Hamburg 1791. - [61] Reich, Fallversuche über die Umdrehung der Erde, Freiberg 1832. [62] Kästner, Geschichte der Mathematik, 3. Band, Göttingen 1799. S. 422 ff. [63] Kästner, Anfangsgründe der höhern Mechanik, welche von der Bewegung fester Körper besonders die praktischen Lehren enthält, Göttingen 1793. S. 53. [64] Buff, Der Einfluss der Umdrehung der Erde um ihre Axe auf irdische Bewegungen, Ann. d. Chem. u. Pharm., 4. Supplementband. S. 207 ff. - [65] Zöppritz, Ueber den angeblichen Einfluss der Erdrotation auf die Gestaltung von Flussbetten, Verhandl. d. II. deutschen Geographentages, Berlin 1882. S. $47 \mathrm{ff}$. [66] Benoni, Der Einfluss der Axendrehung der Erde auf das geographische Windsystem, Petermann's geogr. Mittheil., 23. Band. S. 95. - [67] D'Alembert, Sur le mouvement des corps pesans, en ayant égard à la rotation de la terre, Hist. de l'acad. royale des sciences, Année 1771. S. 10 ff. - [68] Poisson, Extrait de la première partie d'un mémoire sur le mouvement des projectiles dans l'air, en ayant égard à leur rotation et à l'influence du mouvement diurne de la terre, Compt. rend. de l'acad. franç., tome V. S. 660 ff. - [69] Finger, Ueber den Einfluss der Erdrotation auf parallel zur sphäroidalen Erdoberfläche in beliebigen Bahnen vor sich gehende Bewegungen, Sitzungsber. d. k. k. Ak. d. Wissschftn. zu Wien, Math. Kl., 76. Band. S. 67 ff. - [70] Darapsky, Ueber den Einfluss der Erdrotation auf die Abweichungen der aus gezogenen Rohren abgeschossenen Projektile, Dingler's polytechnisches Journal, 180. Band. S. 98 ff. - [71] Maury, Physische Geographie des Meeres, deutsch von Bötticher, Berlin 1856. S. 29. [72] Martus, Astronomische Geographie; ein Lehrbuch angewandter Mathematik, Berlin 1880. S. 179. - [73] Zöppritz, Recension hiezu, Zeitschr. f. wissensch. Geogr., 1. Jahrgang. S. 77. - [74] Wiegand, Grundriss der mathematischen Geographie, Halle 1869. S. 26 ff. - [75] Hallbauer, Ueber den Einfluss der Axendrehung der Erde auf das Entgleisen von Eisenbahnen, Civilingenieur, 15. Band. S. $170 \mathrm{ff}$. - [76] v. Bär, Ueber ein allgemeines Gesetz in der Gestaltung der Flussbetten, Bull. de l'acad. imp. des sciences-de St. Pétersbourg, tome II., 1860. S. 357. - [77] Braschmann, Note concernant la pression des waggons sur les rails droits et des courants d'eau sur la rive droite du mouvement en vertu de la rotation de la terre, Compt. rend. de l'acad. franc., tome IV. S. 1068 ff. - [78] Lindelöf, Sur l'influence qu'exerce la rotation de la terre sur un corps mu suivant sa surface, Cosmos, tome XV. S. 697 ff. - [79] Perrot, Nouvelle expérience pour rendre manifeste le mouvement de rotation de la terre, Compt. rend. de l'acad. franc., tome IL. S. 637. - [80] Braschmann, Sur l'expérience de M. Perrot, Bull. de l'acad. imp. des sciences de St. Pétersbourg, tome I., 1860. S. 571 ff. - [81] Denzler, Ueber den Einfluss der Rotation der Erde auf die strömenden Gewässer, Mittheil. d. naturf. Gesellsch. zu Bern, 1857. S. 116 ff. - [82] R. Wolf, Zur Erinnerung an Hans Heinrich Denzler, Basel 1874. S. 18. - [83] Ludwig, Einige wichtigere Abschnitte der mathematischen Botanik, Zeitschr. f. math. u. naturw. Unterricht, 14. Jahrgang. S. 162. - [84] Wiesner, Ueber den Einfluss der Erdschwere auf die Grössen- und Formverhältnisse der Pflanzen, Wien 1868. [85] Wiesner, Elemente der Anatomie und Physiologie der Pflanzen, Wien 1881. S. 240 ff. - [86] Günther, Ueber die Vorgeschichte des Foucault'schen Pendelversuches, Sitzungsber. d. phys.-med. Societät zu Erlangen vom 22. Mai 1873. [87] Galileus, Dialogus de systemate mundi, Lugduni 1641. S. 344. - [88] Wallis, Inquiry and directions concerning tides, Phil. Transact., Vol. I. S. 265 ff. [89] D. Cassini, Vom Ursprung, Fortyang und Aufnehmen der Sternkunde und deren Nutzen in der Erdbeschreibung und Schifffahrt, deutsch von Kordenbusch, Nürnberg 1771. S. 101 ff. - [90] Perpendiculorum inconstantia ab Alexandro Calignono nobili Delphinate excogitata; a Petro Gassendo bona fide tradita et pulchro commentario exornata; a Joanne Caramuele Lobkowitz examinata et false reperta, Lovanii 1643. - [91] Gassendi, Novem stellae circa Jovem visae Coloniae exeunte anno 1642 et ineunte 1643 ; accessit observatio geminata in singulos dies aestus maris instar reciprocationis perpendiculorum, Lovanii 1643. - [92] Bouguer, Sur la direction qu'affectent les fils du plomb, Mém. de l'acad. r. des sciences, Année 1754. S. 250 ff. - [93] A. Mayer, Dissertatio de deviatione et reciprocatione penduli, Gryphiswaldae 1767. - [94] Doppelmayr, Historische Nachricht von den Nürnbergischen Mathematicis und Künstlern, Nürnberg 1730. S. 127. [95] R. Wolf, Handbuch der Mathematik, Physik, Geodäsie und Astronomie, 2. Band, Zürich 1872. S. 223. - [96] Foucault, Démonstration physique du mou- 
vement de rotation de la terre au moyen du pendule, Compt. rend. de l'acad. franç., tome XXXII. S. 138 ff. - [97] Hansen, Theorie der Pendelbewegung mit Rücksicht auf die Gestalt und die Bewegung der Erde, Danzig 1853. - [98] Röthig, Der Foucault'sche Pendelversuch; eine historisch-didaktische Studie, Zeitschr. f. Math. u. Phys,, 24. Band, hist.-lit. Abth. S. $153 \mathrm{ff}$ - - (99) Ordinaire de Lacologne, Théorie géométrique du pendule de Foucault, Mém. de la soc. des sciences phys. et nat. de Bordeaux, (2) tome IV. S. $339 \mathrm{ff}$. - [100] Franz, Das Foucaultsche Pendel, Halle 1872. S. 22 ff. - [101] Pick, Der Foucault'sche Pendelversuch, Zeitschr. f. d. Realschulwesen, 1. Jahrgang. S. 135 ff. S. 211 ff. S. 393 ff. [102] Tammen, Ueber den Foucault'schen Pendelversuch, (Carl's) Repert. f. Experimentalphysik, 18. Band. S. 278 ff. - [103] W. Schell, Theorie der Bewegung und Kräfte, Leipzig 1870. S. 55. - [104] Pick, Der Foucault'sche Pendelversuch, S. 401. - [105] Pieper, Zur Kritik des Foucault'schen Pendelversuches, Dessau 1882. S. 10. - [106] Siacci, Il pendolo di Leone Foucault e la resistenza dell' aria, Torino 1878. S. 10. - [107] Bravais, Mémoire sur l'influence qu'exerce la rotation de la terre sur le mouvement d'un pendule à oscillations coniques, Journ. d. mathém. pures et appl., tome XIX. S. 1 ff. - [108] Bravais, Sur les systèmes dans lesquelles les vibrations dextrogyres et levogyres n'effectuent pas de la même manière, Compt. rend. de l'acad. franç., tome XXXII. S. 166. - [109] Onnes, Nieuwe bewijzen voor de aswenteling der aarde, Groningen 1879. - [110] Schering, Recension hiezu, Gött. gel. Anzeigen, 1883. S. 71. - [111] Onnes, Nieuwe bewijzen etc. S. 247 ff. - [112] Ideler, Ueber Eudoxus, Abhandl. d. k. preuss. Akad., Phil.-hist. Kl., 1828. S. 189 ff., 1830. S. 49 ff. - [113] Cornewall Lewis, An historical survey of the astronomy of the anciens, London 1862. S. 153 ff. [114] Schiaparelli, Le sfere omocentriche di Eudosso di Calippo e di Aristotele, Milano 1874. - [115] Schiaparelli, Die homocentrischen Sphären des Eudoxus, des Calippus und des Aristoteles, deutsch von Horn, Abhandl. z. Gesch. d. Math., 1. Heft, Leipzig 1877. S. 101 ff. - [116] H. Martin, Mémoire sur les hypothèses astronomiques d'Eudoxe, de Calippe et d'Aristote, Paris 1881. - [117] Tannery, Seconde note sur le système astronomique d'Eudoxe, Mém. de la soc. des sciences phys. et nat. de Bordeaux, (2) tome V. S. $129 \mathrm{ff}$. - [118] Günther, Studien etc. S. 78. - [119] Le guide des égarés; traité de théologie et de philosophie par Moise ben Maimon... par Munck, tome I., Paris 1856. S. 358. - [120] Hieronymi Fracastori Homocentrica ejusdem de causis criticorum dierum, (ohne Druckort) 1538. - [121] Bedae Venerabilis opera omnia, Vol. I., Coloniae 1612. S. 330. [122] Schiaparelli, Die Vorläufer etc. S. 61. - [123] R. Wolf, Gesch. d. Astr. S. 45 ff. - [124] Ibid. S. 50 ff. - [125] H. J. Klein, Populäre astronomische Encyklopädie, Berlin 1871. S. 120 ff. - [126] Möbius, Elemente der Mechanik des Himmels, auf neuem Wege ohne Hülfe höherer Rechnungsarten dargestellt, Leipzig 1843. S. 46 ff. - [127] R. Wolf, Gesch. etc. S. 79. - [128] Schiaparelli, Die Vorläufer etc. S. 52 ff. - [129] Macrobius, Commentarius in somnium Scipionis, lib. I. cap. 19. - [130] Marcianus Capella, De nuptiis Philologiae et Mercurii libri duo, lib. I. cap. 8. - [131] Narducci, Intorno a vari comenti fin qui inediti e sconosciuti al "Satyricon" di Marziano Capella, Roma 1883. S. 7 ff. - [132] Tycho Brahe, Astronomiae instauratae progymnasmata ... typis inchoata Uraniburgi Daniae, absoluta Pragae Bohemiae 1609. S. 477 ff. - [133] R. Wolf, Gesch. d. Astr. S. $245 \mathrm{ff}$. - [134] Schinz, Würdigung des tychonischen Weltsystemes aus dem Standpunkte des 16. Jahrhunderts, Halle 1856. - [135] Raymarus Ursus, Tractatus astronomicus de hypothesibus astronomicis, sive de systemate mundi, Pragae 1597. - [136] R. Wolf, Gesch. d. Astr. S. 245. - [137] Prowe, Nik. Coppernicus, I. Band, 2. Theil, S. $290 \mathrm{ff}$. - [138] Aristarchi Samii de mundi systemate, partibus et motibus ejusdem liber singularis, cum notis ed. Roberval, $\mathrm{Pa}$ risiis 1647. - [139] Archimedis opera omnia cum commentariis Eutocii, ed. Heiberg, Vol. II., Lipsiae 1881. S. 245. - [140] J. W. H. Lehmann, Ueber den Einfluss der Bewegung der Erde um die Sonne auf die Bewegung eines freihängenden Pendels, Astron. Nachr. Nr. 925. - [141] R. Wolf, Gesch. d. Astr. S. 398. - [142] R. Wolf, Biographieen zur Kulturgeschichte der Schweiz, 1. Cyklus, Zürich 1858. S. 93. - [143] v. Gebler, Galileo Galilei und die römische Curie, 1. Band, Stuttgart 1876. S. 26. - [144] R. Wolf, Gesch. d. Astr. S. 544 ff. - [145] J. J. v. Littrow, Wunder des Himmels, S. 117 ff. - [146] Bessel, Bestimmung der Entfernung des 61. Sternes des Schwanes, Astron. Nachr. Nr. 365. 366. - [147] Gyldén, Die Grundlehren der Astronomie, Leipzig 1877. S. 363. - [148] Ch. Dufour, Mémoire sur une nouvelle méthode pour déterminer la distance de quelques étoiles, Bull. de la soc. Vaudoise des sciences phys. et nat., tome X. S. 1 ff. - [149] J. J. v. Littrow, 
Wunder des Himmels, S. 121 ff. S. 134 ff. - [150] W. v. Struve, Sur le coefficient constant dans l'aberration des étoiles fixes, St. Pétersbourg 1843. - [151] Wernicke, Die Entdeckung der endlichen Lichtgeschwindigkeit durch Olaus Römer, Zeitschr. f. Math. u. Phys., 25. Jahrgang, hist.-lit. Abtheilung. S. 1 ff. - [152] Nik. Coppernicus, Ueber etc. S. 29, - [153] Menzzer, Ueber den Zusammenhang der Rotation und Revolution, die dritte von Coppernicus entdeckte Bewegung der Erde und das Rotationsgesetz, Halberstadt 1868. - [154] R. Wolf, Gesch. d. Astr. S. 228. - [155] Nik. Coppernicus, Ueber etc., S. 10 der Anmerkungen. [156] Th. Gilbert, Les preuves mécaniques de la rotation de la terre, Bull. des sciences math. et astron., (2) tome VI. S. $189 \mathrm{ff}$. - [157] Bohnenberger, Beschreibung einer Maschine zur Erläuterung des Gesetzes der Umdrehung der Erde, Tübingen 1817. - [158] Günther, Studien etc. S. 86. - [159] Ibid. S. 40. [160] Nik. Coppernicus, Ueber etc., S. 22 der Anmerkungen. - [161] Göbel, Ueber Kepler's astronomische Anschauungen und Forschungen; ein Beitrag zur Entdeckungsgeschichte seiner Gesetze, Halle 1871. - [162] Himmer, Astronomische Geographie, Kaiserslautern 1883. S. 20. - [163] Göbel, Ueber etc. S. 45. [164] Ibid. S. 62 ff. - [165] Ibid. S. 72 ff. - [166] Ibid. S. 80 ff. - [167] Ibid. S. 101 ff. - [168] Ibid. S. 107 ff. - [169] Ibid. S. 120. - [170] Autenheimer, Elementarbuch der Differential- und Integralrechnung, Weimar 1865. S. 402. [171] Wettstein, Die Strömungen des Festen, Flüssigen und Gasförmigen und ihre Bedeutung für Geologie, Astronomie, Meteorologie und Klimatologie, Zürich 1880. S. 11 ff. - [172] Ibid. S. 18. - [173] Zöppritz, Recension hiezu, Mittheil. d. Gesellsch. f. Erdkunde zu Berlin, 7. Band. S. 240 ff. - [174] Günther, Geophysikalische Hypothesen, geprüft durch Libellen- und Pendel-Apparate, Humboldt, 2. Jahrgang. S. 328 ff. - [175] Pilar, Grundzüge der Abyssodynamik, Agram 1881. S. 41 ff. - [176] Mädler, Populäre Astronomie, 6. Auflage, herausgeg. von Klinkerfues, Strassburg 1882. S. 382 ff. - [177] Prowe, Nik. Coppernicus, I. Band, 1. Theil. S. 244. - [178] Laplace, Sur la diminution de l'obliquité de l'écliptique, qui résulte des observations des anciens, Conn. des temps pour l'an 1811. [179] Mädler-Klinkerfues, Pop. Astr. S. 396. - [180] Ibid. S. 28. - [181] Möbius, Die Elemente etc. S. 287. - [182] Cro]l, On the physical cause of the change of climate during geologicaI epochs, Phil. Mag., (4) Vol. XXVII. S. 130. - [183] Gehler's physikalisches Wörterbuch, 2. Auflage, VIII. Band, Leipzig 1836. S. 879 ff. [184] Ibid. S. 882. - [185] Croll, On the excentricity oj the earth's orbit, and its physical relation to the glacial epoch, Phil. Mag., (4) Vol. XXXII. S. 119 ff. - [186] Croll, On the change of the obliquity of the ecliptic, its influence of the climate of the polar regions and on the level of the sea, ibid. Vol. XXXII. S. $430 \mathrm{ff}$. - [187] R. Wolf, Gesch. d. Astr. S. 158. - [188] Ibid. S. 159. - [189] Gehler's phys. Wörterb., 2. Aufl., IX. Band, 3. Abtheilung, Leipzig 1840. S. 2129 ff. [190] Aristotelis libri reliqui cum Averrois in eosdem paraphrasibus, Venetiis 1566. tom. VI. pars 2. - [191] Benfey, Orient und Occident, 2. Jahrgang. S. 753 ff. [192] v. Segner, Astronomische Vorlesungen, 1. Theil, Halle 1775. S. 188. [193] Gehler's phys. Wörterb., 2. Aufl., IX. Band, 3. Abtheilung, Leipzig 1840. S. 2133 ff. - [194] Ibid. S. 2146 ff. - [195] Günther, Studien etc. S. 46 ff. [196] Schiaparelli-Horn, Die homoc. Sphären etc. S. 125 ff. - [197] Werner, De motu octavae sphaerae tractatus, Norimbergae 1522. - [198] Fracastor, Homocentrica etc. fol. 11. - [199] Günther, Der Wapowski-Brief des Coppernicus und Werner's Traktat über die Bewegung der achten Sphäre, Mittheil. d. Copp.-Vereins f. Wissensch. u. Kunst zu Thorn, 2. Heft. S. 3 ff. - [200] Prowe, Nik. Coppernicus, I. Band, 2. Theil. S. $217 \mathrm{ff}$. - [201] Sir Isaac Newton's mathematische Principien der Naturlehre, Berlin 1872. S. 455 ff. - [202] v. Lang, Einleitung in die theoretische Physik, 1. Theil, Braunschweig 1867. S. $117 \mathrm{ff}$. - [203] Gerlach, Die Bestimmung der Gestalt und Grösse der Erde, Wien 1782. S. 119 ff. [204] Newton, Math. Princ. etc. S. 459. - [205] D'Alembert, Untersuchungen über die Präcession der Nachtgleichen und die Nutation der Erdaxe, deutsch von Seuffert, Nürnberg 1857. - [206] Ibid. S. 32 ff. - [207] Laplace, Sur les variations de l'obliquité de l'écliptique, et de la précession des équinoxes, Conn. des temps pour l'an 1827. - [208] Th. Gilbert, S. 215 ff. - [209] Ibid. S. 218 ff. [210] Ibid. S. 221 ff. - [211] Th. Gilbert, Recherches sur les mouvements relatifs, Ann. de la soc. scientif. de Bruxelles, III (A). S. 70 ff. - [212] Th. Gilbert, Étude historique et critique sur le problème de la rotation d'un corps solide autour d'un point fixe, ibid. II (B). S. 255 ff. - [213] Munker, Eine elementare Erklärung der Präcessionsbewegung mit Berücksichtigung der Reibung, Abhandl. d. naturf. Gesellsch. zu Nürnberg, 7. Band. S. 193 ff. - [214] Poggendorff, Bio- 
graphisch-literarisches Handwörterbuch zur Geschichte der exakten Wissenschaften, 1. Band, Leipzig 1863. S. 741. - [215] Munker, S. 202 ff. - [216] Gehler's Phys. Wörterb., 2. Autl., IX. Band, 3. Abtheilung, S. 926 ff. - [217] Folie, Existence et grandeur de la précession et de la nutation diurne, Bruxelles 1882. [218] Gehler's Phys. Wörterb., 2. Aufl., IX. Band, 3. Abtheilung, S. 2144. [219] Israel, Abriss der mathematischen Geographie, Wiesbaden 1882. S. 6. [220] Bradley, A letter to the Rt. Hon. George Earl of Macclesfield concerning an apparent motion observed in some of the fixed stars, Miscellaneous works and correspondence, published by Rigaud, Oxford 1832. S. 17 ff. - [221] D'Alembert, Untersuchungen etc. S. 42 ff. S. 56 ff. - [222] Gehler's Phys. Wörterb., 2. Aufl., IX. Band, 3. Abtheilung, S. 2164 ff. - [223] C. F. A. Peters, Numerus constans nutationis ex ascensionibus rectis stellae polaris deductus, Petropoli 1842. [224] v. Lindenau, Versuch einer neuen Bestimmung der Nutations- und Aberrationsconstanten, Berlin 1842. - [225] Lundahl, De numeris nutationis et aberrationis constantibus atque de parallaxi annua stellae polaris, Helsingfors 1842. - [226] Nyrén, Bestimmung der Nutation der Erdaxe, St. Petersburg 1872. [227] Tägert, Ueber die Einwirkung der Ebbe und Fluth auf die Präcession und Nutation, sowie auf die Drehungsgeschwindigkeit der Erde, Siegen 1880. [228] Mädler-Klinkerfues, Pop. Astr. S. 113. - [229] C. Neumann, Ueber die Principien der Galilei-Newton'schen Theorie, Leipzig 1870. S. 15. - [230] R. Wolf, Gesch. d. Astr. S. 731. - [231] Lambert, Cosmologische Briefe über die Einrichtung des Weltbaues, Augsburg 1761. S. 126. - [232] Ibid. S. 134. - [233] W. Herschel, On the proper motion of the sun and solar system, Phil. Transact., Vol.LXXV. S. $247 \mathrm{ff}$. - [234] P. Prévost, Mémoire sur le mouvement progressif du centre de gravité de tout le système solaire, Bode's astronom. Jahrbuch für 1786. [235] R. Wolf, Biogr. z. Kulturgesch. d. Schweiz, 4. Cyklus, Zürich 1862. S. 180. - [236] Argelander, Ueber die eigene Bewegung des Sonnensystemes, St. Petersburg 1837. - [237] Mädler-Klinkerfues, Pop. Astr. S. 439. - [238] Doppler, Beiträge zur Fixsternkunde, Prag 1847. - [239] Newcomb, Populäre Astronomie, deutsch von Engelmann, Leipzig 1881. S. 530.

\section{Kapitel V.}

\section{Die Graphik im Dienste der physischen Erdkunde.}

§. 1. Kartenprojektion. Nachdem die Erde einmal als rund anerkannt war, handelte es sich darum, entweder ihre Gesammtoberfläche oder doch Theile derselben in einer Ebene darzustellen. Diess war die Aufgabe der Kartenprojektionslehre, deren Anfänge wir bis in ziemlich entlegene Zeiten zurückverfolgen können. Gehörte die Kugel zu jenen Flächen, welche die höhere Geometrie als d evelop pa bel bezeichnet, welche somit auf einer Ebene ohne Riss oder Falte ausgebreitet werden können, so würde die Herstellung von Erdbildern keine besonderen Schwierigkeiten bieten. Da diess jedoch nicht der Fall, da vielmehr die Kugelfläche mit der Ebene unter gar keinen Umständen zur vollständigen Deckung zu bringen ist, so können $\mathrm{Ab}$ weichungen zwischen Original und Kopie niemals gänzlich vermieden werden, und der Kartenzeichner hat lediglich darauf zu sehen, dass die Fehler, welche er begeht, gegenüber dem von ihm augenblicklich angestrebten Zwecke möglichst wenig in's Gewicht fallen. Es sei gleich hier bemerkt, dass die Kugelgestalt der Erde, obwohl sie nach den Ergebnissen von Kap. I und III keine reine ist, gleichwohl von 
der theoretischen Kartographie unbedenklich festgehalten werden darf, indem Wiechel fand, dass für einen Maassstab $>1: 50000000$ $<1: 100000$ die Abplattung solange ausser Beachtung bleiben darf, als die Maschenweite des Gradnetzes eine Breite von $5 \mathrm{~cm}$ nicht übersteigt [1]. Noch weniger ist natürlich an die geoidischen Anomalieen zu denken.

Die Geschichte unserer Disciplin beginnt*) keinesfalls vor Thales, der jedoch nicht sowohl die Erd- als vielmehr die Himmelskugel zur Gewinnung brauchbarer Sonnenuhren abzubilden versucht haben soll. Von ihm mögen wohl die Milesier A naximander, Hekatäos und Aristagoras direkt und indirekt angeregt gewesen sein, deren letzterer um $500 \mathrm{v}$. Chr. eine eherne Tafel in Sparta vorzeigte, in welche die Umrisslinien des ganzen Erdkreises eingegraben waren [6]. Später scheint dann Dikäarch als Kartograph aufgetreten zu sein, doch fehlte seinen rohen Konceptionen nach B e rger's Untersuchungen [7] noch ganz die mathematische Direktive; Eratosthenes führte mittelst der von Agathemeros ausdrücklich als „trapezförmig“ bezeichneten Abbildungsart das erste Gradnetz ein: die Parallelkreise wurden gerade Linien, die Meridiane ebenfalls, während aber erstere ihren Parallelismus beibehielten, konvergirten letztere nach oben, so zwar, dass der durch Syene hindurchgehende Meridian auf der Parallelenschaar senkrecht stand [8]. Da es sich nur um die rĩ oixoouśvin handelte, reichte dieses einfache Schema aus. Hipparch erfand zu astronomischen Zwecken die stereographische Projektion, welche diesen ihren Namen aber erst siebzehnhưndert Jahre später von dem Jesuiten Aquilonius erhielt, Marinus der Tyrier die Plattkarten, und nach Art dieser letzteren fertigte $\mathrm{P}$ tolemäus seinen berühmten und für das ganze Mittelalter maassgebend gewordenen Atlas an, dessen technische Ausführung er einem gewissen Ag a thodämon übertrug [9]. Ausser diesen geometrisch angelegten und nach den Weltgegenden orientirten**) Karten gab es auch geographische Faustzeichnungen, die Itin erarien oder Strassenkarten, welche die Krümmung der Erdoberfläche völlig ignorirten: unter ihnen ragt als ein historisch höchst merkwürdiges Denkmal die sogenannte tabula Peutingeriana hervor***).

*) Historische Abrisse der Projektionslehre hat man von D'A vezac [2], von Breusing [3] und von dem Verf. dieses [4]; eine mehr populäre Uebersicht über die wichtigsten Momente gab Le Monnier [5].

**) Die heute Jedermann in Fleisch und Blut übergegangene Orientirung geographischer Karten, bei welcher Norden oben, Süden unten sich befindet, ist erst verhältnissmässig neuen Datums. Wir haben über diese bisher zu wenig beachtete Frage einige, zunächst allerdings nur fragmentarische Notizen gesammelt [10], aus welchen erhellt, dass die orientalischen Völker - vermuthlich im Zusammenhange mit der ihnen eigenthümlichen Weise des Schreibens und Zählens von rechts nach links - gerade die der unseren entgegengesetzte Anordnung für die naturgemässe hielten. Die von Marinelli [11] reproducirte Weltkarte von Alby aus dem VIII. hat ebenso wie die einem angelsächsischen PriscianusKodex entstammende Karte aus dem X. Jahrhundert gar Osten oben, Westen unten.

***) Dieselbe stellt nicht etwa ein einheitliches Werk vor, vielmehr ist sie wahrscheinlich im Laufe der Zeiten aus sehr verschiedenartigen Bestandtheilen zusammengewachsen. Der äusserste Osten z. B. ist, wie neuerdings Tomaschek [12] wahrscheinlich zu machen gewusst hat, einem alten Vorbilde aus der Periode der Diadochen entnommen und verhältnissmässig gut ausgeführt. 
Solche Diagramme hatte vermuthlich Propertius bei seinen Worten (Eleg. IV)

${ }_{n}$ Cogor et e tabula pictos ediscere mundos,

Ventus in Italiam qui bene vela ferat"

im Auge, und von wenig anderem Kaliber mag wohl auch das Kartenkabinet des Kaisers Augustus gewesen sein. Immerhin hat Philippi es wahrscheinlich zu machen gewusst, dass die berühmte „Weltkarte" des Agrippa wenigstens nicht völlig der Projektion entbehrte [13].

Die Kartographie des patristischen Zeitalters verlor das Wesen einer mathematischen Uebertragung gekrümmter auf ebene Flächen vollständig aus den Augen, höchstens bei der Weltkarte des Anonymus von Ravenna ist insoferne noch eine Spur dieses Bewusstseins nachzuweisen, als die Gelehrten darüber im Unklaren sind, ob dieselbe kreisrund oder rechteckig gewesen sei [14]. Man weiss Marinelli's Mittheilungen zufolge [15] von etwa einem Dutzend Weltkarten aus dem früheren Mittelalter, doch sind dieselben fast sämmtlich verloren gegangen. Namentlich muss diess bedauert werden von den Kunstwerken, welche sich im Besitze Karl's des Grossen befanden, von dessen Enkel Ludwig aber vernichtet wurden. "Inter ceteros thesauros, ${ }^{,}$ so berichtet der Biograph Einhard [16], ac pecunias tres mensas argenteas et auream unam praecipuae magnitudinis et ponderis esse constat ... Tertiam, quae ceteris et operis pulchritudine et ponderis gravitate multum excellit, quae ex tribus orbibus connexa, totius mundi descriptionem subtili ac minuta figuratione complectitur, et auream illam, quae quarta esse dicta est, inter heredes suos atque in elemosinam di. videndae partis augmentum esse constituit. " Wahrscheinlich hat man es hier mit sogenannten Radkarten zu thun, wie sie im frühesten Mittelalter fast ausschliesslich üblich waren [17]. Auch die Araber brachten, was bei ihrem Sinn für das Mathematische Wunder nehmen darf, keinen rechten Fortschritt zuwege, wie Peschel [18] des Näheren dargelegt hat; die Weltbilder Edrisi's und Istachri's bleiben bedeutend hinter Dem zurück, was die späteren Alexandriner schon geleistet hatten; ja eine von D ewulf [19] veröffentlichte alt-arabische Karte der Nilländer ist um nichts besser, als ein rohes Croquis der Gegenwart.

Erst die Bedürfnisse der mehr und mehr aufstrebenden Nautik riefen einen Fortschritt zum Besseren hervor. Th. Fischer hat in einer höchst lesenswerthen Studie [20] den Nachweis geführt, dass die Seekarten den Italienern ihren Ursprung verdanken, und dass, wie die Karte des Luxoro zeigt, schon um 1300 n. Ghr. die Eintragung der Küstenlinien in ein wirkliches Netz mit grosser Genauigkeit erfolgte. Man nennt diese Abbildungen $\mathrm{K}$ ompasskarten, welche nicht ganz treffende Bezeichnung zu mancherlei Missverständnissen führte; Breusing hat diese letzteren aufgeklärt und den Charakter dieses Kartentypus vollkommen klargestellt [21]. Das einer Kompasskarte nachträglich zu unterlegende Gradnetz ist durchaus nicht etwa, wie man früher wohl annahm, ein cylindrisches, sondern vielmehr ein konisches [22]. Namentlich in Spanien erhielt sich die mit der Erweiterung des geographischen Horizontes immer unverlässlicher werdende Kunst des Segelns nach dem blossen Kompassstrich länger als anderswo, ja selbst im vorigen Jahrhundert bedienten sich die Piloten des mittel- 
ländischen Meeres noch ungraduirter Karten. Die Portugiesen waren, wie wir besonders aus einer von Gelcich citirten Schrift des Hernan Colon ersehen [23], ihren östlichen Nachbarn schon im Laufe des XVI. Jahrhunderts bedeutend vorausgekommen.

Die ersten selbstständigen Kartographen der Neuzeit waren die Deutschen Stabius und Werner und der Lothringer Walther Lud, ihnen schlossen sich Oronce Finée, Sebastian Münster, Postellus, die beiden Apian und Andere an. Breusing hält es für wahrscheinlich [24], dass Seitens der Nautiker dann wieder auf die Plattkartenprojektion des Marinus zurückgegriffen wurde, als sich Prinz Heinrich der Seefahrer von der Nothwendigkeit steter Breitenbestimmungen überzeugt hatte. Man begann, die ptolemäische Kartensammlung wieder neu aufzulegen; bis 1500 waren schon sechs neue Auflagen derselben erschienen [25]. Breusing ist in der Lage, nicht weniger als 61 Kartenzeichner deutscher Abstammung namhaft zu machen, die alle vor 1575 lebten [26]. Eine förmliche Revolution brachte Gerhard Mercator hervor, der namentlich in Holland Schule-bildend wirkte [27]; die Namen Hondius, Ortelius, Janssonius können diess bezeugen. Später ragt Homann unter den Verfertigern von Karten und Atlanten hervor [28]; seine Werke behaupteten sich so lange, bis neuerdings wieder jener Umschwung eintrat, dessen Signatur die Verbindung einer hoch entwickelten Technik mit geometrischer Strenge bildet. Die Sitte, der Karte einen Maassstab zur Abschätzung von Distanzen beizugeben, rührt nach Steinhauser [29] von Peter Descelliers (1553) her*).

Neuere Mathematiker haben sich vielfach damit beschäftigt, ganz allgemein die Grundsätze zu fixiren, denen eine gute Karte entsprechen soll, und zugleich die Grösse der - wie wir oben sahen, unvermeidlichen - Fehler zu bestimmen, welche bei jeder Projektionsart sich einstellen. In seiner uns bereits bekannten Abhandlung erörtert Wiechel sorgfältig alle einschlägigen Umstände; es ist, abgesehen von besonderen Zwecken, darauf zu halten, dass die Mitte der Karte völlig fehlerlos abgebildet sei, dass die geographischen Koordinaten nach einheitlichem Maassstabe abgegriffen werden können, dass endlich der Kartenmittelpunkt womöglich auch Berührungspunkt der Kugel mit der das Bild enthaltenden Tangentialebene werde. Wiechel bringt die wichtigeren Eigenschaften eines guten Kartenbildes mit dem Gewichte 2, die minder wichtigen mit dem Gewichte 1 in Anschlag und sieht sich so in der Lage, die Vorzüge der verschiedenen Me-

*) Es wäre eine historische Ungerechtigkeit, gänzlich von chinesischer Kartographie zu schweigen, über welche wir Himly [30] interessante Aufschlüsse verdanken. Eine "Karte des Reiches" entstand bereits um 1311-1320 n. Chr. unter der Aegide" des Mongolenkaisers Wu-Tsung. Dieselbe wurde während der Regierung der Ming-Dynastie umgeändert und $1799 \mathrm{neu}$ herausgegeben. Die Projektion ist roh, aber doch vorhanden; jede Provinz ward in ein Rechteck von ungleichen Seiten hineingezwängt, die aber doch jeweils Distanzen von 100 li entsprechen sollen; der Maassstab der Karte ist also nicht der gleiche, wenn man von West nach Ost oder von Süd nach Nord fortschreitet. Auch giebt es alte Karten für den Seeverkehr nebst Segelanweisungen, die auf den chinesischen Kompass Bedacht nehmen und stets vorschreiben, wie viel Striche - im Chinesischen heisst es "Buchstaben" - zu nehmen sind, wenn ein bestimmtes Ziel erreicht werden soll. 
thoden tabellarisch gegen einander abwägen zu können. Insbesondere kommen in Frage die Principien der Konformität und der A equivalenz; bei ersterer wird gefordert, dass Original und Kopie einander in den kleinsten Theilen ähnlich sein sollen, bei letzterer, dass zwei gleichgrosse Flächentheile der Kugel auch wieder durch gleiche ebene Flächenstücke wiedergegeben werden. Den Kartenfehler, den als mathematischen Begriff zuerst $\mathrm{H}$. W e ber [31] der Diskussion unterstellt hat, definirt Eisenlohr [32] in folgender Weise. Man lege durch alle Punkte der Karte, für welche der Maassstab der nämliche ist, die is ometrischen Kurven; jene kürzesten Linien, welche auf diesen senkrecht standen, verwandeln sich in Gerade. Sie erleiden gar keine Verzerrung, wohl aber unterliegen solcher alle übrigen, und am meisten werden betroffen dịe den isometrischen Linien parallel verlaufenden. Dieser Verzerrungsgrad kann sonach als ein passendes Maass für den Kartenfehler gelten; ist derselbe für einen beliebig kleinen Theil der Karte bekannt, so wird ein Ausdruck für die Grösse des Gesammtfehlers nach dem Verfahren der kleinsten Quadrate hergeleitet. Die Karte erscheint dann mit dem geringsten Kartenfehler behaftet, wenn der Begrenzungslinie selbst der Charakter der Isometrie eignet.

Ein in theoretischer Hinsicht wichtiges Lehrbuch der Kartenprojektionslehre ist dasjenige von Tis s ot [33], welches grundsätzlich nur von dem einen Lehrsatze Gebrauch macht, dass einem Systeme orthogonaler Kurvenschaaren der einen Fläche im Allgemeinen nur ein einziges ebensolches System auf der anderen Fläche entspricht. Ein alle bekannten Abbildungsweisen in ihrem gegenseitigen Verhältniss charakterisirendes Handbuch hat der Italiener Fiorini [34] geschrieben. In deutscher Sprache behandeln unseren Gegenstand Möllinger [35], Steinhauser [36], Coordes [37] und Wenz [38], ersterer mehr an ein mathematisches, letztere an das grössere Publikum sich wendend. Als ein in mehrfacher Beziehung bahnbrechendes

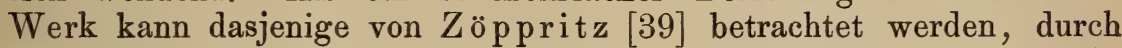
welches der Kredit, in welchem bisher manche der üblichen Konstruktionsweisen steht, bedenklich erschüttert wird.

§. 2. Die gebräuchlichen Projektionsmethoden. In diesem Paragraphen sollen die wichtigeren unter den gegenwärtig in der praktischen Kartographie verwendeten Abbildungsweisen kurz beschrieben werden. Absolute Vollständigkeit wird nicht angestrebt; wer tiefer gehen will, nehme eines der oben citirten Lehrbücher oder das für den vorliegenden Fall ebenfalls sehr werthvolle Kompendium von Gretschel [40] zur Hand. Naturgemäss werden wir den Zwecken der physikalischen Geographie bei unserer Uebersicht besonders Rechnung tragen.

a) Orthographische Projektion. Ein in unendlicher Entfernung befindliches Auge betrachtet die Erdkugel, von welcher es somit gerade die Hälfte sieht. Jene Gegenden, die in der Nähe des Punktes liegen, in welchem eine vom Centrum nach dem Augpunkte gezogene Gerade die Kugelfläche schneidet, werden sehr genau, die um $90^{\circ}$ von jenem Punkte abstehenden Theile höchst ungenau abgebildet. Man bedient sich deshalb dieser Projektion nicht eben gerne, nur für solche Him- 
melskörper, wie den Mond, die sich von selbst uns orthographisch darstellen, empfiehlt sich dieselbe. Die den Uebergang vom Original zum Bild und umgekehrt vermittelnden Formeln hat Thoulet hergeleitet [41].

b) Stereographische Projektion. Hier befindet sich das Auge in der Kugelfläche selber, während zur Bildebene entweder die im Antipodenpunkt des Augpunktes an die Kugel gelegte Berührungsebene oder irgend eine andere ihr parallele Ebene genommen wird. Man unterscheidet für gewöhnlich eine stereographische Polar- und Aequatorialprojektion, je nachdem nämlich der Augpunkt in einen der Erdpole oder aber in den Umfang des Gleichers fällt. Indessen können sich auch andere Lagen als momentan vortheilhaft erweisen, wie denn z. B. der englische Oberst James mittelst der nach ihm benannten Abart der stereographischen Projektion eine Weltkarte herzustellen vermochte, welche sämmtliche Erdtheile, das einzige Australien ausgenommen, umfasste [42]. Was unserer Projektion zum entschiedenen Vortheil gereicht, ist der Umstand, dass sie beliebig grosse Theile der Kugelfläche*) zu verzeichnen gestattet; hierauf sich stützend konstruirten im Alterthum und Mittelalter die Verfertiger von Planisphären (Analemmen) und Astrolabien gewöhnlich stereographische Bilder [43]. Allerdings wächst mit dieser Ausdehnung auch der Randfehler; einer von Schumann [44] angegebenen Formel gemäss erscheinen die äussersten Randstücke viermal so gross, als die centralen Partieen. Zwei schöne geometrische Eigenschaften zeichnen die stereographische Projektion aus: Jeder Kreis der Kugel transformirt sich wieder in einen Kreis, und je zwei Kurven des Originales durchschneiden sich unter dem nämlichen Winkel, unter welchem sich auch ihre Bildkurven durchschneiden. Wegen einlässlicherer theoretischer Begründung dieser und anderer Sätze vergleiche man die Werke von v. Bauernfeind [45] und Reusch [46]. Steinhauser bemerkt, dass die stereographische Projektion auch zur Darstellung der Land- und Wasserhälfte unserer Erde sehr geeignet sei [47]; der Augpunkt erhält dann eine Lage in $50^{\circ}$ geogr. Breite.

c) Gnomonische Projektion. Verlegt man das betrachtende Auge in den Mittelpunkt der Kugel und bildet deren Oberfläche auf einer beliebigen Tangentialebene ab, so hat man die centrale oder gnomonische Projektion, welche nach D'A vezac's Meinung (s. o.) [48] vielleicht schon Thales kannte und anwendete. Nähere Nachweisungen sowohl über die Geschichte dieser Projektion, als auch über deren mathematischen Charakter finden sich in einer Abhandlung des Verfassers [49]. Die erste selbstständige Schrift darüber hat den Jesuiten Borgondio zum Autor und stammt aus dem Anfange des vorigen Jahrhunderts [50]. Später schritt man dazu, der Kugel einen regulären

*) Völlig unerreichbar ist nur der dem Standpunkt des Zeichners diametral gegenüberliegende Punkt. Diese Thatsache ist von principieller mathematischer Bedeutung. Die vulgäre Anschauung vindicirt ebenso, wie die sogenannte nichteuklidische Geometrie, der geraden Linie zwei unendlich entfernte Punkte; in der euklidischen Geometrie rücken beide zu einem einzigen uneigentlichen Punkt zusammen. Nach den Anschauungen der modernen Funktionentheorie, welche die Ebene nur als stereographisches Bild der Kugel auffasst, besitzt auch die Ebene nur Einen unzugänglichen Punkt. 
Körper umzubeschreiben und auf dessen Seitenflächen je einen aliquoten Theil der Kugelfläche zu übertragen; so wählte Reichard (1803) das Hexaeder, Élie de Beaumont (1863) das Dodekaeder [51]. Letzterer suchte dabei gewissen geologischen Anschauungen Boden zu verschaffen, welche er sich über das die Erde angeblich überdeckende pentagonale Gebirgsnetz gebildet hatte, und aus einem ganz ähnlichen Grunde tritt neuerdings Beguyer de Chancourtois für die gnomonische Projektion ein; er will ausser dieser nur noch die stereographische zur Darstellung einer vollen Halbkugel zulassen. Auch für ihn ist die Ansicht maassgebend, dass Gebirgsketten auf einen längs eines Hauptkreises klaffenden Sprung der Erdrinde hindeuten, und verhielte sich dieses wirklich so, dann würde allerdings die vorliegende Abbildungsmanier eine sehr hohe orographische Bedeutung erlangen. Wir theilen freilich diese Meinung nicht, geben aber gerne zu, dass unter dem rein geometrischen Gesichtspunkte Chancourtois' Abbildung der Erdoberfläche auf den acht Flächen eines regelmässigen Oktaeders sehr schöne Bilder liefert [52]. Am meisten empfiehlt der Genannte die stete Verbindung „de trois séries de cartes imbriquées", so besonders der dodekaedrischen, ikosaedrischen und triakontaedrischen Projektion [53]. Wer sich über die Ziele der von Chancourtois beabsichtigten Reform unterrichten will, muss seine dem geologischen Kongress zu Bologna unterbreiteten Mittheilungen nachsehen; dort hebt jener die Wichtigkeit des Studiums ,des faits d'alignement" besonders hervor und erwähnt u. a. als eines in vulkanistischer Beziehung sehr bemerkenswerthen Umstandes, ein einziger Blick auf eine in seinem Sinne hergestellte Karte belehre darüber, dass eine durch den Vesuvkrater und durch die Insel Santorin gezogene Gerade der Axenrichtung der Pyrenäen parallel verlaufe [54]. Ein hübsches gnomonisches Kärtchen der Südpolargegenden giebt Krümmel [55], um die Unrichtigkeit gewisser Eintheilungen der dortigen Meeresräume durch diese hier besonders passende centrale Abbildung der grössten Kreise zu widerlegen. - In neuerer Zeit beginnen die Seefahrer das Segeln auf dem Hauptkreise, als auf der kürzesten Verbindungslinie zweier Erdorte, sehr zu bevorzugen und bedürfen hiezu der sogenannten orthodromischen Seekarten. Hilleret [56] und Rayet [57] gaben Vorschriften zur Anfertigung solcher Karten; wir werden sofort von einer ganz anderen Seite her auf dieselben zurückzukommen haben.

d) Mercator'sche Projektion. Um die Mitte des XVI. Säculums stellten sich die Unvollkommenheiten der gewöhnlichen Kompasskarten (s. o. §. 1) so deutlich heraus, dass die Nautiker die Nothwendigkeit einer Verbesserung nicht mehr verkennen konnten. Gerhard Mercator (1512-1594) versprach in einem denkwürdigen Schreiben, welches er am 23. Februar 1546 an den Kardinal Granvella richtete, und dessen Uebersetzung Breusing in seine bekannte Lebensbeschreibung des grossen Kosmographen aufgenommen hat [58], er werde eine Anzahl von seemännischen Nothständen seiner Zahl näher prüfen und ihnen Abhülfe schaffen, und er hat Wort gehalten. Anno 1569 ward von ihm der Stich seiner grossen nautischen Weltkarte vollendet [59]. Die Meridiane werden in der nach Mercator benannten Projektion durch aequidistante Gerade, die Parallelkreise ebenfalls durch Gerade und zwar durch solche dargestellt, die auf der erstgenannten 
Schaar senkrecht stehen. Dagegen ist jetzt die Gleichabständigkeit der Parallelen in Wegfall gekommen; der Abstand zweier solcher Linien wächst proportional der trigonometrischen Sekante der geographischen Breite, und da sec $90^{\circ}=\frac{1}{0}=\infty$ ist, so liegt Nord- wie

Südpol in unendlicher Entfernung*). Generalkarten der Erde können sonach im Sinne Mercator's sehr gut erstellt werden, sobald man sich begnügt, nur die niedrigen Breiten gut, die höheren dagegen sehr weit auseinandergezogen zu erhalten. Die Abbildung ist übrigens, wovon ihr Begründer natürlich noch keine Ahnung haben konnte, eine konforme. Was ihren besonderen Werth für den Schiffer anlangt, so ist Folgendes zu berücksichtigen. Segelt ein Schiff unaufhörlich nach dem nämlichen Kompassstriche, so bewegt es sich auf einer doppelt gekrümmten sphärischen Kurve, welche sämmtliche Meridiane unter konstantem Winkel durchschneidet und den Pol zum asymptotischen Punkt hat; sie erreicht denselben also niemals, legt sich vielmehr in unzähligen Windungen enger und enger um denselben herum. Nennt man $\alpha$ diesen Schnittwinkel, $\sigma$ einen Bogen der Loxodrome - diesen Namen führt die Kurve gewöhnlich - , $\lambda, \beta$ und B die Länge, Breite und vergrösserte Breite des Anfangspunktes von $\sigma$, so gelten die folgenden Relationen:

$$
\begin{gathered}
\operatorname{tg} \alpha=\frac{\cos \beta d \lambda}{d \beta}, \cos \alpha=\frac{d \beta}{d \sigma}, \\
B=\int_{0}^{\beta} \frac{d \beta}{\cos \beta}=\log \operatorname{tg}\left(45^{\circ}+\frac{1}{2} \beta\right)=\log \frac{1+\sin \beta}{\cos \beta} \\
=-\log \frac{\cos \beta}{1+\sin \beta}=\frac{1}{2} \log \frac{1+\sin \beta}{1-\sin \beta} .
\end{gathered}
$$

Mit Hülfe dieser Formeln lässt sich, wie zumal sehr hübsch in einer Schrift v. Friesach's [61] dargethan ist, eine elementare Theorie der loxodromischen Figuren begründen**). Natürlich aber wäre für den Praktiker damit wenig gewonnen. Nun bringt es aber Mercator's Projektionsverfahren ganz von selbst mit sich, dass sich die Loxodrome in eine gerade Linie verwandelt; es ergiebt sich diess einfach aus dem geometrischen Satze über die Wechselwinkel an Parallelen. Jetzt ist also wirklich erreicht, was von den Verfertigern der mittelalterlichen

*) Man hüte sich, diese in gewissem Sinne allerdings als cylindrisch zu bezeichnende Projektion mit der gewöhnlichen cylindrischen oder PattkartenProjektion zu verwechseln, welch' letztere, wie erwähnt, von Marinus eingeführt und sogar von D. Cassini unter einem anderen Namen empfohlen wurde [60]. Auch die perspektivische Methode, welche vom Kugelcentrum aus jeden Punkt auf den Mantel eines umbeschriebenen Cylinders verlegt und diesen Mantel nachher in eine Ebene aufrollen lässt, eine Methode also, welche gewissermassen eine Erweiterung der gnomonischen Abbildung repräsentirt, ist keineswegs mit jener Mercator's identisch, obschon auch bei ihr die Pole unendlich weit hinausrücken. Eine geometrische Betrachtung zeigt, dass der Abstand zweier den Breiten $\beta_{1}$ und $\beta_{2}$ entsprechenden Parallelkreise in diesem Falle durch Const. $\chi\left(\operatorname{tang} \beta_{2}-\operatorname{tang} \beta_{1}\right)$ ausgedrückt wird, und da ja auch tang $90^{\circ}=\infty$ wird, so ist das Schlussergebniss allerdings ein ganz analoges.

**) Eine ausführliche "Geschichte der loxodromischen Kurve" ist vom Verf. schon früher veröffentlicht worden [62]. 
Kompasskarten auf einem unrichtigen Wege angestrebt wurde; die Distanzmessung auf der See lässt sich ohne Fehler durch blosse An-

Fig. 53.

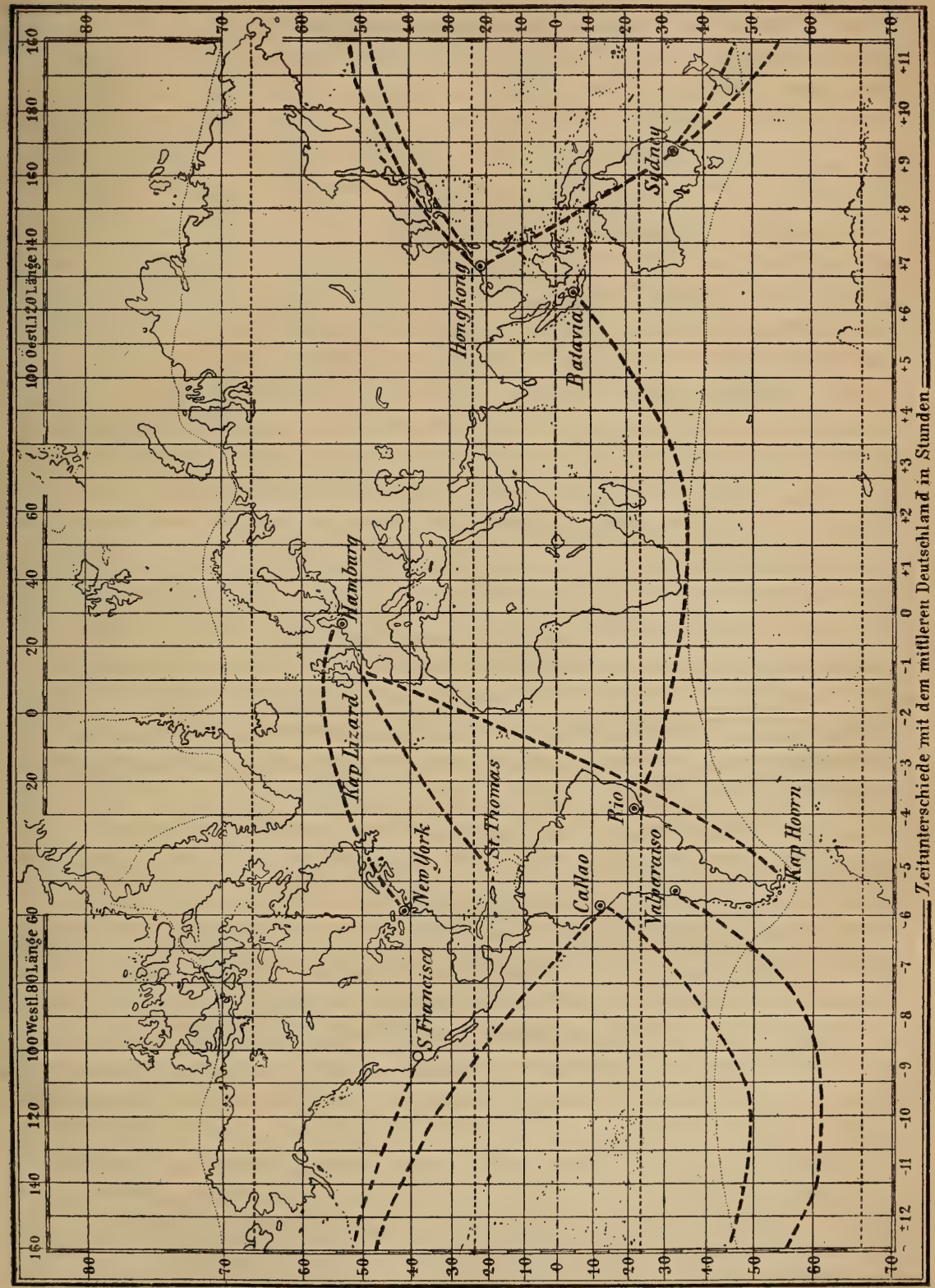

wendung von Lineal und Cirkel bewerkstelligen. - So lange die Schiffahrt eine rein loxodromische war, befriedigten die „Seekarten mit wachsenden Breiten", wie man sich wohl auch ausdrückte, jedes 
Bedürfniss. Nachdem aber, wie erwähnt, die vervollkommneten Mittel der Neuzeit das Segeln nach der kürzesten Distanz wieder wünschenswerth und möglich erscheinen liessen, musste es darauf ankommen, die üblichen Mercator'schen Seekarten hiefür zu adaptiren, sei es, dass man, wie diess v. Friesach [63] und Gelcich [64] thaten, Tabellen berechnete, sei es, dass man mit Albini [65] und Asmus [66] graphische Mittel zur Eintragung grösster Kreise in die MercatorKarten an die Hand gab. Fig. 53, die nach der schönen Karte der Seewege von Schück [67] gearbeitet ist, stellt uns neun kürzeste Linien (zwischen Hongkong und Sydney, Sydney und Callao, Sydney und Valparaiso, Hongkong und Callao, Hongkong und San Francisco, Rio de Janeiro und Batavia, Kap Hoorn und Kap Lizard, St. Thomas und Kap Lizard, New-York und Hamburg) vor Augen. Man ersieht hieraus sehr deutlich, dass ein Hauptkreisbogen um so weniger von einer Geraden abweicht, je mehr sich seine Richtung der meridionalen nähert, während ein Bogen, der zwei auf demselben Parallel gelegene Orte verbindet, die stärkste Krümmung aufweist.

e) Konische Projektionen. Der allgemeine Gedanke, welcher dieser Manier zu Grunde liegt, ist der, dass der abzubildenden Kugelzone, die natürlich auch bis zur ganzen Kugel anwachsen kann, ein Kegelmantel umbeschrieben wird, den man alsdann abwickelt. Ptolemäus hat zuerst diesen Gedanken realisirt, auch Mercator ist auf ihn zurückgekommen [68]; Delisle und Murdoch haben lediglich Mercator's Idee etwas weiter ausgebildet. Für den Fall, dass eine grössere Genauigkeit angestrebt wird, vermehrt man die Zahl der abgestumpften Kegel, welche sich um das abzubildende Stück der Kugelfläche herumlegen, und erhält so die polykonische Projektion, welche von Hilgard [69] bei der nordamerikanischen Küstenvermessung angewandt wurde; auch für die neuen österreichischen Provinzialkarten war nach Frischauf [70] ein ähnliches System maassgebend. Eine Abart, nämlich die uns bereits bekannte cylindrische Projektion, erhält man, wenn man den umschliessenden Kegel in einen Kreiscylinder degeneriren lässt. Soll die konische Abbildung sich auf die ganze Erde erstrecken, so gelangt man, wie Steinhauser [71] zeigt, zu den sternförmigen Projektionen.

f) Halbsternprojektionen. An sich würde es ja allerdings möglich sein, die Mantelfäche des Bildkegels bis zum Südpole verlängert zu denken, und Lambert's isosphärische Kegelprojektion, Braun's stereographische Kegelprojektion beruhen z. B. auf einer solchen Anordnung. Dem Princip der Aehnlichkeit zwischen Original und Kopie wird jedoch dadurch nur schlecht gedient. Man nimmt also lieber dem Südpol (eventuell dem Nordpol) seine Punkt-Eigenschaft, rollt die Südhälfte der Erdkugel in Streifen auf und sucht diese Streifen, die natürlich keinen weiteren Zusammenhang mehr haben, so zu legen, dass in jeden derselben ein ungetheilter Erdtheil zu liegen kommt. "Es giebt, ${ }^{\text {" }}$ sagt Steinhauser [72], „drei solche Projektionen, die von Müller (1807), einer Kreuzblüthe mit vier Blättern vergleichbar, die sternförmige Projektion von Jäger, resp. Petermann mit acht und die gleichartige von Herm. Berghaus mit fünf strahlenartigen Ansätzen." Ferner ist noch zu erwähnen die von A rnd erdachte und von Gerster [73] beschriebene Halbsternprojektion, welche auch bei Dar- 
stellung der nördlichen Hemisphäre darin die übliche konische Abbildung ändert, dass bei ihr der Mantel des Bildkegels die Erdkugel nicht berührt, sondern in zwei geeignet zu wählenden Parallelkreisen durchschneidet. Steinhauser hat an jener Methode das auszusetzen [74], dass die bessere Darstellung der Mittelmeerländer, des inneren Hochasiens und der Union auf Kosten einer unverhältnissmässigen Verbreiterung der Aequatorialgegenden erkauft werde, und bringt deshalb, ohne den ursprünglichen Plan preiszugeben, Abänderungen in Vorschlag.

g) Bonne's Projektion. Bei der gewöhnlichen Kegelprojektion werden die Meridiane konvergirende gerade Linien, die Parallelen koncentrische Kreise. Dadurch werden jedoch letztere von ersteren nicht mehr in dem richtigen Verhältnisse getheilt. Stellt man letzteres her, so hören die Meridiane auf, geradlinig zu sein, sie werden gekrümmt und bilden auch nicht mehr, wie früher, durchgängig rechte Winkel mit den Parallelkreisen. Dieser Nachtheile unerachtet ward bisher diese Projektion des Franzosen Bonne vielfach benützt, und auch Steinhauser [75] glaubt derselben für die Darstellung selbst grösserer Erdräume nicht entrathen zu können.

h) Zenitale Projektionen. Postellus ist [76] der Erfinder dieses Verfahrens, das darauf ausgeht, alle Punkte der Kugel, die von dem als Kartenmitte angenommenen Punkte gleichweit entfernt sind, auch wirklich auf dem Umfange eines Kreises zu vereinigen. Man hat verbesserte Methoden dieser Art von Lorgna, Lambert und Airy („Balance of errors“) [77]; das Vorzüglichste leistet aber zweifellos die neuerdings in der uns bereits bekannten Arbeit von Wiechel angegebene Zenitalprojektion [78].

i) Globularprojektionen. Dieser Name ist jüngst auf eine ziemlich rohe Konstruktionsmanier des Loriti aus Glarus (Glareanus) angegewandt worden [79], obwohl die Bezeichnung selbst erst von dem Engländer Arrowsmith herrührt. Später ward dann Nell [80] bei der Erwägung des Umstandes, dass gleiche Abschnitte von Meridianen und Parallelkreisen durch die meisten Projektionen in sehr ungleiche Stücke umgewandelt $\mathrm{zu}$ werden pflegen, zu dem nachstehend formulirten Probleme geführt: „Es sollen in einem Kreise zwei Systeme von Linien so gezeichnet werden, dass alle Kurven des einen Systemes von jeder Kurve des anderen in proportionale Theile zerlegt werden. Es findet dabei noch die Bedingung statt, dass alle Linien des einen Systemes (Meridiane) durch zwei bestimmte, einander gerade gegenüberliegende Punkte des Kreisumfanges gehen sollen. ${ }^{.}$Da unter dieser Voraussetzung schwer konstruirbare transscendente Linien sich ergeben würden, so hat Debes [81] die Meridiane annähernd durch Kreise ersetzt und damit erst die ganze Methode für die kartographische Praxis verwerthbar gestaltet. Eine von ihm für Supan's yphysische Erdkunde" gezeichnete schöne Uebersichtskarte der Tiefenverhältnisse im Weltmeere besitzt ein nach der Globularprojektion gefertigtes Netz.

k) Aequivalente Projektionen. Eine herzförmige Abbildung der ganzen Erde, welche bereits zu Anfang des XVI. Jahrhunderts der Nürnberger Astronom J. Werner in Aufnahme zu bringen versuchte, besitzt bereits die ihrem Autor freilich verborgen gebliebene Eigenschaft, das Flächenraum-Verhältniss der sphärischen Figuren unverändert 
zu lassen [82]. Weitaus die zweckdienlichste unter den zahlreich vorhandenen äquivalenten Projektionsmethoden ist aber die homalographische, 1805 von Mollweide erfunden, 1857 von Babinet durch dieses Kunstwort bezeichnet [83]. Namentlich die homalographische Polarprojektion zeichnet sich durch ihre Einfachheit aus, die äquatoriale ist verwickelter, weil bei ihr sämmtliche Mittagskreise zu Ellipsen werden. Neuerdings hat Coatpont [84] mittelst eines ganz einfachen geometrischen Transformationsprocesses aus jeder stereographischen Abbildung eines Theiles der Erde eine äquivalente herzuleiten gelehrt.

l) Apian's Projektion. Dieselbe ist nicht sowohl wissenschaftlich, wohl aber historisch sehr beachtenswerth, zu ihrer Zeit war sie sehr beliebt, und u. a. ist auch der von dem Genueser Agnese für Kaiser Karl V. gezeichnete Portulan*) ihr entsprechend gehalten, welchem Wieser [85] eine eigene Monographie gewidmet hat. Eigentlich gab Peter Apian zwei etwas verschiedene Methoden an, deren eine jedoch auf seine eigenen Werke beschränkt blieb. „Beide haben “ nach Breusing [86] - „gemein, dass der mittlere Meridian und der Aequator durch zwei sich rechtwinklig schneidende gerade Linien dargestellt werden. In der einen ist der mittlere Meridian in 18 Theile getheilt, und durch die Theilpunkte sind gerade Linien als Breitenparallele gelegt. Der Aequator ist in 36 Theile, also ebenfalls in Theile zu $10^{\circ}$, getheilt, die aber gegen die Breitegrade um $1 / 3$ verkürzt sind, um die Figur nicht zu sehr auszudehnen, und durch diese Theilpunkte und die Pole sind dann Meridiane gelegt. " Die Erde präsentirt sich in Folge dieser Darstellungsweise, die allerdings viel Willkürlichkeit verräth, in Form eines plattgedrückten Herzens.

m) August's epicykloidische Projektion. Die Epicykloide ist eine transscendente Kurve; sie wird von irgend einem Punkte eines Kreises beschrieben, der auf der konvexen Seite eines anderen Kreises rollt. Eine Kurve dieser Art schickt sich nun, wie F. August fand [87], trefflich als Randkurve für eine die ganze Erde in sich aufnehmende Karte. Die Projektion selbst ist konform; die Erdpole fallen in die Spitzen der Epicykloide. Beachtenswerth erscheint, dass die Karte zwar den in §. 1 skizzirten strengen Forderungen Eisenlohr's nicht völlig genügt und auch nicht genügen kann, weil sich die Pole in ihr befinden, dass aber für einen weit überwiegenden Theil des Ganzen doch immer der Kartenfehler ein Kleinstes wird.

n) Die Quincuncialprojektion Eine Erfindung des Amerikaners Peirce [88]. Mit Hülfe der elliptischen Funktionen wird ein gewöhnliches stereographisches Abbild der Erde so transformirt, dass der Pol in den - wie wir wissen, einzig vorhandenen - unendlich fernen Punkt der Bildebene übergeht. Auf letzterer entstehen unendlich viele Quadrate, deren jedes die ganze Erdoberfläche in sich aufnimmt. Nach Peirce empfiehlt sich sein Verfahren vorzugsweise für meteorologische und magnetische Karten, die Geophysik wäre mithin direkt bei demselben interessirt. Wir lassen diess vorläufig dahingestellt; jedenfalls

*) Portulane nannte man im späteren Mittelalter jene Seekarten, auf welchen die Lage der Häfen mit besonderer Genauigkeit angegeben war. Die ihnen meistentheils beigegebenen Beschreibungen leisteten den Kapitänen einen ähnlichen Dienst, wie diess heute die von den Admiralitäten edirten Segelanweisungen (s. o. §. 1) thun. 
aber eignet sich nach v. Oppolzer [89] die Quincuncialprojektion sehr gut zur Veranschaulichung des Verlaufes centraler Sonnenfinsternisse.

o) Die Gauss'sche Projektion. Gauss war es, der zuerst ganz allgemein die von der dänischen Akademie zur Preisbewerbung ausgeschriebene Aufgabe löste [90]: irgend eine Fläche auf einer anderen Fläche konform abzubilden. Eine spezielle Anwendung hievon bot sich ihm bei Gelegenheit der von ihm selbst geleiteten hannöver'schen Landesvermessung dar; er substituirte dem - als durch Rotation entstanden vorausgesetzten - Erdsphäroid eine Kugel, deren konstantes Krümmungsmaass jenem des Ellipsoides längs eines bestimmten Parallelkreises gleich war, und verwandelte so jedes Problem der sphäroidischen in ein solches der sphärischen Trigonometrie. Die analoge Uebertragung ist unlängst von Craig [91] auch für ein dreiaxiges Ellipsoid durchgeführt worden.

Wir geben uns der Hoffnung hin, dass diese gedrängte Uebersicht über die Methoden der Landkartenprojektion ihren Zweck erreichen werde: den Leser so zu orientiren, dass, wenn ihm beim Studium irgendwelcher geophysikalischer Schriften irgend ein Projektionsverfahren vorkommt, das Verständniss desselben ihm keine Mühe bereite.

§. 3. Chorographie und Terrainzeichnung. Die Chorographie lehrt die graphische Wiedergabe solcher Theile der Erdoberfläche, bei welchen ihrer geringeren Ausdehnung halber von der Berücksichtigung: der Erdrundung abgesehen werden darf. Als erstes Erforderniss guter chorographischer Darstellung erscheint die genaue Vermessung des betreffenden Landstriches, und wenn alsdann der Maassstab gegeben ist, nach welchem die gemessenen Längen - die Winkel bleiben selbstverständlich intakt - auf das Papier übertragen werden sollen, so gilt es weiter, dafür zu sorgen, dass die Vertikalunterschiede der einzelnen Partieen sich möglichst ungezwungen dem Beschauer nach Art und Grösse vor Augen stellen. Diess zu leisten, bleibt der Terrainzeichnung vorbehalten.

Offenen Sinn für diese im Alterthum und Mittelalter kaum gepflegte Disciplin bethätigten zuerst die Geographen und Mathematiker des Reformationszeitalters. Eine geradezu mustergültige Mappirungsarbeit sind die von Philipp Apian (dem Jüngeren) hergestellten "bayrischen Landtafeln", deren Verfertiger die ausgebildetste topographische Kenner- und Künstlerschaft an den Tag legt [92]. Einige Zeit vorher hatte Joachim Rheticus die erste brauchbare Anleitung dazu verfasst, ein Land mittelst Messschnur und Boussole ,in Grund zu legen“, ein den Unterschied zwischen den "tabulae geographicae und den "tabulae chorographicae" scharf betonendes und durchführendes Werkchen, durch dessen Herausgabe sich Hipler [93] den Dank aller Geschichtsfreunde erworben hat. Neues Leben kam in diese für den Fortschritt der wissenschaftlichen Landeskunde so wichtigen Bestrebungen, als der Altdorfer Professor Prätorius [94] den zur Terrainaufnahme hervorragend geeigneten Messtisch erfand, mit dessen Hülfe Schickard [95] seine württembergischen "Landtafeln" zu Stande brachte. Schickard war es auch [96], der das für die Chorographie fundamentale geodätische Problem stellte und löste, welches fälschlich 
den Namen Pothenot's trägt, noch früher aber bereits die Aufmerksamkeit des mit seinen Gradmessungsarbeiten beschäftigten Snellius (Kap. I, \&. 5) auf sich gezogen hatte. Den deutlichsten Einblick in den allmähligen Fortschritt dieses Theiles chorographischer Arbeit gewinnt man, wenn man die geschichtlichen Forschungen von Ruge [97] nnd von R. Wolf [98] zu Rathe zieht, welche beide mit minutiöser Treue die Entwickelung bezüglich des sächsischen und des schweizerischen Landesvermessungswesens schildern.

Wir erfahren durch Ruge, wie politische Kurzsichtigkeit den Plan des älteren Apian, eine genaue Karte des herzoglichen, wie des kurfürstlichen Sachsens anzufertigen, vereitelte, wie dann aber Kurfürst August die Nothwendigkeit einer guten Landestopographie immer mehr erkannte und verschiedene Versuche nach dieser Richtung hin veranlasste. Was Criginger, Magdeburg und Scultetus, die mehr auf ihre eigenen Mittel angewiesen waren, leisteten, erhob sich wenig über das Niveau der Mittelmässigkeit, dagegen kann das Vermessungswerk des Markscheiders Oeder, der ausser Messkette und Magnetnadel auch noch den Quadranten zu Hülfe nehmen durfte und sich staatlich unterstützt sah, als ein Meisterwerk gelten [99]. Auf 96 Blättern des sächsischen Landesarchives sind die einzelnen Theile Sachsens mit solcher Genauigkeit abgebildet, dass man, wenn man die Generalstabskarte daneben hält, wesentliche Abweichungen nirgends herausfindet*). In mancher Hinsicht noch lehrreicher ist das Wolf'sche Werk, weil in ihm von geodätisch-chorographischen Operationen auf durchschnittenem und vielfach unwegsamem Gebiete die Rede ist. Während der Glarner Tschudi um 1530 noch eine äusserst rohe, dem Typus der mittelalterlichen Radkarten nachgebildete Zeichnung der Urkantone (vgl. Fig. 54) in sein Schweizerwerk aufnahm [100],

Fig. 54 .

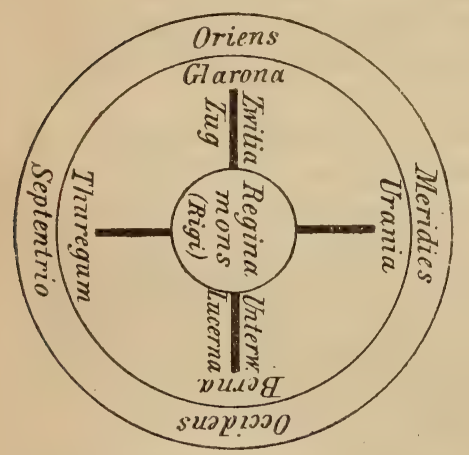
lieferte Conrad Gyger, ein Züricher Maler, bereits 1667 eine Karte seines Heimathlandes, die nach Wolf [101] für jene Zeit auch die weitest gehenden Anforderungen befriedigen musste. Wir verfolgen dann weiter unter der sicheren Leitung unseres Gewährsmannes die Etappen, welche durch die Namen Scheuchzer, Mallet, Tralles, Horner, Eschmann u. s. w. gekennzeichnet sind, und langen so endlich bei G. H. Dufour. [102] an, der, in der trefflichen Schule der napoleonischen Ingenieur-Geographen gebildet, jene allseitig als mustergültig anerkannten Karten des Schweizerlandes schuf.

Eine sehr anziehend geschriebene Uebersicht über die Ausbildung der territorialen Kartographie hat Peschel [103] gegeben. Er feiert mit Recht die Verdienste eines Delisle und D'Anville und datirt

*) Herr Prof. Ruge hat diese Vergleichung dadurch sehr erleichtert, dass er von einzelnen $\mathrm{O}$ e d e r'schen Blättern einen das Original genau wiedergebenden Abzug machen liess. Ein solcher liegt dem Schreiber dieses zur Zeit vor. 
von der Cassini'schen Gradmessung für Frankreich eine neue Epoche geographischen Fortschrittes. In vielen Ländern erscheint die Kartenzeichnung und Chorographie freilich nur als ein Anhängsel der Kriegswissenschaft, und nur selten leitet ausschliesslich das wissenschaftliche Interesse. Besonders nennenswerth erscheinen uns in dieser Beziehung die grossartigen Aufnahmen, welche der Graf Marsigli für sein Donau-Werk [104] in Ungarn und Bosnien durch den Nürnberger Ingenieur J. C. Müller [105] bewerkstelligen liess, sowie Peter Anich's Tyrolische Landesvermessung, die ursprünglich fast ein reines Privatunternehmen war und vom Staate erst dann kräftiger unterstützt wurde, als sich ihr grosser Nutzen nicht mehr verkennen liess [106]. Eine werthvolle Ergänzung zum Peschel'schen Werke bietet v. Sydow's inhaltreiche geschichtliche Skizze [107].

Seit fünfzig Jahren etwa ist, indem man den Messtisch durch den Theodoliten ersetzte, die Nivellirinstrumente durch Anbringung der Wasserwage *) verbesserte und auch zur Ausgleichung kleinerer Dreiecksnetze die rationellen Methoden der Wahrscheinlichkeitsrechnung verwendete, die niedere Geodäsie - diesen Namen führt der uns zur Zeit beschäftigende Theil der Geographie im Gegensatze zu der die Gradmessungsarbeiten betreibenden höheren Geodäsie - eine ganz neue Wissenschaft geworden. Wir können uns selbstverständlich nicht auf dieses für uns transscendentale Gebiet verlieren, verweisen vielmehr, soweit die ältere Literatur in Frage kommt, lediglich auf die Lehrbücher von Puissant [109] und J. J. v. Littrow [110], während der neueste Stand unseres Wissens und Könnens in dem uns bereits bekannten ausgezeichneten Werke v. Bauernfeind's (§. 2) und, das Nivelliren anlangend, in Stampfer's Vorlesungen [111] zum erschöpfenden Ausdruck gelangt. Die Schnellaufnahme oder Tachymetrie wird in jüngster Zeit von verschiedenen Geodäten, wie Porro, Schlesinger, A. Schell u. a., eifrig befürwortet, und wir glauben sie schon aus diesem Grunde, wie auch deswegen nicht unerwähnt lassen zu sollen, weil sie möglicherweise für den reisenden Geographen einige Bedeutung gewinnen könnte, für dessen feldmesserische Bedürfnisse übrigens Kaltbrunner's Rathgeber umfassend Sorge trägt [112]. Ein tachymetrisches Instrument haben Tichy und Starke konstruirt und zur Anwendung empfohlen [113].

Die gleiche Erwägung leitet uns, wenn wir der sogenannten Photogrammetrie auch an dieser Stelle einige Worte widmen. Eine ganz originelle Art, den photographischen Apparat für die Erdphysik auszunützen, ist die von Bessels unter dem Druck der Umstände erdachte [114], die uns in der Lehre von der Gletscherbewegung wieder beschäftigen wird. Stolze theilt mit [115], dass mit Hülfe des von Meydenbauer angegebenen Instrumentes die Konstruktion topo-

*) Die Wasserwage ist allerdings älteren Ursprunges; sie ist spätestens im Jahre 1666 und zwar nicht, wie es gewöhnlich heisst, von Therenot, sondern, nach R. W olf's Untersuchungen [108], von dem Pariser Mechaniker Chapotot erfunden worden. Seine volle Wirksamkeit war aber der geniale Gedanke, welcher den Erfinder geleitet hatte, erst dann zu entfalten im Stande, als der sogenannte Fehlerkalkul sich auszubilden begann, als man somit in die Lage kam, die Ungenauigkeiten, welche beim Aufsetzen oder Anhängen der Libelle mit unterlaufen müssen, ihrem Werthe nach zu schätzen und dadurch zu eliminiren. 
graphischer Karten durch blosse photographische Aufnahmen bewerkstelligt werden könne; es lasse sich mit jenem Apparate ganz ebenso arbeiten, wie früher mit dem Messtische. Stolze fertigte 1875 in Gemeinsamkeit mit Hölzner nach 250 photographischen Platten eine Karte der Ruinen von Persepolis [116]. Von Beautemps-Beaupré und Laussedat [117] stammt der Grundgedanke der Photogrammetrie, den Meydenbauer [118] und Jordan [119] weiter ausgeführt haben. G. Hauck hat einen auf dem geometrischen Principe der trilinearen Verwandtschaft beruhenden Apparat konstruirt, der dazu dient, durch Umfahren des orthogonalen Grund- und Aufrisses irgend eines Gebildes sofort das organisch beschriebene centralperspektivische Bild desselben von einem dritten Schreibstift gezeichnet zu erhalten [120], oder auch aus zwei perspektivischen Aufnahmen unmittelbar den Aufriss herzuleiten [121]. Diese geistreiche Vorrichtung scheint in Verbindung mit der unglaublichen Vervollkommnung der sogenannten Momentanphotographie (durch Obernetter u. A.) der Photogrammetrie eine noch bedeutendere Zukunft zu sichern. G. Fritsch behauptet, dass die Gelatine-Emulsions-Photographie wegen der Charaktertreue, welche die nach diesem Verfahren gefertigten Landschaftsbilder bewähren, sich ganz besonders zur Berücksichtigung für Forschungsreisende eigne [122].

§. 4. Darstellung der Höhenverhältnisse, Isohypsen und Isobathen. Wir können mit Wolkenhauer [123] in den Bestrebungen, auch der dritten Dimension des Raumes kartographisch gerecht zu werden, fünf Perioden unterscheiden, welche allerdings zeitlich nicht strenge getrennt sind, sondern vielfach in einander übergreifen und auch sachlich gewisse gemeinsame Kennzeichen aufweisen.

a) Die perspektivische Abbildung. Den alten Vorschlag Strabon's, die Gebirge graphisch wie die Zähne einer Säge oder eines Kammes darzustellen, einen Vorschlag, den auch sämmtliche ptolemäische Atlanten acceptirten [124], sehen wir seit Anfang des XVI. Jahrhunderts dahin modificirt, dass man von Bergzügen und Einzelbergen eine perspektivische Zeichnung in die Karte aufnimmt. Letztere wird also gewissermassen zum Landschaftsgemälde; zu dem Besten und in rein künstlerischer Beziehung Vollkommensten, was nach diesem naiven Verfahren geschaffen ward, gehören Philipp Apian's Bilder des bayrischen Hochgebirges [125] und Delkeskamp's aus der Vogelperspektive gezeichnete Ansichten der Schweiz und der Rheinufer [126]. Gewöhnliche Kartenzeichner liessen eine derartige Gewissenhaftigkeit natürlich sehr vermissen, und es kam soweit, dass man eine Reihe derartiger "Maulwurfshaufen" einfach als Typus eines Gebirges verwerthete, ohne auf den individuellen Charakter desselben irgend Rüicksicht zu nehmen [127]. Aehnlich machen es noch heute die Japaner, wie Knipping [128] berichtet; auch die im Jahre 1795 von einem Sklaven des Königs von Ava gezeichnete Karte, deren Früh (s. u.) erwähnt, befolgt dieses sich eben offenbar ganz ungesucht darbietende Princip. Doch erkennt man bereits bei Apian das Bestreben, den Beleuchtungsverhältnissen Rechnung zu tragen, und damit eine Anbahnung des Ueberganges von der ersten zur zweiten Periode. 
b) Die primitive Schraffirung. Jemehr man der Vogelperspektive vor der landschaftlichen den Vorzug gab, um so mehr schrumpften die Hügelketten zu dünnen raupenförmigen Gebilden zusammen, die durch Seitenansätze oder Schraffen endlich eine wirkliche Raupengestalt empfiengen. "Die ersten Anfänge hievon", so heisst es bei Peschel-Leipoldt [129], ggewahrt man schon auf Joh. Bapt. Homann's ,Provincia Brisgoiat vom Jahre 1718; auch La Condamine's Karte von Quito (erschienen im Jahr 1751) und die Karten von Cook's Werken zeigen Schraffen; aber noch in dem Atlas von Malte Brun (Paris 1804) begegnen wir der Hügelform. Erst am Beginne dieses Jahrhunderts hat der Engländer Arrowsmith die dachförmige Schraffirung allgemein eingeführt." Schon Gyger und Peyer von Schaffhausen, dessen Karte R. Wolf [130] nachrühmt, es sei in ihr die Terrainzeichnung recht brav behandelt, kennen übrigens die Schraffen, ja sogar in Giuscardini's 1566 erschienener „Beschreibung Niederlands" (deutsch von Federmann in Basel) sind die in Form gleichschenkliger und stumpfwinkliger Dreiecke zur Darstellung gebrachten Berge mit Schattenstrichen ausgerüstet.

c) Die französische Methode der schiefen Beleuchtung. Allmählig begann man sich die Abhänge der Berge schief beleuchtet vorzustellen, indem man annahm, die Sonnenstrahlen sollten ein- für allemal von einer bestimmten Seite her - etwa von Nordwest - und unter einem bestimmten Winkel - am, besten von $45^{\circ}$ - einfallen. Die so wichtigen Böschungsverhältnisse bleiben bei dieser Auffassung freilich etwas im Dunklen, und so ist die Methode auch, trotz mancher Verbesserungsvorschläge von Chauvin und Ziegler [131], der sofort zu besprechenden Lehmann'schen gegenüber in den Hintergrund getreten, doch beweist Dufour's konsequent im altfranzösischen Geiste bearbeitetes Kartenwerk der Schweiz, was sich auch aus einem an sich nicht eben vollkommenen Verfahren machen lässt; konnte doch Petermann darüber das folgende Urtheil fällen [132]: "Die Dufour'sche Karte in 25 Blättern vereinigt eine genaue Aufnahme mit meisterhafter, naturgemässer Zeichnung und schönem, geschmackvollem Stiche in so ausgezeichneter Weise, in einem so harmonischen Ganzen, und giebt ein so naturwahres Bild der imposanten Alpennatur, dass wir sie unbedingt als die vorzüglichste Karte der Welt ansehen".

d) Die Lehmann'sche Manier. In einer kleinen Schrift [133] von 1799, welcher nach mehr denn einem Decennium das ein ausgereiftes System in sich bergende Hauptwerk [134] nachfolgte, schlug der damalige sächsische Ingenieurlieutenant J. G. Lehmann vor, die schiefe Beleuchtung durch die vertikale zu ersetzen. Jeder Punkt im Terrain ist von seinem Zenit aus beleuchtet, so dass mithin eine Horizontalebene das Maximum des einfallenden Lichtes, eine Vertikalebene aber gar kein Licht empfängt. Erstere wird demnach ganz schwarz, letztere ganz weiss gezeichnet, die zwischenliegenden Flächen werden um so. dunkler gezeichnet, je grösser ihr Böschungswinkel, d. h. der Winkel ist, welchen sie selbst in ihrer Verlängerung, resp. ihre Tangentialebene, mit der horizontalen Ebene einschliessen würden. Auf den ursprünglich weissen Grund werden schwarze Striche aufgetragen, und zwar in um so grösserer Anzahl, je steiler die Böschung wird. Nach Lehmann's Theorie, die auch Bach [135] adoptirt, gilt, da 
Winkel $>45^{\circ}$ in der Natur kaum vorkommen *) und deshalb auch von der Situationszeichnung nicht berücksichtigt zu werden brauchen, folgendes Verhältniss zwischen Schwarz und Weiss:

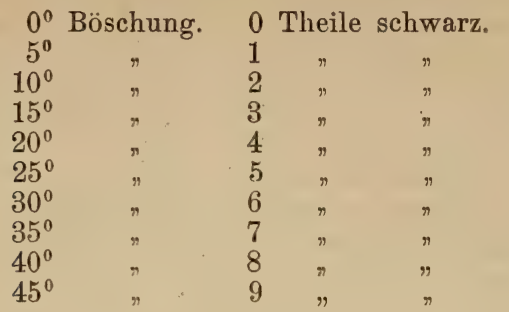

$\begin{array}{ccc}9 & \text { Theile } & \text { weiss } \\ 8 & n & " \\ 7 & " & " \\ 6 & " & " \\ 5 & n & " \\ 4 & " & " \\ 3 & " & " \\ 2 & n & " \\ 1 & " & " \\ 0 & n & n\end{array}$

Diese Eintheilung ist jedoch nicht als massgebend $\mathrm{zu}$ betrachten; vielmehr haben verschiedene Staaten auch verschiedene Normen: O bermair giebt in seinem auch sonst sehr lesenswerthen Aufsatze [140] eine übersichtliche Darstellung dieser ganz konventionellen Bestimmungen.

Es giebt mancherlei Abänderungen der Lehmann'schen Methode. Die wichtigste derselben ist diejenige v. Müffling's, welche auch als Generalstabsmanier bezeichnet wird [141]. Bei ihr werden schwarze Striche angewendet, die nicht blos durch das Verhältniss ihrer Breite zum angrenzenden weissen Zwischenraum, sondern auch durch besondere Formen die Grösse der Böschung charakterisiren.

Die Anbringung der Lehmann'schen Schraffen geschieht so, dass deren Richtung die Linie des kürzesten Falles, des Wasserablaufes, kennzeichnet. Gehören zu ein und derselben Berghöhe verschiedene Böschungsverhältnisse, so bestimmen Anfang und Ende der nämlichen Strichskala eine um den Berg sich herumziehende krumme Linie, für

*) Kaum über irgend ein anderes geometrisches Verhältniss bei'm Vorkommen in der Natur täuscht sich der Ungeübte so leicht, wie über die Grösse der Neigungswinkel. Durchweg werden dieselben überschätzt, fast nie ereignet sich der gegentheilige Irrthum. Bezeichnet man mit $m$ die Erhebung der Kammlinie eines Gebirges, mit $\mathrm{n}$ die Entfernung des Lothfusspunktes vom Fusse der Gebirgskette, so ist $\operatorname{arctg} \frac{m}{n}, d$. h. eben die Gesammtböschung, stets nur ein kleiner Winkel; nach v. Sonklar [136] überschreitet er in den Ostalpen niemals $27^{\circ}$. Selbst das so schroff aussehende Matterhorn weist nur eine Böschung von $50^{\circ}$ auf, der steile Abfall der Zugspitze gegen den Eibsee hin (etwa $60^{\circ}$ ) gehört zu den grössten Seltenheiten [137]. Nach Na umann [138], der Élie de Beaumont folgt, gelten folgende. Werthe: Grösste erlaubte Steigung der französischen Chausseen: $2^{0} 52^{\prime}$; Maximalneigung der Simplonstrasse: $5^{0} 43^{\prime}$; Grenze gefahrbringender Neigungen für abwärts fahrende Wagen: $9^{\circ} 10^{\prime}$; Grenze der von aufwärts sich bewegenden Fuhrwerken noch zu bewältigenden Neigungen: $13^{\circ}$ : grösste Neigung, welche ein beladenes Maulthier zu überwinden vermag: $29^{\circ}$; Die Militärschriftsteller treffen nachstehende Festsetzungen [139]: Bei $10^{\circ}$ Neigung ist Schuss und Stoss der Infanterie nach aufwärts unwirksam; bei $20^{\circ}$ kann Infanterie nicht mehr in geschlossener Ordnung manoeuvriren, Reiter können im Trab noch ganz kurze Strecken nach oben zurücklegen; bei $35^{\circ}$ kann sich allenfalls noch der einzelne Tirailleur, jedoch nur mit grossen Schwierigkeiten, bewegen, bei $40^{\circ}$ muss er, wenn der Boden mit Gras bewachsen ist oder sonst Anhaltspunkte darbietet, sich seiner Hände bedienen. Böschungswinkel $\geqq 45^{\circ}$ sind in Ausnahmsfällen und mit künstlichen Hülfsmitteln, wie Steigeisen u. dgl., bezwungen worden. 
deren sämmtliche Punkte die absolute Höhe die gleiche ist. Hiedurch gewinnen diese Linien eine erhöhte Bedeutung, denn an und für sich werden durch Lehmann's Methode ja nur relative Höhen angegeben. Nun aber haben wir den Uebergang zu dem vollkommensten Hülfs. mittel der modernen Terrainkunde, zu den Niveaukurven.

e) Die äquidistanten Linien*). Nach Licka [144] war der französische Ingenieur Millet de Mureau der Erste, der seit 1748 auf Fortifikationsplänen jedem eingezeichneten nivellirten Punkte dessen Höhenzahl oder Cote (Quote) beisetzte. Doch verfiel er noch nicht auf die Idee, alle Punkte von gleicher Cote durch einen Kurvenzug mit einander zu verbinden, auf eine Idee, die schon zwanzig Jahre vorher, wie ebenfalls Licka (a. a. O) zeigte, von dem Holländer Cruquius bei der Auslothung des Flusses Merwede realisirt worden war. Philippe Buache, welchem Peschel [145] diese Erfindung zuschreibt, muss die Ehre allerdings dem Cruquius abtreten, doch hat er auf seiner Karte des Aermelkanales, von welcher unsere Fig. 55

Fig. 55 .

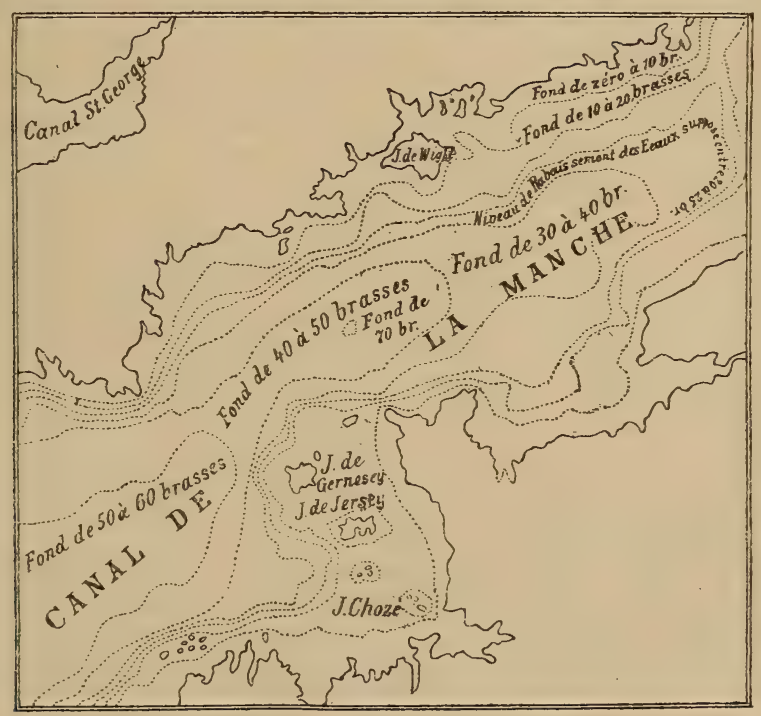

eine fragmentarische Abbildung liefert, immerhin diese Ortskurven gleicher absoluter Meerestiefe, die sogenannten Is obathen, erstmalig mit grösserer Genauigkeit ausgezogen und festgelegt („pour montrer comment se font les jonctions des terres, soient prochaines soient éloignées $^{\text {( }) . ~} 1771$ legte Du Carla von Genf die eigentliche erste Höhenkurvenkarte, allerdings nur diejenige einer imaginären Insel, der Pariser Akademie vor, um zu zeigen, dass man durch Linien gleicher absoluter Meereshöhe, d. h. durch Isohypsen, für das Festland das

*) Wir machen im Folgenden Gebrauch von den eingehenden historischen Nachweisungen über die Höhenkurren, welche man Früh [142] und Steinh a u s e r [143] verdankt. 
Gleiche erreichen könne, was Buache's Isobathen für den Meeresgrund leisteten. Dupain-Triel machte 1791 eine Isohypsenkarte von Frankreich bekannt, und letzteres Land war es auch, dessen Kartographen sich des neuen Verfahrens mit besonderer Energie bemächtigten. 1801 gab Haxo einen Situationsplan des Idro-See's, 1811 Clerc einen solchen des Golfes von Spezia, 1812 Bautraud einen solchen von Corfu, und die Genieschule von Metz nahm die Methode der gleichabständigen Linien seit 1802 in den Rahmen ihrer Pflicht-Lehrgegenstände auf. Die erste Karte, die keine Schraffen - man erinnert sich, dass letztere mit den Terrainkurven durchaus nicht unverträglich sind -, sondern blos die letzteren enthält, ist die dänische vom Jahre 1845; von 1852 stammt eine Darstellung des Züricher See's mit Isobathen. Die Nordamerikaner dagegen begannen schon weit früher, in ibre Hafenpläne genaue Niveaulinien einzutragen, wie die Florida-Karte (1829) beweist [146]. In Oesterreich gieng der Feldzeugmeister v. Hauslab, ein um die Geschichte der Kartographie hochverdienter Forscher, mit gutem Beispiele voran, und heute kann in allen Kulturländern die Anerkennung der Methode als eine vollkommene gelten. Gleichwohl kann sie in völliger Isolirung den hochentwickelten Anforderungen kein Genüge thun, welche der moderne Geograph an seine Kartenbilder zu stellen pflegt, und so hat man auch an ihr vielfach gebessert, $a b$ und zu wohl auch gekünstelt. Steinhauser subsumirt diese mannigfaltigen Versuche unter systematischen Gesichtspunkten, und zwar mit folgenden Worten [147]: „Einfache Horizontallinien vermögen bekanntlich noch weniger ein plastisches Bild der Körper zu gewähren, als es die Drahtgitter vermögen, die man beim Unterrichte in der Krystallographie anwendet. Man hat sonach auf Mittel gedacht, um den Horizontalen (für den Fall der Unthunlichkeit der Ausführung in Schraffen) einen plastischen Ausdruck zu verschaffen. Wir stossen bei der Uebersicht der bisherigen Leistungen auf so vielerlei Versuche, dass eine vorläufige Angabe der verschiedenen Eigenheiten angezeigt erscheint. Wir finden nämlich: A) Uebersichts. karten mit reinen Horizontalen ohne Schraffen, ohne Schummerung und ohne Farbenton, B) solche mit Anwendung von Schraffen oder Schummerung, und solche mit Farbentönen, und zwar mit einer Farbe in verschiedenen Abwechselungen steigend oder fallend oder C) mit mehreren Farben und in diesem Falle entweder D) nach willkürlicher Wahl oder E) nach einer fortwährenden oder F) wiederkehrenden Steigerung, endlich G) Karten mit erhabenen Schichten, sei es durch die Presse oder in anderer Weise. Ferner kann man eine Unterscheidung machen zwischen H) unbestimmten Schichten (mit verwaschenen Grenzen), sozusagen Studienkarten, auf welchen blos die Intensität der Färbung die wachsende Erhebung andeutet, und I) zusammengezogenen Schichten, uämlich solchen, wo mit Vorbedacht charakteristische Merkmale aus angrenzenden Schichten vereinigt wurden, gerade so, wie man bei historischen Karten zuweilen genöthigt ist, Uebergangsveränderungen der Zwischenperioden ersichtlich zu machen, oder wie ein Bauzeichner die Projektionsfläche eines Durchschnitts wechselt, um einen wichtigen Theil, der vor oder hinter das Profil fällt, sichtbar zu machen. Bei strenger Durchführung der Schichten ist noch zu berücksichtigen K) ob alle Schichten gleichweit abstehen, oder L) nur eine Anzahl der- 
selben, oder $\mathrm{M}$ ) ob sie nach einem bestimmten arithmetischen oder geometrischen Verhältnisse an Höhe wachsen. " C. Ritter's Bergkarte Europa's und Zeune's in die „Gea“ aufgenommene Erdkarte (1830) können höchstens der Klasse H) beigezählt werden, die erste wirkliche Schichtenkarte unseres Kontinentes erschien mit einem Kommentar im Jahre 1833 zu Kopenhagen, besorgt von Olsen und Bredstorff. Diese Methode der Höhenschichten dürfte eine bedeutende Zukunft vor sich haben, zumal wenn Polychromie und Schummerung dabei in geeigneter und vor Allem nicht in aufdringlicher Weise zur Anwendung gelangen. Allerdings ist die Frage der Farbenwahl keine ganz leicht zu lösende, wie sich aus den dahin zielenden Ausführungen bei Peschel-Leipoldt [148] ergiebt. Je höher, desto dunkler bei Landkarten, je tiefer, desto dunkler bei Wasserkarten, dieser von zwei so hervorragenden Kartographen, wie v. Hauslab und v. Sonklar, aufgestellte Grundsatz verdient, allseitig beherzigt zu werden. - - In der graphischen Rechenkunst ist statt Isohypsen der Name Isoplethen üblich; wenn $\mathrm{z}=\mathrm{f}(\mathrm{x}, \mathrm{y})$ die Gleichung einer Fläche ist, so kann man dadurch, dass man dem z successive alle möglichen Spezialwerthe ertheilt, ein deutliches Bild der Fläche, resp. der ihr entsprechenden Funktion erhalten [149]. - Eine gute Uebersicht über den momentanen Stand der exakten Kartenzeichnung gewähren Spezialarbeiten von Ziegler [150] und Becker [151]. Heinr. v. Littrow verbreitet sich [152] in ansprechender Weise über das Verhalten, welches man bei der Abbildung submariner Gegenden mittelst Isobathen zu beobachten habe*).

Gleich hier ergreifen wir die Gelegenheit, uns über einen Begriff auszusprechen, der für die gesammte Geophysik von fundamentaler Tragweite ist. In Fig. 56 sehen wir eine Schaar von Isohypsen (resp. Isobathen) dargestellt; die Linien bei A, B, C, D, E, F stehen gleichzeitig auf sämmtlichen Kurven senkrecht. $\mathrm{Zu}$ jedem System geometrischer Kurven existirt nämlich ein zweites System sogenannter orthogonaler Trajektorien, und je ein Individuum dieses letzteren schneidet je ein Individuum des ersteren unter rechten Winkeln. Da nun, wo von den gestrichelten Linien zwischen zwei unmittelbar aufeinanderfolgenden Niveaulinien ein relativ grosses Stück enthalten ist, kann die Steigung offenbar nur eine langsame, allmählige sein, während dort, wo die Terrainkurven sich zusammendrängen, die grösste Steilheit statthaben wird, in unserer Figur also bei C. Man kann also, um einen bestimmten Ausdruck zur Beurtheilung des Grades der Steilheit zu haben, so definiren: Das Gefälle ist umgekehrt proportional dem Stück der orthogonalen Durchschnittskurve,

*) Man hat die allzugrosse Buntheit solcher Schichtenkarten gerügt. Es ist deshalb vielleicht nicht überflüssig, auf das von Cayley [153] aus einer tiefgehenden philosophisch-geometrischen Untersuchung abstrahirte Ergebniss hinzuweisen, nach welchem bei noch so verschlungenen Grenzlinien einer Karte gleichwohl vier Farben als ausreichend zur vollständigen Bezeichnung aller dieser Grenzen erkannt wurden. 
welches zwischen zwei benachbarten Isohypsen enthalten ist. Dieser Terminus Gefälle wird theilweise auch von der mathematischen Physik benützt; gewöhnlich aber dient zur Bezeichnung analoger Grössen das Wort Gradient, und zwar spricht man, je nachdem an die Stelle der Isohypsenschaar ein System von Linien gleicher Wärme oder gleichen Luftdruckes getreten ist, von einem thermometrischen oder barometrischen Gradienten, und es kommt dann nur noch darauf an, die Eine Willkürlichkeit, welche in der Proportionalität gelegen ist, durch eine zweckmässige, den Bedingungen des speziellen Falles angepasste Zusatzbestimmung hinwegzuschaffen. -

Ein Terrainbild wird durch einen beigesetzten Höhenquerschnitt ungemein verdeutlicht. Buache lieferte als Ergänzung zu seiner uns bereits bekannten Seekarte [154] ein Längenprofil des Kanal-Grundes und Pasumot ein ebensolches für die Kordilleren, Pyrenäen und Alpen [155]. 1791 erschien Dupain-Triel's Länderprofil: „La France, considérée dans les différentes hauteurs de ses plaines." Sehr viel Gewicht legte A. v. Humboldt auf solche Darstellungen und zugleich darauf, dass ihm die Priorität, dergleichen zuerst in grösserem Maassstabe ausgeführt zu haben, gewahrt bleibe. Indem er Frém ont's Kartirung der westlichen Unionsländer lobend bespricht, sagt er u. a. [156]: „Da ich glaube, der Erste gewesen zu sein, der es unternommen hat, die Gestaltung ganzer Länder (die iberische Halbinsel, das Hochland von Mexiko und die Kordilleren von Südamerika) in geognostischen Profilen darzustellen (die halb-perspektivischen Projektionen eines sibirischen Reisenden, des Abbé Chappe, waren auf blosse und meist sehr alberne Schätzungen von Flussgefällen gegründet), so ist es mir eine besondere Freude, die graphische Methode, welche die Erdgestaltung in senkrechter Richtung, die Erhebung des Starren über dem Flüssigen darstellt, auf die grossartigste Weise angewandt zu sehen."

§. 5. Flächenmessung. Es dürfte hier der Ort sein, Einiges einzuschalten über ein Geschäft, dessen Ausübung dem Kartographen nicht selten zu schaffen macht, und welches auch bei physikalischgeographischen Forschungen oft genug sich aufdrängt; wir erinnern nur an Rigaud's messende Vergleichung des festen und flüssigen Elementes auf der Erdoberfläche [157]. Wir meinen die mechanische Planimetrie, die Bestimmung des Flächeninhaltes unregelmässig begrenzter Figuren.

a) Arithmetisches Mittel. Man beziehe die Figur auf ein rechtwinkliges Koordinatensystem und stelle sie dar als algebraische Summe von gemischtlinigen Trapezen, dessen parallele Seiten Ordinaten sind, während eine dritte Seite durch ein Stück der Abscissenaxe, eine vierte durch einen wie immer gestalteten Kurvenbogen dargestellt ist. Es kommt also nur noch auf den Flächeninhalt eines solchen Trapezes an. Zieht man, die beiden parallelen Seiten mit eingerechnet, n gleichabständige Ordinaten und bezeichnet mit a das Stück der X-Axe zwischen den Grenzordinaten, so ist der gesuchte Inhalt mit um so grösserer Annäberung gleich a mal dem arithmetischen Mittel aus den n Ordinaten, je grösser $n$ ist. Uebrigens sind Rikatscheff [158] und Graf Wilczek [159] unabhängig von einander darauf gekommen, 
dass man weit genauer rechnet, wenn man der üblichen Formel

Arithm. Mittel $=\frac{1}{\mathrm{n}}\left(\mathrm{y}_{1}+\mathrm{y}_{2}+\mathrm{y}_{3}+\ldots+\mathrm{y}_{\mathrm{n}-1}+\mathrm{y}_{\mathrm{n}}\right)$

den anscheinend paradoxen Ausdruck

Arithm. Mittel $=\frac{1}{n}\left(\frac{y_{1}}{2}+y_{2}+y_{3}+\ldots+y_{n-1}+\frac{y_{n}}{2}\right)$

substituirt.

b) Simpson'sche Regel. Rationeller ist die von Simpson [160] gegebene Vorschrift, welche die zwischen den einzelnen Ordinaten gelegenen Kurvenstiicke, statt mit geraden Linien, mit den sich ihnen weit besser anschmiegenden Bogen einer Parabel vertauscht, wenigstens soweit blos paare Ordinaten in Frage kommen. Welcher Art also etwa der Bogen $z w i s c h e n y_{6}$ und $y_{7}$ sei, bleibt unerörtert, der Bogen zwischen $\mathrm{y}_{6}$ und $\mathrm{y}_{8}$ dagegen gilt seiner ganzen Ausdehnung nach als parabolisch. Da nun einem von Archimedes ausgehenden Satze zufolge jedes Parabelstück leicht quadrirt werden kann, so ist, unter n eine gerade Zahl verstanden, der Flächeninhalt des obigen Trapezes gleich

$$
\frac{\mathrm{a}}{3 \mathrm{n}}\left[\mathrm{y}_{1}-\mathrm{y}_{\mathrm{n}}+2 \cdot \sum_{\mathrm{h}=1}^{\mathrm{h}=\frac{1}{{ }^{2}} \mathrm{n}}\left(\mathrm{y}_{2 \mathrm{~h}}+\mathrm{y}_{2 \mathrm{~h}}-1\right)\right] .
$$

Eine möglichst einfache rechnerische Deduktion dieser Formel giebt R. Wolf [161]. Verfeinerte Methoden dieser Art besitzt man von Cotes, Stirling und ganz besonders von Gauss; doch ist es nicht wahrscheinlich, dass diese mechanische Quadratur direkt geophysikalischen Zwecken förderlich werden könnte. Eine gute Spezialschrift ist diejenige Mansi on's "Sur l'évaluation des aires planes" (Gent 1882).

c) Methode der Wägung. Man wiegt das herausgeschnittene Flächenstück auf einer feinen Wage $a b$ und thut ein Gleiches mit der Flächeneinheit. Das Gewichtsverhältniss ist dann auch das gesuchte. Auf diesem überaus mühsamen Wege ist Rigaud (s. o.) vorgegangen, auch erscheint es nicht unwahrscheinlich, dass in ähnlicher Weise Archimedes manche überraschende Thatsache ermittelt hat, um sie nachher erst strenge zu erweisen.

d) Instrumentale Messung. Das Princip dieser vielgestaltigen Methode scheint uns Purvis durch die nachfolgende Betrachtung [162] am Besten verdeutlicht zu haben. Ein geradliniger Stab $\mathrm{AB}=1$ (Fig. 57) gelange nach und nach in die Lagen $\mathrm{EF}, \mathrm{GH}, \mathrm{JK}, \mathrm{CD}$, so dass er schliesslich das gemischtlinige Viereck $\mathrm{ABDC}$ überstrichen hat. Bezeichnet man mit $\mathrm{f}$ dessen Inhalt, mit $\mathrm{n}$ die Länge des Weges, welchen der Mittelpunkt des Stabes während der Bewegung senkrecht gegen die Anfangsrichtung zurückgelegt hat, so ist $\mathrm{f}=\mathrm{ln}$. Wird senkrecht zum Stabe ein von dessen beiden Enden gleichweit entferntes Rad angebracht, so messen dessen Umdrehungen den Weg n. Ist dagegen das Rad nicht am Stabe selbst, sondern, bei sonst gleicher Richtung, um mLängeneinheiten vom Mittelpunkt entfernt angebracht, so ist die Grösse der Raddrehung $=\mathrm{n}-\mathrm{m} \Theta$, wo $\Theta$ den von $\mathrm{AB}$ und $\mathrm{CD}$ 
gebildeten Winkel bezeichnet. Nun führe man den Stab aus der Endin die Anfangsstellung zurïck, während die Enden vertauscht sind, dann ist, wenn $\mathrm{n}_{1}$ die entsprechende Bedeutung hat, der Inhalt $\mathrm{ln}_{1}$; eventuell ist wieder der Weg $=\mathrm{n}_{1}-\mathrm{m} \Theta$. Der Gesammtweg eines Peripheriepunktes ist in jedem Falle $=\mathrm{n}-\mathrm{m} \Theta-\left(\mathrm{n}_{1}-\mathrm{m} \Theta\right)=\mathrm{n}-\mathrm{n}_{1}$, und damit ist für den Inhalt der vom oberen Ende des Stabes allein beschriebenen Figur der Werth $1\left(n-n_{1}\right)$ gefunden. Das Amsler'sche Planimeter, dessen sich die Geographen, seiner Bequemlichkeit halber, gerne bedienen, bildet insoferne einen speziellen Fall, als sein unteres Stabende gezwungen ist, einen Kreisbogen zu beschreiben. Favaro's verdienstvolle Arbeit [163] belehrt uns über die mannigfachen Fortschritte, welche von Oppikofer, Wetli und J. M. Hermann an bis zu Amsler und Reitz diese als Planimeter oder Integratoren bezeichneten Instrumente gemacht haben. Für die Theorie derselben sind namentlich die Schriften von Trunk [164] und E. Fischer [165] zu beachten; principiell auf derselben Basis beruhen viele der selbstregistrirenden Instrumente, besonders die Indikatoren für das Ebbeund Fluth-Phänomen.

§. 6. Anderweite Darstellungen der Erdoberfläche oder ihrer einzelnen Theile. Es ward bis jetzt als selbstverständlich betrachtet, dass die Nachbildung der Erde oder einzelner Erdpartieen auf dem Zeichnungspapier zu erfolgen habe. Doch giebt es auch andere Erdbilder, welche zum Theile für die physische Erdkunde einiges Interesse besitzen und daher kurz besprochen zu werden verdienen.

a) Reliefbilder. Dieselben sind namentlich zur Darstellung von Gebirgsgegenden von jeher gerne angewendet worden und geben gewiss die Möglichkeit zu einer leichteren Orientirung, obwohl sie nur selten dem Fehler entgehen, die Höhendimension im Verhältniss zu den beiden Plandimensionen ungebührlich zu bevorzugen*). Das Beste in diesem Genre hat aus naheliegenden Gründen von je die Schweiz geliefert. Pfyffer in Luzern arbeitete 10 Jahre lang an seinem berühmt gewordenen Relief der den Vierwaldstättersee umgebenden Bergzüge [166]; ebenso bearbeitete Eugen Müller aus Unterwalden die ganze Innerschweiz [167]. Ja die Meyer-Weiss'sche Generalkarte der Schweiz, die erste, welche dieses Namens wirklich würdig war, gieng gewissermassen aus einer Relief-Arbeit hervor [168], denn J. R. Meyer hatte sich, ehe er an jenes Werk gieng, zuvor die Mühe gegeben, die gesammte Alpenkette von Mayenfeld in Graubündten bis Villeneuve am Rhonefluss in erhabener Arbeit herzustellen. Nähere Nachrichten darüber gab er in einer besonderen Schrift [169]. Bei Peschel-Leipoldt [170] finden die von Winkler in München angefertigten Reliefs lobende Erwähnung.

b) Globen. Zur Verfertigung von Erdgloben setzt man das Kugelnetz aus möglichst vielen, schmalen Kreiszweiecken zusammen, welche mit möglichst geringer Dehnung oder Faltung beim Aufziehen

*) Je kleiner der modellirte Landstrich ist, um so besser fällt natürlich das Relief aus. So befindet sich in Oberstdorf im Allgäu ein Zinkguss-Modell des die Illerquellen umschliessenden Hochgebirges, welches die charakteristischen Gipfel und Thaleinschnitte mit musterhafter Treue zum Ausdruck bringt. 
in Kugelzweiecke übergehen. Im vierten Buche seiner berühmten populären Geometrie [171] lehrt Albrecht Dürer fünfzehn Segmente zu diesem $Z$ wecke anzufertigen ( die Spera, wenn man sie durch ihre Mittagslinien zerschneidet, und in ein Planum legt, so gewinnt sie die Gestalt eines Kamms"). Lowitz wollte achtzehn Segmente genommen haben, für gewöhnlich aber liess man es bei zwölf derselben bewenden, entsprechend den zwölf Zeichen des Zodiakus [172]. Sehr gründlich beschreibt die bei Anfertigung eines Globus nöthig werdenden Manipulationen Steinhauser [173]. Neuerdings bedient man sich beim Unterrichte vielfach der Reliefgloben, die für die Erde also etwa das leisten, was die in Kap. III, §. 9 der ersten Abtheilung erwähnten Mond-Modelle von Dickert, W. Witte u. s. w. für unseren Satelliten zu leisten beabsichtigen.

c) Panoramen. Betrachtet man den Gesichtskreis als Direktrix eines geraden Cylinders und bildet aus dem eigenen Standpunkte jeden in der Nähe des Horizontes befindlichen Punkt auf dem Mantel dieses Cylinders ab, so erhält man ein Panorama. Das erste Rundgemälde dieser Art scheint der Hauptmann Micheli du Crest verfertigt zu haben, als er, der in die bekannte Henzi-Verschwörung zu Bern verwickelt war, die Aarburger Citadelle beziehen musste [174]. Er bestimmte durch geometrisches Nivellement und barometrische Messung die Seehöhe seines Observatoriums, visirte dann die entfernten Gipfel des Berner Oberlandes an, mass ihre Höhenwinkel mit Rücksicht auf die Depression des Horizontes (Kap. I, §.4), für welche er Picard's Tafeln zu benützen in der Lage war, entnahm die Distanzen aus der Scheuchzer'schen Karte und brachte so, indem er noch die Horizontalwinkel mittelst eines Azimutalquadranten bestimmte, 1755 das erste Alpenpanorama zu Stande*). Sehr schöne Rundsichten der Schweizer Gebirge zeichnete später der uns bereits bekannte E. Müller [175]. Die noch immer ausstehende theoretische Begründung des Panoramenzeichnens ist erst vor Kurzem durch Frischauf [176] gegeben worden, der zur Erleichterung der Rechnung Tabellen konstruirte und auch auf die entstellenden Einflüsse der terrestrischen Refraktion Rücksicht nahm. Die sich mehr und mehr vervielfachenden Entwürfe zu Gebirgsrundsichten, welche in den Zeitschriften der Alpenvereine mitgetheilt werden, scheinen zu beweisen, dass der von Frischauf, dem als Mathematiker und Alpenkenner gleich gut berufenen Forscher, ausgestreute Same auf fruchtbaren Boden gefallen ist.

[1] Wiechel, Rationelle Gradnetzprojektion, Civilingenieur, 1879. S. 420 ff. - [2] D'Avezac, Coup d'oeil historique sur la projection des cartes de géographie, Bull. de la soc. de géogr. de Paris, 1863. I. S. 257 ff. S. 438 ff. - [3] Breusing, Leitfaden durch das Wiegenalter der Kartographie bis zum Jahre 1600 mit besonderer Berücksichtigung Deutschlands, Frankfurt a. M. 1883. - [4] Günther,

*) Micheli du Crest schildert sein Werk (a. a. 0.) mit folgenden Worten: „Prospect géométrique des montagnes neigées, dittes Gletscher, telles qu'on les découvre, en temps favorable, depuis le château d'Aarbourg dans les territoires des Grisons, du canton d'Ury, et de l'Oberland du canton Berne." Seine geographische Bildung dürfte hiernach seiner mathematischen nicht gleichgekommen sein. 
Die Kartenprojektionslehre im Verlaufe des letzten Jahrzehntes, Wagner's geogr. Jahrbuch, 9. Band. S. 407 ff. - [5] Le Monnier, Zur Geschichte der Kartographie, Deutsche Rundschau f. Geogr. u. Stat,, 21. Jahrgang. S. 391 ff. S. 437 ff. [6] Peschel-Ruge, Geschichte der Erdkunde bis auf Carl Ritter und Alexander マ. Humboldt, München 1877. S. 50. - [7] Berger, Die geographischen Fragmente des Eratosthenes, Leipzig 1880. S. 142 ff. - [8] Ibid. S. 169 ff. - [9] Breusing, Leitfaden etc. S. 1 ff. - [10] Günther, Die Kosmographie des Heinrich Schreiber von Erfurt, Zeitschr. f. wissensch. Geogr., 2. Band. S. 60. - [11] Marinelli, Die Erdkunde der Kirchenväter, deutsch von L. Neumann, Leipzig 1883. S. 68 ff. [12] Tomaschek, Zur historischen Topographie von Persien, 1. Theil, Wien 1883. - [13] Philippi, Zur Rekonstruktion der Weltkarte des Agrippa, Marburg 1880. - [14] Marinelli, Die Erdkunde etc. S. 74. - [15] Ibid. S. 62 ff. - [16] Einhardi vita Karoli magni, ed. Pertz, Hannoverae 1863. S. 33 ff. - [17] Peschel-Ruge, Geschichte etc. S. 101. - [18] Ibid. S. 145 ff. - [19] Dewulf, Note sur un manuscrit de Djellal-Ed-din-es-Siouti, Bull. de la soc. de géogr. de Paris, 1875. I. S. 449 ff. - [20] Th. Fischer, Die italienischen Seekarten und Kartographen des Mittelalters, Zeitschr. d. Gesellsch. f. Erdk. zu Berlin, 17. Jahrgang. S. 1 ff. [21] Breusing, Zur Geschichte der Kartographie, Zeitschr. f. wissensch. Geogr., 2. Band. S. 129 ff. S. 180 ff. - [22] Ibid. S. 187. - [23] Gelcich, Ein Beitrag zur Geschichte der Seekarten, ibid. 4. Band. S. 28 ff. - [24] Breusing, Leitfaden etc. S. 3. - [25] Ibid. S. 5. - [26] Ibid. S. 14 ff. - [27] Ruge, Ueber einige niederländische Kartographen, Ausland, 1881. S. 21 ff. - [28] Unser Homann, ibid. 1879. S. 373 ff. - [29] Steinhauser, Die Weltkarte des Peter Descelliers, Mittheil. d. k. k. geogr. Gesellsch. zu Wien, 1875. S. 587 ff. - [30] Himly, Ueber zwei chinesische Kartenwerke, Zeitschr. d. Gesellsch. f. Erdkunde zu Berlin, 14. Band. S. 181 ff. - [31] H. Weber, Ueber ein Princip der Abbildung der Theile einer krummen Fläche auf einer Ebene, Journal f. d. reine u. angew. Mathem., 67. Band. S. 229 ff. - [32] Eisenlohr, Ueber Kartenprojektion, Zeitschr. d. Gesellsch. f. Erdkunde zu Berlin, 10. Band. S. 305 ff. - [33] Tissot, Mémoire sur la représentation des surfaces et les projections des cartes géographiques, Paris 1881. - [34] Fiorini, Le projezioni delle carte geografiche, Bologna 1881. - [35] Möllinger, Lehrbuch der wichtigsten Kartenprojektionen, Zürich 1882. - [36] Steinhauser, Elemente der mathematischen Geographie und Kartenprojektion, Wien 1880. - [37] Coordes, Kleines Lehrbuch der Landkartenprojektion, Cassel 1881. [38] Wenz, Die mathematische Geographie in Verbindung mit der Landkartenprojektion, München und Leipzig 1883. - [39] Zöppritz, Leitfaden der Kartenentwurfslehre, Leipzig 1884. - [40] Gretschel, Lehrbuch der Kartenprojektion, Weimar 1873. - [41] Thoulet, Mémoire sur les projections orthographiques, Bull. de la soc. de géogr. de Paris, 1875. S. 468 ff. - [42] Steinhauser, Math. Geogr. etc. S. 101. - [43] R. Wolf, Geschichte der Astronomie, München 1877. S. 162 ff. [44] Schumann, Ueber eine elementare Bestimmung der Verzerrung bei der stereographischen Polarprojektion, Zeitschr. f. math. und naturw. Unterricht, 12. Band. S. 163 ff. - [45] v. Bauernfeind, Elemente der Vermessungskunde, ein Lehrbuch der technischen Geometrie, Stuttgart 1879. S. $497 \mathrm{ff},-[46]$ Reusch, Die stereographische Projektion, Leipzig 1881. - [47] Steinhauser, Math. Geogr. etc. S. 101. - [48] D'Avezac, Un coup d'oeil etc. S. 465 ff. - [49] Günther, Die gnomonische Kartenprojektion, Zeitschr. d. Gesellsch. f. Erdk. zu Berlin, 18, Band. S. $137 \mathrm{ff}$. [50] Borgondio, Mapparum constructio in planis sphaeram tangentibus, Romae 1718. - [51] Gretschel, Lehrbuch etc. S. 47 ff. - [52] Chancourtois, Carte du globe en projection gnomonique avec le réseau pentagonal superposé, Bull. de la soc. de géogr. de Paris, 1874. II. S. 291 ff. - [53] Chancourtois, Programme d'un système de géographie, ibid. 1874. II. S. 240 ff. - [54] Congrès géologique inter-

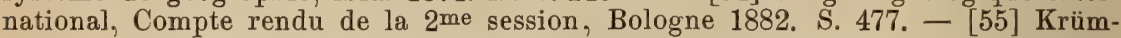
mel, Versuch einer vergleichenden Morphologie der Meeresräume, Leipzig 1879. S. 17. - [56] Hilleret, Nouveau système de cartes marines pour la navigation de grand cercle, Compt. rend. de l'acad. de France, tome LXXXII. S. 1995 ff. [57] Rayet, Note sur quelques propriétés géométriques du canevas des cartes orthodromiques équatoriales, Mém. de la soc. de Bordeaux, (2) tome II. S. $135 \mathrm{ff}$. [58] Breusing, Gerhard Kremer, genannt Mercator, der deutsche Geograph, Duisburg 1869. S. 13 ff. - [59] Ibid. S. 28. - [60] Günther, Die Kartenprojektionslehre etc. S. 416. - [61] v. Friesach, Ueber die Loxodromie und loxodromische Figuren, Graz 1874. - [62] Günther, Studien zur Geschichte der mathematischen und physikalischen Geographie, Halle 1879. S. 333 ff. - [63] v. Friesach, Beschreibung einer Tabelle zur Erleichterung der Schifffahrt im grössten Kreise, 
Sitzungsber. d. k: k. Akad. d. Wissensch. zu Wien, Math.-naturw. Kl., 53. Band, II. Abtheilung, S. 258 ff. - [64] Gelcich, Eine neue Tabelle zur Erleichterung der Schifffahrt im grössten Kreise, beziehungsweise zur Einzeichnung eines grössten Kreises in Mercator's Projektion, Zeitschr. f. d. Realschulwesen, 8. Jahrgang. S. 14 ff. - [65] Albini, Metodo grafico per risolvere un triangulo sferico sulla projezione di Mercator, Rivista Maritima, X. S. 425 ff. - [66] Asmus, Darstellung eines grössten Kreises in Mercator-Projektion, Ann. d. Hydr. u. marit. Meteor... 1879. S. 151 ff. - [67] Schück, Die Wege des Oceans für Segelschiffe, Hamburg 1875. - [68] Steinhauser, Math. Geogr. etc. S. 127. - [69] Hilgard, Note on the polyconic projection, The Analyst, III. S. $117 \mathrm{ff}$. - [70] Frischauf, Die Spezialkarte der österreichisch-ungarischen Monarchie im Maasse von 1:75000, Jahrb. d. österr. Tour.-Cl., 12. Jahrgang. S. 1 ff. - [71] Steinhauser, Ueber Kegelprojektionen der ganzen Erdoberfläche, Zeitschr. f. d. Realschulwesen, 8. Jahrgang. 4. Heft. - [72] Steinhauser, Math. Geogr, etc. S. 116. - [73] Gerster, Dr. Arnd's Halbsternprojektion, Zeitschr. f. Schulgeogr., 3. Jahrgang. S. 128 ff. - [74] Steinhauser, Ueber die Anwendung der Kegelprojektion, Zeitschr. f. wissensch. Geogr., 4. Band. S. 34 ff. - [75] Steinhauser, Math. Geogr. S. 128 ff. - [76] Postellus, Cosmographicae disciplinae compendium, Basileae 1561. - [77] Gretschel, Lehrbuch etc. S. $240 \mathrm{ff}$. - [78] Günther, Die Kartenprojektionslehre etc. S. 430. [79] Breusing, Leitfaden etc. S. 11. - [80] Nell, Vorschlag zu einer neuen Kartenprojektion, Heidelberg 1852. - [81] Debes, Dr. Nell's modificirte Globularprojektion, Leipzig 1883. - [82] Günther, Studien etc. S. 299 ff. - [83] Steinhauser, Math. Geogr. etc. S. 110. - [84] Coatpont, Propriétés et construction d'une carte des deux continents en projection azimuthale équivalente, Bull. de la soc. de géogr. de Paris, 1877. I. S. 151 ff. - [85] Wieser, Der Portulan des Infanten Philipp II. von Spanien, Sitzungsber. d. k. k. Akad. d. Wiss. zı Wien, Phil.-hist. Kl.. LXXXII. S. 541 ff. - [86] Breusing, Leitfaden etc. S. 10. - [87] F. August, Ueber eine konforme Abbildung der Erde nach der epicykloidischen Projektion, Zeitschr. d. Gesellsch. f. Erdkunde zu Berlin, 9. Band. S. 1 ff. - [88] Peirce, A quincuncial projection of the sphere, Amer. Journal of mathem., Vol. II. S. $394 \mathrm{ff}$. - [89] v. Oppolzer, Syzygientafeln für den Mond, Leipzig 1881. S. 21 ff. [90] Gauss, Allgemeine Auflösung der Aufgabe, die Theile einer gegebenen Fläche so abzubilden, dass die Abbildung dem Abgebildeten in den kleinsten Theilen ähnlich wird, Altona 1835. - [91] Craig, Projection conforme de l'ellipsoide sur la sphère, Amer. Journal of mathem., Vol. III. S. 114 ff. - [92] Günther, Peter und Philipp Apian, zwei deutsche Mathematiker und Kartographen, Prag 1882. S. 119 ff. - [93] Hipler, Die Chorographie des Joachim Rheticus; aus dem Autographon des Verfassers mit einer Einleitung herausgegeben, Zeitschr. f. Math. u. Phys., 21. Band, hist.-lit. Abtheilung, S. 125 ff. - [94] Doppelmayr, Historisehe Nachricht von den Nürnbergischen Mathematicis und Künstlern, Nürnberg 1730. S. 86. - [95] Schickard, Kurze Anleitung, wie künstliche Landtafeln aus rechtem Grund zu verfertigen, Tübingen 1669. - [96] J. J. J. Hoffmann, Das Pothenot'sche Problem und seine Auflösung, Aschaffenburg 1825. S. 7. - [97] Ruge, Geschichte der sächsischen Kartographie im XVI. Jahrhundert, Zeitschr. f. wissensch. Geogr., 2. Band. S. 89 ff. S. 143 ff. S. 223 ff. - [98] R. Wolf, Geschichte der Vermessungen in der Schweiz, als historische Einleitung zu den Arbeiten der schweizerischen geodätischen Commission, Zürich 1879. - [99] Ruge, Gesch. etc. S. 231. - [100] R. Wolf, Gesch. d. Verm. etc. S. 7. - [101] Ibid. S. 29 ff. - [102] Ibid. S. 243 ff. - [103] Peschel-Ruge, Gesch. etc. S. 668 ff. - [104] Comte de Marsigli, Danubius Pannonicus-Mysicus, observationibus geographicis, astronomicis, hydrographicis, historicis, physicis perlustratus. Hagae Comitum 1726. - [105] Doppelmayr, hist. Nachr. etc. S. 138 ff. - [106] Mazegger, Peter Anich und Blasius Hueber und deren Karte von Tyrol, Zeitschr. d. d. u. östr. Alpenver., 12. Band. S. $164 \mathrm{ff}$. - [107] v. Sydow, Die Kartographie in Europa bis zum Jahre 1857, Petermann's geogr. Mittheil., 1857. S. 73 ff. - [108] B. Wolf, Matériaux dirers pour l'histoire des mathématiques, Bullett. di bibliogr. e di storia delle scienze mat. e fis., tomo II. S. 313 ff. - [109] Puissant, Traité de topographie, d'arpentage et de nivellement, Paris 1807; Supplém. 1810. - [110] J, J. v. Littrow, Chorographie, Wien 1833. - [111] Stampfer, Theoretische und praktische Anleitung zum Nivelliren, 7. Aufl., bes. von Herr, Wien 1872. - [112] Kaltbrunner, Der Beobachter; allgemeine Anleitung zu Beobachtungen über Land und Leute für Touristen, Exkursionisten und Forschungsreisende, deutsch von Kollbrunner, Zürich 1882. S. 21 ff. - [113] A. Schell, Die Terrain-Aufnahme mit der tachymetrischen Kippregel von Tichy und Starke, Wien 1881. - [114] Bessels, Die amerikanische Nordpolexpedition, Leipzig 1879. 
S. 399. - [115] Stolze, Ueber den photographischen Theodoliten von Meydenbauer, Verh. d. Gesellsch. f. Erdk. zu Berlin, 6. Band. S. 243. - [116] Stolze, Persepolis, Bericht über seine Aufnahmen achämenidischer und sâsânidischer Denkmäler in Fârs, ibid. 10. Band. S. 251 ff. - [117] Girard, Laussedat's Arbeiten in Bezug auf die Anwendung der Photographie zur Aufnahme von Plänen, Photogr. Archiv, 6. Band. S. 316 ff. - [118] Meydenbauer, Ueber Anwendung der Photographie zur Architektur- und Terrain-Aufnahme, Zeitschr. f. Bauwesen, 17. Jahrgang. S. 61 ff. - [119] Jordan, Ueber die Verwerthung der Photographie zu geometrischen Aufnahmen (Photogrammetrie), Zeitschr. f. Vermessungswesen, 5. Band. S. 1 ff. - [120] G. Hauck, Neue Construktionen der Perspektive und Photogrammetrie, Journal f. d. reine u. angew. Mathem., 95. Band. S. 7 ff. - [121] Ibid. S. 23 ff. - [122] G. Fritsch, Die Anwendbarkeit der modernen Photographie auf Reisen, Verhandl. d. Gesellsch. f. Erdk. zu Berlin, 10. Band. S. 277 ff. - [123] Wolkenhauer, Die kartographische Darstellung der senkrechten Gliederung der Erdoberfläche, Deutsche Rundschau f. Geogr. u. Stat., 3. Jahrgang. S. 1 ff. [124] Ibid. S. 3. - [125] Günther, Peter und Philipp Apian etc. S. 122. [126] Wolkenhauer, Die kartogr. Darstell. etc. S. 4. - [127] Simony, Das Landschaftsbild als illustrirendes Element für eine wissenschaftliche Alpenkunde, Zeitschr. d. d. u. öst. Alpenver., 11. Band. S. 103. - [128] Knipping, Ueber eine neue Karte von Japan und ihre Quellen, Mittheil. d. deutschen Gesellsch. f. Naturu. Völkerk. Ostasiens. 11. Heft. S. 23. - [129] Peschel-Leipoldt, Physische Erdkunde, 1. Band, Leipzig 1875. S. 561. - [130] R. Wolf, Gesch. d. Verm. etc. S. 36. - [131] Wolkenhauer, Die kart. Darst. etc. S. 5. - [132] R. Wolf, Gesch. d. Verm. etc. S. 280. - [133] J. G. Lehmann, Darstellung einer neuen Theorie zur Bezeichnung der schiefen Flächen, Leipzig 1799. - [134] J. G. Lehmann, Die Lehre vom Situationszeichnen oder Anweisung zum richtigen Erkennen und genauen Abbilden der Erdoberfläche in topographischen Karten und Situationsplänen, Dresden 1812-16. - [135] Bach, Die Theorie der Bergzeichnung in Verbindung mit Geognosie, Stuttgart 1853. S. 9. - [136] v. Sonklar, Allgemeine Orographie, Wien 1873. S. 85. - [137] Peschel-Leipoldt, Phys. Erdk., 1. Band. S. 568 ff. [138] Naumann, Lehrbuch der Geognosie, 1. Band, Leipzig 1858. S. 311. [139] Buschbeck- v. Helldorf, Feld-Taschenbuch für Offiziere aller Waffen der deutschen Armee, 1. Theil, Berlin 1874. S. 505. - [140] Obermair, Ueber Kartenlesen und Kartenbeurtheilung, Zeitschr. d. d. u. öst. Alpenver., 12. Band. S. 144 ff. - [141] Buschbeck- v. Helldorf, Feld-Taschenb. etc. 1. Theil. S. 767. — [142] Früh, Zur Geschichte der Terraindarstellung, Zeitschr. f. wissensch. Geogr., 2. Band. S. 156 ff. S. 214 ff. - [143] Steinhauser, Beiträge zur Geschichte der Entstehung und Ausbildung der Niveaukarten, sowohl See- als Landkarten, Wien 1857. [144] Lička, Zur Geschichte der Isohypsen, Zeitschr. f. Vermessungswesen, 9. Band. S. 40 ff. - [145] Peschel-Ruge, Gesch. d. Erdk. S. 703. - [146] Map of the Territory of Florida connected with the Delta of Missisippi, 1829. - [147] Steinhauser, Beitr. etc. S. 12 ff. - [148] Peschel-Leipoldt, Phys. Erdk., 1. Band. S. 568 ff. [149] v. Ott, Das graphische Rechnen und die graphische Statik, 1. Theil, Prag 1879. S. $163 \mathrm{ff} .-[150]$ Ziegler, Ueber Topographie und topographische Karten, Vierteljahrsschrift d. naturf. Gesellsch. zu Zürich, 18. Jahrgang. S. 297 ff. - [151] Becker, Die Kartographie in der Weltausstellung, Mittheil. d. k. k. geogr. Gesellsch. zu Wien, 1874. S. 385 ff. - [152] Enr. di Littrow, Sulle carte idrografiche e sulla rappresentazione del fondo del mare mediante linee isobate od in plastica, Rivista Maritima, XII. S. 191 ff. - [153] Cayley, On the colouring of maps, Proceed. of the r. geogr. society, 1879. S. 289 ff. - [154] Wolkenhauer, Zur Geschichte der Tiefenmessungen, Deutsche Rundschau f. Geogr. u. Stat., 1. Jahrgang. S. 592. [155] Peschel-Leipoldt, Phys. Erdk., 1. Band. S. 567. - [156] A. v. Humboldt, Ansichten der Natur mit wissenschaftlichen Erläuterungen, Stuttgart und Augsburg 1859. S. 59. - [157] Rigaud, On the relative quantities of land and water on the surface of the terraqueous globe, Transact. of the Cambr. phil. society, Vol. VI. S. $289 \mathrm{ff}$. - [158] Rikatscheff, Ueber die tägliche Aenderung der Temperatur in St. Petersburg, Wild's Repertorium f. Meteorol., 3. Band. S. 166 ff. [159] Graf Wilczek, Ueber die Berechnung des arithmetischen Mittels, Zeitschr. d. öst. Ges. f. Meteor., 10. Band. S. 213 ff. - [160] Simpson, Mathematical dissertations on physical and analytical subjects, London 1743. - [161] R. Wolf, Handbuch der Mathematik, Physik, Geodäsie und Astronomie, 1. Band, Zürich 1869. S. $201 \mathrm{ff} .-$ [162] Purvis, On Amsler's Planimeter, Phil. Mag., (4) Vol. XLVIII. S. $11 \mathrm{ff}$. - [163] Favaro, Geschichte der mechanischen Planimetrie, Wien 1873. - [164] Trunk, Die Planimeter, deren Theorie, Praxis und Geschichte, Halle 1865. 
- [165] E. Fischer, Die mechanische Planimetrie, ihre geschichtliche, theoretische und praktische Bedeutung, Zürich 1868. - [166] R. Wolf, Biographieen zur Kulturgeschichte der Schweiz, 2. Band, Zürich 1859. S. 234 ff. - [167] Ibid. S. 235. [168] Ibid. S. 242. - [169] J. R. Meyer, Beschreibung eines neu verfertigten Reliefs, welches eine der interessanten Schweizerlandschaften nach der Natur darstellt, Aarau 1803. - [170] Peschel-Leipoldt, Phys. Erdk., 1. Band. S. 571. [171] Albr. Dürer, Underweysung der messung mit dem zirckel und richtscheyt, Nürnberg 1525. - [172] Kästner, Geschichte der Mathematik, 1. Band, Göttingen 1796. S. 689. - [173] Steinhauser, Math. Geogr. etc. S. 131 ff. - [174] R. Wolf, Biogr. etc., 1. Band, Zürich 1858. S. 256 ff. - [175] R. Wolf, Gesch. d. Verm. etc., S. 138 ff. - [176] Frischauf, Das Zeichnen und Bestimmen von Panoramen, Neue deutsche Alpenzeitung, IV. Nr. 23; Die Sannthaler Alpen, Graz 1877. S. 269 ff. 
Dritte Abtheilung.

\title{
Geophysik im engeren Sinne; dynamische Geologie.
}

\author{
Kapitel I. \\ Die Wärmeverhältnisse des Erdinneren.
}

§. 1. Das Eindringen der Sonnenwärme. Die Temperaturverhältnisse einer obersten Schicht der Erdkruste müssen für sich betrachtet werden, da sie von der Stärke der Insolation unmittelbar abhängig sind. Bis zu einer gewissen Tiefe machen sich die täglichen, bis zu einer grösseren Tiefe auch die jährlichen Temperaturschwankungen fühlbar, alsdann begegnen wir einer als neutral zu bezeichnenden Schicht, und erst jenseits letzterer beginnt jener Raum, dessen Wärme man als Eigenwärme der Erde betrachten darf. Wir haben es hier vorläufig nur mit jenem äussersten Kugelringe zu thun.

Entdeckt ward die Existenz der neutralen Schicht durch die Beobachtungen La Hire's und D. Cassini's an einem im Keller der Pariser Sternwarte aufgestellten Thermometer, welches seit mehr denn 100 Jahren ununterbrochen $11,82^{\circ}$ zeigt; nach Graf J. D. Cassini de Thury [1] beträgt dort die Jahresschwankung höchstens $0,02^{\circ}$, nach Bouvard ein klein wenig mehr. Aus diesen Beobachtungen, sowie späteren von Saussure, Hamilton, A. v. Humboldt schliesst Muncke, dessen treffliche Arbeiten über die Erdwärme [2] uns hier vielfach zur Richtschnur dienen, dass der Wärmeunterschied von Tag und Nacht bei 3 Fuss, der monatliche Einfluss bei 5 Fuss, der Unterschied in den Jahreszeiten endlich bei 30 Fuss verschwinde [3]. Fourier's rein theoretische Untersuchung wollte im ersteren Falle den Fuss durch das Meter ersetzen [4]; er stützte sich dabei auf die praktisch freilich wohl kaum zulässige Annahme, dass die Werthe der Temperaturschwankungen in einer geometrischen Reihe abnehmen, wenn die Tiefe in arithmetischer Progression wächst. Weitere Forschungen von Kupffer, Herrenschneider, Rudberg u. a. wurden in den Schatten gestellt durch die zusammenfassende Schrift Quetelet's [5], der für den jährlichen Gang der Bodentemperatur in der noch wirklich insolirten Schicht nachstehende Formel aufstellte: $\mathrm{y}=$ $a \sin (x+b)+c$; hierin ist $y$ die Thermometerhöhe für die von einem 
beliebigen Zeitpunkte an gerechnete Epoche x, c die mittlere Jahrestemperatur für das benützte Thermometer, a der halbe Unterschied zwischen Maximum und Minimum, b gleichfalls eine der Beobachtung unterliegende Konstante. Andererseits wollte Poisson [6] ermittelt haben, dass, wenn der Jahresabstand vom Maximum der Temperatur zum Minimum durch $\mathrm{H}$ und $\mathrm{H}^{\prime}$ für die Tiefen $\mathrm{x}$ und $\mathrm{x}^{\prime}$ bezeichnet werde, die Proportion

$$
H^{\prime}: H=1: e^{\frac{1}{5,11655}} \sqrt{\pi}\left(x^{\prime}-x\right)
$$

zu Recht bestehe. Höchst ausgedehnte Versuche verdankt man ferner Muncke (a. a. O.) und G. Bisch of [7], doch lassen sich dieselben nicht wohl zu allgemeingültigen Sätzen verdichten, vielmehr muss man sich mit der Erkenntniss begnügen, dass die Erwärmung des Bodens von der Intensität der Sonnenstrahlung, von den Hydrometeoren und den über den Boden hinstreichenden Luftströmungen abhängig ist. Müttrich [8] hat die forstlichen Beobachtungen für einen grossen Theil Deutschlands gesammelt und ist dabei zu folgenden Resultaten gekommen:

\begin{tabular}{|c|c|c|c|c|c|c|}
\hline Tiefe in $\mathrm{m}$ : & 0,00 & 0,15 & 0,30 & 0,60 & 0,90 & 1,20 \\
\hline \multicolumn{7}{|c|}{ Jahresamplituden. } \\
\hline Im Freien: & 21,6 & 19,5 & 18,3 & 17,4 & 16,1 & 14,8 \\
\hline Im Walde: & 19,1 & 16,9 & 15,1 & 13,4 & 12,0 & - \\
\hline Differenz: & 2,5 & 2,6 & 3,2 & 4,0 & 4,1 & . \\
\hline \multicolumn{7}{|c|}{ Jahresmitteltemperaturen. } \\
\hline Im Freien: & 10,4 & 9,6 & 8,6 & 8,9 & 9,0 & 8,9 \\
\hline Im Walde: & 8,9 & 8,2 & 7,9 & 8,2 & 8,2 & \\
\hline Differenz: & 1,5 & 1,4 & 0,7 & 0,7 & 0,8 & - \\
\hline
\end{tabular}

Eine der wichtigsten Stationen ist die zu Königsberg i. Pr. von Dorn eingerichtete und von ihm in einer eigenen Monographie (daselbst 1872) beschriebene; ausserdem wurden sehr regelmässige Messungen der Bodenwärme auf der Sternwarte Bogenhausen bei München bis zu dem Tode ihres früheren Direktors Lamont angestellt; derselbe hatte ein ca. $6 \mathrm{~m}$ tiefes viereckiges Holzrohr in den Boden eingesetzt und darin auf eine ihm eigenthümliche Weise die Thermometer befestigt. Es ist, wenn obiges der Fall, leicht einzusehen, dass die Tiefe der neutralen Schicht unter verschiedenen Breiten nicht die gleiche sein kann. Bedeutet $t \varphi$ die der geographischen Breite $\varphi$ entsprechende mittlere Bodenwärme, so ist, unter a, b, $\alpha, \beta$ gewisse Erfahrungszahlen verstanden, $t \varphi=a-b \sin ^{2} \varphi$ oder $=\alpha+\beta \cos ^{2} \varphi$, je nachdem man Kupffer [9] oder Kämtz [10] folgt*). Auf Grund der Formel verzeichnete namentlich der Letztere (a. a. O.) seine Is ogeothermen oder Ortskurven gleicher mittlerer Bodentemperatur. Indess verlohnt es bei dem heutigen Stande unseres Wissens nicht, den Verlauf dieser Kurven näher zu untersuchen. Wie leicht bei solchen Bestimmungen Fehler mit unterlaufen, beweist uns das in der Geschichte

*) Beide Formeln besagen im Grunde das Nämliche; es ist, weil $\sin ^{2} \varphi$ $=1-\cos ^{2} \varphi$ gesetzt werden kann, $\alpha=a-b, \beta=b$ zu nehmen. 
der Geophysik zu einer gewissen Beruhmtheit gelangte Beispiel Boussingault's, der [11] ermittelt haben wollte, dass in den Tropengegenden Südamerika's schon in $1 / 2 \mathrm{~m}$ Tiefe die Variationen der Wärme aufhörten, merklich zu sein; dass er hierin irrte, ist von Wild und Hann [12] dargethan worden. Selbst in jenen Ländern dürfte (a. a. O.) ein Hinabsteigen bis zu $5 \mathrm{~m}$ Tiefe nöthig werden, um die neutrale Schicht zu erreichen. Hann giebt auch an, dass Luft- und Bodentemperatur von einander sich bis auf einen ganzen Grad entfernen können, und damit ist der Werth des schon von Bergman gemachten Vorschlages, die mittlere Jahrestemperatur eines Ortes durch Beobachtung eines in die Erde eingegrabenen Thermometers zu erhalten [13], wesentlich gemindert, obwohl man ihn als Nothbehelf immerhin auch künftig gelten lassen mag.

In jenen Ländern, deren mittlere Jahrestemperatur nur sehr wenig über dem Nullpunkte oder gar unterhalb desselben liegt, wird man sehr bald unter dem Erdboden auf eine stets gefrorene und niemals aufthauende Schicht stossen: auf den unterirdischen Eisboden. Gmelin war es, der zuerst die Nachricht nach Europa brachte [14], in Jakutsk habe man das Graben eines Brunnens bei 90 Fuss T'iefe aufgeben müssen, weil die gefrorene Erde nicht mehr zu durchbohren gewesen sei, aber obwohl Pallas [15] Aehnliches aussagte, su glaubten doch L. v. Buch [16] und Andere (z. B. Hansteen) aus theoretischen Gründen diesen Angaben jeden Glauben versagen zu sollen. Jener berühmte Schergin-Schacht in Jakutsk, für den sich Wrangel und v. Middendorff so lebhaft interessirten, ward bis zu einer Tiefe von $116,5 \mathrm{~m}$ hinabgetrieben, und doch war auf dem Grunde die 'Temperatur noch nicht einmal bis zu Null gestiegen [17]. Bei Peschel-Leipoldt finden wir, mit Berufung auf eine von Fritz gezeichnete Karte, die Grenze des ewigen Bodeneises folgendermassen umschrieben [18]: „Sie führt von der Tanamündung (Finmarken, $70^{1} / 2^{0}$ n. Br.) nach Kandalaschka $\left(67^{\circ}\right.$, somit liegt die Halbinsel Kola ganz im Gebiete des Eisbodens), erscheint jenseits des weissen Meeres genau westlich von dem Orte Mesén $\left(66^{\circ}\right)$, überschreitet den Ural unter $62^{\circ}$ n. Br., nähert sich Tobolsk von Nord her bis auf $10 \mathrm{~g}$. M., geht südlich von Tomsk vorüber $\left(56^{\circ}\right)$, durchkreuzt nördlich von dem Austritt der oberen Tunguska den Baikalsee $\left(53^{\circ}\right)$, fällt zwischen $130^{\circ}$ und $140^{\circ}$ ö. L. v. F. nahezu mit dem 50. Parallelkreis zusammen und verlässt nördlich von der Amurmündung $\left(54^{\circ}\right)$ den asiatischen Kontinent. Kamtschatka wird etwa unter $58^{\circ}$ nördlicher Breite von ihr durchschnitten. In Nordamerika beginnt die Eisbodengrenze am Norton-Sund (unter $64^{\circ}$ ), läuft südlich von Fort Simpson vorbei, berührt das Nordende des Winipeg-See's $\left(54^{0}\right)$, sowie das Südende der Hudsonsbay $\left(51^{\circ}\right)$ und endigt auf der Halbinsel Labrador zwischen Nain und Hoffnungsthal $\left(56^{\circ}\right)$. Grönland liegt ganz innerhalb des Eisbodengebietes. " Wild betrachtet [19] die Isotherme von $-2^{\circ}$ als die Südgrenze des fraglichen Gebietes, doch bleibt dabei zu beachten, dass diese Linie auf den Karten als für das Meeresniveau gezeichnet erscheint, und dass die Temperatur für je $100 \mathrm{~m}$ Höhe etwa um $1 / 2^{\circ}$ fällt, so dass also bei $400 \mathrm{~m}$ Seehöhe der Eisboden schon in dem von der $0^{\circ}$ Isotherme durchzogenen Territorium seinen Anfang nehmen kann. Das Vor-

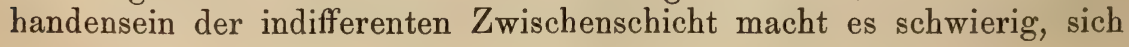


mit den in Krašan's Arbeit „Die Erdwärme als pflanzengeographischer Faktor" (Engler's bot. Jahrb., II, S. 185 ff.) durchgeführten Principien einverstanden zu erklären. Indess ist hier noch nicht der Ort, dieser Frage näher zu treten*).

§. 2. Die Zunahme der Wärme jenseits der neutralen Schicht. Die Frage, wie sich zunächst der Oberfläche die Erdtemperatur verhalte, gehört, wie wir sahen, nicht so sehr in das Gebiet der Erdphysik im engeren Sinne, als vielmehr in dasjenige der Meteorologie. Wie aber steht es jenseits der neutralen Schicht? Anhänger der Nebulartheorie müssen a priori den Schluss ziehen, dass jeder aus einem Zustande äusserster Dislokation der Theilchen in den Zustand der Erstarrung übergegangene Himmelskörper, also auch die Erde, gegen den Mittelpunkt zu wärmer und wärmer werden würde. Es fragt sich, ob die Beobachtungen dem entsprechen.

Schon Athanasius Kircher hatte von Freiberger Grubenarbeitern in Erfahrung gebracht [22], dass in der Tiefe die Hitze zunehme. Eben in diesem Sinne äusserten sich der Mediziner Boerhave [23] und der Physiker Boyle [24]: Der Schweizer J. Ott (1715-1769) erwarb sich, wie R. Wolf [25] berichtet, ein entschiedenes Verdienst dadurch, dass er auf Lambert's Anregung hin Jahre lang Bodentemperaturen in verschiedenen Tiefen mass, und zwar in der ausgesprochenen Absicht, das Fortpflanzungsgesetz der Wärme im Erdinneren auszumitteln. Sieben Thermometer wurden je $1 / 4,1 / 2,1,2,3,4,6$ Fuss tief eingesenkt. Anno 1766 legte Ott seine Ergebnisse der Berner physikalischen Gesellschaft vor, auch bemerkt das Sitzungsprotokoll in der Sprache der damaligen angewandten Mathematik, es liessen sich die Temperaturunterschiede schon so ziemlich auf eine bestimmte krumme Linie bringen. Lambert sandte der Gesellschaft eine "Die Vertheilung der Sonnenwärme in der Erde nach Anleitung der von Herrn Ott darüber angestellten Beobachtungen" betitelte Arbeit ein, die jedoch nicht zum Druck gelangte. Unter die neutrale Schicht herab gelangte Ott freilich nicht. Aus der zweiten Hälfte des XVIII. Jahrhunderts sind nach Muncke's Zeugniss (a. a. O.) dahin gehende Aeusserungen von Freiesleben und Lampadius zu verzeichnen; man vergleiche auch die von Reich [26] gegebene geschichtliche Uebersicht. Mairan, v. Trebra, Saussure und ganz besonders D'Aubuisson ist es zu danken, dass die Diskussion der Frage ununterbrochen Fortschritte machte. Von Ausnahmen abgesehen, deren gleich nachher eigens zu gedenken sein wird, herrschte bald eine gewisse Einstimmigkeit darïber, dass jeder Bewegung auf einem Erdradius gegen den Mittelpunkt hin eine Vermehrung der Temperatur entspreche, und es kam nun darauf an, das Gesetz der geothermischen Tiefenstufen empirisch für verschiedene Verhältnisse zu erkunden. In Kürze lässt sich somit die zu stellende Frage folgendermassen formuliren: Um wieviel Meter muss

*) Anhangsweise bemerkt sei noch, dass schon Hales [20] bei Gelegenheit seiner pflanzenphysiologischen und Mairan [21] bei Gelegenheit meteorologischer Untersuchungen die Nicht-Uebereinstimmung von Boden- und Lufttemperatur behauptet hatten. 
man in der Richtung nach dem Erdcentrum sich vorwärts bewegen und zwar von der unveränderlichen Schicht an - damit das hunderttheilige Thermometer um $1^{0}$ steige? Es ist dabei vorläufig angenommen, dass dieses Wachsthum der Temperatur gleichförmig erfolgt, obwohl diese Annahme natürlich nur den Charakter einer ersten Annäherung besitzt und durch die Praxis vielfache Einschränkungen erleidet.

Die Messung selbst kann nun entweder dadurch geschehen, dass man in tiefen Schachten Beobachtungen der dortselbst zu findenden Luft, oder auch des Grubenwassers, oder endlich auch des den Schacht einschliessenden Gesteines anstellt. Andererseits ist man auch von dem freilich nur im Grossen und Ganzen richtigen Gedanken ausgegangen, dass bewegte Flüssigkeiten die Temperatur in der Gegend ihres Ursprunges nach aussen übermittelten, und hat dem entsprechend Wärmemessungen in artesischen Brunnen und in natürlichen Quellen gemacht. Dass all' diesen Versuchen nur ein sehr relativer Werth für die Lösung des Erdproblemes zukommen könne, erhellt, von Anderem abgesehen, schon aus der im Verhältniss zum Erdhalbmesser äusserst geringen Tiefe, welche dem Menschen zu erreichen gewährt ist. Als das tiefste vorhandene Bohrloch betrachtet man mit v. Dechen [27] gewöhnlich jenes von Sperenberg in der Mark (1272 m), doch erwähnt Huyssen [28] in seiner Uebersicht über die vom preussischen Staate unternommenen Tiefbohrungen, dass man bei Lieth in Holstein eine Tiefe von $1339 \mathrm{~m}$ erreicht habe. Die grösste Stollentiefe mit $1152 \mathrm{~m}$ Tiefe dürften die Kuttenberger Bergwerke aufweisen. Der tiefste artesische Brunnen endlich ist nieht etwa der bekannte von Grenelle bei Paris, sondern er befindet sich in St. Louis. Im Jahre 1865 war man schon $565 \mathrm{~m}$ weit hinabgekommen, ohne das Ziel zu erreichen [29]. Diesen Mängeln jeder subterranen Wärmebestimmung vermag menschliche Kraft nicht abzuhelfen, wohl aber hat man eine anderweite Fehlerquelle erkennen und vermeiden gelernt. Es handelt sich nämlich doch (vgl. das letzte Kapitel der vorigen Abtheilung, §. 5) darum, den thermometrischen Gradienten jener Kurven, der von Bischof mit diesem Namen belegten Chthonisothermen*), zu finden, für welche die Erdtemperatur den nämlichen Werth besitzt. Fig. 58 stellt eine solche Kurvenschaar unmittelbar unter

Fig. 58 .

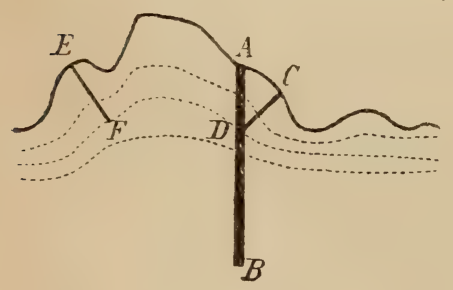

trifft. Poggendorff [30] einem coupirten Terrain dar, die Linien $\mathrm{CD}$ und EF repräsentiren die zur Ermittelung des Gradienten dienenden orthogonalen Trajektorien. Würde nun in A ein Bohrloch angelegt, dessen Richtung A B selbstverständlich mit der Vertikalen übereinstimmt, so dürfte dessen Axe keinesfalls zur Abmessung der Gradienten verwendet werden, da sie ersichtlich die Isothermkurven unter schiefen Winkeln und Studer [31] betonten also mit Recht

*) Da die Worte "Isogeothermen" und "Chthonisothermen" den nämlichen Sinn haben, Synonyma aber in der wissenschaftlichen Kunstsprache möglichst $\mathrm{zu}$ vermeiden sind, so würden wir vorschlagen, die erstere Bezeichnung ausschliesslich für die oberhalb und die letztere ausschliesslich für die unterhalb der neutralen Schicht verlaufenden Kurven zu wählen. 
die Nothwendigkeit, eine auf dem jeweiligen Terrain senkrechte Axe zu wählen, wie CD oder EF in unserer Figur, denn da man annehmen kann, dass die neutrale Fläche ungefähr der Oberfläche parallel verläuft, so wird jene Axe auch annähernd senkrecht stehen zu den zunächst anliegenden Chthonisothermen. Diese Kautel ist namentlich zu berücksichtigen bei den neuerdings zu besonderer Wichtigkeit gelangten Messungen im Inneren eines Tunnels.

§. 3. Temperaturbeobachtungen in Gruben. Die ersten mit einer gewissen Konsequenz durchgeführten Versuchsreihen dieser Art rühren von Gensanne und Lean her [32]. Ersterer fand zu Giromagny bei Belfort $12,5^{\circ}$ in 110 , ferner $13,1^{\circ}$ in $206,19^{\circ}$ in 308 und $22,7^{\circ}$ in 433 Meter Tiefe, letzterer stellte die folgende Tabelle auf:

Sisommerbeobachtungen.

$\begin{aligned} 5,5 \mathrm{~m}: & 18,5^{0} \\ 91,0 \mathrm{~m}: & 29,5^{\circ} \\ 146,0 \mathrm{~m}: & 20,0^{\circ} \\ 295,0 \mathrm{~m}: & 21,7^{0} \\ 329,0 \mathrm{~m}: & 22,7^{\circ} \\ 348,0 \mathrm{~m}: & 26,1^{0}\end{aligned}$

Winterbeobachtungen.

$\begin{array}{rr}5,0 \mathrm{~m}: & 11,1^{0} \\ 91,0 \mathrm{~m}: & 17,2^{0} \\ 183,0 \mathrm{~m}: & 19 ; 0^{0} \\ 293,0 \mathrm{~m}: & 21,1^{0} \\ 329,0 \mathrm{~m}: & 23,3^{0} \\ 366,0 \mathrm{~m}: & 25,5^{0}\end{array}$

Eine ähnliche, wenn schon gleichfalls unregelmässige Zunahme der Erdtemperatur konstatirten Fantonetti in italienischen und A. v. Humboldt in neuspanischen Gruben [33]. Alle diese Messungen bezogen sich jedoch nur auf die Grubenluft, und es wirken mehrere Umstände zusammen, um gerade dieses Element als für die Beantwortung der Frage sehr ungeeignet erscheinen zu lassen. Es war zuerst Cordier, der diese Thatsache feststellte und auf einen verbesserten Beobachtungsmodus drang [34]; er wendet sich jedoch auch gegen die Benützung der Grubenwässer, da man nicht wisse, aus welcher Höhe sie beim Zutagetreten bereits herabgesunken und durch welche Kanäle sie vorher gelaufen seien. Fox hatte durch Einführung des Thermometers in die ausgepumpten Wasser einiger Minen von Cornwall das etwas prekäre Ergebniss erhalten [35], dass die geothermische Tiefenstufe in Kupferbergwerken blos 30, in Zinnbergwerken dagegen 75 englische Fuss betrage. Cordier selbst empfahl angelegentlich das Einschliessen des Instrumentes in den Felsen der Schachte und arbeitete selbst nach diesem Principe drei Jahre hindurch in drei französischen Gruben mit Wärmemessern, welche vorher der Landessternwarte zur Vergleichung vorgelegen hatten. Seine Durchschnittszahl für die Tiefenstufe belief sich auf $25 \mathrm{~m}$. Seit $1828^{*}$ ) besitzt man regelmässige Temperaturbestimmungen aus den preussischen Werken, doch wurden vergleichbare Konstanten nicht erzielt [36]. Mit Aufbietung aller Genauigkeit damaliger Zeit wurden hingegen die in der uns bereits bekannten Arbeit von Reich (s. o.) beschriebenen Beobachtungen ausgeführt. Durch eine Wahrscheinlichkeitsbetrachtung eigenthümlicher und durchaus nicht über jeden Einwurf erhabener Art, der jedoch nicht so leicht eine bessere zu substituiren sein dürfte, sah sich

*) In diesem Jahre veranlasste nämlich $\mathrm{Humboldt}$ die Austheilung von zu diesem Zwecke bestimmten Thermometern an sämmtliche Grubendirektionen des Königreiches.

Günther, Geophysik. I. Band. 
Reich veranlasst, jede Einzelbestimmung für die mit $\mathrm{x}$ bezeichnete Zunahme der Temperatur auf je $100 \mathrm{~m}$ Tiefe mit einem Gewicht P zu versehen, das er auf seine eigene Weise ermittelte, ihm zufolge ist

$$
\mathrm{x}=\frac{100\left(\mathrm{t}_{2}-\mathrm{t}_{1}\right)}{\mathrm{h}_{1}-\mathrm{h}_{2}}, \quad \mathrm{P}=\frac{\left(\mathrm{h}_{1}-\mathrm{h}_{2}\right) \sqrt[4]{\tau}}{\sqrt{\mathrm{D}_{1}}+\sqrt{\mathrm{D}_{2}}} .
$$

Hier bedeuten $h_{1}$ und $h_{2}$ die Meereshöhen der beiden Beobachtungsstationen, $t_{1}$ und $t_{2}$ die daselbst gemessenen Temperaturen, $\tau$ ist die Zeitdauer der Beobachtung in Monaten, während $\mathrm{D}_{1}$ und $\mathrm{D}_{2}$ die grössten Temperaturschwankungen am oberen und unteren Platze vorstellen. Hiernach berechnete Reich die geothermische Tiefenstufe zu 41,84 m. J. Phillips fand in einem noch jungfräulichen Schachte zu Newcastle nicht ganz $33 \mathrm{~m}$, Kupffer im Ural 19,52 m [37], Matteucci endlich erhielt in der Steinkohlengrube zu Monte-Massi in Toskana den ungemein niedrigen Werth von $13,7 \mathrm{~m}$ [38]. Neueren Zusammenstellungen von Zöppritz [39] entnehmen wir, dass Marsilly in der Kohlengrube von Anzin (Nordfrankreich), je nachdem er einen der vier vorhandenen Schachte wählte, $25,9 \mathrm{~m}, 20,7 \mathrm{~m}, 15,6 \mathrm{~m}$ und $15,4 \mathrm{~m}$, Schwartz zu Schemnitz 41,4m, Heckels zu Newcastle 26.9 m ermittelte. Durch ganz abnorme Verhältnisse der Wärmezunahme zeichnet sich die amerikanische Comstockgrube aus, welche Church zuerst allgemein geologisch [40] und dann noch einmal speziell kalorimetrisch [41] g eschildert hat. Eine andere für unsere Zwecke Erfolg versprechende Grube ist der sogenannte Formanschacht in Nevada, jener ersterwähnten benachbart und vielleicht durch sie beeinflusst; wenigstens ist St apff [42] dieser Meinung, weil sich so die sonst auffällige Erscheinung am besten erklärt, dass mit zunehmender Tiefe das Temperaturwachsthum wieder abnimmt. Stapff entwickelt auch für die Gesteinstemperatur $\mathrm{t}$ in der Tiefe $\mathrm{h}$ nach der Methode der kleinsten Quadrate (a. a. O.) eine Formel, welche er später, auf Grund neuer Angaben Forman's, durch eine andere ersetzt [43]; wir führen nachstehend beide an:

$$
\begin{gathered}
\mathrm{t}=10,31+(\mathrm{h}-30,48) \sqrt{0,005568-0,00000391(\mathrm{~h}-30,48)} ; \\
\mathrm{t}=9,92+\mathrm{h} \sqrt{0,004497-0,000002308 \mathrm{~h} .}
\end{gathered}
$$

Stapff's Abhandlungen erscheinen auch noch aus einem anderen Grunde bemerkenswerth, nämlich wegen der darin anzutreffenden Betrachtungen über die wechselseitigen Beziehungen zwischen innerer Gesteinstemperatur, Bodentemperatur und mittlerer Lufttemperatur.

§. 4. Temperaturbeobáchtungen in Bohrlöchern. Dieselben erfreuen sich, selbst wenn nicht noch Anderes hinzukäme, des Vortheils, dass es möglich ist, die Thermometer der einzelnen Stationen genau in der nämlichen Vertikallinie anzubringen. Zuerst scheint sich dieses Umstandes der bekannte Physiker P. Erman bewusst geworden zu sein; er wählte das Bohrloch zu Rüdersdorf unweit Berlin [44], wo 90 Fuss Tiefe dem Steigen des (Réaumur'schen) Thermometers um $1^{0} \mathrm{zu}$ entsprechen schienen. Magnus setzte diese Beobachtungen fort [45], und zwar konstruirte er eigens zu diesem Behufe sein Geothermometer, das sich von den gebräuchlichen Instrumenten wesentlich nur durch seine etwas weitere Röhre und einen Cylinder von angemessener Grösse unterscheidet. Er glaubte, Erman's Zahl 90 
durch 69 ersetzen zu müssen. De la Rive und Marcet [46] bekamen in einem artesischen Brunnen bei Genf $32,55 \mathrm{~m}$ auf $1^{0}$, und siebenundzwanzig Quellen dieser Art in und bei Wien lieferten den Mittelwerth von $27 \mathrm{~m}$. Im Allgemeinen können die aus Beobachtungen an artesischen Brunnen abgezogenen Resultate nicht als die zuverlässigeren gelten, ein Theil des aufgetriebenen Wassers sinkt, sowie es kälter und damit spezifisch schwerer wird, wieder in die Tiefe, und es wird so ein Cirkulationsakt eingeleitet, dessen Wirkungen sich in einer Veränderung der Tiefenstufen offenbaren. Von einer in Pest vorgenommenen Brunnenbohrung berichtet z. B. Zöppritz [47] nach Zsigmondy Folgendes: Der Temperaturgradient, der im Ganzen $1^{0}$ auf $12,6 \mathrm{~m}$ beträgt, vertheilt sich sehr ungleich auf die Tiefe, denn von $58 \mathrm{~m}$ bis $159 \mathrm{~m}$ stieg die Temperatur von $15^{\circ}$ auf $30^{\circ}$, bis $370 \mathrm{~m}$ auf $45^{\circ}$, bis $570 \mathrm{~m}$ auf $60^{\circ}$, bis $900 \mathrm{~m}$ auf $80,9^{\circ} .{ }^{*}$ Diese Anomalien regen auch dieser Katagorie von Messungen gegenüber unwillkürlich zu einem gewissen Skepticismus an*). - Noch weniger Verlass ist selbstverständlich auf die Temperaturen natürlicher Quellen, bei deren Entstehung die meteorischen Gewässer eine völlig unkontrolirbare Rolle spielen; wir werden hierauf in dem den Quellen speziell gewidmeten Kapitel zurückkommen.

Jedenfalls das Sicherste und Beste, was für interne Erdtemperaturen bisher geleistet wurde, verdankt man Dunker's Messungen mit einem vervollkommneten (Magnus'schen) Geothermometer im Bohrloche zu Sperenberg; in einer grossen Abhandlung beschreibt der genannte verdiente Montanist [49] den Plan seiner Untersuchung und die Vorsichtsmaassregeln, welche er anwandte, um jenes Aufsteigen wärmeren und Sinken kälteren Wassers, wovon wir oben sprachen, thunlichst zu verhindern. Er stellte zur Berechnung der Temperatur $t$ aus der Tiefe $\mathrm{h}$ einen für $\mathrm{h}$ quadratischen Ausdruck auf, substituirte ihm aber später einen solchen vom dritten Grade [50]. Die betreffenden Formeln sind diese:

$$
\mathrm{t}=7^{0} 18^{\prime}+0,01298571818 \mathrm{~h}+0,00000125701 \mathrm{~h}^{2}
$$

$\mathrm{t}=7^{0} 18^{\prime}+0,01783521 \mathrm{~h}-0,00000580396 \mathrm{~h}^{2}+0,0000000008726 \mathrm{~h}^{3}$. Beide Relationen, so unsäglich viel Mühe auch an ihre Ableitung, d. h. an die Ermittelung der konstanten Koefficienten, gewandt wurde, leiden doch an einem principiellen Uebelstande. Für $\mathrm{t}=\mathrm{a}+\alpha_{1} \mathrm{~h}+\alpha_{2} \mathrm{~h}^{2}$ und $t=a+\alpha_{3} h-\alpha_{4} h^{2}+\alpha_{5} h^{3}$ ist nämlich resp.

$$
\frac{\mathrm{dt}}{\mathrm{dh}}=\alpha_{1}+2 \alpha_{2} \mathrm{~h}, \quad \frac{\mathrm{dt}}{\mathrm{dh}}=\alpha_{3}-2 \alpha_{4} \mathrm{~h}+3 \alpha_{5} \mathrm{~h}^{2},
$$

und da bei Einsetzung der wirklichen Werthe für die zweiten Differentialquotienten negative Werthe sich ergeben, so schiene zu folgen, dass für

$$
\mathrm{h}=-\frac{\alpha_{1}}{2 \alpha_{2}} \text { resp. } \mathrm{h}=\frac{\alpha_{4} \pm \sqrt{\alpha_{4}^{2}-3 \alpha_{3} \alpha_{5}}}{3 \alpha_{5}}
$$

ein Temperaturmaximum einträte, was doch sachlich nicht wohl mög-

*) Auch diejenigen Versuchsreihen, denen das von Walferdin angegebene selbstregistrirende Thermometer zu Grunde lag, stimmen nicht überein. Arago glaubte der Reibung des Bohrgestänges einen erheblichen Einfluss zuschreiben zu sollen [48]. 
lich ist. Henrich war deshalb wohl im Rechte, sich [51] gegen Dunker's Berechnungsmethode zu erklären, und wir können nicht finden, dass die in dem Streite des Ersteren mit Brauns [52] gegen sein eigenes Verfahren erhobenen Einwände gerechtfertigt wären. Denn Henrich macht geltend, dass Dunker die Summe der Fehlerquadrate nicht zu einem Minimum gemacht und mit $0,7^{\circ}$ einen im Verhältniss zu der Güte des Geothermometers zu hohen wahrscheinlichen Fehler zugelassen habe. Die neue Formel Henrich's, nach welcher $\mathrm{t}=12,273^{\circ}+0,007449 \mathrm{~h}$ zu setzen ist, möchte den Dunker'schen immer noch vorzuziehen sein; ihr wahrscheinlicher Fehler heläuft sich nur auf $0,3^{\circ}$. Darin muss man freilich nach all' diesen Leistungen J. L. A. Roth beistimmen, der als einer der Ersten über die Sperenberger Temperaturmessungen geschrieben hat [53], dass ein festes Gesetz über die Variation der Erdwärme denselben nicht entnommen werden kann.

§. 5. Temperaturbeobachtungen in Tunnels. Systematisch und in grösserem Style hat diese Aufzeichnungen wohl zuerst der bekannte Geologe des Gotthard-Unternehmens, Stapff, betrieben; seine erste grössere Arbeit darüber erschien [54] schon 1877, und später konstruirte er [55] ein vollständiges Temperaturprofil des durchbohrten Gebirgsstockes. Die wichtigsten Resultate Stapff's nahm Koch [56] in seine zusammenfassende Schrift über diesen Gegenstand auf, aus welcher grossentheils die folgenden Mittheilungen herübergenommen sind.

Aus dem Montcenis- und Arlberg-Tunnel besitzt man leider nur sehr geringfügiges Material über die daselbst herrschenden Luft- und Gesteinstemperaturen. Bei'm Gotthard verhält es sich anders; Stapff schob seine Beobachtungsstationen bis $4100 \mathrm{~m}$ vom Südportal und $4400 \mathrm{~m}$ vom Nordportal vor und diskutirte deren Registrirungen mit Bezug auf die mittleren Jahrestemperaturen der Oberfläche, auf die Quellentemperaturen, auf die vertikale Tiefe des Beobachtungsplatzes und auf dessen kürzesten Abstand von der nächsten Seitenwand des Berges. Die mittlere Gesteinstemperatur des centralen Tunneltheiles war $30,43^{\circ}$; der nach erfolgtem Durchschlag sich einstellende Luftstrom bewirkte alldort im Verlaufe zweier Monate blos einen Rückgang von $0,15^{\circ}$ bis $0,21^{\circ}$. Die einzelnen Chthonisothermflächen oder Flächen von gleicher subterraner Temperatur wiesen sehr verschiedene Steigungen gegen die Oberfläche des Berges auf, namentlich vertikal unter dem Hochplateau von Andermatt. Auf der nördlichen Tunnelseite betrug die Wärmestufe anfänglich $20,5 \mathrm{~m}$, ja unter dem steilen Abfall der Wannelen sogar blos 42,6 m; auf der Südseite $45 \mathrm{~m}$ und unter dem Steilkamm der Cima Boita-Misura 62,3 m. Es wird also das Profil der Chthonisothermen wesentlich durch jenes des überlagernden Gebirges bedingt, jedoch dem Sinne nach entgegengesetzt. Fig. 59 kennzeichnet dieses Verhältniss; A A ist der Durchschnitt einer Vertikalebene mit dem Berge selbst, BB die Schnittcurve derselben Ebene mit einer Fläche der Chthonisothermen. Das Tunnelwasser ist kälter als das Gestein, so lange des letzteren Temperatur nicht $24^{\circ}$ bis $25^{\circ}$ übersteigt, bei dieser Grenze aber tritt ein Umschwung ein, die Gewässer übertreffen die Felsen an Wärme. 
Einer von Stapff herrührenden empirischen Formel zufolge steht fest, dass es im Arlberg-Tunnel unter sonst gleichen Umständen wärmer sein muss, als im Gotthard-Tunnel. Für die vorgeschlagene Simplonlinie findet man als centrale Temperatur $45^{\circ}$ bis $48^{\circ}$, für die Mittelstrecke des projektirten Montblanc-Tunnels sogar $51^{\circ}$. Obwohl Eiweiss erst bei $60^{\circ}$ sich zu trüben anfängt, und Menschen im Ruhezustande eine sehr hohe trockene Hitze auszuhalten vermögen man denke nur an die von Poggendorff [57] citirten Versuche eines Banks, Fordyce, Solander und Phipps am eigenen Leibe -, so wird doch in der feuchtwarmen Atmosphäre eines Tunnels das Arbeiten schon bei $40^{\circ}$ mühsam und gefährlich. Den Tunnelprojekten der Westschweiz eröffnet sich hiernach eine schlechte Prognose. Ganz in gleichem Sinne sprach sich auch A. Heim [58] betreffs der Unterführung des Montblanc aus; die sogenannte "Galerie sous vallée", so meint er, werde mit grossen Schwierigkeiten geologischer Natur zu kämpfen haben, und wenn diese auch für den "Grand tunnel" in Wegfall kämen, so erweise sich dort die hohe Temperatur als Hinderniss. Den aus den Schnee- und Eismassen des Berges hergeleiteten Trost vernichtet Heim durch den Hinweis darauf, dass Gletscher erfahrungsgemäss erst dann auf die anruhenden Gesteinsmassen abkühlend wirken, wenn sie in ein Gebiet höherer mittlerer Jahrestemperatur herabgestiegen sind.

§. 6. Allgemeine Resultate und theoretische Schlussfolgerungen. Man mag über den Werth der verschiedenen Versuche, Klarheit über den Temperaturzustand des inneren Erdkörpers zu erlangen, wie immer denken: eine stetige Wärmezunahme von der Oberfläche nach dem Centrum hin lässt sich schwerlich in Abrede stellen. Freilich hat es niemals ganz an Gegnern dieser Auffassung gefehlt. So namentlich in früherer Zeit Moyle [59] und Miller [60], welche mit etwas gesuchten Gründen die Beobachtungen in Gruben mit noch weit mehr Fehlerquellen behaftet sein liessen, als es wirklich der Fall ist. Auch G. F. Parrot hielt [61] die Nichtübereinstimmung der einzelnen Beobachtungsreihen für gross genug, um zu behaupten, dass von einem radialen Zunehmen der Erdtemperatur nicht gesprochen werden dürfe; er schüttete also das Kind mit dem Bade aus. Seinen vorgefassten Meinungen zuliebe gehörte auch Poisson zu dieser gegnerischen Richtung, doch war ihm in der Behauptung, dass man es nicht sowohl mit einer Eigenwärme der Erde, als vielmehr mit einer in ihr aufgespeicherten "chaleur stellaire" ${ }^{\text {zu }}$ thun habe, bereits Aepinus [62] vorangegangen. Die Erde ist nach Poisson [63] als Trabant der den Weltraum durcheilenden Sonne - vgl. den letzten §. des vorletzten Kapitels der vorigen Abtheilung - in Regionen von verschiedener Sternwärme gekommen, und die in diesen Regionen herrschende Temperatur ist stets bis zu einer gewissen Tiefe, jedoch niemals sehr weit, in den Erdkörper eingedrungen; „man kann diesen als einen Felsblock 
betrachten, der vom Aequator nach dem Pole geschafft wurde, aber in einer so kurzen Zeit, dass er nicht ganz zu erkalten vermochte. Die Temperaturzunahme in diesem Blocke würde sich nicht bis zu den Schichten seiner Mitte erstreckt haben." Ausser Humboldt, dem wir diese vorstehende Uebersetzung verdanken [64], haben Pog gend or ff [65], Lamont [66] und Pilar [67] diese sonderbare Theorie bekämpft; Archiac [68] sagt treffend, Poisson müsse sich doch wohl gedacht haben, dass seine Erde direkt einen Stern gestreift habe. Heutzutage ist Poisson's Lehre fast gänzlich vergessen, dafür aber ist später Mohr als neptunistischer Fanatiker gegen die Hypothese einer progressiven Erdwärme aufgetreten [69] und hat zumal aus Dunker's Formeln (s. o. §. 4) Kapital zu schlagen versucht. Es ist ja wahr, gäbe es diesen Formeln zufolge ein Temperaturmaximum in relativ geringer Tiefe, so wäre die Frage in Mohr's Sinne entschieden, doch sahen wir schon, dass man den Fehler in der algebraischen Einkleidung eines Naturgesetzes nicht mit diesem letzteren verwechseln darf. Wir glauben somit, dass alle Einwürfe gegen die von uns vorgetragene Lehre ihr Ziel verfehlt haben. Mohr's eigener Versuch, die innere. Wärme der uns zugänglichen Schichten der Erdkruste nach den Grundsätzen der mechanischen Wärmetheorie aus Bewegungsvorgängen abzuleiten, fand eine treffende Kritik durch F. Pfaff [70], der die ungeheuren rechnerischen Uebertreibungen, die bei Mohr mit unterlaufen, an geeigneten Beispielen kennzeichnete.

Ein gültiges Gesetz der geothermischen Tiefenstufen oder der chthonisothermischen Gradienten aufstellen zu können, davon sind wir freilich noch sehr weit entfernt. Kupffer findet [71] bei Sichtung des zu damaliger Zeit vorliegenden Materiales, dass seine eigenen Beobachtungen am Ural (s. o. §. 4) 24,8 m, die südenglischen, französischen und sächsischen Messungen zusammen 26,9 m, die artesischen Brunnen von Wien, Rochelle und Epinay je 25,4 m, 24,6 m und $22,9 \mathrm{~m}$, gewisse Untersuchungen von Fox endlich resp. $30,2 \mathrm{~m}$ und 28,0 m liefern. Mit gehöriger Beachtung der jeder Zahl zukommenden Gewichte resultirt hieraus ein Werth von $25,37 \mathrm{~m}$ für $1^{\circ} \mathrm{R}$., also von $20,296 \mathrm{~m}$ für $1^{\circ} \mathrm{C}$. Gewöhnlich betrachtet man $30 \mathrm{~m}$ als Durchschnittswerth der Tiefenstufe. Die als "British Association" wohlbekannte grossbritannische Naturforscherversammlung hat einen Ausschuss zur Sammlung von neuen Beobachtungsdaten niedergesetzt und lässt sich durch dessen Schriftführer Everett alljährlich einen Rechenschaftsbericht erstatten [72]. Er that diess schon zweimal [73] und konnte feststellen, dass neuere Bestimmungen in englischen Gruben jeweils die Werthe $26,6 \mathrm{~m}, 34,1 \mathrm{~m}$ und 42,1 $\mathrm{m}$ ergaben.

Die mathematische Analyse vermag der Vertheilung der Wärme auch in jenen Tiefen der Erde nachzuspüren, bis zu welchen keine unmittelbare Sonde mehr hinabzureichen vermag. Fourier und Poisson haben in ihren uns bereits bekannten Untersuchungen über die Wärmeleitung den zu diesem Ende zu beschreitenden Weg vorgezeichnet, W. Thomson führte die Methode weiter aus [74] und stellte die Formeln übersichtlich zusammen [75]. Die Erde wird als ein unendlich ausgedehnter Körper genommen, und zugleich wird vorausgesetzt, vor sehr langer Zeit habe die Temperatur zu beiden Seiten einer den Körper durchschneidenden unendlichen Ebene verschiedene, aber 
konstante Werthe gehabt. - Es sei $\mathrm{k}$ das Leitungsvermögen dieses Körpers, $\mathrm{V}$ die halbe Differenz beider Anfangstemperaturen, $\mathrm{V}_{0}$ deren arithmetisches Mittel, t die seit dem Bestehen jenes Anfangszustandes verflossene Zeit, $\mathrm{x}$ der Abstand eines variablen Punktes von der Trennungsebene, $\mathrm{v}$ die Temperatur der durch $\mathrm{x}$ fixirten Ebene zur Zeit $\mathrm{t}$ (also $d v$ : $d x$ der Gradient der Temperatur); dann ist die partielle Differentialgleichung

$$
\frac{\partial \mathrm{v}}{\partial \mathrm{t}}=x \cdot \frac{\partial^{2} \mathrm{v}}{\partial \mathrm{x}^{2}}
$$

aufzulösen, und zwar muss $\mathrm{v}$, wenn $\mathrm{t}=0$ wird, für ein positives $\mathrm{x}$ in $\left(V_{0}+V\right)$, für ein negatives in $\left(V_{0}-V\right)$ übergehen. Thomson findet successive folgende beide Lösungen *)

$$
\frac{\partial \mathrm{v}}{\partial \mathrm{x}}=\frac{\mathrm{V}}{\sqrt{\pi x \mathrm{t}}} \cdot \mathrm{e}^{-\frac{\mathrm{x}^{2}}{4 x \mathrm{t}}} ; \mathrm{v}=\mathrm{V}_{0}+\frac{2 \mathrm{~V}}{\sqrt{\pi}} \cdot \int_{0}^{\frac{\mathrm{x}}{2 \sqrt{x \mathrm{t}}}} \mathrm{e}^{-z^{2}} \cdot \mathrm{dz}
$$

Wendet man diese Lösung auf unsere Erde an, so begeht man allerdings Fehler, die jedoch angesichts des grossen Volumens der Erde nicht belangreich sein können. Thomson setzt den Diameter der Erdkugel $==8000$ englischen Meilen, $\mathrm{k}=400, \mathrm{t}=100000000$ Jahren und erhält so

$$
\frac{\partial v}{\partial x}=\frac{V}{35400} \cdot e^{-\frac{x^{2}}{160000000}}
$$

Die in Fig. 61 abgebildeten Kurven stellen den Gang der Temperatur im Erdinneren dar. Auf der X-Axe OX nimmt Thomson jedes $a=400000$ engl. Fussen, auf $\mathrm{OY}$ jedes $\mathrm{b}=\frac{1}{354000}$ von $\mathrm{V}$ an. Dann zeigt die Kurve AP'R die Grösse der Temperaturzunahme nach dem Erdcentrum hin, während die Kurve OPQ den Ueberschuss der Temperatur im Erdinnern über jene der Oberfläche zum Ausdrucke bringt. Die Bischef'schen Versuche mit einer glühend gemachten Basaltkugel [77] scheinen diesen theoretischen Ergebnissen nicht zu widersprechen; dieselben wurden neuerdings von A yrton und Perry wieder aufgenommen, und Milne stellte die von letzteren Forschern erzielten Temperaturkurven mit den aus dem Fourier-Thomsonschen Kalkul sich ergebenden in Fig. 60 .

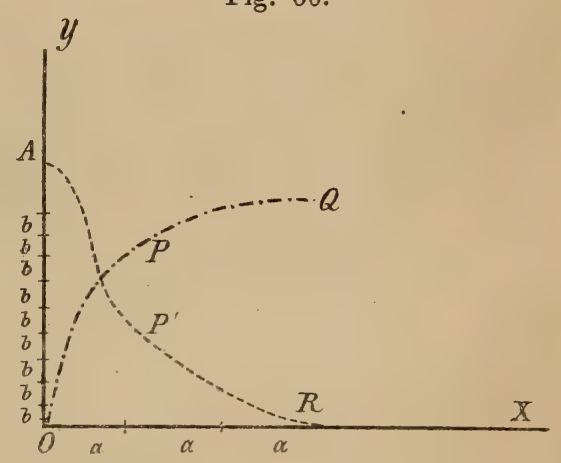
eine kritische Parallele.

Die oft sehr auffallenden Verschiedenheiten in den Werthen der Tiefenstufen finden nicht selten eine ganz zufriedenstellende Erklärung,

*) Thomson selbst deutet (a. a. O.) seine Lösungsmethode nur an; einen ausführlichen Beweis für die Richtigkeit obiger Ausdrücke giebt Hempel' [76]. 
wenn man auch den individuellen Charakter der Gesteinsart in Rechnung zieht, innerhalb deren die Messungen vor sich giengen. Man würde freilich zu weit gehen, wenn man sämmtliche intern-tellurische Wärmeerscheinungen durch chemische Processe entstanden annehmen wollte, doch wird ein anomales Unterbrechen der arithmetischen Progression, in welcher die Erdwärme in homogenem Fels wächst, vielfach eine mineralchemische, häufig eine rein physikalische Deutung zulassen. Kupfer z. B. ist ein sehr gut leitendes Metall, in oder nahe bei einem Kupfergange wird daher, nach Cordier (s. o. §. 3), die Temperatur eine ungewöhnlich hohe sein. Die Kaolinbildung in trachytischem Gesteine wirkt als lokaler Wärmeheerd bei der Comstockgrube; wenigstens erachtet Stapff (s. o. §. 3) die Existenz eines durch Zersetzungsvorgänge entstandenen und nicht sehr tief liegenden - jedoch natürlich nur relativen - Temperaturmaximums für sehr möglich. Zsigmondy's artesischer Brunnen endlich (s. o. §. 4) stand offenbar in unterirdischer Verbindung mit Thermalgewässern, die ja in der Umgegend von Budapest gerade keine Seltenheiten sind.

[1] J. D. Cassini de Thury, Sur la température des souterrains de l'observatoire royal, Mém. de l'acad. franç. des sciences, Année 1786. S. 511 ff. [2] Gehler's physikalisches Wörterbuch, 2. Auflage, 3. Band, Leipzig 1827. S. 986 ff.; ibid. 9. Band, 1. Abtheilung, Leipzig 1838. S. 279 ff. - [3] Ibid. 9. Band, 1. Abtheilung, S. 988. - [4] Fourier, Théorie analytique de la chaleur, Paris 1822. S. V. - [5] Quetelet, Mémoire sur les variations diurne et annuelle de la température et en particulier de la température terrestre à différentes profondeurs, Bruxelles 1837. - [6] Poisson, Théorie mathématique de la chaleur, Paris 1835. S. 500 ff. - [7] Bischof, Die Wärmelehre des Inneren unseres Erdkörpers, Leipzig 1837. - [8] Müttrich, Beobachtungen der Erdtemperatur auf den forstlichen meteorologischen Stationen in Preussen, Braunschweig und Elsass-Lothringen, Berlin 1880. - [9] Kupffer, Mittlere Luft- und Bodentemperatur im östlichen Russland, Ann. d. Phys. u. Chem., 15. Band. S. 176 ff. - [10] Kämtz, Lehrbuch der Meteorologie, 2. Band, Halle 1833. S. 32. - [11] Boussingault, Sur la profondeur, à laquelle se trouve la couche de température invariable entre les tropiques, Ann. de chim. et de phys., tome LIII. S. 226 ff. - [12] Hann, Handbuch der Klimatologie, Stuttgart 1883. S. 32. - [13] Bergman, Physische Erdbeschreibung, deutsch von Röhl, 2. Band, Greifswald 1791. S. 119. - [14] Gmelin, Reisen durch Sibirien ron 1733-1743, 1. Band, Göttingen 1751. S. 601 ff. - [15] Pallas, Reisen durch verschiedene Provinzen des russischen Reiches, 3. Band, St. Petersburg 1776. S. 22. - [16]. v. Buch, Ueber die Temperatur der Quellen, Abh. d. k. preuss. Akad. d. Wissensch., Phys. K1., 1825. S. 95. - [17] Peschel-Leypolät, Physische Erdkunde, 1. Band, Leipzig 1879. S. 188. - [18] Ibid. S. 185 ff. [19] Hann, Handbuch etc. S. 505. - [20] Hales, Vegetable statics or an account of some statical experiments on the sap in vegetables. London 1727. S. 61. [21] Mairan, Sur la cause générale du froid en hiver et de la chaleur en été, Mém. de l'acad. franc., Année 1719. S. 124 ff. - [22] Kircher, Mundus subterraneus, in quo universae naturae majestas et divitiae demonstrantur, tom. II., Amstelodami 1664. S. 184. - [23] Boerhave, Elementa chemiae, tom. I., Lugduni Batavorum 1732. S. 479. - [24] Boyle, Tractatus de temperie subterranearum regionum, Opera varia, Coloniae Allobrogum 1680, vol. I. F, 2 bis H, 4. - [25] R. Wolf, Biographieen zur Kulturgeschichte der Schweiz, 2. Band, Zürich 1859. S. 188 ff. - [26] Reich, Beobachtungen der Temperatur des Gesteins in verschiedenen Tiefen in den Gruben des sächsischen Erzgebirges, Freiberg 1834. S. 138 ff. - [27] v. Dechen, Die nutzbaren Mineralien und Gebirgsarten im deutschen Reiche, Berlin 1873. S. 691. - [28] Huyssen, Ueber die bisherigen Ergebnisse der vom preussischen Staate ausgeführten Tiefbohrungen im norddeutschen Flachland und den bei diesen Arbeiten befolgten Plan, Leopoldina, 1882. S. 192. - [29] Der tiefste artesische Brunnen, Gaea, 5. Jahrgang. S. 497. - [30] Poggendorff, Neue Beobachtungen 
über die Temperatur im Inneren der Erde, Ann. d. Phys. u. Chem., 13. Band. S. 363. - [31] B. Studer, Lehrbuch der physischen Geographie und Geologie, Bern 1847. S. 39 ff. - [32] Gehler's phys. Wörterb., 3. Band. S. 975. - [33] Ibid. S. 978 ff. - [34] Cordier, Sur la température de l'intérieur de la terre. Mém. de l'acad. franç., Année 1827. S. 473 ff. - [35] Fox, On the temperature of mines, Transact. of the royal geolog. society of Cornwall, Vol. II, Vol. III, Vol. V. [36] Gehler's Phys. Wörterb., 9. Band, 1. Abtheilung, S. 247. - [37] Ibid. S. 250 ff. - [38] Matteucci, Observations relatives à la température des couches terrestres dans les puits de Monte Massi, Compt. rend. de l'acad. franç., tome XV. S. $937 \mathrm{ff}$. - [39] Zöppritz, Der gegenwärtige Standpunkt der Geophysik, Wagner's Geogr. Jahrbuch, 8. Band. S. 25 ff. - [40] Church, The Comstock Lode, its formation and history, New York 1879. - [41] Church, The heat of the Comstock Lode, a paper read before the Am. Inst. of Mining Engineers, 1880, II. S. $7 \mathrm{ff}$. [42] Stapff, Ueber Gesteinstemperaturbeobachtungen im Formanschacht, Zeitschr. d. österr. Gesellsch. f. Meteorologie, 16. Band. S. 410 ff. - [43] Stapff, Gesteinstemperatur im Formanschacht und Lufttemperatur von Virginia City, ibid. S. $518 \mathrm{ff}$. - [44] P. Erman, Ueber die mit der Tiefe wachsende Temperatur der Erdschichten nach Beobachtungen im Bohrloche zu Rüdersdorf, Abhandl. d. k. preuss. Akad., Phys. Kl., 1831, S. 269 ff. - [45] Magnus, Geothermometer und damit gemessene Temperatur des Bohrloches zu Rüdersdorf, Ann. d. Phys. u. Chem., 22. Band. S. 146 ff.; ibid. 28. Band. S. 233 ff. - [46] Gehler's phys. Wörterb., 9. Band, 1. Abtheilung, S. 243 ff. - [47] Zöppritz, Der gegenw. Standp. etc. S. 29 - [48] Gehler's phys. Wörterb., 9. Band, 1. Abtheilung, S. 252. - [49] Dunker, Ueber die Benützung tiefer Bohrlöcher zur Ermittelung der Temperatur des Erdkörpers und die deshalb in dem Bohrloche I zu Sperenberg auf Steinsalz angestellten Beobachtungen, Zeitschr. f. d. ges. Naturwissensch., (2) 6. Band. S. $319 \mathrm{ff}$. - [50] Dunker, Ueber die möglichst fehlerfreie Ermittelung der Wärme des Inneren der Erde und das Gesetz ihrer Zunahme mit der Tiefe, Neues Jahrb. f. Min. u. Geol., 1877. S. 590 ff. - [51] Henrich, Ueber die Temperatur im Bohrloche zu Sperenberg und die daraus gezogenen Schlüsse, ibid. 1876. S. $716 \mathrm{ff}$; Ueber die Temperatur jm Bohrloche zu Sperenberg, Zeitschr. f. math. u. naturw. Unterricht, 9. Band. S. 248 ff. - [52] Henrich-Brauns, Zur Frage über die Temperatur des Erdinneren, Gaea, 14. Jahrgang. S. 490 ff. - [53] J. L. A. Roth, Temperaturbeobachtungen in dem Bohrloche zu Sperenberg unweit Berlin, Ann. d. Phys. u. Chem., 148. Band. S. 168 ff. - [54] Stapff. Studien über die Wärmevertheilung im Gotthard, 1. Theil, Bern 1877. - [55] Rapport trimestriel Nr. 30 du conseil fédéral sur la marche des travaux du St. Gothard, Annexe 14, Berne 1880. - [56] A. Koch, Erdwärme und Tunnelbau im Hochgebirg, Wien 1882. - [57] Poggendorff, Biographisch-literarisches Handwörterbuch zur Geschichte der exakten Wissenschaften, 1. Band, Leipzig 1863. S. 97. - [58] A. Heim, Geologische Untersuchungen über das Projekt des Montblanc-Tunnels, Vierteljahrsschr. d. naturf. Gesellsch. zu Zürich, 1882. S. 106 ff. - [59] Gehler's phys. Wörterb., 3. Band. S. 976 ff. - [60] Ibid. 9. Band, 1. Abtheilung. S. 238 ff. - [61] G. F. Parrot, Considérations sur la température du globe terrestre, Mém. de l'acad. imp. des sc. de St. Pétersbourg, (6) tome I. S. 501 ff. - [62] Aepinus, De distributione caloris per tellurem, Petropoli 1761. - [63] Poisson, Théorie etc., S. 428 ff. S. 521 ff. - [64] A. v. Humboldt, Kosmos, 1. Band, Stuttgart und Augsburg 1845. S. 425 ff. - [65] Poggendorff, Zu Poisson's Theorie über die Temperatur des Erdballs, Ann. d. Phys. u. Chem., 39. Band. S. 93 ff. - [66] Lamont, Erklärung der Wärmezunahme im Inneren der Erde nach Herrn Poisson, Jahrb. d. Sternwarte zu München, 1. Band, 1838. - [67] Pilar, Grundzüge der Abyssodynamik, Agram 1881. S. $23 \mathrm{ff}$. - [68] D'Archiac, Histoire des progrès de la géologie, tome I., Paris 1847. S. 29. - [69] Mohr, Geschichte der Erde, Bonn 1875. S. 436; ibid. S. 199. [70] F. Pfaff, Die vulkanischen Erscheinungen, München 1871. S. 166 ff. [71] Kupffer, Ueber Temperaturzunahme in tiefen Erdschichten, Ann. d. Phys. u. Chem., 32. Band. S. 285 ff. - [72] Zöppritz, Der gegenw. Standp. etc. S. 26. [73] Zöppritz, Die Fortschritte der Geophysik, Wagner's Geogr. Jahrbuch, 9. Band. S. 7. - [74] W. Thomson, De motu caloris per terrae corpus, Glasgow 1846. [75] W. Thomson-Tait, Handbuch der theoretischen Physik, deutsch von HelmholtzWertheim, 1. Band, 2. Theil, Braunschweig 1874. S. 439 ff. - [76] Hempel, Ueber den Wärmezustand der Erde, Arch. d. Math. u. Phys., 65. Band. S. 337 ff. [77] G. Bischof, Gesetz der Temperaturzunahme nach dem Erdinneren, Ann. d. Phys. u. Chem., 35. Band. S. 209. 
Kapitel II.

\section{Der innere Zustand der Erde.}

§. 1. Aeltere Hypothesen. Spekulationen über die Beschaffenheit der für den Menschen unzugänglichen inneren Partieen des Erdkörpers scheinen für das Alterthum nichts Anziehendes gehabt zu haben, doch findet sich wohl die eine oder andere dahin zielende Aeusserung, und namentlich kann mit einigem Rechte die zählebige Lehre vom Centralfeuer auf den "Phaedon" Platon's.;) zurïckgeführt werden, wobei natürlich nicht an das von Philolaos in den Mittelpunkt des Kosmos versetzte Centralfeuer [1] gedacht werden darf. Die Kirchenväter bedurften zu Zwecken, die keinen naturwissenschaftlichen Charakter trugen, eines im Inneren der Erde kochenden (Höllen-) Feuers; Zeugniss hiefür legen Tertullian, Augustin, Minucius Felix, Isidorus Hispalensis u. a. ab [2]. Die aristotelische und scholastische Schule hatte, wenigstens soweit sie ihren physikalischen Grundsätzen getreu blieb, nichts mit dieser Lehre zu thun, denn da zwischen die Sphären des Feuers und der Erde jene des Wassers und der Luft eingeschaltet waren, so konnte unmöglich im Inneren der Erde ein Feuer brennen. Diese Theorie der vier Elemente reicht bekanntlich bis tief in die Periode der Renaissance hinein, obwohl die besseren Köpfe längst deren Unhaltbarkeit eingesehen hatten. Unvermögend, etwas Besseres an deren Stelle zu setzen, verfiel man skeptischer Resignation, wie z. B. Giordano Bruno im achten seiner Gespräche dem Fra Castor o die Frage, welchen Urstoff man sich denn eigentlich im Centrum der Erde zu denken habe, in folgender Weise beantwortet [3]: „Wenn der Mittelpunkt ausschliesslich demjenigen Elemente einzuräumen ist, welches das schnellste und allerdurchdringlichste ist, dann gebührt der erste Platz daselbst der Luft, der nächste daran dem Wasser, und der dritte der Erde. Wenn hingegen die Stelle im Mittelpunkte dem schwersten, dichtesten und zusammenhängendsten zukommt, dann gebührt die erste Stelle dem Wasser, die zweite der Luft, die dritte der trockenen Erde. Nehmen wir hingegen die Erde mit dem Wasser verbunden, dann gebührt die erste Stelle der Erde, die zweite dem Wasser allein, die dritte der Luft, so dass, wenn die Elemente einzeln und in der Trennung genommen werden, nach verschiedenen Hinsichten die Stelle im Mittelpunkte verschiedenen Elementen müsste eingeräumt werden."

Das grosse Verdienst, den Sitz jener Erhitzung, deren Existenz sich uns durch die Vulkanausbrüche fühlbar macht, aus den centralen Partieen der Erde heraus und weit näher an deren Oberfläche verlegt zu haben, kommt unstreitbar. Gassendi zu [4]. Die Frage, wie es weiter drinnen im Erdkörper bestellt sei, wurde aber damit wieder eine offene. Leibniz stellte [5] die Ansicht auf, dass unsere Erde

*) Es wird daselbst von den durch die Vulkane emporgeschleuderten

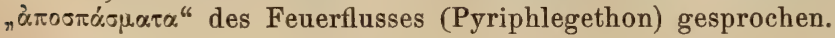


ein im Schmelzzustande befindlicher feurig-flüssiger Klumpen gewesen und allmählig in einen status consistentior " übergegangen sei, und Thoms on hat versucht, mittelst der im letzten Paragraphen des vorigen Kapitels entwickelten Formeln die ungefähre Epoche dieser Metamorphose festzustellen. Sein - von anderer Seite allerdings befehdetes Resultat geht dahin [6], dass die Erstarrung der Erde vor mehr als 20000000 , aber vor weniger als 40000000 Jahren begonnen haben müsse. Während des XVIII. Jahrhunderts erhielt sich ziemlich allgemein die Ansicht, dass nur die äusseren Schichten erkaltet und erstarrt, die tiefer gelegenen aber noch immer gluthflüssig seien; es erhellt diess z. B. sehr klar aus dem zwischen Wiedeburg und v. Justi geführten Streite über die Entstehung der Erde [7]. Auf gewisse Hypothesen von Leslie und Franklin werden wir weiter unten zu sprechen kommen, und nur beiläufig thun wir Halley's sonderbarer Idee Erwähnung, welcher zufolge [8] die Erde hohl wäre und in ihrem Inneren einen Planeten beherbergte, dessen Bewegung die Variationen der magnetischen Elemente bewirkte. A. v. Humboldt versichert [9], von einem gewissen Symmes allen Ernstes zu einer Expedition nach dieser unterirdischen Hohlkugel aufgefordert worden zu sein.

§. 2. Gründe für die Starrheit der Erde. Nachdem in der zweiten Hälfte des verwichenen Jahrhunderts die ersten Versuche, das spezifische Gewicht der Erde zu bestimmen, so viel ausser Zweifel gesetzt hatten, dass die Dichtigkeit nach Innen zunehmen müsse, bildete sich ganz naturgemäss die Anschauung aus, der Erdkern müsse fest und starr sein. Breislak behauptete im Hinblick auf die zu seiner Zeit maassgebenden Ansichten über das Wesen des Erdmagnetismus, der Hauptbestandtheil unseres Planeten sei Magneteisenstein [10]: man kannte dessen Eigengewicht $=7$, und da dasjenige des Gesammtkörpers ungefähr auf 5 , dasjenige der oberflächlichen Schichten aber nur auf 2,5 geschätzt wurde, schien der Gedanke nicht so fremdartig, als er uns heute vorkommt. Das Hirngespinnst der Gebrüder Marschall v. Bieberstein, welche [11] die Erde für ein Konglomerat aus Meteorsteinen ausgaben, konnte sich nur dadurch einige Zeit lang fristen, dass ein so geistvoller Astronom, wie v. Z a ch unstreitig war, sich für dessen Ausbildung interessirte [12]. Die Argumente, welche sich aus solchen Theorien für die Starrheit des Erdkörpers herleiten liessen, konnten ersichtlich nicht von grossem Gewichte sein, und ebensowenig bedeutete Poisson's Negirung des glühendflüssigen Zustandes, von der gegen Schluss des vorigen Kapitels die Rede war. Von ganz anderem und zwar ungleich wissenschaftlicherem Gepräge sind jene Untersuchungen, welche in den vierziger Jahren von dem Begründer der geophysikalischen Schule Englands, von Hopkins, begonnen wurden und den Anstoss zu einer auch heute noch lange nicht abgeschlossenen Diskussion lieferten [13]. Hopkins knüpfte an die Präcessionserscheinungế an und suchte zu zeigen, dass, wenn die Erde flüssig oder selbst nur bis zu einem gewissen Grade plastisch wäre, diese Erscheinungen nach Art und Maass anders auffallen müssten, als wir sie thatsächlich wahrnehmen. Die Dicke der absolut starren Kruste betrüge allermindestens $1 / 5$ bis $1 / 4$ des Erdhalbmessers. Gegen 
316 Dritte Abtheilung. Geophysik im engeren Sinne; dynam. Geologie.

die rechnerische Grundlage, von welcher aus diese Ergebnisse erzielt wurden, ist allerdings Einsprache erhoben worden. G. H. D arwin wies nach [14], dass sein Vorgänger Irrthümer begangen habe, indem nicht die Präcession, sondern blos die Nutation zum Beweise herangezogen werden dürfe, und Delaunay suchte Hopkins durch das Experiment zu widerlegen. Letzterer hatte nämlich angenommen, dass eine wie immer beschaffene Flüssigkeit, in eine rotirende Hohlkugel eingeschlossen, an der Axendrehung derselben gar keinen Antheil nehme, während Delaunay gefunden zu haben glaubte, dass diess doch eintrete, sobald nur die Geschwindigkeit der Umdrehung gehörig sich steigere [15]. Die von Folie gemachte Entdeckung einer täglichen Präcession und Nutation [16] vermag vielleicht auch nach dieser Richtung hin sich nutzbar zu erweisen. Indessen kommen nicht lediglich die Phänomene der Erdaxenschwankung in Betracht, vielmehr hat eine Reihe von Forschern angelsächsischer Abstammung auch aus den Erscheinungen der Gezeiten den Nachweis für die Thatsache herzuleiten sich bestrebt, dass unserem Wohnkörper als Ganzem ein sehr hoher Grad von Unnachgiebigkeit zuerkannt werden müsse, und diese Beweisführung konnte durch Delaunay's Betrachtungen ebensowenig als durch diejenigen Mallet's, welche sich auch wesentlich gegen Hopkins richteten [17], erschüttert werden.

Wie in dem von Ebbe und Fluth handelnden sechsten Kapitel der sechsten Abtheilung des Näheren dargelegt werden wird, sind die durch die anziehende Kraft von Sonne und Mond zu Stande gekommenen Fluthhöhen nicht absolut zu nehmen, vielmehr stellen sie sich dar als Differenz zwischen jenen Höhen, zu welchen die eine absolut starre Kugel bedeckende Flüssigkeit ansteigen würde, und jenen Deformationen des eben in Wirklichkeit nicht ganz starren festen Körpers, die in der genannten Attraktion ihren Grund finden. G. H. Darwin hat diese Beziehungen genau durch den Kalkul geprüft [18], nachdem W. Thomson [19] die Deformation des Erdkörpers unter dem Einfluss der Gestirne auf die wissenschaftliche Tagesordnung gesetzt hatte. Die näheren Umstände sollen uns erst später beschäftigen, für jetzt konstatiren wir als Schlussresultat nur dieses, dass beide Forscher den Starrheitsgrad der Erde sehr hoch und grösser veranschlagen zu müssen glauben, als bei den meisten irdischen Stoffen. Darwin glaubte für diese seine Auffassung neuerdings auch durch die Ueberlegung neue Gründe zu gewinnen, dass sonst der Druck der Kontinentalmassen gegenüber den Meeren Spannungen und Störungen in der Erdkruste hervorrufen müsse [20]. Einen abschliessenden Charakter diesen Feststellungen beizulegen, wäre allerdings verfehlt; W. Thomson selbst erwartet Gewissheit darüber erst von einer ziemlich fernen Zukunft. Die Grösse der Differentialfluth tritt, wie sich theoretisch darthun lässt, am kräftigsten bei der vierzehntägigen Mondfluth hervor, während die Beträge der ebenfalls vorhandenen Fluth von halbjähriger Periode etwa die Hälfte der von jener ersten gelieferten Höhen erreichen würden. Hätte man an geêigneten Orten — wozu gerade unsere am besten ausgestatteten Häfen nicht zu zählen sind selbstregistrirende Fluthmesser aufgestellt, so würde sich aus deren einen hinreichend langen Zeitraum umfassenden Aufzeichnungen nach der Methode der kleinsten Quadrate die relative Grösse jeder einzelnen 
Fluthgattung erschliessen lassen. Allerdings ist die halbjährige Tide durch Regenfall, schmelzendes Eis, ungleichartige Vertheilung von Wasser und Land vielfach gestört, doch würden die durch jene Nebeneinflüsse hereingebrachten sekundären Perioden wohl wieder zu eliminiren sein, wenn die Beobachtungsstationen passend auf dem Erdball - etwa auf Island, Teneriffa, den Kap-Verden, Ascension und St. Helena vertheilt wären. Nur auf diesem Wege dürfte sich dereinst genau eruiren lassen, welches die wahre Grösse des elastischen Nachgebens der Erde gegen die Fluthwirkung von Mond und Sonne ist. $\mathrm{Zu}$ den eifrigen Befürwortern einer ungeheuer grossen Starrheit gehört auch der Amerikaner Barnard [21], der die Fluthphänomene für eine Stahlkugel von den Dimensionen der Erde studirt und daraus den Schluss gezogen haben will, dass jene selbst noch weniger Elasticität als Stahl oder Glas besitzen könne.

§. 3. Gründe für und wider die Elasticität des Erdinneren. Allerdings ist den Anhängern der Starrheitshypothese auch von Seiten anderer Fachmänner widersprochen worden, als blos von Seiten jener, deren wir im vorigen Paragraphen zu erwähnen hatten. Hennessy, der die Geophysiker England's in Rigidisten und Viscidisten eintheilt, macht derartige Gegengründe geltend [22], ebenso Airy [23], der sich an die Kant-Laplace'sche Theorie hält und aus dieser eine mehr und mehr gegen das Centrum hin zunehmende Erhitzung und eine dieser entsprechende Dissociation der inneren Erdbestandtheile folgert. Die principielle Grundlage, auf welche $\mathrm{Thomson}$ und Darwin sich stützen, erscheint keineswegs als ganz sicher fundirt, denn wir sind, wie Hennessy hervorhebt, nicht ohne weiteres berechtigt, die zur Berechnung der Gezeiten einer unzusammendrückbaren Flüssigkeit dienenden und für diesen Fall erprobten Methoden sofort auf eine kompressible Flüssigkeit von nach innen zu wachsender Dichtigkeit zu übertragen, wie sie vielleicht das Innere unseres Wohnkörpers erfüllt. Auch Zöppritz bemerkt hiezu [24]: „Immerhin ist es bemerkenswerth, dass sich nirgendwo mit Entschiedenheit Fluthen von längerer Periode ergeben haben. Es gewinnt dadurch die Vorstellung eines flüssigen Erdinneren wieder an Bedeutung, womit nothwendig der Schluss verknüpft ist, dass die Erdrinde sich mit den Körperfluthen des Inneren periodisch auf- und abbewegt." ${ }^{*}$ Ein weiteres grundsätzliches Bedenken macht Werner Siemens geltend [25], indem er an W. Thomson's übrigens korrekten Betrachtungen tadelt, dass unvermittelt vom Uebergang aus dem flüssigen in den festen Zustand gesprochen werde, während doch die Natur nur einen sehr langsam und allmählig sich vollziehenden Fortschritt vom dünnflüssigen zum zähflüssigen Aggregatzustande kenne, bei welchem der Druck eine Rolle spiele, wogegen derselbe unzureichend sei, eine zähe Flüssigkeit vollends zu verfestigen. Diese Thatsache, welche Siemens seinen Beobachtungen an Glasflüssen entnahm, veranlasst uns, die Untersuchung auf ein ganz anderes Gebiet hinüberzuleiten.

W. Thomson behauptet nämlich, schon um desswillen könne der Zustand der Erde kein anderer als der absolut starre ${ }^{*}$ sein, weil, wenn die Erstarrung derselben im Sinne der Nebularhypothese aussen begonnen und sich nach und nach in's Innere fortgesetzt hätte, die 
erstarrten und damit spezifisch schwerer gewordenen Massen in dem feurigflüssigen Brei hätten untersinken müssen. Abgesehen davon, dass ja doch, wovon weiter unten ein Mehreres, die Grenzfläche zwischen Festem und Flüssigem durchaus keine fixe sein könnte, zwischen beiden vielmehr eine Schicht von weder eigentlich fester, noch auch eigentlich flüssiger Beschaffenheit zwischen inne liegen müsste, ist die Ansicht des schottischen Physikers neuerdings auch durch schlagende direkte Experimente entkräftet worden. Wir haben, als der lunare Vulkanismus besprochen ward (Erste Abtheilung, Kap. III, §. 11), bereits der Versuche von Mallet und von Nies-Winkelmann [26] Erwähnung gethan, und diesen können wir nunmehr diejenigen von Siemens (s. o.) anreihen, aus welchen zu ersehen ist, dass mit dem weiteren Fortschreiten der Abkühlung geschmolzener Glasmassen die Zusammenziehung immer geringer wird, bis dann endlich den Uebergang in den eigentlich festen Zustand sogar eine geringe Ausdehnung begleitet. Zöppritz führt noch Versuche an, welche Whitley mit Messing, Gusseisen, Basalt, Fisher mit fester Lava auf geschmolzener, Millar wiederum mit Gusseisen anstellten, und die sämmtlich dahin gedeutet werden zu müssen scheinen, dass bei'm Erstarren zuerst eine kleine Volumvergrösserung eintritt, die dann bei weiterem Fortgange der Abkühlung allerdings wieder schwindet [27]. Jenen Zwischenzustand zwischen Flüssig und Fest, den Thomson übersah, und dessen Vorhandensein betont zu haben Siemens' Verdienst ist, erkannte neuerdings auch Wrightson bei Kugeln von gegossenem Eisen [28]. Von der gewöhnlichen vulkanischen Lava hat schon Escher v. d. Linth bei seiner Vesuv-Besteigung etwas Aehnliches bemerkt; oft warfen wir," sagt er [29], "grosse Schlackenstücke auf die Lava; sie machten keinen merkbaren Eindruck und prallten eher zurück. ${ }^{*}$

Hält man alle diese Momente zusammen, so scheint doch eine weit überwiegende Wahrscheinlichkeit dafür zu sprechen, dass die Erde ihrem weitaus grössten Theile nach nicht starr, sondern, wo nicht eigentlich flüssig, doch mit plastischer Materie erfüllt zu denken sei. Selbst Reyer, der auf Grund seiner eingehenden Individualstudien über vulkanisches Gestein ein flüssiges Erdinnere verneint, ist diesem unserem vorläufigen Ergebniss nicht entgegen, wenn er von dem in der Tiefe vorhandenen Stoffe sagt [30]: „Die Hauptmasse ist verfestigt, die durchtränkenden Lösungen werden, je tiefer, um so zähflüssiger. Mithin können wir behaupten, dass das ganze Magma mit zunehmendem Drucke an Beweglichkeit verliert, sich also dem starren Zustande nähert. “ Diesem in's Ungemessene wachsenden Drucke müssen wir allerdings noch eine schärfere Beachtung angedeihen lassen, als es bisher geschah; mit ihm wächst aber auch, wie das vorige Kapitel uns lehrte, die Temperatur. Letztere sucht alle Stoffe bei ihrem Steigen zum Schmelzen zu bringen, die allseitig wirkende Pression widersetzt sich dieser Verwandlung, und es ergeben sich solchergestalt Verhältnisse, zu deren vollständiger Beurtheilung uns die Hülfsmittel abgehen; lässt sich doch sogar mit diesen, die ausschliesslich im Laboratorium gewonnen wurden, keine Antwort auf die Frage geben, wo der Punkt liegt, jenseits dessen alle Körper nur noch in geschmolzenem Zustande vorkommen können [31]. Ehe wir auf die beregten Punkte weiter eingehen, stellen wir noch einmal in Kürze unsere bisherigen 
Errungenschaften zusammen. Ihnen zufolge ist blos die Erdkruste starr und auch diese nicht im strengsten Wortsinne, also nicht aller und jeder Elasticität baar; daran schliesst sich nach innen zähflüssige Materie, deren Verfestigung nach unten fortschreitet, jedoch nicht über jede angebbare Grenze hinaus. Laplace legte in der "Mécanique céleste $^{\text {" }}$ ein von Legendre [32] vorgeschlagenes Gesetz der Dichtigkeitszunahme zu Grunde, wonach die einer bestimmten Druckzunahme entsprechende Kompression um so mehr sich verringert, je grösser die bereits erreichte Dichte ist; so käme auf die dem Erdmittelpunkte zuzusprechende Dichte ungefähr diejenige des Silbers oder Bleis. Wie aber, so fragen wir, ist es möglich, dass mit den früheren Ansichten auch dieses Ergebniss vereinigt wurde*)?

\section{§. 4. Die Auffassung des Erdinneren als einer gasförmigen Masse.} Wie es gerade in der Geophysik - man denke nur an die Lehre von den säkulären Oscillationen und von der Gletscherbewegung nicht selten ergeht, so ereignete es sich auch hier: Eine mehr gelegentlich formulirte und von hervorragenden Autoritäten nicht allein zurückgewiesene, sondern verspottete Lehrmeinung gewann nach Jahrzehnten neues Leben, freilich auch in einer gegen früher wesentlich veränderten und verbesserten Form. Hören wir z. B. A. v. Humboldt [34]: „Man hat berechnet, in welchen Tiefen tropfbar flüssige, ja selbst luftförmige Stoffe durch den Druck ihrer auf einander gelagerten Schichten die Dichtigkeit der Platina oder selbst des Iridiums übertreffen würden; und um die innerhalb sehr enger Grenzen bekannte Abplattung mit der Annahme einer einfachen, bis in's Unendliche kompressibeln Substanz in Einklang zu bringen, hat der scharfsinnige Leslie den Kern der Erde als eine Hohlkugel beschrieben, die mit sogenannten ,unwägbaren Stoffen von ungeheurer Repulsivkraft' erfüllt wäre. Diese gewagten und willkürlichen Vermuthungen haben in ganz unwissenschaftlichen Kreisen bald noch phantasiereichere Träume hervorgerufen." Noch vor Leslie hat übrigens schon Franklin [35] sich für diese Idee erklärt; nach ihm bestünde der Erdkern aus einer (elastischen) Flüssigkeit, dichter als jeder feste Körper, und auf ihr schwämme die eigentliche Erdrinde. Muncke, der begreiflicherweise von dieser Auffassung wenig erbaut und ungehalten darüber ist, dass Chladni sich ihr zugeneigt habe, kann gleichwohl nicht umhin, zuzu-

*) Die von Roche [33] aufgestellte Hypothese würde sich mit diesen Thatsachen ganz gut vertragen, allein ihr Urheber hat blos auf die Abplattung, sowie auf die Erscheinungen der Präcession und Nutation Bedacht genommen, nicht aber auf das Fluthphänomen, welches (s. o.) in letzter Instanz eben nicht für, sondern gegen die Festigkeit der Erde spricht. Nach Roche besteht letztere der Hauptsache nach aus einem homogenen, starren Kerne, der nur gegen den Mittelpunkt hin eine geringe Vermehrung der Dichte aufweist und durchschnittlich etwa das spezifische Gewicht 7 hat, sodann aber aus einer den Kern umlagernden Aussenhülle vom spezifischen Gewichte 3, die man sich zum Theile auch aus Flüssigkeiten bestehend denken könnte, deren Dicke aber noch nicht den sechsten Theil des Erdhalbmessers ausmachen soll. Zur Aufstellung dieser - an B reislak (§. 2) gemahnenden - Hypothese veranlasste die Erwägung, dass die neueren Werthe für die Erdabplattung $\left(\frac{1}{289}\right)$ mit einer durchaus flüssigen Erde nicht in Einklang zu bringen seien. 
gestehen, dass ein Ueberschlag mit Zugrundelegung des Mariotte'schen Gesetzes nicht dagegen spreche, indem für komprimirte atmosphärische Luft schon in der Tiefe von 11 Meilen dicht genug sei, um die schwersten uns bekannten Metalle zu tragen [36]. Präciser drückte sich ein berühmter philosophischer Physiker unseres Jahrhunderts, Herbert Spencer [37], aus, indem er die hohle Erdkugel mit gespannten Dämpfen erfüllt sein liess. Dass auch er wenig Anerkennung fand, können wir weder als unbegreiflich, noch auch als tadelnswerth ansehen, denn mit den herrschenden physikalischen Begriffen erschienen solche Abweichungen vom Hergebrachten zu wenig verträglich.

Namentlich unter dem Einflusse der mechanischen Wärmetheorie haben sich seither aber diese Begriffe selbst modificirt und geklärt, die Arbeiten von Cailletet, van der Waals u. A. haben uns die Ueberzeugung beigebracht, dass die bislang gang und gäbe gewesenen Definitionen für Aggregat- und Dissociationszustände nur innerhalb gewisser Grenzen volle Gültigkeit beanspruchen können. Es handelte sich nun darum, die experimentell aus naheliegenden Ursachen unerforschbaren Eigenschaften solcher Zustände wenigstens der Rechnung zu unterstellen, und diesem Probleme hat sich denn auch in A. Ritter's Person ein Physiker von nicht gewöhnlichem Scharfsinne gewidmet. Seine äusserst umfassend angelegte Abhandlung zu welcher uns der atmosphärologische Theil unseres Werkes wieder zurückführen wird, zieht sich durch mehrere Bände der Poggendorff'schen „Annalen“ hindurch [38]. Durch direkte Berechnung der Höhe unserer irdischen Atmosphäre kommt er zu dem Schlusse [39], dass Sauerstoff wie Stickstoff bei ungehindertem Emporsteigen schliesslich in den von ihm im Hinblick auf das bekannte Kondensations .Experiment Thilorier's als Schneewolken-Aggregatzustand bezeichneten Zustand übergehen müssten, hierauf prüft er [40] die Luftverhältnisse in einem in's Innere der Erde hineinreichenden Schachte und entscheidet sich dafür [41], dass, wenn statt der Luft Wasserdampf in dieser Röhre befindlich wäre, die untersten Schichten in Knallgas, die obersten einfach in überhitzten Wasserdampf sich umsetzen würden, während das Mittelgebiet oder Dissociationsgebiet von einem Gemische beider erfüllt zu denken wäre. Weiter studirt Ritter die Vorgänge in einer isentropischen Gaskugel, innerhalb deren die Temperatur, wenn man sich vom Mittelpunkte entfernt, genau nach demselben Gesetze abnimmt, nach welchem die Temperatur einer emporsteigenden Luftquantität durch deren Ausdehnung sich vermindert, was - nebenbei bemerkt - auch zur Aufstellung numerischer Werthe für die chronische Verkleinerung des Sonnendurchmessers führt. Dass dabei das Gesetz von Mariotte und Gay-Lussac als maassgebend angesehen wird, während man doch weiss, dass dasselbe das wahre Verhalten der Gase nur in einer ersten Annäherung darstellt*), liegt in der Natur der Sache und macht nur die numerischen, nicht aber auch die prin-

*) Die Erkenntniss, dass diesem wichtigen Theoreme der Aerostatik nur eine eingeschränkte Bedeutung zuzuerkennen sei, hat sich neuerdings allseitig aufgedrängt und $u$. a. die Reformvorschläge von M. Kuhn [42] und Biehring er [43] in's Leben gerufen. 
cipiellen Resultate unsicher. Man darf auch nicht übersehen, dass die Zuverlässigkeit fraglichen Gesetzes doch erst dann in's Wanken zu gerathen beginnt, wenn die Gesetze sich der Grenze ihrer Verflüssigung nähern, und, wie Andrews fand, können alle uns bekannten Körper, die sogenannten permanenten Gase so wenig wie Alkohol und Wasser ausgenommen, so lange nur als Gase existiren, als ihre Temperatur die mit dem Namen kritischer Punkt belegte Grenze übersteigt. Derselbe liegt für Wasser bei $580^{\circ}$, für schwerer sied- und schmelzbare Körper aber weit höher. Da nun, wie sich gleich zeigen wird, die Untersuchungen Ritter's sehr hohe Wärmegrade wahrscheinlich machen, so darf die rechnerisch nicht wobl zu umgehende Verwendung des Mariotte'schen Gesetzes auch aus einem mehr sachlichen Gesichtspunkte gebilligt werden. Wir weisen übrigens neben Ritter's Originalarbeit auch nachdrücklich auf die gelungene Popularisirung des dort eingehaltenen Gedankenganges hin, welche man Zöppritz [44] verdankt, und auf welche auch wir uns hier zu beziehen keinen Anstand nehmen.

Die Gaskugel, welche wir in's Auge fassten, befindet sich im indifferenten Gleichgewichte; schreitet irgend ein Gewichtstheil radial fort und gelangt auf diesem seinem Wege in Gegenden, wo andere Verhältnisse bezüglich der Dichte, des Druckes und der Temperatur herrschen, so fügt er sich in diese fremden Verhältnisse ein, ohne dass eine Gleichgewichtsstörung entstünde. Wenn die Kugel durch Strahlung Wärme nach aussen abgiebt, so entsteht eine Kontraktion im Inneren, und mit ihr ist eine Erhöhung der Temperatur verbunden, durch welche der externe Wärmeverlust in etwa fünffachem Maasse wieder ausgeglichen wird. Die Rechnung zeigt, dass die Dichte im Mittelpunkt den Werth 143 annimmt, dass dortselbst ein Druck von nicht weniger als 3 Millionen Atmosphären herrscht, und dass, worauf oben schon angespielt ward, die Temperatur auf $100000^{\circ}$ ansteigt. Diese Druckverhältnisse sind allerdings ungeheuer, aber eben deshalb doch eigentlich auch wahrscheinlicher, als es die aus der Thomsonschen Hypothese hergeleiteten sind. Letztere kennen wir genau durch eine interessante mathematische Untersuchung von Sey dler [45]. Dieser entfliesst nämlich das Resultat, dass für eine Stahlkugel von der Grösse unserer Erde der auf einem im Kugelcentrum befindlichen Quadratcentimeter lastende Druck $266^{\circ} 0 \mathrm{~kg}$ betrage. Der wirkliche Werth der Centralwärme dürfte allerdings dem errechneten bedeutend nachstehen, immerhin jedoch $>20000^{\circ}$ sein. Bei solchen Hitzegraden darf wohl angenommen werden, dass jedes einzelne Gas sich in seinem überkritischen Zustande befinde, in einem Zustande also, wo es auch durch den denkbar stärksten Druck nicht mehr flüssig gemacht werden kann. Ueber die physikalischen Eigenschaften eines Gases in so extremen Umständen sind wir begreiflicherweise nur sehr wenig auszusagen im Stande, doch ist nicht zu zweifeln, dass ihre Fundamentaleigenschaft, beliebig gestaltete Hohlräume lückenlos ausfüllen zu können, ihnen gewahrt bleibe. Der ganze Energievorrath des Erdinneren ist nicht aktuelle, sondern einzig und allein potentielle Energie.

Zöppritz lässt es (a. a. O.) bei seiner Zustimmung zu den wesentlichsten Resultaten der Ritter'schen Untersuchung nicht bewenden, er führt uns vielmehr von den eigentlich centralen Partieen, auf welche jeze ersteren ausschliesslich Bezug nehmen, auch wieder 
zur Oberfläche zurück. Bei Zurücklegung dieses Weges sehen wir uns im Geiste nach und nach in Gebieten von den allerverschiedensten Elementarzuständen. Eine Zeit lang begleitet uns das überkritische Gas, welches wir uns wohl als ein ideelles und von den stofflichen Verschiedenheiten der uns bekannten Körperwelt völlig emancipirtes zu denken haben. Mit dem Nachlassen der Hitze beginnen diese Verschiedenheiten wieder in ihr Recht zu treten, es bilden sich Uebergangsschichten, in deren Bereiche erst gewisse und endlich sämmtliche Elemente wieder ihr uns geläufiges Sonderdasein führen. Ist weiterhin die Temperatur für diese Urstoffe unter den kritischen Punkt herabgesunken, so macht sich der bisher paralysirte Druck geltend, und wir durchwandern einen tropfbar flüssigen Kugelring. Je näher der Oberfläche, um so mehr sehen wir diese Flüssigkeit an ihrer Reinheit einbüssen, sie wird trüb, zähe, mit Festkörpern durchsetzt, und ohne feste Trennungsschicht geht sie in die feste Erdkruste über, deren Aussenseite der Mensch bewohnt. Hält man sich an diese hier mit kurzen Strichen gezeichnete Skizze von der Anordnung der inneren Erdbestandtheile, so werden manche Schwierigkeiten aus dem Wege geräumt, die vordem unüberwindlich erscheinen mussten; diese Annahme einer mit überhitzten Gasen erfüllten Hohlkugel beseitigt insbesondere auch eine Unzukömmlichkeit, welche die jetzt herrschende Lehre von der Gebirgsbildung durch Faltung unangenehm empfand. Berechnete man nämlich die Differenz in der Kontraktion der äusseren und inneren Schichten, so ergab sich, wenn mit einem festen Erdkerne gerechnet

Fig. 61.

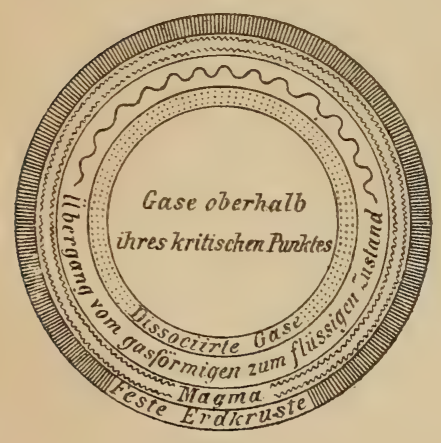
werden musste, eine den Thatsachen widersprechende Zahl, allein nun ist es erlaubt, diese Inkonvenienz einfach durch die Wahl eines geeigneten Ausdehnungskoefficienten der Erdmasse zu heben; jeder beliebige ist verträglich mit einem gasförmigen Erdinneren. Unsere Uebersicht über die zwischen dieser Gaskugel und der dünnen Kruste mitten inne liegenden Schichten liefert uns aber weiter die Ueberzeugung, dass allein deswegen an keiner der umlaufenden plutonischen Theorieen Abänderungen anzubringen sind; der folgende Paragraph wird diese Ueberzeugung befestigen *).

§. 5. Das Magma und die Ryakohypse. Die früher maassgebenden Anschauungen über einen die Erdhöhlung erfüllenden Gluthbrei sind im Vorstehenden zwar beträchtlich eingeschrünkt, sonst aber durchaus nicht über den Haufen geworfen worden. Wir können nach wie vor annehmen, dass wir, wäre uns die Möglichkeit eines tieferen Eindringens in die Erde geboten, in verhältnissmässig nicht einmal sehr bedeutender Tiefe auf jene fluktuirende Schicht geschmolzener Massen stossen würden, für welche neuerdings der ganz bezeichnende

*) In Fig. 61, welche wohl an sich verständlich ist, versuchten wir ein schematisches Bild von den Zustandsänderungen innerhalb der Erde zu entwerfen. 
Name Nagma (von piryul, ich mische) aufgekommen ist. Von unserem Standpunkte bis zu jenem Punkte, wo das Magma seinen Anfang nimmt, rechnen wir die Dicke der Erdkruste; diese Strecke numerisch anzugeben, hat allerdings erhebliche Schwierigkeiten. Ami Boué schätzt ihre Länge [46] auf $100000 \mathrm{~m}$, E. de Beaumont auf $40000 \mathrm{~m}$ bis $50000 \mathrm{~m}$, F. Pfaff [47] schliesst aus seinen geologischen Versuchen auf einen zwischen $80000 \mathrm{~m}$ und $90000 \mathrm{~m}$ liegenden Werth. Aus Henrich's Formel (Kap. I, §. 4) würde folgen, dass in einer Tiefe von $84000 \mathrm{~m}$ bereits eine Temperatur von $2500^{\circ}$ herrscht, durch welche alle uns bekannten irdischen Materialien in den gluthflüssigen Zustand übergeführt werden müssten. Pilar nimmt für die Dicke der festen Erdschale $1 / 50$ bis $1 / 40$ des Radius, im Maximum aber 12 Myriameter an [48] (s. u. §. 6).

Natürlich ist nicht anzunehmen - diess deuteten wir schon oben an -, dass unmittelbar an die untere Begrenzungsfläche der Erdkruste die Oberfläche des internen Gluthmeeres sich anschliesse, vielmehr wird ein Gemenge aus wirklichem Magma zähflüssigster Beschaffenheit und aus schwer schmelzbaren krystallinischen Massen sich zwischen beiden einlagern*). Diese Zwischenschicht schiitzt zugleich die untere Seite der Rinde vor schnellem Abschmelzen. Man mag sich das Verhältniss zwischen dem oberen Festen und dem unteren Flüssigen im Grossen und Ganzen ähnlich denken, wie zwischen der einen gefrorenen See iiberlagernden Eisdecke und dem darunter befindlichen Wasser. Macht man Löcher in erstere, so steigt gleichwohl das Wasser nicht bis zur Aussenseite des Eises empor, weil es spezifisch schwerer denn letzteres ist; ebenso wird auch das schwerere Magma, wenn sich über ihm eine Spalte öffnet, nicht die ganze Länge derselben ausfüllen können. Da wir nähere Details nicht kennen, so haben wir wohl ein Recht anzunehmen, dass die Fähigkeit des Magma's, in der Erdkruste emporzudringen, eine Fähigkeit also, die für die Erkenntniss der vulkanischen Vorgänge von hoher Bedeutung ist, durch das Verhältniss der Dichten von Magma und Kruste an einem bestimmten Orte bedingt sein wird. Mathematisch exakt ist diese Annahme freilich nicht, wohl aber ist sie die zur Zeit bestmögliche.

Setzen wir diess voraus, so ist evident, dass jene Punkte, zu welchen an den verschiedenen Stellen das Magma hinaufreicht, nicht gleichweit vom Erdmittelpunkt entfernt sein können. Diess erkannte zuerst Belli [50], der die Möglichkeit eines Einbrechens der Kruste bestritt; schärfer präcisirt hat die Anschauungen seines ihm offenbar

*) Bei Gelegenheit der in Kap. IV, §. 2 der vorigen Abtheilung erwähnten Polemik, welche Hill und Fisher gegen einander über die Möglichkeit einer Veränderung in der Lage der Erdaxe führten, äussert der Zweitgenannte auch [49], es sei durchaus nicht unbedingt erforderlich, das ganze Erdinnere als flüssig vorauszusetzen, zwischen beiden Aggregatzuständen bilde die Brücke jener der unvollständigen Flüssigkeit (. The only conclusion at which we can arrive is this, if the augmentation of temperature with that of the depth be so rapid that its effect in resisting the tendency to solidify by greater than that of the increase of pressure to promote it, there will be the greatest tendency to become imperfectly fluid, and afterwards to solidify, in the superficial portions of the mass...") Es wird sich später, bei den Gletschererscheinungen, noch Gelegenheit ergeben, auf solche unvollkommen flüssige oder zähflüssige Massen zurückzukommen, deren mechanisches Verhalten, ebenso wie dasjenige gepulverter Körper, erst in jüngster Zeit (durch Boussinesq u. a.) dem Studium zu unterwerfen begonnen wurde. 
nicht bekannt gewordenen italienischen Vorgängers der kroatische Geologe Pilar, an dessen Erörterungen über das Magma wir uns hier theilweise anschliessen. Derselbe denkt sich alle Punkte, welche der Oberfläche des Magma-Gürtels angehören, durch eine Fläche mit einander verbunden, für welche er den Namen der Ryakohypse (ṕś, die Lava, گ̋łos die Höhe) in Vorschlag bringt [51]. Fig. 62 repräsentirt durch den schwarz angelegten Kreis das Magma; die Ryako-

Fig. 62.

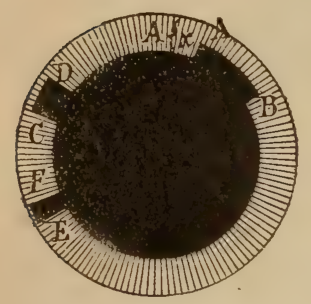
hypse nimmt die Punkte A, B, C, D, E, F in sich auf. Die Erhebung x der Ryakohypse über das eigentliche Niveau des Magma's wird, wenn a die Dicke der Erdrinde, d deren spezifisches Gewicht, D endlich das spezifische Gewicht des Gluthbrei's bezeichnet, mittelst der Gleichung $D \cdot x=d$. a berechnet, woraus für $\mathrm{x}$ und den Abstand des Magma's von der Erdoberfläche $\left(=x^{\prime}\right)$ die Werthe

$$
\mathrm{x}=\frac{\mathrm{a} \cdot \mathrm{d}}{\mathrm{D}}, \mathrm{x}^{\prime}=\mathrm{a}\left(1-\frac{\mathrm{d}}{\mathrm{D}}\right)
$$

sich ergeben. Den Werth des im Subtrahenden stehenden Bruches will Pilar (a. a. O.) durch $\frac{5}{6}$ ersetzt wissen. Es kommt hierauf nicht eben viel an, denn der ganze Ausdruck kann ja selbstverständlich nur die Bedeutung einer ersten Näherung beanspruchen. Bei der Art der betrachteten Flüssigkeit würden strenge genommen noch weitere integrirende Faktoren, wie die Breite der Spaltenöffnung, die Reibung an den Grenzflächen u. s. w. in Betrachtung gezogen werden müssen, wozu es aber an der thatsächlichen Unterlage gebricht.

§. 6. Allgemeines über die Physik der Erdrinde. Wenn von den physikalischen Vorgängen im Inneren der Erdrinde die Rede ist, so muss man offenbar zweierlei Arten von Umformungen mechanischer Natur unterscheiden, solche, welche an der Grenzfläche von Kruste und Magma oder, besser gesagt, innerhalb der unvollkommen-flüssigen Uebergangsschicht, und solche, welche innerhalb der eigentlichen Umhüllungsschale sich vollziehen. Die erstgenannten Processe sind von Pilar [52] fleissig und hingebend, jedoch nicht immer in strengphysikalischem Geiste untersucht worden, und wenn wir im Folgenden einen kurzen Ueberblick über seine Ergebnisse einschalten, erkennen wir diese letzteren darum nicht unbedingt an. Auch von den internen Veränderungen, welche man als intrakrustale den - als ryakokrustal zu bezeichnenden - vorigen gegenüberstellen könnte, kann hier nur ganz im Allgemeinen die Rede sein. Denn zu viele Spezialkapitel der physischen Geographie sind gerade an diesen Fragen betheiligt, als dass irgendwie jetzt schon in Einzelheiten eingegangen werden könnte, so die Lehre von den vulkanischen und seismischen Erscheinungen, von den Hebungen und Senkungen der Kontinente, ganz besonders aber das weite Gebiet der Gebirgsbildungstheorie. Namentlich die letztere hat uns ja überhaupt den Betrieb solcher Studien nahe gelegt und zur Pflicht gemacht.

Pilar geht davon aus, dass die Dicke der Erdrinde durchaus nicht überall die gleiche sei; unterhalb der schlechtleitenden Theile jener rücken ihm zufolge die Chthonisothermen näher an einander, als 
unterhalb der gut leitenden, demnach läge die Ryakohypse unter dem Lande tiefer, als unter dem Meere, bei welch' letzterem sowohl die grössere Wärmekapazität, als auch die gewöhnlich vorhandene Bewölkung die Ausstrahlung der Erdwärme verhindere. Behält a den ihm oben beigelegten Sinn als normaler Durchschnittswerth, während $p_{1}$ die mittlere Seehöhe eines Erdtheiles, $p_{2}$ die mittlere Tiefe eines Weltmeeres bezeichnet, so soll die Dicke der Kruste unter ersterem und unter letzterem bezüglich durch $\left(a+6 p_{1}\right)$ und durch $\left(a+4 p_{2}\right)$ gegeben sein. Die von ihm zum Beweise seiner Thesen herangezogenen Versuche von Jannetaz vermögen jedoch keineswegs zu einer so weit über ihren eigentlichen Zweck*) hinausgehenden Beweisführung die Basis abzugeben. Pilar steht sogar nicht an, den Morästen, Torfmooren, Waldungen, überhaupt jeder die Erdwärme zurückhaltenden Bedeckung des Erdbodens einen maassgebenden Einfluss hinsichtlich der Mächtigkeit des unmittelbar darunter liegenden Krustentheiles zuzugestehen: Er nimmt weiter, und wohl mit Recht, an, dass die Erdkruste aus einzelnen Schollen sich zusammensetzt, und unterscheidet Hebungsschollen und Senkungsschollen, erstere den Kontinenten, letztere den Oceanen entsprechend und durch Mittelzonen mit Bruchlinien von einander getrennt; letztere sind [56] meist geradlinig doch auch krummlinig und speziell wellenförmig begrenzt, $100 \mathrm{~m}$ bis $100000 \mathrm{~m}$ lang und unter den verschiedensten Winkeln zwischen $0^{\circ}$ und $45^{\circ}$ einfallend. Wenn zwei vorher nächstbenachbarte Gebiete der Oberfläche dadurch von einander getrennt werden, dass bei einem Neubildungsprocesse von Schollen das eine der sinkenden, das andere der aufsteigenden Scholle angehört, so entsteht eine Verwerfung. Suess wollte [57] dieses Wort nur dann angewandt wissen, wenn blos der eine Flügel abgesunken ist, während Pilar [58] mit Verwerfung einen die ganze Erdrinde durchsetzenden Spaltenbruch bezeichnet, durch den auch eine Verschiebung der Bruchränder herbeigeführt und unter Umständen das bewirkt wird, dass, wie in England, Schottland und Wales nicht selten, die zeitlich verschiedensten geologischen Formationen unter dem nämlichen Niveau erscheinen. Versuche, welche Pilar mit Holzprismen von trapezförmigem Querschnitt anstellte, indem er dieselben

*) Diese Experimente [53], wie auch die vollkommeneren von S én a r m o n t [54], hatten das Gemeinsame, dass von dem auf seine Wärmeleitungsfähigkeit zu prüfenden Körper eine dünne Platte geschliffen, diese mit einer leicht schmelzbaren Substanz überzogen und nunmehr, nach Zubringung einer Wärmequelle, die Form der Kurve festgestellt wurde, welche den noch nicht geschmolzenen Theil abgrenzte. Doch genügt schon die gewöhnliche Theorie zu dieser Feststellung. Versteht man nämlich unter $\mathrm{V}$ die Temperatur, unter $\mathrm{k}_{\mathrm{x}}, \mathrm{k}_{\mathrm{y}}, \mathrm{k}_{\mathrm{z}}$ die den - mit den Koordinatenaxen zusammenfallenden - thermischen Axen entsprechenden Leitungskoefficienten, so ist die Differentialgleichung der stationären Wärmebewegung im krystallinischen Mittel, je nachdem dieses isotrop oder nicht isotrop ist, eine der nachstehenden beiden Gleichungen:

$\frac{d^{2} V}{d x^{2}}+\frac{d^{2} V}{d y^{2}}+\frac{d^{2} V}{d z^{2}}=0 ; k_{x} \cdot \frac{d^{2} V}{d x^{2}}+k_{y} \cdot \frac{d^{2} V}{d y^{2}}+k_{z} \cdot \frac{d^{2} V}{d z^{2}}=0$.

Die Temperaturfunktion hat in diesen beiden Fällen jeweils den Werth $\frac{\mathrm{m}}{\sqrt{\mathrm{x}^{2}+\mathrm{y}^{2}+\mathrm{z}^{2}}}+\mathrm{n}$ und $\frac{\mathrm{m}}{\sqrt{\mathrm{k}_{\mathrm{x}}^{2} \cdot \mathrm{x}^{2}+\mathrm{ky}^{2} \cdot \mathrm{y}^{2}+\mathrm{k}_{\mathrm{z}}^{2} \cdot \mathrm{z}^{2}}}+\mathrm{n}$, wo $\mathrm{m}$ und $\mathrm{n}$ konstante Zahlen sind; entweder sind hiernach die Isothermflächen koncentrische Kugeln oder aber dreiaxige, ähnliche und ähnlichliegende Ellipsoide, deren Axen sich mit den thermischen Hauptleitungslinien decken [55]. 
in Wasser schwimmen liess, lieferten ihm in Verbindung mit einer einfachen Rechnung*) Anhaltspunkte über den Gleichgewichtszustand dieser theilweise vom Magma getragenen Hub- und Sinkschollen, doch wurden weder die Reibung, noch der Seitendruck in Betracht gezogen.

Wir sind so von den eigentlich ryakokrustalen bereits mitten in die, von jenen ersteren freilich vielfach abhängigen, intrakrustalen Dislokationserscheinungen hineingerathen. Für diese letzteren brachte uns die allerneueste Zeit die beiden grundlegenden Arbeiten von Fisher [59] und Suess [60]. Dem Ersteren zufolge geht das Heben und Senken der Schollen nicht in so relativ einfacher Weise vor sich, wie sich Pilar diess zurechtlegte, man muss sich vielmehr denken, dass alle Ortsflächen gleicher Dichtigkeit und gleichen Aggregatzustandes da, wo sie von einer Ortsfläche geringster Festigkeit durchschnitten werden, Ausbiegungen nach oben und unten erleiden, letzteres jedoch in weit geringerem Maasse. Uns weitere Auszüge aus dem Fisher'schen Werke für die betreffenden Spezialkapitel vorbehaltend, erwähnen wir hier nur noch, dass der englische Geophysiker die Dicke der Erdrinde sehr gering und damit die Erhebung der Ryakohypse sehr hoch anschlägt. - Im Gegensatze zu Fisher, welcher dem Magma und den aus diesem entweichenden Gasen und Dämpfen eine Hauptrolle bei den Ortsveränderungen innerhalb der Erdrinde zuschreibt und bestimmt erklärt, dass die blosse Erkaltungs-Schrumpfung nicht die zureichenden Erklärungsmomente an die Hand gäbe, stellt Suess (a. a. O.) an die Spitze seiner bezüglichen Betrachtungen den für die Freunde, wie für die Gegner seiner Anschaungssweise gleich beachtenswerthen Satz: „Die sichtbaren Dislokationen in dem Felsgerüste der Erde sind das Ergebniss von Bewegungen, welche aus der Verringerung des Volumens unseres Planeten hervorgehen. Die durch diesen Vorgang erzeugten Spannungen zeigen das Bestreben, sich in tangentiale und in radiale Spannungen und dabei in horizontale (d. i. schiebende und faltende) und in vertikale (d. i. senkende) Be-

*) Bei Pilar (a. a. O.) gestaltet sich der Kalkul viel zu verwickelt. Ein gleichschenkliges Trapez A BCD (Fig. 63) vom spezifischen Gewichte $\frac{5}{6}$ schwimmt

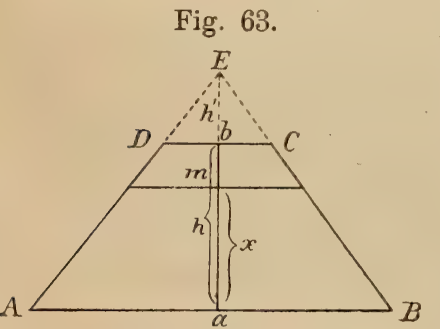

in Wasser (spez. Gew. = 1); bis zu welcher Tiefe $x$ es eintaucht, soll berechnet werden. Die beiden parallelen Seiten mit a und $b$, die Höhe mit $h$, die der Tiefe $x$ entsprechende Parallele mit $\mathrm{m}$ bezeichnend, findet man zuerst durch Anwendung des archimedischen Principes

$$
\frac{5}{6} \cdot \frac{1}{2}(a+b) h=\frac{1}{2}(a+m)(h-x) .
$$

Nun ergänzt man das Trapez zum Dreieck ABE und gewinnt, mit $h^{\prime}$ die Ergänzungshöhe bezeichnend, durch Betrachtung von zwei Paaren ähnlicher Dreiecke die Proportionen $h^{\prime}:\left(h+h^{\prime}\right)$ $h^{\prime}=\frac{b h}{a-b}, m=\frac{a h-(a-b) x}{h}$ und schliesslich

$$
x=\frac{h}{a-b} \cdot\left(-b+\sqrt{\frac{1}{6}\left(a^{2}+5 b^{2}\right)}\right) .
$$

folgt. Für sein Beispiel $\mathrm{a}=20, \mathrm{~b}=4, \mathrm{~h}=60$ berechnet Pilar $\mathrm{x}=18,5$ und den entsprechenden Werth $(18,5415)$ liefert auch unsere unverhältnissmässig einfachere Formel. 
wegungen zu zerlegen. Man hat daher die Dislokationen in zwei grosse Hauptgruppen zu trennen, von welchen die eine durch mehr oder minder horizontale, die andere durch mehr oder minder vertikale Ortsveränderungen grösserer oder geringerer Gebirgstheile gegen einander erzeugt worden sind. " Durch die in diesen Worten signalisirte konsequente Durchführung eines statischen Fundamentaltheoremes führt Suess auf die „Dislokationen durch tangentiale Bewegung ${ }^{*}$ zurück die Faltungen [61], die Schuppenstruktur [62], die Ueberschiebungen [63] und die Blätterbildung [64]; den "Dislokationen durch Senkung " danken ihr Dasein die peripherischen und radialen Sprünge [65], die (bergmännisch so genannten) Horste [66], die Flexuren und Verschleppungen [67] und die Tafelbrüıhe [68]; endlich giebt es auch Dislokationen aus vereinigter Senkung und tangentialer Bewegung " [69], durch welche die am Riesen- und Isergebirge, wie auch am Teutoburger Walde hervortretenden Rückfaltungen und die für die verwickelten Lagerungsverhältnisse der belgischen Kohlenfelder den Schlüssel abgebenden $\mathrm{V}$ orfåltungen bedingt erscheinen*).

$\mathrm{Zu}$ einer Entscheidung darüber, ob die mit einem feurig-flüssigen Erdinneren rechnende Theorie von Pilar und Fisher oder die von ryakokrustalen Phänomenen ganz absehende und ausschliesslich intrakrustale Processe zulassende Kontraktionstheorie von Suess das Richtige treffe, wird die Wissenschaft sobald nicht gelangen, und am allerwenigsten wäre hier der Ort dazu, einer solchen Entscheidung vorarbeiten zu wollen. Jedenfalls ist dieselbe mit abhängig von den neuen Gesichtspunkten, welche aus der Erforschung der Vulkan- und Erdbeben-Erscheinungen zu abstrahiren sind. Diesen letzteren wenden wir uns deshalb jetzt zu.

[1] Schiaparelli, Die Vorläufer des Coppernicus im Alterthum, deutsch von Curtze, Leipzig 1876. S. 8 ff. - [2] Zöckler, Geschichte der Beziehungen zwischen Theologie und Naturwissenschaft, mit besonderer Rücksicht auf Schöpfungsgeschichte, 1. Abtheilung, Gütersloh 1877. S. 137. - [3] Rixner-Siber, Leben und Lehrmeinungen berühmter Physiker am Ende des XVI. und Anfang des XVII. Jahr-

*) Die Erklärungsmethode von Suess dringt jedenfalls von allen zur Zeit bekannten in die individualistischen Eigenthümlichkeiten irgend einer geologischen Phase am tiefsten ein. Diess tritt besonders zu Tage bei den Horsten, bei denen der Wiener Geologe verschiedene Ordnungen zu unterscheiden lehrt, während Pilar für Horste und Gruben, wie sie in Fig. 64a und b abgebildet sind, sich mit der einfachen Notiz begnügt, dass die nach oben schmal zulaufenden Schollen Hubschollen, dagegen die nach unten schmal zulaufenden Senkschollen seien. v. Groddeck giebt der üblichen Regel, wie man bei einem solchen Gebilde die Fortsetzung der plötzlich abbrechenden Schicht aufzusuchen habe, folgende Fassung [70]: Befindet man sich bei'm Anfahren der Kluft im Hangenden derselben, so hat man, nach Durchbrechung der Kluft, in das Hangende des verworfenen Flötzes aufzufahren, im anderen Falle dagegen, wenn man sich bei'm ersten Befahren der Kluft in deren Liegendem hefand, muss auch im Liegenden jenes Flötztheiles gesucht werden. Kürzer [71]: Man fahre über den stumpfen Winkel hin, bis man das abgetrennte Ende wieder findet.

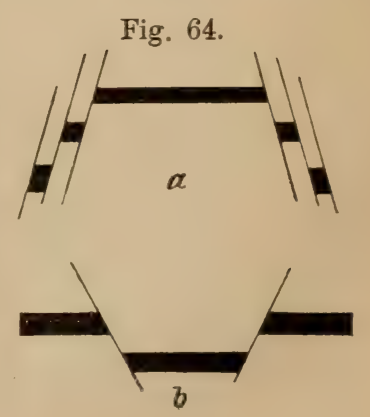


hunderts, Sulzbach 1824. S. 177. - [4] J. C. F. Fischer, Geschichte der Naturlehre, 2. Band, Göttingen 1802. S. 7 ff. - [5] Leibniz, Protogaea seu de prima facie telluris et antiquissimae historiae vestigiis in ipsis naturae monumentis, Lipsiae 1693. S. 40 ff. - [6] Thomson-Tait, Handbuch der theoretischen Physik, deutsch von Helmholtz-Wertheim, 1. Band, 2. Theil, Braunschweig 1874. S. $436 \mathrm{ff}$. - [7] J. C. F. Fischer, Gesch. d. Nat., 6. Band, Göttingen 1805. S. 881 . [8] Halley, On the structure of the internal parts of the earth and the concave habitated of the stell, Phil. Transact., Vol. XVII. S. 563 ff. - [9] A. v. Humboldt, Kosmos, 1. Band, Stuttgart und Augsburg 1845. S. 178. - [10] Breislak, Institutions géologiques, tome VIII, 1. Milan 1818. S. 55. - [11] C. W. und E. F. L. Marschall von Bieberstein, Untersuchung über den Ursprung und die Ausbildung der gegenwärtigen Anordnung des Weltgebäudes, Giessen und Darmstadt 1802. [12] Gehler's physikalisches Wörterbuch, 2. Auflage, 4. Band, 2. Abtheilung, Leipzig 1828. S. 1247. - [13] Hopkins, Rechearches of physical geology, Phil. Transact., Vol. CXXIX. S. 381 ff.; Vol. CXXX. S. 193 ff.; Vol. CXXXII. S. 43 ff. - [14] G. H. Darwin, On the precession of a viscous spheroid, Phil. Transact. Vol. CLXX. S. $447 \mathrm{ff}$. - [15] Delaunay, On the hypothesis of the internal fluidity of the terrestrial globe, Geol. Mag., Vol. V. S. $507 \mathrm{ff}$. - [16] Folie, Sur un critérium astronomique certain de l'existence d'une couche fluide à l'intérieur de l'écorce terrestre, Bruxelles 1882. - [17] R. Mallet, On volcanic energy, Phil. Transact., Vol. CLXIII. S. 151 ff. - [18] G. H. Darwin, On the bodily tides of viscous and semi-elastic spheroids and on the ocean tides on a yielding nucleus, Phil. Transact. Vol. CLXX. S. 1 ff. - [19] Thomson-Tait, Handbuch etc., 1. Band, 2. Theil. S. 419 ff. - [20] G. H. Darwin, Proceedings of the r. society, 1881 . S. $432 \mathrm{ff}$. - [21] Barnard, On the internal structure of the earth considered as affecting the phenomena of precession and nutation, Smithsonian Contributions to knowledge, N. 310, S. 9 ff. - [22] Hennessy, The rigidity of the earth, Nature, Vol. VII. S. 288. - [23] Airy, The interior of the earth, ibid. Vol. XVIII. S. 41 ff. - [24] Zöppritz, Der gegenwärtige Stand der Geophysik, Wagner's Geogr. Jahrb., 8. Band. S. 19. - [25] Werner Siemens, Physikalisch-mechanische Betrachtungen, veranlasst durch eine Beobachtung der Thätigkeit des Vesuv im Jahre 1871, Monatsber. d. k. preuss. Akad. d. Wissensch., 1878. S. 558 ff. - [26] Nies-Winkelmann, Ueber Volumänderungen einiger Netalle bei'm Schmelzen, Sitzungsber. d. k. bayr. Akad. d. Wissensch., Math.-phys. Kl., 1881. S. 63 ff. - [27] Zöppritz, D. gegenw. Stand etc., S. 31. - [28] Zöppritz, Die Fortschritte der Geophysik, Wagner's Geogr. Jahrb., 9. Band. S. 8. - [29] Heer, Escher von der Linth; Lebensbild eines Naturforschers, Zürich 1873. S. 126. - [30] Reyer, Beitrag zur Physik der Eruption und der Eruptivgesteine, Wien 1877. S. 124. - [31] Ibid. S. 109 ff. - [32] Legendre, Recherches Sur la figure des planètes, Mém. de l'acad. franç. des sciences, Année 1784. S. 370 ff. - [33] Roche, Mémoire sur l'intérieur du globe terrestre, Montpellier 1881. - [34] A. v. Humboldt, Kosmos, 1. Band. S. $177 \mathrm{ff}$. - [35] Franklin, Conjectures concerning the formation of the earth, Transact. of the Amer. phil. society, Vol. III. N. 1. - [36] Gehler's phys. Wörterb. 2. Aufl., 3. Band, S. 1071 ff.; 4. Band, 2. Abtheilung, S. 1256. - [37] Spencer, The form of the earth no proof of original fluidity, Phil. Mag., (3) Vol. XXX. S. 194 ff. - [38] A. Ritter, Untersuchungen über die Höhe der Atmosphäre und die Konstitution gasförmiger Weltkörper, Ann. d. Phys. u. Chem., (2) 5. Band, S. 405 ff. S. 543 ff.; 6. Band, S. 135 ff.; 7. Band, S. 304 ff.; 8. Band, S. 157 ff. [39] Ibid. 5. Band, S. 416. - [40] Ibid. S. 419 ff. - [41] Ibid. S. 423 ff. [42] M. Kuhn, Ueber die Beziehung zwischen Druck, Volumen und Temperatur bei Gasen, Wien 1875. - [43] Biehringer. Ueber eine Erweiterung der Gesetze von Mariotte und Gay-Lussac, Zeitschr. f. Math. u. Phys., 26. Jahrgang. S. 377 ff. - [44] Zöppritz, Ueber die Mittel und Wege, zur besseren Kenntniss vom inneren Zustande der Erde zu gelangen, Verhandl. d. I. deutschen Geographentages, Berlin 1882. S. 15 ff. - [45] Seydler, Ueber das Gleichgewicht einer gravitirenden, ursprünglich homogenen Kugel, Sitzungsber. d. k. böhm. Gesellsch. d. Wissenschaften, 1882. - [46] A. Boué, Note sur la symétrie de la surface du globe, Ann. de la soc. géol., (3) tome XVII. S. 451. - [47] F. Pfaff, Allgemeine Geologie als exakte Wissenschaft, Leipzig 1873. S. 302. - [48] Pilar, Grundzüge der Abyssodynamik, Agram 1881. S. 58 ff. - [49] Fisher, On the possibility of changes in the latitudes of places; being an appell to physicists, Geo. Mag., (2) Vol. V. S. 293 ff. - [50] Belli, Pensieri sulla consistenza e sulla densità della crosta solida terrestre, Milano 1851. - [51] Pilar, Grundzüge etc. S. 98 ff. - [52] Ibid. S. 100 ff. - [53] Jannetaz, Rapport sur la pro- 
pagation de la chaleur dans les roches et de leur structure au point de vue de leur origine, Compte rendu du congrès internat. de géol. à Paris, S. 222 ff. [54] Sénarmont, Note sur les propriétés thermiques du tourmaline; Mémoire sur la conductibilité des substances crystallisées pour la chaleur, Ann. de chim. et de phys., Vol. XXI; Vol. XXII; Vol. XXIII. - [55] Plücker-Dronke, Einleitung in die mathematische Theorie der Wärmeverbreitung, Leipzig 1882. S. 82 ff. - [56] Pilar, Grundzüge etc. S. 114 ff. - [57] Suess, Die Entstehung der Alpen, Wien 1875. S. 31. - [58] Pilar, Grundzüge etc. S. 119. - [59] Fisher, Physics of the earth's crust, London 1881. - [60] Suess, Das Antlitz der Erde. Erste Abtheilung, Prag und Leipzig 1883. S. 142 ff. - [61] Ibid. S. 144 ff. - [62] Ibid. S. 149 ff. [63] Ibid. S. $152 \mathrm{ff.}$ - [64] Ibid. S. 159 ff. - [65] Ibid. S. 166. - [66] Ibid. S. 167 ff. - [67] Ibid. S. 171 ff. - [68] Ibid. S. 174 ff. - [69] Ibid. S. 181 ff. - [70] v. Groddeck, Die Lehre von den Lagerstätten der Erze, Wien 1879. S. 22.

- [71] Quenstedt, Epochen der Natur, Tübingen 1861. S. 206.

\section{Kapitel III.}

\section{Die vulkanischen Erscheinungen.}

§. 1. Definition und allgemeine Beschreibung der Vulkane. Als vulkanische $\mathrm{Ph}$ änomene bezeichnet man nach der umfassenden Definition Poulett Scrope's [1] jedwedes Ausstossen fester, flüssiger, halbflüssiger oder gasförmiger Massen durch Spalten der Erdrinde. Damit ist von selbst die vulgäre Identificirung von $\mathrm{Vulkan}$ mit feuerspeiendem Berg als eine allzu beschränkte zurückgewiesen, doch hat sich dieselbe ein solches Uebergewicht zu verschaffen gewusst, dass halb unwillkürlich auch in diesem Kapitel das Wort Vulkan in diesem landläufigen Sinne gebraucht werden wird. In sehr drastischer Weise giebt die Erklärung eines Vulkanes ein wackerer älterer Physiker, Heinrich Müller [2]: „Per montes ignivomos, vi etymologiae, facile patet nos tales intelligere montes, qui frequenti flammarum horrendarum eructatione celebres sunt, ac pro ceteris conspicuis, idemque Vulcanorum appellationem denotare manifestum est, quando et isti nihil aliud indicant, quam officinas quasdam, in quibus viri Vulcanii strenue laborando id efficiunt, ut infernalis quasi furor ipsorum, in cudendis nescio quibus cruciatibus et tormentis saepissime in montium apicibus perterribiles fumos flammasque erumpendo se prodat." Wir werden jedoch sogleich sehen, dass nach den neuesten methodologischen Arbeiten v. Seebach's [3] selbst diese altgewohnte Zusammenwerfung von vulkanischen Bergen und von Feuerbergen nicht mehr aufrecht erhalten werden darf.

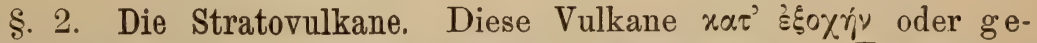
s chichte ten Vulk an e danken ihre Entstehung gewaltsamen Eruptionen, denn der Aufbau derselben hängt nicht sowohl von den aus der Erdrinde unmittelbar hervortretenden feurig-flüssigen Massen, sondern von den Aschenmassen ab, welche durch die Gewalt der Eruption in die Höhe geschleudert werden und bei'm Herabfallen schichtenweise sich um den bereits fertigen Bau herumlegen. So entsteht ein abgestumpfter Kegel, der oben jedoch nicht eigentlich abgeplattet ist, sondern eine 
muldenförmige Einsenkung, den sogenannten $\mathrm{Krater}$, aufweist. In dessen Innerem aber pflegt wieder ein kleiner Aschenkegel aufzusteigen, dessen Axe ausgehöhlt ist, so dass durch diese Röhre die inneren Partieen der Erdrinde mit der atmosphärischen Luft in Kommunikation treten. Natürlich ist dieser Grundtypus der Stratovulkane in voller, sozusagen geometrischer Reinheit nicht immer vorhanden, die äussere Mauer kann theilweise eingestürzt sein, der Aschenkegel und Verbindungsschlöte kann es eine ganze Menge geben, wie denn dem Pico de Teyde und dem Mauna Loa zwei grosse Krater, dem Vesuv 30, dem Aetna sogar an 700 Eruptionsöffnungen zugehören*). Die Kegel sind selten glatt von Oberfläche, vielmehr kann man gerade an ihnen sehr gut die ausnagenden Wirkungen der Luft und der meteorischen Gewässer studiren, welch' letztere, als Giessbäche niederrauschend, die in Südamerika unter 'dem Namen Barranco's [5] vgl. Fig. 66 - bekannten Rinnen in ihre Unterlage eingraben. Die Schichtenstruktur der Aufschüttungskrater tritt nach v. Hochstetter

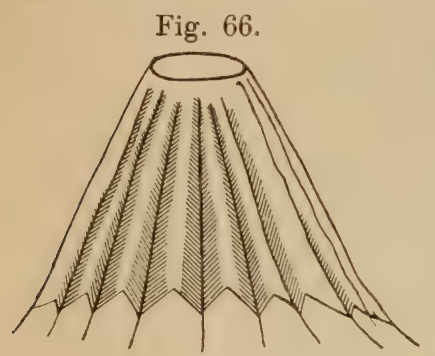
am klarsten bei den neuseeländischen Vulkanen zu Tage, welche dieser Gelehrte deshalb als förmliche Modelle zum Studium empfiehlt [6]. Gewöhnlich bildete sich zuerst, vielleicht submarin, ein aus losen Schlacken- und Aschenbestandtheilen und aus von Wasser durchtränktem Schlamm erbauter Tuffkegel, resp. Tuffkrater, um diesen herum legte sich in vielen Fällen ein Schlackenkegel, zusammengesetzt aus zähflüssigeren und nach erfolgter $\mathrm{Ab}$ kühlung spröderen Erstarrungsprodukten des intrakrustalen Magma's, und wenn nun später noch Lavaströme folgten, so legten sich diese wie ein förmlicher Mantel um den fertigen Tumulus herum als Lavakegel. In Fig. 67 bedeutet nach v. Hochstetter C den Tuffkegel, den eigentlichen Kern des vulkanischen Gebäudes, B den Schlackenkegel und A den Lavakegel; bezeichnet man mit $\gamma, \beta, \alpha$ resp. die

*) Fig. 65 stellt, nach Poulett Scrope [4], den Aetna dar, wie er von

Fig. 65 .

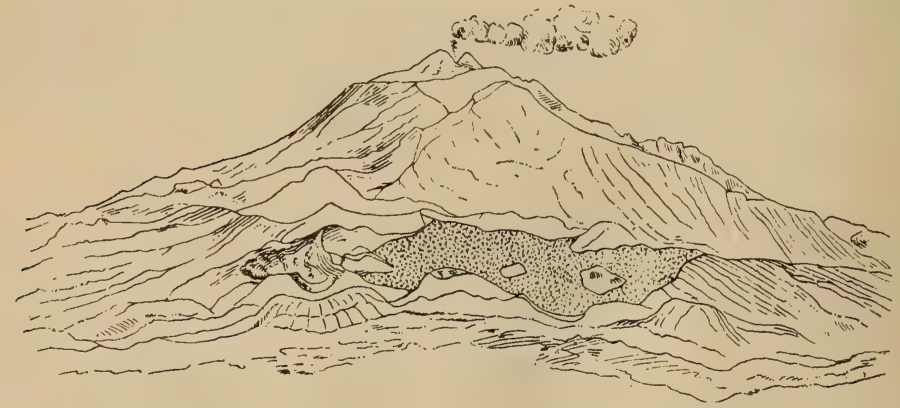

Catania aus sich darstellt; es. soll dadurch zugleich eine allgemeine Vorstellung von dem Aussehen eines feuerspeiendeu Berges vermittelt werden. 
von den einzelnen Kegelmänteln mit der Horizontalebene eingeschlossenen Winkel, so muss, wie die Figur zeigt und wie auch aus der Entstehungsgeschichte selbst hervorgeht, $\gamma>\beta>\gamma$ sein. Unser Diagramm rechtfertigt auch zur Genüge die Wahl der Namen „Aufschüttungs- oder geschichteter Vulkan".

Sehr schätzenswerthe Untersuchungen über diese Gattung von Vulkanen hat Milne [7] angestellt. Was deren äussere Form anlangt, so erweisen sich nach ihm sechs Faktoren als für sie bestimmend. Die geometrische Regelmässigkeit wird um so reiner bewahrt, eine je centralere Lage der Krater besitzt und auch für mehrere einander folgende Eruptionen bewahrt; jede Ungleichmässigkeit im örtlichen und zeitlichen Austreten der Lava beeinträchtigt jene Regelmässigkeit; besonders wirksam erweisen sich dabei das seitliche Ausbrechen der Gluthflüssigkeit und die Bildung parasitischer Kegel; ist die Axe des Schlotes keine vertikale, so dass die Auswurfsprodukte von vorn herein eine gewisse Richtung zu begünstigen genöthigt sind, wie z. B. beim Ausbruch das Oshima im Jahre 1877 beobachtet ward, so muss eine Verbreiterung des Kegels nach der betreffenden Seite hin erfolgen; Gleiches bewirkt der während des Eruptionsaktes herrschende Wind, durch welchen die Ueberwindseite des Berges mehr abgeflacht wird, wie besonders deutlich an dem Fusijama zu sehen; spezifisches Gewicht und Porosität der Baustoffe kommen ebenfalls in Betracht; die Erosionswirkungen können der einmal vorhandenen Regularität weniger anhaben, wohl aber ändern sie langsam und sicher die Neigungswinkel der Bergwände. Eben diese Winkel sind von Milne einer äusserst sorgsamen Betrachtung unterzogen worden. Er liefert auf eigener Tafel fünf Profilkurven, deren eine dem Kumagatake auf Japan, eine dem Vesur entspricht, während die drei anderen dem Fusijama, von verschiedenen Seiten betrachtet, zugehören, und belehrt uns durch den unmittelbaren Augenschein, dass diese Kurven sehr nahe die Krümmung einer logarithmischen Linie wiedergeben. Diese nämliche Kurve aber ist ebensowohl die Kurve gleicher rückwirkender Festigkeit [8], wie auch die Böschungskurve eines auf horizontaler Ebene ruhenden und den in seinen einzelnen Theilen wirkenden Gravitations-, Kohäsionsund Reibungskräften überlassenen Sandhaufens*). Folgende Böschungswinkel sind von Milne. [12] gemessen worden: Fusijama $30^{\circ}$, Osamajama $28^{\circ}$, Ganjosan $31^{\circ}$, Twakisan $30^{\circ}$, Kumagatake $40^{\circ}$ (sämmtliche liegen in Japan). Natürlich macht sich vgl. Fig. 67 - namentlich in den der Spitze näher gelegenen Partieen auch die selbstständige Neigung des etwa bereits

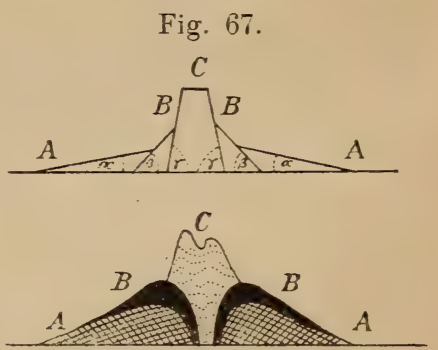

*) Neuere Arbeiten über diese Wechselbeziehungen lassen die angeführte Thatsache allerdings nur als eine Annäherung an die Wirklichkeit erscheinen. Versteht man unter c die Kohäsion per Quadrateinheit, unter h die Höhe, unter $\mathrm{g}$ das Gewicht der Kubikeinheit des den Haufen bildenden Stoffes, unter $\mathrm{f}$ den Reibungskoefficienten, unter $\tau$ das Komplement des Reibungswinkels, unter $\varepsilon$ den Böschungswinkel, so würde den älteren Vorstellungen gemäss die von Français [9] 
vorhandenen Kernkegels geltend, um welchen herum die Aufschüttung: erfolgt.

Neuerdings ist von Suess, der auch die oft frappante Aehnlichkeit der im Gefolge von Erderschütterungen vielfach auftretenden winzigen Sandkegel mit wirklichen Stratovulkanen grossen Styles betont, darauf aufmerksam gemacht worden [13], dass schematische Vorstellungen von der inneren Struktur eines Feuerberges stets ihr Missliches haben. S u es s' Methode, durch Aufsuchen einer Denudationsreihe allmählig von oben nach unten in die Geheimnisse des Vulkangebäudes einzudringen, verspricht für die Zukunft bedeutende Ergebnisse.

§. 3. Domvulkane. Mit diesem Namen bezeichnet v. Se ebach in seiner uns bereits bekannten grundlegenden Abhandlung die Gebilde jener Gattung vulkanischer Thätigkeit, welcher der eruptive, der gewaltsame Charakter fehlt. Wird das Magma mit verhältnissmässiger Ruhe, und ohne dass Dampfentwickelungen ihr Aufsteigen geleiten, in den Verbindungskanälen in die Höhe getrieben, so fliessen die austretenden Lavamassen nach allen Seiten ziemlich gleichmässig ab, in zähflüssigem Zustande kompakte kuppelartige Berge, in leichtflüssigem blos einen die Erdoberfläche deckenförmig überlagernden Mantel bildend. Die Basalt-, Trachyt-, Phonolith- und Andesitkegel, die in vulkanischen Gegenden häufig vorkommen, gehören zu dieser zweiten Kategorie; allerdings konnte diese Einreihung erst in neuerer Zeit so erfolgen, nachdem der früher viel bestrittene plutonische Charakter der betreffenden Gesteinsarten über jeden Zweifel erhaben gelten darf. Die petrographische Beschaffenheit der diese Vulkane aufbauenden Stoffe ist eine völlig andere und zwar eine ungemein gleichartigere, denn die der geschichteten Vulkane, weshalb man wohl auch die Bezeichnung Homogene Vulkane auf sie angewandt hat. Namentlich in Amerika und Schottland haben v. Richthofen und Geikie solche Formen häufig angetroffen; Letzterer sagt ausdrücklich [14], dass während seiner Reisen am Schlangenflusse mit zwingender Gewalt sich ihm die Ueberzengung aufgedrängt habe, dass es ausser dem gewöhnlichen noch einen zweiten und zwar umfassenderen Typus von Vulkanismus gäbe, nämlich den der kraterlosen Entbindung gluthflüssiger Bestandtheile des Erdinneren. Hierher haben wir auch die merkwürdige Erscheinung der sogenannten Lac colithe zu zählen, die in Amerika besonders häufig auftreten und von D a na, G. K. Gilbert, Holmes und anderen transatlantischen Geologen näher beschrieben,

aufgestellte Formel gelten:

$$
\mathrm{c}=\frac{1}{2} \operatorname{gh}\left(\operatorname{tg} \frac{\tau+\varepsilon}{2}-\operatorname{tg} \varepsilon\right)\left(\cos ^{2} \frac{\tau+\varepsilon}{2}-\mathrm{f} \sin \frac{\tau+\varepsilon}{2} \cos \frac{\tau+\varepsilon}{2}\right) .
$$

Löwe erwies aber durch eine äusserst umfängliche Versuchsreihe [10], dass man nothwendig einen veränderlichen Reibungskoefficienten

$$
\mathrm{f}=\frac{\operatorname{cotg} \tau}{\cos \varepsilon}
$$

einsetzen müsse, der um so grösser wird, je grösser man den Böschungswinkel \& wählt, d. h. in je tiefere Schichten man hinabsteigt; hiedurch geht França i s' Formel in nachstehende über [11]:

$$
\mathrm{c}=\frac{\mathrm{gh} \cos ^{2} \tau}{4 \sin \tau \cos ^{2} \varepsilon}\left[1+\operatorname{tg}^{2} \tau \cos \varepsilon-\frac{\cos \varepsilon}{\cos \tau}(1+\sin \varepsilon \operatorname{tg} \tau)\right] .
$$


durch Kinahan aber auch für Irland nachgewiesen wurden [15]. Der Name rührt von G. K. Gilbert her [16], eine Zusammenstellung der über diese merkwürdigen Gebilde veröffentlichten Nachrichten verdanken wir Suess, dessen Werke [17] auch die einen Laccolithen darstellende Fig. 68 entnommen ist. Darin bedeutet A B den Meerespiegel, CD die obere Grenze der Karbon-, EF die obere Grenze der Juraformation, Gden sogenannten „Hillers-Laccolith“, H den ${ }_{\text {Pulpit Lace }}$. Die Laccolithe treten gruppenförmig auf, werden bis zu $2000 \mathrm{~m}$ hoch, während die Peripherie der Basis oft mehrere Kilometer erreicht. Die Erosion der Atmosphärilien hat vielfach bewirkt, dass die den

Fig. 68 .

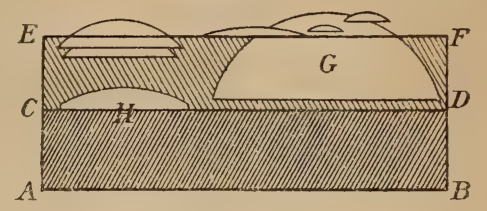

Laccolith bildenden trachytischen Intrusivmassen unverhüllt zu Tage treten, so dass die Suess'sche Denudationsreihe sehr leicht hergestellt werden kann. Die subkarbonischen und Kreideschichten der Erdrinde sind durch die mit majestätischer Ruhe und Gleichmässigkeit aufgestiegenen Magma-Massen nicht zersprengt, aber so enorm aufgetrieben worden, dass sie, die sonst immer horizontal erscheinen, die stärksten Einfallswinkel, von $45^{\circ}$ bis $80^{\circ}$, aufweisen. Von den euganäischen Bergen bei Padua versichert Suess [18], dass sie ähnlichen Intrusivprocessen ihre eigenthümliche Gestalt verdankten.

§. 4. Uneigentliche Vulkane. Wenn wir das Wort "Vulkan“ in dem weiten Sinne des §. 1 beibehalten und von einem solchen auch dann noch reden, wenn nicht blos Lava, eventuell vermischt mit Aschen, Gasen, Dämpfen u. s. w., sondern irgend eine tropfbare oder elastische Flüssigkeit den Spalten der Erde entsteigt, so gelangen wir zu den uneigentlichen Vulkanen*). Auch bei ihnen sind Unterabtheilungen zu machen: die Geysir's, Fumarolen, Solfataren, Mofetten und Schlammvulkane.

a) Geysir's. Nur der Vollständigkeit wegen erwähnen wir dieser heissen Quellen, deren Wassermassen nicht ruhig und kontinuirlich, sondern stoss- und ruckweise nach aussen befördert werden, schon an dieser Stelle, doch versparen wir eine eingehende Besprechung ihrer Eigenschaften auf das von den Quellen im Allgemeinen handelnde Kapitel des zweiten Bandes.

b) Fumarolen. So nennt man Oeffnungen in der Erde, welche neben geringen Quantitäten anderer Gase und Dämpfe vorzüglich Wasserdampf aushauchen. Gewöhnlich kommen die Fumarolen in unmittelbarer Nähe thätiger Vulkane vor. Häufig ist der Wasserdampf, der auf diese Weise geliefert wird, so rein und so frei von den ihn anderwärts trübenden Stoffen (Salzsäure, Schwefelwasserstoff u. s. w.), dass man durch Kondensation desselben brauchbares Trinkwasser gewinnen kann, wie diess nach $\mathrm{K}$. Fuchs [20] die Hirten der wasserarmen Insel Pantellaria thun sollen. Dampfquellen dieser Art giebt es ausser in

*) Diese treffende Nomenklatur entlehnen wir Muncke's sorgfältigem Artikel "Vulkane“ [19], dem wir auch für manche andere Nachweisung zu Dank verpflichtet sind. 
Italien (Ischia, Umgegend des Vesuv) besonders in Island, wo sie vielfach untermengt mit den Geysir's auftreten, in Java, auf der neuseeländischen Nordinsel u. a. a. O. [21]. Bekannt sind die massenhaft im Gefolge des neuentstandenen Feuerberges Yorullo entstandenen Fumarolen, von den Eingeborenen als „Oefen“ (Hornito's) bezeichnet, deren ursprünglich ausserordentlich hohe Temperatur jedoch nach den von Lyell [22] gesammelten Angaben mit der Zeit, und vermuthlich in Folge des allmähligen Abkühlens der ihnen benachbarten MagmaSchichten, sehr bedeutend gegen damals zurückgegangen ist, als Humbold t (1803) seine Messungen vornahm.

c) Solfataren. Nicht principiell, sondern nur mehr graduell verschieden von den soeben geschilderten Dampfquellen sind die Solfataren oder Gasquellen; Fuchs definirt sogar [23] die Fumarolen als wesentlichste Manifestationen des Solfatarenzustandes, welcher einen $\mathrm{Zu}$ stand sehr schwacher, ja beinahe latenter vulkanischer Regsamkeit kennzeichnet. Schwefelwasserstoff und schweflige Säure wiegen nunmehr vor, die Dämpfe treten zurück. Der Name Solfatare, der ursprünglich Schwefelgrube bedeutet, bezog sich zunächst auf einen kleinen Krater in der Nähe von Puzzuoli, der Schwefeldämpfe aushaucht, einmal aber im Jahre 1598 - sich sogar zu einer wirklich eruptiven Aktion aufraffte [24]. Sehr viele Plätze dieser Art sind bekannt, doch kommen auch spontane und plötzliche Aeusserungen des Solfatarenzustandes an Orten vor, welche vor- und nachher sich in vulkanischer Beziehung völlig neutral verhielten. So berichtet vom Rath [25], dass am 25. December 1881 und am 13. Januar 1882 im Golf von Patras sehr energische Exhalationen von Schwefelwasserstoff stattfanden, welche Mengen von Fischen tödteten und von Sturm und Erzittern des Erdbodens begleitet waren. Der Geruch verrieth den ausgeathmeten Stoff als Schwefelwasserstoffgas, und auf die gleiche Ursache wies die Veränderung hin, welche an gefärbten Gegenständen konstatirt werden konnte.

Den Solfataren vielfach ähnlich sind jene Gasvulkane im engeren Sinne, aus welchen als Hauptbestandtheil Wasserstoffgas aufsteigt, welches sich entzünden lässt und dann oft eine ziemliche Weile fortbrennt. Auf diese hüpfenden Flämmchen haben zuerst Spallanzani und Ménard de la Groye die Aufmerksamkeit der wissenschaftlichen Kreise hingelenkt [26]. In Italien findet man dergleichen bei Pietra Mala, wo oft ansehnliche Quantitäten von Knallgas zum Verpuffen kommen, ferner giebt es Gassprudel in Ungarn und Kleinasien [27], in Kurdistan, Indien und am Eriesee [28]. Eine der bemerkenswerthesten Naturerscheinungen in China sind die chinesischen Feuerbrunnen Kia-Tin-Fu, Yung-Hian, Ou-Thung-Kiao und Wei-Yuan-Hian. Huc und Gabet erzählen, gestützt auf die Angaben des Missionärs Imbert, dass in der (westlichsten) Provinz Sse-tschuan auf einem Flächenraume von 50 französischen Quadratlieues nicht weniger als zehntausend solcher Yen thing (Feuerbrunnen) oder Ho thing (Salzbrunnen) angetroffen würden, deren Ausbeutung durch Private oder Gesellschaften schwunghaft betrieben werden [29]. Dieselben liefern zum Theile eine mit Gasen aller Art vermengte Salzsoole, zum Theile aber auch förmliches. Leuchtgas. Weitaus am berühmtesten sind gewiss die ewig brennenden Feuer von Baku am kaspischen Meere, welche für den Gottesdienst 
der Parsen eine hohe traditionelle Bedeutung gewonnen haben. $\mathrm{Ob}$ diese entzündlichen Gase auf vulkanische Processe im Erdinneren hinweisen, oder nicht, kann noch nicht als entschieden gelten, doch ist es wahrscheinlich, da auch sonst in der Umgegend Baku's Spuren dereinstiger Vulkaneität zu Tage treten; am 27. November 1827 wurde die unterirdische Gasentwickelung so stark, dass in dem daghestanischen Dorfe Jakmali ein Feuerstrom, begleitet von Detonationen, hervorbrach, der erst nach vierundzwanzig Stunden wieder erlosch. G. H. Hess analysirte [30] die ihm in hermetisch verschlossenen Röhren übersandten Gase des Baku-Tempels und fand, dass nicht Volta, der darin Sumpfgas erblickt hatte, sondern Spallanzani mit einer früher aufgestellten Hypothese im Rechte gewesen war: es ist Kohlenwasserstoff mit einem leichten Zusatz von Naphtha, welch' letzteres selbst aus Kohlen- und aus Wasserstoff im Verhältnisse von $77,5: 22,5$ besteht. Endlich ist als hierher gehörig noch der in der Saline zu Rheina (nördliches Westphalen) befindliche Windbrunnen zu erwähnen, dessen Gas zur Erleuchtung des genannten Etablissements verwendet wurde [31].

Bei all' diesen Gasvulkanen oder Gasquellen gilt allerdings die ungemein weite Definition Poulett Scrope's (§. 1). In vielen Fällen aber wird, was die Ursachen derselben anbelangt, von eigentlichem Vulkanismus nicht viel die Rede sein können, vielmehr ist gewiss sehr häufig an blosse Erdbrände zu denken*).

*) Erdbrände entstehen meistens dadurch, dass auf irgend eine Weise, nicht selten durch Menschenhand, subterrane Kohlenflötze entzündet werden. So sollte das Steinkohlenflötz des Saarbrückener Beckens im Jahre 1660 durch die Unvorsichtigkeit eines Hirten, jenes von Zwickau anlässlich der Belagerung dieser Stadt im dreissigjährigen Kriege in Brand gerathen sein [32], während die ${ }_{\text {Meissnische }}$ Bergchronik" des Albin us einen Jäger schon 1479 in das jetzt sogenannte „tiefe Pechkohlenflötz" gerathen und durch einen unvorsichtigen Schuss diesen die Katastrophe herbeiführen lässt. Jedenfalls thut schon Agricola (vgl. die gesch.-lit. Einleitung) in seiner Grubenkunde des Brandes Erwähnung: er lebte, wie wir den von Funcke in den Sitzungsberichten der Dresdener "Isis" gegebenen und hier mehrfach benützten Mittheilungen entnehmen, von 1518 "bis 1522 in Zwickau und beschreibt die glimmenden Planitzer Kohlenlager folgendermassen: „Verum incendio principium hominum aetas non novit. Ante quadraginta annos vehementius arsit mons adeo, ut metum incuteret oppido. Quia vero in superficie tantum ardet, verisimile est, eum ab homine primum accensum fuisse." Die dem sächsischen Erdbrande entströmende Hitze gestattete die Anlegung von Treibhäusern auf dem davon betroffenen Terrain, welche fast gar keiner künstlichen Erwärmung bedurften, dafür aber ab und zu einem Ortswechsel sich unterziehen mussten und heute bereits dem gänzlichen Untergange verfallen sind (D. Rundschau $f$. Geogr. u. Stat., 6. Jahrgang. S. 181). Brennende Schichten gab oder giebt es noch in Böhmen, im hessischen Habichtswalde, in Esthland, in Sibirien, am Ausfluss der Rhone und noch in manch anderen Gegenden [33], auch die Erscheinung des brennenden Hügels im Lande der Baschkiren gehört hierher. Ein Blitzschlag war die Ursache dieses Brandes, der mindestens drei Jahre andauerte und durch seinen gleichmässigen, ahsolut un-eruptiven Verlauf für B reislak [34] den Beweis lieferte, dass nur Petroleum oder sonst ein völlig schwefelfreier Stoff in langsamer Gluth sich verzehrte. Muschketov und v. Middendorff wollen mehrere Behauptungen $\mathrm{Humboldt}$ 's über centralasiatische Vulkane auf brennende Flötze (Pseudo-Solfataren) zurückführen [35]; ihnen zufolge gienge auch v. Richthofen's Interpretation der Solfataren von Turfan und Urumtsi [36] zu weit. Salmiak und Schwefel entstünden im russischen Asien nicht selten durch einen Sublimationsprocess aus Kohlenfeldern, und man dürfe nicht gleich an vulkanischen Ursprung denken, auf welch' letzteren auch der von dem berühmten China-Forscher angezogene Reisebericht des Arabers Massudi nicht nothwendig hinweise. 
d) Mofetten. Tritt Kohlensäure an die Stelle der Dämpfe und Gase, welche wir bei Fumarolen und Solfataren kennen lernten, so werden die Gasquellen Mofetten benannt - ein Name, der, wie bei den Schwefelkratern, der provinziellen Terminologie der neapolitani-

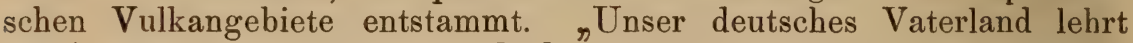
uns, ${ }^{6}$ sagt A. v. Humboldt [37],, wie in den tief eingeschnittenen Thälern der Eifel, in der Umgebung des Laacher See's, im Kesselthal von Wehr und in dem westlichen Böhmen, gleichsam in den Brandstätten der Vorwelt, oder in ihrer Nähe, sich die Ausströmungen der Kohlensäure, als letzte Regungen der vulkanischen Thätigkeit, offenbaren." Die Menge des - bald kalt, bald erhitzt - ausströmenden Gases ist oft recht beträchtlich; B is ch of [38] hat berechnet, dass eine einzige Quelle im Brohlthale pro Jahr 6000 Centner liefere. Vielfach befinden sich die Durchgangsspalten in Grotten, an deren Boden die Kohlensäure, weil sie die atmosphärische Luft an Dichte übertrifft, eine förmliche Schicht bildet. Kleine Thiere, deren Athmungsorgane sich nicht über die Grenzfläche dieser Schicht erheben, fallen in Betäubung und sterben, wenn sie einige Zeit dort zu verbleiben gezwungen sind. Bekannt ist eine solche Höhle in den phlegräischen Feldern bei Neapel, nicht minder die Mofette in der Nähe des Bades Pyrmont. Am öftesten besprochen ist aber wohl das sogenannte "Todesthal" (Guwo Upas) auf Java worden, von dem noch Muncke [39] eine schaudererregende Schilderung entwirft, indess legen die objektiven Berichte neuerer Reisender (Junghuhn's, Bickmore's u. a.) die Annahme nahe, dass jene älteren Beschreibungen ein stark sagenhaftes Gepräge an sich tragen.

e) Schlammvulkane. Für diese Kategorie trifft der Name uneigentlicher Vulkane am meisten zu. Diese Salsen, wie man wohl auch sich ausdrïckt, entstehen im Geleite erdbebenartiger Erscheinungen; allmählig tritt ein stationärer Zustand ein, es bilden sich kleine Kegel, auf deren Spitze sich ein kleines Wasserbecken zeigt, und ans diesem fliesst lettiger Schlamm, unter periodischer Entwickelung von Wasserstoffgas, Kohlensäure oder Stickgas, nach unten [40]. Die berufensten Salsen sind die Maccaluba's Siziliens (arabisch makhlub = umgestürzt; auf Malta heissen so auch unvulkanische Bodensenkungen) [41]. Zweifellos hat von deren Existenz schon Platon, der ja die Insel zu dreien Malen aufsuchte, Kunde gehabt; schreibt er doch im "Phaedon" (vgl. Kap. II, §. 1) dem die Eingeweide der Erde erfüllenden Pyriphlegethon als Bestandtheil feuchte Schlammströme

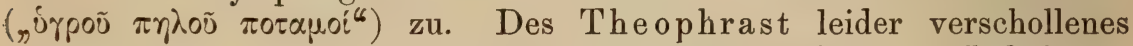
und nur von Diogenes Laertius dem Titel nach uns aufbehaltenes

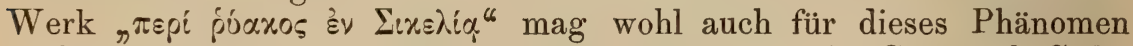
wichtige Eröffnungen enthalten haben. Der römische Geograph Solinus gedenkt desselben [42] in einer Weise, welche es ganz leicht kenntlich macht: „Idem ager Agrigentinus eructat limosas scaturigines, et ut venae fontium sufficiunt rivis subministrandis, ita in hac Siciliae parte solo nunquam deficiente, alterna rejectatione terram terra evomit." Auf Italiens Boden begegnen wir Schlammvulkanen bei Modena, bei Canossa, bei Parma u. a. a. O.; heftiger Regen bringt mitunter die Kegel zum Verschwinden, während sie bei Trockniss wohl auch explodiren. Baku, die Insel Trinidad, Java, Borneo, Barbados sind gleich- 
falls Schaustätten dieser Art vulkanischer Thätigkeit; auf Island birgt eine am Fusse des Krabla befindliche Höhle siedende Schlammmassen, deren Anblick nach Henderson einen grossartig schauerlichen Eindruck gewährt [43], wogegen anderwärts wiederum die Temperatur der zähen Flüssigkeit eine niedrige ist. Ferner breiten sich Komplexe von Salsen zu beiden Seiten der Meerenge von Kertsch aus, welche aus dem asow'schen in das schwarze Meer führt; die Kraterbecken sind unergründlich tief, stossen aber die Leichen hineingefallener kleiner Thiere nach eingetretener Verwesung regelmässig wieder aus [44]. Unsere geographische Aufzählung runden wir ab durch die Nennung der Schlammvulkane auf der Insel Cheduba an der Küste von Arrakan, bei Dembo in Birma, der Volcanito's von Turbaco in Südamerika, und des siebenbürgischen „Höllenmorastes“, welch' letzterer in periodischem Wechsel Schlamm auswirft und Gase aufsteigen lässt [45].

Für die Aktion der Salsen scheint nicht eine und dieselbe unverbrüchliche Grundursache verantwortlich gemacht werden zu dürfen. Jedenfalls ist das Motiv meistentheils kein vulkanisches im gewöhnlichen Sinne. „In manchen Fällen," urtheilt Gü mbel [46], der den allerdings zweckmässigeren Namen Schla m m sprud el eingeführt wissen möchte, , mag die vulkanische Thätigkeit die Entstehungsbedingungen der Eruptionsgase und der bituminösen Stoffe gleichsam mit sich näher an die Oberfläche gerückt und in die höheren Lagen der Schichtgesteine emporgezogen haben, indem hier ein höherer Grad von Wärme und mit demselben die Bedingung der Umbildung organischer Stoffe sich einstellte. Eine derartige Beziehung zwischen Schlammvulkanen und dem Vulkanismus dürfte namentlich auf Sizilien anzunehmen sein. ${ }^{6}$ Umgekehrt will Pilar [47] gerade in dem Auswurfe der Makkaluben nur das Produkt chemischer Vorgänge des Verwesens und Selbstentmischens organisirter Substanzen unter dem Einflusse der Sonnenstrahlen erblicken, während er für die javanischen Sprudel mit v. Hochstetter [48] annimmt, dass in die Bodenspalten eindringendes Meteorwasser die bereits dem Erstarrungszustande sich nähernden Lavaschichten zu oberflächlichen Eruptionen zu reizen vermöge. M. Wagner hat die Schlammvulkane der Taman'schen Halbinsel genau untersucht und sich dahin schlüssig gemacht (s. o.), dass die von Pallas, Gurief und Kulschin für deren Besonderheiten gegebene Erklärung wohl das Richtige treffe: Das Wasser des nur wenige Werst entfernten Liman dringe in einen unterirdischen Gluthheerd ein, und letzterer veranlasse die Wasserzersetzung, welcher elastische Dämpfe nachfolgen. In der That schliesst der vom Küll-tepe ausgestossene Schlamm Schilfreste und Binsenwurzeln ein, die einzig und allein in den benachbarten Sumpfgewässern gewachsen sein können *).

*) Für eine, wenn auch matte und zersplitierte, so doch immer mehr vulkanische Thätigkeit der Schlammvulkane sprechen anscheinend auch 0 . Schneider's Beobachtungen an dem sogenannten Schlangenberg in Transkaukasien [49]. Manche Anzeichen deuten darauf, dass dieser Schlammsprudel eine sehr recente Erscheinung ist und erst in historischer Zeit die nunmehr unter ihm verdeckte Begräbnissstätte durchbrochen hat, deren Knochenüberreste gegenwärtig oben auf schwimmen. Auch Pallas und Dubois de Montpereux haben Aehnliches wahrgenommen.

G ū nther, Geophysik. I. Band. 
§. 5. Reihung und Anordnung der eigentlichen Vulkane. Der erste konsequente Versuch, eine grundsätzliche Scheidung aller wirklichen Feuerberge nach genetischen Normen durchzuführen, rührt von Leopold v. Buch her, der in dem „Ueber die Natur der vulkanischen Erscheinungen auf den kanarischen Inseln und ihre Verbindung mit anderen Vulkanen der Erdfläche" betitelten Abschnitte seines grossen Reisewerkes [50] die Centralvulkane von den Reihenvulkanen trennte. In die erstere Kategorie [51] ordnete er ein die Liparen, den Aetna, die phlegräischen Felder, Gesammt-Island, die azorischen, kanarischen und kapverdischen Inseln, Ascension, die Gallapogos, Marquesas, Bourbon, die Gesellschafts- und Freundschaftsinseln, eventuell den Demawend, Ararat, die sonstigen armenischen und tartarischen Berge und die seither sehr fraglich gewordenen Vulkane von Kordofân. Die Reihenvulkane sollten sich in zwölf selbstständigen Linien gruppiren [52]: Die griechische Inselreihe, die westaustralische Reihe, die Sundareihe, die molukkisch-philippinische Reihe, die von Japan durch die Kurilen nach Kamtschatka hinüberführende Reihe [53], die Reihe der Aleuten, diejenige der Marianen, diejenige von Chile, Quito, von den Antillen [54], von Guatemala und Mexiko. Diese Klassifikation, welche $\mathrm{Buch}$ in einer noch vor der Drucklegung des erwähnten Werkes erschienenen Abhandlung zu begründen gesucht hatte [55], steht allerdings mit den theoretischen Ansichten ihres Urhebers in enger Verbindung, welche (s. u. §. 10) heute viel an ihrem Werthe verloren haben, und so hat dieselbe gegenwärtig auch nicht mehr jene ganz hohe Bedeutung, wie damals, als ihr Humboldt [56] enthusiastisch Beifall zollte, doch entspricht sie immerhin den Thatsachen zu sehr, um nicht, von allen daran sich knüpfenden Hypothesen abgesehen, rein schematisch oder architektonisch ihren Werth zu behaupten. Indess hat schon Fr. Hoffmann, so entschieden auch gerade er zu L. v. Buch's Fahne schwört [57], den Versuch gemacht, den strengen Unterschied zwischen isolirten und gereihten Vulkanen zu verwischen, indem er die Gruppe der liparischen Eilande als verbindendes Zwischenglied zwischen beide Klassen eingeschoben wissen wollte [58]. Charles $\mathrm{D}$ arwin erkennt den Gegensatz überhaupt nicht an und definirt sogenannte Centralvulkane als Reihenvulkane von geringer Ausdehnung auf parallelen Spalten [59]. Das Bestreben, einen sozusagen mathematischen Grundgedanken in der Anordnung der irdischen Vulkane zu entdecken, hat in Schriften, wie diejenigen von Ordinaire (Histoire naturelle des volcans, Paris 1802) und Sickler (Ideen zu einem vulkanischen Erdglobus, Weimar 1812) sind, zu Uebertreibungen geführt. Nach einem von Kalkow sky vor dem geographischen Vereine zu Leipzig gehaltenen Vortrage, welchen wir nur aus einer kurzen Notiz kennen, überdecken die Vulkankurven den südlichen Theil Europa's mit einem förmlichen Netzwerke.

Wichtiger, weil auf unsere modernen vulkanischen Theorieen unmittelbar influirend, ist die Anordnung der feuerspeienden Berge längs den Küsten der Meere oder grosser binnenländischer Wasseransammlungen. Humboldt bemerkt, dass schon Trogus Pompejus, den dann Justinus als Quelle benützte, auf diesen Umstand aufmerksam machte [60], und er theilt weiter eine derselben Wahrnehmung Ausdruck verleihende beachtenswerthe Stelle aus Bembo's Lehrge- 
dicht „Aetna dialogus" mit, welches um die Mitte des XVI. Jahrhunderts verfasst wurde [61]. Zweihundert Jahre später erklärt der Indien-Reisende $\mathrm{Brunel}$ [62]: „Phaenomena terrifica et horrenda sunt vulcanorum eruptiones et terrae motus, quorum mutuus consensus, caussae et effectus a physicis explicari solent. Terras maritimas iis praecipue obnoxias esse propter copiam ingentem corporum inflammabilium, a mari suffectorum, cujusmodi sulphur et bitumen sunt, res satis nota est." Im gleichen Sinne lautete J. R. Forster's auf grossen Reisen gewonnenes Urtheil. Neuere Untersuchungen brachten der Hauptsache nach Bestätigungen, doch ist darauf zu achten, dass mancher erloschene Vulkan, der nunmehr tief im Festlande liegt, einem Meeresbecken der Tertiärzeit sehr wohl benachbart gewesen sein kann, und solche Erscheinungen würden allerdings keine Ausnahme begründen. Immerhin sind (vgl. die eine Randnote zu §. 4) die Vulkane des IliBeckens, welche v. Richthofen an das Gestade eines vorzeitlichen Meeres verlegte, nicht als gesichert zu betrachten, vielleicht die von Stolička im Thian-Schan erkannten Kraterreste ausgenommen [63]. Der Demawend im Albrusgebirge verräth zwar durch seine ganze Bauart, durch seine von Einigen mit der Somma des Vesuv verglichene obere Umwallung und durch aktive Fumarolen seinen vulkanischen Ursprung, dass aber die Rolle des Berges schon lange ausgespielt ist, erhellt schon aus Tietze's Nachweis, es sei die Schichtenstellung der bis zu einer Höhe von $2700 \mathrm{~m}$ hinaufreichenden Sedimentbildungen ausser Beziehung zu irgendwelcher vulkanischer Kraftäusserung [64]. Der vorhin erwähnte Dschebel-Koldadschi im Sudân ist schon von Rüppell [65] wieder aus der Reihe der thätigen Vulkane gestrichen worden. Aehnlich ist es mit einem armenischen Vulkan bestellt, den nach einem von Ly nch nach London gerichteten Briefe [66] der Konsul Taylor zwischen dem Van-See und dem durch seine heissen Schwefelquellen bekannten Orte Diadyn entdeckt haben wollte. Abich, der die im Lande unter dem Namen "die Ofenberge" wohlbekannten Erhebungen schon früher untersucht hatte, leugnet allerdings nicht deren auffallende Aehnlichkeit mit aktiven Vulkanen, hält auch die Thätigkeit derselben für eine erst seit kurzer Zeit erloschene, konstatirt aber mit Bestimmtheit, dass die Berge zur Zeit nur noch im Solfatarenzustande sich befinden [67]. Die innige Beziehung, welche zwischen der Lage der thätigen Feuerberge und dem Meeresstrande obwaltet, kann als eines der wenigen völlig gesicherten Gesetze der Vulkanologie gelten; am weitesten im Binnenlande liegt wohl der grosse Ararat, der sich aber dafür in der Nachbarschaft der gewaltigen Landseen Hocharmeniens befindet. - Wenn Milne Recht hat, bevorzugen übrigens die Vulkane durchgehends solche Meeresküsten, deren Abfall zur Tiefsee ein besonders steiler ist.

§. 6. Geographische Vertheilung der Vulkane. Indem wir uns anschicken, die Ausstreuung der eigentlichen (Strato- und Domvulkane) über die Erdoberfläche festzustellen, müssen wir natürlich einen gewissen Unterschied zwischen thätigen und erloschenen Vulkanen machen, doch darf diese Trennung nicht soweit gehen, beide Gruppen gesondert behandeln zu wollen, da doch der vulkanische Charakter einer Gegend durch das Vorhandensein wirklicher Eruptionskanäle nur 
mittelbar bedingt wird. Wir beginnen mit unserem eigenen Erdtheile und verweisen auf die in Fig. 69 vermittelte Skizze der Vulkan-

Fig. 69 .

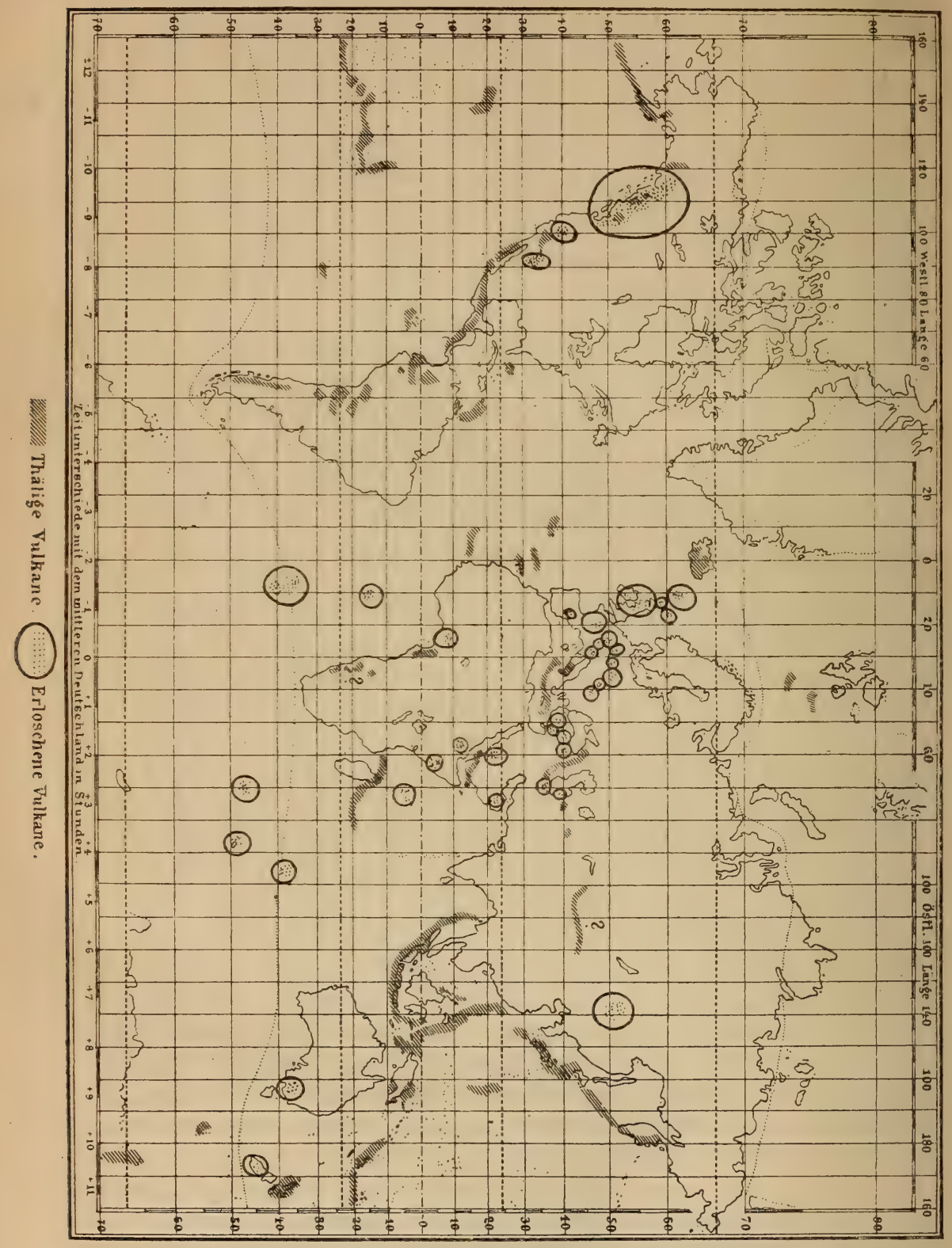

Geographie, welche nach den in den Werken von Poulett Scrope und K. Fuchs enthaltenen Karten gearbeitet ist.

a) Europa. Das vulkanreichste Land Europa's ist Italien, durchzogen von einer Vulkankette, deren Glieder aber, mit Einer Ausnahme, 
westlich des Apennin gelegen sind [68]. In Mittelitalien deuten der See von Bolsena, die Kuppe von Radikofani, die Seen (Maare) von Nemi und Albano, vor Allem aber der Monte nuovo auf vulkanische Entstehung, während Breislak's Behauptung, dass das alte Rom auf den Kratern erloschener Vulkane erbaut worden sei, in v. Buch einen gefährlichen Gegner gefunden hat [69]. Die Grenze zwischen Mittelund Unteritalien markirt die vulkanische Rocca monfina, dann folgen die krater- und fumarolenreichen phlegräischen Felder, denen wohl auch die benachbarten Inseln Procida, Vivara und Ischia - letztere mit dem seit 1302 nicht wieder aus seiner Lethargie erwachten Berge Epomeo - zuzurechnen sind. Oestlich des Apennin steht vereinzelt der Vultur [70]. Der wohlbekannte Vesur am Golfe von Neapel ist der einzige noch rührige Vulkan des europäischen Festlandes; an ihm hat man seiner leichten Zugänglichkeit halber mit Vorliebe vulkanistische Forschungen angestellt, zumal seit unter Palmieri's Leitung [71] ein wohl ausgestattetes Observatorium seinem Krater gegenüber angelegt worden ist. Der Berg hat zwei durch das halbkreisförmige "Atrio del cavallo" getrennte Gipfel, deren einer einen regelmässigen Kegel bildet, während der andere, eine als "Somma" bekannte ringförmige Wand, den Ueberrest des alten, weit grösseren Kraterrandes darstellt. Zur älteren Römerzeit wusste man nichts von den gefährlichen Kräften, die im Inneren des Berges schlummerten, vielmehr erfolgte der erste grosse Ausbruch erst $79 \mathrm{n}$. Chr.; derselbe verschüttete die den Abhang umlagernden Städte Pompeji, Stabiä und Herculanum und machte den älteren Plinius zum Opfer seines Forschungsdranges. Dann trat wieder Ruhe ein, so dass der letzte Ostgothenfürst Teja den Berggipfel, wie schon vor ihm im Sklavenkriege Spartacus, zum letzten Zufluchtsort für seine Volksgenossen wählen konnte. Seit 1631 kann man die zweite, lebhaftere Periode der eruptiven Thätigkeit des Vulkans datiren, welche von jenem Zeitpunkte an bis 1872 nicht weniger als 33 grosse Ausbrüche lieferte, manche derselben ganze Jahre umfassend [72]. - Von der italienischen Inselwelt sind hierher zu rechnen die Liparen, die Insel Vulcano, bedeckt mit Solfataren und der in seiner Arbeit niemals ermattende Stromboli-Vulkan, der den Schiffern durch den seinen zahlreichen Krateröffnungen bei Nacht entsteigenden Feuerschein zur Landmarke dient. Kleinere Inselchen, wie Pantellaria, Felicudi, Lampedosa u. s. w. seien nur im Vorbeigehen erwähnt. Auf Sardinien finden sich [73] die ausgebrannten Vulkane Monte-Ferru und Ara. Auch die submarin-eruptive Thätigkeit macht sich, wie die Bildung der kurzlebigen Insel Ferdinandea im Jahre 1831 beweist, in den italienischen Meeren geltend. Das grosse Sizilien enthält auch den imposantesten feuerspeienden Berg, den Aetna, der uns durch die von Sartorius v. Waltershausen und den Astronomen C. F. Peters ausgeführte grossartige geologisch-geodätische Mappirungsarbeit [74] wissenschaftlich erschlossen wurde, nachdem schon weit früher der Sizilianer Bembo ihm das uns bereits bekannte Gedicht gewidmet hatte. v. Lasaulx, der das unvollendet gebliebene Werk von Sartorius vollendete, beschreibt auch [75] den allerneuesten Ausbruch des Aetna und kennzeichnet dessen Verschiedenheiten gegenüber früheren Aktionen, theilweise nach Nachrichten des Professors Silvestri in Catania, der sich um seinen heimathlichen Vulkan ähnliche Verdienste 
erwerben zu wollen scheint, wie sein Landsmann Palmieri um den Vesuv.

Spanien besitzt nur kleine vulkanische Gebiete in Katalo nien und in den zwischen den Balearen und der Küste gelegenen ColumbretesInseln. Von der Balkanhalbinsel verdient einzig Griechenland Beachtung, namentlich die Cykladengruppe, welche als vulkanische Bestandtheile Milos, Kimolos, Polinos und Nysiros, besonders aber den sehr thätigen Inselvulkan Santorin aufweist [76]. Vom Festlande kommt wesentlich die Halbinsel Methana in Betracht. Nach Reiss und Stübel [77] durchbrachen daselbst zähflüssige Trachyte in vielfacher Aufeinanderfolge die alten Kalkgebirge und häuften sich zu kegelförmigen Rücken auf; das ergossene Material füllte theilweise das Meer an und bildete Inseln. Obwohl seit 2000 Jahren die Ruhe dortselbst nicht mehr unterbrochen ward, möchten die beiden Forscher doch nicht für das vollständige Erloschensein der unterirdischen Regsamkeit einstehen, deren letzte Epoche zweifellos in die historische Zeit fällt.

Russland und Skandinavien entbehren vulkanischer Ueberbleibsel gänzlich, soferne man nicht letzterem auch die Insel Island, das vulkanische Musterland, zurechnen will. Der Hekla im Südwesten, der Krabla oder Krafla im Nordosten der Insel treten am augenfälligsten hervor, doch giebt es überhaupt auf ihr kein vulkanfreies Terrritorium von grösserer Ausdehnung. Im Südwesten zeigt der Vatna-Jökull massenhafte kleinere Kegel, ferner ist daselbst der Snäfall-Jökull zu nennen, und die Eruption von 1875 gab einem neuen Vulkan, dem Oskjagja, das Leben [78].

Die britischen Inseln haben neuerdings, seit Geikie und Kinahan ihre in \$. 3 citirten Untersuchungen veröffentlichten, insoferne die ihnen bisher zuertheilte Stellung geändert, als auf ihnen, namentlich auf den Hebriden, homogene Vulkane vorkommen. - Frankreichs vulkanreichster Bezirk ist die Auvergne, wo nach Fuchs 39 sogenannte "Puys" oder Pik's bei einander liegen [79]. Nicht weit davon entfernt ist der Vulkandistrikt des Velay und Vivarais, ferner ist das Departement Hérault mit 'Tuff und Lavaströmen übersäet. — Oesterreich besitzt in Siebenbürgen einige wirkliche Trachytvulkane und im TokayEperies-Gebirge Hügel, welche sich aus Andesitlaven aufbauten [80]. Im böhmisch-schlesischen Grenzgebirge begegnen wir dem Rautenberg, dem Köhlerberg und dem Vulkan von Messendorf; ein isolirter Vulkan erhebt sich im trentschiner Komitat an der mährisch-ungarischen Grenze. Den ebenfalls ganz vereinzelt auf weiter Ebene sich erhebenden Kammerbühl in Nordwestböhmen lehrte uns Goethe durch seinen hübschen und von feiner Naturbeobachtung zeugenden Aufsatz ,der Kammerberg bei Eger" [81] näher kennen, ohne freilich als eifriger Neptunist mit dem Gesehenen sich gehörig auseinandersetzen zu können. Auch Tyrol bietet für die Ergründung der in die geologische Vorzeit hinaufreichenden Vulkane ein reiches Material. "Bei Predazzo in Südtyrol," sagt Suess [82], ,ist durch das von Nord gegen Süd verlaufende Thal des Avisio und durch das von Osten einmündende Val Travignolo der Schlot eines Vulkans der Triaszeit erschlossen. Es ist eine wunderbare Stelle. Seit im Jahre 1823 Marzari-Pencati die erste Schilderung derselben lieferte, ist sie bis zu dem heutigen Tage der 
Schauplatz stets erneuter Forschungen gewesen, und die Mannigfaltigkeit der Erscheinungen ist noch lange nicht geklärt. ${ }^{6}$

Die - sämmtlich in den Ruhestand übergetretenen - Vulkane Deutschlands behandelt Hesse in einer interessanten Monographie [83], die uns für die nachfolgenden kurzen Notizen wesentlich zur Richtschnur gedient hat. Was die Auvergne für Frankreich, das ist für unser Vaterland das Gebiet der Eifel, das Hochplateau zwischen Rhein, Mosel, Rör und Sauer, ein ächter Tummelplatz vulkanischer Kräfte, dessen Name schon etymologisch einen glühenden, brennenden Landstrich bedeuten soll, und von dem nach dem Zeugniss des Trierer Geognosten Steininger der grosse L. v. Buch geäussert hat [84]: "Die Eifel hat ihres Gleichen in der Welt nicht; sie wird auch ihrerseits Führer und Leiter werden, manche andere Gegend zu begreifen, und ihre Kenntniss kann gar nicht umgangen werden, wenn man eine klare Ansicht der vulkanischen Erscheinungen erhalten will." Für alle Uebergänge zwischen Strato- und Domvulkan liefert dieses Gebirge Typen; vor Allem aber sind die im nächsten Paragraphen einlässlicher besprochenen Vulkanseen oder Maare von Wichtigkeit, deren Steininger [85] acht namhaft macht, deren es aber in Wirklichkeit noch weit mehr giebt [86]. Am Rhein zeichnet sich das Siebengebirge durch seine Trachyt- und (in geringerem Maasse) Basaltbildungen aus, rheinaufwärts begegnen wir als von vulkanischen Gängen durchsetzten Gebirgen dem Taunus, Westerwald, der Haardt und dem Kaiserstuhl [87]. Gümbel vindicirt [88] den sämmtlichen Bimssteinen der Rheinlande wo nicht einen einzigen Ursprungspunkt, so doch einen gemeinsamen vulkanischen Heerd, welchen er am Mittelrheine sucht. Schwarzwald, Odenwald und Spessart ziehen den Vulkanforscher weniger an, um so mehr aber der Vogelsberg wegen seiner mächtigen Basaltbedeckung [89]; unweit Giessen erhebt sich der ehemalige Vulkan Aspenkippel. In der Rhön fesseln uns Basalt- und Phonolith-Ergiessungen, während letztere, ebenso wie Trachyt, in dem basaltreichen Fichtelgebirge fehlen [90]. Endlich ist bei der von Gümbel geleiteten geologischen Landesaufnahme des Königreiches Bayern die merkwürdige Entdeckung gemacht worden, dass die einem ehemaligen Seebecken zu vergleichende weite Ebene, die sich von Nördlingen bis zum Hesselberge erstreckt, das sogenannte Riess, von einem durchaus vulkanischen Untergrunde getragen wird [91]*).

b) Asien. Von einigen armenischen, persischen und - zweifelhaften - innerasiatischen Vulkanen ist bereits die Rede gewesen. Oest-

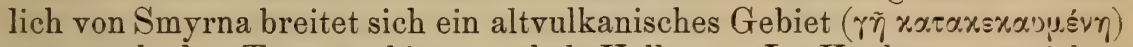
aus, auch das Taurusgebirge enthält Vulkane. Im Kaukasus erreichen die Vulkangipfel (Elbrus und Kasbek) bedeutende Höhen. Arabien kennt jetzt keine thätigen Vulkane mehr, doch fand noch während des XIII. Jahrhunderts im Sehadô-Thale bei Medina eine furchtbare Eruption statt [93]. Für Hindostan ist nur der submarine Ausbruch bei

*) Zwischen Europa und dem eigentlichen Nordpolargebiete liegt als strittiges Territorium die Insel Jan Mayen, deren wir anhangsweise hier gedenken wollen. Dieselbe ist stark vulkanisch; ihre Längsrichtung stimmt nach Kais er [92] mit der Richtung der vulkanischen Spalte überein, über welcher sie allem Vermuthen nach sich erhebt. Parasitische Vulkankegel lassen auf eine jene Längsspalte rechtwinklig durchsetzende Transversalspalte schliessen. 
Pondichery vom Jahre 1757 ganz ausser Zweifel gestellt. Von der indischen Küste an mangelt es dem asiatischen Festlande bis zum äussersten Norden hin ganz und gar an Spuren vulkanischer Manifestationen, dafür weiss von der Halbinsel Kamtschatka Fuchs [94] nicht weniger als zwölf thätige und fünfundzwanzig erloschene Vulkane aufzuzählen, und die Inselwelt erscheint mit diesen in einer für die Einwohner nicht eben erfreulichen Reichhaltigkeit ausgestattet. Die aleutische Inselreihe zählt 48, die kurilische 20 Vulkane [95], Japan endlich ist geradezu das klassische Land der Feuerberge, deren einer, der Fusijama bei Tokio, den Lokalhistorikern zufolge erst im Jahre 286 v. Chr. sich gebildet haben soll [96]. Ueber Formosa mit seinen drei aktiven Vulkanen gelangen wir zu den Philippinen, deren Vulkane, unter welchen der Taal und Mayon hervorragen, von J. Roth für Jagor's Reisewerk beschrieben wurden [97]. An diese Inselgruppe reihen sich Qie Molukken mit dem sehr lebhaften Gamalama auf Ternate, und an diese wieder die Sunda-Inseln. Auf Sumatra kennt man 19, auf Java 46 solche Berge genauer [98]; am Gunong Tengger sammelte Junghuhn, der eigentliche Begründer der physikalischen Geographie Java's, jene Erfahrungen, die zuerst die HumboldtBuch'sche Erhebungstheorie in's Wanken brachten [99]. „Die Vulkane auf Java, " sagt Bickmore [100], "stehen meist in zwei Reihen; die eine fängt bei Kap St. Nikolas an, dem nordwestlichen Ende der Insel, und geht diagonal über dieselbe bis zu ihrem südöstlichen Vorgebirge an der Strasse von Bali. Die andere läuft dieser parallel und erstreckt sich von der Mitte der Sundastrasse bis zur Südküste in der östlichen Länge von Cheribon." An entsetzliche Ereignisse als Folge von Vulkanausbrüchen ist man im hinterindischen Archipelagus gewöhnt; so soll ein Aschen-, Heisswasser-, Schlamm- und Lavenerguss des Galunggong auf Java vom 8. bis 13. Juli 1822 nicht weniger als zwanzigtausend Menschenleben hingerafft haben [101]. In grausiger Erinnerung steht ferner uns Allen die gigantische Erdumwälzung, welche im August 1883 eine förmliche Neubildung der Sundastrasse bewirkte. Offizielle Beleuchtungen des Ereignisses gehen jetzt allmählig ein, und es scheint, dass die ersten Zeitungsmeldungen die Grösse des Unheils noch übertrieben, immerhin aber ist gewiss, dass auf Java die Ortschaften Pulu Merak, Anjer, Tanara, Kramat verwüstet und auch auf Sumatra Telok Benong, die Hauptstadt des Lampong'schen Distriktes, vollkommen vernichtet wurden [102]. Als Ausgangspunkt des unterirdischen Sturmes dürfte der Vulkan der Insel Kratakaua zu betrachten sein; zwischen diesem Eilande und dem nahen Sebessi sollen sich sechzehn neue Krater aufgethan haben, während der Heerd des Riesenbrandes in Trümmer zerfallen ist. Eine Karte der Veränderungen enthält N. 10 von Bd. IX der Berl. Verh.

c) Afrika. Dieser gering entwickelte und dem Eintritt des Meeres sich schroff verschliessende Welttheil ist arm an Vulkanen [103]. An der Guineaküste steigt das mit ehemaligen Kratern reichlicher versehene Camerongebirge auf, welchem die vulkanischen Inseln Fernando Po, St.-Thomé und Annobon als Anhängsel zugerechnet werden müssen. $\mathrm{Ob}$ Zambi und Pembo in Südafrika in aktiv-vulkanischem oder blos im Solfatarenzustande sich befinden, steht noch dahin. Ein Vulkankomplex umfasst das nördliche Madagaskar mit 4, die Comoro- 
Inseln mit 2 thätigen Vulkanen und die Küste von Mozambique mit einem solchen. Vom Aequator ab ist Afrika's Ostrand mit erloschenen Feuerbergen bedeckt, unter denen auch einzelne noch regsame vorkommen, und ebenso verhält es sich mit Abessynien, wo noch zur Ptolemäerzeit Eruptionen beobachtet worden sein sollen [104]. Ein Kranz vulkanischer Inseln umsäumt die Küste; darunter befindet sich der Vulkan Dukhán, der zum letztenmale 1834 in wirkliche Aktion getreten ist*).

d) Australien und Polynesien. Von den zweifellos vorhandenen Vulkanen Neuguinea's hat man ebensowenig wie von denjenigen Neubrittanien's ausreichende Kunde [109]. Neuholland's Kontinent begnügt sich mit den Vulkanhügeln, Kratern und Kraterseen der Kolonie Viktoria. Die polynesischen Inselschwärme weisen thätige und erstorbene Feuerberge zur Genüge auf, so die Salomons-Inseln, die St. Cruz-Inseln, die neuen Hebriden, die Tonga-, Viti-, Schiffer-, Gesellschafts- und MarquesasInseln, endlich auch die kleine Oster-Insel mit ihrem Vulkan Otá-iti [110]. Die Marianen enthalten mindestens vier thätige Vulkane. Plutonischen Ursprunges ist auch die Sandwich-Gruppe, deren grösste Insel Hawaï, im Mauna-Kea, Mauna-Wororai, Ponochooha und Mauna-Loa vier sehr merkwürdige Feuerberge besitzt [111]. An Furchtbarkeit und Grossartigkeit der Ausbruchsphänomene wird der letztere wohl von keinem Konkurrenten erreicht, geschweige übertroffen, namentlich zeichnen ihn die einem See vergleichbaren Lavabecken aus, welche mit geschmolzener Lava gefüllt sind. Bei einem seiner letzten Ausbrüche ereignete es sich, dass die Lava volle drei Viertel eines Jahres, vom November 1880 bis zum August 1881, ununterbrochen ausfloss [112].

Neuseeland's vulkanische Thätigkeit koncentrirt sich im Norden; die Südinsel birgt nur einen kleinen vulkanischen Strich mit grossentheils zerstörten Kratern [113]. Dagegen lassen sich auf der Nordinsel drei getrennte vulkanische Bezirke unterscheiden. Die einzigen noch kräftigen Zeugen dereinstiger Riesenkraft sind der Whakari und Tongariro; sie enthalten zwischen sich jenen eigenartigen, mit heissen Quellen und Solfataren bedeckten Flächenraum, welchen v. Hochs tet ter so anziehend zu schildern wusste [114]. Wir erinnern uns, welchen Gewinn für das Verständniss der Vulkanstruktur gerade die neuseeländischen Vulkane dem genannten Gelehrten gebracht haben (s. o. §. 2).

*) Was dem Kontinent an Reichthum vulkanischer Entwickelung abgeht, ersetzen reichlich die Afrika zugehörigen Inseln im atlantischen Ocean. Die Azoren, welche man mit vielleicht noch mehr Recht freilich für Europa beanspruchen könnte, sind durchweg vulkanische Bauwerke und bekunden diese ihre Herkunft noch jetzt durch unterseeische Eruptionen [105]. Madeira besteht wesentlich aus Tuffschichten, Schlacken und vulkanischer Asche. Für die kanarischen Inseln genügt es, zu sagen, dass auf ihnen, namentlich auf Palma, v. Buch zur Konception seiner jedenfalls grossartigen vulkanistischen Ideen angeregt wurde [106]; der noch immer thätige Pik von Teneriffa ist nach Poulett Scrope [107] durch seine "dreifache Axe" ausgezeichnet. Die Kap-Verden endlich sind gerade jetzt durch die - bereits in Kap. III §. 10 der ersten Abtheilung angeführte - treffliche Arbeit Dölter's [108] in den Vordergrund geologischen Interesses gerückt worden. Dieser Insel-Archipel ist von Dölter als Bestandtheil eines dereinstigen ausgedehnteren Landkomplexes erkannt worden, der aber nicht gerade bis zu den Kanarien und bis zu Madeira sich erstreckt zu haben braucht. Auch St. Helena Fernando da Noroñha, Tristan d'Acunha, St. Paul, Bourbon und Mauritius sind vulkanisch. 
e) Polarregionen. Im nördlichen Eismeere gebricht es an Vulkanen und vulkanischen Erscheinungen gänzlich. An der Südgrenze des indischen Oceans gegen das südliche Eismeer hin stossen wir dagegen schon auf die theilweise vulkanischen Kerguelen; im südlichen Polarmeere selbst ist Young-Island gewiss, Bukle-Island wahrscheinlich, Sawadowski- und Alexanders-Insel möglicherweise vulkanisch [115]. James Clark Ross entdeckte unter $77^{\circ}$ Süderbreite die hohen Zwillingsvulkane Terror und Erebus, deren letzterer Rauch und Flammen ausstiess und offenbar im Stadium hoher Erregung sich befand [116].

f) Nord- und Centralamerika. Die Halbinsel Aljaska ist mit fünf Vulkanen ausgerüstet [117]. Dann folgt das vulkanreiche Kaskadengebirge mit einer Reihe himmelanstrebender Gipfel (Eliasberg, MountBaker, Mount-Vancouver). Die Sierra Nevada bietet im Monte del Diabolo einen erloschenen Vulkan; solche finden sich auch, und zwar in reicher Menge in den Rocky-Mountains, während unter $27^{\circ} 9^{\prime}$ Norderbreite die noch vor 150 Jahren thätigen Virgines-Vulkane gelegen sind [118]. Ratzel, der gründlichste Kenner der nordamerikanischen Union, bemerkt [119], dass eigentlich vulkanische Erscheinungen in deren Bereiche nur sparsam vertreten seien, und dass die letzten dort nachweisbaren Eruptionen in die spätere Tertiärzeit fielen. Jüngeren Datums sind ihm zufolge die Yellowstone-Trachyte, noch neueren aber die grossen Basalt-Ergiessungen jener Gegend.

Mexiko hat neun thätige Feuerberge, unter denen sich der hohe Popocatepetl und der uns durch seine Fumarolen bereits bekannte Yorullo auszeichnen [120]. Minder genau bekannt ist die Anzahl und Wirkungsweise der Vulkane in der Gesammtheit der kleineren centralamerikanischen Republiken (Guatimala, San Salvador, Honduras, Nicaragua und Costarica), doch entfaltet sich in ihnen allen der Vulkanismus auf das Mannigfaltigste. Nach M. Wagner ,ist für die Gebirge Centralamerika's das ungeheure Ueberwiegen der krystallinischen Massengesteine, der plutonischen und rein vulkanischen Bildungen über die geschichteten Formationen durchaus charakteristisch" [121]. Unter den von ihm studirten Vulkanen erkennt der genannte Naturforscher dem Turivalva den Preis zu [122].

Die dem Westrande des südamerikanischen Festlandes paralleì laufende Andenkette ist reich mit feuerspeienden Bergen besetzt, nur zwischen Quito und Peru und zwischen Peru und Chile ist die Reihe unterbrochen [123]. Es genüge, einige der bekannteren Namen herauszuheben. In Quito erheben sich u. a. der Pinchincha und Cotopaxi, während der vielgenannte Chimborazo kein eigentlicher Vulkan ist, in Peru und Bolivia machen der Uvinas und Illascar am meisten von sich reden, unter den chilenischen Vulkanen ragt der höchste aller bekannten Feuerberge, der Aconcagua, hervor, während an der Küste des Landes auch submarine Bildungen vorkommen. Allerdings bestand über den eigentlichen Charakter des Aconcagua lange keine vollständige Klarheit, doch ist dieselbe vor ganz kurzer Zeit erlangt worden, nachdem einer der unermüdlichsten Forschungsreisenden der Jetztzeit, Giissfeld, gerade diesen Gipfel zum Gegenstande der Erkundung sich ausersehen hatte [124].

g) Amerikanische Inseln. Die Bahama-Bank erlebte am 25. November 1837 einen unterseeischen Ausbruch. Den kleinen Antillen 
erkannte schon L. v. Buch, wie wir in §. 5 erfuhren, die Qualität einer selbstständigen Vulkanreihe zu. Der Insel Dominique sollen nach Fuchs [125] nur Solfataren eignen, doch haben sich dieselben neuerdings durch ihre eigenthümlichen Sand-Eruptionen, deren Material Daubrée näher untersuchte, wohl noch einen höheren Platz in der Stufenleiter der vulkanischen Heerde erworben [126]. Die GreatMountains der oceanischen Insel Ascension verrathen Basaltergüsse und Absonderungen von Schlacken; offenkundig vulkanischer Natur ist endlich auch der Archipel der Galapagos, über deren Topographie man durch Th. Wolf's Reisebericht [127] das Nähere erfahren hat.

Hiemit unsere vulkanistische Durchmusterung der Erde beschliessend, bemerken wir noch, dass alle neueren Arbeiten über einzelne Vulkane oder ganze Vulkanzonen sorgfältig in Zöppritz's geophysikalischen Referaten aufgeführt werden $[128]^{*}$ ).

§. 7. Der Eruptions-Akt und die ihn begleitenden Umstände. Bestimmte Anhaltspunkte dafür, dass ein als thätig bekannter, im Augenblicke jedoch in Ruhe verharrender Feuerberg demnächst wieder seine Thätigkeit aufnehmen werde, fehlen im Allgemeinen oder besitzen doch wenigstens nur eine ganz und gar dem Einzelfalle angepasste Bedeutung [129]. Erdbebenerscheinungen und ein dumpf dröhnendes Rollen im Innern bereiten häufig auf eine Eruption vor, aber keineswegs immer, denn während allerdings die Neubildung der Meeresinsel südwestlich von Sizilien und die Entstehung des Monte nuovo in der Bucht von Bajä, den theilweise auf Augenschein beruhenden Angaben Fr. Hoffmann's zufolge [130], durch heftige Erdstösse angekündigt wurden, sind schon gewaltige Eruptionen des Vesur und Mauna-Loa ohne derartige Anzeichen erfolgt. Genaue Verfolgung der leisen Erzitterungen des Bodens im Sinne von Palmieri und De Rossi*) wird sich in vulkanischen Ländern immerhin empfehlen. Versiegen der Brunnen und Quellen und Trübung oder chemische Veränderung des Quellwassers ist häufig Vorbote der Eruption, jedoch ebenfalls nicht als zuverlässiges Prognostikon zu erachten. Die meiste Gewähr bietet immer noch die unablässige Beobachtung des Kratergrundes, wo sich Veränderungen, namentlich Hebungen, einzustellen pflegen, wenn eine Aktion im Anzuge ist. In jenen Ländern, wo sich der Ausgang des Eruptionsschlundes oberhalb der Schneegrenze befindet (Island, Kamtschatka, Aljaska), kommt nicht selten der Schnee auf dem stark erhitzten Gestein zu plötzlichem Schmelzen [132] ***). Der weit verbreitete

*) Die einzelnen Ausbrüche registriren Tschermak's „Mineralogische Mittheilungen" (Bericht von Fuchs) und ebenso das "Bolletino del Volcanismo Italiano".

"**) Mit Hülfe des Mikrophons war es De Rossi möglich [131], durch eine auf seinem Observatorium zu Rocca di Papa angestellte und mehrere Monate umfassende Versuchsreihe zu konstatiren, dass sich die Eruptionen des Vesuv selbst in so grosser Ferne noch fühlbar machen. Das Mikrophon und ein mit demselben in Verbindung gesetztes Aufnahme-Telephon gewähren die Mittel, auch die allerkleinsten vulkanischen Geräusche noch dem Ohre zuzuführen. Das tragische Erdbeben von Ischia gab dem römischen Seismologen Anlass, von Neuem die Vorzüge seines Verfahrens zu empfehlen.

***) Noch Gassendi und Descartes huldigten der Ansicht, schneebedeckte feuerspeiende Berge könne es überhaupt nicht geben, da die innere Wärme den 
Glaube von einem Zusammenhange der atmosphärischen Zustände, namentlich des Barometerstandes, mit den vulkanischen Vorgängen ist, wie die monographische Darstellung von Kries [134] des Näheren ausführt, nicht haltbar, obwohl noch v. Buch und v. Humboldt an solche Beziehungen geglaubt hatten.

Den eigentlichen Ausbruchsakt pflegt ein energischer Stoss einzuleiten, dann ringen sich Dampf- und Gasmassen aus dem Schlote hervor, die ohnehin schon im Krater vorhandenen Aschen- und GeröllAnsammlungen werden in die Lüfte geschleudert, und endlich gelangt die rothglühende eigentliche Lava zum Aufsteigen. Wenn die Spannung der Dämpfe eine grosse, die Kraterwandung dagegen eine dünne ist, so kann es geschehen, dass, um Palmieri's bezeichnenden Ausdruck [135] zu wiederholen, die Lava, ehe sie noch die Mündungsstelle erreicht hat, förmlich durch alle Poren ausschwitzt. Die hinausgestossenen, kugelförmigen Dampfbälle bilden einen nach oben sich mehr und mehr verbreiternden Kegel, welchen die Italiener charakteristisch als Pinie bezeichnen; in deren oberen Partieen ist der Sitz lebhafter elektrischer Ausgleichungsprocesse, durch welche Blitz, Donner und wolkenbruchartige Regengüsse bewirkt werden. Die Barranco's (s. o. §. 2) werden von den letzteren ausgehöhlt. Mit dem Austritt der Lava, welche seltener durch das Mundrohr selber, gewöhnlich aber durch eine unter dem Seitendruck der Flüssigkeit sich öffnende Spalte erfolgt, ist der hier beschriebene typische Akt der Eruption im Wesentlichen beendigt. Das Erscheinen wirklicher Flammen ist vielfach bestritten, von.Abich, Pilla und Forbes aber wohl zur Gewissheit erhoben worden [136]. Im Ganzen fehlt es noch einigermassen an genau geführten Beobachtungsregistern, in welchen jede einzelne Phase des durch seine Grossartigkeit die objektive Auffassung beeinträchtigenden Phänomens aufgezeichnet ist, und um so höher sind daher Julius Schmidt's Untersuchungen am Vulkan Santorin [137] zu schätzen. Nur durch solch' unablässige Beobachtungsarbeit wird sich mit der Zeit auch eine Entscheidung über die Frage herbeiführen lassen, ob wirklich in der Periodicität der Lavaergüsse eine Attraktionswirkung des Mondes und der Sonne sich offenbare. J. Schmidt ist [138] dieser Ansicht, der freilich theoretische Bedenken entgegenstehen, nicht ungünstig gestimmt; auch fehlt es nicht an anderen Aussprüchen in diesem Sinne. So beobachtete, nach Phillips' Zeugniss [139], Palmieri im Jahre 1867 beim Ausbruche des Vesuv eine tägliche Periode mit zwei Maximis und Minimis, welche sowohl im Lavaausfluss durch eine Seitenspalte, als auch im Auswurf der Asche aus dem Krater erkennbar gewesen wäre; auch sollen die Eruptionen zur Zeit der Syzygien kräftiger erfolgt sein, als zu derjenigen der Quadraturen. Manche Eruptionen, ja sogar auch manche Vulkane entbehren gänzlich der Lavafluthen, sei es, dass die Verbindung im besonderen Falle nicht bis zu den tiefer gelegenen MagmaSchichten hinabreicht, sei es, dass der Auftrieb nicht ausreicht, die

gefallenen Schnee sofort verflüchtigen müsse; wenn man also doch beim Aetna, Hekla u. s. w. Feuerwolken aus dem schneeigen Kegel hervorbrechen sehe, so müsse man an eine Bedeckung von weissem Staube oder dergleichen denken. H. Müller [133] tritt dieser Meinung entgegen. 
vorhandene Lava durch die Spitzenöffnung oder durch ein erst zu bildendes seitliches Ausflussloch hindurchzupressen. So fehlen beispielsweise die Lavafelder gänzlich dem Monte nuovo [140].

Jedem Auswurf pflegt eine Periode absoluter, meistentheils jedoch nur relativer Ruhe nachzufolgen; im letzteren Falle strömen allerorts Dämpfe und Gase mit schrillem Pfeifen aus. Man könnte dann (s. o. §. 4) auch von einem anerkannt rührigen Vulkane sagen, er befinde sich momentan im Solfatarenzustande. Der Vulkan verkümmert dann, selbst wenn er nicht, wie es während des Verlaufes der Eruption gar nicht selten geschieht, durch Einstürze an seiner vorherigen Höhe einbüsst. J ag or erzählt [141] von dem Yriga auf Luzon, dass er im XVII. Jahrhundert durch Einsturz aus einem geschlossenen Kesselberg in die durch den Buhi-See ausgefüllte Mulde sich verwandelt habe. Der Dichter A elian behauptete eine langsame Erniedrigung auch vom Aetna, Strabon und Seneca leugneten dieselbe.

Trifft den Krater also auch nicht eine solch' akute Katastrophe, so verfällt er doch mehr und mehr, wenn er entweder durch Bildung neuer Zuführungskanäle oder durch gänzliche Verstopfung des bisherigen Axenschlotes ausser Wirksamkeit zu treten gezwungen wird. Tritt letztere Alternative ein, so sagt man, der Vulkan sei ausgebrannt oder erloschen. Mehrere Krater desselben Vulkanes können successive von dem nämlichen Schicksale ereilt werden; dann sind die niedrigsten und weitesten auch die ältesten. So schliesst am GunungTengger Java's, wie Junghuhn [142] feststellte, der langgezogene elliptische Kuduwong grossentheils den Segoro-Wedi, und dieser wieder zum Theile den fast kreisrunden Brano ein. Als Ueberreste von ehemals aktiven Kratern scheinen auch die Kraterseen oder Maare (s. o. §. 6) angesehen werden zu müssen, von welchen der Laacher See und das sogenannte Pulvermaar bei Gillenfeld die bekanntesten und ausgezeichnetsten sind, wenigstens ist diess die Ansicht Bischof's, eines der besten Kenner dieser sonderbaren Kesselbildungen [143]. Wir sahen schon oben in §. 4, dass auch A. v. Humboldt die , in den tief eingeschnittenen Thälern der Eifel ${ }^{\star}$ dem Boden entströmende Kohlsensäure als letzte Regung früherer vulkanischer Thätigkeit charakterisirt [144]; ihm sind die Maare, welche er neben die Calde ir a's der Azoren stellen möchte, gleichsam Minentrichter*), Zeugen minenartiger Ausbrüche, in welche nach den Explosionen von heissen Gasarten die ausgestossenen lockeren Massen grösstentheils zurückgefallen sind." Andere Forscher freilich, wie vo m Rath und Credner, sehen in den Maaren nicht sowohl Ueberreste, als vielmehr Anfänge

*) Es wäre, um Humboldt's Gelegenheitsausspruch zu bestätigen oder zu widerlegen, erwünscht, die Kurve des Durchschnittsprofiles eines Maares mit jener Kurve zu vergleichen, durch deren Umdrehung um eine vertikale Axe der Minentrichter nach $\mathrm{Culmann} \mathrm{[145]} \mathrm{entstanden} \mathrm{zu} \mathrm{denken} \mathrm{ist.} \mathrm{Während} \mathrm{nämlich} \mathrm{alle}$ militärwissenschaftlichen Werke, bis in die zweite Hälfte unseres Jahrhunderts herein, von der unbewiesenen und sonderbaren Annahme ausgiengen, dass die Gestalt des von der Sprengung erzeugten Hohlraumes diejenige eines Rotationsparaboloides sei, führte der genannte berühmte Mechaniker, gestützt auf die Variationsrechnung und auf sehr plausible Annahmen über den Widerstand der Erdschichten, den Nachweis, dass die Meridiankurve des Hohlkörpers nicht, wie man dachte, ihre konkave, sondern vielmehr ihre konvexe Seite der Axe (kürzesten Verbindungslinie des Minencentrums mit dem Erdboden) zuwenden muss. 
von Vulkanen; „Maare und Stratovulkane sind durch allmählige Uebergänge verbundene Ausbildungsstufen einer und derselben Entwickelungsreihe $^{\text {" }}[146]$.

§. 8. Die Eruptionsprodukte. Die Verschiedenheit der Stoffe, welche vor, in und nach dem eigentlichen Eruptionsakte aus dem Schlunde des Vulkanes ausgeschieden werden, ist eine so überaus grosse, dass es wohl angezeigt ist, dieselben nach den Aggregatzuständen gesondert zu betrachten. Wir gelangen dann zu folgender Uebersicht.

a) Gase und Dämpfe. Die Menge dieser elastisch flüssigen Massen ist eine ungeheure, wie sich aus den ungeheuren Höhen ergiebt, zu welchen dieselben nicht selten emporgeschleudert werden. Durch Messungen von Gunlögsen und Vargas Bedemar [147], deren Basis die Ermittelung des Umkreises bildete, innerhalb dessen die über isländischen Vulkanen schwebenden Rauch- und Feuersäulen noch gesehen wurden, ist festgestellt, dass die im Jahre 1783 dem Hekla entströmten Dampfballen gegen $4800 \mathrm{~m}$ hoch aufstiegen. Die Hauptrolle spielt der Wasserdampf, der in seiner Kondensation das Material zu den typischen Regenschauern liefert, in welchen so oft das mit dem Ausbruche selbst an Verderblichkeit wetteifernde Nachspiel desselben zu erblicken ist. Die mitgerissenen permanenten Gase setzen sich nach Davy und Bischof [148] wesentlich aus Wasserstoffgas und Kohlensäure nebst Salz- und schwefliger Säure zusammen; was allerdings die Kohlensäure anlangt, so ist dieselbe so häufig in den eigentlichen Gasexhalationen nicht nachgewiesen worden, dass die Möglichkeit, ja sogar eine gewisse Wahrscheinlichkeit besteht, es bilde sich fragliches Gas erst nachgerade, während die Lava im Erkalten begriffen ist [149].

b) Asche. Fein vertheilte Asche fehlt bei keiner Eruption, und zwar ist dieselbe eben dieser ihrer Feinheit halber befähigt, in alle Ritzen einzudringen. Ein Aschenregen war es, welcher im Jahre $79 \mathrm{n}$. Chr. der Stadt Pompeji den Untergang brachte, und da stellt es sich heraus, dass die Asche einen hermetischen Verschluss aller von ihr bedeckten Gegenstände gegen den Zutritt von Luft gebildet und somit jene so trefflich konservirt hat, dass die Archäologen durch Ausgiessen der festgebackenen Aschenmodel vollkommene Abdrücke - selbst von menschlichen Leibern - gewinnen können. Ménard de la Gro ye [150] dachte sich die Asche durch die Zerreibung der Lavastücke entstanden, indessen wird die im Inneren des Schlundes herrschende Hitze allein schon genügen, unter dem Einflusse des hinzutretenden urd sofort in Dampf übergehenden Wassers beliebige Felsarten zu pulverisiren; (vgl. die Ansicht Penck's in §. 12). Kieselerde, schwefelsaures Eisen und schwefelsaurer Kalk scheinen nach den verschiedenen Analysen von Vauquelin, Ferrara u. A. die Hauptingredientien der Vulkanasche zu sein, doch fehlt auch Wasser selten ganz, so dass die Asche gewissermassen den Uebergang vom flüssigen zum festen Aggregatzustande repräsentirt. In der That brechen zuweilen - so am 18. Januar 1793 aus dem Unsen - kochende und dampfende Schlammströme aus dem Inneren des Vulkanes hervor, doch darf man diese nicht verwechseln mit den sehr häufig im Gefolge einer Eruption auftretenden Schlammfluthen, die sich erst ausserhalb des Kraters dadurch 
bilden, dass die Vulkanasche durch Regengüsse in einen zähflüssigen Schlamm verwandelt wird. Herrscht zur Zeit des Ausbruches eine lebhaftere Strömung in der Luft, so wird die Asche sehr weit fortgetragen; die Meteorologie hat sogar aus dem Umstande, dass an Stellen, wo man es nicht erwartet hätte, sich Aschenbestandtheile vorfanden, deren Ursprung auf den Pik von Teneriffa hinwies, werthvolle Aufschlüsse über die Richtung des oberen Passatstromes gezogen. Der Aschenregen, welcher die grosse isländische Katastrophe von 1875 begleitete, bedeckte eine Fläche von 5000 Quadratkilometern und gelangte bis nach Norwegen, so dass die Asche, gemäss einer von Mohn angestellten Berechnung, pro Stunde 80,47 km zurückgelegt haben muss [151]. Pogson, Meldrum, Lockyer und v. Bezold (Münchener neueste Nachrichten vom 21. Dezember 1883) halten es nicht für unmöglich, dass das eigenthümliche Phänomen des Nebelglühens, welches an vielen Herbst- und Wintertagen des verwichenen Jahres allerorts in Europa das Interesse weiter Kreise erregte, mit dem enormen Aschenauswurfe der in der Sundastrasse neu gebildeten Vulkane in ursächlichem Zusammenhange steht, resp. stand. Soll doch die Stadt Batavia dadurch in vierzigtägige Finsterniss gehüllt worden sein. v. Bezold erinnert auch daran, dass um die nämliche Zeit, als im Jahre 1831 ein submariner Vulkanausbruch weite Räume des Mittelmeeres durch Aschenmassen verfinsterte, Lichterscheinungen beobachtet wurden, die der vorhin erwähnten auf's Haar glichen und die meteorologische Optik jener Periode ebenso vor ein Räthsel stellten, wie diess auch im gegenwärtigen Falle geschah.

c) Sand. Von der feinen, hellgrauen oder leicht in's Röthliche spielenden Asche ist der schwerere, gewöhnlich schwarz glänzende Sand leicht zu unterscheiden. Gröbere und kompaktere Stücke dieses Sandes, die wohl ursprünglich noch in feurig-flüssigem Zustande sich befanden und in ihrer Gestalt den während ihres Erkaltens maassgebend gewesenen Luftwiderstand verrathen, werden als Lapilli bezeichnet; gewöhnlich finden sich darin Augit- und Feldspathkrystalle mit Bimssteinbrocken vermengt [152].

d) Schlacken und Steine. Die Gewalt der gespannten Dämpfe vermag Schlackentheile und Gestein, wie es im Zustande der Ruhe die Kraterwandungen bekleidet, bis in unglaubliche Entfernungen fortzuschleudern. Haben die Steine eine annähernd sphärische Gestalt, so spricht man wohl von vulkanischen Bomben. Fuchs [153] identificirt sowohl Lapilli als auch Bomben einfach mit Lavastücken, indess wird, wie wir gleich nachher sehen werden, das Wort "Lava " denn doch besser in einem engeren Sinne gebraucht; allerdings acceptirt auch Fuchs die Erklärnng Ménard de la Groye's (s. o.).

e) Obsidian und Bimsstein. Diess sind glasartige Substanzen, erstere von schwarzer, letztere von weisslicher Farbe, und mit muschelförmigem, scharfkantigem Bruche. Sie bilden sich nur aus trachytischen, nicht aber auch aus basaltischen Laven und scheinen einer gewissen Dickflüssigkeit der Lava zu ihrer Entstehung zu bedürfen [154].

f) Tuffe. Zusammengepresste Aschen- und Sand-Konglomerate, bei deren Verbindung auch mitunter meteorisches oder Seewasser seine Dienste leiht, heissen Tuffe, und daraus besteht bei den Stratovulkanen die Mittelsehicht. Man unterscheidet gemeinen Tuff, Posilipptuff 
(aus den phlegräischen Feldern), Peperin, durch Krystalleinschlüsse ausgezeichnet, Trass (im Gebiete der Eifel) und Palagonit, aus starkveränderten vulkanischen Produkten, mit brauner fettglänzender Färbung, bestehend". Ueber die Bildung des durch Sartorius v. Waltershausen mit diesem Namen belegten Palagonites, sowie über die daran von dem genannten Gelehrten und von Bunsen geknüpften Hypothesen vergleiche man, ebenso wie über Peperine, eine den Sachverhalt, namentlich unter dem petrographischen Gesichtspunkte, äusserst gründlich erörternde Abhandlung von Penck [155]. Die Tuffe drücken der Umgegend eines Feuerberges den Stempel auf.

g) Die eigentliche Lava. Diese ist es, welche bei dem Vorgange der Eruption die Hauptrolle spielt, durch deren Gluth der Reflexionsprocess bedingt ist, welcher die über dem Krater schwebende Rauchsäule oder Pinie zur Nachtzeit in eine Feuersäule umwandelt [156].

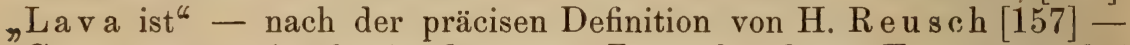
Gesteinsmasse in feurig-flüssigem Zustande, deren Temperatur bei dem Hervorbrechen auf ca. $2000^{\circ}$ C. geschätzt wird"; Magma (Kap. II, §. 5) und Lava sind also nur insoferne unterschieden, als der Druck, welcher das erstere im zähflüssigen oder latent-plastischen Zustande festhielt, nunmehr gewichen ist, so dass der Grad der Fluidität ein höherer geworden. Lava ist ein Gesammtname, kaum werden die Laven irgend zweier Feuerberge in allen Punkten übereinstimmen, wie denn v. Buch am Vesuv allein achtzehn Arten derselben auseinanderhalten zu müssen glaubte [158]. Als glasartiger Fluss besitzt die Lava nur ein sehr geringes Wärmeleitungsvermögen; soll doch der 1669 ausgeflossene Strom noch im Jahre 1809 nicht vollständig erkaltet gewesen sein [159]. Die austretenden Gluthmassen fliessen langsam den Abhang des Berges herab, alles organische Leben auf ihrem Wege vernichtend; nach und nach geräth die Strömung in's Stocken, und alle unter der Lava begrabenen Flächenräume erscheinen nunmehr mit einer harten, schwarzen Kruste bedeckt. So ist es z. B. der Stadt Herculanum am Vesuv ergangen, deren Freilegung somit begreiflicherweise mehr Mühe verursacht, als es bei dem blos in einen Aschenmantel gehüllten Pompeji der Fall war. Die Lava theilt sich in poröse, dichte und glasige ein [160]; zu den porösen Laven gehört die nach ihrem Fundorte so genannte, übrigens auch in der

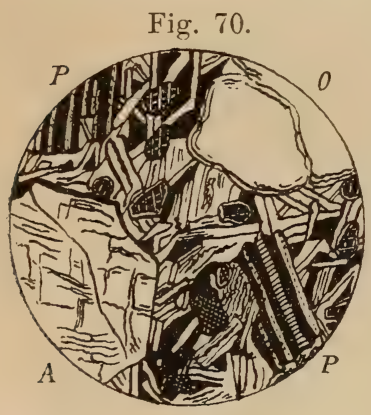
Auvergne vorkommende und von $\mathrm{Faujas} \mathrm{de}$ la Fond [161] bechriebene PuzzolanErde.

Bessere Aufschlüsse noch, als die chemische Zerlegung, gewährt bezüglich der Zusammensetzung der Lava die mineralogischmikroskopische Prüfung, welche an Dünnschliffen vorgenommen wird. Fig. 70 stellt einen solchen nach H. Reusch [162] dar. A bedeutet Augit, P Plagioklas mit Doppelstreifung im polarisirten Lichte, O Olivin; dazu kommt noch schwarzes Glas. Die Probe entstammt der Basaltlava von Jan Mayen. Je nach ihrem petrographischen Charakter konsolidirt sich die Lava statt in den sonst an ihr gewohnten Feldern in eigenartigen Formen, von denen in Fig. 71 
eine der auffallendsten abgebildet ist. Poulett Scrope, welchem wir die Zeichnung entnehmen, sagt darüber [163]: „When the matter is stille more viscous, its accumulation over a minor spiracle occasionally produces a hillock of eurring and concentric ridges, or even a dome or spirelike protuberance. Professor Dana describes some of those upon the slopes of Mauna-Loa in Hawaii as actually taking the figure of a column or upright bottle, or a petrified fountain."

Das physikalische Verhalten der Lava ist neuerdings von Reyer zum Gegenstande einer gehaltvollen Monographie gemacht worden [164], welcher rasch eine zweite, ebenfalls sehr interessante Schrift [165] nachfolgte. Es wird in denselben, neben Anderem, vorzugsweise von der Absorption gasförmiger Körper durch die Lava gehandelt, welche dann, sowie der Druck nachFig. 71.

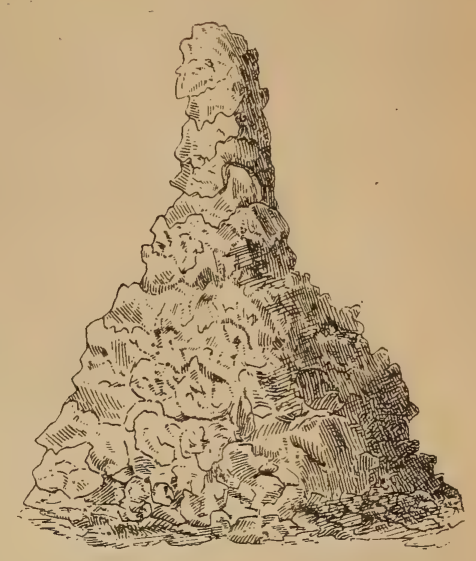
lässt, ebenso wieder die Freiheit aufsuchen, wie diess die von kohlensauren Mineralwassern eingesogenen Gase thun. Ist das Magma nicht oder nur schwach mit gasförmigen Bestandtheilen imprägnirt, so fliesst es als Lava ruhig und ohne besondere Geräusche aus, wogegen die in stärkerem Maasse beigesellten Gase und Dämpfe eine heftige Wallung der Lavafluthen und jenes kennzeichnende S pratzen der Masse hervorrufen, das man von Silberflüssen her kennt; dieses Wort, ursprünglich ein Provinzialismus, hat mehr und mehr eine feste metallurgische Bedeutung gewonnen. Auch die Lavamassen erloschener Vulkane hat Rey er mit in's Bereich seiner Untersuchung gezogen und $u$. a in den keiner glasigen Masse fehlenden Schlier en ein Kriterium für die Frage nachgewiesen, ob krystallinische Gesteine dereinst in wirklichem Flusse sich befanden oder nicht. Im ersteren Falle muss nämlich jede Schliere im Sinne der Fortschreitungsrichtung auseinandergezogen erscheinen.

§. 9. Aeltere vulkanistische Erklärungsversuche. Wir gehen nunmehr von dem deskriptiv-geologischen Theile unserer Aufgabe zu deren physikalischem Theile über, wobei wir der hier mehrfach benützten geschichtlichen Zusammenstellungen von M un ck e [166] und Re y e r [167] mit Dank erwähnen. Die Griechen fanden an den Vulkanen, von denen der Stromboli und Aetna bereits dem Homer und Hesiod bekannt gewesen sein dürften [168], so manchen Punkt, der ihrer Neigung zu naturphilosophischer Spekulation Anhalt bot; von Platon's Versuch, die Eruptionen mit seinem Pyriphlegethon in Verbindung zu bringen, ist bereits in Kap. II, §. 1 die Rede gewesen. Ueberhaupt war man geneigt, die vulkanischen Erscheinungen durch die empedokleische Hypothese eines feuerflüssigen Erdkernes zu erklären und dadurch in ursächlichen Zusammenhang mit den Erdbeben zu bringen [169], wie diess besonders deutlich aus des Philon Schrift über die Unzerstörbarkeit der Welt hervorgeht. 
Zahlreichere Belege reiflichen Nachdenkens über Vorkommnisse dieser Art enthält die in naturwissenschaftlicher Beziehung sonst wenig werthvolle römische Literatur. Den in §. 5 erwähnten Trachyt-Durchbruch auf der Halbinsel Methone (jetzt Methana) beschreibt O vid [170] als eine Hebungs- und Berstungserscheinung und entwickelt dabei Ansichten, »welche“, um mit Humboldt [171] zu reden, „mit denen der neueren Geognosie auf eine merkwürdige Art übereinstimmen." Des Lucilius Aetna-Gedicht ist, wie Nehring [172] bemerkt, auf die unmittelbare Aufforderung seines Freundes S en e ca hin geschrieben worden und spiegelt deshalb treu die - schon in der Einleitung lobend hervorgehobenen - geodynamischen Ansichten des scharfen Denkers und Beobachters ab. Seneca weicht darin von Platon und Empedokles ab, dass bei ihm nicht das gesammte Erdinnere von feurig-flüssiger Masse erfüllt, letztere vielmehr in einzelnen kleinen Gluthheerden der Erdrinde angesammelt ist, ganz ähnlich, wie sich Hopkins (s. u. §. 12) die Sache vorstellt. Strömen nun durch die Gesteinsadern die meteorischen Gewässer in jenen Heerd ein, so entwickeln sich gespannte Dämpfe („Spiritus“), welche die eigentliche Explosion und Eruption bewirken [173]. Gerade in dieser Annahme spricht sich die korrektere Denkweise des Seneca aus, indem das Alterthum sonst zwischen diesen Vulkangasen und den gewöhnlichen Winden keinen Unterschied zu machen verstand.

Die Kirchenväterzeit versetzte die Lehre vom Centralfeuer mit gewissen christlichen Dogmen. T ertullian erblickt in den Vulkanen wirkliche Bestandtheile und Manifestationen des unterirdischen Höllenfeners, Minucius Felix, Augustin und Isidor fassen die ersteren als blosse Bilder des letzteren auf [174]. Relativ verdienstlich, weil offenbar von Seneca beeinflusst, ist die Darstellung des $\mathrm{Hrabanus}$ Ma urus, die mindestens ein Jahrhundert lang die Klosterschulen beherrschte: „Die Vulkane enthalten viel Schwefel und stehen gewöhnlich mit dem Meere in Verbindung. Durch diese Kanäle dringt nun das Wasser ein und drängt die Luft nach oben, diese ihrerseits entfacht den Schwefel zu lebhafterem Brande ${ }^{*}$ [175]. Eine im Grossen und. Ganzen ähnliche Gedankenreihe leitet den Ristoro d'Arezzo [176], der die Erscheinung der heissen Quellen in ganz vulkanistischer Weise deutet. Auffallend ist die geringe Theilnahme, welche die arabischen Schriftsteller für ein so merkwürdiges Phänomen an den Tag legten, denn wenn es auch an autoptischen Erfahrungen fehlen mochte, so hatte man doch durch Edrisi, Massudi und Kazwîni Nachrichten über die italienischen, armenischen und hinterindischen Feuerberge. Aber gerade jener letztgenannte Kosmograph weiss über den „Berg von Sizilien" nichts weiter auszusagen [177], als dass sich auf seiner höchsten Spitze schwefelhaltige Quellen fänden, aus denen Feuer und Rauch ausströme.

Erst im XVII. Jahrhundert kam, wesentlich durch Kircher's "Unterirdische Welt" [178], wieder neues Leben in die theoretische Vulkanologie; die Grundansicht dieses Buches ist eine rein plutonistische, der $\mathrm{Humboldt}$ 'schen Ventiltheorie nicht unähnlich. Wesentlich den gleichen Standpunkt nehmen nach Reyer (a. a. O.) S teno, Leibniz, Buffon, Faujas de la Fond und Dolomieu ein. Im Uebrigen kann man unter den massenhaft aufgestellten vulkanistischen Hypothesen, 
welche im Verlaufe des vorigen Jahrhunderts und theilweise noch in dem laufenden aufgestellt worden sind, von der später zu erörternden Theorie Cordier's abgesehen, sechs deutlich gesonderte Kategorieen unterscheiden.

a) Die Parrot'sche Höhlentheorie. Sämmtliche feuerspeiende Berge sind durch eine - nicht näher bestimmte - Kraft aus der Erdrinde heraus gehoben worden; die entstandenen Hohlräume, deren Grösse G. F. Parrot auf Grund der peruanischen Loth- und Pendelbeobachtungen der französischen Akademiker zu berechnen unternimmt, werden durch nachdringendes Magma hie und da wieder ausgefüllt [179]. Auch Boussingault's Mittheilungen über die Anden-Vulkane erscheinen von analogen Vorstellungen beeinflusst.

b) Die elektrischen Theorieen. Der enorme Aufschwung, welchen die Elektricitätslehre zumal in der zweiten Hälfte des XVIII. Jahrhunderts nahm, konnte es nahe legen, dem neu erkannten mächtigen Faktor nunmehr bei allen Naturvorgängen eine führende Rolle zuzuschreiben. Als Hauptquelle für diese Anschauung wird gemeiniglich das in mancher Hinsicht verdienstvolle Werk Sir William Hamilton's [180] genannt. Muncke nennt Stuckely, Patrin, Vivenzio und Bertholon de St. Lazar e als Hauptvertreter dieser Ansicht [181], welcher der kluge B e c c a ri a nur mit der Einschränkung beipflichtete, dass bei'm Auswurfsakte selber allerdings elektrische Processe im Gange seien [182]. A m père meint [183], dass jene elektrischen Elementarströme, von welchen er den tellurischen Magnetismus herleitete, wohl auch vulkanistisch sich geltend machen können, doch geht er nicht so weit, deshalb die vulkanischen Erscheinungen ausschliesslich für den Elektromagnetismus in Beschlag nehmen zu wollen.

c) Die Erdbrand-Theorieen. In §. 4 dieses Kapitels giengen wir kurz auf die Erdbrände, als auf etwas vom wahren Vulkanismus durchaus Verschiedenes, ein. Diese Verschiedenheit wurde von den Geologen einer früheren Epoche in Abrede gestellt. Da man schon im Alterthum und Mittelalter - man denke an das griechische Feuer Mischungen von Schwefel, Erdpech, Naphtha, Kalk, Salpeter u. s. w. kannte, welche auch ohne Luftzutritt brannten, so entschieden sich (Reyer a. a. O.) schon die Alchymisten Higius und Capoa für die Annahme solcher Brandsätze im Inneren der Erde; ihnen folgte der Bergmann Agricola. Lister suchte die Grundursache der Vulkanicität in der durch Oxydation erfolgenden Entzündung von Kies und Alaun [184], und der ältere Lémery brachte diese Hypothese der brennenden und eruptiven Schwefelkieslagen zu hohen Ehren [185], indem er den bekannten Vorlesungsversuch ersann, Eisenfeile unterhalb einer dünnen Erdschicht mit Wasser und Schwefel zu vermischen und dadurch einen Miniaturvulkan zu erzeugen. Man vergleiche für diese Auffassung weiter die Schriften von Krüger [186] und Henkel [187], welch' letzterer die in chemischer Hinsicht interessante, weil mit der herrschenden Phlogistontheorie nicht wohl zu vereinbarende Bemerkung macht [188]: „Nicht das Wasser, nicht das Feuer wirken da, sondern die Luftmaterie mit ihrem sanften Anfall, webenden Umgebung und schleichenden Eindringung wirkt und schafft ... der Kies aber ist die Festung, welche von dem Luftwesen nicht bestürmt, sondern umschlichen und erobert wird." ${ }^{*}$ Dass auch $\mathrm{A}$. Werner für 
die Identität der Vulkane mit brennenden Kohlenflötzen eintrat [189], kann nicht überraschen, wenn man daran denkt, dass dieser Forscher bei all' seiner Genialität seinen Blick nicht über den durch die geologischen Verhältnisse Sachsens ihm vorgezeichneten Horizont zu erheben vermögend war.

d) Die eigentlich chemischen Theorieen. Deren Begründer ist Humphry Davy; er dachte sich die Erde überwiegend aus den Metalloiden Kali, Natron u. s. w. bestehend und verlegte in sie, die durch den Zutritt von Luft und Wasser durchsäuert würden, den Sitz der vulkanischen Thätigkeit [190]. A. v. Humboldt, der gegen Davy's Anschauungen polemisirt, bemerkt übrigens bei dieser Gelegenheit [191], dass jener selbst in späteren Jahren sich von seiner Hypothese losgesagt habe, während Daubeny im Artikel ${ }_{\text {Volcanic }}$ Geology" der "Encyclopaedia Metropolitana" nach wie vor Argumente zu Gunsten derselben herbeizuschaffen bestrebt war. Andere, minder geistvolle Theorieen chemischer Natur brachten Pr zystan ow ski [192] und E. Clarke [193] zu Markte, welch' letzterer im Knallgasgebläse ein Seitenstück der vulkanischen Phänomene erkennen wollte. D'A ubuisson dagegen ist mehr im Allgemeinen der Ansicht [194], dass die ununterbrochen in den Eingeweiden der Erde im Gange befindlichen chemischen Zersetzungen und Verbindungen die vulkanische Aktion aufrecht erhielten*). Die Theorie Janecek's wird im nächsten Kapitel (§. 7) zur Erörterung gelangen.

e) John Herschel's Gleichgewichtstheorie. Sinkt, durch Sedimentbildung oder eine andere Ursache veranlasst, ein Theil der festen Erdkruste gegen den Mittelpunkt hin, so steigt das an einem Orte vertriebene Magma an einem anderen Orte auf, kommt dort mit Wasserdämpfen in Berührung und bewirkt eine Eruption. Fehlen dagegen an jener Stelle die Dämpfe, so tritt eine Hebung des Landes ein [196].

f) G. Bischof's kalorische Theorie. Dieselbe ist von allen bis jetzt besprochenen die einfachste und mit dem mindesten Aufgebote von Mitteln arbeitende. Schon nahe an der Oberfläche herrschen im Inneren der Erde hohe Hitzegrade, und wenn die Oberflächengewässer bis in jene Gegenden hinabgedrungen sind, so bilden sich Wasserdämpfe von genügender Spannkraft, um dünnere Stellen der Rinde zu Spalten zu erweitern und durch diese die Massen geschmolzener Materie, welche dem Orte der Dampflbildung benachbart sind, hinauszuschleudern [197]. Daubeny suchte als Vertreter des Chemismus diese Theorie mit allen Mitteln zu bekämpfen [198].

§. 10. Die Humboldt-Buch'sche Periode. Beide Forscher, A. v. Humboldt, wie L. v. Buch, waren, als sie ihre grossen und folgenreichen Entdeckungen antraten, noch nicht im Mindesten aus dem Banne jenes Ideenkreises herausgetreten, in welchem sie A. Werner's Vorlesungen und Demonstrationen an der Freiberger Bergakademie befangen hatten. In den Cordilleren öffnete sich für Humboldt, auf

*) Gay-Lussac sprach seiner vielfach citirten Behauptung, dass anhydride Chloride sich in der Tiefe mit dem einsickernden Wasser verbinden und so vulkanische Ausbrüche bedingen sollten, selbst nur den Werth eines Versuches zu [195]. Doch sieht auch Daubrée in der Hydratbildung eine mächtige Quelle lokaler Wärmeentwickelung. 
den Kanarien für $\mathrm{Buch}$ eine neue Welt, nachdem der letztere kurz vorher noch den ernsthaften Versuch gemacht hatte, die Trachyt- und Basaltergüsse im französischen Binnenlande (s. o. §. 5) mit seinem neptunistischen Glaubensbekenntniss zu vereinbaren [199]. Seine Betrachtungen über die reihenförmige Verkettung der Vulkane führten ihn dazu [200], grundsätzlich die Eruptionskrater von den Erhebungskratern, als den centralen Aushöhlungen der von ihm so genannten Erhebungsinseln, zu trennen. Mit dieser Auffassung erklärte sich $\mathrm{Humboldt}$ vollkommen einverstanden. Den Grundzug seiner Theorie fasst Ewald [201] präcise in folgender Weise zusammen: „Die Vulkane, denen dieser Name zukommt, d. h. diejenigen, durch welche eine mehr oder weniger andauernde Verbindung der Erde mit der Atmosphäre eingeleitet worden ist, haben sich gebildet, indem heisse gespannte Dämpfe aus der Tiefe gegen die darüber befindliche Erdkruste wirkten und dieselbe in erweichtem Zustande blasenförmig auftrieben. Wenn ein auf diese Weise entstehender, im Inneren hohler Berg durch die Gewalt der Dämpfe an seiner Spitze gesprengt wurde, so bildete sich ein mit einem Gipfelkrater versehener Kegelberg, wenn die Sprengung nicht erfolgte, ein Berg von glockenartiger Gestalt, an welchem Ausbrüche, finden sie überhaupt statt, nur seitlich geschehen konnten." Reihenvulkane müssen in Konsequenz hievon auf ein und derselben in's Magma hinabreichenden Spalte gedacht werden.

Wäre dem so, und könnte man sich ganze Kettengebirge im Humboldt'schen Sinne aus solchen Spalten herausgehoben denken eine Vorstellung, welche Hö fler [202] für die meridional verlaufenden Gebirge der Erde durch eine korrektere genetische Erklärung zu verdrängen versucht hat - , so müssten doch gewiss da und dort auf der Erde Längsgebirge zu finden sein, deren Axenrichtungen sich senkrecht durchsetzen. Der grosse Naturforscher fühlte sehr wohl, dass hier ein Kriterium für seine Theorie des Vulkanismus und der Gebirgsbildung liege, und war deshalb hoch erfreut, dass in Centralasien ein meridional verlaufender Gebirgszug, der angebliche Belur-Dagh, von zwei der Richtung des Parallelkreises folgenden Bergketten, dem Küen-Lün und dem Thian-schan, normal gekreuzt werde. Neuere Forschungen an Ort und Stelle, wie sie von Hayward, Fjedschenko und am erfolgreichsten von Sjewjerzow [203] angestellt sind, lösten Humboldt's Gemälde der centralasiatischen Gebirgswelt in ein Phantasiegebilde auf, indem die Verbindung zwischen jenen beiden Parallelzügen keineswegs durch ein Kettengebirg, sondern einzig und allein durch die Hochlandwüste Pamir hergestellt wird. Damit fällt aber eine der wesentlichsten Stützen der Hypothese.

Auch von anderen Seiten her ward dieselbe, die sich jedoch der ungetheilten Anerkennung aller deutscher und auch vieler französischer Geologen, z. B. E. de Beaumont's, zu erfreuen hatte, lebhaft bekämpft, und zwar war England der eigentliche Sitz der gegnerischen Partei. Hier wirkten Lyell, Daubeny, Scrope als Vertreter der uns bereits aus §. 2 bekannten Aufschüttungstheorie [204]. Die von Beaumont letzterer entgegengehaltenen Gründe [205], dass die steilen Abhänge der meisten Vulkane sich mit einer langsam und allmählig. vor sich gehenden Bildung der Kegelberge nicht vertrügen, sind durch die Untersuchungen Milne's (s. o. §. 2) wohl als endgtiltig widerlegt 
anzusehen. Als endlich auch die Vulkane der Sandwichinseln [206] und jene der Insel Java von Dana und Junghuhn (s. 0. §. 5) als redende Zeugen gegen die $\mathrm{Humboldt-Buch}$ 'sche Theorie erkannt worden waren, verstummte der Widerspruch mehr und mehr, und Peschel konnte [207] mit einigem Rechte die Anhängerschaft des grossen Dioskurenpaares als eine „unlängst ausgestorbene Geologenschule" bezeichnen.

Wie so häufig, hat man jedoch auch hier über das Ziel hinausgeschossen. Man hielt sich zu strikte an die allerdings die grosse Menge bildenden Stratovulkane und übersah völlig die homogenen Vulkane (s. o. §. 3), deren Bildung durch feurig-flüssige Intrusivmassen denn doch von dem, was sich $\mathrm{Buch}$ und $\mathrm{Humboldt}$ gedacht hatten, gar nicht so weit abweicht. So stellt denn auch Suess fest, dass in einem allerdings weit beschränkteren Umfange, als diess Leopold v. Buch unter den bestrickenden Eindrücken der kanarischen SommaKränze gethan habe, die alte Aufblähungstheorie noch als zu Recht bestehend gelten könne [208], und weist zum Belege hiefür auf die jener Anschauungsweise ganz konform gehaltene Darstellung hin, welche einer der hervorragendsten Vulkanforscher unserer Zeit, Abich, von den morphologischen Verhältnissen zweier armenischer Bergmassen, des Palandokän und des Dary-Dagh, entworfen hat [209].

Man würde hieraus zu schliessen haben, dass die Genesis der Strato- und Domvulkane von Anfang an aus verschiedenen Ursachen herzuleiten und zwischen beiden Gattungen ein grundsätzlicher Gegensatz zu statuiren ist. Verschwiegen soll allerdings nicht werden, dass andere Gelehrte, wie Reyer und Sigmund, eine solche Verschiedenheit nicht anerkennen, sondern die homogenen Vulkane sich als durch unausgesetzte Erosion aus den geschichteten entstanden denken [210]. Namentlich soll auch die Beschaffenheit des Magma's einen entscheidenden Einfluss darauf ausüben, ob der Vulkan einen Krater erhält, oder nicht [211].

§. 11. Die nicht-magmatischen Theorieen der neuesten Zeit. Bei den Versuchen, die von selbst sich aufdrängende Frage nach der eigentlichen Herkunft der Lavamassen befriedigend zu beantworten, glaubt eine Reihe von Forschern der Annahme eines feurig-flüssigen Gluthbreies im Inneren der Erde, eines Magma's, vollständig entrathen zu können. Schon Cartesius hielt [212] dafür, dass Schmelzprocesse durch zusammenstürzendes Gestein eingeleitet werden könnten, und die folgenden Jahrhunderte haben analoge Theorieen, für welche wir, ihren sonstigen Abweichungen zum Trotz, den Gesammtnamen nicht$\mathrm{magmatisch}$ vorschlagen zu dürfen glauben, weiter ausgebildet. Wir unterscheiden jedoch auch hier dreierlei Unterabtheilungen, deren Benennung man als Nothbehelfe, bis vielleicht eine zutreffendere Terminologie eingeführt sein wird, gelten lassen wolle.

a) Die Rutschungstheorieen. Eine solche hat Wett ste in [213] aufgestellt. Astronomische Erwägungen bestimmen ihn, anzunehmen, dass alle Erdkörper von einer der Erdrotation entgegengesetzt gerichteten Bewegungstendenz beeinflusst sind, die sich unter dem Aequator am stärksten bemerklich mache. Den Grundsätzen der mechanischen Wärmetheorie zufolge werde durch dieses Gleiten und Fortrutschen 
der Stoffe nicht blos die Erdwärme im Allgemeinen, sondern auch da und dort eine örtliche Schmelzhitze bedingt, welche sich dann vulkanisch äussere. In Kap. IV, §. 8 der zweiten Abtheilung ward die Grundlage des sonst ganz konsequent gehaltenen W ettste in'schen Lehrgebäudes als eine irrige erkannt, und damit ist wohl auch über die Verwerthung dieser Hypothese für den Vulkanismus der Stab gebrochen. Im Uebrigen sei auf die Widerlegungen von Pilar [214] und Z öppritz [215] hingewiesen, welch' letzterer namentlich bemerkt, dass mit der latent-plastischen Beschaffenheit der inneren Erdschichten die Annahme einer Beweglichkeit der einzelnen Theile absolut unverträglich sei.

Weit weniger noch kann das als genügend erachtet werden, was v. Petrinò über die Entstehung der Berge und der feuerspeienden insbesondere sich zurecht gemacht hat [216]. Er glaubt, dass die Centrifugalkraft in jeden Körper das Bestreben gelegt habe, meridional - gegen den Aequator hin fortzuschreiten, und zwar soll unter der Breite $\varphi$ für einen k Kilogramm wiegenden Körper die Grösse dieses "Tangentialschubes" durch

$$
\frac{0,01684 \cdot \mathbf{k} \cdot \sin 2 \varphi}{9,78009+0,03368 \sin ^{2} \varphi}
$$

gegeben sein*). Entstehe dann ein Senkungsfeld, so trete eine oxysmenmässige Vorwärtsbewegung der geschichteten Gesteine " ein, deren Wucht, wenn plötzlich unterbrochen, die stärksten Wärmeentwickelungen bedinge. A. Kirchhoff hat einige Ungeheuerlichkeiten dieser Idee näher beleuchtet [217] und uns dadurch der Pflicht überhoben, an diesem Orte auf dieselbe einzugehen.

b) Die Einsturztheorieen. Die Neptunisten, namentlich Volger und Mohr (in seiner "Theorie der Erde"), halten an einem Rutschen, Gleiten und schliesslichen Hinabstürzen einzelner Theile der Erdrinde in radialer Richtung fest. Das ganze Phänomen der Erdwärme braucht nach Mohr [218] gar nicht plutonistisch aufgefasst zu werden. Das atmosphärische Wasser sickert in die Spalten der Kruste ein und löst dadurch den Zusammenhang der Stoffe, welche nunmehr ihrem Gravitationsbestreben nachgeben können; zudem wirkt der Uebergang amorpher in krystallinische Bildungen und die Selbstentmischung der Kohlen u. s. w. als Wärmequelle mit. Fr. Pfaff hat den Versuch, die zum Schmelzen der Felsen erforderliche Hitze in dieser Weise thermodynamisch entstehen lassen zu wollen, treffend widerlegt: Erstens ist nur vom langsamen Niedergleiten und nicht vom gewaltsamen Einsturz die Rede; wäre aber auch letzteres der Fall und man würde nach den Regeln von R. Mayer und Joule das der lebendigen Kraft des herabstürzenden Blockes entsprechende Wärmeäquivalent berechnen, so fände sich freilich ein hoher Werth, der aber, auf die einzelnen Quadratmeter der auftreffenden Fläche ausgetheilt, nicht entfernt

*) Wie sorglos v. Petrin ò mit mathematischen Dingen umspringt, beweist allein schon der Umstand, dass er aus der angeführten Formel ein Maximum des Schubes für $\varphi=45^{\circ}$ berechnet, während dasselbe doch erst eintritt für

$$
\varphi=\arcsin \frac{9,78009}{2 \cdot 9,78009+0,03368}^{.} \text {. }
$$

Zudem steht doch die Resultante aus Centrifugal- und Schwerkraft stets normal auf der Niveaufläche. 
an jene Temperaturgrade hinanreicht, welche die Lava thatsächlich besitzt [219].

c) Die Kontraktions- und Fältelungstheorieen. Der eigentliche Vater dieser Lehre, die zweifellos auf einen höheren Grad wissenschaftlicher Durchbildung und Bedeutung Anspruch machen kann, ist der Engländer Mallet, der dieselbe in einer inhaltsreichen Abhandlung [220] und später in einem selbstständigen Werke vorgetragen hat, das wir durch v. Lasaulx' Vermittelung auch in deutschem Gewande [221] besitzen; höchstens könnte C. Prévost's Theorie der Erdbildung [222] als eine Art von Vorläuferin gelten. Suess in seiner berühmten ersten Arbeit über Gebirgsbildung [223], Geikie [224] und neuerdings Reusch [225] haben ähnliche Ideen entwickelt, während von Scrope [226] und J. Roth [227] der Widerstand gegen dieses nicht-magmatische, sondern vielmehr geotektonische System des Vulkanismus organisirt wurde.

Mallet nimmt seinen Ausgang von der allseitig zugestandenen Thatsache, dass unser Erdkörper in einem noch immer andauernden Zustande der Abkühlung und Kontraktion sich befinde. Doch werden in diesem Zustande vier verschiedene Perioden auseinandergehalten. Zuerst entsteht eine dünne, biegsame und deshalb auch leicht deformirbare Kruste; alsdann muss dieselbe aufbersten, es müssen sich partielle Wasseransammlungen bilden, während das Erdsphäroid im Ganzen noch rothglühend ist; im dritten Stadium verdickt sich die Kruste, es tritt ein bemerkbarer Tangentialschub ein, die Oberfläche nimmt in den Grundzügen bereits ihre noch heute wahrnehmbare Konfiguration an; zum vierten endlich ist die Rinde dick und starr geworden, die weitere Abkühlung und Zusammenziehung geht nur in sehr langsamem Tempo vor sich. In diesem Zustande soll sich die Erde heutzutage befinden. Obwohl aber die Verhältnisse sich so sehr konsolidirt haben, ist doch den während der früheren Perioden allmählig herausgebildeten Linien des geringsten Widerstandes diese ihre Eigenschaft verblieben. Längs dieser Kurven, deren eine sich um den stillen Ocean herumzieht, tritt eine unausgesetzte Zerdrückung und Zerknickung der Gesteinsmassen ein, und diese Arbeit verwandelt sich an Ort und Stelle in eine Wärme, gross genug, um das feste Material in geschmolzene Lava überzuführen, und mittelst dieser verwandelt sich in einem Kreisprocesse die Wärme zurück in mechanische Arbeit, nämlich in das Hinausschleudern der Lavamassen. Diess ist nur der Grundgedanke des Mallet'schen Systems; derselbe wird, mehrfach mit Anklängen an die Wettsteinsche Hypothese, weiter ausgeführt. $\mathrm{R}$ oth wirft besonders ein [228], dass sowohl Mallet's Kalkul, wie seine geologischen Experimente mit illusorischen Voraussetzungen operirten, letztere deshalb, weil die Verhältnisse durchfeuchteter - im neueren Sprachgebrauche latentplastischer - Gesteine ganz andere seien, als diejenigen trockener. Auch nehme der unzweifelhaft geführte Nachweis, dass es schon zur Triaszeit Vulkane gegeben habe - man denke nur an jenen von Predazzo (§. 5) - dieser Theorie eine Stütze weg, da sie ja den Vulkanismus ausschliesslich den recenten Erdbildungsperioden vorbehalten wissen wolle. Endlich sei ganz unerklärlich, dass die grösste aller gehobenen Festlandflächen, Innerasien, der Vulkane gänzlich entbehre. - Eine genügende Antwort auf diese Einwände dürfte noch nicht gegeben sein. 
H. Reusch führt dagegen die Idee Mallet's nach einer anderen Seite weiter aus, indem er dieselbe mit jenen eigenartigen Veränderungen in der petrographischen Beschaffenheit der Felsarten in Verbindung bringt, welche man als Regional- und als Kontakt-Metamorphismus kennt, und zugleich auf die neueren - in Kap. II der achten Hauptabtheilung näher zu erörternden - Untersuchungen der schweizerischen Geologen A. Heim und Baltzer über die Faltenbildung innerhalb der Erdrinde Bezug nimmt. "Hierbei werden das Grundgebirge und die regional-metamorphosirten Gesteine lokal in erhitztem Zustande vom Erdinneren zu einem höheren Niveau getrieben, als ihre ursprüngliche Lagerstätte war, während durch die Faltung diese Gesteine zugleich noch höher erhitzt werden. Die Bildung von Spalten, durch welche die Erdrinde in Stücke zertheilt wird, begleitet die Faltung. Durch dieselben erhalten die von komprimirten Gasen und Dämpfen erfüllten, bis und über Schmelztemperatur erhitzten Massen Ausgang. Diese Massen werden sowohl von Gesteinen der archäischen Formation, deren Bildungsweise hierbei ausser Betracht bleiben kann, als wohl auch von regional-metamorphosirten Schichten, deren ursprüngliche Beschaffenheit während des Erhitzens (Diffusion) verloren ge. gangen, ausgemacht [229]." Fig. 72 stellt nach A. Baltzer *) dar, wie zwischen dem Engelhorn (e) und dem Gstellihorn (g) im Berner Oberlande die Schichten des schwarz angelegten Gneisses $(G)$ und des weiss gelassenen Malmes (M) in einander übergreifen, während a, b, c isolirte Malmnester im Gneiss, $1,2,3,4,5$ isolirte Gneisskomplexe im Malm signalisiren. Dadurch soll auch erklärt werden, wie es kommt, dass ein und derselbe Vulkan in verschiedenen Zeiten Materialien von sehr verschiedenem Charakter auszuwerfen vermag [231]. So ganz rathlos dürfte bei richtiger Auffassung des Schlag-

Fig. 72.

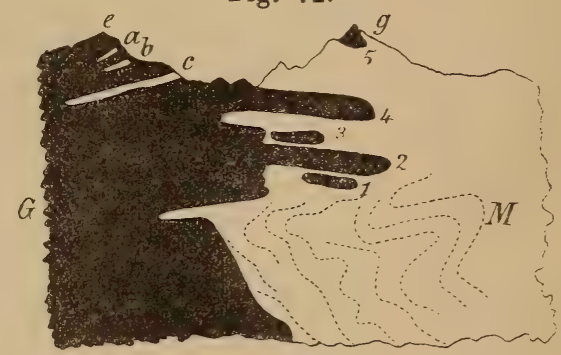
wortes doch auch die auf das „Magma“ (Kap. II, §. 4) zurückgreifende Theorie der fraglichen Thatsache wohl nicht gegenüberstehen. Wir wenden uns nunmehr dieser Theorie oder, besser gesagt, der Gesammtheit der unter den Begriff „magmatisch" fallenden Hypothesen zu.

§. 12. Die magmatischen Theorieen der neuesten Zeit. Aus der Kant-Laplace'schen Nebulartheorie folgt für Jedermann, der sich mit der geistvollen Interpretation derselben durch Tschermak [232] einverstanden erklärt, dass der Vulkanismus nicht blos ein begrenzt-tellurisches, sondern ein kosmisches Phänomen darstellt. Die Meteorite

*) Gegen die Ergebnisse dieses Forschers, wie auch Heim's, hat Fr. Pfaff sowohl in der Vereinszeitschrift der deutschen geologischen Gesellschaft, als auch in einer besonderen Schrift [230] energisch Widerspruch erhoben, indem er namentlich behauptete, dass die bekannten Zeichnungen der Faltenstruktur zwar einer geistreichen Kombination, nicht aber dem wirklichen Verhalten der Natur entsprächen. Ganz unerwarteterweise beginnt Fr. Pfaff dem Wasser eine äusserst einflussreiche Rolle bei allen geologischen Vorgängen anzuweisen. 
(Kap. II, §. 13 der ersten Abtheilung) haben mit den irdischen Eruptionsprodukten grosse Aehnlichkeit; sie mögen - freilich nicht vom Monde wohl aber von noch gluthflüssigen Weltkörpern herstammen, in welchen explosionsfähige Gase eingeschlossen sind. „Die vulkanische 'Thätigkeit, " sagt Tschermak [233], „deren Zeugen jene geheimnissvollen Stein- und Eisenmassen gewesen, lässt sich vergleichen mit den heftigen Bewegungen in den äusseren Schichten der Sonne, mit den schwächlichen vulkanischen Regungen auf der Erde, mit den grossartigen eruptiven Erscheinungen, von denen uns die Mondkrater erzählen *). Ist dem aber so, dann ist für die Existenz eines Magma's, wie auch Zöppritz [235] betont, ein neuer und gewichtiger Beleg gewonnen. Auch Suess, der in seinen uns bekannten beiden Werken die Schrumpfungstheorie in genialer Weise vertritt, räumt trotzdem das Vorhandensein jenes festflüssigen Uebergangskörpers ein, indem er durch dessen anfängliche Intrusion und nachmalige Erstarrung die Bildung der sogenannten Baccolithe, dieser mächtigen Pfeiler und Träger späterer Gebirgsbildung, erklärt [236]. Endlich hat (vgl. §. 8) Penck die vulkanischen Eruptionsprodukte als natürliche Abkömmlinge eines Magma's hinzustellen gewusst: „Die Bildung von Bomben, Lapilli, Sanden und Aschen könnte man mit dem Aufschäumen einer Flüssigkeit vergleichen. Ist die Flüssigkeit sehr beweglich, so reissen die entweichenden Gase Theile der Flüssigkeit mit sich fort. Ist die Flüssigkeit zähe, oder die Gasentwickelung ruhiger, so wird sie über die Wandungen eines niedrigen Gefässes überschäumen, in einem hohen dagegen wird sie zerstäubt werden. Zur Bildung vulkanischer Auswürflinge ist also nichts weiter nöthig, a priori, als ein Magma, aus dem Gase entweichen " [237]. Wir sehen: Während auf der einen Seite gewisse Momente des Eruptionsaktes sich mittelst der magmatischen Vorstellungsweise am Ungezwungensten erklären lassen, drängt das Bestreben, die Eruption als Ganzes überhaupt kausal zu verstehen, auf die Annahme hin, dass jenseits der starren Erdkruste eine in feuriger Wallung befindliche Schicht beginne. Darüber aber, wie man sich auch in diesem Falle den vulkanischen Process zu denken habe, sind noch immer Verschiedenheiten in der Auffassung möglich.

Zirkel, der sozusagen einen vermittelnden Standpunkt gegenüber der im vorigen Paragraphen gekennzeichneten Lehrmeinung einnimmt, gesteht der Kontraktionstheorie die Spaltenbildung in der Erdkruste zu, glaubt aber, dass bei weiterer Zusammenziehung die Lava durch eben diese Spalten in die Höhe gepresst werden müsse [238]. Sein Differenzpunkt im Verhältniss zu Mallet ist also, bei Licht besehen,

*) Bemerkt sei, dass Tschermak die von Carpenter-Nasmyth entwickelte und in Kap. III, §. 11 der ersten Abtheilung dieses Buches auseinandergesetzte Deutung des lunaren Vulkanismus missbilligt. Er meint, dass, wenn diese (im Grunde der Mallet'schen Theorie analoge und für den anscheinend schon völlig ausgebrannten Mond auch erheblich annehmbarere) Hypothese der Wahrheit entspreche, dass dann auch bei der Zusammenziehung des sich seinem Gefrierpunkte nähernden Wassers eruptive Erscheinungen sammt Kraterbildung beobachtet werden müssten, was doch noch niemals der Fall gewesen sei. Es ist doch fraglich, ob nicht die so höchst eigenartigen Gebilde, welche $\mathrm{Hag}$ e $\mathrm{n}$ b a chBischoff beim Zerspringen einer mit Wasser gefüllten und der Frostwirkung ausgesetzten Bombe erhielt [234], als Belege gegen Tschermak's Behauptung in's Gefecht geführt werden könnten. 
nur der, dass er die Massen, welche die Lava liefern, schon von vorn herein bestehen lässt, während jener sie erst aus dem Akte der Kontraktion selbst herleitet. Man scheint übersehen zu haben, dass die von einem der um die Physik des Erdinneren verdientesten Physiker einer früheren Periode, von Cordier, in einem eigenen Werke [239] formulirte Hypothese ganz auf das Gleiche hinauskommt (vgl. §. 9). Aehnlich urtheilt der Oxforder Geologe Prestwich [240], der in dem eindringenden Wasser zwar nicht die bestimmende Ursache des Ausbruches selber, wohl aber der meisten begleitenden Umstände desselben erblicken will. Durch diese Charakterisirung des Wassers tritt Prestwich in einen gewissen Gegensatz zu Dücker [241], der dem Glauben huldigt, dass ohne den Eintritt des Meerwassers, welcher durch die Spalten in die von der Zusammenziehung der Kruste geschaffenen Hohlräume erfolgt, der Anstoss zu der den Ausbruchsakt einleitenden Explosion gar nicht gegeben werden könnte. Pilar giebt zu bedenken, dass solch direkte Spalten-Eruptionen, die ohne unmittelbares vertikales Niedersteigen der Risse bis zur Oberfläche des Magma's nicht denkbar wären, zwar nicht geradezu unmöglich, gewiss aber zu den Seltenheiten zu zählen seien [242]. Dass auf diese Art Daueröffnungen, die nicht bald wieder durch laterale Schiebung geschlossen würden, entstehen könnten, erscheint ihm völlig ausgeschlossen, wohl aber hält er es für möglich, dass die Aufdrückung sogenannter Quetschfalten zur Bildung dauerhafterer Schlöte führen könne. Der Bau der japanesischen Feuerberge lasse solche Haupt- und darauf senkrechte Nebenspalten unschwer erkennen. Fig. 73 a und $b$, die wohl ohne Erläuterung für sich selbst spricht, bringt die gezwungene Oeffnung derartiger Schlünde im Sinne Pilar's zur Anschauung. Für Pilar's Hypothese spricht entschieden der Umstand, dass deren Urheber aus ihr eine Ansammlung der Vulkane an den steil geböschten Seiten der Längsgebirge zu einer Zeit folgerte, da ihm Milne's bezügliche Erfahrungen (s. o.

Fig. 73.

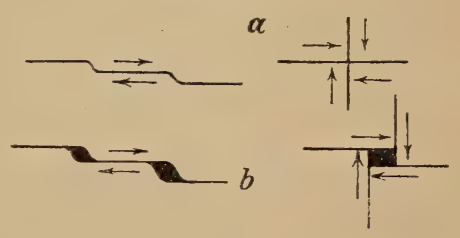
§. 5) noch gar nicht bekannt sein konnten. Bei all' diesen Theorieen ist die Frage, ob das Magma eine so beträchtliche Ausdehnung besitzt, wie wir in §. 5 des vorigen Kapitels feststellen zu können glaubten, nur eine untergeordnete. Man könnte auch Hopkins folgen, der (s. Kap. II, §. 5) zwar die Erde für wesentlich starr erklärte, gleichwohl aber, eben des vulkanischen Phänomens halber, die Existenz lokaler Lava-Reservoirs im Inneren der Erde zulassen wollte und von Thomson wegen dieser seiner Annahme keinen Widerspruch erfuhr. Man ist über diese Hypothese, die auch durch unseren Versuch, für das Magma eine weit grössere Ausdehnung zu retten, keineswegs beseitigt wird, vielleicht etwas zu schnell zur Tagesordnung übergegangen, denn neuere Untersuchungen, die Dutton an den Bruchfeldern der Hochplateaux westlich der Rocky Mountains gemacht hat [243], bedingen ein Zurückgreifen auf $\mathrm{Hop}$ kins' Vorstellungen. Wenigstens lässt in diesem Sinne Suess sein gewichtiges Urtheil vernehmen [244]: „Nach Dutton werden solche Behälter, sie werden Maculae genannt, im Inneren der Erde neu gebildet, und es wird die von Cl. King neuerlich betonte Ansicht 
vom Flüssigwerden durch Verminderung des Druckes mit dieser Voraussetzung in Verbindung gebracht." Dass Dutton persönlich den Inhalt dieser Lavanester nicht, wie Hopkins, aus dem ehemals gluthflüssigen Zustande des gesammten Erdinneren abgeleitet wissen will, thut nichts zur Sache selber; vielleicht begünstigen derartige Hohlräume auch das örtliche Einsinken oder - nach Reyer - Nachsacken des Vulkanes und des angrenzenden Gebirges.

Persönlich würden wir, wie heute die Dinge liegen, den mit den Gasexplosionen des Magma's als mit der eigentlichen causa movens der vulkanischen Phänomene rechnenden Theorieen den Vorzug geben. In diesem Sinne hat Sollas [245] unlängst eine leider nur ganz kurze Andeutung gegeben; im Magma befinden sich grosse Quantitäten Wasserdampfes eingeschlossen, welche sich sofort wieder aus demselben losringen, sobald irgendwo der auf der Oberfläche lastende Druck nachlässt, sobald also plötzlich eine (Seiten-)Spalte sich öffnet. Mit Pilar's Quetschfalten verträgt sich diese Ansicht ganz gut; doch ist noch darauf aufmerksam zu machen, dass nach der neuen vulkanistischen Theorie von Siemens (s. Kap. II, §. 3) das durch Verdampfung eingedrungenen Wassers entstandene Dampfquantum sich als viel zu geringe erweist, um so gewaltige Explosionen liefern zu können, dass vielmehr von der Annahme nicht Umgang genommen werden kann, es müssten auch brennbare Wasserstoffverbindungen unmittelbar aus dem Magma ausgeschieden werden und im Rohre des Kraters mit in die Höhe steigen. Sehr treffend schildert auch Reyer am Schlusse seines uns wohlbekannten geschichtlich-kritischen Essay's die Reihenfolge der in ihrer Gesammtheit als Vulkanausbruch bezeichneten Ereignisse. Durch die Kontraktion der Erdkruste werden Verwerfungen und Spaltbildungen erzeugt, ohne welche das Emporsteigen und die Zerstäubung der Magma-Gase nicht möglich wäre. Er spielt dabei auf eine passend gewählte Analogie aus der Physik des alltäglichen Lebens an: „Wie die gespannte Kohlensäure im Syphon das Aufsteigen und Sprudeln des Säuerlings, nicht aber dessen Durchbruch durch das Ventil bewirkt, so verursachen die Gase im Magma allerdings auch das Aufsteigen und Zerstäuben des Gluthbreies, sind aber nicht im Stande, sich selbst das Loch oder, besser gesagt, die Spalte bis an die Erdoberfläche zu machen."

Dass diese Analyse des verwickelten Processes alle Schwierigkeiten kläre und hebe, welche der Vulkanismus schon heute in sich schliesst und voraussichtlich trotz aller Bemühungen noch ferner in sich schliessen wird, soll nicht behauptet werden, wiewohl keine andere Theorie mehr leisten dürfte. Sei dem aber, wie ihm wolle, soviel steht zu hoffen, dass die den Zusammenhang der Wissenschaften unter sich leugnende Auffassung von Reusch*) ebenso energisch von den Vertretern aller betheiligten Disciplinen desavouirt werden werde. Die

*) Folgendes sind seine Worte [246]: „Es ist überhaupt an der Zeit, dass es nicht mehr in demsélben Grade, wie früher, den räsonnirenden Physikern überlassen wird, die Frage von der Ursache des Vulkanismus zu beantworten. Das Problem ist naturhistorisch und muss in erster Linie von den beobachtenden Naturhistorikern, in diesem Falle also den Geologen, behandelt werden." Nur die Eine Frage: Ist Reyer's Schrift über die Eruptivgesteine eine physikalische oder geologische? Doch wohl beides! 
Lehre von den vulkanischen Erscheinungen kann nur von jenem steten Ineinandergreifen der mathematischen, experimentellen und - im engeren Sinne - beschreibenden Geologie weitere Erfolge erwarten, durch welches sie ihren heutigen und ganz gewiss nicht verächtlichen Wissensstand erreicht hat.

§. 13. Die vegetative Bekleidung der Vulkane. Die Flora der feuerspeienden Berge mit den geologischen Besonderheiten der letzteren in organischen Zusammenhang zu bringen, ist in neuerer Zeit mit grossem Glücke versucht worden. Es ist vielleicht schon kein blosser Zufall, dass ein solcher Berg, der Aetna, zuerst es war, an dem Bembo seine vergleichenden Studien über die vertikale Anordnung der Pflanzenformen und über deren Aehnlichkeit mit dem Wechsel der Vegetation in meridionaler Richtung anstellte [247], vielleicht auch kein Zufall, dass das vulkanreichste Land der Erde, Japan, den Anstoss zum erstmaligen Gebrauch des Wortes "Pflanzengeographie (Menzel) gegeben hat [248]. Dass die intensivere Wärme der von dem Kraterrohre nur durch dünne Wände getrennten Abhänge sich auch in dem floristischen Charakter dieser Aussenseite geltend machen könne, soll jedenfalls nicht principiell in Abrede gestellt werden, obwohl man nicht, wie geschehen (vgl. die Randnote in $\S .5$ und A. $\mathbf{\text { . }}$ Humboldt's Bemerkungen [249] über die Schneelosigkeit des Aconcagua und Cotopaxi), der doch sehr häufig intermittirenden Thätigkeit der Vulkane allzuviel aufzubürden berechtigt ist. Dass die innere Wärme solcher Berge eine agronomische Bedeutung habe, ist allerdings ein allgemeiner Glaube; rauf vulkanischem Boden gedeiht die Rebe", sagt Scheffel im „Ekkehard". Was hier zum Schlusse erörtert werden soll, bezieht sich auf eine Reihe exakter Beobachtungsresultate $\mathrm{R}$ ein's [250], die allerdings auch wieder in keinem anderen Lande, als auf den japanischen Inseln, gewonnen worden sind.

In der Meteorologie wird sich uns Gelegenheit geben, den auf verhältnissmässig rasch vor sich gehender Erwärmung und Wiedererkaltung gewisser Landpartieen beruhenden Gegensatz zwischen Land- und Seewinden auf der einen und zwischen Berg- und Thalwinden auf der anderen Seite $\mathrm{zu}$ studiren. Dieser letztgenannte Windwechsel macht sich nun an den japanischen Vulkanen deshalb besonders bemerklich, weil das vulkanische Gestein durch seine Eigenwärme die Aktion der Sonnenstrahlen energisch unterstützt und dadurch eine besonders lebhafte Auflockerung der darüber ruhenden Luftschichten bewirkt, durch welche dann auch wieder ein starker bergaufwärts wehender Strom bedingt wird. Diesem folgend, schreitet die Vegetation von der Thalsohle nach dem Gipfel zu in die Höhe. Jene Arten, welche einen alpin-polaren Charakter besitzen, steigen am höchsten und benützen jede Aufschüttung eines neuen Eruptionskegels, um an diesem noch höher hinaufzusteigen. Am weitesten entfernt vom Seespiegel begegnet man Pflanzen sibirischen und kamtschatkalischen Ursprunges, welche durch Monsune und Meeresströmungen an die Küsten des Inselreiches gelangt und dort dem Thalwinde überantwortet waren. Nach Rein (a. a. O.) ist in manchen Fällen die Beschaffenheit der Vegetation ein viel wichtigeres, viel sichereres Kriterion für das relative Alter der einzelnen Kratere, als die des Gesteines". 
[1] The Poulett Scrope, Volcanos; the character of their phenomena etc., London 1872. S. 6. - [2] H. Müller, De montibus ignivomis seu vulcanis, Altdorfi 1710 . S. 3. - [3] v. Seebach, Vorläutige Mittheilung über die typischen Verschiedenheiten im Bau der Vulkane und deren Ursache, Zeitschr. d. deutschen geol. Gesellsch., 18. Band. S. 643 ff. - [4] Poulett Scrope, The Volcanos, S. 341. [5] Peschel-Leipoldt, Physische Erdkunde. 1. Band, Leipzig 1879. S. 204. [6] v. Hochstetter, Neuseeland, Stuttgart 1863. S. 85 ff. - [7] Milne, On the form of volcanos, Geol. Mag.. (2) Vol. V. S. 337 ff.; Further notes on the form of volcanos, ibid. (2) Vol. VI. S. 506 ff. - [8] v. Stockar, Die logarithmische Linie als Kurve der rückwirkenden Festigkeit, nachgewiesen am Anlauf des Pfeilers, der Säule und des Pyramidalkörpers mit quadratischem Querschnitt, Archiv d. Math. und Phys., 34. Theil. S. 431 ff. - [9] Français, Mémorial de l'officier du génie, Metz 1820. N. 4. - [10] Löwe, Alte und neue Versuche über Reibung und Kohäsion von Erdarten, München 1872. - [11] Ibid. S. 81 ff. - [12] Milne, On the form etc. S. 340. - [13] Suess, Das Antlitz der Erde, 1. Abtheilung, Prag und Leipzig 1883. S. 190. - [14] Geikie, The lava-fields of north-western Europe, Nature, Vo]. XXVIII. S. 3. - [15] Pilar, Grundzüge der Abyssodynamik, Agram 1881. S. 78 ff. - [16] G. K. Gilbert, Report on the geology of the Henry Mountains, Washington 1877. - [17] Suess, Das Antlitz etc. S. 198. - [18] Ibid. S. 199 ff. - [19] Gehler's Physikalisches Wörterbuch, II. Auflage, 9. Band, 3. Abtheilung, Leipzig 1840. S. 2321 ff. - [20] K. Fuchs, Vulkane und Erdbeben, Leipzig 1875. S. 51. - [21] Peschel-Leipoldt, Phys. Erdk., S. 226. - [22] Lyell, Principles of geology, vol. I, London 1830. S. 378. - [23] K. Fuchs, Vulkane etc., S. 45. [24] Ibid. S. 47. - [25] vom Rath, Ueber eine massenhafte Exhalation von Schwefelwasserstoff in der Bucht von Missolunghi, Monatsber. d. k. preuss. Akad. d. Wissenschaften, 1882. - [26] Gehler's Phys. Wörterbuch, 9. Band, 3. Abth. S. 2331 ff. - [27] Ibid. S. 2333. - [28] Ibid. S. 2335. - [29] Huc-Gabet, Wanderungen durch das chinesische Reich, deutsch von Andree, Leipzig 1855. S. $129 \mathrm{ff}$. - [30] G. H. Hess, Composition du gaz des feux de Bacou, St. Petersbourg 1836. - [31] Gehler, 9. Band, 3. Abth. S. 2337. - [32] v. Gutbier, Beschreibung des Zwickauer Schwarzkohlengebirges, Zwickau 1834. S. 81. - [33] Gehler, 9. Band, 3. Abth. S. 2340. - [34] Breislak, Institutions géologiques, tome III, Milan 1814. S. 435. - [35] A. v. Middendorff, Ueber den Vulkanismus in Centralasien, Ausland, 1879. S. 634 ff. - [36] v. Richthofen, China, 1. Band, Leipzig 1877. S. 216 ff. - [37] A. v. Humboldt, Kosmos, 1. Band, Stuttgart und Augsburg 1845. S. 226. - [38] Bischof, Ueber die natürlichen Kohlensäure-Exhalationen am Laacher See, Schweigger's Journal, 56. Band. S. 147 ff. - [39] Gehler, 9. Band, 3. Abth. S. 2329. - [40] Humboldt, Kosmos, 1. Band. S. 233. - [41] Ibid. S. 448. [42] Solinus, Memorabilia Mundi, cap. V. - [43] Gehler, 9. Band, 3. Abth. S. 2328. - [44] M. Wagner, Der Kaukasus und das Land der Kosaken in den Jahren 1843 bis 1846, 1. Band, Dresden und Leipzig 1848. S. 10 ff. - [45] Gümbel, Ueber das Eruptionsmaterial des Schlammvulkans von Paterno am Aetna und über Schlammvulkane im Allgemeinen, Sitzungsber. d. k. bayr. Akad. d. Wissensch., Math.-phys. Kl., 1881. S. 256 ff. - [46] Ibid. S. 271 ff. - [47] Pilar, Grundzüge etc. S. 13 ff. - [48] v. Hochstetter, Die Vulkane Java's, Sitzungsber. d. k. k. Ak. d. Wissensch. zu Wien, Math.-naturw. K]., 36. Band. S. 128 ff. - [49] O. Schneider, Ueber den Schlammvulkan von Boshie-Pranysl in Transkaukasien, Verhandl. d. Berl. anthropol. Gesellschaft, 1878. S. 21 ff. - [50] v. Buch, Physikalische Beschreibung der kanarischen Inseln, Berlin 1825. S. 321 ff. - [51] Ibid. S. 328 ff. - [52] Ibid. S. 353 ff. - [53] Ibid. S. 379 ff. - [54] Ibid. S. 392 ff. - [55] v. Buch, Ueber die Zusammensetzung der basaltischen Inseln und über Eruptionskratere, จ. Leonhard's mineralog. Taschenbuch, 1821. S. 391 ff. - [56] Humboldt, Kosmos 1. Band. S. 249. - [57] Fr. Hoffmann, Geschichte der Geognosie und Schilderung der vulkanischen Erscheinungen, Berlin 1838. S. 131 ff. - [58] Fr. Hoffmann, Ueber die geognostische Beschaffenheit der Liparen, Ann. d. Phys. u. Chem., 26. Band. S. 81 ff. - [59] Ch. Darwin, Geological observations on the volcanic islands, London 1844. S. 127. - [60] Humboldt, Kosmos, 1. Band. S. 253. [61] Ibid. S. 455. - [62] Brunel, Observationes phaenomenorum quorundam factae. in insulis africanicis. Franciae et Borbonii, Ephem. Soc. Meteorol. Palat., 1788. S. 396. - [63] Peschel-Leipoldt, Phys. Erdk., S. 234. - [64] Ueber den Vulkan Demavend in Persien, Gaea, 13. Jahrgang. S. 251. - [65] Rüppell, Reisen in Nubien, Frankfurt a. M. 1829. S. 151. - [66] Lynch, Proceedings of the royal geogr. society, Vol. XIII. S. 213. - [67] Abich, Ein vermeintlich thätiger Vulkan an den Quellen des Euphrat, Bull. de la soc. imp. des natural. de Moscou, 
tome XLIII. S. 1 ff. - [68] K. Fuchs, Vulkane etc. S. 261 ff. - [69] Fr. Hoffmann, Gesch. etc. S. $125 .-[70]$ K. Fuchs, Vulkane etc. S. 268. - [71] Peschel, Abhandlungen zur Erd-und Völkerkunde, herausg. v. Löwenberg, 2. Band, Leipzig 1878. S. 520 ff. - [72] K. Fuchs, Vulkane etc. S. 271. - [73] Ibir. S. 278. - [74] W. Sartorius v. Waltershausen, Atlas des Aetna, Weimar 1859. - [75] v. Lasaulx, Die neueste Eruption des Aetna vom 22. Dezember 1882, Humboldt, 2. Jahrgang. S. 213 ff. - [76] K. Fuchs, Vulkane etc. S. 276 ff. - [77] Die vulkanischen Gebirge von Aegina und Methana, Naturforscher, 1. Jahrgang. S. 13 ff. - - [78] Island's jüngste vulkanische Phänomene, Ausland, 1879. S. 243 ff. - [79] K. Fuchs. Vulkane etc. S. 256 ff. - [80] Ibid. S. 260. - [81] Goethe's sämmtliche Werke in vierzig Bänden, 40. Band, Stuttgart 1869. S. 33 ff. - [82] Suess, Das Antlitz etc. S. 206. - [83] Hesse, Die erloschenen Vulkane Deutschlands, Reichenbach i. V. 1883. - [84] Steininger, Bemerkungen über die Eifel und die Auvergne, Mainz 1824 S. 32. - [85] Steininger, Die erloschenen Vulkane in der Eifel und am Niederrhein, Mainz 1820. S. 175 ff. - [86] Hesse, Die erl. etc. S. 11 ff. - [87] Ibid. S. 32 ff. - [88] Gümbel, Geologische Fragmente aus der Umgegend von Ems, Sitzungsber. d. k. hayr. Akad. d. Wissensch., Math.-phys. Kl., 1881. S. 239. [89] Hesse, Die erl. etc. S. 49. - [90] Ibid. S. 55. - [91] Gümbel, Ueber den Riesvulkan und über vulkanische Erscheinungen im Rieskessel, Sitzungsber. d. k. bayr. Ak. d. Wissensch., Math.-phys. Kl., 1870. S. 153 ff. - [92] Kaiser, Jan Maijen, Gaea, 18. Jahrgang. S. 697. - [93] K. Fuchs, Vulkane ete. S. 288. [94] Ibid. S. 290 ff. - [95] Ibid. S. 294 ff. - [96] Ibid. S. 296. - [97] Jagor, Reisen in den Philippinen, Berlin 1873. S. 333. - [98] K. Fuchs, Vulkane etc. S. 302 ff. - [99] Junghuhn, Java, seine Gestalt, Pflanzendecke und innere Bauart, deutsch von Hasskarl, 2. Band, Leipzig 1852. S. 606 ff. - [100] Bickmore, Reisen im ostindischen Archipel in den Jahren 1865 und 1866, deutsch von Martin, Jena 1869. S. 32. - [101] Ibid. S. 51 ff. - [102] Der Vulkanismus im Sundagebiete und die Katastrophe vom August 1883, Deutsche Rundschau f. Geogr. u. Stat., 6. Jahrgang. S. 81 ff. - [103] Fuchs, Vulkane etc. S. 281. - [104] Ibid. S. 284. - [105] Ibid. S. 326 ff. - [106] v. Buch. Phys. Beschr. etc. S. 284 ff. [107] Scrope, The Volcanos etc. S. 229. - [108] Dölter, Die Vulkane der Kap. Verden und ihre Produkte, Graz 1882. - [109] K. Fuchs, Vulkane etc. S. 309. [110] Ibid. S. 337 ff. - [111] Ibid. S. 340 ff. - [112] Die Eruption des MaunaLoa auf Hawaii, Gaea, 18. Jahrgang. S. 139 ff. - [113] K. Fuchs, Vulkane etc. S. 338. - [114] J. Müller, Lehrbuch der kosmischen Physik, Braunschweig 1875. S. 581 ff. - [115] K. Fuchs, Vulkane etc. S. 343. - [116] Peschel-Ruge, Geschichte der Erdkunde bis auf Carl Ritter und Alexander v. Humboldt, München 1877. S. 507. - [117] K. Fuchs, Vulkane ete. S. 310 ff. - [118] Ibid. S. 313, [119] Ratzel, Physikalische Geographie und Naturcharakter der Vereinigten Staaten von Nordamerika, München 1878. S. 144 ff. - [120] K. Fuchs, Vulkane etc. S. 313 ff. - [121] M. Wagner-Scherzer, Die Republik Costa Rica in Südamerika, Leipzig 1856. S. 37. -- [122] Ibid. S. 261. - [123] K. Fuchs, Vulkane etc. S. 320. - [124] Verhandl. d. Berl. Gesellsch. f. Erdkunde, 9. Bd. S. 329; 10. Bd. S. 481. - [125] K. Fuchs, Vulkane etc. S. 333. - [126] Eruption vulkanischen Staubes auf Domingo, Gaea, 16. Jahrg. S. 411 ff. - [127] Th. Wolf, Ein Besuch der Galapagos-Inseln, Heidelberg 1879. - [128] Zöppritz, Der gegenwärtige Stand der Geophysik, Wagner's geogr. Jahrb., 8. Band. S. 38 ff. - [129] Peschel-Leipoldt, Phys. Erdk., S. 218. - [130] Fr. Hoffmann, Gesch. etc. S. 451 ff. - [131] Eine interessante Anwendung des Mikrophons auf vulkanische Erscheinungen, Ausland, 1879. S. 179. [132] Peschel-Leipoldt, Phys. Erdk., S. 219. - [133] H. Müller, De montibus ignivomis etc. S. 30. - [134] Kries, De nexu inter terrae motus vel montium ignivomium eruptione et statum atmosphaerae, Acta nova soc. Jablonov., tom. IV. S, 40 ff. - [135] Palmieri, Der Ausbruch des Vesur vom 26. April 1872, deutsch von Rammelsberg, Berlin 1872. S. 17. - [136] Peschel-Leipoldt, Phys. Erdk., S. 221. - [137] Vulkanstudien bei Santorin, Gaea, 10. Jahrgang. S. 641 ff. [138] Ibid. S. 647. - [139] Phillips, Vesuvius, London 1869. S. 112. - [140] PeschelLeipoldt, Phys. Erdk., S. 225. - [141] Jagor, Reisen etc. S. 107 ff. - [142] Junghuhn-Hasskarl, Java, 1. Band. S. 605. - [143] Hesse, Die erl. etc. S. 11. [144] Humboldt, Kosmos, 1. Band. S. 226. - [145] Culmann, Der Minentrichter, Vierteljahrsschr. d. naturf. Gesellsch. zu Zürich, 16. Jahrgang. - [146] H. Credner, Elemente der Geologie, Leipzig 1876. S. 134. - [147] Bedemar, Om vulkaniska produkter fra Island. Kjöbnhavn 1817. - [148] Bischof, Die Bedeutung der Mineralquellen und Gas-Exhalationen bei Bildung und Veränderung der Erdoberfläche, Schweigger's Journal, 66. Band. S. 125 ff. S. 225 ff. - [149] Gehler, 9. Band, 
3. Abth. S. $2261 \mathrm{ff}$. - [150] Ménard de la Groye, Observations avec réflexions sur l'état et les phénomènes du Vesuve pendant une partie des années 1813 et 1814, Journal de physique, tome LXXX. S. 400. - [151] S. o. [78]. - [152] Gehler, 9. Band, 3. Abth. S. 2264. - [153] K. Fuchs, Vulkane etc. S. 102 ff. [154] Ibid. S. 103 ff. - [155] Penck, Ueber Palagonit- und Basalt-Tuffe, Zeitschr. d. deutschen geol. Gesellschaft, 18. Band. S. $504 \mathrm{ff}$. - [156] Ibid. S. $90 \mathrm{ff}$. [157] H. Reusch, Ueber Vulkanismus, deutsch von Herrmann, Berlin 1883. S. 5. - [158] v. Buch, Geognostische Beobachtungen auf Reisen durch Deutschland und Italien, 2. Band, Berlin 1809. S. 174. - [159] Gehler, 9. Band, 3. Abth. S. 2268. - [160] Ibid. S. 2269. - [161] Faujas de la Fond, Recherches sur les volcans éteints de Vivarais et Velay, avec un discours sur les volcans brûlés, Vol. I, Paris 1778. - [162] Reusch-Herrmann, Ueber Vulkanismus, S. 7. - [163] Scrope, The volcanos, S. 73. - [164] Reyer, Beitrag zur Physik der Eruptionen und der Eruptivgesteine, Wien 1877. - [165] Reyer, Vulkanologische Studien, Jahrb. d. k. k. geol. Reichsanstalt, Wien 1878. S. 89 ff. - [166] Gehler, 9. Band, 3. Abth. S. 2274 ff. - [167] Reyer, Ansichten uiber die Ursachen der Vulkane, Gaea, 19. Jahrgang. S. 218 ff. - [168] A. v. Humboldt, Kosmos, 1. Band. S. 449. [169] Peschel-Ruge, Gesch. d. Erdkunde etc. S. 64 ff. - [170] Ovidii Metámorph. liber, v. 296-306. - [171] Humboldt, Kosmos, 1. Band. S. 251. - [172] Nehring, Die geologischen Anschauungen des Philosophen Seneca, 2. Theil, Wolfenbüttel 1876. S. 5. - [173] Ibid. S. 9. - [174] Zöckler, Geschichte der Beziehungen zwischen Theologie und Naturwissenschaft, mit besonderer Rücksicht auf Schöpfungsgeschichte, 1. Band, Gütersloh 1877. S. 287. - [175] Heller, Geschichte der Physik von Aristoteles bis auf die neueste Zeit, 1. Band, Stuttgart 1882. S. 177. - [176] La composizione del mondo di Ristoro d'Arezzo, ed. Narducci, Roma 1859. S. 117. - [177] Zakarija ben Muhammed ben Mahmûd el-Karzwîni's Kosmographie, 1. Halbband, deutsch von Ethé, Leipzig 1868. S. 339 ff. - [178] Kircher, Mundus subterraneus, in quo universae naturae majestas et divitiae demonstrantur, Amstelodami 1664. - [179] G. F. Parrot, Grundriss der Physik der Erde und Geologie, Riga und Leipzig 1815. S. 257 ff. - [180] Hamilton, Observations on mount Vesuvius, mount Etria and other volcanos of the two Sicilies, London 1772. - [181] Gehler, 9. Band, 3. Abth. S. 2279 ff. - [182] Beccaria, Lettere del elettrizismo naturale e artificiale, Torino 1753. S. 226. - [183] Gehler, 9. Band, 3. Abth. S. 2288. - [184] Lister, On the nature of earthquakes and volcanos, Phil. Transact., Vol. XIV. S. 512 ff. - [185] Lémery, Explication physique et chimique des feux souterrains, des tremblements de terre, des ouragans, des éclairs et du tonnerre, Mém. de l'acad. franc, Année 1700. S. 101 ff. - [186] Krüger, Gedanken von der Ursache des Erdbebens, Halle 1756. - [187] Henkel, Pyritologia oder Kieshistorie, Leipzig 1825. - [188] Ibid. S. 867. - [189] A. Werner, Versuch über die Entstehung der Vulkane durch Entzündung mässiger Steinkohlenflötze, als Beitrag zur Geschichte des Basaltes, Höpfner's Magazin, 4. Band. - [190] Davy, On the phenomena of volcanos, Phil. Transact., Vol. CLVIII. S. 241 ff. - [191] Humboldt, Kosmos, 1. Band. S. 247. - [192] Przystanowski, Untersuchungen über den Ursprung der Vulkane in Italien, Leipzig 1822 . [193] Clarke, Experiments with the oxygen and hydrogen blow-pipe, Cambridge 1817. - [194] D'Aubuisson, Traité de géognosie, Vol. II, Paris 1819. S. 211. - [195] Gehler, 9. Band, 3. Abth. S. 2286. S. 2297. - [196] Ibid. S. 2289 ff. [197] Bischof, Die Wärmelehre im Inneren unseres Erdkörpers, Leipzig 1837. S. 250 ff. - [198] Gehler, 9. Band, 3, Abth. S. 2295 ff. - [199] Fr. Hoffmann, Gesch. etc. S. 128. - [200] Ibid. S. 133. - [201] Bruhns, Alexander v. Humboldt, eine wissenschaftliche Biographie, 3. Band, Leipzig 1872. S. 147. [202] Höfler, Die Meridionalgebirge, Jahresber. d. Ver. f. Geogr. u, Stat. zu Frankfurt a. M., 1882-83. - [203] Kohn, Sjewjerzow's Bemerkungen über die meridionalen Erhebungen der Pamir-Wüste und ihr Verhältniss zu Humboldt's Bau des Bolor, Zeitschr. f. wissensch. Geogr., 1. Jahrgang. S. 55 ff. - [204] Fr. Hoffmann, Gesch. etc. S. 234. - [205] Peschel-Leipoldt, Phys. Erdk., S. 206 ff. -[206] Ibid. S. 203. - [207] Peschel-Ruge, Gesch. etc. S. 65. - [208] Suess, Das Antlitz etc. S. 200. - [209] Abich, Geologische Forschungen in den Kaukasusländern, 2. Band, 1. Abtheilung, St. Petersburg 1882. S. 76 ff. $-[210]$ Hesse, Die erl. etc. S. 4. - [211] Reyer, Vulkanol. Stud., S. 473 ff. - [212] Reyer, Ansichten etc. S. 220. - [213] Wettstein, Die Strömungen des Festen, Flüssigen und Gasförmigen und ihre Bedeutung für Geologie, Astronomie, Meteorologie und Klimatologie, Zürich 1880, S. 62 ff. - [214] Pilar, Grundzüge ete. S. 41 ff. [215] Zöppritz, Recension zu Wettstein, Verhandl. d. Ges. f. Erdk. zu Berlin, 
7. Band. S. 59 ff. - [216] v. Petrinò, Die Entstehung der Gebirge, erklärt nach ihren dynamischen Ursachen, Wien 1879. S. 69 ff. - [217] A. Kirchhoff, Recension hiezu, Zeitschr. f. wissensch. Geogr., 1. Jahrgang. S. 37 ff. - [218] Mohr, Ueber die Ursache der Erdwärme, Neues Jahrb. f. Min., Geol. u. Paläont., 1875. S. $371 \mathrm{ff}$. - [219] Fr. Pfaff, Die vulkanischen Erscheinungen, München 1871. S. 167 ff. [220] Mallet, On volcanic energy: an attemt to develop its true origin and cosmical relations, Phil. Transact., Vol. CLXIII. S. 147 ff. - [221] Mallet, Ueber vulkanische Kraft, deutsch von v. Lasaulx, Bonn 1874. - [222] C. Prévost, Quelques propositions relatives à l'état originaire et actuel de la masse terrestre etc., Compt. rend. de l'acad. franç., tome XXXI. S. 461 ff. - [223] Suess, Die Entstehung der Alpen, Wien 1875. S. 47 ff. - [224] Geikie, On some points in the connection between metamorphism and volcanic action, Transact. of the Edinb. geol. society, Vol. II. S. 287 ff. - [225] Reusch-Herrmann, Ueber Vulkanismus, S. 26 ff. - [226] Scrope, On Mallet's theory of volcanic energy, Geol. Mag., (2) Vol. I. S. 38 ff. - [227] J. Roth, Ueber die neue Theorie des Vulkanismus des Herrn R. Mallet, Zeitschr. d. deutschen geol. Gesellschaft, 27. Band. S. 551 ff. - [228] Ibid. S. 564 ff. - [229] Reusch-Herrmann, Ueber Vulkanismus, S. 30 . [230] Fr. Pfaff, Der Mechanismus der Gebirgsbildung, Heidelberg 1880. S. $104 \mathrm{ff}$. - [231] Reusch-Herrmann, Ueber Vulkanismus, S. 32. - [232] Tschermak, Ueber den Vulkanismus als kosmische Erscheinung, Sitzungsber. d. k. k. Ak. d. Wiss. zu Wien, math.-naturw. Kl., 75. Band, 1. Abth., S. 151 ff.; Die Bildung der Meteoriten und der Vulkanismùs, Sirius, (2) 4. Band. S. 149 ff. - [233] Ibid. S. 157. - [234] Hagenbach-Bischoff, Sprengwirkungen durch Eis, Ber. d. naturf. Ges. zu Basel, 7. Band. S. 185 ff. - [235] Zöppritz, Der gegenw. etc. S. 35. - [236] Suess, Das Antlitz etc. S. 318 ff. - [237] Penck, Studien über lockere vulkanische Auswürflinge, Zeitschr. d. deutschen geol. Gesellschaft, 17. Band. S. 127. - [238] Zirkel, Ueber den muthmasslichen ursprünglichen Zustand der älteren Eruptivgesteine, Oest. Monatsschr. f. Wissensch. u. Kunst, 1872. S. 594 ff. - [239] Cordier, Essay sur la température de l'intérieur de la terre, Paris 1827. - [240] Prestwich, Some observations of the causes of volcanic action, Nature, Vol. XXIV. S. $471 \mathrm{ff}$. [241] Dücker, Tagebl. d. 52. Versamml. deutscher Naturf. u. Aerzte, Baden 1879. S. 197 ff. - [242] Pilar, Grundzüge etc. S. 179 ff. - [243] Dutton, Report on the geology of the high plateaus of Utah, Washington 1880. S. $116 \mathrm{ff}$. S. $128 \mathrm{ff}$. [244] Suess, Das Antlitz etc. S. 240. - [245] Sollas, The connection between the intrusion of volcanic action, Nature, Vol. XXIV. S. 472. - [246] Reusch-Herrmann, Ueber Vulkanismus, S. 33. - [247] Humboldt, Kosmos, 1. Band. S. 490. [248] Ibid. S. 375. - [249] Ibid. S. 483. - [250] Rein, Ueber Berg - und Thalwinde und ihre Beziehungen zur Vegetation der vulkanischen Gebirge, Gaea 15. Jahrgang. S. $681 \mathrm{ff}$.

Kapitel IV.

\section{E r d b e b e $n$.}

§. 1. Beschreibung einzelner Erdbebenphänomene und Erdbebengebiete. Die erste Vorbedingung zur Erklärung, ja selbst nur zum richtigen Verständnisse der Menge verwickelter Erscheinungen, welche wir mit dem Namen Erdbeben zusammenzufassen gewohnt sind, ist die Beschaffung eines ausgiebigen Beobachtungsmateriales. Aus leicht verständlichen und in der Natur des Menschen nur allzusehr begründeten Ursachen ist dieser Forderung jedoch nur sehr schwer nachzukommen, und keine der aus dem Alterthum und Mittelalter auf uns gekommenen Nachrichten kann auf Zuverlässigkeit Anspruch machen. Den richtigen Weg der Notizensammlung betrat zuerst Scheuchzer 
aus Zürich [1], der im Jahre 1697 Fragezettel an eine Reihe von Gelehrten sandte, in welchen Fragen über die näheren Umstände einiger in der Schweiz empfundener Erdstösse (bei Basel und Eglisau) zur Beantwortung vorgelegt waren; die Wissbegierde des Fragestellers erstreckte sich auch auf mancherlei andere erdphysikalische Gegenstände, als auf Veränderung in der Lufttemperatur und in den magnetischen Verhältnissen, auf das Vorkommen von Fossilien in der Gegend des Adressaten, auf Gletscher, Feuerkugeln, Sternschnuppen, Nordlichter u. s. w. Durchdachte Vorschläge zur Aufstellung von Fragebogen, deren richtige Ausfüllung uns eine vollständige Statistik der Erdbebenerscheinungen liefern würde, hat Pilar [2] gemacht, indem er sorglich alle in Betracht kommenden Punkte erörterte. Wir werden bald sehen, dass das wenige, was man zur Zeit über den mechanischen Charakter eines bestimmten Erdbebens aussagen kann, statistischen Aufnahmen und natürlich auch einer rationellen Bearbeitung des von diesen gebotenen Stoffes verdankt wird.

Soweit die aussereuropäischen Länder in Frage kommen, verfügt die Forschung meist nur über gelegentliche Berichte von Reisenden u. dgl.*). Nur Japan macht eine Ausnahme, weil dort erstlich deutsche Naturforscher, wie Knipping [4] und E. Naumann [5], ein sorgsames Auge auf diese Vorfälle haben, und weil zweitens die Japanesen selbst seit Jahrhunderten ihr Interesse dafür durch genaue Aufschreibungen bethätigten **). In unserem Welttheile hat Italien den wenig erfreulichen Vor'ug, von Erschütterungen des Bodens am meisten heimgesucht zu werden, und so konnte es nicht fehlen, dass eine umfangreiche Literatur über italienische Beben entstand. Dahin ist in erster Linie zu zühlen das klassische Werk von Mallet [6], durch welches unser unsicheres Wissen über die Einzelheiten solcher Phänomene zuerst eine festere Fundamentirung erhielt; Mallet hatte seine Erfahrungen in Kalabrien gesammelt, jenem unglücklichen Lande, das. schon im Jahre 1783 eine - von Dolomieu und Grimaldi [7] beschriebene - Katastrophe dieser Art erlebt hatte. Ihren speziellen Historiographen besitzen die Erdbeben Italiens in De Rossi, dem eifrigen Vertreter eines selbstständigen Wissenszweiges der unterirdischen Physik. Das Erdbeben von Belluno ist von Bittner [8] und Falb [9] charakterisirt worden, während für das südliche Italien im Allgemeinen Suess [10] die Grundlinien der Erforschung vorzeichnete.

*) Als eine verdienstliche Ausnahme ist Wynne's Studie über das nordostindische Erdbeben von $1878 \mathrm{zu}$ nennen [3]. Auch in den neuspanischen Staaten beginnt man die Nothwendigkeit einer sozusagen offiziellen Registrirung der seismischen, wie der vulkanischen Ereignisse immer deutlicher einzusehen, namentlich in Chile und Guatemala, wo Rockstroh diese Angelegenheit von Staatswegen in die Hand genommen hat.

**) Die Nachrichten der japanischen Annalenschreiber reichen bis in das dritte vorchristliche Jahrhundert hinauf. Natürlich läuft des Fabelhaften genug mit unter, doch wird die Darstellung, je mehr sie sich der neueren Zeit nähert, eine immer genauere, wie denn die in Kap. III, §. 6 erwähnte Angabe von einer plötzlichen Erhebung des gigantischen Fusijama im Jahre 285 v. Chr. durch einen eingeborenen Geographen später ausdrücklich für eine Sage erklärt wird. Von 1676 an werden die seismischen Berichte zahlreich und minutiös. Japan's Literatur enthält 5 Erdbebenkalender, 13 Schilderungen besonders furchtbarer Ereignisse und 2 theoretische Abhandlungen über Erschütterungen. Die „British Association" ernannte Miln e zum seismischen Reporter für Japan. 
Für die entsetzliche Heimsuchung, welche über den Badeort Casamicciola auf Ischia ergieng, fehlt es, da erst eine kurze Zeit seitdem verstrichen ist, noch an einem wissenschaftlich erschöpfenden Berichte, doch hat Ratzel [11] einstweilen sehr umsichtig die Thatsachen zusammengestellt, während das schwächere Erdbeben, das zwei Jahre früher an gleicher Stelle stattgefunden hatte, in v. Lasaulx [12] einen Beschreiber fand. - Sehr gute monographische Arbeiten besitzen wir auch über einzelne mitteleuropäische Erdbeben und Schüttergebiete, so von Hantken v. Prudnik [13] und Pilar [14] über Agram, von Yeitteles [15] über Karpathen und Sudeten, von Suess [16] über Niederösterreich, von Höfer [17] über Kärnthen; das grosse deutsche Beben von 1872 schilderte v. Seebach [18], das mehr periodische Erzittern des Herzogenrather Territoriums verfolgte v. Lasaulx [19] in zwei den verschiedenen Stadien gewidmeten Schriften. Dasjenige Land Europa's, in welchem zur Zeit am meisten für die statistischnaturhistorische Erforschung der Erdbeben geleistet wird, ist jedoch wahrscheinlich die kleine Schweiz. Es besteht dort eine eigene "schweizerische Erdbebenkommission" unter der Leitung des Berner Physikers A. Forster, und die Organisation des Beobachtungs- und Nachrichtendienstes ist eine so gute, dass, wie der Rechenschaftsbericht des Präsidenten über zwei Monate des Jahres 1881 beweist [20], auch die leichtesten Zuckungen der Kontrole nicht entgehen konnten. Das gesammte im Verlaufe zweier Jahre aufgespeicherte Material legte A. Heim den zu Linththal versammelten Mitgliedern der schweizerischen naturforschenden Gesellschaft vor [21], dabei konstatirend, dass innerhalb der Grenzen der kleinen Republik von November 1879 bis Ende Dezember 1880 nicht weniger als 69, im einzigen Jahre 1881 sogar 166 Stösse bemerklich waren, worunter 18 bedeutendere. In Deutschland hat sich der naturwissenschaftliche Verein zu Karlsruhe durch das Vorgehen der schweizerischen Gesellschaft angeregt gefühlt, einen Ausschuss zur Kontrole der in sein Bereich fallenden Erderschütterungen niederzusetzen.

Für die Wissenschaft der Erdbebenkunde hat De Rossi auf dem Titel eines allerdings hochverdienstlichen Werkes [22] die Bezeichnung endogene Meteorologie in Vorschlag gebracht*). Wir glauben diesen Namen ablehnen zu sollen, da unseres Erachtens durch ihn die Gefahr nahe gelegt wird, von vorn herein die Ergründung des wirklichen Sachverhaltes an eine bestimmte und nichts weniger als feststehende Theorie geknüpft zu sehen, während doch gewiss die von uns (s. u. §. 9) als tektonisch zu bezeichnenden Erdbeben nicht das Mindeste mit Veränderungen im Luftkreise zu thun haben. Nach wie vor dürfte, wenn ein Fremdwort gewählt werden soll, das Wort Seis-

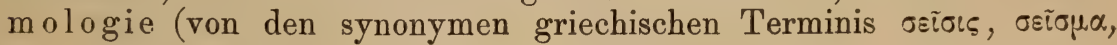

*) Nach Neumayer's offiziellem Protokoll [23] fasste der in Rom zusammengetretene zweite internationale Meteorologen-Kongress folgenden Beschluss: ${ }_{n}$ Nachdem der Kongress mit grossem Interesse den Bericht über Herrn De Rossi's Forschungen betreffs der Phänomene, die er unter dem Namen ${ }_{\text {Endogene Meteo- }}$ rologie " zusammenfasst, angehört hat, drückt derselbe den Wunsch aus, jene Forschungen fortgesetzt $\mathrm{zu}$ sehen, und weist auf die Beziehungen hin, die zwi6chen diesen Phänomenen und denjenigen der allgemeinen Meteorologie bestehen können." In dieser Form ward schliesslich auch der Beschluss redigirt [24]. 


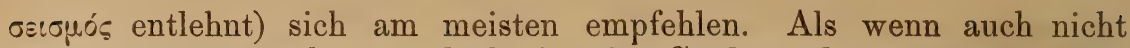
strenge systematische, so doch für das Studium der seismischen Erscheinungen wichtige und nützliche Schriften verdienen diejenigen Favaro's [25] genannt zu werden, während die mehr mathematischexperimentelle Seite unserer Disciplin in R. Mallet [26] einen hervorragenden Vertreter fand. Umfassende Kataloge der seismischen Phänomene verdankt man ebenfalls den beiden Mallet [27] und J. Schmidt [28], für frühere Zeit Karl v. Hoff [29]; auch Perrey hat solche Zusammenstellungen in einer ganzen Reihe von Schriften gemacht, von denen es hier genügen möge, die bedeutendste [30] zu nennen. Kurz, aber musterhaft umsichtig findet sich der heutige Stand der Erdbebenforschung gekennzeichnet in einem Schriftchen von J. Roth [31], auf welches wir selbst in den folgenden Paragraphen sehr häufig Bezug zu nehmen haben werden; ein ähnliches lieferte Toula [32].

§. 2. Allgemeine Schilderung des Verlaufes einer Erderschütterung. Es ist nicht leicht, das Wesen eines Erdbebens in einer allen Anforderungen genügenden Weise zu definiren. In Kap, IV, §. 2 der vorigen Abtheilung lernten wir gewisse langsame Bewegungen der Erdrinde kennen, welche sich in geringen Ortsveränderungen eines freihängenden Pendels oder der Luftblase einer Wasserwage bemerklich machen, dabei aber - eben der gleichmässigen und nicht abrupten Form ihres Auftretens halber - nicht den uns hier beschäftigenden Erscheinungen zugezählt werden dürfen. Alle rein oberflächlichen Gleichgewichtsstörungen sind jedoch ebenso auszuschliessen, wie etwa Bergstürze oder Erdschlipfe, der Zusammenbruch zugänglicher Höhlen, die Wirkungen von Orkanen u. s. w., obschon mit all' diesen Ereignissen nicht selten ein ganz namhaftes Erzittern benachbarter Theile der Erdoberfläche verbunden zu sein pflegt. Roth bezeichnet [33] rals Erdbeben die vorübergehende Bewegung des Erdbodens, deren unter der Oberfläche gelegene Ursache von unten nach oben, von der Tiefe nach aussen wirkt ${ }^{4}$, und an dieser Fixirung des Begriffes wollen auch wir hier uns genügen lassen. Bemerkt sei jedoch zugleich, dass nicht lediglich das Festland, sondern auch der Meeresboden solchen Erschütterungen ausgesetzt ist, welche deshalb auch im nächsten Paragraphen gesondert zu betrachten sein werden. Den Erdbeben stellt man die Seebeben gegenüber.

Die Erdbeben sind eine weit häufigere Erscheinung, als man gemeiniglich glaubt, wie denn A. v. Humboldt [34] der Ansicht ist, dass zu keiner Zeit die innere Thätigkeit der Erdrinde vollständig authöre, dass vielmehr am einen oder anderen Orte diese Aktion ununterbrochen sich geltend mache. Wenn die erwähnten Listen der Erdbebenstatistiker ziemlich für jedes Jahr eine Zunahme der beobachteten Erdstösse erkennen lassen, so darf aus diesem Umstande natürlich nicht auf eine wirkliche Vermehrung solcher Vorfälle, sondern nur auf eine Vermehrung der Beobachter und auf eine erhöhte Aufmerksamkeit dieser letzteren geschlossen werden, doch dient die $\mathrm{Zu}$ nahme immerhin dazu, für die Wahrscheinlichkeit von Humboldt's Behauptung Propaganda zu machen [35]. Die für das vorige Kapitel so wichtige Frage der geographischen Vertheilung braucht uns hier 
nicht zu beschäftigen, denn soviel lässt sich schon nach unseren heutigen Erfahrungen übersehen, dass kein Land der Erde sich einer absoluten Immunität den Erdbeben gegenüber rühmen kann, obgleich natürlich die einen mehr, die anderen weniger häufig und stark betroffen werden. Im Alterthum hielt man, gestützt auf die Autorität des Dichters Pindar und des Naturhistorikers Plinius [36], die Insel Delos, Aegypten und Gallien für erdbebenfreie Gebiete, eine Ansicht, welche Seneca mit spöttischen Seitenhieben auf die derselben anhängenden Leute, als eine „credula natio philosophorum “, bekämpfte [37]. Selbst manche vulkanreiche Gegend ist sicherer, als gewisse durchaus unvulkanische und trotzdem von steten Stössen heimgesuchte Landstriche. Peschel glaubte in seinem interessanten Aufsatze ᄁüber das gegenwärtige Wissen von den Erdbeben “ [38] immerhin einige Anhaltspunkte für eine relative Erdbebenfreiheit erkannt zu haben, und Leipoldt formulirt [39] seine Ergebnisse dahin, „dass Erdbeben seltener werden 1) im Abstand von thätigen Vulkanen, 2) im Abstand von vormals thätigen Vulkanen, 3) im Abstand von dem Erderschütterer Poseidon, also im Binnenlande und nicht auf Halbinseln, Inseln oder Küstengestaden, 4) im Abstand von jung erhobenen Gebirgen, überhaupt auf grösseren Tiefebenen (obgleich auch sie nicht gänzlich frei sind), 5) in alten Erdtheilen im Gegensatze zu den jüngeren. ${ }^{6}$ Es wird (a. a. O.) darauf hingewiesen, dass gewisse Felsgebilde, die Livingstone in Afrika antraf, vollständig aus dem stabilen Gleichgewichte herausgerathen waren und gleichwohl seit unvordenklicher Zeit in diesem Zustande verharrten, während auch der leiseste Erdstoss ihren Fall herbeiführen musste. Aehnliche erosive Gesteinsformationen, die alles inneren Haltes zu entbehren scheinen, kommen den von Pechuël-Lösche dem Frankfurter Geographentage vorgelegten Zeichnungen zufolge auch am Congo vor. Kant vertheidigte mit Lebhaftigkeit den Satz, dass die Meeresufer am stärksten bedroht seien, indem er auf Kleinasien, Nordafrika, Peru, die iberische und die apenninische Halbinsel hinwies [40]; am schlimmsten sind nach ihm Südamerika, Italien und die Inseln des indischen Oceans daran [41]. Soviel ist gewiss, dass es relativ immune und daneben auch, wie sich Roth (a. a. O.) ausdrückt, habituelle Stossgebiete giebt. So sucht sich Suess, um vergleichende Normen für die seismischen Gesetze trotz der zu supponirenden Ungleichartigkeit der Ursachen zu erhalten, für seine.Untersuchungen, gewissermassen als Paradigmen, vier örtlich weit auseinanderliegende $\mathbf{S}$ chü tt erg e bi e te heraus, nämlich dasjenige der nordöstlichen Alpen, dasjenige des südlichen Italiens, dasjenige des centralamerikanischen Festlandes und dasjenige der Westküste von Südamerika [42].

Was die Stärke des Erdstosses anlangt, so ist dieselbe, je nach den Umständen, eine ungemein verschiedene. Manchen Ortes befindet sich der Boden in einem fast nie unterbrochenen Zustande des Erzitterns Monate und selbst Jahre hindurch; man spricht dann von Erdbebenschwärmen [43] (Grossgerau). Weit seltener und weit gefährlicher sind die von schwächeren Stössen eingeleiteten und gefolgten, selbst aber durch wenige, rasch nach einander erfolgende, energische Rucke des Bodens ausgezeichneten Erdbeben im engeren Sinne. Drei Stösse, deren stärkster 3 bis 4 Sekunden anhielt, reichten 
am 26. März 1812 hin, Stadt und Provinz Caracas vollständig zu verwüsten. Hie und da freilich ist die Dauer eine weit längere, so bei dem furchtbaren Erdbeben von Riobamba (4. Februar 1797), wo in Zeit von vollen zwei Monaten kaum ein Nachlassen der Intensität zu verspüren war, so bei dem grossen nordamerikanischen Erdbeben von 1811, dessen Phasen sich an eine gewisse Periode zu halten schienen [44], so beim phokischen Beben, das nach J. Sch mid t vom 31. Juli 1870 bis zum 1. August 1873 nicht weniger als 35 Hauptstösse, von kleineren Erschütterungen abgesehen, zu unterscheiden gestattete [45].

In früherer Zeit glaubte man einen dreifachen Unterschied in der Art der Erdstösse statuiren zu sollen, obgleich schon Seneca, dessen gesundes Urtheil ja mehrfach schon unser Staunen erregte, das Richtige getroffen hatte, indem er, selbst einem griechischen Vorgänger die Ehre gebend, nachstehende Definition aufstellte [46] : „Duo genera sunt, ut Posidonio placet, quibus movetur terra. Utriusque nomen est proprium: altera succussio est, cum terra quatitur et sursum et deorsum movetur, altera inclinatio, qua in latera nutat navigii more. ${ }^{\text {" }}$ Die inclinatio des Römers wird heute als undulatorische Bewegung bezeichnet, der Name succussorische Bewegung ist dagegen für ein stossweises Auf- und Niederschwingen des Bodens beibehalten worden [47]. Erstere Art der Bewegung ist die weitaus gefährlichere, da sie den Zusammenhalt der Bauwerke am unheilbarsten löst, während die einfache Oscillation, wenn sie auch Menschen und Häuser in die Höhe zu schnellen, ja sogar nach Hamilton [48] die Gipfel der Berge in eine hüpfende Bewegung gerathen zu lassen vermag, meist keine so furchtbaren Trümmerhaufen schafft, wie jene. Dolomieu berichtet [49] als Augenzeuge, dass bei dem furchtbaren Erdbeben von 1783 die mehr am Rande der Schütterzone gelegenen Städte Messina und Reggio zwar furchtbar zugerichtet gewesen seien, dass man aber doch jedes zerfallene Haus noch als Individuum habe erkennen können, während das Städtchen Polistena, das die stärkste Amplitude der Undulation wegen seiner centralen Lage im Schüttergebiete auszuhalten hatte, in eine form- und unterschiedslose Gesteinsmasse verwandelt worden sei. Was die oben genannte dritte Bewegungsform, die rotatorische, anlangt, so ist dieser "moto vorticoso" als ein spezieller Fall der succussorischen erkannt worden [50]. Eine einfache mechanische Ueberlegung lehrt, dass ein Stoss, der nicht durch den Schwerpunkt eines - theilweise beweglichen - Körpers hindurchgeht, eine Drehung dieses Körpers hervorrufen muss. Falb theilt ein auffallendes Beispiel einer solchen Verdrehung mit [51], welches er an einer Friedhofspyramide zu Farra im Friaul beobachten konnte. Letztere bestand, so wie sie aus der Hand des Steinhauers hervorgegangen war, aus sieben genau an einander anschliessenden $\mathrm{Be}-$ standtheilen, und jedes einzelne dieser Stücke war gegen die beiden zunächst darauf folgenden um mehrere Grade verrückt worden, während die vertikale Hauptaxe des Monumentes nur eine geringe Parallelverschiebung erfahren hatte.

Die Fortpflanzungsgeschwindigkeit der Stosswellen suchten Mallet und Fr. Pfaff durch geologische Experimente, Abbot durch Minensprengungen mit Dynamit zu ermitteln [52]. Blos für Granit fanden sich leidlich stimmende Zahlen, indem für dieses Gestein der durch- 
IV, §. 2. Allgem. Schilderung des Verlaufes einer Erderschütterung. 375

s

schnittliche Weg der Welle pro Sekunde etwas mehr als $500 \mathrm{~m} \mathrm{zu}$ betragen scheint. Wäre der Zwischenraum zwischen dem Ausgangsorte eines Erdbebens und einem zweiten Orte $(=\mathrm{a})$ mit homogenem Felse von der Dichtigkeit $d$ und dem Elasticitätsmodul E erfüllt, so wïrde nach den bereits von Newton [53] aufgefundenen Sätzen von der Bewegung im elastischen Mittel der Weg a in der Zeit a : $\sqrt{\mathrm{gE}: \mathrm{d}}$ zurückgelegt werden, unter g, wie üblich, die Fallbeschleunigung verstanden. Diess ist nun nicht der Fall, die Zusammensetzung der Erdrinde ist vielmehr häufig die denkbarst heterogene, allein es fehlt uns durchaus an Mitteln, den Grad der Heterogeneität im Einzelfalle richtig zu schätzen, und wenn man deshalb weiss, dass für den Ort A, welcher anscheinend zunächst über der Erregungsstelle lag, das Erdbeben zur Zeit $t_{1}$, dagegen für den ( $\left.u m A B=a\right)$ abstehenden Ort $B$ zur Zeit $t_{2}\left(t_{2}>t_{1}\right)$ bemerklich wurde, so werden wir doch im Allgemeinen den Bruch a: $\left(t_{2}-t_{1}\right)$ als einen angenäherten Werth für die Fortpflanzungsgeschwindigkeit anzusehen berechtigt sein. "Sieht man, sagt $\nabla$. Seebach [54], „wie nahe die ... Orte übereinstimmen, obschon sie auf den verschiedensten Radien des Centrums von zum Theil völlig verschiedener geologischer Bildung liegen, so wird man der Ansicht von O. Volger beipflichten müssen, welcher 1858 schon meinte, dass die unendliche Mannigfaltigkeit der geologischen Verhältnisse sich gegenseitig aufheben und zu einem mittleren Gesammtverhalten führen müsse." Für das Erdbeben von Amt-Gehren findet der genannte Seismologe eine Sekundengeschwindigkeit von $742 \mathrm{~m}$, für jenes von St. Goar von 567,6 m, für jenes in der Basilicata von 259,7 m [ว̌]]. Von den Fortpflanzungsverhältnissen der Erdbebenfluthen handelt §. 3 .

Die Ausdehnung der von einem bestimmten Erdbeben in Mitleidenschaft gezogenen Oberflächenpartieen ist eine sehr verschiedene [56]. Oft ist der Erschütterungsbezirk nur ein ganz geringer, während das zu trauriger Berihmtheit gelangte Erdbeben von Lissabon (1. November 1755) ${ }^{1 / 13}$ der gesammten Erdfläche erzittern liess. Fr. Hoffmann spricht von einzelnen äusserst merkwürdigen Beispielen für beide entgegengesetzte Möglichkeiten [57]. Es gilt diese Verschiedenheit nicht blos bezüglich der horizontalen, sondern auch der vertikalen Verbreitung der Stösse. So fuhren im Jahre 1812 die Bergleute aus gewissen Gruben des Erzgebirges schleunigst aus, weil sie durch heftige Zuckungen der Erde in Schrecken gesetzt worden waren, die an der Oberfläche ganz und gar nicht sich hatten spüren lassen, und gerade die umgekehrte Erfahrung soll sich nach Berzelius den Grubenarbeitern von Persberg und Falun in Dalekarlien aufgedrängt haben [58].

Nachhaltige geologische Folgen sind den Erdbeben im Allgemeinen nicht abzusprechen. Die alten Geographen und Naturforscher hatten auch auf diese morphologische Bedeutung der Erdstösse ihr Augenmerk gerichtet; Seneca behauptet, dass das früher vom Meere völlig abgeschlossene Thessalien durch ein Erdbeben entsumpft und entwässert worden sei [59], und Plinius führt Beispiele seismischer Insel- und Landbrückenbildungen an [60]. Der entstehenden Spalten gedenkt Seneca nicht minder ausdrücklich [61]; dieselben sind gewöhnlich nur klein, häufig aber gross genug, um ganze Häuser mit ihren Insassen zu verschlingen. Bisweilen klappen die Ränder der 
Erdbebenspalten wieder so genau auf einander, dass das Vorhandensein jener nur durch eingeklemmte Gegenstände erkennbar wird, nicht selten aber ergeben sich auch Verwerfungen und Niveauverschiebungen; so wollte man nach dem Agramer Erdbeben die Wahrnehmung gemacht haben, dass eine auf entferntem Berge gelegene Kapelle jetzt auch von Standorten aus sichtbar geworden sei, die früher ihrer tiefen Lage halber eine solche Möglichkeit nicht geboten hätten. Die Spalten verlaufen häufig radial, wie die Speichen eines Rades, und in diesem Falle treten aus ihnen mitunter jene eigenthümlichen Sandkratere hervor, verbunden mit Gas- und Schlammausscheidungen. Roth [62] zählt acht charakteristische Ereignisse dieser Art auf; auch in Resnik bei Agram hat man nach dem grossen kroatischen Erdbeben solche Neubildungen bemerkt. Versiegen von Quellen und Flüssen oder wohl auch das Hervortreten neuer strömender Gewässer ist nach Seneca [63] ebenso im Gefolge von Erschütterungen zu erwarten, wie der Aufstau der Flüsse durch Schuttmassen und Terrainhebungen. Veränderungen grossen Styles sind hingegen eine Ausnahme. Bergstürze und Rutschungen wurden sowohl bei dem schrecklichen kalabrischen Erdbeben als auch bei dem phokischen (von J. Schmidt) konstatirt [64]. Das aufgeregte Meer reisst wohl auch grössere Stücke vom Uferlande ab (vgl. §. 3), doch werden instantane oder rhapsodische Hebungen und Senkungen (so drückt man sich der langsam und kontinuirlich vor sich gehenden säkulären Oscillationen halber aus) nur bei besonders lange dauernden und ungestümen Erdbeben beobachtet [65] Suess, von dem das oben angeführte bezeichnende Kunstwort herrührt, hat die Verhältnisse an der südamerikanischen Westküste, .wo eben Fitzroy und Ch. Darwin unwiderlegliche Zeugnisse seismischer Vertikalverschiebungen von grösserem Betrage gefunden haben wollten [66], zum Gegenstande seines besonderen Studiums gemacht [67] und als dessen Schlussfazit den Satz formulirt [68]: „Bei keiner der zahlreichen seitherigen Erschütterungen des westlichen Südamerika ist eine Erhebung des Landes bemerkt worden."

Wir beenden diesen das empirische Rohmaterial der Seismologie sammelnden Paragraphen mit dem Hinweise darauf, dass künftig auch die Seehöhe des Ortes, an welchem ein Erdstoss sich fühlbar machte, mehr als bisher in Betracht gezogen werden sollte. Ein italienischer Physiker, Diamilla-Müller, ist für die Berücksichtigung auch dieses geographischen Elementes mit Beibringung mathematischer Motive eingetreten [69].

§. 3. Seebeben und Erdbebenfluthen. Wir sahen bereits oben, dass der Meeresgrund ebensowenig, wie das Festland, als vor Erschütterungen gesichert betrachtet werden darf. Wenn Schiffe bei ruhiger See heftig zu schwanken beginnen, wenn das umgebende Wasser aufzischt, Blasen treibt und Gasgerüche aushaucht, wie diess alles bei dem grossen peruanischen Erdbeben vom 30. März 1828 im Hafen von Callao beobachtet worden sein soll, so muss man wohl an einen submarinen Gasausbruch oder dergleichen denken [70]. Solche eigentliche Seebeben im engeren Sinne sollten, strenge genommen; nicht zusammengeworfen werden mit den gigantischen Fluthen, welche im Gefolge eines jeden litoralen Erdbebens aufzutreten pflegen. Indess kann diese 
Unterscheidung wohl nur in den seltensten Fällen wirklich gemacht werden, wie denn auch der in seinen Klassifikationen so genaue v. Sonklar beide Phänomene unter einem gemeinsamen Gesichtspunkte zusammenfasst. „Wird durch ein starkes Erdbeben, " sagt er [71], „gleichviel ob dessen Centrum nahe der Küste oder von derselben entfernt, immer aber im Bereiche des Meeres liegt, der Boden des letzteren heftig erschüttert, so wird der Gleichgewichtszustand der Wassermasse plötzlich und, je nach der Stärke der Erschütterung, nicht selten in einem Grade gestört, der für die Küsten und für die Menschen, die da wohnen, von den zerstörendsten Folgen begleitet ist. Das Meer geräth dabei in eine heftige oscillirende Bewegung, die alle Tiefen desselben ergreift, sich durch eine der gewöhnlichen Fluth ziemlich nahe kommende Geschwindigkeit der Fortpflanzung, sowie durch eine radienförmige Ausbreitung nach allen Richtungen bis zu den entferntesten Gestaden des betroffenen Meeres auszeichnet." Dass der wahre Stosspunkt weiter drinnen im Festlande liegen und doch ein solches Erdbeben gleichfalls eine Hochfluth nach sich ziehen sollte, glaubt v. Sonklar [72] in Abrede stellen zu müssen. Die Geschichte lehrt uns Ereignisse dieser Art in Menge kennen, und der genannte Forscher hat alle Mittheilungen darüber mit Sorgfalt aufgezeichnet (a. a. O.). Strabon war sehr geneigt, die Wirkung von Erdbebenfluthen in Meerengen und Landeinschnitten zu erkennen, wie er denn nach H. Fischer [73] sowohl den Durchbruch des Thales Tempe, als auch jenen des Bosporus auf Erdstösse zurückführt, die allgemein-dynamischen Lehren des Lampsaceners Straton (vgl. die Einleitung) nach einer bestimmten Richtung hin präcisirend; vielleicht hat ihn auch sein anerkannter geographischer Scharfblick richtig geleitet, da die Grenzlinie zwischen Asien und Europa in jener Gegend wirklich mit dem Rande einer Schütterzone zusammenfällt. Thukydides führt den plötzlichen Rückgang und den darauf folgenden Wiederandrang der See, wodurch 425 v. Chr. die Insel Euböa betroffen wurde, wohl mit Recht auf ein Erdbeben zurück [74]. จ. Hoff berichtet [75], dass im Jahre 1510 eine Erdbebenfluth in Konstantinopel 109 Moscheen und 1070 Häuser mit sich fortgerissen habe. Auch bei'm Lissaboner Erdbeben wurden weit furchtbarere Verwüstungen, als durch die eigentlich seismischen Wirkungen, durch den plötzlichen Eintritt einer $26 \mathrm{~m}$ hohen Meereswoge in den Tejo herbeigeführt. Vorder- und Hinterindien kennen derartige Katastrophen, wie wir weiter unten sehen werden, nur zu gut, doch reicht kein Land der Erde in dieser Beziehung an die südamerikanische Westküste heran, wo z. B. am 28. Oktober 1746 die Hafenstadt Callao vollständig von der Oberfläche weggefegt ward. Die Worte „el mar se retire" genügen bei den bekanntlich sehr häufigen Erdbeben von Peru und Chile, um das Volk zu veranlassen, alle etwaigen Rettungsarbeiten einzustellen und die schleunige Flucht zu ergreifen, denn die Erfahrung hat gelehrt, dass eine solch' unnatürliche Ebbe in kürzester Frist mit riesenhaften Fluthbergen abwechselt. Wir besitzen seit einigen Jahren gehaltvolle monographische Schilderungen solcher Erdbebenfluthen; so beschrieb Griesbach (76) die Katastrophe von Arica und Tacna (13. August 1868), bei welcher an jeden der drei Einzelstösse auch ein Ueberfluthen der Küste sich anschloss, und Geinitz [77] sammelte alle Nachrichten 
über das Erdbeben von Iquique in Peru (9. Mai 1877), wo acht Sturzwellen nacheinander über diese unglückliche Hafenstadt sich ergossen. In letztgenanntem Falle scheint an ein wirkliches Seebeben gedacht werden zu müssen, wenigstens formulirt Geinitz die aus den Korrespondenzbeobachtungen gezogenen Resultate in folgendem Satze: „An den Orten, welche von der stärksten Erschütterung gleichzeitig betroffen wurden, also an den Orten innerhalb des Kreises des ersten und stärksten Stosses, trat auch die Fluthbewegung des Oceans zuerst und gleichzeitig auf. Freilich gehen auch hier die Angaben, sowohl betreffs der Zeit, als auch in Bezug auf die Art und Weise der Bewegung, ob sie nämlich mit einer Welle, oder einem Rückzug der See begonnen, vielfach auseinander. Es ist nicht möglich, aus der Kombination der Orte, an denen die Fluth gleichzeitig auftrat, durch isorachische Linien*) sich das Centrum, von dem die Bewegung ausgieng, zu konstruiren. Soviel erscheint als sicher, dass das Centrum des Erdstosses, und mithin auch die Fluthwellen, nicht auf dem festen Lande, sondern einige Seemeilen (vielleicht 50 ?) westwärts von der Küste und zwar südwestwärts von Iquique gelegen war. ${ }^{\text {" }}$

An diese peruanische Erdbebenfluth hat sich eine längere theoretisch-polemische Auseinandersetzung geknüpft. Graf Berg vermisste[78] in Geinitz's Schrift die ausreichende Kausalerklärung des Vorganges; Ch. Darwin's Hinweis auf einen Aufsaugungsprocess des Wassers [79] befriedigte ihn begreiflicherweise auch nicht, und so entschied er sich (a. a. O.) für eine durch das Erdbeben bewirkte instantane Hebung der Küste, welche das Niveau des Meeres heftig beeinträchtige. Nach dem, was oben (§. 2) iiber die seismisch-rhapsodischen Schwankungen der südamerikanischen Westküste ausgesagt wurde, fehlt für Graf Berg's Auffassung der Sache der eigentliche thatsächliche Untergrund. Dem gegenüber hielt Geinitz [80] daran fest, dass eine durch submarine Stösse ausgelöste Wellenbewegung des Meeres eine zutreffendere Erklärung liefere, und uns erscheint dieser Modus auch jetzt noch als der natürlichere, obwohl Graf Berg [81] in umfänglicher Replik nochmals für seine Theorie eintrat. Abweichend von beiden führt der Amerikaner Rachel die Bildung der Fluthwelle auf eine Senkung des Meeresbodens zurück [82].

Es versteht sich, dass für das Fortschreiten der Erdbebenwellen im Weltmeere ganz dieselben Normen gelten müssen, welche die Physik überhaupt für die Wellenbewegung als gültig erkannt hat. Ausser Geinitz selbst haben sich noch Birgham [83] und ganz besonders v. Hochstetter [84] mit den Fortpflanzungsverhältnissen der seismischen Wogen beschäftigt; ja der letztere hat sogar gezeigt, dass man vermittelst der von Bache und Airy entwickelten Formel $h=v^{2}: g$ (h Tiefe des Gewässers, in welchem sich Wellen mit der Geschwindigkeit $\mathrm{v}$ verbreiten, $\mathrm{g}=9,80896 \mathrm{~m}$ ) einen ungefähren Schluss von jenen Verhältnissen auf die durchschnittliche Tiefe der betreffenden Meere machen kann. Unsere Figur 74 giebt nach den Ermittelungen des berühmten österreichischen Geologen ein Bild davon, wie die Erdbebenwelle das pazifische Weltmeer durchlief, indem alle Orte, welche

*) Isorachieen nennt Whewell jene Kurven, welche die Punkte gleicher Gezeitenphase (höchste Fluth oder tiefste Ebbe) auf der Erdoberfläche verbinden. 
von ersterer $\mathrm{n}(=1,2,3 \ldots 19)$ Stunden nach dem Eintreten der peruanischen Katastrophe erreicht waren, durch einen Kurvenzug mit einander in Verbindung gebracht wurden. Diese Linien gleicher

Fig. 74.

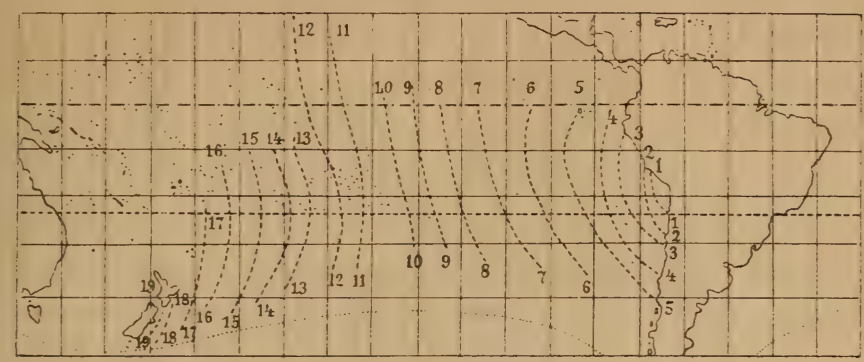

Erdbebenfluthphase haben im freien Ocean, wie es die Theorie fordert, eine angenähert kreisförmige Gestalt, die erst von dem Momente an Verzerrungen erleidet, in welchem die Wellen bei'm Eintritt in einen der zahlreichen polynesischen Inselarchipele Brechungen und Beugungen erleiden. Die Tonga- und Viti-Gruppe löschten in Verein mit dem quer sich vorlegenden neuseeländischen Landmassiv die Bewegung förmlich aus, so dass weiter westlich nichts mehr von derselben zu verspüren war. Sowohl die Mareographen, als auch, was noch merkwürdiger, die Barographen der alten und neuen Welt markirten vom 27. August 1883 an deutlich die oceanischen und atmosphärischen Wellen, welche von dem Erdbeben in der Sunda-Strasse ausgiengen. General Strachey ist zur Zeit mit der Sichtung des Materiales beschäftigt.

Neuestens hat Suess mit Aufgebot höchster - geophysikalischer sowohl wie linguistischer - Gelehrsamkeit den Zusammenhang zwischen den Erdbeben und den Sintflutherzählungen der verschiedenen alten Nationen in's richtige Licht zu setzen unternommen [85]. Unterstützt von hervorragenden Assyriologen hat er den Keilschriftbericht des sogenannten „Izdubar-Epos", welches eine auffallende Aehnlichkeit mit der noachischen Legende bekundet, näher geprüft und dargethan, dass als primäre Ursache der dort beschriebenen Ueberschwemmung Mesopotamiens ein vermuthlich von Drehstürmen begleitetes Erdbeben im Gebiete des persischen Meerbusens anzusehen sei [86]; das Alluvionenterrain des Euphrat und Tigris begünstigte wesentlich das sicher bezengte Hervorsprudeln des Wassers aus der Tiefe. Suess erklärt diese auffallende Erscheinung in folgender Weise [87]: „Dieses Hervortreten grosser Wassermassen aus der Tiefe ist ein Phänomen, welches in bezeichnender Weise die Erderschütterungen in den Alluvialgebieten grosser Flüsse begleitet. Es breitet sich in diesen grossen Flächen zu beiden Seiten des Stromes weithin das Grundwasser in den jungen Ablagerungen aus, und seine obere Grenze steigt allmählig gegen rechts und gegen links mit der Entfernung vom Strome mehr und mehr über den Stand des Mittelwassers. Was unter dieser Grenze liegt, ist durchfeuchtet und beweglich; der Boden über derselben ist trocken und brüchig. Treten nun seismische Undulationen in solches 
Gebiet, so bricht der obere spröde Theil des Bodens in langen Spalten auf, und aus den Brüchen tritt gewaltsam bald in grossen Massen, bald in vereinzelten, selbst mehrere Meter hohen Strahlen das Grundwasser rein oder als schlammige Masse hervor." Ganz die gleiche Grundursache war im Spiele, als (1827) ein beträchtlicher Theil des sogenannten Ran of Kachh im Meere versank; es soll bei diesem Anlass auch ein riesiger Damm, der „Ullah-Bund“ oder Gottesdamm genannt, aus dem Boden gestiegen sein und dem übrigen Lande zur Rettung gedient haben. Suess hat, auf Grund der Berichte von Burnes und Wynne, den Sachverhalt näher geprüft und gefunden [88], dass der Ullah-Bund gar kein wirklicher Damm, sondern nur eine natürliche Bodenterrasse ist, über welche hinaus das Grundwasser nicht genügend weit vorgedrungen war, um auch die dahinter liegenden Landstrecken ebenso, wie das angeschwemmte Vorterrain, unterspülen und bei'm Eintritte des Erdbebens mit sich fortreissen zu können. Oberhalb des Gottesdammes waren eingreifende geologische Veränderungen des Indus-Delta's nicht zu konstatiren.

§. 4. Anzeichen und Schutzmittel. So ziemlich Alles, was sich über die etwaige Vorausbestimmung .von Erdbeben und über die Mittel der Abhülfe gegen deren unheilvolle Folgen aussagen lässt, hat Favaro in seinen beiden uns aus $\S .1$ bekannten Monographieen gesammelt, welche uns denn auch jetzt zur hauptsächlichsten Vorlage dienen. Nach den übereinstimmenden, dadurch aber freilich noch lange nicht zuverlässigi gewordenen Nachrichten römischer Schriftsteller, welchen sich auch später der Kirchenhistoriker Eusebius anschloss, soll Anaximander die Spartaner vor einem bald nachher eingetretenen Erdbeben gewarnt haben und Diogenes Laertius schreibt eine gleiche Prophetengabe dem Pherekydes zu [89]. Anno 1343 machte der auch mit dem exakten Wissen seiner Zeit wohl vertraute Dichter $\mathrm{Pe}$ trarca dem Kardinal Colonna die Mittheilung von einer geglückten Erdbebenprognose [90]: „Praevenerat quidem, mirum dictu! instantis mali fama, religioso quodam episcopo, astrorumque curioso, e vicina quadam insula aliquot ante diebus periculum nuntiante: sed ut fere nunquam conjecturis ad verum penetrant, non maritimum sed terrestrem motum praeâixerat, ruituramque Neapolim a. d. septimum calendis

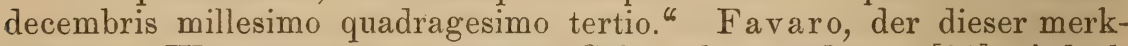
würdigen Weissagung ein eigenes Schriftchen widmete [91], jedoch eben auch nur die geschichtliche Wahrheit der Thatsache, nicht aber deren seismologischen Grund festzustellen in der Lage war, lässt uns die Wahl, in dem himmels- und erdkundigen Geistlichen einen Bischof Jakob von Capri oder Wilhelm von Ischia zu erblicken. All' diese Nachrichten zwingen uns zwar die Stellung der Frage auf, ob es überhaupt Anzeichen für eine regelrechte Erdbebenprognose gäbe, sie führen uns aber der Lösung dieser Frage in keiner Weise näher. Wenn Teloni behauptet, Anaximander habe aus der Betrachtung der Gestirne, Anaximenes aus dem Vogelfluge, Pythagoras endlich aus dem Geschmacke des Brunnenwassers seine Prophezeiungen geschöpft [92], so ist diess offenbar wenig mehr, als leeres Gerede ohne Hintergrund.

Höchstens die Wasserzeichen, wie sich Cantor in seiner Rezension des ersten Werkchens von Favaro (Beil. z. allg. Zeit. vom 
18. August 1875) ausdrückt, verdienen vielleicht als wirkliche prognostische Merkmale nicht ganz und gar von der Hand gewiesen zu werden. Wenn wir auch gar nichts über die Art und Weise der Wasserbeobachtung eines Pythagoras und Pherekydes wissen, so fehlt es uns doch nicht an bestimmter lautenden Angaben anderer Autoren. Plinius z. B. behauptet [93], dass das Wasser der Brunnen vor und nach dem Erdstosse Veränderungen aufweise, und nach Favaro [94] wird Analoges von Sguario und dem Bologneser Mönch Augusti bezeugt. Cardanus, bei allen Excentricitäten doch ein kluger Kopf und scharfer Beobachter, sagt hierüber [95]: ${ }_{>}$Cum aquae puteorum sulphur metallicumve aliud redolent, aut titubant, aut turbantur, aut incalescunt, aut picantur praeter actionem, terrae motum imminere praenuntiant. " Ein hervorragender französischer Physiker, HervéMangon, verfestigte diese immer noch schwankende Theorie dưch Beobachtungen, welche er am artesischen Brunnen zu Passy anstellte, und welche an Tagen, deren Verlauf in weit entfernten Ländern, z. B. in der Schweiz, durch ein Erdbeben gekennzeichnet war, eine auffallende Trübung des Wassers ergaben [96]. Taramelli bestätigt diese Wahrnehmung, gestiitzt auf seine in Belluno gemachten Erfahrungen. Favaro macht deshalb [97] ganz mit Recht den Vorschlag, ein ausgedehntes System physikalisch-chemischer Quellen- und Brunnenuntersuchung in's Leben zu rufen, damit die Möglichkeit, aus den Wasserzeichen wirklich brauchbare Kriterien für die Prophezeiung von Erderschütterungen zu gewinnen, näher erforscht und an Stelle vager Hypothesen eine Anzahl beglaubigter Thatsachen gesetzt werde*).

$\mathrm{Ob}$ Elektricität und Magnetismus in irgendwelcher ursächlicher Beziehung zu den Erdstössen stehen, wissen wir nicht mit Bestimmtheit. Kurz vor dem Lissaboner Unglück sollen zwar in verschiedenen physikalischen Kabineten Europa's die Anker von den Hufeisenmagneten abgefallen sein, welch' letztere sonach plötzlich an ihrer Koercitivkraft eingebüsst haben müssten. Dem gegenüber behauptete A. Bertrand bestimmt, es gebe weder meteorologische, noch magnetische Vorzeichen, und die Unruhe der Deklinationsnadeln während des Aktes selber sei eine ganz mechanische Folge des Stosses [100]. Immerhin will Quetelet [101] die — seltenen - Erdbeben Belgien's stets von elektrischen und magnetischen Unregelmässigkeiten begleitet gefunden haben, und auch Serpieri [102] hat mancherlei Material in diesem Sinne gesammelt. Favaro endlich berichtet [103] nach Rouvet von Störungen der Telegraphenleitungen, welche im September 1875 auf

*) Man darf, wenn man Beziehungen zwischen seismischen und hydrologischen Erscheinungen ausmitteln will, wohl auch an die mancherlei von glaubwürdigen Zeugen berichteten Schwankungen des Wasserstandes erinnern, welche Erdstösse auf weit entlegenem Gebiete zur Folge hatten. In Kant's "Geschichte und Naturbeschreibung der merkwürdigsten Vorfälle des Erdbebens, welches an dem Ende des MDCCLV. Jahres einen grossen Theil der Erde erschüttert hat", wird gemeldet [98], dass das Niveau der Seen von Como und Neufchatel, sowie eines kleinen Landsee's bei Meiningen damals in zuerst unerklärlicher Weise sank, dass ferner die Teplitzer Thermalquellen plötzlich versiegten, um sodann blutroth und mit Schlamm versetzt wieder hervorzusprudeln. Und W al te n berger berichtet [99]: "Der Hechtsee (bei Kufstein) gerieth ebenso wie der Achen- und Walchensee in heftige Wallung an dem Tage, an welchem das Erdbeben zu Lissabon stattfand." 
der Insel Martinique in Begleitung einer Erderschütterung aufgetreten seien. Künftiger Forschung eröffnet sich hier ersichtlich noch ein weites Feld.

Dass meteorologische Anomalieen mit Erdbeben Hand in Hand giengen, ist zwar nicht selten behauptet, niemals aber bewiesen worden, und Kries glaubte jede Beziehung dieser Art vollkommen leugnen zu müssen [104]. In Italien hat sich über diese Frage jüngst eine lebhafte Diskussion zwischen den Fachmännern entsponnen. Monte erklärte [105], ein erkennbarer Parallelismus im Gange des Barometers, Anemometers und Erdbebenmessers sei nicht nachweisbar; Bertelli dagegen wollte die von ihm bemerkten mikroseismischen Bewegungen als nur graduell von den Erdstössen verschieden anerkannt wissen und widersetzte sich [106] Monte's Versuch, jene leisen Erzitterungen aus der Elasticität des Bodens und aus der verschiedenen Erwärmung der Luftschichten abzuleiten. Melzi endlich trat auf Bertelli's Seite, indem er sich auf seine Bearbeitung von 700 Anemometermessungen stützte [107]. Auch hier ist's noch lange nicht an der Zeit, irgend ein abschliessendes Urtheil zu fällen. Jul. Schmidt in seinen „Erdbebenstudien " ist nicht abgeneigt, einer gewissen Abhängigkeit der Erschütterungen vom Barometerstande das Wort zu reden. Nicht minder, wie die Meteorologie als solche, hat auch deren Theildisciplin, die meteorologische Optik, prognostische Kriterien liefern sollen. So wollte Gemma Frisius das Erdbeben vom Januar 1563 auf Grund eines eigenthümlichen Aussehens der Sonne während der vorausgegangenen Weihnachtstage prognosticirt haben [108]. In Kant's uns bereits bekannter Abhandlung vom Lissaboner Erdbeben ist zu lesen [109], dass man als Vorboten des letzteren eine am 14. Oktober 1755 zu Locarno am Lago maggiore gesehene Lichterscheinung betrachtete; es erhob sich ein rother Dampf, aus welchem rother Schnee herabfiel, und an diesen Schneefall reihten sich furchtbare Regengüsse an. Näheres über atmosphärisch-optische Vorzeichen enthält ein Aufsatz von Fron [110]; wie ungemein prekär die Sache ist, brauchen wir aber nicht erst besonders hervorzuheben.

Kaum besser steht es mit den Versuchen, astronomische Vorgänge mit den Erdbeben zu parallelisiren und für letztere eine periodische Wiederkehr zu eruiren. Soweit die Anziehung des Mondes und der Sonne dabei in Frage kommt, verweisen wir auf §. 9. Dagegen muss jetzt schon ein Wort über das angebliche Wechselverhältniss zwischen den seismischen Erscheinungen und der uns aus Kap. II, §. 6 der ersten Abtheilung bekannten elfjährigen Periode der Sonnenflecke eingeschaltet werden. Wie wenig bei solchen Vergleichen auf sichere Ergebnisse zu zählen ist, mag uns der Eine Umstand lehren, dass Poëy [111] der stärkeren und Kluge [112] der schwächeren Bedeckung der Sonne mit Flecken eine Zunahme der vulkanisch-seismischen Thätigkeit auf der Erde entsprechend gefunden haben will. Fritz, dem man gewiss keinen allzugrossen Skepticismus nach dieser Richtung hin vorwerfen kann, scheint trotzdem irgendwelchen $\mathrm{Zu}$ sammenhang zwischen tellurischer und solarer Aktion nicht für erwiesen zu halten [113].

Wir überzeugen uns, dass es mit zuverlässigen Kennzeichen, aus denen der Eintritt seismischer Ereignisse entnommen werden könnte, 
überaus schlecht bestellt ist. Die Unruhe und Angst der Thiere, welche für schwache einleitende Stösse vielleicht ein feineres Gefühl haben mögen, ist allerdings ein Faktor, mit welchem bis zu einem gewissen Grade gerechnet werden kann; so glauben die Cubaner nach Knapp [114], dass die von ihnen als Familiengenosse geschätzte zahme Hausnatter (Majitá domestica) vor Ausbruch eines Erdbebens die Häuser zu verlassen und auf's freie Feld sich zu flüchten pflege. Pilar that auch ganz wohl daran, in seinem Fragebogen (s. §. 1) sorgfältige Beobachtung der Hausthiere dringend anzuempfehlen. Man darf aber nicht vergessen, dass das Verhalten der Thierwelt keineswegs nur den Erdbeben, sondern überhaupt jeder aussergewöhnlichen Naturerscheinung gegenüber das nämliche ist. So berichtet Mädler von den totalen Sonnenfinsternissen, welche er 1851 zu Brest-Litowsk und 1860 zu Vitoria beobachtete, dass eine hochgradige Verwirrung gerade der zahmen Thiere sich bemächtigte $[115]^{*}$ ).

Die Schallphänomene endlich, die nicht selten einem Erdbeben vorausgehen und dasselbe begleiten - man vergleiche darüber die Angaben A. v. Humboldt's [117] und v. Seebach's [118] -, sind nichts weniger als ein untrüglicher Vorbote. So weiss man [119], dass in der Nähe der mexikanischen Bergstadt Guanaxuato sich hie und da ein furchtbares unterirdisches Gebrüll („bramidos y truenos subterraneos") vernebmen lässt, welches die Bewohner zur Flucht veranlasste und gleichwohl noch niemals von wirklichen Stössen gefolgt war. Sorgfältige Beachtung hat diesen Tönen Jul. S ch midt geschenkt, als er den Vulkan von Santorin untersuchte; im Berichte [120] wird

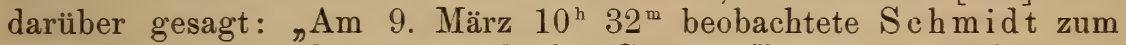
erstenmale das wahre unterirdische Getöse (Rombo, Ruido oder Bramido), bei dem jede Angabe der Richtung unmöglich ist. Dasselbe wiederholte sich am 10. März mehrmals nach vorausgegangenem Rauchen und Brausen, ebenso in den darauffolgenden Tagen. Von grossem Interesse sind die viel- und sorgfältigen Unterscheidungen der vulkanischen Töne, welche Schmidt macht: Brausen, Heulen, Orgelton, Pfeifen, Rollen, Donner, Lärm, Gurgeln, Brüllen."

Jene Schutzmittel also, welche der Mensch erst dann anzuwenden hätte, wenn er die Gefahr einer seismischen Katastrophe sicher im Anzuge weiss, sind nach dem gegenwärtigen Stande unseres Wissens ziemlich bedeutungslos. Es fragt sich aber, ob es nicht noch anderweite Schutzvorrichtungen gebe, die ein für allemal angebracht werden und ganzen Landkomplexen oder doch wenigstens einzelnen Gebäulichkeiten eine relative Sicherheit gewährleisten könnten. Bereits die Alten haben solche Möglichkeiten recht reiflich erwogen. Plinius erklärte [121] , aedificiorum fornices" für die besten Zufluchtsörter; Städte mit wenig solider Fundamentirung, wie Venedig, oder aber mit recht vielen Gewölben und Kellerlöchern würden sich hiernach einer gewissen Immunität erfreuen. Der genannte Römer schreibt eine

*) Was die Prophezeiungen des französischen Kapitäns Delaunay (nicht zu verwechseln mit dem bekannten Mathematiker) anbetrifft, welchen zufolge die Jahre 1883 und 1886 durch Kataklysmen sich auszeichnen sollten, so hat ein von F aye der Pariser Akademie über erstere erstatteter Bericht denselben jeden wissenschaftlichen Werth abgesprochen [116]. 
solche dem Artemistempel zu Ephesus zu [122]. Die Stadt Capua soll in ähnlicher Weise durch die grosse Anzahl der in ihr und um sie herum angebrachten Brunnen gesichert gewesen sein. Favaro, der sich in längerer Ausführung über die antiseismische Bedeutung der Brunnen von Udine verbreitet [123], berichtet auch [124] von analogen Angaben Fromond's und Genestri's und schildert eingehend den von einem ungenannten Erdbebenforscher ausgegangenen Versuch, die Nützlichkeit subterraner Hohlräume physikalisch zu erklären [125]. Aus einer Stelle im Varro scheint übrigens hervorzugehen, dass die ganze Idee auf etruskischem Boden erwuchs, wo ja von jeher physische Mysterien gehegt worden sind [126].

Am gleichen Orte giebt Plinius den Rath, die für ein und denselben Ort im Wesentlichen konstante Richtung der Erdstösse zu ermitteln und in diese Richtung die Längsaxen neu anzulegender Gebäude zu verlegen. Mit ersterer Behauptung hat es nach Serpieri seine Richtigkeit, obwohl es natürlich an Ausnahmen nicht mangelt [127]. Ein gewisser Sguario gedachte auf dieser Annahme mathematische Vorschriften aufzubauen; eine seiner "regulae architectonicae" lautet z. B., wie folgt [128]: "Ut nempe, bini oppositi parietes cujuslibet aedificii omnino aequales, cum figura, numero, magnitudine et situ fenestrarum, januarumque tum crassitie, delectu et distributione fictilium saxorum, et laterum compinguntur, ut inde ratum sit, utriusque muri centrum gravitatis aequabiliter a solo distare. ${ }^{\star}$ Wer sich genauer über den gewiss merkwürdigen Gegenstand unterrichten will, den verweisen wir auf die erschöpfenden Spezialstudien von Favaro [129], aus welchen wir hier nur einiges Wenige anführen können. De Rossi's Gesetz [130] ( allo scotimento di una linea di frattura segue l'ondulazione trasversale de' suoi labbri“) giebt ihm die Mittel an die Hand, verständige Rathschläge für die Orientirung der Häuser innerhalb eines habituellen Stossgebietes zu ertheilen. Dass mit diesen Rathschlägen auch etwas geleistet werden kann, beweist das Beispiel Casamicciola's. Dort befanden sich bis zum 4. März 1881, an welchem Tage das erste Erdbeben (s. o. §. 1) eintrat, zwei genau in Bauart und Anlage mit einander übereinstimmende Kirchen; nur lief bei der einen die Hauptaxe den Bruchlinien parallel, bei der anderen stand sie darauf senkrecht. Die erstere blieb erhalten, die letztere sank in Trümmer [131]. Die Japaner, von deren richtigem Verständniss für seismologische Dinge wir bereits zu sprechen hatten, waren schon früher, wie Favaro zeigt [132], an die Frage der Auffindung architektonischer Schutzmassregeln herangetreten; ein französischer Ingenieur, Lescasse, hat dieselben an Ort und Stelle einem gründlichen Studium unterzogen und systematische Folgerungen daraus abzuleiten gesucht [133]:

In seinen geschichtlichen Nachweisungen kommt $F$ a va ro auch[134] auf die gegen Ausgang des vorigen Jahrhunderts vielfach angepriesenen Erdbebenableiter zu sprechen, deren Wertb natürlich ein rein fiktiver ist. Priestley dachte an hochfliegende Drachen, um einen Ausgleich zwischen Luft- und Erdelektricität herbeizuführen, Vivenzio stellte sogar die "Para-tremuoti“ und "Para-volcani“" als gleichberechtigt neben die "Para-tuoni“. Am einlässlichsten beschäftigten sich mit dieser sonderbaren Lehre der Philanthrop Bertholon de St. Lazare [135] und der deutsche Physiker Wiedeburg [136]. 
Bis zu welchen Ungereimtheiten die Phantasie sonst gescheidter Männer sich verstieg, beweist aber besonders klar das Beispiel des Göttinger Philosophen Hollmann, der die Erdrinde an vielen Stellen durchbohren und so dem im Inneren der Erde wüthenden Feuer einen gefahrlosen Abzug verschaffen wollte. In dieser Form hat uns wenigstens Kant [137] die Idee seines Fachgenossen überliefert.

§. 5. Seismographen und Seismometer. Die italienischen Forscher der neuesten Zeit, De Rossi, Palmieri, Serpieri u. s. w., scheinen übereinstimmend der Ansicht zu sein, dass sorgsame Beobachtung und Registrirung auch der schwächsten Erzitterungen des Bodens immer noch die meiste Gewähr für die rechtzeitige Warnung vor grösseren Erschütterungen biete. Es kommt also darauf an, solche Apparate zu konstruiren, die entweder blos überhaupt ein Schwanken des Bodens erkennen lassen (Seismographen) oder auch gleichzeitig die Möglichkeit einer messenden Verfolgung des ganzen Vorganges gewähren (Seismometer). Es ist auch kein geringes Maass von Scharfsinn an die Verfertigung brauchbarer Apparate dieser Art gesetzt worden, doch ist das Ziel noch lange nicht erreicht. Mit J. Roth ,kann man aussprechen: die roheren Instrumente genügen nicht, die sehr feinen sind sehr theuer und bedürfen der Ueberwachung, es fehlt an allgemein einführbaren, billigen und dabei sicheren und genauen Apparaten" [138]. Wir beschreiben im Folgenden einige der bekannteren Vorrichtungen, ohne auf Vollständigkeit Anspruch zu machen. Von Hengler's Schwungwage und Zöllner's Horizontalpendel sprechen wir nicht mehr ausdrücklich, obwohl nach seines Erfinders Angabe letzteres nur zu empfindlich auf Bodenerschütterungen reagirt; als es im Keller der Leipziger Universität angebracht war, gab es stets dann einen starken Ausschlag, wenn eines der im Hause befindlichen Kollegienzimmer sich zu füllen begann [139]. Unsere Aufzählung ist der Hauptsache nach eine chronologische.

a) Salsano's Pendel. Ueber diese Pendelvorrichtung eines neapolitanischen Mechanikers liegt uns nichts vor als ein Bericht Muncke's, der sich sehr abfällig äussert [140]. Ein schweres Gewicht soll an einem sehr langen Faden aufgehängt und an seinem unteren Ende mit einem Pinsel versehen werden, durch welchen auf einer unterlegten Strichrose von Papier die Schwingungsrichtungen aufzuzeichnen wären.

b) Cacciatore's Seismograph. Wir entlehnen unsere Mittheilungen hierüber dem Werke von A. Jakob [141]. Eine flache, kreisrunde Schale ist mit Quecksilber gefüllt und mit acht äquidistanten Löchern versehen, deren jedes in ein kalibrirtes Gefäss von bestimmter Grösse mündet. Die Schale wird nach den Weltgegenden orientirt. Auch ein leiser Stoss wird bewirken, dass sich die Schale nach einer bestimmten Seite senkt, und wenn man also z. B. nachher findet, dass z. B. in dem gegen Südwesten stehenden Auffangglase am meisten Flüssigkeit sich befindet, so hielt der Erdstoss offenbar im Ganzen die Richtung Nordost-Südwest ein. Eigentliche Messungen sind auf diese Weise jedoch wohl niemals angestellt worden, und $\mathrm{Humboldt}$, der die vollkommeneren Methoden der experimentellen Seismologie nicht mehr erlebte, durfte mit Recht sagen [142]: „Die Erschütterungswellen werden durch Pendel und Seismometer-Becken ziemlich genau 
in ihrer Richtung und totalen Stärke, keineswegs aber in der inneren Natur ihrer Alternanz und periodischen Intumescenz untersucht. ${ }^{\text {" }}$

c) Mallet's Säulen-Apparat. Man lasse sich aus Marmor oder Eisen kleine Säulen anfertigen, deren Höhen gleich sind, während die Durchmesser ihrer Grundflächen in arithmetischer Progression wachsen. Aus diesen Cylindern bilde man zwei auf einander normal stehende Reihen, die auf fester Basis stehen, während rings herum lockerer Sand aufgeschüttet ist. Die umgefallenen Säulchen ergeben die Stossrichtung ziemlich genau [143].

d) Palmieri's Erfindungen. Das Observatorium des Vesuv ist bekanntlich mit Instrumenten ganz nach Palmieri's eigener Angabe ausgerüstet. Ausser einer Schrift des Direktors selbst [144] ist auch der schöne Bericht Peschel's [145] über seinen Besuch in jener Anstalt zu vergleichen. Die Signalisirung von Erdstössen erfolgt nach dreierlei verschiedenen Maximen, doch wird jeder Zeitverlust dadurch vermieden, dass sich auf einem Tische in Mitte des Beobachtungszimmers die drei nach den Instrumenten I, II, III gerichteten Fernrohre befinden. Nummer I ist eine gewöhnliche, horizontal schwingende Magnetnadel, Nummer II eine Inklinationsnadel, Nummer III endlich eine Stahlnadel, welche durch zwei geeignet angebrachte Magnete in einer bestimmten Richtung festgehalten wird. Jedes Fernrohr ist mit einer Poggendorff'schen Spiegelablesung versehen, welche die unablässigen kleinen Oscillationen der Nadeln zu verfolgen gestattet. Für gewöhnlich versieht ein Gehülfe den laufenden Dienst, und der Vorstand, der in Neapel seinen Lehrpflichten obzuliegen hat, wird erst dann telegraphisch herbeigerufen, wenn die nicht magnetische Nadel in lebhaftere Schwingungen geräth. Um die einzelnen kleineren Erdstösse sich selbst registriren zu lassen, ist ein Chronometer im Thurme der Warte mit einer galvanischen Batterie derartig verbunden, dass der Strom bei'm leisesten Erzittern des Hauses intermittirt und so die Uhr zum Stehen bringt. Im gleichen Augenblicke wird ein Anker angezogen und dadurch, ähnlich wie bei'm Morse'schen Telegraphen, auf einem abrollenden Papierstreifen ein Punkt markirt. Horizontale Stösse zu fixiren, dient eine Cacciatore'sche Schale, nur mit 16, statt, wie sonst, mit 8 Löchern versehen; um aber auch der vertikalen Komponente der seismischen Bewegung gerecht zu werden, bedient sich Palmieri eines Spiraldrahtes, der oben an einem Messinggalgen befestigt ist und am unteren Ende einen kleinen Magnetkörper trägt; im Ruhezustande schwebt dieser genau oberhalb eines mit Feilspänen gefüllten Napfes. Der geringste vertikale Ruck genügt, um den Magneten in die Späne hineintauchen zu machen, und sowie man diese wieder abgenommen hat, ist auch schon wieder die Adjustirung beendet.

e) v. Seebach's Uhrhemmung. „Eine beliebige gut gehende Uhr, welche auch Sekunden zeigt, wird auf 0 Zeit gestellt. Das Pendel wird aus seiner Gleichgewichtslage gebracht und in seiner Stellung festgehalten dadurch, dass der um ein Geringes schwerere Arm eines Hebels hemmend in das Steigrad eingreift. An dem anderen leichten Hebelarme hängt an einem schlaffen Faden ein Gewicht, welches auf einer kleinen Säule von geringer Stabilität aufliegt. Bei einem Erdbeben wird die Säule umgestürzt werden, das Gewicht fällt und löst einen schweren Hebelarm aus dem Steigrad aus, wodurch dann das 
Pendel schwingen und die aufgezogene Uhr den Eintritt des Stosses anzeigen kann" [146]. Diese Art von Seismometer beschränkt sich sonach auf genaue Bestimmung des wichtigen Zeitelementes. Gleiches $\mathrm{zu}$ leisten ist bestimmt

f) Kreil's Registrirtrommel. Ein Schreibstift zeichnet auf einer rotirenden, berussten Trommel eine Kurve, deren Diskontinuitäten auf einen Erdstoss schliessen lassen [147].

g) v. Lasaulx's Seismochronograph. Eine kleine schwere Kugel drückt in der Ruhelage so auf eine Feder, dass deren Axe mit dem vertikalen Durchmesser der ersteren Eine Gerade bildet. Ein Erdstoss bringt sie aus dem labilen Gleichgewicht, sie rollt in einen der Einschnitte des umgebenden Holztellers und charakterisirt dadurch, ähnlich, wie bei Cacciatore, die Stossrichtung. Gleichzeitig aber arretirt ein an der Feder befestigter Hebelarm das Pendel einer daneben stehenden Uhr, welche sonach genau den Moment der ersten Erschütterung angiebt [148].

h) Bertelli's Tromosismometer. Derselbe besteht nach des Erfinders eigener Darlegung aus folgenden drei Theilen [149]: dem seismoskopischen Indikator, einem elektrischen Läutewerk, dem Isosismometer zur Messung der horizontalen und dem Orthosismometer zür Messung der vertikalen Komponente eines Stosses. Hauptbestandtheil des Isosismometers ist ein Pendel, dessen Linse die mikrosismischen Bewegungen macht; dieselben werden mit Hülfe eines total reflektirenden Prismas mikroskopisch beobachtet und auch aufgezeichnet, so dass, wenn die Erschütterung vorüber ist, ein graphisches Tableau vorliegt, aus welchem man ersehen kann, wie sich die Intensitäten der den einzelnen Strichen entsprechenden Stossrichtungen zu einander verhielten. *)

i) G. Wagner's Erdbebenmesser. Nachdem Knipping aus seinen vielfältigen Beobachtungen in Japan die Lehre gezogen hatte, dass bei

*) Bertelli's Apparat, von dessen stetigem und exaktem Funktioniren sich der Verf. im Barnabitenkloster zu Florenz persönlich zu überzeugen Gelegenheit hatte, ist auch von De Rossi in seinem mikrosismischen Institute zu Rocca di Papa im Albanergebirge - vgl. Favaro's Beschreibung desselben [150] - aufgestellt worden und liefert gute Resultate. Man muss jedoch viele Vorsicht anwenden, um nicht Oscillationen, welche in Wahrheit eine ganz andere Ursache haben, auf Erschütterungen intrakrustaler oder ryakokrustaler Natur zurückzuführen. Man denke nur z. B. an jene schwachen Bodenbewegungen, von denen in Kap. IV, §. 2 der zweiten. Abtheilung nach D'Abbadie und Plantamour die Rede war, und die keinesfalls zu den mikroseismischen gerechnet werden dürfen. Aber auch die mit der Sonnenbestrahlung variirende Bewegung festen Mauerwerkes, welche den Astronomen wohl bekannt ist und mit die Veranlassung war, dass man neuerdings die Sternwarten mehr und mehr auf ebener Erde anlegt, kommt in Betracht, wenn der Registrirapparat in einem Thurme oder hohem Hause sich befindet. Untersuchungen, die Rockwood mit feinen Libellen angestellt hat, liessen erkennen [151], dass ein Punkt im Mauerwerke eines Thurmes jeden Tag eine kleine Ellipse beschrieb, deren grosse Axe 2,54 Centimeter, deren kleine Axe 1,06 Centimeter betrug, so zwar, dass die letztere ungefähr mit der Mittagsebene zusammenfiel. War der Thurm nicht isolirt, sondern an ein niedrigeres Gebäude angebaut, so erlitt die Insolationskurve eine Verzerrung, deren Charakter sich schon von vorn herein annähernd bestimmen liess. Sonderbarerweise haben Förster und Gould in den Schwankungen der Sternwartenpfeiler eine derjenigen der Sonnenfleckenfrequenz entsprechende Periode von 11 Jahren bemerkt (D. Rundschau f. Geogr. u. Stat,, 6. Jahrgang. S. 172 ff.). 
häufiger Wiederkehr der Erdbeben auf alle die bekannteren Mechanismen kein rechter Verlass sei [152], gieng G. W a g n er [153] an die Konstruktion einer minder leicht versagenden Vorrichtung. AE und $\mathrm{BC}$ (Fig. 75) sind zwei in $\mathrm{F}$ einander rechtwinklig durchsetzende Stäbe, EF und CF sind kurz, während der Fig. 75. Arm BF eine bedeutende Länge besitzt. Durch

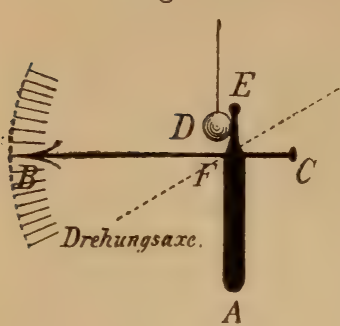
F geht eine horizontale Axe, und das ganze System befindet sich im Gleichgewichtszustande. Von der Decke hängt eine schwere Kugel D herab, welche im normalen Zustande EF gerade tangirt, ohne es auch nur im Geringsten von seiner vertikalen Richtung abzulenken. Jeder noch so leichte Horizontalstoss stört das Gleichgewicht, und der lange Arm BF macht ansehnliche Schwingungen, deren Amplitude ein Maass für die Stärke des Stosses giebt.

Für Vertikalstösse dagegen empfiehlt Wagner [154] einen Schwimmkörper, dessen Form die des Rotationskörpers von geringstem Widerstande sein soll (Meridiankurven solcher Körper haben Euler [155] und Grunert [156] zu bestimmen gelehrt); die Bewegung desselben soll dann auch wieder durch ein Hebelwerk auf einen Zeiger vergrössert übertragen werden. Als sehr brauchbar ward Wagner's Instrument auch von den Engländern anerkannt [157]; noch mehr ist es diess durch eine von Peal [158] daran angebrachte Verbesserung geworden, durch welche auch dem chronographischen Elemente Rechnung getragen wird.

k) Neuere englische Seismographen. Dieselben, über die wir hier nur nach Zöppritz's Referaten [159] berichten können, sind von Gray und Milne auf die Beobachtung japanischer Erdbeben angewandt worden und wesentlich seismische Kurvenzeichner. Man hat mit ihrer Hülfe das auch schon den Italienern geläufige Resultat erhalten, dass die seismische Bewegung eine unregelmässige, schwankende ist, die in ihrem Verlaufe oft verschiedene Maxima und Minima aufweist. Unsicherer, weil mit den annalistischen Aufzeichnungen nicht harmonirend, ist jedenfalls der von den britischen Forschern aufgestellte Erfahrungssatz, dass die Erdbeben häufiger und mit grösserer Energie im Winter als im Sommer auftreten sollten. Merian's Erdbebenstatistik für Basel hat allerdings ein 'ganz analoges Ergebniss geliefert [160].

§. 6. Geometrie und Mechanik der seismischen Punkt- und Liniensysteme. Ohne zunächst noch irgend welche Hypothese über den Sitz und das wahre Wesen der seismischen Kraftäusserungen zu Hülfe zu nehmen, vermag man doch theoretische. Normen für die Bestimmung gewisser seismologischer Fundamentalelemente aufzustellen. Am nächsten liegt offenbar der Gedanke, durch zusammenfassende Betrachtung von Korrespondenznachrichten jenen Punkt der Erdoberfläche aufzusuchen, in welchem das Erdbeben seine grösste Kraft entfaltete, und nunmehr die Ausstrahlung der Kraft nach verschiedenen Richtungen hin zu studiren. In diesem Sinne gieng als der Erste ein deutscher Mathematiker, Egen, planmässig vor, indem er die Stoss- 
punkte für das rheinische Erdbeben vom Jahre 1828 zusammenstellte und dadurch gleich anfangs den positiven Erfolg erzielte, eine von Nöggerath aufgestellte Hypothese, nach welcher das Erdbeben mit einem Vesuv-Ausbruch zusammenhängen sollte, als unhaltbar zu erweisen [161]. Muncke, durch Egen's Arbeit angeregt, machte sodann darauf aufmerksam, dass auch die Erschütterungen von Lima (1746), Lissabon (1755) und Kalabrien (1783) einen centralen Ausgangspunkt erkennen liessen [162]. Eine bestimmtere geometrische Form erhielt die Sache jedoch erst durch Hopkins und durch Mallet in den Berichten, welche sie resp. in den Jahren 1847 und 1858 der „British Association" vorlegten. Allmählig bildete sich auch eine brauchbare Terminologie heraus, deren wesentliche Bestandtheile wir anführen wollen. Legt man durch alle Punkte der Erdoberfläche, welche den Stoss im nämlichen Momente verspürten, eine Kurve, so ist diess nach Mallet eine Koseisme, nach Jul. Schmidt eine Isochrone, nach v. Seebach endlich, dessen Bezeichnungsweise den meisten Anklang gefunden hat, eine Homoseiste, während Punkte, in welchen sich das Phänomen gleich stark offenbarte, einer Is o seiste angehören [163]. Gesetzt nun, der eigentliche Heerd des Erdbebens sei ein Punkt (Erdbebencentrum) - eine Annahme, an der freilich sehr bald erhebliche Aenderungen angebracht werden müssen, und die nur als eine erste rohe Näherung gelten kann —, so müsste offenbar aus der Anordnung der Homoseisten auf die Lage dieses Centrums ein Schluss zu ziehen sein. Denken wir uns aus dem Centrum auf die Erdoberfläche ein Loth gefällt, die Erdbebenaxe („prime ver-

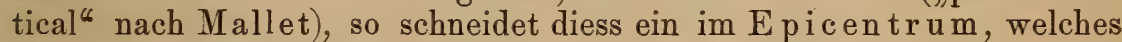
also auf der Erdoberfläche gelegen ist; die Entfernung zwischen einer Homoseiste und dem Epicentrum mag nach v. Seebach [164] der Axialabstand heissen, während sich für die Distanz von Centrum und Epi. centrum vielleicht der Name Centraltiefe empfehlen möchte. Die Richtung des Stosses bildet mit dem Horizonte einen wohl niemals völlig auf Null herabsinkenden Winkel, den Emersionswinkel. Für den Axialabstand $\mathrm{a}$, die Centraltiefe $\mathrm{h}$ und den Emersionswinkel $\varepsilon$ besteht ersichtlich, wenn die Erdoberfläche als völlig eben vorausgesetzt wird, die Relation $h=a \operatorname{tg} \varepsilon$; wäre $\varepsilon=0^{\circ}$, so würden Centrum und Epicentrum offenbar zusammenfallen, während ein völlig vertikaler Stoss $\left(\varepsilon=90^{\circ}\right)$ nach dieser Formel überhaupt nicht vorkommen kann, wenn nicht zugleich a den Werth Null hat; dann ist nämlich $h=0 . \infty$, also gleich einer endlichen Grösse. Es ist ferner einleuchtend, dass, wenn die Fortpflanzung der Stösse in homogenem Mittel vor sich gienge, die entstehenden Kugelwellen den planen Erdboden in koncentrischen Kreisen schneiden müssten. Thatsächlich sind nun freilich die Homoseisten nur ganz ausnahmsweise kreisförmig, doch müssen sie wohl oder übel betrachtet werden, als hätten sie diese Form, indem sonst die Auffindung des Epicentrums nicht möglich wäre. Um unsere Kenntniss von diesem Theile seismischer Nomenklatur abzurunden, sei noch bemerkt, dass der geometrische Ort der Punkte stärkster Erschütterung als Pleistoseiste bezeichnet wird, und dass man von Orten, welche mitten im Schüttergebiete vom Erdbeben ganz unbehelligt blieben, zu sagen pflegt, sie lägen auf einer Erdbebenbrücke. 
Unter der, wie erwähnt, nur sehr bedingt zulässigen Voraussetzung, dass eine Homoseiste ein Kreis sei, ist die Lage des Epicentrums leicht zu finden. Man zieht zwei Sehnen $\mathrm{AB}$ und $\mathrm{CD}$, halbirt $\mathrm{AB}$ in $\mathrm{E}$ und $\mathrm{CD}$ in $\mathrm{F}$ und errichtet in $\mathrm{E}$ und $\mathrm{F}$ Senkrechte auf den Sehnen; der Durchschnittspunkt dieser Senkrechten ist das Epicentrum. Von diesem zum Centrum selbst kann man durch Anwendung verschiedener Methoden gelangen, deren eine topographische, eine andere chronometrische Messungen zur Vorbedingung hat.

a) Methode von Mallet. Man untersucht an dem vom Erdbeben betroffenen Orte zunächst, ob sich Mauern und Wände mit deutlich erkennbaren Spalten vorfinden. Ist diess der Fall, so ist das Weitere einfach, und Mallet hat denn auch in seinem Werke über das neapolitanische Erdbeben auf diese Weise sehr brauchbare Werthe erhalten. Es sei nämlich in Fig. 75, welche wir dem für die mathematische Seite der Aufgabe sehr instruktiven Werke von Falb [165] entnehmen, ABCD eine vertikale Mauer, in welcher sich ein mit dem Horizont den Winkel $\alpha$ bildender Riss zeigt. Man kann dann sicher sein, dass die Stossrichtung mit dem gezeichneten Pfeile übereinstimmt, der selbst mit A B den Emersionswinkel $\varepsilon$ einschliesst, und dann ist $\alpha+\varepsilon=90^{\circ}$; dabei ward, was allerdings nur selten der Fall sein wird, die Ebene ABCD als mit der Vertikalebene des Stosses zusammenfallend angenommen; im allgemeineren Falle würde die Berechnung von $\varepsilon$ durch

Fig. 76 .

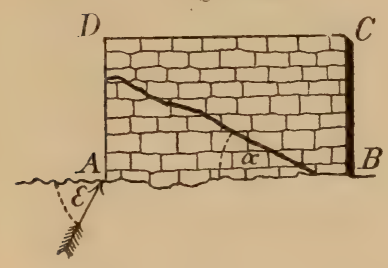
sphärische Trigonometrie zu bewerkstelligen sein. Der Dienst, den uns hier die Maueröffnung leistete, kann natürlich auch durch irgendwelche andere dem Erdbeben entsprungene Ortsveränderung geleistet werden, wie denn z. B. Falb in einem Hause zu Belluno ein auf Füssen stehendes Kästchen traf, welches in Folge der Schwankung des Tisches, auf welchem es sich befand, von diesem herabgerutscht war und dabei seinen Weg durch eingekritzelte Parallelstreifen auf dem Tische verrathen hatte. Da der letztere selbst unverrückt stehen geblieben war, so hatte der beobachtende Forscher ein Mittel zur Bestimmung des Emersionswinkels, wie er es sich nicht besser wünschen konnte. Ist aber $\varepsilon$ bekannt, so hat man, da der Axialabstand a aus der Karte entnommen werden kann, der obigen Beziehungsgleichung zufolge auch die Centraltiefe h. Führt man diese Berechnung für mehrere Homoseisten durch und zieht aus den Einzelresultaten ein wahrscheinlichstes dadurch, dass man die Homoseisten mit ihren Radien proportionalen Gewichten versieht, so erhöht sich die Genauigkeit.

Eine besondere Formel entwickelt Mallet für den Fall, dass ein fester Körper von einigermassen geometrisch-regelmässiger Gestalt durch den Erdstoss umgeworfen worden ist. Die Masse dieses Körpers sei M, der Abstand seines Schwerpunktes von der Umkippungsaxe a, die Geschwindigkeit der seismischen Bewegung im Momente des Stosses sei $v$, dann ist die lebendige Potenz des Stosses $=\frac{1}{2} \mathbf{M}^{2}$. Die von demselben geleistete Arbeit besteht eben in der Umkippung des Körpers; da lebendige Potenz und Arbeitsgrösse einander gleich sind, da 
IV, §. 6. Geometrie u. Mechanik d. seism. Punkt- u. Liniensysteme. 391

ferner die Arbeit der Strecke a offenbar umgekehrt proportional ist, so besteht die Gleichung $\frac{1}{2} \mathrm{Mv}^{2}=\frac{\mathrm{T}}{\mathrm{a}} \cdot \mathrm{f}(\varphi)$, wo $\mathrm{T}$ das Trägheitsmoment des Körpers mit Bezug auf die Drehaxe, $f(\varphi)$ aber eine noch zu fixirende Funktion des Winkels $\varphi$ bedeutet, welchen die Gerade, auf der a abgemessen ist, mit der Vertikalen bildet. Mallet findet so

$$
v=\sqrt{\frac{2 \mathrm{~T}}{\mathrm{aM}} \cdot \frac{\mathrm{g}(1-\cos \varphi)}{\cos ^{2} \varphi}}
$$

Noch ist allerdings der Emersionswinkel nicht bestimmt. Wenn aber gleichzeitig bekannt ist, dass eine Kugel, die vorher vom Boden den vertikalen Abstand b hatte, von ihrem Platze heruntergeworfen und an einen Ort geschleudert wurde, der von jener Vertikalen b den Horizontalabstand c besitzt, so wird

$$
\operatorname{tg} \varepsilon=\frac{\mathrm{b}}{\mathrm{c}}-\frac{\mathrm{cg}}{2 \mathrm{v}^{2}} \text {. }
$$

Nähere Erörterungen können nachgesehen werden in dem Abschnitte „Erdbebenkunde“, den v. Seebach für Neumayer's Handbuch des Forschungsreisenden bearbeitet hat [166].

b) Methode von Falb. Von einem Orte A gesehen, habe der Ort B das Azimut $\alpha$, von B aus gesehen habe der Ort A das Azimut $\beta$. Das Azimut der horizontalen Stosskomponente sei in $A=\alpha_{1}$, in $B=\beta_{1}$. Die Längenentfernung von $A$ und $B$ heisse $d$. Bringt man dann an den von Falb gegebenen Formeln einige kleine Umformungen an und bezeichnet mit $\varepsilon_{1}$ und $\varepsilon_{2}$ die den Punkten A und B entsprechenden Emersionswinkel, so ist [167] die Centraltiefe

$$
\mathrm{h}=\mathrm{d} \cdot \frac{\sin \left(\varepsilon_{1}-\varepsilon_{2}\right)}{\sin \varepsilon_{1} \sin \varepsilon_{2}} \cdot \frac{\cos \frac{\alpha_{1}-\beta_{1}+\alpha_{2}-\beta_{2}}{2}}{\cos \frac{\alpha_{1}-\beta_{1}-\alpha_{2}+\beta_{2}}{2}} .
$$

Das Verfahren hat den Vortheil, von der vorhergehenden Verzeichnung der Homoseisten und Ermittelung des Epicentrums unabhängig zu sein. Eine zweite Falb'sche Methode behandeln wir um desswillen hier nicht eingehender, weil sie zu enge mit den immer unzuverlässigen Schallerscheinungen verkettet ist [168].

c) Methode von V. Seebach. Durch diese, deren mathematische Formulirung Minnigerode übernommen hatte, sollen gleichzeitig die - konstant angenommene - Fortpflanzungsgeschwindigkeit c, der Zeitpunkt des ersten Anstosses $t$ und die Centraltiefe $h$ gefunden werden, und zwar ausschliesslich durch Diskussion eines Systemes von Zeitangaben, ohne die Beobachtung der immer nur misslich zu erforschenden Spaltenrichtungen. C (Fig. 76) ist der Erdmittelpunkt, $\mathrm{E}$ das Epicentrum, A der Punkt der Erdkugelfläche, in welchem diese von der Geraden CE getroffen wird, M irgend ein erschütterter Punkt. AM, der Axialabstand, ist bekannt (= a); dann hat man zur Bestimmung des Winkels $\mathrm{ACM}=\varphi$ die Proportion $\varphi: 360=\mathrm{a}: 2 \rho \pi$ ( $\rho$ Erdhalbmesser), woraus $\varphi=\frac{180 \mathrm{a}}{\rho \pi}$ folgt.

Fig. 77.

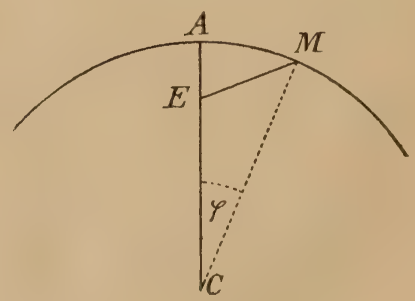


Die Distanz EM ist gleich ct, der Cosinussatz ergiebt für das Dreieck EMC :

$$
\mathrm{r}^{2}=\rho^{2}+(\rho-\mathrm{h})^{2}-2 \rho(\rho-\mathrm{h}) \cos \varphi .
$$

Rechnet man zur Rechten aus, berücksichtigt, dass $1-\cos \varphi=2 \sin ^{2} \frac{1}{2} \varphi$ ist, setzt für $r$ seinen Werth ct ein und zieht die Wurzel aus, so wird

$$
\text { ct }=\sqrt{\mathrm{h}^{2}+4 p(p-\mathrm{h}) \sin ^{2} \frac{1}{2} \varphi} \text {. }
$$

Nun setze man noch $2 \rho \sin \frac{1}{2} \varphi=y$, dann ist

$$
c t=\sqrt{h^{2}+y^{2}\left(1-\frac{h}{\rho}\right)} \text {. }
$$

Der Brnch $\frac{h}{\rho}$ ist nach Allem, was wir über den stets intrakrustalen Sitz der seismischen Kraft wissen, sehr klein und darf deshalb vernachlässigt werden; so kann die letzterhaltene Gleichung auch in dieser Form geschrieben werden: $c^{2} t^{2}-y^{2}=h^{2}$. Das ist aber die Gleichung einer Hyperbel, deren Halbaxen $h$ und $\frac{h}{c}$ sind. Die Ordinate $y$ darf unter gewöhnlichen Umständen mit dem Axialabstande a identificirt werden, denn es ist $y=2 \rho \sin \frac{1}{2} \varphi=2 \rho\left(\frac{1}{2} \varphi-\frac{1}{48} \varphi^{3}+-\ldots\right)$ $=\rho \varphi$, wenn die weiteren Reihenglieder als einflusslos bei Seite gelassen werden. Wenn aber die Winkel in absolutem Maasse gegeben sind, so dass $180^{\circ}$ durch $\pi$ ersetzt wird, so hat man eben $a=\rho \varphi$.

Die ermittelte Hyperbel lehrt nun v. Se ebach, dem wir bisher folgten, graphisch für die Bestimmung der seismologischen Fundamentalelemente zu verwerthen. Er lässt den Mittelpunkt der Kurve mit dem Epicentrum zusammenfallen, trägt auf der Abscissenaxe Längeneinheiten (Myriameter) und auf der Ordinatenaxe mit gleichem Maassstabe Zeiteinheiten (Minuten) auf, konstruirt die zugehörige Kurve und sieht nun zu, ob die in den bezüglichen Punkten errichteten Senkrechten sich genau auf dem Umfange der Hyperbel durchschneiden. „Der Grad der Genauigkeit, mit der diess geschieht, giebt hiebei zunächst einen Maassstab für die Güte der Zeitbestimmungen an und muss für sich und bei guten Zeitbestimmungen zugleich auch erkennen lassen, ob der Oberflächenmittelpunkt richtig bestimmt worden ist oder nicht" [169]. Nachdem die Hyperbel gezeichnet vorliegt, sind die drei Grössen c, t und h durch einfache Zeichnung erhältlich. c ist nämlich die Tangente des halben Asymptotenwinkels, $t$ ist gleich einer beliebigen Abscisse, dividirt durch $\mathrm{c}$, und $\mathrm{h}$ ist, wie wir bereits wissen, durch eine der Halbaxen gegeben. v. Seebach und Minnigerode haben somit das Folgende geleistet: Durch punktweise Konstruktion einer Hyberbel die Fundamentalgrössen direkt und graphisch zu ermitteln*).

*) v. Seebach's Hyperbel ist eine ganz andere, als diejenige, zu welcher Hopkins in seinem Berichte von 1847 sich geführt sah. Falb begeht also in dem von uns mehrfach citirten Buche eine Verwechselung, indem er die Kurven 
Kortum hat in einer dem uns bekannten Werke v. Lasaulx's eingefügten Spezialuntersuchung allerdings gezeigt [172], dass kleine Fehler in den Zeitangaben schon einen sehr erheblichen Einfluss auf die berechnete Centraltiefe ausüben. Derselbe thut weiter dar, dass und wie mit Hülfe der Methode der kleinsten Quadrate die nothwendigen Korrekturen anzubringen seien.

Der wunde Punkt all' dieser vom theoretischen Standpunkt aus so schönen Theorieen ist nun freilich der, dass ein eigentliches Erdbebencentrum nicht existirt, indem der Heerd der Stösse oft einen ziemlichen Umfang besitzt. Heim hebt z. B. hervor, dass selbst bei jenen schweizerischen Erdbeben, welche nicht auf grosse Dislokationen im Erdinneren hindeuten, trotzdem das Intensitätscentrum nicht durch einen Punkt, sondern durch eine langgestreckte Zone repräsentirt gedacht werden musste [173]. v. Seebach hat wenigstens eine Andeutung darüber gemacht, wie sich die Gestalt des Erdbebenheerdes in jener der Homo- und Isoseisten wiederspiegeln müsste. Wir ver. weisen für diese mehr geologische Seite der Frage auf §. 9, halten aber daran fest, dass die mathematische Erörterung immerhin ihre hohe Brauchbarkeit zur Eruirung angenäherter Werthe unter allen Umständen beibehält.

§. 7. Theoretische Spekulationen über die Natur der Erdbeben. Wir glauben den Zweck, welchen dieser Paragraph sich vorgesetzt hat, am besten dadurch zu erreichen, dass wir für die frühere Zeit eine synchronistische, für die spätere dagegen eine sachliche Anordnung wählen. Die meist willkürlichen und nicht auf eigentlicher Analyse des zu durchdringenden Phänomenes beruhenden Erklärungen, welche das Alterthum und Mittelalter liebte, lassen sich so am besten überblicken.

a) Hypothesen der Orientalen. Einige Nachrichten über dieselben findet man zusammengestellt in der Abhandlung von Lersch [174], welche sich uns auch in ihren übrigen Theilen sehr brauchbar erwiesen hat. Im Wesentlichen herrscht, sowohl bei den alten Japanern, wie auch bei den Indern und Talmudisten, die Mythologie vor, indem ein unter der Erde befindliches Ungeheuer (Leviathan, Celebrant) durch Zuckungen seine Anwesenheit zu verspüren geben soll. Die heilige Schrift beschreibt hie und da Erdbeben in sehr zutreffender Weise (vgl. besonders Psalm 113), doch ist es kaum möglich, wie unlängst versucht worden ist [175], aus solchen gelegentlichen Aphorismen heraus eine „biblische Erdbebentheorie ${ }^{*}$ zu formuliren.

b) Griechische Hypothesen. Hier stehen wir, auch wenn wir uns an die älteste Zeit halten, schon auf weit festerem Boden, weil Aristoteles uns über die bis zu seinem Auftreten gehegten Meinungen genaue Mittheilungen gemacht hat [176]. Im archaistischen Zeitalter betrachtete man solch' furchtbare Ereignisse, wie die Erdbeben, freilich auch mit abergläubischem Auge, man opferte dem „Erderschütterer" Poseidon, um solche Schrecknisse abzuwenden, oder bildete sich wohl

des englischen und des deutschen Geologen einem und demselben Zwecke dienen lässt [170], indessen nimmt er bei einer späteren Gelegenheit seine frühere Behauptung ausdrücklich zu v. Seebach's Gunsten zurück [171]. 
auch ein, der unter dem Aetna begrabene Gigant Enkelados mache das Land umher erzittern. Aber schon von Anaximander berichtet Ammianus Marcellinus [177], er habe die Erdbeben auf die in Folge langer Dürre oder auch heftiger Regengüsse entstehenden Risse des Erdbodens zurückgeführt. Anaximenes bildete diese Vorstellung weiter aus, indem er die Annahme hinzufügte, dass das durch besagte Spalten in's Innere der Erde hinabträufelnde Wasser Rutschungen und Einstürze veranlasse. Demokrit schrieb die Hauptschuld bei der Erzeugung von Erdbeben den Regengüssen zu, welche das bereits durchfeuchtete und mit Wasser vollgesogene Erdreich treffen. Anaxagoras dagegen ist der Urheber jener Lehre, zu welcher sich nachmals auch Aristoteles selbst bekannte, dass nämlich die Luft sich in den Höhlungen des Erdkörpers verfange und nunmehr ungestüm einen Ausweg suche*). Auf einen analogen Standpunkt stellte sich, wenn uns Lucrez die Wahrheit berichtet, der sonst von den Lehren des Stagiriten vielfach abweichende Epikur [182]; derselbe war übrigens verständig genug, zuzugeben, dass durchaus nicht jedes Erdbeben auf die nämliche Ursache zurückgeführt zu werden brauche [183]. Gleicherweise erklärte sich Strabon nur bedingt für Aristoteles, während er - und diess ist mit Rücksicht auf die in §. 3 abgehandelte Suess'sche Theorie der Alluvionalbeben äusserst merkwürdig auch eine neptunistische Deutung mancher Erscheinungen auf die Reisemittheilungen des Aristobulos begründete. Auf Wärmedifferenzen im Erdinneren als auf den Grund von Kataklysmen wies Straton hin [184], der von allen Griechen wohl am schärfsten über die Fragen der dynamischen Geologie nachgedacht hatte (vgl. die Einleitung). Die Byzantiner, welche durch den berühmten Ingenieur Anthemios bereits einige Begriffe von der Expansivkraft des Wasserdampfes besassen, scheinen das Erzittern des Bodens in rationellerer Weise statt mit dem unbestimmten aristotelischen Begriff der Luft, mit demjenigen der aus erhitzten Flüssigkeiten aufsteigenden Dämpfe in Zusammenhang gebracht zu haben [185].

*) Nehring macht [178] die der näheren Erwägung wohl nicht unwürdige Bemerkung, dass vielleicht die ab und zu in den Gebirgen zu findenden Windoder Wetterlöcher den Alten ihren Irrthum betreffs der innigen Verwandtschaft von Luftströmungen und Erdbeben nahegelegt haben möchten. "Wenn man," sagt ein ortskundiger Beschreiber [179], „an heissen Sommertagen in nächster Nähe einer solchen Spalte vorübergeht, fühlt man einen ziemlich starken kalten Luftzug, der aus derselben herausdringt; im Winter hingegen findet das Gegentheil statt, nämlich die äussere Luft dringt in die Spalte hinein." Eine sehr merkwürdige Höhle dieser Art hat Krejč̌ĺ bei Gelegenheit der böhmischen geologischen Landesaufnahme entdeckt; nur ist die Temperatur der dortselbst ausströmenden Luft keine so sehr veränderliche. Die feuchtwarme Luft bildet manchmal sogar eine Rauchsäule über dem Gipfel der Anhöhe, doch ist an solfatarenoder mofettenartigen Ursprung nicht zu denken [180]. Für Nehring's Auffassung liesse sich neben Anderem auch der originelle Aufsatz "Von den Gletscheren auf dem Grimselberg, und denen alldorten sich befindenden Crystall-Gruben" anführen, welchen der uns aus der geschichtlichen Einleitung (S. 28) wohl bekannte Luzerner Naturforscher Cappeler in Altmann's Monographie der schweizerischen Gletscherwelt einrücken liess [181], denn dort wird angenommen, die den Berg durchstreichende Luft setze sich in abgeschlossenen Höhlen und Kammern fest, und dort würden ihr die zur Bildung der Krystalle nothwendigen Bestandtheile entzogen. 
c) Römische Hypothesen. Lucretius billigte die Zurückhaltung seines Meisters Epikur, er hielt Einsturz-Erdbeben, vulkanische Erdbeben und durch das Einströmen von Winden hervorgebrachte Erdbeben für möglich [186]. Plinius begnügte sich seiner Gewohnheit gemäss damit, ältere Doktrinen einfach zu reproduciren, aber Seneca suchte der Sache mehr auf den Grund zu gehen. Ganz richtig erkannte er [187], dass der Sitz der Erdstösse in gar nicht beträchtlicher Tiefe zu suchen sei. Im Uebrigen nahm er an, dass sein motus

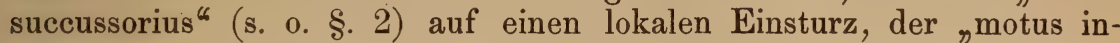
clinatorius" dagegen auf die Wirkung eingeschlossener gespannter Gasmassen hindeute. Die lebendige Kraft derselben kennzeichnet er treffend mit den Worten [188]: „Nobis quoque placet hunc spiritum esse, qui possit tanta conari, quo nihil est in rerum natura potentius, nihil acrius, sine quo nec illa quidem, quae vehementissima sunt, valent. ${ }^{6}$ Darüber, dass Seneca's „spiritus" etwas ganz anderes ist, als der Wind des Aristoteles, äusserten wir uns schon in $§ .9$ des vorigen Kapitels.

d) Arabische Hypothesen. Bei den Arabern dürfen wir nicht erwarten, etwas anderes als griechische Lesefrüchte, hie und da in etwas missverstandener Form, aufzufinden. Das Beste, weil zugleich Sinn für ein deskriptives Verfahren Bekundende, was uns von Jenen aufbehalten ward, ist As-Soyutí's genaue Beschreibung des mesopotamisch-syrischen Erdbebens vom Jahre 1157 oder 1158 n. Chr., mit welcher uns Sprenger bekannt gemacht hat [189]. Kazwîni lässt uns [190] die Wahl zwischen zwei Annahmen: entweder entsteht ein Erdbeben durch einen chemischen Process in den Eingeweiden der Erde, der an die in den Adern eines kranken Menschen tobende Fiebergluth erinnert, oder aber durch Einstürze und Bergschlipfe. Mit orientalischem Gleichmuth versteht sich der Autor über die Pflicht eingehender Prüfung hinwegzusetzen : „Gott aber weiss besser, wie es sich in Wahrheit mit diesen Dingen verhält."

e) Hypothesen des abendländischen Mittelalters. Beda Ven erabilis kennt die aristotelische ebenso wie die Einsturz-Hypothese [191]. Aehnlich Hrabanus Maurus, der nur ein wenig vielseitiger ist, indem er dreierlei Gründe zulïsst: „die Erdbeben können entweder durch die Bewegung der Winde im Inneren der Erde, oder aber durch das Schwappen des Wassers*), oder aber durch Einstürze des durchwühlten und unterwaschenen Bodens erklärt werden" [193]. Die

*) Diese oscillirende Bewegung der Bodendecke entnimmt Hraban möglicherweise einer zu ihm durchgedrungenen Notiz über die Erdbebentheorie des Demokrit (s. o.), oder auch den strabonischen Nachrichten über die Spaltung und Zerbröckelung inundirter Schwemmländer. Bis in die neuere Zeit herein erhielten sich Ansichten dieser Art, wie denn z. B. in einer 1670 publicirten und durch Wieder-Abdruck der jetzigen Generation näher gerückten Beschreibung der Nilquellen Nachstehendes zu lesen ist [192]: „Die Einwohner sagen, der gantze Berg sey voll Wassers und gaben zum Zeichen dessen dieses zu betrachten, dass der gantze Platz um den Brunnen herum zitterte, welches eine offenbare Anzeigung, dass Wasser darunter verborgen.... Erwehnte Einwohner, wie auch der Kaiser selbst, welcher mit seinem Heer zugegen war, berichteten, die Erde hette selbiges Jahr nicht sonders viel gebebt wegen der grossen Dürre und trocknen Jahrs-Zeit; aber in andren Jahren zittre und bebe sie dermassen, dass man zu diesem Orte kaum ohne Gefahr kommen könne." Die ganze Erde als einen von Wasser vollgesogenen Schwamm sich zu denken, war eine Lieblingsvorstellung des Mittelalters. 
Scholastiker, voran der heilige Thomas, folgten auch in diesem Falle unentwegt den Spuren ihres Lehrers Aristoteles [194], von dessen Theorie Froidm on t noch vierhundert Jahre später sagen konnte [195]: "Sententia Aris to telis verissima est, spiritum subterraneum esse causam terrae motus effectricem." So sehen wir auch manchen Gelehrten im Gefolge des Aristoteles dahinwandeln, der im Uebrigen nicht der peripatetischen Schule zuzurechnen ist; Ristoro d'Arezzo z. B. fertigt den Gegenstand kurz ab, wie folgt [196]: „Ed alcuna stagione si vede e sente tremuoti, e sente tremare la terra, e tremare tutta la provincia, e cadere monti, e case, e torri, e già furo vedute profondare cittadi: e sentonsi tremuoti piccoli, li quali non fanno danno; e già avemo veduto e sentito uscire il vento della terra." Es möchte uns fast wundernehmen, dass Ristoro keine astrologische Deutung des Vorganges zu Hülfe nimmt, denn erstens sagen ihm sonst derlei Erklärungsweisen am meisten zu, und zweitens hätte es ihm an Vorbildern in dieser Hinsicht nicht gefehlt. Favaro hat wenigstens in

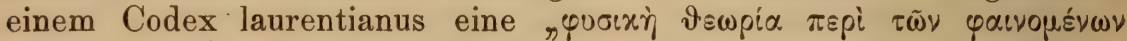

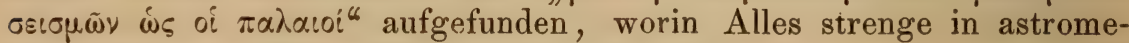
teorologischem Sinne abgehandelt wird [197].

Wir verlassen das Mittelalter und wenden uns der neueren Zeit zu. Zu Beginne derselben hatte das theoretische Wissen vom Erdbeben also den Stand erreicht, dass man entweder der aristotelischen Lehre vom Windfang beipflichtete, oder an die Expansion gespannter Gase und Dämpfe dachte oder endlich chemische Vorgänge als im Spiele befindlich annahm, wie diess besonders Cardanus that, welcher Salpeter, Erdharz und Schwefel in absteigender Linie als die seismischen Motoren bezeichnete [198]. Bemerkenswerth ist, dass Galilei, offenbar mit Rücksicht auf Aristoteles, gelegentlich die Frage formulirte [199]: "Sè la cagione de' terremoti si deva stimare essere sopra o sotto la terra?" Die thermodynamische Anschauung des Straton scheint sich lediglich der bergbaukundige Agricola angeeignet gehabt zu haben [200]. Wir bemerken noch abschliessend, dass der bekannte Chemiker van Helmont eine scharfe und nach dem Urtheile von Lersch [201] zutreffende Kritik an allen ihm bekannten Erdbebentheorieen übte, ohne freilich selbst etwas Positiveres bieten zu können. Die modernen Hypothesen glauben wir am besten in vier gesonderte Gruppen bringen zu können, wobei manche in ihrer Originalität absurde Theorie freilich ausgeschlossen wird. Dahin gehört z. B., was Kant [202] über die Phantasmen eines gewissen Gautier, eines Malers, aussagt, der aus dem stärkeren Anprall der Sonnenstrahlen gegen die Westküste der Kontinente sowohl die Umdrehung der Erde um ihre Axe, als auch die Erschütterungen der Erdfeste herleiten wollte.

f) Die elektrischen Theorieen der neueren Zeit. Zu Gunsten der Annahme, dass bei den Erdstössen auch die Elektricität eine Rolle spiele, hat man schon von jeher die Erzählung des Tacitus von den bei'm Untergange der Städte Helice und Bura gesehenen Lichterscheinungen zu verwerthen gesucht, welche also lautet [203]: „Eodem anno duodecim celebres Asiae urbes collapsae nocturno motu terrae: quo improvisior graviorque pestis fuit. Neque solitum in tali casu effugium subveniebat ... effulsisse inter ruinam ignes, memorant." Eine 
Fülle ähnlicher Nachrichten liegt in der Literatur vor, allein in physikalischer Hinsicht scheint uns damit sehr wenig bewiesen, weil ja bekannt ist, wie leicht in Folge von Erdstössen Feuersbrünste gewöhnlicher Art entstehen. Die Priestley-Lichtenberg'sche Periode machte mit der elektrischen Interpretation der seismischen Phänomene Ernst. Priestley selbst erblickte darin einen den Gewittern entsprechenden Ausgleich zwischen den „Elektrifikationen" der Luft und der Erde [204], Sarti glaubte die ungeheure Fortpflanzungsgeschwindigkeit der Erdbebenwellen lediglich mit derjenigen der elektrischen Fluida in Parallele stellen zu können [205], Vassalli-Eandi betrachtete als wesentliches Motiv der Erschütterungen eine Art elektrolytischen Processes [206]. Unter den weiteren überzeugungstreuen Anhängern der Elektricitätshypothese sind zu nennen Stuckely [207], der wie Priestley an einen Ausgleich starker elektrischer Spannungen dachte, Bin a [208], der sich die Erde mit Wasserbehältern in Schwefelund Bitumen-Verschluss angefüllt dachte, welche nach der Art einer Leydener Flasche wirken sollten, Cavallo [209], der nach Beccaria sogar einen Vorlesungsversuch zur Veranschaulichung dieser Verhältnisse angab, und der französische Ingenieur Ch. F. Lambert, der zufolge einer Angabe von Muncke [210] den Hergang folgendermassen erklärte: „Dadurch, dass die östlichen Winde die flachere Seite Südamerika's in grösster Feuchtigkeit, dagegen die Westküste des grossen Kontinents nur zu gewissen Zeiten feucht erhalten, soll sich die Elektricität in Folge der die zwischen beiden liegende Station stets trocken erhaltenden Winde, namentlich der östlichen, auf den gebogenen Kämmen der Andeskette anhäufen, weil sie weder durch trockene Luft, noch auch durch die trockene Erde entweichen kann ... Sie durchströmt dann die metallischen Adern, feuchte Erdschichten, Flüsse und Wasseransammlungen, bahnt sich mit Gewalt einen Weg, wenn sie keinen findet, und erzeugt durch die starken Entladungen Bebungen des Bodens, Spalten, Zerreissungen, Verflüchtigungen der Körper, die hiezu geeignet sind, chemische Zersetzungen z. B. Verbrennungen des Schwefels und Anthracits, mit Einem Worte alle die Erscheinungen, welche wir bei den Erdbeben und vulkanischen Ausbrüchen wahrnehmen". - In dem Maasse, in welchem die Elektricitätslehre immer neue Gebiete sich dienstbar machte, wurden auch die Erdbebentheorieen vielseitiger. Matteucci brachte die schnelle Wiederholung der Erdstösse mit den Entladungsschlägen einer galvanischen Batterie in Zusammenhang [211]. Neuerdings ist aber besonders der Elektromagnetismus zum Helfer in der Noth geworden, wie denn z. B. Stoppani [212] die Frage aufwirft: „Potrebbe un grande squilibrio elettromagnetico produrre un terremoto? Non si troverebbe ragione per negare una tale possibilità." Systematisch ist diese Auffassung von Pilar [213] zu begründen versucht worden, der die Erde für ein RiesenSolenoid erklärt und dafür hält, dass die den Erdkörper umkreisenden Elementarströme in etwelche Unordnung gerathen; doch scheint es, dass der genannte Geologe keinesfalls in der Existenz jener A mpère'schen Ströme die primäre Ursache der Erdbeben erblickt (s. u. §. 9). In nicht sehr klarer Weise bringt auch eine unlängst erschienene Schrift von Gringmuth die Erdbeben in Beziehung zu den Schwankungen des Erdmagnetismus. 
g) Die chemischen Theorieen der neueren Zeit. Von Lémery's vulkanistischer Hypothese, welche derselbe auch als für die Erdbeben gültig erachtete, war in §. 9 des vorigen Kapitels die Rede. Kries gieng in seiner oben erwähnten Schrift über die Ursache der Erderschütterungen (s. o. §. 4) von Davy's chemischer Theorie des Erdinneren aus, nach welcher die Metalloide das Wasser zerlegen und dadurch Wasserstoffgas erzeugen sollen; dasselbe verbände sich mit eindringendem Sauerstoff und hinwiederum mit diesem zu rasch verpuffendem Knallgas*). A mi Boué will der chemischen Affinität neben der allerdings auch von ihm stark betonten Bewegung des elektromagnetischen Fluidums einen Platz unter den erzeugenden Agentien des Phänomenes gewahrt wissen [215]. Gründlicher durchdacht ist $J$ a neček's Verbrennungstheorie [216]. In heissen Erdinneren, so argumentirt der kroatische Chemiker, dürften sich die chemischen Elemente vielfach, statt in eigentlichen Verbindungen, blos in mechanischen Gemengen, ähnlich unserer atmosphärischen Luft, vorfinden. Wird aber eine solche Mischung explosiv, so tritt vermuthlich eine Reassociation der Bestandtheile ein, die nicht ohne mechanische Folgen bleiben könnte. Die Verbrennung nach der Entzündung ist keine vollständige, vielmehr geht der Verbrennungsprocess ruck- und absatzweise vor sich, und damit stünde vielleicht der in §. 2 erörterte Umstand in Verbindung, dass bei den Erdbeben der erste und stärkste Stoss häufig von schwächeren Nachstössen begleitet wird.

h) Die magmatischen Druck- und Explosionstheorieen der neueren Zeit. Ueber diese dürfen wir uns.kürzer fassen, da die magmatischen Theorieen des Vulkanismus im Grossen und Ganzen auch die seismischen Processe zu umfassen pflegen. Die Urquelle dieser Anschauung, welche in den Vulkanen Sicherheitsventile gegenüber den Erdbeben sehen zu sollen glaubte, ist Kircher's „Mundus subterraneus“, aber v. Humboldt und v. Buch haben dieselbe durch das Schwergewicht ihrer Autoritäten erst zu einer zeitweilig herrschenden gemacht. Allerdings macht sich der Erstere selber den Einwurf [217], dass die unterirdische Kraft meistens nicht in unmittelbarer Nähe sich am stärksten zu bethätigen pflege, doch hindert ihn diess nicht, den Jahrzehnte lang mit Andacht wiederholten und von Vielen fast zu einer Art geologischen Dogma's erhobenen Satz zu formuliren (a. a. O.): „Die thätigen Vulkane sind als Schutz- und Sicherheitsventile für die nächste Umgegend zu betrachten." Selbst in einer der neuesten Zeit angehörigen Broschüre von Möhl begegnen wir Sätzen, wie den folgenden ]218]: „Bei den Erdbeben haben wir ... gleichsam den Versuch zu der im Vulkane beschriebenen Dampfquellbildung zu erblicken. Die in unterirdischen Höhlen angesammelten Dämpfe detoniren, es erfolgt ein Stoss, mehrere Stösse, es wird jahrelang gerüttelt, bald

*) Psychologisch schwer erklärlich ist es, dass Davy, nachdem er seine chemische Theorie der Vulkanbildung ausgebildet hatte, gerade für die Erdbeben sich selbst von seinen Principien lossagte und eine auf sehr schwachen Füssen stehende dynamische Hypothese in Aufnahme zu bringen versuchte. Er hatte durch Versuche ermittelt, dass Thon sich ausdehnt, wenn er mit Wasser befeuchtet wird; daraus schloss er, dass die im Inneren der Erdrinde befindlichen Thonlager das meteorische Wasser in sich aufnehmen, an Volumen zunehmen und so das interne Gleichgewicht stören (214]. 
hier, bald dort, die Dämpfe finden einen Ausweg, und die Ruhe ist wieder hergestellt, oder aber, die Dämpfe können nicht detoniren, sie drücken aber kontinuirlich, sie bewirken die langsamen Hebungen, denen anderorts Senkungen die Hand bieten." Man glaubt den alten Seneca reden zu hören, dessen im Hohlvolumen abgesperrter „Spiritus" sich einen Ausweg sucht.

Unrecht wäre es, die allerdings auch auf Annahme einer Explosion hinauslaufenden Hypothesen Carl's und vom Rath's mit der Ventiltheorie zusammenzuwerfen. Boutigny hatte aus einem eigenthümlichen Ausbruch glühender Dampfmassen aus geschmolzener Lava, durch welchen dereinst einmal am Aetna ein grosses Unglück entstanden war, den Schluss gezogen [219], dass hier das sogenannte Leidenfrost'sche Phänomen in Mitte liege, und Carl machte von dieser Grundlage aus - ähnlich wie es vor ihm bereits Mallet angedeutet hatte, einen Versuch zur Erklärung der Erdbebengenese. Der rheinländische Arzt Leidenfrost bemerkte als der Erste [220], dass, wenn Wasser auf eine stark erhitzte Metallplatte fällt, kleine Tropfen des ersteren nicht verdampfen, sondern eine sphäroidale Form annehmen, wahrscheinlich, weil eine intermediäre Dampfschicht vorhanden ist. Erkaltet jedoch die Platte, so wird das Wasser plötzlich und mit Geräusch in Dampf verwandelt; tritt diese Erscheinung im Grossen ein, so ist nicht selten eine Zertrümmerung des Dampfkessels ihre Folge. So könnte nun nach Carl [221] das einsickernde Meteorwasser an der Oberfläche des Magma's sehr wohl zuerst den „sphäroidalen Zustand ${ }^{*}$ annehmen und nachher, wenn aus irgend einem Grunde die örtliche Temperatur sich vermindert, die Veranlassung zu Explosionen und Eruptionen bieten. - vom Rath's Erklärung des Unglücksfalles auf Ischia kennen wir nur aus einem Citate Thomassen's [222]. Ueberhitzte Wassermassen, wie solche auf der thermenreichen Insel wohl nicht selten sich bilden, werden fortgeführt und gelangen an eine Stelle geringeren Druckes, wo sie sich mit grosser mechanischer Kraftentwickelung einen Durchbruch bahnen können.

i) Die Einsturztheorieen. Die beiden Gelehrten, welche die altgriechische Lehre vom Entstehen der Erdbeben durch intrakrustale Zusammenbrüche und Einstürze wieder zu Ehren brachten, waren Boussingault und Necker [223]*). Zu den eifrigen Befürwortern dieser Hypothese gehören natürlich die Neptunisten Mohr in seiner "Geschichte der Erde", Bischof, der in seinem Versuche, manche Erdbeben von Bergschlipfen herzuleiten, allerdings gegen die jetzt allseitig angenommene Definition des Wortes „Erdbeben“" verstösst [225],

*) Lersch führt von einem seismologischen Schriftsteller, Namens Seyfert, über den er der leidigen Gewohnheit der Jetztzeit gemäss keine näheren literarischen Nachweise beibringt, dessen Namen wir aber auch im Poggendorffschen Lexikon vergeblich aufsuchten, folgenden bezeichnenden Ausspruch [224] an: Andere haben gemeinet, weil die Erde ein alter Kasten, und mithin auch ihrer innern Beschaffenheit nach baufällig sei, so entstehe daher eine oftmalige Veränderung in dem Eingeweide derselben, die hernach auch auf der Oberfläche merklich werde. Sie haben zu dem Ende unsern Erdboden mit einem alten Gebäude verglichen, und gemeinet, dass so wie jenes ron selbst einfalle, also auch die Erde Risse bekomme und das Einstürzen derselben begreiflich gemacht werden könne." 
und Volger [226]. Das dreibändige Werk des Letzteren erkennt für die häufigen Erdstösse in der Schweiz keine andere Ursache an, als das Nachgeben unterirdischer Gewölbe in Folge von Auslaugungen der Gyps- und Steinsalzlager u. s. w., und in dieser seiner Einseitigkeit liegt seine Schwäche. Man hat sich neuerlich vielleicht etwas gar zu skeptisch und ablehnend gegen die Einsturzhypothese verhalten, die auf verkarstete und höhlenreiche Gegenden - wie nach Fraas auf die Länder am Jordan [227] - und auch auf das Walliser Rhonethal vielleicht doch ganz wohl anwendbar sein dürfte; Palmieri dachte auch bei Casamicciola mehr an eine Bodensenkung, als an ein eigentliches Erdbeben. Es ist übrigens noch zu bemerken, dass der Unterschied zwischen dieser Theorie und der heutzutage den Vorrang behauptenden geotektonischen Erklärungsweise kein so sehr beträchtlicher ist, indem man mit Reyer [228] eben in der Bildung der nachher wieder vernichteten Hohlräume vielfach eine Wirkung der Rindenschrumpfung anzuerkennen hat.

§. 8. Die Perrey-Falb'sche Hypothese. In Kan t's physischer Geographie lesen wir [229]: „Herr Bouguer, ein berühmter französischer Akademiker, erzählt, dass bei seinem Aufenthalt in Peru ein Gelehrter, welcher Professor der Mathematik auf der Universität zu Lima werden wollte, ein Buch unter dem Titel einer astronomischen Uhr der Erdbeben geschrieben habe, darinnen er sich unternimmt, diese aus dem Laufe des Mondes vorher zu verkündigen." Ganz die gleichen Zwecke, wie jener Kreole, verfolgte lange Jahre hindurch mit rühmlichem, wennschon einer besseren Sache würdigem Eifer der Franzose Perrey, von dessen zahlreichen Arbeiten hier nur sein Hauptwerk [230] erwähnt sein möge. Perrey glaubte, dass im Magma unter dem attraktiven Einflusse des Mondes - und der Sonne - ganz ebenso eine Fluthwelle in 24 Stunden umlaufen müsse, wie im Weltmeere. Wäre die gemeinsame Grenzfläche von Erdrinde und Magma eine glatte Kugelfläche, so würden diese Gezeiten des Pyriphlegethon's keine anderen als Druckwirkungen zur Folge haben, da aber die Innenseite der Kruste mit Unebenheiten versehen ist, so staut sich an diesen die seismische Welle, und die darüber liegenden Theile des festen Kugelringes können, woferne sie nur einigermassen lose verbunden sind, aus ihrem Zusammenhange gebracht werden - es entsteht ein Erdstoss [231]. Ohne zunächst von Perrey etwas zu wissen, hat Falb in drei grösseren selbstständigen Schriften [232] und in einer Reihe von Abhandlungen für eine im Wesentlichen ähnliche, wennschon in den Einzelheiten verbesserte Ebbe- und Fluththeorie des feurig-flüssigen Erdinneren Propaganda zu machen gesucht; er nahm im Gegensatze zu seinem Vorgänger an, dass die glühende Materie durch den Gravitationszug der Gestirne in die Kanäle und Spalten der Erdkruste hineingepresst wird, dort erkaltet und während des Erkaltungsprocesses Explosionen hervorruft. Man mag über Falb's Theorie denken, wie man will, jedenfalls ist das Bestreben dieses Forschers, exakt zu schliessen, voll anzuerkennen. Günstig für ihn gestimmt sind manche Geologen von Ruf, wie v. Lasaulx [233], Pilar [234], der den Gezeiten allerdings eine sekundäre, aber doch eben eine Rolle bei'm Zustandekommen der Erdstösse zuweist, und J. Schmidt, der in den 
Ausbrüchen von Santorin eine unmittelbare Korrespondenz mit der Stellung von Sonne und Mond bemerkt haben will [235]. Auch Peschel glaubte, dass, wenn im Inneren der Erdrinde, wodurch immer veranlasst, ein akuter Spannungszustand eingetreten sei, die seismische Woge das latente Erdbeben sozusagen auszulösen vermögend sei [236]; ausserdem ist auch eine Abhandlung von Weitzel [237] beizuziehen. Die grosse Mehrzahl der Fachmänner steht zu Falb's Aufstellungen gegnerisch, und in der That kann man sich der Ansicht, dass im feindlichen Heerlager die besseren Gründe zu finden sind, nicht leicht verschliessen, sobald man die polemischen Erörterungen von K. Fuchs [238] und Hörnes [239] aufmerksam prüft. Namentlich Hörnes' Abhandlung verdient an diesem Orte eine sorgfältige Analyse.

Es wird hier zuerst daran erinnert [240], dass Falb die einzelnen astronomischen Faktoren nicht immer korrekt kombinire, sondern eine unterstützende Wirkung einzelner derselben auch dann noch erwarte, wenn sich dieselben thatsächlich in ihren Aktionen hemmen. Nach Falb müsste in der zeitlichen Vertheilung der Erdbeben eine zwiefache Periodicität vorhanden sein, und er glaube dieselbe auch aus Mallet's Katalog (s. o. §. 1) herausgelesen zu haben [241], allein weder die österreichischen, noch die italienischen Beben entsprechen dieser Annahme [242]. Gegen die Zusammenwerfung von vulkanischen und seismischen Erscheinungen spricht zumal der ruhige und obstruktionslose Verlauf der Lavaergüsse auf den Sandwichinseln [243]. Weitere schwere Bedenken ergeben sich, wenn man die geringe Tiefe des Erschütterungsheerdes, den Gegensatz dieser oft minimalen Centraltiefe zu dem weiten Verbreitungsbezirke, die Art der Fortpflanzung und das Fortschreiten der Stosspunkte in Betracht zieht [244]. Falb will den Radius des Schütterkreises der Centraltiefe annähernd proportional setzen [245]; diese Meinung ward vollständig durch das Erdbeben von Ischia widerlegt, wo nur die nähere Umgebung Casamicciola's hart betroffen wurde. Das letzte steyrische Erdbeben werde Falb nicht anders zu erklären vermögen, als dass er je eine besondere Vulkanspalte unter die Orte Leoben, Bruck, Kapfenberg, Kindberg, Kriegberg, Sömmering, Schottwien und Gloggnitz verlege. Und Fuch s erhebt den vielleicht $\mathbf{z u}$ scharfen, aber doch nicht ganz unberechtigten Vorwurf (a. a. O.), dass zu eilfertig, und ohne hinlänglich scharfe Kritik, jeder an irgend einem Punkte der Erdoberfläche konstatirte Stoss zu Gunsten des Systemes verwerthet zu werden pflege. Die gefährlichste Kritik übt man an einer Theorie stets dann, wenn man ihr eine andere und Besseres leistende gegenüberstellt; diess thut Hörnes in der Schlussabtheilung seines Werkchens [246], und wir selbst hoffen durch Vorführung der modernen seismologischen Lehren im nächsten Paragraphen zu dem gleichen Ziele zu gelangen.

§. 9. Grundsätzliche Unterscheidung vulkanischer und tektonischer Erdbeben. Der philosophische Grundfehler von Falb's Doktrin liegt unseres Erachtens in dem für die Bestrebungen des Autors sonst sehr ehrenvollen Worte [247]: „Eine Theorie darf kein Flickwerk, sondern muss ein einheitliches Ganzes vorstellen." Wer dieses hodegetische Axiom zu scharf betont, läuft immer Gefahr, sich in starren Doktrinarismus zu verlieren und zu vergessen, dass zwar stets von gleichen 
Ursachen auf gleiche Wirkungen, nicht aber umgekehrt von gleichen Wirkungen auf identische Ursachen geschlossen werden darf. Die Humboldt-Buch'sche Theorie litt an demselben Gebrechen, und auch Ch. Darwin irrte, indem er behauptete [248], dass bei Vulkanausbrüchen die magmatischen Fluthen einen offenen, bei Erdbeben dagegen einen verstopften Gang fänden. C. F. Naumann's Versuch, die vulkanischen Erdbeben principiell von jenen zu unterscheiden, bei deren Entstehung nicht an die Mitwirkung eines Feuerberges zu denken gestattet ist, und für welche zunächst der freilich nicht bezeichnende Ausdruck plutonis che Erdbeben gewähltwar, stiess auf A.v. Humboldt's Widerspruch [249]. Gegenwärtig ist die Trennung eine schärfere, indem den vulkanischen Erdbeben die tektonischen, d. h. die aus lokalen Verschiebungen im Schichtenbau der Erdrinde entspringenden Erdbeben gegenübergestellt werden. J. Roth [250] kennzeichnet diesen Gegensatz kurz und klar mit folgenden Worten: "Nach dem heutigen Stande der Untersuchungen, die nicht als abgeschlossen anzusehen sind, bezieht man das Eintreten der Erdbeben auf zwei Ursachen: ein Theil steht im Verbande mit thätigen Vulkanen*), ein Theil wird zurïckgeführt auf Ausgleichung der Spannungen, welche durch die fortdauernde Raumverminderung der festen Erdkruste, besonders ihrer tieferen Regionen, bedingt sind."

Die Aufgabe des Erdbebenforschers spitzt sich unter diesen Verhältnissen mehr und mehr dahin zu, für ein bestimmtes Land die habituellen Stosslinien aufzusuchen. In gewissem Sinne ist diess allerdings ein geometrisches Problem, nur darf man bei der Lösung desselben nicht in's Schablonenhafte verfallen, wie diess Élie de Beaumont sammt seinem getreuen Anhänger Chancourtois that, als er die Erdoberfläche in ein Netz regelmässiger Fünfecke eintheilte und den im Inneren der Erde wirksamen Kräften vorschrieb, sich nur längs einer dieser Begrenzungslinien bethätigen zu können [253]. Eine Musterarbeit ist die in §. 1 citirte von Höfer über die Schütterlinien von Kärnthen. Es sind diess Bruchränder, welche vom oberen Laufe der Mur bis hinab zum Triglav reichen, eine west-östliche Streichungsrichtung erkennen lassen und gut zu den durch Thaldepressionen bezeichneten Längsbrüchen der Gebirge stimmen. Natürlich kann eine

*) Man ist vielleicht, nachdem man sich einmal aus den Banden der exklusiv-vulkanistischen Anschauungen losgerungen hatte, etwas allzu geneigt gewesen, den Wirkungskreis der vulkanischen Beben zu beschränken. Wichtig genug bleiben dieselben auch dann, wenn man sich völlig auf den Boden der neveren Seismologie stellt. So hängen nach Ratzel [251] im nordamerikanischen Westen die Erschütterungen auf's Engste mit dem Spiele der dort thätigen oder auch vielfach nur schlummernden vulkanischen Kräfte zusammen, wie denn das grosse Erdbeben vom 26. März 1872 gerade in die Vulkanreihe am Ostfusse der Sierra Nevada hineinfiel. Gerade auch Suess, der Bannerträger der tektonischen Lehre, aber zugleich ein eminent kritischer Naturforscher, beansprucht unter den italienischen Erdstössen den Löwenantheil für die vulkanischen. Für Sizilien und Kalabrien müsse man drei Kategorieen von Erschütterungen aufstellen [252]: solche, die ihr Centrum in einem Feuerberge haben und sich in undulirenden Bewegungen über eine grössere Fläche ausbreiten (Eruptivstösse), solche, die, ebenfalls von einem Vulkane aus, nach bestimmten Richtungen ausstrahlen ( $\mathrm{Ra}$ dialstösse), und endlich solche, die zunächst gar keinen vulkanischen Charakter an sich zu tragen schienen, die man aber darum doch nicht ohne weiteres als ausser jeder Wechselwirkung zu Vulkanen stehend zu betrachten ein Recht habe. 
Vernarbung der Bruchränder eintreten, dann erlischt in jener Gegend die seismische Kraft vorübergehend und wohl auch dauernd. Um über die inneren Dislokationsvorgänge möglichst Klarheit zu erhalten, empfiehlt sich besonders genaue Verfolgung der Ortsveränderungen, welchen die Punkte grösster Stossintensität unterworfen sind; diesem Wandern der Stosspunkte haben Heim [254] und Hörnes ihre Aufmerksamkeit geschenkt, welch' letzterer in einer an Beobachtungsresultaten reichen Abhandlung [255] u. a. auch das Fortschreiten der Stosspunkte an der Innenseite von Kettengebirgen studirt und geodynamisch im Sinne von Kap. II, §. 6 - erklärt. Er stellt die eigentlichen Schütterzonen, welche auf das Absitzen innerer Zonen auf wahren Verwerfungsspalten hinweisen, den mit Querbrüchen zusammenfallenden Radiallinien entgegen. Spezialisirt werden in neuester Zeit manche tektonische Erderschütterungen als Stauungserdbeben, und dürfte nach Hörnes und Prudnik (s. o. §. 1) vor Allem der Agramer Katastrophe dieser Charakter beizulegen sein. Höfer (a. a. O.) folgert aus seinen eigenen alpinen Untersuchungen in Verbindung mit älteren Ergebnissen Merian's und Jourdy's vom Jura, dass die Staukraft im Alpengebiet, von der venetianischen bis zur bayrischen Ebene, eine meridionale Richtung einhält. - Auf dem gleichen physikalischen Boden scheint nach den vorliegenden, nicht aus erster Quelle stammenden Berichten, welche wir Jakob [256] verdanken, die Gewölbeschubtheorie des Jesuitenpaters Kolberg zu beruhen.

Während aber diese nur mit dem Lateraldruck in einer kontinuirlich schrumpfenden und sich faltenden Kruste operirende Lehrmeinung eine strenge intrakrustale genannt zu werden verdient, fehlt es auch nicht an einer Hypothese, welche die tektonischen Beben zwar als solche anerkannt wissen, dieselben aber auf ryakokrustale Ursachen zurückgeführt sehen möchte. Viele Mühe um Ausbildung dieser letzteren hat sich Pilar [257] gegeben. Man erinnert sich noch seiner im zweiten Kapitel geschilderten Darstellung der Lageveränderungen von Hub- und Senkschollen, welche in das feurigflüssige Magma eintauchen und dadurch zu mancherlei Verwerfungen Anlass geben, die selbst dann wieder die Ursache von Erdbeben werden können. Letztere werden also nach Pilar dadurch verursacht, dass sich Spalten bilden, dass zweitens eine alternirende Bewegung der Keilschollen eintritt, dass durch diese und die aus ihr folgende Verkeilung rasches Oeffnen und Wiederschliessen der Ritzen bedingt ist, und dass endlich das Magma selbst eine Eigenbewegung zeigt (s. §. 8). Die Erdbebenbrücken glaubt $\mathrm{Pilar}$ mit Interferenzerscheinungen in Verbindung bringen zu sollen [258]; dass in der That Neutralisirung seismischer Wirkungen durch Interferenz zweier Erdbebenwellen gerade keine Seltenheit ist, lehren evident Heim's Erfahrungen in den Stossgebieten der Schweiz.

[1] R. Wolf, Biographieen zur Kulturgeschichte der Schweiz, 1. Bàn, Zürich 1858. S. 189. - [2] Pilar, Grundzüge der Abyssodynamik, Agram 1880. S. 151 ff. - [3] Wynne, Notes on the earth-quake in the Punjab of March 2 d, 1878, Journal of the asiatic society of Bengal, Vol. XLVII, b. S. $131 \mathrm{ff} .-[4]$ Knipping, Verzeichniss von Erdbeben, wahrgenonmen in Tokio, Japan, vom September 1872 bis November 1877, Mittheil. d. Ges. f. Natur-u. Völkerkunde Ostasiens, 
1877, 14. Heft. S. 117 ff. - [5] E. Naumann, Ueber Erdbeben und Vulkanausbrüche, ibid. 15, Heft. S. $163 \mathrm{ff}$. - [6] R. Mallet, The great Neapolitan earthquake of 1857. London 1862. - [7] Grimaldi, Descrizione de' tremuoti accaduti nelle Calabrie nel 1783, Napoli 1784. - [8] Bittner, Beitrag zur Kenntniss des Erdbebens von Belluno vom 29. Juni 1873, Wien 1874. - [9] Falb, Gedanken und Studien über den Vulkanismus, Graz 1876, S. 25 ff. - [10] Suess, Die Erdbeben des südlichen Italien, Denkschr. d. k. k. Akad. d. Wissensch., 34. Band, Math.-phys. Kl. S. $1 \mathrm{ff}$. - [11] Ratzel, Das Erdbeben auf Ischia am 28. Juli, Ausland, 1883. S. 661 ff. S. 735 ff. S. 893 ff. - [12] v. Lasaulx, Das Erdbeben von Casamicciola auf Ischia, Humboldt, 1. Jahrgang. S. 1 ff. - [13] Hantken v. Prudnik, Das Erdbeben von Agram im Jahre 1880, Budapest 1882. - [14] Pilar, Grundzüge etc. S. 156 ff. - [15] Jeitteles, Bericht über das Erdbeben vom 15. Januar 1858 in den Karpathen und Sudeten, Wien 1858. - [16] Suess, Die Erdbeben Niederösterreichs, Denkschr. d. k. k. Akad. d. Wissensch., 33. Band, Math. - phys. Kl. S. $1 \mathrm{ff}$. - [17] Höfer, Die Erdbeben Kärnthen's und deren Stosslinien, Wien 1880. - [18] v. Seebach, Das mitteldeutsche Erdbeben vom 6. März 1872; ein Beitrag zur Lehre vom Erdinneren, Leipzig 1873. - [19] v. Lasaulx, Das Erdbeben von Herzogenrath am 12. Oktober 1873; ein Beitrag zur exakten Geologie, Bonn 1874; Das Erdbeben von Herzogenrath im December 1881, ibid. 1878. - [20] A. Forster, Uebersicht der schweizerischen Erdbeben im November 1881, Gaea, 18. Jahrgang. S. $82 \mathrm{ff}$; Uebersicht der schweizerischen Erdbeben im December 1881, ibid. S. 142 ff. - [21] Heim, Erdbebenbeobachtungen in der Schweiz 1880-81, Gaea, 19. Jahrgang. S. 248 ff. - [22] De Rossi, Meteorologia endogena, vol. I, Milano 1879, vol. II, ibid. 1882. - [23] Neumayer, Bericht über die Verhandlungen des zweiten internationalen Meteorologen-Kongresses in Rom vom 14. bis 22. April 1879, Hamburg 1880. S. 11. - [24] Ibid. S. 88. - [25] Favaro, Intorno ai mezzi usati dagli antichi per attenuare le disastrose consequenze dei terremoti, Venezia 1874; Nuovi studî intorno ai mezzi usati dagli antichi per attenuare le disastrose consequenze dei terremoti, Venezia 1875. - [26] R. Mallet, The first principles of experimental seismology, London 1862. - [27] R. u. J. Mallet, The earthquake catalogue, Rep. of the british association for the advancement of science, 1858. - [28] Jul. Schmidt, Studien über Erdbeben, Leipzig 1875. [29] v. Hoff-Berghaus, Chronik der Erdbeben und Vulkanausbrüche, Gotha $1840-41$. - [30] Perrey, Propositions sur les tremblements de terre et les volcans, Paris 1863. - [31] J. Roth, Ueber Erdbeben, Berlin 1882. - [32] Toula, Ueber den gegenwärtigen Stand der Erdbebenfrage, Wien 1881. - [33] Roth, Ueber Erdbeben, S. 5. - [34] A. v. Humboldt, Kosmos, 1. Band, Stuttgart und Augsburg 1845. S. 218. - [35] Roth, S. 7. - [36] C. Plinii Secundi historiae naturalis libri XXXI, lib. II. cap. 82. - [37] Nehring, Die geologischen Anschauungen des Philosophen Seneca, 1. Theil, Wolfenbüttel 1873. S. 29. - [38] Peschel, Abhandlungen zur Erd- und Völkerkunde, herausgeg. von Löwenberg, 2. Band, Leipzig 1878. S. $281 \mathrm{ff}$. - [39] Peschel-Leipoldt, Physische Erdkunde, 1. Band, Leipzig 1879. S. 261. [40] Kant's Schriften zur physischen Gengraphie, herausgeg. von F. W. Schubert, Leipzig 1839. S. 253 ff. - [41] Ibid. S. 232. - [42] Suess, Das Antlitz der Erde, 1. Abtheilung, Prag und Leipzig 1883. S. 103 ff. - [43] Roth, S. 8. - [44] Ibid. S. 9. - [45]'J. Schmidt, Studien etc. S. $41 \mathrm{ff}$. S. $118 \mathrm{ff}$ - - [46] Nehring, Die geol. Ansch. etc. 1. Theil. S. 25. - [47] Roth, S. 25. - [48] Hamilton, Account of the earthquakes, which happened in Italia from Februar to May 1783, Phil. Transact. Vol. LXXIII. S. 169 ff. S. 209 ff. - [49] Dolomieu, Sur le tremblement de terre de la Calabrie, Rome 1784. S. 50 ff. - [50] Roth, S. 26. - [51] Falb, Gedanken etc. S. 280. - [52] Roth, S. 24. - [53] Sir Isaac Newton's mathematische Principien der Naturlehre, deutsch von Wolfers, Berlin 1872. S. $353 \mathrm{ff}$. [54] v. Seebach, Das mitteld. ete. S. 180. - [55] Ibid. S. 178. - [56] Roth, S. 21. - [57] Fr. Hoffmann, Geschichte der Geognosie und Schilderung der vulkanischen Erscheinungen, Berlin 1838. S. 342 ff. - [58] Ibid. S. 41. - [59] Nehring, 1. Theil. S. 20. - [60] Plinius, lib. II. cap. 89. - [61] Nehring, 1. Theil. S. 22. [62] Roth, S. 14. - [63] Nehring, 1. Theil. S. 23 ff. - [64] Roth, S. 17. [65] Ibid. S. 15. - [66] Ch. Darwin, Geological observations on the volcanic islands, 2. ed., London 1876. S. 237. - [67] Suess, Das Antlitz etc. S. 124 ff. [68] Ibid. S. 137. - [69] Diamilla-Müller, Lettere scientifiche per il popolo Italiano, Milano 1873. S. 440 ff. - [70] Roth, S. 13. - [71] v. Sonklar, Von den Ueberschwemmungen, Wien, Pest und Leipzig 1883. S. 5. -- [72] Ibid. S. 8. [73] H. Fischer, Ueber einige Gegenstände der physischen Geographie bei Strabo; ein Beitrag zur Geschichte der alten Geographie, Wernigerode 1878. S. 7. - 
[74] Thukydides, De bello Peloponnesiaco, lib. VII. cap. 89. - [75] v. Hoff-Berghaus, Chranik etc. S. 244. - [76] Griesbach, Die Erdbeben der Jahre 1867 und 1868, Mittheil. d. k. k. geogr. Ges. in Wien, 12. Band. S. 204 ff. - [77] Geinitz, Das Erdbeben von Iquique am 9. Mai 1877, Petermann's geogr. Mittheil., 1878. S. 454 ff.; Nova Acta d. leop.-kar. Akad. der Naturforscher, 40. Band. S. 385 ff.; Gaea, 15. Jahrgang. S. 650 ff. - [78] Graf Berg, Die Flutherscheinungen des Meeres bei Erdbeben, Gaea, 17. Jahrgang. S. 9 ff. - [79] Ch. Darwin, Naturalist's voyage round the world, London 1841. S. 309. - [80] Geinitz, Die Fluthwellen bei Erdbeben, Gaea, 17. Jahrgang. S. 409 ff. - [81] Graf Berg, Die Flutherscheinungen bei Erdbeben, ibid. 18. Jahrgang. S. 260 ff. - [82] Rachel, Nochmals die Fluthwellen und das Zurückweichen des Meeres bei Erdbeben, ibid. 18. Jahrgang. S. 19 ff. - [8:3] Birgham, Die Erdbebenfluth im grossen Ocean, Globus, 1878. S. 216 ff. $-[84]$ v. Hochstetter, Die Erdbebenfluth im pacifischen Ocean, Peterm. geogr. Mittheil., 1869. S. 222 ff. - [85] Suess, Das Antlitz etc. S. 25 ff. - [86] Ibid. S. 92. - [87] Ibid. S. 43. - [88] Ibid. S. 61. - [89] Favaro, Intorno ai mezzi etc. S. 28. - [90] Francisci Petrarcae epistolae de rebus familiaribus, ed. Fracassetti, Vol. I, Florentiae 1859. Ep. V. - [91] Favaro, Intorno al probabile autore di una predizione di terremoto riferita da Petrarca, Venezia 1876. - [92] Teloni, Dei terremoti, loro cagioni, effetti e malori che producono e loro preservativa in generale, Viterbo 1703. - [93] Plinius, lib. II. cap. 81. - [94] Favaro, Intorno ai mezzi etc. S. 37. - [95] Cardanus, De subtilitate libri XXI, Basileae 1553. S. 85. - [96] Favaro, Intorno ai mezzi etc. S. 39 ff. - [97] Ibid. S. 42 ff. - [98] Kant, Schriften etc. S. 242 ff. - [99] Waltenberger, Das bayrische Hochland und Salzburg nebst den angrenzenden Gebieten von Tyrol, Augsburg 1880. S. 305. [100] Favaro, Intorno ai mezzi etc. S. 69. - [101] Quetelet, Météorologie de Belgique, comparée à celle du globe, Bruxelles et Paris 1867. S. 422. - [102] Serpieri, Il terremoto d'Italia del 12 marzo 1873 e leggi e fenomeni communi a molti terremoti, Pesaro 1874. - [103] Favaro, Nuovi studî etc. S. 133 ff. [104] Kries, Von den Ursachen der Erdbeben, Utrecht 1820 - [105] Monte, Sperienze comparative sui sismometri, fatte nell' osservatorio di Livorno, Livorno 1873. - [106] Bertelli, Risposta ad alcune obiezioni del prof. Pietro Monte intorno ai moti microsismici, Bull. del Volcanismo Italiano, vol. I. S. 123 ff. - [107] Melzi, Sulla relazione dei moti tromometrici e la velocità del vento, Atti dell' accad. pont. dei lincei, 1875. S. 356 ff. - [108] Gemma Frisius, De naturae divinis characterismis libri II, Antverpiae 1565, I. S. 40 ff. - [109] Kant, Schriften etc. S. 234. - [110] Fron, Sur la prévision de certains tremblements de terre, Compt. rend. de l'acad. franç., tome LXXIV. S. 331 ff. - [111] Poëy, Rapport entre les taches solaires, les tremblements de terre aux Antilles et au Mexique et les éruptions volcaniques sur tout le globe, ibid. tome LXXVIII. S. 51. - [112] Kluge, Ueber Synchronismus und Antagonismus von vulkanischen Eruptionen und die Beziehungen derselben zu den Sonnenflecken und erdmagnetischen Variationen, Leipzig 1866. - [113] Fritz, Die Beziehungen der Sonnenflecken zu den magnetischen und meteorologischen Erscheinungen der Erde, Haarlem 1878. S. 241. [114] F. Knapp, Mittheilungen aus der cubanischen Thier- und Pflanzenwelt, Abhandl. d. naturf. Gesellsch. zu Nürnberg, 6. Band. S. 60. - [115] Mädler, Populäre Astronomie, 7. Aufl., bes. v. Klinkerfues, Strassburg 1882. S. 416. [116] Die Prophezeiung des Herrn Delannay über Erderschütterungen in den Jahren 1883 und 1886, Ausland, 1883. S. 917. - [117] Humboldt, Kosmos, 1. Band. S. $214 \mathrm{ff} .-[118]$ v. Seebach, Das mitteld. etc. S. $110 \mathrm{ff}$. - [119] Humboldt, Kosmos, 1. Band. S. 216. - [120] Vulkanstudien bei Santorin, Gaea, 18. Jahrgang. S. 645. - [121] Plinius, lib. II. cap. 82. - [122] Ibid. lib. XXXVI. cap. 21. - [123] Favaro, Intorno ai mezzi etc. S. 95 ff. - [124] Favaro, Nuovi studî etc. S. 99 ff. - [125] Ibid. S. 103 ff. - [126] Favaro, Intorno ai mezzi etc. S. 44. [127] Ibid. S. 138. - [128] Sguario, Specimen physico-geometricum de terrae motibus ad architecturae utilitatem concinnatum, Venetiis 1756. S. 41. - [129] Favaro, Norme di costruzioni per aumentare la resistenza degli edifizi contro il terremoto, Venezia 1883. - [130] De Rossi, Met. end., tomo I. S. 200 ff. [131] Favaro, Norme etc. S. 43. - [132] Ibid. S. 49 ff. - [133] Lescasse, Études sur les constructions Japonnaises et sur les constructions en général an point de vue des tremblements de terre, et description d'un système destiné à donner une grande sécurité aux constructions en maçonnerie, Paris 1877. - [134] Favaro, Intorno ai mezzi etc. S. 129 ff. - [135] Bertholon de St. Lazare, De l'électricité des météores, tome I, Lyon 1787. S. 399 ff. - [136] Wiedeburg, Ueber die Erdbeben und die allgemeinen Nebel von 1783, Jena 1784. - [137] Kant, Schriften etc. 
S. 279. - [138] Roth, S. 28. - [139] Zöllner, Ueber eine neue Methode zur Messung anziehender und abstossender Kräfte, Ann. d. Phys. u. Chem., 150. Band. S. 133. - [140] Gehler's Physikalisches Wörterbuch, 2. Aufl., 3. Band, Leipzig 1827. S. $824 \mathrm{ff}$. - [141] Jakob, Unsere Erde; astronomische und physische Geographie, Freiburg i. B. 1883. S. 329. - [142] Humboldt, Kosmos, 1. Band. S. 211. [143] R. Mallet, The earthquake catalogue, S. 98 ff. - [144] Palmieri, Il sismografo dell' osservatorio Vesuviano e quello della specola universitaria, Napoli 1874. - [145] Peschel, Abhandl. etc., 2. Band, Leipzig 1878. S. 521 ff. - [146] v. Seebach, Das mitteld. etc. S. 187. - [147] Kreil, Ueber einen neuen Erdbebenmesser, Wien 1856. - [148] v. Lasaulx. Das Erdbeben von Herzogenrath etc. S. $148 \mathrm{ff}$; - [149] Bertelli, Tromosismometro, Roma 1874. S. 3. - [150] Favaro, Nuovi studî etc. S. 83 ff. - [151] Ibid. S. 117 ff. - [152] Knipping, Verzeichniss von Erdbeben, wahrgenommen in Tokio, Japan, etc. S. 117. - [153] G. Wagner, Bemerkungen über Erdbebenmesser und Vorschläge $\mathrm{zu}$ einem neuen Instrumente dieser Art, ibid. 15. Heft. S. 216 ff. - [154] Ibid. S. 222. - [155] Euler, Methodus inveniendi lineas curvas maximi minimive proprietate gaudentes, Lausannae et Genevae 1744. S. 51 ff. - [156] Grunert, Der Rotationskörper des kleinsten Widerstandes, Archiv der Mathematik und Physik, 45. Theil. S. 237 ff. - [157] Physical notes, Nature, Vol. XXIV. S. 113. - [158] Peal, A new sismometer, ibid. S. 461. - [159] Zöppritz, Die Fortschritte der Geophysik, Wagner's geogr. Jahrbuch, 9. Band. S. 14. - [160] Merian, Ueber die in Basel wahrgenommenen Erdbeben nebst einigen Untersuchungen über Erdbeben im Allgemeinen, Basel 1834. - [161] Egen, Ueber das Erdbeben am Rhein im Jahre 1828, Ann. d. Phys. u. Chem., 13. Band. S. 153 ff. - [162] Gehler, Phys. Wörterb., 2. Aufl., 9. Band, 3. Abth., Leipzig 1840. S. 2304. - [163] v. Seebach, Das mitteld. etc. S. 143. - [164] Ibid. S. 129. - [165] Falb, Gedanken etc. S. 197. [166] Neumayer, Anleitung zu wissenschaftlichen Beobachtungen auf Reisen, Berlin 1875. S. 317 ff. - [167] Falb, Gedanken etc. S. 211. - [168] Ibid. S. 213 ff. - [169] v. Seebach, Das mitteld. etc. S. 161. - [170] Falb, Gedanken etc. S. 206. - [171] Falb, Ueber die Erdbeben und ihren Zusammenhang mit dem Stande der Sonne, Sirius (2) 4. Band. S. 17. - [172] v. Lasaulx, Das Erdbeben von Herzogenrath etc. S. $116 \mathrm{ff}$. - [173] Heim, Erdbebenbeob. etc. S. 250. - [174] Lersch, Ueber die Ursachen der Erdbeben; ein historischer Rückblick, Gaea, 15. Jahrgang. S. 213 ff. S. 296 ff. S. 356 ff. S. 423 ff. - [175] Rahmer, Die biblische Erdbebentheorie; eine exegetische Studie, Leipzig 1881. - [176] Aristoteles, Meteorol., lib. II. cap. 7. - [177] Ammianus Marcellinus, Rerum gestarum lib. XVII. cap. 7. - [178] Nehring, Die geol. Ansch. etc., S. 36. - [179] Die Wetterlöcher in den Alpen, Ausland, 1872. S. 599. - [180] Krejcí, Ueber Exhalationen warmer Luft am Gipfel des Kahlenberges bei Lobositz, Sitzungsber. d. k. böhm. Ges. d. Wissensch., 1881. S. 59 ff. - [181] Altmann, Versuch einer historischen und physischen Beschreibung der helvetischen Eisberge, Zürich 1751. S. 128 ff. - [182] Lucretius, De rerum natura, lib. VI. v. $534 \mathrm{ff}$. - [183] Lersch, Ueber die Urs. etc. S. 219. - [184] Ibid. S. 220. - [185] Ibid. S. 296 ff. - [186] Lucretius, lib. VI. v. 534 ff.; v. $639 \mathrm{ff}$; v. $703 \mathrm{ff}$. - [187] Nehring, Die geol. Ansch. etc. S. 38. - [188] Seneca, Naturales Quaestiones, lib. VI, cap. 21. - [189] Sprenger, As-Soyutís work on earthquakes, Journal of the as. soc. of Bengal, Vol. XII, b. S. 746 ff. [190] Zakarija Ben Muhammed Ben Mahmûd El-Kazwîni's Kosmographie, 1. Halbband, deutsch von Ethé, Leipzig 1868. S. 303 ff. - [191] Lersch, Ueber die Urs. etc. S. 297. - [192) Der Ursprung des Nils; nach Erasmus Franciscus „Neu polirter Geschicht-, Kunst- und Sitten-Spiegel ausländischer Völker," Deutsche Rundschau f. Geogr. und Stat., 6. Jahrgang. S. 123 ff. - [193] Heller, Geschichte der Physik von Aristoteles bis auf die neueste Zeit, 1. Band, Stuttgart 1882. S. 177. [194] Favaro, Nuovi studî etc. S. 19. - [195] Froidmont, Meteorologicorum libri VI, Lovanii 1646. S. 283. - [196] La composizione del mondo di Ristoro d'Arezzo, ed. Narducci, Roma 1859. S. 21 ff. - [197] Favaro, Nuovi studî etc. S. 22 ff. [198] Rixner und Siber, Leben und Lehrmeinungen berühmter Physiker am Ende des XVI. und am Anfang des XVII. Jahrhunderts, 2. Heft, Sulzbach 1820. S. 66. - [199] Favaro, Nuovi studî etc. S. 13. - [200] Nehring, Die geol. Ansch. etc. S. 36. - [201] Lersch, Ueber die Urs. etc. S. 298 ff. - [202] Kant, Schriften etc. S. 265. - [203] Corn. Taciti ab excessu divi Augusti Annal. lib. II. cap. 27. [204] Priestley, Geschichte und gegenwärtiger Zustand der Elektricität, nebst eigenthümlichen Versuchen, deutsch von Krünitz, Berlin und Stralsund 1771. [205] Sarti, Saggio di congetturi sui terremoti, Lucca 1783. - [206] Vassalli-Eandi, Rapport sur le tremblement de terre qui a commencé le 2 avril 1808, Turin 1808. 
- [207] Stuckely, The philosophy of earthquake natural and religious, London 1750. - [208] Bina, Ragionamento sopra la cagione de terremuoti, Perugia 1751. [209] Cavallo, Vollständige Abhandlung der Lehre von der Elektricität, aus dem Englischen, Leipzig 1785. S. 184 ff. - [210] Gehler's phys. Wörterb., II. Aufl., 9. Band, 3. Abtheil. S. 2318 ff. - 211] Matteucci, Influenza dell' elettricità terrestre sui temporali, Bologna 1829. - [212] Favaro, Intorno ai mezzi etc. S. 80. - [213] Pilar, Grundzüge etc. S. 114 ff. - [214] Gehler, II. Aufl., 9. Band, 3. Abtheil. S. 2320. - [215] A. Boué, Parallèle des tremblements de terre, des aurores boréales et du magnétisme terrestre, Bull. de la soc. géol., (2) Vol. XVIII. S. 466 ff. - [216] Janeček, Rada jugoslavenske akademije znanosti i umjetnosti, Agram 1881. S. 202 ff. - [217] Humboldt, Kosmos, 1. Band. S. 222. - [218] Möhl, Erdbeben und Vulkane, Berlin 1878. - [219] Boutigny, Studien über die Körper im sphäroidalen Zustand; neuer Zweig der Physik, deutsch von Arendt, Leipzig 1868. S. 49. - [220] Leidenfrost, De aquae communis nonnullis qualitatibús tractatus, Duisburgi 1756. - [221] Carl, Der Leidenfrost'sche Versuch im Erdinneren als Erklärung der Ursache der Erdbeben und der vulkanischen Eruptionen, Repert. f. Experimentalphysik, 1. Band S. 264 ff. - - [222] Thomassen, Die Katastrophe von Ischia, Gaea, 19. Jahrgang. S. 577 ff. - [223] Necker, On a probable cause of certain earthquakes, Phil. Mag., (3) Vol. XIV. S. 111. - [224] Lersch, Ueber die Urs. etc. S. 358. - [225] Bischof, Lehrbuch der chemischen und physikalischen Geologie, 3. Band, Bonn 1866. S. 472 ff. - [226] Volger, Untersuchungen über das Phänomen der Erdbeben in der Schweiz, Gotha 1857-58. - [227] Fraas, Aus dem Orient, Stuttgart 1867. S. 78. - [228] Reyer, Höhlen und Einstürze, Gaea, 18. Jahrgang. S. 628 ff. - [229] Kant, Schriften etc. S. 273 ff. - [230] S. o. [30]. - [231] Ibid. S. 7. - [232] Falb, Grundzüge zu einer Theorie der Erdbeben und Vulkanausbrüche, Graz 1869; Gedanken und Studien über den Vulkanismus, Graz 1876: Von den Umwälzungen im Weltall, Wien 1881. - [233] v. Lasaulx, Das Erdbeben von Herzogenrath etc. S. 146. - [234] Pilar, Grundzüge etc. S. 148 ff. - [235] J. Schmidt, Studien etc. S. 179. - [236] Peschel-Leipoldt, Physische Erdkunde, Leipzig 1879. S. 267 ff. - [237] Weitzel, Einiges zu Falb's Theorie der Erdbeben und Vulkanausbrüche, Mittheil. d. naturw. Vereins für Rügen und Vorpommern, 13. Band. - [238] K. Fuchs, Bericht über die vulkanischen Ereignisse des Jahres 1871, Neues Jahrb. f. Miner. u. Geol., 1872. S. 718 ff. [239] Hörnes, Die Erdbebentheorie Rudolf Falb's und ihre wissenschaftliche Grundlage kritisch erörtert, Wien 1881. - [240] Ibid. S. 42 ff. - [241] Falb, Von den Umw. etc. S. 161. - [242] Hörnes, Die Erdbebentheorie etc. S. 55 ff. - [243] Ibid. S. 90 ff. - [244] Ibid. S. 110 ff. - [245] Falb, Von den Umw. etc. S. 252 ff. [246] Hörnes, Die Erdbebentheorie etc: S. 118 ff. - [247] Falb, Gedanken etc. S. 15. - [248] Ch. Darwin, Kleinere geologische Abhandlungen, deutsch von Carus, Stuttgart 1878. S. 35. - [249] Peschel-Leipoldt, Phys. Erdk., 1. Band. S. 260. - [250] Roth, S. 30. - [251] Ratzel, Physikalische Geographie und Naturcharakter der Vereinigten Staaten von Nordamerika, München 1878. S. 145 ff. [252] Suess, Die Erdb. d. südl. Italien, S. 23 ff. - [253] E. de Beaumont, Sur la corrélation des directions des différents systèmes de montagnes, Compt. rend. de l'acad. franc., tome XXXI. - [254] Vgl. [21]. - [255] Hörnes, Erdbebenstudien, Jahrb. d. k. k. geol. Reichsanstalt, 28. Band. - [256] Jakob, Unsere Erde. S. 343 ff. - [257] Pilar, Grundzüge etc. S. 127 ff. - [258] Ibid. S. 137. 


\section{$\mathrm{N}$ a $\mathrm{m}$ e $\mathrm{n}-\mathrm{In} d \mathrm{e} \mathrm{x}$.}

\section{A.}

Abano (Pietro de) 142. - Abbot 374. - Abendroth 76. - Abich 22. 339. 348. 358. 366. 368. - Abraham a Sta. Clara 28. - Abraham bar Chija 135. Abulfeda 132. - Abul Hassan Ali 133. 152. - Acacius 130. - Adams 60. 100. 218. - Adhémar 107. 252. - Aelian 349. - Aepinus 120. 309. 313. - Aetius 2. - Agatharchides 6. - Agathemeros 272. - Agathodaemon 272. - Agesianax 114. - Agnese 282. - Agricola (Georg) 33. 335. 355. 396. - Agricola (Rudolf) 142. - Agrippa 273. - Airy 19. 62. 68. 84. 103. 109. 175. 177. 184. 191. 195. 196. 378. - Albert (d. Gr.) 11. 32. - Albini 280. 297. - Albinus 335. - Albîrunî 9. - Albrecht 174. 190. - Alexander (d. Gr.) 5. - Alfraganus 140. 153. - Alfons (v. Kastilien) 46. 237. 245. - Alhazen (Ibn Haitham) 9. 138. - Alkhazînî 9. - Alkmaion 210. - Alliacus 32. - Al Mamun 140. - Alpetragius 235. - Altmann 17. 33. 394. 406. - Ammianus Marcellinus 393. 406. Amsler 294. 298. Ampère 355. 387. - Anaxagoras 3. 31. 77. 114. 129. 392. Anaximander 3. 272. 380. 393. - Anaximenes 3. 380. 393. - Andree 26. 366. Andrews 321. - Angström 87. 88. 96. - Anich 285. 297. - Anthemios 394. Apian (Peter) 69. 71. 76. 94. 282. 284. 297. 298. - Apian (Philipp) 71. 94. 283. 286. 297. 298. - Apollonios 236. - Apulejus 5. 32. - Aquilonius 272. - Arago 57. 70. 76. 100. 103. 112. 125. 127. 144. 175. 307. - Archimedes 130. 134. 139. 152. 196. 239. 269. 293. 326. - Arena (Philippus) 192. 200. - Arendt 407. - Argelander 266. 271. - Aristagoras 272. - Aristarchos 211. 239. 269. - Aristobulos 394. - Aristoteles 4. 5. 10. 13. 17. 32. 71. 130. 133. 139. 152. 154. 216. 234. 235. 254. 267. 269. 270. 368. 393. 394. 395. 396. 406. - Aristyllos 253. - Arnd 280. 297. - Arrowsmith 281. 287. - Aryabhatta 211. - Ascherson 22. - Asmus 280. 297. - As-Soyutí 395. 406. - v. Asten 91. 96. - Asterios 123. 128. Attalos 255. - Atwood 170. - August (A.) 282. 297. - August (Kurfürst) 289. Augusti 381. - Augustin 130. 314. 354. - Augustus (Kaiser) 273. 406. - Autenheimer 270. - Auwers 241. - Ayrton 311.

\section{B.}

Babinet 282. - Bach 287. 298. - Bacharach 165. 189. - Bache 378. Backlund 91. 96. - Bacon (Roger) 11. 111. 127. - Bacon (v. Verulam) 14. 32. 95. - Baden Powell 125. - v. Bär 225. 226. 268. - v. Baeyer 145. 146. 154. Baille 186. 191. - Bailly 139. 153. 243. - Baily 63. 175. 186. 191. - Baltzer 361. - Banks 309. - Barnard 317. 328. - Bartels 153. - Bassano 34. v. Bauernfeind 139. 153. 208. 210. 276. 285. 296. - Baumgartner 127. 190. Bautraud 290. - Bazaine 85. - Beaugrand 155. - Beaumont (Élie de) 277. 288. 323. 357. 402. 407. - Beautemps-Beaupré 286. - Beccaria 122. 144. 153. 167. 355. 368. 396. - Becker 291. 298. - Beda (Venerabilis) 131. 235. 395. - Beer 
103. 115. 126. 127. - Bell 83. - Belli 112. 323. 328. - Bembo 338. 341. 365. - Benfey 270. - Benoni 221. 268. - Benzenberg 80. 95. 220. 268. - Bequerel 77. - Graf Berg 378. 401. - Bergel 130, 152. - Berger 3. 5. 6. 7. 31. 32. 138. 152. 277. 396. - Berghaus (H. K. W.) 19. 24. 34. 404. 405. - Berghaus (Hermann) 280. - Bergman 17. 18. 33. 302. 312. - Bernoulli (D.) 15. - Bernoulli (Jak.) 72. 94. - Bernoulli (Joh.) 15. 154. - Bertholon de St. Lazare 355. 384. 405. Bertelli 219. 267. 381. 386. 387. 406. - Bertrand (A.) 381. - Bertrand (J. L. F.) 183. - Berzelius 375. - Bessel 75. 76. 77. 91. 95. 100. 111. 113. 115. 127. 144. 145. 149. 150. 153. 154. 173. 174. 175. 176. 181. 186. 191. 192. 193. 195. 200. 209. 215. 241. 267. 269. 270. - Bessels 22. 175. 190. 285. 297. - Besso 172. 190. v. Bezold 350. - Bezout 24. 34. - Bianchi 227. - Bianchini 97. 100. 125. Bickmore 336. 344. 367. - Biehringer 328. 328. - v. Biela 70. 71. - Bielmayr 230. - Bina 397. 407. - Biot 73. 78. 87. - Birgham 378. 405. - Birnbaum 132. 152. - Birt 116. - Bischof 28. 35. 120. 154. 301. 3C4. 311. 312. 313. 336. 349. 350. 356. 366. 367. 368. 399. 406. - Bittner 370. 404. - Black 116. - Blaeu 141. - Blanford 25. 26. 34. - Boccaccio 11. - Bode 18. 33. 46. 56. 66. 92.96. 124. 128. 213. 267. 271. - Böckh 211. 267. - Böddicker 103. 126. - Böhm 60. 93. - Boerhave 303. 312. - Bötticher 268. - v. Boguslawski 81. 93. - Bohnenberger 148. 154. 160. 173. 181. 190. 244. 255. 257. 270. - Fürst Boncompagni 114. 127. - Bond 75. 111. 116. 127. - Bonifacius 131. - Bonne 281. - Bonnet 17. 93. 124. - Bonpland 20. 21. - Borda 173. - Borelli 69. - Borenius 175. 194. - Borgondio 276. 296. - Bory St. Vincent 34. - Bos 29. - Boscovich 60. 144. 153. 191. - Boucheporn 213. - Boué (Ami) 323. 328. 397. 407. - Bouguer 111. 143. 153. 167. 173. 189. 190. 228. 268. 400. - Boussinesq 328. - Boutigny 398. 407. - Bouvard 262. 300. - Bowditch 175. - Boyle 303. 312. - Bradley 241. 242. 243. 263. 264. 271. - Brahe (Tycho) 48. 103. 212. 213. 219. 241. 245. 246. 255. 269. - Brahmegupta 211. - Brandes 80. 83. 95. - Braschmann 225. 226. 268. - Braun 280. - Brauns 308. 313. - Bravais 22. 132. 269. - Bredichin 59. 77. 95. - Bredstorff 291. - Breislak 315. 319. 328. 335. 366. - Bremiker 190. - Breusing 14. 15. 32. 272. 273. - Brewster 125. - Brezina 80. 95. - Brinkley 241. - Brocard 32. - Bromme 26. - Brorsen 76. 78. 87. - Brousseau 145. Browning 103. - Bruchhausen 192. - Bruhns 21. 33. 93. 95. 368. - Bruns 200. 201. 203. 204. 205. 206. 207. 208. 209. 210. - Brunel 339. 366. - Buache 18. 22. 33. 289. 290. 292. - v. Buch 8. 19. 21. 22. 27. 33. 302. 312. 338. 341. 344. 345. 347. 348. 352. 356. 357. 358. 366. 367. 368. 398. 402. - Budde 44. 51. - Bürg 262. - Bürgi 172. - Büsching 17. - Buff 221. 222. 268. - Buffon 37. 39. 51. 71. 191. 213. 354. - Bunsen 47. 65. 352. - Bunt 229. 230. 231. - Burckhardt 262. - Burmeister 22. 33. - Burnes 379. 380. - Burnet 37. 124. - Burrow 144. 153. - Buschbeck 298. - Butler 221. - Buys-Ballot 19.

\section{C.}

Cacciatore 385. 386. - Cailletet 320. - Calandrelli 241. - Caleagnini 212. 267. - Cáldas 21. 33. - Camus 143. 153. - Cannabich 23. 34. - Canonica 144. - Canstedt 25. - Cantor 142. 153. 380. - Capeller 28. 394. - Capoa 355. - Capuanus (de Manfredonia) 136. - Caramuel (v. Lobkowitz) 227. 268. - Cardanus 73. 78. 232. 381. 396. 405. - Carl 189. 269. 399. 407. - Carlier 153. Carlini 167. 184. - Carové 267. - Carpenter 113. 116. 119. 120. 121. 127. 362. - Carrington 61. 93. - Carus 407. - Cassani 114. 127. 128. - Cassini (Dominic) 55. 85. 88. 95. 100. 115. - Cassini (J. de Thury) 98. 142. 143. 153. - Cassini (J. D. de Thury) 144. 153. 300. 312. - Cassiodorus 142. - Cavallo 396. 407. Cavendisch 184. 186. 191. - Cayley 291. 298. - Celsius 17. 143. - Chabas 210. 267. - Chabaille 32. - Chacornac 67. - Chalmers 125. - v. Chamisso 21. Chancourtois (Béguyer de) 277. 296. 409. - Chapotot 285. 297. - Chappe 292. Chardin 85. - Chasles 142. 153. 188. - Chaturveda 211. - Chauvin 287. Chazelles 16. 42. - Cheops 183. - Childrey 85. 95. - Chladni 78. 83. 89. 95. 319. - Chrysostomus 130. - Church 306. 313. - Clairaut 70. 143. 153. 155. 162. 178. 179. 180. 180. - Clarke (A. R.) 150. 151. 154. 191. - Clarke (D. E.) 356. 368. - Clausius 49. 52. 165. 184. - Clavius 240. - Clemens 56. 92. - Clüver 37. Coatpont 282. - Colbert 142. - Coleridge 68. - Colon (Chr.) 13. 142. Colon (H.) 274. - Colonna 380. - Cook 16. 287. - Coombe 230. - Coordes 275. 296. - Coppernicus 130. 136. 152. 212. 213. 214. 216. 219. 228. 236. 238. 239. 240. 243. 245. 251. 255. 267. 269. 270. 327. - Cordier 305. 312. 313. 355. 363. 
369. - Cornelius 26. 34. 48. 49. 52. 65. 93. - Cornewall Lewis 234. 269. Cornu 186. 191. - Cortambert 25. - Cotes 162. 293. - Coulomb 184. 185. Coulvier-Gravier 79. - Couplet 142. 174. - Crahay 230. - Craig 282. 297. Cramer (J. A.) 28. - Cramer (W.) 29. 35. - Credner 349. 367. - Criginger 284. Croll 107. 252. 253. 270. - Crookes 77. 184. - Cruquius 289. - Culmann 349. 367. - Curtze 212. 245. 267. 327. - Cusa (Kardinal) 56. 92. 211. - Cysatus 54. 69. - Czolbe 49. 52.

\section{D.}

D'Abbadie 21. 219. 387. - D'Acosta 13. 32. - Daguerre 116. - Dahlander 193. 209. - v. Dalberg 77. 95. - Dalby 144. 153. - D'Alembert 16. 100. 145. 155. 162. 223. 257. 262. 263. 268. 270. 271. - D'Avezac 272. 276. 295. 296. Dalla Vedova 29. - Dampier 16. - Dana 332. 353. 358. - Daniel (Pater) 124. - Dante Alighieri 11. 12. 32. 114. 127. - D'Anville 284. - Darapsky 224. 268. - D'Archiac 310. 313. - D'Arrest 67. 94. 101. 126. - Darwin (Ch.) 21. 27. 35. 40. 125. 189. 338. 376. 378. 402. 405. 407. - Darwin (G. H.) 19. 161. 186. 194. 209. 215. 267. 316. 317. 328. - Daubeny 356. 357. - Daubrée 19. 49. 347. 356. - D'Aubuisson 303. 356. 368. - Davy 350. 356. 368. 397. - Dawes 56. 103. De Ball 67. - Debes 281. 297. - - Dechen 24. 304. 312. - De Gasparis 67. De la Condamine 16. 143. 153. 189. 191. 287. - De la Hire 55. 100. 112. 115. 116. 142. 300. - Delambre 85. 95. 103. 190. 234. - De la Rive 307. - De la Rue 103. - Delaunay (Astronom) 216. 316. 328. - Delaunay (Kapitän) 382. 405. De Laune 73. 94. - Delisle 60. 88. 280. 284. - Delkeskamp 286. - v. Dellingshausen 74. 94. - Deluc 17. - Demokrit 3. 129. 392. 395. - Denzler 167. 189. 226. 268. - De Rossi 19. 347. 370. 371. 384. 387. 404. 405. - De Rostan 89. Descartes (Cartesius) 37. 38. 347. 358. - Descelliers 274. 296. - Des Hayes 175. - Desmarest 23. 34. - Desor 22. - De Vico 98. 125. - Dewulf 273. 296. Diamilla-Müller 376. 404. - Dickert 116. 295. - Djell-al-Eddin 296. - Diels 2. 31. - Dieterici 32. - Dikaearch 5. 272. - Dingler 189. 268. - Diodoros 130. Diogenes Laertius 83. 336. 380. - Dionysodoros 139. - Dixon 144. 153. - Döderlein 13. 32. - Döllen 197. - Dölter 119. 128. 345. 367. - Dörffel 69. 80. 94. - Dolomieu 354. 370. 374. 404. - Donati 75. - Doppelmayr 268. 297. - Doppler 266. 271. - Döring 136. - Dorn 301. - Dozy 29. - Dove 14. 19. 21. - Draper 116. - Drobisch 183. 191. - Dronke 329. - Drude 26. - Dubois de Montpereux 387. - Du Carla 289. - Ducretet 259. - Dücker 363. 369. - Dürer 295. 299. - Dufour (G. H.) 284. 287. - Dufour (L.) 17. 133. 137. 152. 241. 269. Duhamel 113. - Dulong 66. - Dunker 307. 308. 310. 313. - Dupain-Triel 290. 292. - Duperrey 175. - Duponchel 65. 93. - Du Prel 40. 51. 125. 128.

\section{E.}

Edlund 91. - Edrisi 10. 273. 354. - Egen 388. 389. 406. - Eimmart 113. - Einhard 273. 296. - Eisenlohr 275. 282. 296. - Eisenschmidt 143. 153. Ekphantos 211. - Emery 160. - Empedokles 3. 31. 353. 354. - Emsmann 93. 96. 128. - Encke 70. 90. 91. 94. 96. 100. 149. 154. 156. - Engelmann 92. 118. 125. 271. - Engler 303. - Enkelados 392. - Ennis 43. 51. - Ephräm 130. Epikuros 395. - Eratosthenes 5. 134. 138. 139. 140. 143. 152. 153. 272. 296. Erigena (Scotus) 130. - Erman 21. 306. 313. - Escher (v. d. Linth) 22. 318. 328. - Eschmann 284. - Eschweiler 239. - Ethé 32. 368. 406. - v. Ettingshausen 127. 164. 190. - Eudoxos 234. 235. 269. - Euklides 44. - Euler 16. 50. 52. 60. 89. 96. 127. 131. 152. 231. 388. 406. - Eusebius 380. - Eutokios 152. 269. - Everest 145. 154. - Everett 310. - Ewald 21. 357.

\section{F.}

Fabricius 54. - Fahle 133. 152. - Falb 370. 374. 389. 390. 391. 392. 399. 400. 401. 404. 406. 407. - Fantonetti 305. - Faraday 76. - Fatio (de Duiller) 85. 89. 95. - Faujas de la Fond 352. 364. 368. - Favaro 18. 33. 114. 127. 294. 298. 372. 380. 381. 383. 384. 396. 404. 405. 406. 407. - Favre 17. - Faye 41. 45. 51. 57. 59. 70. 85. 93. 196. 209. 383. - Federmann 287. - v. Feilitzsch 63. - Fellner 11. 32. - Fergola 143. 151. 154. - Fernel 140. 143. 153. - Ferrara 350. - Fessel 
258. - Fick 49. 52. - Fjedschenko 357. - Finger 175. 176. 190. - Fiorini 275. 296. - Fischer (E.) 294. 299. - Fischer (E. G.) 64. 124. 128. - Fischer (H.) 6. 32. 404. - Fischer (J. C.) 95. 328. - Fischer (Ph.) 175. 180. 100. 196. 197. 198. 206. 209. - Fischer (Th.) 273. 296. - Fisher 216. 318. 323. 326. 327. 328. 329. - Fitzroy 376. - Fixlmillner 60. - Flammarion 95. - Flamsteed 241. - Flaugergues 54. 73. 94. 98. - Fliedner 169. 190. - v. Fleisehl 191. - Förster 387. - Folie 262.263. 271. 316. 328. - Fontana 100. 102. 126. 240. - Fontenelle 124. 128. - Forbes 112. 348. - Fordyce 309. - Forel 17. 133. - Forman 306. 313. - Forster (A.) 371. 404. - Forster (J. R.) 16. 27. 33. 339. - Foster 175. - Foucault 219. 227. 228. 229. 230. 231. 232. 258. 259. 268. 269. - Fourier 91. 92. 96. 300. 310. 311. 312. - Fournier 15. 33. - Fraas 399. 402. - Fracassetti 405. - Français 331. 332. 366. - Franciscus 406. - Franklin 19. 99. 315. 319. 328. - Franz 230. 269. - Fraunhofer 47. 62. - Freiesleben 303. - Frémont 292. - Freycinet 175. - Friedlein 230. - v. Friesach 278. 280. 296. - Frischauf 144. 153. 280. 295. 297. 299. - Fritsch 286. 298. - Fritz 62. 93. 302. 382. 405. - Fröbel 24. 34. - Froidmont 395. 406. - Froment 258. 260. - Fromond 383. - Fron 382. 405. - Früh 286. 289. 298. - Fuchs 333. 334. 340. 342. 344. 347. 351. 366. 367. 368. 400. 401. - Funcke 335. - Furttenbach 221. - Fusinieri 83.

G.

Gabet 334. 366. - van Galen 178. 190. - Galilei 18. 33. 54. 92. 97. 112. 114. 118. 127. 169. 227. 240. 241. 244. 267. 268. 269. 271. 396. - Galle 100. Galloway 266. - Garthe 229. - Gaspari 34. - Gassendi 220. 227. 244. 268. 314. 347. - Gatterer 17. - Gautier (von Genf) 62. 93. - Gautier (Maler) 396. - Gauss 19. 60. 145. 154. 156. 165. 186. 189. 192. 193. 229. 232. 266. 282. 293. 297. - GayLussac 21. 75. 320. 356. - Geelmuyden 89. 96. - v. Gebler 269. - Gehler 24. 96. 126. 139. 153. 178. 190. 217. 267. 270. 271. 312. 313. 328. 366. 367. 368. 406. 407. - Geikie 25. 34. 332. 342. 360. 366. 369. - Geinitz 123. 128. 377. 378. 405. - Geissler 47. 70. - Geistbeck 26. 34. - Gelcich 137. 152. 274. 280. 296. 297. - Gelpke 37. - Gemma Frisius 382. 405. - Genestri 383. - Gensanne 305. Gerlach 145. 150. 154. 191. 209. 256. 270. - Gerster 280. 297. - Gherardi 124. - Ghetaldi 137. 152. - Gilbert (G. K.) 332. 333. 366. - Gilbert (Th.) 131. 152. 244. 258. 259. 270. - Gilbert (W.) 14. 32. 216. 267. - Giordano Bruno 314. Giraldus 18. - Girard 298. - Giuscardini 287. - v. Glasenapp 267. - Glaser 26. - Gmelin 302. 312. - Godin 143. 175. - Göbel (F. A.) 22. - Göbel (K.) 245. 246. 270. - Goethe 342. 367. - Götz 29. - Goldbacher 5. 32. - Goldfuss 28. 35. - Goldschmidt 67. - Goodwin 124. - Gould 266. 387. - Granvella 277. - Gray 388. - Green 165. 189. - Gregor (von Nyssa) 36. 130. - Gregor (von Tours) 89. - Gregory 214. 259. 267. - Gretschel 275. 296. 297. - Griesbach 377. 405. - Grimaldi (F. M.) 115. - Grimaldi (L.) 370. 404. - Gringmuth 391. - Grisebach 21. - v. Groddeck 327. 329. - v. d. Gröben 64. 93. - Groombridge 241. - Grote 211. 267. - Grove 50. 52. - Grube 162. 189. - Gruithuisen 37. 116. 157. 158. 189. - Grunert 338. 406. - Gümbel 79. 95. 337. 343. 366. 367. Günther 31. 32. 94. 96. 126. 152. 153. 189. 190. 209. 267. - Güssfeldt 346. Guglielmini 220. 268. - Gunlögsen 350. - v. Gutbier 366. - Guthe 29. 35. 152. - Gurief 337. - Gyger 284. 287. - Gyldén 215. 241. 267. 269.

\section{$\mathrm{H}$.}

Haase 67. 93. - Habenicht 45. - Hadley 15. - Häser 3. 31. - Häussler 92. 96. - Hagenbach-Bischoff 362. 369. - Hales 303. 312. - Hall (A.) 101. 102. 126. - Hall (B.) 175. - Hallbauer 225. 268. - v. Haller 28. - Halley 15. 70. 75. 82. 90. 94. 155. 315. 328. - Hamberger 171. 190. - Hamilton 300. 355. 374. 404. - Hamnuna (Rabbi) 211. - Hampden 131. - Hann 26. 34. 193. 194. 209. 302. 312. - Hansen 109. 110. 229. 269. - Hansteen 19. 21. 154. 302. - Hantken v. Prudnik 371. 402. 404. - Harding 67. 154. - Harriot 54. - Hartsoeker 83. - Hartwig 100. 126. - Hassel 34. - Hasskarl 367. - Hauck 286. 298. - Haughton 184. - Hauptmann 17. - Hausen 50. 60. 92. 218. - v. Hauslab 178. 290. 291. Hausmann 23. 34. - Haxo 290. - Hayes 22. - Hayward 357. - Heckels 306. Heel 153. - Heer 24. 34. 328. - Heeren 132. 152. - Hegel 52. 66. 93. 125. Heiberg 152. 239. 269. - Heim 26. 309. 313. 361. 371. 392. 403. 406. - Heinsius 
75. 94. - Heinrich (Prinz) 274. - Heis 80. 81. 85. 87. 88. 95. 96. - Hekataeus 3. 272. - Hell 100. - v. Helldorf 298. - Heller 4. 52. 211. 267. 368. 406. v. Hellwald 27. 34. - Helmert 175. 190. 207. 209. 210. - Helmholtz 48. 52. 74. 94. 189. 209. 313. 328. — van Helmont 396. - Hempel 311. 313. - Hencke 67. - Henderson 241. 337. - Hengler 156. 157. 158. 159. 186. 385. - Henkel 355. 368. - Hennessy 100. 126. 317. 328. - Henrich 308. 313. 323. - Henry (M.) 145. - Henry (Pr.) 126. - Henzi 295. -- Herakleides Pontikos 211. 237. - Heraklit 3. Hermann 294. - Herodot 3. 4. 120. 152. - Herrenschneider 300. - Herrick 67. - Herrmann 368. 369. - Herschel (A.) 81. - Herschel (J. der Aelt.) 25. 34. 57. 92. 252. 356. - Herschel (J. der Jüng.) 175. 190. - Herschel (W.) 51. 55. 57. 60. 73. 92. 94. 101. 103. 122. - Hervé-Mangun 381. - Hertz 217. 267. - Hesiod 2. 353. - Hess 335. 366. - Hesse 343. 367. 368. - Hevelius 69. 72. 94. 102. 113. 114. 115. 127. - Higius 355. - Hiketas 211. - Hilgard 280. 297. - Hill 216. 223. - Hilleret 277. 296. - Himly 274. 296. - Himmer 246. 270. - Hind 67. 150. 154. - Hindenburg 127. 128. 209. - Hipler 212. 267. 283. 297. - Hipparch 5. 6. 216. 225. 226. 253. 254. 272. - Hippokrates 3. 4. - Hirzgarter 114. 240. Hochstetter 23. 34. - v. Hochstetter 26. 34. 330. 337. 345. 366. 378. - Höfer 371. 402. 404. - Höfler 357. 368. - Hölzner 286. - Höpfner 368. - Hörnes 400. 401. 403. 407. - v. Hoff 24. 34. 372. 377. 404. - Hoffmann (Fr.) 24. 28. 33. 34. 35. 51. 168. 338. 347. 366. 367. 368. 375. 404. - Hoffmann (K. F. V.) 24. 34. - v. Hoffmann (J. J. J.) 297. - Hofmann 22. - Holden 103. - Holetschek 86. 94. 96. 103. 126. 137. 152. - Hollmann 384. - Holmes 332. - Holmquist 153. - Holzamer 267. - Homann 274. 287. 296. - Homer 2. 129. 139. 353. - Hondius 274. - Hooke 103. 220. 241. - Hopkins 19. 315. 316. 328. 354. 363. 364. 389. 392. - Horaz 8. - Horn 269. 270. - Horner 21. 85. 224. - Hornstein 77. 95. - Horrebow 62. - Houghton 26. - Houzeau 86. 88. 90. 96. 102. 126. Hrabanus Maurus 11. 354. 395. - Huber (J.) 41. 51. - Huber (V. A.) 18. 33. Huc 334. 366. - Hueber 297. - Huggins 46. 51. 77. 90. 91. 117. - Hughes 26. - Hugues 26. - Hull 29. 35. - Hullmann 238. - v. Humboldt 7. 9. 11. 14. 15. 16. 19. 20. 21. 26. 27. 31. 32. 33. 35. 37. 64. 67. 77. 78. 81. 83. 85. 90. 92.93. 94. 95. 96. 127. 152. 167. 190. 195. 209. 267. 292. 296. 298. 300. 305. 310. 315. 319. 328. 334. 335. 336. 338. 344. 348. 349. 354. 356. 357. 358. 365. 366. 367. 368. 369. 372. 383. 388. 401. 404. 405. 406. 407. - Huygens 191. 102. 113. 124. 128. 171. 173. 190. - kHuyssen 304. 312 .

\section{J.}

Jacobi 109. 126. 150. 260. - Jäger 280. - Jagor 133. 152. 344. 348. 367. - Jakob (A.) 385. 403. 406. 407. - Jakob (T.) 125. - Jakob (Bischof) 380. Jallabert 17. - James 150. 183. 276. - Janeček 356. 398. 407. - Jannetaz 325. 328. - Janssen 52. 53. 63. 76. 116. - Janssonius 274. - Ibn el Wardi 32. 211. Ibn Junis 140. - Ibn Tofeil 235. - Ideler 234. 269. - Jeitteles 371. 403. Jelinek 230. - Imbert 334. - v. Jolly 187. 188. 191. - Jones 86. 87. 88. 96. Jordan 22. 33. 286. 298. - Jorge Juan 143. - Joule 49. 359. - Jourdy 403. lsaak-ben-Josef 132. - Isenkrahe 155. 156. 188. 189. - Isidorus (Hispalensis) 10. 11. 131. 314. 354. - Issel 160. 189. - Israel 271. - Istachri 10. - Jungius 14. - Junghuhn 336. 344. 349. 358. - v. Justi 315. - Justinus 338.

\section{K.}

Kämtz 19. 301. 312. - Kästner 4. 17. 18. 31. 33. 55. 60. 92. 111. 117. Kaiser (F.) 100. 101. 105. 126. - Kaiser (W.) 343. 367. - Kalippos 234. 269. Kalkowsky 338. - Kaltbrunner 285. 297. - Kane 22. - Kant 18. 33. 36. 37. 38. 39. 40. 41. 43. 44. 45. 46. 48. 51. 52. 60. 64. 68. 71. 83. 88. 89. 93. 94. 97. 109. 110. 122. 124. 127. 128. 151. 168. 190. 247. 317. 367. 381. 382. 384. 396. 399. 405. 406. 407. - Kapp 27. 35. - Karl (d. Gr.) 273. 296. - Karl (V.) 282. Karsten 29. - Kater 174. 176. 190. - Katibi 211. - Kazwîni 10. 32. 132. 354. 368. 395. 406. - Keith Johnston 26. - Keller 164. 167. 189. - Kempf 63. Kepler 14. 32. 48. 50. 54. 67. 69. 71. 72. 73. 94. 101. 112. 127. 154. 245. 246. 247. 248. 249. 250. - Kirch 54. - Kircher 14. 15. 32. 33. 124. 128. 303. 312. 354. 368. 398. - Kirchhoff (A.) 7. 26. 27. 32. 35. 108. 126. 359. 368. - Kirchhoff (G.) 46. 47. 51. 57. 58. 59. 92. 232. - Kirkwood 67. - Kinahan 332. 342. - King 
363. - Klee 213. - Klein 44. 45. 51. 52. 75. 91. 95. 96. 116. 120. 122. 123. 127. 128. 150. 154. 189. 236. 269. - Kleomedes 139. - Klinkerfues 45. 51. 52. 63. 93. 94. 99. 125. 126. 127. 270. 271. 405. - v. Klöden 25. 34. - Klose 138. - Kluge 382. 405. - Knight 226. - Knipping 286. 298. 370. 387. 403. 406. - Koch 308. 313. - Köler 130. 135. 152. - Kohn 368. - Kolberg 403. Koldewey 22. 136. Kollbrunner 297. - v. Konkoly 103. - Kordenbusch 227. 268. - Kortum 393. Kosmas (Indopleustes) 130. - Krašan 393. - Krates 6. - Krejcí 394. 406. Kries 348. 367. 381. 397. 405. - Kropatschek 17. 33. - Krüger (A.) 241. Krüger (J. G.) 355. 368. - Krümmel 277. 296. - Krünitz 406. - v. Krusenstern 175. - Kuhn 320. 329. - Kulik 171. 190. - Kuschin 337. - Kunth 21. - Kunzek 189. - Kupffer 19. 300. 301. 306. 310. 312. - Kysaeus 60. 93.

\section{L.}

Lacaille 85. 144. 153. 154. - Lacroix 24. 34. - Lactantius 130. - Lagrange 19. 50. 144. 163. 165. 189. - Lalande 70. - Lambert (F. Ch.) 397. - Lambert (J. H.) 38. 51. 86. 96. 100. 108. 126. 265. 271. 280. 281. 303. - Lambton 145. - Lamey 122. 128. - Lamont 19. 62. 301. 310. 313. - Lampadius 303. - Lancaster 126. - Landgrebe 25. - Lang 120. - v. Lang 180. 183. 190. 191. 256. 270. - van Langren 114. - Langley 53. 59. 66. - Laplace 19. 36. 38. 40. 41. 43. 44. 45. 48. 50. 51. 52. 60. 68. 73. 83. 89. 94. 97. 109. 127. 128. 144. 145. 151. 218. 220. 250. 251. 253. 255. 262. 264. 290. 317. 319. 361. - v. Lasaulx 341. 360. 367. 371. 386. 392. 400. 404. 405. 406. 407. - Lassell 67. - Latini 12. 32. 135. - Laussedat 286. 298. - Lavater 27. - Lean 305. - Lecat 218. - Lecoq 24. 34.

- Legendre 319. 328. - Lehmann (J. G.) 287. 288. 289. 298. - Lehmann (J. W. H.) 50. 73. 94. 240. 269. - Lehmann (P.) 27. 34. - Lehmann (R.) 29. 35. - - Lehmann-Filhès 80. 83. 95. - Leibniz 15. 37. 51. 124. 314. 328. 354. - Leidenfrost 398. 407. - Leipoldt 26. 34. 74. 94. 95. 119. 128. 137. 152. 154. 168. 189. 287. 291. 294. 298. 299. 302. 312. 366. 367. 368. 373. 404. 407. - Lémery 355. 368. 397. - Le Monnier 143. 153. - v. Le Monnier 272. 296. - v. Leonhard 366. Leo Thrax (Kaiser) 89. - Lepaute 70. - Lepsius 139. 152. - Lersch 393. 396. 399. 407. - Lescasse 384. 405. - Lescarbault 67. - Leslie 111. 315. 319. Letoschek 26. - Letronne 255. - Leukipp 129. - Leverrier 66. 252. - Lewis 85. - Liais 54. 87. 92. - Libri 12. 32. - Lička 289. 298. - Lichtenberg 17. 122. 397. - - Liebig 12. 32. - Liesganig 144. 153. 167. 189. - Lindelöf 225. 268. - v. Lindenau 90. 149. 154. 262. 264. 271. - Link 23. 34. - Linsser 105. 126. - Lionardo da Vinci 13. 112. 212. 267. - Lippert 26. 34. - Lissajous 233. - Lister 355. 368. - Listing 135. 145. 149. 153. 154. 171. 174. 190. 199. 209. v. Littrow (H.) 291. 298. - v. Lictrow (J. J.) 98. 99. 100. 125. 126. 153. 217. 241. 253. 254. 263. 267. 269. 285. 297. - v. Littrow (K.) 7. 32. - Livingstone 373. - Lockyer 52. 62. 93. 103. 350. - Löwe 332. 366. - Löwenberg 33. 127. 367. 404. - Lohrmann 115. 123. 127. - Lohse 59. 69. - Longomontan 213. 238. Loomis 48. 65. - Lorgna 281. - Loriti (Glareanus) 281. - Lossen 168. 190. Lottin 22. - Louville 155. - Lowitz 295. - Loys de Cheseaux 90. 96. - Lubbock 19. - Lucretius 8. 40. 394. 406. - Lucilius 8. 354. - Lud 274. - Ludwig 226. 268: - Ludwig (der Deutsche) 273. - Ludwig (XV.) 143. - Lübeck 172. 190. - v. Lüdingshausen-Wolff 60.93. - v. Lütke 175. - Lulofs 18. 33. - Lundahl 264. 266. 271. - Luther (Astronom) 67. - Luther (Martin) 212. - Luxoro 273. - Lyell 334. 357. 366. - Lyman 99. 125. - Lynch 339. 336.

\section{M.}

Macclesfield (Lord) 263. 271. - Machin 263. - Mac Laurin 162. - Maclear 145. 154. 241. - Macrobius 9. 112. 237. 269. - Mädler 22. 33. 51. 70. 71. 88. 94. 96. 99. 108. 111. 115. 116. 117. 123. 125. 126. 127. 128. 213. 252. 266. 267. 270. 271. 382. 405. - Mästlin 112. 113. - Magdeburg 284. - Magelhaens 132. Magini 216. - Magnus 306. 307. 313. - Maimonides 235. 269. - Main 266. Mairan 15. 85. 88. 89. 96. 303. 312. - Maire 144. 153. - Malapert 54. - Malaspina 173. 176. 190. - Mallet (J.) 405. - Mallet (R.) 19. 120. 128. 284. 316. 318. 341. 360. 361. 362. 369. 370. 372. 374. 385. 389. 390. 400. 403. 404. 405. 406. Malte Brun 287. - Mansion 293. - Maraldi 102. 103. 142. - Marat 88. - Marcet 307. - Marcianus Capella 10. 237. 269. - Mareia 10. - Marié-Davy 112. - Ma- 
rinelli 27. 29. 31. 35. 130. 152. 272. 273. 296. - Marinus 272. 274. 278. - Mariotte 16. 33. 44. 75. 320. 321. - Marius 54. - Marschall v. Bieberstein 315. 318. Graf Marsigli (C.) 227. - Graf Marsigli (L.) 285. 297. - Marsilly 306. - Martens 22. 33. - Marthe 23. 29. 34. - Martin 210. 234. 267. 269. - Martins 22. 33. Martius 21. - Martus 146. 224. 225. 268. - Marzari-Pencati 342. - Marx 120. Mascart 159. 180. - Maskelyne 144. 153. 167. 181. 182. 183. 189. 191. - Mason 144. 153. - Massudi 9. 335. 354. - Mathieu 175. - Matteucci 306. 313. 397. 407. - Matthiessen 109. 126. - Ma-twan-lin 69. - Maupertuis 143. 144. 153. - Maury 19. 224. 268. - Max II. (v. Bayern) 29. - Maxwell 185. 191. - Mayer (A.) 227. 268. - Mayer (Chr.) 144. 153. - Mayer (R.) 216. 359. - Mayer (Tob. d. Aelt.) 17. 105. 115. 116. 127. 265. - Mayer (Tob. d. Jüng.) 17. 18. 33. - Mazegger 297. Méchain 144. - v. Mechow 56. 96. - Megasthenes 3. - Mehren 32. - Meibauer 91. 96. - Meissel 43. 51. - Melanchthon 212. - Meldrum 350. - Melloni 112. 127. - Melzi 381. 405. - Ménard de la Groye 334. 350. 351. 367. - Mercator 126. 274. 277. 278. 280. 296. 297. - Menzel 365. - Menzzer 152. 212. 243. 267. 274. - Merz 103. - Messier 85. - Metzger 207. 210. - Meunier 83. - Meydenbauer 41. 51. 123. 128. 285. 286. 298. - Meyer (R.) 26. 294. 299. - Meyer (W.) 67. 70. 94. - Micheli du Crest 295. - Michell 184. - vs Middendorff 22. 32. 335. 336. - Millar 318. - Miller 46. 51. 309. - v. Miller-Hauenfels 75. 94. Millet de Mureau 289. - Minnigerode 391. 392. - Minucius Felix 314. 354. Mitterpacher 18: 33. - Möbius 50. 52. 237. 269. 270. - Möllinger 275. 296. Mohn 350. - Mohr 310. 313. 359. 369. 399. - Mollweide 282. - Molyneux 241. - Monge 144. - Montaigne 100. - Montfaucon 130. - Montucla 153. 237. Morse 386. - Mossotti 112. 114. 127. - Moyle 309. - v. Müffling 288. - Müller (E.) 294. 295. - Müller (F.) 280. - Müller (H.) 113. 114. 127. 329. 347. 366. 367. Müller (J.) 26. 34. 75. 95. 133. 138. 152. 186. 191. 367. - Müller (J. C.) 285. Münster 13. 274. - Müttrich 301. 312. - Muncke 24. 34. 88. 139. 178. 262. 300. 301. 303. 319. 333. 336. 353. 355. 385. 389. 397. - Munk 235. 269. - Munker 260. 262. 270. 271. - Murdoch 280. - Muschketov 385. - Musschenbroek 140. Musset 227.

\section{N.}

Narducci 32. 238. 269. 368. 406. - Nasmyth 53. 103. 113. 116. 119. 120. 121. 127. 128. - Nasr-ed-din 254. - Naumann (E.) 370. 404. - Naumann (G. F.) 288. 298. 402. - Neckam 114. - Necker 399. 407. - Nehring 8. 9. 32. 354. 368. 394. 404. 406. - Neison 99. 113. 116. 117. 118. 119. 123. 125. 127. 128. - Nell 281. 297. - Neumann (C., Geograph) 29. - Neumann (C., Mathematiker) 265. 271. - Neumann (K. J.) 6. 32. - Neumann (L.) 296. - Neumayer 86. 96. 371. 390. 404. 406. - Newton (H. A:) 81. - Newton (J.) 15. 32. 37. 38. 39. 44. 51. 70. 72. 73. 77. 94. 124. 126. 141. 142. 143. 151. 152. 155. 156. 161. 162. 164. 165. 169. 170. 171. 172. 173. 176. 177. 183. 188. 190. 220. 245. 247. 250. 255. 256. 257. 263. 270. 271. 375. 404. - Niebuhr 21. - Nies 120.128. 318. 328. - Nöggerath 389. Nordenskiöld 22. 33. 90. 96. - Norwood 141. - Notter 114. 127. - Novara (Domenico di) 216. 251. - Nürnberger 50. 52. 143. 153. - Nyrén 38. 51. 264. 271.

\section{0.}

Obermair 288. - Obernetter 286. - Oeder 284. - Oefverboom 153. Ohlert 45. 46. 51. - Olbers 67. 70. 76. 83. 90. 94. 95. 96. 220. - Olmsted 81. Olsen 291. - Oltmanns 21. 173. 190. - Omons 131. 135. - Onnes (Kamerlingh) 232. 233. 240. 269. - Opelt (F. W.) 115. 127. - Opelt (M.) 116. 127. - Oppikofer 294. - v. Oppolzer 156. 158. 188. 283. 297. - Ordinaire 338. - Ordinaire de Lacologne 230. 269. - Origanus 213. 238. - Origenes 211. - Orontius Finaeus 274. - Orosius 11. - Ortelius 374. - Oudemans 103. 207. 209. - Outhier 143. 153. - Ovidius 8. 354.368.

\section{P.}

Pagani 230. - Palander 153. - Palisa 67. - Pallas 16. 28. 35. 78. 95. 302. 312. 337. - Palmieri 341. 342. 347. 348. 367. 385. 386. 399. 406. - Paraira 162. 189. - Parmenides 130. - Parnisetti 219. 267. - Parrot (Ch. F.) 23. 34. Parrot (J. F.) 23. 34. 309. 313. 355. 368. - Parthey 152. - Passarge 33. - Pa- 
sumot 292. - Patrin 355. - Paucker 180. 190. - Payne 125. - Peal 388. 406. Pechuël-Lösche 373. - Peirce 282. 297. - Peiresc 72. - Peirinsius 227. 268. Pelz 138. 152. - Penck 195. 209. 350. 352. 362. 368. 369. - Percy (v. Northumberland) 69. - Perrey 372. 399. 400. 404. - Perrot 157. 189. 225. 268. - Perry 311. - Pertz 296. - Peschel 9. 12. 13. 19. 21. 24. 26. 27. 32. 33. 34. 35. 94. 95. 114. 125. 127. 128. 130. 132. 139. 152. 154. 190. 267. 273. 284. 285. 287. 289. 291. 294. 296. 298. 299. 302. 312. 366. 367. 368. 373. 385. 401. 404. 406. 407. - Petermann 32. 268. 280. 287. 297. - Peters (C. A. F.) 175. 182. 183. 189. 191. 267. 271. 341. - Peters (C. F. W.) 175. 190. 241. - Petit (A. T.) 66. - Petit (J.) 69. 94. Petrarca 11. 380. 405. - - v. Petrinò 359. 369. - Petrus Martyr 13. 78. - Peurbach 251. - Peutinger 272. - Peyer 287. - Pfaff (Fr.) 19. 310. 313. 323. 328. 361. 369. 374. - Pfaff (J. F.) 64. - Pfyffer 294. - Phaedon 314. 336. - Pherekydes 380. - Philipp II. (v. Spanien) 297. - Philippi 273. 296. - Phillips 306. 348. 367. - Philolaos 210. 211. 267. 314. - Philon 383. - Phipps 309. - Piazzi 67. 73. 83. 94. - Piazzi Smyth 84. 88. - Picard 141. 142. 143. 153. 295. - Pick 133. 152. 230. 231. 269. - Pickering 102. - Pictet 17. - Pieper 232. 269. Pilar 84. 95. 270. 310. 313. 323. 324. 325. 326. 327. 328. 337. 359. 363. 364. 366. 368. 369. 370. 371. 382. 397. 400. 403. 406. 407. - Pilla 348. - Pindar 373. Pindter 152. - Pingré 85. - Placidus Heinrich 54. - Plana 167. 184. - Plantamour (E.) 175. 190. - Plantamour (P.) 159. 189. 219. 250. 267. 387. - Planté 43. 51. - Plateau 36. 42. 43. - Platon 2. 3. 211. 267. 314. 336. 353. 354. Pleischl 28. 35. - Plinius 11. 69. 227. 228. 255. 373. 375. 380. 383. 393. 394. 404. 405. - Pluche 252. - Plücker 329. - Plutarch 2. 7. 77. 112. 114. - Poëy 382. 405. - Poggendorff 35. 157. 169. 185. 190. 191. 260. 262. 267. 270. 309. 310. 312. 313. 320. 386. 399. - Pogson 71. 350. - Poisson 19. 50. 83. 89. 91. 92. 96. 223. 224. 266. 268. 301. 309. 310. 312. 313. 315. - Poinsinet de Sirry 228. - Poinsot 230. 260. - Pokorny 26. 34. - Poletto 136. 152. - Polybius 6. - Pond 241. Porro 285. - Posch 139. 153. - Posidonius 5. 6. 139. 374. - Postellus 274. 281. 297. - Pothenot 284. 297. - Pouillet 92. 96. 174. 175. - Poulett Scrope 19. 329. 330. 335. 340. 345. 353. 357. 360. 366. 367. 369. - Poynting 188. 191. Prätorius 283. - Pratt 197. 209. - Prévost (C.) 360. 369. - Prévost (P.) 266. 271. - Prestwich 363. 369. - Priestley 384. 397. 406. - Priscianus 272. Pritchett 100. - Proctor 103. 126. 266. - Propertius 273. - Prowe 255. 267. 269. 270. - Prshewalski 22. - v. Przystanowski 356. 368. - Ptolemäus 5. 7. 28. 32. 69. 134. 139. 210. 212. 216. 235. 236. 237. 272. 280. - Puissant 145. 285. 297. - Purvis 293. 298. - Pusch 29. 35. - Pytheas 6. 129. - Pythagoras 97. 130. 210. 235. 267. 380 .

Quenstedt 329. - Quetelet 30. 35. 81. 114. 127: 300. 312. 381. 405.

\section{R.}

Rachel 378. 405. - Rahmer 406. - Raimarus Ursus 213. 238. 269. - Rammelsberg 367. - Rankine 50.52. 75. - vom Rath 334. 349. 366. 398. - Ratzel 22. 26. 29. 131. 346. 357. 391. 402. 406. 407. - v. Raumer 24. 34. - Rayet 277. 296. - Réaumur 120. 306. - Reclus 25. 34. - Redhouse 84. 85. 95. - Redtenbacher 40. 52. - Regiomontanus 69. 24. 212. 251. - Regner 88. - Reich 186. 191. 220. 268. 303. 305. 306. 312. - Reichard 277. - v. Reichenbach 158. Rein 22. 34. 365. 369. - Reinhardt 69. 94. 95. - Reis 60. - Reiss 342. - Reitz 294. - Remeis 103. 126. - Repsold 175. - Reusch (F.) 276. 296. - Reusch (H.) 352. 360. 361. 364. 368. 369. - Reye 57. 58. 59. 93. - Reyer 318. 328. 353. 354. 355. 358. 364. 368. 399. 407. - Rheticus 283. 297. - Riccioli 14. 15. 32. 115. 117. 141. 143. 213. 216. 238. - Richer 172. 173. 190. - Richelot 260. - v. Richthofen 22. 23. 29. 34. 168. 332. 335. 339. 366. - Riedl v. Leuenstern 116. - Riemann 44. 133. - Riess 76. - Rigaud 263. 271. 292. 293. 298. - Rikatscheff 292. 298. - Rink 33. - Ristoro (v. Arezzo) 12. 32. 135. 354. 368. 395. 406. - Rittenhouse 98. - Rittau 16.33. - Ritter (A.) 44. 51. 65. 93. 320. 321. 328. - Ritter (C.) 16. 23. 27. 28. 31. 33. 34. 35. 152. 267. 291. 296. 367. - Ritter (E.) 150. 154. Rixner 327. 406. - Roberval 239. 269. - Robison 163. - Roche 109. 126. 319. 328. - Rockstroh 370. - Rockwood 387. - Röhl 17. 18. 33. 312. - Römer 241. 242. 270. - Röthig 229. 259. 269. - Rohde 209. - Rohlfs 86. 96. - Roscoe 96. 
- Rose 78. 79. 95. - Rosenberger 32. - Ross 346. - Rosse (Lord) 103. 112. 127. - Rost 54. 55. 115. - Roth (Fr.) 26. 34. - Roth (J.) 344. 360. 369. 372. 373. 376. 385. 402. 404. 406. - Rothmann 85. 213. 244. - Rouvet 381. - Roy 144. 153. - Rozet 195. 209. - Rudberg 300 - Rüppell 21. 339. 366. - Ruge 31. 33. 152. 267. 284. 296. 297. 367. 368. - Rumowski 175. - Russegger 21. Russell 116. 128. - Rutherfurd 47. 51. 116.

\section{S.}

Sabine 21. 62. 174. 175. 176. 190. - Sadebeck 139. 146. 153. 154. - Safǎrik 98. 99. 125. 156. 189. - Saigey 30. 35. 92. 96. 194. 195. 209. - Salomo (Bischoff) 131. - Salsano 385. - Salviati 227. - van de Sande Bakhuyzen 102. 126. - Santini 191. 209. - Sarpi 114. 127. - Sarti 396. 406. - Sartorius von Waltershausen 31. 341. 352. 367. - Saussure 17. 300. 303. - Savart 87. v. Schaper 52. - Schaub 230. - Schaubach 234. - v. Scheffel 305. - Scheibner 156. - Scheiner 54. 60. 92. - Scheidt 51. - Schell (A.) 285. 297. - Schell (W.) 231. 269. - Schelle 230. - Schellen 43. 92. - Schergin 302. - v. Scherzer 367. - Scheuchzer 17. 28. 33. 284. 295. 369. - Schiaparelli 48. 51. 81. 82. 89. 95. 96. 101. 103. 104. 105. 106. 126. 210. 211. 234. 235. 237. - Schickard 283. 297. Schidlofsky 63. - Schjellerup 47. - Schinz 238. 269. - Schlagintweit 25. 34. 136. - Schlesinger 285. - Schlömilch 164. 189. - Schlötel 51. - Schlüter (A.) 267. - Schlüter (H.) 111. - Schmick 107. 108. 123. 126. 128. 216. - Schmidt (J. C. E.) 24. 34. 149. 154. 175. 184. 191. 198. - Schmidt (Jul.) 75. 86. 100. 101. 114. 115. 116. 118. 119. 123. 127. 348. 372. 374. 376. 382. 383. 389. 400. 404. Schmidt (K.) 24. 34. - Schmidt (W.) 12. 32. 136. 152. - Schneider 337. 366. Schön 85. 96. - Schöner 94. - Schönfeld 218. 267. - v. Schorlemmer 96. Schorr 100. 126. - Schouw 27. 35. - Schrader 224. 229. - Schreiber (Grammateus) 296. - v. Schreibers 80. 95. - Schröter 89. 99. 102. 110. 115. 118. 122. 126. 127. - Schubert (F. W. A.) 33. 93. 127. 154. 190. 404. - Schubert (Th.) 89. 150. 197. - Schück 280. 297. - Schülen 56. - Schumacher (A.) 21. 33. Schumacher (H. C.) 127. 145. 153. 154. 175. - Schumann 276. 296. - Schwabe 54. 62. - Schwartz 306. - Schwedoff 74. 75. 94. - Schweigger 366. 367. Schweizer 169. 190. - Schwerd 141. 153. - Schyrlaeus (de Rheita) 101. 114. 126. - Scotus Erigena 11. - Scoresby 22. 33. - Secchi 47. 51. 52. 53. 55. 56. 58. 59. 60. 63. 64. 66. 82. 83. 92. 93. 95. 100. 103. 105. 126. 229. - Sédillot 132. 152. ₹. Seebach 19. 329. 332. 366. 371. 375. 383. 386. 388. 390. 391. 393. 403. 404. 405. 406. - v. Segner 255. 270. - Seidel 98. 125. - Selander 144. - Sénarmont 325. 329. - Senebier 17. - Seneca 8. 9. 32. 54. 69. 94. 349. 354. 368. 373. 374. 375. 376. 394. 398. 406. - - Serpieri 87. 96. 381. 383. 384. 405. Servet 28. 35. - Seuffert 270. - Severianus 130. - Seydler 321. 328. - Seyfert 399. - Sguario 380. 384. 405. - Shems-ed-din (Demitschki) 10. 32. - Short 100. - Siacci 232. 269. - Siber 327. 406. - Sickler 338. - Siebert 93. - Siemens (Werner) 317. 318. 328. 364. - Siemens (William) 207. 208. - Sjewjerzow 357. 368. - Sigmund 358. - Silberschlag 37. 51. 64. - Silvestri 341. - Simony 26. 298. Simpson 293. 298. - Sire 259. - Smith (L.) 79. 95. - Smithson-Tennant 37. Snellius 140. 141. 143. 153. 216. 284. - v. Sömmering 61. 93. - Sohncke 153. 188. - Solander 309. - Solinus 336. 366. - Sollas 364. 369. - Sommer 40. 51. Sommerville (Mary) 25. 34. - Somoff 260. - v. Sonklar 288. 291. 298. 377. 404. - Spallanzani 334. 335. - Spartacus 341. - Spencer 320.328. - Spix 21. Spörer 52. 59. 60.61.63. 66. 93. - Sprenger 139. 153. 267. 395. 406. - Stabius 274. - Stadius 216. - v. Stälin 152. - Stampffer 285. 297. - Stapff 306. 307. 308. 309. 312. 313. - Stark (A.) 54. 227. - Stark (W.) 213. 267. - Starke 285. 297. - Staudacher 54. - Stebnitzki 168. 169. - Steinhauser 137. 178. 274. 275. 276. 280. 281. 289. 290. 295. 296. 297. 298. 299. - Steininger 343. 367. Steinschneider 132. - Stenagoras 16. - Steno 15. 354. - v. Sterneck 176. 184. 190. - Stieler 26. - Stirling 162. 293. - v. Stockar 366. - Stölzle 152. Stolička 339. - Stoll 158. 189. - Stolze 285. 286. 298. - Stone 253. 266. Stoppani 397. - Strabon 6. 7. 9. 32. 286. 349. 377. 394. - Strachey 379. Straton 5. 6. 374. 394. 396. - Struve (O. v.) 241. - Struve (W. v.) 63. 90. 96. 145. 146. 154. 169. 182. 241. 243. 270. - Stuckely 355, 396. 406. - Studer 8. 17. 25. 30. 32. 33. 377. 394. 396. - Studnička 26. 34. - Stübel 324. - Suchsland 89. 96. - Supan 26. 281. - Svanberg 92. 96. 144. 153. - Swedenborg 38. 51. 125. - Swift 101. - Sylvabelle 60. - Symmes 315. 


\section{$\mathrm{T}$.}

Tacchini 52. 59. - Tacitus 396. 406. - Tägert 217. 264. 271. - Tait 162. 163. 166. 178. 189. 190. 199. 202. 209. 217. 313. 327. - Tallaria 212. - Tammen 230. 269. - v. Tanner 154. - Tannery 234. 269. - Taramelli 381. - Tarde 54. Taylor 339. - Teja 341. - Teloni 380. 405. - Terby 102. 103. 104. 126. Tertullian 314. 354. - Terzago 83. 95. - Teuffel 8. 32. - Thales 2. 130. 135. 272. 276. - Theodor (v. Mopsuestia) 130. - Theon 235. - Theophanes 6. Theophrast 2. 15. 31. 336. - Theopomp 3. - Thevenot 285. - Thilo 61. 93. Thomas (Aquinas) 11. 211. 395. - Thomassen 399. 407. - Thomson 19. 40. 47. 50. 109. 162. 163. 166. 178. 189. 190. 199. 202. 209. 217. 311. 312. 313. 315. 316. 317. 318. 328. 363. - Thoulet 276. 296. - Thukydides 377. 405. - Toaldo 219. - Tollin 28. 35. - Tomaschek 272. 296. - Torell 22. 33. - Toula 372. 404. Tournefort 16. - Tralles 284. - v. Trebra 303. - Trogus Pompejus 338. - Trübner 25. - Trunk 294. 298. - Tschackert 11. 32. - Tschermak 83. 347. 361. 362. 369. - v. Tschirnhaus 112.

\section{$\mathrm{U}$.}

Ule 25. - Ulloa 128. 143. 175. - Unferdinger 178. 179. 180. 181. 191. Unverzagt 226.

\section{V.}

Vadian 142. - Valentiner 128. - v. Valvasor 28. 35. - Vargas Bedemar 350. 367. - Varenius 14. 15. 27. 32. - Varro 2. 142. 237. 383. - Vassali-Eandi 397. - Vauquelin 350. - Venturi 127. 267. - Vergilius 8. - Vetter 26. - Vincenz (v. Beauvais) 11. - Virgilius (Bischoff) 130. - Visconti 255. - Vitruvius 8. 237. - Vivenzio 355. 384. - Vogel 52. 68. 70. 94. 105. - Vogt 33. - Volger 359. 375. 399. 407. - Volta 335. - Voltaire 101. 143.

\section{W.}

van der Waals 320. - Wackerbarth 211. - Wagner (G.) 387. 388. 406. Wagner (H.) 24. 27. 29. 34. 35. 135. 152. 191. 313. 328. 367. 405. - Wagner (M.) 337. 346. 366. 367. - Walbeck 191. 209. - Walferdin 307. - Wallis 227. 268. - Waltenberger 381. 405. - Wapowski 255. 270. - Wappäus 22. 29. 34. Wargentin 100. - Warin 175. - Warren de la Rue 116. - Webb 67. - Weber (H.) 275. 296. - Weber (W.) 145. 155. 156. - Weinek 75. - Weiss (E.) 82. 86. 87. 95. - Weiss (J. H.) 294. - Weissenbach 158. - Weitzel 401. 407. - Wenz 275. 276. - Werner (A.) 19. 355. 356. 368. - Werner (J.) 255. 270. 274. 281. Werner (K.) 11. 32. - Wernicke 220. 242. 270. - Wertheim 189. 209. 313. 328. - Westphal 94. 127. - Wetli 294. - Wettstein 249. 250. 270. 358. 359. 360. 368. - Weyprecht 22. 33. - Whewell 14. 19. 125. 128. 378. - Whipple 116. Whiston 55. 56. 57. 58. 92. 125. - Whitney 318. - Wichmann 111. - v. Widmanstätten 79. 80. - Wiechel 272. 274. 281. 295. - Wiedeburg 55. 92. 315. 384. 405. - Wiedemann 21. 74. 95. - Wiegand 268. - Wieser 282. 297. - Wiesner 226. 268. - Graf Wilczek 292. 298. - Wild 302. - Wilhelm (von Conches) 11. 32. - Wilhelm (Bischoff) 380. - Wilhelm (Landgraf) 85. - Wilkins 124. Williams 26. 69. 94. - Winkelmann 120. 128. 318. 328. - Winkler (Geograph) 25. - Winkler (Topograph) 294. - Winnecke 99. 125. - Witelo (Vitellion) 127. - Witte (Wilhelmine) 116. 295. - Wittstein 207. - Wohlwill 14. 32. - Wolf (R.) 54. 61. 62. 64. 65. 68. 72. 90. 92. 93. 94. 95. 96. 99. 103. 115. 125. 126. 127. 128. 143. 150. 153. 154. 173. 188. 189. 190. 226. 228. 238. 241. 243. 266. 267. 268. 269. 270. 271. 285. 286. 287. 293. 296. 297. 298. 299. 303. 312. 403. - Wolf (S.) 116. - Wolf (Th.) 347. 367. - v. Wolf 108. 113. 124. 126. 127. - Wolfer 68. Wolfers 51. 94. 155. 188. 404. - Wolkenhauer 286. 298. - Wollaston 47. Woodward 37. - v. Wrangel 302. - Wright 79. 87. 95. 96. - Wrightson 318. - Wüllner 42. 51. - Wundt 30. 50. 52. - Wurm 66. - Wu-Tsung 274. Wynne 370. 380. 403.

Gūnther, Geophysik. I. Band. 


\section{$\mathrm{X}$.}

Xenophanes 129.

\section{Y.}

Young 59. 66. - Yvon Villarceau 200.

\section{Z.}

v. Zach 154. 167. 175. 189. 315. - Zachariae 207. - Zacharias (Papst) 131. 152. - Zamminer 25. - Zanotti-Bianco 196. 209. - Zech 156. 189. 200. 201. 209. - Zeller 2. 31. - Zenker 74. 75. 78. 94. 95. - Zeune 22. 34. 291. Ziegler 287. 291. 298. - Zimmermann 19. 33. - Zirkel 362. 369. - Zittel 22. - Zöckler 15. 32. 36. 37. 51. 124. 128. 130. 152. 327. 368. - Zöllner 18. 33. 40. 44. 47. 48. 49. 51. 52. 58. 59. 61. 63. 64. 65. 72. 74. 75. 76. 77. 93. 94. 95. 98. 107. 109. 111. 125. 126. 127. 155. 156. 157. 158. 185. 187. 188. 189. 216. 267. 385. 406. - Zöppritz 30. 35. 165. 188. 189. 191. 219. 221. 222. 224. 250. 268. 270. 275. 296. 306. 307. 313: 317. 318. 321. 328. 347. 359. 362. 367. 368. 369. 406. - Zsigmondy 307. 312. - Zucchi 102.

\section{Verbesserungen und Zusätze.}

S. 22 , Z. 25 v. u. und S. 33 , Z. 7 v. o. 1. Nordenskiöld.

S. 26 , Z. 5 v. o. ergänze vor und: Gu y ot, Physical geography, London 1873.

S. 33 , Z. 21 v. u. 1. lanarischen Inseln.

S. 67 , Z. 10 v. o. ergänze nach Goldschmidt: Watson.

S. 80 , Z. 8 v. o. 1. Brezina.

S. 84, Z. 6 v. u. und S. 88, Z. 22 v. u. 1. Piazzi Smyth.

S. 90 , Z. 15 v. u. 1. Nebelspektrums.

S. 105 , Z. 26 v. o. 1. Thyle.

S. 116, Z. 4 v. u. 1 . Abtheil. II.

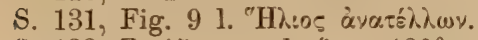

S. 138 , Z. 15 v. u. $1 . \zeta_{1}=180^{\circ}-89^{\circ} 48^{\prime}, \quad \zeta_{2}=180^{\circ}-89^{\circ} 35^{\prime}$.

S. 140, Z. 17 v. u. und S. 141, Z. 17 v. o. $1 . \Gamma$ statt $\gamma$.

S. 157, Z. 21 v. o. ergänze nach Kapitel: der dritten Abtheilung.

S. 190, Z. 28 v. 0. 1.125 statt 88 .

S. 192 , Z. 20 v. o. l. $f\left(x, y, z, a_{1}, a_{2} \ldots a_{n}\right)=0$.

S. 201 , Z. 26 v. o. l. mechanischen Arbeit.

S. 220, Z. 22 v. u. l. Ostwestrichtung statt Mittagslinie.

S. 242, Fig. 42 l. durchweg e statt l.

S. 249, Z. 4 v. u. 1. Erdkunde statt Erde.

S. 276 , Z. 8 v. u. lies: Völlig unerreichbar ist nur der eigene Standpunkt des Zeichners.
S. 324 , Fig. 62 l. a $\{x$ statt $A\{x$.
S. 346, Z. 10 v. o. 1. Nord-, Central- und Südamerika.
S. 356 , Z. 9 v. u. l. Entdeckungsreisen.
S. 391, Z. 17 v. o. $1 . \alpha_{2}$ und $\beta_{2}$ statt $\alpha$ und $\beta$.
S. 392 , Z. 5 v. u. 1. Hyperbel.
S. 407 , Z. 16 r. o. 1. 9 . Band, S. 264 fr. 




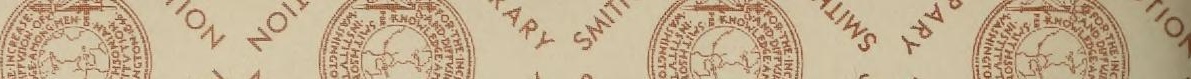

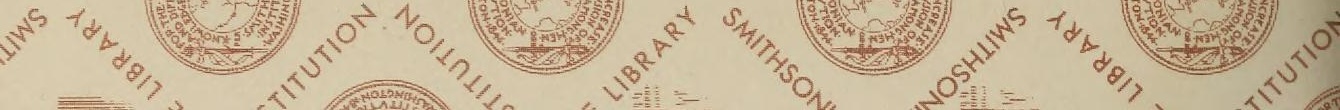

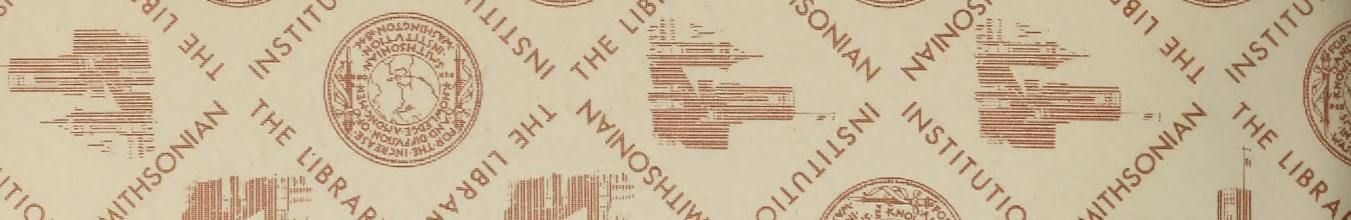

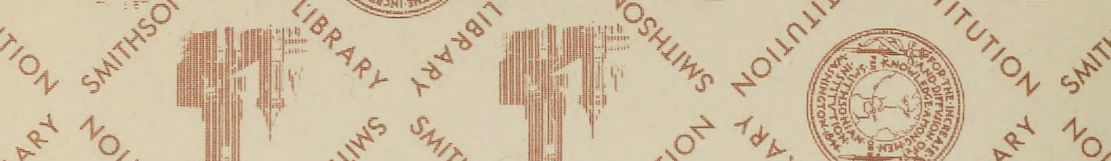

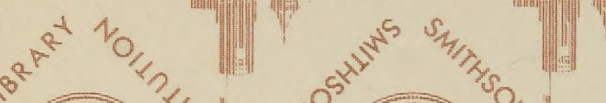

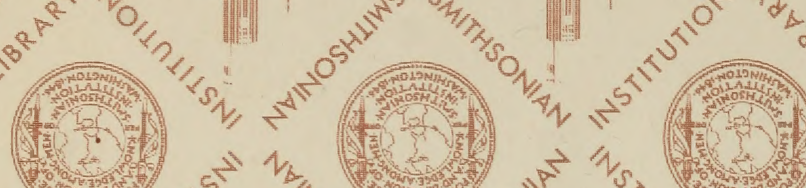

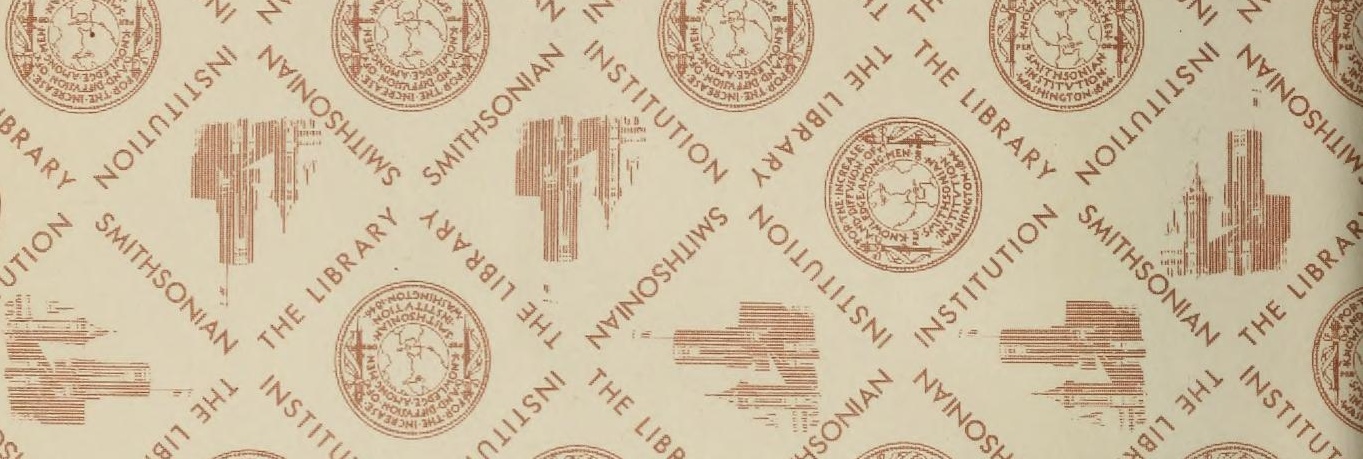

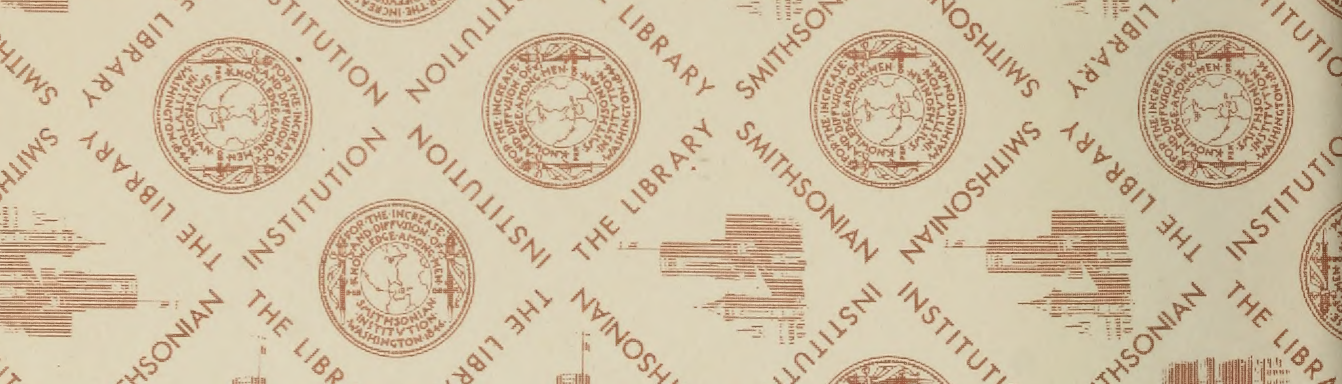

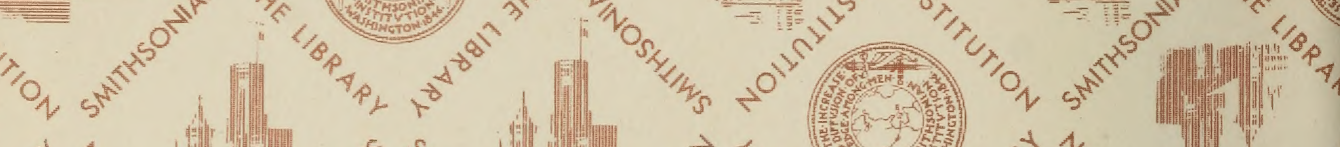

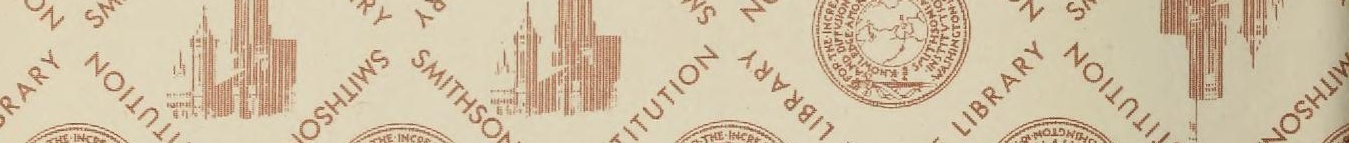

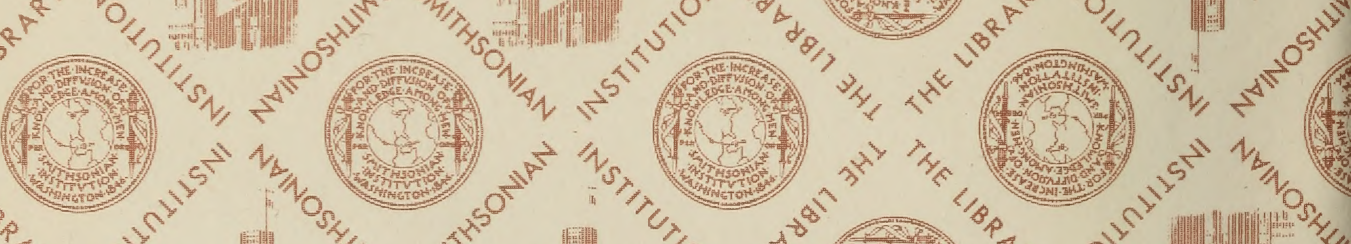

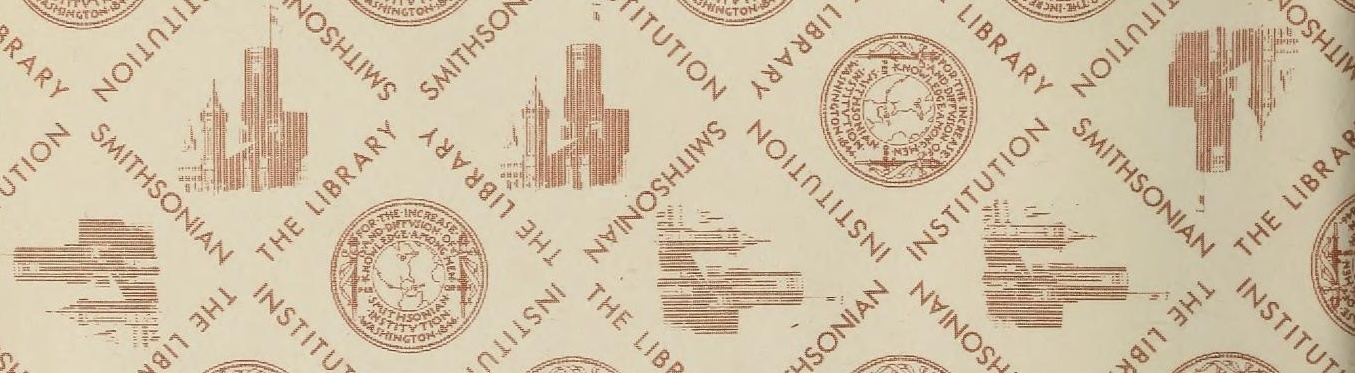

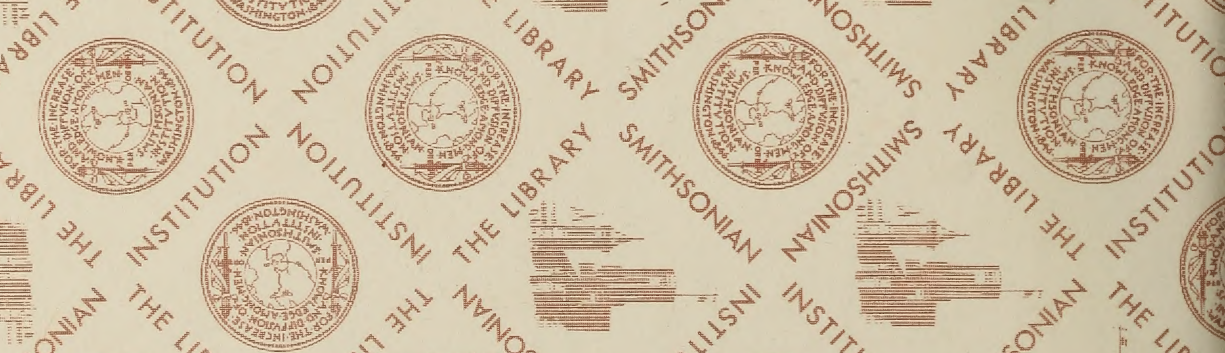

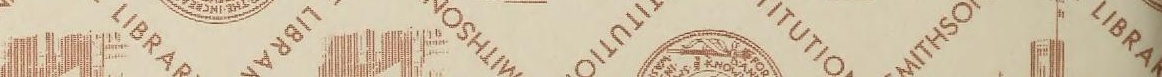



SMITHSONIAN INSTITUTION LIBRARIES

39088 00377546

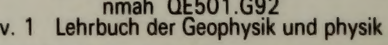

